\title{
Geology of the Apollo 16 Area, Central Lunar Highlands
}

GEOLOGICAL SURVEY PROFESSIONALAPAER 1048

Prepared on behalf of the National Aeronautics and Space Administration

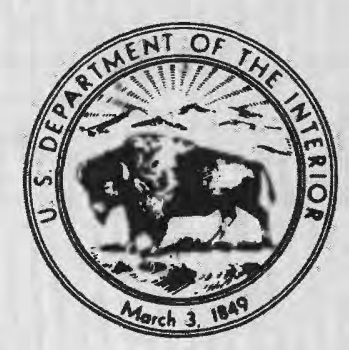


GEOLOGY OF THE APOLLO 16 AREA, GENTRAL LUNAR HIGHLANDS 

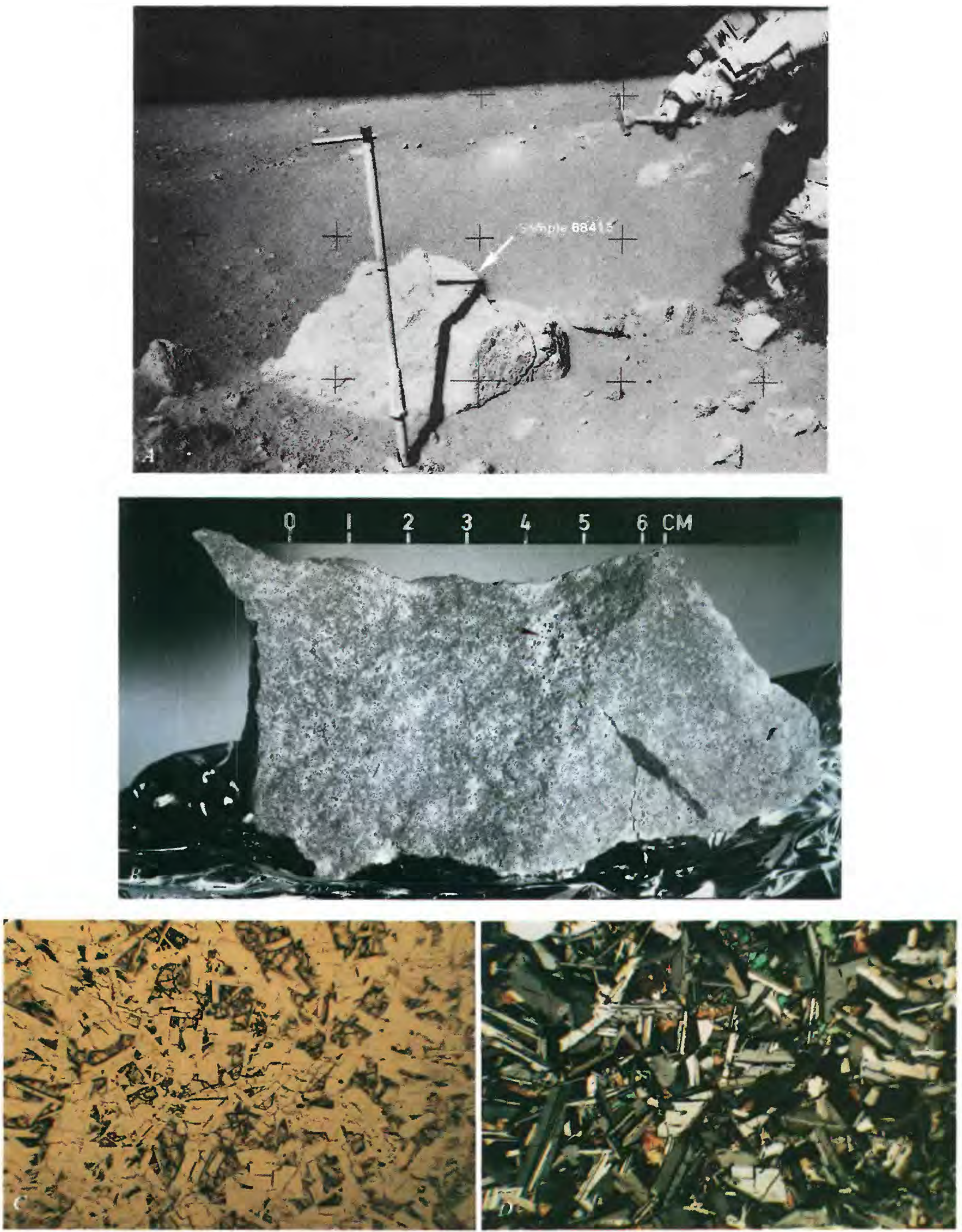

Crystalline rock 68415 . A. White angular boulder at Station $8,3.4 \mathrm{~km}$ northeast of South Ray crater, source of samples 68415 and 68416 . Long-handled scoop casts shadow westward across boulder. Hasselblad frame No. AS16-108-17697. B, Fresh broken surface of rock 68415 showing fine-grained crystalline texture with local vug-filling plagioclase (arrow). Lunar Receiving Laboratory No. S- $73-39590$. $C$, Photomicrograph of typical texture in 68415 and 68416 showing twinned plagioclase (gray and white) and clinopyroxene (bright colors). Cross-polarized light. Long side is $2.75 \mathrm{~mm}$. $D$, Same as $C$ in plane-polarized light showing subophitic texture of plagioclase and darker high-relief pyroxene. 


\section{Geology of the Apollo 16 Area,}

\section{Central Lunar Highlands}

Edited by GEORGE E. ULRICH, CARROLL ANN HODGES, and WILLIAM R. MUEHLBERGER

GEOLOGICAL SURVEY PROFESSIONAL PAPER 1048

Prepared on behalf of the National Aeronautics and

Space Administration

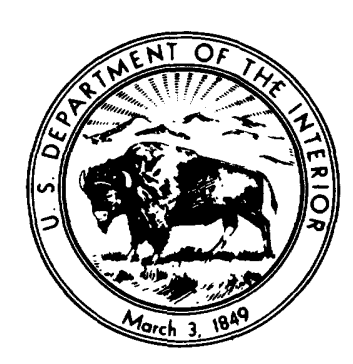

UNited StATES GOVERNMENT PRINTING OFFICE, WASHINGTON : 1981 


\title{
UNITED STATES DEPARTMENT OF THE INTERIOR \\ JAMES G. WATT, Secretary
}

\author{
GEOLOGICAL SURVEY
}

Doyle G. Frederick, Acting Director

Library of Congress Cataloging in Publication Data

Geology of the Apollo 16 area, central lunar highlands

Contributions to astrogeology. Geological Survey Professional Paper 1048 Bibliography; p. 534-539.

Supt. of Docs. No.: I 19.16:1048

1. Lunar geology. 2. Project Apol10. I. Ulrich, George E. II. Hodges, Carroll Ann. III. Muehlberger, William R. IV. United States. National Aeronautics and Space Administration. V. Series. VI. Series:

United States. Geological Survey. Professional Paper 1048. QB592.G47 $559.9^{\prime} 1$

80-607170

For sale by the Superintendent of Documents, U.S. Government Printing Office Washington, D.C. 20402 
"There you are, our mysterious and unknown Descartes highland plains, Apollo 16 is going to change your image."

John Young could hardly have known the truth of his prediction when he first set foot on the lunar surface at the Apollo 16 landing site. His mission was the most surprising geologically and has generated the most controversy of all six Apollo landings. The Descartes region of the central lunar highlands, since its first serious consideration as a site for manned exploration 4 years earlier, had been strongly supported as a place to sample volcanic rocks much different from those of the maria and the basin margins. Three days of field exploration ranging 4 to $5 \mathrm{~km}$ from the lunar module failed to turn up a single recognizable volcanic rock. Instead, a variety of breccias, complicated beyond belief, were collected from every location. Crystalline rocks were found whose textures were clearly igneous (see frontispiece), but they were not volcanic. And therein lies the heart of the geologic mystery of Descartes.

"Well it's back to the drawing boards, or wherever geologists go" (T. K. Mattingly, Apollo 16 Command Module Pilot from lunar orbit).

\section{PREFACE}

This volume contains the final results compiled by the Apollo Field Geology Investigations Team for the Apollo 16 mission. Some of the data presented here were reported in preliminary form shortly after the mission (ALGIT, 1972a, 1972b; AFGIT, 1973; Batson and others, 1972; Muehlberger and others, 1972), but most of the discussion and interpretations that follow are products of individual efforts which have incorporated much of the large body of data available from postmission studies of the rocks, the geophysical and geochemical data, and the extensive collection of photographs taken by the Apollo 16 astronaut crew on the lunar surface and from orbit. The chapter format was chosen to permit individual authors to develop their ideas independently, and we trust this approach will serve to stimulate rather than confuse the reader.

Our purpose in this volume is to summarize the field observations at the Apollo 16 site and to bring together the various interpretations placed upon these observations by the astronauts and the Field Geology Team. Much of the extensive geochemical and geophysical data published since 1974 on the Apollo 16 site has not been incorporated or referred to here. The intent is not to provide a grand synthesis but rather to document the local and regional geologic relations and to summarize what inferences can be made from them. Our expectation is that the volume will be used as a reference for researchers desiring more complete information on the geologic context of the Apollo 16 samples and on the interpretations of those intimately involved with the planning, execution, and analysis of the geologic exploration.

John Young, Charles Duke, and Kenneth Mattingly deserve special credit for the quality of their performance while exploring this complex area on the surface, from lunar orbit, and later in discourse with the lunar science community. Their continuing interest in the developing story of Descartes began with an unwavering enthusiasm for geologic training exercises in the field. With the able help of Anthony England, mission scientist and communicator during the EVA's, and Friedrich Horz, their geologic trainer in Houston, their competence as scientific investigators reached the high level shown by their ready adaptation to the unexpected conditions encountered on the mission.

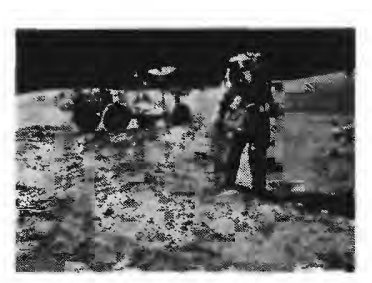

A significant stimulus to the exceptional performance on the Moon was provided by the outstanding backup crew, Fred Haise, Edgar Mitchell, and Stuart Roosa, whose high scientific standards the prime crew was continuously challenged to surpass. We hope that the monthly mission-oriented field exercises planned and executed by members of the Field Geology Team prior to the Apollo 16 flight provided the variety of experience in field situations that enabled the crew to make the appropriate observations and geologic judgments required during the mission.

We received valuable assistance before, during, and after the mission from the following associates of the U.S. Geological Survey who are not credited elsewhere but who nonetheless made significant contributions directly or indirectly to the preparation of this volume: $\mathrm{N}$. G. Bailey, F. E. Beeson, B. M. Bradley, V. J. Fisher, M. H. Hait, E. D. Jackson, R. H. Jahns, D. E. Johnson, J. S. Loman, R. S. Madden, R. Carroll, W. E. Miller, R. A. Mills, J. C. Nuttall, D. L. Peck, R. E. Sabala, L. T. Silver, R. B. Skinner, L. B. Sowers, G. A. Swann, H. F. Thomas, J. W. VanDivier, and D. E. Wilhelms. Immensely helpful editing by James Pinkerton in preparing the manuscripts for publication was a monumental task and is greatly appreciated.

M. B. Duke, Curator, and R. B. Laughon, Assistant Curator, Lunar Receiving Laboratory, Johnson Space Center, Houston, very kindly made arrangements for members of the Field Geology Team to study the Apollo 16 and 17 thin-section collections and to use their photographic equipment for illustrating some of the discussions in the field geology chapters of this report. 



\section{CONTENTS}

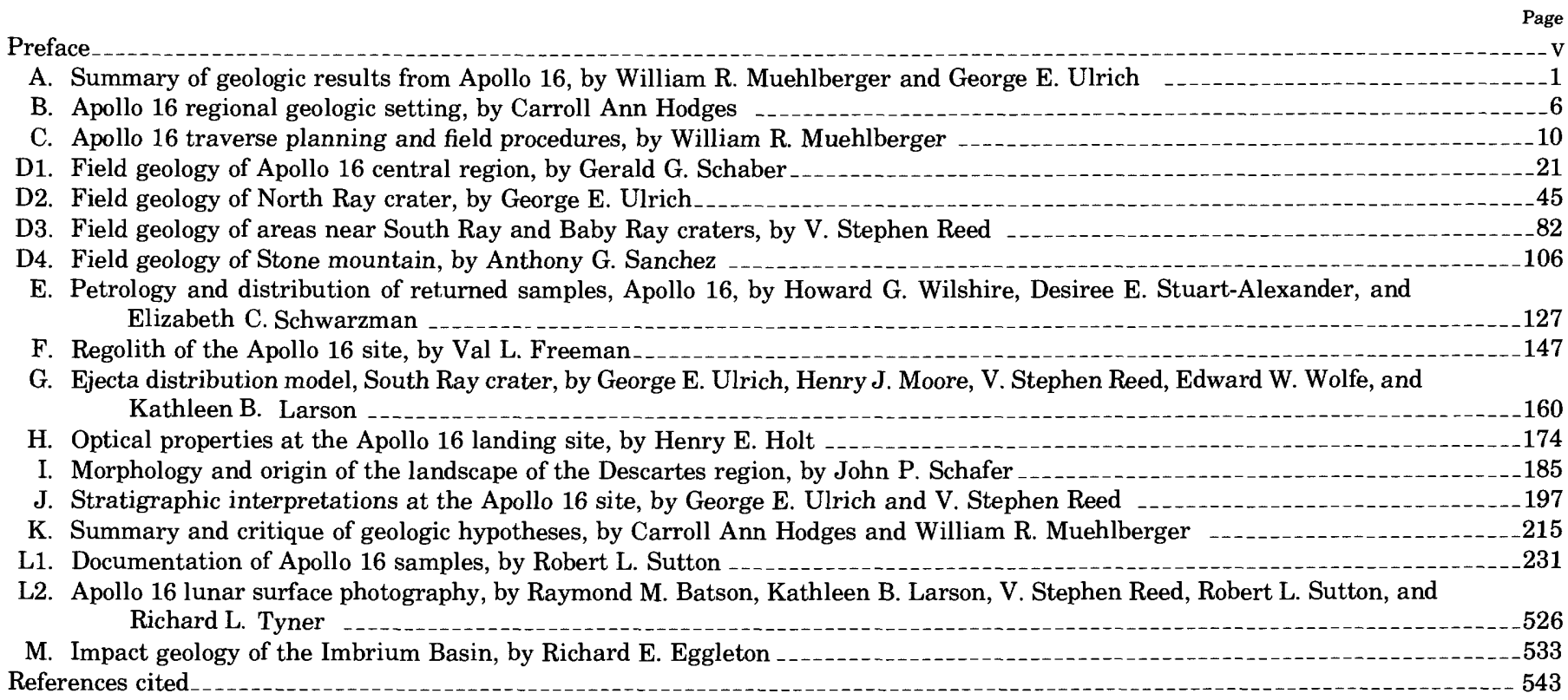

\section{ILLUSTRATIONS}

[Plates are in separate case]

Frontispiece. Crystalline rock 68415 .

Plate 1. Geologic map of the Apollo 16 landing site and vicinity, by Carroll Ann Hodges.

2. Apollo 16, Descartes landing site.

3-11. Photographic panoramas taken on the lunar surface:

3. From within and near the lunar module.

4. The ALSEP area and partial panoramas of House and Outhouse rocks.

5. Stations 1 and 2 and a partial panorama of Buster crater.

6. Stations 4,5 , and 6 on Stone mountain.

7. Stations 8, 9, and 13, and partial panoramas of Shadow rock.

8. Station 11, North Ray crater, including sketch map.

9. Station 11, including telephoto mosaics.

10. Telephoto mosaics of Stone mountain taken from the lunar module and station 2 and of Smoky mountain taken from station 11.

11. Telephoto mosaics of South Ray crater, Baby Ray crater, Stubby crater, and the central and northern parts of the traverse area, taken from station 4 .

12. Map of the impact geology of the Imbrium basin of the Moon, by Richard E. Eggleton. 


\section{ABBREVIATIONS AND ACRONYMS}

AET

AFGIT, ALGIT

ALSEP

ANT

$\mathrm{AP} / \mathrm{C}$

ASE

CC

CDR

$\mathrm{C} / \mathrm{S}$

CSM

CSVC

CSSD

CTR

DC

DMB

DPS

DS

DSB

DT

END CTR

EVA

EXP

FIIR

HFE

IR

KREEP

LAC

LM

LMB

LMP

LOC
Apollo Elapsed Time, time after launch of ${ }^{-}$ mission from Kennedy Space Center

Apollo Field (Lunar) Geology Investigation Team

Apollo Lunar Surface Experiment Package

Anorthosite-norite-troctolite rock suite

Analytical plotter, model C

Active Seismic Experiment

Capsule communicator at Mission Control in Houston, A. W. England

Commander, John W. Young

Central Station controlling the ALSEP

Command Service Module, spacecraft that orbited Moon during EVA's.

Core Sample Vacuum Container

Contact Soil Sampling Device (Surface Sampler)

Crater

Dark-haloed crater

Dark-matrix breccia

Descent Propulsion System on LM

Down-sun sampling, photograph

Down-sun before sampling, photograph

Drive tube, also core tube

End crater

Extravehicular activity; astronaut activity outside the LM

Experiment

Fine-grained intersertal igneous rock

Heat-Flow Experiment

Interagency Report, U.S. Geological Survey

Lunar rock or soil with high concentrations of potassium, rare-earth elements, and phosphorus

Lunar Aeronautical Chart

Lunar Module

Light-matrix breccia

Lunar Module Pilot, Charles M. Duke, Jr.

Photograph of sample showing location with respect to LRV or LM
LPM

LRL

LRV

LSM

LSPET

META-ANT

MISC

MPA

N RAY CTR

PAN

PEN-2

PPAN

POIK

PSE

REE

ROVER

RTG

SCB

SEQ

SPL

S RAY CTR

SRC

STA

STEREO

STEREOPAIR

SURF SPLR

SWC

USA

USB

USD

UV CAMERA

XS, XSUN

XSA

XSB

XSD

,+- Y FOOTPAD

,$+-Z$ FOOTPAD
Lunar Portable Magnetometer

Lunar Receiving Laboratory

Lunar Roving Vehicle

Lunar Surface Magnetometer

Lunar Sample Preliminary Examination Team

Metamorphosed anorthosite-norite-troctolite Miscellaneous

Mortar Package Assembly

North Ray crater

Photographic panorama, normally $360^{\circ}$

Location of second penetrometer reading

Partial panorama

Poikiloblastic or poikilitic

Passive Seismic Experiment

Rare-earth elements

Lunar Roving Vehicle

Radioisotopic Thermoelectric Generator

Sample collection bag

Scientific equipment bay, in LM

Sample

South Ray crater

Sample return container

Station, sampling location on traverse

Stereoscopic sequence or offset in photographs Overlapping pair of photographs that give a three-dimensional view

Surface sampler (also CSSD)

Solar Wind Composition device

Up-sun, after sampling, photograph

Up-sun, before sampling, photograph

Up-sun, during sampling, photograph

Far-ultraviolet camera, positioned in shade of the LM

Cross-sun, sampling photograph

Cross-sun, after sampling, photograph

Cross-sun, before sampling, photograph

Cross-sun, during sampling, photograph

Front and rear footpads, respectively, of LM

Left and right footpads, respectively, of LM 


\title{
A. SUMMARY OF GEOLOGIC RESULTS FROM APOLLO 16
}

\author{
By William R. Muehlberger and George E. Ulrich
}

INTRODUCTION

The Apollo 16 mission to the central lunar highlands has provoked a variety of stimulating debates concerning the nature of the original lunar crust, the effects of impact processes on this crust, and the interpretation of lunar landforms from photographic evidence. Considerable disagreement remains about ultimate sources of the samples returned from the Cayley plains and the Descartes mountains. Although the major problems of origin and lunar processes may not be resolved in this volume, it is hoped that subsequent research will take into account the facts of field relations as recorded by the cameras and first-hand observations of the astronauts.

The arrangement of topics in this volume is partly chronologic in that discussions of geologic setting and mission planning are followed by sections on the field geology of four geographic areas sampled by the astronauts: central Cayley plains, North Ray crater, vicinity of South Ray and Baby Ray craters, and Stone mountain. These observation sections are followed by topical discussions on the petrology, regolith, South Ray ejecta distribution, optical properties, morphology, and stratigraphy of the landing site. A summary discussion of the source materials for the Cayley plains and Descartes mountains in the light of available data concludes the interpretive part of the volume. Supplementary sections on the surface photography and the documentation of samples collected by Apollo 16 are updated revisions of U.S. Geological Survey Interagency Reports, Astrogeology 48, 50, 51, 54, prepared immediately after the mission. Twelve folded plates in the separate case include nine plates of lunar surface panoramas mosaicked from 70 -mm photographs and annotated with respect to geographic features and geologic data, a premission photomosaic map of the landing site (scale 1:25,000), a postmission geologic map of the landing-site region $(1: 200,000)$, and a postmission map of Imbrium-basin-related geology (1:5 million) for the near side of the Moon.

Some geographic names not yet approved by the International Astronomical Union are used informally in the text and figures where identification or reference to their location is considered essential to the discussion for purposes of context or clarification.

A glossary of abbreviations and acronyms used in the texts, illustrations, photographic and sample catalogs, and the photographic panoramas is appended to the volume.

The paragraphs that follow in this chapter are essentially abstracts of each of the succeeding separately authored chapters. Thus this section serves as an overview or extended abstract of the volume that incorporates the major conclusions reached in the independent chapters in the order in which they occur, beginning with the regional geologic setting and ending with the summary of geologic hypotheses.

Chapter A.-The Apollo 16 landing site permitted investigation of two geologic units that are widespread in the lunar highlands: light plains and mountainous "hilly and furrowed" terra, both superposed on old cratered terrain. Outside the landing area, they are embayed by, and are therefore older than, the maria. A volcanic origin for these units, generally accepted prior to the mission, was not supported by the mission results. Various hypotheses of impact-related origins have been proposed to explain the crudely stratified, impact-generated breccias found at the site.

Chapter B.-Apollo 16 was the only site within the central lunar highlands to be explored by astronauts on the surface. It is on the Cayley plains, which are relatively level as compared with the adjacent rugged Descartes mountains. The site is about $70 \mathrm{~km}$ west of the Kant plateau, which marks part of the third ring of the Nectaris basin, and about $600 \mathrm{~km}$ west of the center of that basin. Other multiringed basins that probably influenced the geology of the landing site are Imbrium, centered about $1,600 \mathrm{~km}$ to the northwest, and Orientale, centered $3,500 \mathrm{~km}$ to the west-southwest.

A geologic map of the landing site and vicinity (pl. 1) prepared after the mission illustrates a current interpretation of the distribution of geologic materials. 
The geologic aspects of the Cayley plains and Descartes mountains can be summarized as follows: (1) The surface units are Imbrian in age; the plains surface has a cratering age that is similar to, if not identical with, that of Orientale basin ejecta; cratering ages of the Descartes materials are not so well defined because of their rugged topography, but they are at least as old as Imbrian. (2) The site is within the "sphere of influence" of the Imbrium basin, as evidenced by the radial sculpturing of highlands northwest of the site and by the ridgy morphologic aspect of the Descartes mountains that appears nearly continuous with the Imbrium sculpture. Thus Imbrium ejecta and local material disrupted by the ejecta produced both the mountains and the plains. (3) Because of proximity to the Nectaris basin, the Apollo 16 stratigraphic column probably includes Nectaris basin ejecta at depth, but the basin is so old that these materials are no longer exposed, except perhaps in the lowest walls of the largest craters.

Chapter C.- The three lunar-surface traverses of the Apollo 16 mission were designed to insure maximum return of useful data for a community of scientists and engineers with widely varying objectives. Because the time available for geologic investigations and other experiments was limited, an intricate system of priorities was established for both station locations on each traverse and tasks to be performed at each station. The astronaut crew, John Young and Charles Duke, kept abreast of the planning and the constantly changing priorities, in addition to learning how to travel to and from the Moon. Their terrestrial field training for 18 months before the mission was designed to simulate the lunar traverses and to develop their skills in identifying and describing significant geologic features while photographically documenting and sampling the rocks and soils representing these features.

As a result, all primary geologic objectives were essentially achieved. Well-documented samples were returned from Cayley plains, North and South Ray crater ejecta, and Stone mountain materials that may be representative of the Descartes mountains in this part of the lunar highlands. Photographic coverage of all sampling areas and the entire traverse route and telephoto views of all important points remote from the traverse area were obtained.

Chapter D1-D4.-The central region of the Apollo 16 landing site was investigated at three locations, LM/ ALSEP, station 1, and station 2. The samples documented probably represent materials of the underlying Cayley plains down to depths of $70 \mathrm{~m}$ or more and ejecta from more distant regions (specifically North and South Ray craters). The percentage of rock types collected from each station was clearly affected by time constraints and may therefore not be representative of the stratigraphic sequence. The most intensively sampled area, LM/ALSEP, probably yielded the most representative collection of the Cayley plains materials. The rock types are similar in all respects to those collected at other stations during the mission. They include fine- to medium-grained, moderately homogeneous crystalline rocks; rocks composed primarily of glass; and breccias, by far the dominant type. The variety of rock types collected indicates that the Cayley plains breccias are heterogeneous and suggests that they are composed of isolated pockets of both light and dark breccias deposited by a turbulent process.

Extensive sampling and photography on the rim (station 11) and near the outer edge of the continuous ejecta blanket (station 13) of North Ray crater provide a basis for stratigraphic interpretations in the northern part of Apollo 16 traverse area. Breccias on the rim and walls are of two main types, light matrix and dark matrix. The areal distribution and petrographic relations of the boulders sampled or photographed suggest a generalized stratigraphic sequence within the crater and, by extrapolation, in the northern part of the landing site. The light-matrix boulders are friable, rounded, and heavily filleted. Their abundance on the rim and upper-crater wall suggests that they were derived from the upper part of the section. The darkmatrix boulders are coherent and appear to be the latest ejecta to fall on the crater rim. One of these, Outhouse rock, was the source of several igneous and metaclastic fragments. Most of the dark-matrix breccias may be derived from a deeper horizon near the present crater floor.

Several types of evidence other than the fresh-rayed appearance argue for the youthfulness of North Ray crater. Spallation exposure ages of 27 to 51 m.y. have been reported for five North Ray rocks. Within that time interval, a very thin regolith (approximately a centimeter thick) formed locally; it thickens to $15 \mathrm{~cm}$ or more where it forms fillets around the friable lightmatrix boulders.

South Ray and Baby Ray craters are fresh blocky craters in the southwestern part of the Apollo 16 landing site. Rays from South Ray can be traced as far as 10 $\mathrm{km}$ from the crater to the vicinity of North Ray crater. Although South Ray crater itself was not actually visited by the astronauts, Cayley plains materials ejected from it probably are present at most stations. Station 8 was purposely located on a bright ray from the crater to insure collection of South Ray materials; 
dark-matrix breccias and light-gray igneous rocks were the two main rock types sampled. They appear to represent two lithologic units in South Ray crater, dark-matrix breccias being the upper unit.

The South Ray event, if correctly dated by the 1 - to 4-m.y. exposure ages in the boulders, apparently deposited ejecta recognizable only in the coarse debris at station 8 , about five crater diameters away. Associated soils are reported to give much older ages. No ejecta from the younger Baby Ray crater were recognized in the sample suite, although such materials may be present in small amounts.

Three sampling localities were established on Stone mountain at the south limit of the traverse area with the objective of collecting materials representative of the Descartes mountains. The two highest stations (4 and 5) appeared on premission photographs to be outside ray patterns related to South Ray crater, but contamination by South Ray ejecta appears likely at Station 4. The location of station $4 a$ on the edge of ejecta from Cinco $a$ crater suggests that samples collected might contain local material from a depth of $15 \mathrm{~m}$ on Stone mountain. Sampling at station 5, on the wall of a small crater shadowed from South Ray and void of visible blocky ray material, would be expected to include rocks of the Descartes mountains. Station 6 , on a bench at the base of Stone mountain very near a ray, may be a mixture of fragments from the Cayley plains and materials of the Descartes mountains.

Chapter E.-Apollo 16 rocks are classified by a descriptive scheme into three groups: crystalline rocks, subdivided as igneous $\left(\mathrm{C}_{1}\right)$ or metamorphic $\left(\mathrm{C}_{2}\right)$; glass $(\mathrm{G})$; and breccias $\left(\mathrm{B}_{1}-\mathrm{B}_{5}\right)$, subdivided on the basis of clast and matrix colors and proportions. These rocktype symbols are used throughout this volume.

The crystalline igneous rocks consist of 1 certain and 1 possible anorthosite, 11 fine-grained ophitic to intersertal rocks of troctolitic to anorthositic composition, and 1 troctolite enclosed in fine-grained meltrock of the same composition. Derivation of the fine-grained igneous rocks by impact melting of feldspathic plutonic source rocks is indicated by the common occurrence of unmelted relics derived from coarse-grained plutonic rocks and a bulk compositional range like that of the plutonic rocks with essentially the same compositions.

Metamorphic crystalline rocks studied consist of 1 medium-grained granoblastic rock considered to be a product of metamorphism in a plutonic environment prior to excavation and 10 poikiloblastic rocks. Gradation from poikiloblastic to unequivocally igneous textures in these rocks is taken as evidence of metamorphic origin with minor melting.
Five breccia types have been derived by comminution of a first-cycle breccia that consisted of anorthositic clasts in a fine-grained matrix ranging from melt texture to metamorphic texture. The first-cycle breccia is considered to be multiring-basin ejecta because it contains clasts of plutonic rock whose origin appears to be deep in the lunar crust. These breccias have been modified to varying degrees by subsequent smaller impacts.

Rocks representative of first-cycle breccias are sufficiently abundant in the Apollo 16 collection that least-metamorphosed samples may be identified. From some such samples displaying minimum modification, it should be possible to date the crystallization of the original crustal rocks, the preexcavation metamorphism of these rocks, and the time of excavation. A review of age data shows that most samples selected for isotopic measurement are so severely modified by subsequent impact that the ages are ambiguous. The samples petrologically most favorable for dating significant and identifiable events in the histories of the rocks are tabulated with the hope that they will help in obtaining unambiguous ages, because such data from Apollo 16 rocks are now so scarce that basin chronologies are only speculation.

The distribution of the various sample types shows no significant differences between Cayley and Descartes materials. Statistical and compositional data on soils support the view that the Cayley Formation and materials of the Descartes mountains are facies of the same ejecta deposit. The Cayley Formation may contain a somewhat higher proportion of matrix consisting of melt and powdered rock.

Chapter F.-The appearance of the regolith is generally that of a rocky gray soil. Rays from young craters in hard substrata are distinguishable mainly as local concentrations of blocky fragments. The brightness of a ray appears to result from a combination of the density and the angularity of fragments, both of which are higher for South Ray than for North Ray crater.

The regolith thickness on the plains has a median value of between 6 and $10 \mathrm{~m}$ based on photogrammetric measurements of concentric craters. The thickness of regolith on Stone mountain ranges from a minimum of 5 to $10 \mathrm{~m}$ to more than $20 \mathrm{~m}$ and may vary greatly owing to the accumulation of mass-wasted debris on a softer, weaker bedrock that may underlie much of the Descartes mountains.

Regolith compositions for most of the site are chemically similar except for North Ray soils, which are significantly enriched in alumina and depleted in iron, 
titania, and nickel by comparison with the remaining stations. Soils from station 4 tend to be intermediate in titania and nickel content with respect to soils from the plains and North Ray crater. As a group, the soil samples are a homogenized mixture of the bulk rock analyses from the entire site.

Chapter G. - South Ray crater ejecta totaling 5 to 10 million $\mathrm{m}^{3}$ are scattered over the Apollo 16 landing site in an irregular pattern that reflects a nonuniform mantle of debris. The ejecta thin rapidly from about $10-15 \mathrm{~m}$ at the crater rim to an estimated $1 \mathrm{~cm}$ or less of equivalent uniform thickness at the southern sample localities (stations 4, 5, 6, 8, and 9) and to less than $1 \mathrm{~mm}$ at the northern localities (stations 11 and 13). The power function best describing this thinning has a slope of approximately -3.0 . The fragment population on the lunar surface (for sizes larger than $2 \mathrm{~cm}$ ) can account for most of the total volume of ejecta, although an equal amount of finer grained material can be accommodated by the model.

Ray material from South Ray Crater can be determined best by the combined evidence of computerenhanced orbital photographs and the density of fresh rock fragments observed on the lunar surface. Station 8 has the highest potential for materials from South Ray; next most likely are stations 9, 6, 4, and 5. The probability of identifying South Ray ejecta from field data for areas farther away than these stations (3.5-4 $\mathrm{km}$ from the crater) is remote. Possible exceptions are station 2 samples taken within a bright ray patch in the central part of the landing site.

Chapter H.-An investigation of the photometric properties of the Apollo 16 landing site indicates that albedo values of several areas, including the rim of South Ray crater, are 50 to 55 percent, the highest measured at any Apollo site. Measurements for the sampled areas range from 15 percent at the central area, 20 percent in the Stone mountain and station 8 areas, to 24 percent at North Ray crater.

The polarimetric properties of the north and east wall of North Ray crater reveal that very little, if any, crystalline material is present in that area and that most of the rocks are more highly shocked than the Fra Mauro breccias at Cone crater.

Chapter I.-Four highland terrain types have been morphologically defined in the Descartes mountains in and adjacent to the Apollo 16 landing site. Lineated patterns of crater chains, ridges and scarps, and crosslineations represent three of these. These features exhibit both erosional and depositional characteristics whose orientations show that they were formed by the
Imbrium impact event. The main highlands mass probably is a tongue of Imbrium basin ejecta. The fourth highland terrain type is represented by isolated mountains inferred to be older Nectarian massifs projecting through the mantle of Imbrium ejecta.

The mountain terrain can be traced beneath the Cayley plains. The plains materials are thin enough along some margins to reveal a subdued reflection of the buried mountain terrain but thick enough in central parts to conceal the mountainous unit. The gradational character of the morphologic contact between plains and mountains does not indicate intergradation between the units but rather the overlapping of Cayley fill on the edge of slightly older mountain terrain.

The smooth to gently undulating surface of the Cayley plains indicates high mobility of the plainsforming materials at the time of their deposition. Of the hypotheses currently offered, the concept that the plains represent fluidized ejecta from one or more multiring basins is most consistent with the morphologic evidence.

Chapter J.-The ejecta deposits from craters that penetrated materials beneath the Apollo 16 landing site, together with the morphologic characteristics of the craters themselves, provide the best clues for a stratigraphic interpretation of the region. The Cayley plains, whatever their source, consist of three textural rock units: light-matrix breccias, dark-matrix breccias, and nearly holocrystalline rocks. These materials are locally mixed but form a gradational assemblage compatible with a crudely layered sequence of rocks whose chemical composition is grossly homogeneous.

At the north end of the traverse area, samples from the ejecta of North Ray crater reveal a population dominated by friable light-matrix breccias. These rocks, easily eroded, account for the convex upper slopes of the crater wall and the rounded and deeply filleted boulders on the rim and ejecta blanket. The lowermost materials of the crater's floor mound are most likely represented by coherent glass-rich dark-matrix rocks found as sparse unfilleted blocks on the rim. The third main lithologic type is coherent light-gray igneoustextured rock that occurs interstitially in light-matrix breccias and as inclusions within dark-matrix breccias. This type, the holocrystalline rocks, reaches sizes of 50 $\mathrm{cm}$ at station 8 and occurs as smaller angular rocks in the central part of the landing site.

The relative abundances of the holocrystalline rock and the dark-matrix breccias at stations 8 and 9 and the photographic evidence for layering within South Ray and Baby Ray craters suggest that the crystalline rocks occur as large lenslike masses underlying and grading upward into melt-rich to melt-poor breccias 
within the upper $150 \mathrm{~m}$ over much of the site. A discontinuous resistant layer at about this depth, becoming shallower in the South Ray area, may be reflected as benches in some crater walls (such as South Ray) and by floor mounds in other kilometer-size craters within the Cayley plains. In the south-central and eastern parts of the landing site plains and everywhere in the nearby mountains, evidence for this layer is lacking.

The materials of the Descartes mountains in and adjacent to the traverse area show little evidence of layering. The dominant rock type below the regolith at the highest point sampled on Stone mountain is most likely light-matrix breccia. The upper $100 \mathrm{~m}$ or so of the North Ray crater wall appears to have the same lithology, possibly representing similar materials of Smoky mountain. The lack of coherent blocks in the ejecta of a fresh Copernican crater (Dollond E), about 1 $\mathrm{km}$ in depth, $35 \mathrm{~km}$ south of the landing site, and the high reflectance of the Descartes mountains indicate that they are made up mainly of friable light-matrix breccias.

Chapter K.-Several hypotheses have been proposed to explain the origin of the terra plains and the hilly and furrowed terra, both of which are nonvolcanic according to evidence from the Apollo 16 mission. Orbital and surface results of the mission, together with postmission photogeologic investigations, suggest that ejecta from the Imbrium basin constitutes a major part of both plains and mountains at this site.

The younger Orientale basin provides a model for investigating basin deposits. Both erosional and depositional landforms occur in the ejecta blanket around the basin, and conspicuous lineations, together with lobate escarpments, strongly indicate lateral flow of materials. Pitting and grooving by secondary impact occurred contemporaneously with deposition of primary hummocky ejecta. Smooth plains deposits appear to be a late-stage fluid facies that ponded in topographic lows. Extrapolation from this young wellpreserved basin to the older and larger Imbrium basin implies similar origins for similar morphologic features. Hummocky ejecta, plains, and secondary craters are recognizable around Imbrium. The close spatial as- sociation of Cayley-type plains with the Fra Mauro formation is strong evidence for a genetic relation to Imbrium. Furthermore, ridged Fra Mauro-type materials shown on Apollo orbital photographs appear to extend as far as the Kant plateau, forming a depositional unit that partly filled the crater Descartes.

The hypothesis considered most defensible is that primary ejecta from the Imbrium basin, which itself must have included a mixture of preexisting crustal materials, and probably debris incorporated en route, formed rugged deposits as far away as the Kant plateau. The resulting Descartes mountains were sculptured penecontemporaneously by secondary projectiles, also from Imbrium. Fluid, perhaps partly molten, ejecta entrained in these debris flows pooled in topographic lows. The morphology of plains within the belt circumferential to Imbrium is produced by a planar facies of ejecta from Imbrium. Because the ages of the Cayley-type planar surfaces, as determined by crater-erosion models and crater-frequency distributions, are equivalent to those of Orientale ejecta, "crater-clocks" appear to have been reset in some way by the Orientale event.

The Cayley Formation may have been somewhat analogous to a gigantic ignimbrite-incorporating lenses or pods of molten material in a matrix of cooler debris that flowed into topographic lows and produced subplanar deposits. The molten blobs must have retained heat long enough and been of sufficient magnitude to mobilize and thermally metamorphose the debris around them. Since igneous textures developed, cooling must have been relatively slow locally, possibly allowing this partly molten material to acquire the anomalous remanent magnetism recorded at the surface.

The Cayley Formation and the materials of the Descartes mountains, both largely derived from the Imbrium basin, may be veneered by debris from the Orientale basin or smoothed by the seismic effects of that basin impact. Nectaris ejecta (Janssen Formation) is undoubtedly present at depth. Conclusive identification of these various basin deposits in the samples returned from the Apollo 16 site awaits further investigation. 


\title{
B. APOLLO 16 REGIONAL GEOLOGIC SETTING
}

\author{
By Carroll Ann Hodges
}

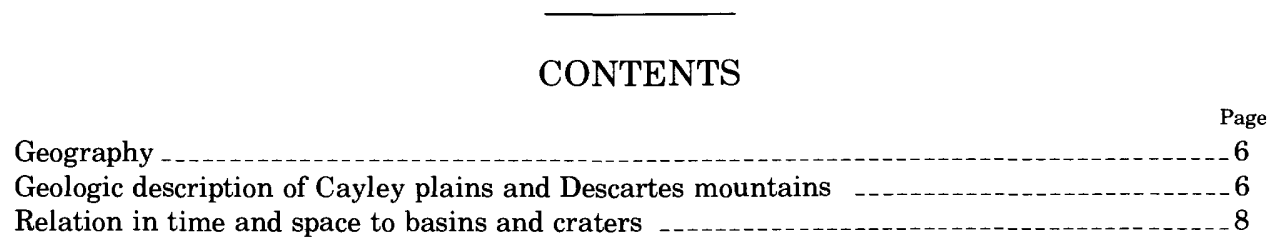

\section{ILLUSTRATIONS}

FIGURE 1. Composite photograph of the lunar near side showing geographic features and multiring basins

2. Photographic mosaic of Apollo 16 landing site and vicinity

\section{GEOGRAPHY}

Apollo 16 landed at approximately $15^{\circ} 30^{\prime}$ E., $9^{\circ} \mathrm{S}$. on the relatively level Cayley plains, adjacent to the rugged Descartes mountains (Milton, 1972; Hodges, 1972a). Approximately $70 \mathrm{~km}$ east is the west-facing escarpment of the Kant plateau, part of the uplifted third ring of the Nectaris basin and topographically the highest area on the lunar near side. With respect to the centers of the three best-developed multiringed basins, the site is about $600 \mathrm{~km}$ west of Nectaris, 1,600 $\mathrm{km}$ southeast of Imbrium, and 3,500 km east-northeast of Orientale. The nearest mare materials are in Tranquillitatis, about $300 \mathrm{~km}$ north (fig.1).

\section{GEOLOGIC DESCRIPTION OF CAYLEY PLAINS AND DESCARTES MOUNTAINS}

The principal geologic objective of the mission was investigation of two major physiographic units, the Cayley plains and the Descartes mountains (fig. 2). Materials of both local units had been interpreted as volcanic before the mission (Milton, 1968; Wilhelms and McCauley, 1971; Milton, 1972; Hodges, 1972a; Elston and others, 1972a,b,c; Trask and McCauley, 1972; Head and Goetz, 1972), mainly on the basis of their topographic expression. Much of the surrounding central highlands was assumed to be largely primitive crustal material, bombarded repeatedly by impact.

The Cayley plains are of Imbrian age according to stratigraphic relations, crater size-frequency distributions, and crater degradation models (Wilhelms and McCauley, 1971; Trask and McCauley, 1972;
Soderblom and Boyce, 1972). The type area of the Cayley Formation is east of the crater Cayley, north of the landing site (Morris and Wilhelms, 1967); the name was extended to the apparently similar plains material at the Apollo 16 site (Milton, 1972; Hodges, 1972a). These materials were presumed to be representative of the widespread photogeologic unit, Imbrian light plains, which covers about 5 percent of the lunar highlands surface (Wilhelms and McCauley, 1971; Howard and others, 1974). Characteristics include relatively level surfaces, intermediate albedo, and nearly identical crater size-frequency distributions.

The plains were first interpreted as smooth facies of Imbrium basin ejecta (Eggleton and Marshall, 1962), but as the characteristics and apparent age of the materials were better defined, a volcanic origin became the favored hypothesis (Milton, 1964; Milton, 1968; Wilhelms and McCauley, 1971; Milton, 1972; Hodges, 1972a; Elston and others, 1972a,b,c; Trask and McCauley, 1972). Frequency distributions of superposed craters are lower on the plains than on the Fra Mauro Formation (Imbrium ejecta), and plains materials are superposed on Imbrium sculpture, indicating that the plains postdate the Imbrium basin. This age relation is further supported by the crater-erosion model (Boyce and others, 1974). In morphology and mode of occurrence, the plains resemble mare materials; surfaces are relatively level, and the plains are confined to craters and broad depressions, suggesting local derivation and fluid emplacement. In the landing site area and elsewhere, craters 0.5 to $1.0 \mathrm{~km}$ in diameter commonly have conspicuous central mounds on their floors. Throughout the central highlands (Wil- 
helms and McCauley, 1971), Cayley-type plains are especially prominent in large old craters-Ptolemaeus, Albategnius, and Hipparchus. Where adjacent to the maria, as at the type area of the Cayley Formation, the plains are embayed or overlapped by mare lavas. Orbital geochemical data obtained during the Apollo missions indicate that the higher albedo of the plains
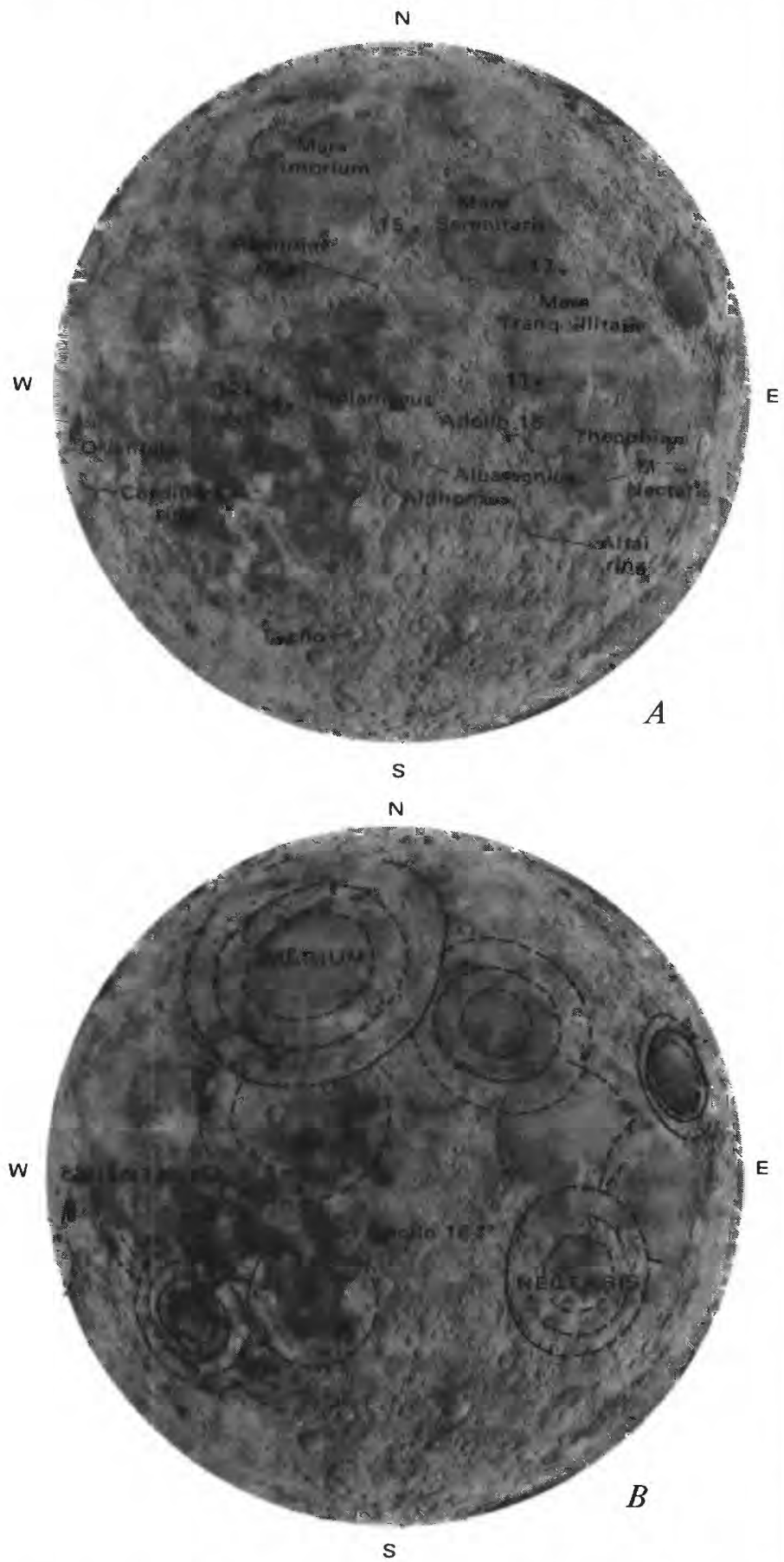

Figure 1.-Lunar near side. $A$, Location of major features mentioned in the text; Apollo landing sites indicated by numbers. $B$, Major rings of near-side multiring basins in relation to Apollo 16 landing site. From Wilhelms and McCauley (1971). materials is produced by an aluminum-to-silicon ratio higher than in rocks of the maria (Adler and others, 1973).

In several places, large subdued craters appear to be mantled by Cayley-type materials, suggesting that a relatively thin deposit was emplaced on an older surface. To account for the apparent differential compaction in the upper layer, ash falls or flows, or possibly mass-wasted debris, were proposed as the depositional materials (Howard and Masursky, 1968; Cummings, 1972). In the large crater Alphonsus, dark conelike structures interpreted as volcanic vents occur along graben in the plains material, an association that supported the volcanic interpretation of the plains (McCauley, 1969).

The Descartes mountains topography is virtually unique on the Moon. No other deposits of identical morphology have been recognized, although similar hilly and furrowed materials of Imbrian age have been mapped in several places (Wilhelms and McCauley, 1971). Sixty kilometers south of the landing site, the materials overlap and nearly fill the degraded $50-\mathrm{km}$ crater Descartes; they are clearly depositional and perhaps $1 \mathrm{~km}$ or more thick (Milton, 1972). No genetic relation to a local impact crater is apparent, and the morphology of the hills and furrows suggested an origin analogous to terrestrial volcanic extrusions or fissure cones to Trask and McCauley (1972). A partly gradational relation with the Cayley Formation was proposed prior to the mission (Milton, 1972; Hodges, 1972a; Elston and others, 1972a,b,c). Although superposed crater populations indicate an Imbrian age for most of the Descartes mountains (Trask and McCauley, 1972), a patch of unusually high albedo near the north rim of the crater Descartes was interpreted as a Copernican pyroclastic deposit (Head and Goetz, 1972).

As a result of the wide acceptance of these volcanic interpretations, developed independently by several authors, premission models of lunar history generally incorporated: (1) a Moonwide, postbasin, premare episode of fluid or pyroclastic volcanism producing Cayley-type plains and (2) a later and more localized phase of relatively viscous extrusive activity, best exemplified by the Descartes mountains. The Apollo 16 mission was designed to test these hypotheses.

The impact origin of the rocks returned from the landing site forced reinterpretations of the geologic units (pl. 1), Textures of the highly feldspathic samples are nearly all indicative of shock metamorphism of various degrees. The rocks are mainly breccias, but even the relatively few crystalline rocks contain "ghost clasts" indicating thermal metamorphism and recrystallization.

New interpretations of the landing-site geology must 
now explain not only the brecciated nature of the rock samples but also all of the characteristics previously ascribed to volcanism. Extrapolation of the data from the Apollo 16 site to similar photogeologic units elsewhere imposes new constraints on the framework of lunar geologic history.

\section{RELATION IN TIME AND SPACE TO BASINS AND CRATERS}

Impact sources and emplacement mechanisms for the geologic units at the landing site and for similar materials elsewhere are not readily apparent. Although local derivation of the rocks has been suggested (Oberbeck and others, 1974a, b; Head, 1974), large multiringed basins now appear to have had pervasive influence throughout the Moon's geologic history (Howard and others, 1974) and probably contributed material to the landing site. Youngest and best preserved of these basins is Orientale, whose outer and most conspicuous ring is the Cordillera, $930 \mathrm{~km}$ in diameter. Next youngest-and largest on the near side-is the Imbrium basin, whose outer ring, the Apennine, is $1,340 \mathrm{~km}$ across; this basin and its ejecta (Fra Mauro Formation) form the stratigraphic and structural base of the Imbrian System (Wilhelms, 1970). The sequence of basin formation becomes progressively ambiguous with increasing age, but Nectaris, nearest the Apollo 16 site, is one of the best preserved of the pre-Imbrian basins on the near side. Its most prominent ring, the Altai, is $840 \mathrm{~km}$ in diameter. Its ejecta blanket, the Janssen Formation (StuartAlexander, 1971), denotes the base of the Nectarian System, immediately preceding the Imbrian System in the time-stratigraphic nomenclature established on the east limb and farside areas of the Moon (StuartAlexander and Wilhelms, 1975). Because of age and proximity, each of these enormous impact events almost certainly influenced the latest stratigraphic and structural development of the entire central highlands including the landing site area.

Inasmuch as multiringed basins formed throughout the Moon's early history, unraveling the stratigraphic column at any given place requires an estimate of the thickness of ejecta contributed by these basins as well as by locally derived material.

Nectaris basin.-The Apollo 16 area, only $600 \mathrm{~km}$ from the center of Nectaris, is well within range of the continuous ejecta from the Nectaris basin, but the Imbrian age of the Cayley and Descartes units sampled precludes their derivation from that basin. Further, no deposits as fresh in appearance as the Descartes mountains occur elsewhere around the Nectaris basin. The Nectaris ejecta that should be present at the site must be buried by these younger materials.

Imbrium basin. - The Apollo 16 site is about 1,600 $\mathrm{km}$ southeast of the center of the Imbrium basin and

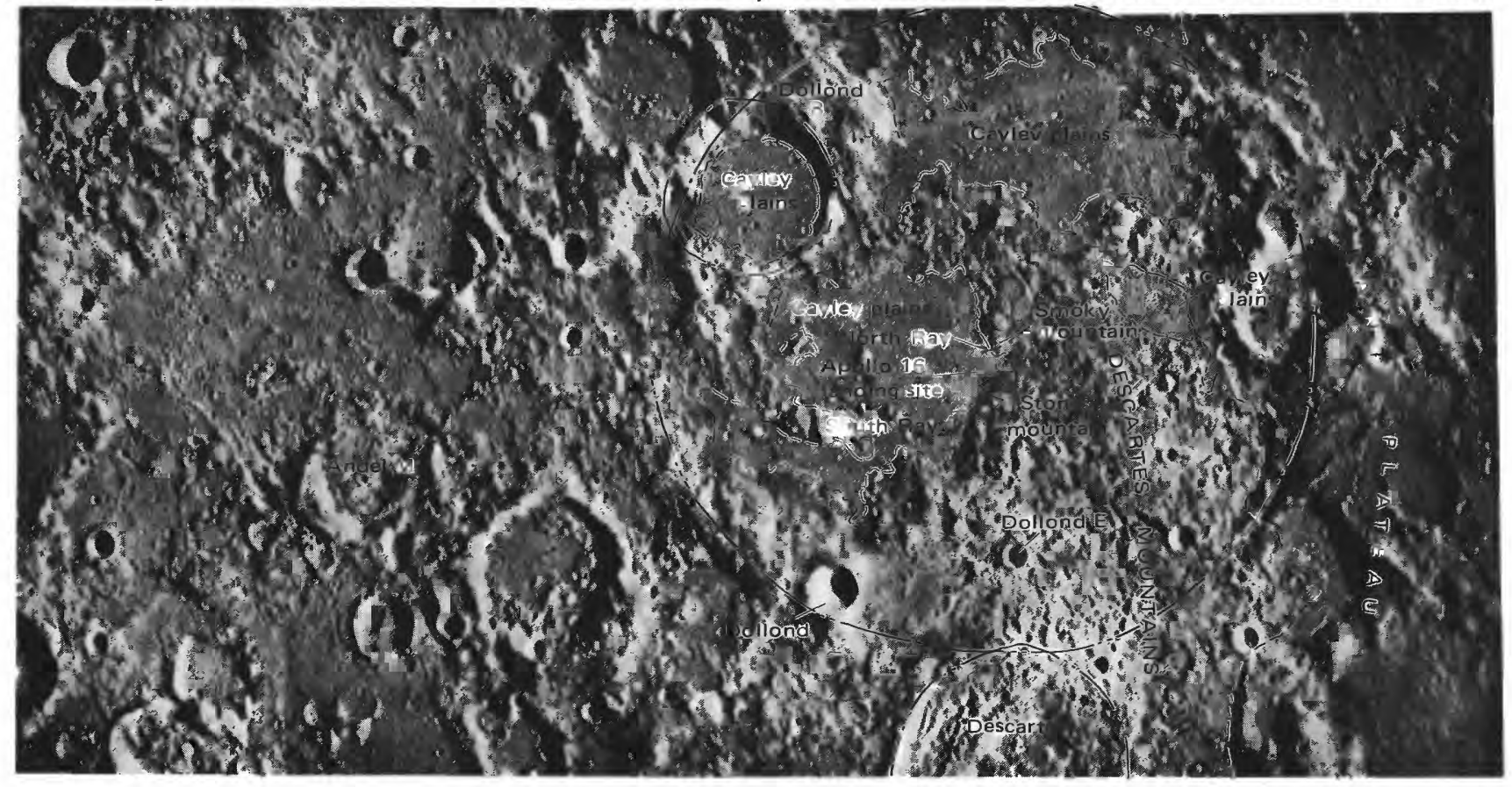

Figure 2.-Apollo 16 landing site and vicinity. Andel M, $130 \mathrm{~km}$ west of the site, may be filled with as much as $1 \mathrm{~km}$ of mixed Imbrium ejecta and debris from its destroyed north rim. Prominent ridges and furrows trending predominantly southeast reflect Imbrium sculpture (secondary cratering) and possible flow lineations in primary ejecta. (Apollo 16 mapping-camera frames 439 , $440,441,442$.) 
within a well-defined belt of plains peripheral to that basin in both the central highlands (Eggleton and Schaber, 1972) and on the north (Lucchitta, 1978). Although the site is beyond the range of Imbrium ejecta previously mapped (Wilhelms and McCauley, 1971), this spatial association of plains and basin suggests a genetic relation (Eggleton and Marshall, 1962; Eggleton and Schaber, 1972). Size-frequency distribution of superposed craters, crater degradation models, and stratigraphic relations indicate that the central plains are younger than the Fra Mauro Formation (Wilhelms and McCauley, 1971; Greeley and Gault, 1970; Soderblom and Boyce, 1972), whereas two patches of northern plains are equivalent in age to Fra Mauro Formation (Boyce and others, 1974).

The Descartes mountains may be composed of Imbrium ejecta banked against the Kant plateau, analogous to the deceleration ridges (Trask and McCauley, 1972) of the Hevelius Formation trapped by preexisting crater walls around Orientale (Hodges, 1972b; Hodges and others, 1973). Smaller scale analogs have been described within the ejecta blanket of a crater only $3.5 \mathrm{~km}$ in diameter (Head, 1972). Discontinuous Fra Mauro materials occur west of the site where the crater Andel M (fig. 2) appears to have been partly filled by Imbrium ejecta that destroyed its north rim (Moore and others, 1974).

Orientale basin. - The Apollo 16 site is about 3,500 $\mathrm{km}$ from the center of Orientale-well beyond any previously recognized extent of that basin's ejecta. The Cayley-type plains, however, appear to be contemporaneous with the Hevelius Formation (McCauley, 1967), which is the continuous ejecta from Orientale and which includes a conspicuous planar facies of broad extent, mainly at the distal margin of the textured ejecta (Soderblom and Boyce, 1972; Hodges and others, 1973). In order to account for the age of the plains surfaces, as deduced from cratering models, Orientale was proposed as the source of the uppermost deposits of both mountains and plains at the Apollo 16 site (Chao and others, 1973; Hodges and others, 1973). Theoretical analyses of ejecta volume argue that ejecta from Orientale may be dispersed over the entire Moon (Moore and others, 1974); broad distribution of crater ejecta is demonstrated photogeologically by young craters such as Tycho, whose rays extend more than $3,000 \mathrm{~km}$ (Baldwin, 1963).

Local craters. - Because of stratigraphic constraints, local craters are an unsatisfactory source for the materials at the Apollo 16 site. The Cayley plains are younger than any large adjacent craters, all of which have clearly been sculptured by Imbrium ejecta. A pre-Imbrian crater $150 \mathrm{~km}$ in diameter centered on the landing site has been conjectured (Milton, 1972; Head, 1974), but materials formed by such a crater would be several kilometers deep at the landing site and are not likely to have been included in the sample collection. Head (1974) proposed that the plains were essentially floor materials of a $60-\mathrm{km}$ crater whose rim crest includes Stone and Smoky mountains. This seems impossible, however, for such a crater would have to be younger than the Descartes mountains of Imbrian age, yet older than the pre-Imbrian crater Dollond B (fig. 2), an obvious incongruity; even allowing the Descartes mountains and the plains to be pre-Imbrian would require the plains to be sculptured, and they are not. Furthermore, this mechanism, requiring local origin within craters, cannot be extrapolated, inasmuch as craters containing Cayley-type plains are generally considerably older than the enclosed plains, and some plains (for example, at the Cayley Formation's type locality) are not within craters.

A possible derivation of plains materials by local secondary cratering was advocated by Oberbeck and others (1975), who demonstrated that the mass of ejecta from a secondary crater far exceeds the mass of the primary projectile at increasing distances from the continuous ejecta blanket. The pervasiveness of Imbrium sculpture caused by secondary projectiles around the Apollo 16 site indicates that such cratering, together with mass wasting and extensive lateral transport, could have concentrated material in topographic lows, although the crater size-frequency distributions of the surficial plains suggest a younger age for the deposits than is accountable by this postulate. The potential sources for rocks returned from the Apollo 16 mission are reexamined in Hodges and Muehlberger (this volume) after presentation of field data and pertinent orbital information.

To summarize the position of the Cayley plains and Descartes mountains in space and time: (1) The units are Imbrian in age, and the uppermost plains deposits are essentially contemporaneous with the formation of the Orientale basin; cratering ages of the Descartes materials are not so well defined because of their rugged topography, but they are at least as old as Imbrian. (2) Because of proximity to the Nectaris basin, stratigraphy at the Apollo 16 site must surely include Nectaris ejecta at depth, but the basin is too old to have produced the materials now at the surface. (3) The site is within the "sphere of influence" of the Imbrium basin, as indicated by the sculpturing produced by gouging of secondary projectiles, and Imbrium deposits may well be present. (4) The hypothesis that Orientale ejecta reached the site is based largely on the apparent contemporaneity of that basin with the surficial plains deposits. Deposition of Orientale ejecta on the order of several tens of meters (a speculation not represented on the accompanying geologic map, pl. 1) seems required to "reset" the Imbrium "crater clocks." 


\section{APOLLO 16 TRAVERSE PLANNING AND FIELD PROCEDURES}

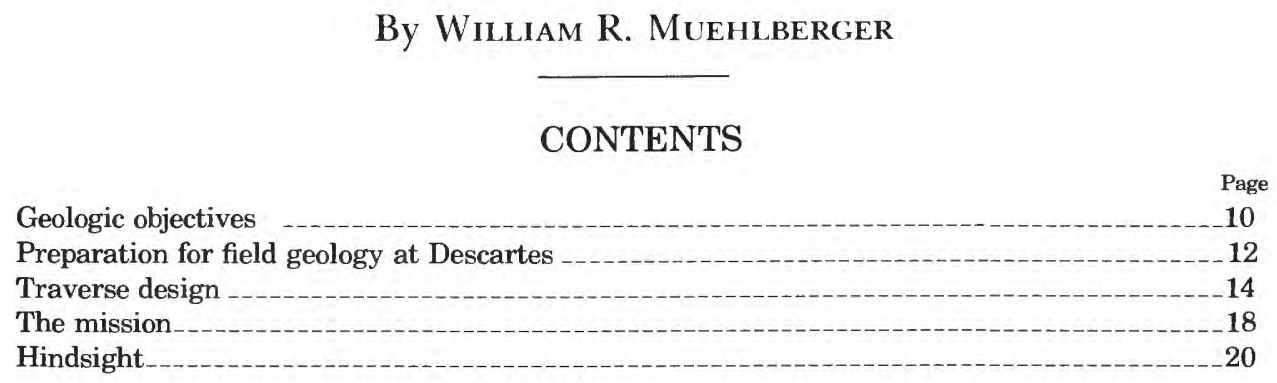

\section{ILLUSTRATIONS}

FIGURE 1. Composite photograph of near side of the Moon showing the Apollo landing sites

2. Photograph showing Apollo 16 landing site and regional lunar features

3. Photographs illustrating sampling equipment and techniques used on Apollo 16

4. Diagram showing premission traverses and geologic objectives

5. Photograph showing locations of actual Apollo 16 traverses

\section{GEOLOGIC OBJECTIVES}

The geologic objectives of the Apollo 16 mission were to understand better the nature and development of the highland area north of the crater Descartes, including an area of Cayley plains and the adjacent Descartes mountains, and to study processes that have modified highland surfaces. The objectives were to be met through the study of the geologic features both on the surface and from orbit and through analyses of the samples returned.

The plans for the mission finally evolved from backroom discussions and formal review between interested personnel: scientists, engineers, and, foremost, the astronauts themselves. The premission plan as finalized shortly before launch underwent modification during the mission as the science support team evaluated revised times available for traverses, problems that arose during the mission, and changing geologic concepts of the area being investigated.

Highlands materials had been collected at the Apollo 14 and 15 landing sites (fig. 1): from the continuous ejecta blanket of the Imbrium basin at Apollo 14; from the base of the Apennine front, the outer ring of mountains bounding the Imbrium basin, at Apollo 15. Each of these sites yielded highlands materials of different types that could be related to Imbrium basin formation.

At the Apollo 16 site, materials of both a widespread highlands plains unit and the rugged Descartes mountains were of interest; neither geologic unit had yet been sampled in the Apollo reconnaissance of the Moon.

Ray materials from two small but conspicuous Copernican craters, North Ray and South Ray, both on the Cayley plains, mantle a considerable part of the traverse area, on both plains and adjacent mountains

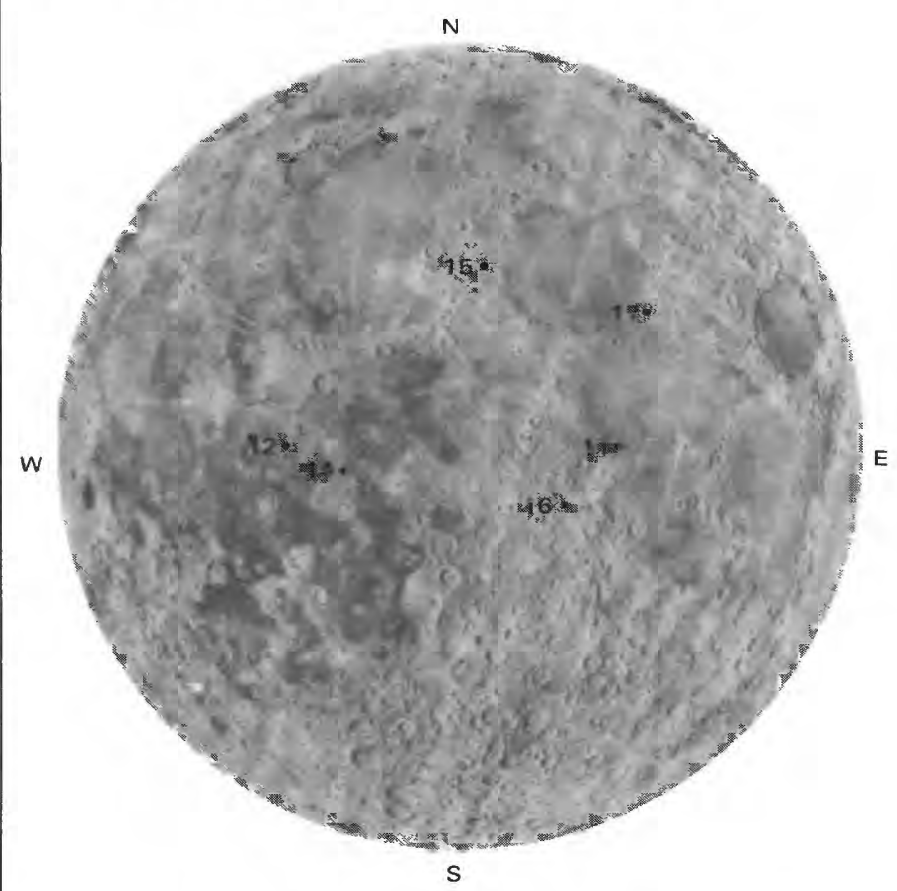

FIGURE 1.-Near side of the Moon showing the Apollo landing sites. 
(Hodges, 1972a; Elston and others, 1972a, b). Impact craters of Imbrian to late Copernican age are prominent throughout the region (fig. 2). Rimless to low- rimmed, irregular depressions were mapped as craters of either secondary impact from Theophilus, $300 \mathrm{~km}$ to the east, or volcanic origin.

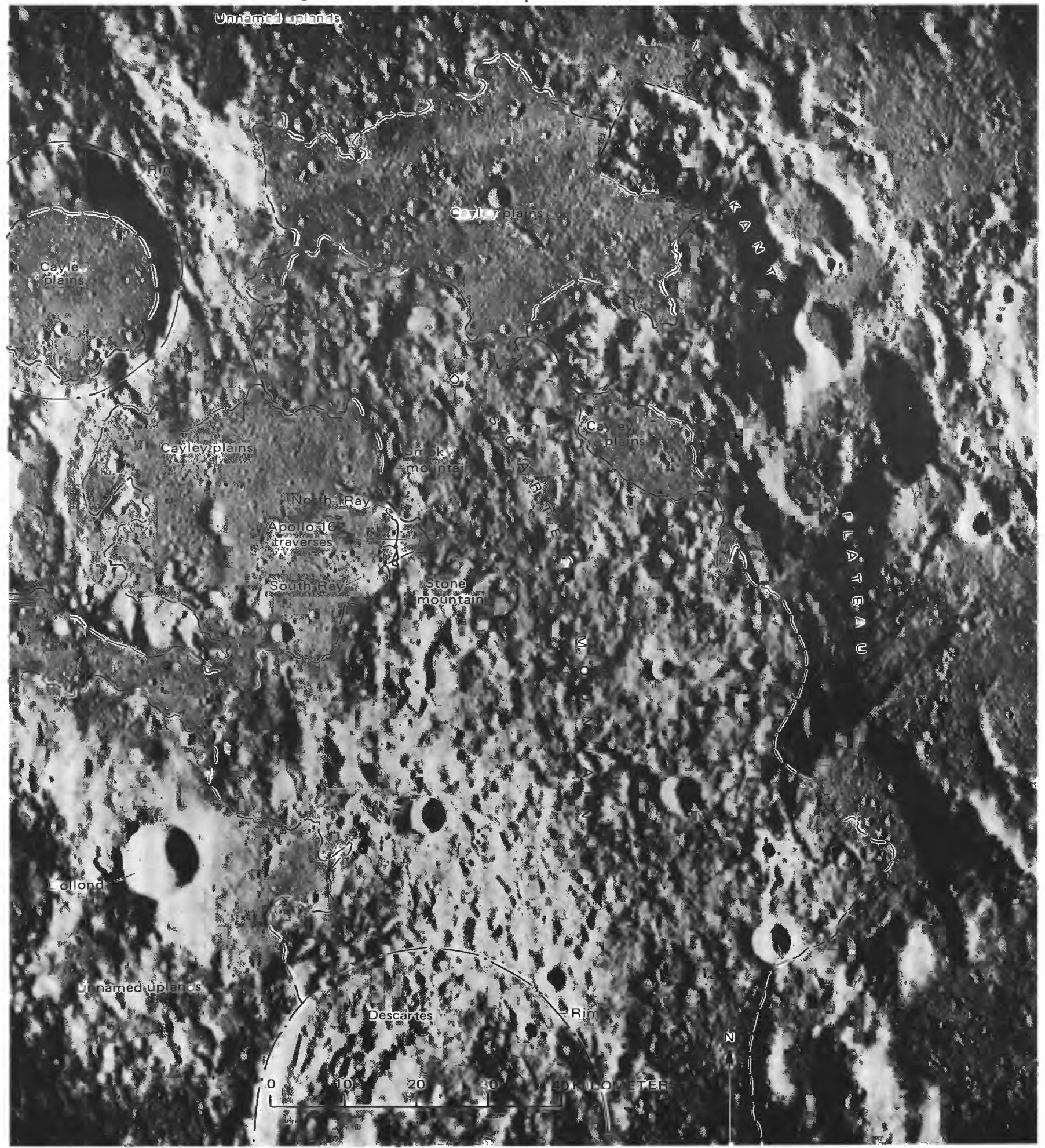

FIGURE 2.-Apollo 16 landing site, traverses, and regional lunar features. From AFGIT (1973) and Hodges and others (1973). Reprinted with permission of the American Association for the Advancement of Science and Pergamon Press. 
Lithologic layering in the Cayley plains was suggested by albedo bands and ledges in the walls of several craters and by mounds in the floors of craters about $1 \mathrm{~km}$ in diameter. Lithologic layering in the materials of the Descartes mountains was suggested by topographic benches and bands of slightly varied albedo on the flanks of Stone mountain. Materials at depth beneath the Cayley plains were interpreted as including both the Fra Mauro Formation derived from the Imbrium basin and ejecta from the nearer but older Nectaris basin (Hodges, 1972a). Elston and others $(1972 b)$ projected the flank of a highly cratered preImbrian hill beneath the traverse region. The depth to these units was unknown, but all were believed to be well below the depth of local cratering and therefore unlikely to be sampled in the traverse area.

\section{PREPARATION FOR FIELD GEOLOGY AT DESCARTES}

The name of the game in traverse planning is maximum science return. Most surface experiments and the central station of the Apollo Lunar Surface Experiments Package (ALSEP) that telemetered data to Earth required deployment by the astronauts, or required astronaut voice data transmission as in the procedure for the Lunar Portable Magnetometer. Each of these types of operations required rapid deployment (using minimum time), and a definite period of time was allocated to each experiment.

The geologic experiment was more difficult to structure, and the observations, sampling, and photography necessary to satisfy the collective geologic community required time and equipment beyond that available. For example, a fourth traverse or Extravehicular Activity (EVA) was requested by the Field Geology Experiment Team (with the concurrence of the astronauts) in order to study South Ray crater and its ejecta blanket. This request was denied because it would have gone beyond the time limits deemed safe for the LM systems. As time was extremely limited, an intricate system of priorities was established for both station locations and tasks performed at each station. The development of priorities involved many individuals and advocate groups for the various aspects of the traverse activities. The final system of priorities and contingency plans appeared in the "Lunar Surface Procedures" and "Science Contingency Plan" documents for the mission.

The field training of the astronauts developed their abilities to identify and describe the significant geologic features in view, to sample and document photographically the geologic units at a sampling site, to document the significant relations of areas remote from the traverse line by use of telephoto cameras and description, and to integrate previous observations into a general geologic picture of the landing site.

Both sampling procedures and photographic techniques evolved with experience during training and throughout the actual missions. Sampling procedures focused on obtaining a truly representative collection of materials at the site while staying within severe weight restrictions. In addition to standard sampling procedures (illustrated in fig. 3), several special techniques were used to: (1) support studies of the surface character of the regolith, the optical properties of the

Figure 3.-Sampling equipment and techniques used on Apollo 16. $A$, Sample 61295 broken from large rock under gnomon. Regolith samples were taken from fillet surrounding rock. Photograph taken to include LRV to assist in locating sample areas. Station 1, Plum crater. AS16-109-17804. B, Gnomon in standard position with color chart leg toward sun and near sample to be collected. Gray scale and color chart on leg and wand gives true color; bands are $2 \mathrm{~cm}$ wide, for photographic scale; wand is mounted in gimbels to give local vertical. Station 5, cross-sun view. AS16-110-18024. $C$, Same as $B$ but with sample 65035 removed. Station 5 , cross-sun view. AS16-110-18025. $D$, Sampling area of $B$ and $C$ after collection of rake sample. Gnomon leg at right edge. Station 5, cross-sun view. AS16-110-18026. E, Sample 60018 being chipped from large rock by Astronaut Charles Duke. Rake being used for scale. Wires in rake are spaced $1 \mathrm{~cm}$ apart. Cuff checklist of notes strapped to astronaut's wrist, above hammer. Camera lens sun-shade and sample bags hanging from a clip below the camera are visible. Station 10. AS16-116-18689. F, Astronaut John Young breaking chips from spall zone, Outhouse rock, North Ray crater. Sample bags being carried by hand because clip under camera fell off. Each bag is numbered and called out by astronaut when sample is placed in it. Camera and mounting bracket on astronaut's chest, and cuff checklist clearly visible. AS16-116-18647. G, Tongs being used as scale for sample site. Astronaut John Young pulling rake. Rim of North Ray crater; LRV in background; white breccia boulder sampling area on skyline. AS16-106-17340. H, Tongs holding rock 60115 , just removed from small depression (arrow) in which rock had lain on lunar surface. Station 10. AS16-11418446. $I$, Closeup stereo view of boulder 1 at station 8 showing textural details of breccia not visible in small samples returned. AS16-108-17693/17694. J, Scoop being used as locator. Dark stripe on handle used as guide by the astronaut to give proper distance for closeup photography. Sample 60275 marked by arrow. Sampling station at LM. AS16-117-18833. $K$, Area of $J$ after removal of sample 60275 with scoop. AS16-117-18835. L, Scoop, gnomon, and sample collection bag (SCB). The unlatched and open top shows two single core tubes (drive tubes) stowed within the bag. This bag can be carried by hand or attached to the astronaut's life support system. Individual samples in their numbered bags are stored in the SCB. Station 4, down-sun, before sampling. AS16107-17464. $M$, Double core attached to extension handle. Lower tube about half driven. Upper tube (number 29) visible. Station 8 , AS16-108-17682. $N$, Double core hammered to total depth. Station 8, location changed from that shown in M. AS16-108-17686. $O$, Hinged rack (in open position) on rear of LRV, showing (rightto-left) rake, both tongs, and penetrometer drum in stowed position for travel. Lunar portable magnetometer deployed at end of $15-\mathrm{m}$ cable. Other equipment under seats. AS16-114-18433. 
lunar surface, the unabraded surfaces of lunar rocks, boulder erosion and filleting, the adsorption of mobile elements in shaded areas, cosmic ray tracks in large and small boulders, and chemical homogeneity throughout single units and (2) support future studies on uncontaminated lunar soil. Horz and others (1972) described these procedures and special samples returned, including an X-ray description of the cores collected.

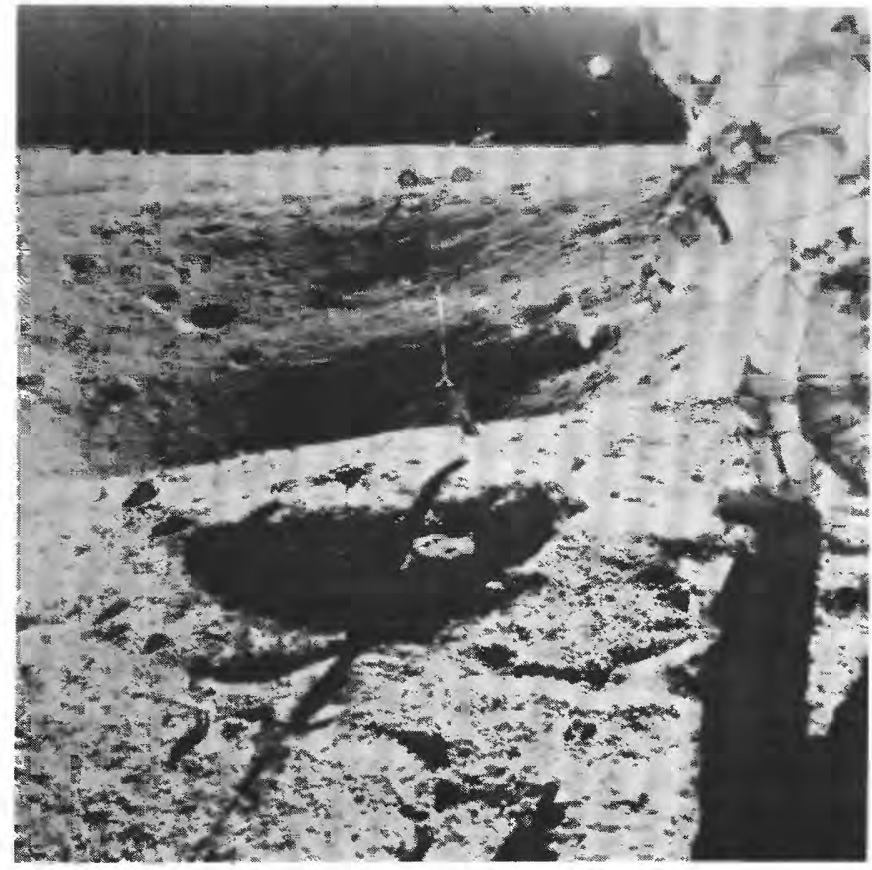

A

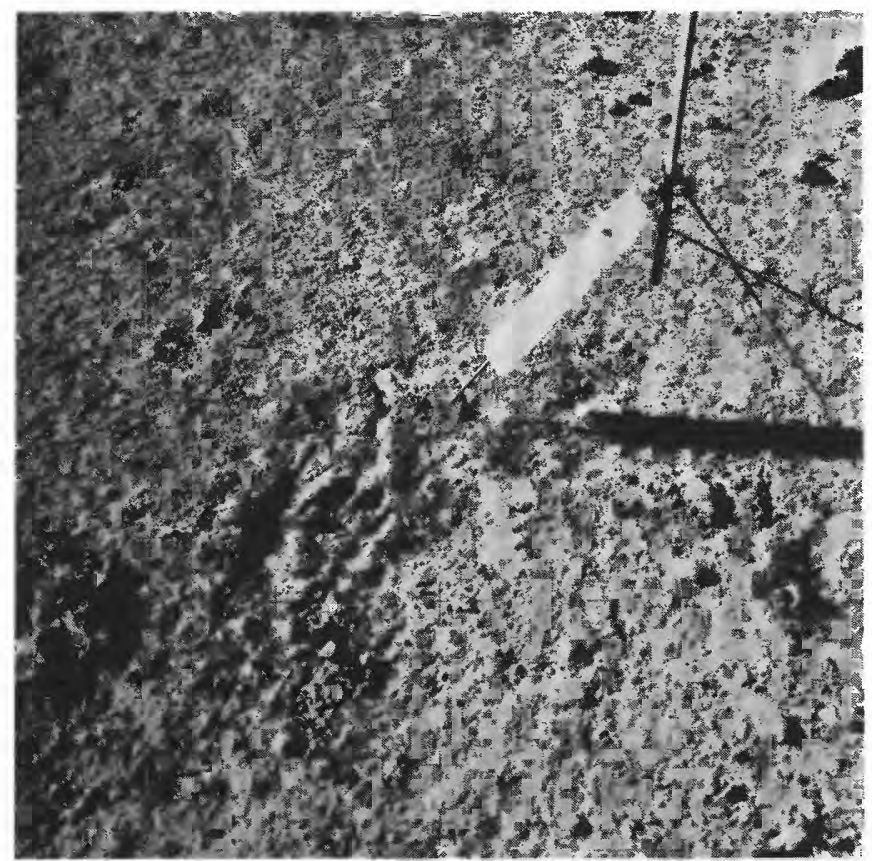

C
Photographic requirements included two panoramas at each station, one taken immediately upon arrival at the station, the other just prior to leaving the station, so that the undisturbed surface could be studied, sample locations more easily identified, and a stereobase established for detailed study. Telephoto surveys were made from two stations to obtain a stereobase of Stone and Smoky mountains for analysis of lineaments like those first recognized on Mount Hadley during Apollo

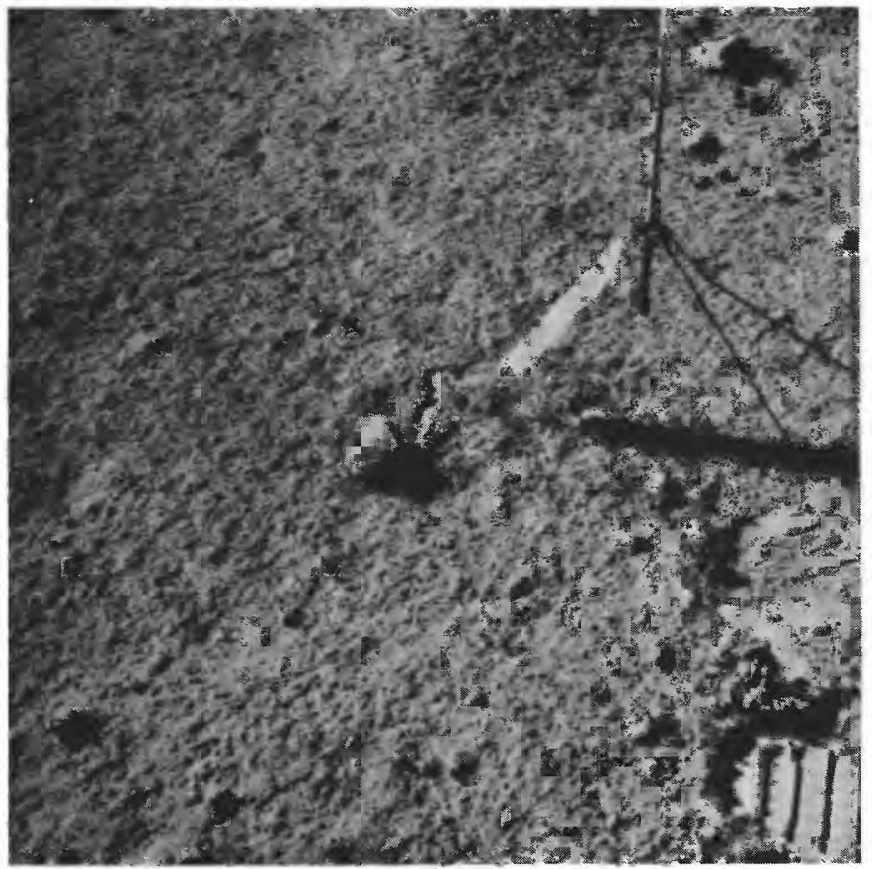

B

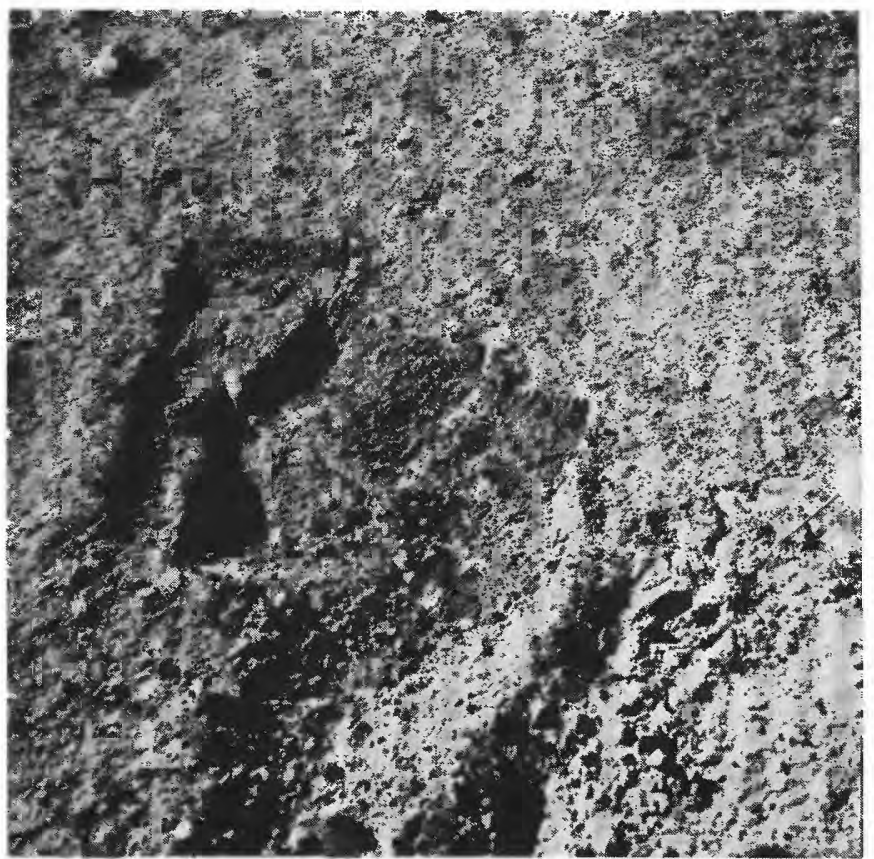

$D$ 
15. In addition, two polarimetric surveys were made at station 11: one to establish calibration control in the near-field of a sampled area and one of the inaccessible interior of North Ray crater taken from the rim.

Finally, the photographs required included a standard set for sample documentation, closeup stereopairs for analysis of rock textures, and "flight-line" stereo, that is, a series of photographs perpendicular to a boulder that would provide a stereo base for study.

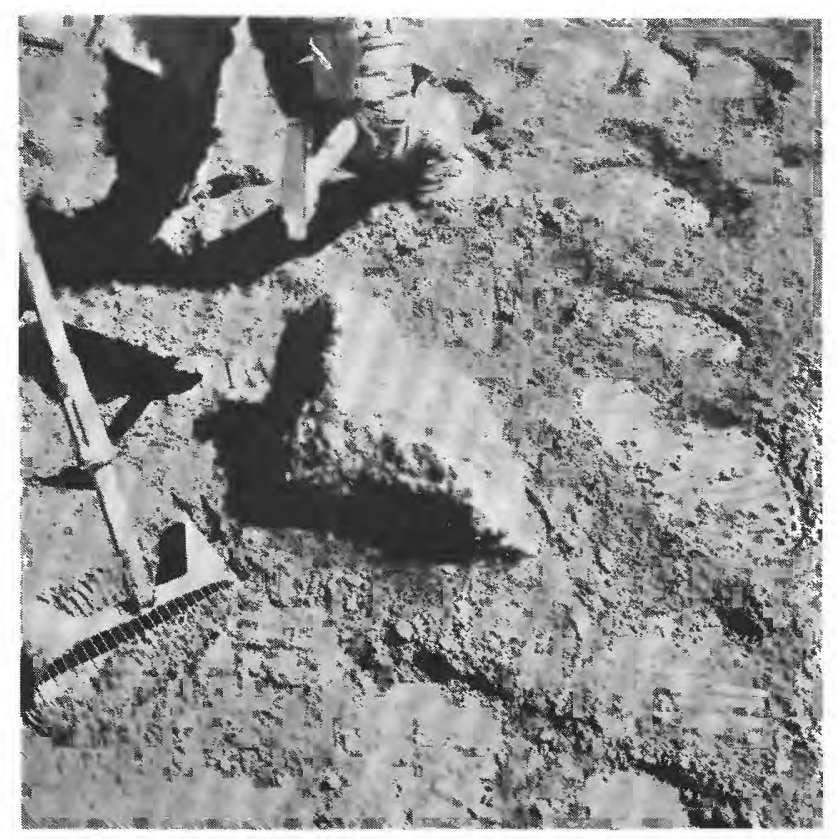

E

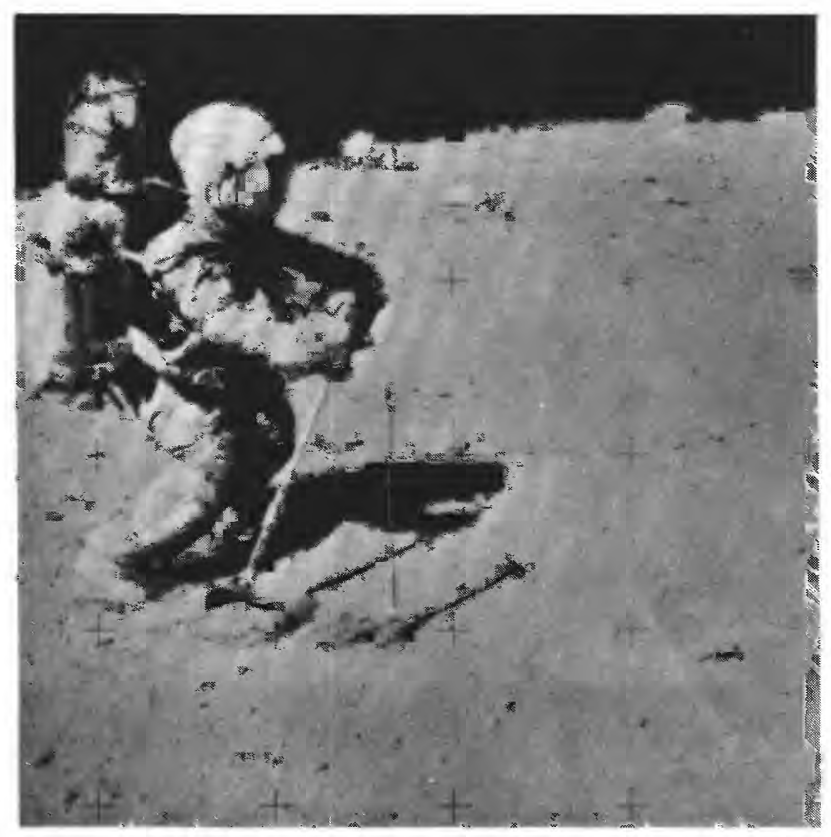

G

\section{TRAVERSE DESIGN}

The three traverses (one per EVA) were designed to optimize investigations of the Cayley plains and the Descartes mountains (fig. 4). For that purpose, a preliminary photomosaic and topographic base map, plate 2, was prepared from existing Apollo 14 Hasselblad photographic coverage 9 months before the mission. This allowed detailed traverse planning to start de-

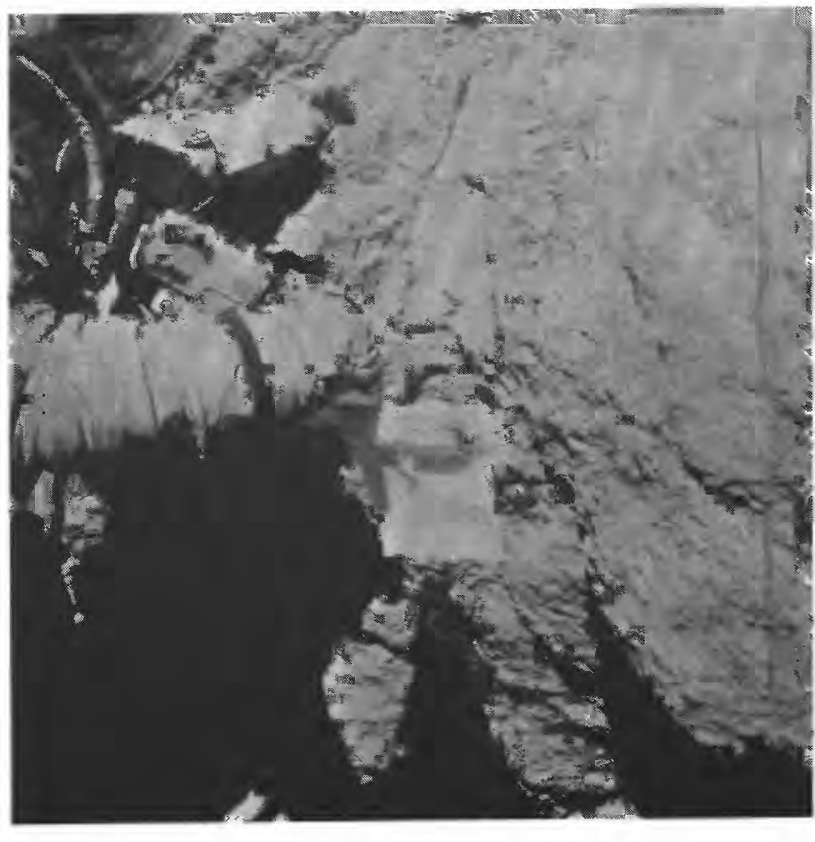

F

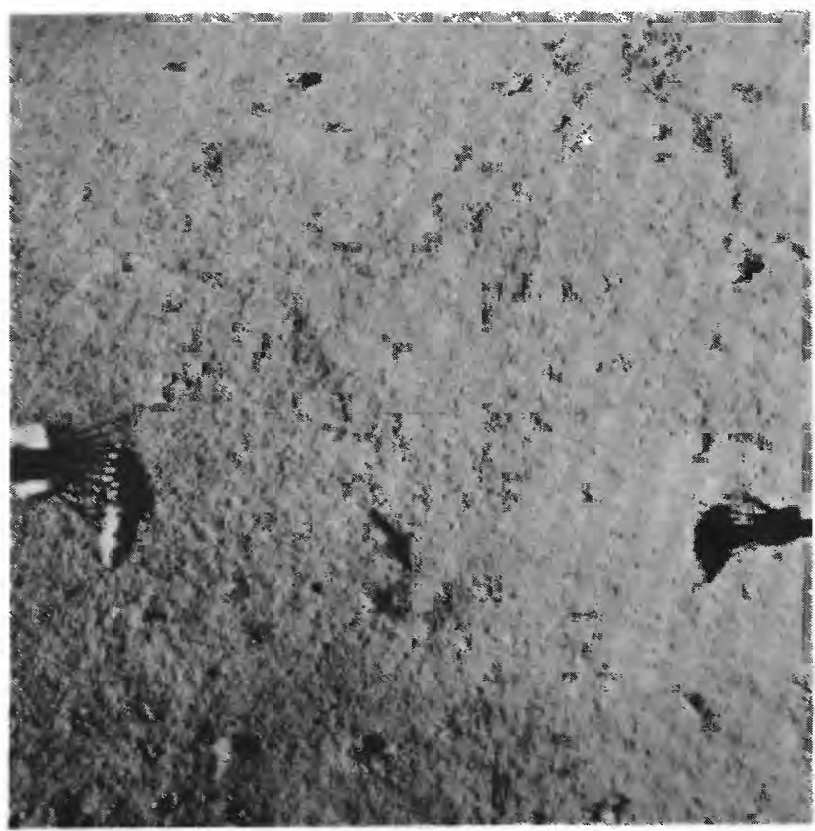

H 
spite the low resolution of the photography and long before more accurate maps became available. The Cayley Formation was to be sampled during each traverse in order to determine lateral variations of the stratigraphic section between North Ray and South Ray craters, the petrology of the formation throughout the area, and the characteristics of the upland plains regolith. The prime sampling areas were located at Flag and Spook craters and in the vicinity of the LM and ALSEP, where crater dimensions suggested that the unit might be sampled to depths of approximately $60 \mathrm{~m}$. Avoiding ray material so as to obtain locally derived samples of Cayley Formation was a major consideration in the LM-Spook-Flag sampling areas.

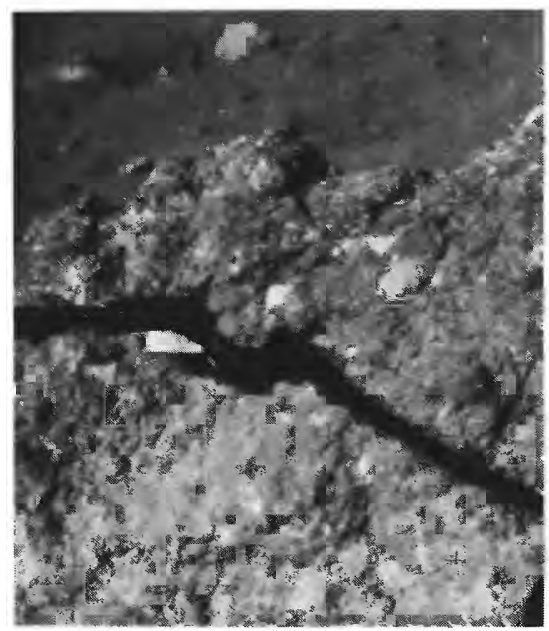

$I-L$

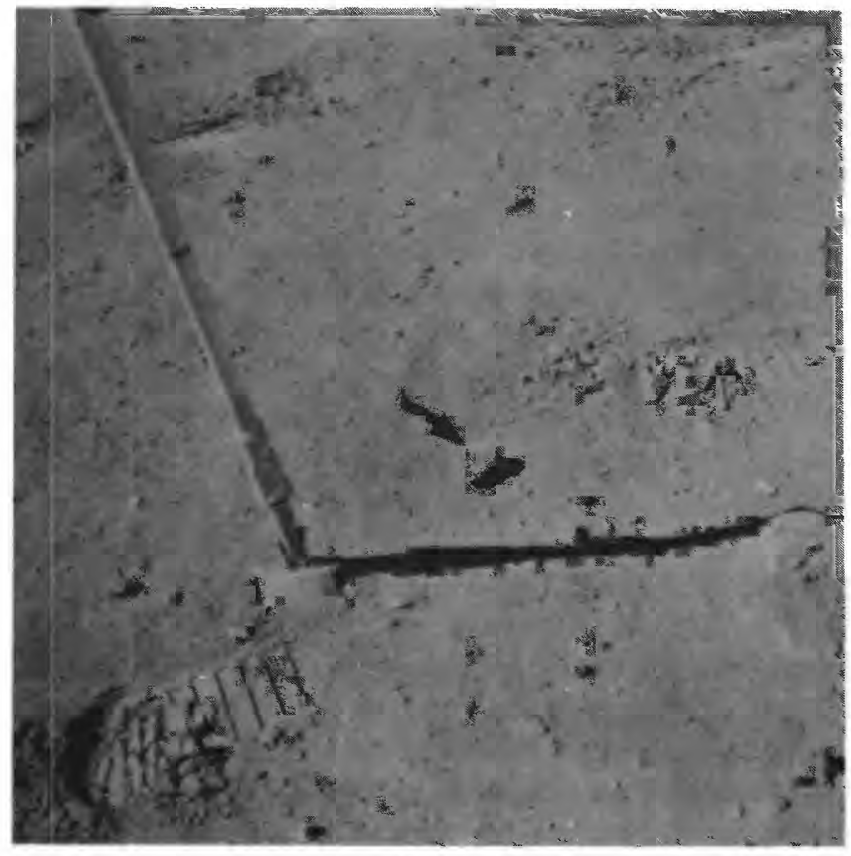

Prime sampling sites for deeper parts of the Cayley were in the ejecta of North Ray and South Ray craters.

The short distance between Flag and Spook craters, about $1 \mathrm{~km}$, made it possible early in the lunar surface activities (EVA-1) to test the lateral continuity of bedrock layers. Good stratigraphic correlations in these craters could provide a solid base for extending the stratigraphy into the LM-ALSEP area and a geologic basis for the interpretation of the Active Seismic Experiment profile. It was hoped that the stratigraphy could then be carried northward through Palmetto to North Ray crater and southward to South Ray crater. Both Flag and Spook craters are degraded and have a veneer of South Ray ejecta across or near them. Station

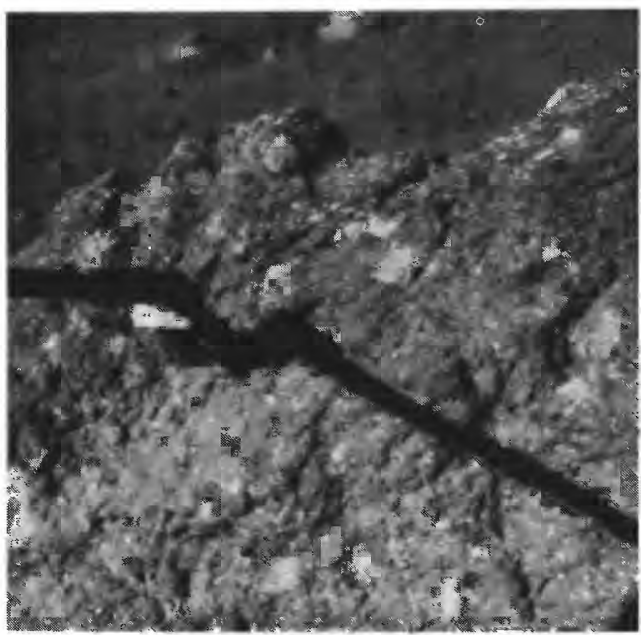

$I-R$

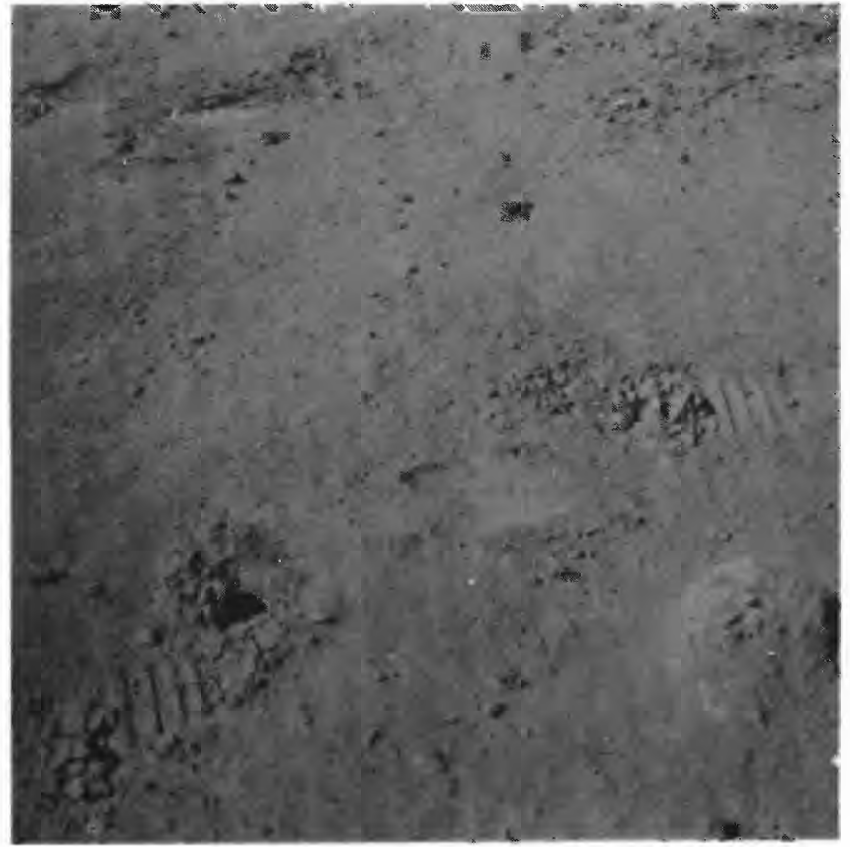

K 
1 was located on Plum crater, a small fresh crater on the rim of Flag crater, thought large enough to have penetrated the entire Flag crater ejecta blanket, and station 2 was on Buster crater, thought to have penetrated the upper layer of the underlying Cayley Formation even though it lies on the outer part of the ejecta blanket of Spook crater. A third station, for sampling, coring, and experiments in soil mechanics in the ALSEP area, was moved late in the planning stages to

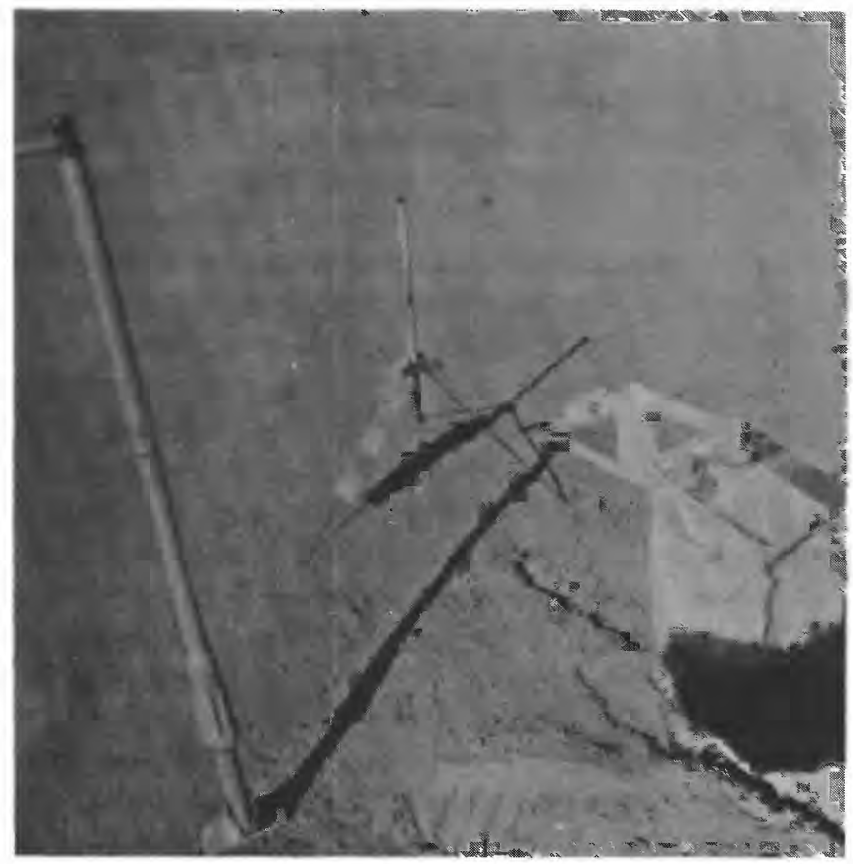

$L$

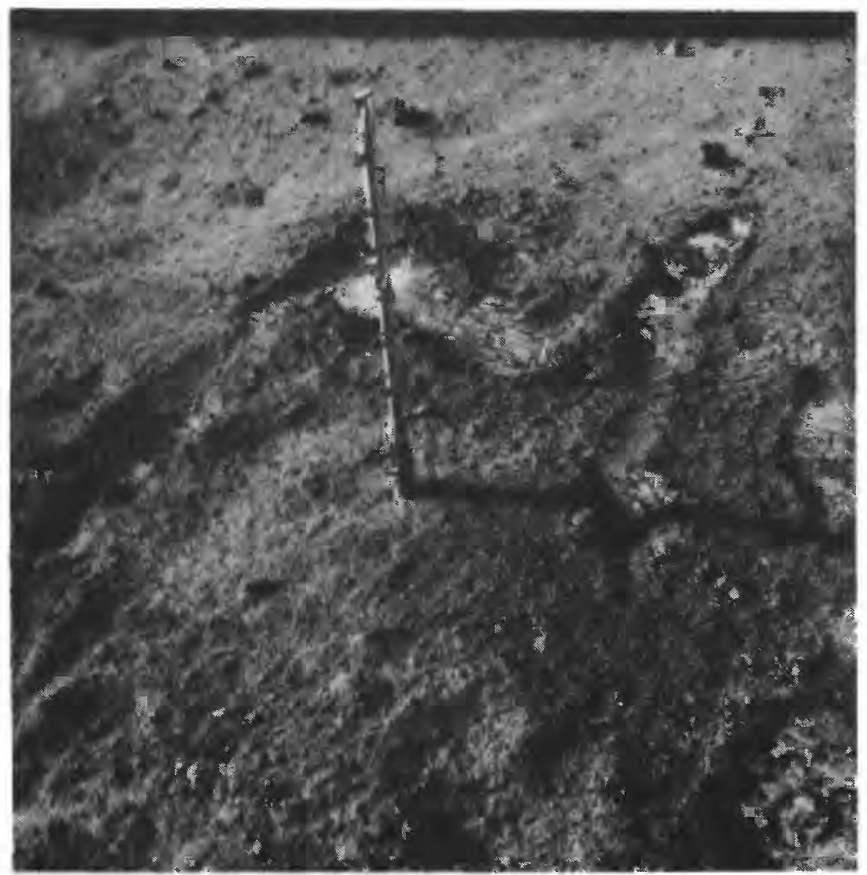

the end of EVA-2 so that maximum sampling time could be spent at Flag and Spook craters.

Deeper parts of the Cayley Formation were assumed to have been excavated by the larger North Ray and South Ray impacts and exposed near the rim of North Ray crater (stations 11, 12, and 13, fig. 4) and in the ray deposits of South Ray crater (station 8).

On the second traverse, stations 4,5 , and 6 on the flank of Stone mountain were the principal sampling

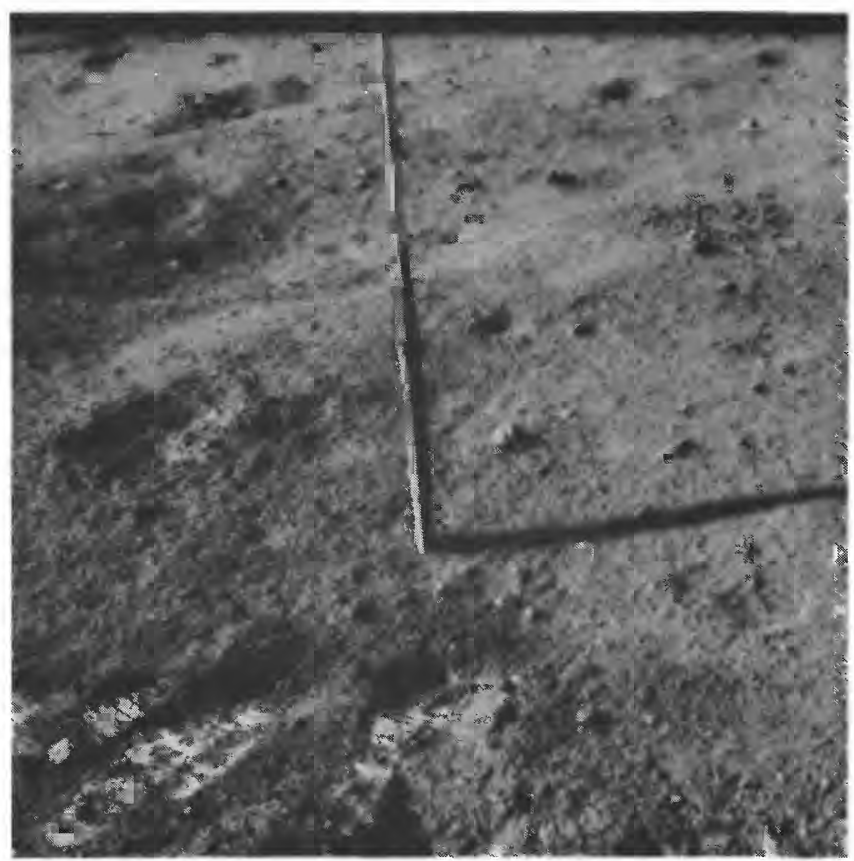

$M$

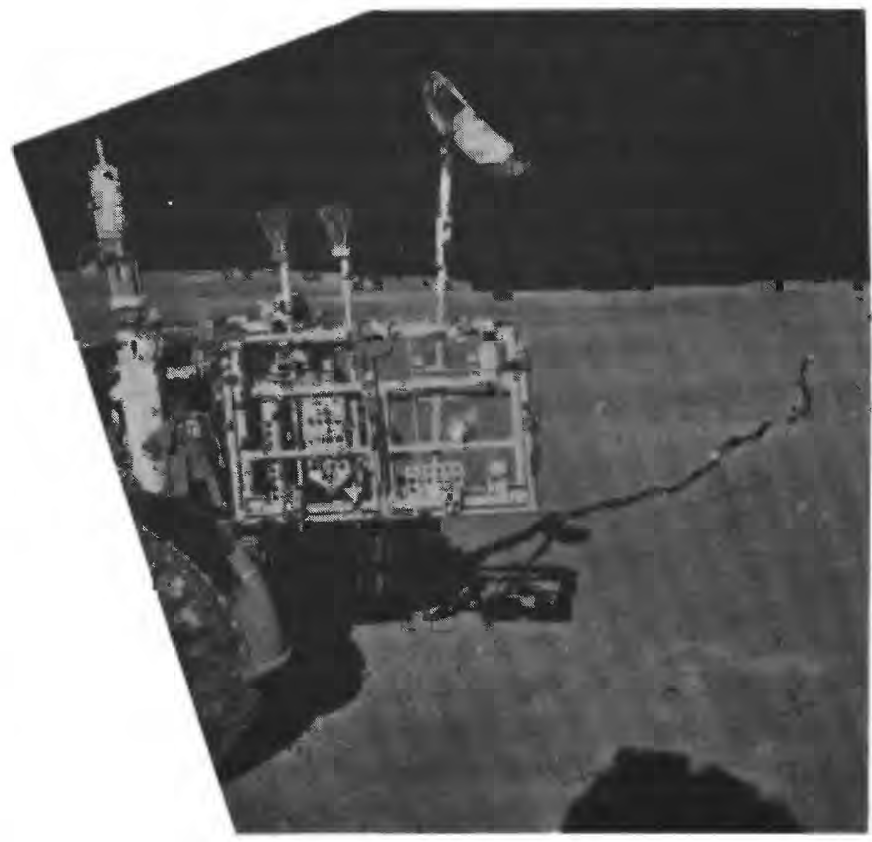

$O$ 
sites for Descartes mountains materials (fig. 4). These stations were on benches delineated on the premission topographic map (U.S. Army Topographic Command, 1972). The station farthest upslope (station 4) was located between Cinco $d$ and $e$, a pair of craters that must penetrate the regolith, excavating blocks of Stone mountain material. It was hoped that ray material from South Ray crater, anticipated at these stations, could be recognized and avoided. In addition to employing a wide variety of sampling techniques, penetrometer tests of soil were to be performed; the elevation of the station would permit good telephoto viewing of the rim and interior of South Ray and Baby Ray craters on the plains. Locations of the lower stations on Stone mountain (5 and 6) were spaced at equal intervals down the slope but subject to change if the astronauts observed outcrops, blocky-rimmed craters, or other features of particular interest on their outbound traverse. Station 14, on the lower slopes of Smoky mountain, was planned for the third traverse in order to compare the two mountain units.

The rim of North Ray crater, nearly $1 \mathrm{~km}$ in diameter and more than $200 \mathrm{~m}$ deep, was the prime site for obtaining the deepest samples of Cayley plains. The younger South Ray crater was believed inaccessible because of the blockiness of the ejecta blanket and the large deep craters (Trap-Wreck-Stubby) that obstructed the direct route from the LM. Although many large blocks were observed in the ejecta of North Ray crater, there appeared to be relatively smooth approaches along which the astronauts could drive to the crater rim or at least to within walking distance of it. Seven stratigraphic layers within the crater were interpreted on the basis of albedo differences (Elston and others, 1972a, b, c) visible on premission photographs having a resolution no better than $5 \mathrm{~m}$. Lateral variations in these bands across the crater, a large dark central mound on the crater floor, and a 25-m-long dark boulder on the crater rim were identified as features of interest. Stations 11 and 12, approximately $200 \mathrm{~m}$ apart on the crater rim, were located as end points of a sampling strip that would provide materials representative of all layers penetrated, except possibly the top one. Station 12 was at the huge dark block named "House rock" by the astronauts, assumed, in premission planning, to be visible from a distance and therefore useful as a navigation aid. To guarantee samples from the uppermost layers of the Cayley

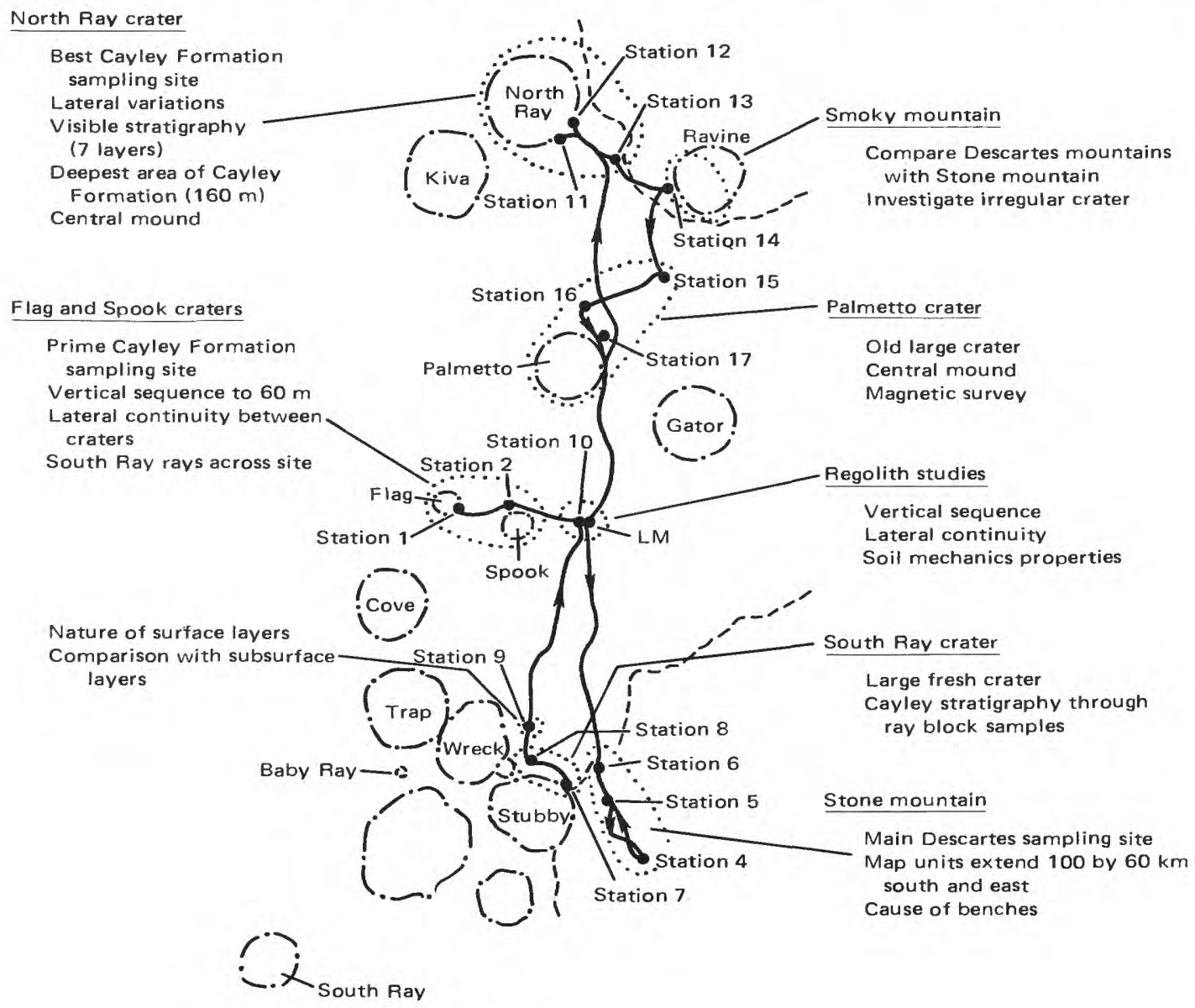

FIGURE 4.-Planned traverses and geologic objectives. 
plains, station 13 was established far out on the ejecta blanket. A wide variety of photographic techniques was planned to document the compositional, textural, and stratigraphic relations of the returned samples: panoramas from several locations for stereoviewing, 500-mm telephotography of far crater wall, near- and far-field polarimetric surveys, close-up stereo for textural details of individual boulders, "flight-line" stereo of large boulders, as well as conventional photographic documentation during sampling.

Palmetto crater, about the same diameter as North Ray crater, is older and very subdued; a few large fresh craters occur near its rim. Stations 16 and 17 (fig. 4) were selected as the best places for sampling Palmetto ejecta. In addition, the outbound traverse was specifically planned along the Palmetto rim so that the astronauts could observe features within the crater and on its ejecta blanket not visible on the premission photographs and thereby recommend changes in the plan for the end of the traverse. Station 15 was planned at a small fresh crater for sampling the local top layer of the Cayley Formation to establish lateral continuity. Stations 15, 16, and 17 were also planned as magnetometer stations designed to determine whether magnetic anomalies occur around a large crater (Palmetto).

Rays from South Ray crater were visible across much of the landing site area on premission photographs, but the nature of the ejecta in rays was unknown. Either a blanket of debris of various sizes or a string of blocks and associated fines that produced secondary craters, or perhaps a combination of both, was thought to account for the apparent characteristics. Ascertaining the composition of rays was essential in order to assign samples collected to their proper source craters.

Ideally the procedure for sampling these rays would have included intensive study of several widely separated patches, as each patch represents only a small volume of the crater ejecta. The more patches studied, the better the stratigraphic sampling of the crater, despite the fact that most ray material in the vicinity of the LM was likely derived from only the upper quarter or less of the crater. South Ray material was expected in cores from the LM/ALSEP and station 8 areas and in some of the surficial samples returned. Station 8 , near the rim of Stubby crater in the brightest ray patch accessible, was planned specifically to obtain materials from South Ray crater. Sampling by all techniques available was designed to obtain a variety of rock types representative of stratigraphic units. Trenching and coring was expected to indicate the thickness of nearsurface units; special samples from the top and bottom of large boulders and from the soil beneath such boulders might provide an exact date of the South Ray impact. Photographs of secondary craters and the boul- ders that formed them would indicate azimuths toward the source.

The objectives of station 9 required a mature regolith surface, free of recent contamination by ejecta from fresh young craters. The station location had to be selected by the crew as they traveled, although the general area was delimited prior to the mission. The primary purpose of this station was to study the surface of the regolith visible in photographs and telescopes and analyzed by nonpenetrating geochemical and geophysical devices. The station had to be in a patch of Cayley Formation of "typical" or "average" albedo such that the data could be extrapolated regionally. A series of successively deeper samples were to be collected to determine the nature of the regolith. Samplers were designed to collect uppermost layers of surface grains, and a surface skim sample was to be collected, as well as a deeper scoop sample directly under the skim. A special vacuum-sealed short core was designed to protect the most pristine sample yet returned from the Moon, and several padded bags were included to preserve fragment surfaces (see Horz and others, 1972, for details).

A very readable booklet on details of premission planning for various surface and orbital experiments and hardware aboard the Apollo 16 mission was written by Simmons (1972).

\section{THE MISSION}

Several mechanical and operational problems arose during the mission that prevented exact execution of the premission plans. Because a mechanical problem developed in the CSM engine, the lunar landing was delayed for three revolutions, or nearly 5 hours. This delay changed the mission plans. To keep the astronauts' work day within acceptable medical limitations, a sleep period was assigned first upon landing instead of an immediate EVA. This change precluded observing the flanks of Stone mountain for lineaments like those seen on Mount Hadley at the Apollo 15 landing site. The second of two planned telephoto panoramas to be taken during EVA-1 for stereo study of Stone mountain was cancelled because of lack of time and was taken instead at the start of EVA-3. This panorama, taken at high sun angle, shows no shadow lineaments.

During EVA-2 (fig. 5), problems with the LRV navigation system, a lack of landmarks, and difficult trafficability combined to stop the astronauts short of the prime goal near Cinco $e$. In order to preserve the schedule at station 8 and 9 and to keep enough time at station 10 to do the preplanned tasks and, if required, to remove the broken cable on the Heat Flow Experiment, station 7 was cancelled. This station, planned for 15-minutes duration, was intended for sampling of a 


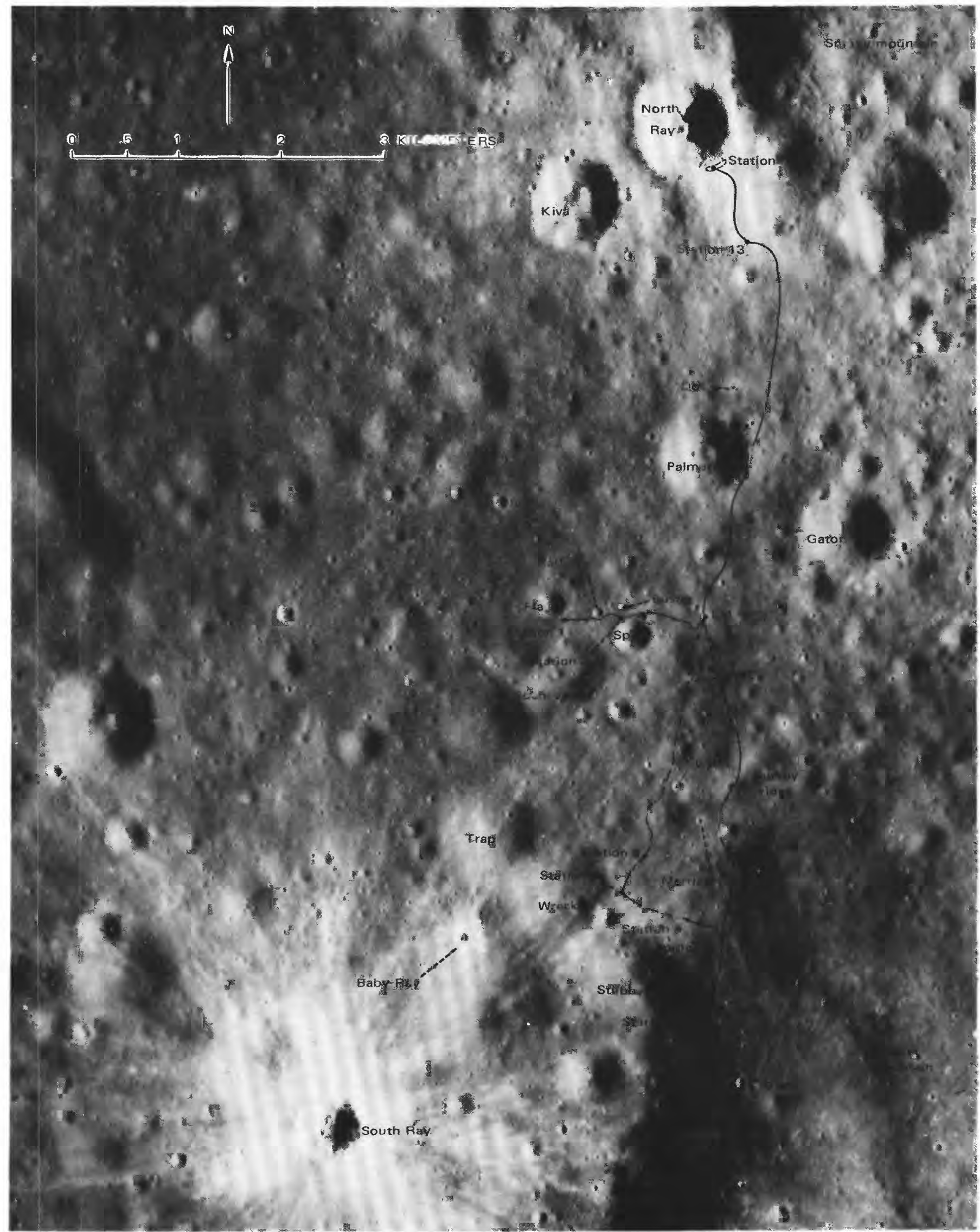

Figure 5.-Actual traverses. Apollo 16 panoramic-camera frame 4618. 
fresh crater near the mapped Descartes-Cayley contact and a telephoto survey of Smoky mountain and the interior of Stubby crater.

EVA-3 was shortened from 7 to 5 hours when it was decided to lift off from the lunar surface at the preplanned time rather than extend the lunar surface stay and risk problems with nearly depleted LM systems. All activities other than those scheduled for North Ray crater were cancelled. The astronauts drove the LRV to the rim of the crater without difficulty, allowing time for nearly all of the preplanned tasks for stations 11 and 12 to be accomplished. The near-field polarimetric survey was cancelled and a second abbreviated telephoto panorama into North Ray crater was taken from near House rock. The operational aspects of the mission are described in the Apollo 16 preliminary science report (Baldwin, 1972). Despite exigencies that developed through the mission, all of the primary geologic tasks were carried out: sampling of the Cayley plains, of ejecta from North Ray and South Ray craters, and of materials from Stone mountain, representative of the Descartes mountains; photographic coverage of all sampling areas, the entire traverse route, and telephoto views of all important points remote from the traverse route.

\section{HINDSIGHT}

Photogeologic interpretations for this mission were hampered by the low resolution of the best available premission photographs. As it turned out, nearly all the large blocks ( $5 \mathrm{~m}$ or larger) had been located (Boudette and others, 1972), but because the an- nounced resolution of the photographs was $5 \mathrm{~m}$ or poorer, it was not certain whether features at or near the limit of resolution were real or simply artifacts of photoprocessing. The number of boulders identified and the blockiness predicted from radar studies of the site convinced us that travel through the rays from both South Ray and North Ray craters would be difficult if not impossible. The virtual absence of rocks on North Ray, except for those identified before the mission, was startling. Had the spacing of blocks on South Ray rays been known, the mission might have been designed differently: an alternative considered was a dash to Stone mountain along with deployment of the ALSEP on EVA-1, followed by EVA's to South Ray and Baby Ray craters, and then to North Ray crater. Better geologic data from the youngest crater rims could have helped immeasurably to determine the nature of the Cayley Formation, its composition, and stratigraphic makeup. Data from a fresher or larger crater on Stone mountain, remote from South Ray crater ejecta, could have better defined the character of the materials composing the Descartes mountains.

Certainly if we had better understood, before the mission, the enormity of the events forming the Imbrium and Orientale basins and the potential extent of their ejecta, we would have considered geologic alternatives to the volcanic interpretation of the units at the Apollo 16 site. The geologic field training might thus have been different, many of the special sampling experiments might never have been scheduled for this mission, and as a result, the time available for geologic traverses would have been allocated differently. 


\title{
D1. FIELD GEOLOGY OF APOLLO 16 CENTRAL REGION
}

\author{
By Gerald G. Schaber
}

CONTENTS
The LM/ALSEP station
Station 1 -
Station 2 -
Summary

\section{ILLUSTRATIONS}

FIGURE 1. Planimetric map of the LM/ALSEP area Page

2. Photograph showing distribution of ejecta near the Apollo 16 landing site

3. Photographic-topographic map and stereopairs of the central part of the landing site

4. Diagram showing size and distribution of fragments photographed along traverses

5. Map showing block distribution within $10 \mathrm{~m}$ of panorama site north of the LM

6. Sketch map of landing site and central region

7-10. Photographs:

7. Sample 60016

8. Sample 60018

9. Sample 60025

10. Sample 60315

11. Planimetric map of station 1

12. Map showing block distribution within $10 \mathrm{~m}$ of northeast station 1 panorama

13-18. Photographs:

13. Sample 61016

14. Samples 61135 and 61195

15. Sample 61295 (including stereopair)

16. Sample 61015

17. Sample 61175 (including stereopair)

18. Large filleted boulder at Flag crater

19. Planimetric map of station 2

20. Map showing block distribution within $10 \mathrm{~m}$ of station 2 panorama

21-24. Photographs:

21. Sample 62235 (including stereopair)

22. Sample 62255

23. Sample 62275 (including stereopair)

24. Sample 62295 (including stereopair)

\section{TABLES}

TABLE 1. Number and percentages of rocks $(>2 \mathrm{~g})$ documented at the LM/ALSEP station

2. Number and percentages of rocks $(>2 \mathrm{~g})$ documented at station 1

3. Number and percentages of rocks $(>2 \mathrm{~g})$ documented at station $2 \ldots 42$

\section{THE LM/ALSEP STATION}

The central region of the Apollo 16 landing site includes three major areas-LM/ALSEP, station 1, and station 2-all underlain by materials of the Cayley plains. The LM/ALSEP station comprises five general areas-Lunar Module or LM, Apollo Lunar Surface Experiments Package or ALSEP, station 10, station $10^{\prime}$, and the Lunar Roving Vehicle or LRV final parking site-ranging from approximately $70 \mathrm{~m}$ east to $140 \mathrm{~m}$ southwest of the LM (pls. 3 and 8; fig. 1). All five sites lie within but at the east edge of distinct ray material ejected from South Ray crater $5.7 \mathrm{~km}$ to the southwest (fig. 2).

The Cayley plains in the LM/ALSEP region are broadly undulating and slope to the southwest; the maximum relief within a radius of $400 \mathrm{~m}$ from the LM 
site is $25 \mathrm{~m}$ (fig. 3). The amount of surface covered by 2 to $20-\mathrm{cm}$ fragments ranges from 1.3 to 6 percent and averages about 2 percent (figl 4). Blocks as large as 0.5 $\mathrm{m}$ are relatively common (fig. 5). The largest boulder
(33 $\mathrm{m}$ north of ALSEP) is several meters across. The rocks are uniformly distributed, not deeply buried, and are poorly filleted, some are perched, unburied, and lack fillets entirely. The rocks with little or no fillet are

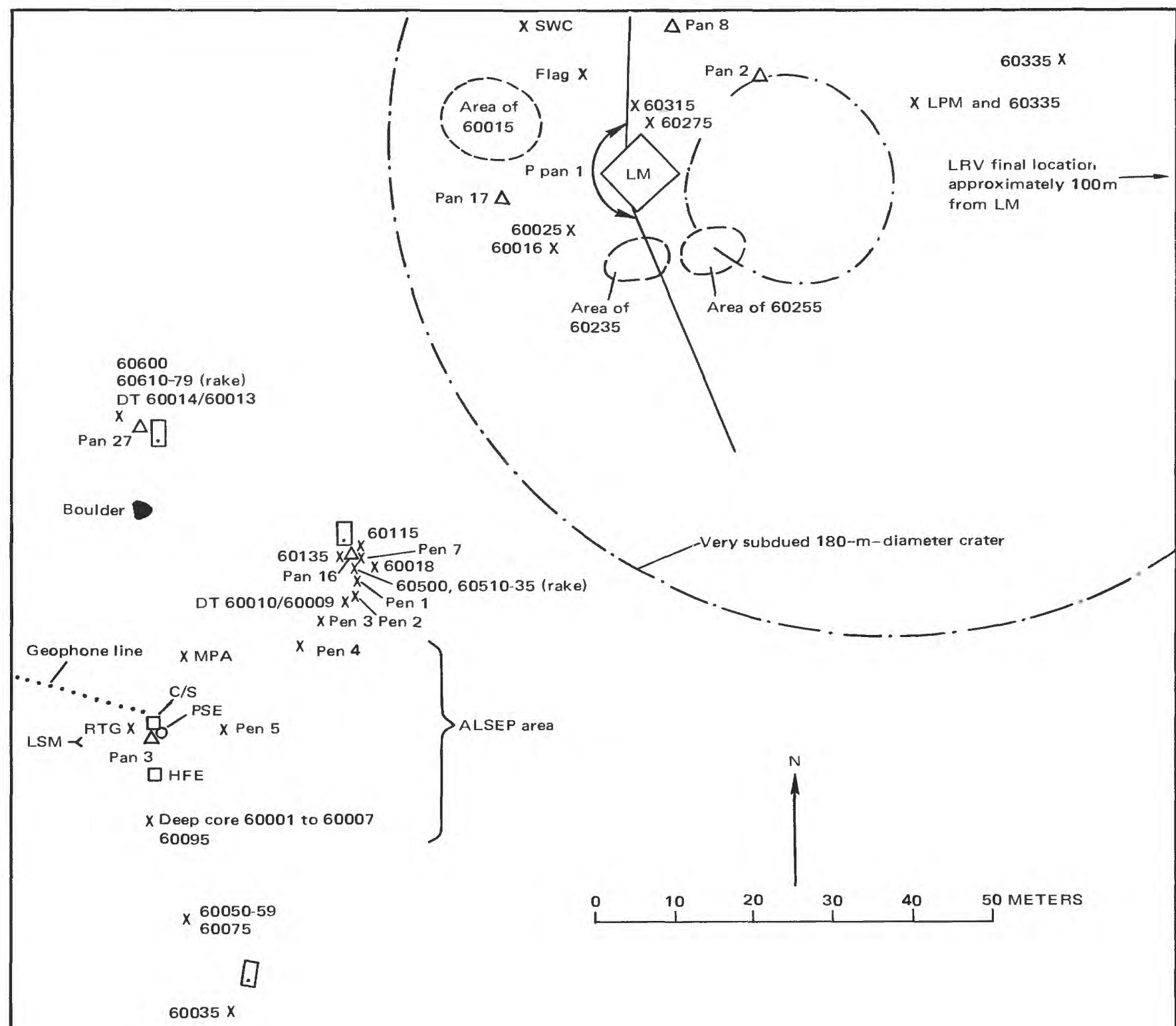

EXPLANATION

\begin{tabular}{|c|c|c|c|}
\hline j. & Crater rim & PSE & Passive seismic experiment \\
\hline$\times 60335$ & Sample locality and number & LSM & Lunar surface magnetometer \\
\hline DT & Drive tube & HFE & Heat-flow experiment \\
\hline $\begin{array}{l}P \text { pan } \\
\triangle \text { Pan } 2\end{array}$ & $\begin{array}{l}\text { Partial panorama } \\
\text { Panorama location and number }\end{array}$ & RTG & $\begin{array}{l}\text { Radioisotopic thermoelectric } \\
\text { generator }\end{array}$ \\
\hline & LRV; dot on front & MPA & Mortar package assembly \\
\hline$X$ Pen 5 & $\begin{array}{l}\text { Penetrometer reading, location } \\
\text { and number }\end{array}$ & $\begin{array}{l}\text { LPM } \\
\text { SWC }\end{array}$ & $\begin{array}{l}\text { Lunar portable magnetometer } \\
\text { Solar wind composition }\end{array}$ \\
\hline $\mathrm{c} / \mathrm{s}$ & Central station & & \\
\hline
\end{tabular}

Figure 1.-Planimetric map of the LM/ALSEP area. 


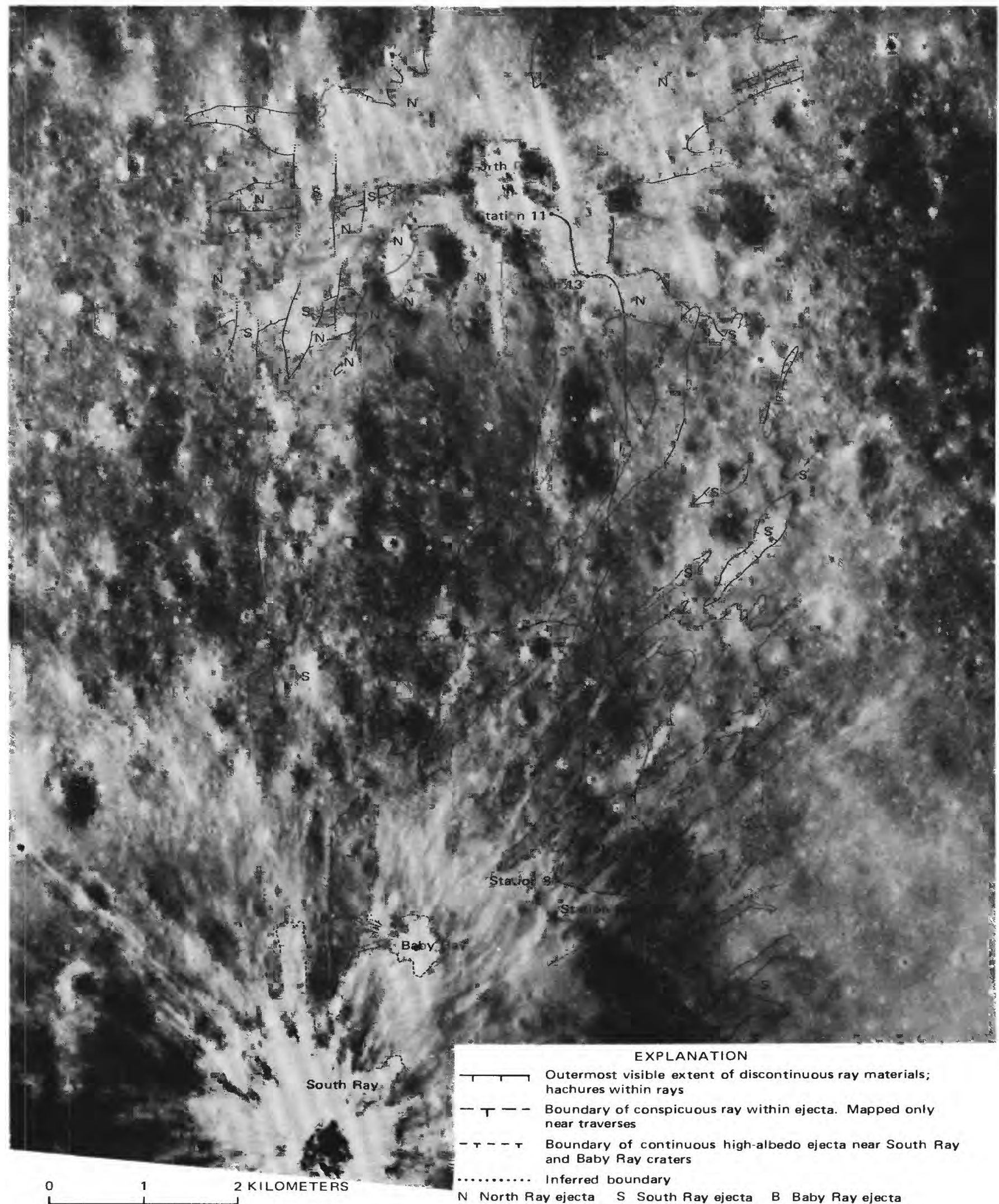

FIGURE 2.-Distribution of ejecta near the Apollo 16 landing site. Derived from second-generation film positives of Apollo 14 orbital photographs AS14-69-9520 and 9522 (500 mm), using stereoanalytic plotter (from Muehlberger and others, 1972). 


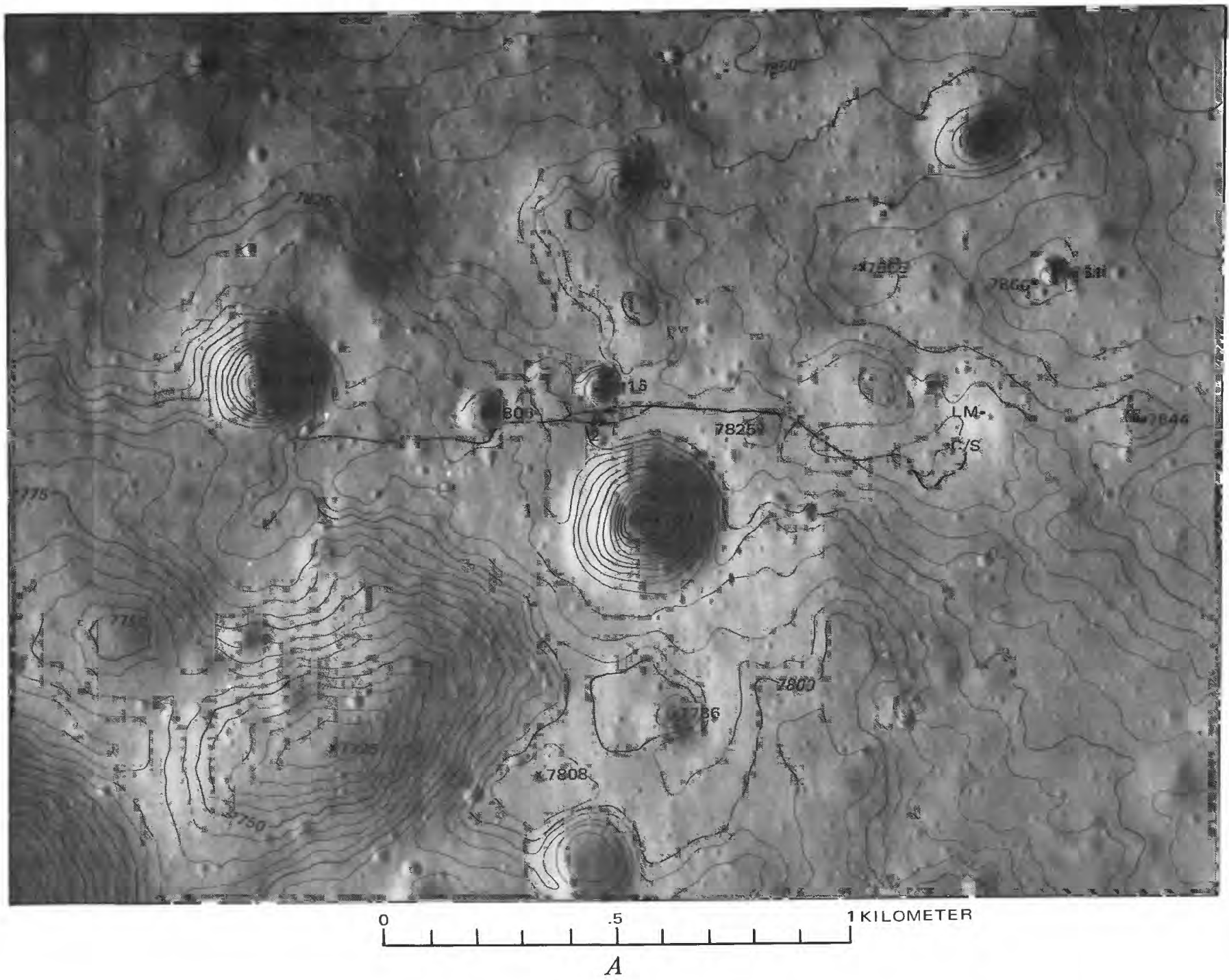

Figure 3.-Map and stereopairs of the central part of the landing site. A, Contour map of Apollo 16 central landing site region superimposed on Apollo 16 panoramic photograph, frame 4618. LM sites and EVA-1 traverse indicated. Contour interval, 5 m; arbitrary datum. Geographic names on figure 6. Topography compiled on AP/C plotter by G. M. Nakata from panoramic-camera photographs AS16-4618 and 4623. B, Stereopair showing the hummocky nature of the Apollo 16 landing site and central traverse region. Area of coverage identical to $3 A$. C, Stereopair showing the Lunar Module (arrow) on the lunar surface in the Descartes highlands. Note the relatively fresh 30 -m-diameter crater $10 \mathrm{~m}$ east of the LM. Same photographs as in $3 A$ and $B$, greatly enlarged. 

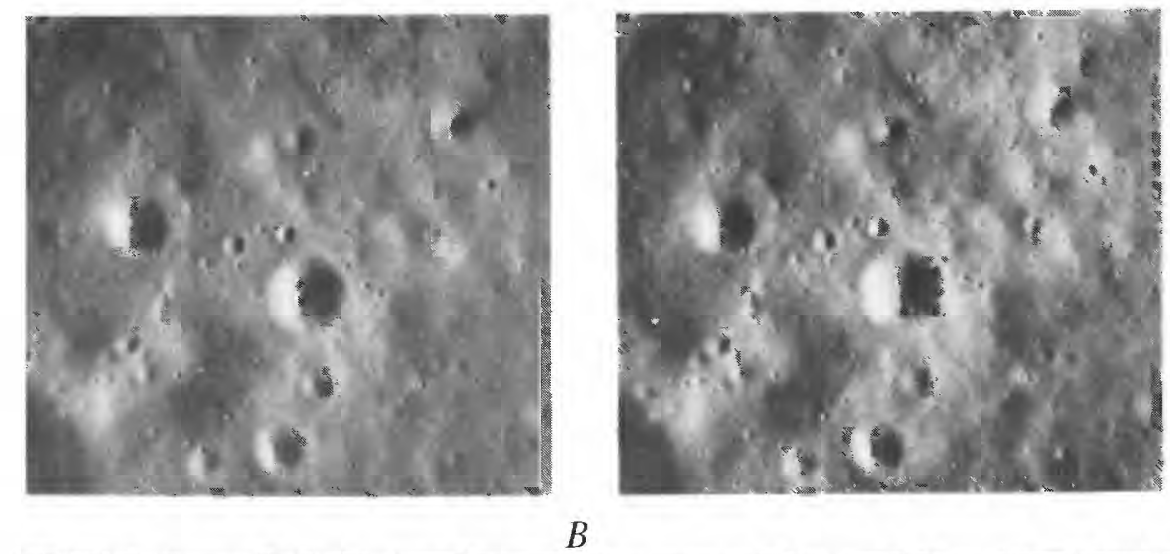

$B$
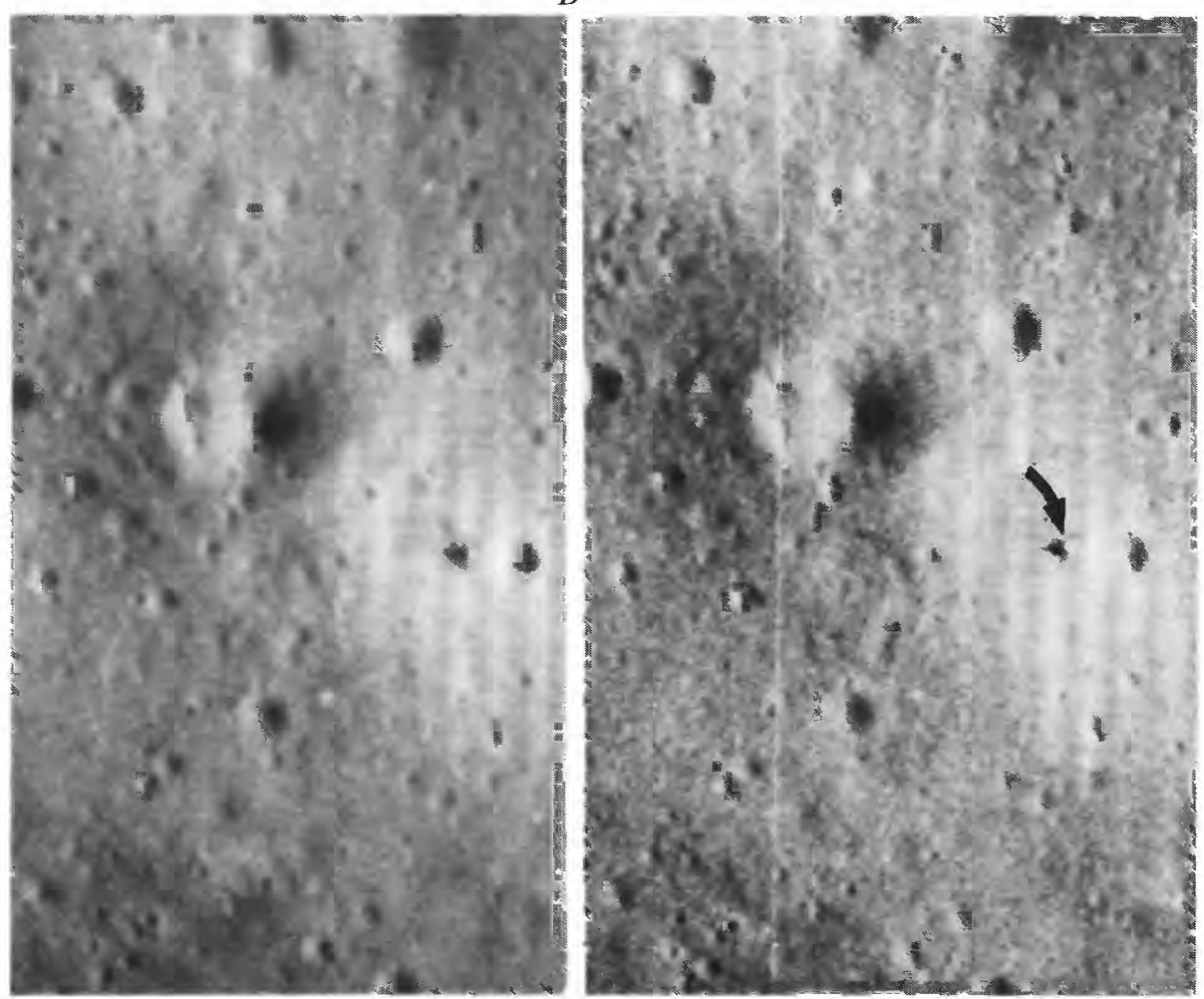

C

FIGURE 3.-Continued. 


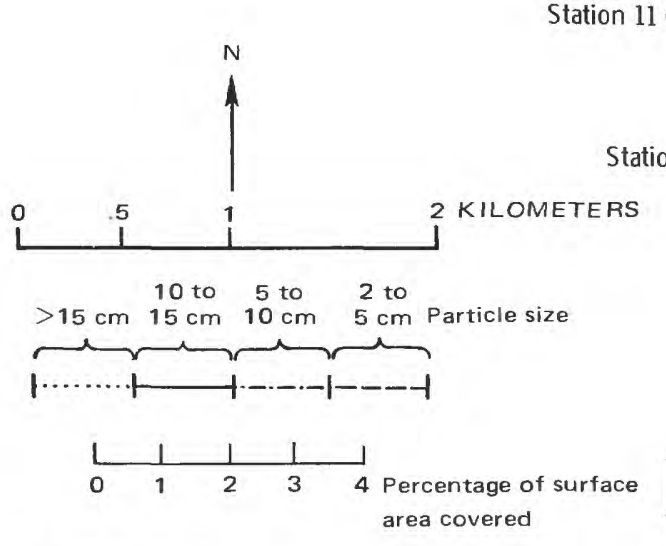

\footnotetext{
S South Ray ejecta

N North Ray ejecta

I Interray area
}

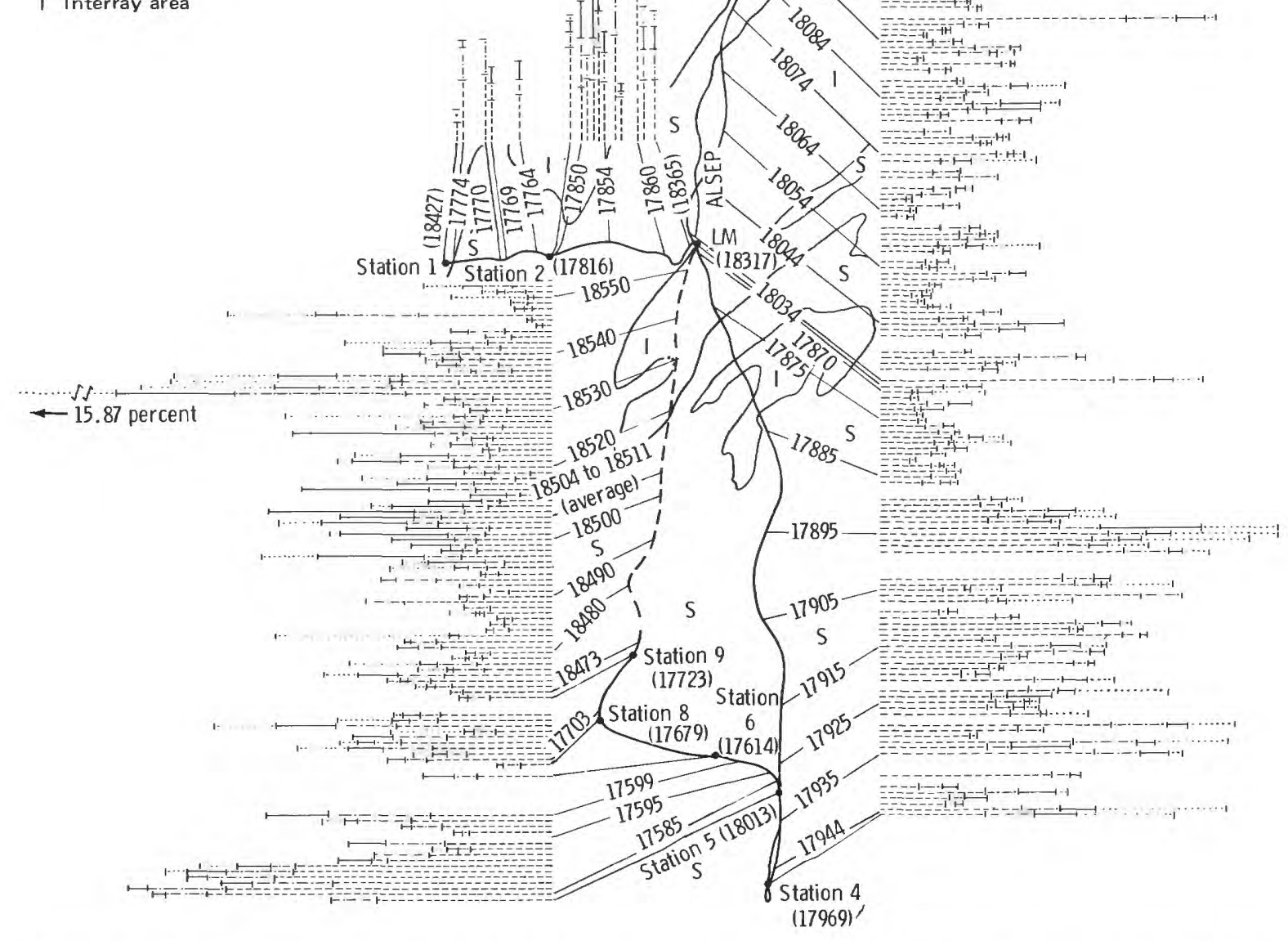

FIGURE 4.-Size distribution of fragments larger than $2 \mathrm{~cm}$ as determined from lunar surface photographs. Each line represents a size-distribution determination from a single photograph. Length is proportional to surface area covered by fragments as shown by bar scale. Five-digit numbers identify photographs; leaders tie them to their approximate positions along the traverse path (from Muehlberger and others, 1972). 
thought to represent ejecta from South Ray crater. The largest boulder near ALSEP has a well-developed fillet and may have been ejected from the older North Ray crater.

The LM landed on the western wall of a very subdued crater, approximately $180 \mathrm{~m}$ in diameter, $10 \mathrm{~m}$ west of a moderaely subdued crater about $30 \mathrm{~m}$ in diameter. There are eight very subdued craters $125 \mathrm{~m}$ to $360 \mathrm{~m}$ in diameter within a radius of $400 \mathrm{~m}$ from the LM (fig. 6). Ejecta from these craters with excavation depths of $25 \mathrm{~m}$ to $70 \mathrm{~m}$ may be included in the material sampled at this station.

The ALSEP was deployed in an intercrater area

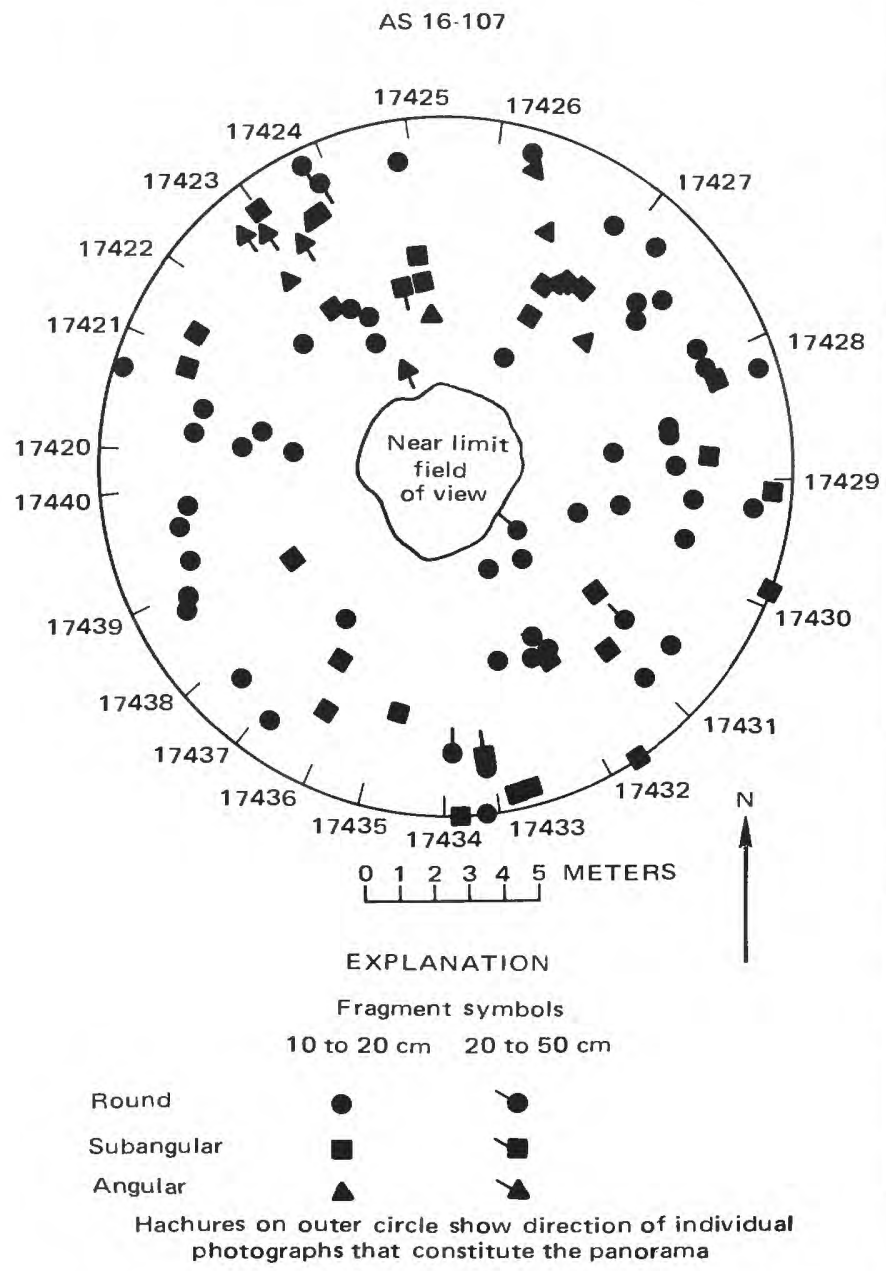

Figure 5.-Rock distribution within $10 \mathrm{~m}$ of the panorama site north of the LM (see pl. 3, pan 8). about $3.5 \mathrm{~m}$ higher than the elevation of the LM. Stations 10 and $10^{\prime}$ were on the western rim crest of the crater in which the LM landed (fig. 6). Smaller, younger craters are common in the LM/ALSEP area, ranging from numerous $0.5 \mathrm{~m}$ to $2 \mathrm{~m}$ secondaries (probably produced by ejecta from South Ray crater) to less common primary craters as large as $40 \mathrm{~m}$ in diameter. Samples collected in the LM/ALSEP area include all eight categories of rocks described in the petrology section of this report (Wilshire and others, this volume; Wilshire and others, 1973): crystalline rocks (igneous, metaclastic), glass, and five types of breccias (table 1). The only other station where all rock types were collected was station 11. LM/ALSEP and 11 were the most thoroughly sampled of mission 16 stations.

The source areas and depths of the LM/ALSEP samples are not known with certainty, but some assumptions can be made. As the LM site is on the eastern edge of a distinct ray from South Ray crater (fig. 2), a large proportion of the samples collected may be from that source. The $30-\mathrm{m}$ crater just east of the LM site (figs. 1, 3A), however, may have ejected material from as deep as $6 \mathrm{~m}$ in the floor debris of the LM crater. A possible secondary source of sampled material is the reworked ejecta from the eight very subdued craters mapped within a $400-\mathrm{m}$ radius of the LM (fig. 6).

Many of the rocks collected in the LM/ALSEP area are at least partly glass coated and range from highly angular to subround (figs. 7-10). In general, the fine-

\begin{tabular}{|c|c|c|}
\hline Category & Number of rocks collected & Percentage \\
\hline Igneous: & & \\
\hline $\mathrm{C}_{1}$ & 3 & 5.4 \\
\hline $\begin{array}{l}\text { Metaciastic: } \\
\quad \mathrm{C}_{2}\end{array}$ & 11 & 19.6 \\
\hline $\begin{array}{l}\text { Breccia: } \\
\mathrm{B}_{1} \text { (light matrix }\end{array}$ & & \\
\hline light clast) & 14 & 25.0 \\
\hline $\begin{array}{l}\mathrm{B}_{2} \text { (light matrix, } \\
\text { dark clast) }\end{array}$ & 4 & 7.1 \\
\hline $\mathrm{B}_{3}$ (light and dark & 6 & 10.7 \\
\hline $\mathrm{B}_{4}$ (dark matrix, & & \\
\hline $\begin{array}{l}\text { light clast } \\
\mathrm{B}_{5} \text { (dark matrix, }\end{array}$ & 8 & 14.3 \\
\hline dark clast) & 1 & 1.8 \\
\hline G & 9 & 16.1 \\
\hline Total & 56 & 100.0 \\
\hline
\end{tabular}



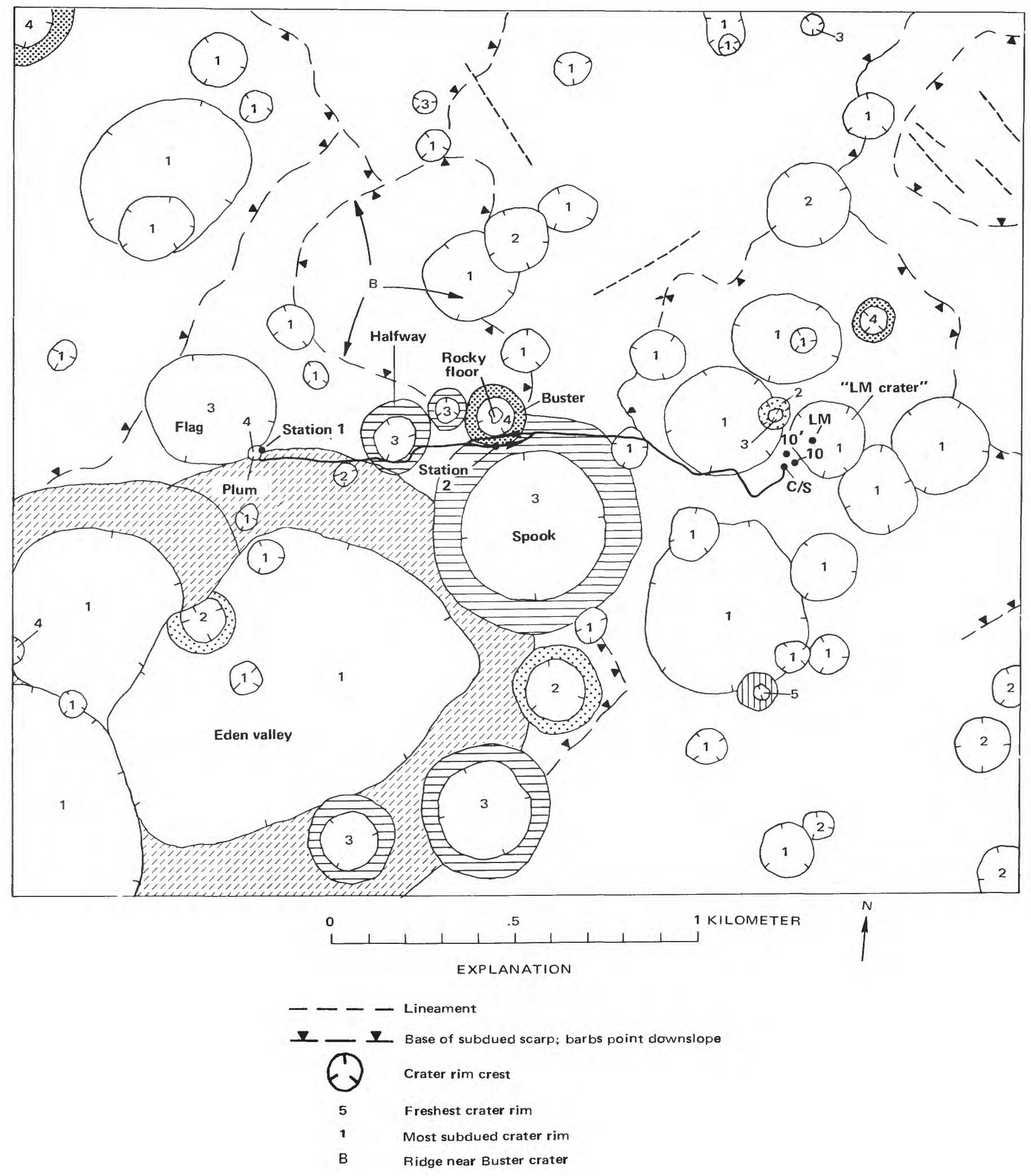

FIGURE 6.-Sketch map of landing site and central region showing distribution of fresh to greatly subdued craters of significant size and their relation to EVA-1 traverse stations. 


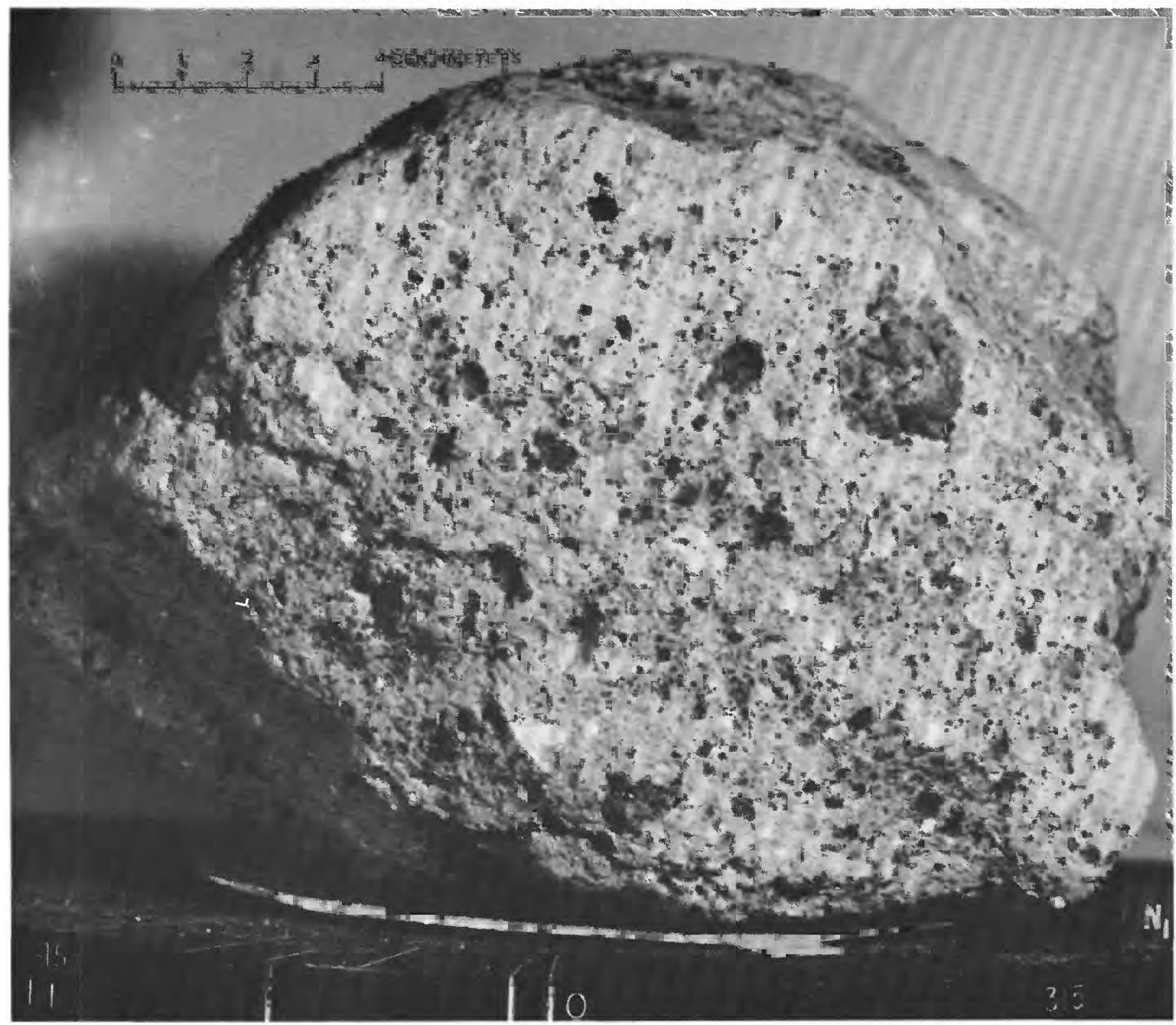

Figure 7.-Sample 60016. NASA photograph S-72-43829. 

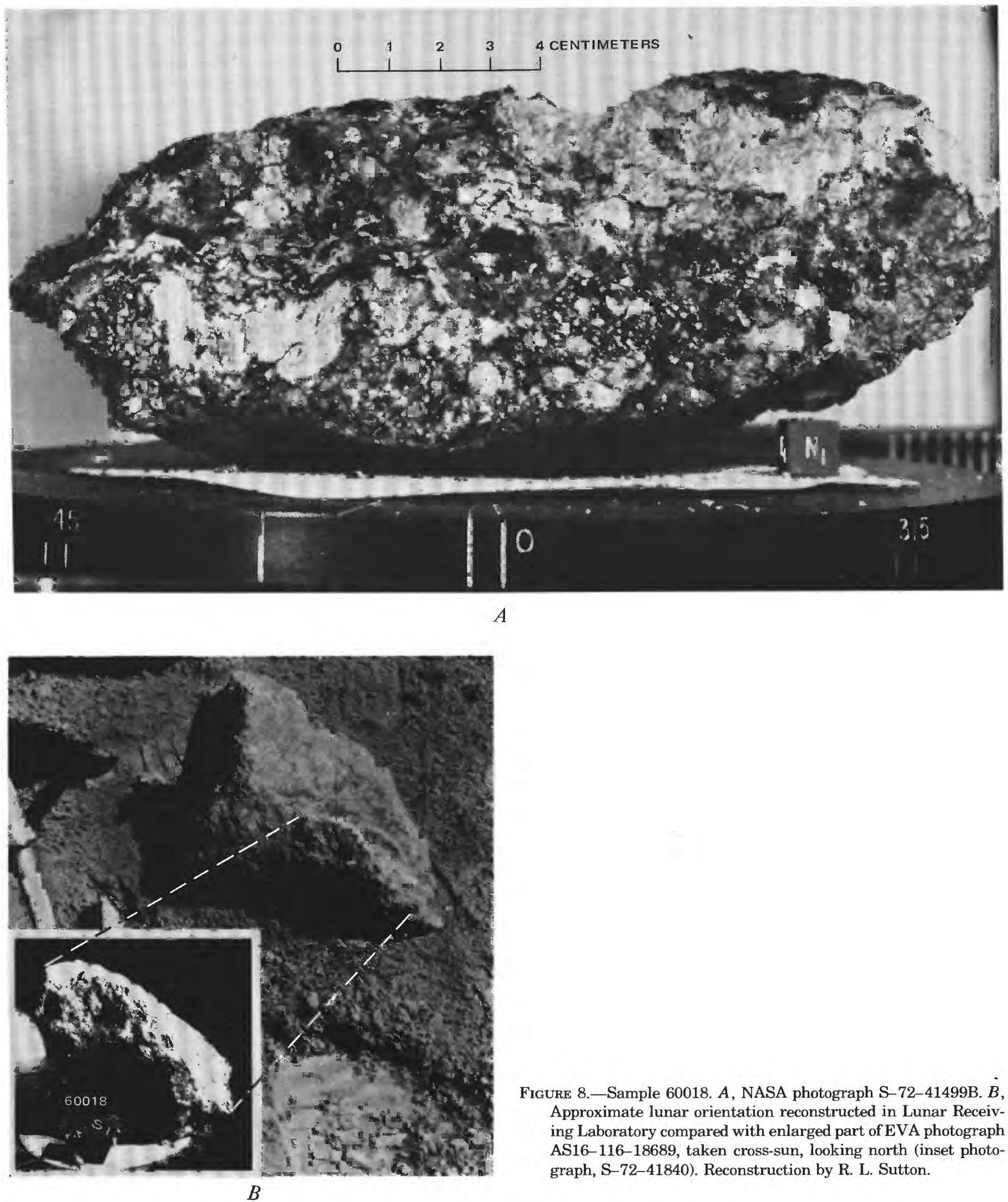

Figure 8.-Sample 60018. A, NASA photograph S-72-41499B. B, Approximate lunar orientation reconstructed in Lunar Receiving Laboratory compared with enlarged part of EVA photograph AS16-116-18689, taken cross-sun, looking north (inset photograph, S-72-41840). Reconstruction by R. L. Sutton. 

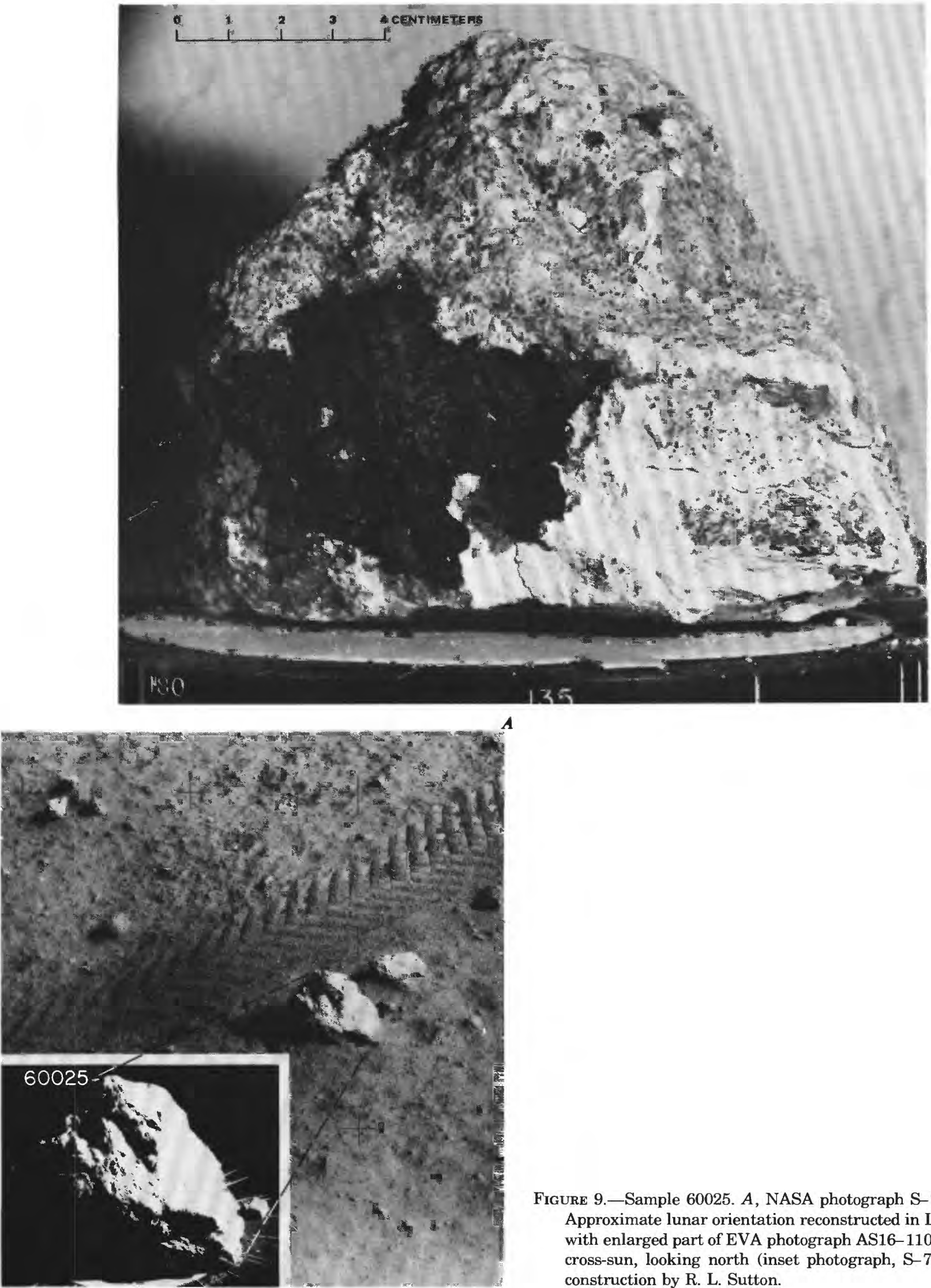

$A$

Figure 9.-Sample 60025. A, NASA photograph S-72-42593b. $B$, Approximate lunar orientation reconstructed in LRL, compared with enlarged part of EVA photograph AS16-110-17886, taken cross-sun, looking north (inset photograph, S-72-44019). Reconstruction by R. L. Sutton. 


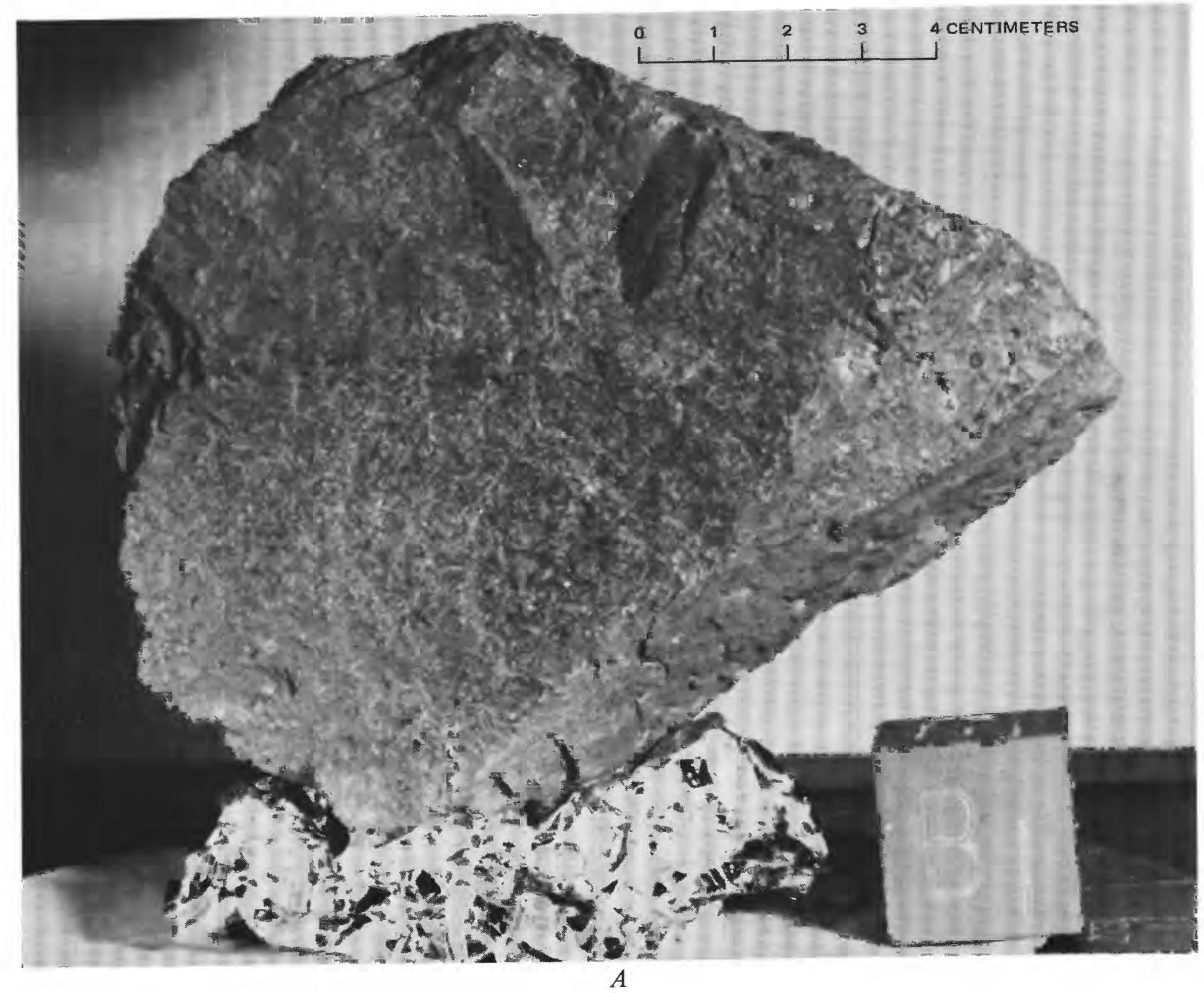

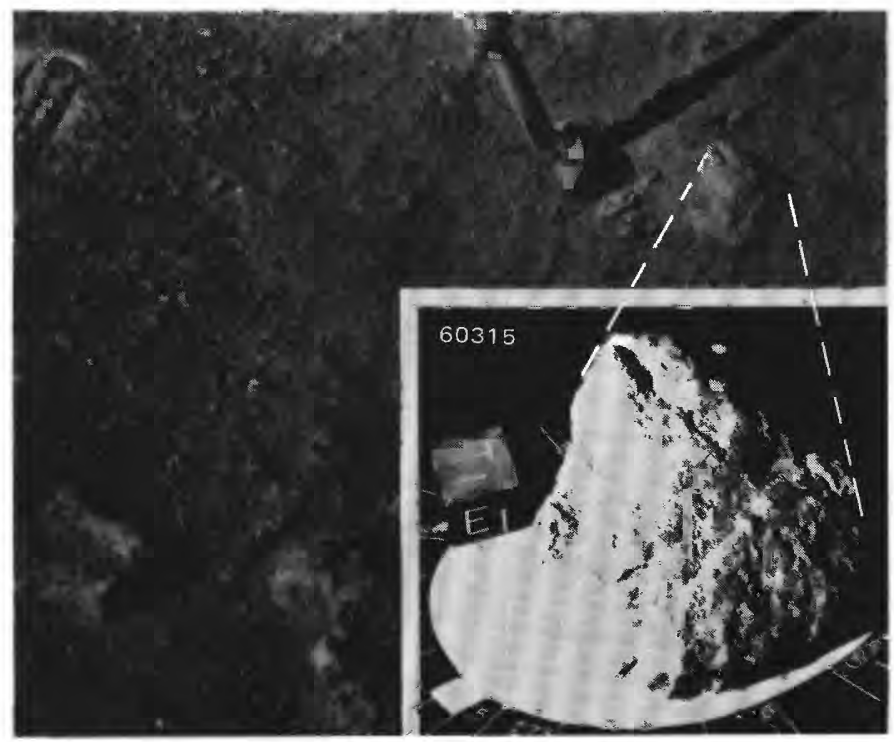

B
Figure 10.-Sample 60315. A, NASA photograph S-72-41572. B, Approximate lunar orientation reconstructed in the LRL compared with an enlarged part of EVA photograph AS16-11718836, taken oblique to sun, looking southwest (inset photograph, S-72-41842). Reconstruction by R. L. Sutton. 
grained chalky and crystalline rocks, approximately 5 percent of the rocks observed by the crew, are smaller (6- to $12-\mathrm{cm}$ range) than most breccia fragments.

Documentation photographs of the samples collected at the LM/ALSEP station show that most of the rocks were either perched or only slightly buried, indicating that many samples from this station may be South Ray material.

The soil in the LM/ALSEP area is in general medium gray, but patches of high-albedo soil are present near the ALSEP. White soils are more abundant to the west (toward stations 1 and 2), where they underlie a thin, darker surface layer. The soil in the LM/ALSEP area generally is firm except in the intercrater area of the ALSEP, where it was found to be exceptionally loose and powdery. Soil of the intercrater regions associated with very subdued 200 - to 300 -m diameter craters typically is less compact than the walls and rim crests of such craters (Schaber and Swann, 1971).

SpeciaI samples collected at LM/ALSEP include a deep drill core at the ALSEP, double-core tubes at 10 and $10^{\prime}$, rake samples at 10 , and the Lunar Portable Magnetometer (LPM) sample at the LRV final park position (fig. 1). The deep-core, rake, and double coretube samples may contain North Ray crater ejecta but should contain material representative of the Cayley plains beneath the LM/ALSEP station. The deep drill core $(223 \mathrm{~cm})$ may have penetrated the ejecta from the "LM" crater and the subdued crater, 270-m diameter, immediately west of the station (see fig. 6). Two Lunar Portable Magnetometer readings were taken in the LM/ALSEP vicinity, the first the ALSEP site, the second at the LRV finaI park position (approximately $80 \mathrm{~m}$ east of the LM). The ALSEP site remanent field strength was very high, 231 gammas, the LRV park reading considerably lower, 121 gammas. This difference represents a field magnitude gradient of 370 gamma $/ \mathrm{km}$, the maximum recorded during the mission. The minimum gradient measured was 1.2 gammas $/ \mathrm{km}$ between station 5 and the LRV final park position (Dyal and others, 1972, p. 12-5).

Near the LRV final park location (fig. 1), two LPM measurements were made to calculate the magnetic field of a surface rock sample (60335) in order to determine the totaI magnetization. The magnetic field was found to be below the resolution of the LPM (Dyal and others, 1972 , p. 12-6).

The passive seismometer (PSE) deployed at the ALSEP station was the most sensitive of the four lunar seismograph stations in operation at that time. On the basis of the initial 45-day record of operation, seismic events occurred at a rate of 10,000 per year; the rate at the Apollo 14 site was 2,000 per year, and at the 12 and 15 sites, 700 per year (Latham and others, 1972, p.
9-1). The higher sensitivity of the Apollo 16 seismometer has been attributed by Latham and others to the depth and elastic properties of the regolith, the inference being that the ApoIIo 16 regolith is deeper or weaker, or both.

The results of both the active and passive seismic experiments at Apollo 16 indicate that the regolith is not underlain by competent lava flows. Rather, the seismic velocities recorded suggest that a brecciated or impact-derived debris unit of undetermined depth underlies a 12.2-m-deep regolith. Petrographic analysis of the returned samples (almost entirely breccias) supports this hypothesis.

\section{STATION 1}

Station 1 was Iocated near the rim of Plum crater approximately $1,400 \mathrm{~m}$ west of the LM and $45 \mathrm{~m}$ lower. Plum crater, $30 \mathrm{~m}$ across and $5 \mathrm{~m}$ deep, is on the rim of Flag crater, $290 \mathrm{~m}$ in diameter (pl. 5, pans 4 and 5; fig. 11) and $40 \mathrm{~m}$ deep. When formed, Flag crater probably penetrated $60 \mathrm{~m}$ into the underlying Cayley plains material, but it has been partly filled by talus. The crater is subdued, having only a slightly raised rim, and no rocky exposures are visible in its walls or floor. Small subdued craters as large as $10 \mathrm{~m}$ in diameter are common in the area.

The east part of station 1 appears to be crossed by a very faint ray from South Ray crater, but rock fragments $>2 \mathrm{~cm}$ are less abundant ( 0.6 to 1.8 percent) than at station 2 or at the LM/ALSEP area (figs. 2, 4, 12 ).

Rocks larger than $10 \mathrm{~cm}$ cover only 0.2 percent of the surface at this station, whereas at station LM/ALSEP rocks of similar size cover 0.3 to 0.9 percent (fig. 4 ). The crew mentioned that South Ray crater ray material was visible about $50 \mathrm{~m}$ east of the station 1 area.

Samples ( $>2 \mathrm{~g}$ ) collected at station 1 , in table 2, are predominantly breccias of types $B_{2}, B_{3}$, and $B_{4}$. The complete absence of $B_{1}$ breccias, at least in the samples collected, may be significant with respect to the low

\begin{tabular}{|c|c|c|}
\hline Category & Number of rocks collected & Percentage \\
\hline Igneous: & & \\
\hline $\mathrm{C}_{1}$ & 1 & 3.3 \\
\hline Metaclastic: & & \\
\hline $\mathrm{C}_{2}$ & 2 & 6.7 \\
\hline $\begin{array}{l}\text { Breccia: } \\
\mathrm{B}_{1---}\end{array}$ & 0 & \\
\hline 等 & 3 ( 1 in rake) & 10.0 \\
\hline & 10 (7 in rake) & 33.3 \\
\hline $\mathbf{B}_{4}$ & 4 ( 3 in rake) & 13.3 \\
\hline \multicolumn{3}{|c|}{ ( } \\
\hline G & 10 ( 7 in rake) & 33.3 \\
\hline Total & 30 & 99.9 \\
\hline
\end{tabular}


proportion of South Ray material in this station area relative to station LM/ALSEP, where 25 percent of the samples are $B_{1}$ breccias.

Four large samples, $61016\left(\mathrm{~B}_{4} ; 11,745 \mathrm{~g}\right), 61135\left(\mathrm{~B}_{3}\right.$; $245 \mathrm{~g}), 61195(\mathrm{G} ; 586 \mathrm{~g}), 61295\left(\mathrm{~B}_{3} ; 172 \mathrm{~g}\right)$, were collected from the rim crest of Plum crater (pl. 5, pan 5), and are probably ejecta from that crater (figs. 13-15). Large samples $61015\left(\mathrm{~B}_{2} ; 1,803 \mathrm{~g}\right)$ and $61175\left(\mathrm{~B}_{3} ; 543 \mathrm{~g}\right)$ were collected away from the Plum rim crest and in an arc concentric to and about $30 \mathrm{~m}$ from the rim crest of Flag crater (pl. 5, pans 5 and 6; figs. 16, 17). These samples may represent original ejecta from Flag crater, or possibly Flag rim materials reejected by Plum crater, which undoubtedly penetrated the upturned bedrock beneath Flag crater. A distinct, but smooth and somewhat subdued bench occurs in Plum approximately $3 \mathrm{~m}$ below the surface. No outcrop is visible, but the benched topography suggests a change in cohesion of the materials in the walls of the crater. This change may reflect the contact beween Flag ejecta and raised bedrock in the eroded rim of Flag crater and may be the source area of the large, filleted, partly buried boulder from which sample $61295\left(\mathrm{~B}_{3}\right)$ was collected (fig. $15 B$; pl. 5, pan 5).

The largest of the Plum crater samples are $B_{3}$ and $B_{4}$ type breccias, whereas samples related to Flag crater are in the $B_{2}$ and $B_{3}$ categories. The $B_{2}$ breccias at this station may represent the deepest excavation level ( 60 $\mathrm{m}$ ) of Flag crater, a stratigraphic horizon not tapped by the smaller Plum crater $(5 \mathrm{~m})$. Sampling of all rock

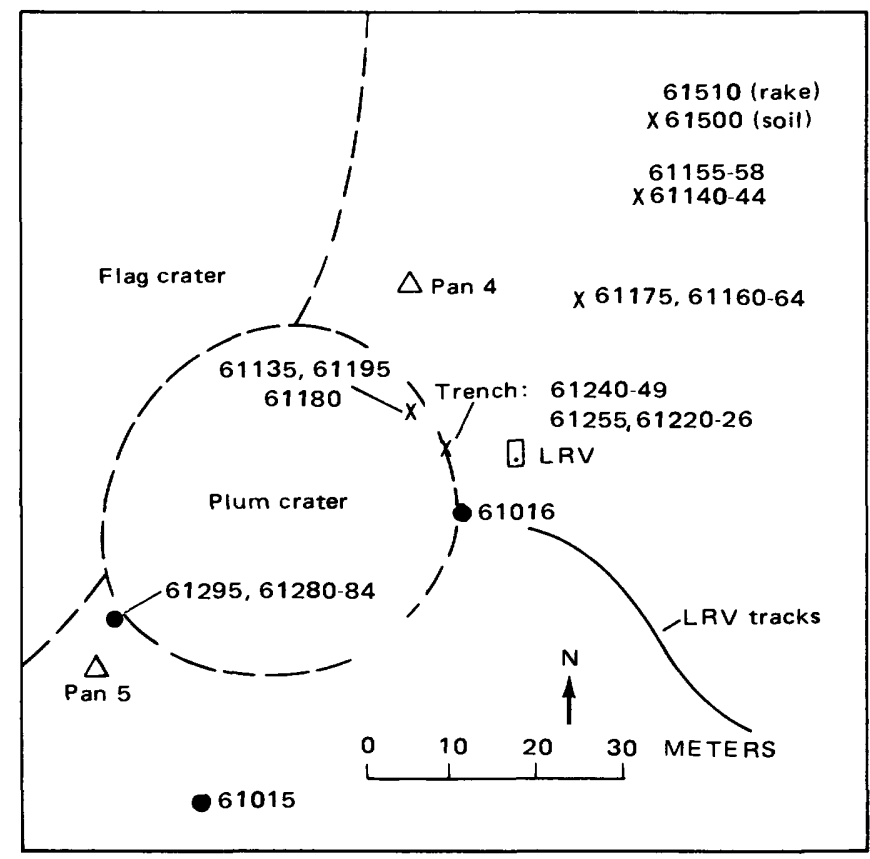

FIGURE 11.-PIanimetric map of station 1. types present at this station may not have been statistically sufficient because of time constraints.

At two places on the rim of Plum crater, the astronauts noted white regolith beneath a top layer of gray soil 1 to $2 \mathrm{~cm}$ thick. At one of these places, the light material lay beneath the gray on the fillet of a large boulder (fig. 18). This suggests that the fillet was formed by one of two mechanisms: (1) shedding of light material from the rock followed by postfillet deposition of a thin dark layer or (2) deposition of light material followed by darkening of the surface. White soil was observed at the trench site on the northeast rim west of Plum crater, where the top centimeter of gray soil was underlain by several tens of centimeters of white soil.

Other samples collected at station 1 included those from the trench $(61240,61245$ to 61249,61255 and 61220 ), a fillet soil (61280 at 61295-boulder), and two surface soil samples (61160 and 61180).

The crew observed that the large rocks were clearly more abundant on the rim crests of both Flag and Plum craters than in the intercrater areas, indicating that

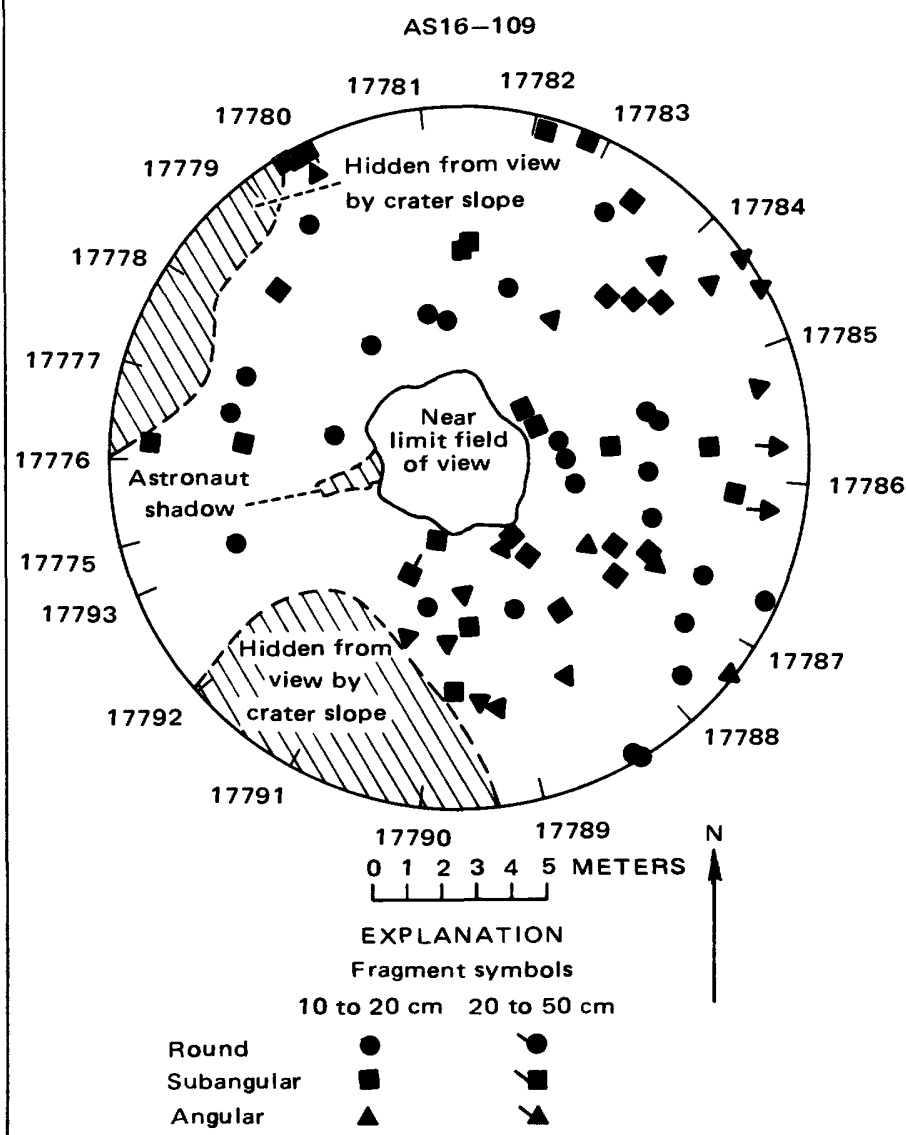

Hachures on outer circle show direction of individual photographs that constitute the panorama

FIGURE 12.-Rock distribution within $10 \mathrm{~m}$ of site of panorama 4 station 1. 


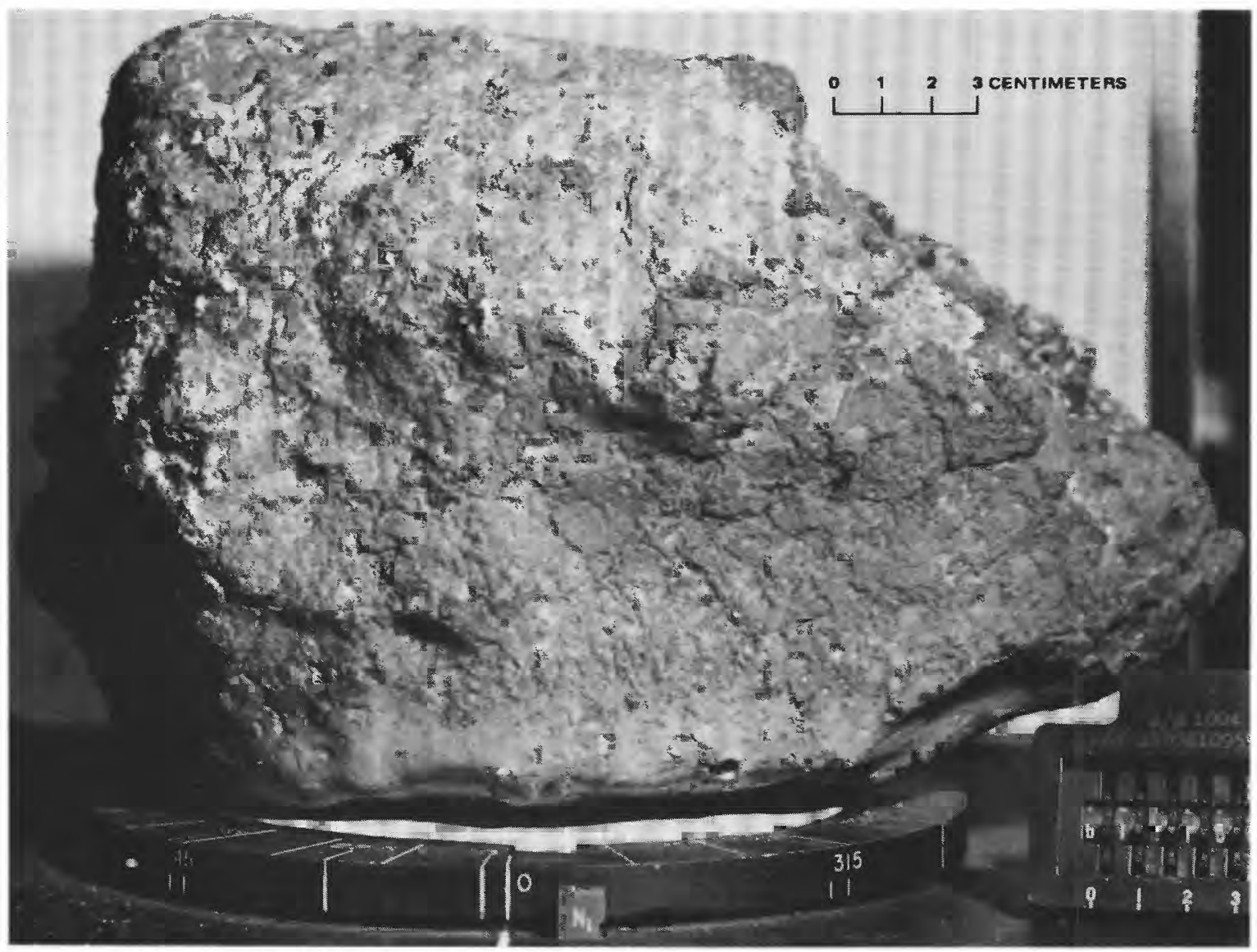

FIGURE 13.-Sample 61016. NASA photograph S-72-41545. (See Sutton, fig. 24B, this volume, for lunar orientation).

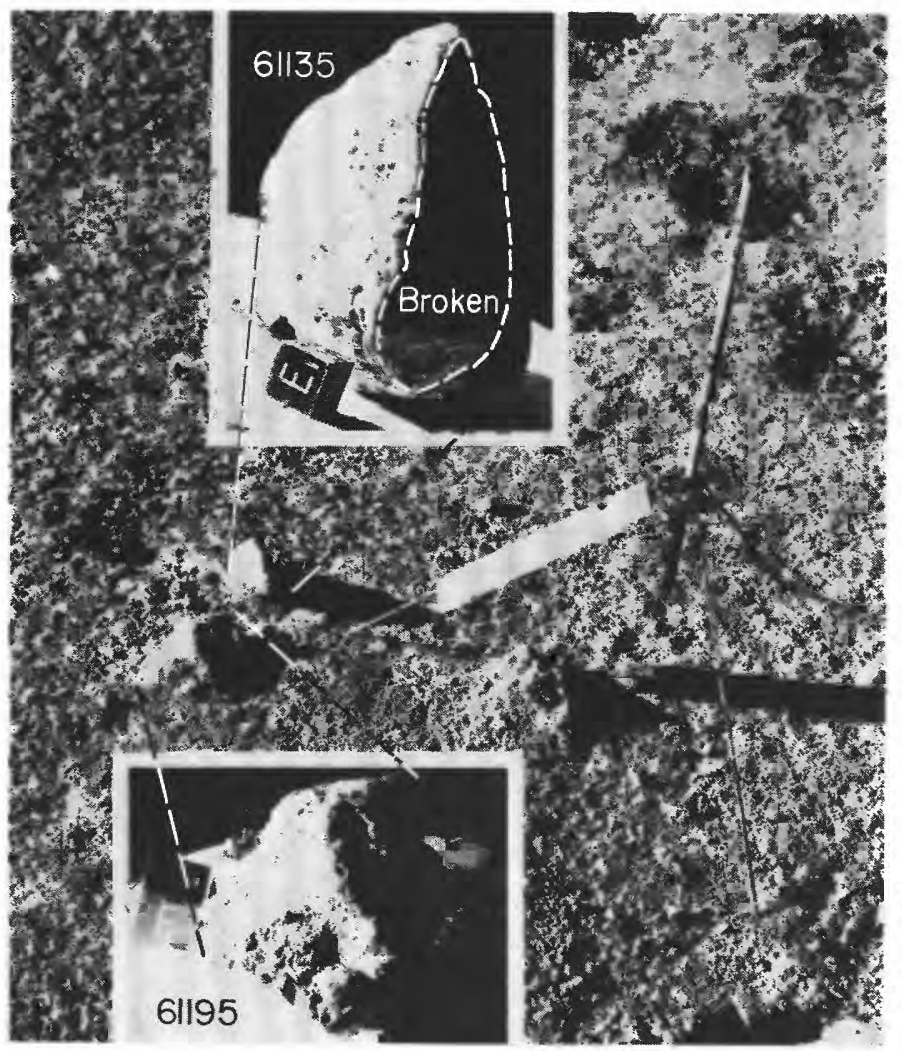

TFigure 14.-Samples 61135 and 61195 showing approximate lunar orientations reconstructed in the LRL compared with an enlarged part of EVA photograph AS16-114-18405, taken cross-sun, looking south (inset photographs, S-72-41609 and 43315, respectively). Reconstruction by R. L. Sutton. 

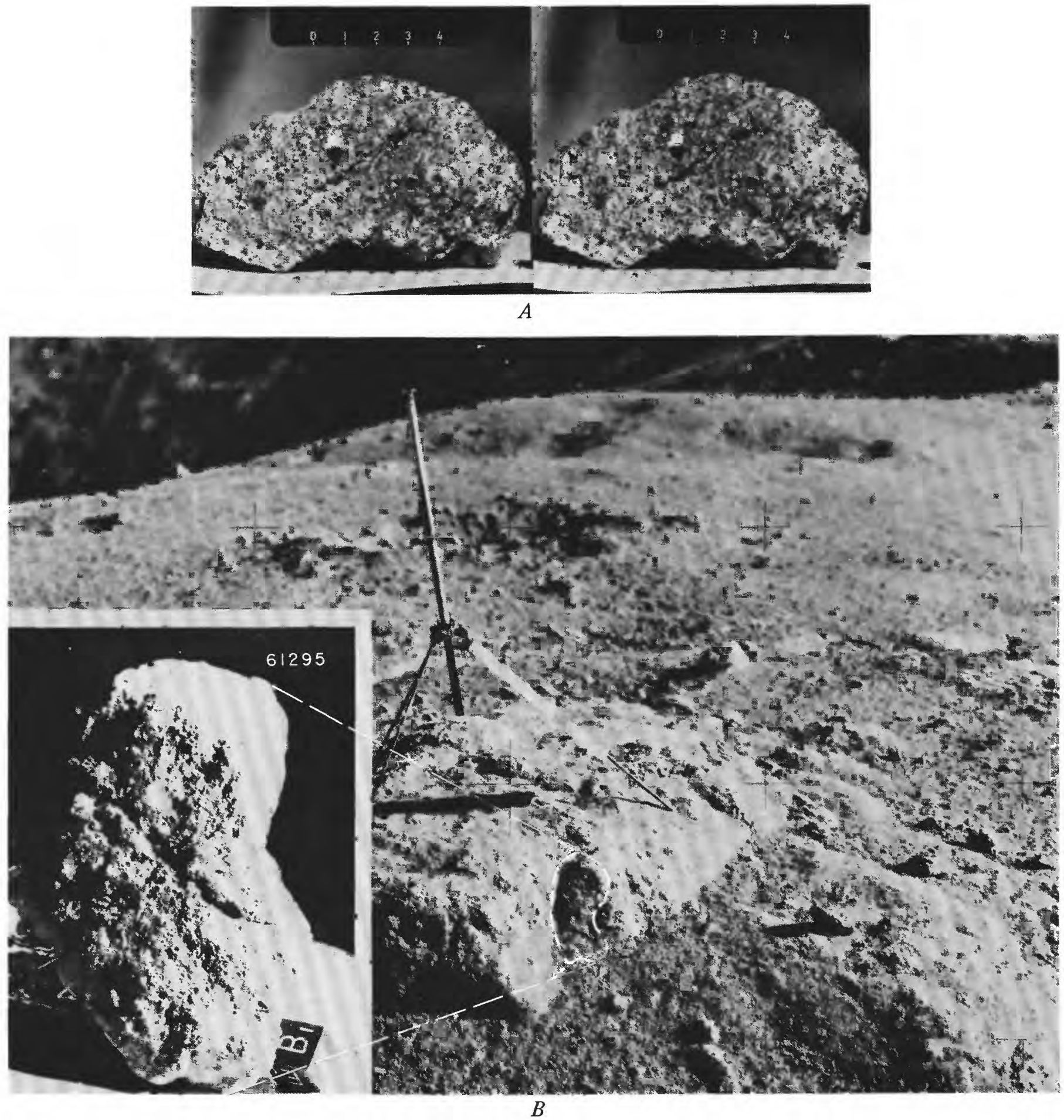

Figure 15.-Sample 61295. A, Stereopair composed of NASA photographs S-72-40946B and 40946. B, Approximate lunar orientation reconstructed in the LRL compared with an enlarged part of EVA photograph AS16-114-18412, taken cross-sun, looking north (inset photograph, S-72-40967). Reconstruction by R. L. Sutton. 
these craters are the most recent source of the deposits. Two very large craters $180 \mathrm{~m}$ south of station $1(450-\mathrm{m}$ diameter and $630-\mathrm{m}$ diameter, "Eden valley") may have contributed ejecta to the area from depths of 90 to $130 \mathrm{~m}$ before the impact at Flag crater (fig. 6). The significance of these materials in the collected samples has not been ascertained.

The surface rocks at station 1 are considerably less abundant, more eroded, less angular, and distinctly more buried than at station LM/ALSEP, demonstrating (pls. 3, 4, and 5) the scarcity of fresh South Ray ejecta at station 1 .

\section{STATION 2}

Station 2, located approximately $850 \mathrm{~m}$ west of the $\mathrm{LM}$, is just north of Spook crater ( $370 \mathrm{~m}$ diameter) and on the blocky south rim of Buster crater $(90 \mathrm{~m}$ diameter) (pl. 5, pan 6; fig. 19). The area is crossed by a faint ray of high-albedo material thought to be derived from South Ray crater, $5.7 \mathrm{~km}$ to the southwest (fig. 2). Subdued, grooved lineaments radial to South Ray crater cross the area.

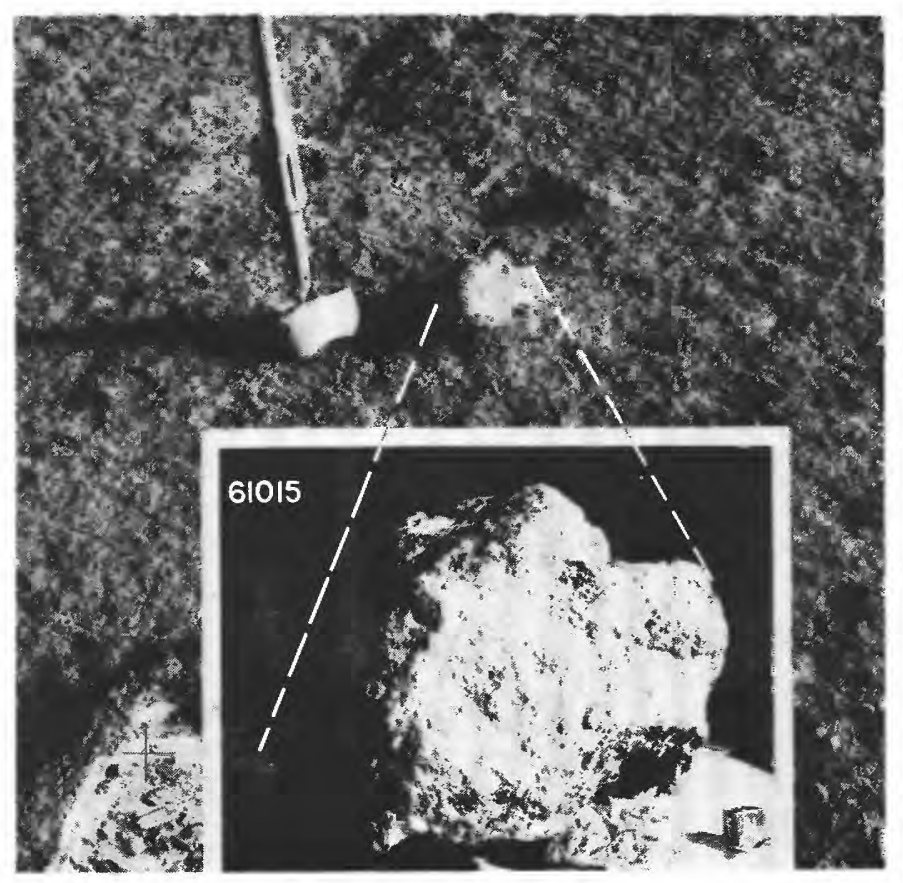

FigURE 16.-Sample 61015 showing approximate lunar orientation reconstructed in the LRL compared with an enlarged part of EVA photograph AS16-109-17808, taken cross sun, looking north (inset photograph, S-72-41058). Reconstruction by R. L. Sutton.
Fragments as large as $0.5 \mathrm{~m}$, but mostly 5 to $10 \mathrm{~cm}$, are scattered over the station area; they cover 1.6 to 2.6 percent of the surface, averaging 2.0 percent (figs. 4 , 20). Rocks larger than $5 \mathrm{~cm}$ cover 0.4 to 1.5 percent of the surface, averaging less than 0.8 percent. Most fragments are angular to subangular and are perched or only slightly buried. Fillets are rare.

Station 2 lies within the continuous ejecta blanket of both Spook and Buster craters. Samples collected should include some material from both craters, although Buster is more clearly associated with surface rock fragments. Spook crater is symmetrical with a subdued but slightly raised rim; no rock exposures are discernible on the walls. Buster crater is about $100 \mathrm{~m}$ north of Spook crater and is superimposed on its outer rim. The rim of Buster is fairly sharp, the inner walls fairly steep. Ninety percent of the floor and a large part of the walls and rim of Buster crater are covered by blocky debris that trends northeast across the crater floor (pl. 5, pan 6). The rocks in the crater floor, as large as $5 \mathrm{~m}$, are angular. The crew discerned northeasttrending planar structures dipping northward within the blocks and a parallel organization of the blocks.

Buster crater penetrates about $18 \mathrm{~m}$ into the south end of a subtle ridge, $15-18 \mathrm{~m}$ high (maximum) and $700 \mathrm{~m}$ long, that trends northwest from the station area ("B" in fig. 6). The conspicuous blocks on the floor of Buster crater may have been derived from this ridge. Halfway crater, $155 \mathrm{~m}$ west of Buster and off the ridge, is slightly more subdued and has very few associated blocks. The nature and distribution of the blocks in the floor and walls of Buster (pl. 5, pan 7) suggest that it penetrated a more coherent substrate than most craters of similar size and age in this region. A bench recognized in the blocky part of the wall of Buster crater may represent the change in coherence between the regolith and the inferred bedrock.

Spook crater penetrated $75 \mathrm{~m}$ into the Cayley plains; its location on the northeast edge of the "Eden valley" crater complex (penetration to $120 \mathrm{~m}$ ) suggests that some of the material ejected may be from the earlier "Eden valley" impact (fig. 6).

A total of eight rocks larger than $2 \mathrm{~g}$ were collected from the station 2 vicinity; they represent both crystalline and breccia types, as shown in table 3 .

The percentage of the $B_{1}$ breccias collected from stations LM/ALSEP ( 25 percent), station 1 ( 0 percent), and station 2 (37 percent) appears to show a relation to the presence of continuous-ejecta deposits from South 

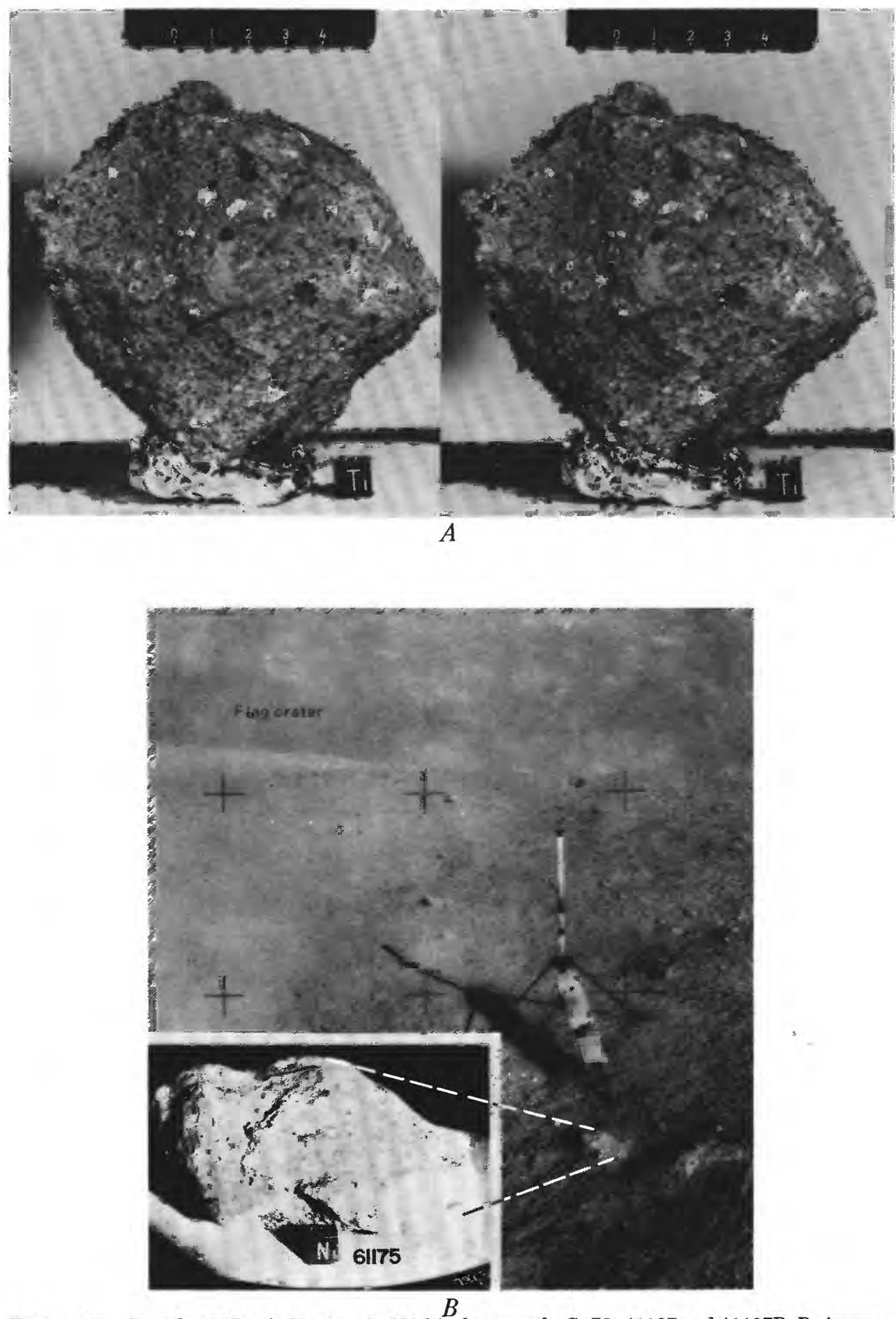

Figure 17.-Sample 61175. $A$, Stereopair, NASA photographs S-72-41197 and 41197B. $B$, Approximate lunar orientation reconstructed in the LRL compared with EVA photograph AS16-10917798, taken down sun, looking west (inset photograph, S-72-40966). Reconstruction by R. L. Sutton. 


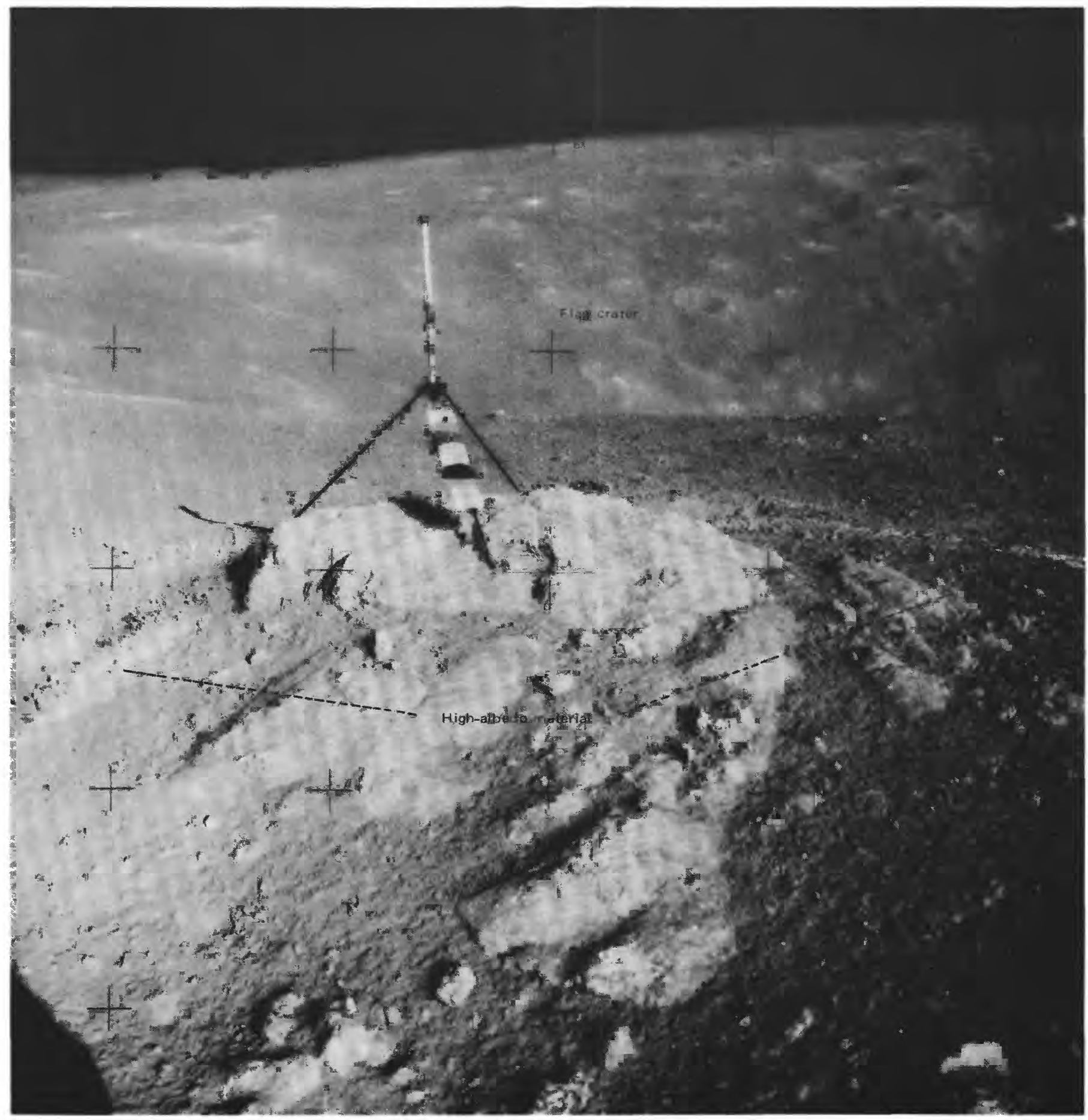

FIGURE 18.-Large filleted boulder showing high-albedo material kicked by astronauts (AS16-109-17802). 


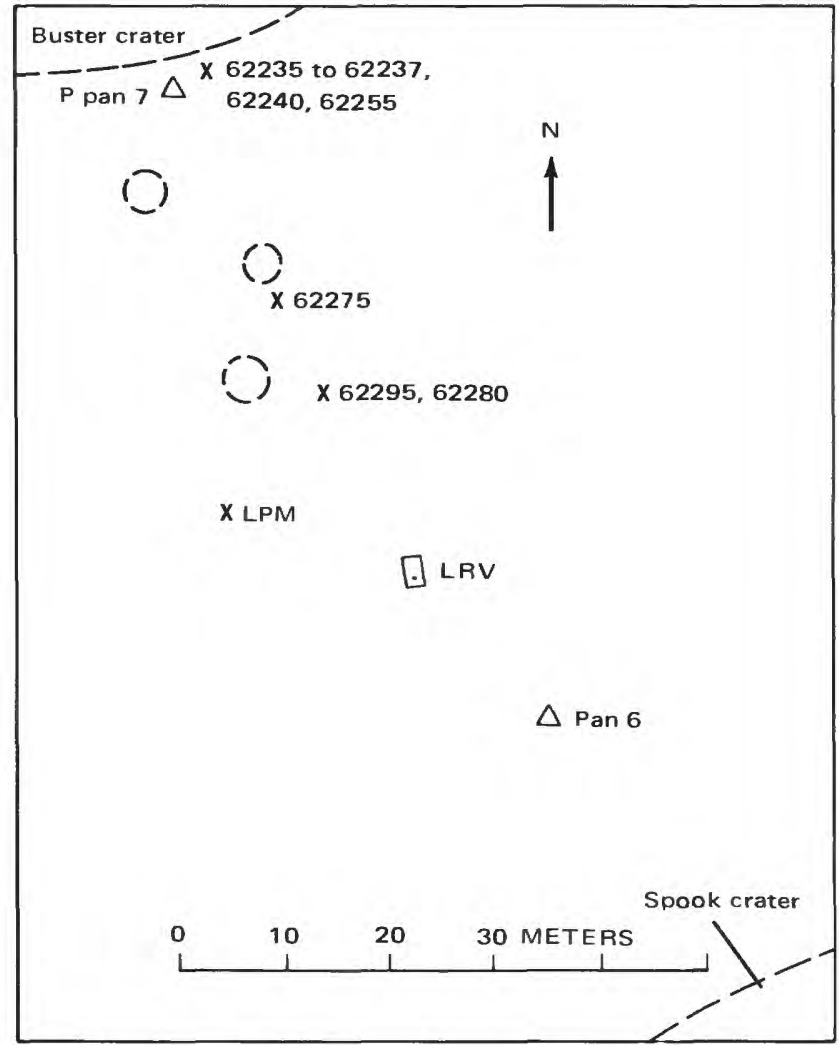

FIGURE 19.-Planimetric map of station 2. For explanation of symbols see figure 1 .

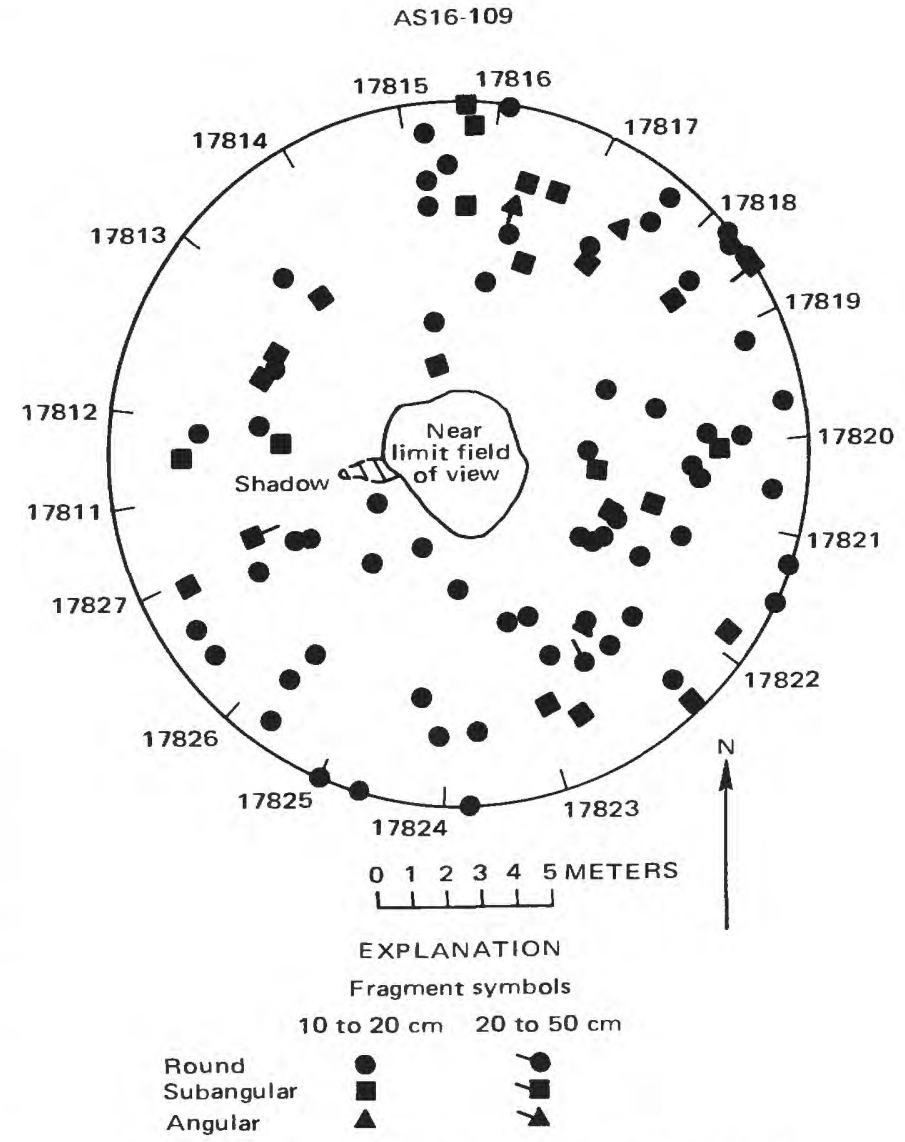

Hachures on outer circle show direction of individual photographs that constitute the panorama.

FIgURe 20.-Rock distribution within $10 \mathrm{~m}$ of site of station 2 panorama.

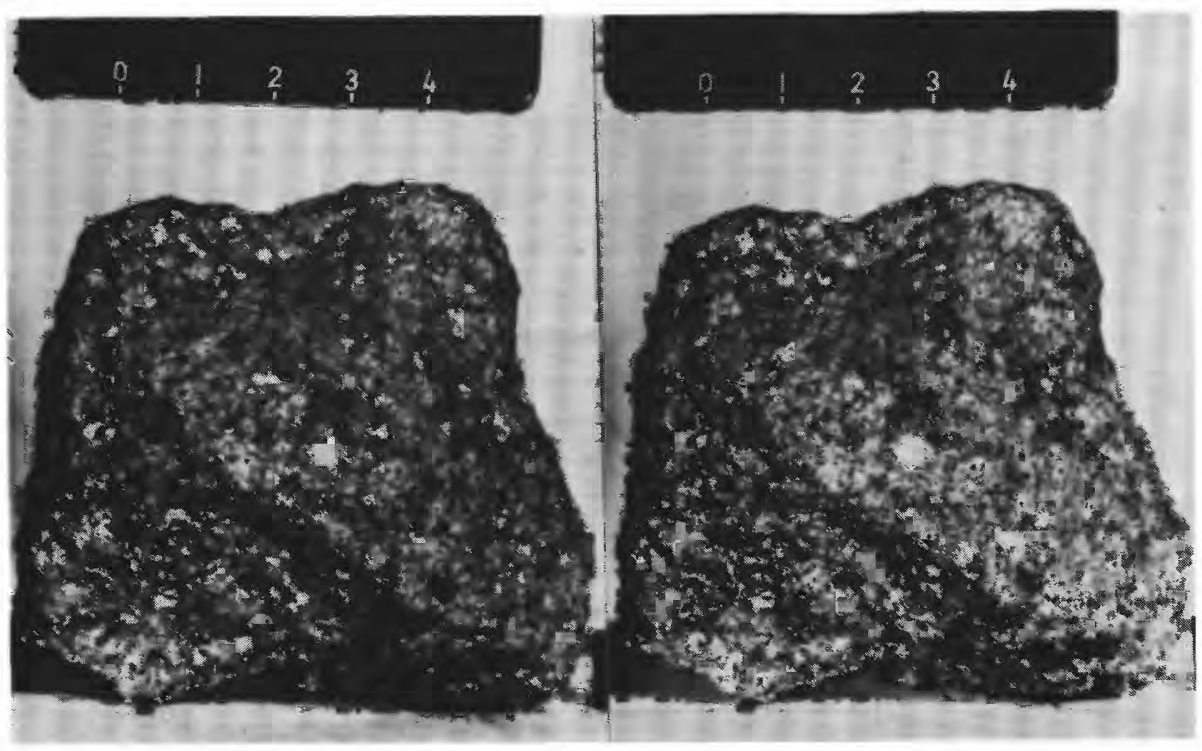

Figure 21.-Sample 62235. A, Stereopair (NASA photographs S- 72-41280 and 41280B). B, Samples 62235,62236 , and 62237 showing approximate lunar orientation reconstructed in the LRL compared with an enlarged part of EVA photograph AS16-109-17838, taken cross-sun, looking south (inset photographs, S- 72-41424, 41837, and 41838, respectively. Reconstruction by $R$. L. Sutton. 


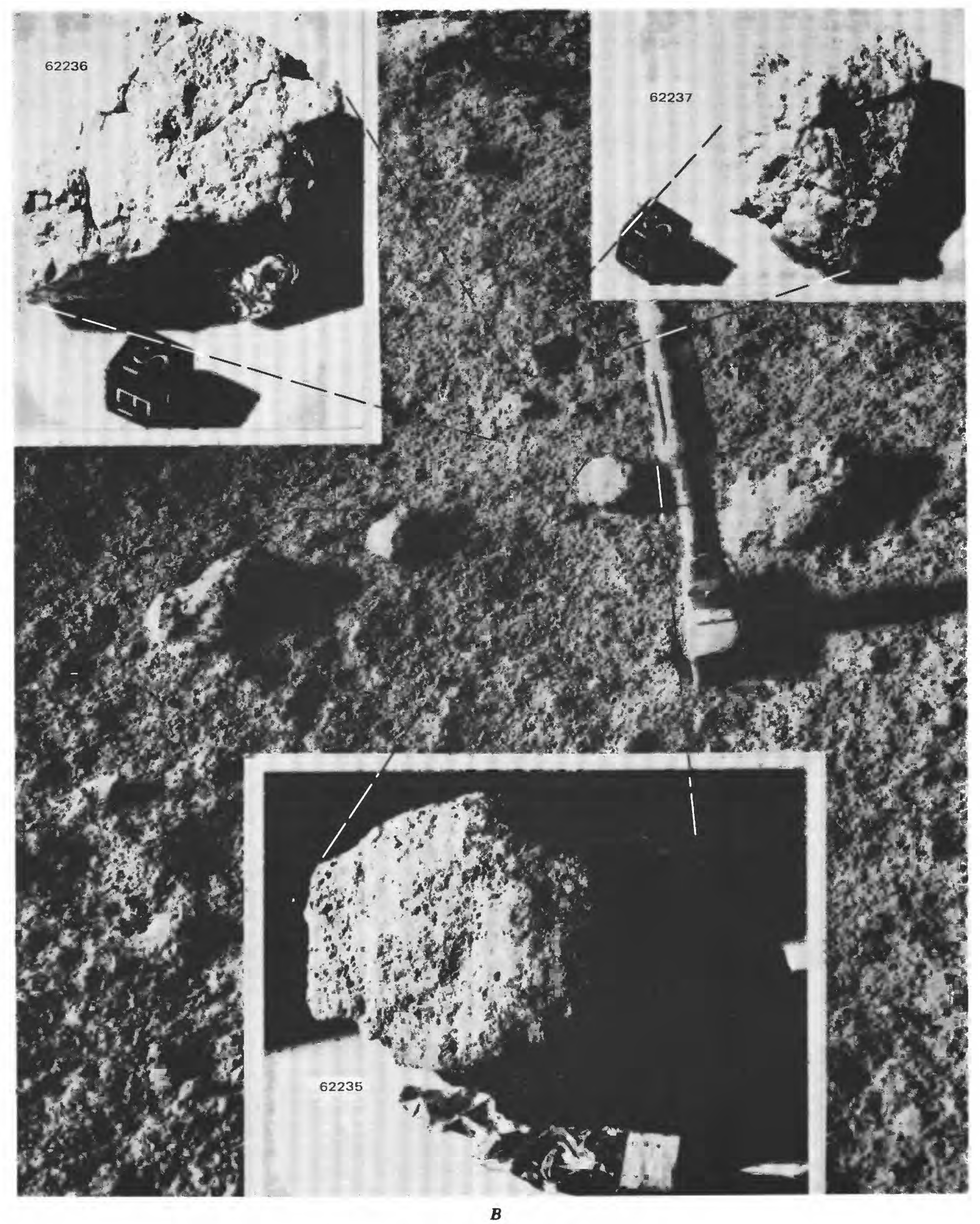

Figure 21.-Continued. 
TABLE 3.-Number and percentages of rocks ( $>2 \mathrm{~g})$ documented at station 2

\begin{tabular}{|c|c|c|}
\hline Category & Number of rocks collected & Percentage \\
\hline Igneous: & & \\
\hline $\mathrm{C}_{1}$ & 1 & 12.5 \\
\hline $\begin{array}{l}\text { Metaclastic: } \\
\text { C }\end{array}$ & 1 & 125 \\
\hline Breccia: & & \\
\hline $\mathrm{B}_{1-\ldots-}$ & 3 & 37.5 \\
\hline $\mathrm{B}_{2}$ & 2 & 25.0 \\
\hline $\mathrm{B}_{3}$ & $\overline{1}$ & 12.5 \\
\hline$B_{4}$ & 0 & 0 \\
\hline Total & 8 & 100.0 \\
\hline
\end{tabular}

Ray crater. South Ray ejecta crosses stations LM/ ALSEP and 2 but is extremely sparse at station 1 . This relation does not appear to hold, however, when the sample types collected at stations 6 and 8 are examined. Although these stations are much closer to South Ray crater, no $B_{1}$ breccias were collected from either site. If indeed the $B_{1}$ rocks at the stations LM/ALSEP, 1 , and 2 sites are related to South Ray ejecta, they would have to represent a very shallow horizon within that crater, deposited primarily downrange. The association is tenuous at best. Breccia type $\mathrm{B}_{4}$ was not sam-
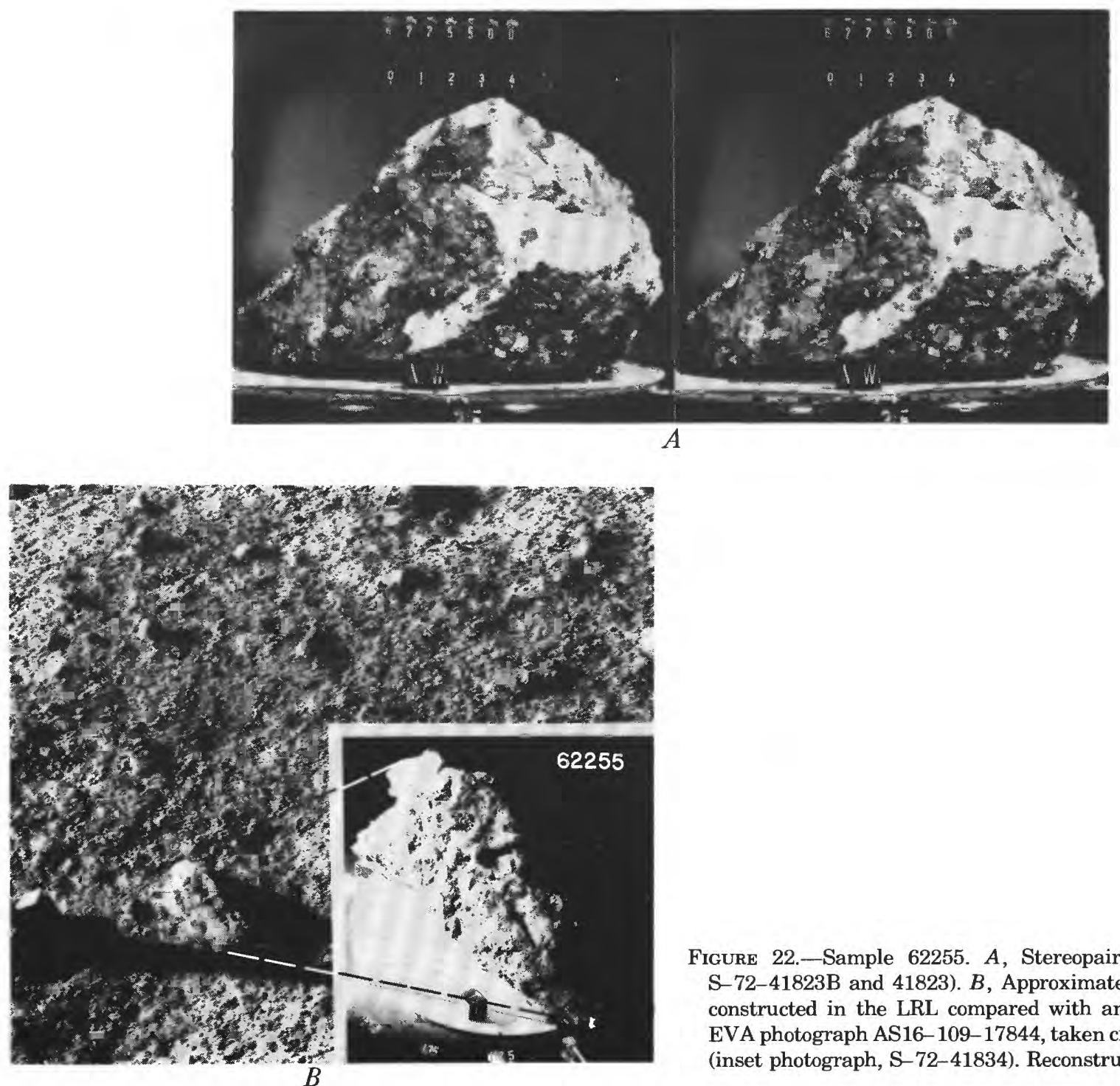

Figure 22.-Sample 62255. A, Stereopair (NASA photographs S-72-41823B and 41823). B, Approximate lunar orientation reconstructed in the LRL compared with an enlarged part of the EVA photograph AS16-109-17844, taken cross-sun, looking south (inset photograph, S-72-41834). Reconstruction by R. L. Sutton. 
pled at station 2 but made up 14 percent of the rocks collected at LM/ALSEP and 13 percent of those returned from station 1 .

The planimetric map of station 2 (fig. 19) clearly shows that most sampling was done closer to Buster crater rim than to Spook crater. The samples collected nearest Spook were $62295\left(\mathrm{C}_{1}\right)$ and 62280 (soil) at a distance of about $70 \mathrm{~m}$. Photographs and orientation diagrams for the station 2 large rocks are shown as figures 21 to 24 .
Astronaut Duke commented regarding Buster crater, "The blocks are angular, but they are definitely coming out of Buster." The most recent source of collected samples therefore may have been Buster crater, which probably reexcavated much Spook crater material.

The surface soil at station 2 is medium gray with a higher albedo soil below the upper centimeter or so, similar to light soil at the ALSEP and at station 1 . The compaction and granularity of the soils are typical of

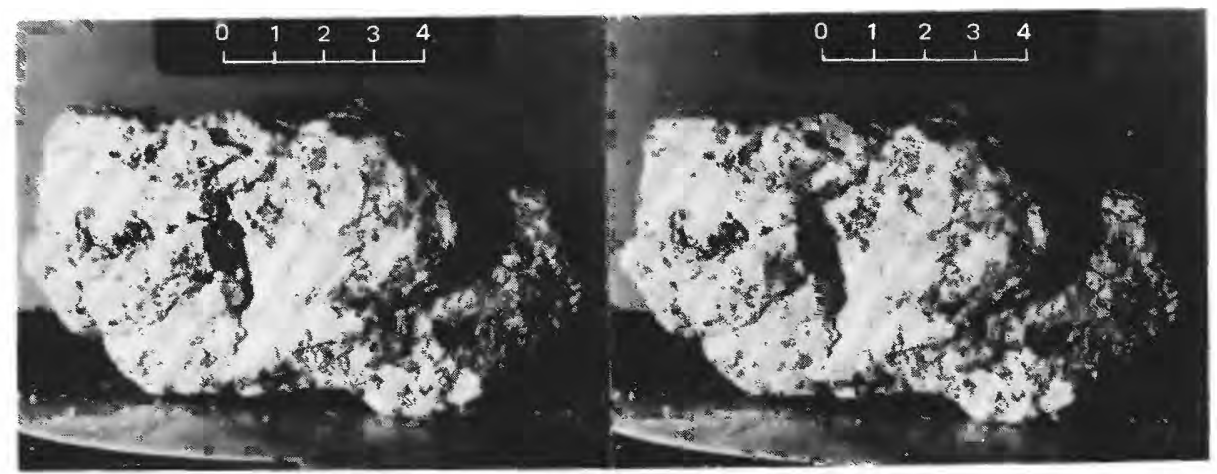

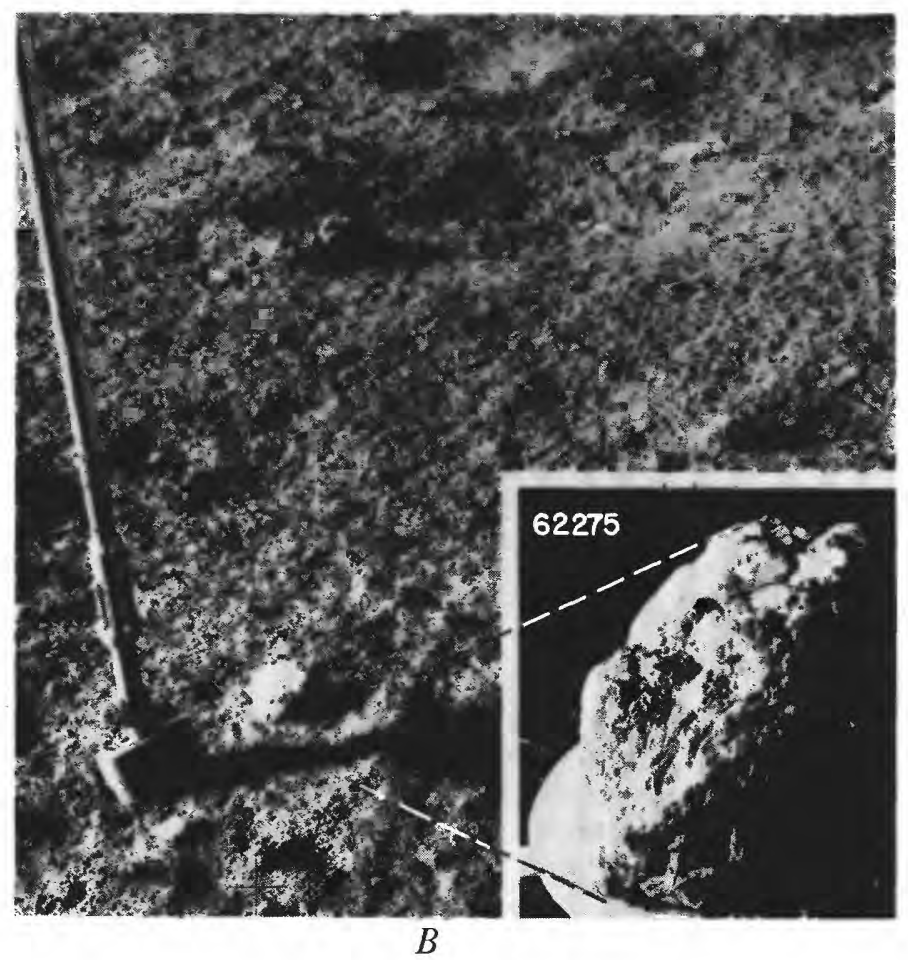

Figure 23.-Sample 62275. A, Stereopair (NASA photographs S-72-40922B and 40922). B, Approximate lunar orientation reconstructed in the LRL compared with an enlarged part of EVA photograph AS16-109-17846, taken cross-sun, looking south. The sample is fragile and minor breakage has occurred; shadow details were impossible to duplicate accurately in the laboratory (inset photograph, S-72-41426). Reconstruction by R. L. Sutton. 
the area. Small craters as much as $2 \mathrm{~m}$ in diameter are distributed fairly uniformly; they are generally subdued but a few small fresh craters, possibly South Ray secondaries, have sharp rims on which cloddy ejecta is discernible.

\section{SUMMARY}

The samples collected from stations LM/ALSEP, 1 , and 2 most probably represent materials of the Cayley plains to depths of $70 \mathrm{~m}$ or more and materials from the upper layers within South Ray crater. The proportions of rock types collected from each station were constrained by time available and may not be clearly indicative of the rocks present at depth.
The variety of rock types collected at stations LM/ ALSEP, 1 , and 2 indicates that the Cayley plains breccias are heterogeneous and suggests that they are composed of pockets of both light and dark breccias deposited by a turbulent process characteristic of large-basin ejecta emplacement.

The great amount of South Ray ejecta within the central plains of the landing site, suggested by the distribution of high-albedo materials radial to that crater (fig. 2), appears to be a heterogeneous collection of light and dark breccias including all types collected throughout the region traversed during the mission.

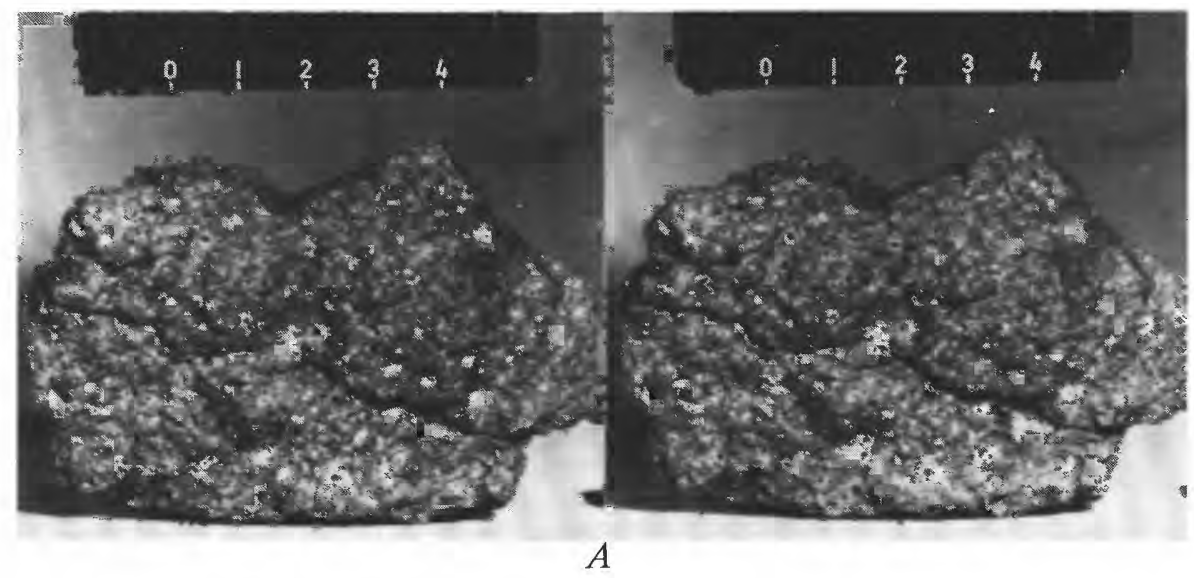

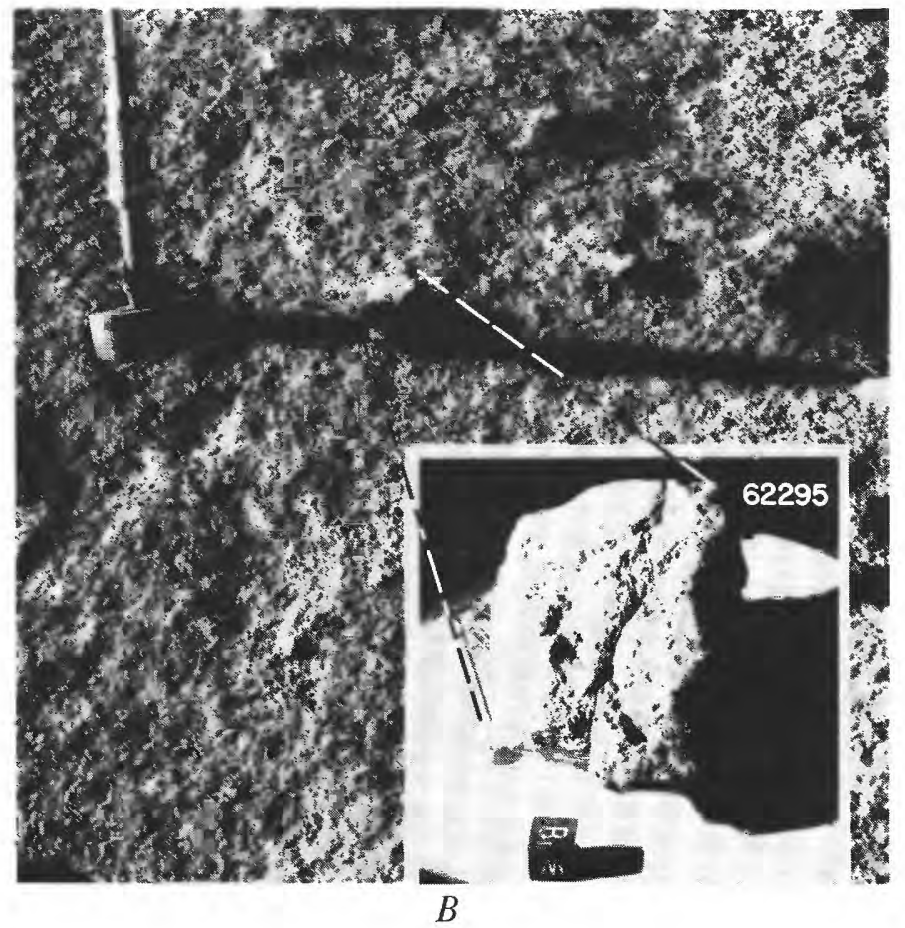

FigUre 24.-Sample 62295. A, Stereopair (NASA photographs S-72-44492 and 44492B). B, Approximate lunar orientation reconstructed in the LRL compared with an enlarged part of EVA photograph AS16-109-17848, taken cross-sun, looking south (inset photograph, S-72-42563). Reconstruction by R. L. Sutton. 


\section{D2. GEOLOGY OF NORTH RAY CRATER}

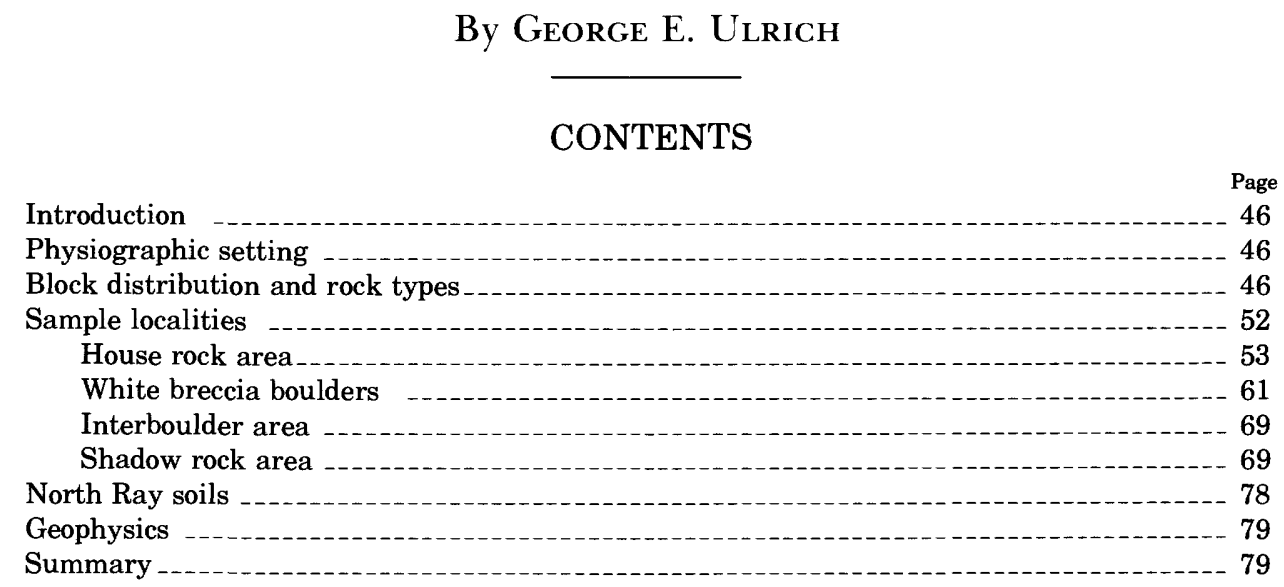

\section{ILLUSTRATIONS}

1. Hypsographic map of the Apollo 16 site

2. Photograph of northern part of Apollo 16 landing site

3. Topographic map of North Ray crater and vicinity

4. Stereopair showing northeast wall of North Ray crater from east panorama station

5. Map of boulders, craters, and ejecta grooves in North Ray crater area

6. Maps showing block distribution within $10 \mathrm{~m}$ of station 11 and 13 panoramas

7-11. Photographs:

7. Dark-matrix breccia boulder in White breccia boulder area

8. Partial panorama of House rock and Outhouse rock at station 11

9. Partial panorama and sketch of Shadow rock at station 13

10. Fillets and sample locations, White breccia boulders

11. Stereopair and sketch map showing surface texture and clast distribution, White breccia boulder -........57

12. Map and histogram showing proportions of light and dark fragments counted in surface panoramas at North Ray

crater -

13. Maps showing location of rocks and soils collected at stations 11 and 13

14. Histogram of abundance of rock types collected from four localities at North Ray crater

15-21. Photographs:

15. Stereopair of sample 67915

16. Sample 67955

17. Impact-spalled area on east face of Outhouse rock

18. Sample 67935

19. Sample 67937

20. Sample 67956 -

21. Three dark-matrix breccias

22. Photomicrographs of ophitic texture in fragment 67948

23. Telephotograph of large light-matrix breccia blocks on northeast wall of North Ray crater

24-27. Photographs:

24. Broken fragments and fines of sample 67455

25. Stereopair and photomicrograph of sample 67455

26. Sample 67475 .

27. Samples $67016,67035,67415$, and stereopair of 67435

28. Photomicrographs of metamorphic clasts within light-matrix breccias

29. Photographs of samples $67015,67075,67115$, and stereopairs of 67055 and 67095

30. Photomicrographs of a typical light-matrix breccia, 67075

31. Photographs of Shadow rock and closeup of surface texture

32. Photograph of sample 60017

33. Photomicrograph of sample 60017

34. Photograph showing estimated exposure to sunlight beneath overhang of Shadow rock during one lunation _..-_..-.-80 


\section{TABLES}

Page

1. Distribution of blocks at North Ray crater by size and shape -

2. Rock samples greater than $2 \mathrm{~g}$ from the House rock area

3. Rock samples greater than $2 \mathrm{~g}$ from the White breccia boulders area

4. Rock samples greater than $2 \mathrm{~g}$ from the Interboulder area

5. Rock samples greater than $2 \mathrm{~g}$ from the Shadow rock area, station 13, on outer North Ray ejecta

6. North Ray crater soil samples greater than 26 g

\section{INTRODUCTION}

North Ray crater was the primary sampling target of the last of three traverses made during the Apollo 16 mission. Its apparent youth minimizes the chance of contamination by ejecta from younger craters; its deep exposures, $230 \mathrm{~m}$ into the subsurface, reveal stratigraphic differences to approximately that depth. Orbital and surface photographs illustrating the vertical sequence of units exposed in the wall of North Ray crater, together with the rocks and soils collected on its rim and ejecta blanket and the crew's first-hand observations, provide the controlling data for interpreting a stratigraphic model in this area of the landing site. This model is extended to the larger region explored by Apollo 16 in Ulrich and Reed (this volume).

\section{PHYSIOGRAPHIC SETTING}

North Ray crater lies at the foot of Smoky mountain and is one of the highest sampling sites in the landing area. Its setting is well illustrated from a surface perspective on plate 11 (pan 34). Station 4, on Stone mountain, is at approximately the same elevation; the rim of South Ray crater, $10 \mathrm{~km}$ to the south, is about $170 \mathrm{~m}$ lower (fig. 1). About $1 \mathrm{~km}$ across, North Ray crater straddles a ridge approximately $50 \mathrm{~m}$ high and a little narrower than the crater rim. The crest of this ridge, informally named North Ray ridge, is nearly parallel to the base of Smoky mountain. Its similarity in morphology to Smoky mountain and to the Descartes highlands in general was not recognized until after the mission when orbital photography with lowsun-angle illumination became available (fig. 2). The top of the ridge is $400 \mathrm{~m}$ below the top of Smoky mountain, which suggests that the ridge may be a downfaulted segment of the mountain and therefore that North Ray crater may expose material from part of the Descartes mountains in its walls.

That part of the crater interior visible from the rim is shown by the postmission topographic map (fig. 3). The crest is rounded but falls off rapidly to the steep crater wall, whose upper slopes are generally convex, ranging from $27^{\circ}$ at the top to $34^{\circ}$ in the lower half. Precipitous drops in the foreground slopes below the rim crest made photographing the lowest parts of the crater wall impossible. Only the upper 60 percent of the crater wall is observable from the vantage point at station 11 (figs. 3, 4). The rounded form of the crater rim, the smooth walls with few blocky areas, and the predominance of breccias in the observable rocks on the surface are evidence that the target materials impacted by North Ray crater were breccias of relatively low strength.

\section{BLOCK DISTRIBUTION AND ROCK TYPES}

The concentration of blocks on the rim of North Ray crater was considerably lower than anticipated. The low frequency of fragments was observed on the approach to the crater rim. Fragments range from $25 \mathrm{~m}$ to less than $1 \mathrm{~m}$ in maximum diameter. Most of the large boulders observable on postmission orbital photographs, mapped here on figure 5, had been identified on premission photographs. Within $10 \mathrm{~m}$ of the site of panorama 18 (pl. 8), fragments $10 \mathrm{~cm}$ and larger cover 4.3 percent of the surface (figs. $4,6 A$ ); at station 13 , $0.75 \mathrm{~km}$ away, they cover only 0.5 percent with about one-fourth as many fragments (fig. $6 B$ and panorama 23, pl. 7). Nearly 70 percent of the fragments counted at these stations are rounded (fig. 6; table 1). At station 11 , more than 20 percent are larger than $20 \mathrm{~cm}$ in diameter, at station 13 , only 10 percent.

All the blocks with discernible textures are clastic in appearance. Their matrices range from dark to light gray, as seen in the black-and-white photographs. The

TABLE 1.-Distribution of blocks at North Ray crater by size and shape
[Number of blocks counted and percentage of total within $10 \mathrm{~m}$ of center of station [Number of blocks counted and percentage of total within $10 \mathrm{~m}$ of center of station
panoramas. Data from figure 6]

\begin{tabular}{lcccc}
\hline Shape & $\begin{array}{ccc}10-20 \\
\mathrm{~cm}\end{array}$ & $\begin{array}{ccc}20-50 \\
\mathrm{~cm}\end{array}$ & $\begin{array}{c}>50 \\
\mathrm{~cm}\end{array}$ & Total percent \\
\hline
\end{tabular}

\section{Station 11-rim crest}

\begin{tabular}{|c|c|c|c|c|c|}
\hline $\begin{array}{l}\text { Rounded } \\
\text { Subangular } \\
\text { Angular }\end{array}$ & $\begin{array}{r}145 \\
44 \\
13\end{array}$ & $\begin{array}{r}35 \\
11 \\
3\end{array}$ & $\begin{array}{r}0 \\
0 \\
10\end{array}$ & $\begin{array}{r}180 \\
55 \\
26\end{array}$ & $\begin{array}{l}69.0 \\
21.0 \\
10.0\end{array}$ \\
\hline Total & 202 & 49 & 10 & 261 & \\
\hline Size percent & $\mathbf{7 7 . 4}$ & 18.8 & 3.8 & & 100.0 \\
\hline
\end{tabular}

\begin{tabular}{|c|c|c|c|c|c|}
\hline \multicolumn{6}{|c|}{ Station 13-outer ejecta blanket } \\
\hline $\begin{array}{l}\text { Rounded } \\
\text { Subangular } \\
\text { Angular - }\end{array}$ & $\begin{array}{r}41 \\
13 \\
8 \\
\end{array}$ & $\begin{array}{l}6 \\
1 \\
0 \\
\end{array}$ & $\begin{array}{l}0 \\
0 \\
0 \\
\end{array}$ & $\begin{array}{r}47 \\
14 \\
8\end{array}$ & $\begin{array}{l}68.1 \\
20.3 \\
11.6 \\
\end{array}$ \\
\hline Total & 62 & 7 & 0 & 69 & \\
\hline Size percent & 89.9 & 10.1 & 0 & & 100.0 \\
\hline
\end{tabular}




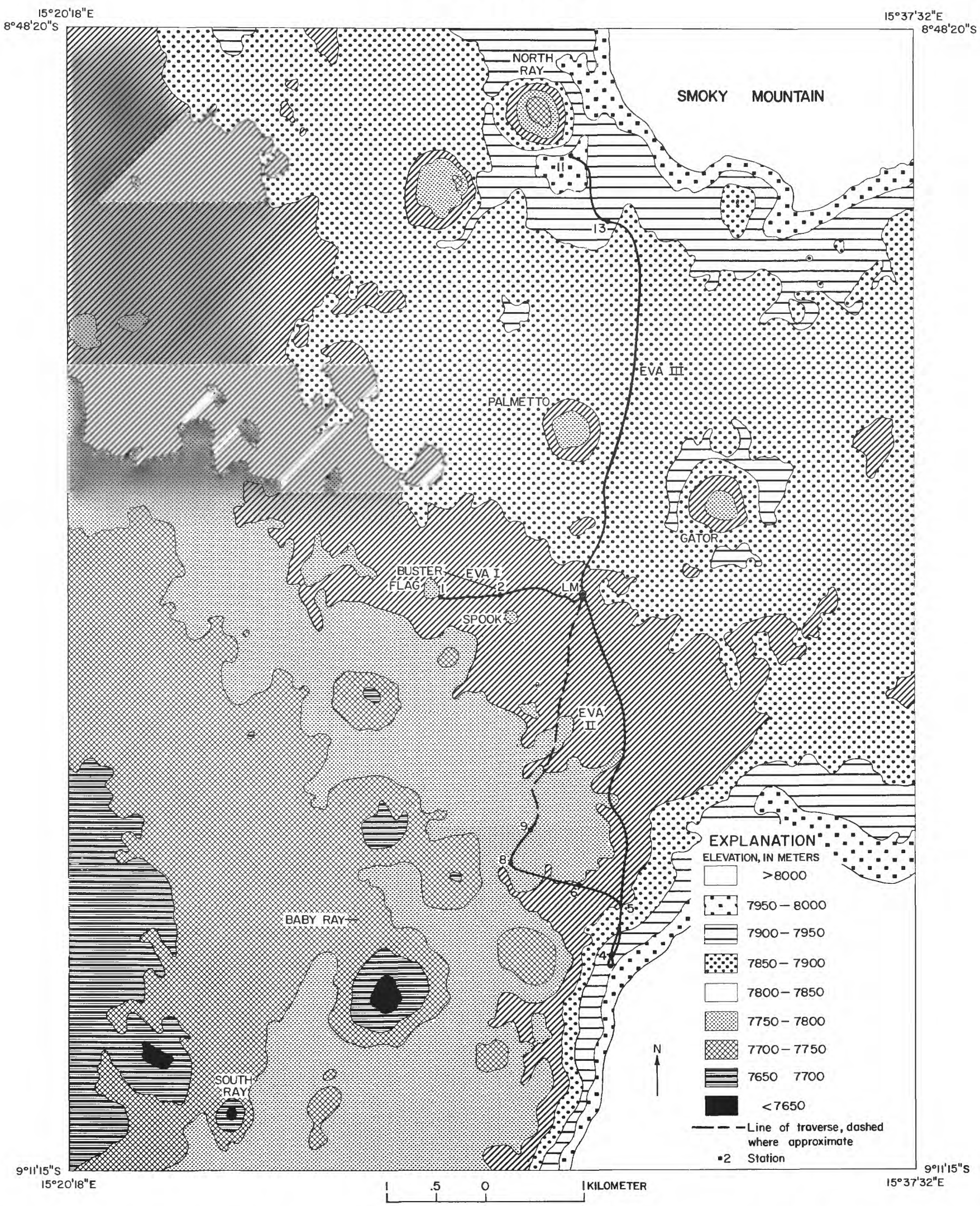

Figure 1.-Hypsographic map of the Apollo 16 site showing topographic zones in 50-m increments. Modified from Muehlberger and others (1972) and AFGIT (1973). Copyright 1973 by the American Association for the Advancement of Science. 


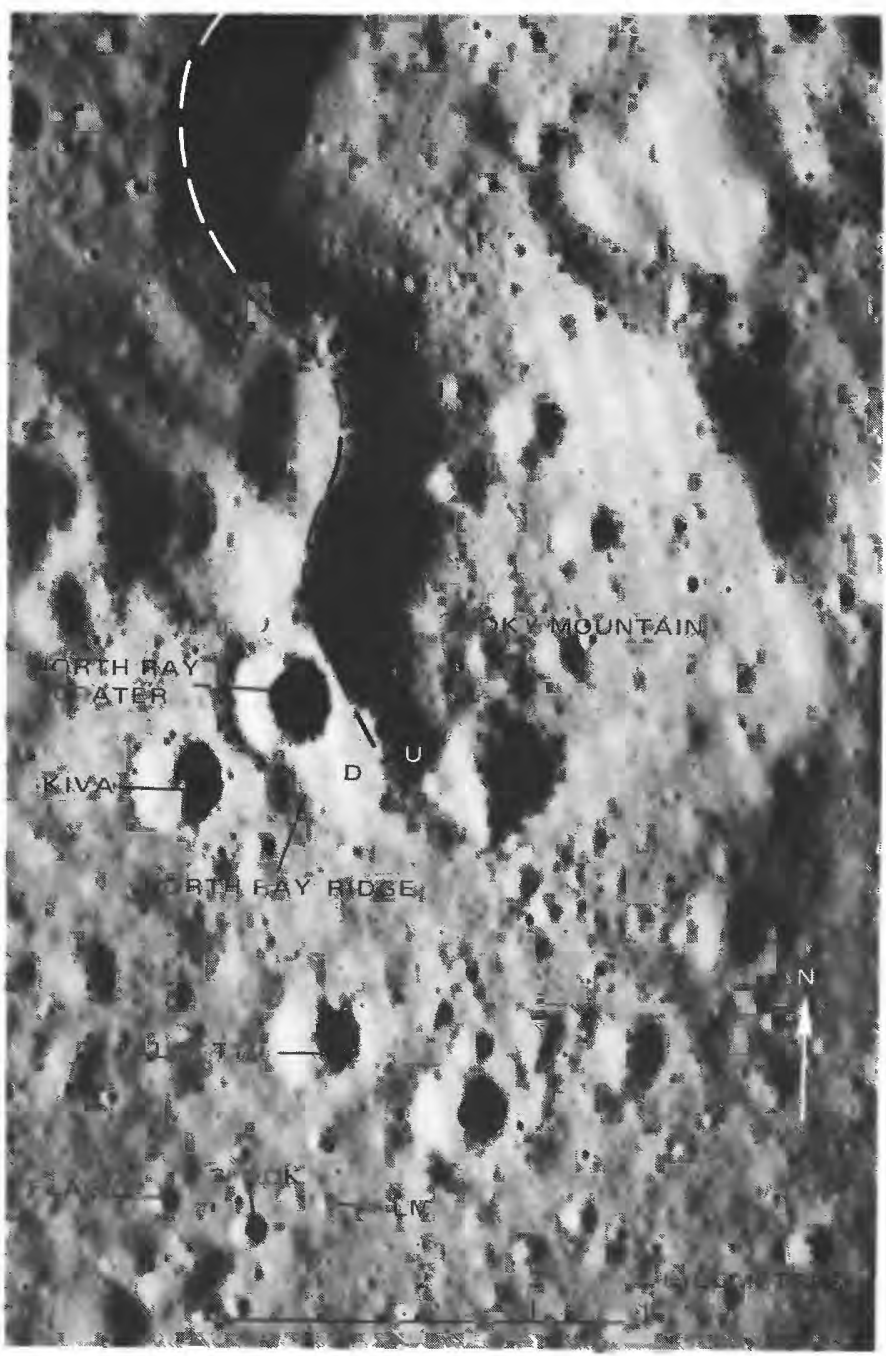

Figure 2.-Northern part of Apollo 16 landing site, showing principal named features. Dashed line, possible fault; U, upthrown side; D, downthrown side. Apollo 16 panoramic camera frame 4558, sun elevation $16^{\circ}$. From Ulrich (1973) Reprinted with permission of Pergamon Press. 


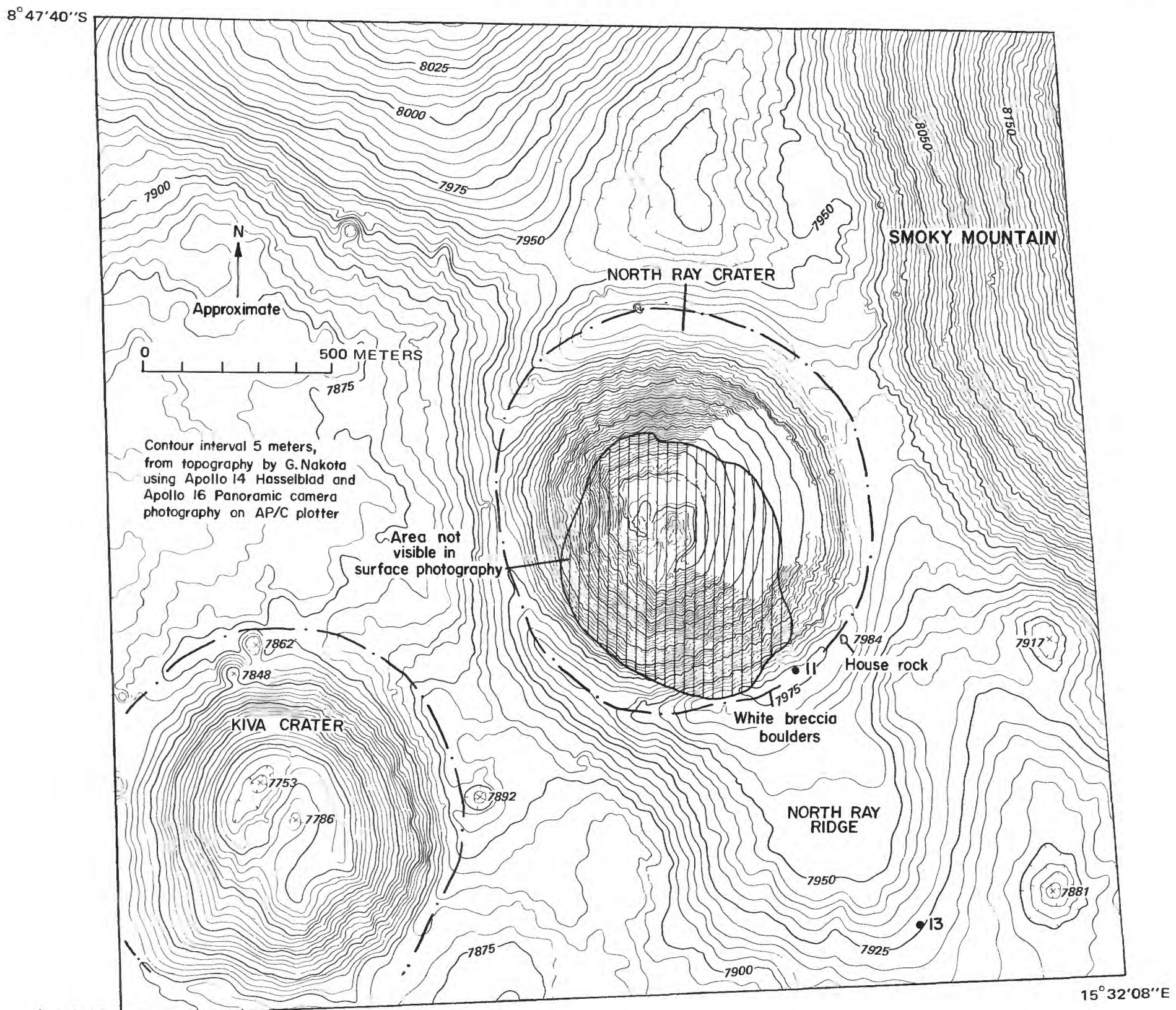

$8^{\circ} 52^{\prime} 37^{\prime \prime} \mathrm{S} 15^{\circ} 27^{\prime} 12^{\prime \prime} \mathrm{E}$

FIGURE 3.-Topographic map of North Ray crater showing station localities and area visible from rim. Contour interval $5 \mathrm{~m}$. Topography by G. M. Nakata from Apollo 16 panoramic camera frames 4618 and 4623. From Ulrich (1973). Reprinted with permission of Pergamon Press. 

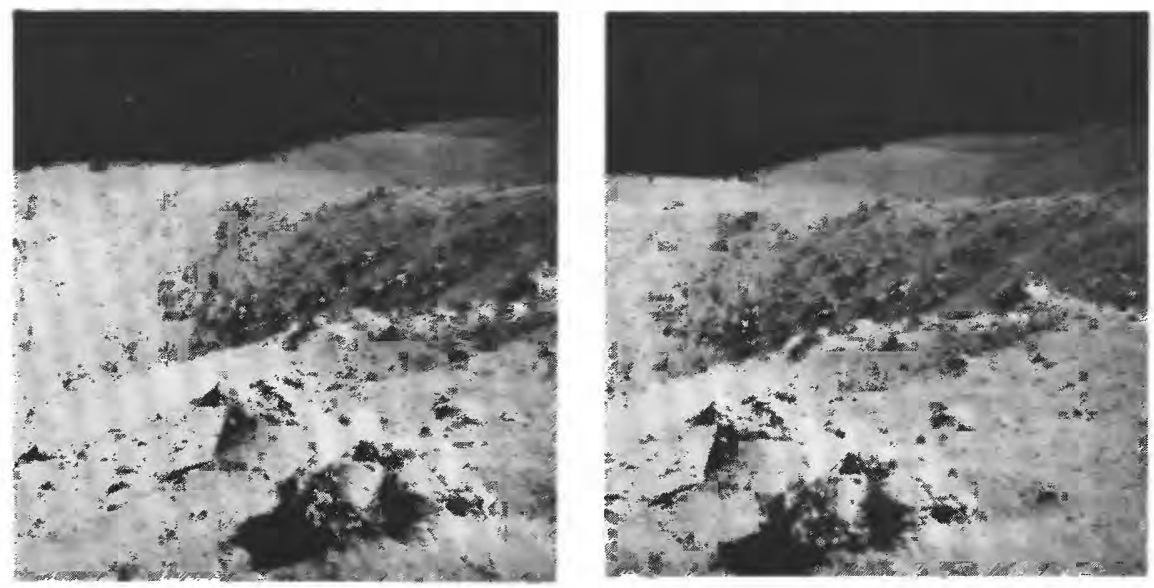

FIGURE 4.-Stereopair showing northeast wall of North Ray crater from east panorama station. Foreground shows typical slopes inside rim crest. AS16-106-17301, 17302.

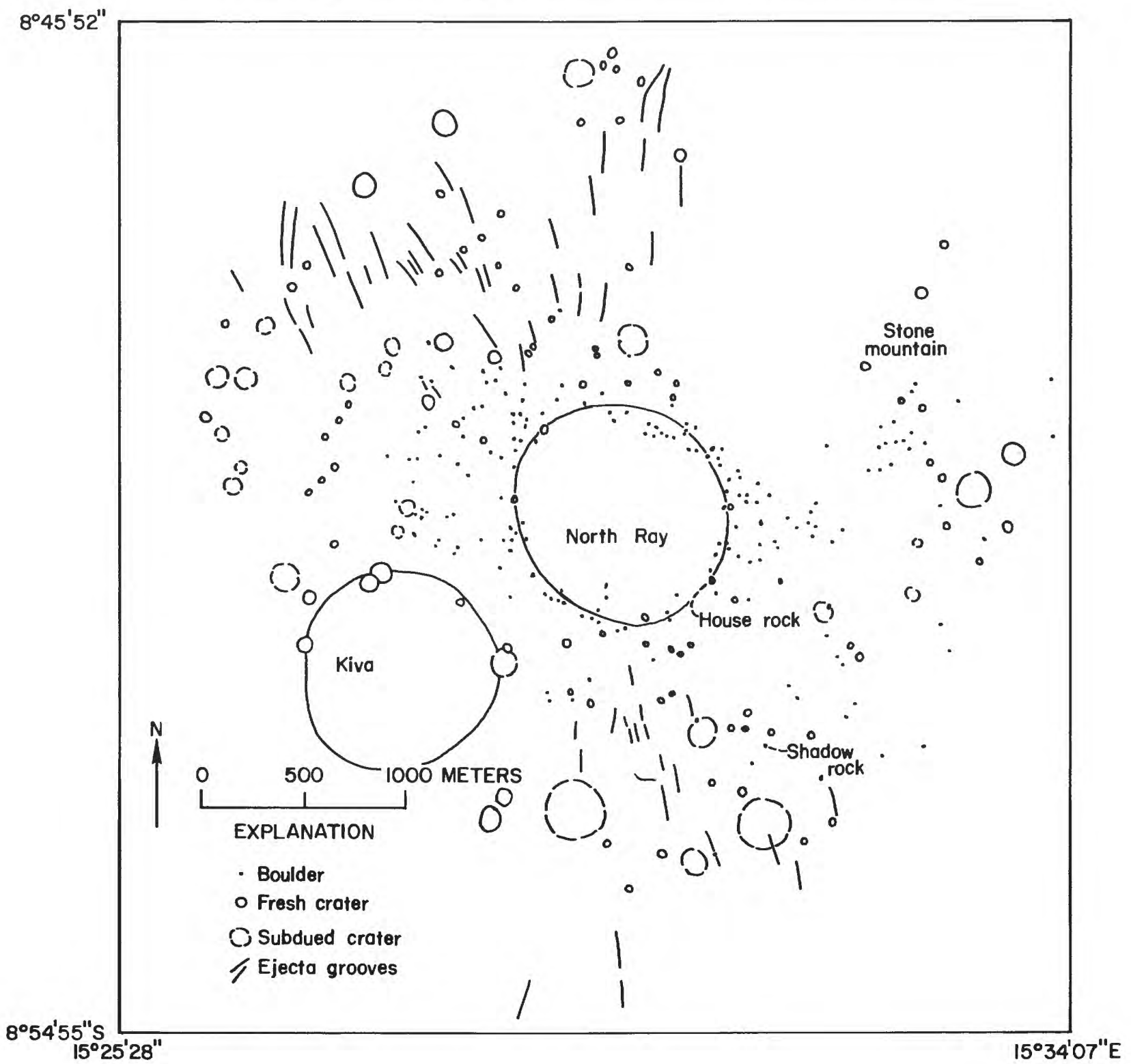


AS16-106

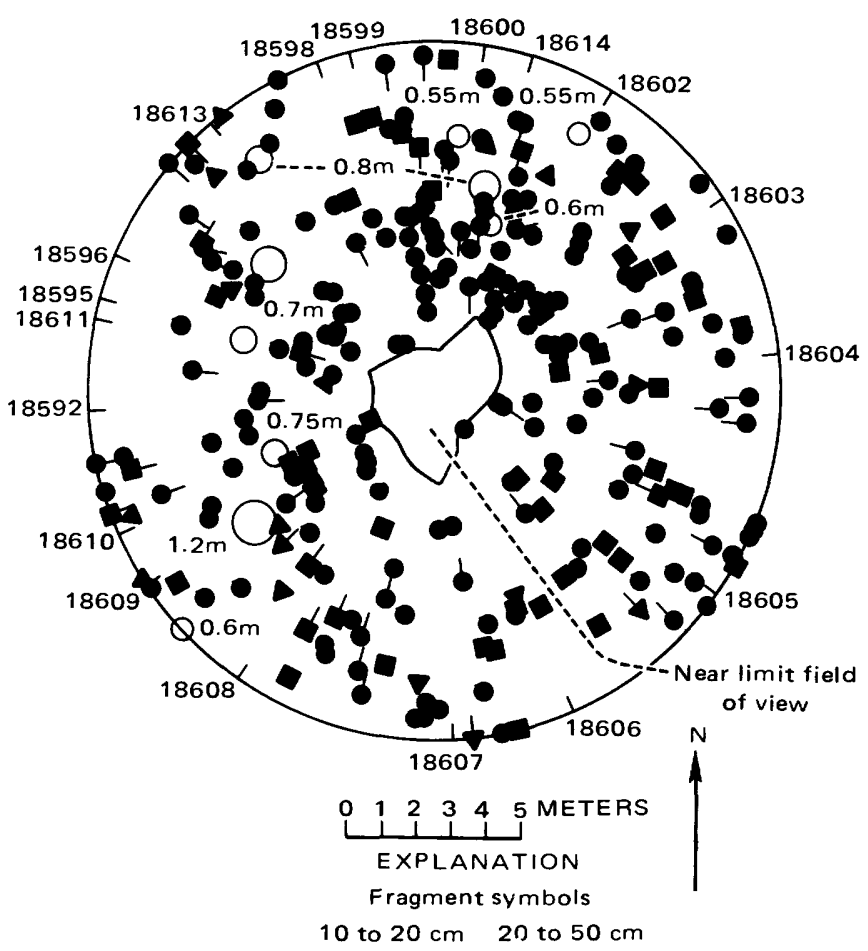

Round

Subangular

Angular

Hachures on outer circle show direction of individual

photographs that constitute the panorama

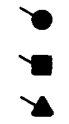

0

$A$

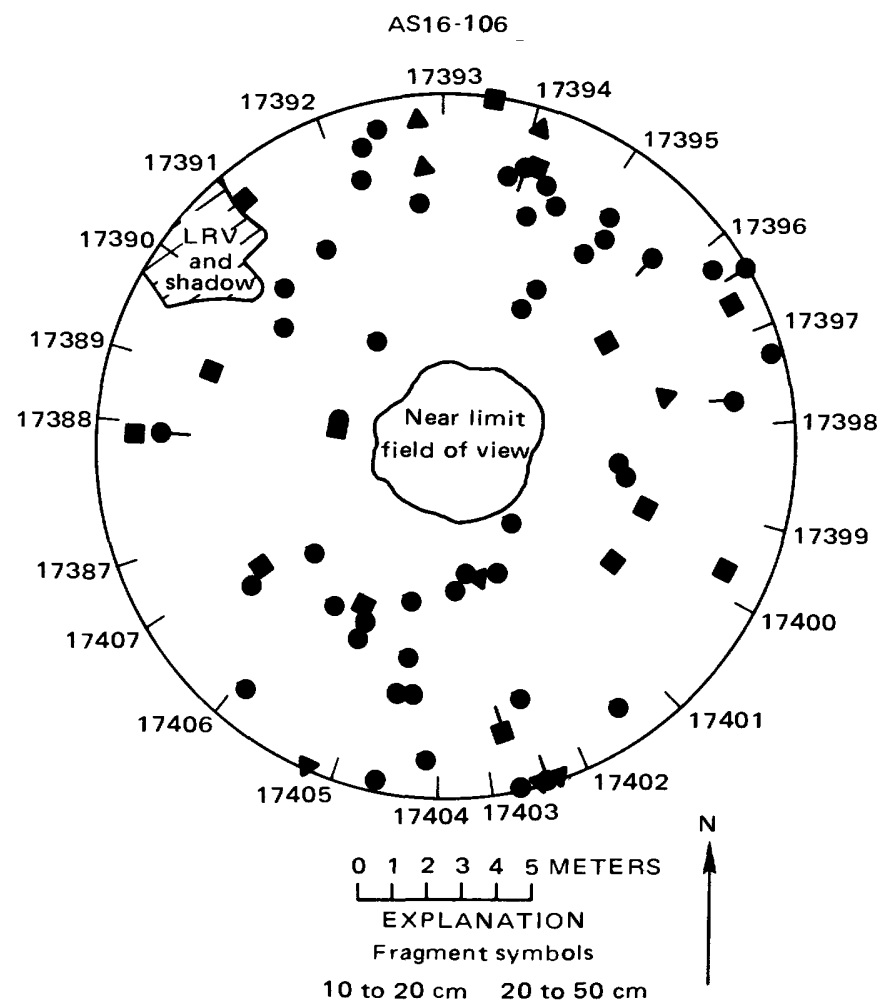

Round

Subangular Angular

Hachures on outer circle show direction of individual photographs that constitute the panorama

$B$

FIgURE 6.-Block distribution within $10 \mathrm{~m}$ of sites of station 11 and station 13 panoramas. $A$, Station 11. $B$, Station 13 . From Muehlberger and others, 1972.

FIGURE 5.-Map of boulders, craters, and ejecta grooves in North Ray crater area. Data from Apollo 16 panoramic camera frames 4563 and 4623 . 
dark-matrix rocks consistently exhibit angular edges and pronounced jointing, and few have soil fillets developed at their bases (figs. 7-9).

Light-matrix boulders are distinctly more rounded, more crudely jointed, and more deeply filleted by soil inferred to be their own residual debris (figs. 10 and 11). The rock sample characteristics, discussed below and by Wilshire and others (this volume), reflect similar differences in coherence or friability. Megascopically and microscopically, textures indicate that variations in rock colors and coherence are produced by differences in amounts of impact melt incorporated in the rocks and in rates of cooling.

Of more than 800 rocks in the near field of four photographic panoramas taken on the rim and ejecta blanket of North Ray crater, 70 to 90 percent are relatively light colored (fig. 12). These include the lightand medium-gray-matrix breccias $\left(\mathrm{B}_{1}, \mathrm{~B}_{2}\right.$, and $\mathrm{B}_{3}$ of Wilshire and others, this volume) and probably some igneous and metaclastic rocks $\left(\mathrm{C}_{1}\right.$ and $\left.\mathrm{C}_{2}\right)$ that are indistinguishable from the light-matrix breccias in surface photographs. Rocks consisting largely of glass (class G of Wilshire and others, this volume) may be counted as dark rocks (dark-matrix breccias, $B_{4}$ and $B_{5}$ ) except where large amounts of light-colored soil adhered to their surfaces. The percentage of dark rocks increases from about 10 in the western part of the southeast rim (panorama 19 and sketch, pl. 8) to nearly 30 at a location midway between the White breccia boulders and House rock. About 20 percent of the fragments at Shadow rock are dark.

\section{SAMPLE LOCALITIES}

In order to reconstruct the stratigraphic sequence in North Ray crater, the distribution and concentration of the several rock types with respect to their location on the crater wall and floor were studied. The sampled area is subdivided into four localities, the White breccia boulders, the Interboulder area, the House rock

TABLE 2.-Rock samples greater than $2 \mathrm{~g}$ from the House rock area

\begin{tabular}{|c|c|c|c|c|c|}
\hline \multirow[b]{2}{*}{$\begin{array}{l}\text { Sample } \\
\text { No. }\end{array}$} & \multicolumn{3}{|c|}{ Weight group (g) } & \multirow{2}{*}{$\begin{array}{l}\text { Classification } \\
\text { (Wilshire and } \\
\text { others, this } \\
\text { volume, } \\
\text { table 1) }\end{array}$} & \multirow[b]{2}{*}{ Geologic significance } \\
\hline & $2-25$ & $25-100$ & $100+$ & & \\
\hline 67915 & $-\cdots$ & $\ldots$ & $x$ & $\mathrm{~B}_{4}$ & $\begin{array}{l}\text { Representative of House and } \\
\text { Outhouse rocks. }\end{array}$ \\
\hline 67935 & ---- & --- & $x$ & ${ }^{1}\left(\mathrm{C}_{2}\right)$ & $\begin{array}{l}\text { Metaclastic matrix from Out- } \\
\text { house rock. }\end{array}$ \\
\hline 67936 & --- & $x$ & $\ldots$ & $\mathrm{C}_{1}$ & $\begin{array}{l}\text { Same as 67935, in impact-spall } \\
\text { zone. }\end{array}$ \\
\hline 67937 & ---- & $x$ & --- & $\mathrm{B}_{4}$ & $\begin{array}{l}\text { Dark-matrix breccia from im- } \\
\text { pact spall zone. }\end{array}$ \\
\hline $\begin{array}{l}67945 \\
67946 \\
67947\end{array}$ & $\begin{array}{l}x \\
x \\
x\end{array}$ & $\begin{array}{l}--- \\
--- \\
---\end{array}$ & $\begin{array}{l}--- \\
----\end{array}$ & $\begin{array}{l}\mathrm{B}_{4} \\
\left(\mathrm{~B}_{4}\right) \\
\left(\mathrm{B}_{4}\right)\end{array}$ & $\begin{array}{l}\text { Rock from "east-west split." } \\
\text { Do. } \\
\text { Do. }\end{array}$ \\
\hline 67955 & $\hat{-\cdots}$ & --- & $x$ & $\mathrm{~B}_{1}$ & $\begin{array}{l}\text { Light-matrix clast from Out- } \\
\text { house rock. }\end{array}$ \\
\hline 67956 & $x$ & ---- & ---- & $\mathrm{C}_{1}$ & $\begin{array}{l}\text { Igneous fragment from Out- } \\
\text { house rock. }\end{array}$ \\
\hline 67975 & ---- & $-\cdots$ & $x$ & $\mathrm{~B}_{2}$ & $\begin{array}{l}\text { Fragment in soil near Outhouse } \\
\text { rock. }\end{array}$ \\
\hline
\end{tabular}

'( ) Provisional classification by Wilshire and others, this volume, table 1. area and the Shadow rock area (fig. 13), whose names were derived from descriptive terms used by the crew. All but Shadow rock are on the crater rim crest. Shadow rock is approximately $0.75 \mathrm{~km}$ southeast of the

TABLE 3.-Rock samples greater than $2 \mathrm{~g}$ from the White breccia boulders area

\begin{tabular}{|c|c|c|c|c|c|}
\hline \multirow[b]{2}{*}{$\begin{array}{l}\text { Sample } \\
\text { No. }\end{array}$} & \multicolumn{3}{|c|}{ Weight group (g) } & \multirow{2}{*}{$\begin{array}{c}\text { Classification } \\
\text { (Wilshire and } \\
\text { others, this } \\
\text { volume, } \\
\text { table 1) }\end{array}$} & \multirow[b]{2}{*}{ Geologic significance } \\
\hline & $2-25$ & $25-100$ & $100+$ & & \\
\hline 67016 & $-\cdots$ & --- & $x$ & ${ }^{1} \mathbf{B}_{3}\left(\mathbf{B}_{2}\right)$ & Large loose rock on crater rim \\
\hline 67025 & $x$ & ---- & $-\cdots$ & $\mathbf{B}_{2}\left(\mathbf{B}_{3}\right)$ & Coherent fragment, possibly \\
\hline 67035 & ---- & ---- & $x$ & $\mathbf{B}_{2}$ & $\begin{array}{l}\text { "Three-rock" breccia } 20 \mathrm{~m} \text { inside } \\
\text { rim crest. }\end{array}$ \\
\hline $\begin{array}{l}67215 \\
67415\end{array}$ & --- & --- & $\stackrel{x}{x}$ & $\begin{array}{c}\text { Unclass } \\
\mathbf{B}_{1}\end{array}$ & $\begin{array}{l}\text { Unopened rock in padded bag. } \\
\text { Friable rock at base of light- }\end{array}$ \\
\hline 67435 & --- & -..- & $\times$ & ${ }^{2}\left(B_{4}\right)$ & $\begin{array}{l}\text { Glass-coated; may be dark- and } \\
\text { light-matrix breccia. }\end{array}$ \\
\hline 67455 & $-\cdots$ & $-\ldots$ & $x$ & $\mathbf{B}_{2}$ & $\begin{array}{l}\text { Fragments off top of } 6 \mathrm{~m} \text { light- } \\
\text { matrix breccia boulder. }\end{array}$ \\
\hline 67475 & $-\cdots$ & $-\cdots$ & $x$ & $\mathrm{~B}_{4}$ & $\begin{array}{l}\text { Clast from the same boulder as } \\
67455\end{array}$ \\
\hline 67485 & $\times$ & ---- & ---- & $\left(\mathrm{C}_{2}\right)$ & $\begin{array}{l}\text { Fragment in soil near } 67455 \\
\text { light-matrix boulder. }\end{array}$ \\
\hline $\begin{array}{l}67486 \\
67487\end{array}$ & $\begin{array}{l}x \\
x\end{array}$ & ---- & 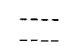 & $\begin{array}{l}\left(\mathrm{B}_{1}\right) \\
\left(\mathrm{C}_{2}\right)\end{array}$ & $\begin{array}{l}\text { Do. } \\
\text { Do. }\end{array}$ \\
\hline 67488 & $\hat{x}$ & --- & - n & $\left(\mathrm{C}_{2}\right)$ & $\begin{array}{l}\text { Do. } \\
\text { Do. }\end{array}$ \\
\hline $\begin{array}{l}67489 \\
67515\end{array}$ & $\begin{array}{c}x \\
\cdots--\end{array}$ & $x$ & ---- & $\stackrel{\left(\mathrm{B}_{2}\right)}{\mathrm{B}_{2}}$ & $\begin{array}{l}\text { Bo. in rake sample near } \\
\text { Breccia in rater } \\
6755 \text { light-matrix boulder. }\end{array}$ \\
\hline $\begin{array}{l}67516 \\
67517\end{array}$ & $\begin{array}{l}x \\
x\end{array}$ & ---- & ---- & $\mathbf{B}_{2}\left(\mathbf{B}_{1}\right)$ & $\begin{array}{l}\text { Do. } \\
\text { Do. }\end{array}$ \\
\hline 67518 & $\begin{array}{l}x \\
x\end{array}$ & $-\cdots$ & $-\cdots$ & $\begin{array}{l}\mathrm{B}_{2}\left(\mathrm{~B}_{1}\right) \\
\mathrm{B}_{2}\left(\mathrm{~B}_{1}\right)\end{array}$ & $\begin{array}{l}\text { Do. } \\
\text { Do. }\end{array}$ \\
\hline $\begin{array}{l}67519 \\
67525\end{array}$ & $\begin{array}{l}x \\
x\end{array}$ & --- & ---- & $\begin{array}{l}\mathrm{B}_{2}\left(\mathrm{~B}_{1}\right) \\
\mathrm{B}_{3}, \mathrm{~B}_{3}\end{array}$ & $\begin{array}{l}\text { Do. } \\
\text { Do. }\end{array}$ \\
\hline 67526 & $x$ & --- & --- & $\mathrm{B}_{2}\left(\mathrm{~B}_{1}\right)$ & Do. \\
\hline $\begin{array}{l}67527 \\
67539\end{array}$ & $\begin{array}{l}x \\
x \\
x\end{array}$ & $-\cdots$ & --- & $\begin{array}{l}B_{2}\left(B_{1}\right) \\
B_{2}\left(B_{1}\right)\end{array}$ & $\begin{array}{l}\text { Do. } \\
\text { Do. }\end{array}$ \\
\hline 67549 & -- & $x$ & --- & $\mathrm{B}_{2}$ & Do. \\
\hline $\begin{array}{l}67555 \\
67556\end{array}$ & x & $x$ & - n & $\begin{array}{l}\mathbf{B}_{2} \\
\mathrm{~B}_{2}\end{array}$ & $\begin{array}{l}\text { Do. } \\
\text { Do. }\end{array}$ \\
\hline 67557 & $x$ & --- & -- & Unclass & Do. \\
\hline $\begin{array}{l}67508 \\
67559\end{array}$ & - & $x$ & --- & $\begin{array}{l}\text { Unclass } \\
\left(\mathrm{C}_{2}\right)\end{array}$ & $\begin{array}{l}\text { Do. } \\
\text { Olivine basalt* in rake sample } \\
\text { near } 67455 \text { boulder }^{3}\end{array}$ \\
\hline 67565 & $x$ & -.- & --- & $\mathrm{C}_{2}$ & $\begin{array}{l}\text { Basalt } t^{*} \text { in rake sample near } \\
67455 \text { boulder. }\end{array}$ \\
\hline $\begin{array}{l}67566 \\
67567\end{array}$ & $\begin{array}{l}x \\
\times\end{array}$ & - n & --- & $\begin{array}{l}\mathrm{C}_{2} \\
\mathrm{G}\end{array}$ & $\begin{array}{l}\text { Do. } \\
\text { Breccia in rake sample near } \\
6745 \text { bolder }\end{array}$ \\
\hline 67568 & $x$ & --- & ---- & $\mathrm{G}$ & Do. \\
\hline $\begin{array}{l}67569 \\
67575\end{array}$ & $\begin{array}{l}x \\
x\end{array}$ & --- & --- & $\underset{G}{G}$ & $\begin{array}{l}\text { Do. } \\
\text { Do. }\end{array}$ \\
\hline 67576 & $x$ & - n & -- & $\mathrm{G}$ & $\begin{array}{l}\text { Do. } \\
\text { Do. }\end{array}$ \\
\hline 67605 & --- & $x$ & $\ldots$ & $\mathrm{B}_{2}$ & $\begin{array}{l}\text { Fragment from soil sample in } \\
\text { rake area. }\end{array}$ \\
\hline 67615 & $x$ & --- & $\cdots$ & $\mathrm{C}_{2}$ & $\begin{array}{l}\text { Basalt" in rake sample } 10 \mathrm{~m} \text { in- } \\
\text { side rim crest. }\end{array}$ \\
\hline $\begin{array}{l}67616 \\
67617\end{array}$ & $\begin{array}{l}\times \\
\times\end{array}$ & ---- & --- & $\begin{array}{l}\mathrm{C}_{2} \\
\mathrm{C}_{2}\end{array}$ & $\begin{array}{l}\text { Do. } \\
\text { Basaltic breccia* in rake sample } \\
10 \mathrm{~m} \text { inside rim crest. }\end{array}$ \\
\hline 67618 & $x$ & -..- & ---- & $\mathrm{C}_{2}$ & $\begin{array}{l}\text { Do. } \\
\text { Do. }\end{array}$ \\
\hline 676 & $\hat{x}$ & $-\cdots-$ & $-\cdots$ & $\mathrm{C}_{2}^{2}$ & $\begin{array}{l}\text { Metaclastic rock in rake sample } \\
10 \mathrm{~m} \text { inside rim crest. }\end{array}$ \\
\hline 67626 & $x$ & -..- & ---- & G & $\begin{array}{l}\text { Breccia in rake sample } 10 \mathrm{~m} \text { in- } \\
\text { side rim crest. }\end{array}$ \\
\hline 67627 & --- & $x$ & --- & G & Do. \\
\hline $\begin{array}{l}67628 \\
67629\end{array}$ & $\begin{array}{ll}--- \\
---\end{array}$ & $\begin{array}{l}x \\
x\end{array}$ & $\begin{array}{l}--\cdot \\
----\end{array}$ & $\begin{array}{l}G \\
G\end{array}$ & $\begin{array}{l}\text { Do. } \\
\text { Basalt" clast from light-matrix } \\
\text { breccia. }\end{array}$ \\
\hline 67635 & $x$ & --- & ---- & $\mathrm{B}_{1}$ & $\begin{array}{l}\text { breccia in rake sample } 10 \mathrm{~m} \text { in- } \\
\text { side rim crest. }\end{array}$ \\
\hline 67636 & $x$ & $-\ldots$ & ---- & $\mathrm{B}_{\mathrm{r}}$ & Do. \\
\hline & $\begin{array}{l}x \\
x\end{array}$ & --- & --- & ${\stackrel{B}{B_{2}}}_{\mathrm{B}_{2}}$ & $\begin{array}{l}\text { Do. } \\
\text { Do. }\end{array}$ \\
\hline 67639 & $\hat{x}$ & --- & $\cdots$ & $\begin{array}{l}\mathbf{b}_{2} \\
\mathrm{~B}_{2}\end{array}$ & $\begin{array}{l}\text { Do. } \\
\text { Do. }\end{array}$ \\
\hline $\begin{array}{l}67646 \\
67647\end{array}$ & $x$ & $x$ & $-\cdots$ & $\begin{array}{l}\mathrm{B}_{2} \\
\text { Unclass }\end{array}$ & $\begin{array}{l}\text { Do. } \\
\text { Do. }\end{array}$ \\
\hline 67648 & $x$ & --- & --- & $\mathrm{B}_{2}$ & Do. \\
\hline & $\begin{array}{l}x \\
x\end{array}$ & $-\cdots$ & ---- & $\begin{array}{l}\mathbf{B}_{2} \\
\left(\mathbf{B}_{3}\right)\end{array}$ & $\begin{array}{l}\text { Do. } \\
\text { Do. }\end{array}$ \\
\hline & $x$ & -..- & --- & $\mathrm{B}_{2}$ & \\
\hline 67 & $x$ & -.-- & --- & $\mathrm{C}_{2}$ & Ultramafic?* in rake sample \\
\hline 67668 & $x$ & --- &.--- & $\mathrm{C}_{2}$ & $\begin{array}{l}\text { Basaltic breccia* in rake sam } \\
\text { fo recido rim }\end{array}$ \\
\hline 67669 & $x$ & ---- & --- & $\left(B_{3}\right)$ & $\begin{array}{l}10 \mathrm{~m} \text { inside rim crest } \mathrm{m} \text { in- } \\
\text { Breccia in rake sample } 10 \mathrm{~m} \text {. }\end{array}$ \\
\hline 67676 & $x$ & --- & ---- & $\mathrm{C}_{2}$ & $\begin{array}{l}\text { Basalt' in rake sample } 10 \mathrm{~m} \text { in- } \\
\text { side rim crest }\end{array}$ \\
\hline
\end{tabular}


crest, but still on continuous North Ray ejecta. For each of the four areas, the rock samples weighing more than $2 \mathrm{~g}$ are tabulated and their geologic significance indicated in tables 2 to 5 . Their occurrence by rock type is graphically compared in figure 14. The larger soil samples and their location and geologic significance are given in table 6 .

\section{HOUSE ROCK AREA}

The largest boulder visited and one established as a sampling target before the mission is House rock. It is an angular, predominantly dark-matrix boulder, approximately $25 \mathrm{~m}$ long and $12 \mathrm{~m}$ high, at the northeastern limit of the crater-rim-crest traverse area (figs. 8,$13 ;$ pl. 8, pan 28). It was so named when Astronaut Duke, on first observing it at station 11, compared its size to that of a house. Less than $1 \mathrm{~m}$ away on the south end of House rock is a 3-m boulder of similar texture, anonymously named Outhouse rock, the source of most of the rock samples collected at this locality.

TABLE 4.-Rock samples greater than $2 \mathrm{~g}$ from the Interboulder area

\begin{tabular}{|c|c|c|c|c|c|}
\hline $\begin{array}{l}\text { Sample } \\
\text { No. }\end{array}$ & $2-25 \mathrm{~g}$ & $25-100$ & $100+$ & $\begin{array}{c}\text { Classification } \\
\text { (Wilshire and } \\
\text { others, this } \\
\text { volume) }\end{array}$ & Geologic significance \\
\hline 67015 & $\ldots$ & --- & $x$ & ${ }^{\prime} \mathrm{B}_{3}\left(\mathrm{~B}_{3}\right)$ & Large loose rock inside rim crest \\
\hline 67055 & 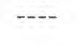 & --- & $x$ & $\mathbf{B}_{2}\left(\mathbf{B}_{3}\right)$ & $\begin{array}{l}\text { Collected for abundant black } \\
\text { clasts (more than } 67035 \text { ). }\end{array}$ \\
\hline 67075 & --- & --- & $x$ & $\mathbf{B}_{\mathbf{t}}$ & $\begin{array}{l}\text { Found as two broken pieces of } \\
\text { white shocked rock. }\end{array}$ \\
\hline 67095 & --- & $-\cdots$ & $x$ & G & Collected for appearance as \\
\hline 67115 & --- & --- & $x$ & ${ }^{2}\left(\mathbf{B}_{3}\right)$ & $\begin{array}{l}\text { Same location as 67095; more } \\
\text { rounded. }\end{array}$ \\
\hline 67235 & ---- & --- & $\times$ & Unclass & Unopened rock in padded bag. \\
\hline 67705 & $x$ & --- & $\ldots$ & (G) & $\begin{array}{l}\text { Fragment in rake soil on rim } \\
\text { crest. }\end{array}$ \\
\hline 67706 & $x$ & ---- & -.-- & Unclass & Do. \\
\hline 67715 & $x$ & --- & $-\ldots-$ & $\mathbf{B}_{4}$ & $\begin{array}{l}\text { Basalt* probably clast from } \\
\text { light-matrix breccia. }^{3}\end{array}$ \\
\hline 67716 & $x$ & --- & --- & $\mathbf{B}_{4}$ & $\begin{array}{l}\text { Breccia, probable clast from } \\
\text { light-matrix breccia. }\end{array}$ \\
\hline 67717 & $x$ & ---- & --- & $\mathbf{B}_{4}$ & Do. \\
\hline 67718 & $\cdots$ & $x$ & -.-- & $\left(\mathbf{B}_{3}\right)$ & Do. \\
\hline 67719 & $x$ & --- & -..-- & $\mathbf{B}_{4}$ & Do. \\
\hline 67725 & $x$ & -- & - & $\mathrm{B}_{4}$ & $\begin{array}{l}\text { Breccia in rake sample on rim } \\
\text { crest. }\end{array}$ \\
\hline 67726 & $x$ & --- & -.-- & $\mathbf{B}_{4}$ & Do. \\
\hline 67728 & $x$ & -..- & $\ldots$ & G & $\begin{array}{l}\text { Fragment in rake sample on rim } \\
\text { crest. }\end{array}$ \\
\hline 67729 & & $x$ & -... & G & Do. \\
\hline 67735 & $x$ & --- & $\ldots$ & $\mathbf{B}_{5}\left(\mathbf{B}_{3}\right)$ & Do. \\
\hline 67736 & $x$ & --- & -..- & $\mathrm{C}_{2}$ & $\begin{array}{l}\text { Olivine basalt with ultramafic } \\
\text { inclusion; zapped on all } \\
\text { sides.* }\end{array}$ \\
\hline 67737 & $x$ & --- & $-\cdots$ & $\mathbf{B}_{4}$ & Basalt* probable clast from \\
\hline 67738 & $x$ & --.- & -.-- & $\mathbf{B}_{4}$ & Do. \\
\hline 67739 & $x$ & --- & --- & $\mathrm{B}_{4}$ & $\begin{array}{l}\text { Fragment in rake sample on rim } \\
\text { crest. }\end{array}$ \\
\hline 67745 & $x$ & $\ldots$ & ---- & $\mathrm{B}_{4}$ & $\begin{array}{l}\text { Basalt* in rake sample on rim } \\
\text { crest. }\end{array}$ \\
\hline 67746 & $x$ & --- & ---- & $\mathrm{C}_{2}$ & $\begin{array}{l}\text { Norite?* in rake sample on rim } \\
\text { crest. }\end{array}$ \\
\hline 67747 & $x$ & --- & -- & $\mathrm{C}_{2}$ & $\begin{array}{l}\text { Troctolite?* in rake sample on } \\
\text { rim crest. }\end{array}$ \\
\hline 67748 & $x$ & --- & ---- & $\mathrm{C}_{2}$ & $\begin{array}{l}\text { Fragment in rake sample on rim } \\
\text { crest. }\end{array}$ \\
\hline 67749 & $x$ & --- & ---- & $\mathbf{B}_{2}$ & $\begin{array}{l}\text { Breccia in rake sample on rim } \\
\text { crest. }\end{array}$ \\
\hline 67755 & $x$ & $\ldots$ & --- & $\mathbf{B}_{2}$ & Do. \\
\hline $\begin{array}{l}67756 \\
67757\end{array}$ & $\stackrel{x}{x}$ & ---- & --- & $\mathrm{B}_{3}$ & Do. \\
\hline 67758 & $\hat{x}$ & $-\cdots$ & $\ldots$ & $\mathbf{B}_{2}$ & $\begin{array}{l}\text { Do. } \\
\text { Do. }\end{array}$ \\
\hline 37759 & $x$ & $\ldots$ & -..- & $\mathbf{B}_{2}^{2}$ & Do. \\
\hline 67766 & $x$ & --- & --- & $\overrightarrow{\mathbf{B}}_{2}^{2}$ & Do. \\
\hline 67769 & $x$ & --- & --- & $\mathrm{B}_{2}$ & Do. \\
\hline 67775 & $x$ & -.-- & -..- & $\mathbf{B}_{2}$ & Do. \\
\hline 67776 & $x$ & --- & $\ldots$ & $\mathbf{B}_{2}$ & Do. \\
\hline
\end{tabular}

TABLE 5.-Rock samples greater than 2 g from the Shadow rock area, station 13, on outer North Ray ejecta

\begin{tabular}{|c|c|c|c|c|c|}
\hline $\begin{array}{c}\text { Sample } \\
\text { No. }\end{array}$ & $2-25 g$ & $25-100$ & $100+$ & $\begin{array}{c}\text { Classification } \\
\text { (Wilshire and } \\
\text { others, this } \\
\text { volume) }\end{array}$ & Geologic significance \\
\hline 60017 & --.- & ---- & $x$ & ${ }^{1} \mathbf{B}_{4}\left(\mathbf{B}_{5}\right)$ & $\begin{array}{l}\text { Large rock broken off from } 2 \mathrm{~m} \\
\text { area on southwest side of } \\
\text { Shadow rock. }\end{array}$ \\
\hline 63335 & ---- & $x$ & --- & ${ }^{2}\left(\mathbf{B}_{5}\right)$ & $\begin{array}{l}\text { Chip rock broken off from } 2 \mathrm{~m} \\
\text { area on southwest side of } \\
\text { Shadow rock. }\end{array}$ \\
\hline 63355 & ---- & $x$ & ---- & $\mathbf{B}_{4}$ & Do. \\
\hline 63505 & $x$ & ---- & --- & $\left(B_{4}\right)$ & $\begin{array}{l}\text { Fragment in rake soil 5-10 m } \\
\text { west of Shadow rock }\end{array}$ \\
\hline 63506 & $x$ & ---- & ---- & $\mathrm{C}_{1}$ & Do. \\
\hline 63507 & $x$ & --- & --- & $\mathbf{B}_{3}$ & Do. \\
\hline 63508 & $x$ & --- & --- & $\mathbf{B}_{3}$ & Do. \\
\hline 63509 & $x$ & --- & --- & $\mathbf{B}_{2}$ & Do. \\
\hline 63525 & $x$ & ---- & --.- & $\left(\mathbf{B}_{4}^{2}\right)$ & Do. \\
\hline 63526 & $x$ & --- & --- & $\left(\mathbf{B}_{4}\right)$ & Do. \\
\hline 63527 & $x$ & ---- & $\ldots$ & $\left(\mathbf{B}_{4}\right)$ & Do. \\
\hline 63528 & $x$ & --- & $\ldots$ & $\left(B_{4}\right)$ & Do. \\
\hline 63529 & $x$ & -..- & -..- & (B) & Do. \\
\hline 63535 & $x$ & ---- & $\ldots$ & $\left(\mathbf{B}_{4}\right)$ & Do. \\
\hline 63537 & $\hat{x}$ & $\ldots$ & $\ldots$ & $\left(\mathrm{C}_{2}\right)$ & Do. \\
\hline 63538 & & $x$ & ---- & $\left(\mathrm{C}_{2}\right)$ & Do. \\
\hline 63545 & $x$ & -.-- & $\ldots$ & $\left(\mathrm{C}_{2}\right)$ & Do. \\
\hline 63546 & $\hat{x}$ & -..- & --. & $\left(\mathrm{B}_{4}\right)$ & Do. \\
\hline 63547 & $x$ & $\ldots$ & $-\ldots$ & $\left(\mathrm{C}_{2}\right)$ & Do. \\
\hline 63549 & $\ldots$ & $x$ & $-\ldots$ & $\left(\mathrm{C}_{2}\right)$ & Do. \\
\hline 63555 & $x$ & $-\cdots$ & --- & $\left(\mathbf{B}_{4}\right)$ & Do. \\
\hline 63556 & $x$ & -... & -..- & $\left(\mathrm{C}_{2}\right)$ & Do. \\
\hline 63557 & $x$ & --- & --.-- & $\left(\mathrm{B}_{4}\right)$ & Do. \\
\hline 63558 & $x$ & -.- & -..- & $\left(\mathrm{C}_{2}\right)$ & Do. \\
\hline 63559 & $\hat{x}$ & $-\cdots$ & - & (G) & Do. \\
\hline 63566 & $x$ & --- & ---- & (G) & Do. \\
\hline 63567 & $x$ & --- & $\ldots$ & (G) & Do. \\
\hline 63568 & $x$ & -..- & - & (G) & Do. \\
\hline 63575 & $x$ & - & -..- & (G) & Do. \\
\hline 63577 & $x$ & $-\ldots$ & --_- & $\left(\mathrm{B}_{4}\left(\mathrm{C}_{2}\right)\right)$ & Do. \\
\hline 63578 & $\ddot{x}$ & $\ldots$ & -- & $\left(\mathbf{B}_{3}\right)$ & Do. \\
\hline 63579 & $x$ & --_- & -- & $\left(\mathbf{B}_{3}\right)$ & Do. \\
\hline 63585 & .... & $x$ & -..- & $\left(\mathrm{C}_{2}\right)$ & Do. \\
\hline 63587 & $\times$ & -... & $\ldots$ & $\left(\mathrm{B}_{3}\right)$ & Do. \\
\hline 63588 & $\hat{x}$ & --- & -- & $\left(\mathbf{B}_{2}\right)$ & Do. \\
\hline 63589 & $x$ & $-\cdots$ & $-\cdots$ & $\left(\mathbf{B}_{3}\left(\mathbf{B}_{3}\right)\right)$ & Do. \\
\hline 63595 & $x$ & -..- & --- & $\left(\mathrm{B}_{3}\right)$ & Do. \\
\hline 63596 & $\ddot{x}$ & -..- & $-\ldots$ & $\left(\mathbf{B}_{3}\right)$ & Do. \\
\hline 63597 & $x$ & $\ldots$ & --- & $\left(\mathrm{B}_{3}\right)$ & Do. \\
\hline 63598 & $\hat{x}$ & -- & $-\ldots$ & $\left(\mathbf{B}_{3}\right)$ & Do. \\
\hline
\end{tabular}

${ }_{2} \mathrm{~B}_{4}\left(\mathrm{~B}_{5}\right)$ Alternative classification by Wilisional classification by Wilshire and others (this volume).

TABLE 6.-North Ray crater soil samples greater than $26 \mathrm{~g}$

\begin{tabular}{|c|c|c|c|c|c|}
\hline $\begin{array}{c}\text { Sample } \\
\text { No.* }\end{array}$ & $\begin{array}{l}\text { White breccia } \\
\text { boulder area }\end{array}$ & $\begin{array}{c}\text { Interboulder } \\
\text { area }\end{array}$ & $\begin{array}{l}\text { House } \\
\text { rock } \\
\text { area }\end{array}$ & $\begin{array}{l}\text { Shadow } \\
\text { rock } \\
\text { area }\end{array}$ & $\begin{array}{c}\text { Geologic } \\
\text { significance }\end{array}$ \\
\hline $63320-4$ & -... & -..- & ---- & $x "$ & $\begin{array}{l}\text { "Shadowed" soil on surface } \\
\text { under northwest overhang of } \\
\text { Shadow rock. }\end{array}$ \\
\hline $63340-4$ & --- & $-\cdots$ & -- & $\times \mathrm{S}$ & $\begin{array}{l}\text { Soil beneath } 63320 \text { under } \\
\text { northwest overhang of } \\
\text { Shadow rock. }\end{array}$ \\
\hline $63500-4$ & --- & --- & $-\cdots$ & $\times \mathbf{R}$ & $\begin{array}{l}\text { Rake soil 5-10 m west of Shadow } \\
\text { rock. }\end{array}$ \\
\hline 67010 & --- & $x$ & $-\cdots$ & $-\mathbf{R}$ & $\begin{array}{l}\text { Residue in sample collection bag } \\
\text { No. } 7\end{array}$ \\
\hline 67020 & $x$ & --.- & -- & $\mathbf{R}$ & $\begin{array}{l}\text { Residue in Buddy Secondary } \\
\text { Life Support System bag with } \\
\text { rock } 67016 \text {. }\end{array}$ \\
\hline $67030-4$ & $x$ & ---- & - & $\therefore \mathbf{R}$ & $\begin{array}{l}\text { Residue in sample bag with rock } \\
67035 \text {. }\end{array}$ \\
\hline 67410 & $x$ & $\ldots$ & -- & $\ldots$ & $\begin{array}{l}\text { Residue in sample bag with rock } \\
67415 .\end{array}$ \\
\hline 67450 & $x$ & --- & --- & $\ldots R$ & $\begin{array}{l}\text { Residue in sample bag with rock } \\
67455 .\end{array}$ \\
\hline $67460-4$ & $x$ & -..- & --- & F & $\begin{array}{l}\text { Fillet at boulder from which } \\
67455 \text { and } 67475 \text { were col- } \\
\text { lected. }\end{array}$ \\
\hline $67480-4$ & $x$ & -..- & -- & - R & $\begin{array}{l}\text { Reference soil for comparison } \\
\text { with } 67460 \text {; same location as } \\
\text { sample } 67510 \text {. }\end{array}$ \\
\hline $67510-4$ & $x$ & --- & --.- & $\ldots-S^{-}$ & $\begin{array}{l}\text { Soil in rake sample near large, } \\
\text { light-matrix breccia boulder. }\end{array}$ \\
\hline $67600-4$ & $x$ & --- & ---- & $\mathbf{R}$ & $\begin{array}{l}\text { Rake soil collected about } 25 \mathrm{~m} \\
\text { east of } 67510 \text {; inside rim crest. }\end{array}$ \\
\hline 67610 & $x$ & $\ldots$ & ---- & $-\mathbf{S}^{-}$ & $\begin{array}{l}\text { Soil in rake sample from same } \\
\text { location as } 67600 \text {. }\end{array}$ \\
\hline $67700-4$ & ---- & $x$ & --- & $-\cdots \mathbf{R}$ & $\begin{array}{l}\text { Rake soil from half way between } \\
\text { White breccia boulders and } \\
\text { House rock. }\end{array}$ \\
\hline $67710-4$ & $\ldots$ & $x$ & --- & $\ldots \mathbf{S}$ & $\begin{array}{l}\text { Soil in rake sample from same } \\
\text { location as } 67700 \text {. }\end{array}$ \\
\hline 67910 & --- & -- & $x$ & $-\ldots \mathbf{R}$ & $\begin{array}{l}\text { Residue in sample collection bag } \\
\text { No. } 4 \text {. }\end{array}$ \\
\hline $67940-4$ & ---- & -.-- & $x$ & $\ldots+\mathbf{S}$ & $\begin{array}{l}\text { Soil from "east-west split" be- } \\
\text { tween House and Outhouse } \\
\text { rocks. }\end{array}$ \\
\hline
\end{tabular}




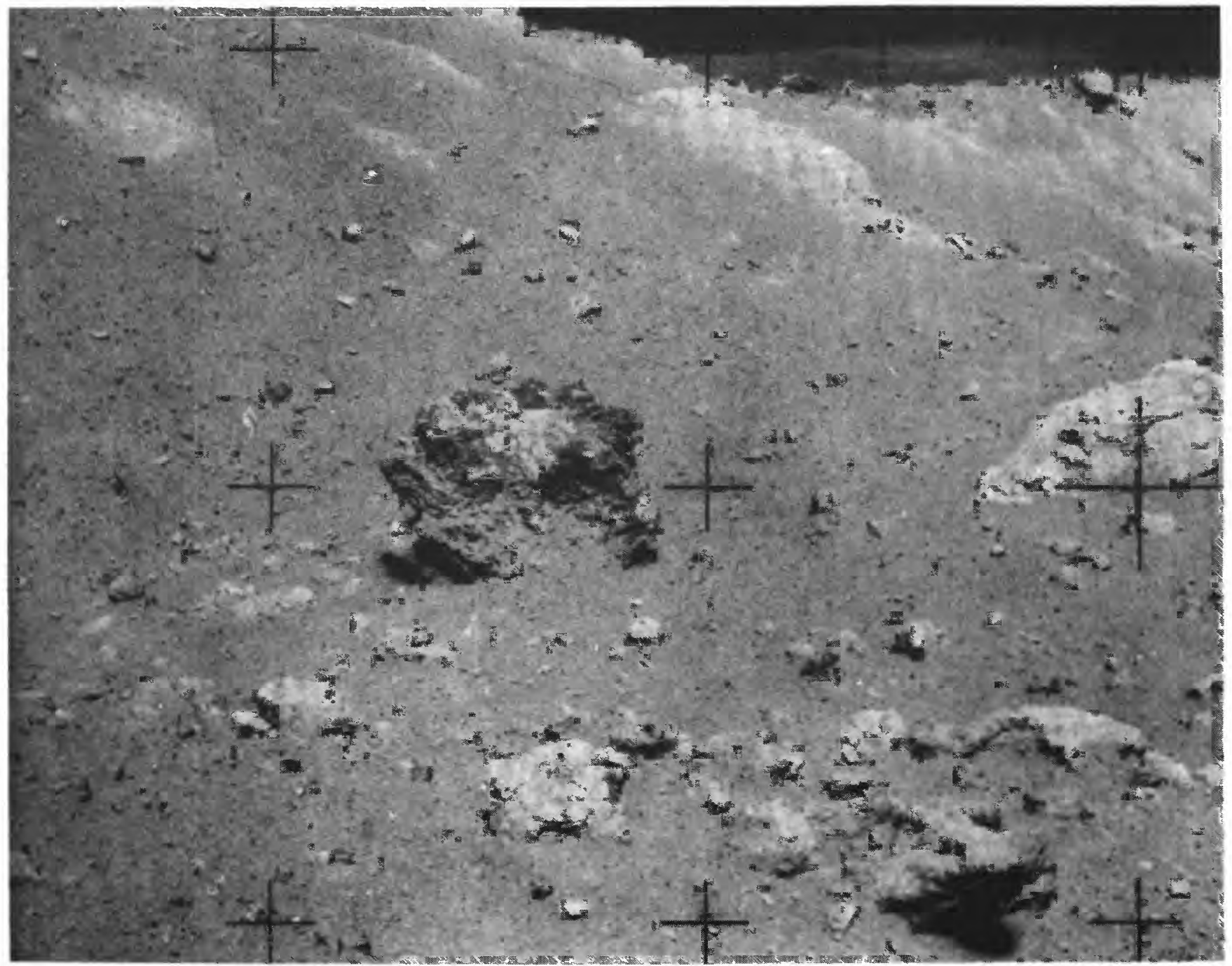

FigURE 7.-Dark-matrix breccia boulder in White breccia boulder area. For location see panorama 19, pl. 8. 
NORTH RAY CRATER

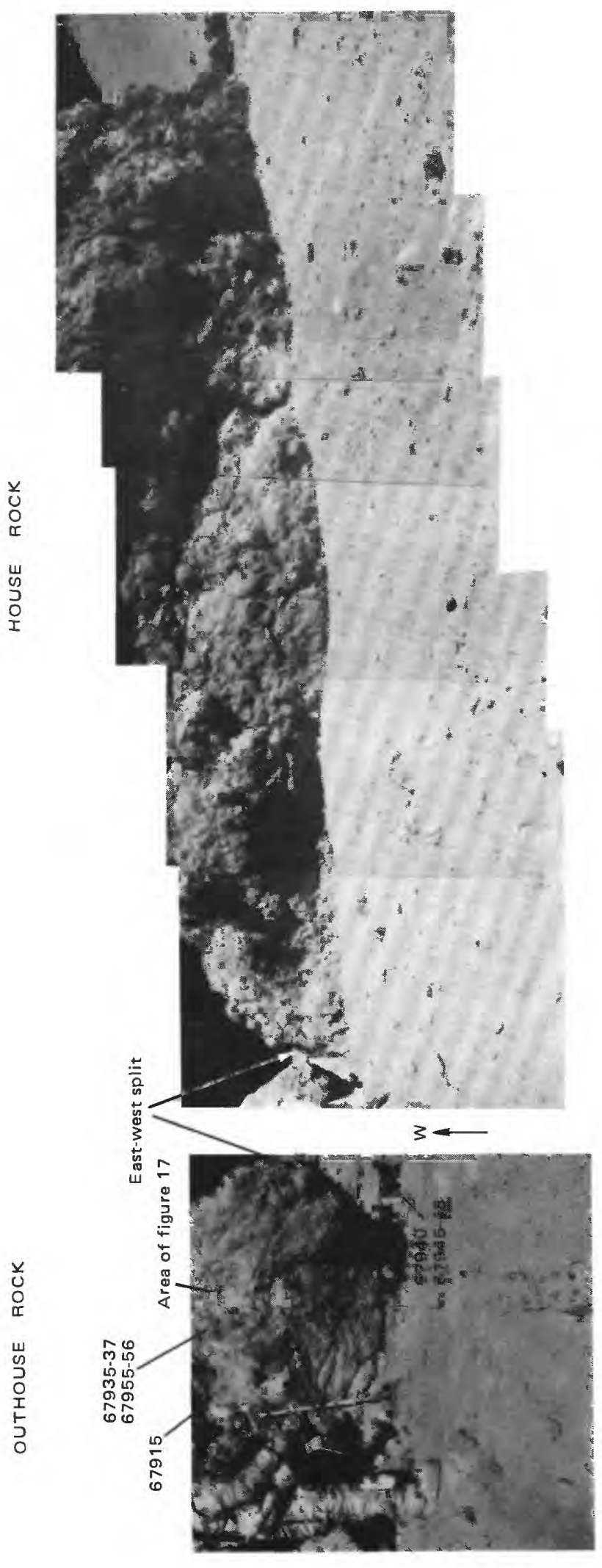

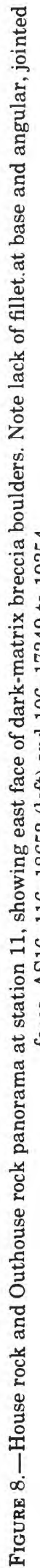



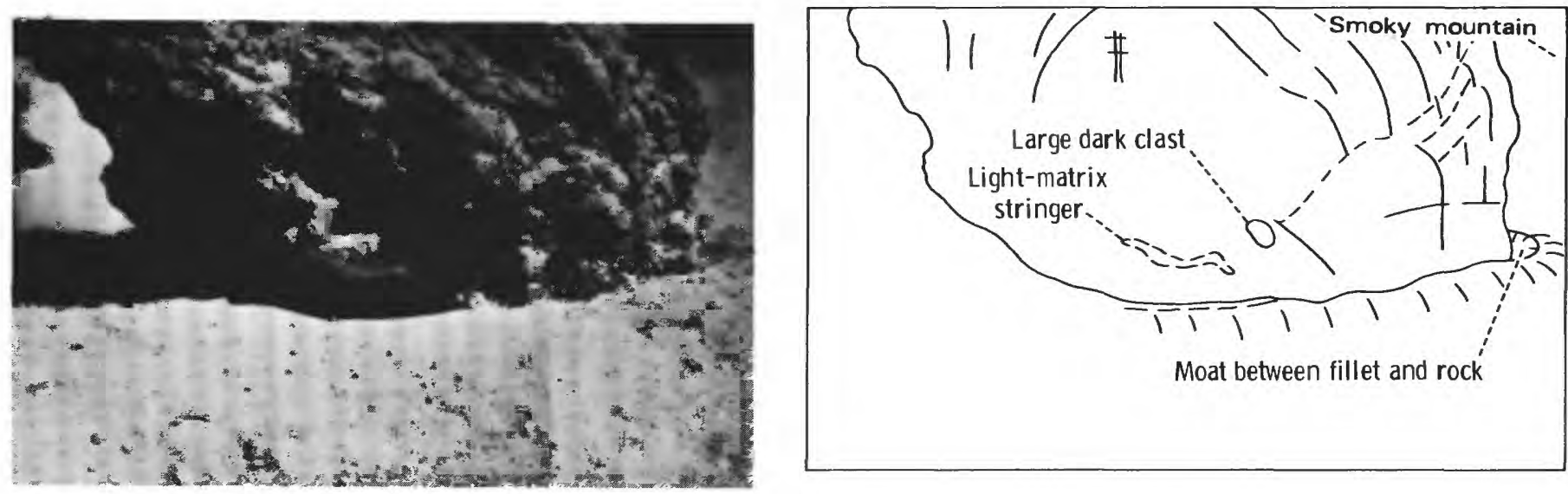

A

$B$

Figure 9.-Shadow rock panorama at station 13. $A$, South face of 5-m-wide boulder of dark-matrix breccia. AS16-106-17413 to 17415. $B$, Sketch map of fractures and clasts.

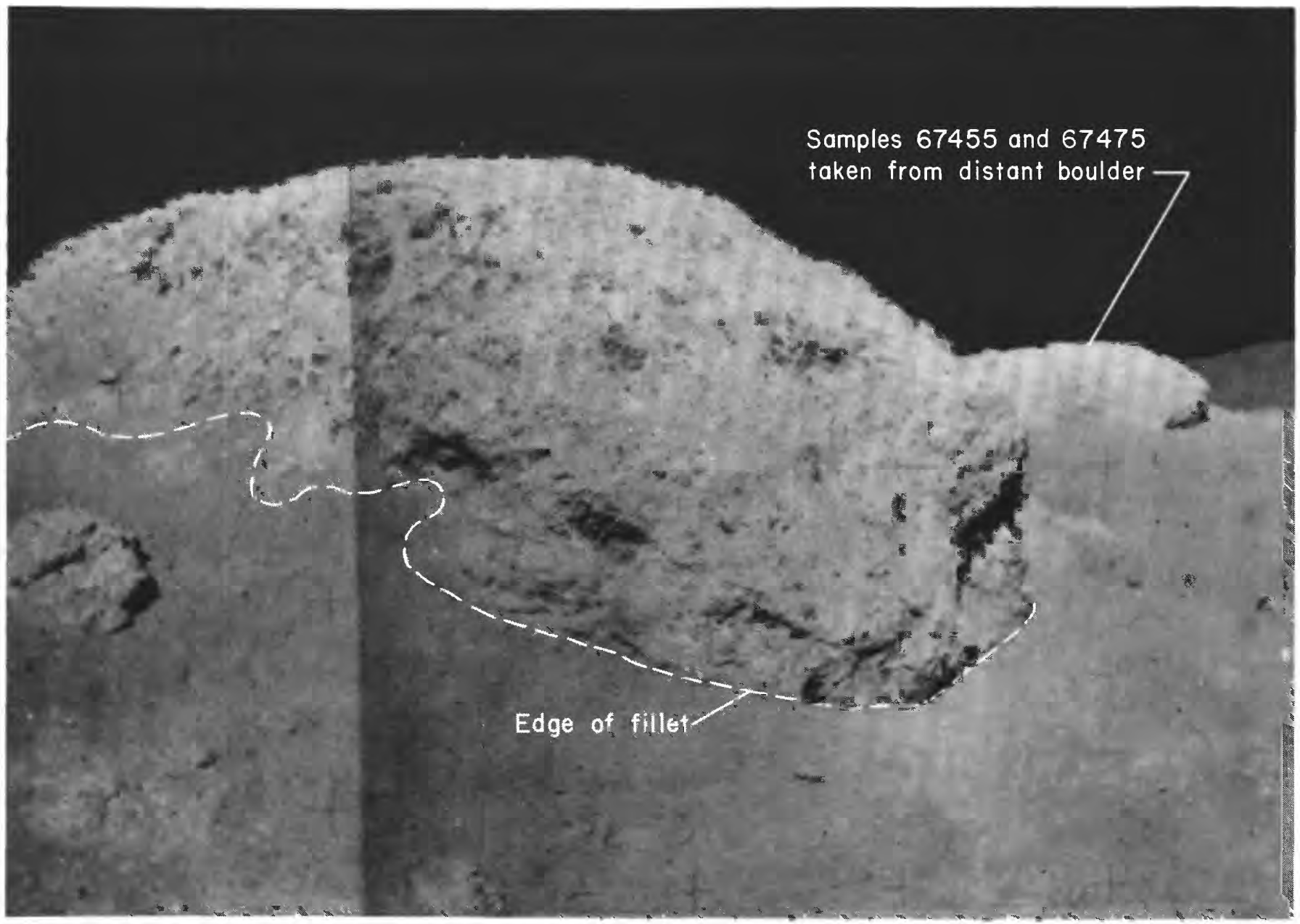

FigURE 10.-White breccia boulders showing rounded outlines and deeply filleted margins. AS16-106-17325 and 17326. 

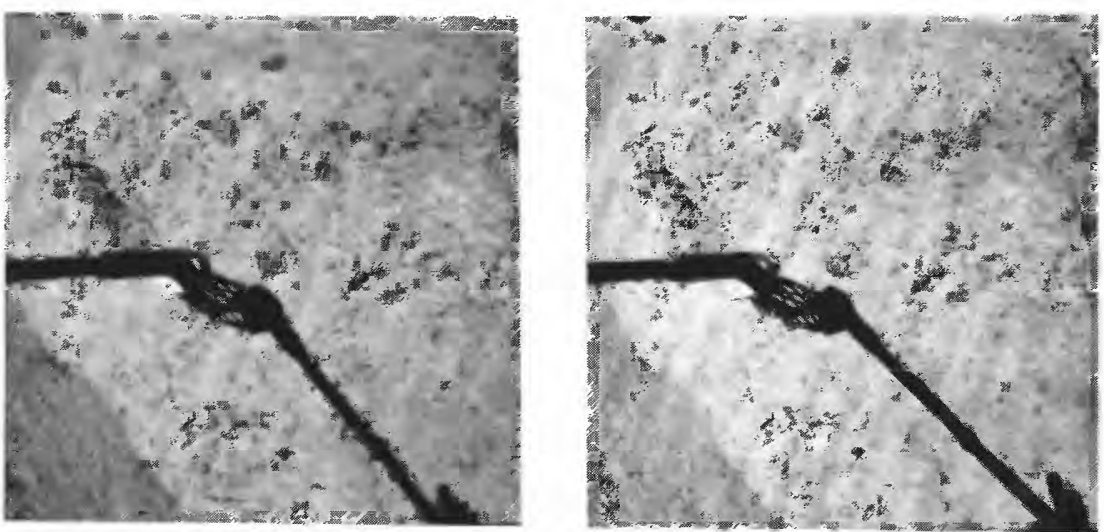

A

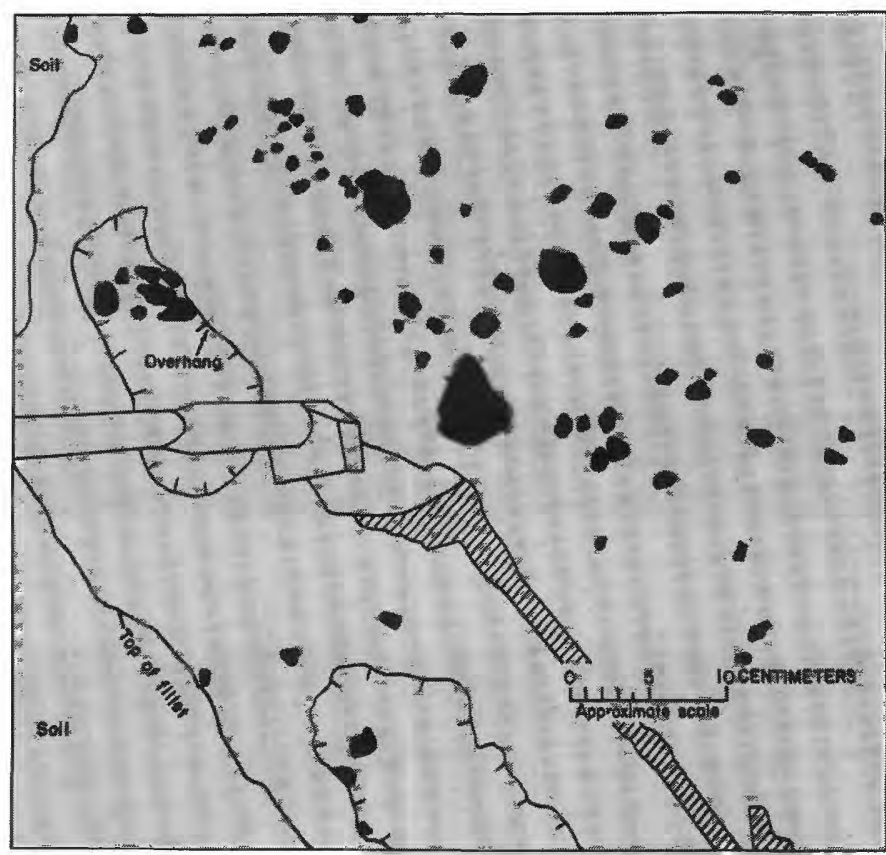

$B$

Figure 11.-Surface texture and distribution of dark clasts, White breccia boulder. $A$, Stereopair showing surface texture. AS16106-17327 to 17328 . $B$, Sketch map showing distinction of dark clasts and top of fillet. 


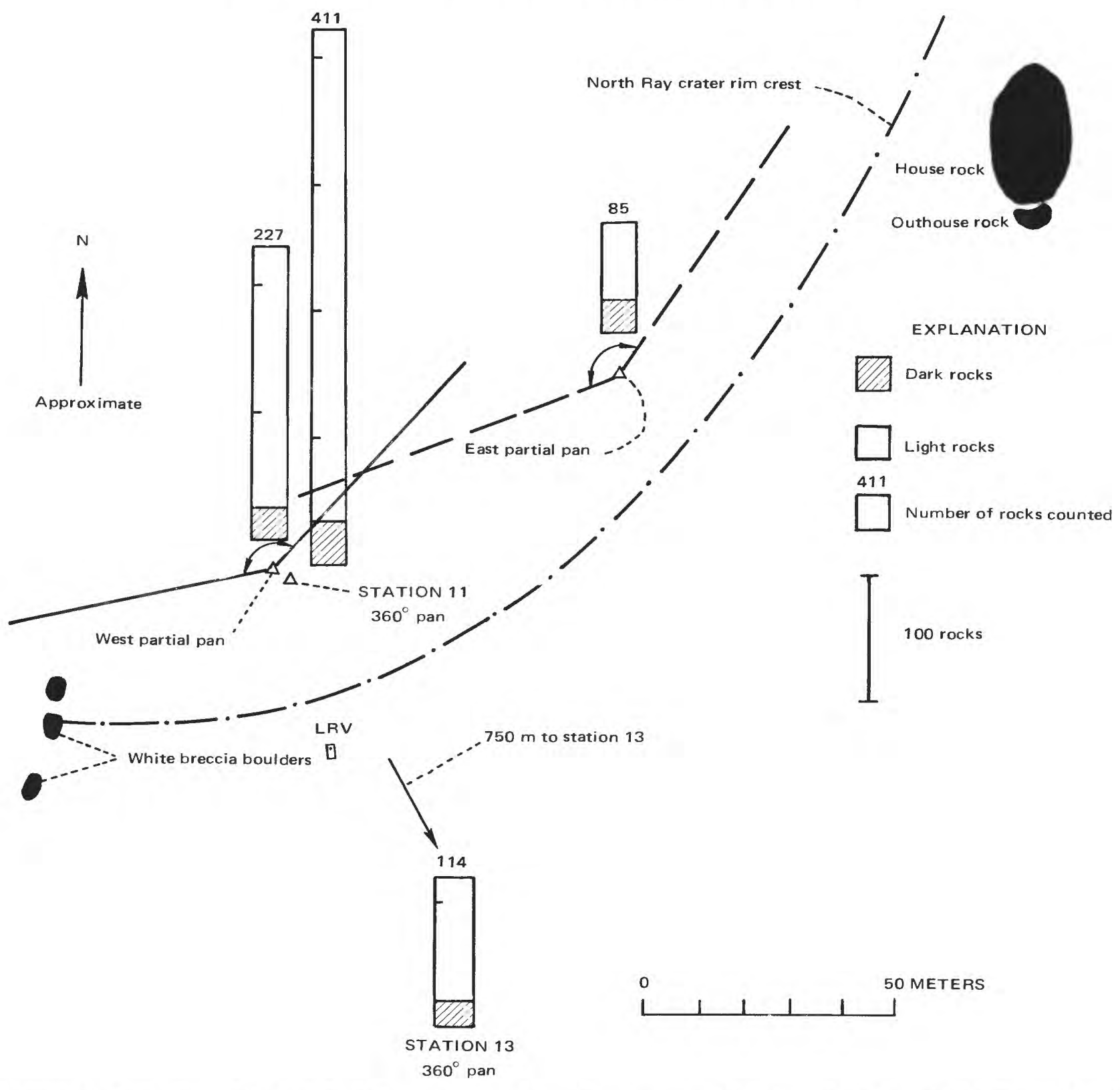

Figure 12.-Proportions of light and dark fragments counted in surface panoramas. Data from plate 7, pan 23, plate 8, pans 18 and 19 , and plate 9 , pan 20 . Boulder map from Sutton (this volume). 


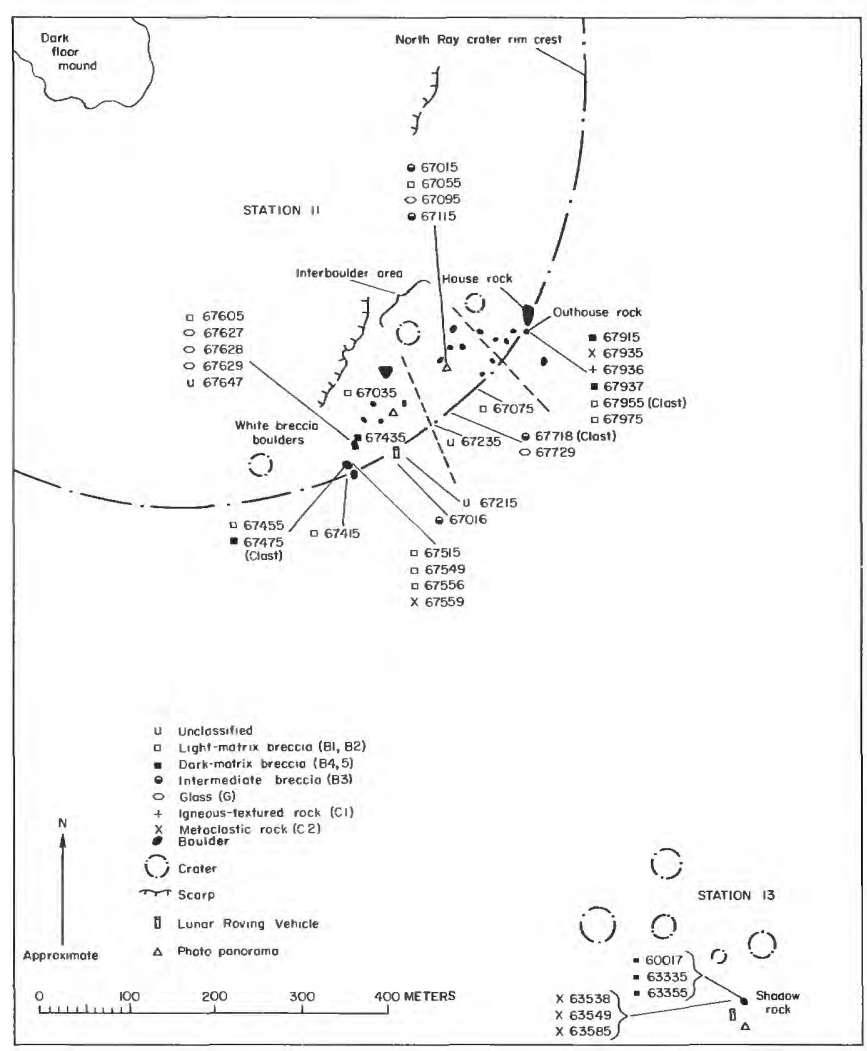

A

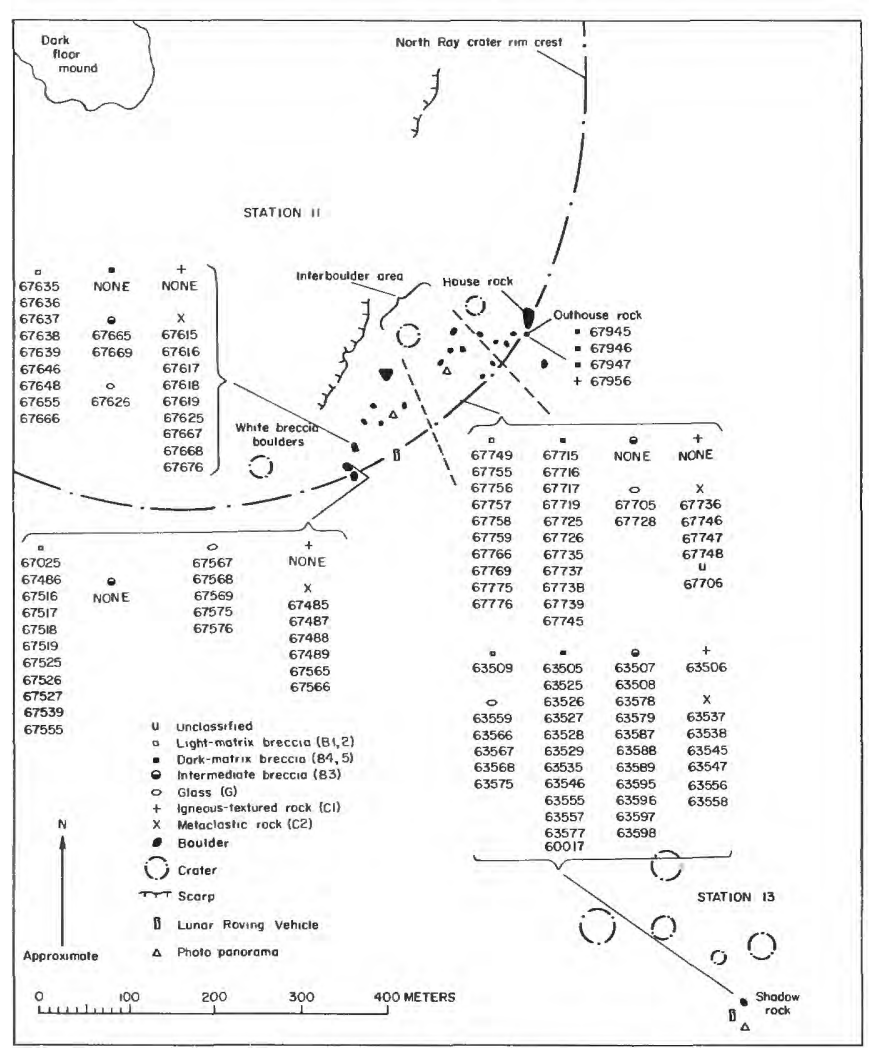

B

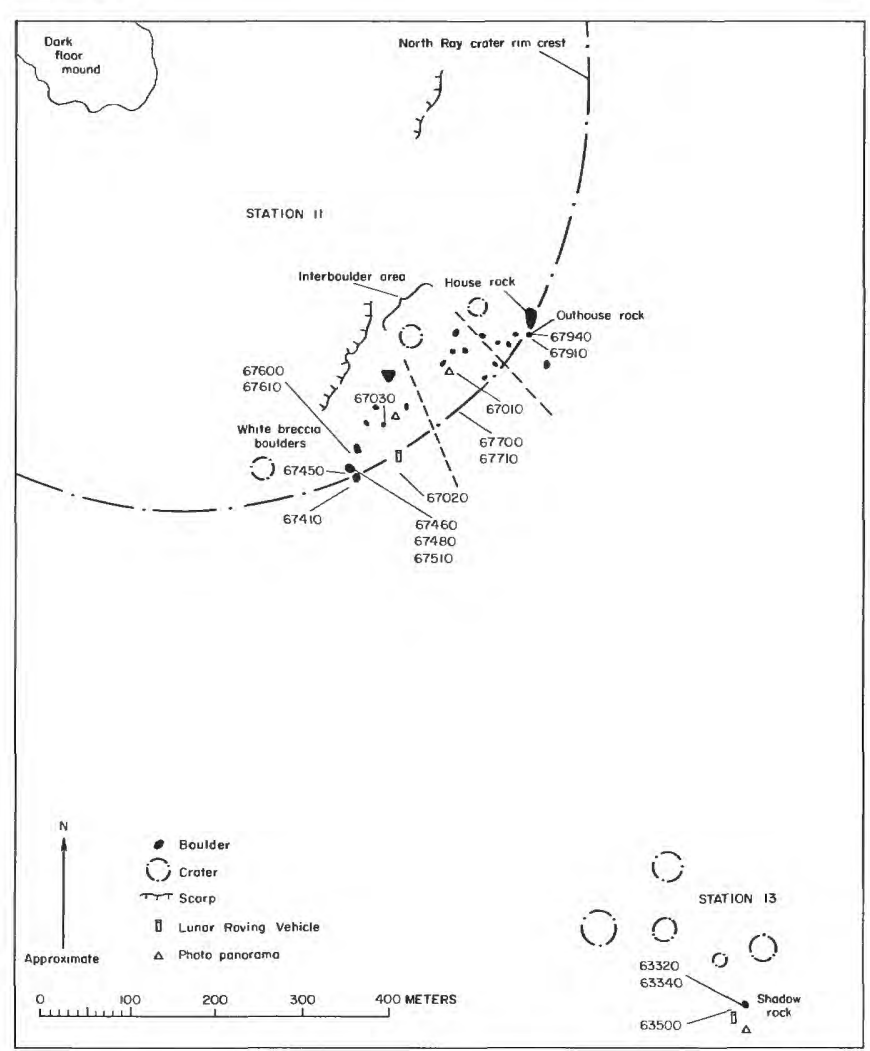

C
Frgure 13.-Location of rocks and soils collected at stations 11 and 13. $A$, Rocks weighing more than $25 \mathrm{~g}$. $B$, Rocks weighing 2 to $25 \mathrm{~g}$. $C$, Soil samples weighing more than $26 \mathrm{~g}$. 


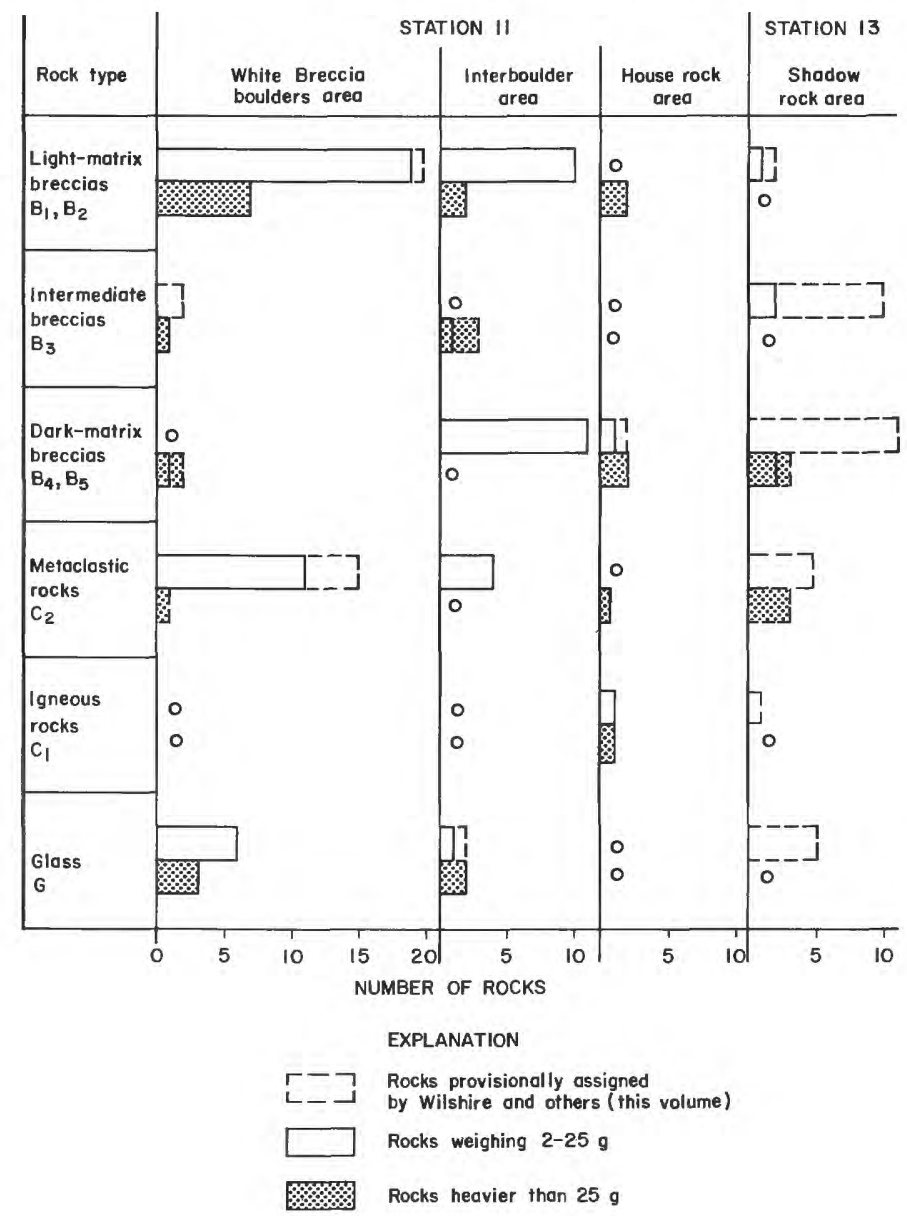

- No rocks ossigned

FIGURE 14.-Abundance of rock types collected from four localities at North Ray crater.
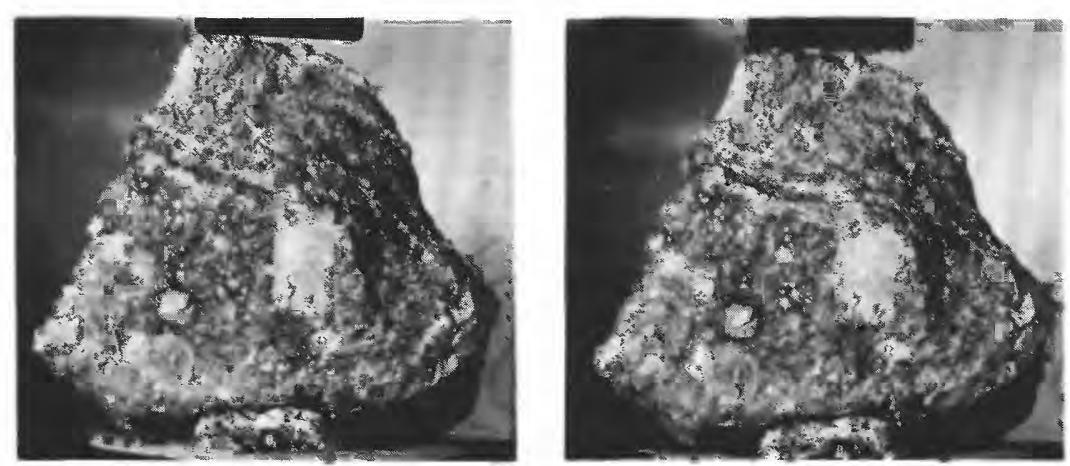

FigURE 15.-Sample 67915, a dark-matrix breccia, the largest fragment collected from Outhouse rock. Scale in centimeters. NASA S-72-43917 and 43917B. 
Six samples larger than $25 \mathrm{~g}$ were collected from the east face of Outhouse rock (table 2). The largest, 67915, is probably most representative of both large boulders (fig. 15), and its exact position on Outhouse rock is known (Sutton, this volume). It is a dark-matrix breccia containing a wide variety of clasts (Roeder and Weiblen, 1974a). Two plateau ages for 67915 determined by the ${ }^{40} \mathrm{Ar}-{ }^{39} \mathrm{Ar}$ method, $3.91 \pm 0.05$ and $3.99 \pm 0.05$ b.y. (Kirsten and others, 1973 , p. 1760 and 1762), are considered to have selenochronologic significance. The lower age was determined on an anorthosite clast, the higher age from the matrix. The precision indicates that an age of about $3.95 \mathrm{~b} . \mathrm{y}$. for both samples is likely.

Other fragments collected from the face of Outhouse rock are mainly dark-matrix breccias and coherent metaclastic and igneous rocks $\left(\mathrm{B}_{4}, \mathrm{~B}_{5}, \mathrm{C}_{2}\right.$, and $\mathrm{C}_{1}$ of Wilshire and others, this volume), a common lithologic association. One exception was a clast of light-matrix breccia, 67955 (fig. 16), selected for its unshocked appearance from the edge of an impact-spalled area (fig. 17), where the face of Outhouse rock had been struck by a high-velocity projectile. Other types of clasts within the boulder are represented by 67935 (fig. 18) and 67937 (fig. 19), metaclastic $\left(\mathrm{C}_{2}\right)$ rocks. A third type of clast, 67956 (fig. 20), is an igneous $\left(\mathrm{C}_{1}\right)$ rock having a subophitic texture much like that of 68415 (see Reed, fig. $9 B$, this volume) and 65055 (see Sanchez, fig. 20, this volume). Parts of Outhouse rock are highly fractured, presumably as a result of the North Ray impact. The spalled area outlined on figure 17 apparently resulted from a much younger impact within the past few hundred thousand years based on ${ }^{26} \mathrm{Al}$ measurements on 67937 (Eldridge and others, 1973, p. 2119). Other rocks likely to show effects of this event are 67935 and 67936. Local melting during the North Ray event is indicated by the dark glass splashes on the face of Outhouse rock (fig. 17) and the glass coating on fragments elsewhere on the rim crest.

Loose undocumented fragments and soil were collected in the east-west split between House and Outhouse rocks. Three of the four small rocks collected are dark-matrix breccias (67945-47, fig. 21). The fourth and smallest, 67948 , may be a relict inclusion of mare basalt; it contains 40 to 50 percent mafic minerals with an ophitic texture (fig. 22). These rocks are most likely all fragments spalled from the large boulders.

Several lines of evidence suggest that these darkmatrix boulders came from a lower horizon near or at the bottom of North Ray crater. They are perched on the crater rim within the shallow depressions formed by their impact and are not overlain by subsequent debris; they are clearly late arrivals in the sequence of crater ejecta. This perched position is typical of the deepest material in terrestrial impact and explosion craters. In size and color, the rocks resemble the coarse rubble on the crater floor and, by comparison with the central mounds in nearby craters, may represent a more resistant stratum near the floor of the craters (Hodges, 1972a; Ulrich and Reed, this volume). Dark rocks are sparse on the crater rim crest (10-30 percent, fig. 12). The more abundant light-matrix breccias here and radially away from the rim probably represent shallower materials overlying the dark-matrix rocks in the crater wall. The large 10-m blocks in the northeast wall of the crater appear in telephotographs to be light-matrix breccias (fig. 23, and pl. 9, pan 36) with some degree of lateral continuity, suggesting at least a crude stratigraphic relation to the materials above and below. The slightly convex shape of the crater wall as seen from the southeast rim (fig. 4) indicates that relatively softer, less coherent materials in the upper wall overlie more resistant material at depth.

\section{WHITE BRECCIA BOULDERS}

A group of rounded light-colored boulders was another major sampling target at the rim of North Ray, about $50 \mathrm{~m}$ west of the LRV parking spot. The sampling done in the vicinity of the LRV was within this area, and the largest number of samples from station 11 was collected at this westernmost location, as shown in figure 13. The classification and geologic significance of all the rocks weighing more than $2 \mathrm{~g}$ (figs. $13 A, B$ ) are given in table 3 .

The most distinctive characteristics of the rocks here are the well-rounded profiles, deeply filleted margins, and light-gray to white color (fig. 10). The lengths of the largest boulders are about four times their height. The returned samples typically are light-matrix breccias, which are generally very friable and contain coherent clasts of dark-matrix breccia (fig. 11). The rock probably most representative of these boulders is sample 67455 (fig. 24), collected from several loose fragments on top of a boulder approximately $6 \mathrm{~m}$ long and $1.5 \mathrm{~m}$ high (figs. 10 and $25 \mathrm{~A}$ ). A light-colored clast from this sample has a plateau age of $3.91 \pm 0.12 \mathrm{~b} . \mathrm{y}$. determined by the ${ }^{40} \mathrm{Ar}-{ }^{39} \mathrm{Ar}$ method (Kirsten and others, 1973 , p. 1762), essentially the same as the age of 67915 from Outhouse rock. This rock, like many of the rocks of this group, crumbles so badly that it is impossible to reconstruct its lunar orientation. The friable texture is expressed microscopically by extensive irregular fracturing through the matrix and around the more coherent clasts (fig. 25B), referred to as glass selvages by Wilshire and others (this volume, fig. $4 A$ ). 


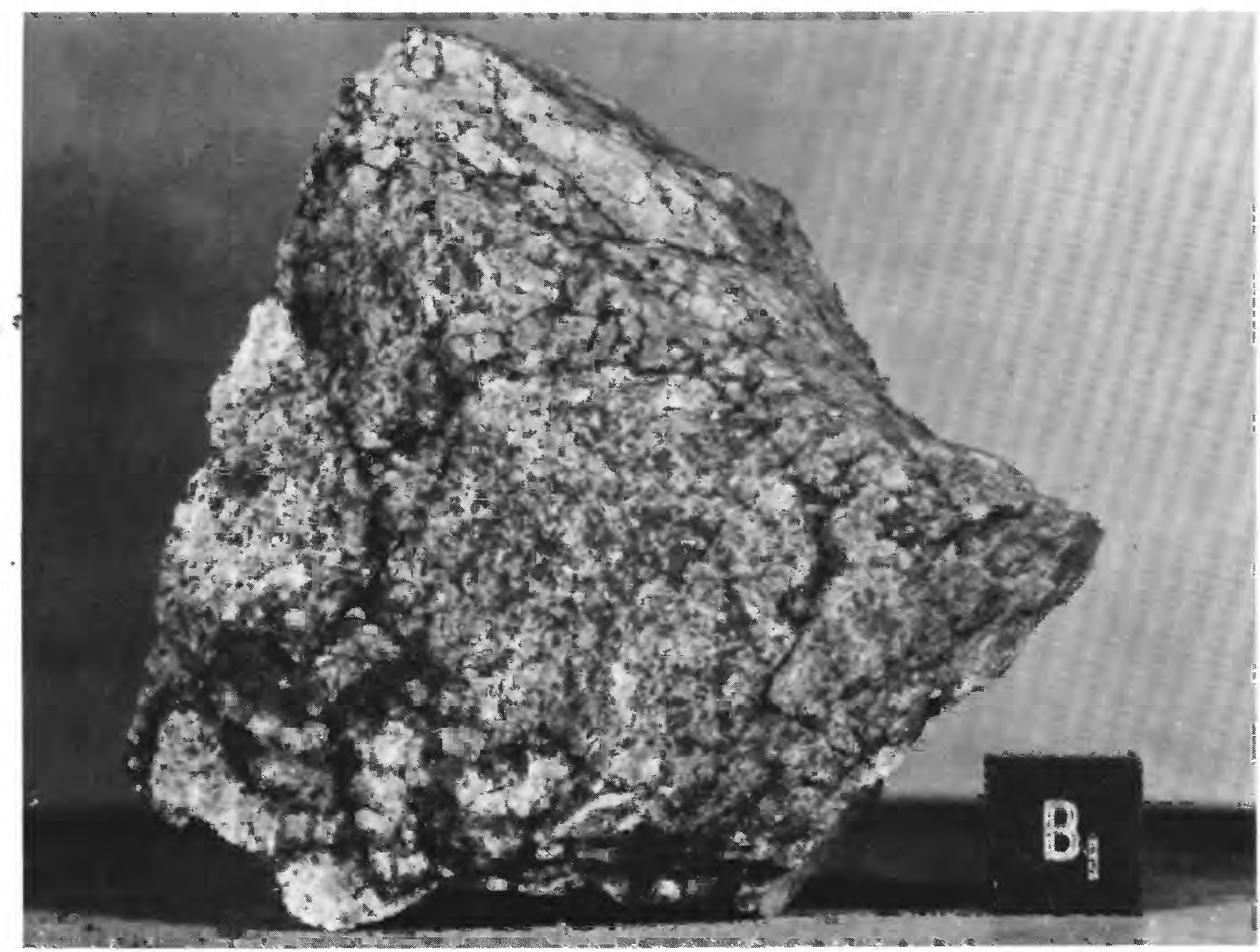

FIGURE 16.-Sample 67955, a clast of light-matrix breccia from Outhouse rock. Cube is $1 \mathrm{~cm}$. NASA S-72-45681. 


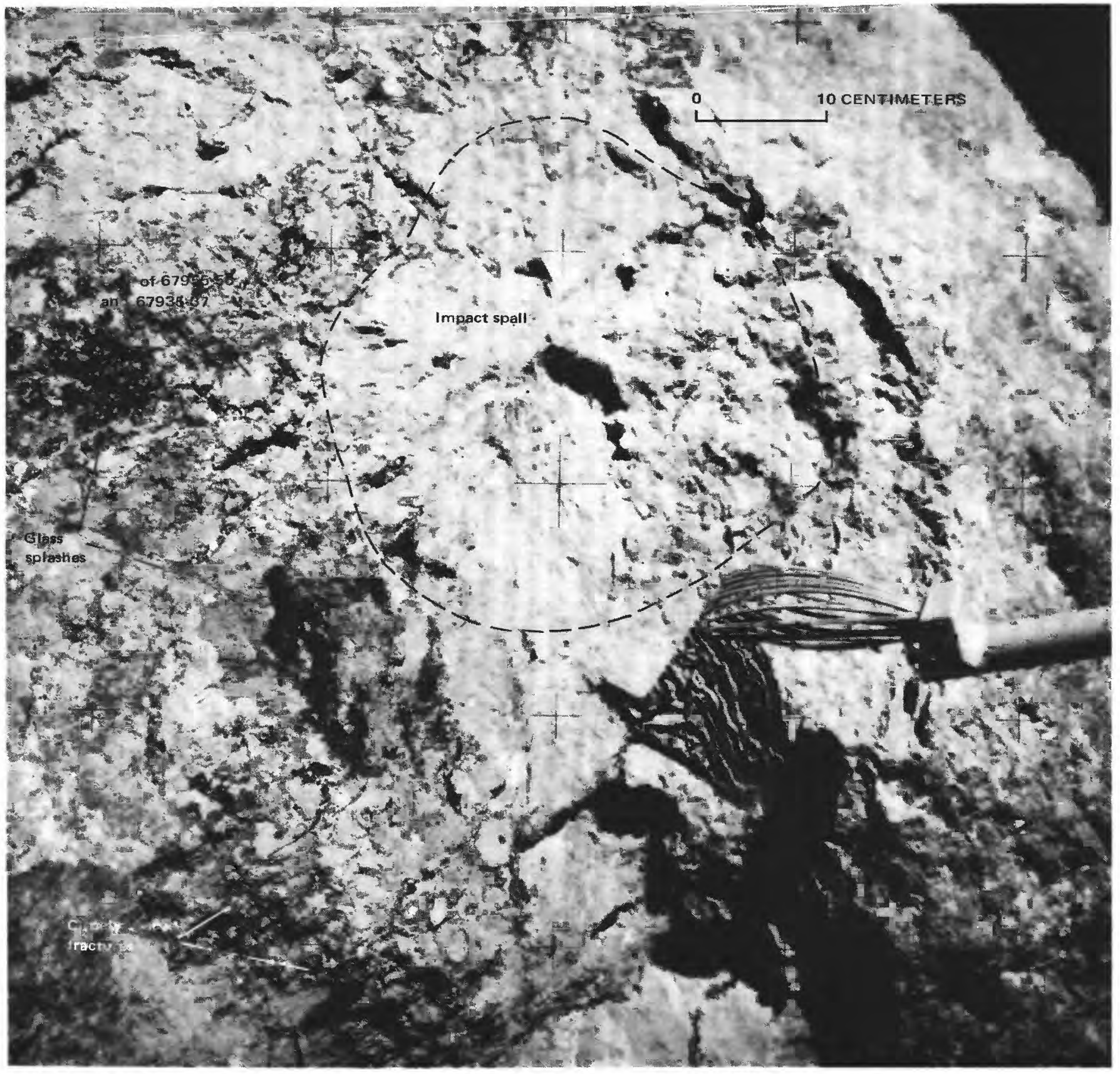

FiguRE 17.-Impact-spalled area on east face of Outhouse rock. AS16-106-17345. 


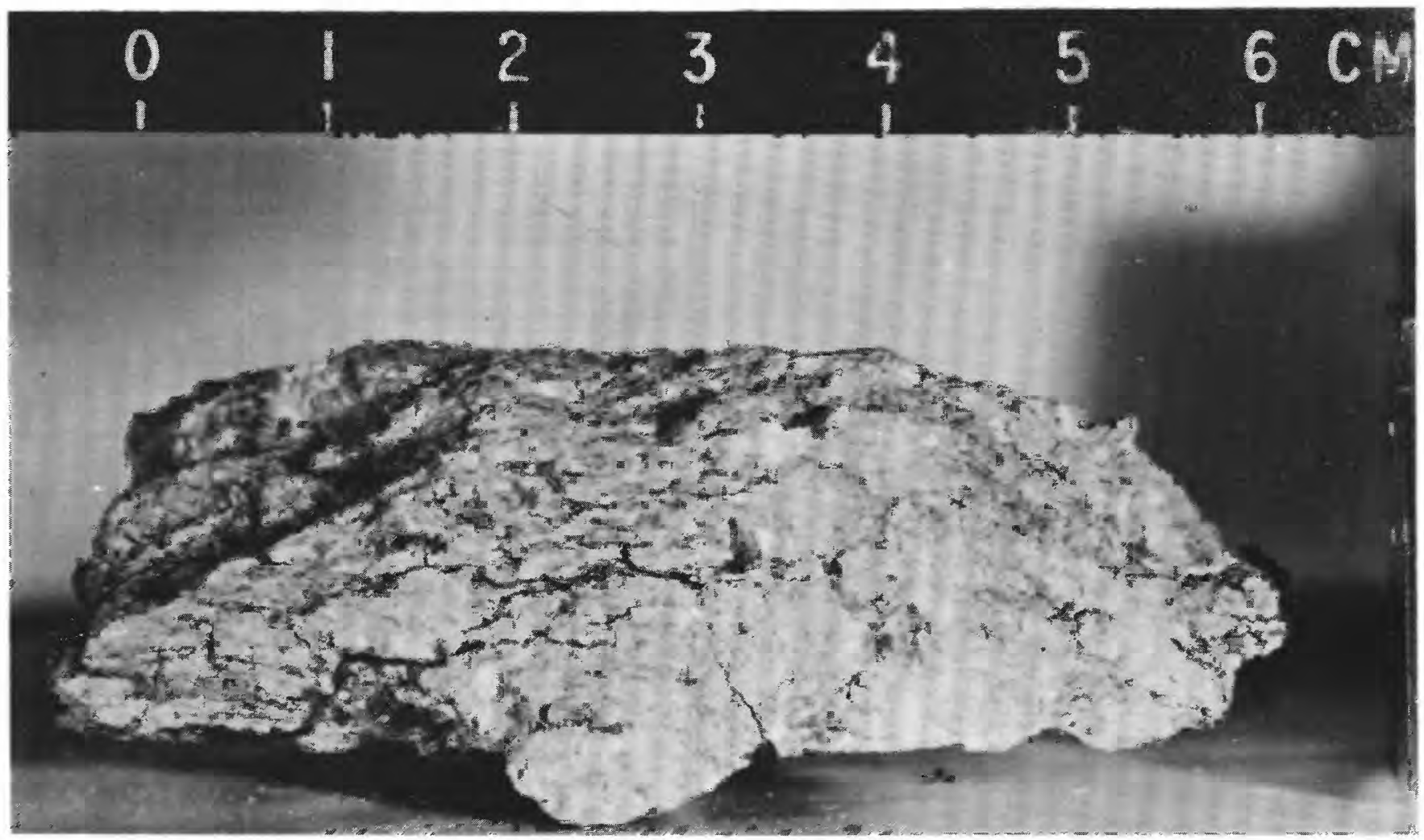

FigURE 18.-Sample 67935, a metaclastic rock broken off the east face of Outhouse rock. NASA S-72-37784.

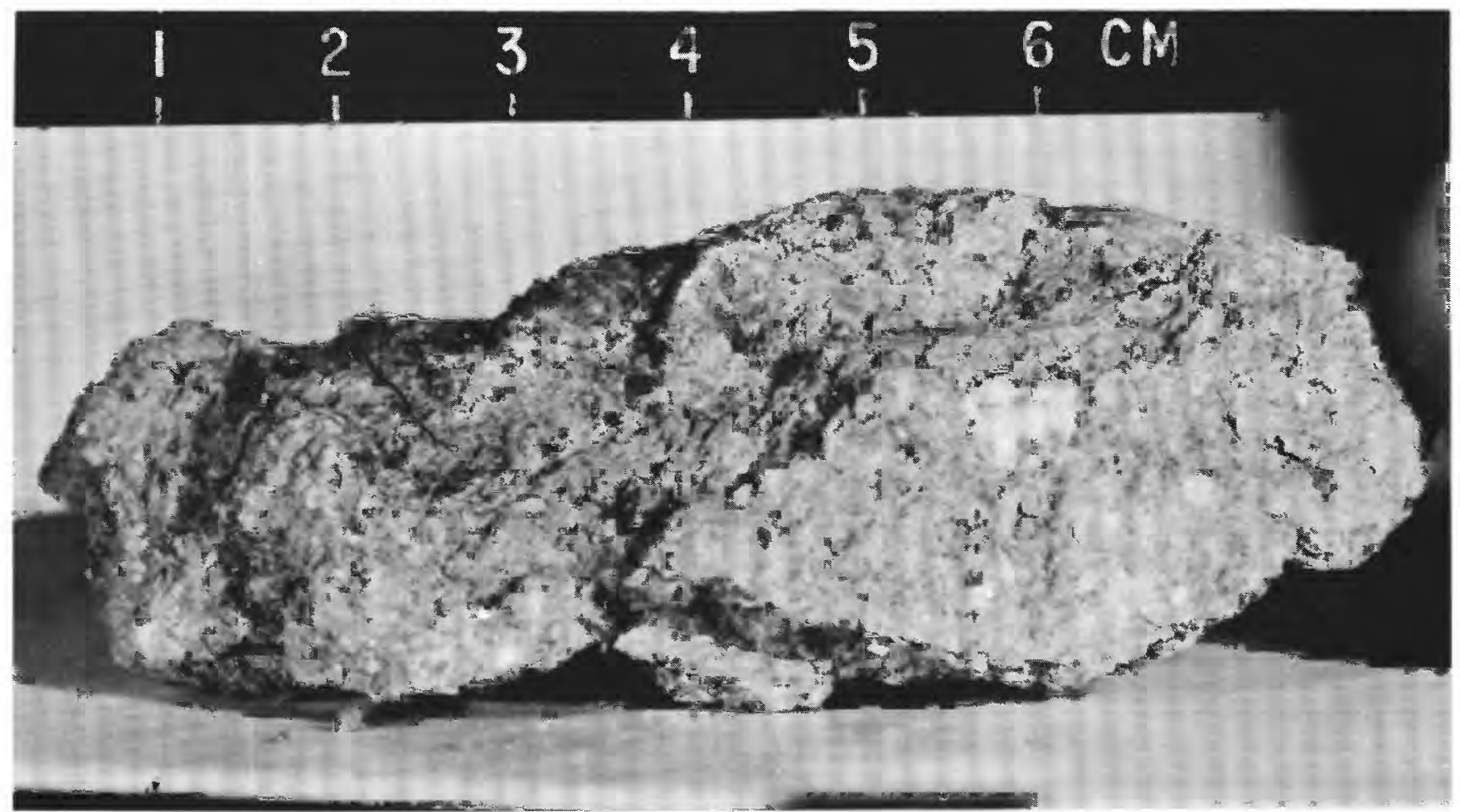

FigURE 19.-Sample 67937, a metaclastic rock from Outhouse rock. NASA S-72-37771. 


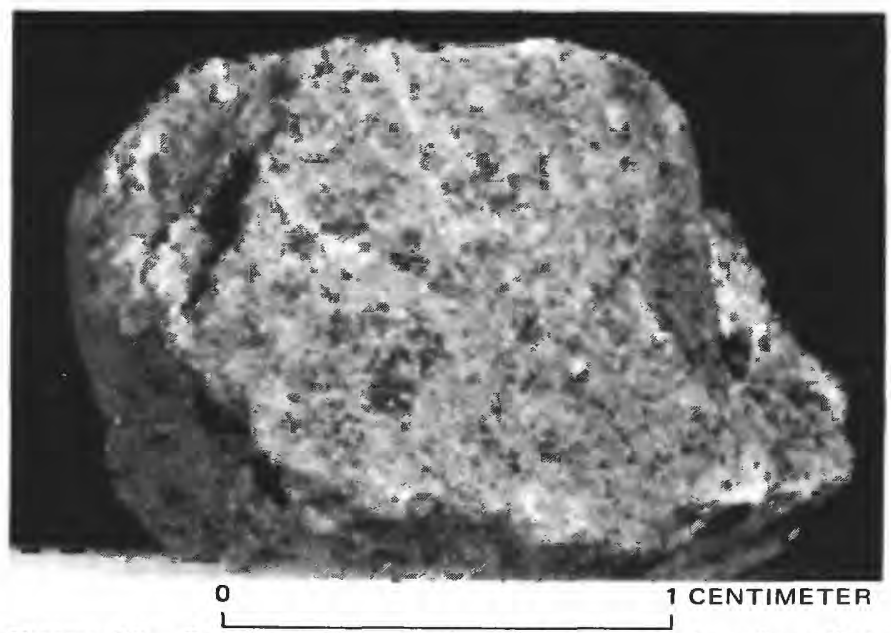

Figure 20.-Sample 67956, a rock with igneous texture from Outhouse rock. NASA S-72-37547.

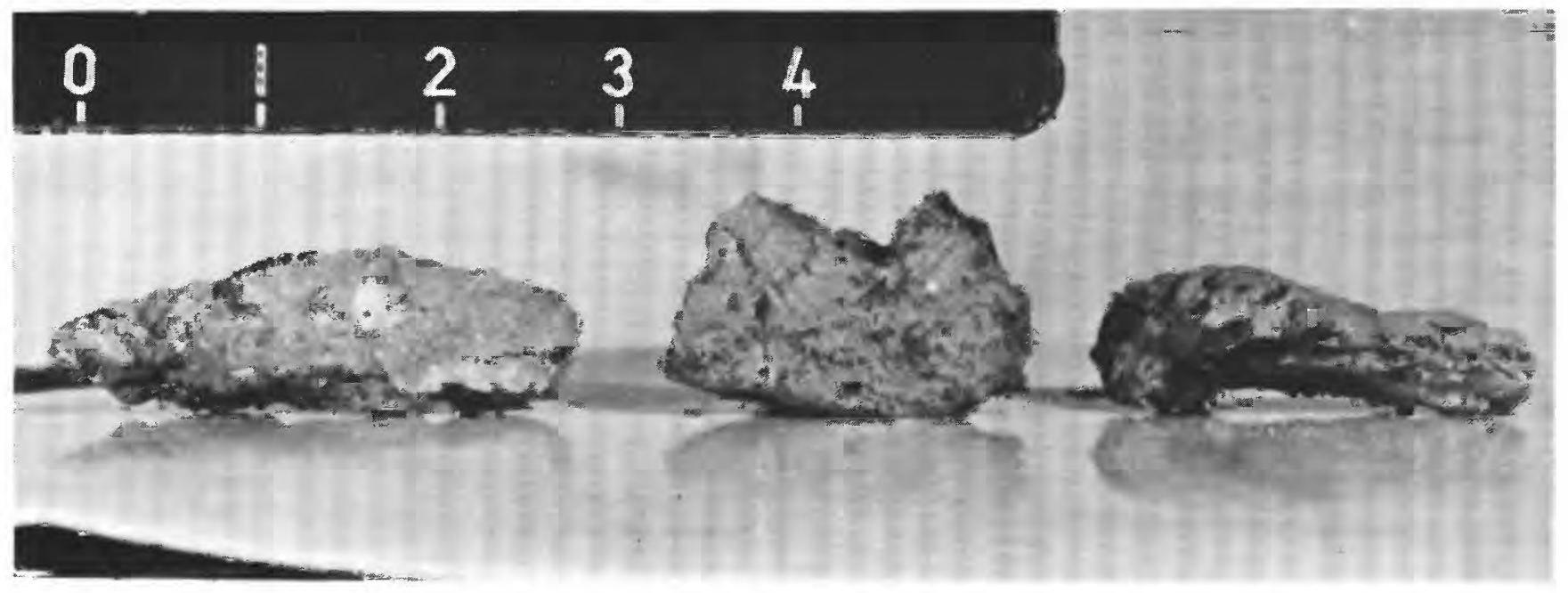

FigURE 21.--Three dark-matrix breccias collected from the east-west split between House and Outhouse rocks; left to right, 67945, 67946,67947 . Scale in centimeters. NASA S-72-38977. 


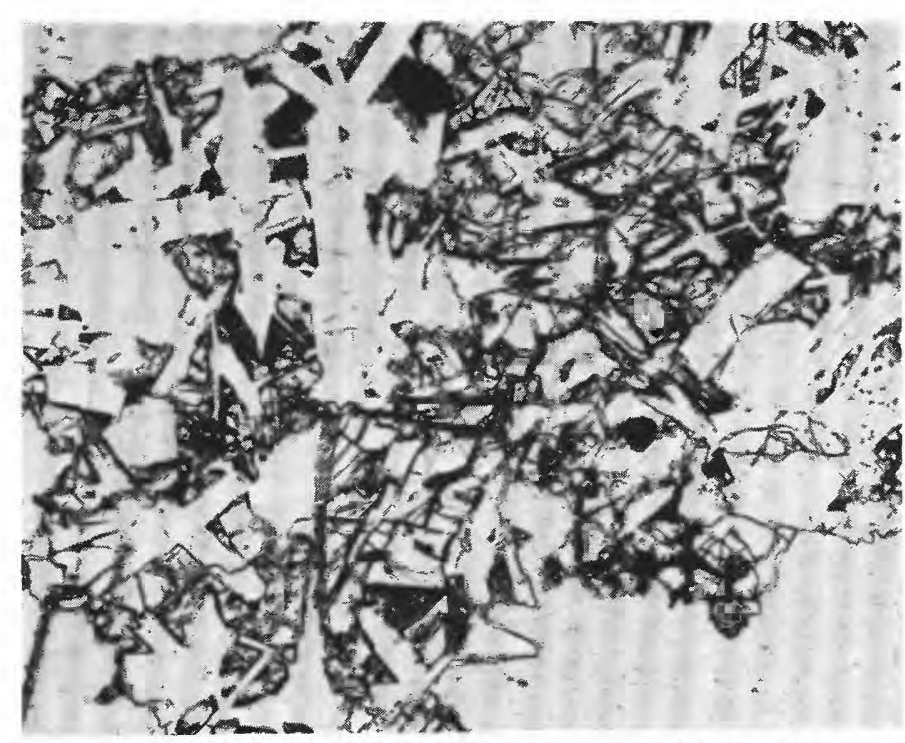

0

1 MILLIMETER

\section{A}

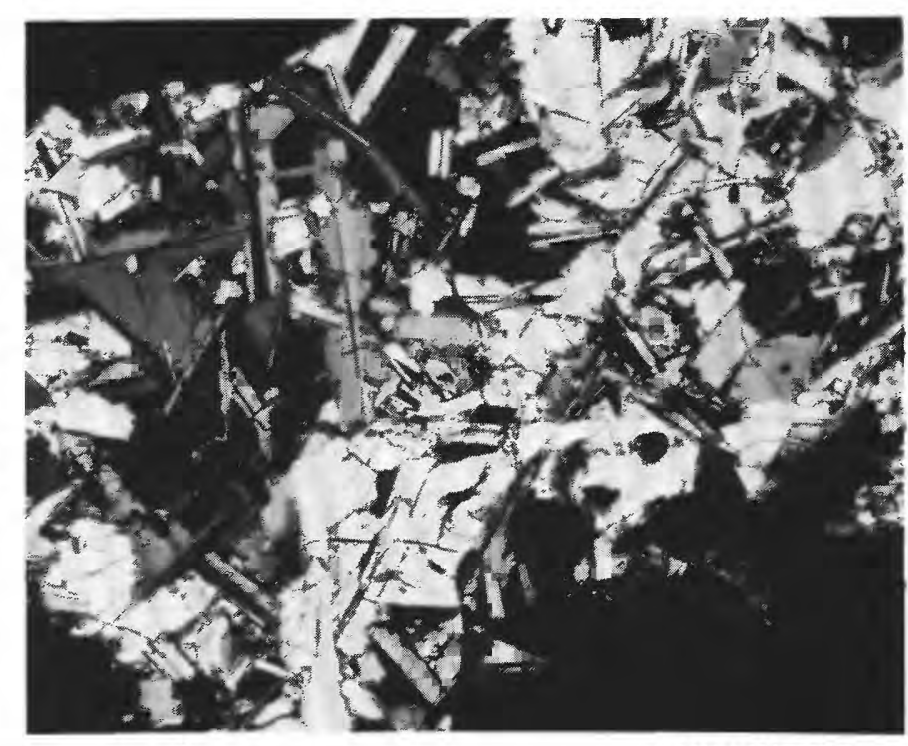

1 MILLIMETER

\section{B}

FIGURE 22.-Ophitic fragment $67948(1.59 \mathrm{~g})$ collected from the east-west split between House and Outhouse rocks. $A$, Photomicrograph of 67948,15 showing pyroxene (high relief) and plagioclase laths. Plane-polarized light. $B$, Same samples as $A$, cross-polarized light.

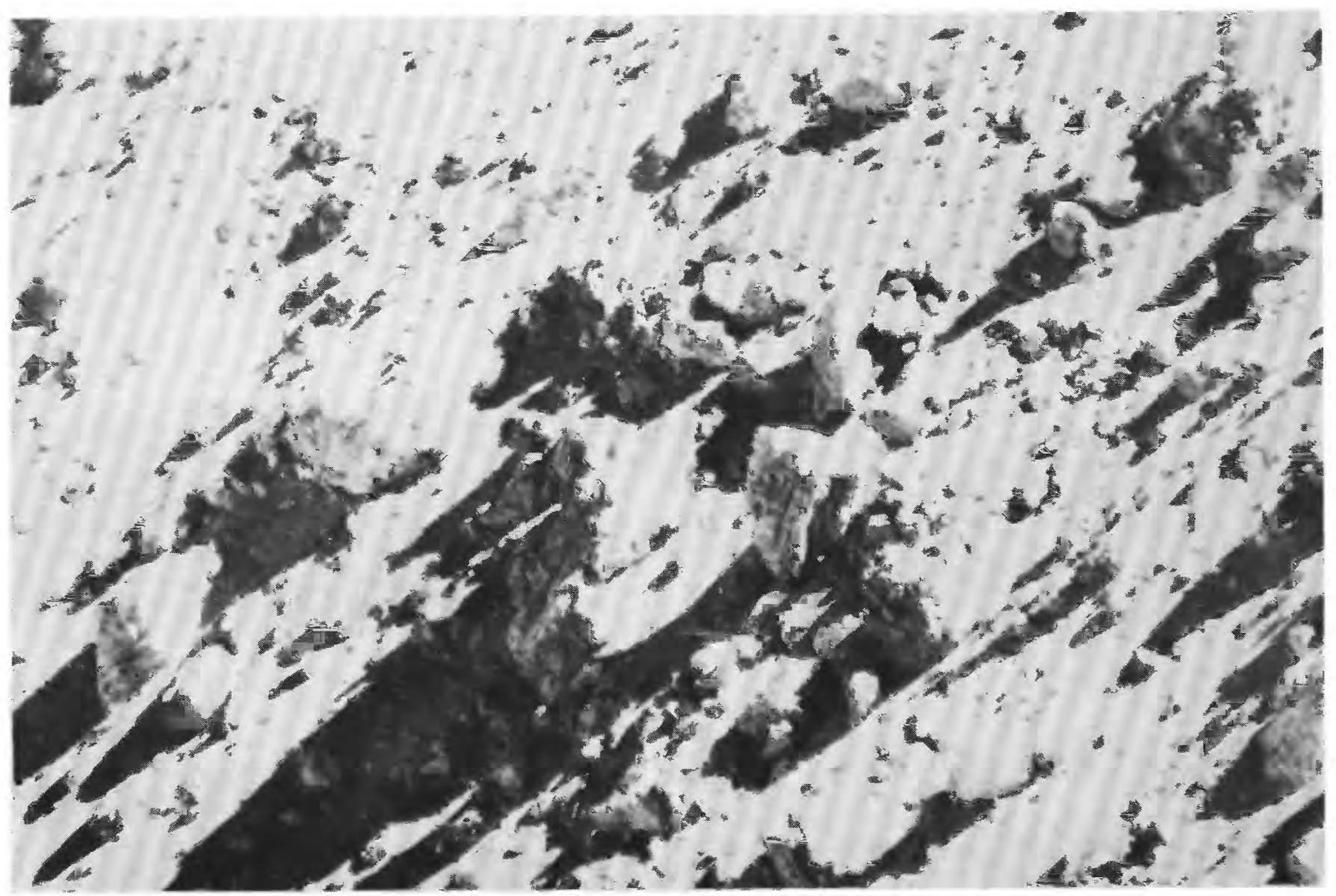

FigURE 23.-Telephotograph of large light-matrix breccia blocks on northeast wall of North Ray crater. Intentionally underexposed to enhance textures in shadows. From AFGIT (1973). Reprinted with permission of the American Association for the Advancement of Science. 


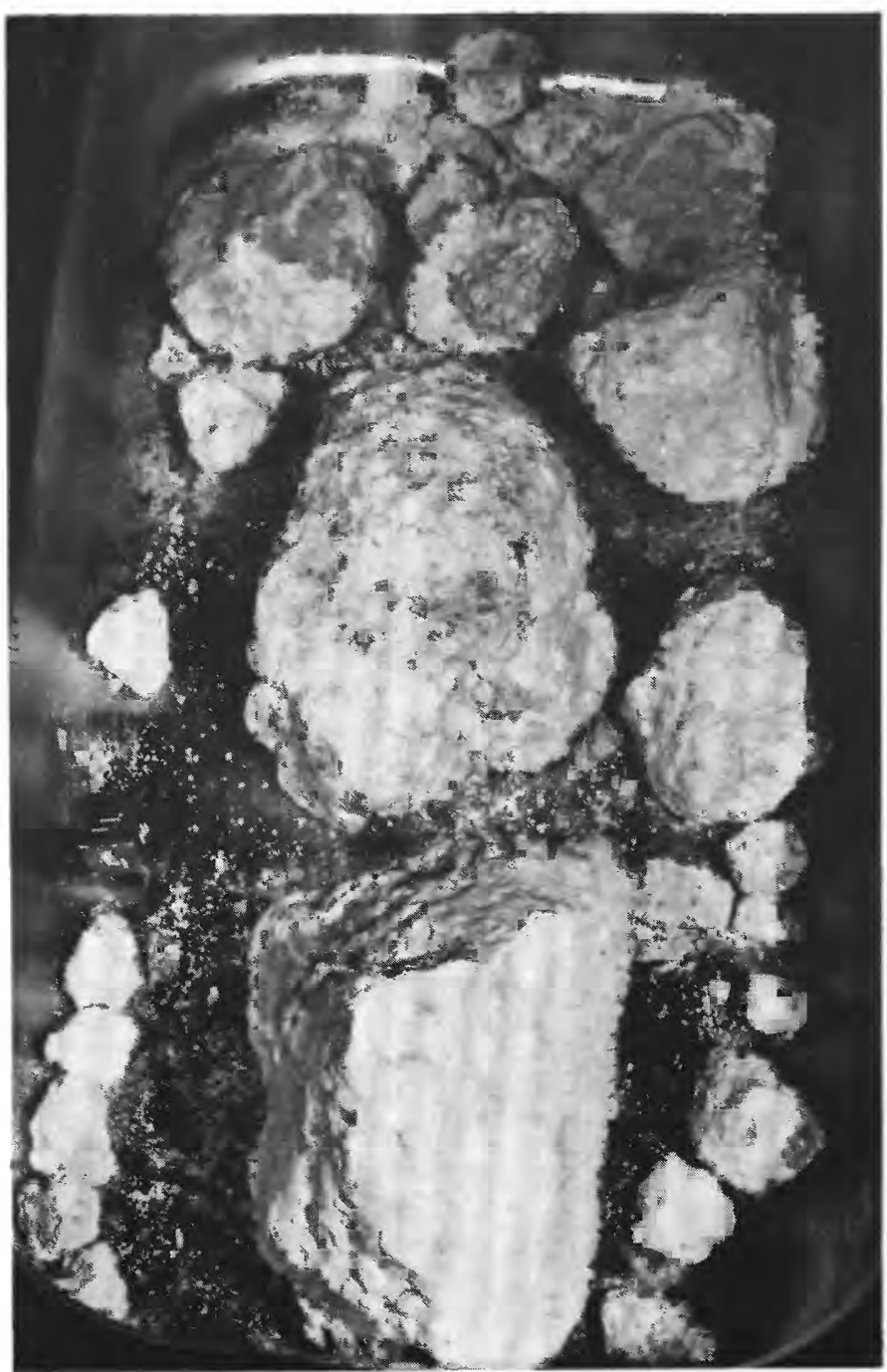

Figure 24.-Broken fragments and fines of sample 67455, a lightmatrix breccia collected from the top of a White breccia boulder illustrated in figures 10 and $25 \mathrm{~A}$. Note few small dark clasts. NASA S-72-38194. Cube is $1 \mathrm{~cm}$. 

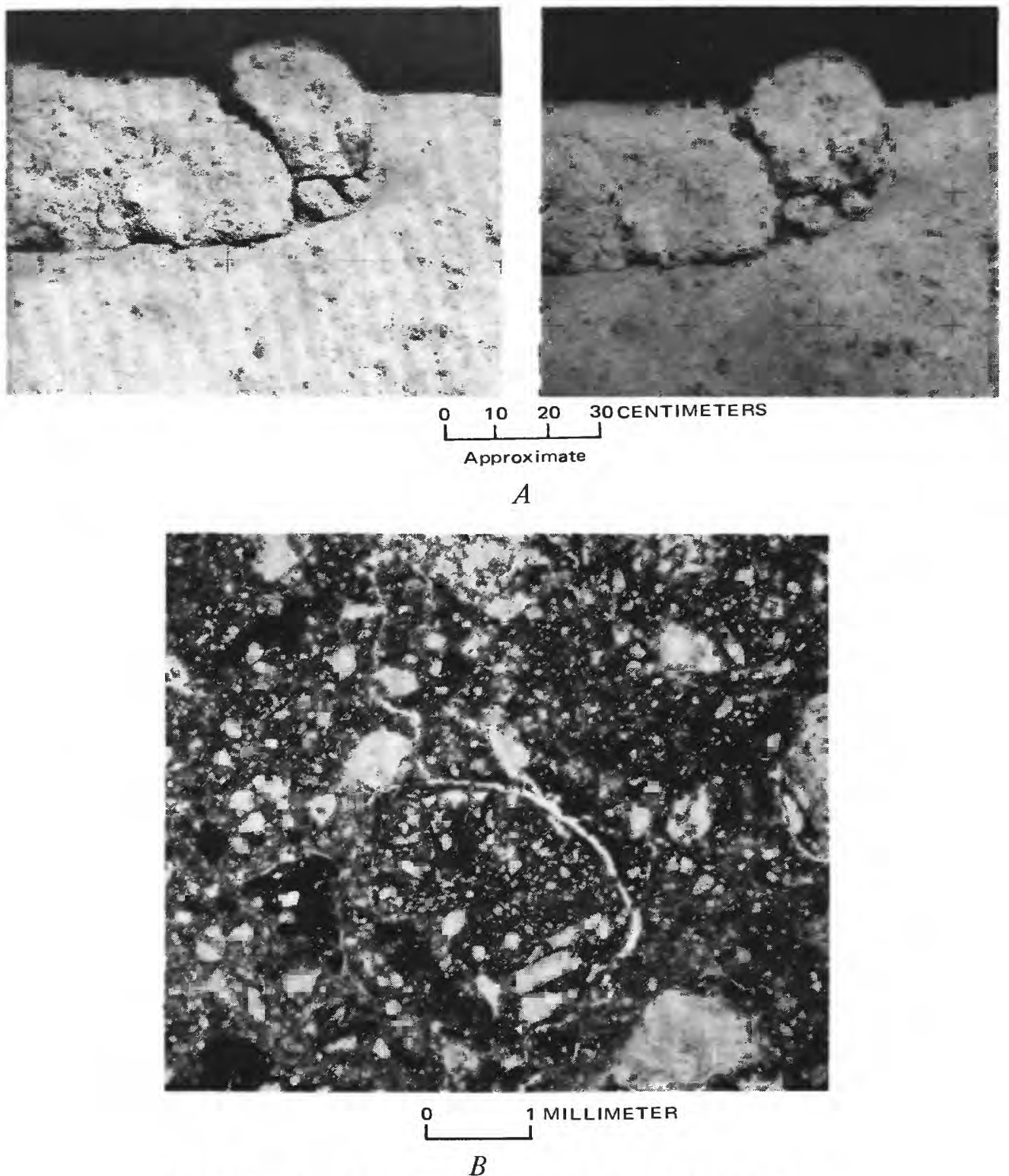

Figure 25.-Sample 67455. A, Stereopair of the top of a White breccia boulder and the fragments of sample 67455 before sampling. AS16-106-17331, 17332, $B$, Photomicrograph of 67455, 57 illustrating irregular fractures that penetrate the matrix of shocked feldspar grains but avoid dark-matrix clasts. Plane-polarized light. 
The rapid mechanical breakdown of these rocks relative to the dark-matrix boulders may be explained by a combination of thermal cycling, which doubtless causes unequal expansion of the dark clasts and light matrix, and micrometeorite bombardment of the surface whereby the rock disintegrates along the irregular fractures and the more coherent fragments collected in the rake samples are preferentially preserved. These processes do not appear to be as effective in the darkmatrix boulders.

A dark-matrix breccia clast (67475) collected from the same boulder as 67455 illustrates very well the criteria by which some clasts can be identified, even when separated from their host. Three views of 67475 (fig. 26) show the weathered surface, a fresh darkmatrix surface, and a surface coated with the feldspathic host material. Fragment 67718 from a rake sample in the Interboulder area is another specimen whose surfaces reveal its relation to the host (see Smith and Steele, 1972, p. 81).

Other samples in the White breccia boulder area that exceed $100 \mathrm{~g}$ in weight and probably represent the majority of rocks there are shown in figure 27 . The only crystalline rocks recognized by Wilshire and others (this volume) are 16 rake samples classified as metaclastic $\left(\mathrm{C}_{2}\right)$; all but one of these weigh less than $25 \mathrm{~g}$. Their occurrence as smaller rocks suggests only that they are residual coherent clasts "weathered" out of the local boulders. Two examples of such clasts within light-matrix breccias are 67415 and 67455 (fig. 28).

One rock, 67215 (also weighing more than $100 \mathrm{~g}$ ), was collected because of its unabraded rock surface. It is described by Horz and others (1972, p. 7-25) as a moderately tough breccia. This rock has not been studied (as of this writing).

\section{INTERBOULDER AREA}

Approximately midway between the White breccia boulders and House rock is a sampling area chosen because it was relatively free of large rocks (fig. 13). From this location, a third photographic survey (east panorama, pl. 9, pan 20; and fig. 4) was taken of the far crater wall. (Table 4 and figs. $13 A, B$, and $29 A-E$ show the types of breccias collected in this area.) Lightmatrix breccias, typified by 67055 and 67075 (fig. 29B, $C$ ), are abundant but not as predominant as in the White breccia boulder area. The appearance of sample 67075 in this section is typical of a crushed anorthosite $\left(\mathrm{B}_{1}\right)$ breccia (fig. 30). Samples 67015 and 67115 (fig. $30 A, E$ ), assigned to the intermediate $\mathrm{B}_{3}$ class by Wilshire and others (this volume) are considered here to be light-matrix breccias because of their matrix color and friable textures. The one dark-matrix fragment col- lected $(67718,49 \mathrm{~g})$ is covered with white material (Smith and Steele, 1972 , p. 82-1) indicative of its former location within a light-matrix host. Rock 67095 (fig. 29D), glass-coated and cemented, is a good example of the glass of class G of Wilshire and others (this volume). Astronaut Young associated it with a 1-m secondary crater on the North Ray rim; it may be an exotic arrival postdating the North Ray event or, alternatively, a fragment of late-stage melt from North Ray.

Fragments weighing less than $25 \mathrm{~g}$ and collected in the Interboulder area (see figs. $13 B, 14$ ) reflect a concentration of intermediate-gray-matrix breccias $\left(B_{3}\right)$ collected mainly in the rake sample (67715-67776). This breccia class appears to be transitional between the light- and dark-matrix breccias and is most commonly listed with light-matrix breccias as an alternative designation by Wilshire and others (this volume). Its origin may be considered similar to that of the light-matrix breccias, with some enrichment in the dark glass components. Consequently, a selective concentration of more resistant clasts of $\mathrm{B}_{3}$ material occurs as residuum from an inferred light-matrix $\left(B_{1}\right.$ and $\left.B_{2}\right)$ host rock. Rock 67235 , like 67215 from the White breccia boulder area, has not been studied as of this writing but is described by Horz and others (1972, p. 7-25) as a hard recrystallized breccia in appearance.

\section{SHADOW ROCK AREA}

Station 13 was planned for the outer edge of the continuous ejecta blanket of North Ray crater. The objective was to collect a radial sample in the region where the shallowest stratigraphic material would be present. As the outer edge of the ejecta blanket was not identifiable, the astronauts selected a location in the vicinity of several large boulders described while enroute to the crater rim crest.

The primary source of rock samples greater than 25 g was the single large boulder named Shadow rock, about $5 \mathrm{~m}$ long and about $4 \mathrm{~m}$ high. It has a distinct moat around its base (fig. 9), presumably part of a shallow secondary crater created by impact of the boulder when ejected from North Ray crater. No fillet of material was shed from its surface. Its shape and apparent resistance to erosion suggest that it is similar to the dark-matrix breccias in the House rock area. And its color and texture are typical of dark-matrix rocks (illustrated close-up in figure 31 ).

Of the rock samples collected at station 13 , (table 5) only one, 60017, weighs more than $100 \mathrm{~g}$ (fig. 32). It is very dark, fine grained, and vesicular and apparently has a high percentage of glass in its matrix. Prominent elongate vugs or vesicle pipes were noted by Astronaut 


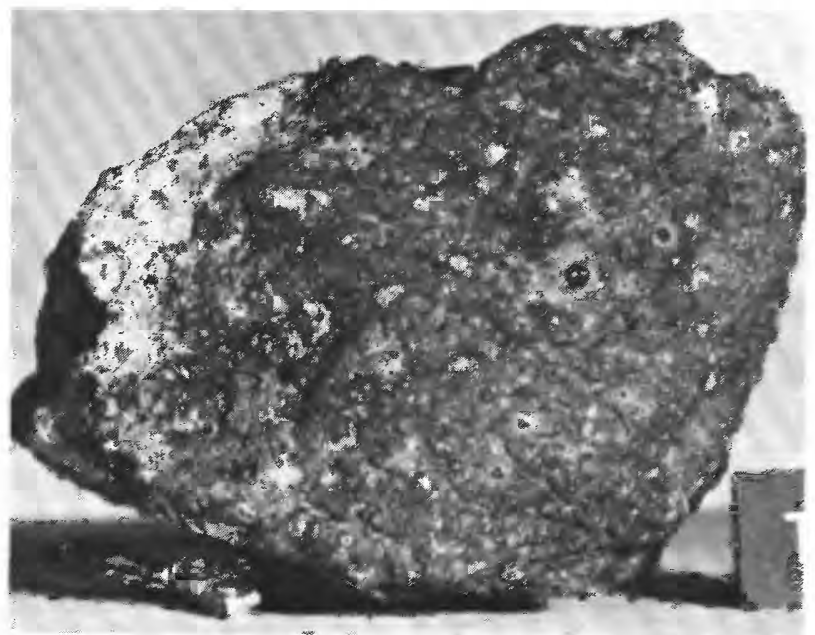

A

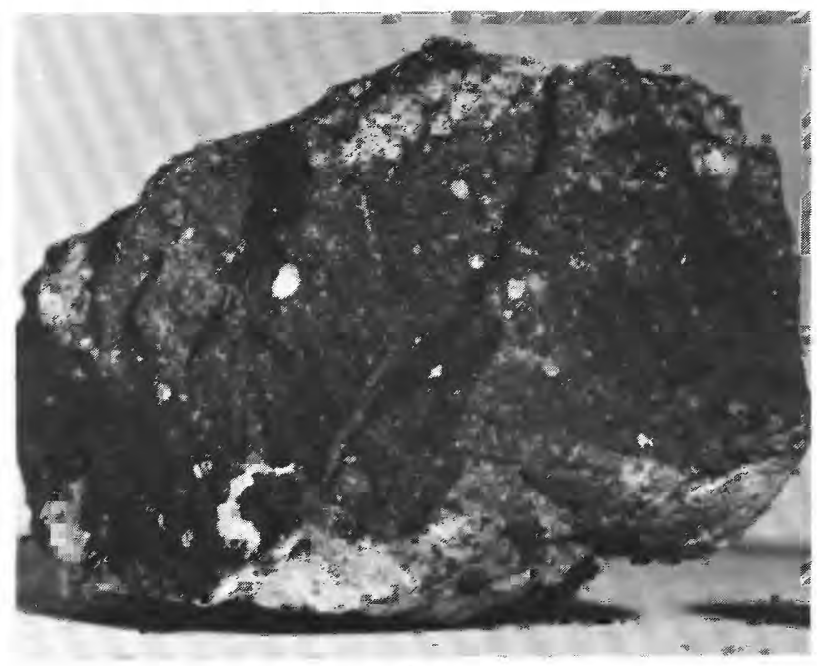

B

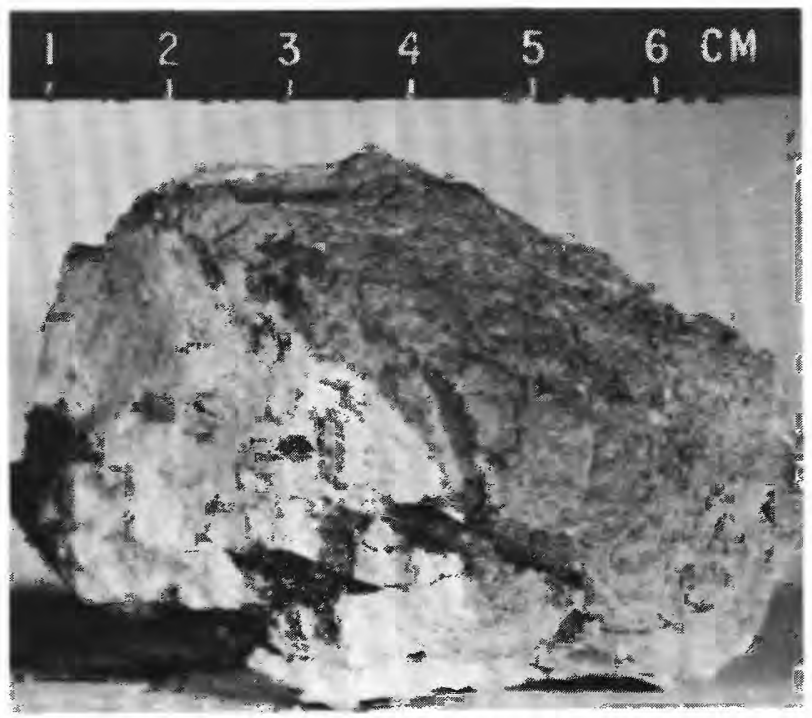

C

Figure 26.-Sample 67475, a dark-matrix clast from the White breccia boulder of 67455 . $A$, Weathered surface with glass-lined zap pits (NASA S-72-43359). $B$, Fresh broken surface showing white feldspathic clasts (NASA S-72-43363). $C$, Broken surface showing coating of light feldspathic matrix of host material (NASA S-72-37958). 


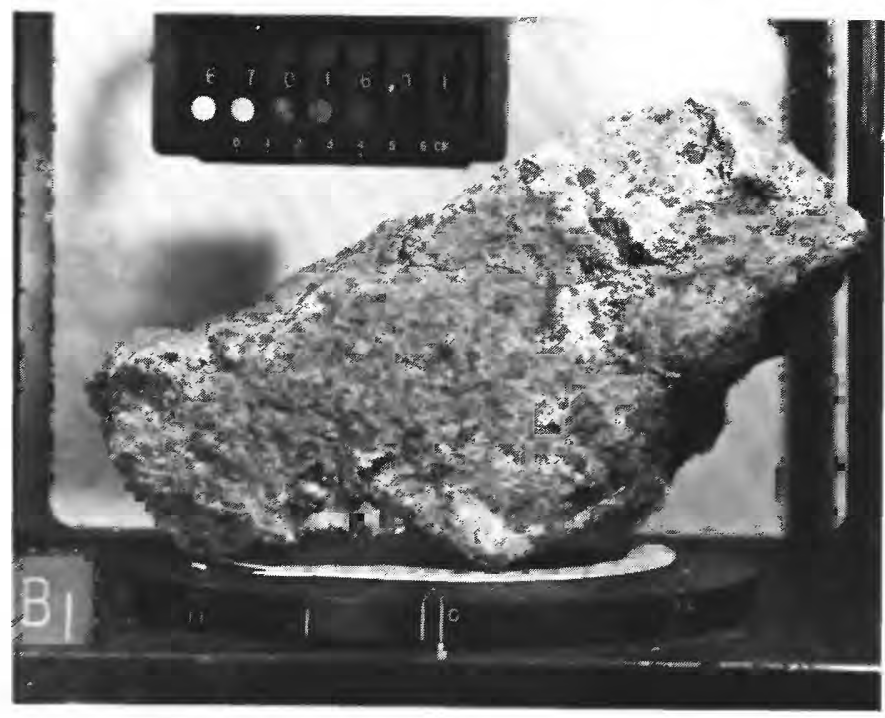

$A$

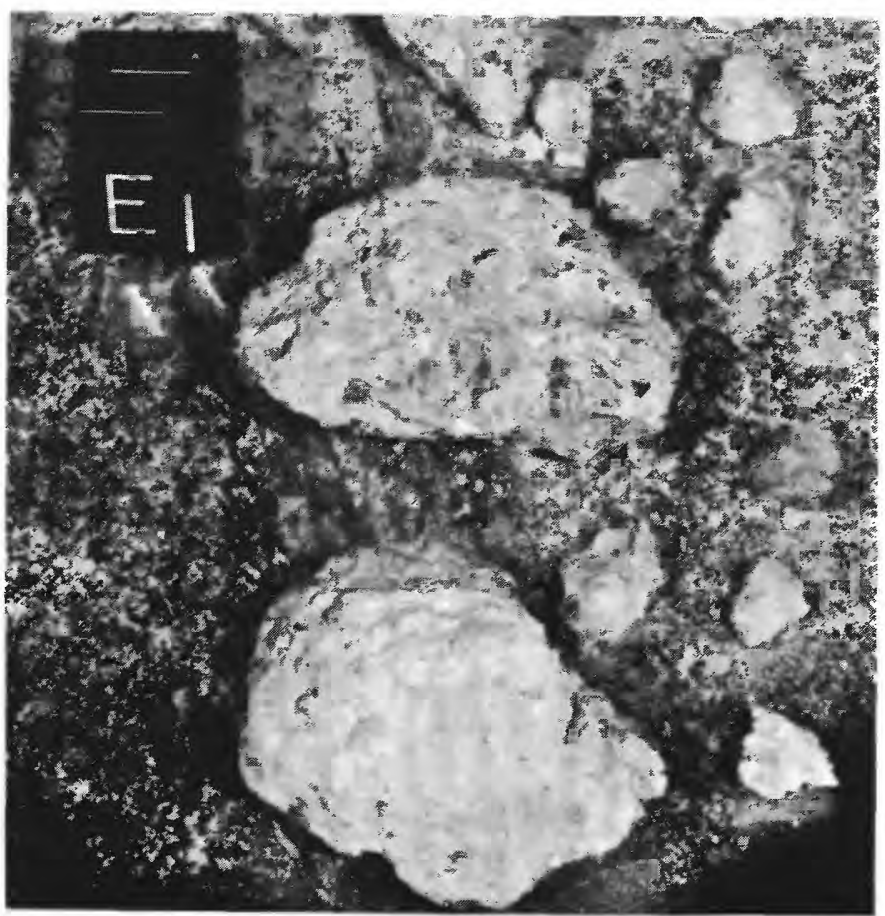

$B$

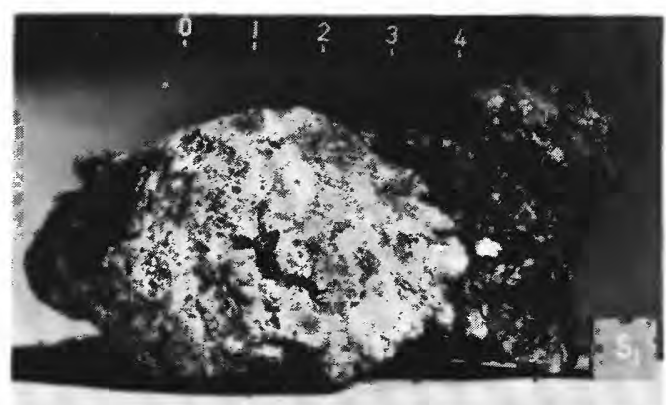

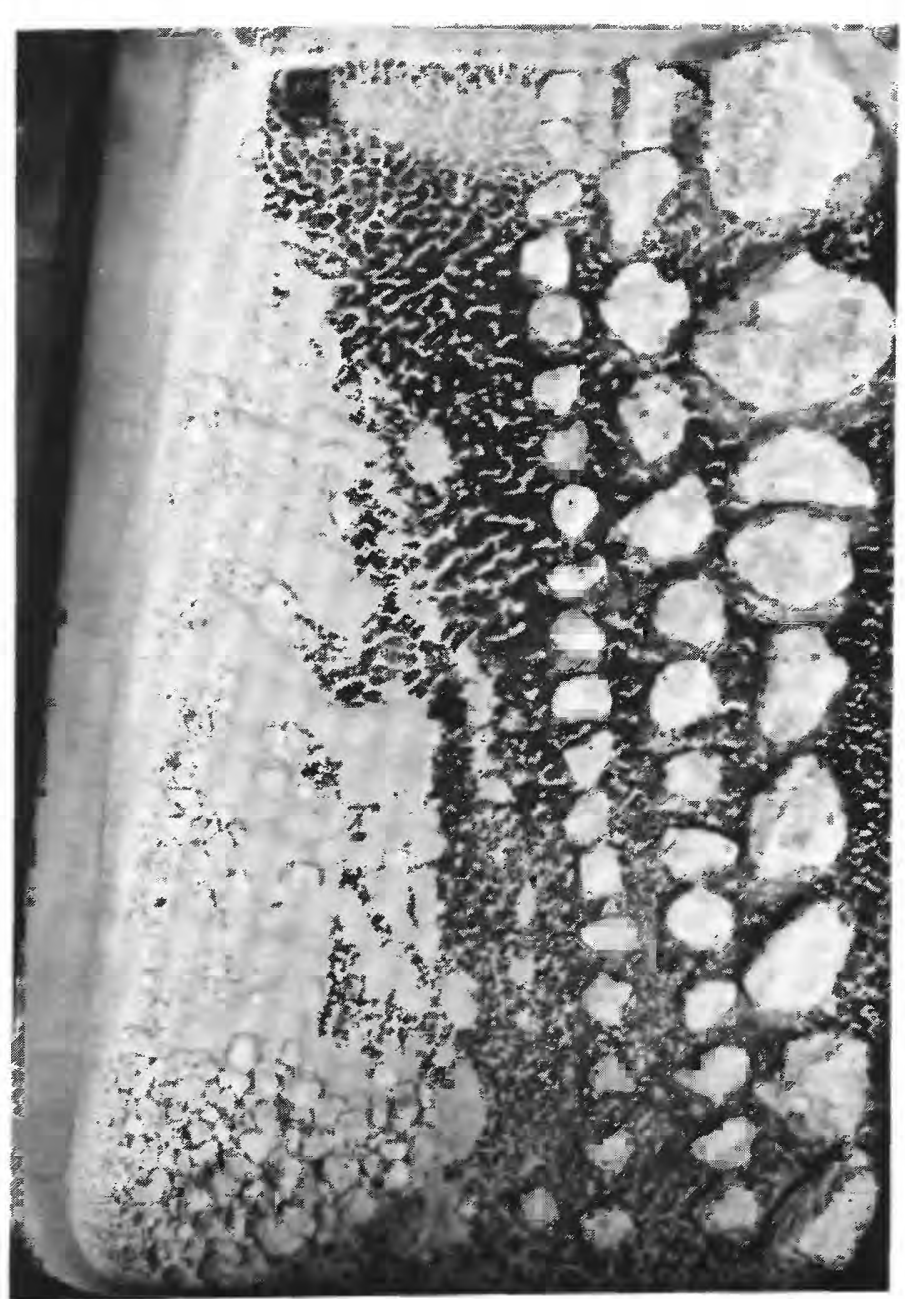

0 5 CENTIMETERS

\section{C}

Figure 27.-Several rocks heavier than $100 \mathrm{~g}$ collected in the White breccia boulder area. $A$, Part of 67016 , intermediate-gray matrix ( $B_{3}$ of Wilshire and others, this volume). S-72-39230. B, 67035, light-matrix $\left(\mathrm{B}_{2}\right)$ broken in transit, $\mathrm{S}-72-37542 . C, 67415$, lightmatrix $\left(\mathrm{B}_{1}\right)$ broken in transit, $\mathrm{S}-72-39038 . D, 67435$, half light, half dark. ( $B_{4}$ of Wilshire and others, this volume). S-72-43897 stereopair

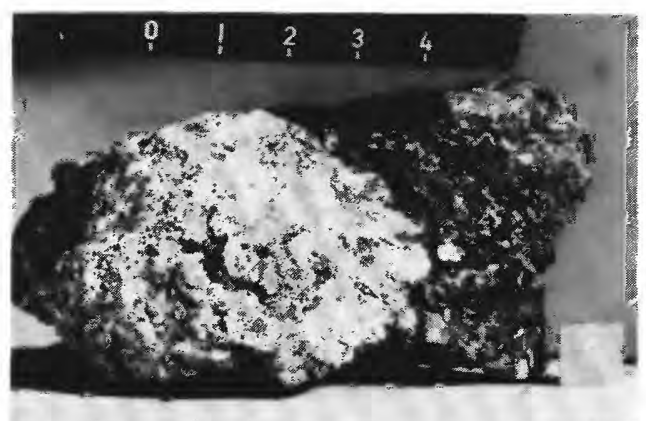



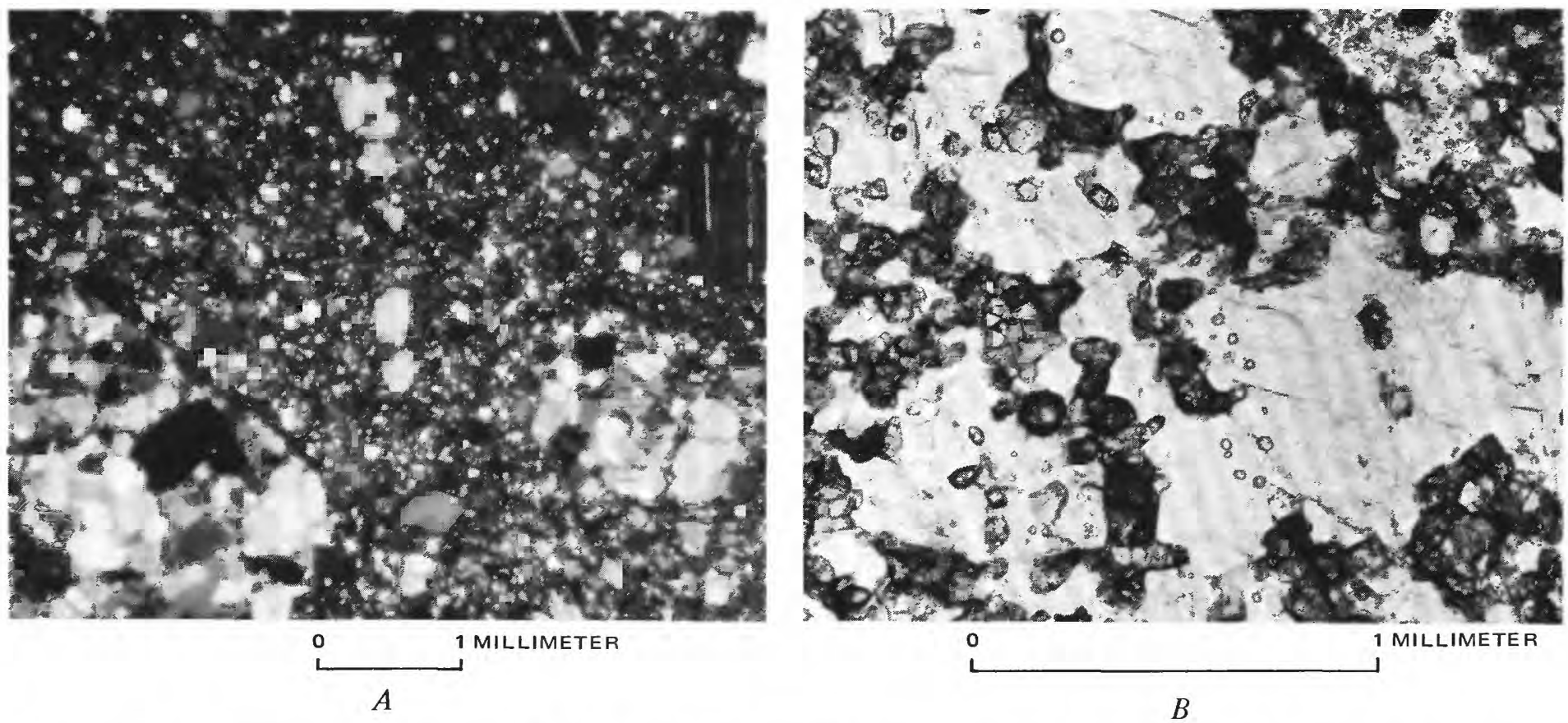

Figure 28.-Photomicrographs of metamorphic clasts within light-matrix breccias. $A$, Granoblastic plagioclase clasts in matrix consisting predominantly of crushed feldspar; 67415,14 ; cross-polarized light. $B$, Poikiloblastic plagioclase enclosing mafic minerals; 67455,57 ; plane-polarized light.

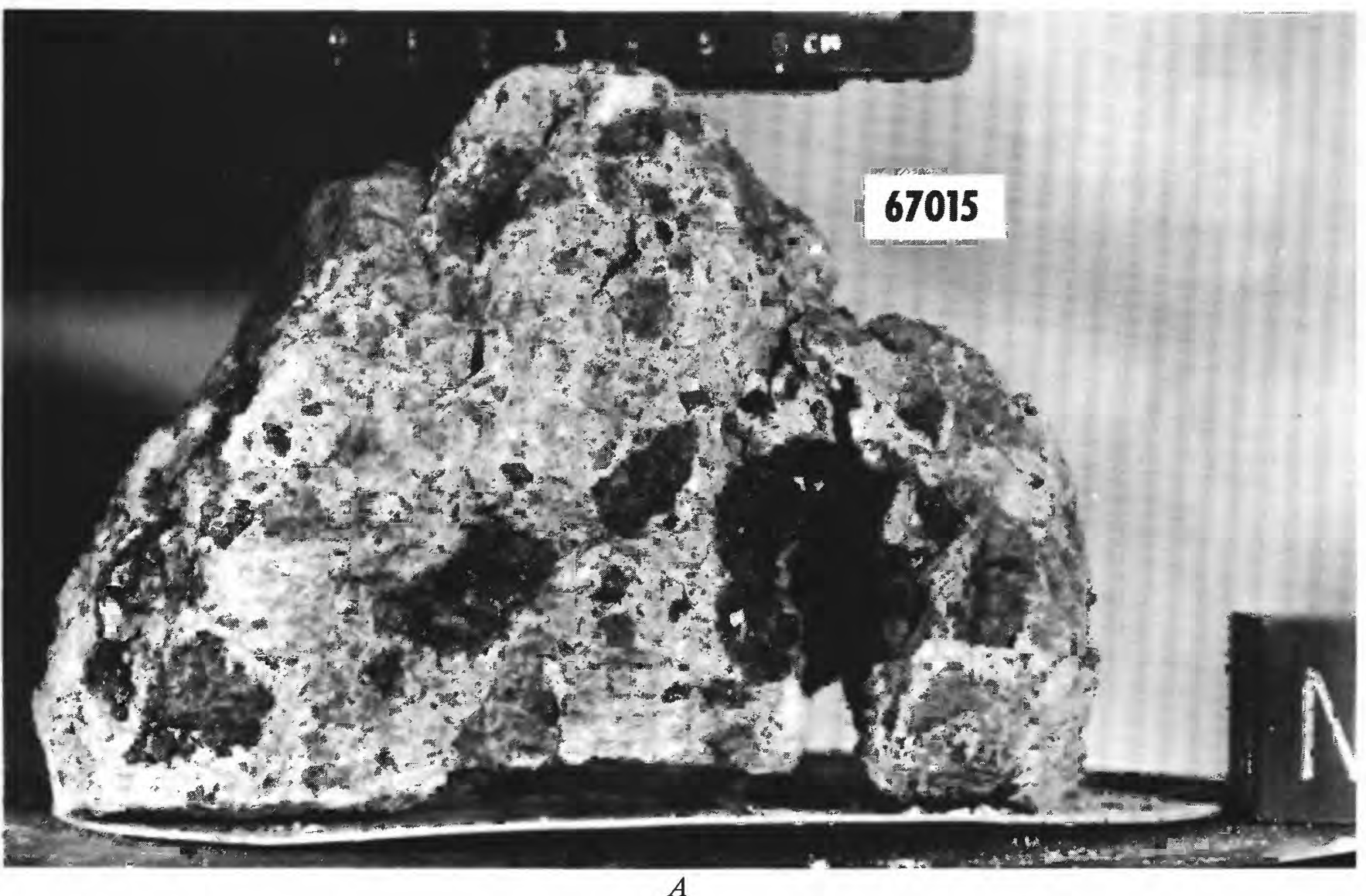

Figure 29.-Caption on facing page. 

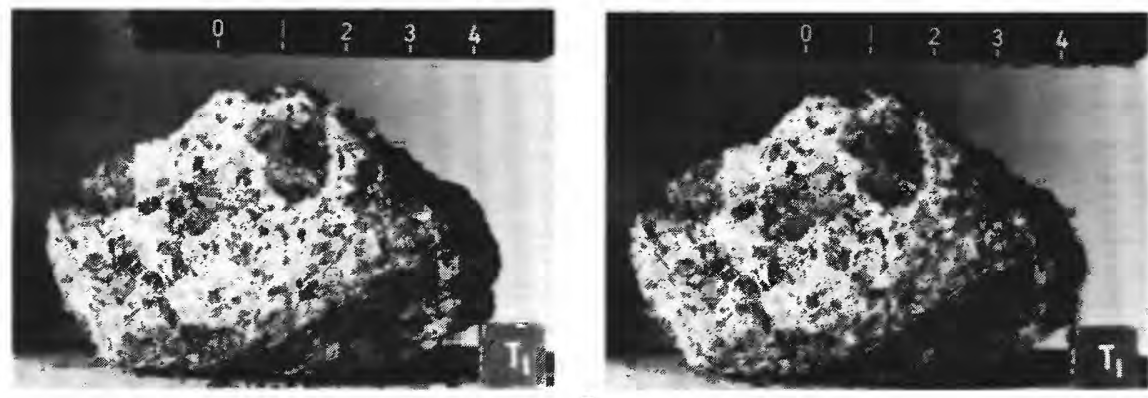

$B$

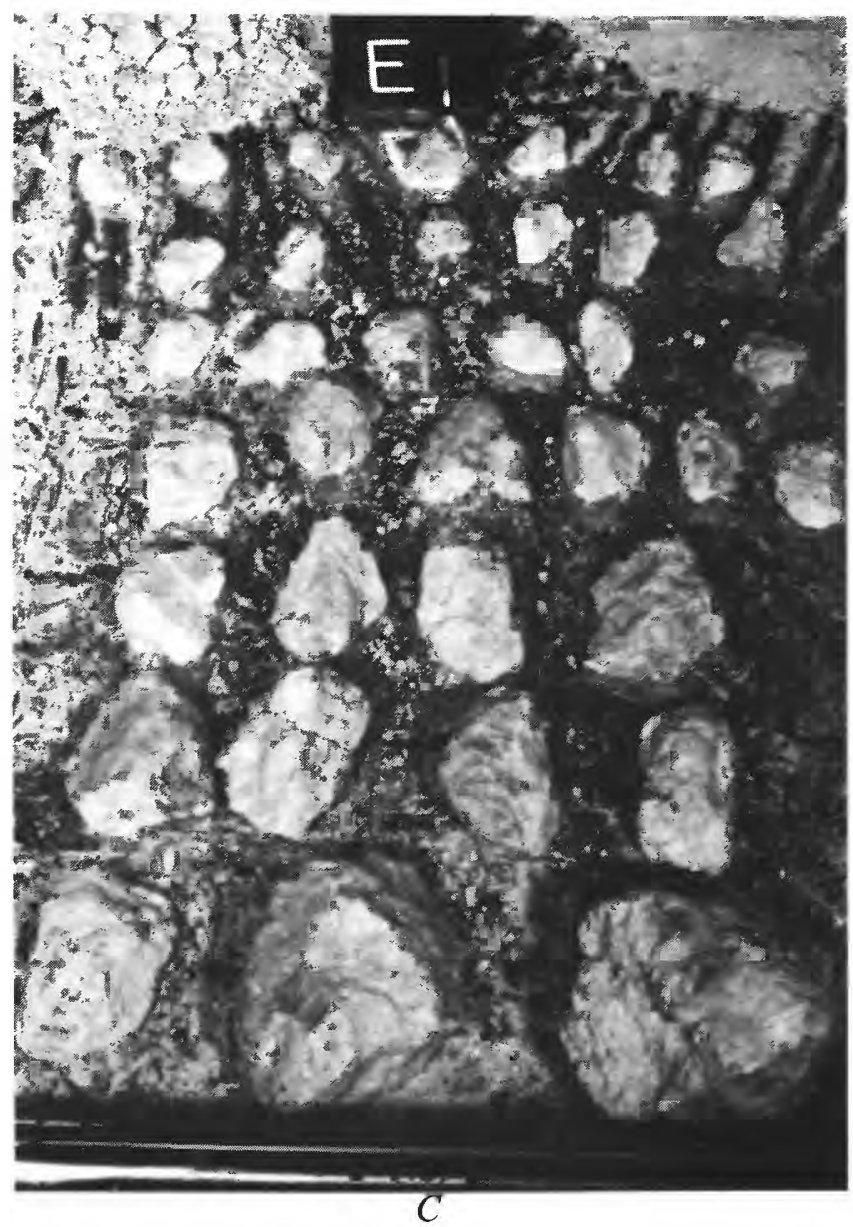

FiguRE 29.-Rocks heavier than $100 \mathrm{~g}$ collected from the Interboulder area. $A, 67015$, light-matrix $\left(\mathrm{B}_{3}\right.$ of Wilshire and others), S-72-37216. $B, 67055$, light-matrix $\left(\mathrm{B}_{2}\right), \mathrm{S}-$ 72-43880 stereopair. $C, 67075$, light-matrix $\left(\mathrm{B}_{1}\right), \mathrm{S}-72-37539 . D, 67095$, glass coated $(\mathrm{G})$, S-72-43076 stereopair. $E$, 67115 , light-matrix (B ${ }_{3}$ of Wilshire and others), S-72-37718. 

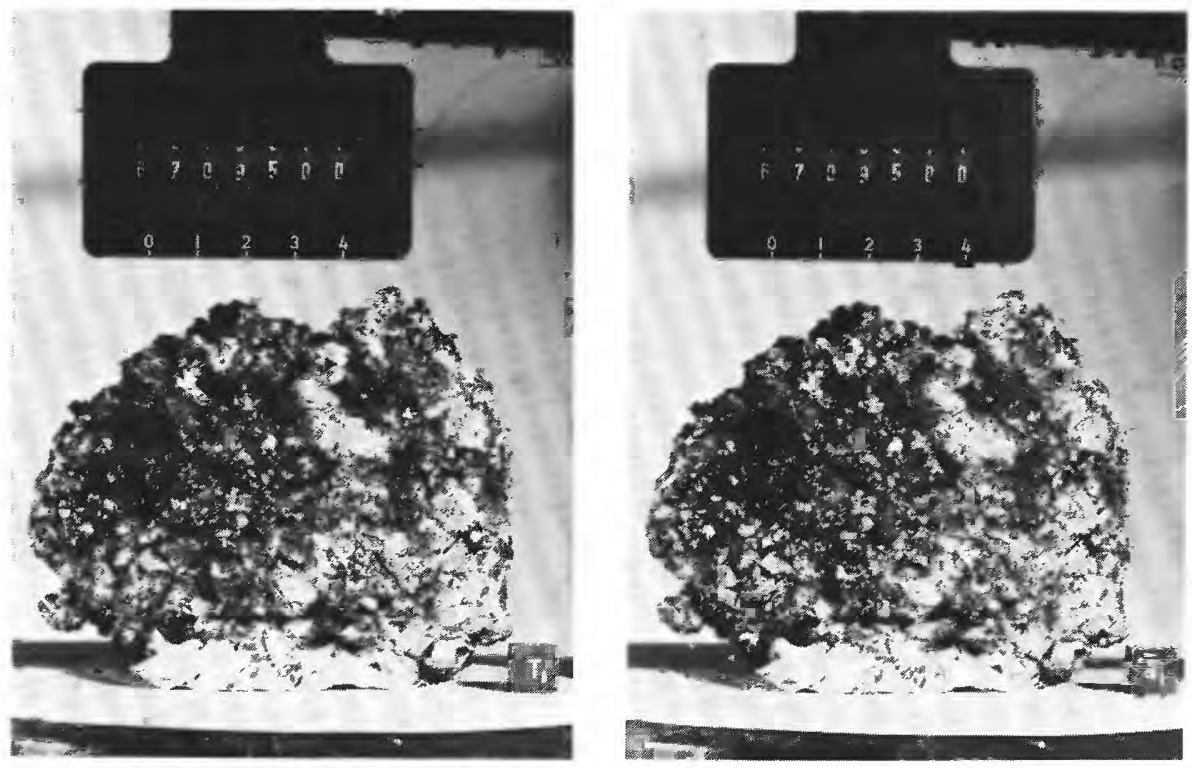

$D$

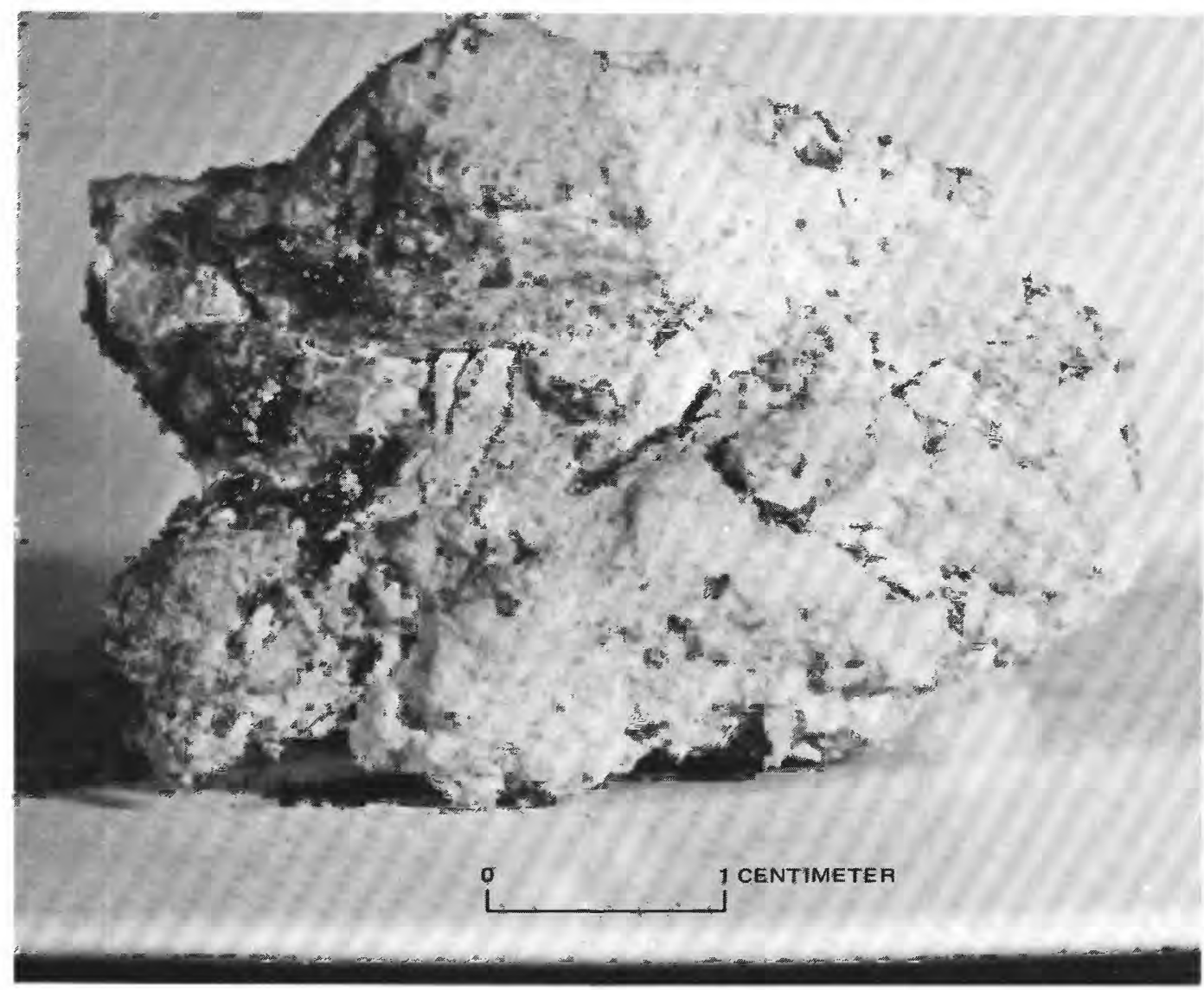

E

Figure 29.-Caption on preceding page. 

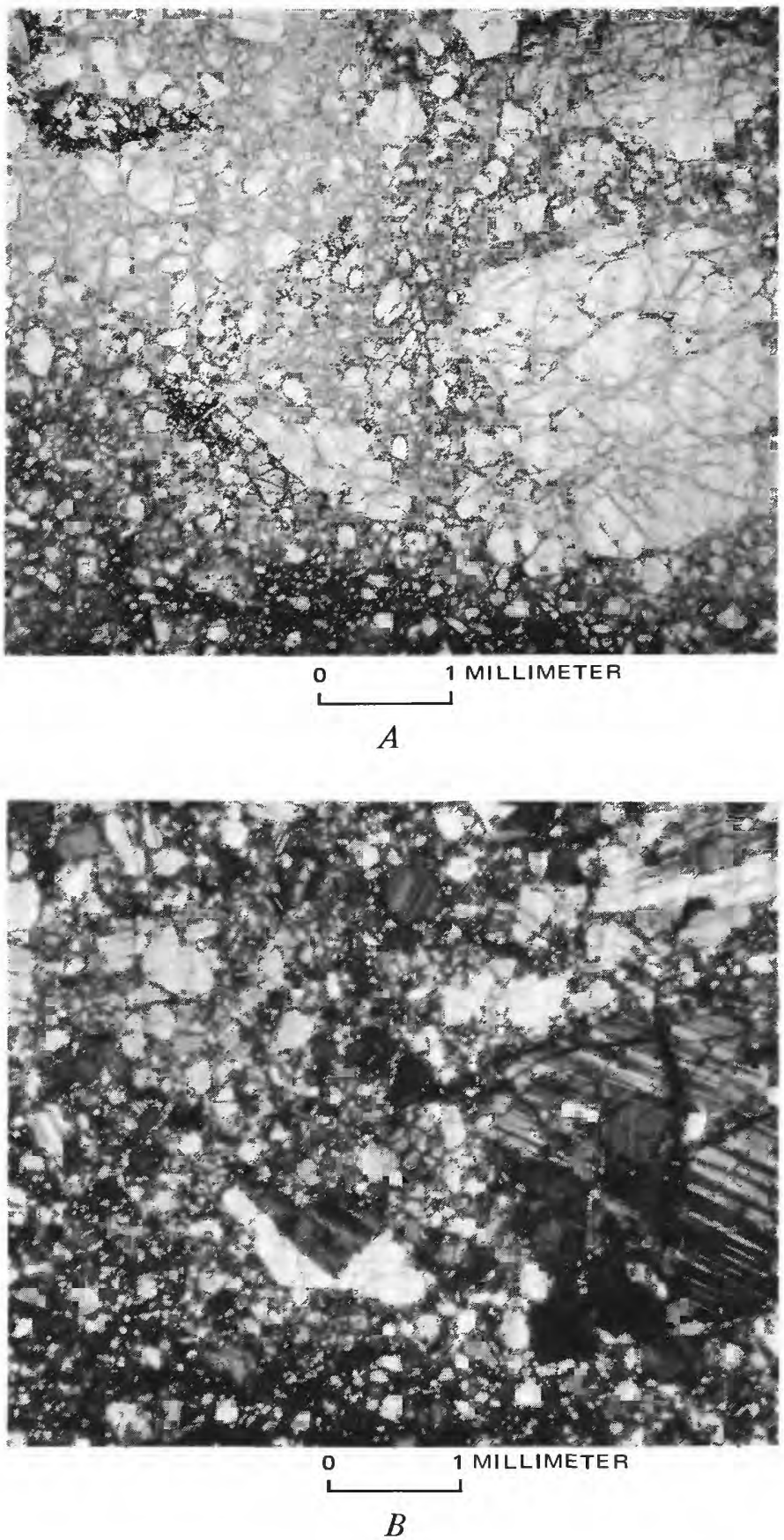

FIGURE 30.-Photomicrographs of a typical light-matrix breccia from the Interboulder area. $A$, Plane-polarized light. $B$, Crosspolarized light. Glass occurs as veinlets within larger plagioclase clasts and in fine-grained matrix. 


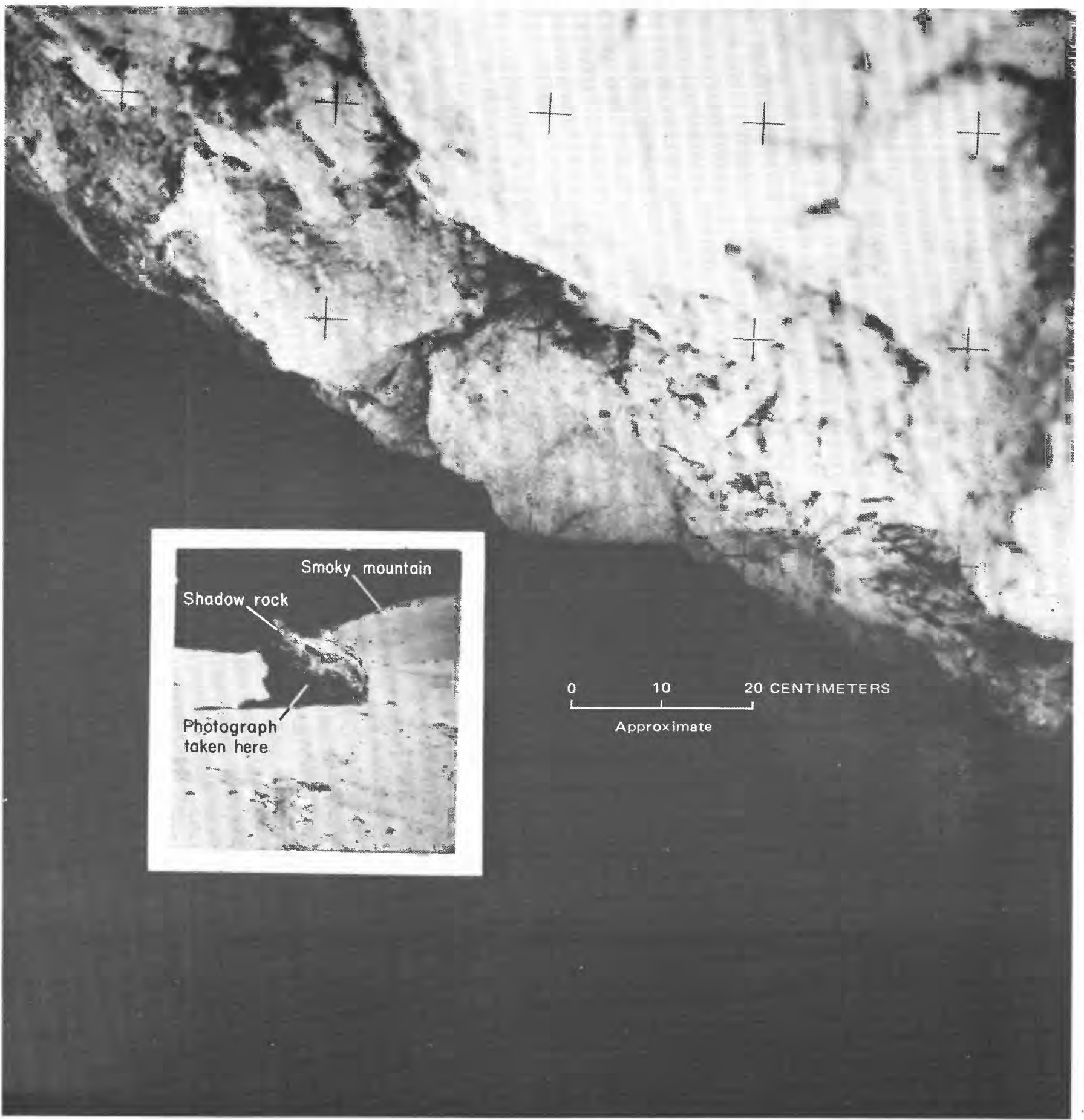

FIGURE 31.-Surface texture of Shadow rock. Closeup of overhanging southwest corner (arrow). AS16-106-17410; inset photograph AS16-106-17393; view is northeast. 


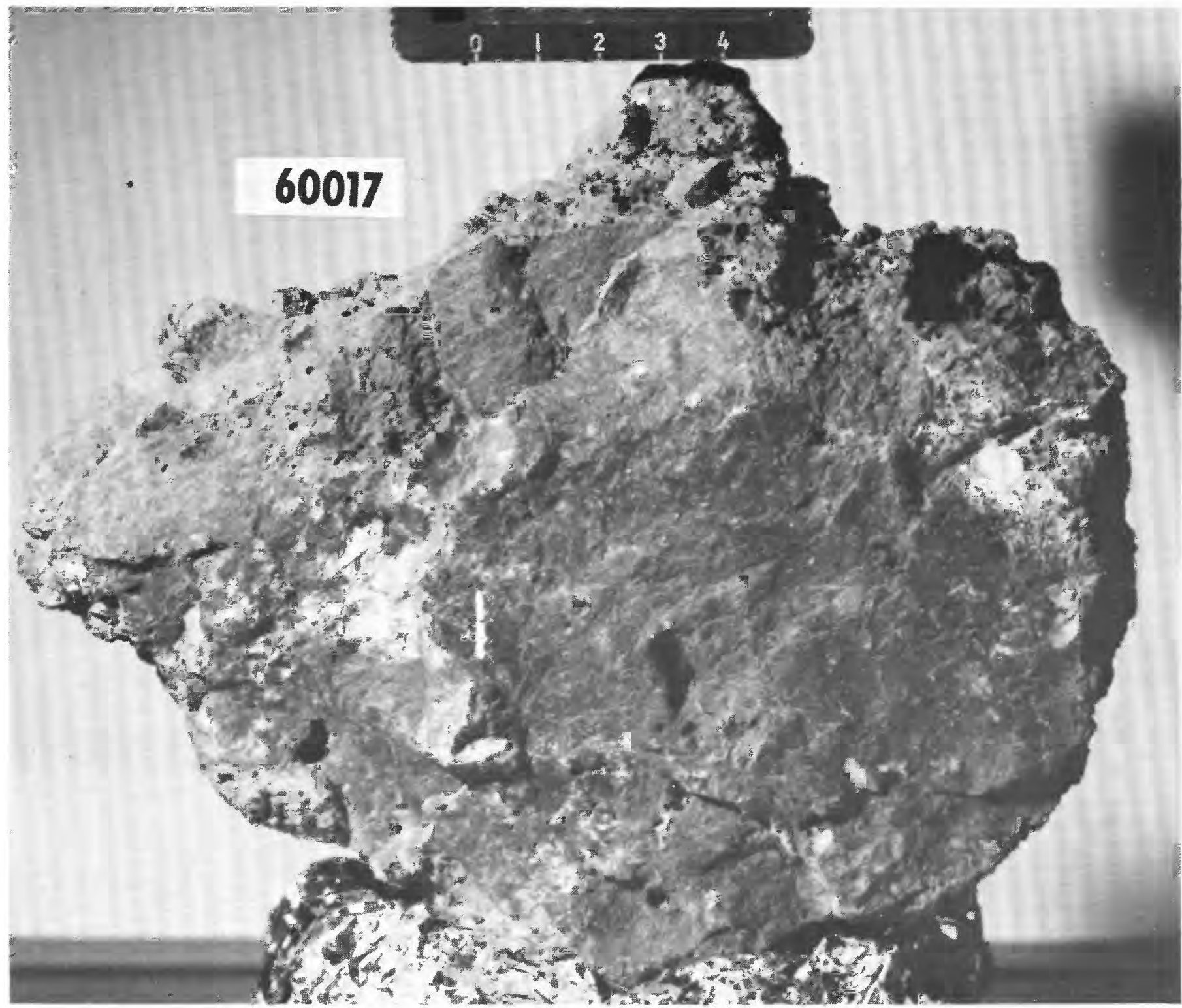

FIGURE 32.-Dark-matrix breccia, 60017, $\left(\mathrm{B}_{4}\right)$ from near Shadow rock. Scale in centimeters. NASA S-72-36943. 
Duke. Microscopically, it can be seen that plagioclase microlites crystallized out of the glassy matrix and vesiculation probably occurred during the quenching of the glass; some late-stage vesiculation is indicated by abruptly terminated laths at some vesicle boundaries (fig. 33). The remaining samples weighing more than $25 \mathrm{~g}$ are dark-matrix $\left(\mathrm{B}_{4}, \mathrm{~B}_{5}\right)$ and metaclastic $\left(\mathrm{C}_{2}\right)$ rocks. Of the samples less than $25 \mathrm{~g}$, a large number (nine) are tentatively classified as intermediategray-matrix breccias $\left(\mathrm{B}_{3}\right)$ (Wilshire and others, this volume); 11 are dark-matrix breccias (fig. 14). Metaclastic and glassy rocks collected in the rake sample, 5 to $10 \mathrm{~m}$ west of Shadow rock, probably represent rocks high in the North Ray walls. Removal from these assignments of samples of uncertain classification (fig. 14) leaves few samples that can be interpreted with confidence.

The most significant rocks, then, are the largest samples derived from a known local source, Shadow rock. Like House rock and Outhouse rock, Shadow rock must have been derived from North Ray crater and deposited late in the ejecta sequence; otherwise later deposits would have banked against its northwestern side. Whereas most of the local blocks are light colored (fig. 12), Shadow rock belongs to a small group of dark rocks that are larger and more angular than most of the fragments (about 20 percent of all the blocks in view). It is probably part of a discontinuous ray of dark resistant breccias from a deep unit that is overlain by light-matrix rocks in North Ray crater.

\section{NORTH RAY SOILS}

The soils on the rim of North Ray crater are distinct from those at other sampling stations within the traverse area in that they are generally very thin and light in color. They are similar to one another in modal and chemical composition (Heiken and others, 1973, p. 261-263). Light-matrix breccias are especially abundant in these soils (approximately 40 percent, G. J. Taylor and others, 1973, fig. 8).

The soils at each of the sampling localities (table 6) were described by the astronauts. At the White breccia boulders, where large fillets occur around the very friable rocks, Duke commented, "The regolith here $* * *$ on this crater rim is really soft. We're sinking in on the slopes about six inches or so" (see fig. 10). Elsewhere it was a centimeter or less as indicated by the bootprints in the station 11 panorama (pl. 8, pan 18). At the Interboulder area, illustrated in the foreground of figure 4, descriptions were, "Right under the upper dull-gray soil there's a layer of whitish material, much like it was at South Ray" and "It's hard under there $* * *$ there must be a big rock under here. I can't

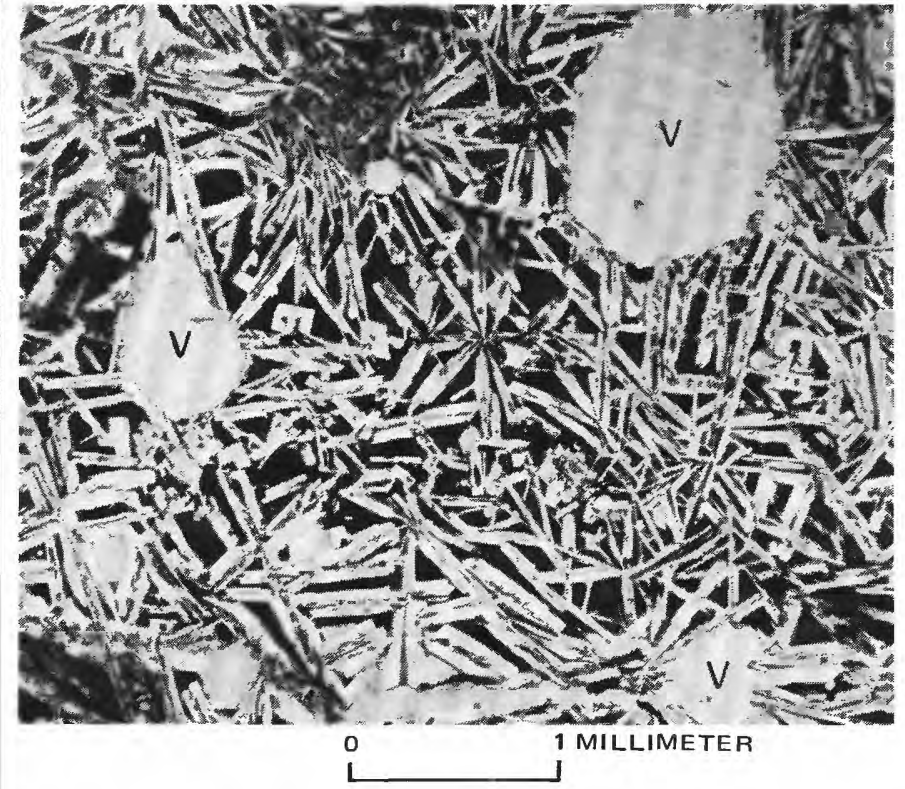

FIGURE 33.-Photomicrograph of 60017,112 , showing vesicles (V) that both conform to and crosscut plagioclase quench crystals in glassy dark-matrix breccia. Plane-polarized light.

get the rake in *** It's all white under here. Down about a centimeter or less, it's all white" (Duke). This color difference, gray on the surface and white below, was also described near Shadow rock (station 13) and everywhere else at the site except stations LM, 8, and 9. It is probably caused by the accumulation of agglutinates at the surface (Adams and McCord, 1973, p. 171), a process that may also account for the dark tongues of surface debris seen draping the upper wall of North Ray in figure 3 . The lighter areas between these tongues may represent more active soil movement downslope, where darker soils have slid away. Low scarps commonly border the more stable gray slopes, and a few boulder tracks are present where larger fragments have rolled or slid downward.

The agglutinate contents of the darker soils, much lower than elsewhere in the traverse area, indicate a lack of maturity and thus the low relative age of North Ray soils (McKay and Heiken, 1973, p. 42). Exposure ages have been reported as 30 to 60 m.y. (Schaeffer and Husain, 1973, p. 1858; Kirsten and others, 1973, p. 1775; Turner and others, 1973, p. 1903; Marti and others, 1973, p. 2039).

At House rock, Duke, while attempting to sample the east-west split (fig. 8), reported, "This soil here is very hard and the rake really won't go into it. It's bending tines***." The purpose of sampling in the eastwest-trending opening was to obtain materials (soil 67940) shielded from the solar wind and to identify, by 
comparison with a nearby reference soil sample (67960), the components concentrated or redistributed by the solar wind. No chemical or modal differences are found in these soils (Heiken and others, 1973, p. 262); only minor contributions of soil-size particles spalled from the adjacent boulders are recognized. Adams and McCord (1973, fig. 4 and p. 170), however, found a lower reflectance for $67941^{1}$ when compared with 67461 from the White breccia boulder area, even though the agglutinate contents are the same (20 percent). They attribute the lower reflectance of the House rock soils to enrichment in dark-matrix breccia fragments.

At Shadow rock the astronauts collected a soil sample from beneath the overhang on the west end of the rock in the deepest recess (fig. 31). It was hoped that the sample had been permanently in shadow since the rock was emplaced, and the investigators intended to determine whether volatile elements had been concentrated in such a cold trap. The shadow at the time of sampling is shown in figure 34; the sun elevation angle was $46^{\circ}$ above horizontal, its azimuth was $12^{\circ}$ north of east. At sunrise and sunset, the maximum pr: gression of the sun's azimuth is $1^{\circ}$ to $2^{\circ}$ north of an east-west line. This and the estimated movement of sunlight into the shadowed area (shown on fig. 34) during a single lunation make it unlikely that any exposed soil remains permanently shadowed, despite Astronaut Duke's observation that the shadowed area was downslope (beneath the rock). A second soil sample (63340) was collected from beneath the first and therefore was a buried soil rather than an exposed shadowed soil.

The North Ray soils have not been found to differ significantly in lithophile trace-element abundances; strontium contents are slightly higher in these soils than elsewhere, probably reflecting higher plagioclase contents in North Ray target materials (Philpott and others, 1973, p. 1433). North Ray rim soils (including 67941) exhibit no apparent differences in carbon content but as a group are significantly lower in carbon than all other Apollo 16 soils measured by Moore and others (1973, p. 1616). If carbon content is mainly a product of solar wind effects, the contribution on the rim of North Ray crater is relatively small and is the same for the east-west split as in unshielded areas.

The apparent meteoritic component in the North Ray soils is lower than elsewhere; this too is indicative of relative immaturity (see Freeman, this volume).$$
\mathrm{mm}
$$
m.

\section{GEOPHYSICS}

Geophysical data in the North Ray area consist of a single three-vector reading on the Lunar Portable Magnetometer at station 13 . The resultant magnetic anomaly reported was about 300 gammas, down and to the southwest, the largest recorded at this site and larger than any recorded at Apollo 14 or 15 sites (Dyal and others, 1972 , p. 12-7). This and the readings from station 2 and in the LM area are interpreted by Strangway and others (1973, p. 113-114) as indicative of a breccia blanket of the order of $1 \mathrm{~km}$ thick under the Cayley plains. This blanket, by their hypothesis, was emplaced within a field of a few thousand gammas cooled from a temperature higher than $700^{\circ} \mathrm{C}$, forming a moderately welded rock mass with a high remanent magnetization.

The only lunar rocks known at this time (1974) to have stable magnetization sufficient to fit this model are a moderately welded, dark-matrix soil breccia (15498) from Dune crater at the Hadley-Apennine (Apollo 15) site and an Apollo 11 chip from soil 10085 (Strangway and others, 1973, p. 113). As unwelded materials and (surprisingly) highly welded and igneous rocks do not carry strong remanent magnetizations, it is possible that the large magnetic fields required are produced by local or regional impact events (such as $10-\mathrm{km}$ or larger craters) wherein only the melted and rapidly cooled breccias retain the transient fields. The igneous-textured rocks cooled slowly enough that the short-lived impact-induced fields had disappeared by the time they passed through the Curie point. The melt-poor light-matrix breccias, never hot enough to pass through the Curie point, therefore were not magnetized.

\section{SUMMARY}

North Ray crater proved to be an excellent source for a large variety of samples and photographs representing the best available documentation for stratigraphic interpretations anywhere in the Apollo 16 traverse area. The rounded form of the crater rim and the convex shape of its generally smooth walls indicate a target material of relatively low strength.

Rocks on the rim and wall of North Ray crater are mainly of two types: light-matrix and dark-matrix feldspathic breccias with clasts and inclusions of glassy to crystalline texture. The large boulders $(0.2 \mathrm{~m}$ and larger) are mainly light-matrix breccias $\left(\mathrm{B}_{1}, \mathrm{~B}_{2}\right.$ of Wilshire and others, this volume); many have wellrounded profiles and have accumulated deep fillets of soil by erosion of their friable surfaces. Similar rocks occur as possible outcrops in the upper half of the crater wall. Dark-matrix rocks $\left(\mathbf{B}_{4}, \mathbf{B}_{5}\right)$ make up 10 to 30 percent of the boulders present and appear to be very 
resistant to erosion. Generally perched or sitting within shallow depressions, they are interpreted as the deepest material exposed in the crater wall and therefore the latest to be deposited on the crater rim.

The small fragments ( 2 to $25 \mathrm{~g}$ ) collected in soils and rake samples reflect in part the more resistant components contained interstitially and as clasts within the larger boulders. These include the coherent dark- and intermediate-gray $\left(\mathrm{B}_{3}\right)$ breccias, metaclastic $\left(\mathrm{C}_{2}\right)$ rocks, and holocrystalline fragments with igneous textures $\left(\mathrm{C}_{1}\right.$ of Wilshire and others). The metaclastic and holocrystalline rocks were documented from the matrix of only one boulder, the dark-matrix breccia called Out- house rock. Light-matrix breccias and glass-coated fragments (G) are common locally in the smaller samples and as clasts from the dark-matrix breccias.

The sample suite is divided into four subgroups based on their locations. Three are on the rim crest of North Ray, the fourth is near the edge of the continuous ejecta blanket. Of 148 rock samples, only a fourth weigh more than $25 \mathrm{~g}$, but these probably represent the abundance and distribution of rock types more accurately than do the smaller fragments. Light-matrix breccias characterize two of the three rim crest areas; dark-matrix breccias with associated metaclastic and igneous inclusions are typical of the large dark boul-

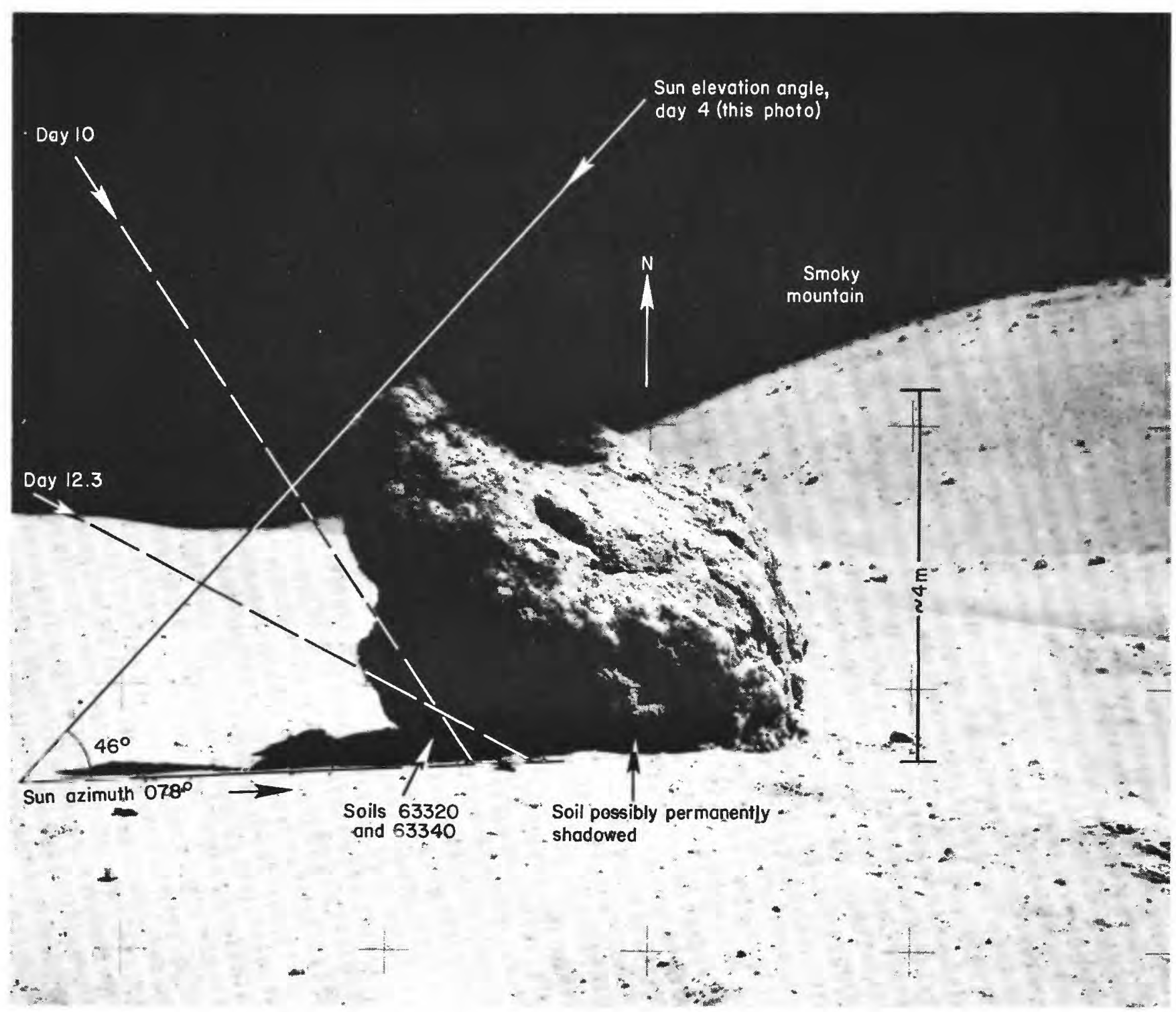

FIGURE 34.-Estimated exposure to sunlight beneath overhang of Shadow rock during one lunation. Predicted sun-elevation angles (dashed lines) for earth days 10 and 12.3 correspond to inclined surface on Shadow rock above soil sample 63320. Angle error due to changing sun azimuth is $2^{\circ}$ to $3^{\circ}$. AS16-106-17393. 
ders at one rim crest site and at station $13,0.75 \mathrm{~km}$ away. Shadow rock, at station 13, appears atypical of the normally light-colored block population on the outer rim. It is therefore interpreted as part of a discontinuous ray extending southeast from the crater rim. The light-matrix materials that constitute the main fragment population are derived from at least the upper half of North Ray (possibly deeper) and overlie a zone of dark material indicated by a small mound on the crater floor. The stratigraphic implications for other parts of the landing site are discussed by Ulrich and Reed (this volume).

The generally thin regolith (about $1 \mathrm{~cm}$ ) thickens to $15 \mathrm{~cm}$ or more where it forms fillets around the friable light-matrix boulders. The soils on this fresh crater rim are generally very light gray but not as light as those immediately beneath the surface. Their mineral compositions, while distinct from other areas, are reported to be very similar within the North Ray ejecta blanket. Mass movement on the steep crater wall and rim has transported soil and a few blocks toward lower areas.

Magnetic readings from the Lunar Portable Magnetometer were high where measured at station 13 . They are believed (Strangway and others, 1973) to reflect moderately welded breccias that were emplaced and cooled from temperatures higher than $700^{\circ} \mathrm{C}$ in a field of a few thousand gammas. In view of the apparent lack of remanent magnetization in more crystalline rocks, it is suggested here that the magnetic field was very short lived and was induced by a large local or regional impact event affecting only melt-rich breccias that cooled rapidly, thereby retaining the transient field. 


\section{D3. GEOLOGY OF AREAS NEAR SOUTH RAY AND BABY RAY CRATERS}

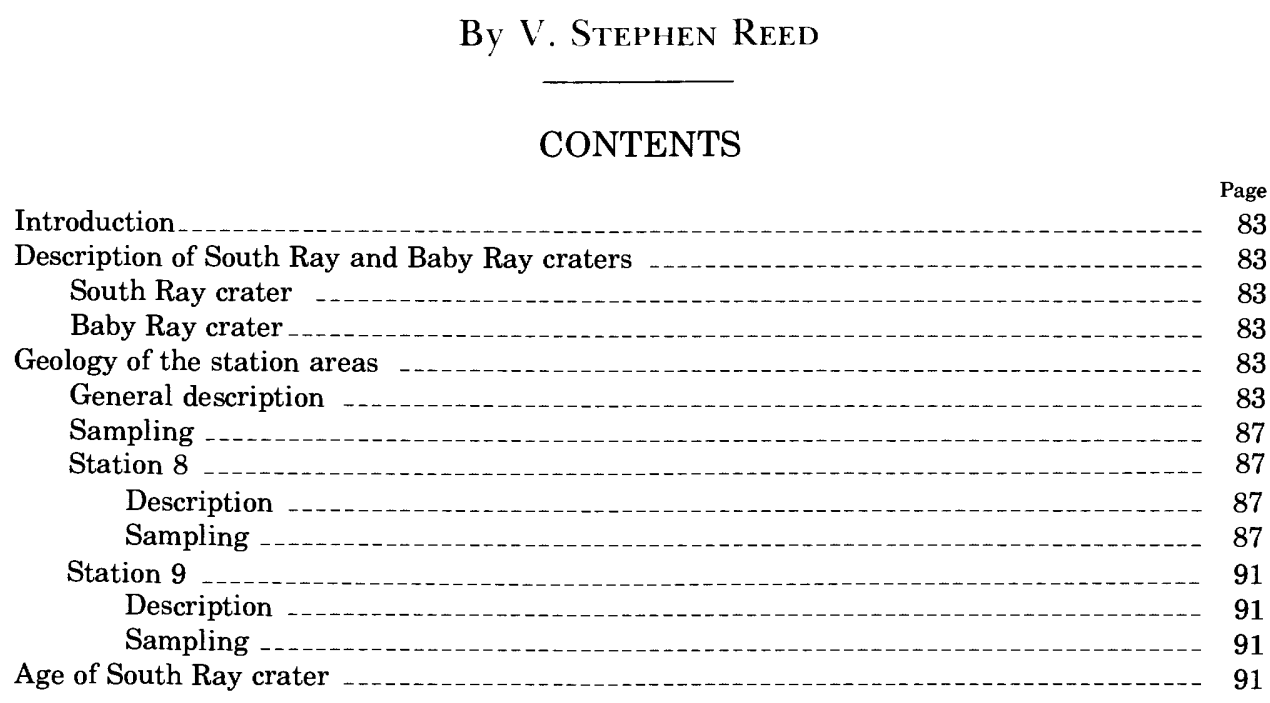

\section{ILLUSTRATIONS}

FIGURE 1. Geologic and topographic maps and photograph of South Ray crater and surrounding area

2. Photograph showing prominent features of South Ray crater .

3. Telephoto mosaics of South Ray crater and Baby Ray crater

4. Map of ejecta from South Ray crater

5. Photograph showing features of Baby Ray crater

6. Planimetric map of station 8

7. Planimetric map of station 9

8. Stereopairs of 68115 (and closeup), $68415,68416,68815$, and 69955

9. Photomicrographs of rocks shown in figure 8

10-17. Photograph and sketch map:

10. $15-m$ crater at station 8

11. Boulder 1, station 8

12. Boulder 1, station 8 (closeup)

13. Boulder 2, station 8 , showing location of samples 68415 and 68416

14. Boulder 3 , station 8 showing location of sample 68815

15. Station 9 boulder showing location of sample 69935

16. Station 9 boulder showing texture on shadowed side

17. Bottom of overturned boulder at station 9 showing location of sample 69955

18. Schematic cross section through South Ray crater

\section{TABLES}

TABLE 1. Samples collected at stations 8 and 9

2. Reported crystallization ages for samples 68415 and 68416

3. Chemical compositions of samples 68415,68115 , and 68815 , station $8 \ldots$

4. Reported exposure ages of rocks collected at stations 8 and 9 


\section{INTRODUCTION}

The surface of the southern part of the Apollo 16 landing site is dominated by fragmental debris derived from South Ray crater (fig. 1). Although the crater was not actually visited, several samples collected can be directly attributed to that impact event. Premission maps by Hodges (1972a) and Milton (1972) from Apollo 14 orbital photographs show a distinct ray pattern around the crater. Traverse station 8 was planned as a sampling site for ray material excavated from South Ray crater, station 9 as an interray sampling site. South Ray Crater, $680 \mathrm{~m}$ in diameter and $135 \mathrm{~m}$ deep, is near the western flank of the Descartes mountains on a plains surface underlain by the Cayley Formation. Mapped as a young Copernican crater by Hodges (1972a), it appears extremely fresh, with a sharp, raised rim and abundant blocky ejecta (fig. 2). A smaller, 130-m diameter crater, Baby Ray, lies about $1.8 \mathrm{~km}$ northeast of South Ray crater, also in smooth plains. Younger than South Ray crater (mapped as the youngest Copernican crater material by Hodges, 1972a), its rays overlie the South Ray debris.

The two major rock types collected in the station 8 and 9 areas are dark-matrix breccias and light-colored igneous rocks. This paper presents evidence that the rock samples collected are impact ejecta from South Ray crater and that they represent some of the materials visible in the walls of the crater.

\section{DESCRIPTION OF SOUTH RAY AND BABY RAY CRATERS}

\section{SOUTH RAY CRATER}

South Ray crater is a fresh-appearing blocky crater with a sharp, raised rim (figs. 2, 3). About $50 \mathrm{~m}$ below the rim crest, a discontinuous terrace is visible on the low-sun photographs. The interior of the crater is extremely blocky; a large mound of blocky debris occupies the central part of the floor. A few dark patches are visible in the upper third of the crater wall.

On the high-sun Apollo 16 photographs, bright rays extend at least $15 \mathrm{~km}$ northeast, overlying North Ray crater ejecta, $10 \mathrm{~km}$ to the north (fig. 4) (ALGIT, 1972a and AFGIT, 1973). Blocks were deposited in abundance as far as Survey ridge, $4.5 \mathrm{~km}$ to the northeast, where the highest concentration of blocks found. during the traverse occurred (Muehlberger and others, 1972). It is unlikely that the $10-\mathrm{m}$ relief on Survey ridge is constructional, made up of ejecta from South Ray, as ridges with amplitudes of 10 to $30 \mathrm{~m}$ are common on the plains. The ridge probably formed by the intersection of two large old subdued crater rims that intercepted a mass of South Ray impact debris traveling on a low trajectory.
The ejecta are distributed asymmetrically around South Ray crater, being practically absent southwest of the crater. Boulders appear concentrated mainly in three directions (fig. 1) that correspond roughly to the three principal trends of high-albedo material. One of these blocky rays trends directly toward stations 8 and 9 . Several linear grooves on the surface are radial to South Ray crater. At the ends or along the margins of many of the grooves are large boulders. The continuous ejecta thins rapidly outward from the crater, as several dark-haloed craters have excavated dark material from beneath the light South Ray ejecta.

\section{BABY RAY CRATER}

Baby Ray crater (figs. 3, 5) is a fresh blocky crater, $130 \mathrm{~m}$ in diameter, about $1.8 \mathrm{~km}$ northeast of South Ray crater on the rim of an old, subdued $1.1-\mathrm{km}$ crater. Debris ejected from Baby Ray overlies South Ray ejecta. High albedo of the underlying South Ray material makes it difficult to trace the rays much farther than the limit of the continuous ejecta. Scattered blocks are visible in the orbital photographs and abundant in the telephotographs. In general, the blocks on Baby Ray are smaller and more numerous than on South Ray.

The interior of Baby Ray crater is unusual in the following respects. About one-third of the way down the western crater wall is a faint discontinuous concentric terrace (fig. 5). In the eastern wall are two distinct terraces, one in the upper wall, discontinuous across the crater, another that extends almost across the entire width of the crater. These may be slump features rather than terraces reflecting different lithologies. A small dark-haloed crater nested in the center of Baby Ray is similar to other nested craters of the same size range within the landing area. Some subsurface stratum, perhaps more consolidated than the overlying material, may have influenced this morphology (Quaide and Oberbeck, 1968).

\section{GEOLOGY OF THE STATION AREAS}

\section{GENERAL DESCRIPTION}

Of all Apollo 16 traverse stations, station 8, on the north edge of a high-albedo ray, had the highest probability of location in predominantly South Ray material. Station 8 was planned as a prime sampling station of ejecta from South Ray crater, $3.3 \mathrm{~km}$ (about 5 crater diameters) to the southwest. Station 9 , between two visible rays near the rim of a $110-\mathrm{m}$ subdued crater about $400 \mathrm{~m}$ northeast of station 8 , was planned for collection of surface samples in Cayley plains in an area free of South Ray debris. Although stations 4, 5, and 6 were designed for collection of Descartes mate- 


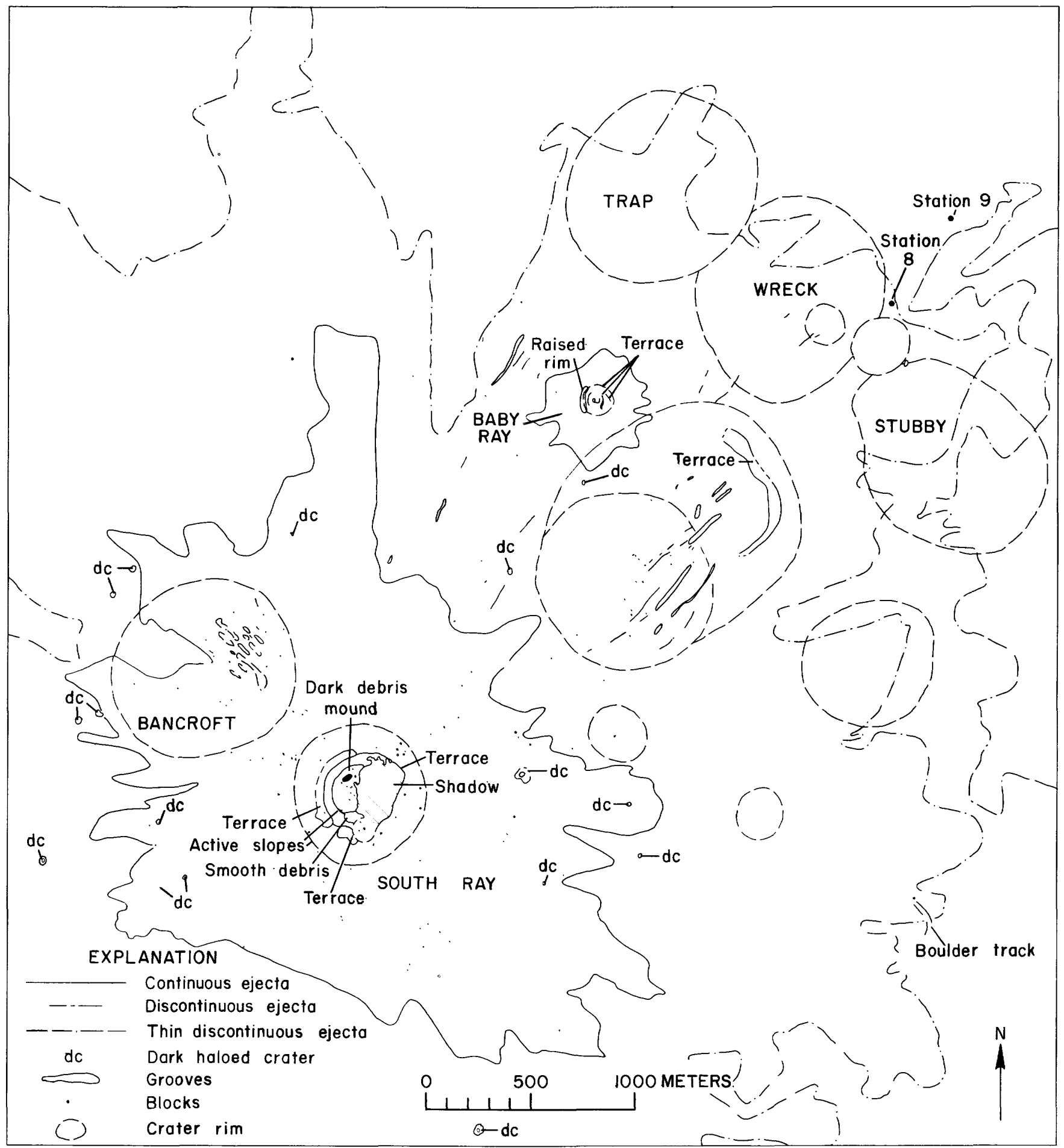

A

FIgURE 1.-South Ray crater and surrounding area. A, Geologic map. B, Apollo 16 panoramic camera frame 4623 on which the geologic map was compiled. $C$, Topographic map of the southern part of the Apollo 16 landing site. Prepared by G. M. Nakata from Apollo 16 panoramic camera frames 4618 and 4623 . 


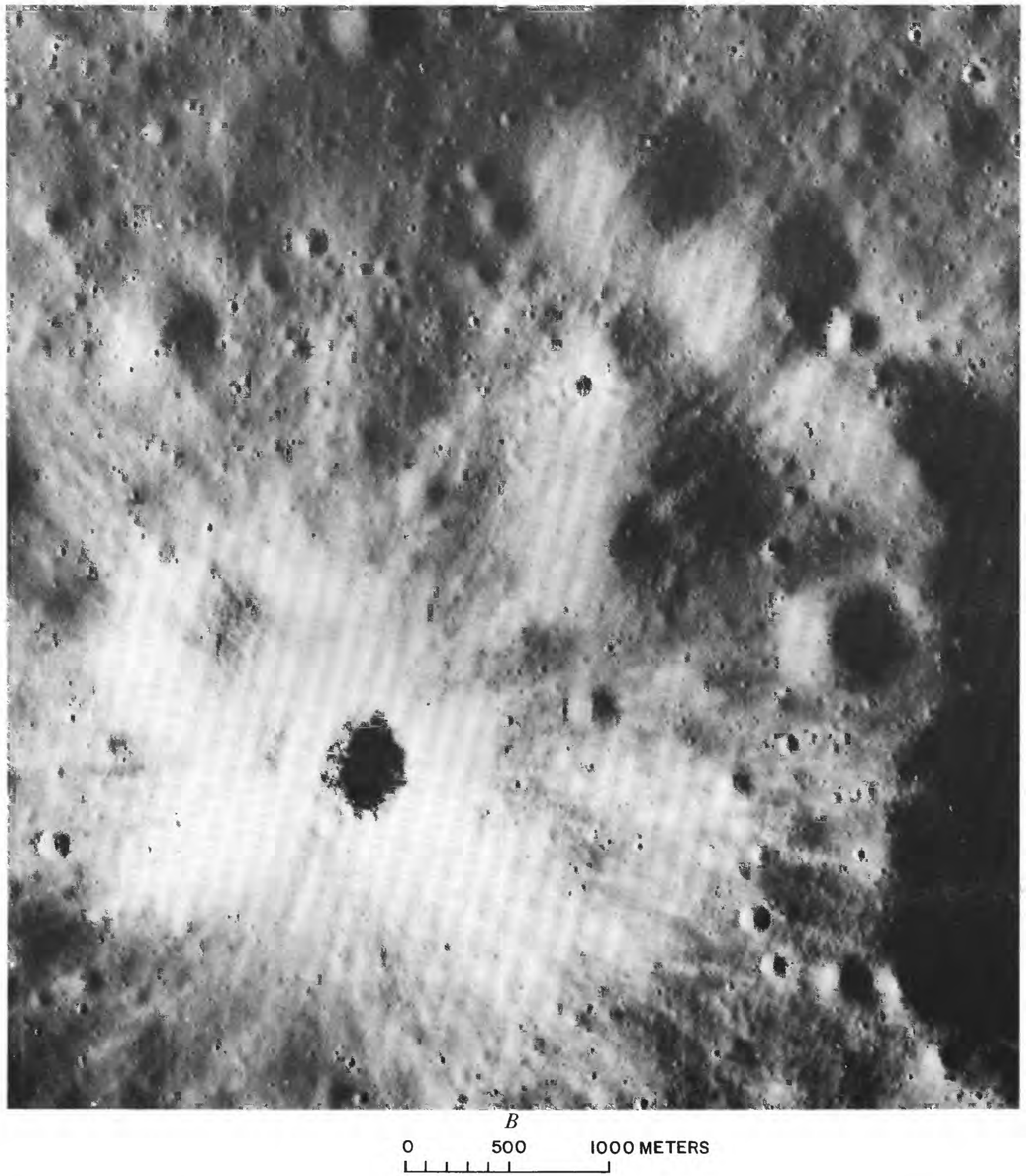

Figure 1.-Continued. 


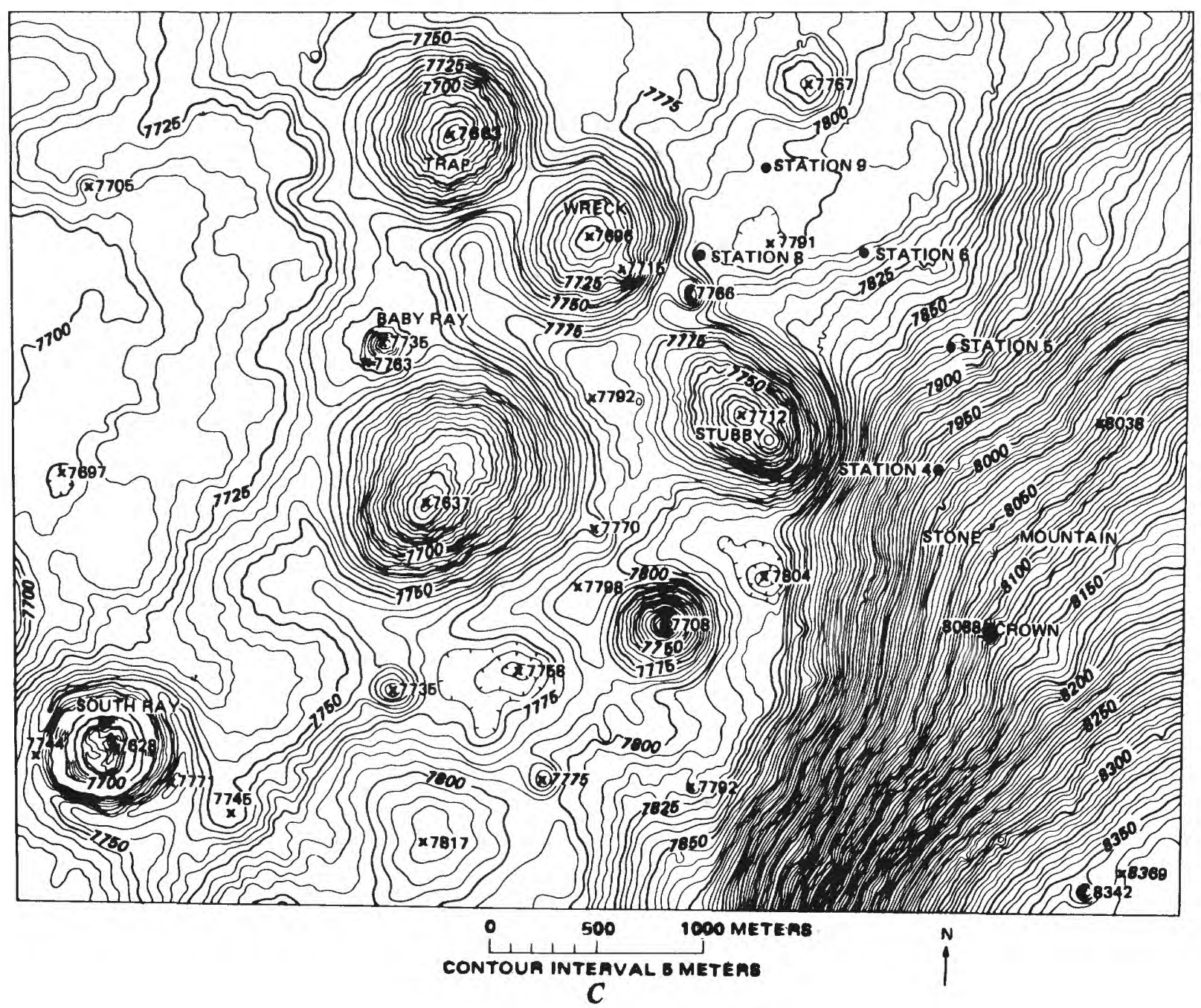

Figure 1.-Continued.

rials on Stone mountain, there is evidence (Sanchez, this volume; Muehlberger and others, 1972) of contamination by South Ray debris.

At station 8 , fragments larger than $2 \mathrm{~cm}$ occupy about 3 percent of the surface, between stations 8 and 9, as much as 6 percent (Muehlberger and others, 1972). In the area of station 9 , the fragment population drops to 2 percent, and in the LM/ALSEP area, fragments range from less than 1 percent to as much as 3 percent of the surface, the percentage of larger rock fragments (greater than $15 \mathrm{~cm}$ ) decreasing northward.

The stratigraphy at stations 8 and 9 was complex prior to the deposition of South Ray ejecta. As station 8 is within the ejecta blankets or continuous rim deposits of four craters having a diameter of about $1 \mathrm{~km}$, the regolith in the vicinity of these stations is probably made up of a series of several overlapping ejecta blankets. Superposed on this surface is debris excavated from South Ray crater that apparently consists mainly of blocks with very minor distinguishable fines. Evidence against South Ray's being the source of fine material in the soils collected around these stations is the considerably older exposure age of the soils relative to the age of rocks more convincingly representative of South Ray crater (McKay and Heiken, 1973; Schaeffer and Husain, 1973; Adams and McCord, 1973; D. A. Morrison and others, 1973; Behrmann and others, 1973; Huneke and others 1973b; Kirsten and others, 1973; Drozd and others, 1974).

Counts of light and dark fragments in the down-sun photographs in the panoramas, where the reflectance most nearly approaches the albedo of the surface, indicate that at least 75 percent are dark breccias. This estimate is probably somewhat low, as it is difficult to distinguish a dark-colored rock having a flat surface directed toward the sun from a light-colored rock. 


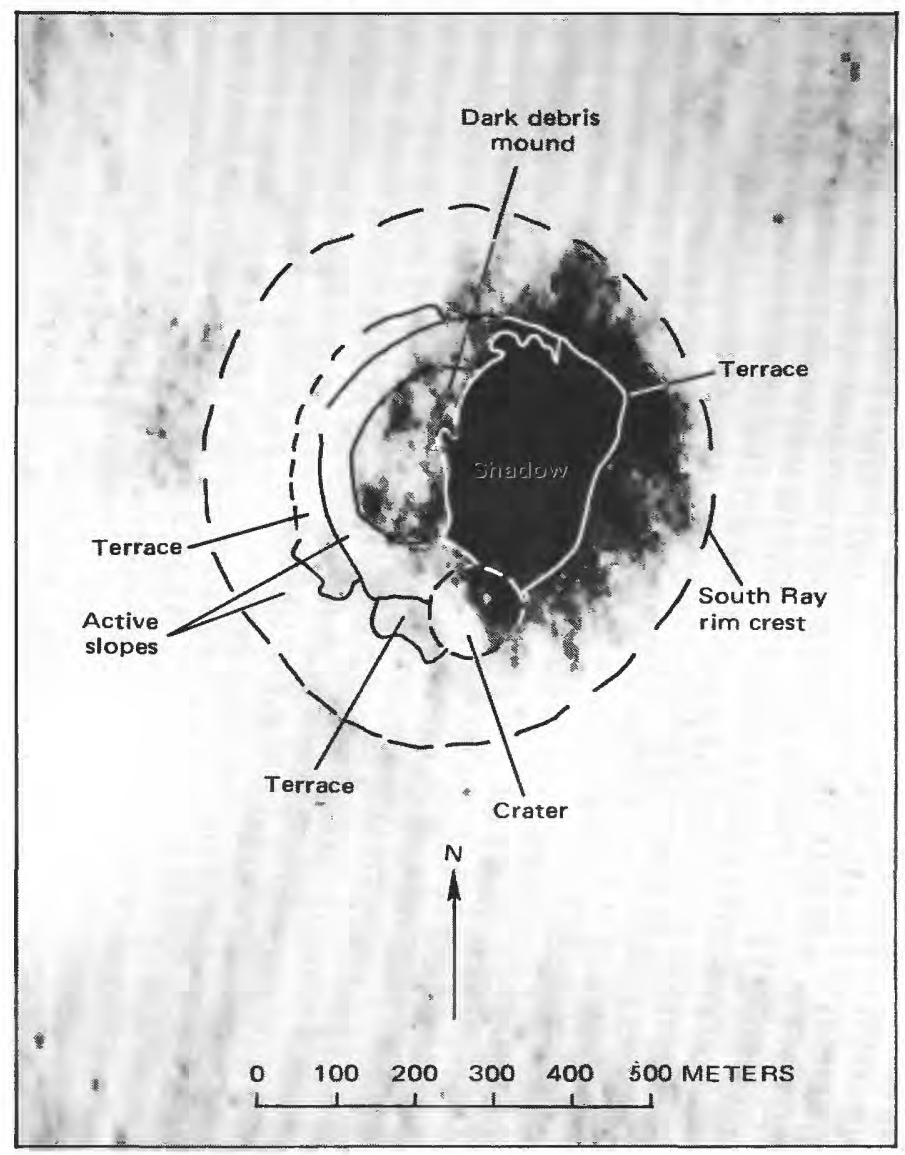

Figure 2.-Prominent features of South Ray crater. Photograph enlarged from Apollo 16 panoramic camera frame 4623 (fig. 1B).

SAMPLING

Three 0.5 - to $1.5-\mathrm{m}$ boulders were sampled at station 8 , one 0.5 -m boulder at station 9 (figs. 6 and 7). Several soil samples and small fragments were collected from the surface. These samples are shown by rock type in table 1 . The larger samples are pictured in figure 8 and photomicrographs of parts of the samples in figure 9 .

\section{STATION 8}

\section{DESCRIPTION}

Station 8 is located on an undulating surface near two subdued 15- to 20-m craters. Regionally the surface slopes gently up to the northeast. Several scattered rock fragments, most of which are in the size range of $5-20 \mathrm{~cm}$, are visible on the surface. The largest block in the area, one from which sample 68815 was collected, is about $1.5 \mathrm{~m}$ across.

A small $(15-20 \mathrm{~m})$ subdued crater provides direct evidence for the presence of South Ray ejecta in the station 8 area (fig. 10). Boulder 1 , from which sample 68115 was collected (fig. 11), is perched on its rim. On the northeast wall, small fragments are abundant and small, fresh craters numerous. The opposite wall is nearly devoid of rocks and fresh craters. The downrange side of this old crater (the side facing South Ray crater) appears to have collected South Ray debris, whereas the uprange side was ballistically shadowed.

\section{SAMPLING}

Boulder 1. Boulder 1, approximately $1.5 \mathrm{~m}$ across, perched on the northeast rim of its own secondary crater, is rounded in appearance and friable (fig. 11). A large fragment chipped from the boulder (sample 68115) is a dark-matrix dark-clast breccia $\left(B_{5}\right)$ that separated from the boulder along fracture planes intruded by glass. The boulder itself has a predominantly dark matrix with an abundance of light clasts $\left(\mathrm{B}_{4}\right.$ ?, fig. 12). Sample 68115 may represent only the matrix.

The presence of a few small vesicles (fig. 12) suggests that the boulder was at one time partly molten. One area where some of the light clasts have been smeared out appears to have been heated sufficiently to allow mobilization of the matrix. The many fractures in the rock probably account for its friable nature. Dark glass was injected along some of these fractures.

Boulder 2. Boulder 2, a light-gray rock about onehalf $\mathrm{m}$ across, was reported by Astronaut Duke to be representative of several he could see on the surrounding surface. Two samples were collected, 68415 from the side and 68416 from the top (fig. 13). The boulder appears homogeneous in photographs of its surface, but minor differences in phenocryst content are seen in the

TABLE 1.-Samples collected at stations 8 and 9

\begin{tabular}{|c|c|c|c|}
\hline \multicolumn{4}{|c|}{ A. Boulder samples } \\
\hline & & Rock type $^{1}$ & Location \\
\hline $\begin{array}{l}68035 \\
68115 \\
68415 \\
68416 \\
68815 \\
69935 \\
69955\end{array}$ & 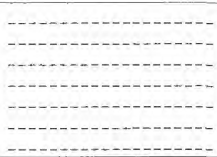 & $\begin{array}{l}\mathrm{B}_{2} \\
\mathrm{~B}_{5} \\
\mathrm{C}_{1} \\
\mathrm{C}_{1} \\
\mathrm{~B}_{5} \\
\mathrm{~B}_{4} \\
\mathrm{C}_{1}\end{array}$ & $\begin{array}{l}\text { Small fragment near raked area. } \\
\text { Boulder 1, station } 8 \text {. } \\
\text { Boulder } 2 \text {, station } 8 \text {. } \\
\text { Boulder } 2 \text { station } 8 \text {. } \\
\text { Boulder } 3 \text {, station } 8 \text {. } \\
\text { From top of boulder, station } 9 \text {. } \\
\text { From bottom of boulder, station } 9\end{array}$ \\
\hline
\end{tabular}

B. Other samples

\begin{tabular}{|c|c|}
\hline Description & Location \\
\hline $\begin{array}{l}68002 / 68001 \\
68120 \\
68500 \\
68505 \\
68510 \\
68820 \\
68840 \\
69001 \\
69903,69904 \quad \text { Rouble drive tube } \\
69920 \\
69940 \\
69945 \\
69960\end{array}$ & $\begin{array}{l}10 \mathrm{~m} \text { west of } 15 \text {-m crater. } \\
\text { Near boulder } 1 \text {, station } 8 \text {. } \\
\text { From within rake area. } \\
\text { Collected with the soil } 68500 \text {. } \\
\text { From } 1 \mathrm{~m}^{2} \text { area near } 15-\mathrm{m} \text { crater. } \\
\text { At base of boulder } 3 \text {, station } 8 \text {. } \\
5 \mathrm{~m} \text { from boulder } 3 \text {, station } 8 \text {. } \\
10 \mathrm{~m} \text { NW. of station } 9 \text {. } \\
\text { Near station } 9 \text { boulder. } \\
\text { Beside station } 9 \text { boulder. } \\
\text { Do. } \\
\text { Collected witn soil } 69940 \text {. } \\
\text { Beneath station } 9 \text { boulder. }\end{array}$ \\
\hline
\end{tabular}

' Rock types from Wilshire and others (1973, and this volume):

$\mathrm{C}_{1}$-Crystalline igneous

$\mathrm{C}_{2}$-Metaclastic

$\mathrm{B}_{2}$-Light-matrix, dark-clast brecia

$\mathrm{B}_{4}$-Dark-matrix, light-clast breccia

${ }_{2}$ Twelve rake sample framents were collected from a 1-m-square area on the north rim of a 15-m subdued crater. Of the 12, 6 were igneous and metamorphic rocks, 6 partially melted breccias (LSPET, 1972). Of the rake fragments examined by Wilshire and others (this volume), 3 are $B_{2}$ breccias $(68515,68517$, and 68519$), 3 C_{2}$ metaclastic rocks $(68526,68527$, and 68535). 


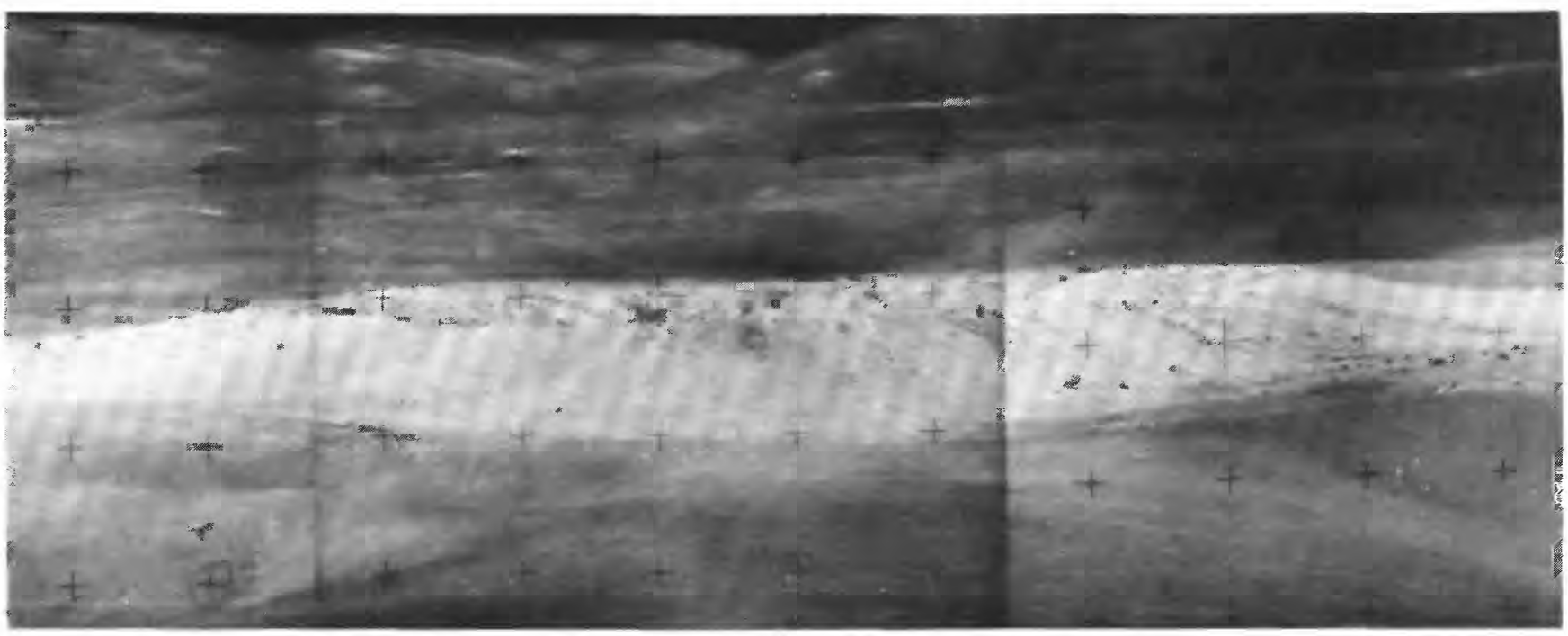

$A$

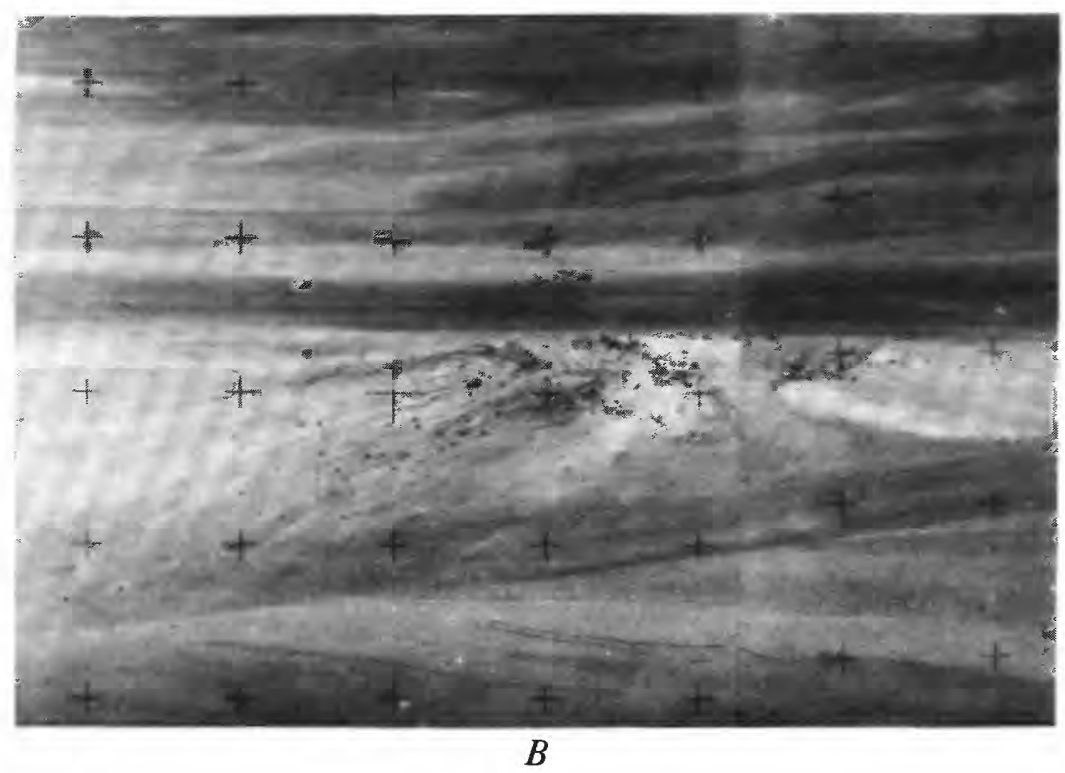

FigURE 3.-Telephotographs of South Ray crater (top) and Baby Ray crater (bottom) taken from station 4 on Stone mountain (AS16112-18246, 18247, and 18256, South Ray, and AS16-112-18253 and 18254, Baby Ray). South Ray is about $680 \mathrm{~m}$ in diameter. 


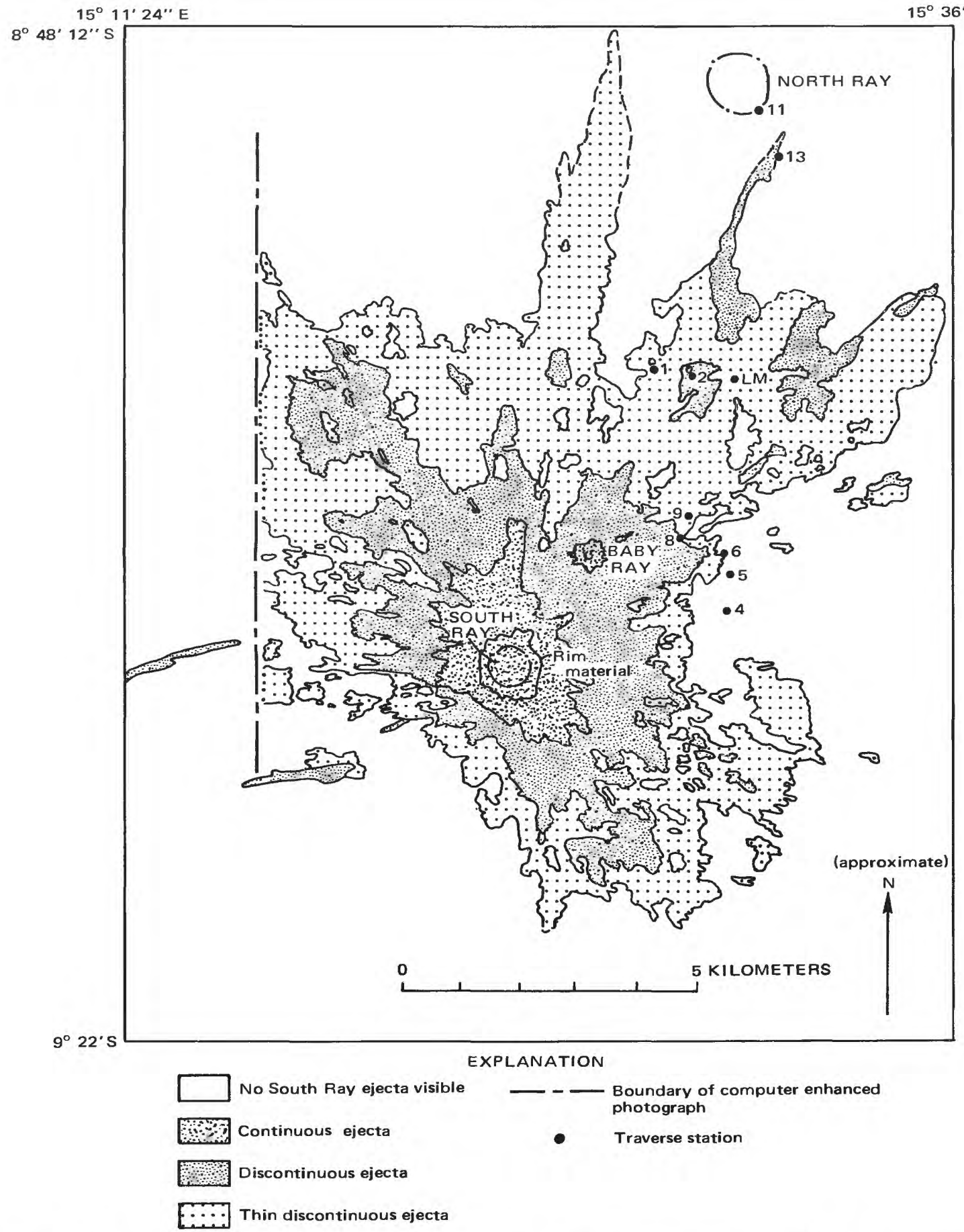

FIGURE 4.--Map of debris ejected from South Ray crater. Compiled on computer-enhanced Apollo 16 panoramic camera frame 5328 . 


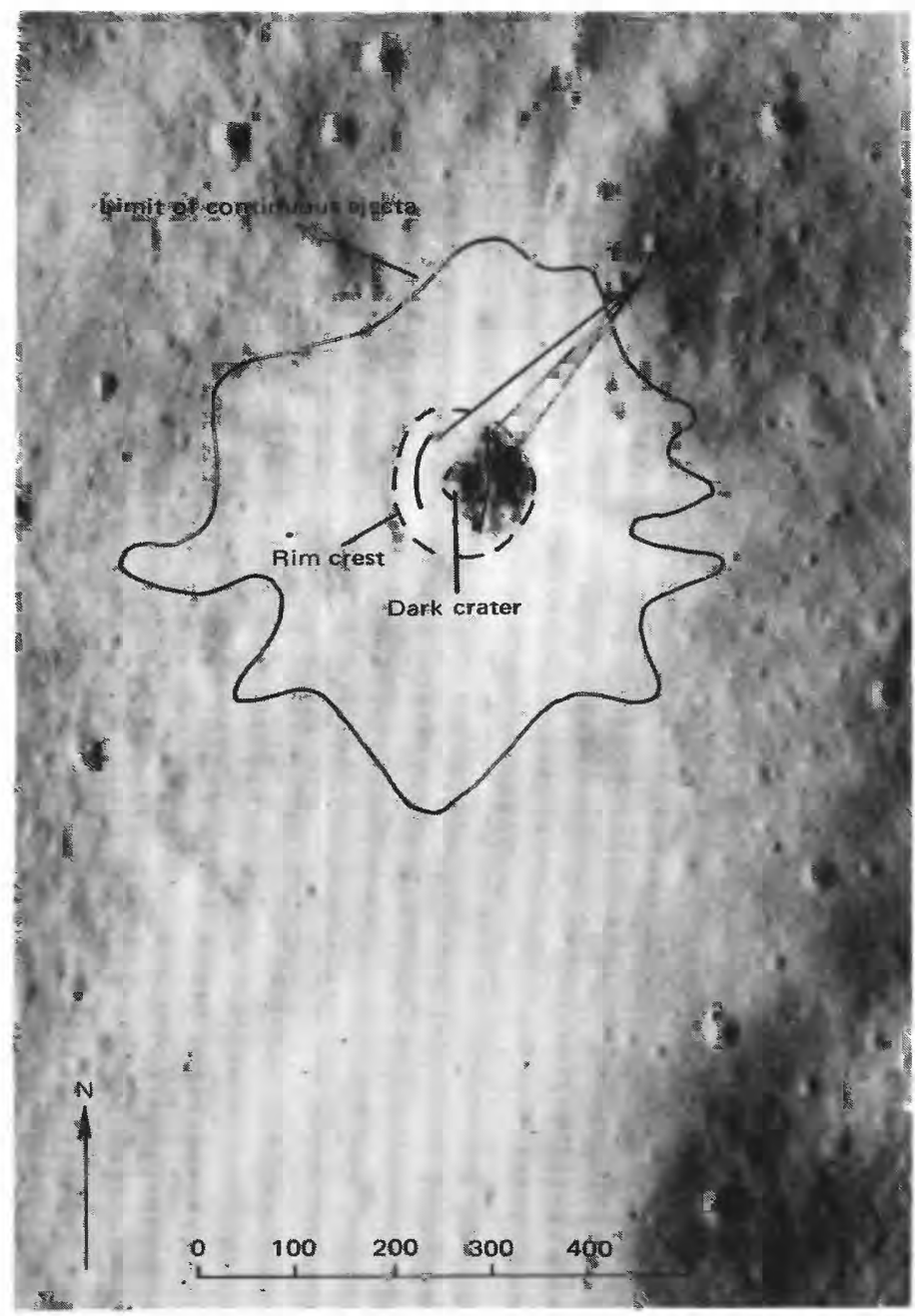

Figure 5.-Features of Baby Ray crater. Photograph enlarged from Apollo 16 panoramic camera frame 4623 (fig. $1 B$ ).

samples. Both samples are fine-grained, highly feldspathic rock (Wilshire and others, 1973). Sample 68415 , an igneous-textured rock, is composed of 79.3 percent plagioclase, 4.8 percent olivine, 4.4 percent augite, and 10.3 percent pigeonite (Helz and Appleman, 1973). Plagioclase $A n_{98-56}$ makes up 75 volume percent (Hodges and Kushiro, 1973). Both samples are texturally homogeneous but have a few shocked plagioclase inclusions in a fine-grained matrix (fig. $9 B$ ). It has been suggested that these rocks were produced not by partial melting of the deep lunar interior but rather by shock melting of an anorthositic rock (Wilshire and others, 1973; Helz and Appleman, 1973; Hodges and Kushiro, 1973; Walker, Longhi, Grove, and others, 1973; L. A. Taylor and others, 1973; and Warner and others, 1974) and rapid crystallization (Hodges and Kushiro, 1973; Nord and others, 1973) and that the

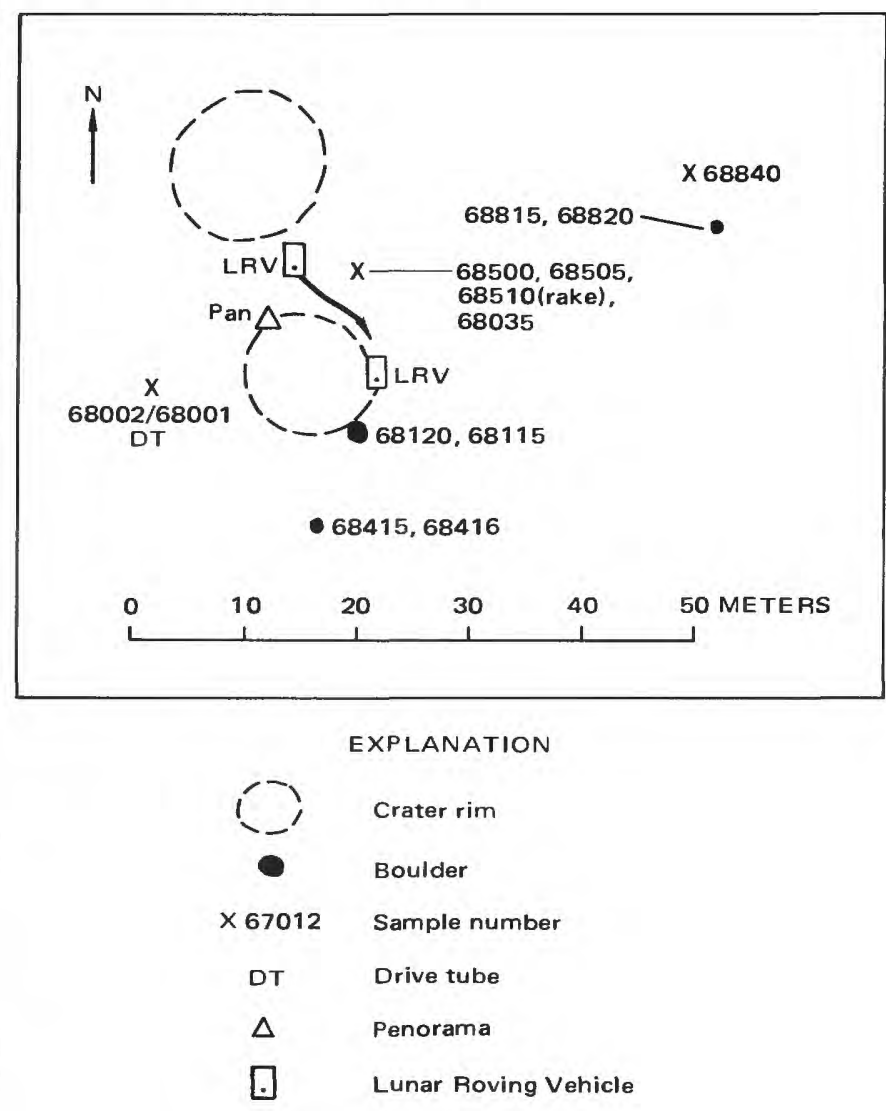

FigURE 6.-Planimetric map of station 8 showing locations of samples.

inclusions represent unmelted anorthosite (Helz and Appleman, 1973, Wilshire and others, 1973).

Boulder 3. The third boulder sampled (fig. 14) at station 8 , a $1.5-\mathrm{m}$ dark boulder about 40 m northeast of boulders 1 and 2, is very coherent and angular and has only a few small fractures. Scattered large vesicles are visible. A "fillet" soil sample collected on the north side of the rock appears to be old regolith pushed up when the boulder landed rather than a fillet formed by rock degradation.

Sample 68815, termed a "fluidized lithic breccia," (Brown and others, 1973) contains a variety of basaltic and anorthositic clasts. Swirls of basaltic and feldspathic glasses or pockets of glass are common. Most of the material that has flowed is of plagioclase composition, whereas the basalt clasts have sharp unmelted boundaries (Brown and others 1973). Large, wormlike tubular vesicles are present (LSPET, 1972). Sample 68815 , similar to 68115 , is a dark-matrix dark-clast $\left(\mathrm{B}_{5}\right)$ breccia. The dark clasts in both differ only slightly from the matrix, and gas cavities are well developed in the matrices (Wilshire and others, 1973).

The bulk chemical compositions of rocks from station 

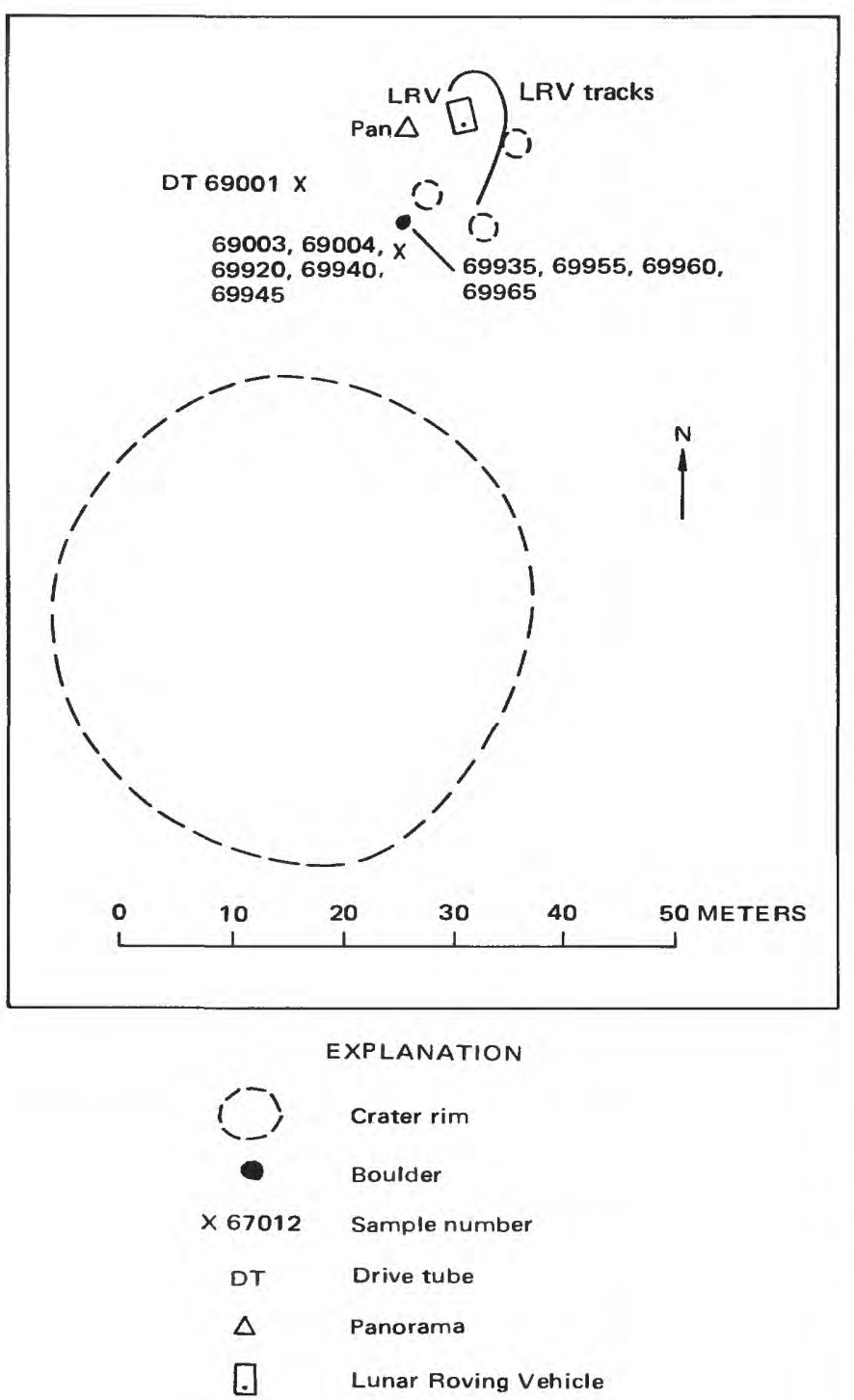

FIGURE 7.-Planimetric map of station 9 showing locations of samples. Symbols same as in figure 6 .

8 boulders, shown in table 3 , reveal a close similarity in their chemistry that reflects a common source mate-

TABLE 2.-Chemical compositions of samples 68415,68115 , and 68815 , station 8

\begin{tabular}{|c|c|c|c|}
\hline $\begin{array}{l}\text { Rock type } \\
\text { Sample No. }-1 .-1 \\
\text { Source }\end{array}$ & $\begin{array}{c}\mathrm{C}_{1} \\
68415,79 \\
\text { Boulder } 2 \\
\text { (Nava, 1974) }\end{array}$ & $\begin{array}{c}\mathrm{B}_{5} \\
68115 \\
\text { Boulder } 1 \\
\text { (S. R. Taylor and others, 1974) }\end{array}$ & $\begin{array}{c}\mathrm{B}_{5} \\
68815,120 \\
\text { Boulder 3 } \\
\text { (Scoon, 1974) }\end{array}$ \\
\hline $\begin{array}{l}\mathrm{SiO}_{2} \\
\mathrm{Al}_{2} \mathrm{O}_{3} \\
\mathrm{FeO} \\
\mathrm{MgO} \\
\mathrm{CaO} \\
\mathrm{Na}_{2} \mathrm{O} \\
\mathrm{K}_{2} \mathrm{O} \\
\mathrm{H}_{2} \mathrm{O} \\
\mathrm{TiO}_{2} \\
\mathrm{P}_{2} \mathrm{O}_{5} \\
\mathrm{MnO} \\
\mathrm{Cr} \mathrm{O}_{2} \\
\mathrm{~S}\end{array}$ & $\begin{array}{c}45.9 \\
28.19 \\
4.01 \\
4.41 \\
16.39 \\
.47 \\
.060 \\
-.28 \\
.072 \\
.048 \\
.07\end{array}$ & $\begin{array}{c}44.8 \\
27.6 \\
5.10 \\
5.79 \\
15.4 \\
.47 \\
.06 \\
--.- \\
.34 \\
---- \\
--- \\
---\end{array}$ & $\begin{array}{r}45.33 \\
27.59 \\
5.17 \\
5.38 \\
15.56 \\
.48 \\
.17 \\
.05 \\
.48 \\
.21 \\
.05 \\
.08 \\
.06\end{array}$ \\
\hline Total & 99.90 & 99.56 & 100.61 \\
\hline
\end{tabular}

rial despite the varied histories recorded in their textures.

\section{STATION 9 \\ DESCRIPTION}

Station 9, about $400 \mathrm{~m}$ northeast of station 8 , is in an area of lower albedo. The surface is considerably smoother than at station 8 , where there are many small, sharp-rimmed fresh craters. The small craters at station 9 are rimless and subdued. The fragment population varies in both size and abundance; fragments are fewer and mean size is smaller than at station 8 .

\section{SAMPLING}

At station 9, the sampling was confined to the immediate vicinity of one boulder, about one-half $\mathrm{m}$ across, perched on the north rim of a small crater that may be a secondary crater formed by the boulder. Two rock chips were taken from the boulder, 69935 from the top and 69955 from the bottom. The photographs show that the rock consists predominantly of dark material but has a large component of light material (fig. 15), visible as discrete clasts as well as "streamed" through the boulder (fig. 16). Sample 69935 came from a predominantly dark part of the boulder. The boulder appears coherent, mostly angular, and is fractured throughout. Although most of the bottom was soilcaked, some of the rock is visible. One part of the bottom face is covered with dark glass. No glass was reported by the crew on the top, but apparently some glass has been injected into fractures.

Sample 69935 is a dark-matrix light-clast breccia $\left(\mathrm{B}_{4}\right)$. The sample from the bottom, 69955 (fig. 17), is an igneous $\left(\mathrm{C}_{1}\right)$ clast form within the dark matrix. Most of the other clasts in this boulder appear to be breccias.

Several soil samples designed to collect successively deeper regolith material were taken in the vicinity of the boulder: first, two surface samples $(69003,69004)$ collected the uppermost layer of regolith; then a skim sample $(69920$, penetration $5 \mathrm{~mm}$ ), a scoop sample (69940, penetration $3 \mathrm{~cm}$ ), and a drive-tube sample (69001, penetration $27 \mathrm{~cm}$ ) were taken. For comparison, a soil sample was collected from beneath the boulder.

\section{AGE OF SOUTH RAY GRATER}

The presence of distinct light-colored rays in the vicinity of stations 8 and 9 in orbital and surface photographs suggests a substantial thickness of South Ray-derived material in this region. The exposure ages of rocks and soils collected at stations 8 and 9 , however, have generated some uncertainty (McKay and Heiken, 1973) as to the amount of South Ray debris actually 

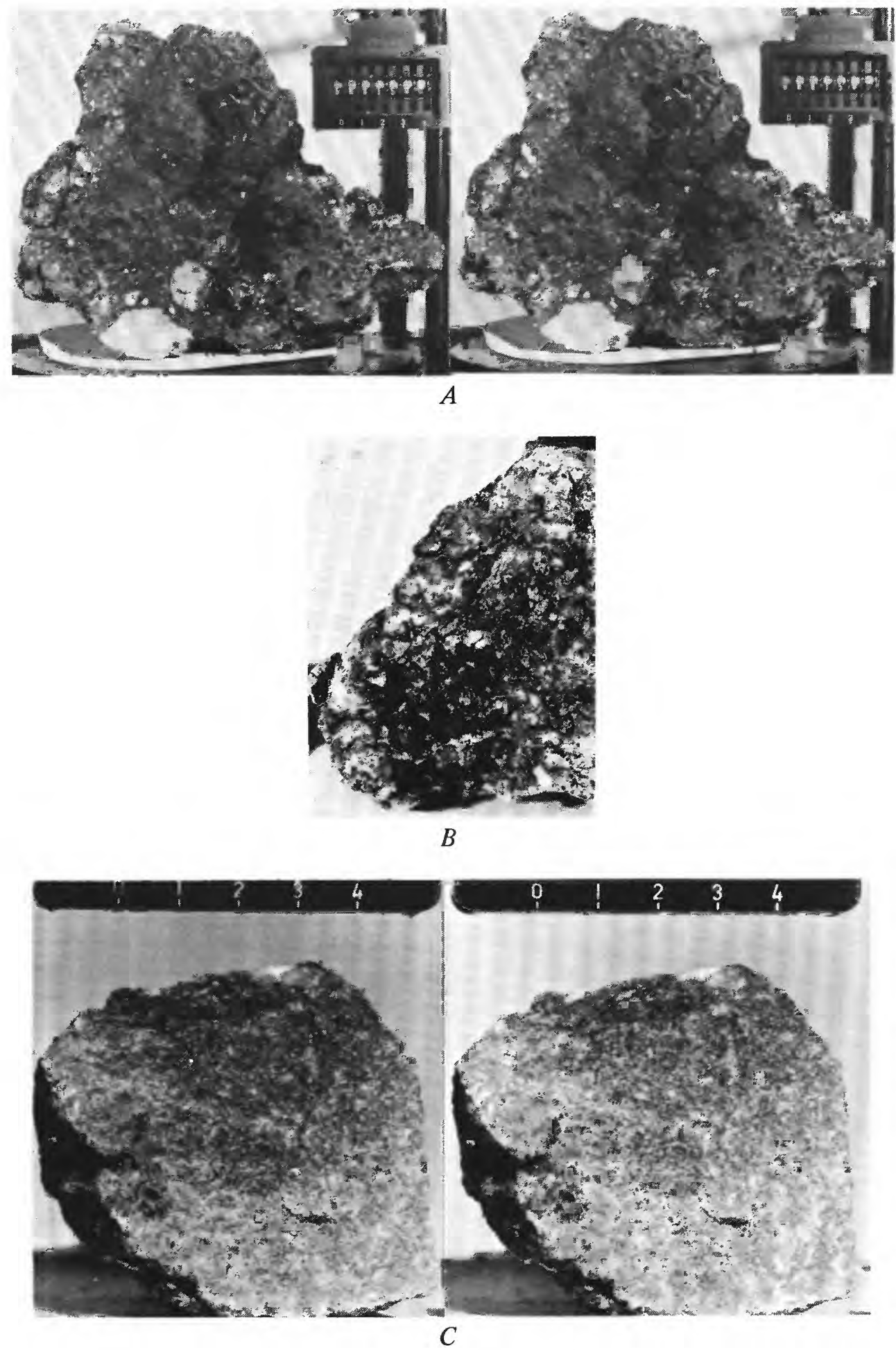

FIGURE 8.-Larger samples collected at stations $8(A-E)$ and $9(F) . A$, Sample 68115 (stereopair), from boulder $1 . B$, Closeup of 68115 showing boulder 3. F, Sample 69955. (stereopair), from 


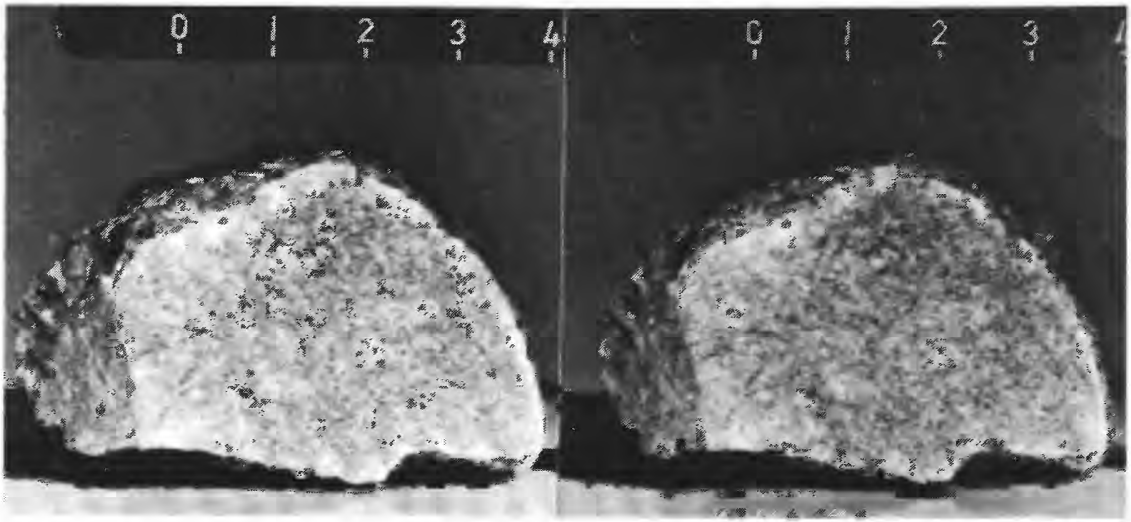

$D$

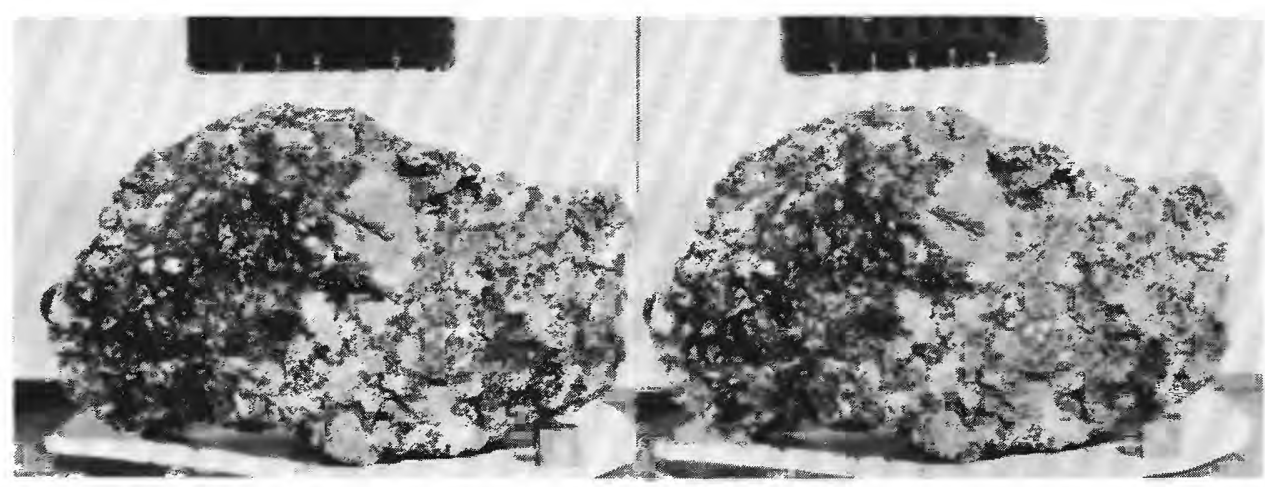

E

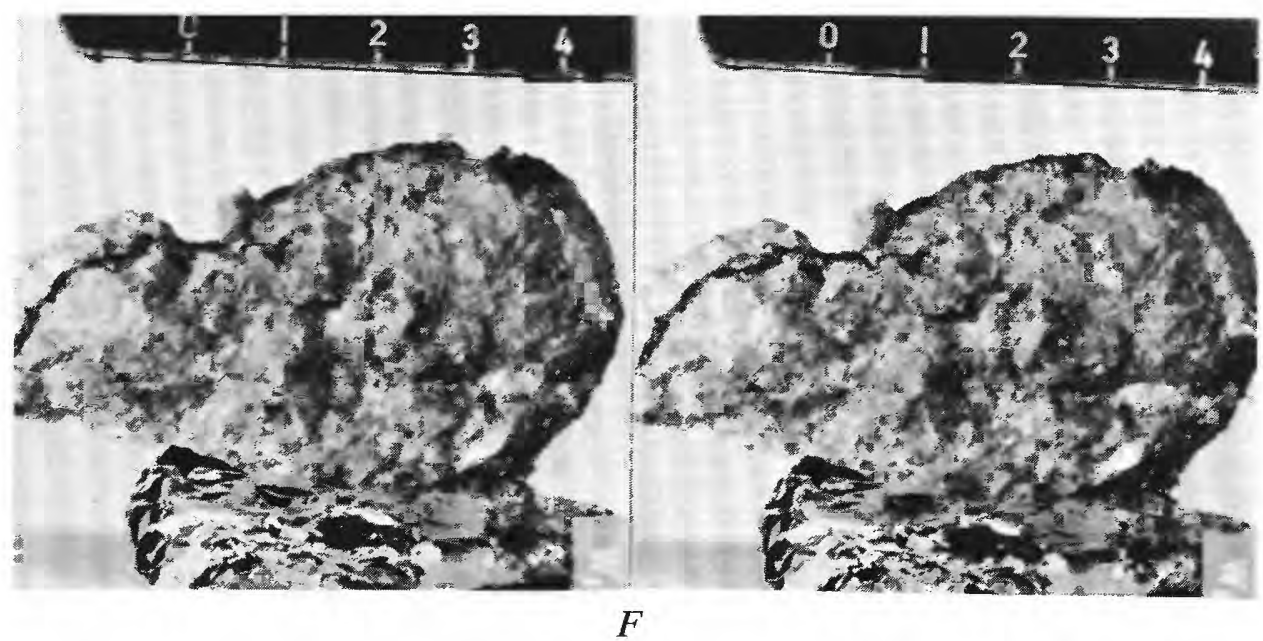

vugs. $C$, Sample 68415 (stereopair), from boulder 2. $D$, Sample 68416 (stereopair), from boulder 2. $E$, Sample 68815 (stereopair), from bottom side of the boulder. Scales in centimeters. 

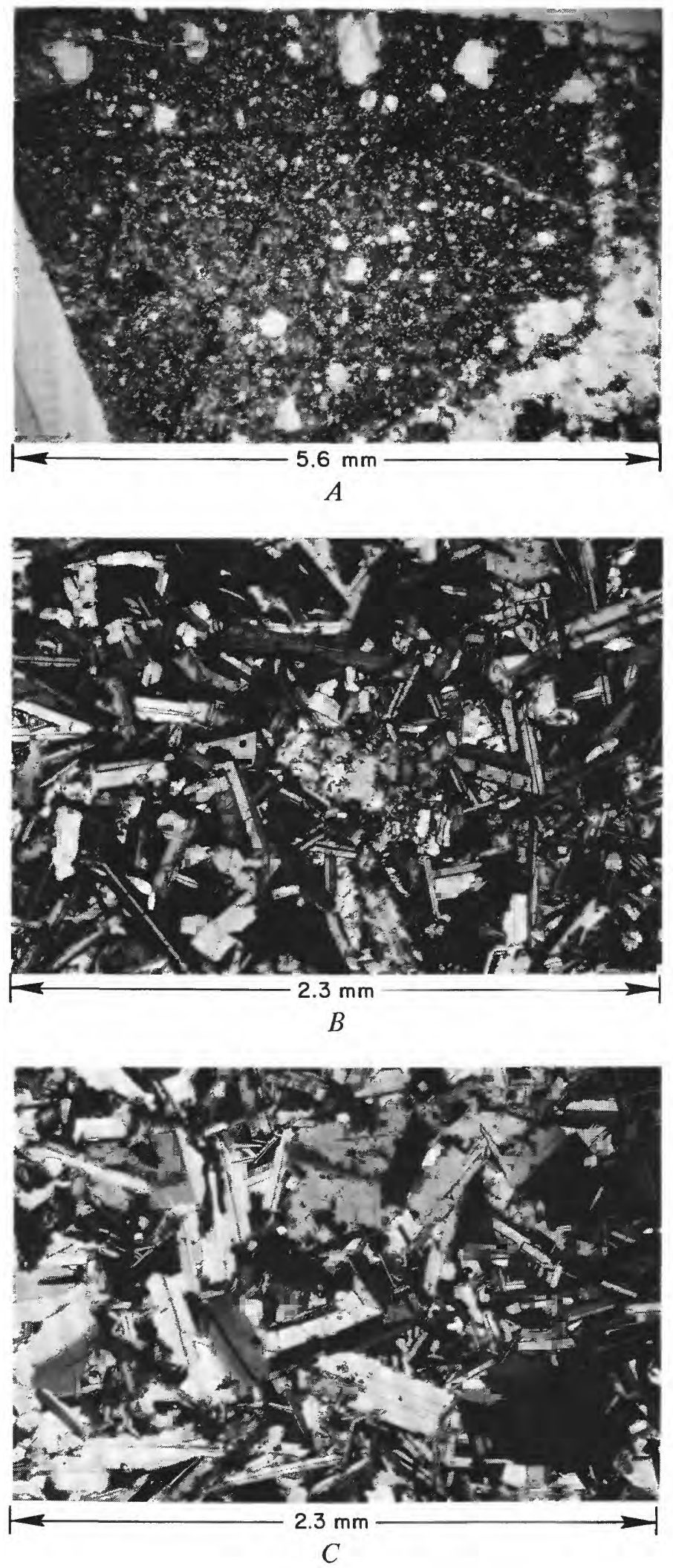

Figure 9.-Photomicrographs of rocks shown in figure 8. A, 68115, 95, plane-polarized light; glass and crushed plagioclase groundmass with relict plagioclast clasts. $B, 68415,142$, cross-polarized light; subophitic plagioclase (twinned laths) and pyroxene with clast of shocked 

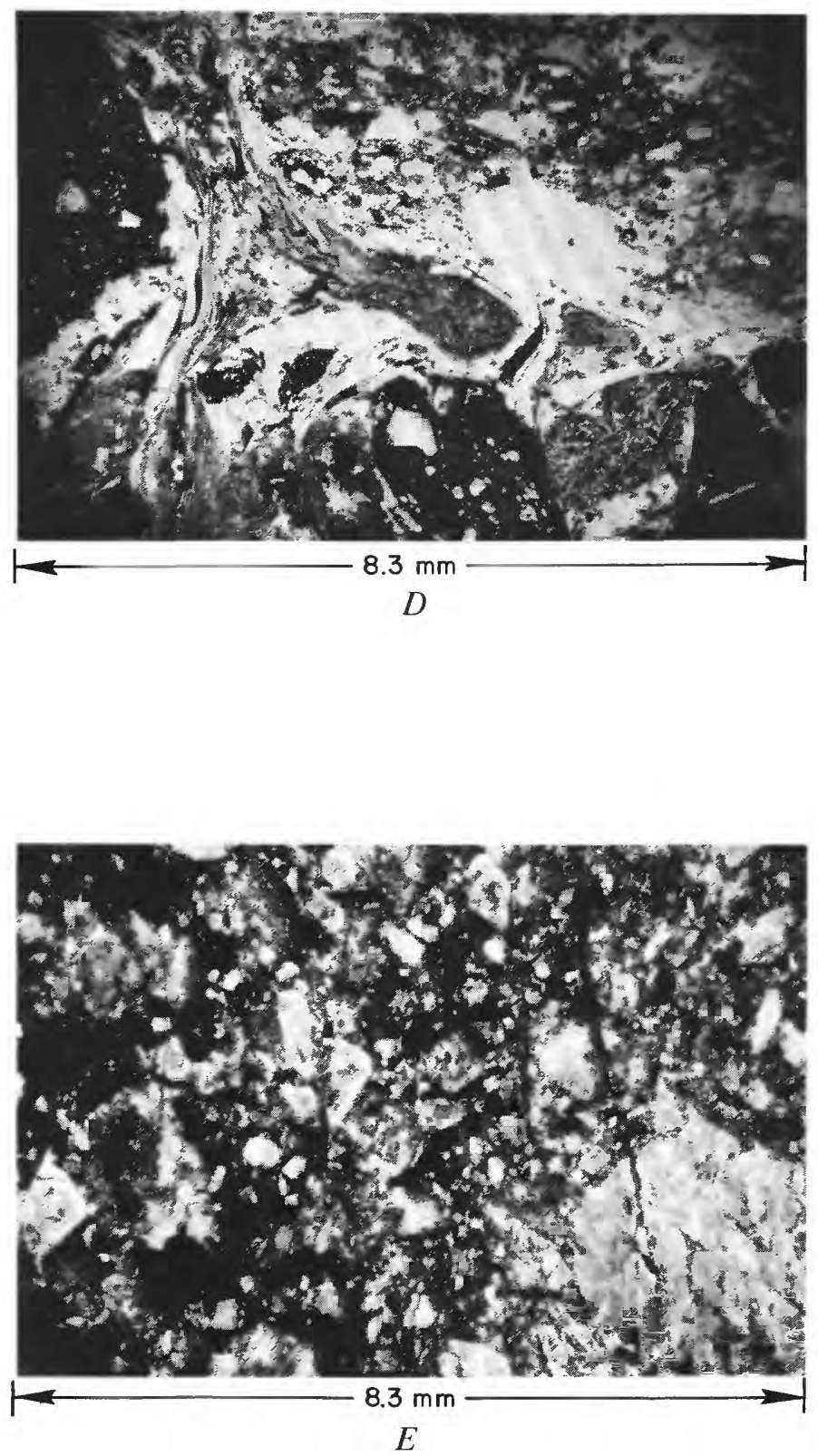

plagioclase in center. $C, 68416,78$, cross-polarized light; seriate twinned plagioclase with pyroxene. $D, 68815,148$, plane-polarized light; brown glass invading polymict breccia indicating several shock events. $E, 69955,30$, cross-polarized light; shocked, partly melted coarsegrained anorthosite. 


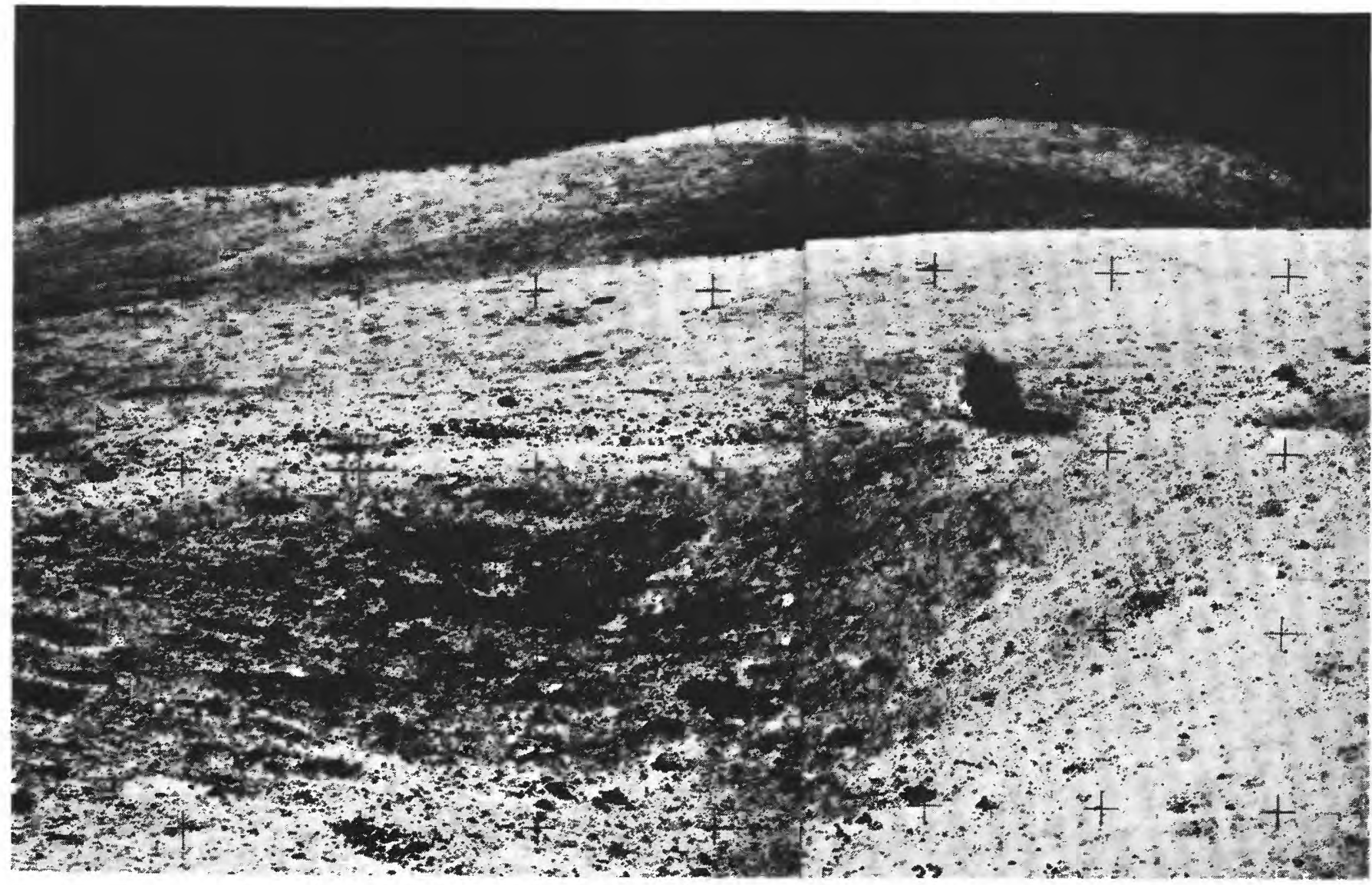

A

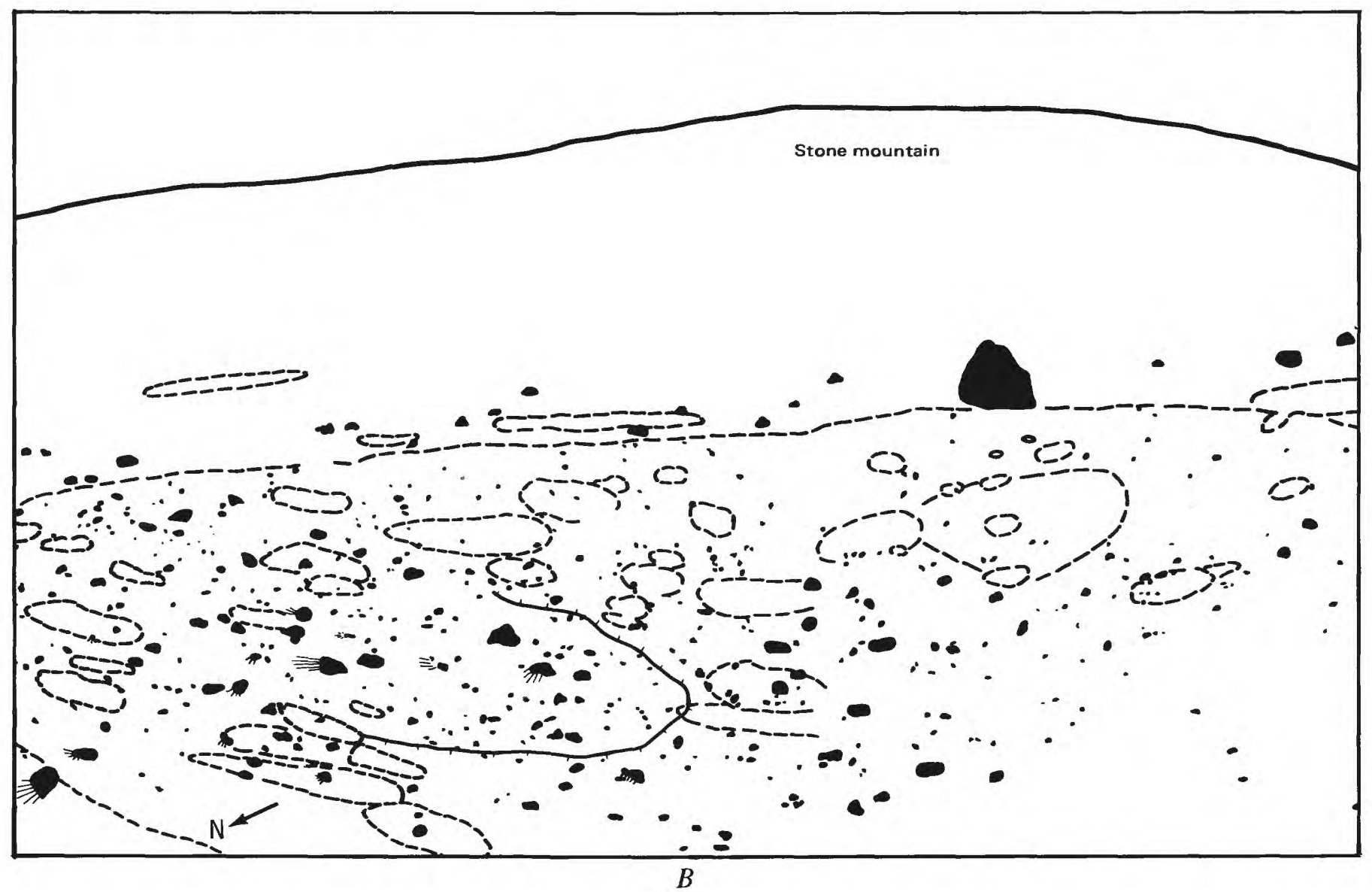



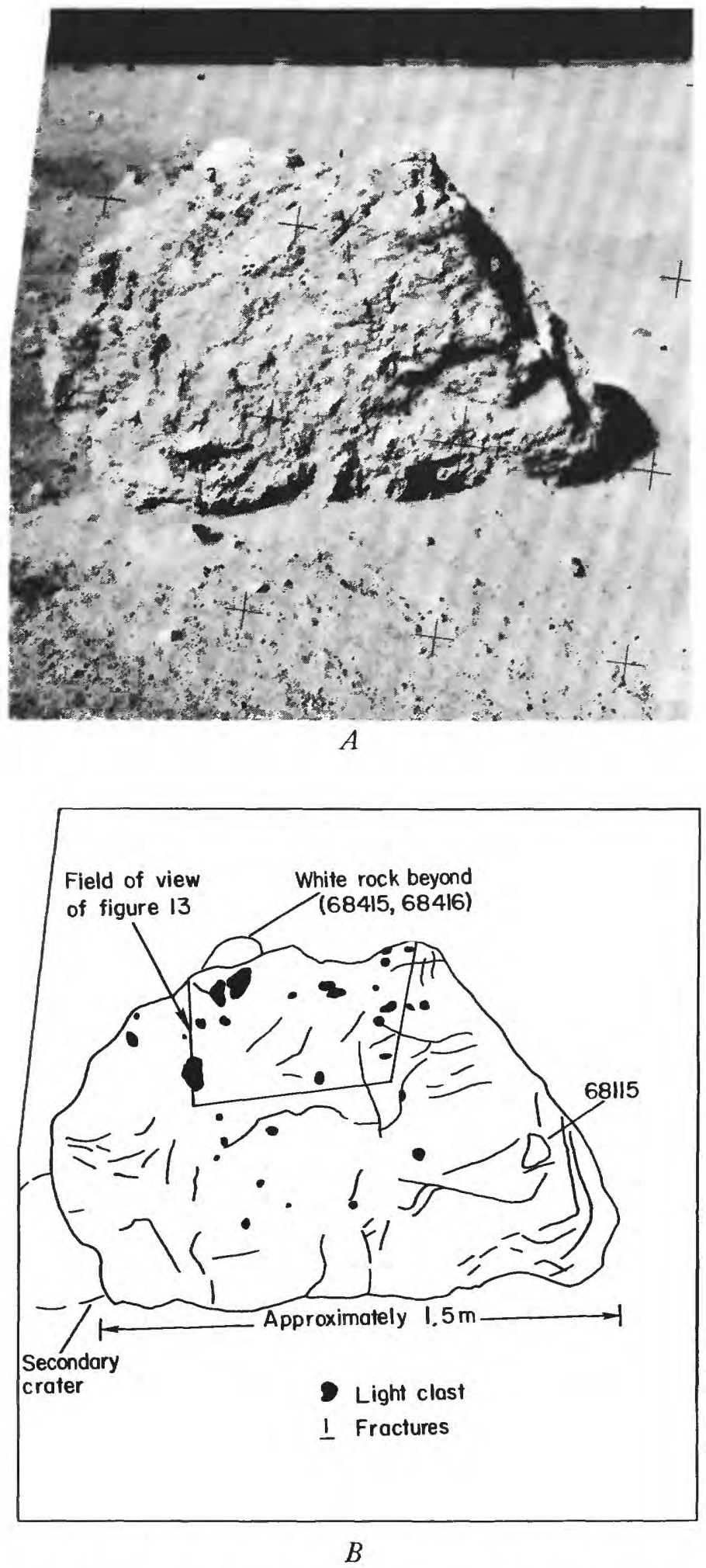

Figure 11.-Boulder 1, station 8. A, Photograph, view is southwest, AS16-108-17689. B, Sketch map. (dashed) drawn from $A$. 


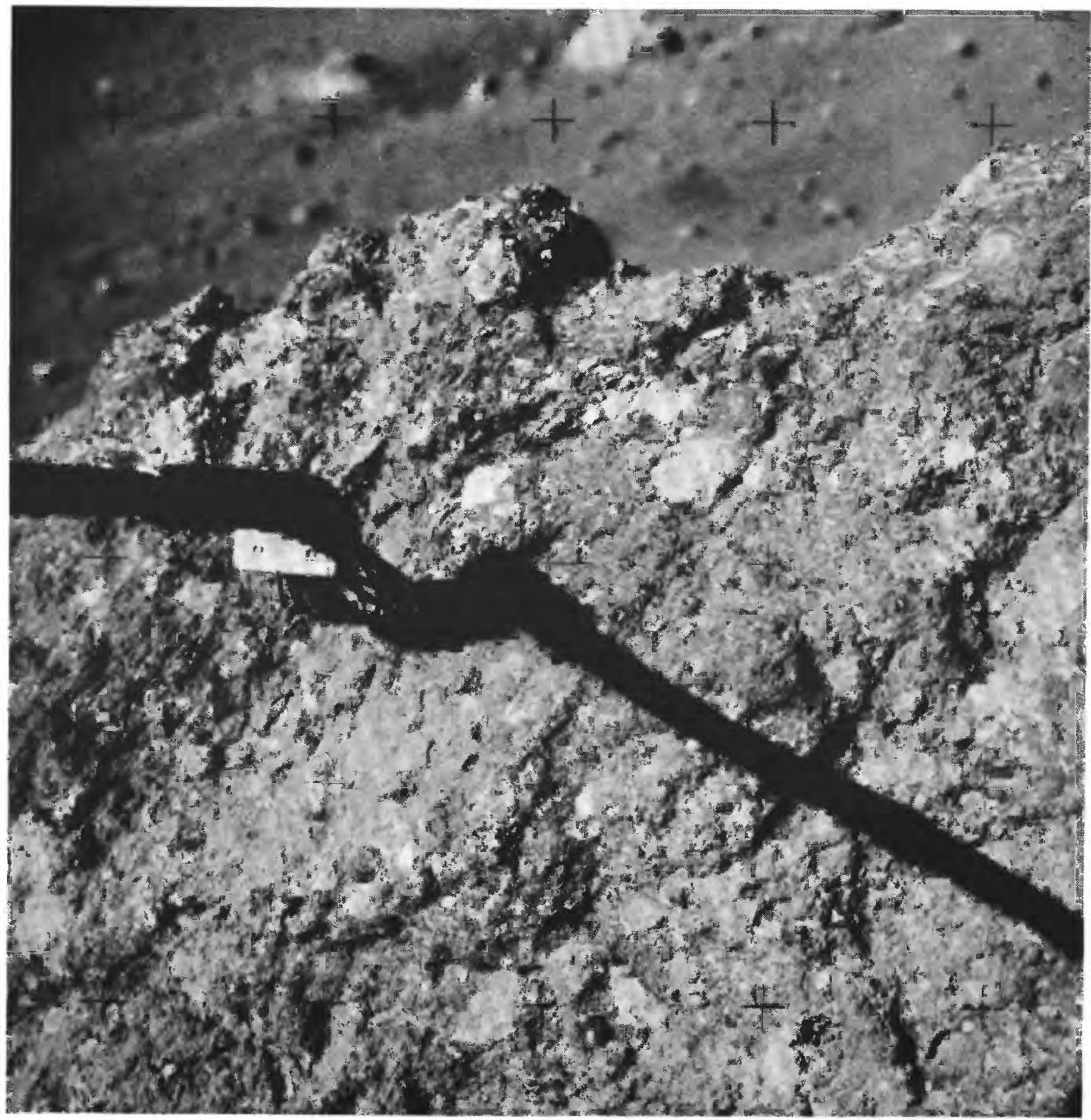

A

Figure 12.-Boulder 1, station 8. A, Closeup view, 


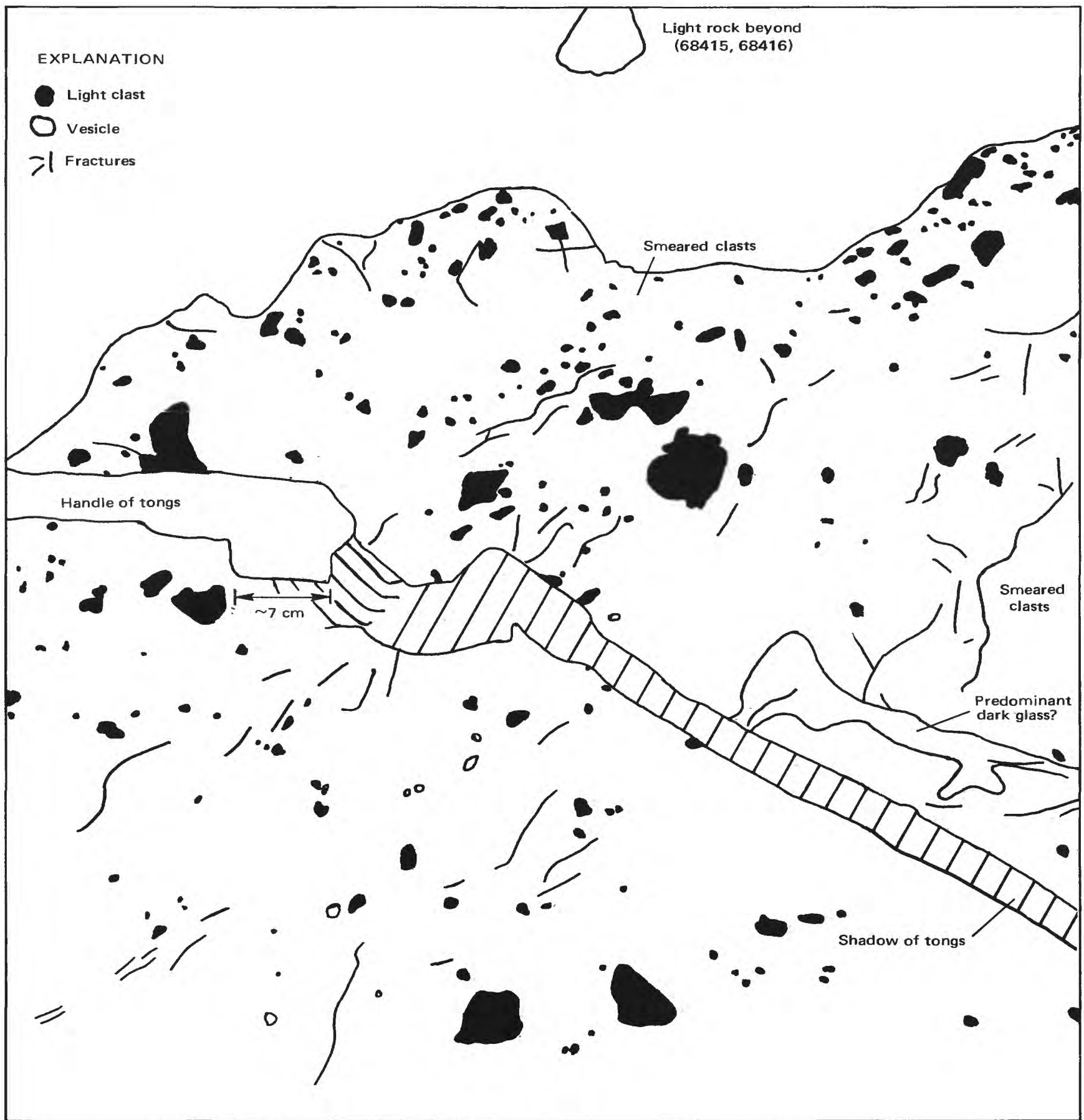

B

Apollo 16 photograph, AS16-108-17694. B, Sketch map. 


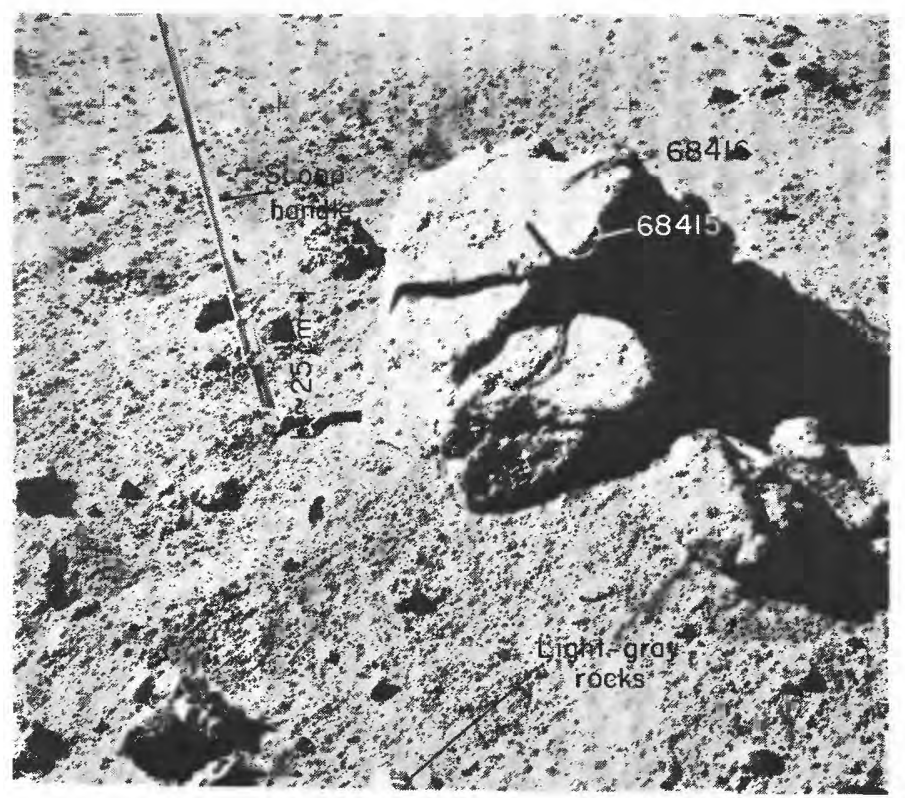

Figure 13-Boulder 2, station 8, showing location of samples collected; view is south (AS16-107-17549).

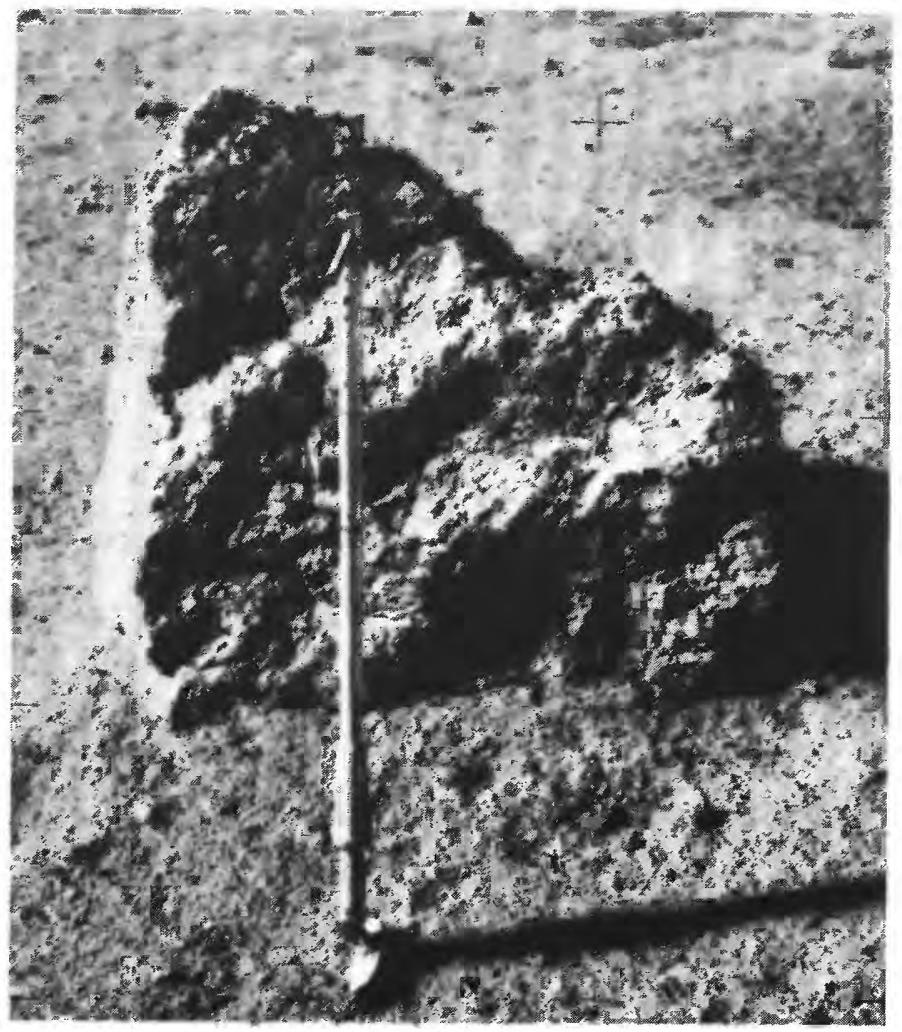

A

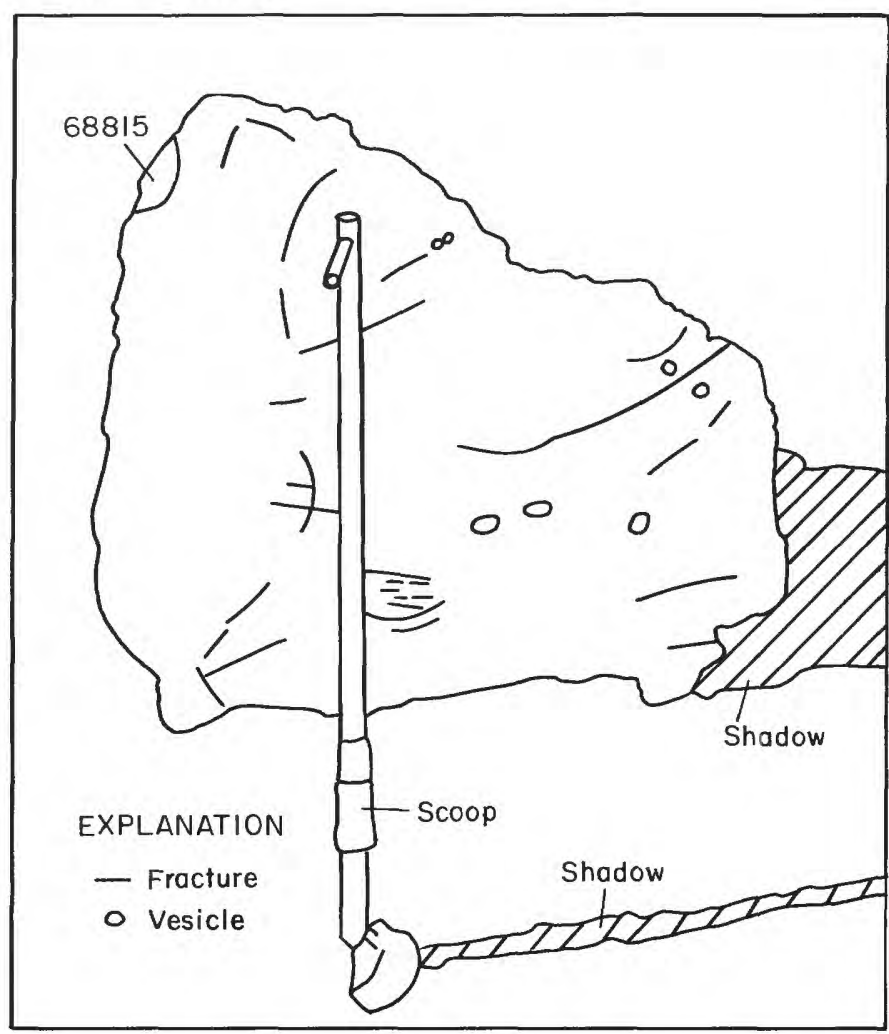

B

Figure 14.-Boulder 3, station 8. A, Photograph before sampling, view is south (AS16-108-17700). B, Sketch map. 


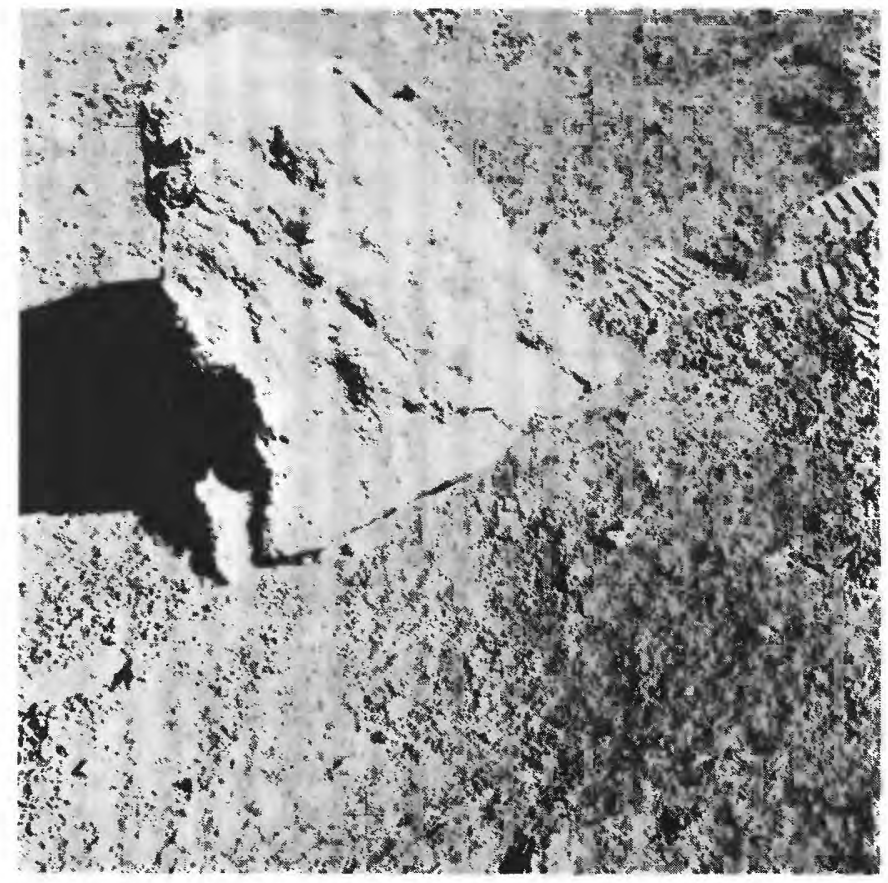

A

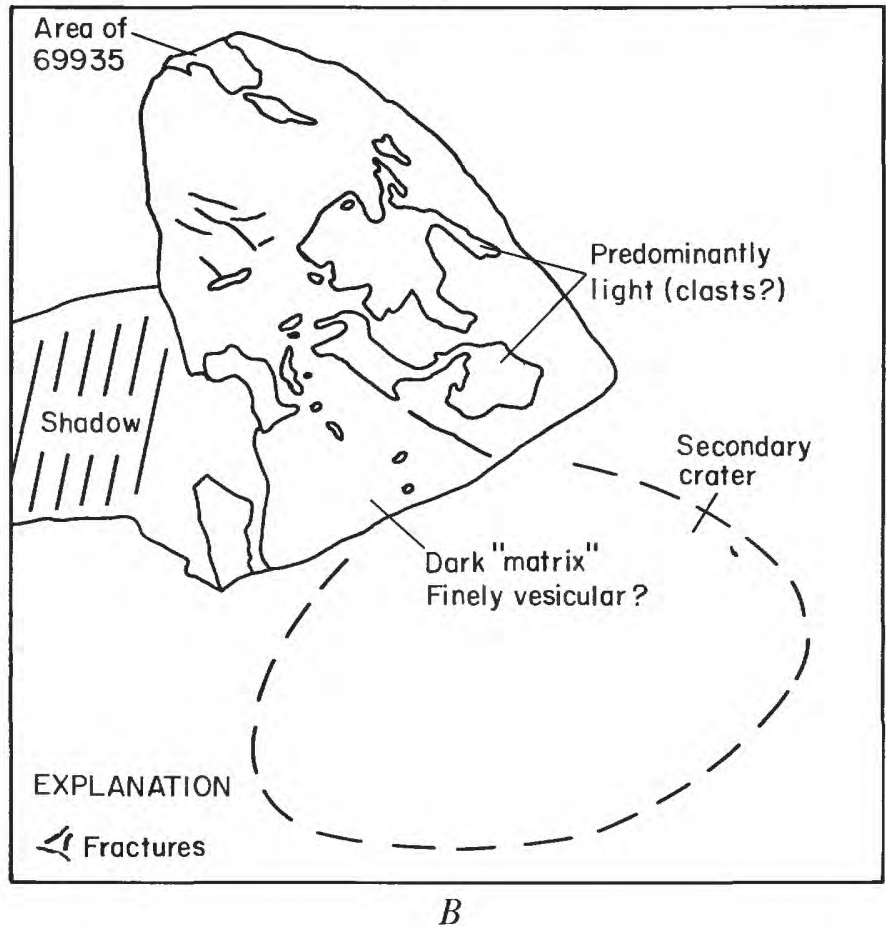

FIGURE 15-Station 9 boulder. $A$, Photograph, view is north, AS16$107-17558$. Boulder is aboui $50 \mathrm{~cm}$ wide. $B$, Sketch map. 


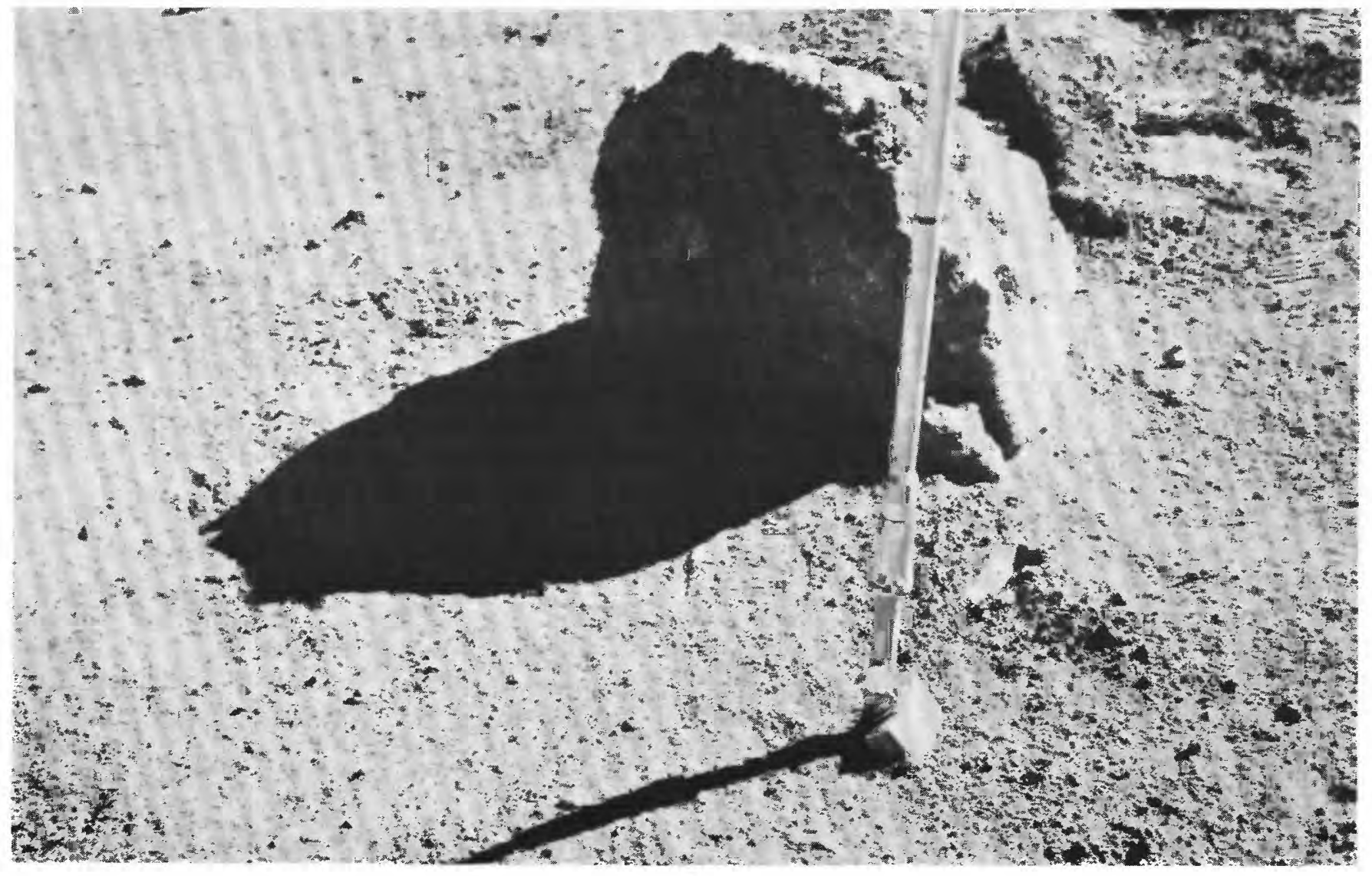

A

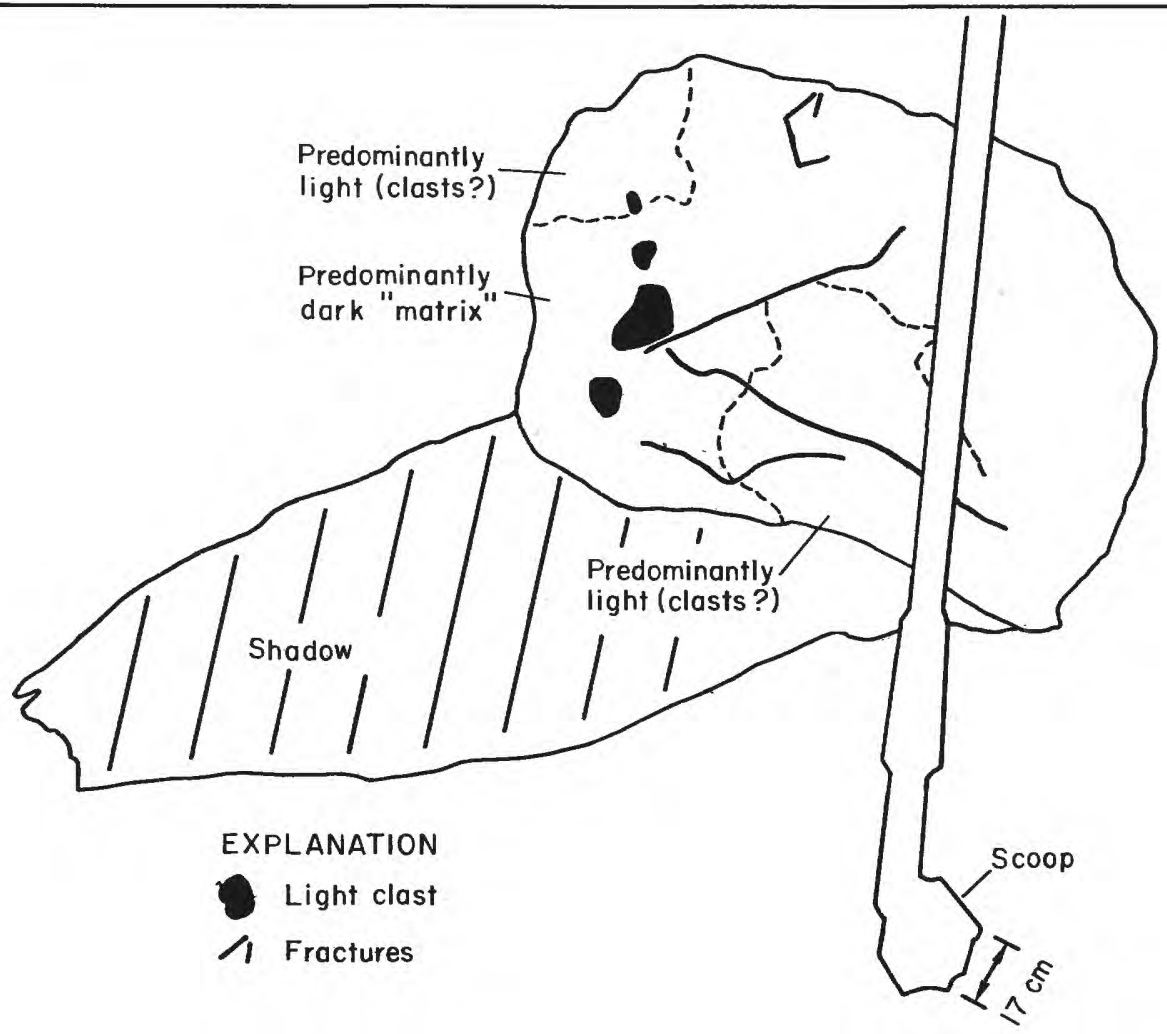



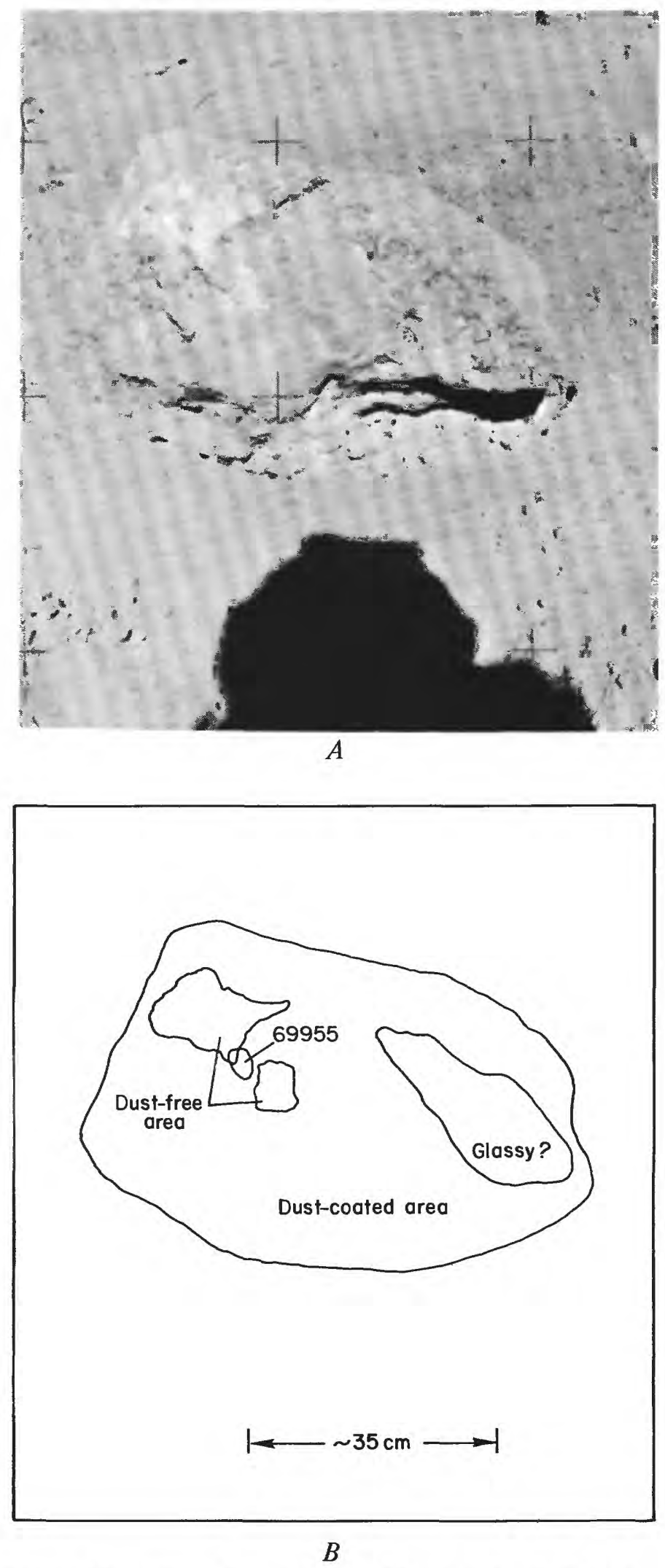

Figure 17.-Bottom of overturned boulder at station 9. $A$, Photograph before sampling, view is west, AS16-107-17576. $B$, Sketch map. 
present. Exposure ages have been calculated for several station 8 and 9 rocks by several investigators (table 4).

The samples collected in the station areas appear to represent two lithologic units penetrated by the South Ray crater. Both light and dark fragments were collected, and light and dark blocks are visible on the rim of South Ray. The upper, dark unit (fig. 18) is about 50 $\mathrm{m}$ thick, the lower, light unit at least $70 \mathrm{~m}$ thick. (See Ulrich and Reed, this volume, for more detail.)

Most of the exposure ages for the station 8 and 9 boulders are about 2 to $3 \mathrm{~m} . \mathrm{y}$., which probably dates the South Ray impact. Older ages, however, indicate that exposure history may be complex or that the different dating techniques used have not'yet been reconciled.

Neukum and others (1973) noted that the surface of 68415 is not saturated with microcraters, indicating it is freshly exposed rock. High exposure ages of 87-105 m.y. contradict this evidence but may represent an earlier exposure history for this boulder, preserved somehow in the material analyzed. Behrmann and others (1973) calculated an exposure age of $2 \mathrm{~m} . \mathrm{y}$. for 68815 and suggest that, prior to its ejection, it was buried at a depth greater than $7 \mathrm{~m}$, which could place the boulder within the upper part of the dark unit prior to its excavation. Drozd and others (1973) calculated a 4.1-m.y.exposure age for $69955,2 \mathrm{~m} . \mathrm{y}$. for 69935 . They suggested that the boulder was in the upper few centimeters of the regolith in the South Ray target area, inverted from its present position for $2.1 \mathrm{~m}$.y., then ejected from South Ray 2 m.y. ago. It seems unlikely, however, that a half-meter boulder near the surface of the South Ray impact point could have survived the event as well as the flight to station 9. More reasonably, the boulder was part of the upper dark layer and was ejected by the South Ray impact 2 m.y. ago. The boulders from which samples 68815,68115 , and 69955 were collected probably all represent the dark unit in

TABLE 3.-Reported exposure ages of rocks collected at stations 8 and 9

\begin{tabular}{|c|c|c|c|}
\hline Rock No. & $\begin{array}{l}\text { Age } \\
(\mathrm{m} . \mathrm{y} .)\end{array}$ & Method & $\begin{array}{l}\text { Age } \\
\text { source }\end{array}$ \\
\hline \multirow[t]{2}{*}{68415} & $\begin{array}{l}2-3 \\
2.2 \pm 0.3\end{array}$ & $\begin{array}{l}\text { Microcraters } \\
{ }^{81} \mathrm{Kr}-{ }^{83} \mathrm{Kr} \text { and } \\
{ }^{{ }^{1} 1} \mathrm{Kr}-{ }^{78} \mathrm{Kr}\end{array}$ & $\begin{array}{l}\text { D. A. Morrison and others, } 1973 \text {. } \\
\text { Behrmann and others, } 1973 \text {. }\end{array}$ \\
\hline & $\begin{array}{l}95-105 \\
87 \pm 5 \\
92.5 \pm 13.3\end{array}$ & $\begin{array}{l}\text { Cosmic ray } \\
{ }^{+0} \mathrm{Ar}-39 \mathrm{Ar} \\
{ }^{*} \mathrm{~K} \mathbf{r}-\mathrm{Kr}\end{array}$ & $\begin{array}{l}\text { Huneke and others, } 1973 \mathrm{a} . \\
\text { Kirsten and others, } 1973 . \\
\text { Drozd and others, } 1974 .\end{array}$ \\
\hline \multirow[t]{2}{*}{68815} & $2.0 \pm 0.2$ & $\begin{array}{l}{ }^{{ }_{1} 1} \mathrm{Kr}-{ }^{78} \mathrm{Kr} \text { and } \\
{ }^{{ }_{1} 1} \mathrm{Kr}-{ }^{{ }^{k 3} \mathrm{Kr}}\end{array}$ & Behrmann and others, 1973 . \\
\hline & $\begin{array}{l}1.7 \pm 0.4 \\
2.04 \pm 0.20\end{array}$ & $\begin{array}{l}{ }^{22} \mathrm{Na}-{ }^{2} 1 \mathrm{Na} \\
{ }^{11} \mathrm{Kr}-\mathrm{Kr}\end{array}$ & $\begin{array}{l}\text { Do. } \\
\text { Drozd and others, } 1974 \text {. }\end{array}$ \\
\hline 68115 & $2.08 \pm 0.32$ & ${ }^{H 1} \mathrm{Kr}-\mathrm{Kr}$ & Do. \\
\hline 68416 & & $\begin{array}{l}\text { Microcraters } \\
{ }^{40} \mathrm{Ar}-{ }^{39} \mathrm{Ar}\end{array}$ & $\begin{array}{l}\text { D. A. Morrison and others, } 1973 . \\
\text { Kirsten and others, } 1973 .\end{array}$ \\
\hline 69935 & $\begin{array}{l}2-3 \\
1.9 \pm 0.2 \\
3.3 \pm 0.3 \\
2.2 \pm 0.3 \\
1.99 \pm 0.37\end{array}$ & 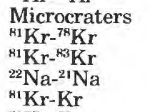 & $\begin{array}{l}\text { D. A. Morrison and others, } 1973 . \\
\text { Behrmann and others, } 1973 . \\
\text { Do. } \\
\text { Do. } \\
\text { Drozd and others, } 1974 .\end{array}$ \\
\hline 69955 & $4.25 \pm 0.41$ & ${ }^{81} \mathrm{Kr}-\mathrm{Kr}$ & Do. \\
\hline
\end{tabular}

South Ray crater, as all three are dark matrix $\left(B_{4}\right.$ and $\mathrm{B}_{5}$ ) breccias. The presence of light-gray rocks and fines on South Ray and Baby Ray craters and in the station areas suggests that igneous rocks 68415 and 68416 from boulder 2 are representative of the underlying light layer (impact melt). Crystallization ages reported for these rocks (table 4) are 3.68 to 4.09 b.y. and 3.87 to 4.00 b.y., respectively. These are inferred to represent the approximate age of emplacement of the fluidized material within the Cayley Formation as proposed by Hodges and Muehlberger (this volume). It seems fairly conclusive that the impact that formed South Ray crater occurred 2 to 3 m.y. ago and that the dark breccias and light igneous rocks sampled at stations 8 and 9 are representative of two discrete layers penetrated by South Ray.

The problem of assigning the samples collected at stations 8 and 9 to South Ray crater arises from the exposure ages of the fines (McKay and Heiken, 1973). Walton and others (1973) and Kirsten and others (1973) reported exposure ages of 180 m.y., 170 m.y., and $240 \mathrm{~m} . \mathrm{y}$. for 68841,69941 , and 69921 , respectively. Schaeffer and Husain (1973) analyzed eight 2- to 4-mm fragments, obtaining exposure ages of 122 to 168 m.y. Adams and McCord (1973) stated that station 8 soils are mature, according to their high agglutinate content.

It appears that little fine debris was sampled that can be attributed directly to South Ray. Two explanations have been proposed: (1) the fines collected represent older regolith ejected by the South Ray impact (McKay and Heiken, 1973) or (2) there is little or no fine South Ray debris in these areas. If the soils do represent older ejected regolith, it would probably be indistinguishable from the preexisting regolith in the station areas. Size analysis of the soils (Butler and others, 1973), however, indicates that there may be recognizable mixing of South Ray and underlying fines and that the coarser fractions are likelier to represent the latest depositional material.

McKay and Heiken (1973) calculated that approximately 20 percent of the material ejected from South Ray was preexisting regolith, based on a regolith thickness of $10-15 \mathrm{~m}$. As the regolith may not be more

TABLE 4.-Reported crystallization ages for samples 68415 and 68416 , station 8

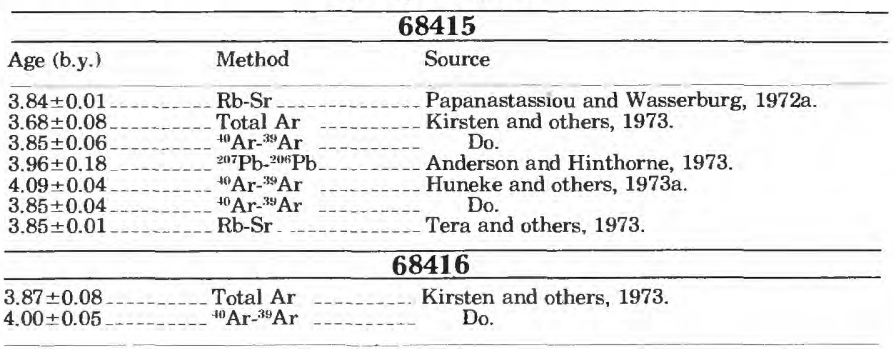




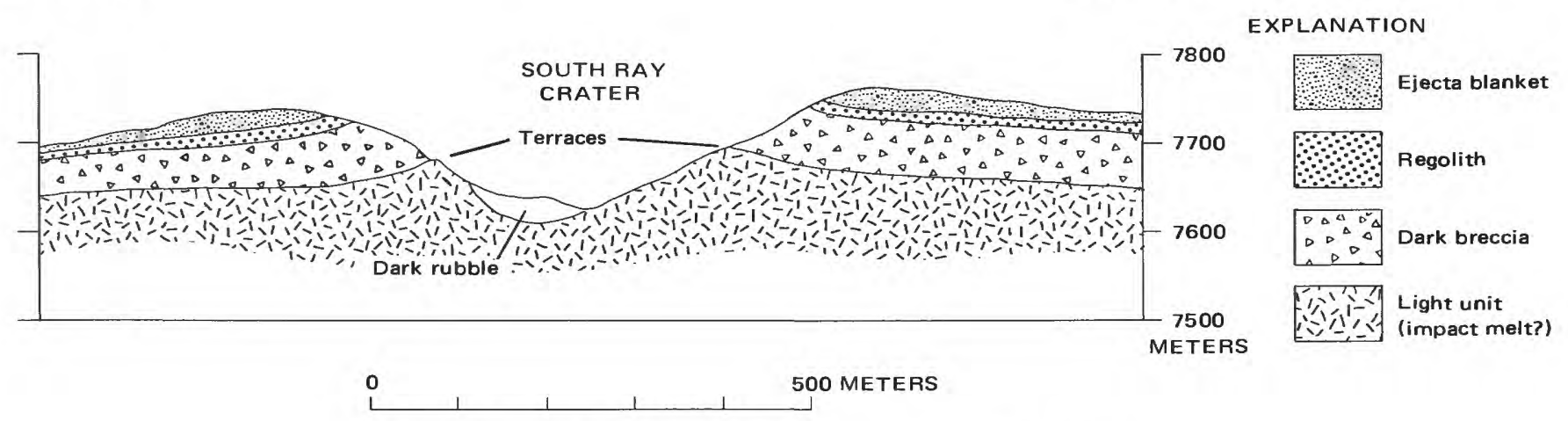

FIGURE 18.-Schematic cross-section through South Ray crater.

than 6-7 $\mathrm{m}$ thick (Freeman, this volume), older regolith in the ejecta may be considerably less than calculated. McKay and Heiken suggested that the amount of freshly produced fine material may be very small. It is possible, then, that little fine material in this area can be attributed directly to South Ray, either as older, preexisting regolith or as freshly produced fines.

If there is little or no soil produced by South Ray in the area, there must be another explanation for the high-albedo rayed surface at station 8 . In several other station areas, the crew reported light-colored soil underlying a thin dark surface layer. At station 8, the soil appears to be a uniform gray. This uniformity may have been produced by churning of the upper few centimeters of the regolith as fragments from South Ray impacted. Such a process, in the absence of much fine debris, could generate a surface of higher albedo. The surface at station 8 (located on a prominent ray) has a rough appearance suggestive of such churning of the upper regolith, whereas the surface at station 9 has a lower albedo and is much smoother, compatible with a less prominently rayed terrain.
The apparent absence of primary South Ray fines is not surprising considering the intense mixing of the upper regolith as the rays were deposited. It is apparent that there was not a "blanket" of material deposited but rather that the high albedo was produced by a turbulent, churning disturbance of the older, darker regolith surface by South Ray ejecta, which deposited only sparse new material as blocks and fragments in the ray-covered area. This is consistent with the conclusion of Oberbeck and others $(1974 \mathrm{a}, \mathrm{b}, 1975)$ that beyond the continuous ejecta blanket, the proportion of primary material present is small relative to the local material excavated by secondaries from the crater. These conclusions are also in agreement with a South Ray ejecta model proposed by Hodges and others (1973) (see also Ulrich and others, this volume) that presents an average thickness of ejecta based on fragment population, evenly distributed over $360^{\circ}$ of arc. According to their preferred model, "an indeterminate, but small amount of South Ray ejecta should be expected in the interray areas, and the materials of the rays should be dominantly coarse debris." 


\title{
D4. GEOLOGY OF STONE MOUNTAIN
}

\author{
By Anthony G. Sanche\%
}

\section{CONTENTS}

$\begin{array}{ll}\text { Introduction } & \text { Page } \\ \text { Geology of the station areas } & \\ \text { Station } 4 & \\ \text { Station } 5 & \\ \text { Station } 6 & \\ \text { Discussion and summary } & \end{array}$

\section{ILLUSTRATIONS}

FIGURE 1. Photograph showing location of traverses 1 and 2 and Stone mountain area

2. Telephotographic mosaic of Stone mountain taken from station 2

3. Photograph of station 4 and vicinity

4. Planimetric map of station 4

5-11. Photographs:

5. Sample 64425

6. Sample 64435 with photomicrographs

7. Stereopair, sample 64475

8. Stereopair, sample 64476

9. Sample 64535

10. Sample 64455 with photomicrographs -

11. Sample 64815

12. Map showing block distribution within $10 \mathrm{~m}$ of station 4 a panorama

13. Photograph of station 5 and vicinity

14. Planimetric map of station 5

15. Map showing block distribution within $10 \mathrm{~m}$ of station 5 panorama

16-22. Photographs:

16. Stereopair of sample 65035

17. Sample 65075

18. Stereopair of sample 65095

19. Stereopair and photomicrographs of sample 65315

20. Stereopair and photomicrographs of sample 65055

21. Stereopair of sample 65015

22. Station 6 and vicinity

23. Topographic map of the Stone mountain area

24. Planimetric map of station 6

25. Map showing block distribution with $10 \mathrm{~m}$ of station 6 panorama

26-30. Photographs:

26. Sample 66075

27. Stereopair and photomicrograph of sample 66035

28. Stereopair of sample 66055

29. Stereo and photomicrographs of sample 66095

30. Stone mountain traverse showing location of boulder fields identified on $16 \mathrm{~mm}$ photographs

\section{TABLES}

TABLE 1 . Block shape and size distribution at stations 4,5 , and 6 


\section{INTRODUCTION}

Stone mountain is a westward projection of the Descartes mountains extending into the southeastern part of the Apollo 16 traverse area. It is approximately 550 $\mathrm{m}$ above the Cayley plains and has a domical morphology.

The largest craters on Stone mountain include
Crown, $100 \mathrm{~m}$ in diameter, and two nearby unnamed craters, $80 \mathrm{~m}$ and $140 \mathrm{~m}$ in diameter; most range from $50 \mathrm{~m}$ down to the limit of resolution. The crater density on Stone mountain is qualitatively the same as that on the adjacent Cayley plains, but craters larger than 100 $\mathrm{m}$ are more abundant on the plains (fig. 1; see also Freeman, this volume). None of the resolvable primary craters on Stone mountain appear to be younger than

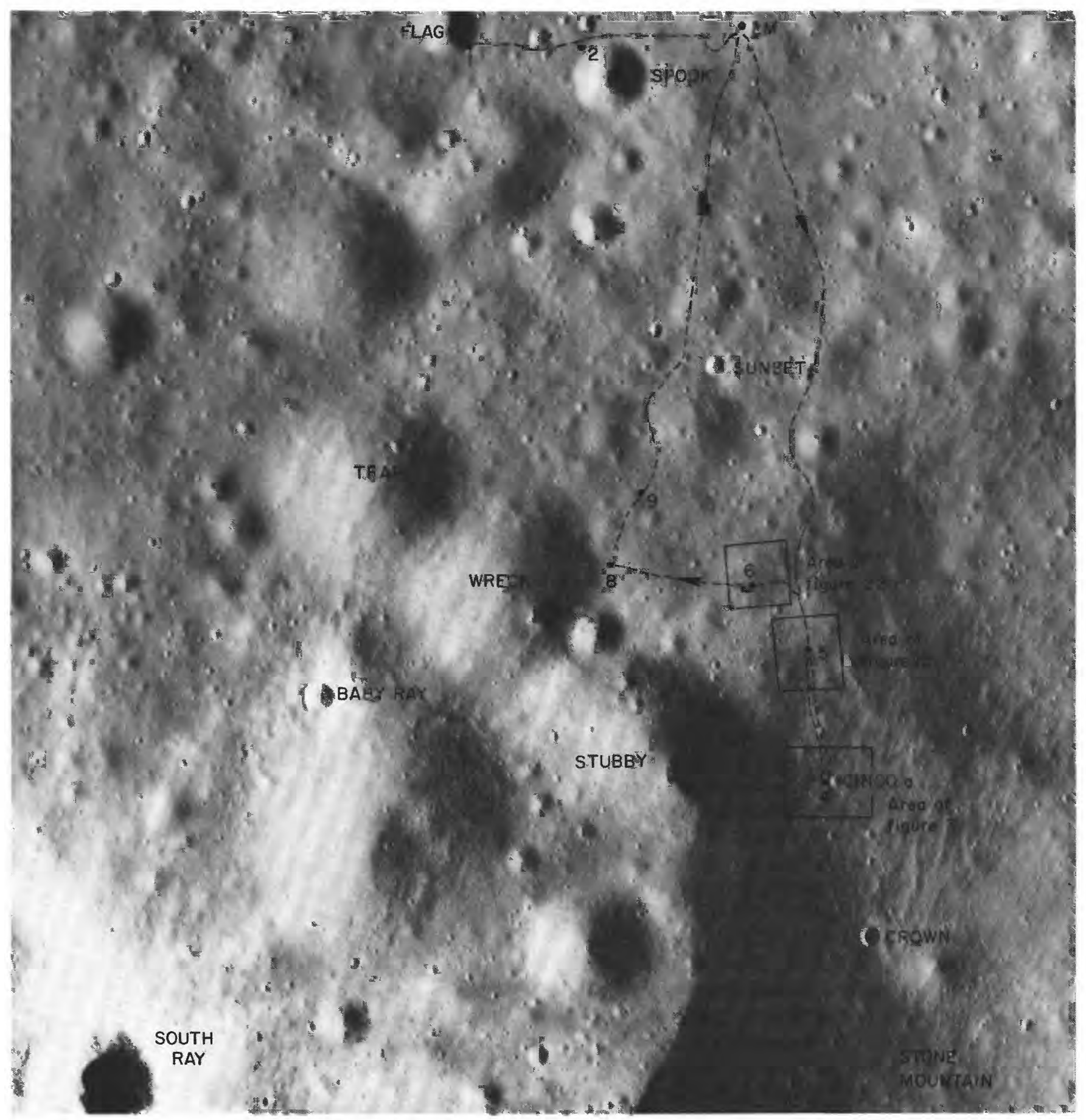

FIGURE 1.-Location of traverses 1 and 2, features discussed in text, and areas covered by figures 3, 13, and 22. Apollo 16 panoramic camera frame 4618. 
the prominent South Ray and Baby Ray craters on the plains.

The average thickness of the regolith on Stone mountain based on radar data and concentric craters (Freeman, this volume) is estimated to be about $7 \mathrm{~m}$. The surface is relatively smooth and undulating. The upper part of the regolith on Stone mountain probably includes ejecta from South Ray crater over much of the surface.

\section{GEOLOGY OF THE STATION AREAS}

The main objective of the sampling at stations 4,5 , and 6 was to collect materials characteristic of the Descartes mountains. This task was constrained by lack of outcrops, difficulty of recognizing craters that penetrated bedrock, contamination by South Ray ejecta, and the lack of obvious characteristics by which to distinguish Descartes material from Cayley. The contact between Cayley and Descartes material was not recognized on the ground; the crew noted the gradual increase in slope but observed no apparent difference in color or texture of regolith.

Station 4, the highest point reached, was about 150 $m$ above the plain on Stone mountain (fig. 2) on a steep slope that was more blocky than expected owing to blocky ray material from South Ray crater. Station 5, lower on the slope and approximately $550 \mathrm{~m}$ north of station 4 , was on a gently sloping bench near a $15-\mathrm{m}$ crater in an area sparsely covered with blocks. Station 6 was on the edge of the Cayley plains at the base of Stone mountain. A subdued 10-m crater and several small craters are present in the station 6 area, and small blocks are fairly common.

The traverse route on Stone mountain is sprinkled with blocks in the 10- to 100 -cm size range interspersed with smaller rocks down to the limit of resolution (2 $\mathrm{cm})$. The crew observed that blocks less than $30 \mathrm{~cm}$ in size are the most abundant. Their observations were confirmed by block counts made from the station panorama (pl. 6, pans 9-12; table 1).

\section{STATION 4}

As a result of this study the location of station 4 has been redetermined at about $100 \mathrm{~m}$ east of the location reported earlier in Muehlberger and others (1972); the new location places the LRV on the outer part of the ejecta blanket of Cinco $a$ crater. Two localities were occupied at station 4: station 4a (the LRV parking spot and principal sampling area, inside the northeast rim of a subdued doublet crater approximately $15 \mathrm{~m}$ across), approximately $40 \mathrm{~m}$ west of the rim of Cinco $a$ crater, and $4 \mathrm{~b}$, about $50 \mathrm{~m}$ south of the LRV (figs. 3 and 4). The regional slope averages $10-15^{\circ}$ down toward the northwest.

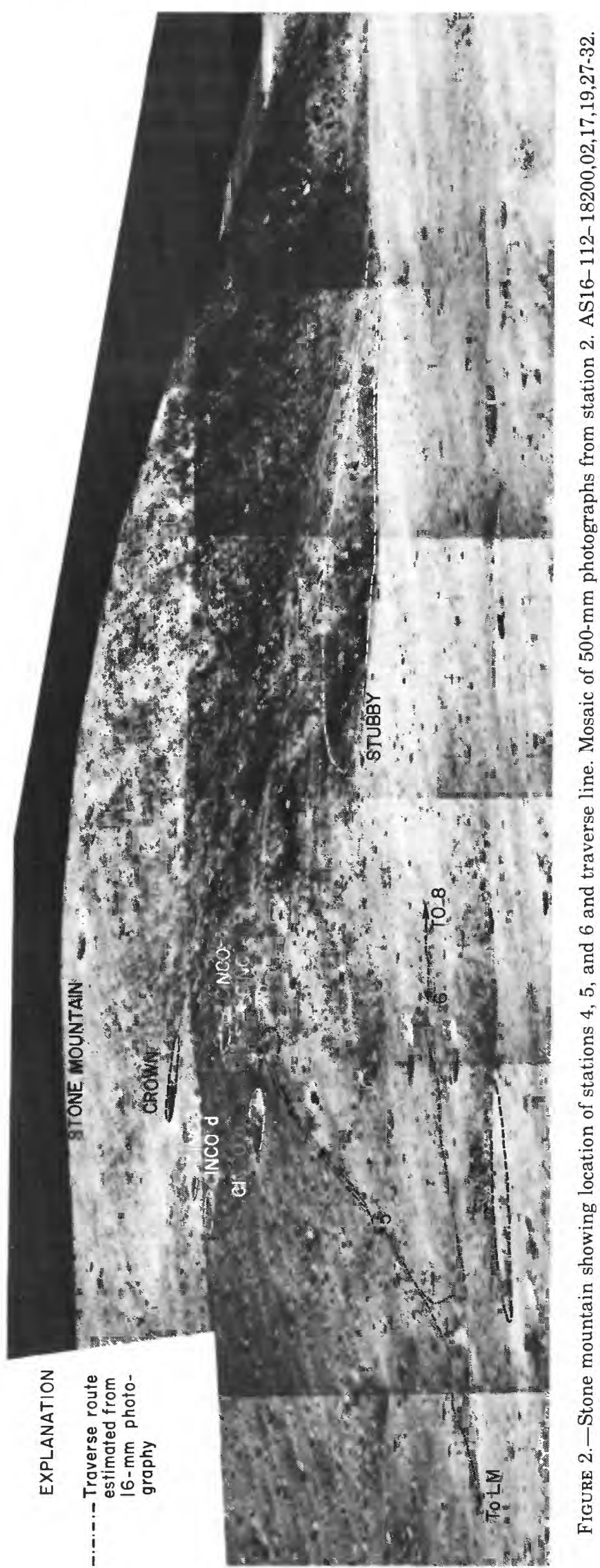


A block field, radial to and possibly derived from South Ray crater, covers part of the sample area at $4 \mathrm{~b}$ (pl. 6, pan 10). Alternatively this block field and that at (pl. 6, pan 9) both may be ejecta from Cinco $a$ crater, 65 $\mathrm{m}$ in diameter and about $15 \mathrm{~m}$ deep. However, larger blocks are present away from the rim of Cinco $a$ rather than being concentrated on it; thus the evidence for Cinco $a$ as a source is not overwhelming.

Indurated regolith samples $(64800,64810)$ from the block-free rim of the crater at $4 \mathrm{~b}$ may be from underlying Descartes material partly derived from Cinco a

TABLE 1.-Block shape and size distribution at stations 4, 5, and 6

\begin{tabular}{|c|c|c|c|c|c|}
\hline \multicolumn{6}{|c|}{ Station 4} \\
\hline & $10-20 \mathrm{~cm}$ & $20-50 \mathrm{~cm}$ & $50 \mathrm{~cm}$ & Total & $\begin{array}{l}\text { Shape } \\
\text { percent }\end{array}$ \\
\hline $\begin{array}{l}\text { Rounded } \\
\text { Subangular } \\
\text { Angular } \\
\text { Total } \\
\text { Size percent }\end{array}$ & $\begin{array}{c}41 \\
55 \\
23 \\
119 \\
76.8\end{array}$ & $\begin{array}{l}2 \\
25 \\
8 \\
35 \\
22.6\end{array}$ & $\begin{array}{l}0 \\
0 \\
1 \\
1 \\
0.6\end{array}$ & $\begin{array}{r}43 \\
80 \\
32 \\
155\end{array}$ & $\begin{array}{r}27.7 \\
51.6 \\
20.7 \\
100.0\end{array}$ \\
\hline \multicolumn{6}{|c|}{ Station 5} \\
\hline $\begin{array}{l}\text { Rounded } \\
\text { Subangular } \\
\text { Angular } \\
\text { Total } \\
\text { Size percent }\end{array}$ & $\begin{array}{c}63 \\
101 \\
26 \\
190 \\
90.1\end{array}$ & $\begin{array}{c}4 \\
9 \\
7 \\
20 \\
9.5\end{array}$ & $\begin{array}{l}0 \\
1 \\
0 \\
1 \\
0.4\end{array}$ & $\begin{array}{r}67 \\
111 \\
33 \\
211\end{array}$ & $\begin{array}{r}31.7 \\
52.6 \\
15.7 \\
100.0\end{array}$ \\
\hline \multicolumn{6}{|c|}{ Station 6} \\
\hline $\begin{array}{l}\text { Rounded } \\
\text { Subangular } \\
\text { Angular } \\
\text { Total } \\
\text { Size percent }\end{array}$ & $\begin{array}{c}28 \\
66 . \\
11 \\
105 \\
92.9\end{array}$ & $\begin{array}{l}2 \\
4 \\
1 \\
7 \\
6.3\end{array}$ & $\begin{array}{l}0 \\
1 \\
0 \\
1 \\
0.8\end{array}$ & $\begin{array}{r}30 \\
71 \\
12 \\
113\end{array}$ & $\begin{array}{r}26.5 \\
62.8 \\
10.7 \\
100.0\end{array}$ \\
\hline
\end{tabular}

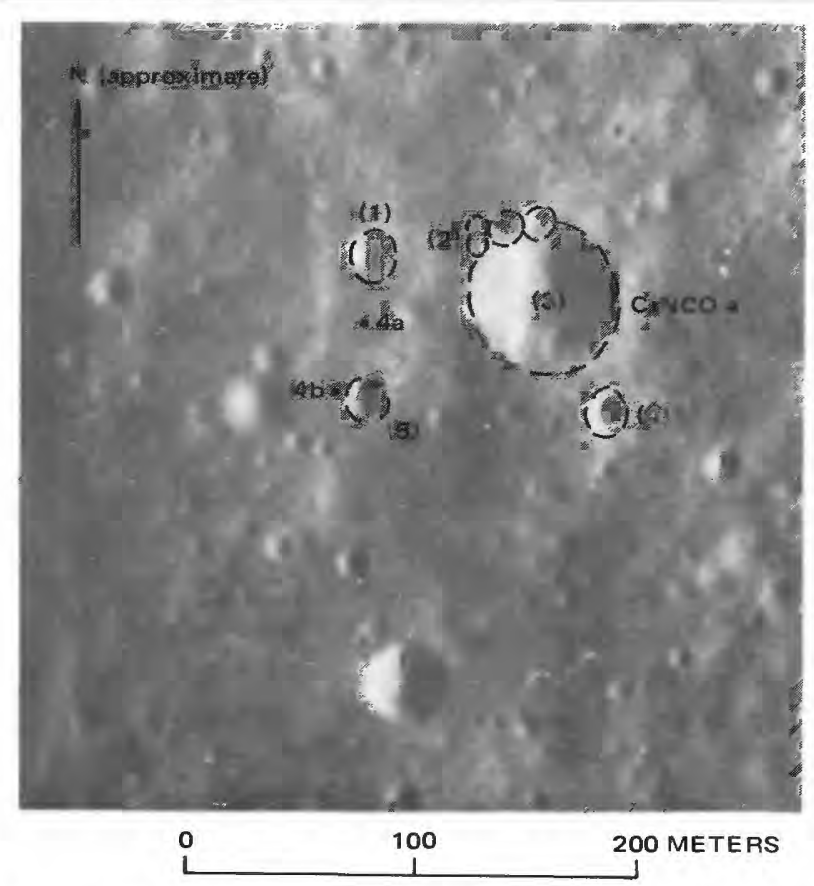

FIGURE 3.-Station 4 and vicinity. Numbers in parentheses indicate features correlated with plate 6 , pans 9 and 10. Apollo 16 panoramic camera frame 4618 . ejecta and reworked by local impact. The regolith surface is light gray. Near the rim of the subdued doublet crater at $4 \mathrm{a}$, white material similar to that at station 1 occurs at a depth of about a centimeter; yet a trench in the floor of the crater exposed no white soil or evidence of layering.

The crew collected samples in the vicinity of the LRV at $4 \mathrm{a}$ but attempted to avoid sampling the large boulder field believed to be ejecta from South Ray crater. One rock, a 14-g light-matrix breccia (fig. $5 ; \mathrm{B}_{2}$ of Wilshire and others, this volume) and $0.3 \mathrm{~kg}$ of soil were collected from the bottom of the trench; a double-core drive-tube sample was also taken; all three of these samples should have come from below South Ray ejecta if it were present on the surface.

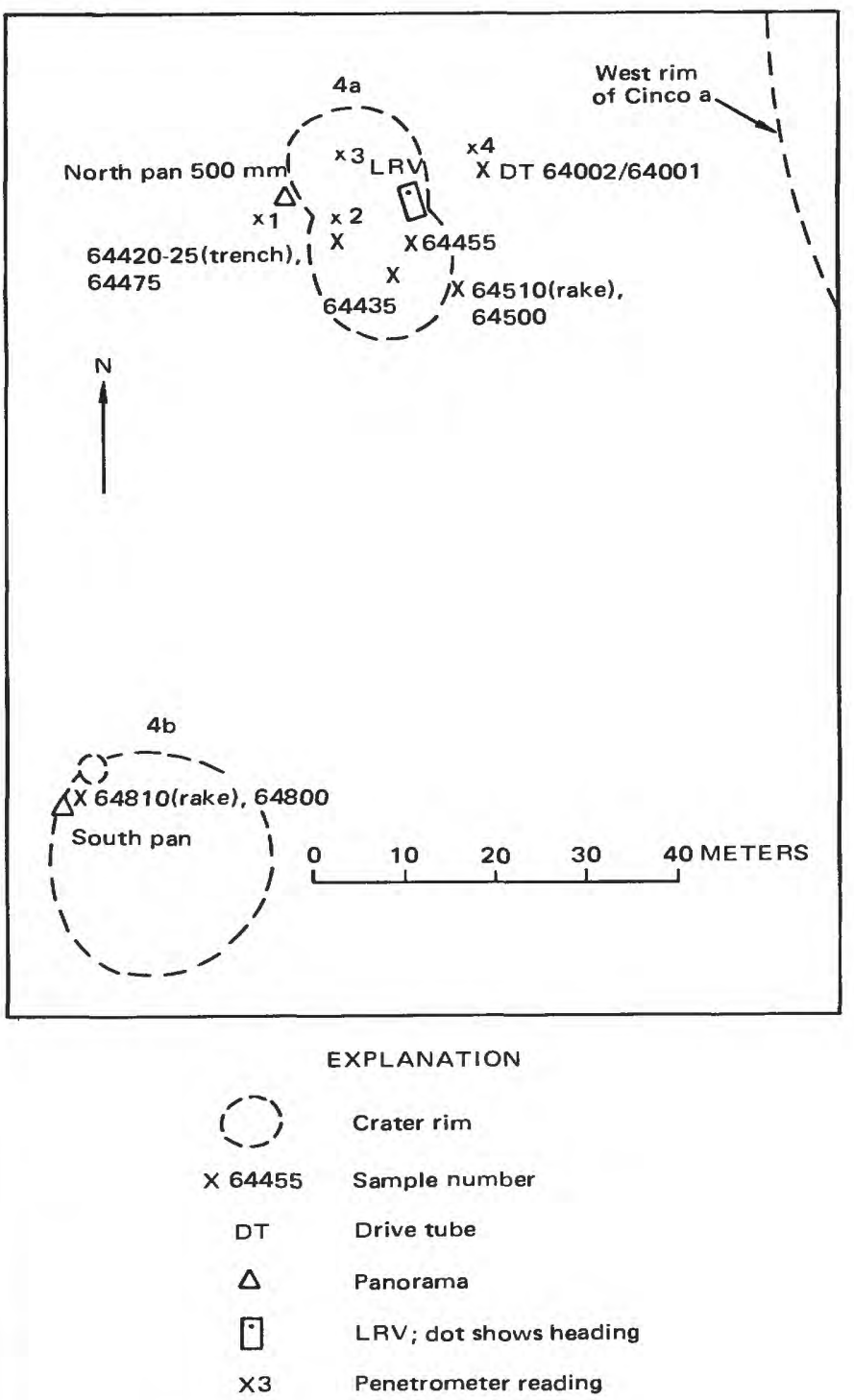

Figure 4,-Planimetric map of station 4 modified from Muehlberger and others (1972). 


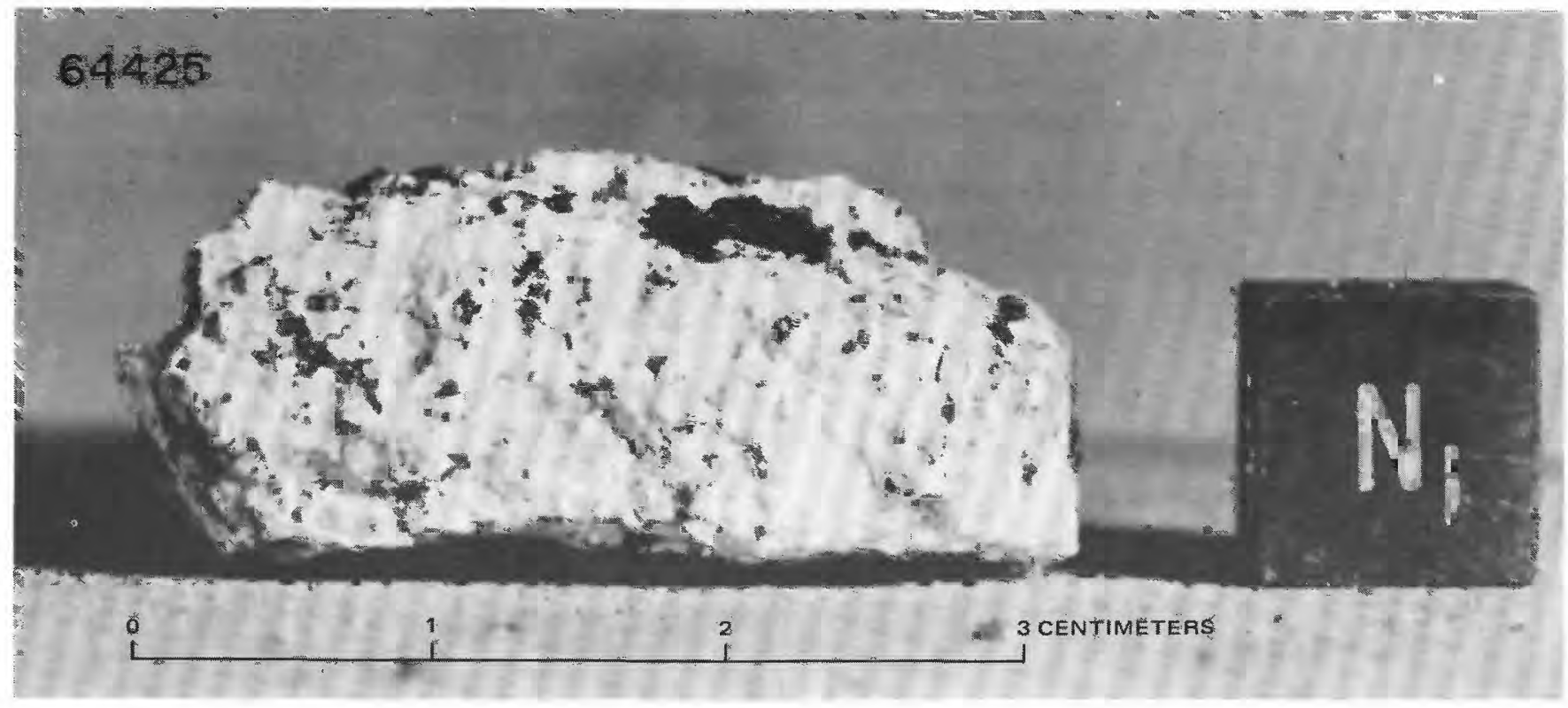

Figure 5.-Sample 64425; light-matrix dark-clast breccia from bottom of trench at station 4a (NASA photograph S-72-41584).

At station $4 \mathrm{~b}$, the blocks are mainly light colored although glass and dust coatings obscure many rock surfaces. Breccia is the predominant rock type in the area, and light clasts are visible in some of the blocks photographed (pl. 6, pan 10). Soil and rake samples consisting mainly of friable, poorly consolidated clods were collected from the northwest rim. No white soil or evidence of layering was found beneath the surface. The blocks on the northeast wall of the crater apparently are breccias containing mainly light but some dark matrices.

The most abundant rocks sampled at station 4 , according to Wilshire and others (this volume), were light-matrix dark-clast breccias $\left(\mathrm{B}_{2}\right)$ and dark-matrix light-clast breccias $\left(\mathrm{B}_{4}\right)$. Their data, however, are heavily weighted by rake samples, and as they point out, many of the small fragments are probably clasts from larger rocks. Eight samples weighing $25 \mathrm{~g}$ or more were collected at station $4 \mathrm{a}$, none at $4 \mathrm{~b}$. Seven of the samples from $4 \mathrm{a}$ are light-matrix dark-clast breccias; one is a metaclastic crystalline rock. From the location of $4 \mathrm{a}$, well within the ejecta blanket of Cinco $a$, these larger fragments may be taken as characteristic of underlying rocks in the area. Sample 64435 (fig. $6 A$ ), the largest light-matrix $\left(\mathrm{B}_{2}\right)$ breccia collected at this station, is described as a cataclastic two-pyroxene, olivine-bearing anorthosite, partly coated with a glass rind (Wilshire and others, this volume). In thin section it appears to consist mainly of crushed feldspar invaded by dark matrix material (fig. $6 B, C$ ). Samples 64475, 64476, and 64535 (figs. 7-9) are additional examples of $\mathrm{B}_{2}$ breccias collected at station 4. Probably most of these samples were deposited as ejecta from South Ray, although the crew attempted to avoid the block field. Other samples collected at this station include a glass-coated anorthosite (64455, fig. 10$)$ and a crushed, annealed mafic rock (64815, fig. 11), both classified as metaclastic $\left(\mathrm{C}_{2}\right)$ by Wilshire and others (this volume). A K-Ar crystallization age of $3.9 \pm 0.2$ b.y. is reported for 64421 (Kirsten and others, 1973) and an exposure age of $210 \mathrm{~m} . \mathrm{y}$. for soil samples 64421 and 64501 . These soils probably are not part of South Ray ejecta, as reliable exposure ages of 2 to $4 \mathrm{~m}$.y. have been reported for rocks believed to be South Ray material collected at stations 8 and 9 (see Reed, this volume).

Within the doublet crater at station $4 \mathrm{a}$, blocks are much less numerous on the southwest wall, a distribution suggesting that this side was probably shielded from South Ray ejecta. Approximately 2 percent of the surface at station $4 \mathrm{a}$ is covered by rocks more than 10 $\mathrm{cm}$ across; blocks as large as $0.8 \mathrm{~m}$ are scattered over the area (Muehlberger and others, 1972). Rocks less than about $5 \mathrm{~cm}$ across are abundant. Most of the blocks are angular, a characteristic of the ejecta believed to be from South Ray crater, but some of the smaller blocks are subround to round (table 1, fig. 12). The angular, perched appearance of the blocks near the LRV suggests derivation from South Ray crater.

At station $4 \mathrm{~b}$, angular blocks are concentrated on the northeast wall and rim of the crater, the rest of the rim being relatively block free. At station $4 \mathrm{~b}$ (pl. 6, pan 10), the east wall of a $20-\mathrm{m}$ crater appears to be plastered with blocks that have destroyed the raised rim of the 
crater. As these blocks appear to be ejecta from South Ray, samples were collected only from the northwest interior wall of the crater, shielded from the South Ray ejecta by being on the uprange side. The strongly asymmetric distribution of these blocks, the lack of recognizable ejecta elsewhere around the crater, the partly buried rim under the block-covered area, and the relatively large size of the crater suggest that it is not of secondary origin but was formed prior to South Ray and was subsequently mantled by South Ray ejecta.

\section{STATION 5}

At station 5, the LRV was parked near the north rim of a 20 -m crater (figs. 13, 14; pl. 6, pan 11). Blocks are asymmetrically distributed within the crater; their

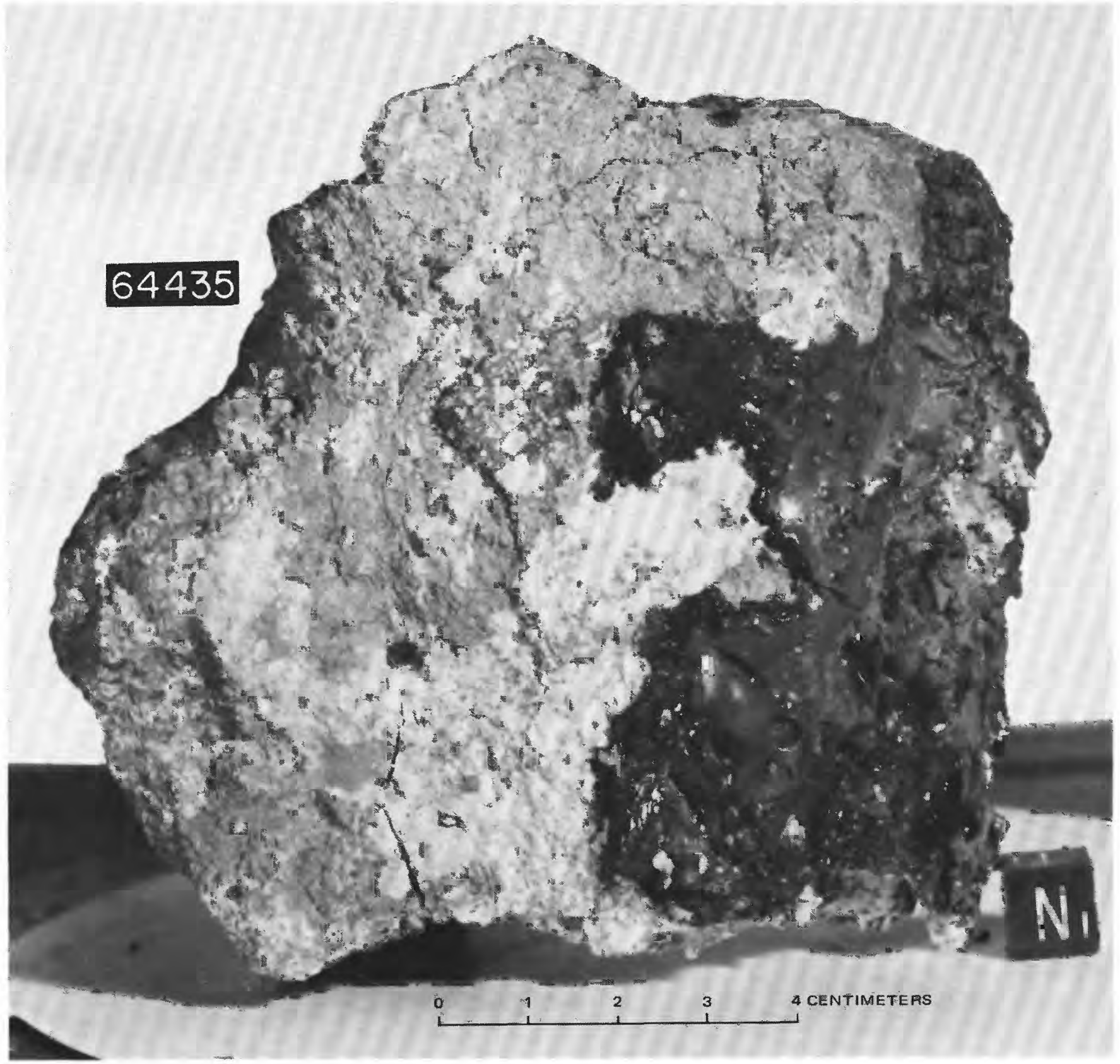

FIGURE 6.-Sample $64435, \mathrm{~B}_{2}$ breccia from station 4. A, NASA photograph S-72-39674. B, Photomicrograph of 64435,73 showing glass rind (dark material, right) and moderately fractured plagioclase feldspar (left). Plane-polarized light. $C$, Same as $B$, cross-polarized light. 

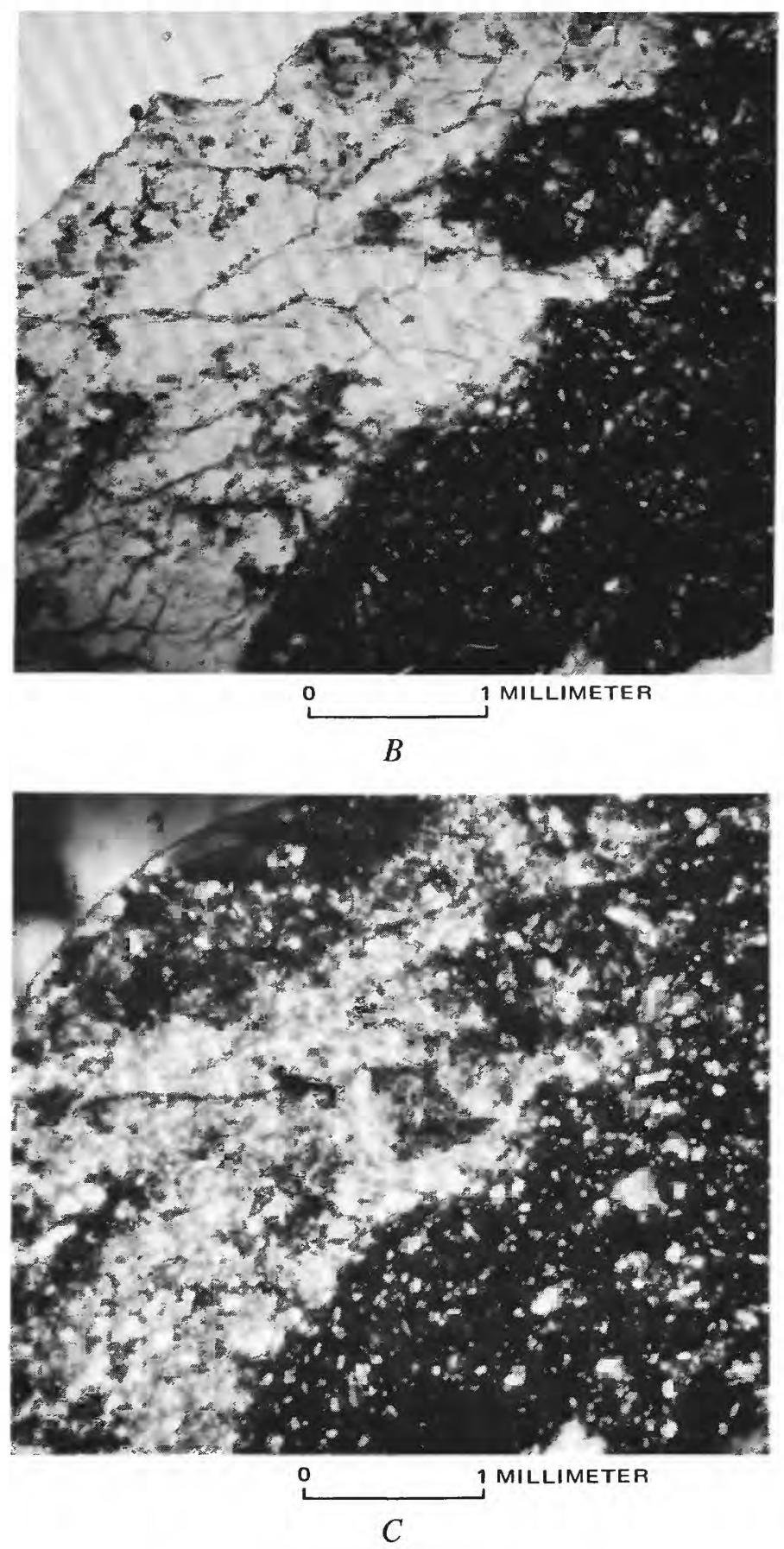

Figure 6--Continued. 


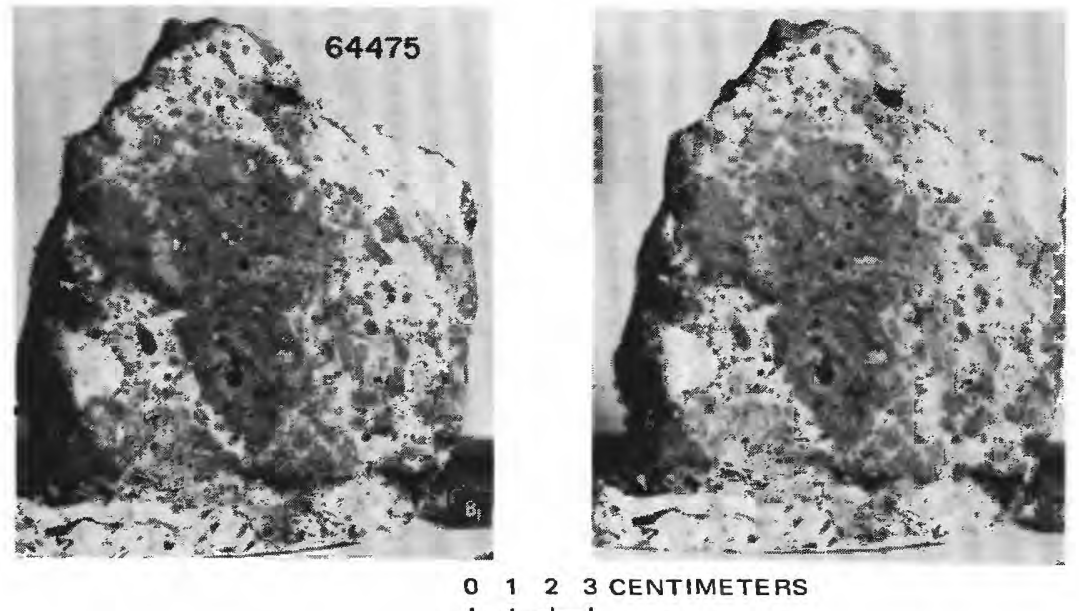

Figure 7-Stereopair of sample 64475 , a coherent $B_{2}$ breccia from station 4 (NASA photographs S-72-43089-43089\$).
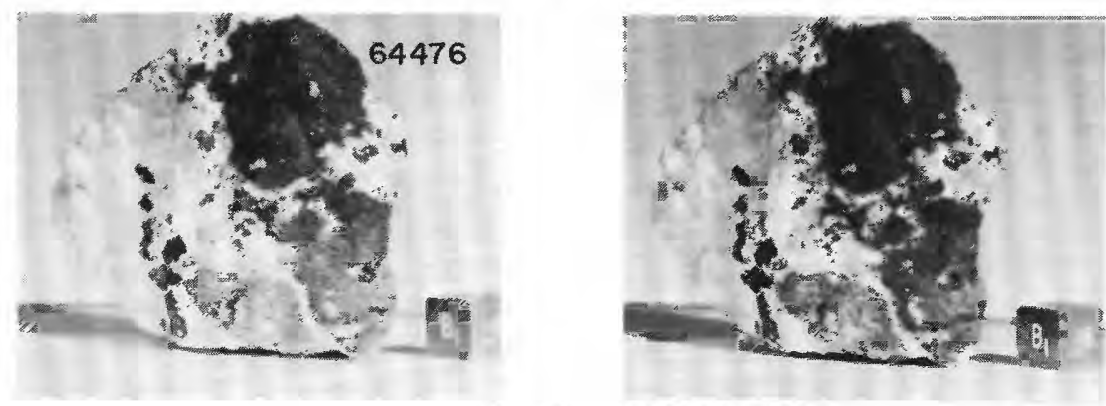

12 CENTIMETERS

Figure 8.-Stereopair of sample 64476, a coherent $\mathrm{B}_{2}$ breccia from station 4 (NASA photographs S-72-43114-43114B).

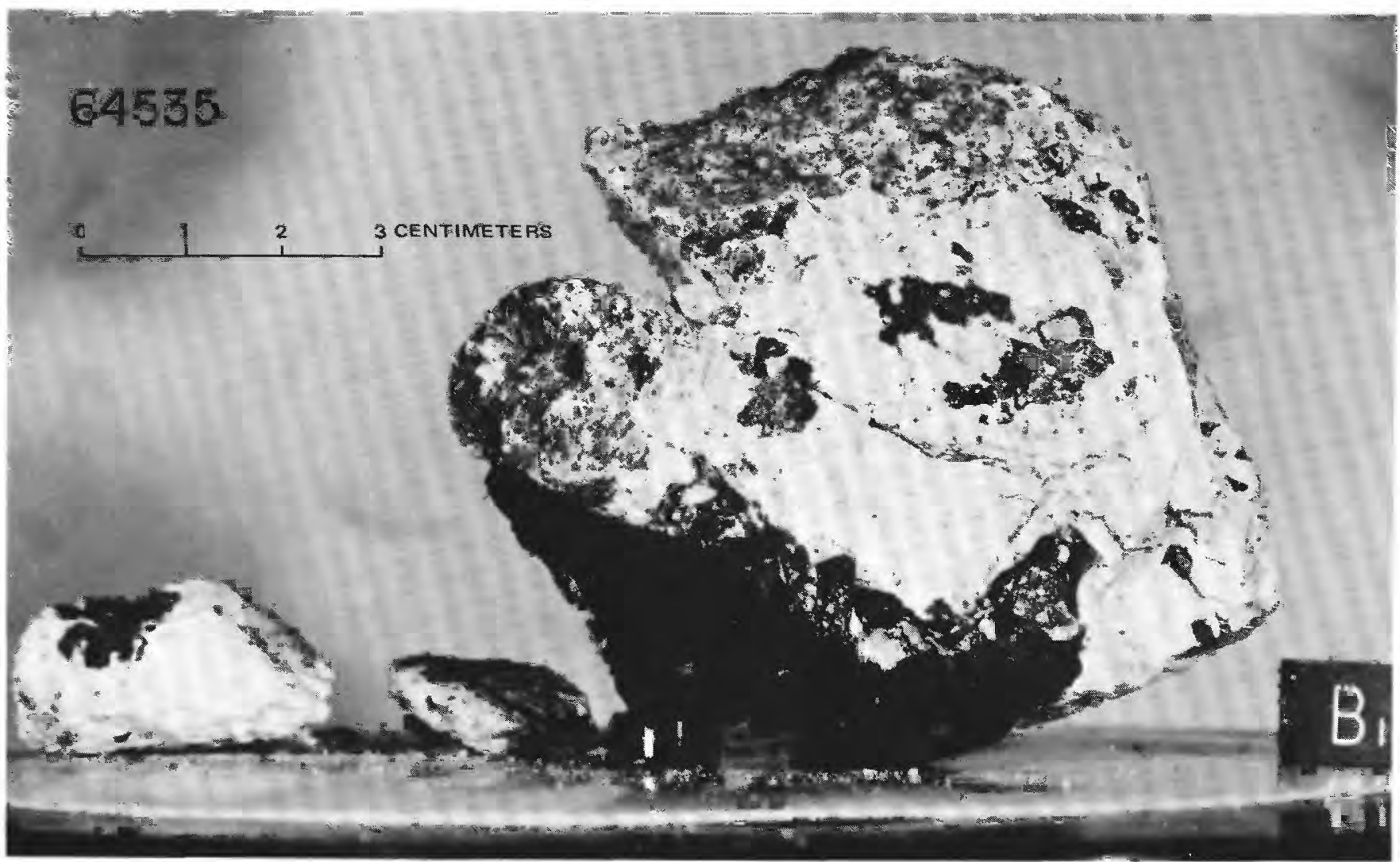

FigURE 9.-Sample 64535, a highly fractured $\mathrm{B}_{2}$ breccia from station 4 (NASA photograph S-72-43420). 


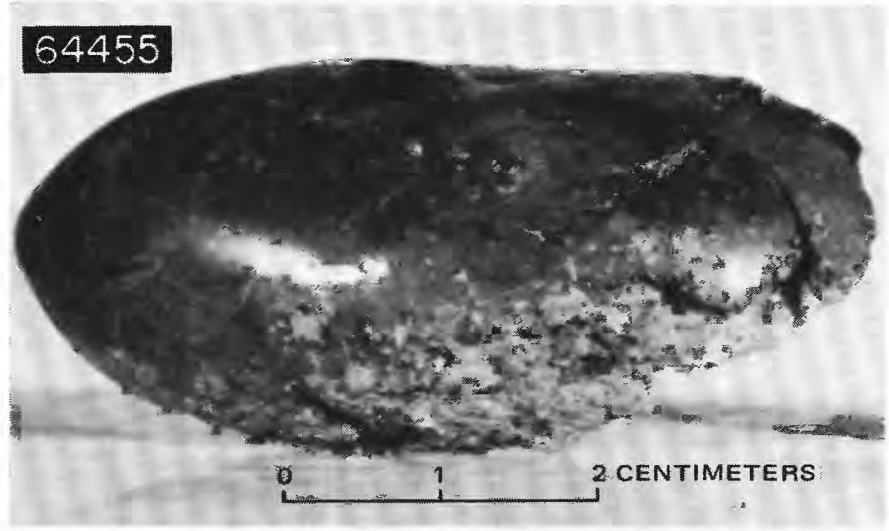

$A$

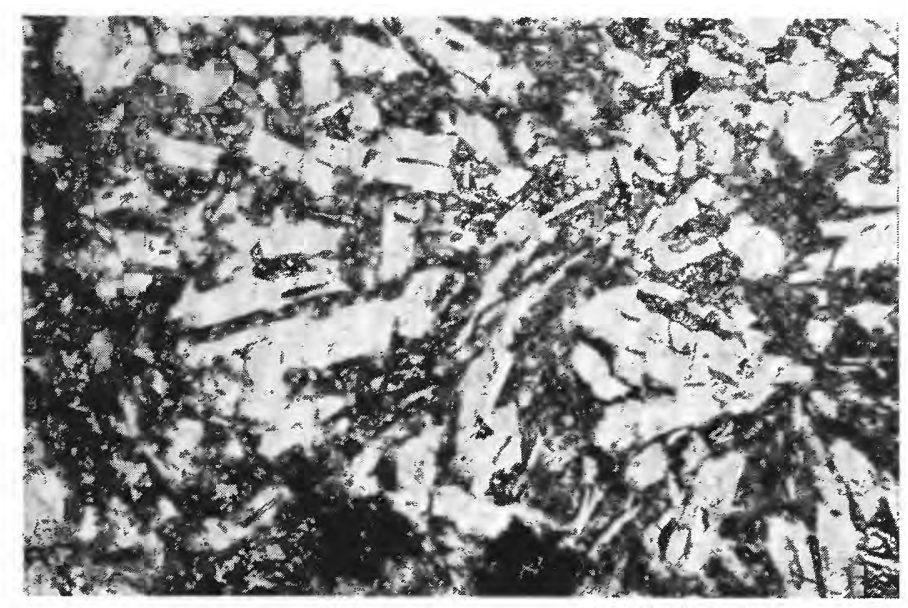

1 MILLIMETER

B

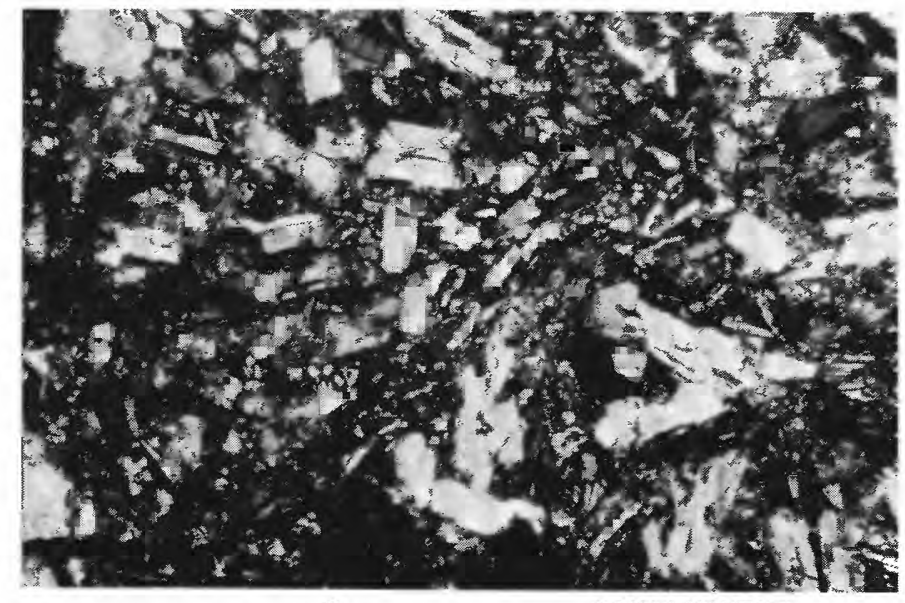

0

1 MILLIMETER

C

FIGURE 10.-Sample 64455, a metaclastic $\left(\mathrm{C}_{2}\right)$ glass-coated rock. $A$, NASA photograph S-72-40130. B, Photomicrograph showing metaclastic texture. Plane-polarized light. $C$, Same as $B$, crosspolarized light.

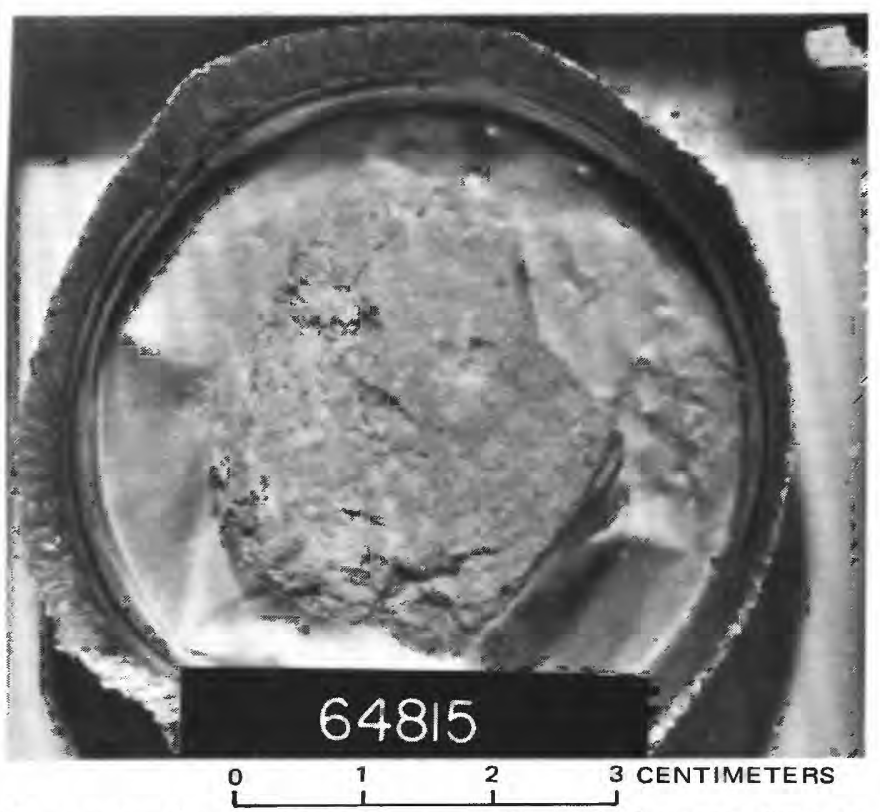

Figure 11.-Sample 64815, an unusually mafic fragment from station 4. NASA photograph S-72-42074.

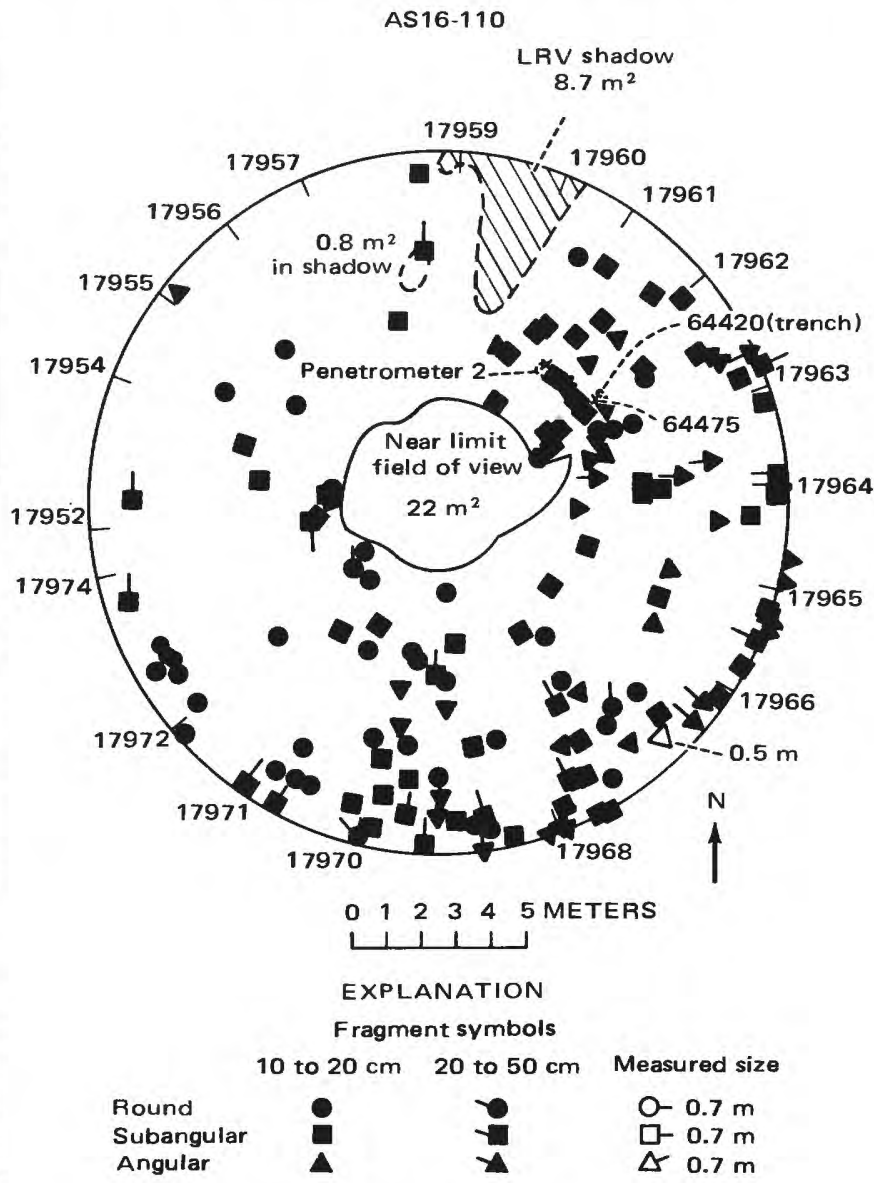

Hachures on outer circle show direction of individual photographs that constitute the panorama

FIGURE 12.-Rock distribution within $10 \mathrm{~m}$ of station $4 \mathrm{a}$. 
scarcity on the southwest wall indicates that the blocks are South Ray ejecta. Large angular blocks are sparsely scattered around the crater; 10 to $20 \mathrm{~cm}$ and smaller fragments are abundant (fig. 15); as observed by the crew and shown on photographs (table 1), station 5 has the highest percentage of rounded boulders on Stone mountain. Fillets occur around some rounded cobbles; some rocks are partly buried, others perched. Soil samples are characteristically gray, although lighter soils were present beneath a gray surface at one locality.

Of the samples collected at station 5, mediumgray-matrix breccias $\left(\mathrm{B}_{3}\right)$ are the most common mainly in rake samples; glasses are also abundant. The largest samples collected are light-matrix dark-clast breccias $\left(\mathrm{B}_{2}\right)$. Of these, 65035, 65075, 65095, and 65315 (figs. 16 to $19 \mathrm{~A}$ ) are classified as cataclastic anorthosites (Wilshire and others, this volume). Typical matrix in $\mathrm{B}_{2}$ breccias is shown in figure $19 B, C$. Two crystalline igneous-textured $\left(\mathrm{C}_{1}\right)$ rocks were collected; the largest is 65055 (fig. 20A). The subophitic texture typical of igneous rocks is shown in figure $20 B, C$. One very large $(1.8 \mathrm{~kg})$ metaclastic $\left(\mathrm{C}_{2}\right)$ rock, 65015 (fig. 21$)$, is described as an anorthosite (LRL, 1972). It was collected from a small depression, possibly a secondary crater. A

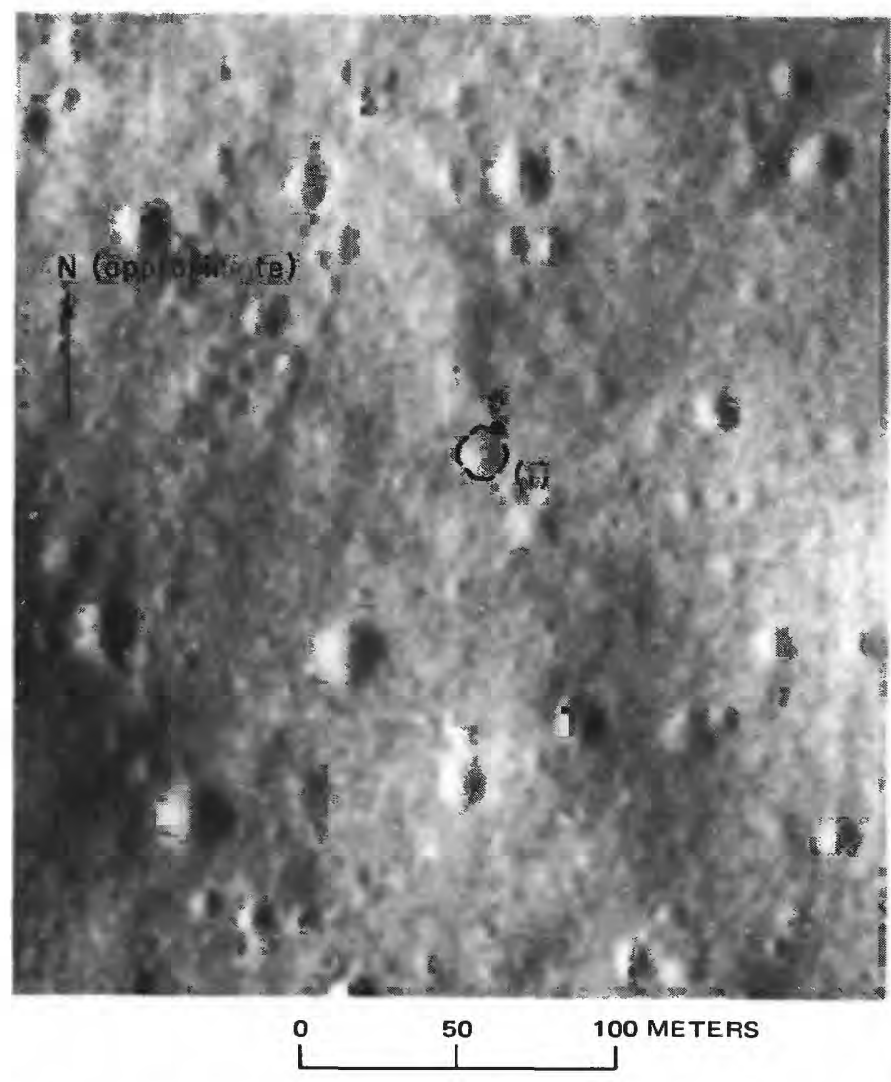

FIGURE 13._Enlargement of orbital photograph showing station 5 and vicinity. Apollo 16 panoramic camera frame 4618.
Rb-Sr crystallization age of 3.92 b.y. reported for this rock (Tera and others, 1973) as well as a ${ }^{40} \mathrm{Ar}-{ }^{39} \mathrm{Ar}$ crystallization age of $3.92 \pm 0.4$ b.y. and an exposure age of $365 \pm 20$ m.y. have been reported (Kirsten and others).

\section{STATION 6}

Station 6 is at the foot of the lowest observable bench on Stone mountain. The LRV was parked near the northeast rim of a subdued $10-\mathrm{m}$ crater (fig. 22). The northwest regional slope is somewhat less steep than at station 4 and 5 (fig. 23). Station 6 was selected before the mission for the purpose of sampling and photographing the base of Stone mountain, its mass-wasted materials, and, if observable, the contact with the Cayley plains. The primary objective was to identify compositional or textural changes between the geomorphic units.

The sampling at station 6 was on the rim and along

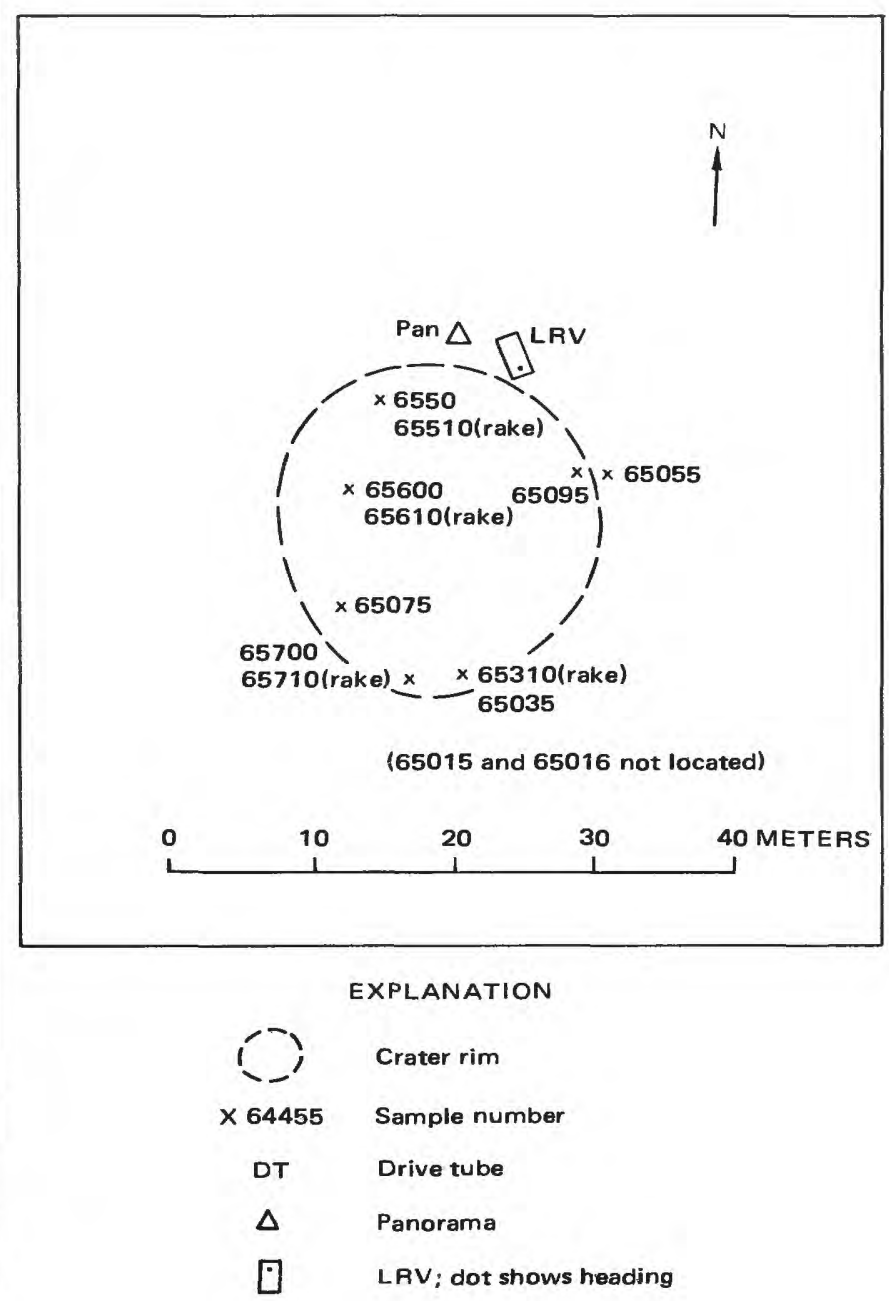

FIGURE 14.-Planimetric map of station 5. 


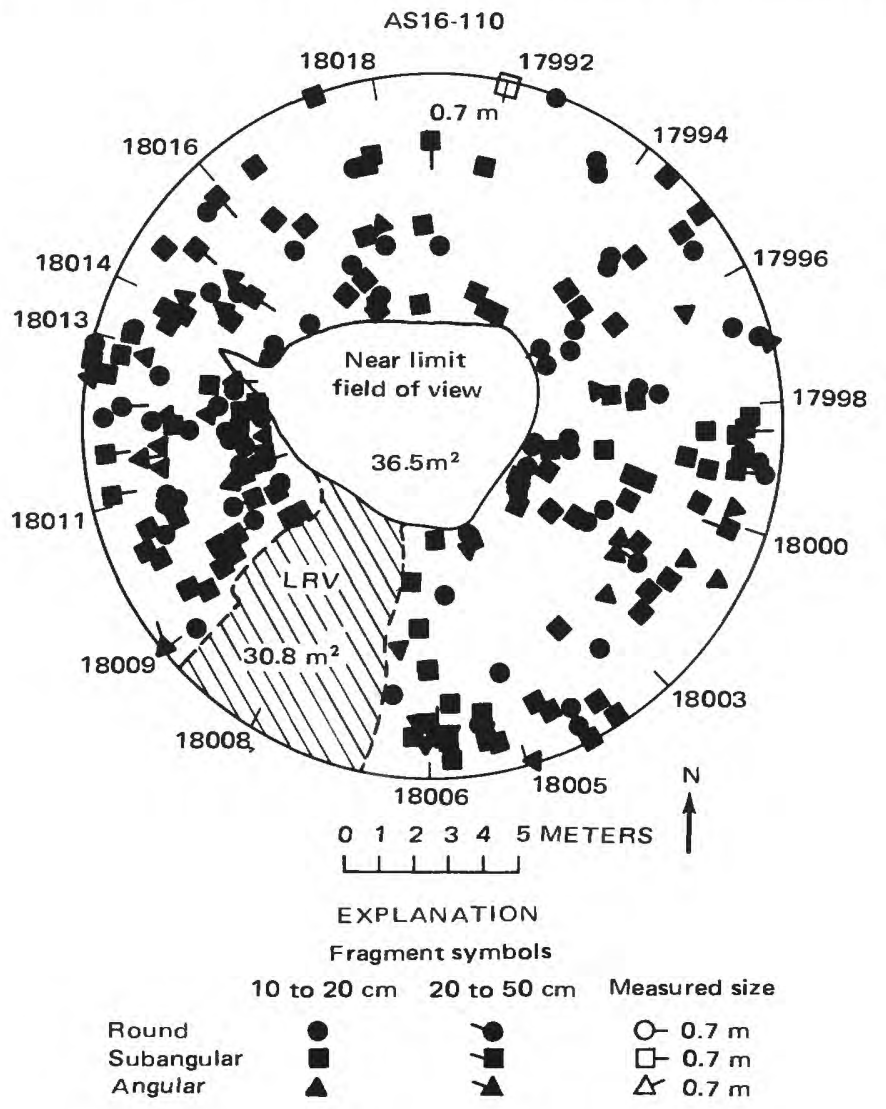

Hachures on outer circle show direction of individual photographs that constitute the panorama

FIGURE 15.-Rock distribution within $10 \mathrm{~m}$ of site of station 5 panorama. See figure 12 for explanation of symbols.
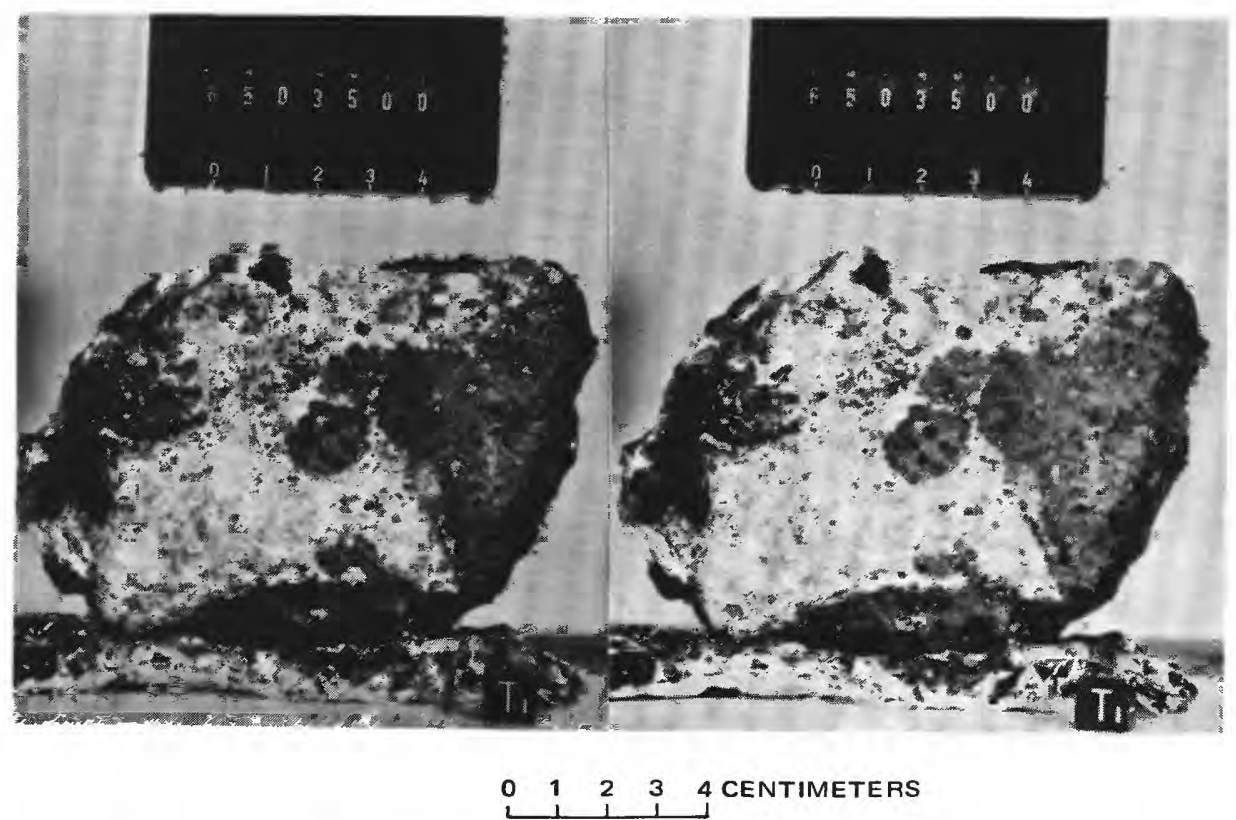

FiguRE 16.-Stereopair of sample 65035 a light-matrix dark-clast $\left(\mathrm{B}_{2}\right)$ breccia (NASA photographs S-72-42057-42057B). 


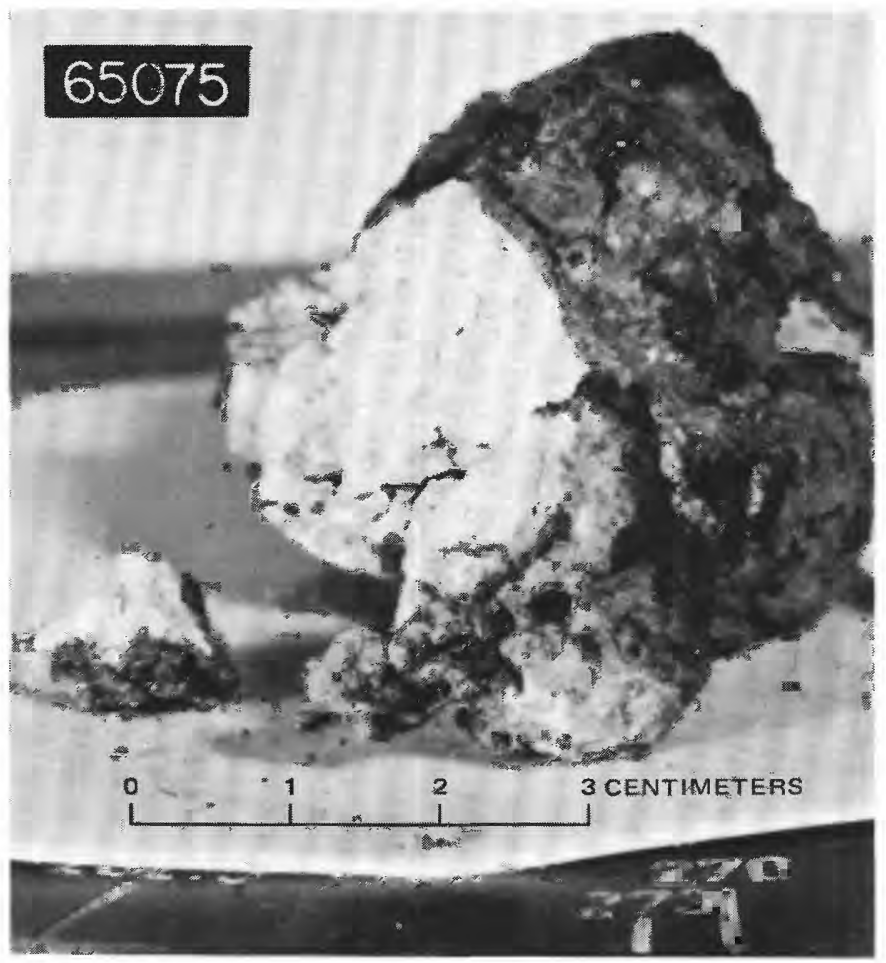

FiguRE 17.-Sample 65075, a highly fractured light-matrix darkclast $\left(\mathrm{B}_{2}\right)$ breccia (NASA photograph S-72-39412).

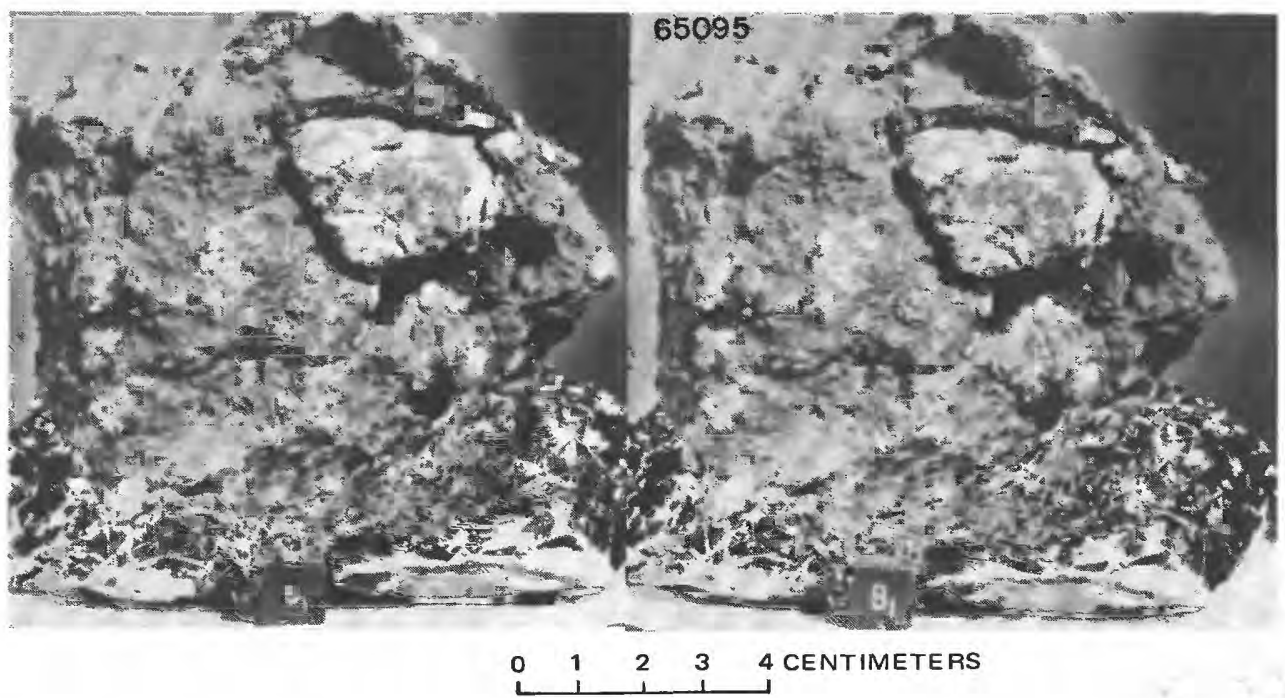

FigURE 18.-Stereopair of sample 65095, a glass-coated light-matrix dark-clast (B2) breccia. NASA photographs S-72-40975-40975B. 


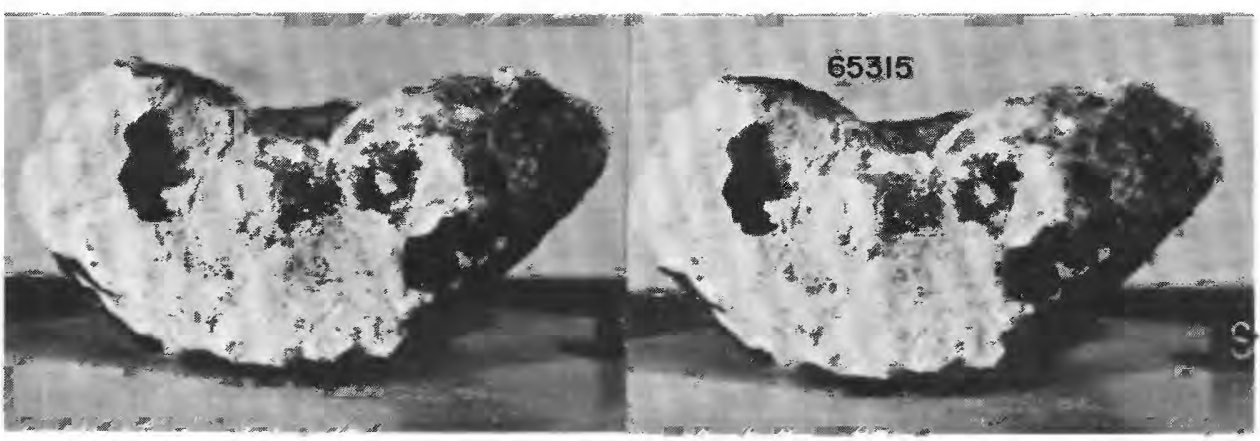

$0 \quad 1 \quad 2 \quad 3$ CENTIMETERS

A
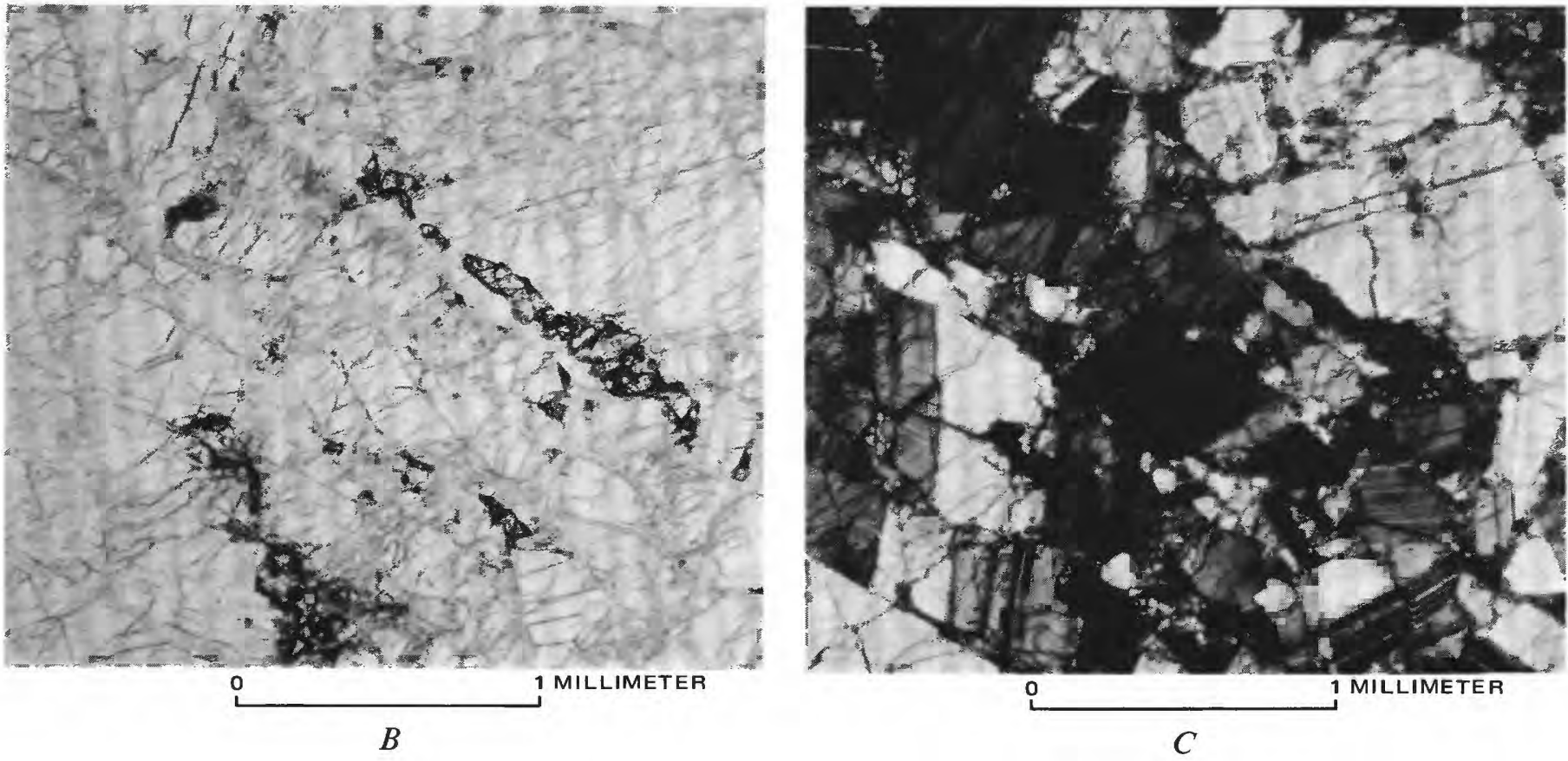

Figure 19.-Sàmple 65315, a light-matrix dark-clast $\left(\mathrm{B}_{2}\right)$ breccia displaying a partly glass-coated surface. $A$, Stereopair. NASA photographs S-72-42103-42103B. $B$, Photomicrograph of a crushed feldspar matrix in 65315 , typical of cataclastic anorthosites. Plane-polarized light. $C$, Same as $B$, cross-polarized light. 

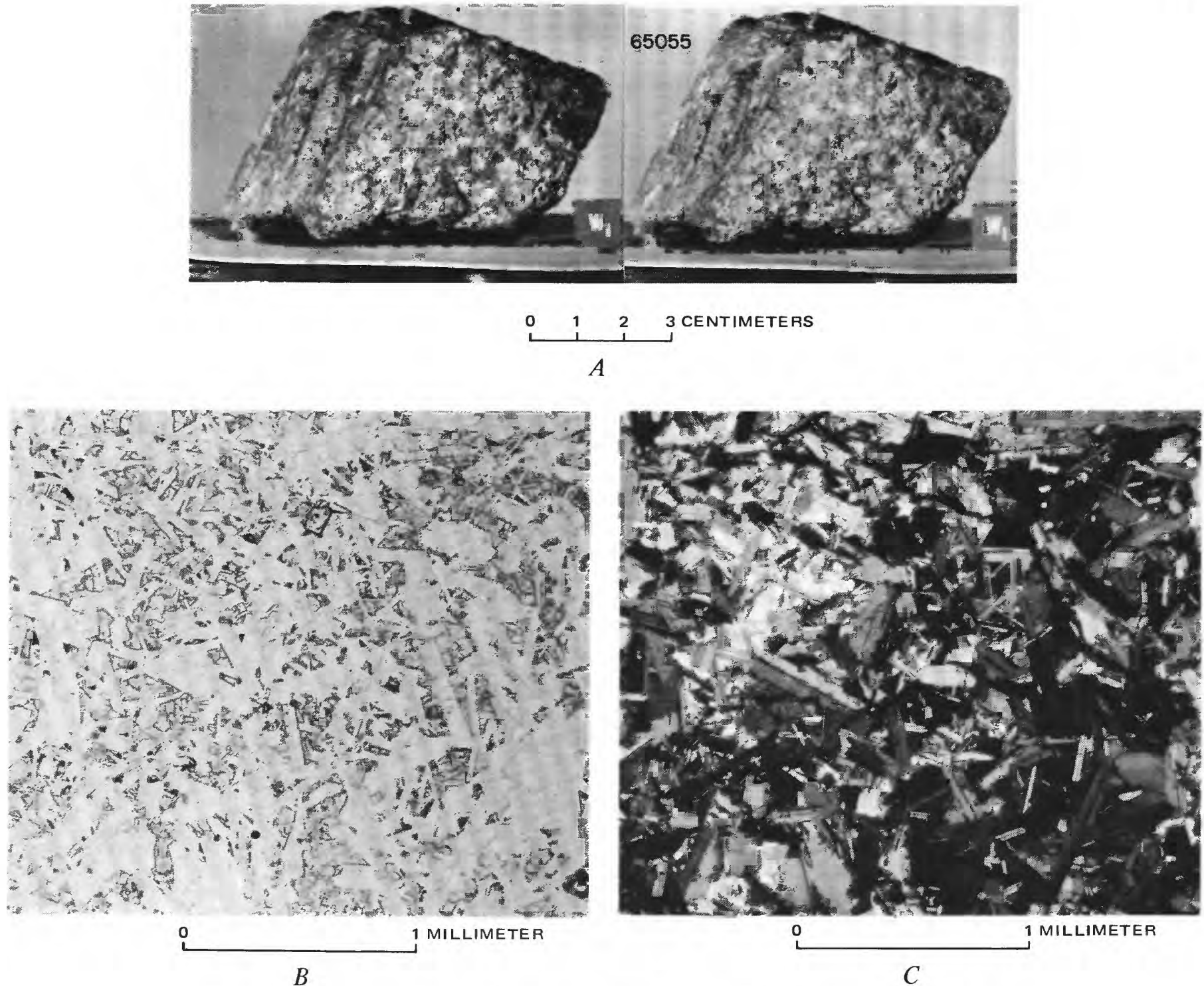

FigURE 20.-Sample 65055, an angular igneous crystalline rock $\left(\mathrm{C}_{1}\right)$. A, Stereopair. NASA photographs S-72-43867B. B, Photomicrograph showing subophitic texture. Plane-polarized light. $C$, Same as $B$, cross-polarized light. 


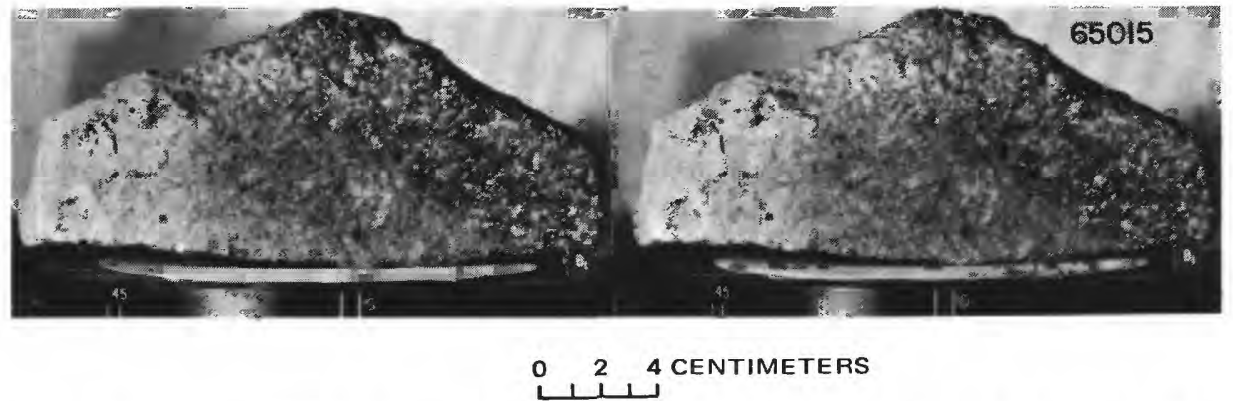

Figure 21.-Stereopair of sample 65015 , a metaclastic rock $\left(\mathrm{C}_{2}\right)$. NASA photographs S72-39209-39209B.

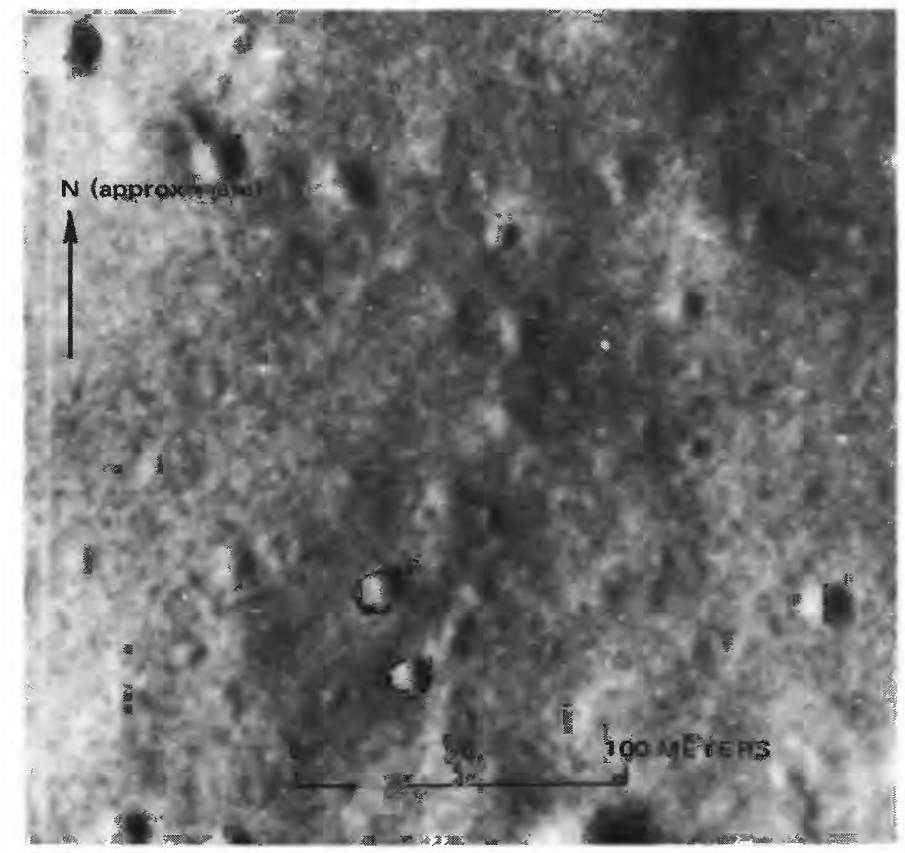

FIgURe 22.-Station 6 and vicinity. Apollo 16 panoramic camera frame 4618 . 


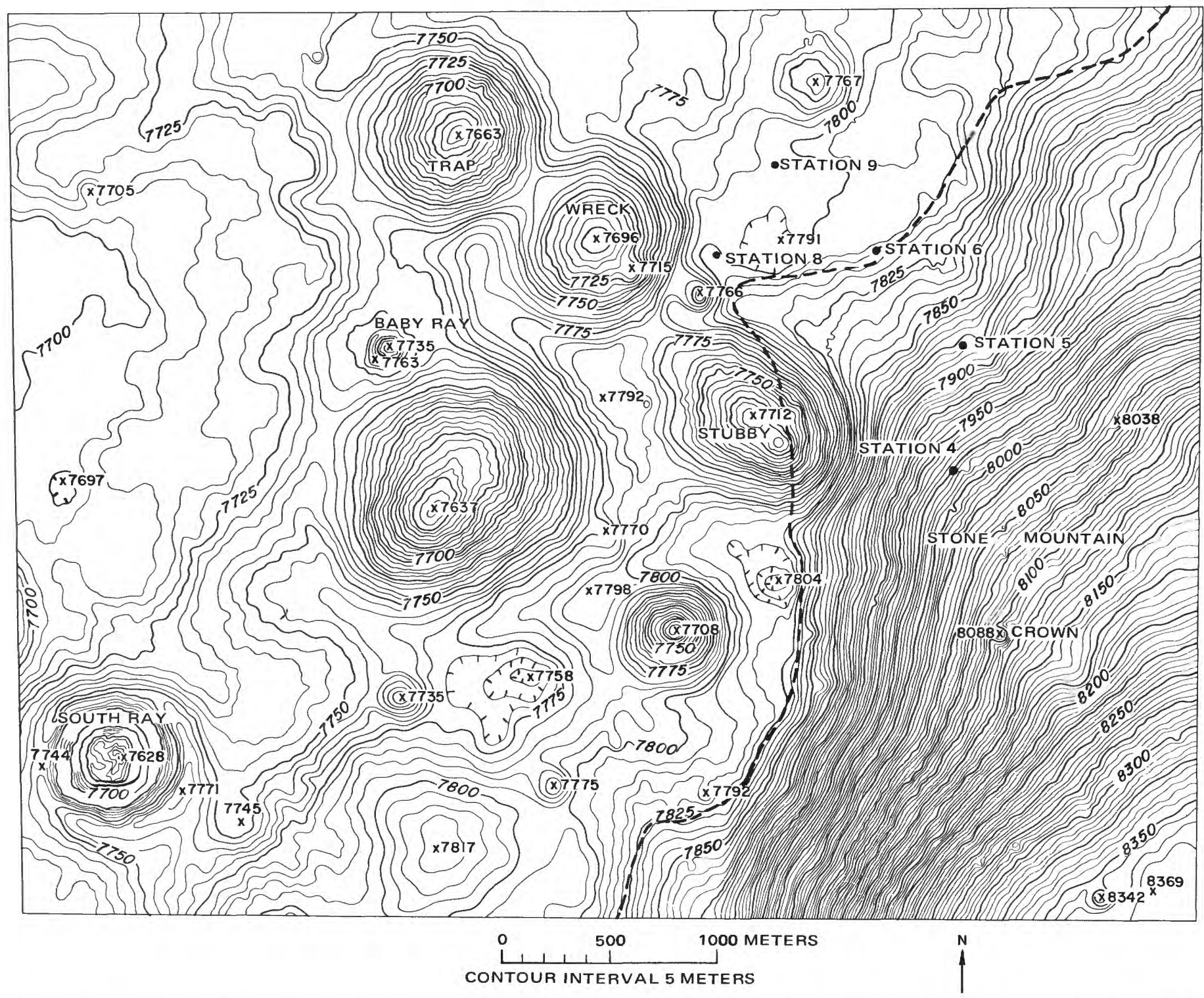

FigURE 23.-Topographic map of the Stone mountain area showing stations 4, 5, and 6 and geologic contact from Hodges (this volume, pl. 1). Photogrammetry by G. M. Nakata. 

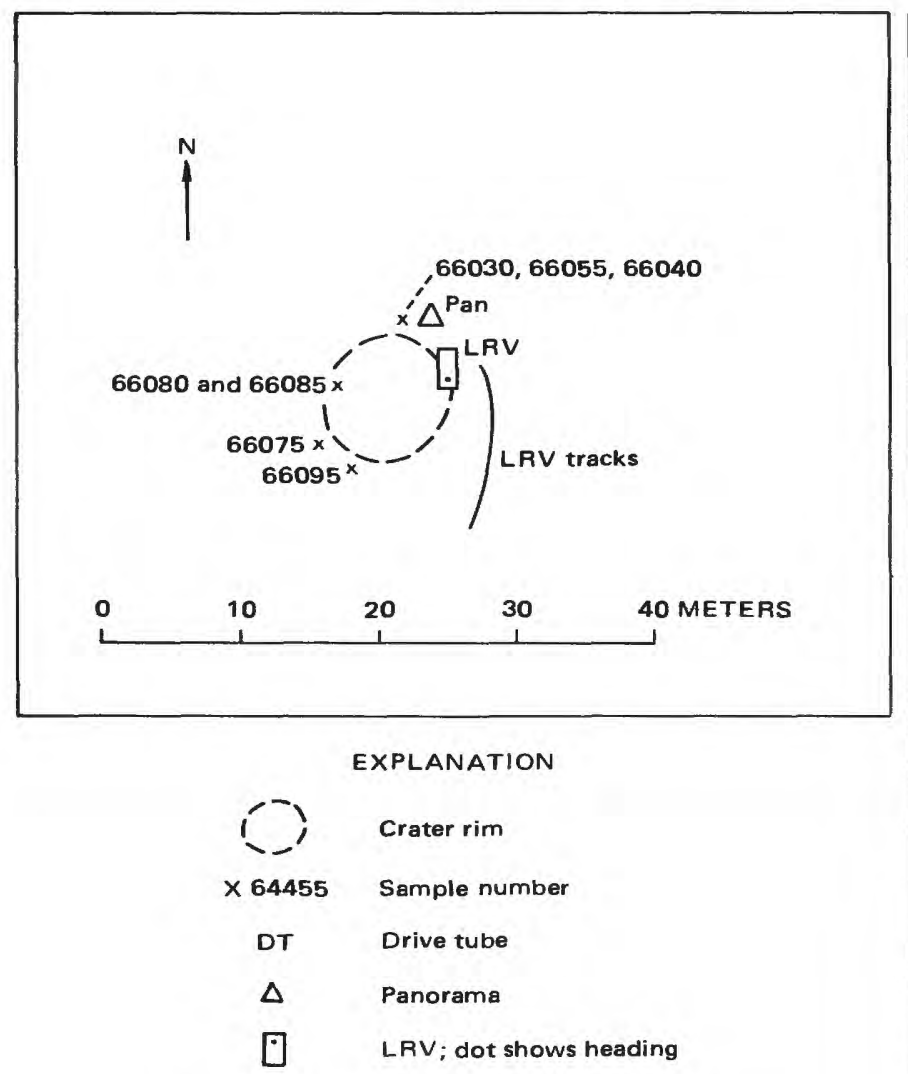

Figure 24.-Planimetric map of station 6.

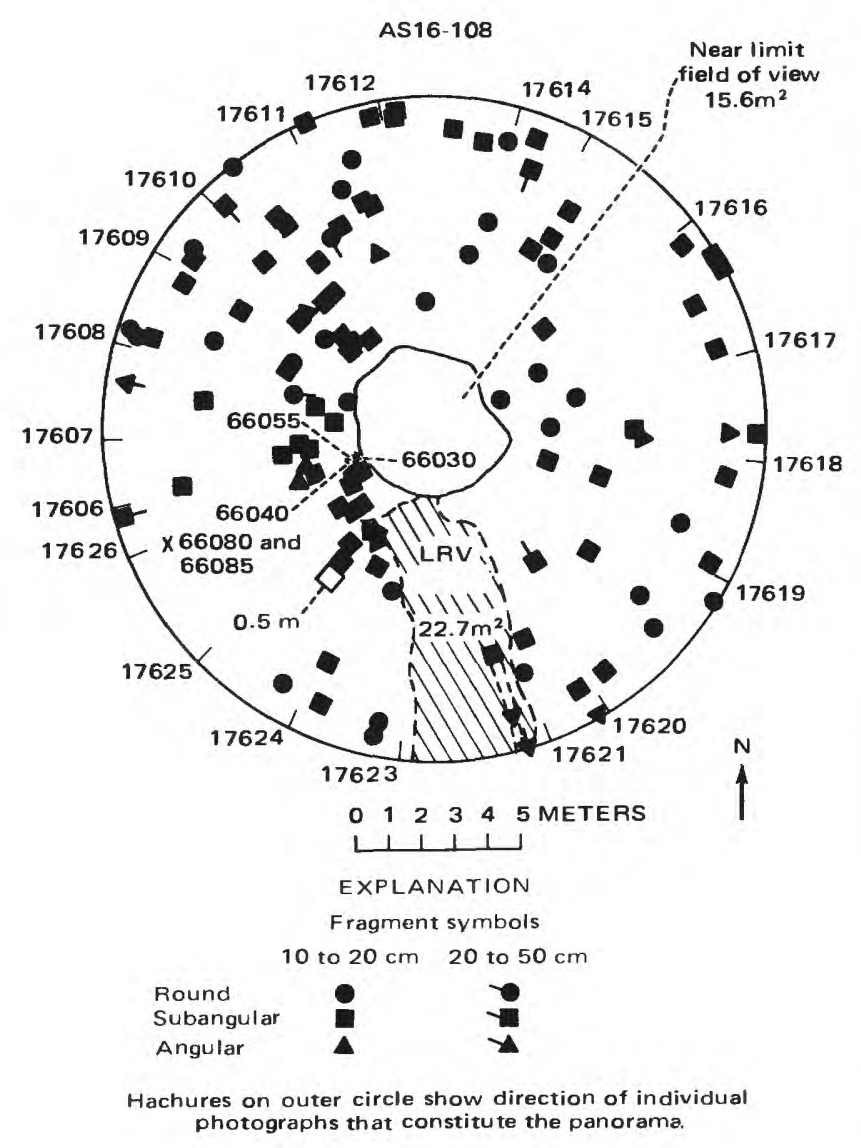

the west wall of the crater where the LRV was parked (pl. 6, pan 12; fig. 24). The surface is covered by numerous small shallow craters; only a few are as large as 10 $\mathrm{m}$. Angular blocks to $0.5 \mathrm{~m}$ are scattered throughout the area; 10 - to $20-\mathrm{cm}$ fragments are most common, covering about 1 percent of the surface, (fig. 25, table 1). As shown on plate 6 , pan 12 , the rock distribution within the subdued $10-\mathrm{m}$ crater at the LRV appears asymmetric; rocks are sparse on the southwest wall, which was probably shielded from South Ray crater ejecta.

The rocks described and photographed exhibit a wide variety of shapes and sizes. Angular glass-coated blocks are scattered over much of the surface. Small white clasts common in many of these rocks indicate that breccias predominate. Fillets are moderately developed around some rocks. Several rocks appear to be partly buried; others appear perched, suggesting that they were transported to their present location as ejecta from South Ray crater.

One white "splotch" of indurated soil, 66080, was collected from the southwest wall of the crater; the regolith elsewhere was apparently gray throughout.

Only four large rock samples were collected at station 6; all have been classified as breccias by Wilshire and others (this volume). Samples 66075 and 66035 (figs. 26 and 27A) are classified as intermediate-graymatrix breccias $\left(\mathrm{B}_{3}\right)$, with approximately equal amounts of dark and light clasts. As shown in figure $27 B, 66035$ has cataclastic texture. Sample 66055 (fig. 28 ) is a light-matrix dark-clast breccia $\left(B_{2}\right)$, described as a cataclastic anorthosite by Wilshire and others (this volume). Sample 66095 (fig. 29A) is a dark-matrix light-clast breccia $\left(\mathrm{B}_{4}\right)$. It weighs more than a kilogram and is highly fractured. The rock has been called "rusty rock" and was the first discovered to contain a significant amount of hydrated iron oxide believed to be of lunar origin (Nunes and Tatsumoto, 1973; Friedman and others, 1974). It can be described as an anorthositic breccia (LRL, 1972) with a locally recrystallized matrix (fig. $29 B, C$ ). ${ }^{40} \mathrm{Ar}-{ }^{39} \mathrm{Ar}$ data suggest that this rock was partly recrystallized by an impact event around 3.6 b.y. ago (Turner and others, 1973, p. 1899).

\section{DISCUSSION AND SUMMARY}

Stations 4 and 5 on the north slope of Stone mountain were selected as the prime localities for Descartes mountains materials. Chemical analyses and petrographic characteristics of the samples collected on Stone mountain do not differ significantly from those of

Figure 25.-Rock distribution within $10 \mathrm{~m}$ of site of station 6 panorama. See figure 12 for explanation of symbols. 


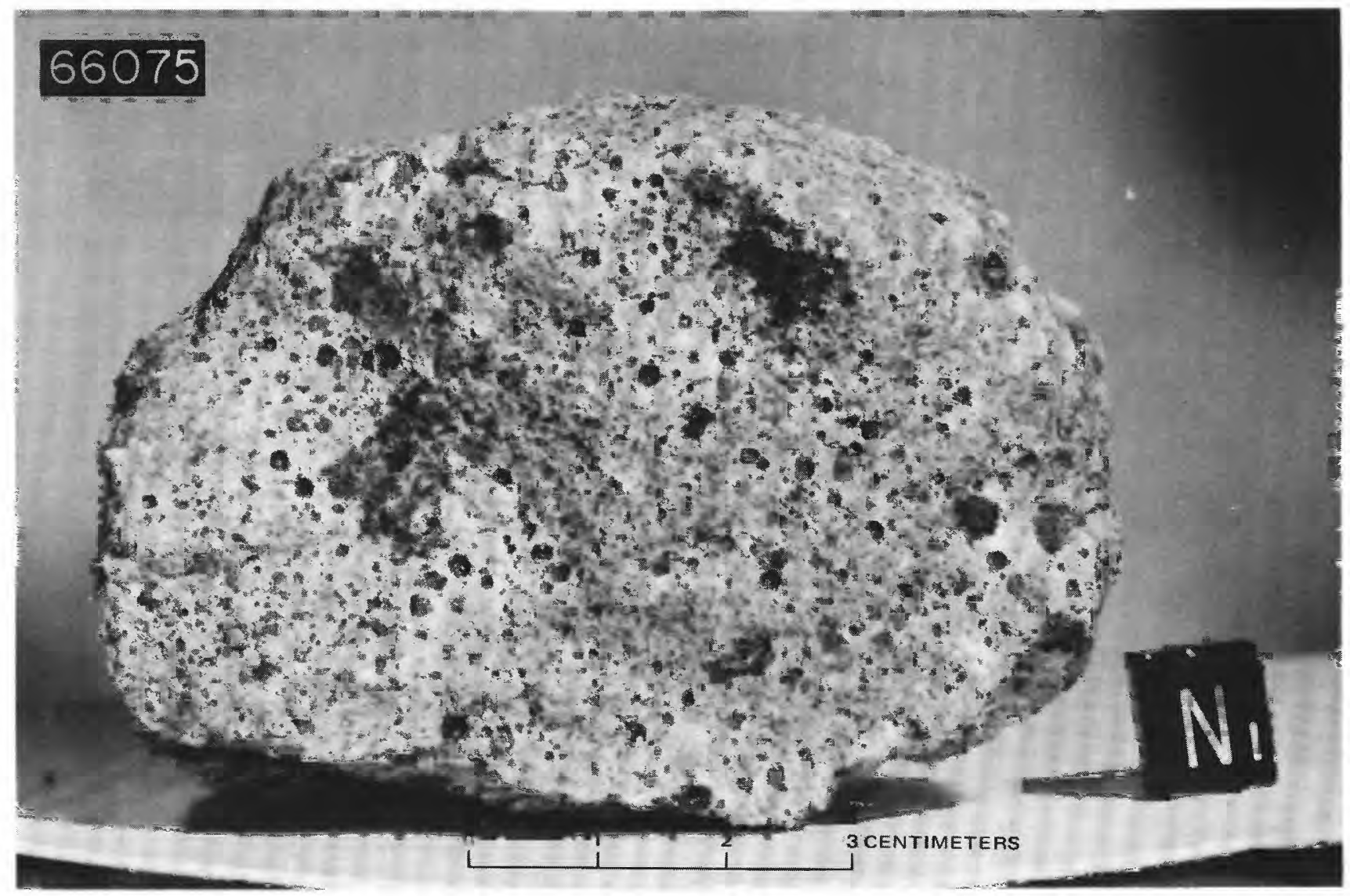

Figure 26. - Sample 66075 , a well-indurated $\mathrm{B}_{3}$ breccia. NASA photograph S-72-37203.

samples from the Cayley plains. As ray materials from South Ray crater occupy much of the landing site, it is possible that underlying Descartes bedrock may not have been sampled. Alternatively, both plains and highlands at this site may be accumulations of similar breccias. Detailed comparisons of soils and rocks from stations 5 and 6 , which lie on opposite sides of the apparent Cayley-Descartes contact, indicate no major chemical differences between the two sample suites. If the materials that formed the Descartes mountains were indeed sampled, then whatever differences exist between the two formations must be expressed by properties other than chemical composition and petrography. The greater abundance of angular blocks of the 20- to $5-\mathrm{cm}$ size fraction at station 4 can be attributed to a relatively heavy concentration of large blocks of ray material there.

From a review of surface evidence (station panorama photographs, Hasselblad 70-mm, and 16-mm photographs), it appears that station 4 may be located on the edge of a minor ray from South Ray crater. From orbit, however, no rays are visible near the station 4 location. Additional evidence for South Ray ejecta is the large asymmetric boulder field of fresh angular blocks ob- served at station 4 . Of the three stations, station 5 has the greatest percentage of rounded boulders on the surface and appears to be contaminated by few angular blocks of South Ray ejecta. Station 6 appears to be located on the edge of a ray from South Ray crater (Freeman, this volume, fig. 1), although no large block fields are visible. As station 6 is at the base of Stone mountain, Descartes materials may have accumulated by mass wasting from the mountain and may be quite thick (see Freeman, this volume). Boulder fields possibly representing South Ray ejecta were identified on 16 -mm photographs along the traverse route (fig. 30 ). Both stations 4 and 6 fall within boulder fields; station 5 does not, although it is near one.

Whether the materials making up the Descartes mountains were actually sampled remains undetermined. Stations 4 and 6 appear to be contaminated by Cayley materials ejected from South Ray crater, although the larger $(25+\mathrm{g})$ samples collected at station 4a are possibly Cinco $a$ ejecta from beneath the regolith. Station 5, which appears to be free of South Ray ejecta, may be the most promising locality from which Stone mountain material may eventually be identified in the sample collection. 

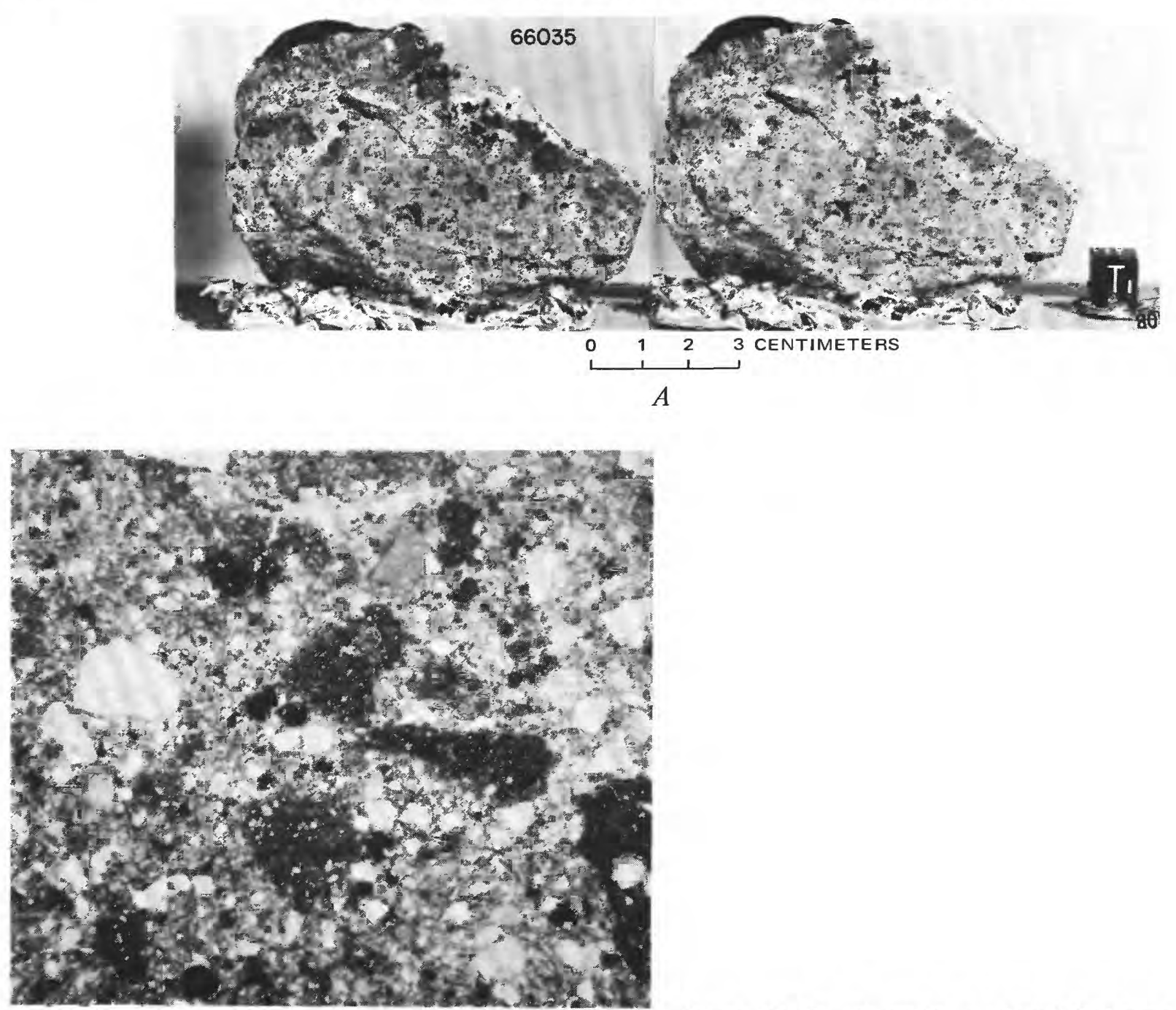

0 1 MILLIMETER

B

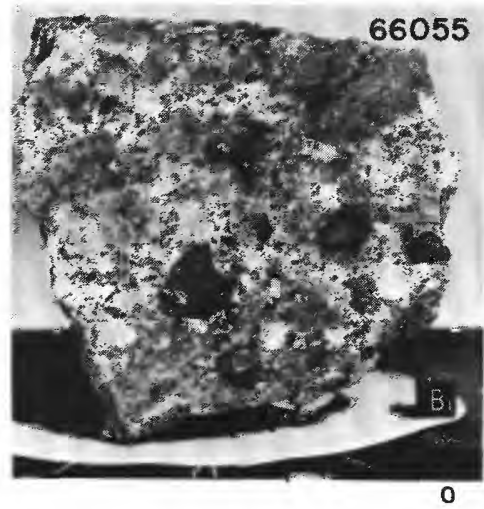

Figure 27.-Sample 66035, a coherent $\mathrm{B}_{3}$ breccia. $A$, Stereopair. NASA photographs S-72-41300-41300B. $B$, Photomicrograph showing cataclastic texture. Plane-polarized light.

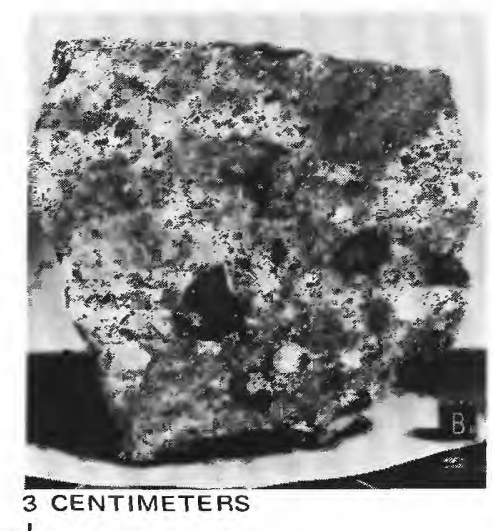

Figure 28.-Sample 66055 (stereopair), a light-matrix dark-clast $\left(\mathrm{B}_{2}\right)$ breccia. NASA photographs S-72-42722-42722b. 


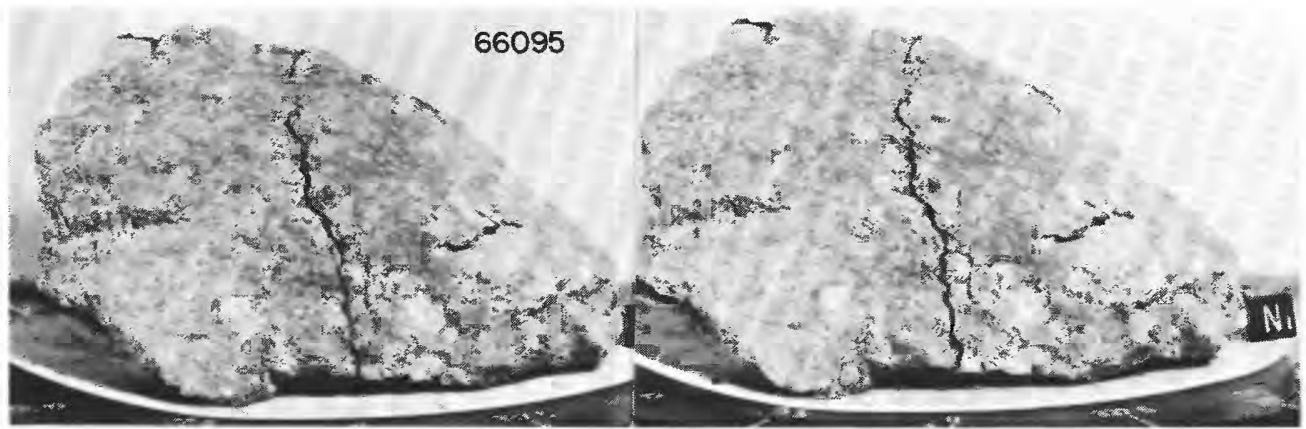

$\begin{array}{llll}0 & 1 & 2 & 3 \\ & \text { CENTIMETER }\end{array}$

A

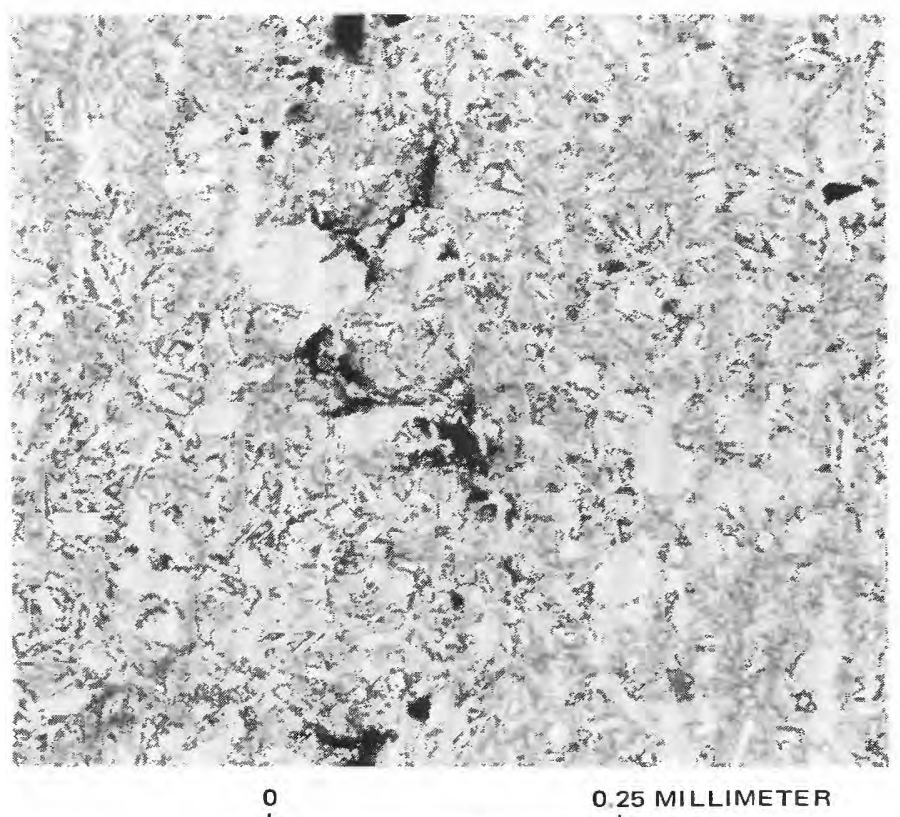

B

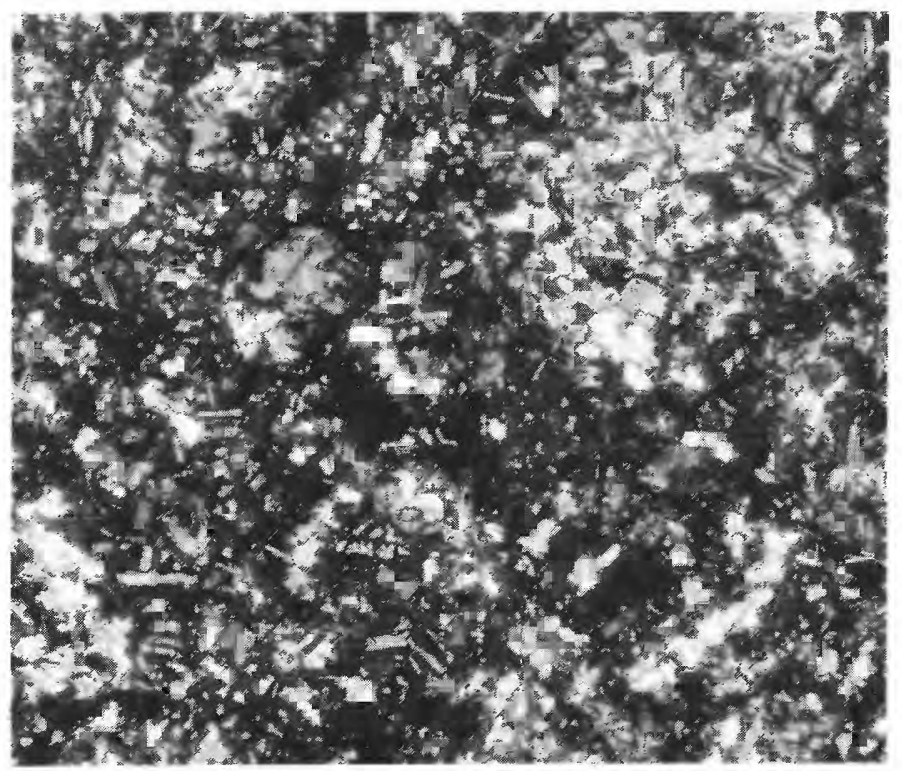

0.25 MILLIMETER

C

FIGURE 29.-Sample 66095, "rusty rock," a highly fractured dark-matrix light-clast $\mathrm{B}_{4}$ breccia. $A$, Stereopair. NASA photographs S-72-41436-41436B. B, Photomicrograph showing ophitic matrix and interstitial opaque minerals that are partly oxidized. $C$, Same as $B$, cross-polarized light. 


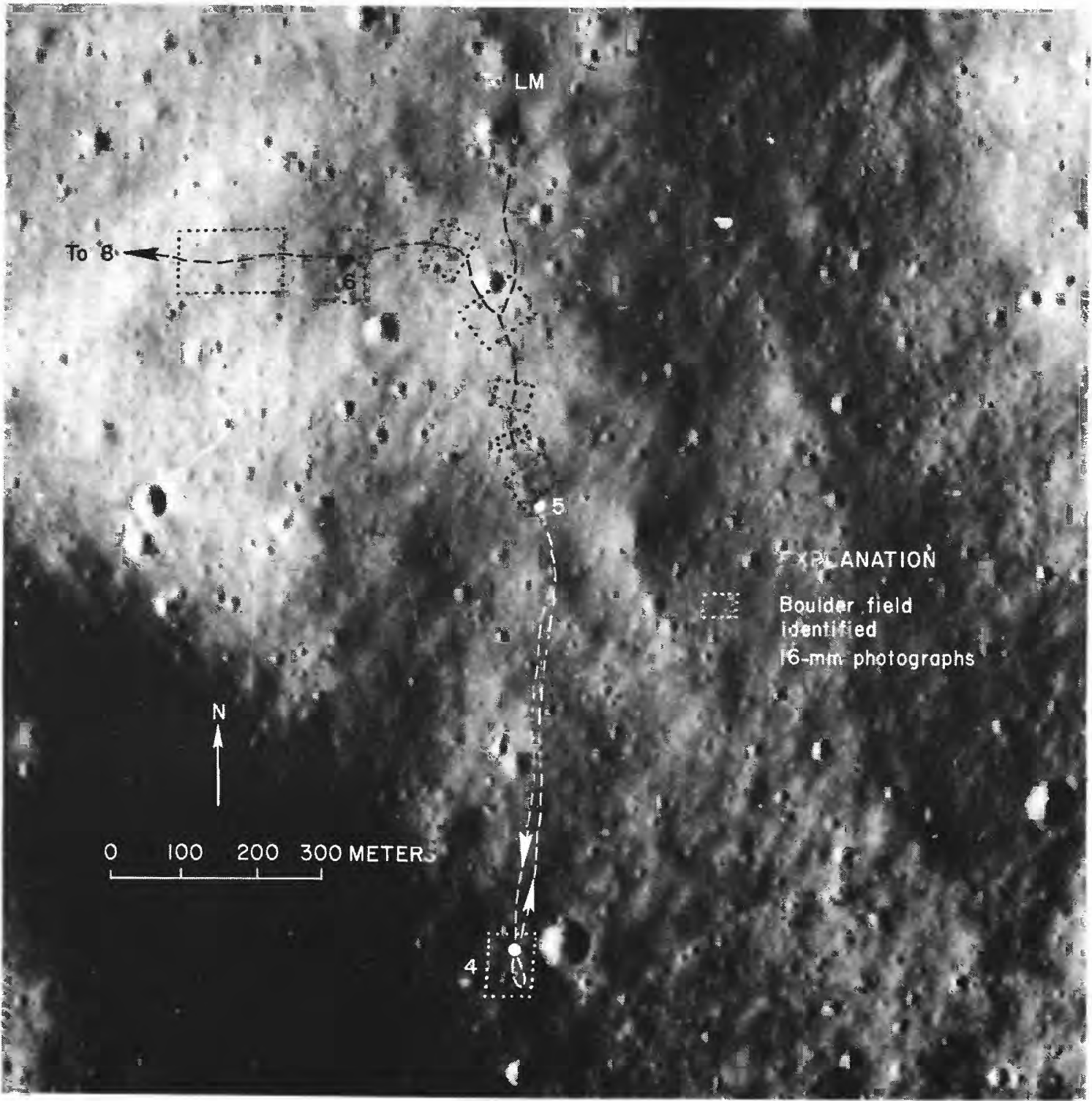

Figure 30.-Boulder fields, possibly South Ray ejecta, identified on 16-mm traverse photographs. 


\title{
E. PETROLOGY AND DISTRIBUTION OF RETURNED SAMPLES, APOLLO 16
}

\author{
By H. G. Wilshire, D. E. Stuart-Alexander, and E. C. Schwariman
}

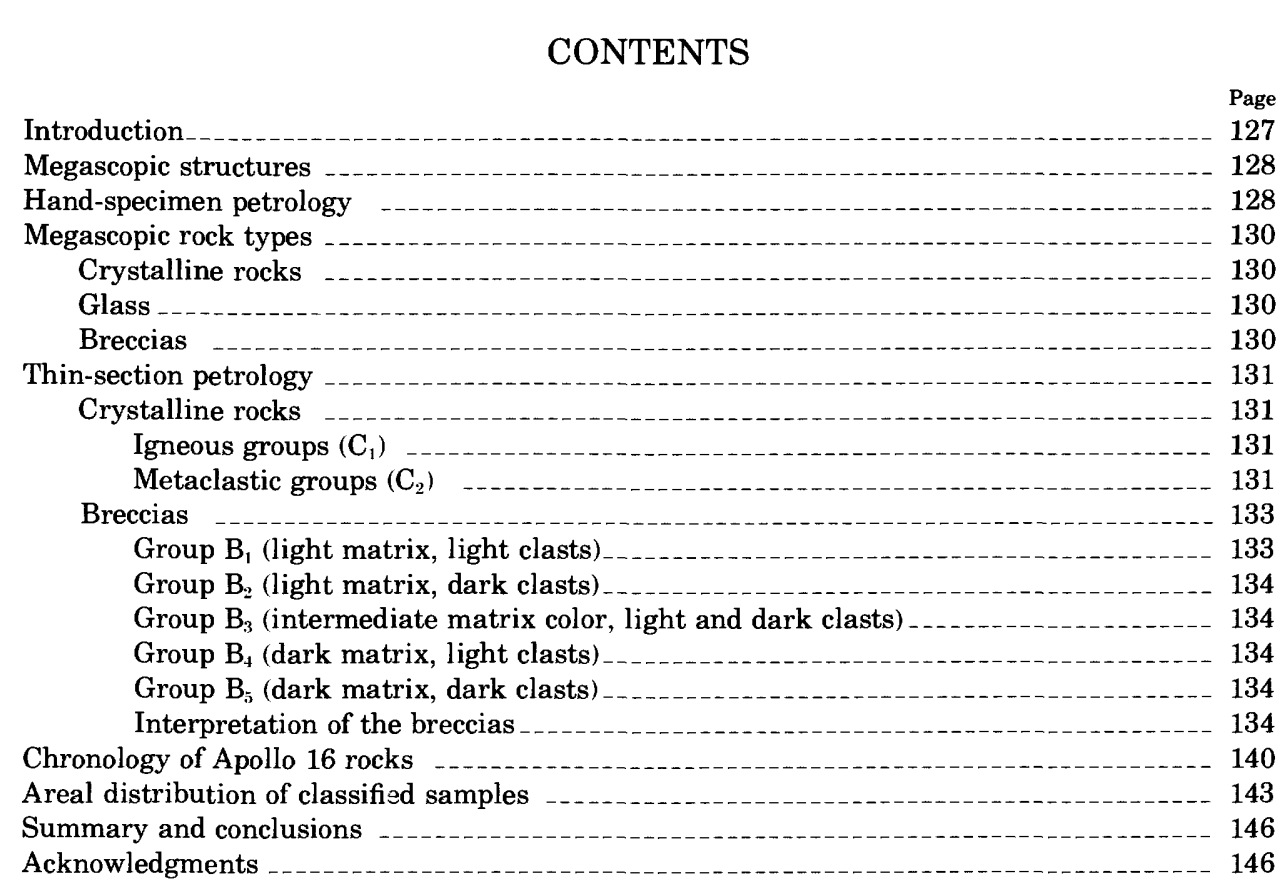

\section{ILLUSTRATIONS}

FIGURE 1. Diagram showing scheme used for classification of Apollo 16 rocks

2. Photomicrographs of Apollo 16 rocks and one Apollo 17 rock

3. Photomicrographs of Apollo 16 metaclastic rock and breccias and photograph of breccia 61015

4. Photomicrographs of Apollo 16 breccias; photograph and photomicrographs of pseudotachylites of Vredefort structure, South Africa

5. Histograms showing distribution of rock types at each sampling station

6. Composite histograms of the two groups of stations

7. Histograms showing distribution of microscopic textures at each of the two groups of stations

\section{TABLES}

1. Megascopic classification of Apollo 16 rock samples heavier than $2 \mathrm{~g}$

2. Microscopic textures of the crystalline rocks and of the matrices of the least-modified breccias

3. Degree of modification of selected Apollo 16 rocks

4. Isotope data on Apollo 16 samples

\section{INTRODUCTION}

Apollo 16 returned about $96 \mathrm{~kg}$ of samples, collected by astronauts Young and Duke over a distance of about $20 \mathrm{~km}$ during the three traverses. About 75 percent of the total by weight are rock fragments larger than 1 $\mathrm{cm}$. The station locations are known for all rocks; 47 rocks heavier than $20 \mathrm{~g}$ (excluding rake samples) have been identified and oriented using lunar surface photographs (Sutton, this volume).

Apollo 16 rocks, like the samples returned by Apollo 14 and nonmare samples returned by Apollos 15 and 
17 , are predominantly fragmental: they consist of clasts (larger than $1 \mathrm{~mm}$ ) and microclasts $(0.1-1 \mathrm{~mm})$ of glass, minerals, and lithic fragments in generally fine-grained matrices. Homogeneous crystalline rocks constitute a small proportion of the samples and have their counterparts as clasts in or matrix components of the breccias; a number of such rocks were collected directly from breccias or were dislodged from breccia samples in transit. It is therefore likely that all the crystalline rocks are either breccia clasts or pieces of breccia matrix.

\section{MEGASCOPIC STRUCTURES}

Reports by the Field Geology Team (Muelhberger and others, 1972) briefly describe fractures and discontinuous color bands in some large breccia boulders photographed by the astronauts. The fractures are multiple sets of irregular to planar joints. Irregular discontinuous light-colored lenses occur in Shadow rock at station 13 (Ulrich, this volume, fig. 9); study of samples suggests that this type of layering results from cataclastic flow of relict feldspathic clasts as a consequence of multiple brecciation.

In addition to planar fractures, hand specimens reveal two structures not visible in most surface photographs: glass coatings and thin light-colored veins. The glass in breccias occurs in three ways in addition to clasts: (1) exterior veneers that have sharp contacts with the coated rock; (2) selvages that have gradational boundaries with the coated rock; (3) veins that commonly form complex anastomosing networks. Thin glass was injected as impact melt into fractures or formed by fusion along fractures beneath a transient impact crater (Wilshire and Moore, 1974). As the crater grew, the glass was excavated by disaggregation along the same fracture systems. The light-colored veins appear to be largely unannealed mineral debris derived from feldspathic clasts and injected into cracks in the breccia matrices. These cracks and the mobilization of crushed feldspathic material apparently result from multiple impact events (Wilshire and others, 1973).

\section{HAND-SPECIMEN PETROLOGY}

The hand-specimen petrology of Apollo 16 rocks was described by Wilshire and others (1973) and will not be repeated in detail. Subsequent examination of thin sections, however, has led to revision of sample classification (table 1) and pointed up the gradational character of the class boundaries. All sources of information available to us were used to compile table 1: our own extensive examination of the samples as members of the Preliminary Examination Team, the Apollo 16 sample information catalog (LRL, 1972), rake sample catalogs (Keil and others, 1972; Phinney and Lofgren, 1973), and other published sources cited in table 2 .

The 468 samples heavier than $2 \mathrm{~g}$ are placed in three major groups, crystalline rocks, glasses, and breccias, and these are further subdivided into nine categories (table 1, fig. 1): two $\left(\mathrm{C}_{1}\right.$ and $\left.\mathrm{C}_{2}\right)$ are subdivisions of the crystalline rocks; one $(G)$ consists of glass; five $\left(B_{1}-B_{5}\right)$ are subdivisions of the breccias; and one (U) consists of unclassified samples. The class boundaries are not rigid, and ambiguities arise in classifying certain rocks. In hand specimen, the finest grained crystalline rocks can be subdivided as "igneous" $\left(\mathrm{C}_{1}\right)$ or "metaclastic" $\left(\mathrm{C}_{2}\right)$ only on the basis of crystallinity and occurrence of angular mineral debris; some thin sections show that even rocks containing comparatively large amounts of mineral debris may have a predominantly igneous texture or a texture that is not easily classified as either igneous or metamorphic. The distinction between fine-grained crystalline rocks and dark-matrix breccias is somewhat arbitrary. The crystalline rocks are generally lighter in color because of coarser grain size and the absence of conspicuous lithic clasts. The matrices of dark-matrix breccias, however, have finer grained igneous or metamorphic textures of the same types as the crystalline rocks. Breccias may be assigned to the $B_{2}$ class (light matrix, dark clasts) rather than $B_{1}$ (light matrix, light clasts) on the basis of a few dark clasts seen in hand specimens that may not have been thin sectioned. The $B_{3}$ group is intermediate in color mainly because of the development of matrix glass. Many of these rocks are the so-called soil breccias, but they may have originated in the same way as some multiply brecciated but little-melted rocks classed as $B_{2}$ breccias or some multiply brecciated and extensively melted rocks classed as $\mathrm{B}_{4}$ or $\mathrm{B}_{5}$ breccias. As certain samples (designated $(\mathbf{F})$ in table 1 ) are known to be nonrepresentative parts of larger rocks, the classification should be used in conjunction with the sample documentation report (ALGIT, 1972b, and Sutton, this volume). And a number of rocks classified as $\mathrm{B}_{4}$ breccias have light-colored fragmental material adhering to one or more surfaces, suggesting that they are clasts from breccias. Despite these practical and conceptual difficulties, classification on the basis of megascopic properties, with subdivision based on available data from microscopy, has the advantage of describing the sample as a whole, whereas many thin sections are known to be quite unrepresentative of the sample. Representative sampling by thin section is generally difficult because of the great complexity im- 
TABLE 1.-Megascopic classification of Apollo 16 rock samples greater than 2 grams

[Sample number in parentheses, tentative identification based on cursory laboratory description. (F), sample nonrepresentative piece from a larger rock. Letter and class number in parentheses, possible alternative classification. (B), possible exotic mare basalt sample]

\begin{tabular}{|c|c|c|c|c|c|c|c|c|}
\hline \multicolumn{2}{|c|}{ Crystalline } & \multirow[t]{3}{*}{ Glass } & \multirow[t]{3}{*}{ Unclassified } & \multicolumn{5}{|c|}{ Breccia } \\
\hline \multirow[b]{2}{*}{ Igneous } & \multirow[b]{2}{*}{ Metaclastic } & & & \multicolumn{2}{|c|}{ Light matrix } & \multirow{2}{*}{ 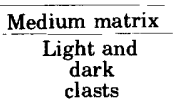 } & \multicolumn{2}{|c|}{ Dark matrix } \\
\hline & & & & $\begin{array}{l}\text { Light } \\
\text { clasts }\end{array}$ & $\begin{array}{l}\text { Dark } \\
\text { clasts }\end{array}$ & & $\begin{array}{l}\text { Light } \\
\text { clasts }\end{array}$ & $\begin{array}{l}\text { Dark } \\
\text { clasts }\end{array}$ \\
\hline$\overline{\mathrm{C}_{1}}$ & $\mathrm{C}_{2}$ & G & $\mathrm{U}$ & $\mathrm{B}_{1}$ & $\mathrm{~B}_{2}$ & $\mathrm{~B}_{3}$ & $\mathrm{~B}_{4}$ & $\overline{B_{5}}$ \\
\hline $\begin{array}{c}60335 \\
60615 \\
60635 \\
(61576) \\
62295 \\
(63506) \\
65055 \\
65785 \\
65795 \\
67936 \text { (F) } \\
67956 \text { (F) } \\
68415 \\
68416 \\
69955(\mathrm{~F})\end{array}$ & $\begin{array}{l}60235 \\
60315 \\
60525\left(\mathrm{~B}_{4}\right) \\
60526 \\
(60527) \\
60616 \\
60619 \\
60625 \\
60626 \\
60627 \\
60636 \\
61156 \\
61225 \\
62235 \\
(62245) \\
(63537) \\
(63538) \\
(63545) \\
(63547) \\
(63549) \\
(63556) \\
(63558) \\
(63585) \\
64455 \\
64576 \\
64815(\mathrm{~B}) \\
64817 \\
65015 \\
65357 \\
65358 \\
65365 \\
65777 \\
65778 \\
65779 \\
(65905) \\
(65906) \\
(67485) \\
(67487) \\
(67488) \\
(67489) \\
(67559) \\
67565 \\
67566 \\
67615 \\
67616 \\
67617 \\
67618 \\
67619 \\
67625 \\
67667(\mathrm{~B}) \\
67668 \\
67676 \\
67736 \\
67746 \\
67747 \\
67748 \\
(67935)(\mathrm{F}) \\
(68525) \\
(68526) \\
(68527) \\
(68535) \\
69945\end{array}$ & $\begin{array}{c}60095 \\
60528 \\
60646 \\
60665 \\
60666 \\
60668 \\
60669 \\
60677 \\
60679 \\
61157 \\
61158 \\
(61195) \\
61546 \\
61547 \\
61548 \\
61549 \\
61555 \\
61556 \\
61558 \\
(63559) \\
(63566) \\
(63567) \\
(63568) \\
(63575) \\
65016 \\
65056 \\
65348 \\
65349 \\
(65355) \\
(65356) \\
65366 \\
65585 \\
65586 \\
65587 \\
(65767) \\
(65768) \\
(65769) \\
(65775) \\
(65776) \\
67095 \\
67567 \\
67568 \\
67569 \\
67575 \\
67576 \\
67626 \\
67627 \\
67628 \\
67629 \\
(67705) \\
67728 \\
67729 \\
(68529)\end{array}$ & $\begin{array}{l}60617 \\
61017 \\
61245 \\
61246 \\
61247 \\
62285 \\
62286 \\
62287 \\
64505 \\
64506 \\
64507 \\
64508 \\
64509 \\
64515 \\
64516 \\
65908 \\
65909 \\
65915 \\
66085 \\
66086 \\
67215 \\
67235 \\
67557 \\
67558 \\
67647 \\
67706 \\
68825 \\
68845 \\
68846 \\
68847\end{array}$ & $\begin{array}{c}60015 \\
60025 \\
60035 \\
60055 \\
60056 \\
60057 \\
60058 \\
60135 \\
60215 \\
60515 \\
60516 \\
60618 \\
60628 \\
60629 \\
62236 \\
62237 \\
62246 \\
64589 \\
64819 \\
(65588) \\
(65759) \\
65789 \\
67075 \\
67415 \\
(67486) \\
67635 \\
67636 \\
67637 \\
67955\end{array}$ & 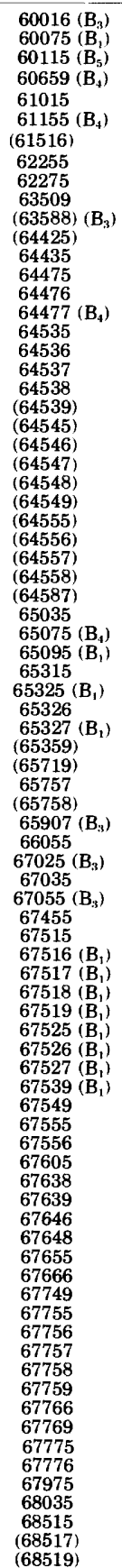 & 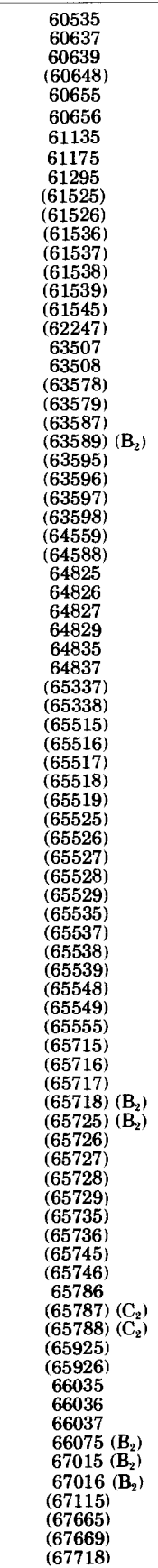 & $\begin{array}{l}60017\left(\mathrm{~B}_{5}\right) \\
60018 \\
60255 \\
60275 \\
60645 \\
(60657) \\
(60658) \\
60667 \\
60676 \\
61016 \\
61568 \\
61569 \\
(61575) \\
63355 \\
(63505) \\
(63525) \\
(63526) \\
(63527) \\
(63528) \\
(63529) \\
(63535) \\
(63546) \\
(63555) \\
(63557) \\
(63577)\left(\mathrm{C}_{2}\right) \\
64478\left(\mathrm{~B}_{3}\right) \\
(64565) \\
(64566) \\
(64567) \\
(64568) \\
(64569) \\
(64575) \\
(64577) \\
(64578) \\
(64579) \\
(64585) \\
(64586) \\
64816\left(\mathrm{C}_{2}\right) \\
64818\left(\mathrm{C}_{2}\right) \\
66095 \\
(67435) \\
67475(\mathrm{~F}) \\
67715 \\
67716 \\
67717 \\
67719 \\
67725 \\
67726 \\
67737 \\
67738 \\
67739 \\
67745 \\
67915 \\
67937(\mathrm{~F}) \\
67945 \\
(67946) \\
(67947) \\
(68516) \\
(68518) \\
69935 \\
\end{array}$ & $\begin{array}{l}60019 \\
(63335) \\
67735\left(B_{3}\right) \\
68115 \\
68815\end{array}$ \\
\hline
\end{tabular}


TABLE 2.-Microscopic textures of the crystalline rocks and of the matrices of the least-modified breccias

[Parentheses enclose station numbers]

\begin{tabular}{|c|c|c|c|}
\hline Igneous & Pokiloblastic & Granoblastic & $\begin{array}{l}\text { Glassy or } \\
\text { fragmental }\end{array}$ \\
\hline $\begin{array}{l}60016 \text { (LM-ALSEP) } \\
60018 \text { (LM-ALSEP) } \\
60019 \text { (LM-ALSEP) } \\
60335 \text { (LM-ALSEP) } \\
60615 \text { (LM-ALSEP) } \\
60618 \text { (LM-ALSEP) } \\
60635 \text { (LM-ALSEP) } \\
60667 \text { (LM-ALSEP) } \\
61015(1) \\
61016(1) \\
62295(2) \\
63506(13) \\
64476(4) \\
64477(4) \\
65035(5) \\
65075(5) \\
65095(5) \\
65359(5) \\
65719(5) \\
65785(5) \\
65795(5) \\
66055(6) \\
66095(6) \\
67025(11) \\
67936(11) \\
67937(11) \\
67956(11) \\
68415(8) \\
68416(8)\end{array}$ & $\begin{array}{l}60255 \text { (LM-ALSEP) } \\
60275 \text { (LM-ALSEP) } \\
60315 \text { (LM-ASLEP) } \\
60526 \text { (LM-ALSEP) } \\
60616 \text { (LM-ALSEP) } \\
60625 \text { (LM-ALSEP) } \\
60645 \text { (LM-ALSEP) } \\
61156 \text { (1) } \\
63505 \text { (13) } \\
64435(4) \\
64478(4) \\
65015(5) \\
65055(5) \\
65356(5) \\
65357(5) \\
65778(5) \\
67435(11) \\
67945(11) \\
68035(8)\end{array}$ & $\begin{array}{l}60115 \text { (LM-ALSEP) } \\
61155 \text { (LM-ALSEP) } \\
65338 \text { (5) } \\
67946(11) \\
67955 \text { (11) } \\
67975(11)\end{array}$ & $\begin{array}{l}60017 \text { (13) } \\
60535 \text { (LM-ALSEP) } \\
60655 \text { (LM-ALSEP) } \\
60656 \text { (LM-ALSEP) } \\
61135 \text { (1) } \\
61175 \text { (1) } \\
61295(1) \\
63507(13) \\
63335(13) \\
66036(6) \\
67015(11) \\
67016(11) \\
67035(11) \\
67075(11) \\
67445(11) \\
67475(11) \\
67735(11) \\
67915(11) \\
68815(8) \\
69935(9)\end{array}$ \\
\hline
\end{tabular}

posed by small-scale changes in degree of granulation and lithologic mixing, degree of melting and thermal metamorphism, and degree of admixture from the projectiles that caused brecciation. Moreover, fewer than 25 percent of the samples have been thin-sectioned at this time (1974).

\section{MEGASCOPIC ROCK TYPES}

The three rock groups and the number to which samples are assigned are defined by their principal characteristics.

\section{CRYSTALLINE ROCKS}

Of the 76 samples classified as crystalline (table 1 ), 14 (group $\mathrm{C}_{1}$ ) appear to be fine- to coarse-grained igneous rocks. They are highly feldspathic, containing irregular plagioclase inclusions up to $10 \mathrm{~mm}$ across and irregularly scattered crystal-lined vugs. Sixty-two crystalline rocks (group $\mathrm{C}_{2}$ ) appear to be metaclastic rocks containing variable amounts of fine angular mineral and lithic debris. The matrix of some is so fine grained that igneous and metamorphic textures cannot be distinguished in hand specimen.

The few rocks that have been thin sectioned are classified in table 2. Two samples of this group, 64815 and 67667, appear in hand specimen to be crushed and annealed mare basalts with ilmenite in about the same proportion given for Apollo 12 and 15 mare basalts.

\section{GLASS}

Of the 53 glass samples, two are spheres, the rest irregular glass fragments and coarse agglutinates containing small amounts of mineral and lithic debris.

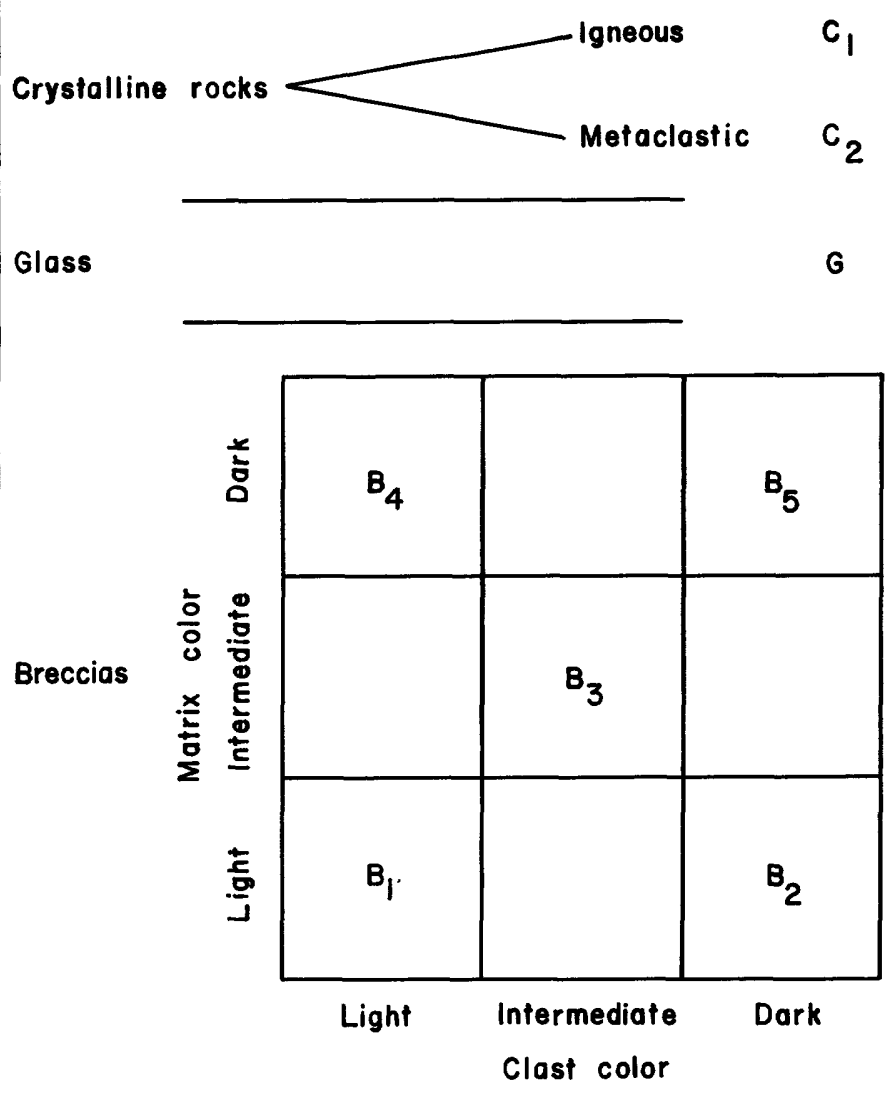

Figure 1.-Scheme used for classification of Apollo 16 rocks. From Wilshire and others (1973).

Many of these samples may have spalled from meltveneered ejecta while the veneer was still molten.

\section{BRECCIAS}

The fragmental rocks are divided into five groups according to proportions of light- and dark-gray clasts and matrix color (fig. 1). Although there are clasts of all shades of gray and of varying crystallinity, two types are clearly dominant: (1) dark-gray aphanitic to finely crystalline hard lithic fragments and (2) white to light-gray partly crushed to powdered feldspathic fragments. Matrices are of mainly three types: lightand medium-gray matrices, generally friable and not visibly altered by thermal events; dark matrices that are made coherent by fusion and thermal metamorphism.

On the basis of clasts and matrices, the 263 samples of breccia are classified into five types, in order of abundance: (1) light matrix breccias with dark clasts (B. $\mathrm{B}_{2}-85$ samples); (2) breccias with medium-gray matrices and roughly equal proportions of light and dark clasts ( $B_{3}-83$ samples); (3) dark-matrix breccias with light clasts $\left(\mathrm{B}_{4}-60\right.$ samples); (4) light-matrix breccias with light clasts $\left(\mathrm{B}_{1}-30\right.$ samples); and (5) dark-matrix breccias with dark clasts $\left(\mathrm{B}_{5}-5\right.$ samples). Because 
clasts of the same color as the matrix are harder to identify, the $B_{1}$ and $B_{5}$ breccias may be more abundant than indicated. Thirty samples (table 1 ) remain unclassified for lack of adequate catalog descriptions and photographs. All are small, and none appear in any way unusual.

\section{THIN-SECTION PETROLOGY}

Thin sections have been studied of 77 samples examined in hand specimen. Although statistics on the clasts in breccias have not yet been compiled, textural characteristics and qualitative data on rock-type distribution allow preliminary subdivision of the megascopic classification.

\section{CRYSTALLINE ROCKS}

\section{IGNEOUS GROUPS $\left(\mathrm{C}_{1}\right)$}

Of the 14 samples of igneous group $\mathrm{C}_{1}$, only two (61576 and 69955) appear to be coarse-grained plutonic rocks; one (65785) is composite coarse- and fine-grained rock. Sample 61576, a 6-g rock, may be a single large grain of plagioclase with a glass coating (Phinney and Lofgren, 1973); 69955, coarse-grained polycrystalline rock, probably is more than 95 percent plagioclase (see Rose and others, 1973), making it one of the few true lunar anorthosites (Wilshire and Jackson, 1972b; Jackson and others, 1975). Sample 65785 (Dowty and others, 1974a) consists of a small fragment of spinel troctolite in a fine-grained feldspathic igneous matrix having essentially the same minerals and bulk composition as the troctolite.

The remaining 11 samples in group $C_{1}$ are finegrained rocks, consisting of approximately 60 percent or more very calcic plagioclase, magnesian olivine and pyroxenes, and metallic $\mathrm{Fe}-\mathrm{Ni}$ with or without magnesian spinel and a variety of minor phases (Dowty and others 1974a; LSPET, 1973; Agrell and others, 1973; Hodges and Kushiro, 1973; Gancarz and others, 1972; Helz and Appleman, 1973; Brown and others, 1973). Textures of these rocks range from intersertal, subspherulitic ("radiate") through fine-grained ophitic to intergranular. All are characterized by abrupt variations in crystallinity and texture (fig. $2 A$ ), due partly to incomplete melting of inclusions $(60335,60615,60635$, $65796,68415,68416$ ) and partly to proximity to vugs, where the grain size is typically coarser (especially $68415,65055)$. In some rocks $(65055,68415,68416)$ a few large plagioclase grains appear to be euhedral phenocrysts (fig. $2 B$ ), but similar grains in sample 60618 (Dowty and others, 1974a) are almost certainly derived by disaggregation and incomplete melting of a coarse-grained spinel-olivine anorthosite into which the fine-grained igneous-textured rock grades. The proportion of unmelted mineral debris is extremely variable, ranging from negligible in 60635 to probably more than 25 percent in samples 60335 and 65795 .

Textural similarity of these fine-grained feldspathic igneous rocks to terrestrial impact melts (Grieve and others, 1974) suggests that they are products of wholerock impact melting. This interpretation, supported by a number of workers (among them, Agrell and others, 1973; Wilshire and others, 1973; Dowty and others, 1974a; Walker and others, 1973; Helz and Appleman, 1973), is substantiated by common occurrence of unmelted relics derived from coarse-grained rocks. This class of rocks has a bulk composition spread like that of cataclastic plutonic clasts in breccias (essentially troctolitic, 62295 and 60335 , to anorthositic, 65795); gradations from melt texture through disaggregated fragments of plutonic rock with interstitial melt texture to plutonic rock of essentially the same bulk composition further support an origin of the fine-grained igneous rocks by impact melting of plutonic rocks. Textures of breccia matrices formed by melting of plutonic feldspathic rocks differ from those of group $\mathrm{C}_{1}$ melt rock only by being finer grained and more variable.

Departures in bulk composition of the melt rocks from single plutonic rock types are to be expected and may result from melting of soils or mixed breccias (Dowty and others, 1974a), homogenization of lithologically layered rocks (see Grieve and others, 1974), and contributions from the projectile that caused melting (see Moore, 1969). Partial melting (Warner and others, 1974) has been postulated as a cause of variation in melt rocks but does not seem likely to be a critical consequence of impact melting (Grieve and others, 1974).

\section{METACLASTIC GROUPS $\left(\mathrm{C}_{2}\right)$.}

The 11 metaclastic rocks examined in thin section, all have poikiloblastic texture except 60619 , which has a medium-grained granoblastic texture that resembles the textures formed by local recrystallization within plutonic igneous rocks (Wilshire, 1974).

The remaining 10 samples consist of variable proportions of angular mineral and lithic debris and small euhedral plagioclase crystals partly to wholly enclosed in larger anhedral mafic mineral grains (oikocrysts) and interstitial "diabasic" material. This constitutes what is termed a poikilitic texture by those favoring an igneous origin of the texture (Simonds and others, 1973; Warner and others, 1973; Crawford, 1974), a poikiloblastic texture by those favoring a metamorphic origin (Wilshire and others, 1973; Bence and others, 1973; Albee and others, 1973b; Hodges and Kushiro, 1973). Angular mineral debris, which occurs either as inclusions in, or interstitial to, mafic oikocrysts, is predominantly plagioclase and olivine, both commonly 

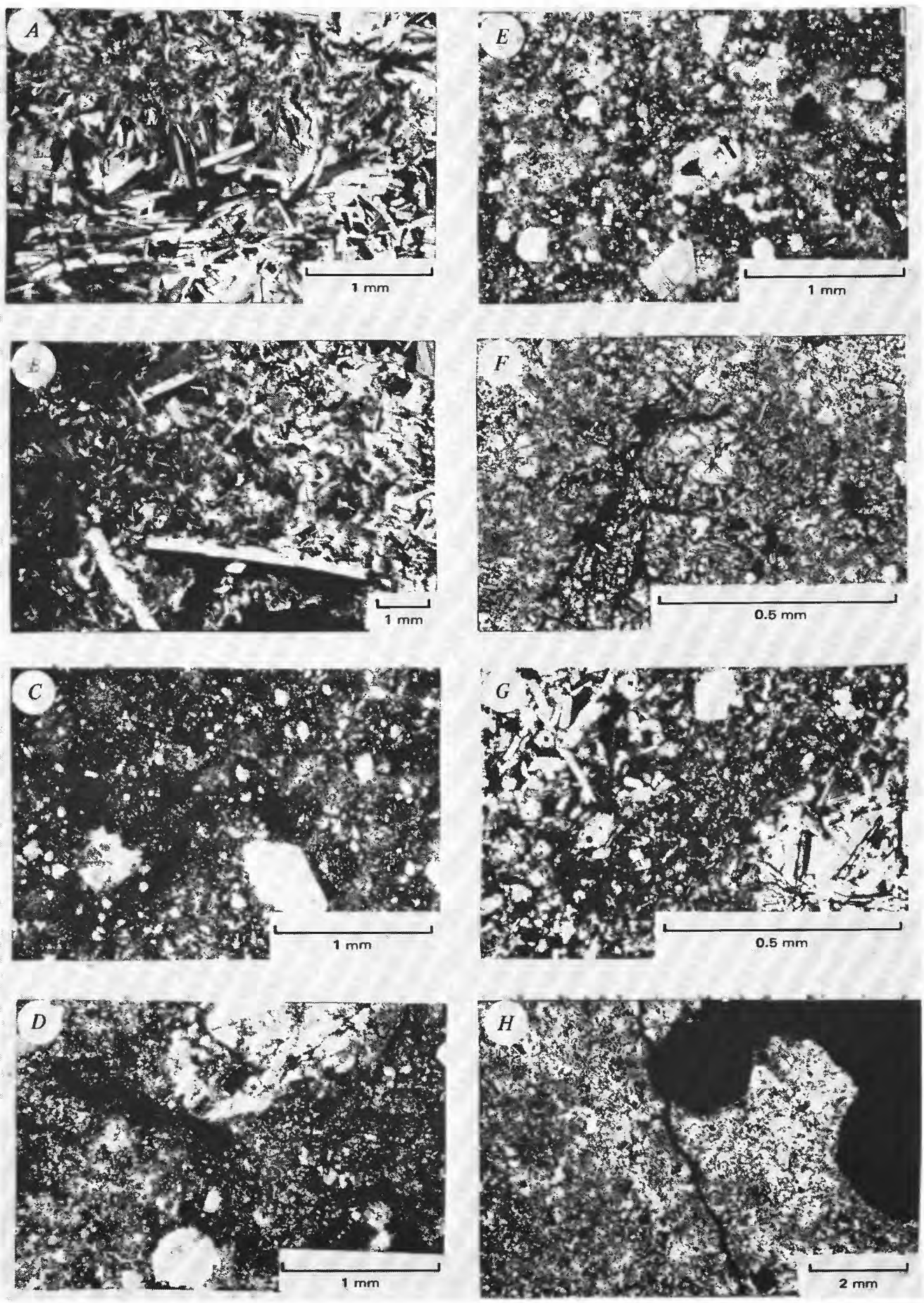

Figure 2.-Photomicrographs of Apollo 16 crystalline rocks and one Apollo 17 rock. A, Sample 68415 (group $\mathrm{C}_{1}$ ), showing textural variations within an impact melt that cooled moderately slowly. Cross-polarized light. $B$, Sample 65055 (group $\mathrm{C}_{1}$ ), showing inequigranular texture within an impact melt that cooled moderately slowly. Cross-polarized light. $C$, Sample 60616 (group $\mathrm{C}_{2}$ ), showing fine-grained poikiloblastic texture. Mafic minerals do not interlock; areas between them have granoblastic texture. Cross-polarized light. $D$, Sample 60625 (group $\mathrm{C}_{2}$ ), medium-grained poikilobastic texture. Mafic minerals interlock; enclosed minerals dominantly very fine grained, anhedral. Cross-polarized light. $E$, Sample 65778 (group $C_{2}$ ), showing coarse-grained poikiloblastic texture. Mafic minerals interlock; note unusual amount of mineral debris (light color). Cross-polarized light. F, Sample 60315 (group $\mathrm{C}_{2}$ ), showing interstitial igneous texture between large poikiloblastic orthopyroxene grains. Plane-polarized light. $G$, Sample 60315 (group $\mathrm{C}_{2}$ ), showing spherical droplets with intersertal to intergranular igneous texture in coarse-grained poikiloblastic rocks. Plane-polarized light. $H$, Apollo 17 sample 76215 , showing transition from poikiloblastic texture (left) in which orthopyroxene oikocrysts enclose abundant mineral debris to ophitic texture with poikilitic clinopyroxene and less mineral debris. Vesicles occur only in the ophitic area. Cross-polarized light. 
zoned. Lithic debris is predominantly medium-grained hornfels derived from troctolitic or gabbroic rocks. Various proportions of euhedral plagioclases, occuring both as inclusions in mafic oikocrysts and interstitially between them, range from equant to lath shaped and appear optically to be zoned. Oikocrysts are most commonly slightly zoned pigeonite or orthopyroxene, but in some rocks are olivine (Simonds and others, 1973).

The degree of development of the poikiloblastic texture varies from incipient, spotty, very fine grained oikocrysts (moderately common in matrices of $B_{4}$ and $\mathrm{B}_{5}$ breccias and dark clasts in $\mathrm{B}_{2}$ and $\mathrm{B}_{3}$ breccias) to coarse grains easily visible in hand specimen (fig. $2 C-E$ ). In the much better examples of this lithologic type returned by Apollo 17 (for example, 76215), a systematic increase in grain size with proximity to cavities can be observed, but thin-section study of Apollo 16 and 17 samples reveals rapid lateral variations from the fine-grained poikiloblastic texture to granoblastic texture and from coarser poikiloblastic textures to those with unequivocal igneous textures (fig. $2 H$ ). Interstitial material with igneous texture (fig. $2 F$ ) has been noted by a number of authors (Delano and others, 1973; Bence and others, 1973; Walker and others, 1973; Hodges and Kushiro, 1973), and spherical blebs with igneous texture (fig. $2 G$ ) are widespread.

The origin of the poikiloblastic texture is still uncertain; some workers favoring crystallization from a melt, others recrystallization in the solid state. Most workers agree that interstitial material with intersertal to intergranular texture ("diabasic" material) indicates the presence of some melt, and the common occurrence of cavities indicates the presence of a vapor phase. There is little doubt that most of these rocks contained at least a small proportion of melt. Moreover, as one attempts to classify these rocks and the fine-grained breccias, the rather subtle and gradational character of the differences between poikiloblastic texture and ophitic texture are often apparent (for example, the rock classified by Simonds and others (1973) as poikilitic in their figure 9, we would probably classify as ophitic and place in group $\mathrm{C}_{1}$ ). We believe, however, that the distinctive textural differences in the coarser grained poikiloblastic rocks between those parts that most workers consider igneous (interstitial "diabasic" material) and the main body of the rock suggest a metamorphic origin of the coarse pyroxene oikocrysts (see Bence and others, 1973). This appears to be substantiated in rock 76215 (fig. $2 H$ ) by the gradation from a coarse-grained poikiloblastic texture in which orthopyroxenes enclose abundant undigested mineral debris to a well-developed ophitic texture with oikocrysts of clinopyroxene and much less mineral debris. It is highly unlikely that both parts of the rock crystallized from a liquid.
The suggestion by Simonds and others (1973) and Warner and others (1973) that gas cavities and flow structures are evidence of igneous origin is equivocal, as cataclastic flow structures in solids are well known and vesiculation of powdered material lacking a liquid phase seems at least possible. In many lunar rocks, gas cavities commonly are locally surrounded by unequivocal melt textures; a good example is the well known Apollo 15 rock 15418; another is Apollo 17 rock 76215 (fig. $2 H$ ), in which spherical cavities are concentrated in the ophitic part of the rock. Lowering of melting temperature by the presence of a gas phase may locally induce melting. The suggestion of Albee and others (1973b) and of Bence and others (1973) that the cavities were present in a glassy precursor of the poikiloblastic rocks seems implausible, especially in view of the shapes and distribution of cavities described by Simonds and others (1973) and concentration of cavities in more extensively melted parts of poikiloblastic rocks.

The nature of the precursor of poikiloblastic rocks remains a critical problem (see Duncan and others, 1973). The statement of Bence and others (1973) that there is little disagreement that the precursor to these rocks was either a polymict highlands breccia or a clast-laden glass is not supported by any facts known to us. While statistical information on relics may aid in solution of this problem, a subjective view of the dominant types of mineral and lithic debris suggests that partly metamorphosed troctolitic rocks were important contributors. Several Apollo 17 poikiloblastic rocks, however, contain scattered mineral debris (plagioclases spongy with inclusions; brown clinopyroxenes) derived from distinctive vug and vein fillings in the blue-gray breccias with which the poikiloblastic rocks are associated. Some mixing of lithologic types is evident.

\section{BRECCIAS}

GROLP B (LIGH MA IRIX, LIGH I CLASTS)

The 30 samples in group $B_{1}$ range from cataclastic plutonic feldspathic rocks to cataclastic hornfels to polymict breccias. Study in hand specimen indicates that many of the coarse-grained feldspathic components of $B_{1}$ breccias were partly metamorphosed to medium-grained hornfels before cataclasis; the hornfelsed parts appear to survive crushing better than the coarse igneous rocks from which they were derived and may be represented disproportionately in thin section. Of the 10 rocks thin sectioned so far (1974), all are cataclastic plutonic feldspathic rocks except 67075 , which may be a polymict breccia, and 67955 , a cataclastic coarsely hornfelsed olivine gabbro. In the eight anorthositic rocks, the matrix is unannealed or weakly annealed crushed anorthosite and the 
clasts are relics that survived the crushing. Sample 67075 contains medium-grained hornfels fragments that apparently were derived from different kinds of anorthositic rocks, as their mineral assemblages are highly varied; mineral debris shows major variations in constituent proportions from thin section to thin section. This rock, as well as some others not yet thin sectioned, may therefore represent mixed lithologies rather than a single rock that has been crushed.

The cataclastic plutonic rocks range from norite through noritic anorthosite to anorthosite. Some noritic anorthosites are olivine bearing (for example, 60025 ), and some anorthosites contain both olivine and spinel (for example, 60618, Dowty and others, 1974a, b). Most of the cataclasites have not undergone severe cataclastic mixing (fig. $3 A, B$ ); the original coarse to very coarse grain size is evident from the size of relict mineral debris (table 3 ). Because of this, individual thin sections may be misleading with respect to the modal composition of the original rock and the textural relations between plagioclase and mafic minerals. In a few of these rocks and similar ones occurring as clasts in other breccia types, textural relations suggest that mafic minerals in the most feldspar-rich rocks are interstitial postcumulus phases (fig. $3 C$ ) but form cumulus phases with or without cumulus plagioclase in the more mafic rocks (fig. $3 D$ ).

\section{GROLP B: (LIGHT MATRIX, DARK (ILASTS)}

The $B_{2}$ breccias are extremely variable, ranging from breccias that have been little modified since the first impact event (for example 64435, 61015) to multicycle breccias, some of which are ploymict (for example, 60016, 67075) (Wilshire and others, 1973). In the 19 thin sections examined, even the simplest, leastmodified breccias show mild rebrecciation of a firstcycle breccia that consisted of highly feldspathic clasts in a fine-grained dark matrix (some relics of which are visible in the lower left part of the rock in fig. $3 E$ ). Rebrecciation resulted in a large-scale fracturing and dilation of the brittle, fine-grained original matrix and injection of the friable feldspathic clast material into the fractures. The injected plagioclase debris remained unannealed (fig. $3 F$ ). The texture of the dark finegrained clasts generally remains unchanged in this brecciation. In these clasts, very fine grained intersertal textures predominate but grade to fine-grained poikiloblastic and granoblastic textures on the one hand and to fine-grained ophitic textures on the other (table 2). Somewhat more severe second-generation brecciation resulted in local fusion of the original dark matrix along fractures (fig. 3G) (Wilshire and Moore, 1974). Small droplets of melt, many with unmelted cores, spalled from the glass selvages during emplacement of the unmelted feldspathic debris (fig. $3 H$ ). Se- vere brecciation accompanied by local fusion adds to the complexity of a second-cycle breccias but involves the same number of impacts. Later impacts tend to break down the friable feldspathic material to smallsize particles and concentrate the tough dark clasts in the coarser size fractions. It is clear from the extraordinary variety of lithologic types (fig. $4 A$ ) in some of these breccias (for example, 67455,60115 ) that mixing of fragments of diverse origin has occurred as well as disaggregation of originally simple breccias.

\section{GROL'P B: (INTERMEDIATE MATRIX COLOR, LIGHT AND DARK CLASTS)}

Of the 83 samples in group $B_{3}$, only 7 have been examined in thin section. These are polymict breccias with a wide range of mostly fine grained lithic clasts, glass, and mineral debris in a friable, glassy to very weakly annealed matrix (fig. $4 B$ ). The thin-sectioned rocks are loosely aggregated regolith material that clearly corresponds to the "soil breccias" returned from other missions. Although their origin has not been determined, they appear to differ little from some polymict breccias of group $\mathrm{B}_{2}$ except for the presence of glass.

GROLP B 4 (DARK WATRIX, LIGHT CLASTS)

A wide variety of lithologic types is represented in the 14 rocks of group $B_{4}$ studied in thin section. The clasts vary from metaclastic fragments with poikiloblastic textures to annealed cataclastic feldspar-rich fragments to rare fine-grained feldspathic igneous fragments (fig. 4C). The matrices are tough and fine grained with igneous or granoblastic textures. Some of the $\mathrm{B}_{4}$ breccias (table 3 ) are little-modified fragments of first-cycle breccias, but the polymict character of many shows repeated impact events, each severe enough to anneal the pulverized rock.

$$
\text { GROL'P B. (DARK VATRIX, DARK CLASTS) }
$$

The four samples in group $B_{5}$ that have been thin sectioned are lithologically very complex, consisting of a variety of dark fine-grained metaclastic rock fragments and mineral debris in a tough, annealed clastic matrix. There is some evidence of derivation by multiple impact of simpler types of breccia. In thin section (fig. $4 D$ ), characteristics of $\mathrm{B}_{2}$ breccias can be discerned; net veins of broken feldspathic debris in dark finegrained igneous-textured rock have survived multiple impacts.

\section{INIERIRE IA IION OI IHE BRECCIAS}

Wilshire and others (1973) attempted to reconstruct the sequence of brecciation leading to diversification of the breccias. Even though no unbrecciated outcrops were found at the Apollo 16 site, the sequence can be established by comparison with products of single im- 

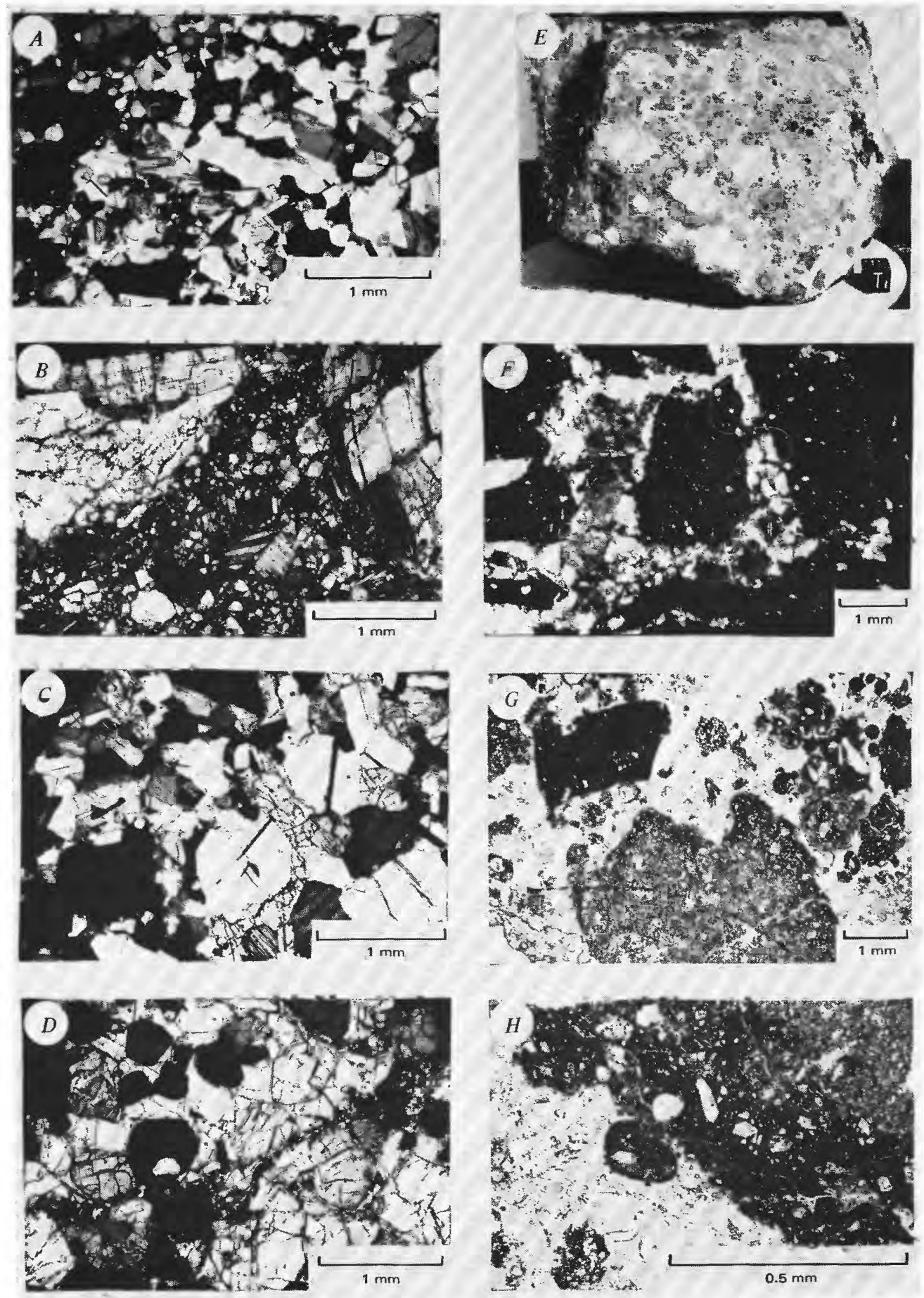

Figure 3.-Photomicrograph of Apollo 16 metaclastic rock and breccias and photograph of breccia 61015. A, Sample 60619 (group $\mathrm{C}_{2}$ ), showing coarse hornfels texture in metaanorthosite. Cross-polarized light. $B$, Sample 62237 ( $\mathrm{B}_{1}$ breccia), showing coarse mineral relics and cataclastic flow structure in troctolite. Cross-polarized light. $C$, Sample 65785 (group $\mathrm{C}_{2}$ ), a lithic relic in cataclasite, having postcumulus olivine (high relief) separating cumulus plagioclase grains twinned. Cross-polarized light. $D$, Sample $674^{3} 35\left(\mathrm{~B}_{4}\right.$ breccia), showing lithic clast in breccia with postcumulus plagioclase (low relief, white) separating cumulus olivine (high relief) and spinel (in extinction) grains. Cross-polarized light. $E$, Sample 61015 (NASA photograph S-72-40585B), showing net-veining of original dark matrix by clastic material derived from the white clasts. $F$, Sample 61015 ( $\mathrm{B}_{2}$ breccia), showing weakly annealed, coarse mineral debris in fractures in original matrix (dark). Cross-polarized light. $G$, Sample 66055 ( $\mathrm{B}_{2}$ breccia), showing glass selvage (dark gray) on lighter gray fragment of original matrix. Note surrounding fragments of spalled selvage in feldspathic debris derived from original clasts. Planepolarized light. $H$, Sample 66055 (B. breccia), showing incompletely spalled ellipsoid of glass selvage. Plane-polarized light. 
TABLE 3.-Degree of modification of selected Apollo 16 rocks

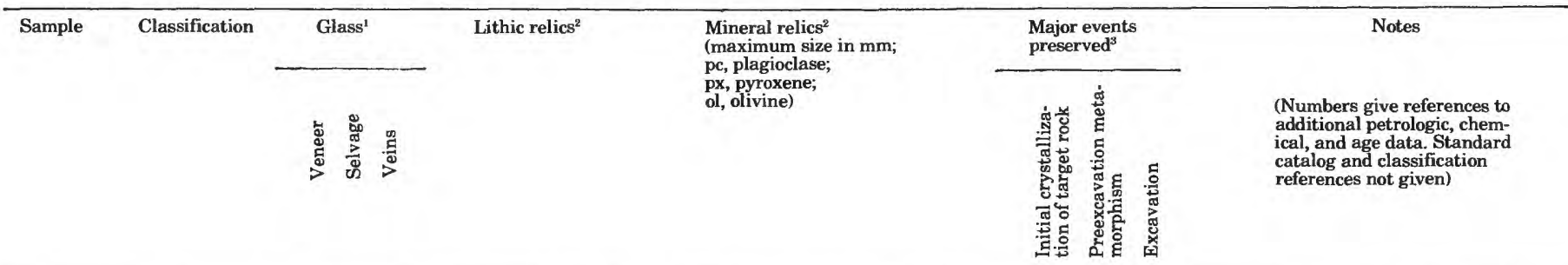

\begin{tabular}{|c|c|c|c|c|c|c|c|c|c|}
\hline 60015 & $\mathbf{B}_{1}$ & $x$ & & $x$ & Medium-grained & pc 12 , possibly 15 & & & Major modification by multiple \\
\hline 60016 & $\mathbf{B}_{2}\left(\mathbf{B}_{3}\right)^{5}$ & & & & $\begin{array}{l}\text { hornfels } \\
\text { Medium-grained } \\
\text { hornfels }\end{array}$ & pe 1 & & & $\begin{array}{l}\text { impact } \\
\text { Major modification by multiple }\end{array}$ \\
\hline 60017 & $\mathbf{B}_{4}\left(\mathbf{B}_{5}\right)$ & & $x$ & & & & & & $\begin{array}{l}\text { Major modification by multiple } \\
\text { impact. }(2,9,10)\end{array}$ \\
\hline 60018 & $\mathbf{B}_{4}$ & $x$ & $x$ & $x$ & $\begin{array}{l}\text { Medium-grained } \\
\text { hornfels, cata- } \\
\text { clastic anortho- } \\
\text { site, troctolite. }\end{array}$ & pe $7 \times 10$ & & & $\begin{array}{l}\text { Major modification by multiple } \\
\text { impact. Some clasts probably } \\
\text { represent first-cycle breccia } \\
\text { matrix. }\end{array}$ \\
\hline 60019 & $\mathbf{B}_{5}$ & $x$ & & $?$ & & & & & $\begin{array}{l}\text { Major modification by multiple } \\
\text { impact. }\end{array}$ \\
\hline 60025 & $\mathbf{B}_{\mathbf{1}}$ & $x$ & & & $\begin{array}{l}\text { Noritic anortho- } \\
\text { site. }\end{array}$ & pc 15 & $x$ & & $\begin{array}{l}\text { Cataclastic noritic anorthosite. } \\
\text { No first-cycle matrix present. } \\
(2,4,10,11,12,13)\end{array}$ \\
\hline 60215 & $\mathbf{B}_{\mathbf{2}}$ & $x$ & & & & pc 6 & $x$ & & $\begin{array}{l}\text { Mafic minerals severely modi- } \\
\text { fied. Cataclastic noritic } \\
\text { anorthosite. No first-cycle } \\
\text { matrix present. }\end{array}$ \\
\hline 60235 & $\mathrm{C}_{2}$ & & & & & pe 10 & $?$ & $?$ & $\begin{array}{l}\text { maarix present. } \\
\text { Insufficient data. }\end{array}$ \\
\hline 60255 & $\mathbf{B}_{4}$ & & $x$ & & & pc 4 & & & $\begin{array}{l}\text { Major modification by multiple } \\
\text { impact. (14) }\end{array}$ \\
\hline 60275 & $\mathbf{B}_{4}$ & $x$ & & $x$ & & & & & $\begin{array}{l}\text { Major modification by multiple } \\
\text { impact. }\end{array}$ \\
\hline 60315 & $\mathrm{C}_{2}$ & & & & & pc 4 & $?$ & $?$ & $\begin{array}{c}\text { Poikiloblastic texture } \\
(10,11,13,15,16,17)\end{array}$ \\
\hline 60335 & $\mathrm{C}_{2}$ & & & & & pc 5, px, ol 3 & $?$ & $?$ & $\begin{array}{l}\text { Ophitic-poikiloblastic texture. } \\
(10,13,18)\end{array}$ \\
\hline 60516 & $\mathbf{B}_{1}$ & & & & & pc 4 , possibly 5 & $x$ & & $\begin{array}{l}\text { Cataclastic anorthosite. No } \\
\text { first-cycle matrix present. } \\
\text { (19) }\end{array}$ \\
\hline 60526 & $\mathrm{C}_{2}$ & & & & & pc 0.1 & $?$ & $?$ & $\begin{array}{l}\text { Poikiloblastic texture. Very } \\
\text { scarce mineral debris. }\end{array}$ \\
\hline 60615 & $C_{1}$ & & & & & pc 0.75 & ? & $?$ & Medium-grained ophitic texture. \\
\hline 60616 & $\mathrm{C}_{2}$ & & & & $\begin{array}{l}\text { Medium-grained } \\
\text { hornfels. }\end{array}$ & pc 0.7, ol 0.1 & $?$ & $?$ & Poikiloblastic texture. \\
\hline 60618 & $\mathbf{B}_{1}$ & & & & & pc greater than 5 & $x ?$ & $x$ & $\begin{array}{l}\text { Cataclastic spinel, olivine- } \\
\text { bearing anorthosite. First- } \\
\text { cycle matrix subspherulitic. } \\
(19,20)\end{array}$ \\
\hline 60619 & $\mathbf{C}_{2}$ & & & & & & & & $\begin{array}{l}\text { Medium-grained hornfels. No } \\
\text { first-cycle matrix present. } \\
\text { (19) }\end{array}$ \\
\hline $\begin{array}{l}60625 \\
60629\end{array}$ & $\mathrm{C}_{2}$ & & & $x$ & & & & $?$ & Poikiloblastic texture. \\
\hline 60629 & $\mathbf{B}_{1}$ & $x$ & & & & pe 3.5 & $x$ & & $\begin{array}{l}\text { Cataclastic anorthosite. No } \\
\text { first-cycle matrix present. } \\
\text { (19) }\end{array}$ \\
\hline 60635 & $\mathrm{C}_{1}$ & & & & & pc 2.5 & $?$ & $?$ & $\begin{array}{l}\text { Medium-grained ophitic texture. } \\
\text { (20) }\end{array}$ \\
\hline 60645 & $\mathbf{B}_{4}$ & & $?$ & & & pc 1.1, px 0.3 & $?$ & $?$ & $\begin{array}{l}\text { Cataclastic anorthosite. First- } \\
\text { cycle matrix weakly poikilo- } \\
\text { blastic. }\end{array}$ \\
\hline $\begin{array}{l}60658 \\
60659\end{array}$ & $\begin{array}{l}\mathbf{B}_{4} \\
\mathbf{B}_{2}\left(\mathbf{B}_{4}\right)\end{array}$ & $x$ & & & & $\begin{array}{l}\text { pe } 1.0 \\
\text { pc } 0.75\end{array}$ & & & $\begin{array}{l}\text { Insufficient data. } \\
\text { Major modification by multiple } \\
\text { impact. (19) }\end{array}$ \\
\hline 60667 & $\mathrm{~B}_{4}$ & & & & Medium-grained & pc 0.6 & & $?$ & $\begin{array}{l}\text { First-cycle matrix? Interser- } \\
\text { tal texture }\end{array}$ \\
\hline 60676 & $\mathbf{B}_{4}$ & & & & & pe 1.6 & & & \\
\hline 61015 & $\mathbf{B}_{2}$ & $x$ & & & & pc 3 & & $?$ & \\
\hline 61016 & $\mathbf{B}_{4}$ & $x$ & & $x$ & & pe 15 & & & Major modification by multiple \\
\hline 62235 & $\mathrm{C}_{2}$ & & & & & pc 2 & $?$ & $?$ & $\begin{array}{l}\text { Poikiloblastic-ophitic tex- } \\
\text { ture. }(25,29)\end{array}$ \\
\hline 62236 & $\mathbf{B}_{1}$ & & & & & pc 4 & $x$ & & $\begin{array}{l}\text { Cataclastic norite or noritic } \\
\text { anorthosite. No first-cycle } \\
\text { matrix present. }\end{array}$ \\
\hline 62237 & $\mathbf{B}_{1}$ & $x$ & & $?$ & Norite & pc 3 & $\times$ & & $\begin{array}{l}\text { Cataclastic olivine-bearing } \\
\text { norite or noritic anorthosite. } \\
\text { No first-cycle matrix present. }\end{array}$ \\
\hline $\begin{array}{l}62246 \\
62255\end{array}$ & $\begin{array}{l}\mathbf{B}_{1} \\
\mathbf{B}_{2}\end{array}$ & $\hat{x}$ & & $x$ & Gabbro(?) & pc 1, px 5 & $x$ & & $\begin{array}{l}\text { Insufficient data. } \\
\text { Cataclastic clinopyroxene- } \\
\text { bearing anorthosite. ( } 8 \text { ) }\end{array}$ \\
\hline 62295 & $\mathrm{C}_{1}$ & & & & & pc 2 & & & $\begin{array}{c}\text { Subspherulitic quench texture. } \\
(10,11,13,18,30,31,32,33)\end{array}$ \\
\hline 63335 & $\left(B_{5}\right)$ & & & & & pc 1 & & & Major modification by multiple \\
\hline 63505 & $\mathbf{B}_{4}$ & & & & & pe 1 & & $?$ & First-cycle (?) matrix, poi- \\
\hline 63506 & $\left(\mathrm{C}_{2}\right)$ & & & & & & & $?$ & $\begin{array}{l}\text { kiloblastic texture. } \\
\text { First-cycle(?) matrix, poi- } \\
\text { kiloblastic to intergranular } \\
\text { texture. }\end{array}$ \\
\hline 64435 & $\mathbf{B}_{2}$ & $x$ & & $x$ & & pe 1.5 & $x$ & $x$ & $\begin{array}{l}\text { Cataclastic two-pyroxene, oli- } \\
\text { vine-bearing anorthosite. } \\
\text { First-cycle matrix weakly poi- } \\
\text { kilitic. }(3,8,34)\end{array}$ \\
\hline 64455 & $\mathrm{C}_{2}$ & $x$ & & $x$ & $\begin{array}{l}\text { Medium-grained } \\
\text { hornfels(?) }\end{array}$ & pc 1 & & & Insufficient data. (35) \\
\hline
\end{tabular}


TABLE 3.-Degree of modification of selected Apollo 16 rocks -Continued.

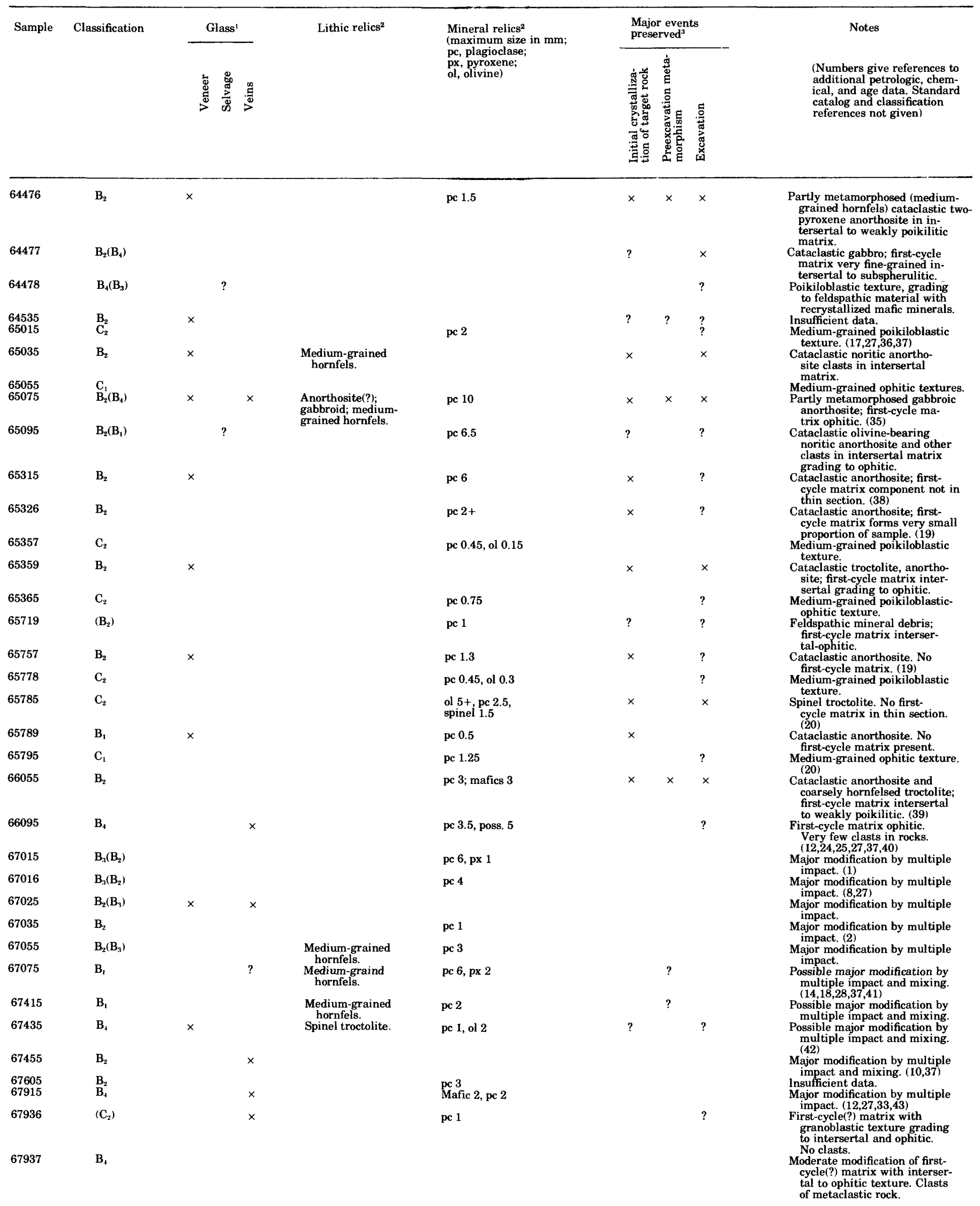




\begin{tabular}{|c|c|c|c|c|c|c|c|c|c|c|}
\hline \multirow[t]{2}{*}{ Sample } & \multirow[t]{2}{*}{ Classification } & \multicolumn{3}{|c|}{ Glass $^{1}$} & \multirow[t]{2}{*}{ Lithic relics ${ }^{2}$} & \multirow{2}{*}{$\begin{array}{l}\text { Mineral relics } \\
\text { (maximum size in mm; } \\
\text { pc, plagioclase; } \\
\text { px, pyroxene; } \\
\text { ol, olivine) }\end{array}$} & \multicolumn{3}{|c|}{ Major events preserved ${ }^{3}$} & \multirow{2}{*}{\begin{tabular}{l} 
Notes \\
\multicolumn{1}{c}{ (Numbers give references to } \\
additional petrologic, chem- \\
ical, and age data. Standard \\
catalog and classification \\
references not given)
\end{tabular}} \\
\hline & & 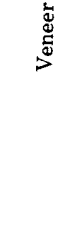 & 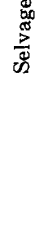 & $\stackrel{\infty}{\stackrel{5}{0}}$ & & & 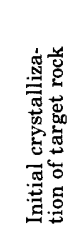 & 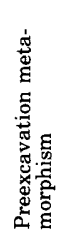 & 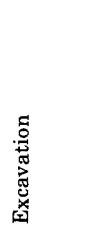 & \\
\hline 67945 & $\mathrm{~B}_{4}$ & $x$ & & & & pc 5 & & & $?$ & $\begin{array}{l}\text { First cycle matrix, poikilo- } \\
\text { blastic texture. }\end{array}$ \\
\hline 67946 & $\left(B_{4}\right)$ & & $?$ & & & & & & & Major modification by multiple \\
\hline $\begin{array}{l}67947 \\
67955\end{array}$ & $\begin{array}{l}\left(\mathrm{B}_{4}\right) \\
\mathrm{B}_{1}\end{array}$ & & $?$ & $x$ & $\begin{array}{l}\text { Medium-grained } \\
\text { hornfels. }\end{array}$ & pe 2 & & $?$ & & $\begin{array}{l}\text { Do. } \\
\text { Cataclastic olivine gabbro } \\
\text { hornfels. No first-cycle } \\
\text { matrix present. (44) }\end{array}$ \\
\hline 67975 & B. & & & & & pe 4 & & & & $\begin{array}{l}\text { Major modification by multiple } \\
\text { impact. }\end{array}$ \\
\hline $\begin{array}{l}68035 \\
68115\end{array}$ & $\begin{array}{l}\mathrm{B}_{2} \\
\mathrm{~B}_{5}\end{array}$ & $x$ & & & & $\begin{array}{l}\text { pc } 3 \\
\text { pc } 2\end{array}$ & & & & $\begin{array}{l}\text { Insufficient data. } \\
\text { Major modification by multiple } \\
\text { impact. }(8,21)\end{array}$ \\
\hline 68415 & $C_{1}$ & & & & & pc 3 & & & & $\begin{array}{l}\text { Medium-grained ophitic texture } \\
\text { Few clasts. }(10,15,18,22,23,24\end{array}$ \\
\hline 68416 & $\mathrm{C}_{1}$ & & & & & pc 8 & & & & $\begin{array}{l}\text { Medium-grained ophitic texture. } \\
\text { Clasts moderately abundant. } \\
(10,11,18,22)\end{array}$ \\
\hline $\begin{array}{l}68515 \\
69955\end{array}$ & $\begin{array}{l}\mathrm{B}_{2} \\
\mathrm{C}_{1}\end{array}$ & $x$ & $x$ & $x$ & & pc 7 & $?$ & & & $\begin{array}{l}\text { Insufficient data. } \\
\text { Cataclastic anorthosite. Sample } \\
\text { from boulder. }(2,10)\end{array}$ \\
\hline
\end{tabular}

'Glass occurs in three modes (Wilshire and Moore, 1974) other than as clasts: (1) veneer-sharply bounded exterior coatings; (2) selvages-coatings with gradational boundaries with the coated rock, (3) veins, commonly occurring in complex, anastomosing patterns. The glass is thought to have formed during comparatively small impact events following initial excavation. ${ }^{2}$ Lithic and mineral relics are considered to be impact target materials that escaped major damage resulting from impact; the matrices of breccias containing these relics were derived by comminution, melting, and thermal meta-morphism of the same types of rock represented by the relics.

${ }^{3}$ This column represents a qualitative attempt to give petrologic guidance in interpreting major events in Apollo 16 rocks. Most Apollo 16 rocks have been multiply brecciated so that their ages are not specifically meaningful. However, some have undergone little reworking since their initial excavation (see Wilshire and others, 1973;; the clasts (relics) in these breccias represent original target material, which consists of plutonic igneous and metamorphic rocks (Wilshire, 1974), and thoroughly metamorphosed or melted material forming their matrix. (Wilshire 1974) may rep typest prevexts

than the coarse-grained igneous rocks from which they are derived.

'Parentheses following letter and class number indicate alternative classification. Parentheses unaccompanied enclose tentative classification. tTextures formed at time of initial excavation of the rock have undergone major modification by subsequent impact(s); age not meaningful with respect to primary excavating event or

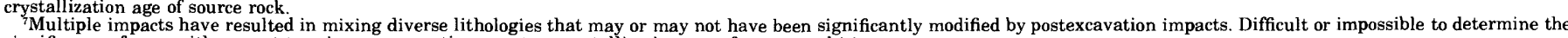
significance of ages with respect to primary excavating event or crystallization age of source rock(s).

${ }^{8}$ Metaclastic rocks have relict lithic and mineral debris in thoroughly recrystallized (granoblastic to poikiloblastic textures) to partly or wholly (intersertal, intergranular, subspherulitic, ophitic textures) melted matrices. Isotopic data (table 4) indicate that relict material may yield minimum ages of target material, whereas whole-rock data yield age of metamorphism. The significance of these data with respect to initial excavating event or crystallization age of the source rock(s) is not known.

References:

$$
\begin{aligned}
& \text { (1) Juan and others, } 1974 \\
& \text { (2) Lual and Schmitt, } 1973 \\
& \text { ( 3) Nunes and others, 1974 } \\
& \text { (4) Schaeffer and Husain, } 1974 \\
& \text { (5) Sclar and others, 1973 } \\
& \text { ( 6) Sclar and Bauer, 1974 } \\
& \text { ( 7) Johan and Christophe, } 1974 \\
& \text { ( 8) S. R. Taylor and others, } 1974 \\
& \text { (9) Kridelbaugh and others, } 1973 \\
& \text { (10) Rose and others, 1973 } \\
& \text { (11) Hodges and Kushiro, } 1973
\end{aligned}
$$

$$
\begin{aligned}
& \text { (12) Nakamura and others, } 1973 \\
& \text { (13) Walker and others, } 1973 \\
& \text { (14) Scoon, 1974 } \\
& \text { (15) Bence and others, } 1973 \\
& \text { (16) Delano and others, } 1973 \\
& \text { (17) Simonds and others, } 1973 \\
& \text { (18) Brown and others, } 1973 \\
& \text { (19) Dowty and others, 1974b } \\
& \text { (20) Dowty and others, 1974a } \\
& \text { (21) Grieve and others, 1974 } \\
& \text { (22) Gancarz and others, } 1972
\end{aligned}
$$

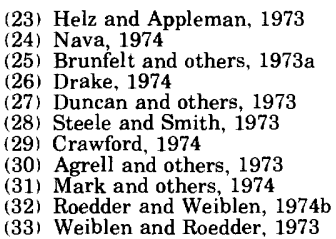

(34) Laul and others, 1974 (35) Grieve and Plant, 1973 (36) Albee and others, 1973a, b (38) Stettler and others, 1974 (39) Fruchter and others, 1974 (40) Friedman and others, 1974 (41) Peckett and Brown, 1973 (42) Prinz and others, 1973a (43) Roedder and Weiblen, 1974a (44) Hollister, 1973 pacts on terrestrial crystalline targets-the Vredefort Ring, South Africa (fig. $4 E$ ) and Sudbury Crater, Canada-impacts that produced a breccia consisting of relics of the target material encased in a dark finegrained annealed (fig $4 F$ ) to partly melted (fig. $4 G$ ) matrix of the same composition. Several Apollo 16 samples approach this simplicity (table 3, footnote 2 and notes on $60018,60616,67936)$, but none has survived untouched. At least slight rebrecciation has affected all, resulting in fracturing of the original matrix and injection of broken feldspathic debris derived from original clasts (forming $\mathrm{B}_{2}$-type breccias from a $\mathrm{B}_{4}$-type parent). Continued brecciation gradually destroyed the remnants of the original target material, although pieces of the tough first-cycle matrix apparently sur- vived. Beyond a certain stage, however, it is not possible to determine whether the different parts of a breccia were originally related or were derived from different sources.

The source rocks from which the Apollo 16 breccias were derived are represented at least in part by the clasts in the simplest, least-reworked breccias. These clasts are consistently of two lithologic types: (1) cataclastic plutonic feldspathic rocks of a troctolite-noriteanorthosite suite; relics show coarse to very coarse grain sizes and pyroxenes with coarse exsolution lamellae (fig. $4 H)$; (2) cataclastic feldspathic hornfelses with medium-grained granoblastic textures, commonly modifications of the plutonic rocks (Wilshire and others, 1972). The hornfelses are far coarser grained 

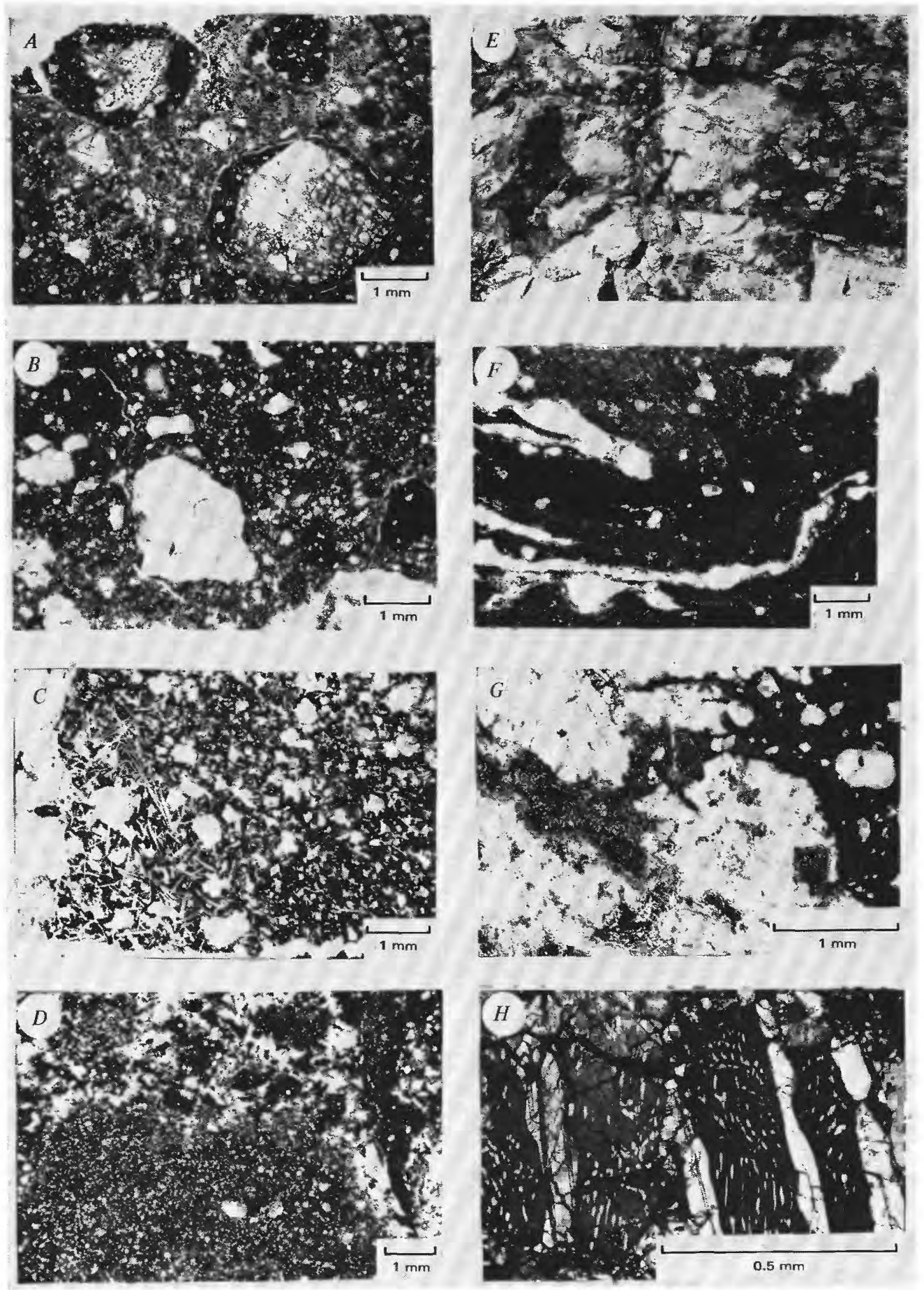

FIGURE 4.-Photomicrographs of Apollo 16 breccias; photograph and photomicrographs of pseudotachylites of Vredefort structure, South Africa, $E-G$. A, Sample 67035 (B. breccia), showing clasts with selvages embedded in a friable light-gray matrix containing a variety of lithic and mineral microclasts. Plane-polarized light. $B$, Sample 61295 ( $\mathrm{B}_{3}$ breccia), showing a variety of clasts, including glass, in a fine-grained glassy matrix. Plane-polarized light. $C$, Sample 60018 ( $\mathrm{B}_{4}$ breccia), showing a cataclastic anorthositic clast at one edge grading into an impact melt zone with ophitic texture, and this into intersertal texture. Plane-polarized light. $D$, Sample $68815\left(\mathrm{~B}_{5}\right.$ breccia), showing a small area in a rock dominated by dark clasts in a dark matrix. This area shows a remnant of $B$, breccia with feldspathic debris in fractures in the fine-grained dark original matrix. Plane-polarized light. E, Pseudotachylite, Vredefort structure, South Africa, showing breccia composed of clasts of crystalline rock in finely comminuted and locally fused material of the same chemical composition as the clasts. Photograph by Warren Hamilton. F, Pseudotachylite in alkali granite, Vredefort structure, South Africa, showing cataclastic flow structures in comminuted alkali granite, metamorphosed to very fine grained granoblastic texture. Crosspolarized light. $G$, Pseudotachylite in Old Granite, Vredefort structure, South Africa; local fused zone showing newly crystallized feldspar laths and flow structure. Cross-polarized light. $H$, Sample 62236 ( $\mathrm{B}_{1}$ breccia), showing coarse irregular and finer regular clinopyroxene exsolution lamellae (white) in orthopyroxene (dark). Cross-polarized light. 
than those forming the matrices of intensely deformed impact breccias. The hornfelsic breccia clasts have the same textures and compositions as $\mathrm{B}_{1}$ group breccias and therefore could have a common origin.

The most common type of crystalline igneous rock, ophitic feldspathic rock, is not present as clasts in the simplest, least-reworked breccias, nor is the coarsely poikiloblastic lithology. Both of these rock types appear in the Apollo 16 samples only as clasts in complex breccias. The balance of evidence indicates that these rocks result from solidification of impact melts.

It seems apparent, then, that the target material for the first major impact event shown in Apollo 16 rocks was a plutonic suite composed of troctolite, norite, and anorthosite that had undergone partial thermal metamorphism prior to impact. These rocks constitute the "ANT" suite of Prinz and others (1973b), whose existence they inferred largely from the chemical compositions of fine-grained, impact-generated hornfelses.

\section{CHRONOLOGY OF APOLLO 16 ROCKS}

Relics of the coarse-grained target materials and of the finely pulverized, partly to wholly melted rock produced in the first major excavation are sufficient to allow us to specify the nature of the products and perhaps to date three significant events: crystallization and differentiation; metamorphism that produced the coarse hornfels; and primary excavation and brecciation. Table 3 presents a qualitative guide to the samples that might yield this information.

Isotope data gathered on Apollo 16 rocks have not generally been systematically directed by the petrology of the collection as a whole. A number of ages (table 4) have been determined on complex rocks with no indication of what part or parts of the rock were measured. Other ages date unknown events that took place after initial excavation and deposition of the Apollo 16 breccias. The problem of terminology (see Wilshire and Jackson, 1972b; Jackson and others, 1975) adds considerably to confusion about the meaning of the ages.

TABLE 4.-Isotope data on Apollo 16 samples

\begin{tabular}{|c|c|c|c|c|c|}
\hline Sample & Rock type & $\begin{array}{c}\text { Part of rock } \\
\text { dated }\end{array}$ & $\begin{array}{l}\text { Age }\left(10^{9}\right) \text {. } \\
\text { (b.y.) }\end{array}$ & $\begin{array}{l}\text { Method and } \\
\text { source }\end{array}$ & Notes \\
\hline 60015 & $\mathrm{~B}_{1}$ & Whole rock & $3.55 \pm 0.05$ & $\mathrm{Ar}^{40}-\mathrm{Ar}^{39}(1)$ & $\begin{array}{l}\text { Age probably time } \\
\text { of shock deforma- } \\
\text { tion. }\end{array}$ \\
\hline 60015 & & .... do & $-3.6-3.8$ & $\mathrm{U}-\mathrm{Pb}(2)$ & \\
\hline 60025 & $\mathrm{~B}_{1}$ & _.do - & $-4.18 \pm 0.06$ & $A r^{10}-A r^{39}(1)$ & $\begin{array}{l}\text { Age of excavation } \\
\text { or minimum age } \\
\text { of crystallization. }\end{array}$ \\
\hline 60315 & $\mathrm{C}_{2}$ & $\ldots$ do & $-3.94 \pm 0.05$ & $A r^{10}-A r^{39}(3)$ & $\begin{array}{l}\text { Maximum age of } \\
\text { metamorphism? }\end{array}$ \\
\hline $\begin{array}{l}60315 \\
60315\end{array}$ & & do do & $\begin{array}{l}-4.03 \pm 0.03 \\
\text { About } 3.99\end{array}$ & $\begin{array}{l}\mathrm{Ar}^{40}-\mathrm{Ar}^{39}(4) \\
\mathrm{U}-\mathrm{Pb}(2)\end{array}$ & $\begin{array}{l}\text { Age of metamorph- } \\
\text { ism. }\end{array}$ \\
\hline 61016 & $\mathrm{~B}_{4}$ & $?$ & $(3.65 \pm 0.04)$ & $A r^{10}-A^{39}(5)$ & $\begin{array}{l}\text { Poorly defined } \\
\text { plateau. Rock } \\
\text { very in- } \\
\text { homogeneous. }\end{array}$ \\
\hline 62242,3 & Anorthosite & Whole rock & $4.5 \pm 0.3$ & $A r^{40}-A^{39}(4)$ & $\begin{array}{l}\text { Total Ar age. May } \\
\text { have excess Ar. }\end{array}$ \\
\hline
\end{tabular}

TABLE 4.-Isotope data on Apollo 16 samples-Continued

\begin{tabular}{|c|c|c|c|c|c|}
\hline Sample & $\begin{array}{l}\text { Rock } \\
\text { type }\end{array}$ & $\begin{array}{l}\text { Part of rock } \\
\text { dated }\end{array}$ & $\begin{array}{l}\text { Age } \\
\text { (b.y.) }\end{array}$ & $\begin{array}{l}\text { Method and } \\
\text { source }\end{array}$ & Notes \\
\hline$\overline{62295}$ & $C_{1}$ & $\ldots$ do & $-4.00 \pm 0.06$ & Rb-Sr (6) & $\begin{array}{l}\text { Age of crystalliza- } \\
\text { tion of melt rock. }\end{array}$ \\
\hline $\begin{array}{l}62295 \\
63502,17 \mathrm{a}\end{array}$ & $\mathrm{B}_{1}$ ? & ? & $\begin{array}{r}3.89 \pm 0.05 \\
3.89 \pm 0.01\end{array}$ & $\begin{array}{l}A r^{406}-A^{334}(7) \\
A r^{10}-A r^{39}(4)\end{array}$ & $\begin{array}{l}\text { "Monomict anor- } \\
\text { thositic breccia." }\end{array}$ \\
\hline $63502,17 \mathrm{~b}$ & $?$ & Whole rock? & $(3.8 \pm 0.3)$ & $A r^{40}-\mathrm{Ar}^{34}(4)$ & $\begin{array}{l}\text { "Aphanitic dark } \\
\text { fragment." No } \\
\text { well defined } \\
\text { plateau. }\end{array}$ \\
\hline $63502,17 \mathrm{c} 2$ & Anorthosite & Whole rock & $(4.1 \pm 0.1)$ & $A r^{40}-\mathrm{Ar}^{39}(4)$ & $\begin{array}{l}\text { "Unshocked anor-, } \\
\text { thositic particle." }\end{array}$ \\
\hline $63502,17 d$ & Plagioclase & - & $-(3.9 \pm 0.3)$ & $A r^{311}-A r^{39}$ & $\begin{array}{l}\text { "Clear plagioclase } \\
\text { crystals," No } \\
\text { well-defined } \\
\text { plateau. }\end{array}$ \\
\hline
\end{tabular}

63503,13,2 Anorthosite Whole rock? 3.98 $0.07 \quad \mathrm{Ar}^{\mathrm{jt}}-\mathrm{Ar}^{39}(8)$

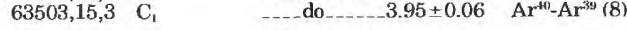
$63503,17 ? \quad ? \quad 4.19 \pm 0.06 \quad \mathrm{Ar}^{30}-\mathrm{Ar}^{38}(9)$ $\begin{array}{llrrr}63503,17 & ? & ? & 4.19 \pm 0.06 & \mathrm{Ar}^{30}-\mathrm{Ar}^{39}(9) \\ 63503,17 & ? & ? & 3.98 \pm 0.04 & \mathrm{Ar}^{30}-\mathrm{Ar}^{39}(9) \\ 63503,17 & ? & ? & 3.99 \pm 0.03 & \mathrm{Ar}^{10}-\mathrm{Ar}^{39}(9) \\ 63503,17 & ? & ? & 3.99 \pm 0.02 & \mathrm{Ar}^{40}-\mathrm{Ar}^{39}(9) \\ 65015 & \mathrm{C}_{2} & \text { Whole rock? } 3.98 ; 3.93 & \mathrm{Ar}^{10}-\mathrm{Ar}^{39} \text { and }\end{array}$

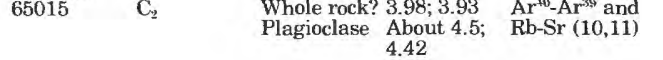

Possible excavation No description. Do.
Do.
Do.

Whole rock, age of metamorphism: plagioclase, minimum age of

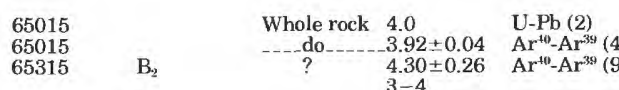
15. Hueneke and others, $1973 \mathrm{~b}$

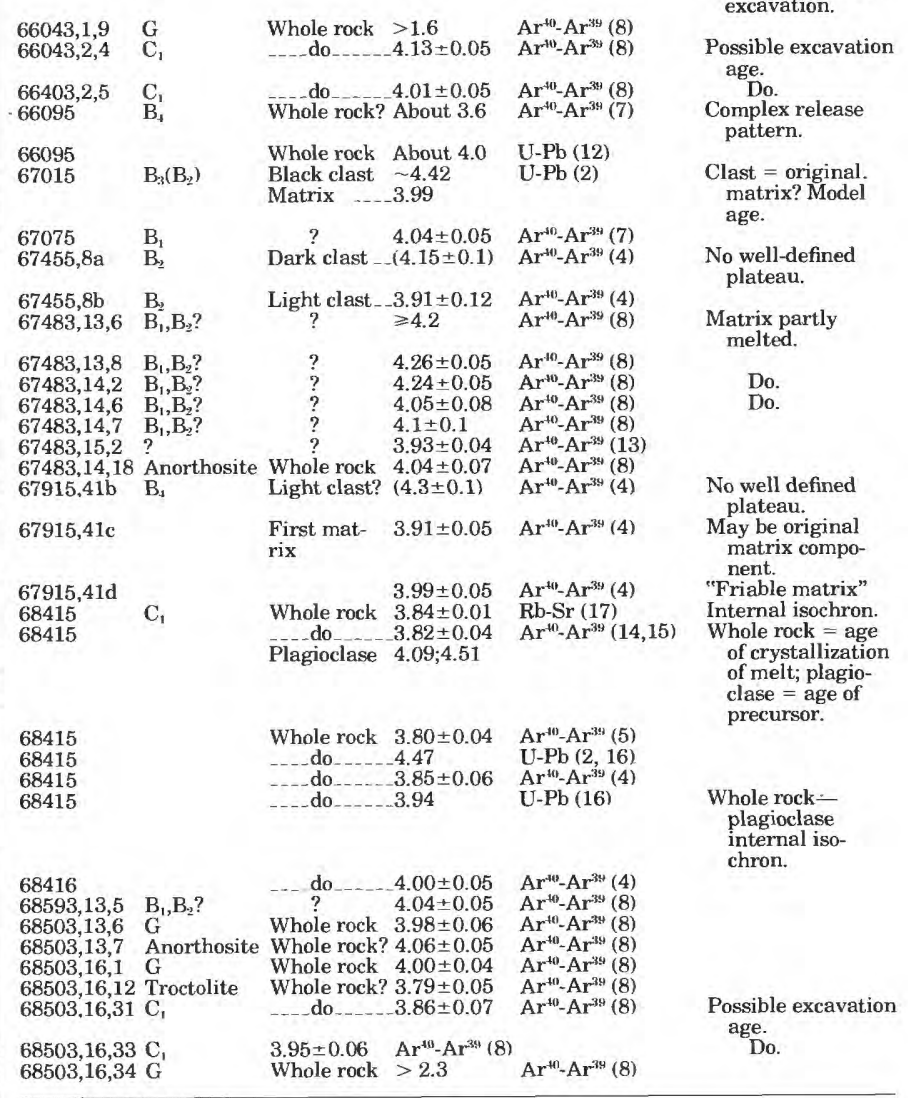
Sources:

1. Schaeffer and Husain, 1974 2. Nunes and others, 1973 3. Husain and Schaeffer, 1973 4. Kirsten and others, 1973 5. Stettler and others, 1973 6. Mark and others, 1974 7. Turner and others, 1973 8. Schaeffer and Husain, 1974 9. Stettler and others, 1974

10. Jessberger and others, 1974 11. Papanastassiou and Wasserburg, 1972b 12. Nunes and Tatsumoto, 1973 13. Albee and others, $1973 \mathrm{~b}$ 14. Hueneke and others, $1973 \mathrm{a}$ 16. Tera and others, 1973

17. Papanastassiou and Wasserburg, 1972a

Interpreted as
two-stage evolu-
tion, old age =
time of crystalli-
zation of parent,
young = time of
excavation.
Possible excavation
age.
Do.
Complex release
pattern.
Clast = original.
matrix? Model
age.
No well-defined
plateau.
Matrix partly
melted.
Do.
Do.

No
1973b
No well defined
plateau.
May be original
matrix compo-
nent.
Wasserburg, 1972a
"Friable matrix"
Internal isochron.
Whole rock = age
of crystallization
of melt; plagio-
clase = age of
precursor.
Dossible excavation
age.
Whole rock-
plagioclase
internal iso-
chron.
Tasserburg, 1972b

t973 have. May 
An effort is made here to point out some of these problems with respect to specific samples and to interpret the data where possible. The discussion is based, as is table 3 , on the assumption that the plutonic rocks, whether clasts in breccias or isolated fragments, were excavated from the deep lunar interior by basinforming impacts (Wilshire, 1974). The significance of their ages, as well as those of rocks that were melted or metamorphosed as a consequence of this excavation, depends on their subsequent history. The petrology of the samples shows that impact events following the initial excavation of Apollo 16 rocks produced effects ranging from minor to effects so profound as to have completely reset radiogenic clocks. Moreover, extreme effects can be registered in small areas of rocks that have not otherwise been much changed since excavation.

Breccias that have been little modified since excavation can be recognized by large areas of unmixed cataclastic feldspathic rock with coarse mineral and lithic relics and large areas of the dark fine grained original matrix; the first-cycle matrix is generally broken, but the pieces commonly are not much rotated. A significant number of Apollo 16 rocks have these characteristics (table 3 ), but few of them have been dated, and none has had all of its components (matrix and plutonic igneous and metamorphic clasts) dated separately. The ages of samples such as soils and the $\mathrm{C}_{1}$ and $\mathrm{C}_{2}$ crystalline rocks are ambiguous because their history since excavation has not been determined.

Age data (table 4) have been determined on eight samples called "anorthosite." Three of these are documented rocks $(60015,60025,67075)$; five are samples from 2 to $4 \mathrm{~mm}$ coarse fines $(62242,3 ; 63503,13,2$; $63502,17, c 2 ; 67483,14,18 ; 68503,13,7)$. Ages range from 3.55 b.y. to $4.5 \pm 0.3$ b.y. Sample 60015 , dated at 3.55 b.y. by ${ }^{41} \mathrm{Ar}{ }^{39} \mathrm{Ar}$, is considered to be the "youngest anorthosite" yet found on the Moon (Schaeffer and Husain, 1974). The hand specimen, however, clearly reveals heavy shock damage that resulted in extensive pulverization, melting, and maskelynitization of the anorthosite. Moreover, some areas have a coarsely sugary texture typical of preexcavation (?) metamorphic textures (Wilshire, 1974). Where information is insufficient to determine the exact nature of the part of the sample dated, the age may be interpreted to represent the age of crystallization of the anorthosite as implied by Schaffer and Husain (1974), the age of preexcavation (?) thermal metamorphism, age(s) of shock deformation, or some averaged combination of these. If the age represents shock deformation, as seems. likely from the extensive shock damage and from its primitive initial ${ }^{8} \mathrm{Sr}$ (Nunes and others, 1974), it has no significance with respect to basin chronology. Sample
61016 , which is texturally similar to 60015 , is a breccia that has undergone extreme shock damage following its excavation and following crystallization of the melt rock matrix that encloses the anorthositic clasts (see references, table 3 ). These events may have no relation at all to the initial excavation of rocks and conceivably are the more extreme results of minor impacts. Moreover, Nunes and others (1974) documented loss of lead from 60015 glass less than 1.3 b.y. ago, indicating further modification by a still more recent event. Sample 60025 , dated by ${ }^{40} \mathrm{Ar}-{ }^{39} \mathrm{Ar}$ at 4.18 b.y., is intensely pulverized and locally partly melted. It is not as badly damaged as 60015, and the age may represent a minimum crystallization age, although no description of the piece analyzed is given. The presence of substantial amounts of olivine and orthopyroxene in the cataclastic parts of the rock as well as unpulverized relics of the original rock suggest that more meaningful ages could be obtained by dating these relics (table 3 ). Sample 67075 , dated by ${ }^{40} \mathrm{Ar}-{ }^{39} \mathrm{Ar}$ at 4.04 b.y., is a complex $B_{1}$ breccia in which a variety of coarse hornfels clasts (preexcavation metamorphism?) are the dominant lithic relic. As the grain size of much of the mineral debris is too coarse grained to have been derived from the hornfelses, the breccia as a whole may be derived from one or more partly metamorphosed plutonic rocks. The whole-rock age of the rock could represent an average of several metamorphic and crystallization ages.

"Anorthosite" samples from the 2- to 4-mm fines dated are accompanied by meager descriptions. As material called "anorthosite" in the literature is commonly hornfels, sometimes glass, and rarely anorthosite, one does not know whether the ages represent time of crystallization of the parent rock, time(s) of thermal metamorphism, or time(s) of melting in a regolith environment.

Two samples called "troctolite," one (62295) a documented rock, and one $(68503,16,12)$ from 2 to 4 $\mathrm{mm}$ coarse fines, have been dated (table 4). Sample 62295 is probably an impact melt (see references, table 3 ), and its age that of crystallization of the melt. The rock does contain a small amount of unmelted relics that could affect the age, producing the spread of ages determined by $\mathrm{Rb}-\mathrm{Sr}\left(4.00 \pm 0.06\right.$ b.y.) and ${ }^{40} \mathrm{Ar}-{ }^{39} \mathrm{Ar}$ $(3.89 \pm 0.05$ b.y.) methods. Whether $68503,16,12$ is an impact melt, a plutonic igneous rock, or a hornfels is not known from the description given, and the significance of the age is therefore unknown.

Other dated samples of apparent impact melt rocks other than glass include documented rocks 68415 and 68416 and $2-4 \mathrm{~mm}$ coarse fines samples $63503,15,3$; $66043,2,4 ; 66043,2,5 ; 68503,16,31$; and $68503,16,33$. Many dates are available for the ophitic rock 68415 
(table 4); they show a range from $3.80 \pm 0.04$ to 4.47 b.y., with a Rb-Sr internal isochron registering $3.84 \pm 0.01$ b.y. A plagioclase separate from 68415 analyzed by Huneke and others (1973a) has a distinctly higher (4.09 b.y.) ${ }^{40} \mathrm{Ar}-{ }^{39} \mathrm{Ar}$ plateau age than the whole rock and a high-temperature release age of about 4.5 b.y. The plagioclase separate may include unmelted relics of the precursor of the rock. Sample 68416 , taken from the same boulder as 68415 (ALGIT, $1972 \mathrm{~b}$ ) and having an essentially identical bulk composition (Rose and others, 1973), yielded a ${ }^{40} \mathrm{Ar}-{ }^{39} \mathrm{Ar}$ whole-rock age of $4.00 \pm 0.05$ b.y. Our descriptions of this sample in hand specimen indicate a higher abundance of relict plagioclase than in 68415 , which may account for the older apparent age of the whole rock. Rocks like 68415 and 62295 are not abundant in the Apollo 16 collection, but the evidence seems good (see Dowty and others, 1974a) that they represent impact melts derived from older, highly feldspathic rocks. Their relatively coarse grain sizes compared with other Apollo 16 impact melt rocks indicate slower cooling, but they did not cool so slowly that isotopic equilibrium was achieved. The ages of these rocks, exclusive of unmelted residual material, may be significant in basic chronology, but are nevertheless ambiguous, as direct ties to plutonic source rocks have not been made.

The 2-4-mm samples that are probable impact melt rocks are identified as "fine-grained intersertal igneous rocks" (Schaffer and Husain, 1973) in the terminology of Delano and others (1973). Such rocks form significant amounts of the matrices of many simple breccias (table 2), but also survive as clasts through multiple impacts. The histories of such materials in 2-4-mm coarse fines are therefore impossible to decipher, and their ${ }^{40} \mathrm{Ar}-{ }^{39} \mathrm{Ar}$ ages cannot be meaningfully interpreted.

Two documented samples $(60315,65015)$ of $\mathrm{C}_{2}$ metaclastic rocks have been dated. Sample 60315 yielded ${ }^{40} \mathrm{Ar}-{ }^{39} \mathrm{Ar}$ ages of $3.94 \pm 0.5 \mathrm{~b} . \mathrm{y}$. and $4.03 \pm 0.03$ b.y. and a U-Pb whole-rock age of 3.99 b.y.; 65015 yielded a Rb-Sr whole-rock age of $3.93 \pm 0.02$ b.y., ${ }^{10} \mathrm{Ar}-$ ${ }^{39} \mathrm{Ar}$ whole-rock ages of $3.92 \pm 0.04$ b.y. and 3.98 b.y., and a U-Pb whole-rock age of 3.99 b.y. These rocks have moderately coarse grained poikiloblastic textures with variable amounts of unrecrystallized mineral and lithic debris. Both dating methods indicate that unrecrystallized plagioclase in 65015 is not in isotopic equilibrium and is much older (4.40-4.5 b.y.) than wholerock ages. Angular plagioclase relics in 60315 are zoned; this chemical disequilibrium suggests that isotopic equilibrium may not have been achieved in this rock either. Differences in whole-rock ages may reflect differences in amount of unrecrystallized debris in the particular parts of the rock analyzed. The whole-rock ${ }^{40} \mathrm{Ar}-{ }^{39} \mathrm{Ar}$ ages are of course older, by an unknown amount, than the age of metamorphism because plagioclase that yields a greater age was present in the rock measured. As lithologic mixing may have occurred during formation of these rocks (see Bence and others, 1973; Albee and others, 1973b), the wholerock $\mathrm{Rb}-\mathrm{Sr}$ and unrecrystallized plagioclase ages may also average rock materials of different ages. The lack of direct ties between these rocks and plutonic rocks makes their times of metamorphism ambiguous with respect to basin chronology.

Of 17 breccias dated (table 4), 10 are parts of six documented rocks $(61016,65315,66095,67015,67455$, and 67915); the rest are samples taken from coarse fines $(63502,17 \mathrm{a} ; 67483,13,6 ; 67483,13,8 ; 67483,14,2$; $67483,14,6 ; 67483,14,7 ; 68503,13,5$ ). Our criteria (table 3 ) indicate that of the analyzed group, only documented samples 65315 and 66095 are likely to yield unambiguous information on basin chronology. Sample 65315 yielded an ${ }^{40} \mathrm{Ar}-{ }^{39} \mathrm{Ar}$ age of $4.30 \pm 0.26$ b.y., interpreted (Stettler and others, 1974) as possibly reflecting the crystallization age of the anorthositic component, with indications of excavation between 3 and 4 b.y., and rebrecciation (converting the rock to a B. breccia) at about 2 b.y. We believe that the excavation age could be determined precisely from the original matrix component of this breccia, but we do not know what component of the rock was dated by Stettler and others (1973). Sample 66095 is dated by U-Pb at about 4.0 b.y. (Nunes and Tatsumoto, 1973); this may represent an excavation age, but its relation to excavation ages of little-modified breccias remains unknown.

Sample 61016 is a complex breccia consisting of extensively shattered, partly maskelynitized, and partly coarsely metamorphosed anorthositic clasts in a finegrained intersertal matrix. Maskelynitization of the plagioclase laths in the matrix indicates that the entire rock was severely shocked after consolidation of the intersertal matrix. The poorly defined ${ }^{40} \mathrm{Ar}-{ }^{39} \mathrm{Ar}$ age of about 3.65 b.y. (table 4) has no significance with respect to basin chronology or crustal formation. Sample 67015 , which may be a complex soil breccia, and 67455 are so thoroughly reworked by multiple impacts that the postexcavation histories of their components are extremely difficult to decipher. Sample 67915 is another very complex rock of which three components have been analyzed. Our classification of the rock as a $\mathrm{B}_{4}$ breccia disregards the extensive glass net-veining; as the event that produced the glass may have altered significant portions of the rock, we regard the ages as ambiguous. Furthermore, the component dated at $3.99 \pm 0.05$ b.y. $(67015,41 \mathrm{~d})$ is called "friable matrix" of 
the breccia by Kirsten and others (1973). The rock as a whole, viewed either as including or excluding the glass veins, does not have a friable matrix; we do not know what was actually dated nor its relation to the rest of the rock.

The seven breccia samples taken from coarse fines (table 4) could have been derived from virtually any source among the breccias; therefore, their significance in basin chronology and crustal formation is unknown.

Five samples of glass $(63503,13,7 ; 66043,1,9$; $68503,13,6 ; 68503,16,1 ; 68503,16,34)$ and one of plagioclase $(63503,17 \mathrm{~d})$ from coarse fines were analyzed (table 4). In many of the documented samples, it is clear that glass formation is among the youngest events in the history of the rocks and presumably is the consequence of comparatively small impacts that do not produce thick ejecta deposits in which the melt could crystallize. The glass ages have no obvious significance with respect to basic chronology or crustal formation.

Five analyzed samples $(63503,17$, four samples from 2 to $4 \mathrm{~mm}$ coarse fines and $67483,15,2$ ) were not well enough described for us to interpret their ages.

Of the 47 samples of Apollo 16 rocks dated, only one appears to have a reasonably unambiguous age: the age of $60025,4.18$ b.y., may represent the minimum crystallization age of this rock, or, if Turner and others (1973) are correct in assuming that degassing in the lunar interior occurs continuously to the time of excavation, the age may represent the minimum age of excavation. However, the ${ }^{40} \mathrm{Ar}-{ }^{39} \mathrm{Ar}$ ages obtained on plagioclase separates from 65015 , which are older than those obtained from the whole rock, and the results obtained by Stettler and others (1974) on 65315 suggest that crustal anorthositic rocks were not degassed prior to excavation. Hence, the ages of the leastdamaged anorthositic components of breccias more likly represent minimum ages of crystallization than time of excavation (Stettler and others, 1974), but both ages could probably be made more reliable by more selective sampling of the hand specimen (see table 3 ). Four other samples that ambiguously date basinforming events are $62295,4.00$ b.y., 3.89 b.y.; 68415, $3.80-3.85$ b.y.; $60315,3.94$ b.y., 4.03 b.y.; and 65015 , 3.93 b.y., 3.98 b.y. The only criterion by which these rocks are identified as possible derivatives of very large impact events is their comparatively coarse grain size. Two of these samples $(68415,4.09-4.5$ b.y ; 65015, $4.40-4.5$ b.y.) yield possible ages of their precursors that may be significant with respect to crustal formation. These results do not appear to us to provide a sound basis for speculating on the chronology of basinforming events or crustal formation. It seems clear however, that useful information can be obtained from the least-damaged breccias, as detailed in table 3 , if they are selected and dated systematically with regard to their petrology.

\section{AREAL DISTRIBUTION OF CLASSIFIED SAMPLES}

The field distribution of all samples classified in table 1 is plotted in histogram (fig. 5). Samples from stations 4,5 , and 13 are heavily weighted by rake samples collected from a small area. The LM-ALSEP and station 11 areas are much better represented by documented samples than the other stations. Samples of all eight rock groups described were found at these two stations, suggesting that more extensive sampling at other stations would have expanded the range of rock types at each station.

The stations can be divided into two groups (1) Cayley plains stations are LM-ALSEP, 1, 2, 6, 8, and 9; LM-ALSEP and station 6 may be mantled by a thin discontinuous veneer of material from the Descartes mountains. (2) Descartes mountains stations are 4 and 5 , located on Stone mountain but possibly partly mantled by ejecta from South Ray crater; and 11 and 13, on the North Ray crater ejecta blanket, which may sample the Descartes mountains.

Although proportions of rock types vary from station to station, depending on thoroughness of documented sampling, there are no distinctive differences in rock populations between the two groups of stations (fig. 5). When all data within the two station groups are combined (fig. 6), some differences appear: Cayley stations have higher proportions of $\mathrm{C}_{1}$ and $\mathrm{C}_{2}$ crystalline rocks and a lower proportion of $\mathrm{B}_{2}$ breccia. According to our view of the breccias, both $B_{1}$ and $B_{2}$ breccias are derivatives of $B_{4}$ types, the $B_{1}$ 's differing from $B_{2}$ 's only by having none of the first matrix component attached. If these close relations are considered, there do not appear to be significant differences in rock populations between sample sites on the Descartes mountains and those on the Cayley plains.

The comparatively small number of samples thin sectioned to date does not allow final conclusions on possible petrographic differences between rocks from the Descartes mountains and the Cayley plains, but the data available (table 2) indicate that differences are not significant. In figure 7, the textures of crystalline rocks and unmodified breccia matrices are placed in the two station groups. The histograms are virtually identical.

Studies of soils from the Apollo 16 site (Delano and others, 1973; G. J. Taylor and others, 1973) suggest that, in general, materials derived from the Cayley plains are comparatively rich in fine-grained igneous 


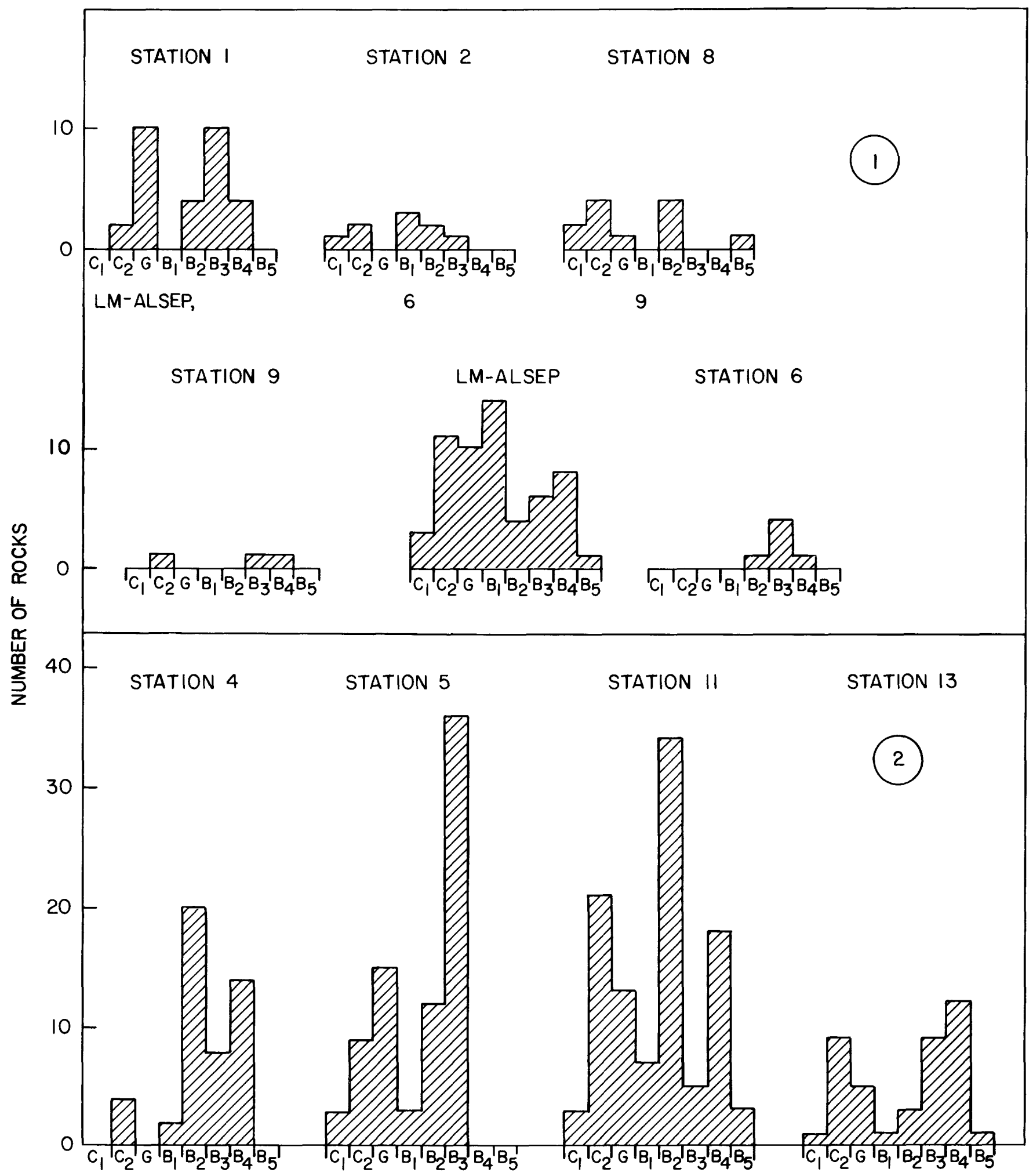

FIGURE 5.-Histograms showing distribution of rock types at each sampling station. Rocks in group 1 are from Cayley plains, those in group 2 from Descartes mountains and the ejecta blanket of North Ray crater.

and poikiloblastic lithic fragments whereas materials derived from the Descartes mountains are comparatively rich in what is termed "ANT" (anorthosite, nor- ite, troctolite) lithic fragments. Heiken and others (1973), who studied a wider size range of particles, found the reverse situation at station 4 on the Des- 


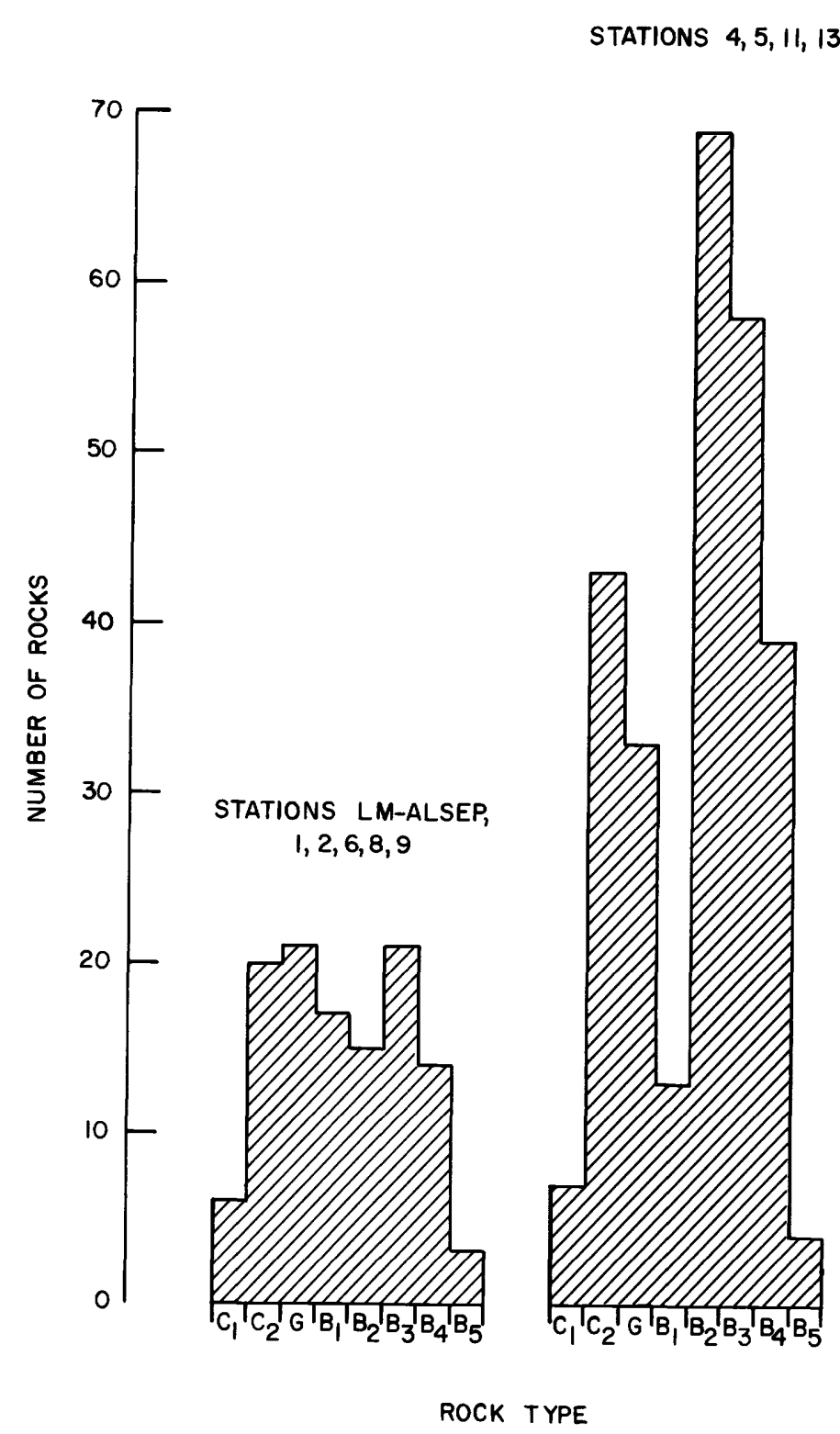

FIGURE 6.-Composite histograms of the two groups of stations.

cartes highlands, where samples had a higher proportion of "medium- and high-grade" metamorphic fragments (poikiloblastic and sheaf-textured rocks) than soils from the Cayley plains or North Ray crater stations. Such differences in the soil components may reflect differences in proportions of clasts and matrix of parent breccias; Cayley soils might be taken as derived from breccias with a larger matrix component than Descartes soils. This type of information is not included with the distribution of the larger rock samples shown by the histograms (figs. 5 and 6 ).

While the bulk chemical composition of soils (LSPET, 1973; Rose and others, 1973) shows little variation, Duncan and others (1973) noted subtle differences between Descartes and Cayley materials that
STATIONS LM-ALSEP, $1,2,6,8,9$

STATIONS

$4,5,11,13$

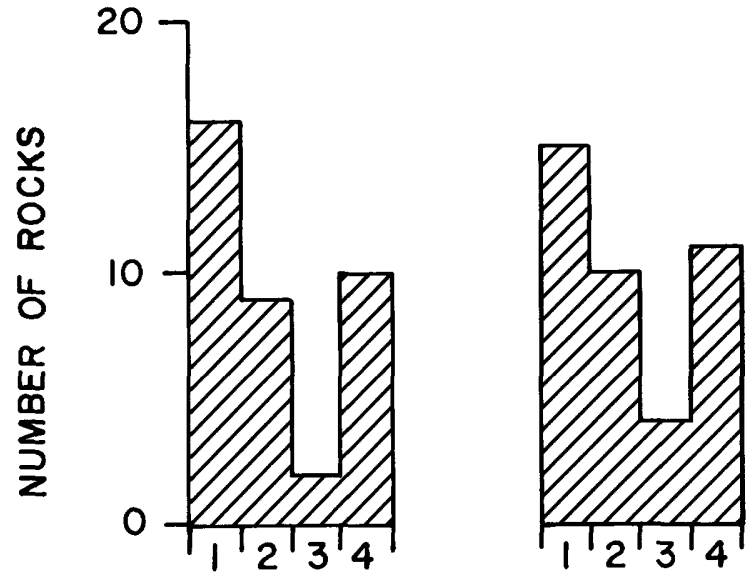

\section{$I=$ Igneous \\ $2=$ Poikiloblastic 3= Granoblastic $4=$ Glassy or fragmental}

FiguRe 7.-Histograms showing distribution of microscopic textures at each of the two groups of stations.

could be accounted for by Descartes materials enriched in "anorthosite" and depleted in "KREEP," "granite," "high-Mg basalt," and the meteoritic component relative to Cayley materials. These differences may reflect compositional differences between matrix and clast components of the first-cycle breccias, perhaps in part a consequence of partial melting (Warner and others, 1974); the statistics on coarse fines and compositional variations indicate a larger proportion of first-cycle breccia matrix in soils of the Cayley Formation.

These results are consistent with the concept of Hodges and Muehlberger (this volume) that the Cayley Formation and Descartes mountains units are lateral facies of the same ejecta deposit. In this view, the Descartes material is the comparatively "dry," clast-rich part of the ejecta, the Cayley Formation the comparatively "wet," matrix-rich part. Ulrich (1973) suggested that at the Apollo 16 site, dark "melt-rich" breccias are relatively abundant at lower elevations, "dry," lightmatrix breccias at higher elevations, concluding that the stratigraphic section consists of light-matrix breccias overlying dark-matrix melt-rich breccias. The soils data are less in accord with this view, unless South Ray crater distributed a considerable amount of debris from the hypothetical dark breccia layer over the southern and central Cayley stations.

Delano and others (1973) utilized the same hypothet- 
ical stratigraphic section but identified the dark layer as either a brecciated volcanic flow or a regolith containing abundant volcanic material ("FIIR"=finegrained intersertal igneous rock). The enrichment of Cayley soils in poikiloblastic and fine-grained intersertal rocks raises the same problem with their hypothesis as with Ulrich's. Moreover, the fine-grained intersertal texture is well developed as impact melt matrix in many breccias, much likelier sources of the "FIIR" than a volcanic flow. The significance of the FIIR ages (Schaffer and Husain, 1973)is unknown, but the range of values from $3.86 \pm 0.07$ b.y. to $4.13 \pm 0.05$ b.y. is much too great for one lava flow.

There seems to be little basis for the supposition (G. J. Taylor and others, 1973) that soil components from the Cayley indicate stratigraphic layering in which the Cayley Formation is composed predominantly of poikiloblastic rocks underlain by a regolith of lightmatrix breccias. The documented rock collection clearly shows that all components of those soils could have been derived from a section composed of a single breccia parent with no vertical lithologic variations. There is even less basis for the postulated bedrock of anorthosite-norite-troctolite (ANT) on which the light-matrix-breccia regolith is thought to have formed (Taylor and others, 1973). The sample data seem rather to support derivation of the soils from ejecta deposits in which an original matrix component (powdered and partly melted rock) was present in somewhat higher proportion than anorthositic clasts in the areas underlain by Cayley Formation than in areas underlain by Descartes materials. Whether these ejecta deposits overlie still older ejecta is not known but seems likely.

\section{SUMMARY AND CONCLUSIONS}

Apollo 16 samples heavier than $2 \mathrm{~g}$ are classified by a descriptive scheme of three groups: (1) crystalline rocks, subdivided as igneous or metamorphic; (2) glass; and (3) breccias, subdivided on the basis of color of clast and matrix and proportions of these components.

The crystalline igneous rocks consist of one certain and one possible anorthosite, 11 fine-grained ophiticto-intersertal rocks of troctolitic to anorthositic composition, and one troctolite enclosed in fine-grained melt rock of the same composition. Derivation of the finegrained igneous rocks by impact melting of feldspathic plutonic source rocks is indicated by common occurrence in the fine-grained rocks of unmelted relics de- rived from coarse-grained plutonic rocks, a bulk compositional spread like that of the plutonic clasts in breccias, and gradations from fine-grained melt textures to plutonic rocks of essentially the same composition.

Metamorphic crystalline rocks studied consist of one medium-grained granoblastic rock, considered to be a product of metamorphism in a plutonic environment prior to excavation, and ten poikiloblastic rocks. We conclude that gradation from poikiloblastic to unequivocal igneous textures in these rocks is evidence of metamorphic origin with minor melting.

The five breccia types have been derived by rebrecciation of a first-cycle breccia that consisted of anorthositic clasts in a fine-grained matrix that varied from melt texture to metamorphic texture. The first-cycle breccia is considered to be multiring basic ejecta, as it contains clasts of plutonic rock derived from deep in the lunar crust. These breccias have been modified in varying degrees by subsequent smaller impacts.

Rocks reflecting modification of first-cycle breccias are sufficiently well represented in the Apollo 16 collection that least-damaged samples can be identified. From such samples, it may be possible to date the crystallization of the original crustal rocks, the preexcavation local metamorphism of those rocks, and the time of excavation. A review of age data shows that most samples selected for isotopic measurement are so severely modified by subsequent impacts that the ages are ambiguous. The samples petrologically most favorable for dating significant and identifiable events in the histories of the rocks are tabulated with the hope that they will help in obtaining unambiguous dates, now so scarce that speculation on basin chronology is at present unwarranted.

The distribution of classified samples shows no significant differences among Cayley and Descartes sample sites. Statistical and compositional data on soils support the view that the Cayley plains and materials of the Descartes mountains are facies of the same ejecta deposit and that a somewhat higher proportion of matrix, melt and powdered rock, was segregated to form the Cayley Formation.

\section{ACKNOWLEDGMENTS}

We are indebted to M. Prinz, University of New Mexico; W. R. Muehlberger, University of Texas; P.D. Nunes, R. L. Sutton, and G. E. Ulrich, U.S. Geological Survey, for review and assistance with this report. 


\title{
F. REGOLITH OF THE APOLLO 16 SITE
}

\author{
By VAL L. Freeman
}

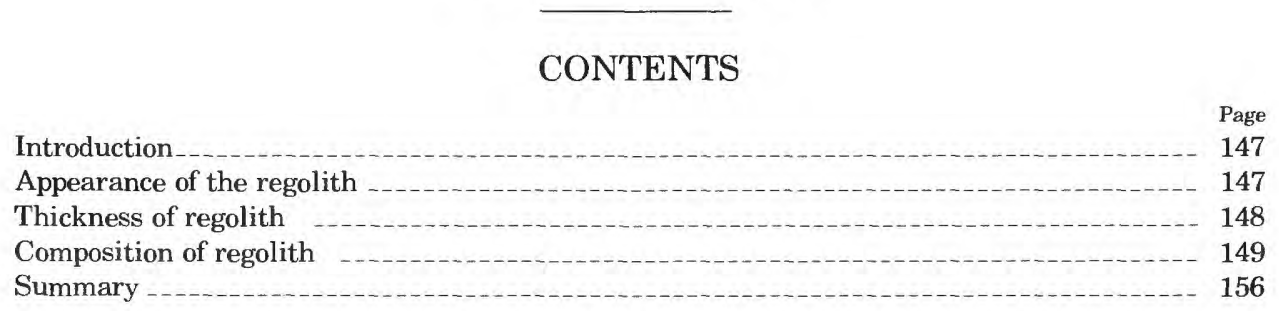

\section{ILLUSTRATIONS}

Figure 1-4. Photographs:

1. Apollo 16 traverse area in high-sun illumination

2. Comparison of lunar surface within and between rays from South Ray crater

3. Comparison of old and young ray-covered areas _

4. Location of concentric craters used to estimate depths of regolith

5. Map of kilometer-size craters in Apollo 16 region

6-9. Variation diagrams, soil samples and rock and soil samples:

6. $\mathrm{FeO}, \mathrm{TiO}_{2}, \mathrm{Al}_{2} \mathrm{O}_{3}$ and $\mathrm{Ni}$

7. $\mathrm{TiO}_{2}$ relative to $\mathrm{Al}_{2} \mathrm{O}_{3}$

8. $\mathrm{Al}_{2} \mathrm{O}_{3}$ relative to $\mathrm{FeO}$

9. Ni relative to $\mathrm{FeO}$

TABLES

2. Apollo 16 rock analyses for $\mathrm{Al}_{2} \mathrm{O}, \mathrm{TiO}, \mathrm{FeO}$, and $\mathrm{Ni} \ldots$

\section{INTRODUCTION}

The lunar regolith is generally defined as the relatively unconsolidated fragmental material that forms the surface layer of the Moon. The term is used for all loose surficial debris and for subunits that can be recognized, such as regolith above, beneath, and mixed with the ejecta of North Ray crater. It is commonly assumed that regolith is solely the product of repeated meteorite bombardment, that is, the accumulation and mixing of impact crater ejecta on the lunar surface. Accordingly, the median thickness of regolith above some stratum is related to the time elapsed since formation of that stratum (Shoemaker, 1971). In this report, the term regolith is used in the several senses defined. "Soil" is used as a synonym for the regolith.

This report describes the regolith at the Apollo 16 site, provides new measurements of its thickness, and examines the composition of the soils in comparison with the rocks within the site.

\section{APPEARANCE OF THE REGOLITH}

Premission investigations of the Apollo 16 site suggested that differences in regolith would be found. Rays of high albedo extending across the surface from South Ray, North Ray, and Baby Ray.craters were seen in orbital photographs (pl. 2). The Cayley plains (LM landing area) and the Descartes mountains (Stone mountain) were considered to be underlain by different bedrock types that would be reflected by differences in composition of regolith. The astronauts on the surface were able to recognize the rays by changes in abundance of rock fragments and secondary craters but otherwise found the surface appearance of the regolith the same throughout the area traversed. No difference between regolith on the Cayley plains and on Stone mountain was observed. An unexpected finding was the presence of a white layer just below the surface at most of the stations (Muehlberger and others, 1972).

The regolith appeared to the astronauts as a gray, 
rocky soil unit with a heavily cratered surface that seemed to lack truly flat areas. The LM touched down in one of the smoothest areas available; local relief amounted to only a few meters except for a fresh $30-\mathrm{m}$ crater immediately east of the LM. The crew observed that this area might be the floor of a very subdued 180-m crater.

The surface along the traverses was crossed by long rays of two ages shown by premission mapping (Elston and others, 1972c), an older set radiating from North Ray crater and a younger set from South Ray crater. The crew's description of the surface gives a picture of the composition and form of a young ray and valuable data on the aging of rays as discussed below. During the three traverses, they crossed many ray segments (fig. 1) on different azimuths, at various distances from their source craters, and under different lighting conditions.

The fresh rays were distinguished by the crew on the basis of concentrations of rock fragments on the surface, the presence of large blocks, the high angularity

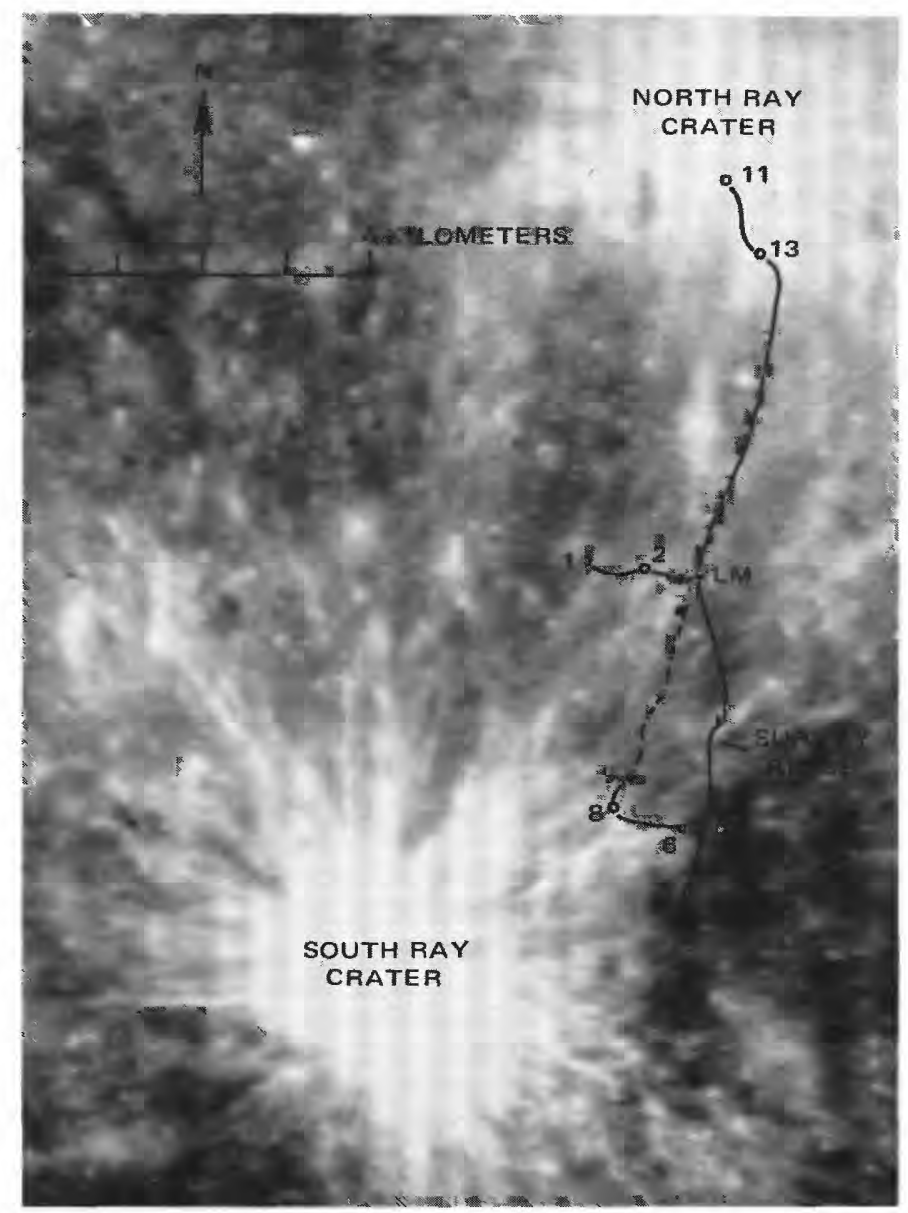

Figure 1.-Apollo 16 traverse area. Apollo 16 panoramic camera frame 5328, computer enhanced to show ray patterns from North and South Ray craters; sun elevation $60^{\circ}$. of the rocks, the absence of dust on the rocks, the presence of secondary craters, and, under favorable lighting conditions, higher albedo of the ray area. No topographic form was associated with rays, and no color or other property of the fine-grained (granules or finer) surface materials was described that would distinguish ray areas from interray areas. The greatest concentration of blocks was seen on Survey ridge within a ray from South Ray crater (fig. $2 A$ ), whereas interray areas were generally devoid of blocks (fig. $2 B$ ). The discontinuous patterns of rays viewed from orbit (fig. 1) within traverse areas apparently do indicate irregularities of the original distribution of ejected rocks. Near Survey ridge, the crew observed that the cobble concentration was clearly the greatest near the center of the ray, decreasing gradually toward the edges. Elsewhere, they were moderately certain of the edge of a ray. Probably both sharply delineated edges and gradational edges of rayed ejecta are common, as indicated by the types of variation in albedo seen on photographs (fig. 1).

On the surface, the astronauts thought they could recognize several rays from North Ray crater. From a distance, they could see very large blocks forming a North Ray ray on the slopes of Smoky mountain. Near Palmetto crater, they noted a concentration of 20 - to $30-\mathrm{cm}$ blocks that also appeared to be a ray from North Ray crater. Photographic measurement of visible blocks (Schaber, this volume, fig. 4; Muehlberger and others, 1972) clearly show the blocks on these older rays and ejecta blanket of North Ray crater to be less abundant than those on rays from South Ray crater (fig. 3). Many blocks in the older rays were reported by the crew as rounded and dust covered.

\section{THICKNESS OF REGOLITH}

Premission work by Oberbeck (1971b) on regolith thicknesses predicted less than $6.7 \mathrm{~m}$ (range of 3.1 to $6.7 \mathrm{~m}$ ) at the Apollo 16 site. Oberbeck obtained a calculated thickness of $22 \mathrm{~m}$ using the total crater population and assuming that all of these craters are of impact origin and that a greater density of craters correlates with a greater thickness of regolith. To explain this difference, Oberbeck (1971b, p. 9) suggested that because most of the craters are subdued and probably of impact origin "a deep regolith has been produced. However, it is further suggested that the regolith and impact craters have been mantled by a deposit that was indurated after deposition. This would produce the subdued appearance of the large craters and provide an indurated formation that could subsequently be modified by recent impact craters to produce a thinner regolith deposit."

The preliminary geologic report after the mission 
(Muehlberger and others, 1972) suggested a regolith thickness of 10 to $15 \mathrm{~m}$ based on the position of a bench in Buster crater.

A new attempt is made here to determine regolith thickness using the relation of crater shape to thickness (Quaide and Oberbeck, 1968) and measurements from a stereo model of Apollo 16 panoramic camera photographs. Ten craters with terraced or concentric internal shapes, indicating an underlying harder layer were examined (fig. 4). The depth from the average ground surface beyond the rim deposit to the top of the hard layer was measured by R. Jordan (U.S. Geological Survey) for each crater. The regolith thickness thus obtained ranged from 3.5 to $8.7 \mathrm{~m}$; reproducibility of measurements was within about $2 \mathrm{~m}$. Half of the craters gave thicknesses of 6.0 to $6.8 \mathrm{~m}$. The only crater other than Buster that permits an estimate of regolith thickness substantiated by lunar-surface photographs is WC crater, $700 \mathrm{~m}$ south of the LM. It is about $40 \mathrm{~m}$ in diameter, and the photographs of WC ejecta taken from the LRV indicate that bedrock was reached. The WC ejecta contains abundant blocks; a regolith thickness of $6.7 \mathrm{~m}$ above bedrock was measured photogrammetrically for WC crater. Other craters in the landing area are larger than the craters cited but are "V" shaped indicating local areas of thicker regolith.

These new measurements of regolith thickness at points of concentric craters are in very close agreement with the results obtained by Oberbeck (1971b) using diameters of the craters. His postulated older, thicker $(22 \mathrm{~m})$ regolith and its covering deposit upon which the presently active regolith has formed were not found on careful examination of the Apollo 16 panoramic camera photographs. Other methods of obtaining the thickness of regolith have yielded different results, summarized here.

The thickness of the regolith in the area of the active seismic experiment was determined as $12.2 \mathrm{~m}$ by Kovach and others (1972, p. 10-1). Although the passive seismic experiment did not measure the regolith thickness directly, Latham and others $(1972$, p. 9-1) stated: "The signal character and background noise at each station have distinctive characteristics apparently related to the depth and elastic properties of the regolith at each site. To explain these differences, the Apollo 16 station, compared to Apollo 12, 14, and 15, must overlie the deepest or weakest regolith, or both, according to criteria now applied. This condition also would explain the much higher sensitivity of the Apollo 16 station."

Zisk and others (1972) concluded from 3.8-cm radar data that there is little distinction between Cayley plains and Descartes mountain areas. "The 70-cm radar shows that the Cayley regolith is freer of meter- sized boulders to depths as great as *** 10 to $15 \mathrm{~m}$ at the landing site *** than is the Descartes regolith." Muehlberger and others (1972, p. 6-26) stated that "the thickness of the regolith on Stone Mountain, based on crater shapes, is similar to that on the Cayley plains." Only one crater on Stone mountain, about 100 $\mathrm{m}$ in diameter $4 \mathrm{~km}$ east of Crown crater, has a terrace indicating the top of a hard layer. Using Oberbeck's (1971b) relation of depth to diameter, the thickness there above a hard layer is less than $12.5 \mathrm{~m}$.

An average thickness of regolith at the Apollo 16 site is difficult to determine from direct observations. The thicknesses found on the Cayley plains range from 3.1 to $15 \mathrm{~m}$. The $12.2-\mathrm{m}$ thickness at the active seismic site is probably greater than the median because the seismic line lay across the ejecta deposits of a very large subdued crater. A subjective evaluation of the data presented above is that on the Cayley plains the median regolith thickness above some bench-forming layer is between 6 and $10 \mathrm{~m}$, generally about $7 \mathrm{~m}$.

Stone mountain has a smaller number of visible craters than the Cayley plain. This is true for the relatively flat top as well as for its steeper slopes. Especially striking is the distribution of $1-1.5-\mathrm{km}$ craters, common on the plain and absent from Stone mountain (fig. 5). As they are of several ages on the plain, not members of a single cluster, it is highly unlikely that original distribution could account for their absence from Stone mountain unless Stone mountain is much younger, and the returned samples do not support a younger age. It is therefore concluded that craters of $1-\mathrm{km}$ diameter have existed on Stone mountain but have been destroyed there at a more rapid rate than on the plain, possibly because of a very weak bedrock, as well as mass movements of debris under the influence of gravity, and shaking of seismic or impact origin.

The 5- to $10-\mathrm{m}$ thickness of regolith indicated on the Descartes mountains by radar and concentric craters represents areas of average thickness on the upper surface, not the lower slopes. Regolith of this thickness might have formed since mass movements stripped the area of an older regolith or since formation of some hard layer on the older regolith. It is probably not the total thickness formed in place since emplacement of the underlying bedrock.

The zone of thick accumulation of mass-wasted debris extends up Stone mountain to an abrupt change in slope about $300 \mathrm{~m}$ southeast of Crown crater, a sharprimmed $100-\mathrm{m}$ crater with no visible boulders in its ejecta. A regolith thickness of at least $20 \mathrm{~m}$ is suggested in this part of the Descartes mountains.

\section{COMPOSITION OF REGOLITH}

The samples from the Apollo 16 site have a high 
degree of chemical consistency indicating that they were derived from a local suite of rocks. Only a few small rock fragments found in the rake samples are exotic and probably not representative of the Descartes area (Warner and others, 1973; Steele and Smith, 1973; Delano and others, 1973). The local suite of rocks is distinct from the rocks found at other Apollo sites (Rose and others, 1973), including the Apollo 14 site that sampled the Fra Mauro Formation. As can be seen from results of orbital chemistry (Adler and others, 1973; Metzger and others, 1973), the Descartes area is typical of the lunar highlands in general. Materials of the Descartes mountains and the Cayley plains are not separable chemically (Delano and others, 1973), although Ulrich and Reed, and Hodges and Muehlberger (this volume) argue that rocks with the highest degree of impact melt may occur within the plains.

Regolith samples were taken from all stations within the Apollo 16 site. They represent both Cayley plains and Descartes mountains, and rays from North and South Ray craters, as well as thin younger regolith on the rim of North Ray crater, and older regolith remote from fresh craters.

In evaluating the chemistry of these samples and the related rocks, only four elements, $\mathrm{Fe}, \mathrm{Ti}$, and $\mathrm{Al}$ as oxides, and $\mathrm{Ni}$, are considered (tables 1 and 2), but the results of analyses for these are in general agreement with conclusions of other workers using other elements. In average $\mathrm{Al}_{2} \mathrm{O}_{3}$ and $\mathrm{TiO}_{2}$ content, the regolith from all stations does not differ greatly except for stations 11 and 13. Station 11 soils, on the rim of North Ray crater, contain less titanium and more aluminum than regolith elsewhere. Soil at station 13 , on the ejecta blanket of North Ray crater, contains a slightly greater amount of titanium and about the same amount of aluminum as station 11 regolith. The differ-

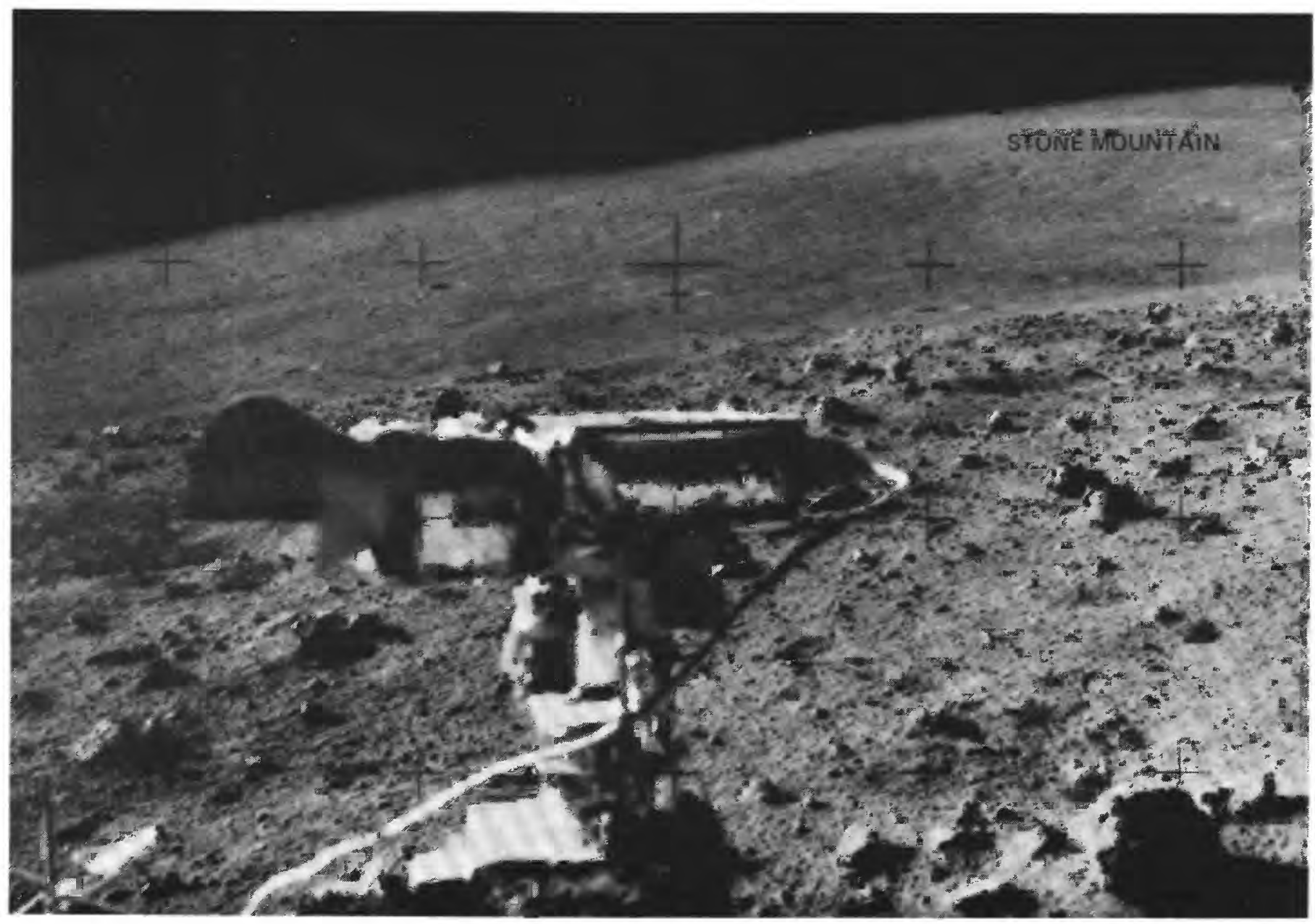

A

Figure 2.-Comparison of lunar surface within and between rays from South Ray crater. $A$, Area within blocky ray on Survey ridge, 5 km from South Ray crater. View is southeast. Photograph AS16-110-17891. B, Area between rays near station 8, $3.3 \mathrm{~km}$ from South Ray crater. View is northeast. Photograph AS16-108-17703. 
ence in titanium may reflect a contribution from Shadow rock at station 13 , which has a relatively high ratio of titanium to aluminum. In absolute amounts of iron, titanium, and aluminum (fig. 6), the regolith samples fall into two groups: (1) stations 11 and 13, dominated by North Ray ejecta with high aluminum content and (2) the remaining stations, with only small differences. Station 4 soils on Stone mountain tend to be intermediate chemically between values at North Ray crater and those from the plains.

The variation of $\mathrm{TiO}_{2}$ relative to $\mathrm{Al}_{2} \mathrm{O}_{3}$ (fig. 7) shows analyses of both rock samples and regolith samples. The regolith samples are grouped near the center of the scatter of rock samples except for a tail of regolith samples collected from North Ray rim (station 11). Similar variations are shown in the $\mathrm{Al}_{2} \mathrm{O}_{3}-\mathrm{FeO}$ diagram (fig. 8). The plots indicate that the regolith was formed by a mixing of the compositions of the rock samples. There is no significant difference in the regolith composition of stations 4,5 , and 6 (on Stone mountain) and stations on the Cayley plain in these plots, although station 4 soils approach North Ray compositions in $\mathrm{Ti}$ and $\mathrm{Ni}$. The regolith samples from the plain and the mountain, though similar to each other, are different from regolith samples collected at other Apollo landing sites, including highland stations at Apollos 14, 15, and 17.

Regolith samples that show a unique composition attributable to North Ray crater ejecta are those taken on the rim or continuous ejecta blanket of the crater. No composition identifiable as South Ray crater ejecta added to the soil can be distinguished in the analyses. Ray materials, even as young as those from South Ray crater, apparently are not identifiable by majorelement content of the regolith. This supports the suggestion that fine-grained materials are lacking in the

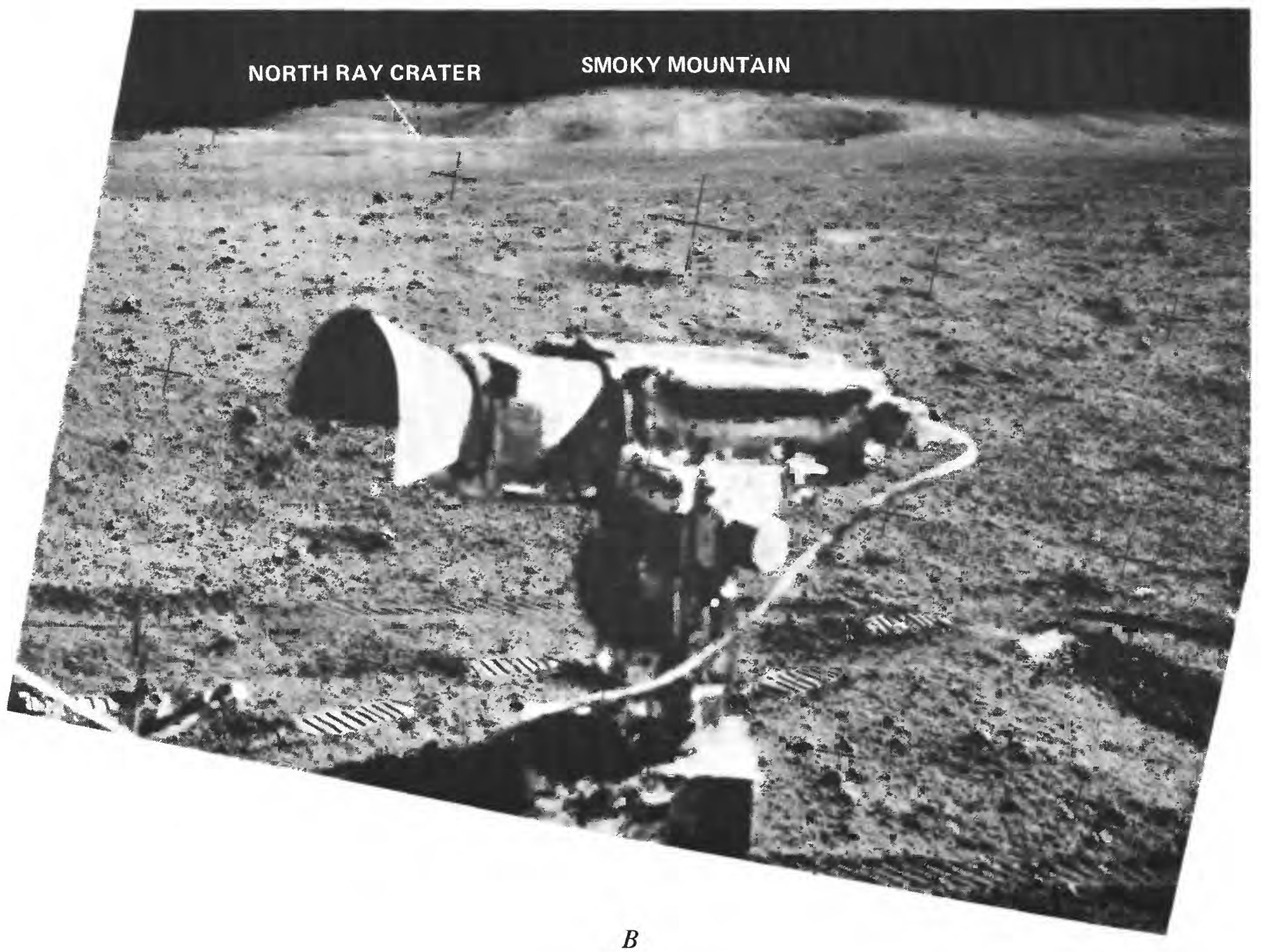

Figure 2.-Continued. 


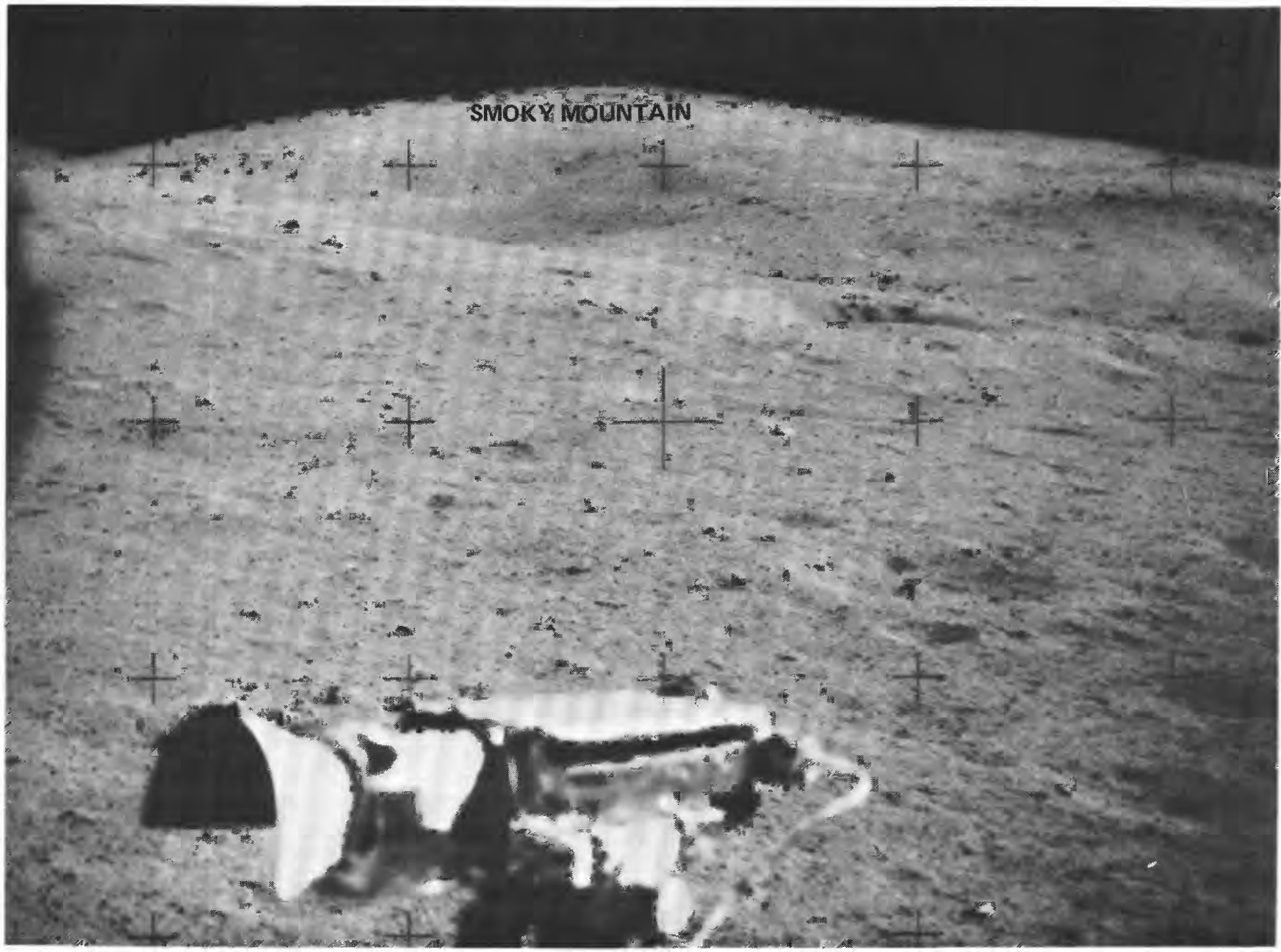

A

Figure 3.-Comparison of old and young ray-covered areas. A, Area of old ray deposit $1.5 \mathrm{~km}$ from rim of North Ray crater. AS16-111-18143, view is northeast. $B$, Area of young ray deposit $4.5 \mathrm{~km}$ from rim of South Ray crater. AS16-110-17898, view is south. 


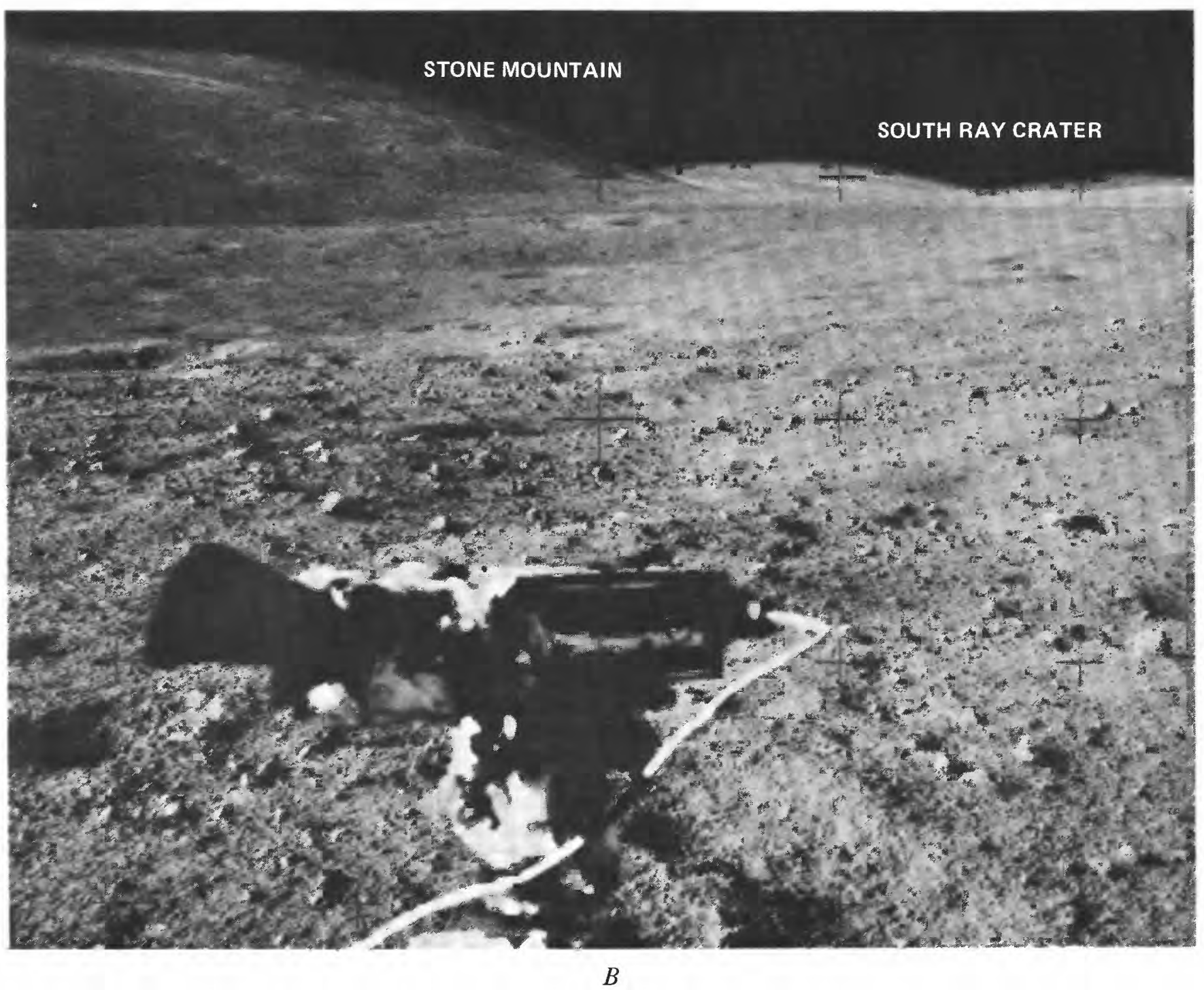

Figure 3.-Continued. 


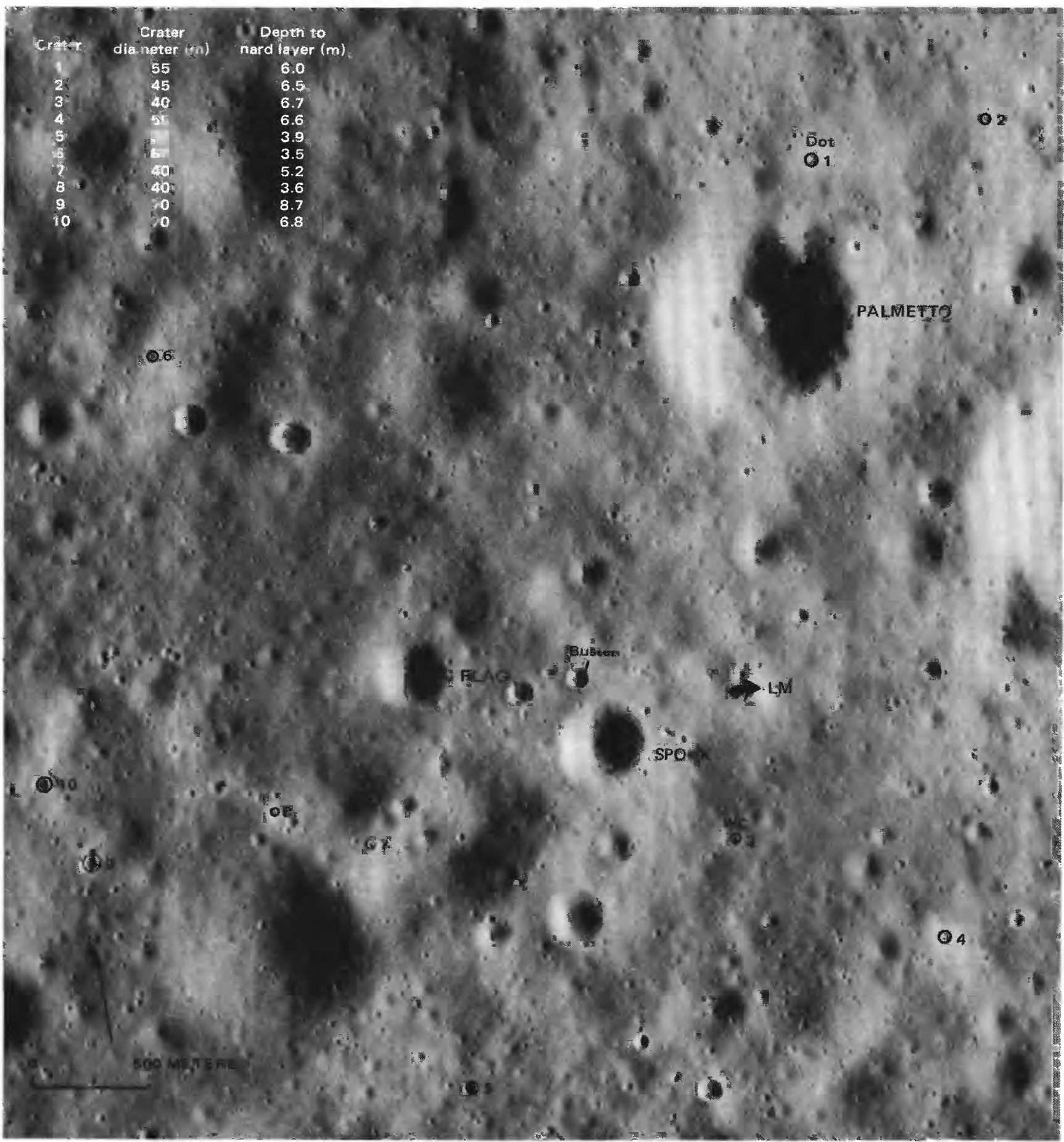

FiguRE 4.-Locations of concentric craters used to estimate depth of regolith. Apollo 16 panoramic camera frame 4623. 


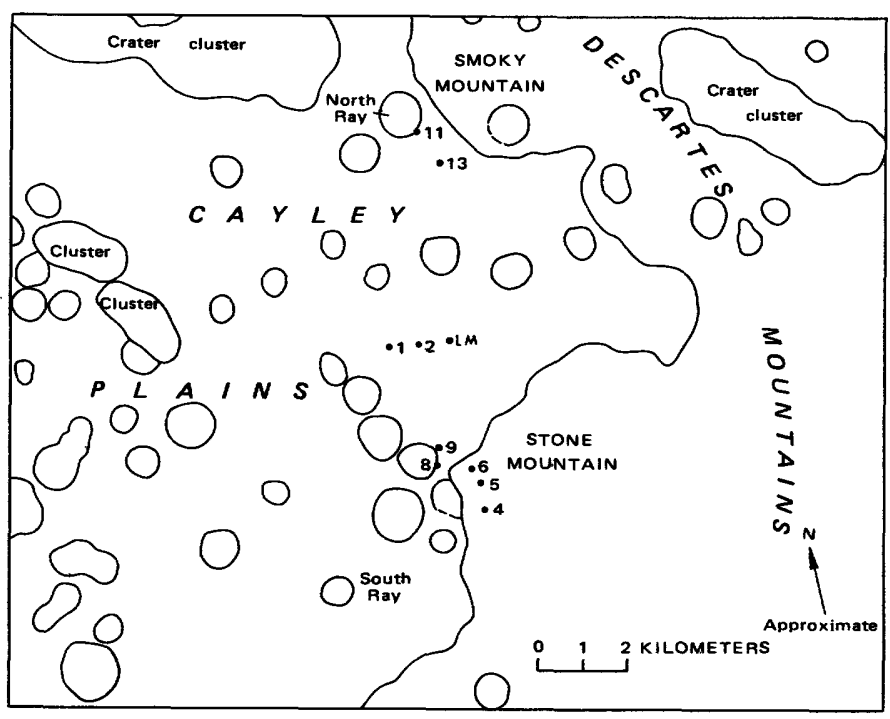

TABLE 1.-Apollo 16 soil analyses for $\mathrm{Al}_{2} \mathrm{O}_{3}, \mathrm{TiO}_{2}$, and $\mathrm{Ni}$

\begin{tabular}{|c|c|c|c|c|c|}
\hline Sample No. & $\mathrm{Al}_{2} \mathrm{O}_{\mathrm{*}}$ & $\mathrm{TiO}_{2}$ & $\mathrm{FeO}$ & $\mathrm{Ni}$ & $\begin{array}{l}\text { References } \\
\text { numbered in } \\
\text { accompanying list }\end{array}$ \\
\hline 60051 & 28.5 & 0.44 & 4.50 & 270 & \\
\hline 60501 & & & & 415 & $2,9,16,17$ \\
\hline $60601-$ & 26.61 & 0.66 & 5.55 & 403 & $1,5,7,10,15$ \\
\hline $61141-$ & 26.45 & 0.58 & 5.12 & 355 & 3,10 \\
\hline $61161-$ & 26.3 & 0.58 & 5.25 & 400 & 10 \\
\hline $\begin{array}{l}61181 \\
61221\end{array}$ & 27.1 & $\begin{array}{l}0.66 \\
0.68\end{array}$ & $\begin{array}{l}5.47 \\
4.96\end{array}$ & $\begin{array}{l}340 \\
135\end{array}$ & ${ }_{137}^{5}$ \\
\hline $61241=$ & 27.03 & 0.67 & $\begin{array}{l}4.90 \\
5.30\end{array}$ & $\begin{array}{l}130 \\
230\end{array}$ & $\begin{array}{l}1,3,7 \\
1,3,7\end{array}$ \\
\hline 61281 & 27.12 & 0.54 & 5.07 & 440 & \\
\hline $61501-$ & 26.83 & 0.52 & 5.23 & 372 & $1,5,10$ \\
\hline $62241-$ & 27.4 & 0.57 & 5.12 & 414 & 3,11 \\
\hline 62281. & 27.1 & 0.57 & $\begin{array}{l}5.5 \\
467\end{array}$ & $\begin{array}{l}380 \\
311\end{array}$ & 15 \\
\hline $63321-$ & $\begin{array}{l}28.9 \\
29.0\end{array}$ & $\begin{array}{l}0.35 \\
0.60\end{array}$ & $\begin{array}{l}4.67 \\
4.54\end{array}$ & $\begin{array}{l}311 \\
345\end{array}$ & $\begin{array}{l}19 \\
19\end{array}$ \\
\hline 63501 & 28.1 & 0.50 & 4.67 & 322 & 4,19 \\
\hline $64421-$ & 27.66 & 0.55 & 4.94 & 323 & $1, \mathbf{4}, 10,17$ \\
\hline 64501 & 27.0 & 0.55 & 4.20 & 320 & 2,7 \\
\hline 64801 & 27.40 & 0.56 & 5.18 & $\begin{array}{l}300 \\
290\end{array}$ & $4,5,17$ \\
\hline 64811 & 26.9 & $\begin{array}{l}0.49 \\
0.70\end{array}$ & $\begin{array}{l}5.59 \\
5.96\end{array}$ & 290 & 18 \\
\hline $\begin{array}{l}65701 \\
65001\end{array}$ & $\begin{array}{l}26.1 \\
26.56\end{array}$ & 0.66 & $\begin{array}{l}5.96 \\
5.69\end{array}$ & $\begin{array}{l}390 \\
414\end{array}$ & $\begin{array}{l}9,16 \\
1,5,7,10,17\end{array}$ \\
\hline 65901 & 26.5 & 0.61 & 5.8 & 500 & 15 \\
\hline 66031 & 27.8 & 0.60 & 5.46 & 417 & \\
\hline $66041 \ldots$ & 26.45 & 0.65 & 5.90 & 428 & $1,3,15,16$ \\
\hline $\begin{array}{l}66081 \ldots \\
67461 \ldots\end{array}$ & $\begin{array}{l}26.7 \\
29.7\end{array}$ & $\begin{array}{l}0.67 \\
0.35\end{array}$ & $\begin{array}{l}6.12 \\
4.14\end{array}$ & $\begin{array}{l}446 \\
120\end{array}$ & $\begin{array}{l}1,3,15,16,17 \\
10,17\end{array}$ \\
\hline (n............ & 29.1 & 0.41 & 4.42 & 147 & 1,9 \\
\hline 67601 & 28.16 & 0.46 & 4.05 & 145 & 1,7 \\
\hline 67701. & 28.79 & 0.38 & 4.08 & 145 & 5,17 \\
\hline -....... & 29.4 & 0.26 & 2.96 & 90 & 18 \\
\hline ........ & 26.4 & 0.58 & 5.67 & 422 & 17 \\
\hline $\begin{array}{l}68501 \\
68821\end{array}$ & $\begin{array}{l}26.78 \\
26.2\end{array}$ & $\begin{array}{l}0.57 \\
0.50\end{array}$ & $\begin{array}{l}5.40 \\
5.40\end{array}$ & $\begin{array}{l}420 \\
550\end{array}$ & $\begin{array}{l}4,5 \\
18\end{array}$ \\
\hline 68841 & 26.5 & 0.58 & 5.65 & $\begin{array}{l}290 \\
290\end{array}$ & 1,17 \\
\hline 69921 & 26.16 & & 5.61 & 422 & \\
\hline 69941 & 25.6 & 0.65 & $\begin{array}{l}5.62 \\
5.73\end{array}$ & $\begin{array}{l}492 \\
530\end{array}$ & $\begin{array}{l}3,7,15 \\
3,5\end{array}$ \\
\hline 6996 & & & & & \\
\hline
\end{tabular}

rays of South Ray crater (McKay and Heiken, 1973).

The variation of nickel relative to iron in the rocks and soils from the Apollo 16 site is shown in figure 9 . The trend line that results from addition of nickel and iron in proportions equal to the average composition of meteoritic matter (Mason, 1962, p. 164-5) has been added to the diagram. Several pairs of data points are joined for comparison: (1) sample 67455 from a lightmatrix breccia boulder at station 11 with sample 67481 , a soil probably derived from light-matrix breccia (ALGIT, 1972b, p. 161 and 167); (2) an average for all station 11 rocks with the average of all soils from the same station; (3) sample 61221, from the white

Figure 5.-Apollo 16 region showing Cayley plains, Descartes mountains, and outline of.craters of about $1 \mathrm{~km}$ in diameter. After Hodges (1972a).

TABLE 2.-Apollo. 16 rock analysis for $\mathrm{Al}_{2} \mathrm{O}_{3}, \mathrm{TiO}_{2}$, and $\mathrm{Ni}$

Averages of values from numbered references, in weight percent; $\mathrm{Ni}$ in parts per million

\begin{tabular}{|c|c|c|c|c|c|}
\hline Sample No. & $\mathrm{Al}_{2} \mathrm{O}_{: \mathrm{z}}$ & $\mathrm{TiO}_{2}$ & $\mathrm{FeO}$ & $\mathrm{Ni}$ & $\begin{array}{l}\text { References } \\
\text { numbered in } \\
\text { accompanying list }\end{array}$ \\
\hline $\begin{array}{l}60015 \\
60017 \\
60018 \\
60025 \\
60315 \\
60335 \\
61016 \\
61156 \\
62235 \\
62275 \\
62295 \\
63335 \\
64455 \\
64567 \\
64815 \\
65015 \\
6695 \\
67016 \\
67075 \\
67115 \\
67435 \\
67455 \\
67629 \\
67915 \\
67955 \\
68415 \\
68416 \\
68815 \\
69935 \\
69955\end{array}$ & $\begin{array}{l}35.7 \\
31.4 \\
24.5 \\
34.9 \\
17.2 \\
24.9 \\
26.7 \\
22.9 \\
28.3 \\
19.4 \\
33.1 \\
20.3 \\
30.9 \\
22.4 \\
21.62 \\
17.33 \\
20.6 \\
24.58 \\
31.0 \\
32.8 \\
31.2 \\
15.9 \\
30.5 \\
24.0 \\
29.4 \\
27.7 \\
28.7 \\
28.5 \\
27.2 \\
31.5 \\
35.2\end{array}$ & $\begin{array}{l}0.15 \\
0.62 \\
0.08 \\
1.29 \\
0.61 \\
0.68 \\
0.64 \\
0.56 \\
1.11 \\
0.04 \\
0.71 \\
0.42 \\
0.65 \\
0.72 \\
1.7 \\
1.20 \\
0.73 \\
.03 \\
\mathbf{0 . 0 7} \\
0.24 \\
\mathbf{0 . 0 5} \\
0.25 \\
0.85 \\
0.5 \\
0.27 \\
0.32 \\
0.31 \\
0.49 \\
0.22 \\
0.01\end{array}$ & $\begin{array}{l}0.26 \\
2.76 \\
4.76 \\
0.54 \\
9.35 \\
4.65 \\
4.42 \\
7.88 \\
4.52 \\
9.650639 \\
2.20 \\
6.13 \\
3.23 \\
5.47 \\
7.08 \\
9.5 \\
8.45 \\
6.59 \\
3.7 \\
2.24 \\
2.60 \\
5.8 \\
3.88 \\
5.29 \\
2.95 \\
3.84 \\
4.02 \\
4.30 \\
4.75 \\
2.34 \\
0.36\end{array}$ & $\begin{array}{c}207 \\
210 \\
16 \\
703 \\
256 \\
335 \\
184 \\
114 \\
1,4,11 \\
-313 \\
26 \\
540 \\
-\cdots \\
-349 \\
482 \\
65 \\
1 \\
62 \\
-22 \\
22 \\
350 \\
-108 \\
108 \\
116 \\
176 \\
206 \\
302 \\
43\end{array}$ & $\begin{array}{l}5 \\
3,5 \\
5 \\
3,6,7,8 \\
1,2,3,4,5 \\
1,3,6,7 \\
1,3,8,9,10,11 \\
1,4 \\
1 \\
12 \\
3,4,6 \\
1 \\
7 \\
20 \\
20 \\
4,5,7,9,13 \\
1,8,9,11 \\
11 \\
1,7 \\
3 \\
12 \\
3,10 \\
7 \\
8 \\
1 \\
1,3,6 \\
3,4,14 \\
1 \\
3 \\
3\end{array}$ \\
\hline
\end{tabular}

References for analysis used:

1. Lunar Receiving Laboratory 1972

2. Morrison, G. H., Nadkarni, R. A., Jaworski, J., Botto, R. B., Roth, J. R., 1973.

3. Rose, H. J., Jr., Cuttitta F. Berman, S., Carron, M. K., Christian, R. P., Dwornik, E. J., Greenland, L. P., and Ligon, D. T., Jr., 1973.

4. Bansal, B. M., Gast, P. W.. Hubbard, N. J., Nyquist, L. E., Rhodes, J. M., Shih, C. Y., and Wiesmann, H., 1973.

5. Taylor, S. R., Gorton, M. P., Muir, P., Nance, W. B., Rudowski, R., and Ware, N., 1973.

7. Haskin, L. A. Helmke, P. A. Blanchard, D. P., Jacobs, J. W., and Telander, K., 1973

8. Nakamura, N., Masuda, A., Tanaka, T., and Kurasawa, H., 1973.

9. Duncan, A. R., Ahrens, L. H., Erlank, A. J., Will is, J. P., and Gurney, J. J., 1973.

10. Wanke, H., Baddenhausen, H., Dreibus, G., Jaqoutz, E., Kruse, H., Palme, H., Spettel, B., and Teschke, F., 1973.

11. Brunfelt, A. O., Heier, K. S., Nilssen, B., and Sundvoll, B., 1973a.

12. Prinz, M., Dowty; E., Keil, K., Bunch, T: F., 1973.

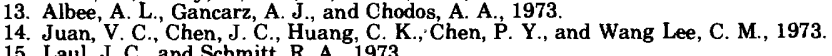

15. Laul, J. C., and Schmitt, R. A., 1973.

16. Baedecker, P. A., Chou, C. L., Sundberg, L. L., and Wasson, J. T., 1972.

17. Compston, W., Vernon, M. J., Chappell, B. W., and Freeman, R., 1973.
18. Mason, Brian, Simkin, T., Noonan, A. F., Switzer, G. S., Nelen, J. A., Thompson, G., and Melson, W. G., 1973.
19. Brunfelt, A. O., Heier, K. S. Nilssen, B. Steinnes, E., and Sundvoll, B., 1973b.

20. Hubbard, N. J., Rhodes, J. M., Gast, P. W., Bansal, B. M., Shih, C. Y., Wiesmann, H., and Nyquist, L. E., 1973. 
layer in the trench at station 1 is joined with sample 61241 , the overlying gray layer possibly derived from the white layer (ALGIT, 1972b, p. 75); (4) an average of all rocks at the Apollo 16 landing site with the average of all soils at the site.

The nearly parallel trend of the lines connecting rocks and soils indicates an addition of nickel and iron in similar proportions during the process of soil formation. The divergence of this trend from that of Mason's indicates that the composition of added meteoritic material at the Apollo 16 site is more Fe-rich (or Nipoor) than that on Earth.

\section{SUMMARY}

The appearance of the regolith is generally that of a rocky gray soil. Rays from young craters in hard substrata are distinguishable mainly as local concentrations of blocky fragments. The brightness of a ray appears to result from a combination of the density and the angularity of fragments, both higher for South Ray than for North Ray crater.

The regolith thickness on the plains has a median value between 6 and $10 \mathrm{~m}$ based on photogrammetric measurements of depth to the first bench in 10 concentric craters. The thickness of regolith on Stone mountain ranges from a minimum of 5 to $10 \mathrm{~m}$ to more than $20 \mathrm{~m}$ and may vary greatly owing to accumulation of mass-wasted debris on a softer, weaker bedrock that may underlie much of the Descartes mountains.

Regolith compositions for most of the Apollo 16 site are chemically similar except for North Ray soils, stations 11 and 13, which are significantly enriched in alumina and depleted in iron, titania, and nickel by comparison with soils from other stations. Soils from station 4 tend to be intermediate in titania and nickel content with respect to soils from the plains and North Ray crater. As a group, the soil samples cluster near the middle of the compositional ranges representing the rocks from all stations.

Iron and nickel show a marked increase from a parent rock to the soil produced by its disintegration. A similar change is seen between the average compositions of rocks and soils and between two soils in superposition. Analyses indicate a component of meteoritic material richer in iron (or poorer in nickel) than the average meteoritic material on Earth.

Figure 6.-Plots of analyses for $\mathrm{FeO}, \mathrm{TiO}_{2}, \mathrm{Al}_{2} \mathrm{O}_{3}$, and $\mathrm{Ni}$ for soil samples taken at traverse stations.

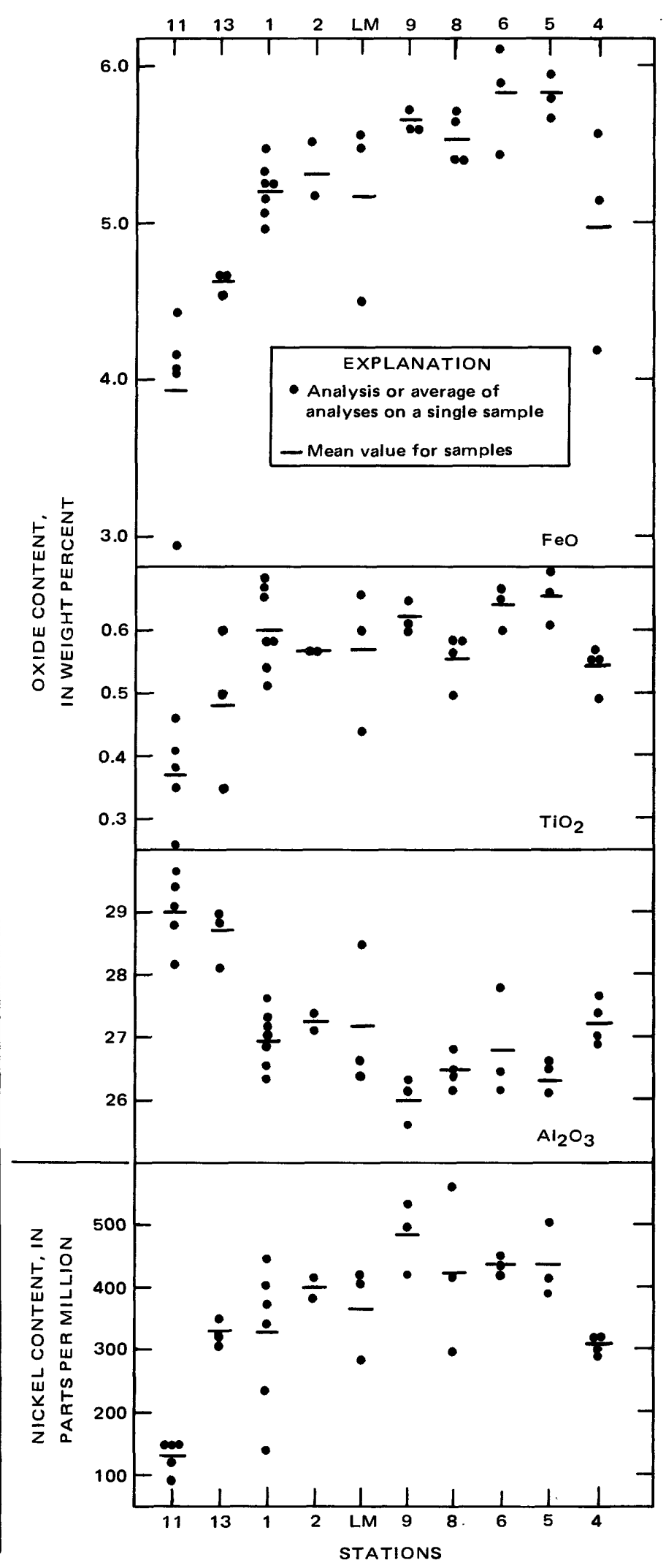




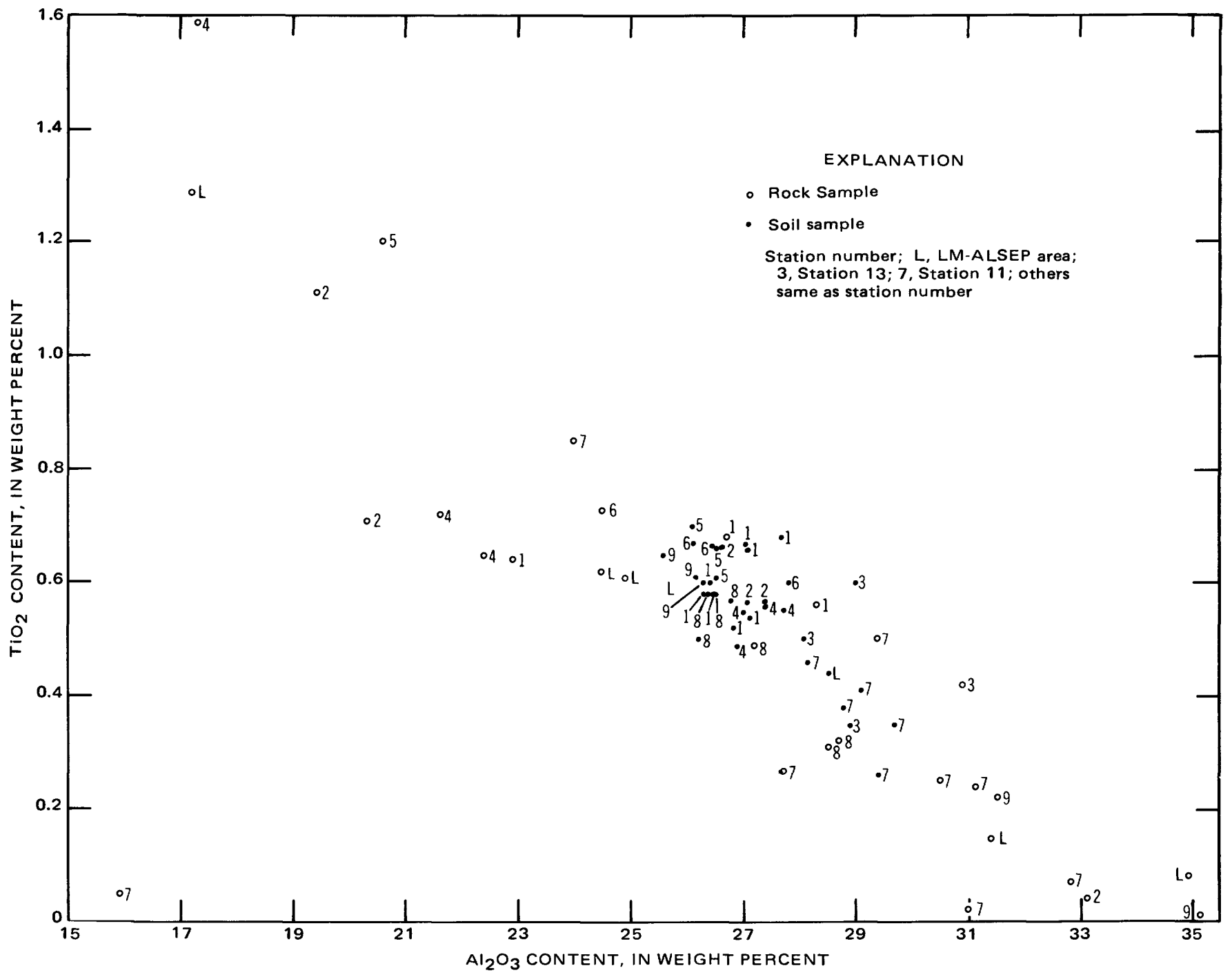

Figure 7.-Plot of $\mathrm{TiO}_{2}$ relative to $\mathrm{Al}_{2} \mathrm{O}_{3}$ for rock and soil samples. Points are averages of all available analyses of each sample. 


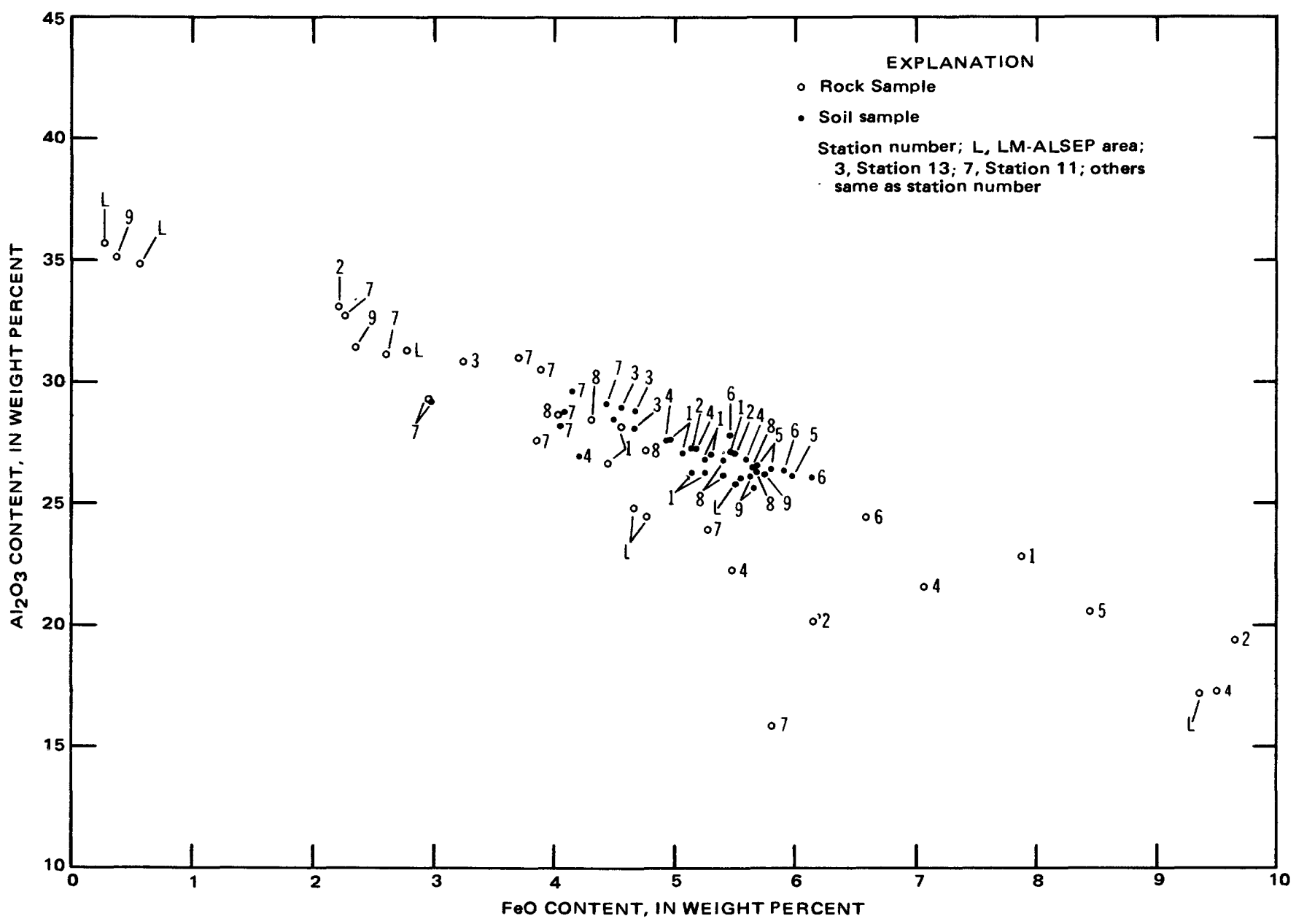

Figure 8.-Plot of $\mathrm{Al}_{2} \mathrm{O}_{3}$ relative to $\mathrm{FeO}$ of rock and soil samples. Multiple analyses of same samples are averaged. 


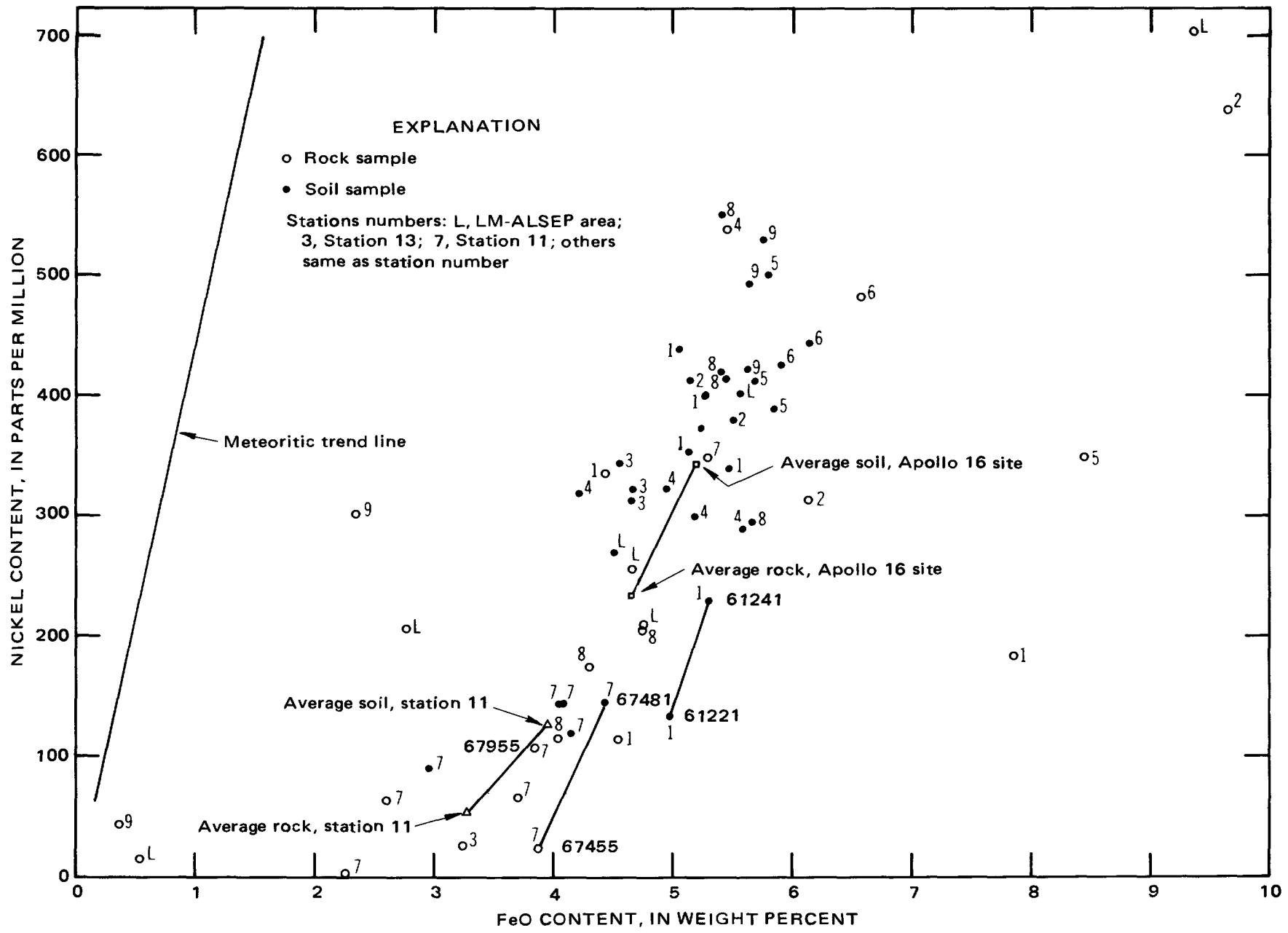

FIGURE 9.-Plot of nickel relative to $\mathrm{FeO}$ of rock and soil samples. Multiple analyses of same samples are averaged. The meteoritic trend line is calculated from average meteorite composition (Mason, 1962) and assumes Fe/Ni remains constant at 17 for material added in soil formation. 


\title{
G. EJECTA DISTRIBUTION MODEL, SOUTH RAY GRATER
}

\author{
By George E. Ulrich, Henry J. Moore, \\ V. Stephen Reed, Edward W. Wolfe, and Kathleen B. Larson
}

CONTENTS

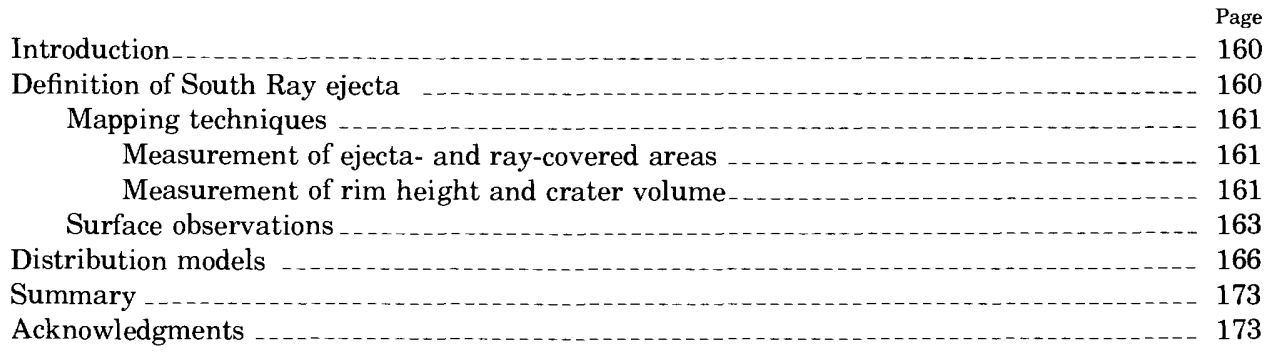

\section{ILLUSTRATIONS}

Figure 1. Premission photomosaic map of Apollo 16 landing site

2. Photograph of Apollo 16 landing site and traverse locations in high-sun illumination

3. Digitally enhanced regenerations of photograph in figure 2

4. Topographic map of South Ray crater and approximation of pre-South Ray surface

5. Outline of hummocky ejecta around South Ray crater rim and rim heights above outer rim margin

6. Map of concentric rings centered on South Ray crater

7. Histogram of area covered by mappable ejecta and rays within each annulus shown in figure 6

8. Histogram of percentage of area covered by ejecta and rays in annuli of figure 6

9. Illustration of terms used for crater measurements discussed in text

10. Ray-covered areas photographed from the Lunar Roving Vehicle

11. Semilogarithmic plot showing model thicknesses of South Ray ejecta relative to distance from the crater rim

TABLES

TABLE 1. Ejecta distribution models for South Ray crater

\section{INTRODUCTION}

South Ray is a fresh, blocky crater, $680 \mathrm{~m}$ across and $135 \mathrm{~m}$ deep, in the southern part of the Apollo 16 landing site. Its bright rays extend northward radially across the traverse area. Sampling of ejecta from South Ray was a prime objective of the mission because of its location on the Cayley plains, $6.2 \mathrm{~km}$ south of the Lunar Module (LM). Direct sampling and photographing of its rim and flanks, where less equivocal provenances could have been established, were prohibited by the distance from the LM, the limited time available for traversing, and the anticipated roughness of the terrain. Therefore additional evidence and interpretation are required to relate certain samples collected to South Ray.

The approach taken here in determining which of the localities sampled lie within rays of ejecta from South Ray crater and to what extent or depth these localities may have been covered by ejecta is to estimate the apparent volume of the crater and then to distribute this volume as ejecta using several models. In one set of models, ejecta are confined within observable ray patterns; in a second set, ejecta are not confined. The purpose of this chapter is to determine a reasonable model for the areal distribution and variation in thickness of ejecta material within rays as a function of distance from South Ray crater. A stratigraphic interpretation of materials ejected from South Ray is treated elsewhere (AFGIT, 1973; Ulrich and Reed, this volume).

\section{DEFINITION OF SOUTH RAY EJECTA}

Part of the problem in defining South Ray ejecta is to 160 
establish those properties that characterize the ejecta on the lunar surface and correlate them with reflected brightness and topography using the best available orbital photography. Block concentrations, surfaces disturbed by the impact of ballistic debris, lineations produced by deposition of ejecta, and individual secondary craters were observed on a local scale by the astronauts and can be seen in photographs taken by them. For a crater the size of South Ray, these features are not resolvable on orbital photographs except at a few places. The properties of crater ejecta seen on orbital photography are reflected brightness and irregularities in topographic expression. Bright areas around young lunar craters photographed under high sun-elevation angles are produced by a combination of effects: (1) concentrations of blocks and rock fragments, (2) steep surface slopes, and (3) composition of material. Brightness contrasts in surface materials of a crater and its ejecta decrease with the age of the crater. Topographic expression of ejecta is most evident near the crater, and its definition is a function of photographic resolution. For South Ray, contrasts in reflected brightness were used to delineate the ejecta on orbital photography, because the high sun-elevation angle of available photographs proved to be a sensitive indicator of ejecta distribution (figs. 1 and 2). The distribution of bright regions, including South Ray, its flanks, and rays or filaments extending radially from it, attest to the crater's youth. Bright areas beyond the rim are inferred to be covered partly to completely by ejecta from the crater.

\section{MAPPING TECHNIQUES}

Previous mapping of ejecta distribution around South Ray consisted of compilation by visual inspection of Apollo 14 photographs (Hodges, 1972a; Elston and others, 1972b; Muehlberger and others, 1972; fig. 1, pl. 2 this volume). Here, digital processing of Apollo 16 panoramic camera photographs taken when the sun-elevation angle was $60^{\circ}$ was used to delineate the distribution of ejecta from South Ray beyond the crater flanks. An unaltered photograph of the landing site, figure 2 , was digitized and, by means of computer filtering techniques, regenerated to enhance reflected brightness variations at three different levels (fig. 3 ). These images, together with figure 1 and selected premission photographs, were the basis for compilation of a ray map of South Ray ejecta (see Reed, fig. 4, this volume). The procedure required a minimum of arbitrary judgment in drawing the boundaries of raycovered areas. The units mapped were designated as continuous, thin to discontinuous, and discontinuous ejecta.

A topographic map of South Ray crater (fig. 4) enables us to estimate the amount of material ejected from
South Ray, the height of the rim (fig. 5), and the thickness of ejecta at the rim.

\section{MEASUREMENT OF EJECTA- AND RAY-COVERED AREAS}

The area covered by mappable rays was measured (at a scale of $1: 50,000$ ) with a planimeter, in concentric annuli (or bands) one crater diameter $(680 \mathrm{~m})$ wide, expanding outward from the crater rim, as illustrated by figure 6. A plot of the area of ejecta measured within each annulus, figure 7 , shows the ejecta-covered areas to be clearly asymmetric in their distribution around South Ray. In each of the third through seventh annuli, however, they remain nearly constant at $7-9 \mathrm{~km}^{2}$ while the total annulus area increases by $2.0 \mathrm{~km}^{2}$ per ring. Beyond the seventh annulus, the ray-covered areas decrease at a nearly constant rate of 0.9 to 1.0 $\mathrm{km}^{2}$ per annulus. Another means of viewing these data is to plot the percentage of total area within each annulus covered by ray material as a function of distance from South Ray rim (fig. 8). The histogram shows that only the six inner annuli are more than 50 percent covered and that all of the Apollo 16 samples come from annuli where less than 57 percent of the area is covered by mappable rays.

\section{MEASUREMENT OF RIM HEIGHT AND CRATER VOLUME}

Using the topographic map of South Ray (fig. 4), a precrater surface was estimated by extrapolating contours from outside the hummocky rim across the existing crater. Intersections of this surface with the crater wall determine the elevation of the original ground surface. Differences in elevation of points on the rim crest and the projected original ground surface beneath the points represent the rim height. Values obtained in this way range between 19 and $26 \mathrm{~m}$; the average is 22 $\mathrm{m}$. Another method of calculating these values is to determine the average difference in elevation between the rim crest and the outer margin of hummocky ejecta, shown in the sketch map (fig. 5) along with elevation differences between the rim crest and this edge. The range in values for rim height by this method is 13 to $28 \mathrm{~m}$, the average about $20 \mathrm{~m}$. From this, we consider the average rim height to be near $20-22 \mathrm{~m}$.

The rim height includes two components, the amount that the original ground surface was uplifted and the thickness of the ejecta deposited on the uplifted surface (fig. 9). For terrestrial explosive craters, the percentage of the total rim height resulting from upwarping of ground surface ranges from 17 to 71 percent (Carlson and Jones, 1965, table 1); for six craters in alluvium 31 to $366 \mathrm{~m}$ across, an average of 45 percent of the rim height is the result of upwarp of the original ground surface. Recent drilling at Meteor Crater, Ariz., reveals that 35 to 60 percent of the present 


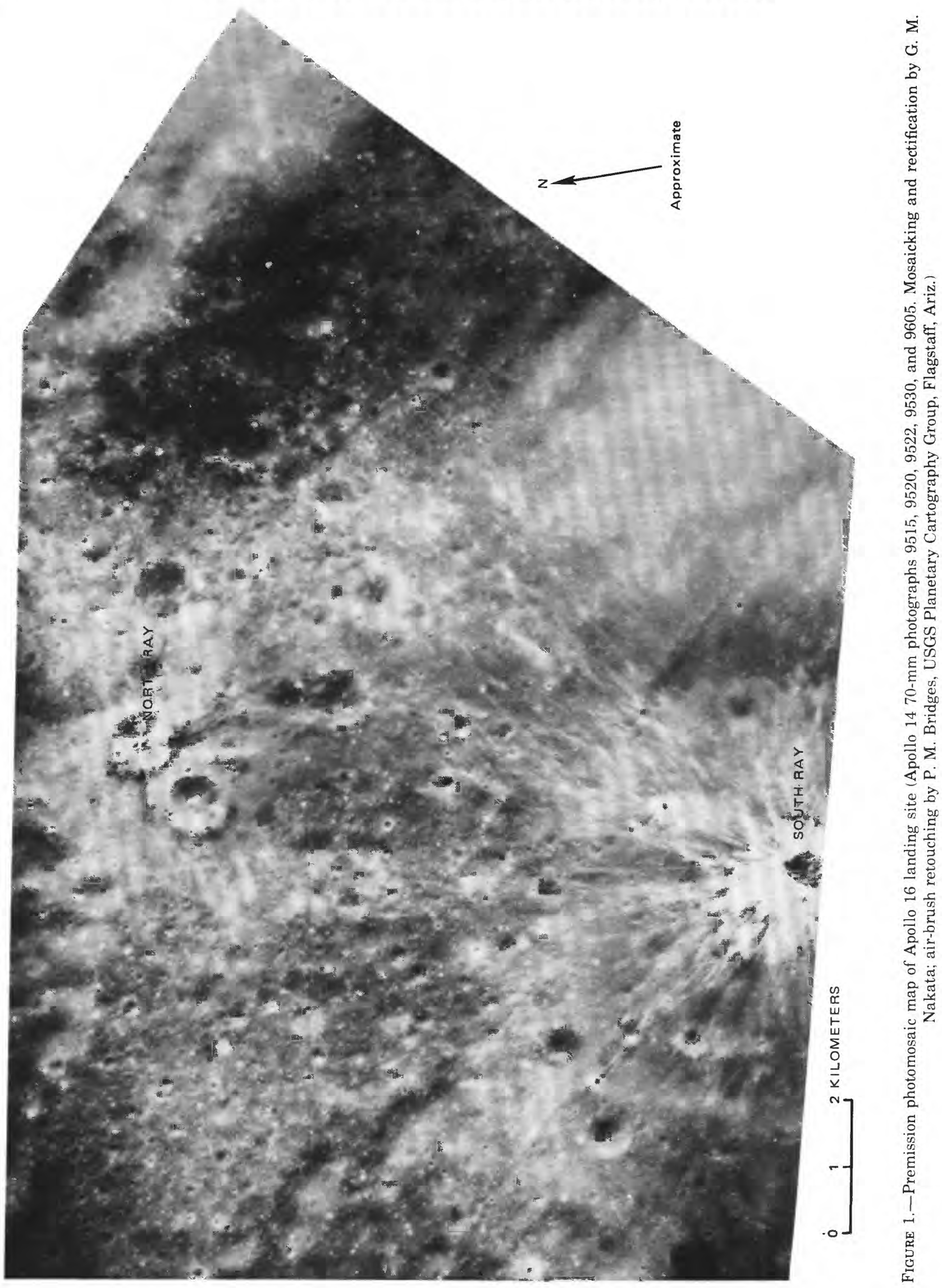




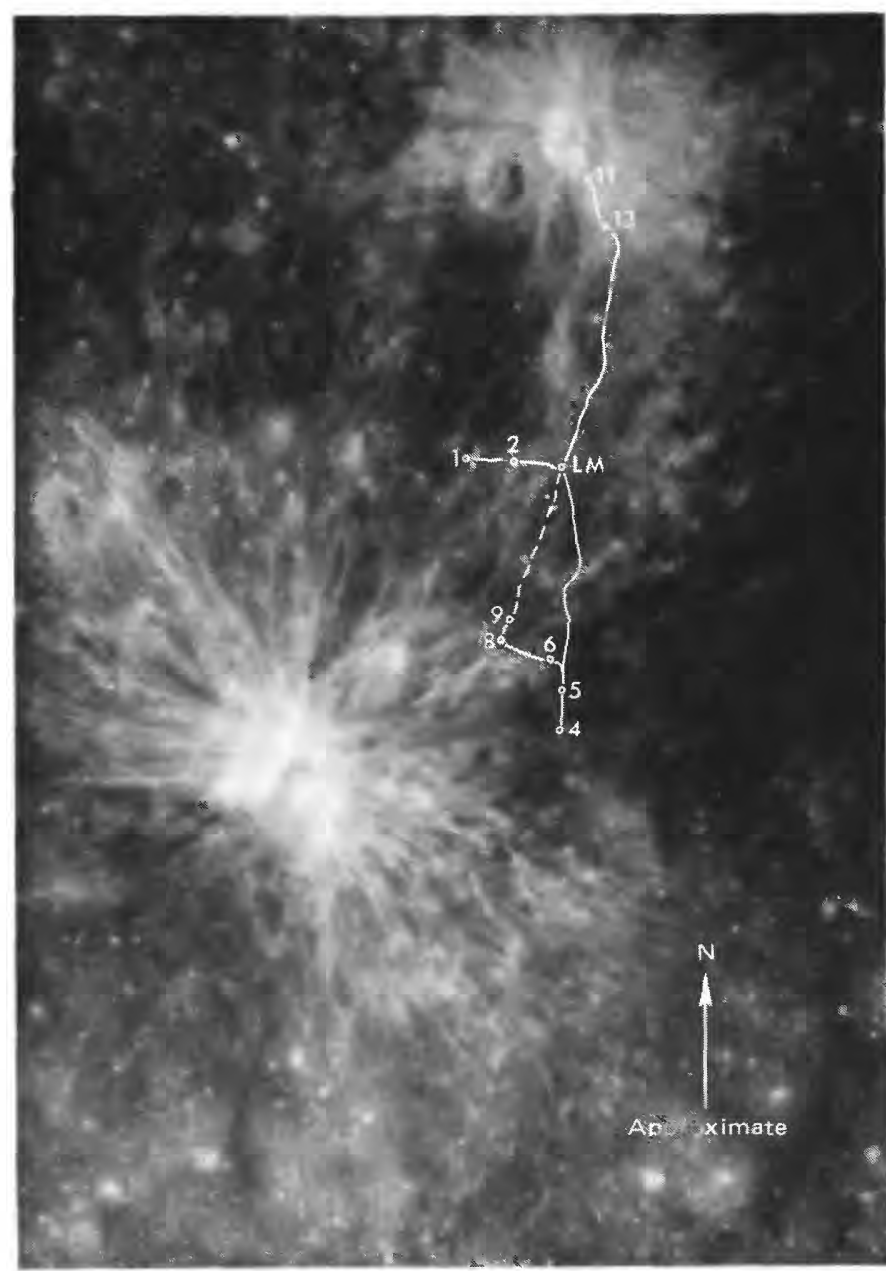

$\begin{array}{lllllll}0 & 1 & 2 & 3 & 4 & 5 & \text { KILOMETERS }\end{array}$

Figure 2.-Apollo 16 landing site and traverse locations, taken from orbit after surface activity was completed. Sun-elevation angle is $60^{\circ}$ (Apollo 16 panoramic photograph 5328).

rim height is the result of uplift of the original ground surface (D. J. Roddy, oral commun., 1974). It is therefore reasonable to assume that 45 to 50 percent or approximately $10 \mathrm{~m}$ of the rim height of South Ray can be attributed to uplift; then that part of the rim height attributable to ejecta is 50 to 55 percent or 10 to $12 \mathrm{~m}$.

Total crater volume was established by dividing the topographic depression into 25 -m-thick disks and adding their volumes to those of the irregular increments at the top and at the bottom (shown in fig. 9). The areas of the upper and lower surfaces of each disk were measured by planimeter, then averaged. This value, multiplied by the disk thickness, provides an estimate of the volume for that increment. The sum of all increments is the volume of the existing crater below the rim crest $\left(15.6\right.$ million $\left.\mathrm{m}^{3}\right)$. The total volume is greater than the apparent crater volume by an amount equal to that part of the crater volume above the precrater surface. When this amount is subtracted, the resulting apparent crater volume is 10.0 million $\mathrm{m}^{3}$.

Apparent crater volume is taken here to represent a reasonable estimate of the volume of ejecta of South Ray. Because data on explosive craters in alluvium (Carlson and Jones, 1965, table 4) indicate that apparent crater mass may be as much as twice the ejecta mass, our ejecta volume could be too large. On the other hand, bulking of material beneath the crater walls and floor can have an opposite effect, making our estimate of ejecta volume a reasonable value in the light of data available. We assume target and ejecta density to be equal, as for craters in alluvium (Carlson and Jones, 1965, p. 1899).

\section{SURFACE OBSERVATIONS}

The astronauts observed secondary craters at several localities during the lunar mission and described rays formed by large concentrations of blocks alined in linear patterns generally radial to South Ray crater. Such areas are discussed and illustrated elsewhere in this volume. (See chapters by Freeman, Holt, Sanchez, Schaber, and Reed.)

Ray-covered surfaces were documented by Hasselblad photography while the LRV was enroute during all three EVA's. On 324 of the 544 frames taken (Batson and others, this volume), the populations of fragments $2 \mathrm{~cm}$ and larger were measured with the aid of a perspective grid within the interval 5 to $10 \mathrm{~m}$ from the camera. The results are illustrated by Muehlberger and others (1972) and reproduced by Schaber (fig. 3, this volume). Several conclusions can be drawn from these data: (1) The abundance of fragments larger than $2 \mathrm{~cm}$ in diameter increases progressively, but somewhat irregularly, toward South Ray crater over the entire traverse area. (2) Ejecta from South Ray crater is characterized along the traverses by a relative abundance (generally 2 to 7 percent surface cover) of angular fragments, commonly perched on the surface (fig. 10A). The surfaces with higher fragment densities also are covered by numerous small craters approximately $2 \mathrm{~m}$ or less in diameter (Reed, fig. 10, this volume). (3) Most of these areas occur in bright-ray patches. A notable example, as shown in figure $10 B$, is Survey ridge, between the LM and station 6 , where approximately 7 percent of the surface area is covered by fragments larger than $2 \mathrm{~cm}$. Station 6 lies on the northeast edge of a fragment-covered surface that coincides with the discontinuous ejecta as mapped from orbital photography (see pl. 6, pan 12). The fragments 2 $\mathrm{cm}$ and larger within $10 \mathrm{~m}$ of station 6 , however, occupy only 1 to 2 percent of the surface (Muehlberger 


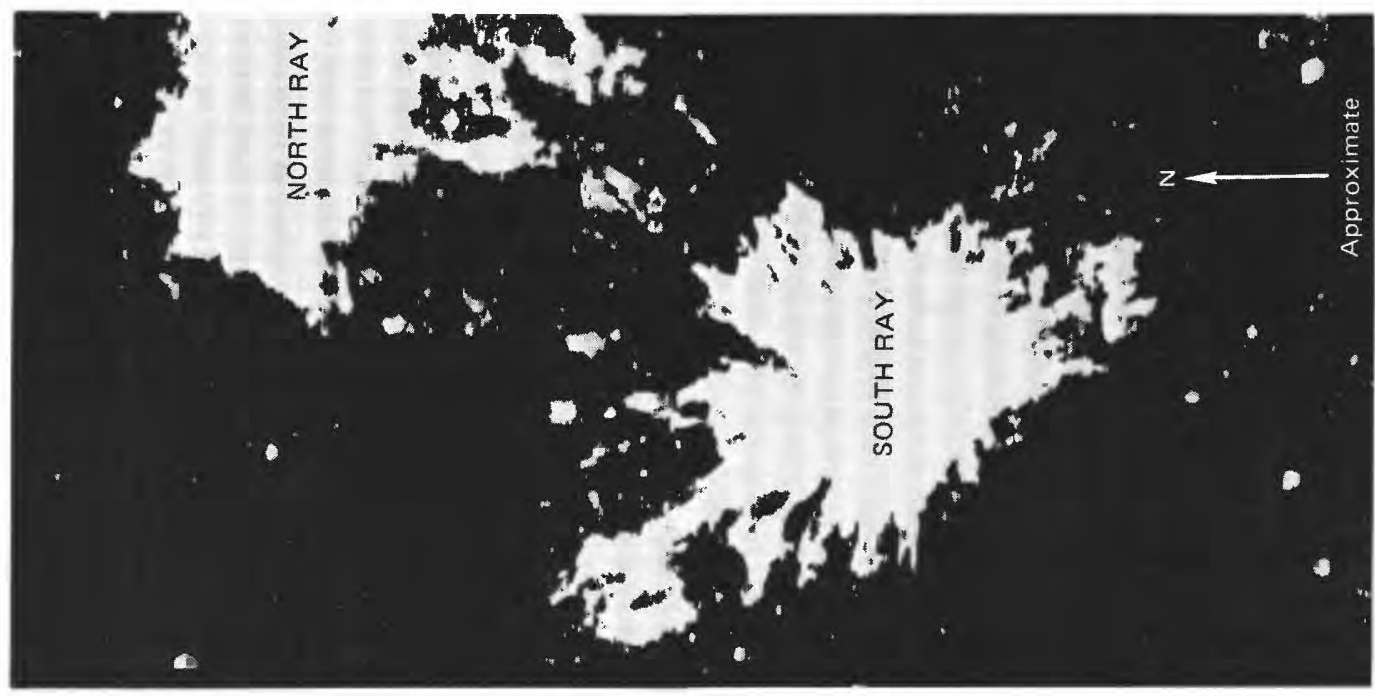

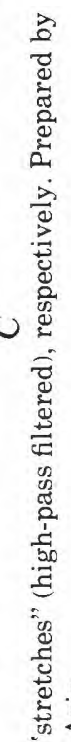

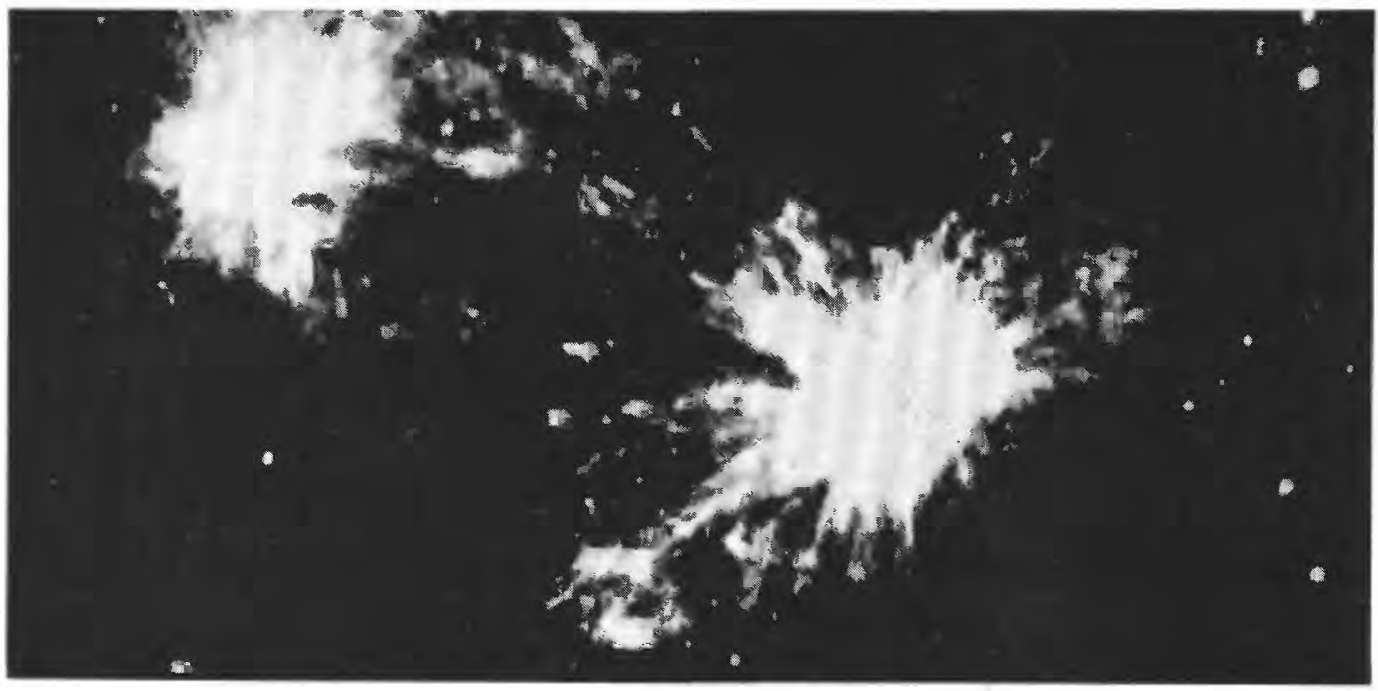

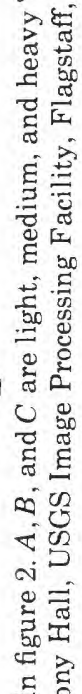

$\infty$ 它

틀

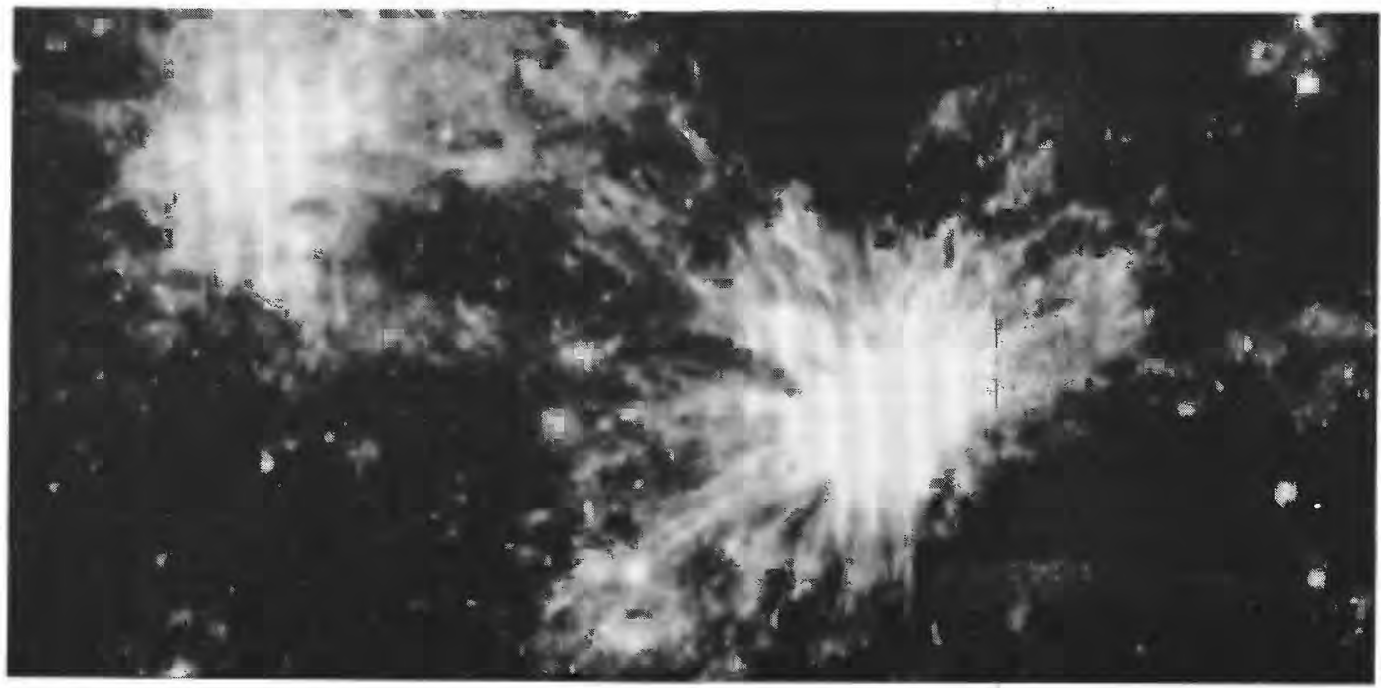




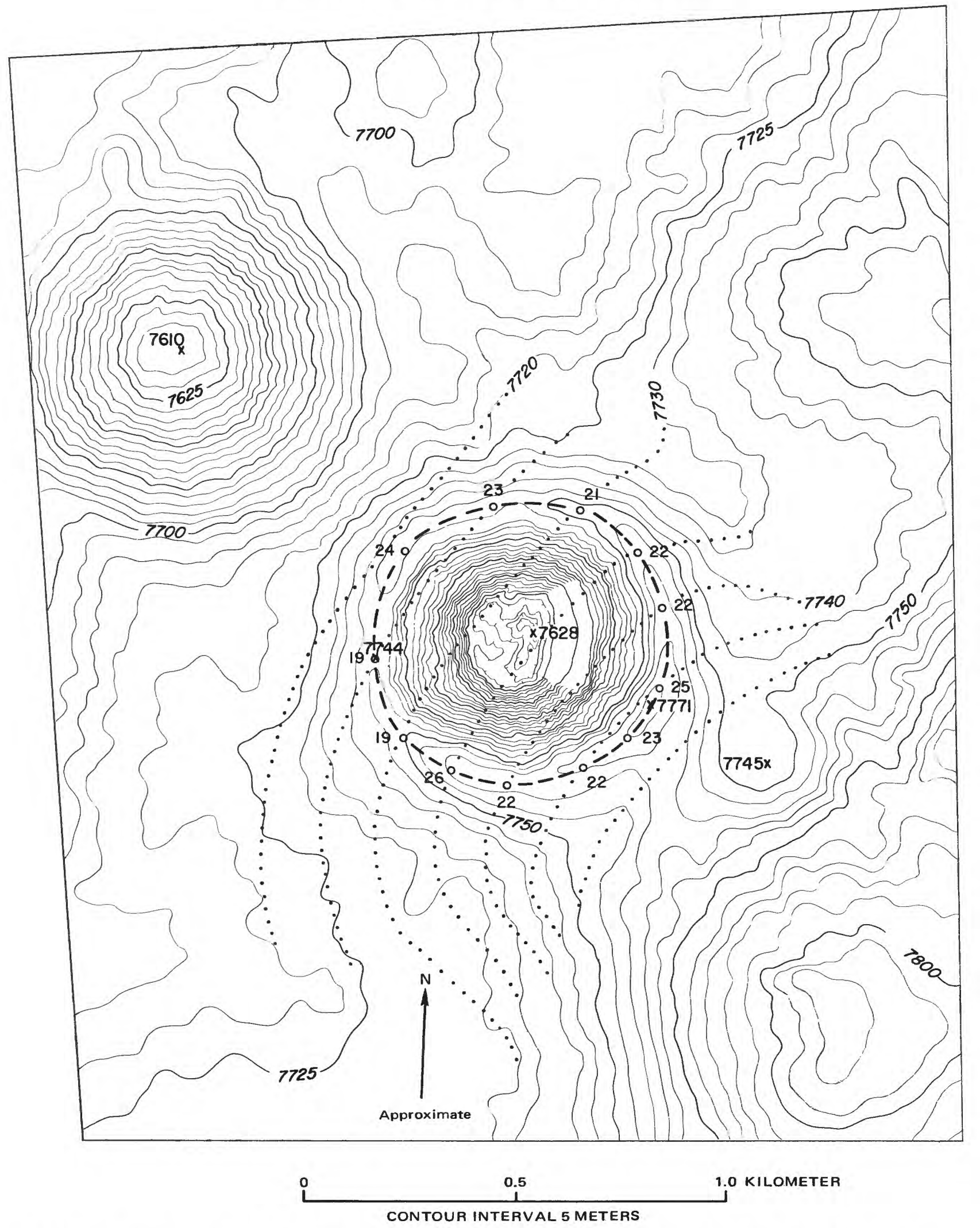

Figure 4.- Topographic map of South Ray crater. Dotted lines are extrapolated contours of pre-South Ray surface. Dashed line shows crater rim crest; numbers are elevations (in meters) of the rim crest above the extrapolated original ground surface. Compilation scale 1:10,000; photographic model from Apollo 16 panoramic camera frames 4618 and 4623 . Topography compiled by G. M. Nakata. 

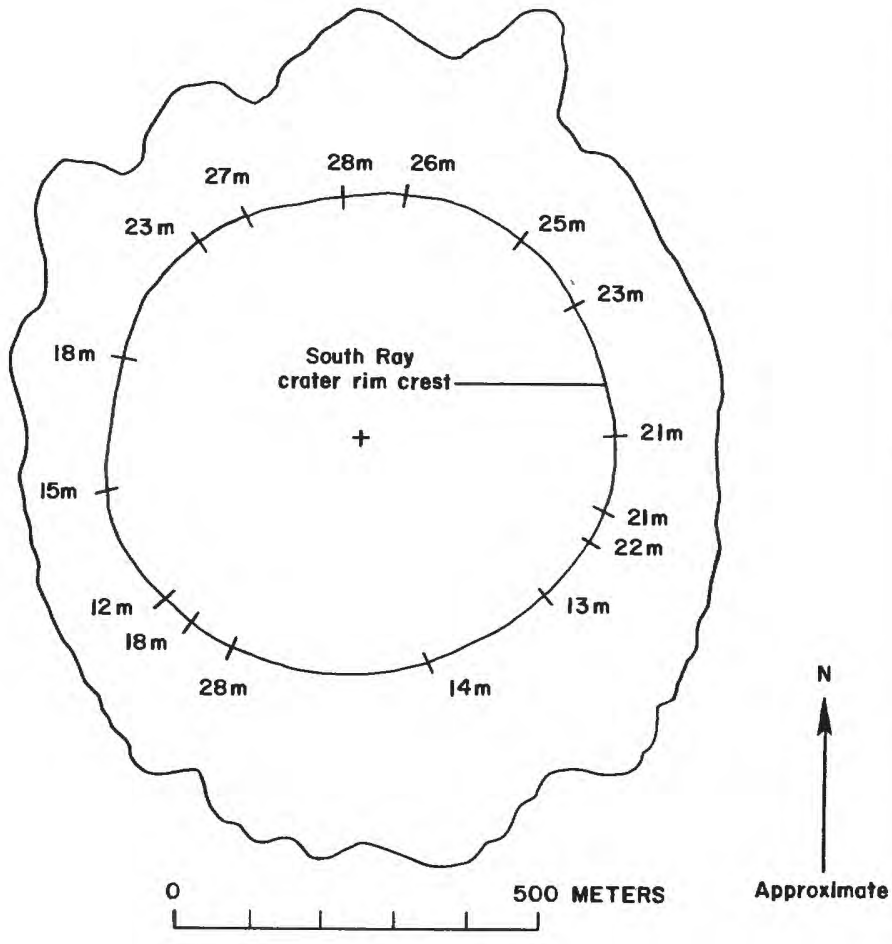

Figure 5.-Outline of hummocky ejecta around South Ray crater rim (from J. P. Schafer, unpub. data, 1973.) Values for height of rim were measured from figure 4 as the difference in elevation between edge of hummocky ejecta and rim crest. Rim-crest diameter averages $680 \mathrm{~m}$.

and others, 1972, fig. 6-6 and table 6-I). (4) By comparison with South Ray, the fragment population of the continuous ejecta of North Ray crater generally occupies less than one percent of the area except on the rim crest, because erosional history is longer and the majority of North Ray rocks are more friable.

Some large concentrations of blocks are unrelated to North or South Ray. The highest block density found anywhere at the site was in an area about $700 \mathrm{~m}$ south of the LM (fig. $10 C$ ), where blocks occupy nearly 16 percent of the surface and probably represent the rim of a fresh young crater $40 \mathrm{~m}$ in diameter. This area lies near a small bright ray radial to South Ray crater, where the block density is much higher than expected for South Ray material at this range $(5.6 \mathrm{~km})$. Farther from South Ray, mappable rays become thin and are difficult to recognize (fig. $10 D$ ).

\section{DISTRIBUTION MODELS}

With the quantitative estimates derived herein, we now combine the orbital and surface information to construct models of ejecta distribution for South Ray crater. Having measured the volume of the apparent crater, 10 million $\mathrm{m}^{3}$, its rim height, $20-22 \mathrm{~m}$, the area within which most of this ejecta was deposited, and the thickness of ejecta at the crater rim, 10-12 m, we can derive expressions that describe the distribution and thickness of ejecta as a function of distance from the crater rim. The additional data of fragment counts per unit area made from photographs on the lunar surface permits a comparison of the volume of fragments larger than $2 \mathrm{~cm}$ in diameter with the ejecta thicknesses predicted by various curves ${ }^{1}$.

Carlson and Roberts (1963) have shown that the thickness of ejecta $(t)$ as a function of distance from the center of the crater $(r)$ can be approximately described by

$$
t=K(r)^{s},
$$

where $K$ is a constant and $s$ is an exponent having values commonly near -2.0 to -3.5 The volume, $V$, of ejecta deposited from the crater rim to infinity is given by

$$
V=2 \pi K \frac{R^{s+2}}{s+2}
$$

where $R$ is the radius of the crater and $s$ is less than minus $2 . R$ for South Ray is $340 \mathrm{~m}$. When $s$ is exactly -2 , another formula applies.

For our purposes, we will consider two general models: (1) All ejecta is confined to the mappable rays (Reed, fig. 4, this volume) and deposited within 16 crater diameters $(r=11,220 \mathrm{~m})$. (2) Ejecta is uniformly deposited from the rim outward to infinity with thickness decreasing according to equation (1). To test these models, we chose several values of $s:-2.0,-2.5,-3.0$, and -3.5 . Corresponding values of $K$ were calculated using equation (2). Thicknesses of ejecta $(T)$ at the crater rim were then calculated using equation (1) with $340 \mathrm{~m}$. Experimental data from explosion craters show that $s$ varies from -1.97 to -3.65 (Roberts and Carlson, 1963) and can steepen to values of -6.5 near the crater rim (Carlson and Jones, 1965). Laboratory experiments with hypervelocity impact craters in sand (Stoffler and others, 1975, p. 4074) follow equation (1) with an average value of $s$ of -3.3 . McGetchin and others (1973) estimated that lunar craters probably obey equation (1) with $s$ near -3.0 . The selected values of $s$, which cover the range of experimental data cited above, are given in table 1 with corresponding values

'Calculation of the thickness of material represented by fragment counts was performed as follows:

The fragments were assumed to have a spherical geometry, producing minimum volume estimates. (Cubic geometry would provide a maximum value, nearly double that calculated here.) Fragment volumes were calculated using median diameters for each fragment-size range: $3.5 \mathrm{~cm}(2-5 \mathrm{~cm}), 7.5 \mathrm{~cm}(5-10 \mathrm{~cm}), 12.5 \mathrm{~cm}(10-15 \mathrm{~cm})$, and $20 \mathrm{~cm}$ (greater than 15 the formula:

Thickness $(\mathrm{m})=\frac{\left.\text { (fraction of area covered) (volume of fragments, } \mathrm{m}^{3}\right)}{\text { ) }}$.

Thicknesses derived from median diameters of fragment-size ranges are smaller than thicknesses calculated from median volumes of the same fragment-size end members (approximately 10 to 25 percent lower). The method used tends to compensate for the bias of fragment-size distributions toward the smaller size ranges. 


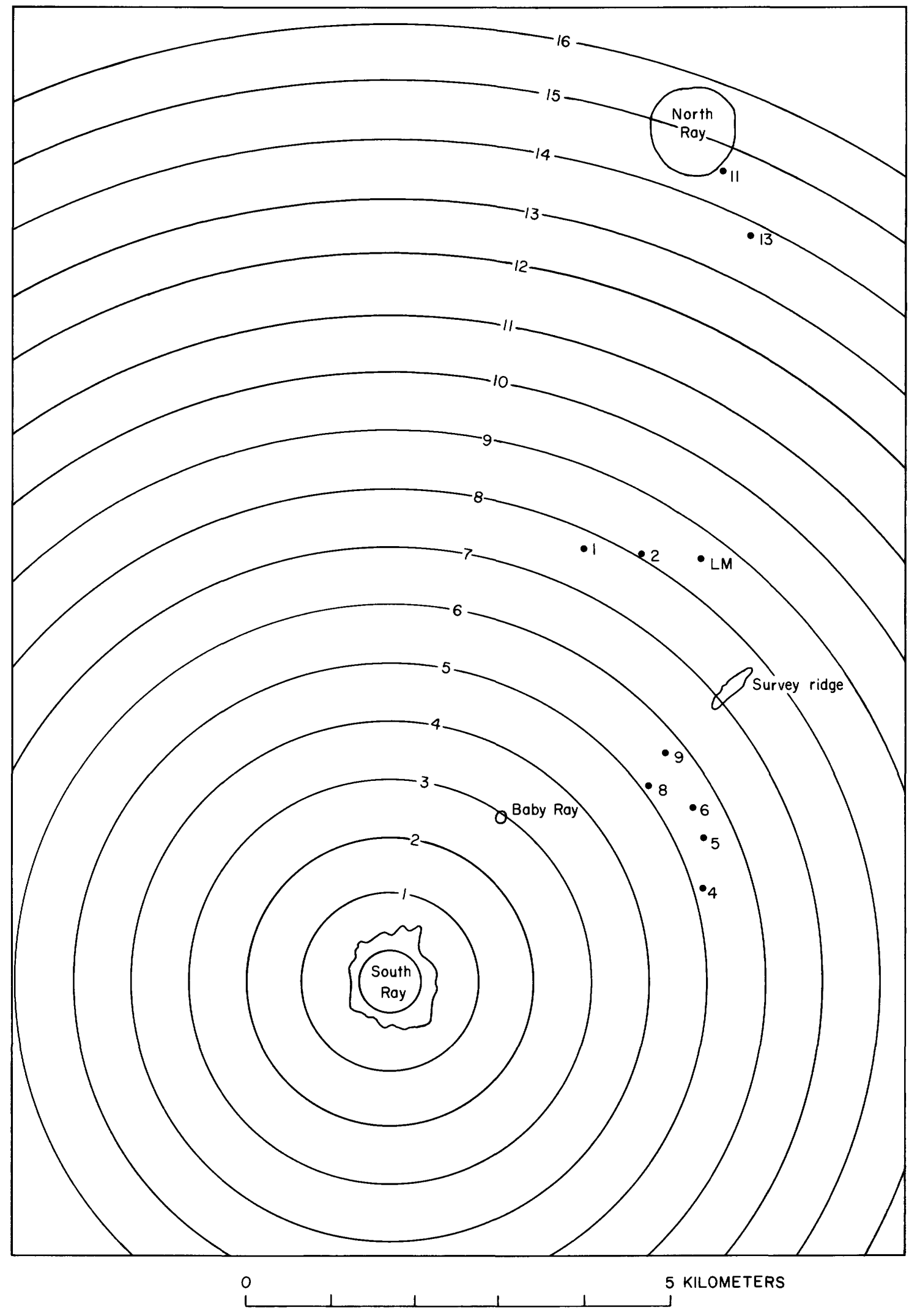

FIGURE 6.-Concentric rings centered on South Ray crater. The radius of each successive annulus is increased by one crater diameter. Area covered by ray material within each annulus was measured by planimeter at 1:50,000 scale. Station locations are shown by dots. 


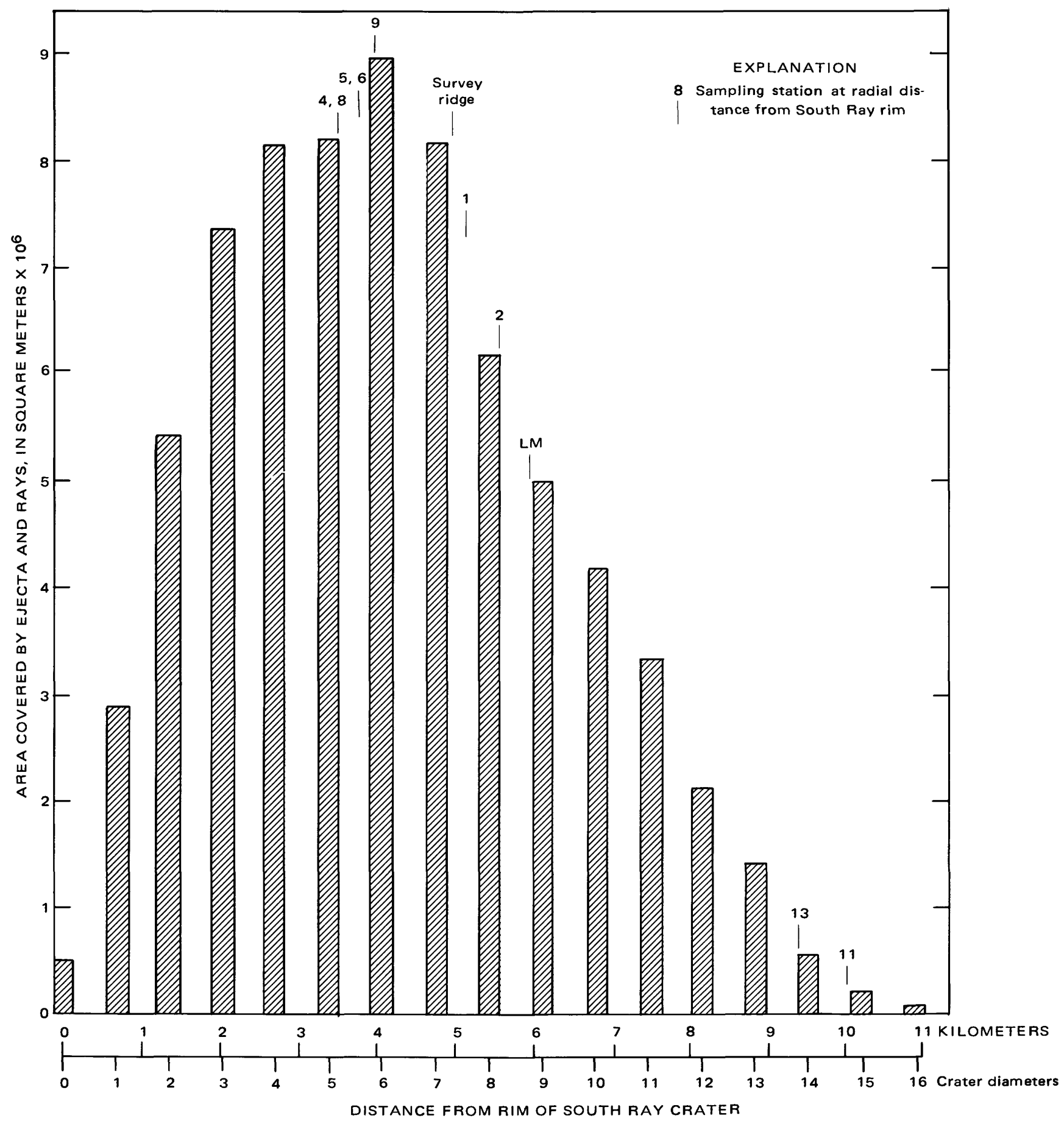

FiguRE 7.-Area covered by mappable ejecta and rays within each annulus shown in figure 6. Measurements are from superposed data of figures 3 and 6 . 


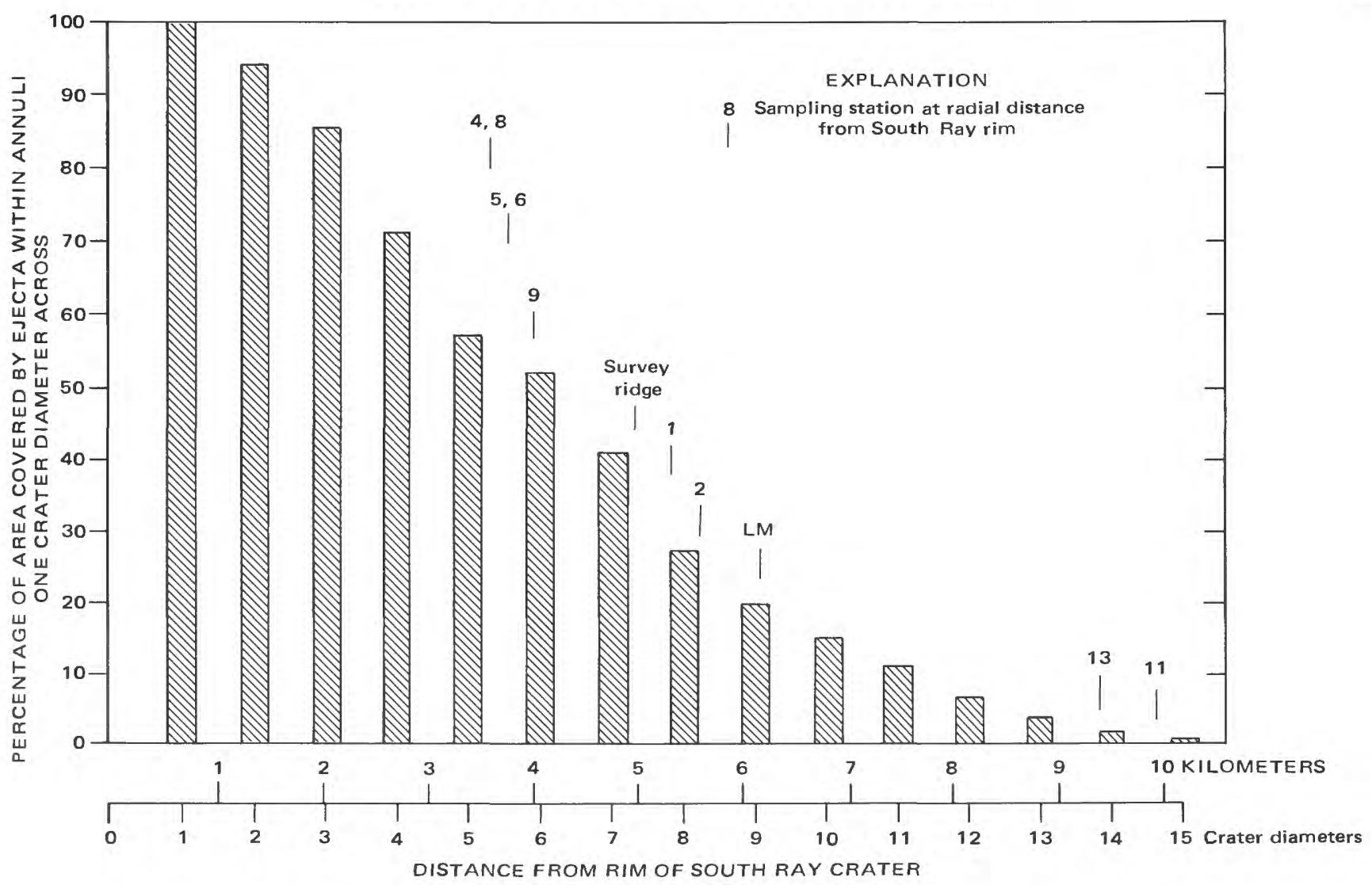

Figure 8.-Percentage of area covered by ejecta and rays in annuli of figure 6 relative to distance from South Ray crater rim.

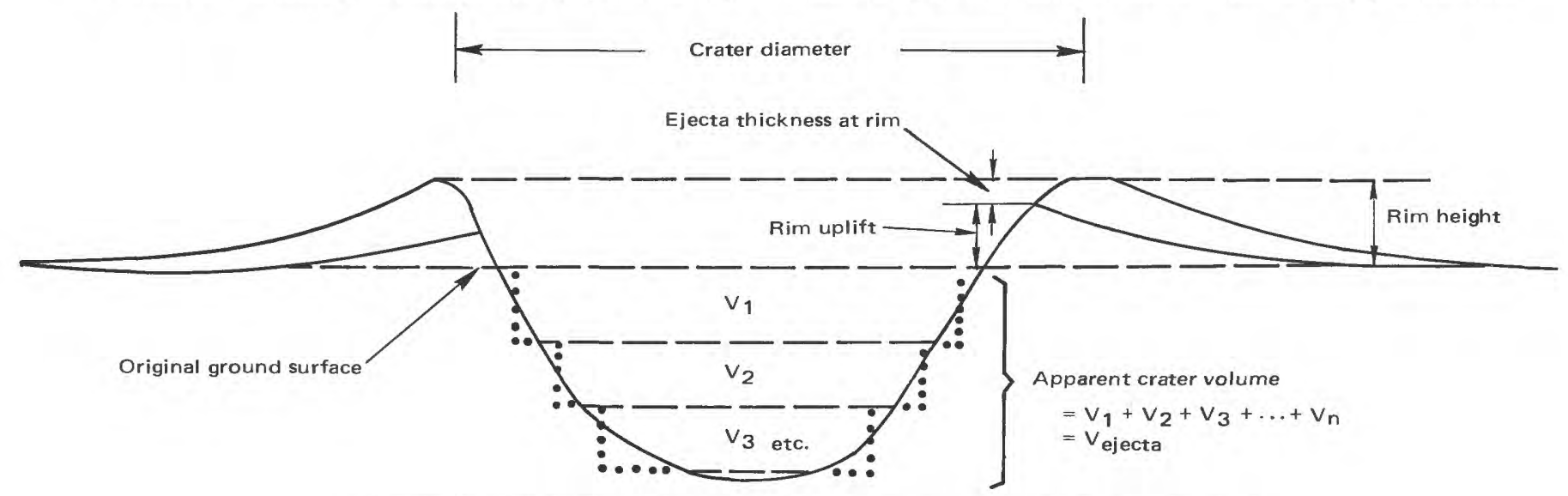

Figure 9 -Illustration of terms used for crater measurements discussed in text. 


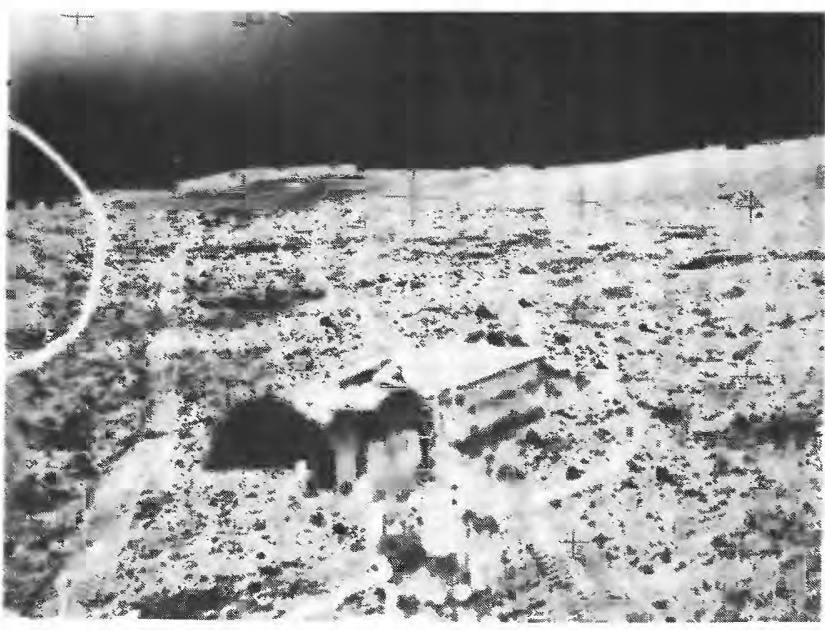

$A$

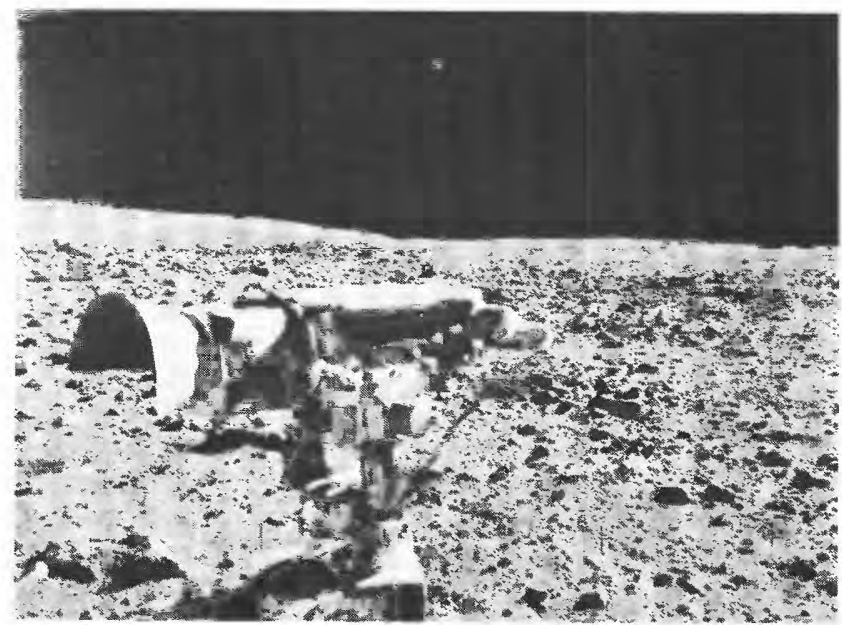

$C$

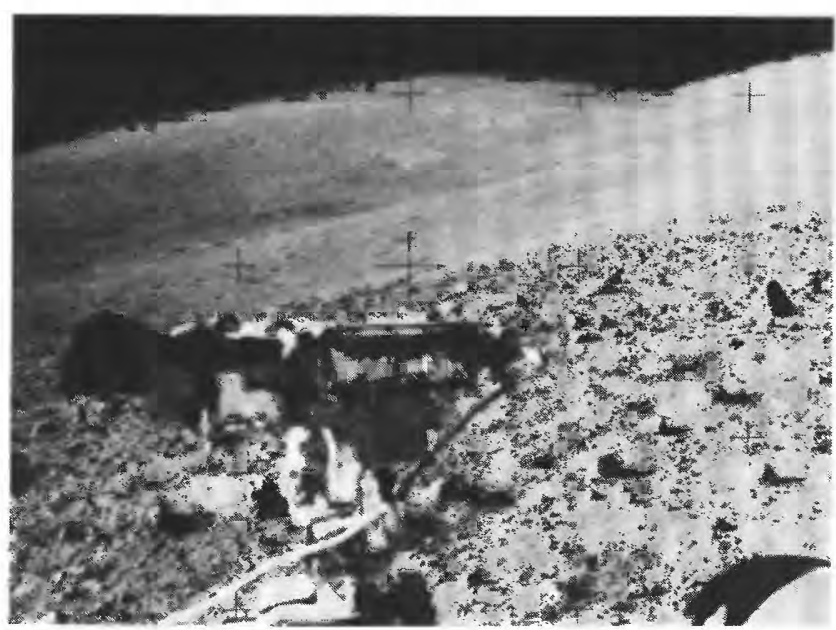

$B$

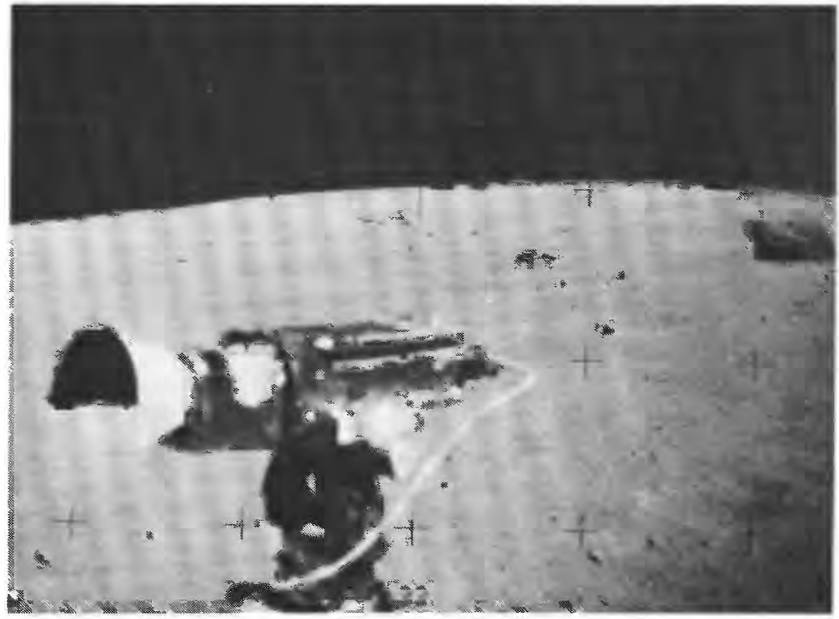

$D$

Figure 10.-Ray-covered areas photographed from the Lunar Roving Vehicle. Television camera obscures part of foreground. $A$, Block field west of the LM taken on return leg of EVA 1, looking east (AS16-109-17860). Percentage of area covered by fragments larger than $2 \mathrm{~cm}$ : 5.3; equivalent to uniform surface mantle $2.1 \mathrm{~mm}$ thick. $B$, Survey ridge, a bright ray area about $5 \mathrm{~km}$ northeast of South Ray crater (AS16-110-17894). Percentage of area covered by fragments larger than $2 \mathrm{~cm}$ : 7.0; equivalent to uniform surface mantle $4.3 \mathrm{~mm}$ thick. $C$, Block field $700 \mathrm{~m}$ south of the LM, near a fresh 40-m-diameter crater (AS16-115-18533). Percentage of area covered is 15.9; equivalent to uniform surface mantle $1.5 \mathrm{~cm}$ thick. $D$, Approach to North Ray crater area. Shadow rock on right is location of station 13 (AS16-111-18155). Percentage of area covered is 0.15 equivalent to uniform surface mantle $0.05 \mathrm{~mm}$ thick. 
TABLE 1.-Ejecta distribution models for South Ray crater [Volume: $10 \times 10^{6} \mathrm{~m}^{3}$; crater radius: $340 \mathrm{~m}$; rim height: $22 \mathrm{~m}$ ]

\begin{tabular}{|c|c|c|c|c|c|}
\hline \multirow[t]{2}{*}{ Factors } & & \multicolumn{4}{|c|}{ Slope of ejecta thickness decay } \\
\hline & & -2 & -2.5 & -3.0 & -3.5 \\
\hline \multirow{3}{*}{$\begin{array}{l}\text { Ejecta confined to } \\
\text { mappable rays. } \\
\text { Total volume de- } \\
\text { posited within } 16 \\
\text { diameters. }\end{array}$} & Constant, $K$ & $-0.068 \times 10^{7}$ & $2.15 \times 10^{7}$ & $60.8 \times 10^{7}$ & $1561 \times 10^{7}$ \\
\hline & $\begin{array}{l}\text { Thickness at rim, } \\
T \text { (meters) } \\
T \text { /rim height }\end{array}$ & $\begin{array}{l}5.9 \\
.27\end{array}$ & $\begin{array}{r}10.1 \\
.46\end{array}$ & $\begin{array}{r}15.5 \\
.70\end{array}$ & $\begin{array}{r}21.5 \\
.98\end{array}$ \\
\hline & $\begin{array}{l}\text { Fraction of volume } \\
\text { beyond } 16 \text { diameters }\end{array}$ & .0 & .0 & .0 & .0 \\
\hline \multirow{4}{*}{$\begin{array}{l}\text { Ejecta uniformly } \\
\text { distributed at all } \\
\text { azimuths to infin- } \\
\text { ity. }\end{array}$} & Constant, $K$ & $-.056 \times 10^{7}$ & $1.47 \times 10^{7}$ & $54.0 \times 10^{7}$ & $1497 \times 10^{7}$ \\
\hline & $\begin{array}{l}\text { Thickness at rim, } \\
T \text { (meters) }\end{array}$ & ${ }^{2} 5.0$ & 6.9 & 13.7 & 20.6 \\
\hline & $\begin{array}{l}\text { Fraction of volume } \\
\text { ejected beyond } 16\end{array}$ & & & & \\
\hline & diameters & 30 & .17 & .03 & .0053 \\
\hline
\end{tabular}

'Calculated from equation using $S=-2$ and $T=5 \mathrm{~m}$

${ }^{2}$ Assumed for calculation.

${ }^{3}$ No ejecta deposited beyond 16 diameters; volume of ejecta accounted for at $5,000 \mathrm{~m}$ from crater rim.

of $K$ and $T$ calculated from equations (2) and (1), respectively. The resulting thickness decay curves (fig. 11) can be compared with the calculated thicknesses of a uniform ejecta deposit represented by fragments (larger than $2 \mathrm{~cm}$ ) (shown in fig. 11 by vertical bars) representing the ranges of thickness determined from individual photographs. These data supersede those illustrated in an earlier paper by Hodges and others (fig. 10,1973 ), whose model assumed an ejecta thickness of $10 \mathrm{~m}$ at the rim and predicted greater maximum thicknesses in the Apollo 16 traverse area than the present model by a factor of three to five from station 8 to station 13.

If the actual volume of ejecta is 5 million $\mathrm{m}^{3}$ rather than the 10 million $\mathrm{m}^{3}$ measured above, model thicknesses plotted in figure 11 and given in table 1 would be half the values indicated and the constant $(K)$ would be half as large.

We can now evaluate the data and select a preferred ejecta thickness distribution model for South Ray crater. The factors to be considered are slope $(s)$, thickness at the $\operatorname{rim}(T)$, and $T /$ rim height given in table 1: the resulting decay curves are plotted in figure 11, together with the ranges of thickness derived from fragment counts. If the fragments greater than $2 \mathrm{~cm}$ show an obvious relation to distance from South Ray crater, as they certainly do at Survey ridge (fig. $10 B$ ) and by their decrease away from South Ray (fig. 11), then there may be a contribution from fragments smaller than $2 \mathrm{~cm}$. McKay and Heiken (1973, p. 45) argue from soil agglutinate contents, exposure ages, and size distribution of experimental crater ejecta that relatively little fine-grained South Ray ejecta (possibly 1 or 2 $\mathrm{mm}$ ) would be expected in ray areas. Holt (this volume), however, maintains that the optical properties of the visible rays are likelier to be a product of finegrained (comminuted) ejecta than of coarse fragmental debris. It is possible that the dilution of fresh fines from South Ray due to mixing with old soils at the site may be so great that dating techniques cannot yet distinguish the younger materials. The volume of fine material is probably not much greater than the volume of all fragments measured. Assuming an extreme case, that the fine-grained volume is twice the fragmental volume, the total thickness of ejecta shown in figure 11 would increase approximately to the tops of the range bars shown for the fragments. The fragments counted may include a pre-South Ray population that in effect reduces the mean values attributable to the South Ray event.

The models for increasing values of $s$ can be reviewed relative to the data of table 1 and the plot of figure 11 . For $s=-2$, the value of $T$ is 5.9 and 5.0 (assumed) for the confined and uniform models, respectively. These values result in thickness-to-rim-height ratios of 0.23 and 0.27 ; that is, 73 to 77 percent of the rim height is attributed to uplift, too high a percentage when compared with experimental data, though not an impossible value. In addition, both models result in an excessive thickness (several millimeters) at the distance where the total volume is used up.

For $s=-2.5$, the decay curves for the confined model produce a reasonable $T /$ rim-height ratio $(0.46)$ because of the required thickness of ejecta $(10 \mathrm{~m})$ at the rim. $T$ is smaller $(6.9 \mathrm{~m})$ for the uniform model, wherein 17 percent of the total volume is still unused at 16 crater diameters. If the volume of fine-grained ejecta (less than $2 \mathrm{~cm}$ ) were more than twice that of the fragments counted and if the fragments are assumed to have a cubic rather than spherical geometry, the decay curves for $s=-2.5$ produce a reasonable model. But because the total volume of 10 million $\mathrm{m}^{3}$ used in our calculations may be high by a factor of two, we believe that the preferred decay curve (fig. 11) must lie below that for $s=-2.5$.

For $s=-3.0$, the thickness-decay curves appear to be in fair agreement with the computed fragment volumes provided an additional volume of fines approximately equal to the fragment volume is allowed. This amounts to the equivalent of a few millimeters at station 8 and a few tenths of a millimeter at North Ray crater. The model gives $T / \mathrm{rim}$-height ratios of 0.62 and 0.70 , or $30-38$ percent uplift, in reasonably good agreement with experimental data.

Finally, for $s=-3.5$, the values of $T(20.6$ and $21.5 \mathrm{~m})$ and $T /$ rim-height ratio (0.94 and 0.98$)$ are too high relative to experimental data, and the corresponding thicknesses from figure 11 are too low relative to fragment counts. This model is therefore eliminated in favor of the model based on our measurements and calculations wherein $s=-3.0$.

It must be pointed out that the preferred model is only a best estimate at this time. The equations used 


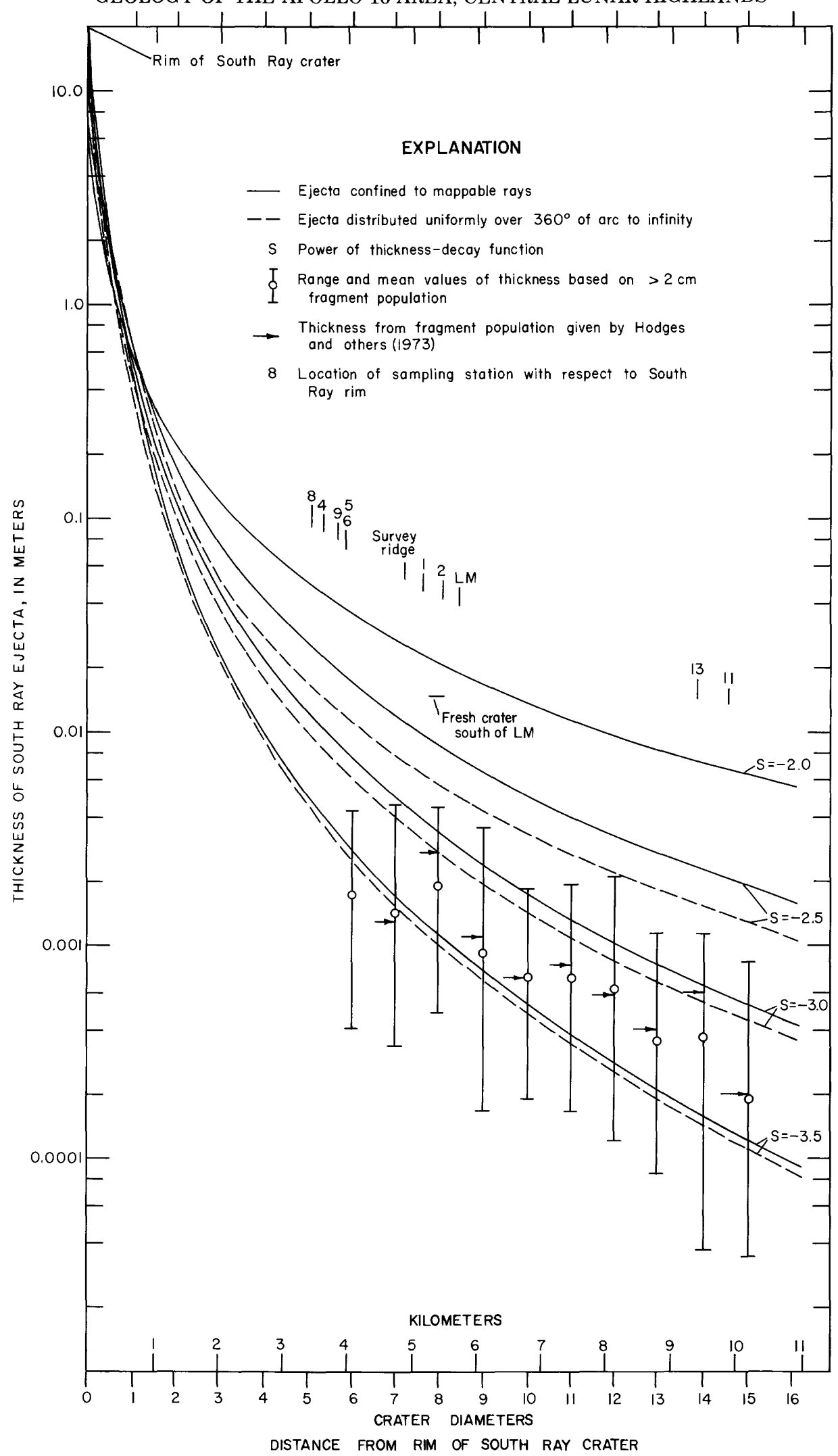

FIGURE 11.-Semilogarithmic plot showing thickness of ejecta relative to distance from rim of South Ray crater. Curves are based on data from table 1 and calculations using equations 1 and 2 (see text) for total ejecta volume of 10 million $\mathrm{m}^{3}$. 
here may not be an exact representation of the ejecta decay function. Other, more explicit functions may be required to describe in detail the thickness of ejecta as a function of distance from the crater; such refined data are not available at this time.

\section{SUMMARY}

South Ray crater ejecta totaling about 10 million $\mathrm{m}^{3}$ covers the Apollo 16 landing site in an irregular radial pattern that reflects a nonuniform mantle of scattered debris. The ejecta thins rapidly from perhaps $10-15 \mathrm{~m}$ at the crater rim to $1 \mathrm{~cm}$ or less at the southern station localities $(4,5,6,8$, and 9$)$ and less than 1 $\mathrm{mm}$ at the northernmost stations (11 and 13). Using the general equation where thickness is a function of the crater radius to describe the thinning of ejecta with increasing distance from the crater, the preferred exponent for the radius is -3.0 . The fragment population on the lunar surface (for sizes larger than $2 \mathrm{~cm}$ ) accounts for a significant part of the total volume of ejecta. An equal amount of material finer than $2 \mathrm{~cm}$ can reasonably be accommodated by the preferred model.

Review of the photographic data, enhancement of the various levels of reflectance directly related to South Ray crater, and observations of evidence for ray materials on the surface provide a basis for assigning a South Ray origin to selected sample localities. With the information available at this time, we believe that station 8 has the highest potential for collection of South Ray fragments and fines; next highest are stations 9, 6 , 4 , and 5 in that order. The probability of collecting or identifying South Ray ejecta at stations farther away ( $>5 \mathrm{~km}$ from the crater) is considered very remote with the possible exception of station 2 samples, which may have been from the bright area at that locality. Determination of the provenance of individual samples will rely on additional evidence of other parametersangularity, perchment, abundance of microcraters, particle-track ages, and rare-gas ages.

\section{ACKNOWLEDGMENTS}

This paper benefitted significantly from comments and suggestions of D. J. Roddy and W. R. Muehlberger. The work was done under NASA Contract T-5874A, except for that of H. J. Moore, done as part of NASA Experiment S-222. 


\section{H. OPTICAL PROPERTIES AT THE APOLLO 16 LANDING SITE}

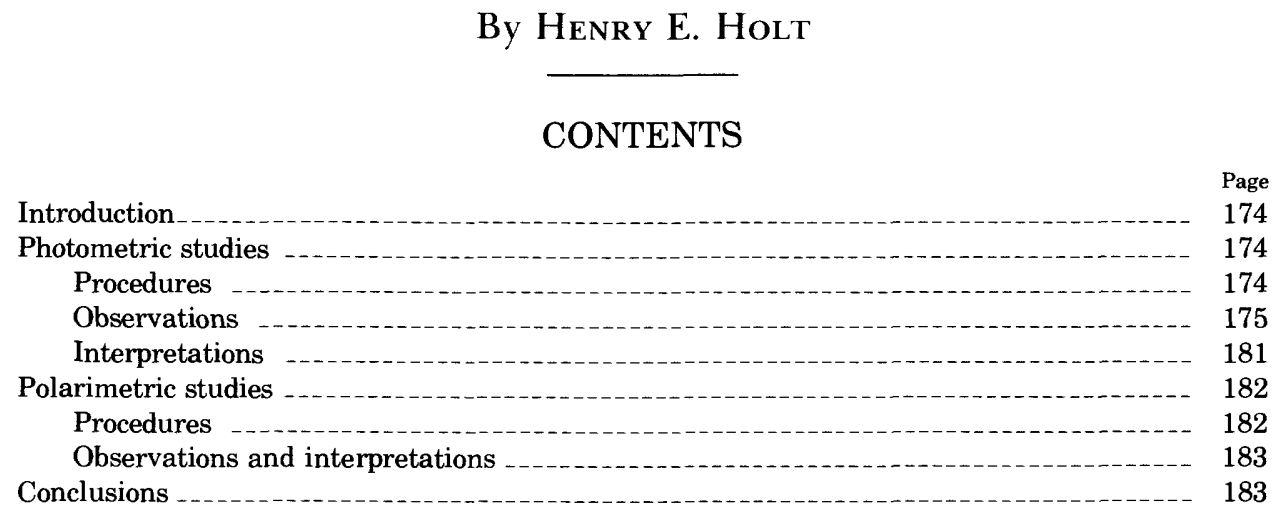

ILLUSTRATIONS

FIGURE 1. Graph showing comparison of telescopically measured photometric function with measured luminances at stations 8 and 13 - 135

2. Map showing albedo variations within the Apollo 16 site

3. Photograph of the Apollo 16 landing site, sun elevation angle $60^{\circ}$

4. Computer-generated enlargements of northern, central, and southern areas outlined in figure 2

5. Photograph of north wall and southeast rim of North Ray crater and digitized image showing degree of polarization for the same scene

\section{INTRODUCTION}

The optical properties at the Apollo 16 landing site in the central highlands can be characterized by measurements from surface and orbital photographs. The purpose of this study is to interpret the optical variations over the landing area in relation to the local geology as deduced from the soil and rock samples photographed and collected at the traverse stations. The data provide an opportunity to observe, in some detail, bright rays and older regolith surfaces in the landing site and to compare the optical nature of the Cayley Formation with the adjacent Descartes mountains. Finally, polarimetric studies were conducted with photographs taken through a polarizing filter at two locations on the rim of North Ray crater to determine the degree and orientation of reflected polarized light.

\section{PHOTOMETRIC STUDIES}

The brightness reflectances or albedos of materials on the Moon's surface, measured under prescribed lighting conditions, constitute the photometric properties of those materials. Determination of these properties provides an independent method of estimating the age and composition of texture of lunar surface materials.

\section{PROCEDURES}

The Apollo 16 mission provided the first opportunity to test the photometric function of the fine-grained highland regolith for small-scale variations. Photographs taken down-sun, which include the astronaut's shadow, allow the measurement of surface reflectance from approximately $50^{\circ}$ to near $0^{\circ}$ phase angle. Microdensitometer scans were made across photographs taken at stations 6,8 , and 13 . The film-density luminances (or percent reflectances) were calculated and plotted relative to phase angle (fig. 1).

Down-sun photographs of the lunar surface at each traverse station were utilized in determining the photometric properties of the undisturbed soil and rock materials. These materials normally appear darker when disturbed. At the Apollo 16 landing site, however, patches of lighter materials were exposed below a thin surface layer at stations $1,2,4 a, 5,11$, and 13 . Surface areas within a few degrees of zero phase angle were scanned by densitometer and the film-density 


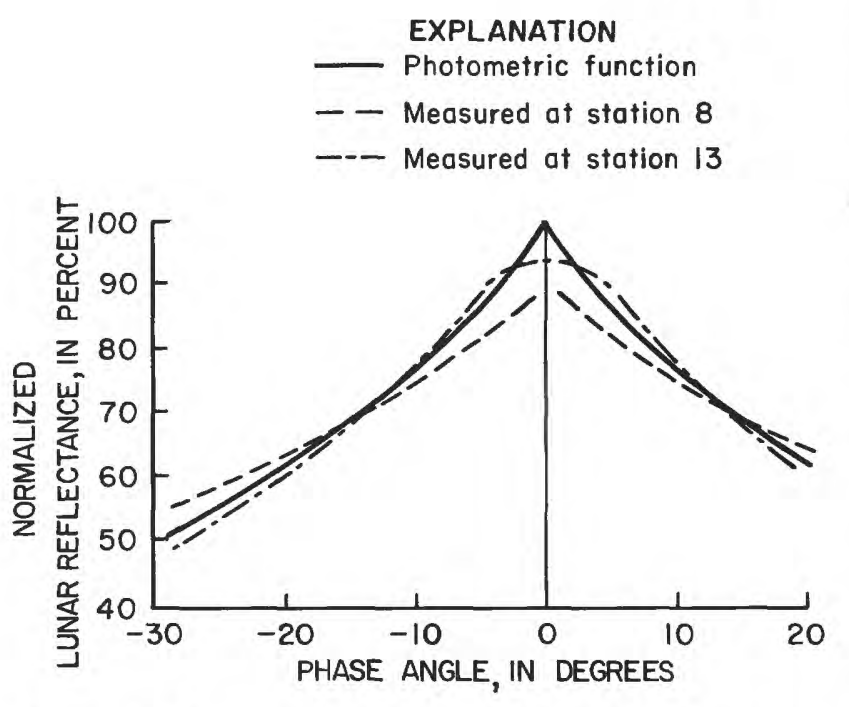

Figure 1.-Comparison of telescopically measured photometric function with measured luminances from photographs AS16-106-17386 (station 13) and AS16-108-17702 (station $8)$.

luminances calculated. The Hasselblad cameras with $60-\mathrm{mm}$ and $500-\mathrm{mm}$ focal length lenses used on the lunar surface were calibrated for variation in film density as a function of absolute light intensities of photographed objects. Photometric control before and after the mission was obtained from film measurements of the photometric chart and gnomon photographed on the lunar surface and from film sensitometry data. The camera orientation with respect to lunar azimuth, lunar vertical, and position of the sun was established for each measurement, and the measured luminances were then converted to $0^{\circ}$ phase-angle reflectance for albedo determination. The resultant albedo value of the regolith is the down-sun reflectance expressed as a percentage of the solar irradiance; for instance, 14 percent albedo indicates that 14 percent of the solar light is reflected.

Albedo distributions over the Descartes landing area were mapped from orbital panoramic camera frame 5328 , taken under high sun angle $\left(60^{\circ}\right.$ elevation) and $10^{\circ}$ forward tilt, producing a $19^{\circ}$ phase-angle view of the lunar surface. Relative film densities were digitized on a Joyce-Loebel microdensitometer at a scanning aperture of $50 \mu^{2}$, approximately equivalent to an integrated area of $9 \mathrm{~m}^{2}$ on the lunar surface. The film densities are proportional to the normal albedos of the lunar surface materials, and the density variations were calibrated to the albedos determined in the down-sun surface photographs at the traverse stations. A photomap showing the distribution of albedo levels was produced by relating appropriate range of digital numbers to quantified albedo levels. Areas of slope were determined from a topographic map of Descartes landing area (U.S. Army Topographic Command, 1972); slope direction and steepness were computed, and the albedo deviation from a level surface was calculated using the average lunar photometric function. In areas beyond the topographic map coverage, the slopes were compared with known slopes by stereoscopic study to determine slope direction and steepness. The topographic corrections were applied to the albedo levels to neutralize the effects of topographic slopes.

\section{OBSERVATIONS}

Slight differences in the slopes of the photometric function curves occur at phase angles near zero, indicating that variations in the backscattering nature of lunar fine-grained materials are minor. The lunar photometric function for mare surface (Holt and Rennilson, 1970) is very similar to that of the curves for stations 8 and 13 , which is remarkable considering the differences in composition of bedrock. Apparently, the soil textures resulting from the comminution of lunar material by cratering produces the unique backscatter and lunar photometric function while composition controls the albedo.

The albedo map of a $500-\mathrm{km}^{2}$ area (fig. 2) can be compared with an orbital photograph at similar scale (fig. 3). The mapped area is dominated by the two bright areas of North Ray and South Ray craters and their radiating ejecta patterns. Map units 6 and 7, representing albedo levels of 11 through 15 percent, cover more than 58 percent of the mapped area. Where map unit 5 occurs, representing 15 to 17 percent albedo, there is nearly always clear evidence of relatively recent, bright small craters or diffuse ray patterns. The more clearly radial, diffuse to discontinuous bright ray material from North Ray and South Ray craters makes up unit 4 , which ranges from 17 to 20 percent normal albedo. Map unit 3, ranging from 20 to 25 percent albedo, represents continuous to discontinuous streaks of ejecta from South Ray crater, both raylike patterns and continuous ejecta from North Ray crater, and rim deposits on many smaller craters. The rim deposits of North Ray crater and the outer parts of the continuous ejecta from South Ray crater make up map units 1 and 2 , varying from 25 to 40 percent albedo. The unit with the highest reflectance, about 40 to 60 percent normal albedo, makes up most of the crater wall of North Ray crater, the wall, rim, and some continuous ejecta of South Ray crater, and the rim and wall of Baby Ray crater.

The albedos of the fine-grained regolith at the traverse stations in the Descartes landing area range from 14 to 32 percent. The albedos of the regolith at the 


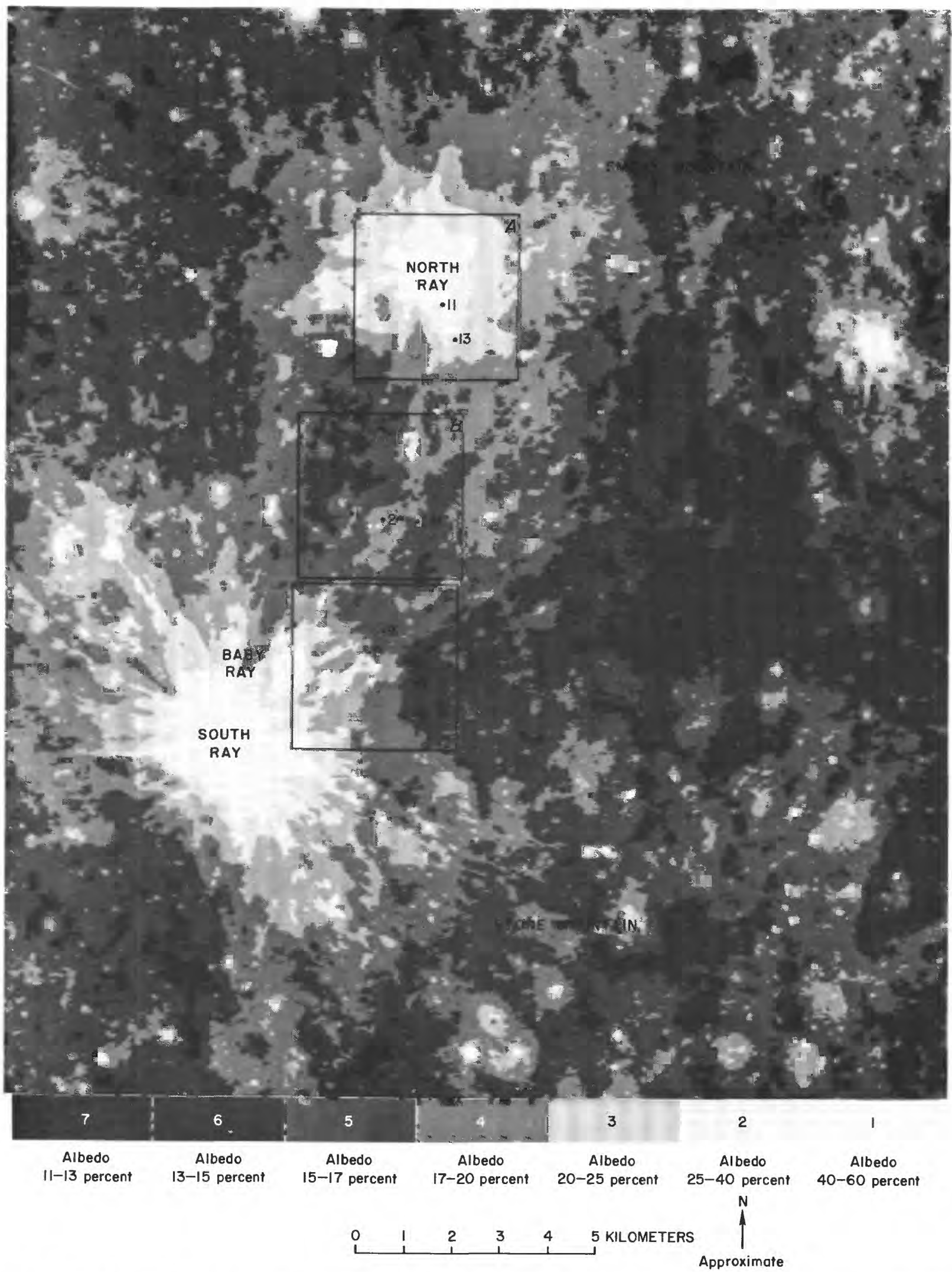

Figure 2.-Albedo of the Apollo 16 site based on Apollo 16 panoramic camera frame 5328. Normal albedos, divided into seven percentage ranges, are shown by the gray scale. Enlargements of areas A, B, and C are shown in figure 4. Numbered localities are stations on EVA traverses. Albedo corrections were made for topographic slope elements measured on the premission topographic map (U.S. Army Topographic Command, 1972). 


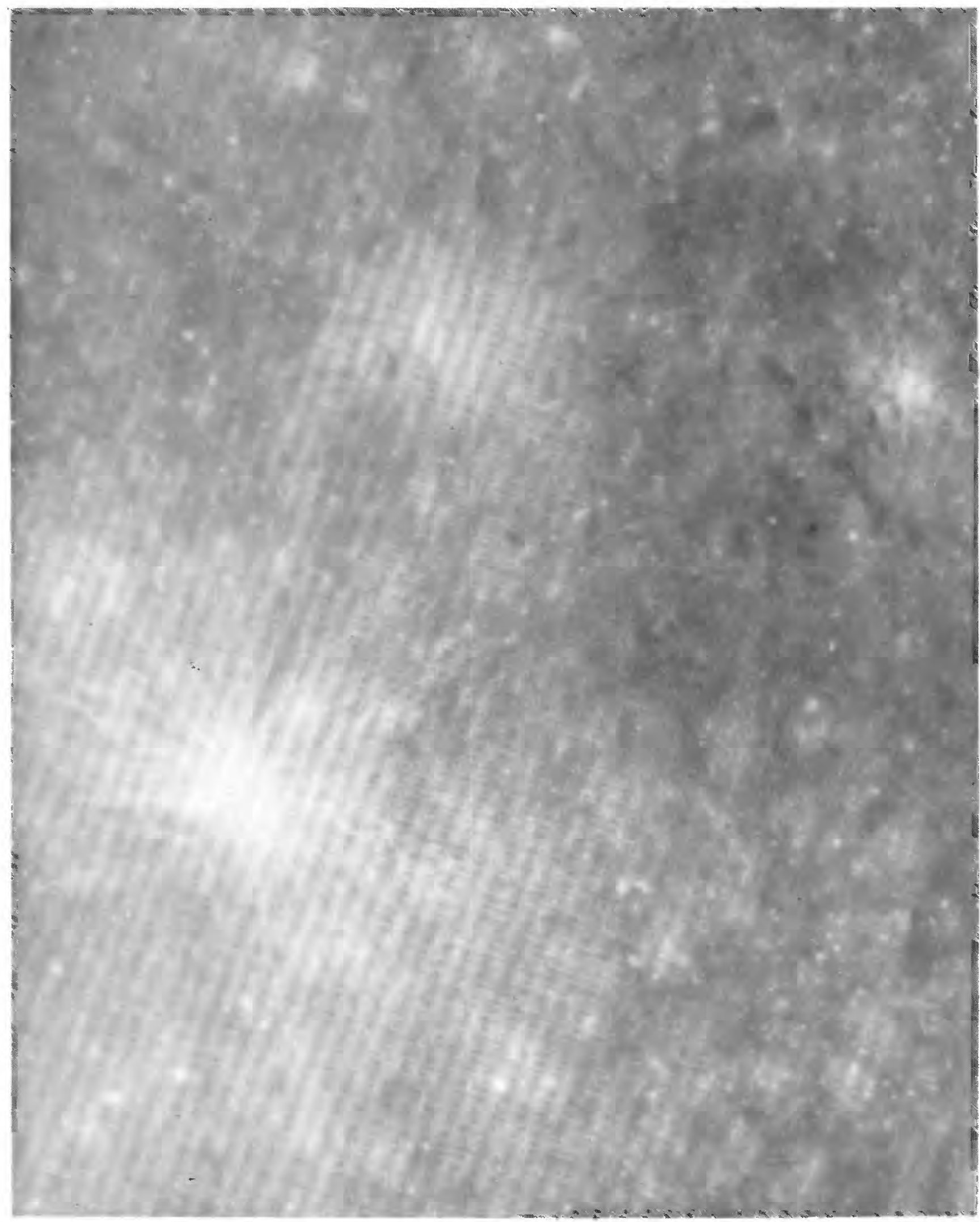

Figure 3.-The Descartes landing area as viewed on Apollo 16 panoramic camera frame 5328. Scale of photograph is same as albedo map of figure 2 . Sun elevation $60^{\circ}$, camera tilt $10^{\circ}$ from vertical toward the west, producing a phase angle of $19^{\circ}$. 


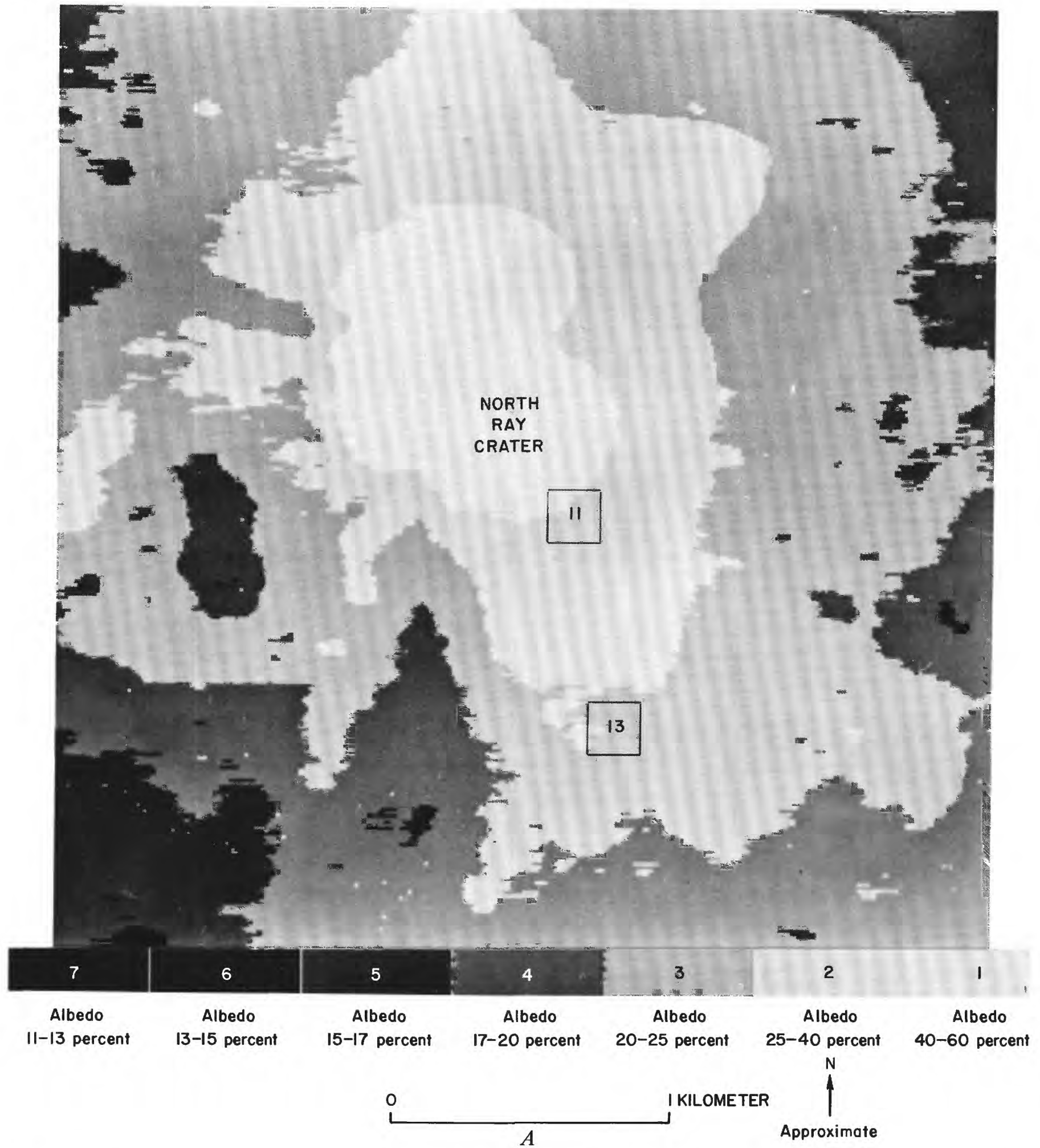

Figure 4.-Computer-generated enlargements of areas A, B, and C outlined in figure 2. Station locations identified by number inside scribed areas. Gray shades represent same ranges as given in figure 2. A, Area A. B, Area B. C, Area C. 


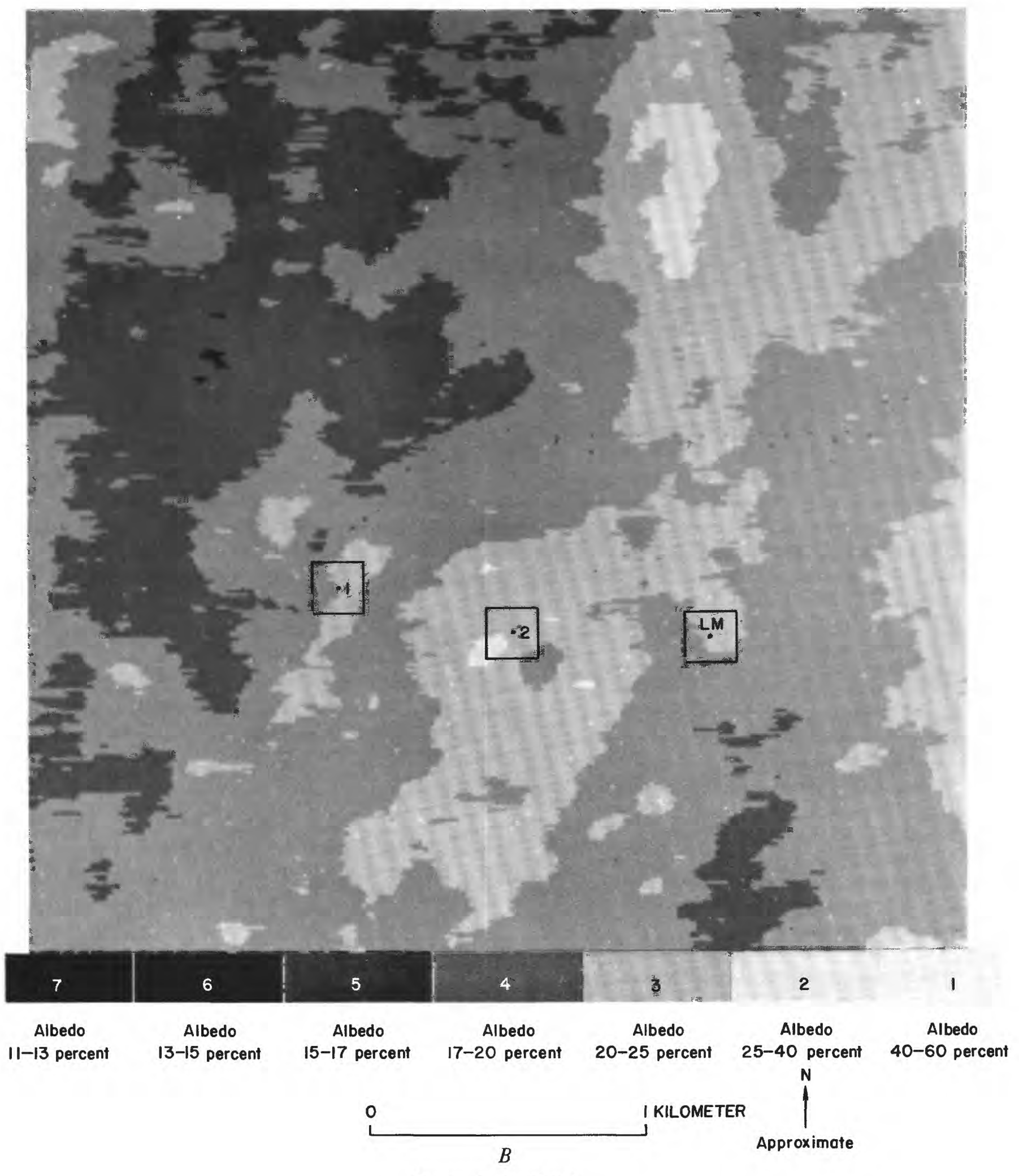

Figure 4.-Continued. 


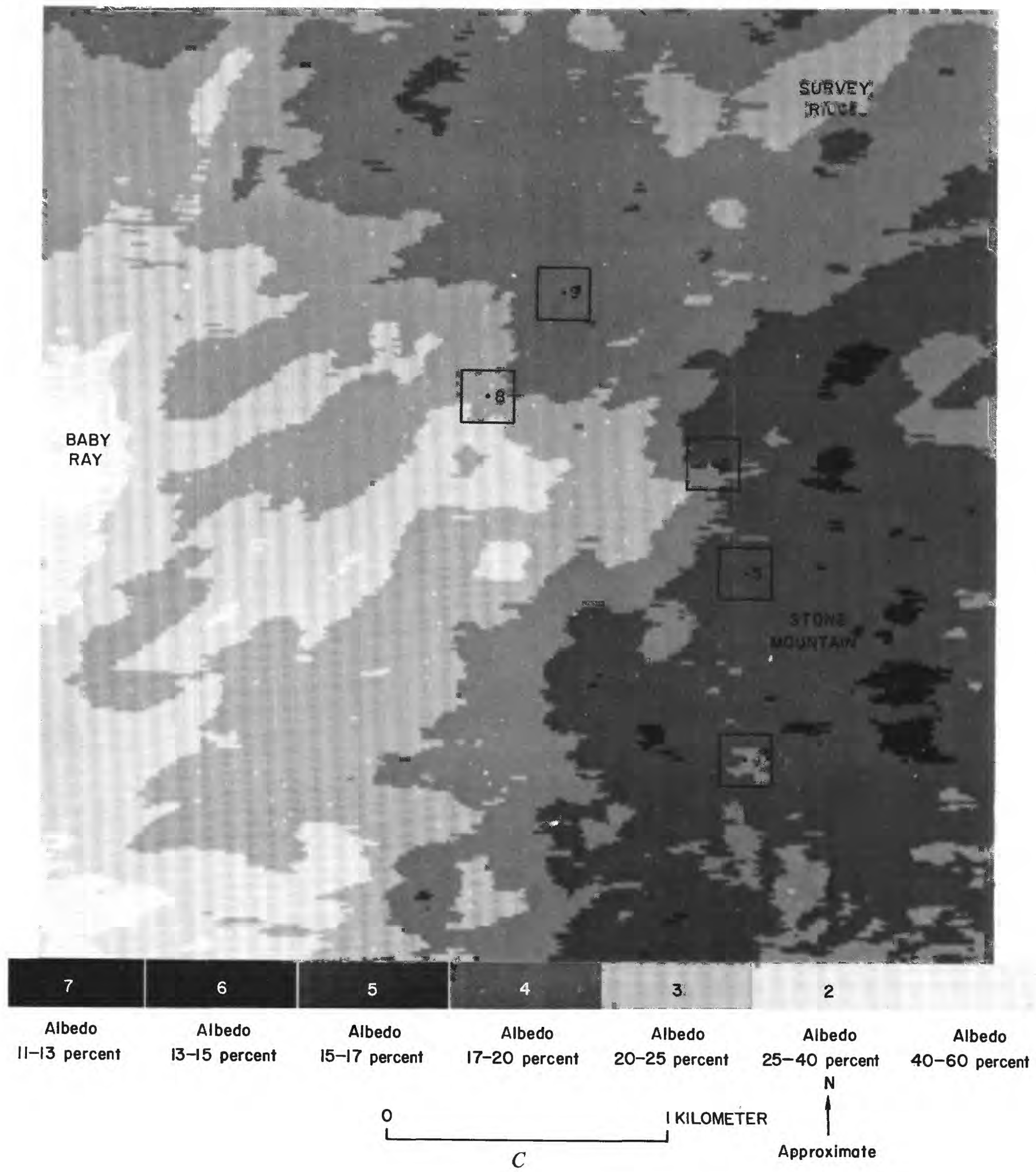

Figure 4.-Continued. 
traverse stations fall into three groups (fig. 2) that appear to be controlled by proximity to North Ray and South Ray craters. Stations 11 and 13 (fig. $4 A$ ) are situated on the bright North Ray crater ejecta and exhibit albedos of 21 to 32 percent. The albedos of stations $1,2,6,8,9$, and LM vary from 16 to 19 percent over the discontinuous ray area between North Ray and South Ray craters. Stations 4 and 5 on Stone mountain show 14 to 15 percent albedo. Rock measurements vary from 18 to 51 percent; the brightest rocks are the light-matrix breccias on the rim of North Ray crater. The bright raylike materials on the rim of South Ray crater reach a maximum albedo of 60 percent, the brightest materials on the walls of North Ray crater 52 percent. These high albedos are more than twice the highest telescopically measured lunar albedo of 24 percent on the crater walls of Aristarchus (Pohn and Wildey, 1970). The extremely wide range of albedos, 14 to 60 percent, is the greatest of any lunar landing area. The high values stem from the high resolution possible with lunar surface photography relative to that from a telescope.

\section{INTERPRETATIONS}

Units 1, 2, 3, and 4 on the albedo map can be clearly related to ejecta from identifiable craters. Unit 5 is traceable around isolated craters, forming a pattern radiating from South Ray and North Ray craters, and occurs as small diffuse irregular patches of probable ejecta. Albedo units 6 and 7 represent the more mature regolith surface where lighter subsurface materials have not been excavated or recycled to the surface for a long period of time.

The albedo map does not indicate any measurable differences between the optical properties of the regolith overlying the Cayley Formation and the regolith on Descartes materials of Stone and Smoky mountains. The range of albedo values over both areas is similar, suggesting that there is no significant difference in gross chemical composition of the regolith materials. Soil samples collected from both the Cayley Formation and Stone mountain are reportedly similar in chemical composition (LSPET, 1972) although their percentages of agglutinates, glasses, mineral, and lithic fragments vary. The regolith over the Apollo 16 area may be heterogeneous on a local scale; it becomes more homogeneous on a regional scale, presumably through the maturing action of the repetitive small cratering events. The chemical and optical properties of the more mature soil areas suggest that the regolith over the Cayley plains and Descartes mountains was derived from a similar suite of rocks.

Soil samples obtained from traverse stations consist of various mixtures of agglutinates, glassy fragments, light-colored lithic fragments, and dark lithic fragments (Heiken and others, 1973). As a soil "ages" or matures on the surface, it becomes darker, the agglutinate content increases, and the soil becomes finer grained (Adams and McCord, 1973). The soils from stations 4 and 5 are the darkest, having the highest agglutinate content and the smallest average grain size of the traverse stations. Lighter soils (stations 11 and subsurface 1) are coarsest, have a higher percentage of light-colored lithic fragments and the lowest percentage of agglutinates.

Soils at the other stations are intermediate between the lighter and darker soils and could be considered mixtures of the two types. The lighter soils at station 11 are immature soils of North Ray crater ejecta; samples of soils collected in areas of high-albedo ray patches (station 8, map unit 4) are not clearly derived from South Ray crater. The coarser fractions, lighter color, and lower proportion of agglutinates in the soils from stations 1,2, and 6 suggest the contamination, probably by South Ray fine-grained ejecta, of a more mature preexisting soil at these locations.

The combination of surface photographs, crew observations, soil samples, and albedo mapping from orbital pictures permits a detailed study of the character of recent ray ejecta and provides insights into the aging process of rays. The crew recognized discontinuous ray patches as concentrations of rock fragments on the surface along linear trends. Changes in albedo were not noticed near the edge of a ray patch, and no characteristic of the fine-grained regolith was described that could identify ray areas. The rock fragments in ray areas were mainly less than $5 \mathrm{~cm}$ across; they covered from less than 1 to as much as 7 percent of the surface area, with the most frequent size range comprising 2to 5-cm cobbles (Muehlberger and others, 1972). The interray and ray areas delineated on orbital photography generally appear to have similar fragment frequency in the high-resolution surface photograph although local ray segments identified on the surface are not necessarily visible on orbital photographs.

The lighter colored ray materials gradually darken, by an aging process that must be similar to regolith darkening, until their surfaces become indistinguishable from adjacent interray areas. The upper surface of ray material will darken with increase in agglutinate and reduction of the average grain size as well as by mixing with darker preray regolith, both laterally and from below. Gardening by numerous small impact cratering events has been estimated to take $10 \mathrm{~m} . \mathrm{y}$. to turn over the uppermost centimeter at least once (Gault and others, 1974). The occurrence of $2-3 \mathrm{~cm}$ of darker soil overlying lighter material at stations 1,2 , 6,11 , and 13 is reasonably consistent with a North Ray crater source 50 to 60 million years ago. South Ray 
crater fine-grained ejecta would be expected to show little aging in 2 to $4 \mathrm{~m} . \mathrm{y}$.

\section{POLARIMETRIC STUDIES}

The polarimetric properties of rocks and soils at North Ray crater were investigated to determine the degree and orientation of polarized light reflected from those materials in the north and northeast crater wall. Measurements of these properties help to establish the abundance of brecciated rocks and the lack of crystalline material at that location.

On the high-sun $\left(19^{\circ}\right.$ phase angle) Apollo 16 orbital pictures, individual rays from South Ray crater can be observed to extend at least $10 \mathrm{~km}$ northward, overlapping North Ray ejecta west and southeast of North Ray crater. Rays become slightly discontinuous about $3 \mathrm{~km}$ from South Ray crater. Rays extend eastward over Stone mountain as far as $7 \mathrm{~km}$ fromisouth Ray crater. Continuous ejecta and rays from North Ray crater appear to extend only $3 \mathrm{~km}$ and $5 \mathrm{~km}$, respectively. This more restricted distribution may result from the greater age of North Ray crater (50 m.y., Walton and others, 1973) compared with South Ray crater (2-4 m.y., McKay and Heiken, 1973) and consequently greater mixing and aging of the ray materials. North Ray crater excavated more than three times as much material as South Ray crater, and its ejecta must have been scattered over a significantly larger area than covered by the present distribution of visible South Ray crater ejecta. Most of the traverse area should have been nearly continuously covered by North Ray ejecta and ray materials. Lighter materials were observed 2 to $3 \mathrm{~cm}$ below a darker gray surface layer at many stations and may represent North Ray crater ejecta.

The rays are features that become more visible as the phase angle approaches zero (also referred to as the opposition effect), a property of fine-grained materials. Those rays that become most visible at opposition contain a higher proportion of light soil. Rock fragments show a Lambertian type reflectance, greatest relative to the fine-grained regolith at $30^{\circ}$ to $50^{\circ}$ phase angle. Surface fragments tend to reduce the overall opposition effect except where the fragments are covered by a dust layer. As described by Muehlberger and others (1972), rock-fragment concentrations are commonly similar in ray and interray areas; hence the light soils must be the controlling factor. Several areas of rock concentration were considered rays by the crew, but those areas do not exhibit consistently high albedo at low phase angles, indicating that light soil is not present (station 4 and 5 are examples). In one of the brightest areas crossed, Survey ridge, albedo 24 percent, as much as 7 percent of the surface is covered by fragments larger than $2 \mathrm{~cm}$ (Muehlberger and others, 1972; Schaber, this volume, fig. 2). A similar concentration of fragments occurred near station 5 , where the soil albedo was 14 percent compared with 24 percent at Survey ridge. The ray patterns are visible at low phase angles only because lighter colored fine-grained material occurs as ray material, with or without any concentration of rock fragments.

\section{PROCEDURES}

A polarizing filter attached to the lunar surface Hasselblad camera permitted measurement of the degree of polarization and the orientation of the plane of maximum polarization of light reflected from the lunar surface. Three photographs were needed, one each with the polarizing filter at the 0,45 , and $90^{\circ}$ positions. To obtain the data needed, overlapping photographs were taken at one filter position through a $120^{\circ}$ sector across North Ray crater from station 11 . The filter was then rotated to the second position and the sector rephotographed. This was repeated a third time in the final filter position. Differences in image intensity of the same image element or object in the three photographs are a function of the amount and orientation of the linear component of polarized reflected light from that object.

Three sets of polarization frames were selected for computer processing from the returned photographs: frames AS16-106-17239, 17241, 17257, 17259, 17266, and 17268 from the southwestern panoramic position at station 11, and frames AS16-106-17283, 17296, and 17310 from the northeastern panoramic position at station 11. The data for computer reduction were taken from second-generation master positives. The sets of photographs were digitized. and the frames filtered using a 3-by 3-pixel matrix to smooth the data. The first frame (horizontal polarization) became the prime photograph against which the remaining two were registered. Camera displacements between frames were sufficiently large to yield stereopairs from frames within a given set. Registration of stereopairs to pixel resolution is extremely difficult and requires lengthy computer processing. To reduce expensive computer time, a special set of positive transparency enlargements of the digitized photographs was made. The frames were then registered visually and displacement coordinates were determined for 70 to 80 points in each frame. These point displacements were used to compute linear interpolation of the displacement coordinates. This interpolation factor was applied to each photograph element. The registrations, while still imperfect, were within 5 pixels in the far field.

The three registered frames were used to compute 
the degree of polarization and the angle of its maximum. Following this calculation, a nine-gray-step conversion table was generated to illustrate areas of equivalent polarization in the three sets, one taken at high phase angle (shown in fig. 5). Polarization values on overlapping areas of the photograph sets are in relatively good agreement.

\section{OBSERVATIONS AND INTERPRETATIONS}

A comparison of the polarimetric functions of returned samples with those of rocks in accessible or remote areas permits some correlation and classification of materials at a distance. In the area of North Ray crater, for instance, such a study shows three polarimetrically distinct materials: (1) a region of regolith that covers Smoky mountain (area A, fig. 5A) and dark smooth material on the crater wall (area $\mathrm{B}$, fig. $5 A$ ), (2) blocky material on the crater wall (area C, fig. $5 A$ ), and (3) a region on the west wall of the crater (left side of pl. 8, pan 19) characterized by high albedo and by relatively high degree of polarization for that phase angle. It was found that individual rock fragments ranging in width from $25 \mathrm{~cm}$ in the foreground to $10 \mathrm{~m}$ on the northwest rim have low degrees of polarization. All rock fragments around North Ray crater show less than half the polarization measured on the Apollo 11

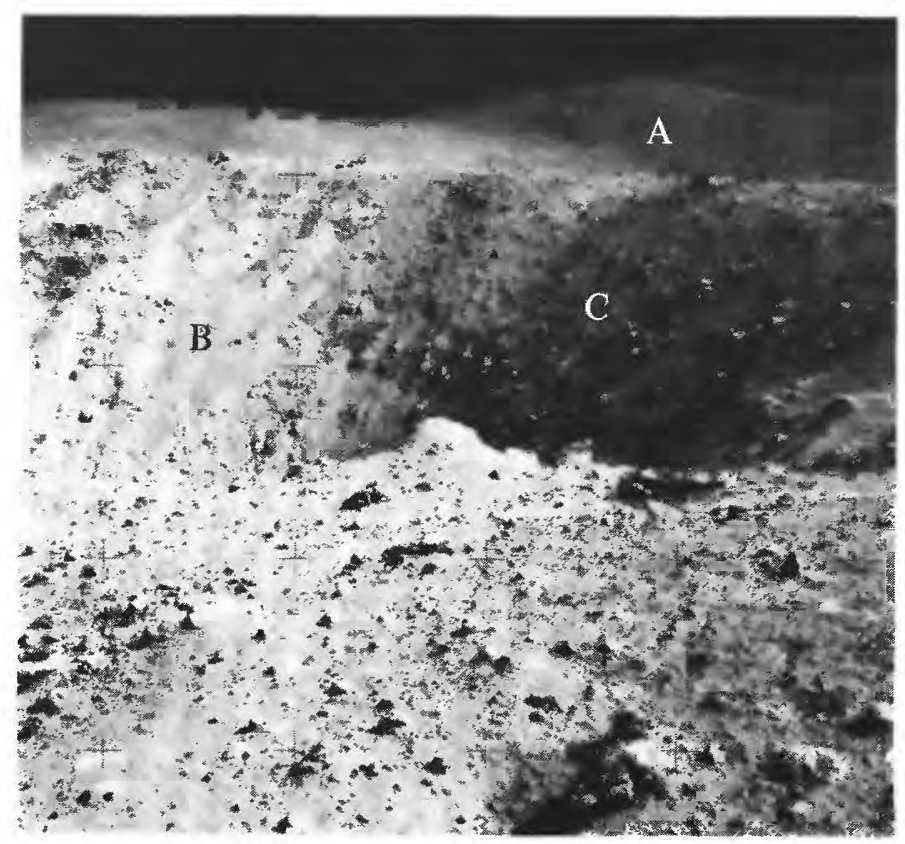

A and 12 crystalline rocks and one-half to two-thirds the polarization measured on Apollo 14 breccia samples 14305, 14311, and 14321 from the Fra Mauro region (Swann and others, 1978). The rock surfaces around North Ray crater apparently contain little crystalline material that can polarize reflected light.

\section{CONCLUSIONS}

A rather uniform upper-soil layer evolved over the Descartes landing area during its geologic history prior to the formation of North Ray crater. The soil matured (darkened) to a nearly uniform albedo of 12 to 14 percent over both the Cayley plains and the Descartes mountains. Because a similar-looking soil developed over both terrains, it seems probable that the subsurface material is of similar bulk composition.

The North Ray cratering event scattered predominantly light subsurface material (mostly as coarsegrained fragmental soil) over a large area, including most, if not all, of the traverse areas. Surficial processes aged the upper $2-3 \mathrm{~cm}$ of the widely dispersed
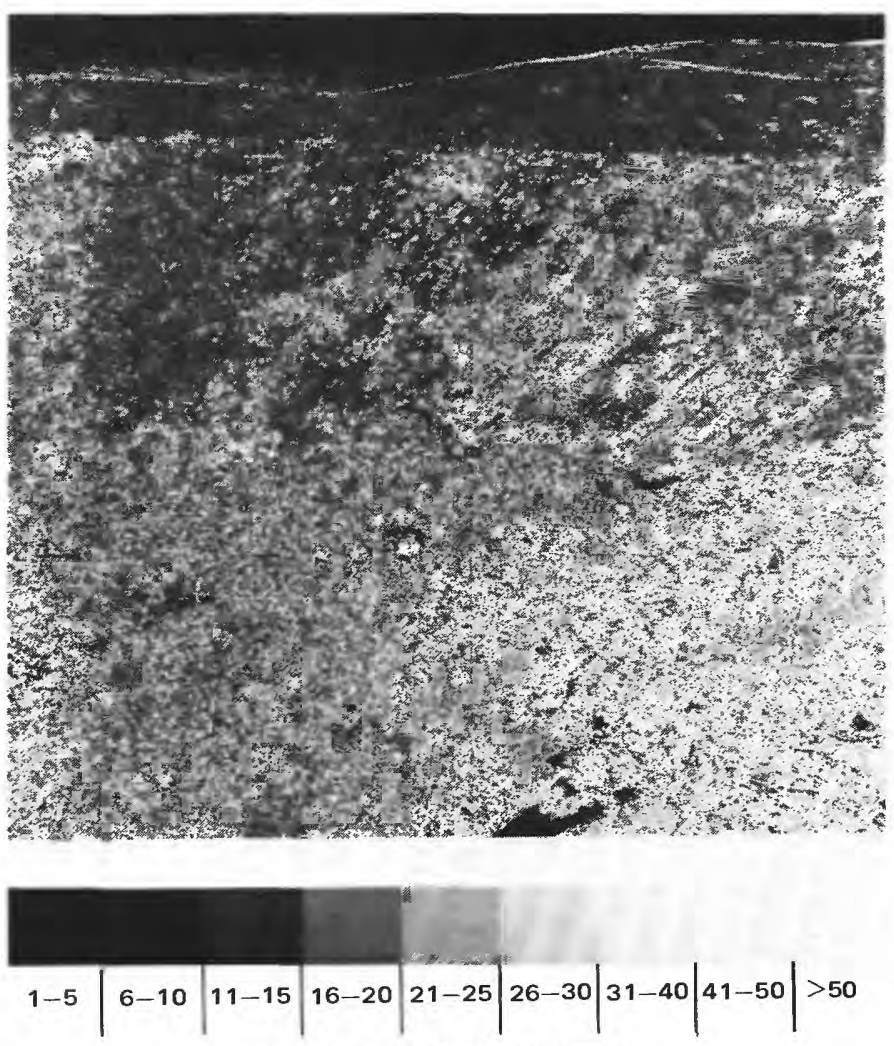

POLARIZATION, IN PERCENT

$B$

FIGURE 5.-Polarimetry of north wall and southeast rim (near field) of North Ray crater. $A$, One frame (AS16-106-17239) from the left polarization panorama. Filter oriented horizontally. This frame was the basis for registering the two additional filter positions. $B$, Computer printout of polarization data from the scene in $A$. Degree of polarization, divided into nine percentage ranges, is shown by gray scale. Apparent mean of polarization in this scene is 10 to 11 percent; maximum polarization approximately 30 percent on a few rocks. 
light fragmental soil, destroying the typical ray structure. Most of the continuous to discontinuous ray materials merged into a diffuse halo around North Ray crater having albedos of 25 to 30 percent on the rim deposits, decreasing outward to 16 to 18 percent as far as $8 \mathrm{~km}$ away.

The South Ray crater event, 2 to 4 million years ago, scattered light subsurface material over much of the traverse area. The light discontinuous patches of ray materials are visible, in the author's opinion, because of the light fine-grained component of the ejecta rather than the fragment population (2-7 percent of area) over the surface of a ray. The Baby Ray impact event scattered more light-colored subsurface material over distances of a few kilometers. The surficial gardening processes should have had little effect in altering or darkening ray materials from South Ray and Baby Ray craters. The surface albedo patterns over the Descartes area are produced by a combination of the older North Ray and the younger South Ray and Baby Ray ejecta deposits and the preexisting nearly uniform regolith surface. Bright, continuous-to-discontinuous ejecta (albedo units 1, 2, 3, and 4) cover 23 percent of the mapped area. More diffuse lightened regolith (unit 5) in patterns radial to North Ray and South Ray craters occupies more than 18 percent of the area and probably represents a mixture of light ejecta with preexisting regolith.

The rocky surfaces around North Ray crater rim and within the crater wall contain little crystalline material that can polarize reflected light. The polarimetric properties of these rocks suggest that they are much more highly shocked than the Fra Mauro breccias from Cone crater at the Apollo 14 site. No areas, layers, or blocks of intermediate to strong polarization such as would be expected for relatively unshocked basaltic crystalline rock were observed. On the basis of unpublished laboratory measurements on crushed anorthosite, all measurements at North Ray crater are consistent with the polarimetric properties of highly brecciated and shocked material of predominantly anorthositic composition. 


\section{MORPHOLOGY AND ORIGIN OF THE LANDSCAPE OF THE DESCARTES REGION}

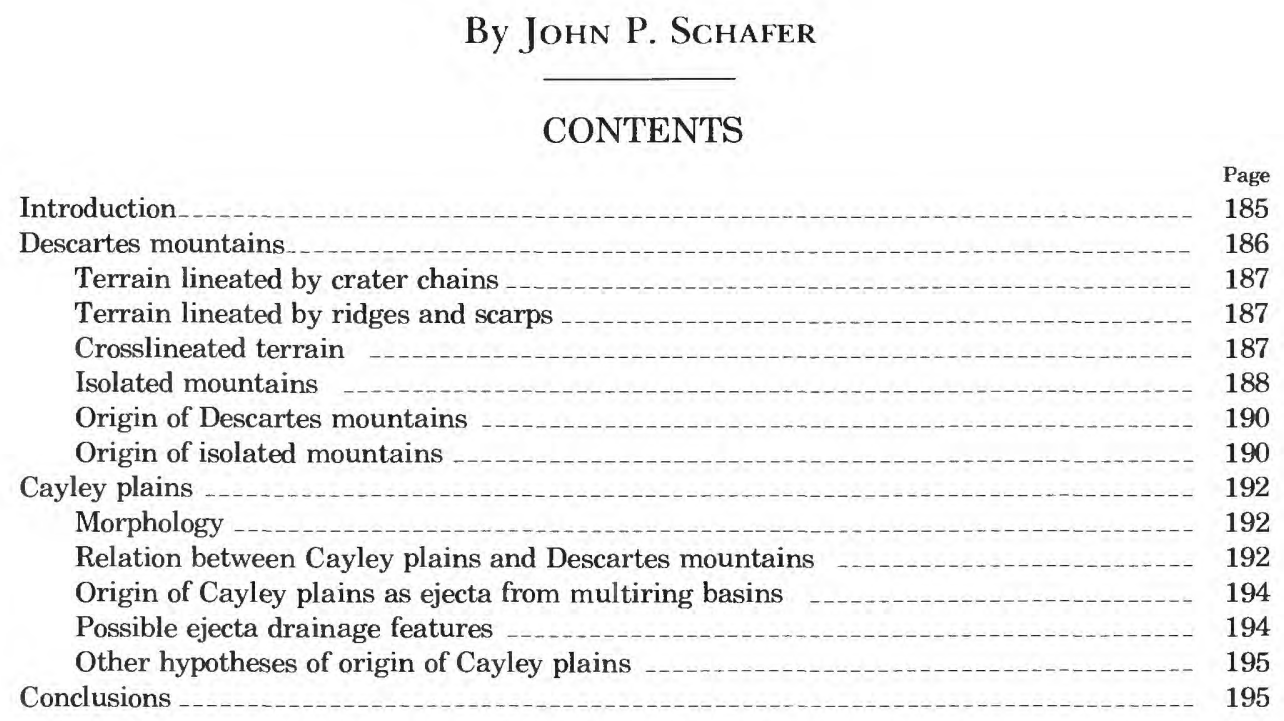

\section{ILLUSTRATIONS}

Figure 1. Orbital photograph of the Descartes region 186

2. Photograph of Apollo 16 landing site and vicinity - ... 188

3. Sketch map of morphologic features of Descartes region shown on figure 2

4. Oblique photograph of Descartes region showing Imbrium sculpture

5. Generalized topographic map of Cayley plain at and west of the Apollo 16 landing site

\section{INTRODUCTION}

The origin of the landscape and materials of the central lunar highlands has been a subject of discussion and disagreement since before the Apollo 16 mission. The dominant premission hypotheses of volcanic origin were contradicted by examination of the returned samples, mostly impact breccias. The materials have been reinterpreted as ejecta of local craters or of distant multiringed basins. The various hypotheses for origin of the geologic units are summarized by Hodges (this volume).

A credible hypothesis must explain not only the character of the materials but also the morphology of the landscape. This study of the surface morphology of the Descartes region (fig. 1) includes the mapping of certain features within an area of about $2,900 \mathrm{~km}^{2}$ (figs. 2 and 3 ) in order to determine constraints that the morphology may place upon genetic hypotheses for the region. Photogeologic interpretation of landforms produces inferences rather than certainties, and such interpretation has more bearing on some problems than on others. For example, interpretation of landforms may well reveal whether they are intrinsic to the ejecta believed to constitute the highlands or were imposed on those materials after their deposition. Such interpretation has little to say about how much of the ejecta was derived from primary impact craters or basins and how much was derived from mixing of local subjacent materials by secondary impacts. This study has been made within the framework of the geologic map of the region (pl.1), which includes topographic contours (interval $50 \mathrm{~m}$ ) for part of the area. Premission maps of the region (Milton, 1972; Hodges, 1972a; Elston and others, 1972b) show some of the morphologic features.

Topographic unconformities-breaks between landforms or groups of landforms-are critical in a morphologic study. They separate surfaces of different ages or of the same age but produced by different processes. The principal topographic unconformity in the Descartes region is that between the Descartes 


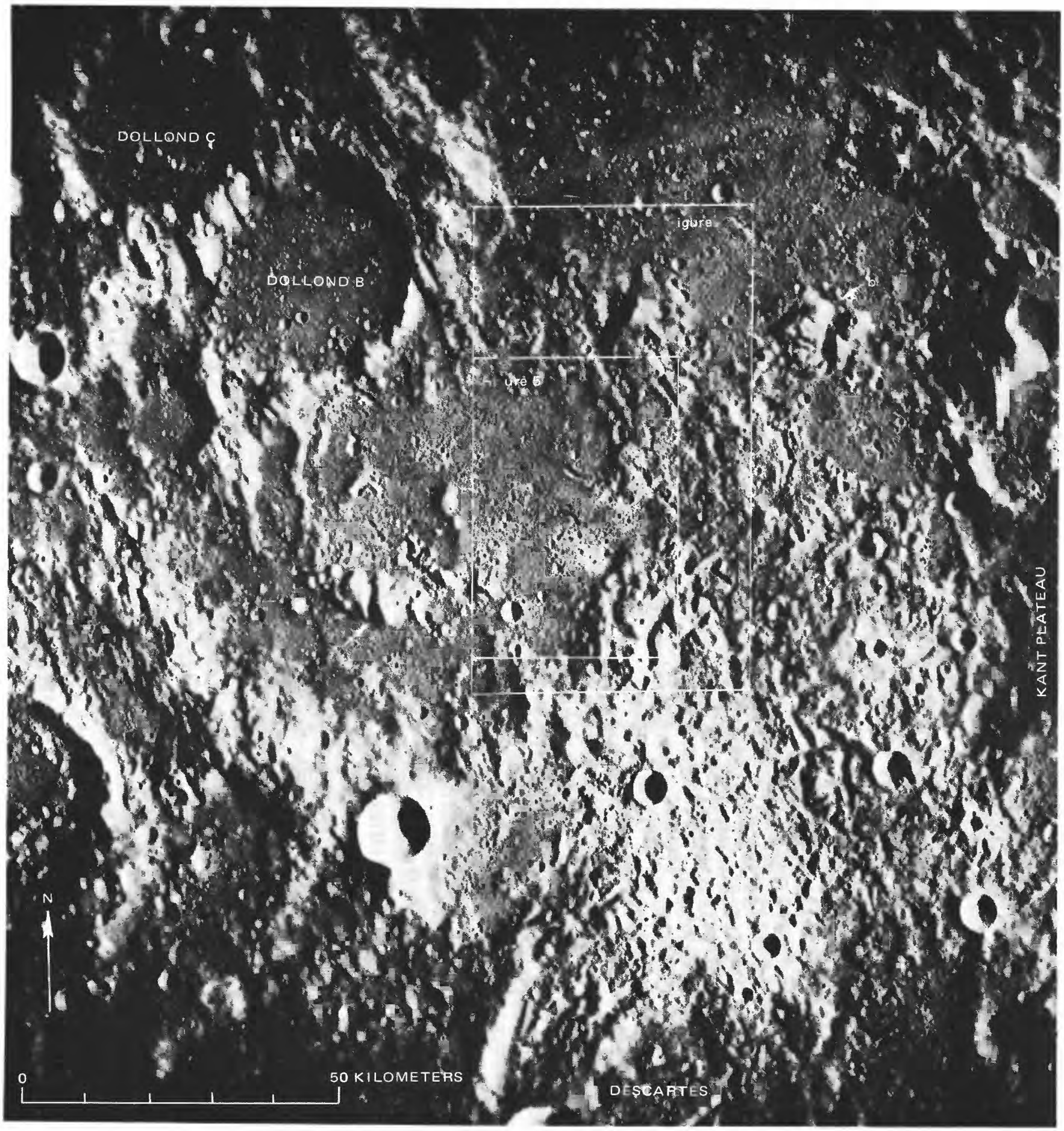

FIGURE 1.-Orbital photograph (Apollo 16 mapping camera frame 0440) of the Descartes region. Rectangles outline areas of figures 2, 3 , and 5 . Letters indicate localities referred to in text.

mountains and Cayley plains. The main problem is to determine how the landscape was differentiated into these rugged highlands and smooth plains.

\section{DESCARTES MOUNTAINS}

The highlands within and adjacent to the area of figures 2 and 3 contain terrains mainly of three aspects that are interrelated and intergradational: lineated by crater chains, lineated by ridges and scarps, and crosslineated. Small patches of knobby terrain occur within areas of other terrain types. Several isolated mountains of distinctive form and relief are mapped as a separate unit, probably Nectaris ejecta. 


\section{TERRAIN LINEATED BY CRATER CHAINS}

The terrain in the east-central part of the area, east of Stone and Smoky mountains and extending northwest beyond the mapped area, is characterized by chains and irregular groups of craters. Most of these craters are 0.7 to $2.0 \mathrm{~km}$ in diameter. All show greater degradation than do the younger, sharper craters shown on the geologic map (pl. 1) by Hodges as Imbrian, Eratosthenian, or Copernican in age. All such younger craters, except North Ray and South Ray, are omitted from the sketch map (fig. 3).

The crater chains have an average trend of northnorthwest. Some, such as the chain at A on the sketch map (fig. 3), $14 \mathrm{~km}$ long and made up of at least 13 craters, are notably sinuous. The longest crater lineament in this area, and the most conspicuous on the photographs, is that extending from $\mathrm{B}$ to $\mathrm{C}$ (fig. 3), a distance of $27 \mathrm{~km}$. This lineament, however, is a composite feature, consisting of three separate crater chains, connected fortuitously at D by a pair of younger craters (mapped on pl. 1 by Hodges, as Copernican secondary craters, perhaps satellitic to Theophilus) and at $\mathrm{E}$ by a broad depression of uncertain origin. The relatively deep, steep-walled, sharp-rimmed trough at $\mathrm{F}$ (fig. 3 ) has a slightly beaded shape in plan view, and an identifiable crater at each end, is parallel to nearby chains, and is very similar to the more closely spaced sections of other chains (as at A). Such troughs are inferred to result from very closely spaced craters. Sharp narrow creases at the junction of opposing slopes occur in a few places, generally in deep crater chains or troughs.

The upland surface between mapped craters is undulating to hilly and ridged. One of the largest remnants of this surface is the undulating plateau on the southwest side of the trough at F (fig. 3). The highland salient at B (fig. 3) is the north end of a broad ridge, considerably obscured by craters, that appears to extend south-southeast to Smoky mountain. Such ridges are roughly parallel to the crater chains.

The Cayley plains embayment in which Apollo 16 landed is continuous eastward with a conspicuous topographic sag in the highlands. Within that sag, somewhat degraded craters such as those that form the crater chains in the adjacent areas to the north and south are notably absent.

\section{TERRAIN LINEATED BY RIDGES AND SCARPS}

Ridges and scarps are conspicuous in a belt that extends from about $20 \mathrm{~km}$ north of Smoky mountain to at least $25 \mathrm{~km}$ south of Stone mountain and includes those mountains; terrain of this type is extensive to the southwest and west outside the area of figure 3 . The belt forms the high west margin of the Descartes mountains that overlooks the adjacent Cayley plains and the Apollo 16 site. It includes west-facing scarps, apparently somewhat degraded by colluviation, such as the high west slope of Smoky mountain (G, fig. 3) and the smaller scarp that crosses the top of Stone mountain (H, fig. 3). Low sinuous ridges lie at the foot of the highland slope at $J$ and $K$ (fig. 3). The Cayley plains embayment in which Apollo 16 landed separates the belt into north and south segments.

The mountain tops stand about $500-600 \mathrm{~m}$ above the Cayley plains; relief within the mountains generally does not exceed 200-300 m. Although some craters are present, chains of them do not constitute the dominant landform as in the terrain to the east and north. The most conspicuous landforms here are the somewhat sinuous ridges (fig. 1) that trend north to northnorthwest. The furrows between them are mostly shaped by intersection of the side slopes of the ridges and lack the series of bowl-shaped concavities of the crater chains. The walls of the furrows, unlike the walls of eraters, do not meet remnants of upland surface with topographic unconformity; rather, the slopes are continuously convex over the crests of ridges.

Patches of knobby terrain showing few or no lineations are dominated by subcircular, smoothly convex knobs, 1.0 to $2.5 \mathrm{~km}$ in diameter and about 50 to $200 \mathrm{~m}$ high. A group of three knobs occurs at L (fig. 3), just southeast of Stone mountain; others in and just beyond the southwest corner of the area of figure 3; outside the area, similar knobs occur in the terrain lineated by ridges and scarps and in other terrain units.

\section{CROSSLINEATED TERRAIN}

A large area southeast of the Apollo 16 site, of which only a small part appears in the southeast corner of figures 2 and 3 , shows two sets of directional features: one of crater chains, ridges, and noncratered furrows that trend northwest to north as in other parts of the highlands; one of features that trend northeast to north-northeast. The intersection of these transverse sets produces a crosshatched, blocky landscape.

The conspicuous northwest boundary of this crosslineated terrain is a northeast-trending, southeast-facing scarp. The well-preserved straight segments of the scarp at $M$ and $N$ (fig. 3) are sharp at both crest and base; between these segments, the scarp is obscured by a cluster of craters younger than the scarp. The sharpness with which the scarp cuts across ridges, furrows, and craters shows that it postdates many of these morphologic features. The scarp segment at $\mathrm{N}$ curves into, and appears to be continuous with, the west wall of the north-south trough at P (fig. 3 ), whose beaded shape indicates that it is a chain of closely spaced craters. This apparent continuity may be only fortuitous, as the boundary of the crosslineated 
terrain appears to continue southwest as a low, straight ridge at $\mathrm{Q}$ (fig. 3; not easily visible on fig. 2). This ridge, at most a few tens of meters high, is directly on line with the crest of the scarp and is connected with it by an albedo boundary (lighter material southeast of the line). Southwest of the ridge at $\mathrm{Q}$, the position of the terrain boundary is not clearly shown.

\section{ISOLATED MOUNTAINS}

Certain isolated mountains standing above their

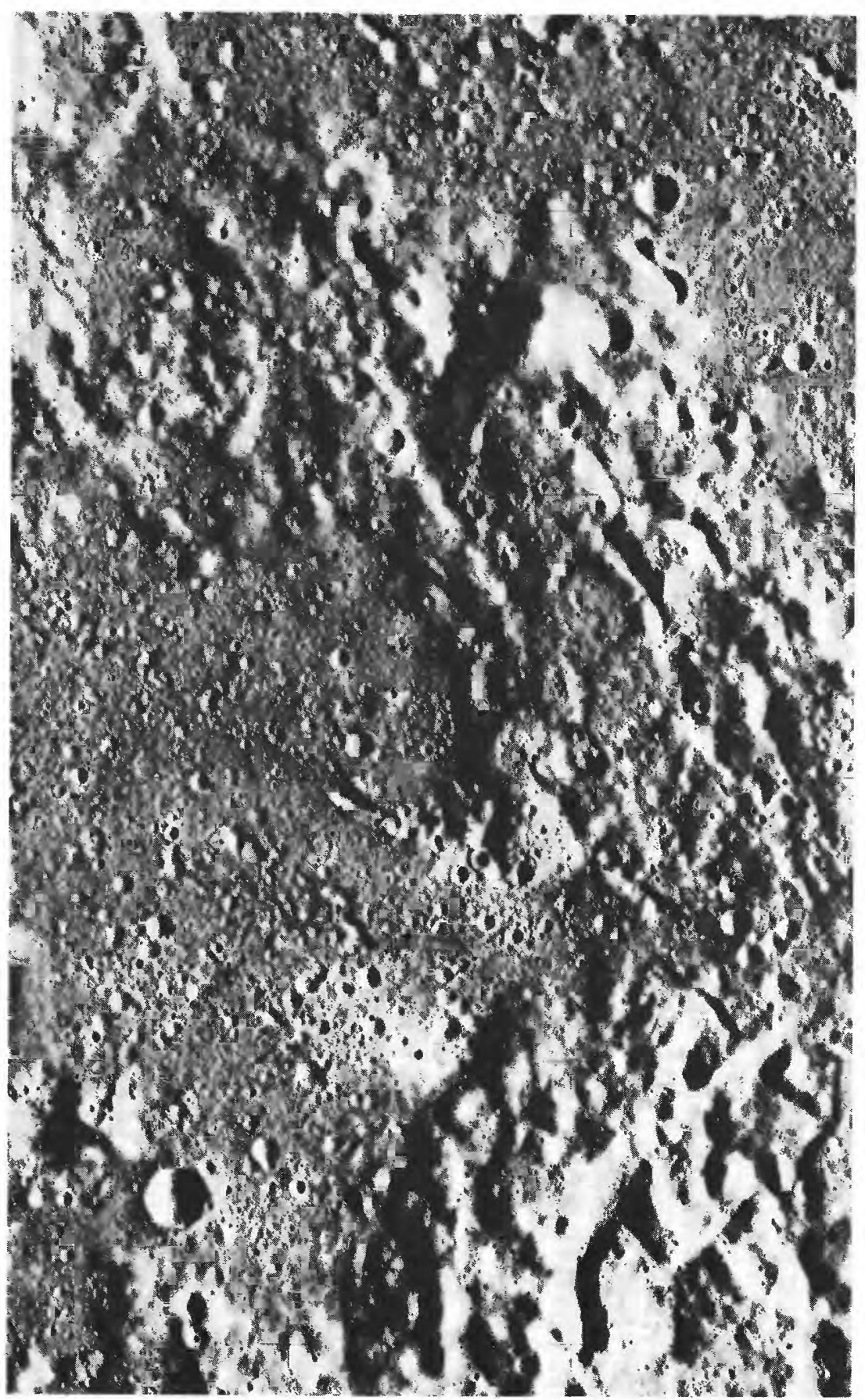

O 5 TO KILOMETERS

FIgURE 2.-Orbital photograph of Apollo 16 landing site and vicinity. Apollo 16 mapping camera frame 0440; photographic base for figure 3 . 
surroundings have been identified as terrain probably different from the rest of the Descartes mountains (Hodges, this volume, pl. 1; Elston and others, 1972b). They commonly have a distinctive, roughly trapezoidal form produced by relatively straight scarps on one or more sides; some of the mountains are cut across by straight troughs. Some of these blocky mountains appear to be tilted. Only two occur within the area of

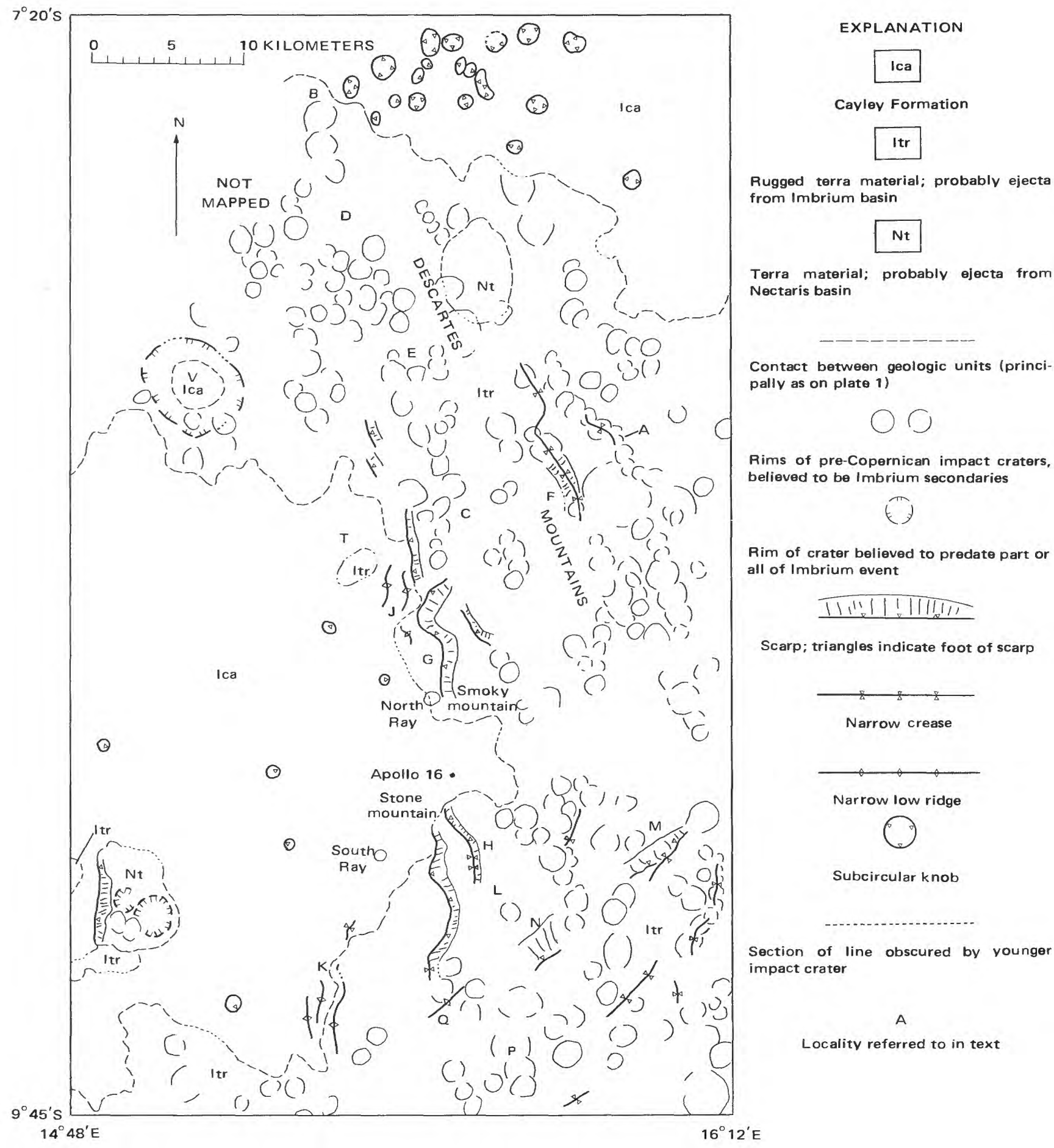

FIGURE 3.-Sketch map of morphologic features of Apollo 16 landing site vicinity. Derived principally from study of three stereopairs: Apollo 16 mapping camera frames 0439 and 0441, 1265 and 1266, 2179 and 2180. Area and scale same as figure 2 . 
figure 3 (shown as map unit Nt), others lie just outside that area.

The isolated mountain in the southwest part of the area of figure 3 stands about $500 \mathrm{~m}$ above the surrounding Cayley plain; its west side is a steep, straight scarp. A larger massif of this terrain lies $7 \mathrm{~km}$ to the west (a, fig. 1). Two shallow, saucer-shaped depressions on this mountain are tentatively interpreted as degraded craters older than other craters shown on the map (fig. 3).

The isolated mountain (map unit Nt) in the northcentral part of the area of figure 3 stands well above the surrounding Descartes mountains and has a generally smooth surface, without the rough texture and numerous craters of the highlands. A larger massif of this terrain lies $20 \mathrm{~km}$ to the east (b, fig. 1) and appears to be an outlier of the Kant plateau.

\section{ORIGIN OF DESCARTES MOUNTAINS}

The most conspicuous feature of the landscape of the Descartes mountains is the north to northwest lineation that pervades the terrains lineated by crater chains and by ridges and scarps and continues southward as one of the two sets of features of the crosslineated terrain. Extensive areas of such lineation, radial to the Imbrium basin, occur to the west and northwest, and are designated Imbrium sculpture (pl. 12). This similarity has led to general agreement among the authors in this volume that the lineation is Imbrium sculpture related to the impact event that formed the Imbrium basin.

Within the terrain lineated by Imbrium sculpture, the chains of craters are most likely erosional effects of secondary impacts. The craters mapped on figure 3 show only a moderate range of degradation, likely explained as the result of different degrees of mantling of secondary craters by ejesta from other secondary craters or by primary ejecta.

The origin of the terrain lineated by ridges and scarps is not so obvious. The furrows between the ridges show no indication of being crater chains. Some furrows in Imbrium sculpture have been suggested to be endogenetic in origin: fractures, perhaps with some accompanying volcanic activity, produced by the shock of the Imbrium impact (for instance, Scott, 1972; other references in Howard and others, 1974, p. 323). The furfurrows in this area, however, do not match Scott's criteria for volcano-tectonic origin; they are sinuous and lack the linearity expected of fractures and are mostly shaped by the intersection of the convex slopes of the ridges. I therefore infer a depositional origin for the ridges and that the furrows are the concavities between adjacent ridges. Such depositional ridge-andfurrow terrain may be compared to the radially lineated and braided part of the Hevelius Formation, the ejecta blanket of the Orientale basin (Moore and others, 1974, p. 75; Howard and others, 1974, p. 312), or to similar terrain in the Fra Mauro Formation, the ejecta blanket of the Imbrium basin (Hodges and others, 1973, p. 21).

Some sharp creases and scarp crests that occur in the Imbrium sculpture appear much fresher than other features of the Imbrium landscape, yet their orientations show that they are part of that landscape. Most of these sharp features are at the tops or bottoms of steep high slopes and probably owe their apparent freshness to the still rapid colluviation of the slopes. The crests are still being undercut, and the creases are being maintained by continued intergrowth of colluvium from facing slopes. The less rapid colluviation on lower, gentler slopes has permitted the rounding of scarp crests and creases.

The position of the Descartes mountains just outside the third (main) ring of the Nectaris basin has led to the suggestion that the mountains are dominantly a blanket of Nectaris ejecta and that Imbrium sculpture was superposed on it, mainly by erosion by primary projectiles from Imbrium, with little actual addition of Imbrium ejecta deposits (Wilhelms, 1972a; Head, 1974, p. 83). I believe, however, that the morphologic features of the area support the interpretation that the Imbrium sculpture of the Descartes mountains is intrinsic to the materials of which the mountains are formed and that they are therefore part of the ejecta blanket deposited during the Imbrium event. The evidence is: (1) The ridge-and-furrow morphology of at least part of the mountains, as discussed here, indicates a depositional rather than erosional origin. (2) On a larger scale, there are broad ridges within the mountains, such as that which extends from B (fig. 3) south-southeast to Smoky mountain. The Imbrium sculpture of such ridges is parallel to them, indicating that both features were formed at the same time. (3) The main part of the mountains as a whole forms a belt parallel to the Imbrium sculpture, between the west foot of the Kant plateau and the scarp along the west side of the Smoky mountain-Stone mountain belt (fig. 4). (4) The southward extension of the furrowed highlands into Descartes crater, through the northeast wall of the crater, has the form of a compound tongue extending south-southeast, with internal lineaments in the same direction (figs. 1 and 4; Hodges and Muehlberger, this volume, fig. 6). This is parallel to the Imbrium sculpture but more than $100^{\circ}$ from a radial to the center of the Nectaris basin. Thus the large forms and the detailed features of the highlands are congruent, indicating that they were formed in a single event. This corroborates similar conclusions reached 


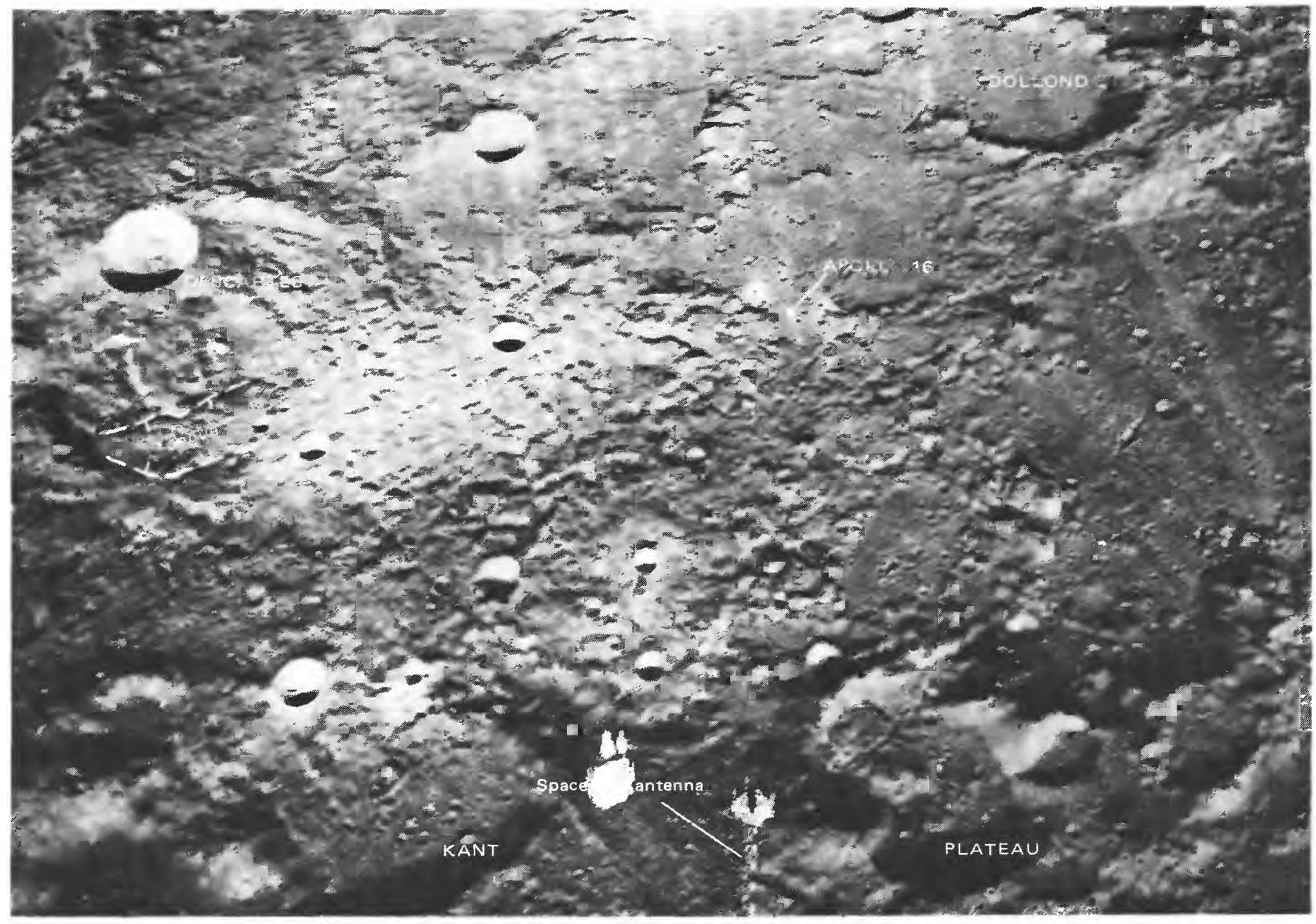

Figure 4.-Westward-looking oblique view of Descartes region from orbit, showing Descartes mountains with furrowed patterns parallel to Imbrium sculpture. Apollo 16 mapping camera frame 0556.

by Moore and others (1974, p. 94) and Hodges and Muehlberger (this volume).

The crosslineated topography, with its two sets of intersecting lineaments, poses a more complicated problem. The data within the study area are compatible with the conclusions of Hodges and Muehlberger (this volume, fig. 6) that the doubly lineated terrain "may have been caused by a surge of ejecta up the flanks of the Kant plateau and subsequent deflection southwestward." Within the area of figure 3, the southwest-trending scarp at $\mathrm{M}$ to $\mathrm{N}$ appears to cut across some southeast features and is interrupted between $\mathrm{M}$ and $\mathrm{N}$ by a south-southeast-trending crater chain. This overlap of features presumably all developed in a very brief period of time during the Imbrium event. If these two sets of lineations are the erosional and depositional results of movement of ejecta in two directions, then this is adequate to explain the morphology, making comparisons with deceleration dunes (Moore and others, 1974, p. 79; Hodges and Muehlberger, this volume) unnecessary.

The west-facing scarps along the Smoky mountainStone mountain belt are possibly fault scarps. Their concentration along the generally steep west face of the highlands indicates that they may be near-surface gravity-controlled features. One possible fault block includes the ridge in which North Ray crater was excavated (Ulrich, 1973, fig. 5). All are considerably degraded and may well have formed during or immediately following the Imbrium impact. The sinuous narrow ridges along the foot of the highland slope ( $\mathrm{J}$ and K, fig. 3) might also have resulted from gravity collapse.

\section{ORIGIN OF ISOLATED MOUNTAINS}

The two isolated mountains within the area of figure 3 are identified mainly by comparison with better examples just outside that area. The massifs westsouthwest of the Apollo 16 site (a, fig. 1; southwest part 
of fig. 3) are very similar in form to part of the rim of Dollond B, which is interpreted as a Nectarian crater that has been sculptured and partly buried by Imbrium ejecta (pl. 1). The massifs northeast (and north) of the site (b, fig. 1; north-central part of fig. 3) are, in both position and morphology, outliers of the Kant plateau, a part of the third ring of the Nectaris basin. The isolated mountains are therefore tentatively inferred to be Nectarian materials projecting through the mantle of Imbrium ejecta, themselves bearing at most a thin mantle of such ejecta (pl. 1). The blocky forms may result from faulting caused by the Imbrium impact.

\section{GAYLEY PLAINS} MORPHOLOGY

The Cayley plains in the central lunar highlands, as elsewhere, are most strikingly characterized by their "ponded" appearance and by the sparsity or absence of lineaments except for chains of impact craters of Copernican age. The following description of Cayley refers almost entirely to the plain on which Apollo 16 landed; other plains nearby have similar characteristics.

A map of the east half of the landing-site plain (fig. 5) shows smoothed contours produced by eliminating, as far as possible, younger impact craters. The surface thus delineated is very smooth, having, in most parts, only gentle undulations. The total relief in this area of about 25 by $38 \mathrm{~km}$ is about $400 \mathrm{~m}$. The principal feature of the surface is the slope eastward and southeastward to an enclosed depression north of South Ray crater. The slopes between the $8,000-\mathrm{m}$ contour near the west edge of the map and the 7,750-m contour in the depression are about $15 \mathrm{~m} / \mathrm{km}$ west from the depression and $10 \mathrm{~m} / \mathrm{km}$ northwest from the depression (17 $\mathrm{m} / \mathrm{km}$ is $1^{\circ}$ ). These slopes are comparable to those of mare basalts at the margin of Mare Serenitatis (Muehlberger, 1974, p. 104), interpreted as the results of initial flow gradients and gentle tectonic tilting. If this general slope results partly from tilt of the stereoscopic model (compare Eggleton and Schaber, 1972, p. 29-8), the actual slope is even less.

\section{RELATION BETWEEN CAYLEY PLAINS AND DESCARTES MOUNTAINS}

Parts of the contact between plains and mountains are not sharp and are difficult to map, particularly at large scale. The gradational zone between the two types of landscape commonly shows the numerous small craters and even texture characteristic of the Cayley, together with the more irregular relief and variable texture of low parts of the highlands.

Where the highland surface descends abruptly to the plain, as along many parts of the Smoky mountainStone mountain belt, the zone of uncertainty of the contact is narrow, commonly less than $0.3 \mathrm{~km}$. This minimal width of the zone probably represents colluvium at the angle between plain and highland. No features as much as $1 \mathrm{~km}$ wide on the map are identified as colluvial deposits.

Where the highland surface descends more gently to the plain, the zone of uncertainty of the contact is wide, more than $2 \mathrm{~km}$ at $\mathrm{S}$ (fig. 5). The uncertainty is mainly the result of the slight difference between gentle slope and plain; such an originally gentle slope is unlikely to have accumulated great amounts of colluvium. Several broad low hills in the adjacent northeast part of the Cayley plain are shown by the contours of figure 5 . Only one of these hills was mapped as a projecting hill of highland material (pl. 1; T, figs. 3 and 5); others are almost as conspicuous. This somewhat subdued hilly topography evidently represents a continuation of highland materials form the north, probably thinly and discontinuously covered by Cayley.

Certain features along the west side of the Smoky mountain-Stone mountain belt that may have resulted from slumping, probably during or immediately following the Imbrium event, appear to be overlapped by Cayley. The scarps on the west side of Stone mountain decline northward and disappear at the contact. The scarp $10 \mathrm{~km}$ north of North Ray crater lies in part directly along the contact, as if the possibly down-dropped block on the west side of the scarp were tilted southward and partly covered by Cayley. Some low hills below the contact (as at U, fig. 5) may be either depositional hills of highland materials or collapse blocks mantled by Cayley. The narrow ridges at $\mathrm{J}$ and $\mathrm{K}$ (fig. 3), whether depositional or collapse features, are recognizable not only on the lower slopes of the highlands but also within the edge of the Cayley, where they are shown by the contours ( $J$ and $K$, fig. 5) to have a relief of a few tens of meters at most.

The features described here show that highlands landforms appear on the adjacent plain in several different settings; that farther out on the plain the forms are more subdued because of filling of the swales between them by Cayley material; and that postImbrium colluvium is recognizable only as a minor feature at the scale of figure 3.

These observations support the conclusions that (1) the Descartes mountains terrain extends beneath the Cayley plains; (2) the Cayley plains are formed by a basin fill that is thick enough in some places to conceal completely the rugged topography of the mountain materials but thin enough in at least some marginal areas to reveal a subdued and mantled mountain terrain; and (3) the gradational character of the contact be- 


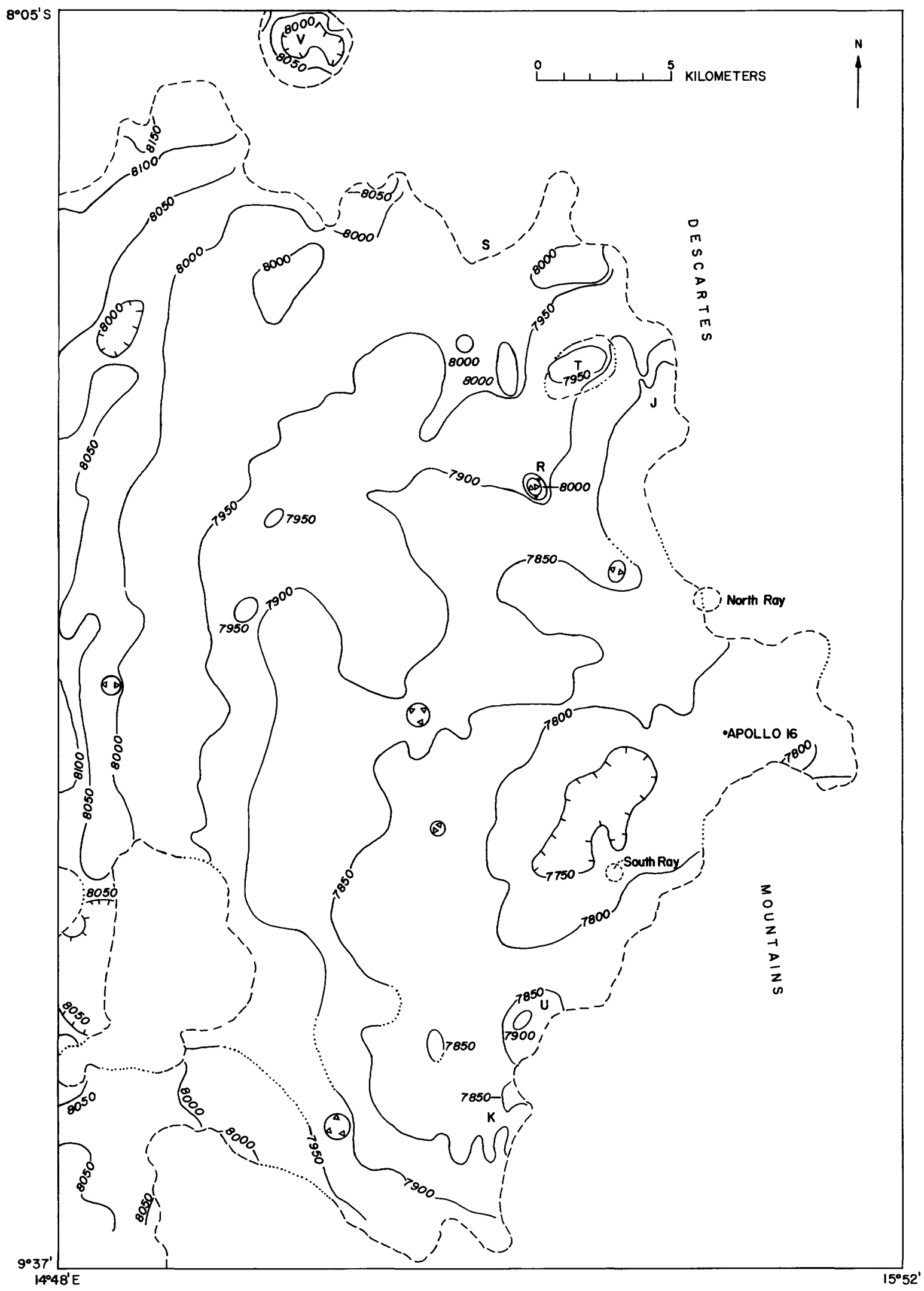

FIGURE 5.-Generalized topographic map of Cayley plain near the Apollo 16 landing site. Contours derived from topographic map of plate 1; smoothed in an attempt to eliminate effects of later impact cratering and to restore approximately the original depositional surface. Contour interval, $50 \mathrm{~m}$. Dashed line, boundary of Cayley plains; dotted where obscured. See figure 3 for explanation of other symbols. 
tween plains and mountains is mostly the result of the overlapping of Cayley fill on the edge of the mountains rather than concealment of the contact with colluvium. None of the gradational character of the morphologic contact is attributed to actual intergradation of the two deposits.

The features on the Cayley plains mapped as subcircular knobs are small domical or conical hills, 0.7 to 1.5 $\mathrm{km}$ in diameter, which occur in groups (north part of fig. 3) or singly. In as much as most of those within the area of the 50-m contours are shown by only one contour, their exact heights are not known. However, the knob at R (fig. 5) is more than $100 \mathrm{~m}$ high. Only those knobs that are clearly distinct from crater rim segments are sketched on figures 3 and 5. The knobs are much sharper in form than the summits of almost all hills in the uplands except for some knobs scattered among larger hills. They occur both near the margin and in the middle of plains, where the Cayley fill may be inferred to be much thicker. Partial submergence of mountain terrain by Cayley fill would seem unlikely to produce such small, sharp knobs scattered across a plain, and I infer that the knobs are not the summits of partly buried hills rising from beneath Cayley. It is possible that such knobs "may be constructional landforms intrinsic to the Cayley Formation," formed by emission of fragmental or fluid material from the Cayley itself (Eggleton and Schaber, 1972, p. 29-8, 29-15).

\section{ORIGIN OF CAYLEY PLAINS AS EJECTA FROM MULTIRING BASINS}

The discovery that the Cayley plains samples at the Apollo 16 site were mostly breccias led to a reevaluation of the possibility that the plains materials were ejecta from one or more multiring basins (Eggleton and Schaber, 1972) and specifically to the concept that the Cayley Formation was transported as fluidized Imbrium ejecta and deposited in lowlands. The ponded character of the Cayley fill certainly demonstrates that at the time of deposition it was much more mobile than the material that became the mountains, perhaps because of higher proportions of impact melt and finely crushed material. The marginal relations between these terrains and the complete absence of Imbriumlineated morphology on the Cayley surface demonstrate that at least the upper part of the fill is younger (if only by minutes) than the mountain materials (or than the Imbrium sculpture of those materials).

The most critical observation to explain is the concentration of the Cayley in large depressions. Deposition of relatively mobile ejecta in thicknesses sufficient to conceal completely the morphology of the buried mountains under present Cayley plains must have been accompanied by at least fleeting emplacement of substantial amounts of such ejecta over the rest of the mountains. If a proposed Orientale contribution alone were "several hundred meters" thick (Boyce and others, 1974 , p. 21), this would require the draining of much of the material off the mountains to avoid the widespread concealing of the Imbrium morphology. Most of that morphology has a local relief of only a few hundred meters, and many of the Imbrium secondary craters are only $100-300 \mathrm{~m}$ deep. Even if much of the mobile ejecta drained off open slopes and out of swales onto a Cayley plain, many craters and troughs would have been subdued or actually filled. A lesser thickness of this superposed ejecta layer, say the "local thicknesses of 50 to $100 \mathrm{~m}$ or more" of Hodges, Muehlberger, and Ulrich (1973, p. 19), veneering an existing plain of Imbrium origin, would pose a lesser morphologic problem. Despite this unresolved difficulty, the general hypothesis of origin of the Cayley from large-basin impact processes faces fewer morphologic problems than any of the others discussed below and appears to be the most likely one at present. A plains facies of Orientale basin ejecta has been clearly identified around Orientale (Chao and others, 1975 , p. 384), and such a facies most likely accompanied Imbrium basin ejecta too.

\section{POSSIBLE EJECTA DRAINAGE FEATURES}

Several features in the area are consistent with a hypothesis of drainage of mobile ejecta from higher to lower ground. Mantling of a crater 5.5-7 km in diameter at $\mathrm{V}$ (figs. 3 and 5 ) by the highlands material indicates that the crater predates part or all of the Imbrium ejecta. The crater is mapped as containing a "puddle" of Cayley $3.5 \mathrm{~km}$ in diameter whose saucershaped surface has a relief of about $100 \mathrm{~m}$ and is at about the same elevation as the Cayley plain $4 \mathrm{~km}$ to the south. Unlike the many craters less than $3 \mathrm{~km}$ in diameter, this crater was large enough to accumulate its own pool of mappable Cayley.

The topographic sag in the highlands east of the Apollo 16 site contains many relatively young craters, including some Copernican secondaries; the surface between them has a smooth Cayley-like texture, particularly in the west part of the sag, and an undulating topography. Various maps of the area (for example, fig. 3; Milton, 1972; Hodges, 1972a; Elston and others, 1972b) have put the contact between Cayley plains and Descartes mountains at approximately the same place, where undulations not characteristic of Cayley become conspicuous. Chains of Imbrium secondary craters occur immediately to the north and south and must 
have continued across the sag but are now absent from an area $4-5 \mathrm{~km}$ wide. The drainage of mobile ejecta into the sag from slopes no more than a few kilometers long may have obscured any Imbrium secondary craters once present but did not sufficiently conceal the rest of the surface to make it mappable as Cayley. The general absence of Imbrium secondary craters on the lower slopes of the mountains, along the contact with Cayley, may also be the result of ejecta drainage from mountains toward plains.

The small plateau on the west side of the trough at $\mathrm{F}$ (fig. 3) has very low relief, comparable to much of the Cayley, but a less regular texture, and is clearly part of the mountains rather than the Cayley plains. The slopes draining to this plateau were evidently of too small extent for a recognizable amount of Cayley-type material to accumulate on the plateau.

\section{OTHER HYPOTHESES OF ORIGIN OF CAYLEY PLAINS}

Another hypothesis of origin of the Cayley Formation suggests that the plains materials gradually "were emplaced as ejecta of secondary craters made by impact of fragments ejected from many distant craters and basins and as a result of deposition and secondary cratering by material ejected from nearby highland primary craters" (Oberbeck and others, 1974a, p. 112; see also Oberbeck and others, 1975). Like the multiringbasin ejecta hypothesis, this hypothesis is constrained by the difficulty that ejecta fall on highlands and lowlands alike. Secondary ejecta, furthermore, is likelier to contain smaller proportions of impact melt and finely crushed material than is the ejecta of multiring basins and therefore to be less mobile and less capable of draining off highlands onto plains. The primary and secondary craters in the region that are younger than the Imbrium secondary craters of the Descartes mountains seem too few and too small to produce the plains by this process, but that aspect deserves quantitative study. For the concentration of material in lowlands, this hypothesis appears to rely mainly on the gravity descent of material loosened by impact on crater rims and on landslides. These processes are not likely to be adequate for deposition of plains material in an extensive lowland such as that at the Apollo 16 site, where: much of the highland margin is rather gently sloping; there is little evidence of landsliding, as discussed above; and some of the higher parts of the plains surface (as at the left edge of fig. 5) occur around isolated peaks that could not supply enough material to build up those parts. It seems likely that colluviation from the side walls of depressions smaller than that at $\mathrm{V}$ (figs. 3 and5) may actually encroach on and eventu- ally conceal tiny puddles of Cayley fill, thereby producing a lower limit of area of mappable Cayley. Cratering (both primary and secondary) on the Cayley itself probably maintains some relief rather than act as an agent of smoothing.

Crater fallback material as a source of Cayley was emphasized by Head (1974, p. 91), who stated that "Cayley plains in the Apollo 16 landing site area probably owe much of their original smoothness to the relatively smooth fallback deposits formed during the unnamed crater B events." Distinctive Descartes mountains materials, however, drape the rim of this crater and descend into it, disappearing beneath the Cayley fill. Thus the crater is older than the Descartes mountains mass, which therefore covers any fallback material of the crater.

A "liquefaction" hypothesis for the origin of both Cayley plains and maria has been proposed by Bastin (1974), who suggested that at times of high nearsurface temperatures, low areas on the Moon's surface, though not liquid, had a sufficiently low viscosity for the surfaces to relax more or less completely, becoming level. The relations in this area where the Cayley materials bury and lap up onto the margins of the mountains clearly do not fit that hypothesis.

\section{CONCLUSIONS}

From study of the morphologic features of the Descartes region, the following conclusions can be drawn:

1. The lineated terrain types of the Descartes mountains include both erosional (secondary cratering) and probably depositional features (ridges).

2. The trends of these forms show that they originated in the direction of the Imbrium basin.

3 . The congruence between the terrain features and the overall shape of the Descartes mountains supports the hypothesis that the mass as a whole is a tongue of Imbrium basin ejecta.

4. The morphology of the crosslineated part of the mountains is in agreement with the hypothesis that some of the ejecta that crossed this area had been deflected southwestward from the west side of the Kant plateau.

5. A few isolated mountains are interpreted as projecting blocks of older materials, probably including Nectaris basin ejecta.

6 . The generally very smooth surface of the Cayley plains indicates high mobility of the plains-forming materials at the time of their deposition.

7. The Descartes mountains materials and morphology descend beneath and are buried by Cayley plains materials, which, at the Apollo 16 site, occupy a 
depression that may be a pre-Imbrium crater mantled by Imbrium ejecta.

8. The hypothesis of deposition of the Cayley fill as relatively mobile ejecta from one or more multiring basins seems more consistent with the morphology of the area than does any other hypothesis.
The principal question faced by this hypothesis is whether such ejecta could drain freely from highlands to plains and whether that process would have obscured the Imbrium terrain features to a greater degree than is apparent. There is some evidence of such drainage producing local crater filling. 


\title{
J. STRATIGRAPHIC INTERPRETATIONS AT THE APOLLO 16 SITE
}

\author{
By George E. Ulrich and V. Stephen Reed
}

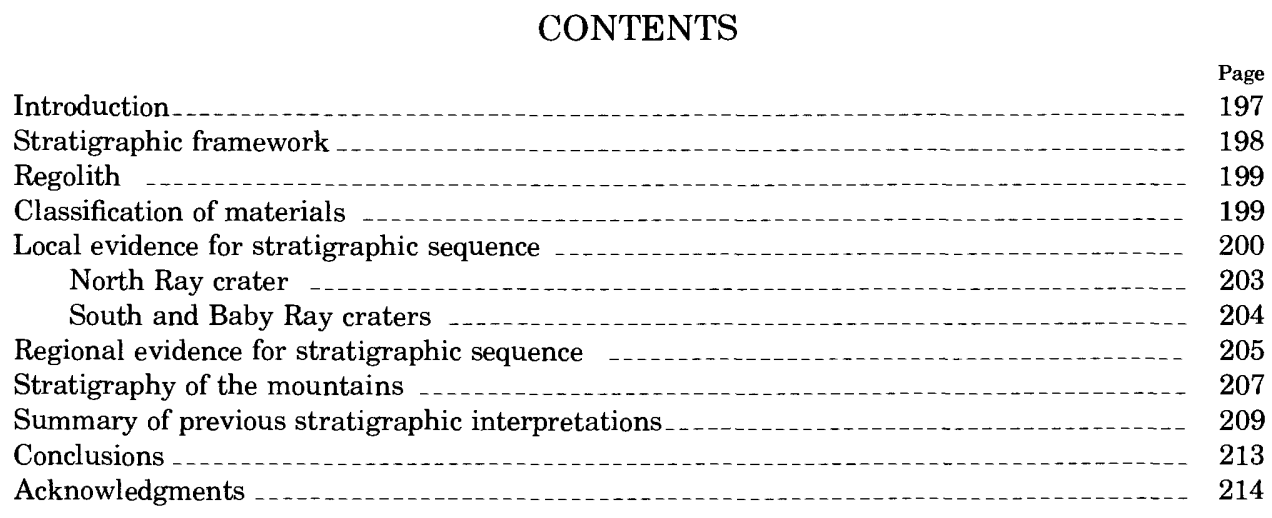

\section{ILLUSTRATIONS}

1. Photographs of light-matrix breccia on rim crest of North Ray crater

2. Photographs of dark-matrix breccia boulder at station 8

3. Photographs of white angular boulder at station 8 and sample 68415 and photomicrograph of 68415

4. Schematic cross section showing the southeastern wall and floor of North Ray crater

5. Cross sections of terrestrial and lunar impact craters _.

6. Schematic cross section through South Ray crater

7. Partial panoramas and sketch maps showing block populations and ejecta patterns of South Ray and Baby Ray craters

8. Photomap of the Apollo 16 region showing kilometer-size craters with and without floor mounds

9. Photographs of the Descartes highlands and crater Dollond E 10-16. Cross sections:

10. North and South craters from AFGIT (1973)

11. North Ray crater from Hodges and others (1973)

12. North Ray crater from Ulrich (1973) _........

13. North Ray and South Ray craters from Delano and others (1973)

14. Schematic stratigraphy of the landing site from Taylor and others (1973)

15. Cross section of the landing site modified from Head (1974)

16. Geologic eross section proposed in this paper for the Apollo 16 traverse area

\section{TABLE}

TABLE 1. Physical parameters (in meters) of craters with floor mounds within the Apollo 16 area

\section{INTRODUCTION}

"The geologist $* * *$. has been forced to rely almost exclusively upon the accidental exposure of underlying formations by uplift and erosion. Hardly a geologic map exists which does not depend upon assumptions about invisible rocks, many of which might be verified or disproved by drilling.

"A deep hole has two important scientific aspects: first, the materials from otherwise inaccessible depths become available for study by the powerful methods of laboratory physics and chemistry; second, the hole itself provides a means for introducing instruments for observing physical properties in place. Both of these contribute towards the understanding of the earth's third dimension."

These statements from a panel on Solid Earth Problems report (National Academy of Sciences, 1974) are directly applicable to studies of the Moon's third di- 
mension. Impact craters are the holes from which the hidden materials are brought to the surface and deposited in a somewhat orderly and predictable fashion. High-resolution orbiting cameras are the instruments with which we can observe the source materials more or less in place within the crater walls. Since we do not have ready access to the products of uplift and erosion on the Moon, craters are our drill holes for resolving the subsurface tratigraphic sequence.

A fundamental objective of the surface exploration at Descartes was to determine the composition and stratigraphic relations of materials underlying the only landing site available to Apollo exploration within the lunar central highlands. Prior to the mission, photogeologic interpretations were based on analyses of the landforms regionally (Milton, 1968, 1972; Trask and McCauley, 1972) and at the Apollo 16 landing site specifically (Hodges, 1972a; Elston and others, 1972c; Head and Goetz, 19722): From 'compari-o sons with terrestrial landforms, the level, marelike materials filling crater floors and the high-standing, young-looking mountains suggested to these investigators a model of volcanic units having different physical properties.

More detailed stratigraphic interpretations of light and dark layers in the walls of North and South Ray craters were illustrated prior to the mission by Elston and others (1972b) from large-scale mapping with an analytical stereoplotter and the best available Apollo 14 orbital photographs. While their volcanic model for these layers and the seven units recognized in North Ray crater was not borne out by the mission results, their identification of differences in material reflectance was supported by evidence collected on the surface. The larger boulders at the landing site, together with the returned samples, show that these differences are a function of rock texture rather than chemical composition.

In this chapter, we evaluate the new evidence pertaining to stratigraphic relations at the Apollo 16 site in the light of the field data as we understand them: interpretations from surface and orbital photographs, the petrography of the rock and soil samples, and first-hand observations of John Young and Charles Duke, who collected the data.

\section{STRATIGRAPHIC FRAMEWORK}

Early studies on the stratigraphy of the Moon (Shoemaker and Hackman, 1962; Wilhelms, 1970) depended on telescopic observations of the topographic appearance of basin floors (the maria), basin rims and outlying radial structures, crater ray patterns, crater size-frequency distributions, and other features that might demonstrate relative ages by superposition of geologic units. These regional relations were a logical basis for the systematic, small-scale mapping of the near side of the Moon, and despite early confusion between time-stratigraphic and rock-stratigraphic terminology (a problem well treated by Mutch, 1970, p. 125-139, and Wilhelms, 1970, p. F23), the primary sequence from old lunar highlands to regional basin deposits, to mare materials, and finally to the young crater deposits has withstood the test of surface investigations.

Within this framework, the Apollo 16 site is located near the mappable outer limits of radial ejecta deposits from the Imbrium basin (rugged terra material of Hodges, pl. 1, this volume). This widespread ejecta unit constitutes the Fra Mauro Formation as defined by Wilhelms (1970). New mapping by Eggleton (pl. 12, this volume) shows its distribution on the near side of the Moon. The Fra Mauro defines the base of the Imbrium System and as such is a time-stratigraphic unit (Wilhelms, 1970). The landing site lies within the probable area of earlier deposition of ejecta derived from the Nectaris basin, centered $600 \mathrm{~km}$ to the east, which predates the Imbrium event (Hodges, this volume; Stuart-Alexander and Howard, 1970).

Most of the area traversed and sampled by Apollo 16 is situated on rolling plains mapped as the Cayley Formation by Milton (1972) and Hodges (1972a). The distinctive physical characteristics of this formation photogeologically are its subplanar surface, its light color relative to the maria, and its crater density, which is significantly greater than that of mare surfaces and greater than that of adjoining highlands. Typically the unit occurs within topographic lows in the lunar highlands, both in large degraded crater floors and in irregular intermountain areas. The border between plains and mountains varies from gradational to a relatively sharp break in slope. On orbital photographs of low resolution, this contact appears more abrupt and distinct than at higher resolution. Schafer (this volume) has demonstrated that the strongest evidence for the relative ages of the Cayley and adjacent highlands of the Descartes mountains is the marked embayment of the plains upon the highlands, a relation indicating the later arrival or formation of the plains materials. The lower crater density on the mountains is an apparent contradiction to this interpretation, but the combined effects of slope movement and low coherence of the mountain materials probably account for this difference, as noted by Freeman (this volume). Northwest of the landing site and elsewhere in regions of Imbrium influence, the Cayley Formation is clearly superposed on Imbrium radial texture (Hodges, this volume; Schafer, this volume) and therefore must postdate the Fra Mauro For- 
mation, although not necessarily by a long period of time. Relative ages of Cayley-type plains in other areas, based on crater populations, have been determined by Soderblom and Boyce (1972) and Boyce and others (1974), to be younger by a significant margin than the Fra Mauro Formation nearer the Imbrium basin. The margin of difference may be questioned on several grounds, and it remains possible that the plains at Apollo 16 may have been emplaced so closely behind the Fra Mauro Formation that the two might be indistinguishable by most dating techniques.

\section{REGOLITH}

Prior to the mission, an impact-generated regolith was assumed to mantle most of the landing site. Based on the diameters and presumed depths of concentric craters within the plains, Oberbeck $(1971 \mathrm{~b})$ predicted that a regolith less than $6.8 \mathrm{~m}$ thick would blanket the traverse area, but he chose an average thickness of $22 \mathrm{~m}$ on the basis of crater population and the implied depth of gardening. Freeman, based on concentric craters on Apollo 16 orbital photographs (this volume), calculated a median regolith thickness of $7 \mathrm{~m}$, with values ranging from 3 to $15 \mathrm{~m}$. Kovach and Watkins (1973) reported a regolith thickness of $12.2 \mathrm{~m}$ from shallow seismic data in the ALSEP area, and AFGIT (1973) estimated a 10 - to $15-\mathrm{m}$ thick regolith on the basis of the smallest blocky and flat-bottomed craters.

Much of the surface on the rim crest of North Ray crater, according to the astronauts' descriptions and photographs, is a thin veeer $(1-2 \mathrm{~cm})$ of soil that Heiken and others (1973) regarded as being very immature. The consensus of observations appears to be that the regolith, whose base is poorly defined as a somewhat harder substrate beneath the unconsolidated surface debris, ranges in thickness from near zero to possibly several tens of meters.

A major geologic goal was to look beneath this regolith through the windows provided by impact craters of widely ranging diameters and to sample their ejecta. To that end, the traverses were planned so as to visit the youngest craters within driving range, those least contaminated by other ejecta deposits (see Muehlberger, this volume). Cayley plains materials should have been found within the walls and ejecta of Flag and Spook craters (stations 1 and 2) from depths as great as $50-75 \mathrm{~m}$, in the rays of South Ray crater, whose depth is $135 \mathrm{~m}$, and on the rim of North Ray crater from depths down to $230 \mathrm{~m}$. Sampling from below the regolith posed a more difficult problem on Stone and Smoky mountains because no fresh blocky craters were known to be accessible. The astronauts had to try to distinguish between true Descartes materials and South Ray contamination on the surface. An alternative hope was that the core tube (64001-02) on Stone mountain would collect uncontaminated regolith derived from underlying bedrock.

\section{CLASSIFICATION OF MATERIALS}

Four types of materials were recognized megascopically at Descartes by astronauts Young and Duke: soils and soil clods, light-matrix breccias, dark-matrix breccias, and igneous-textured rocks. These materials are recognizable in photographs of most boulders larger than about $0.5 \mathrm{~m}$.

(1) Soils and soil clods are ubiquitous on the surface. They are the primary component of the regolith and are not subdivided further here.

(2) Light-matrix breccias (LMB's) are distinctly fragmental, having both light- and dark-colored clasts and an overall light-colored appearance (fig. 1). ${ }^{1}$

LMB's are characterized by a generally rounded shape resulting from their friable nature, and commonly by deep soil fillets around their bases, especially in the North Ray area. They are equivalent to the $B_{1}$, $B_{2}$, and some $B_{3}$ rocks of Wilshire and others (1973), the cataclastic anorthosites and polymict breccias (Types II and I) of LSPET (1972), the LMB's of Warner and others (1973), and the plagioclase-rich breccias of Steele and Smith (1973).

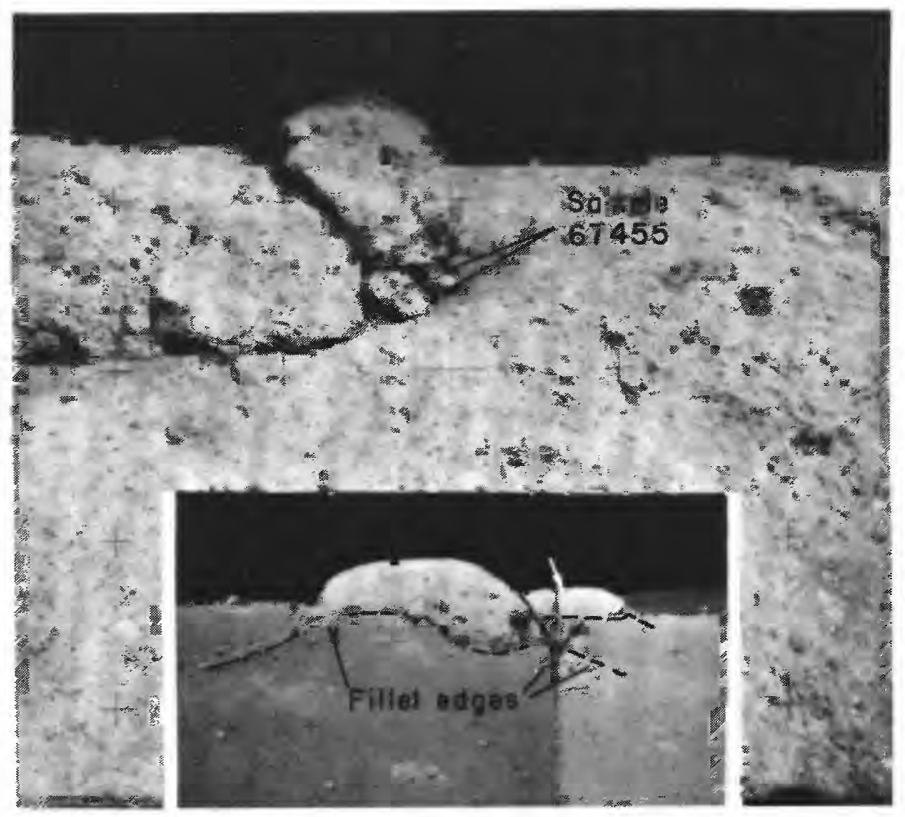

Figure 1.-Light-matrix breccia on rim crest of North Ray crater. Note friable appearance in close-up view (AS16-106-17332) and deeply filleted bases of boulders (AS16-106-17323 and 17324). Arrow on inset points to location of close-up view. From Hodges and others (1973). Reprinted with permission of Pergamon Press.

In this discussion light and dark are used as general descriptors of the gray level observed for dominant rock matrices in photographs. 
(3) Dark-matrix breccias (DMB's) also are fragmental but are typically dark colored and angular; blocks commonly are perched on the surface, surrounded by a shallow moat resembling a secondary crater formed by the impact of the block (fig. 2). Returned samples of these rocks are very coherent and rich in matrix glass, which imparts their dark color. DMB's are equivalent to the $\mathrm{B}_{4}, \mathrm{~B}_{5}$, and some $\mathrm{B}_{3}$ rocks of Wilshire and others (1973), the partially molten rocks (type IV) of LSPET (1972), the glassy, metamorphosed, and melted breccias of Warner and others (1973), and the vitric breccias of Warner and others (1974).

(4) Igneous-textured rocks are relatively common in the rake samples but are represented in the surface photographs by only one boulder sampled at station 8 (Reed, this volume), from which 68415 and 68416 were taken (fig. 3). Smaller rocks in that area, however, have a similar appearance, typically very light gray to white, being homogeneous and fine grained in texture, and somewhat more angular than the LMB's. These rocks are holocrystalline and highly feldspathic in hand specimen; they contain crystal-lined vugs and irregular inclusions of plagioclase (Wilshire and others, 1973 , p. 2382). Horz and others (1972, p. 7-30) described the sampled boulder as a breccia; we interpret the homogeneous texture of the two returned samples and their lack of any adhering matrix material as good evidence that the boulder is completely crystalline and a uniformly igneous-textured rock. Helz and Appleman $(1973$, p. 657) agree with our interpretation on the basis of crystal growth-rate estimates. Astronaut Duke described it as follows: "Look at that beauty, John. That is a crystalline rock, no breccia***. There's a lot of this rock here, scattered all over***. It's pure feldspar." This rock is equivalent to the $\mathrm{C}_{1}$ class of Wilshire and others (1973), the igneous and high-grade metamorphic (type III) rocks of LSPET (1972), the nonmare basalts of Hubbard and others (1972), the anorthositic rocks of Hubbard and others (1973), the highland, or feldspathic, basalts of Reid and others (1972), and the melt-rock breccias of Warner and others (1974). Helz and Appleman (1973) concluded that this rock is a hybrid mixture of Apollo 16-type soil and breccia, melted by impact at the lunar surface. It crystallized through a two-stage cooling process of early rapid super-cooling and late, much slower cooling within an undefined larger mass. Pearce and Simonds (1974) cited the high content of metallic iron within the crystalline (mesostasis-rich, basaltic, and poikilitic) rocks as additional evidence for long cooling histories. We interpret the texture of this boulder at station 8 as reflecting an impact melt with a relatively long cooling history in a subsurface environment whose depth was between 50 and $130 \mathrm{~m}$ in the area of South Ray crater. Other rocks with igneous textures probably reflect a similar environment, and those in the southern half of the traverse area may also be ejecta from South Ray crater.

Other rock types are well defined in the sample suite but not generally distinctive in the surface photographs. These include the glasses (class $\mathrm{G}$ of Wilshire and others, 1973), metaclastic rocks (class $\mathrm{C}_{2}$ ), and the $\mathrm{B}_{3}$ breccias intermediate between light- and darkmatrix rocks. The mineralogical similarity of most Apollo 16 rocks indicates that the textural types form a continuous series. The degree of melting and rate of cooling control the predominant matrix type as well as the degree of recrystallization in a given rock. The series inferred extends from nearly pure glass through dark-matrix breccias to light-matrix breccias (with low glass contents), to the original source rock, coarse-grained anorthosite and anorthositic gabbro of Wilshire and others (this volume). If the melt-rich end of the series goes through a slow cooling stage, the fine-grained igneous textures of $\mathrm{C}_{1}$ rocks can be explained. If melting is incomplete, metaclastic $\left(\mathrm{C}_{2}\right)$ textures result. As the boundaries between various textural types are gradational, intermediate members of the series are to be expected.

\section{LOCAL EVIDENCE FOR STRATIGRAPHIC SEQUENCE}

The case for orderly layering in the Apollo 16 traverse area relies largely on interpretation of features observed on the crater walls, distribution of rock types relative to the craters from which they were ejected, and petrographic differences in the samples. The only craters to which rock samples can be assigned with certainty are North Ray, and to a lesser extent, South Ray. Soil samples can be reliably related to a crater only for North Ray, which was comprehensively sampled on its rim, whereas there is doubt about the presence of South Ray soils at station 8 (McKay and Heiken, 1973). Subsequent discussions are based on photographic and sample data derived from stations closest to those craters and on attempts to reconstruct, if only crudely, a probable sequence of materials that constitute the uppermost several hundred meters at the landing site. The discussion here refers to the subregolith materials observed within the landing site. Moonwide, the Imbrian plains are characterized by a morphology, crater population, and albedo similar to the plains at Descartes, but we do not suggest that the stratigraphic sequence interpreted here is necessarily inherent to the surface expression of similar units elsewhere.

Layering is certainly present at the Descartes site and probably everywhere on the Moon at some scale. 


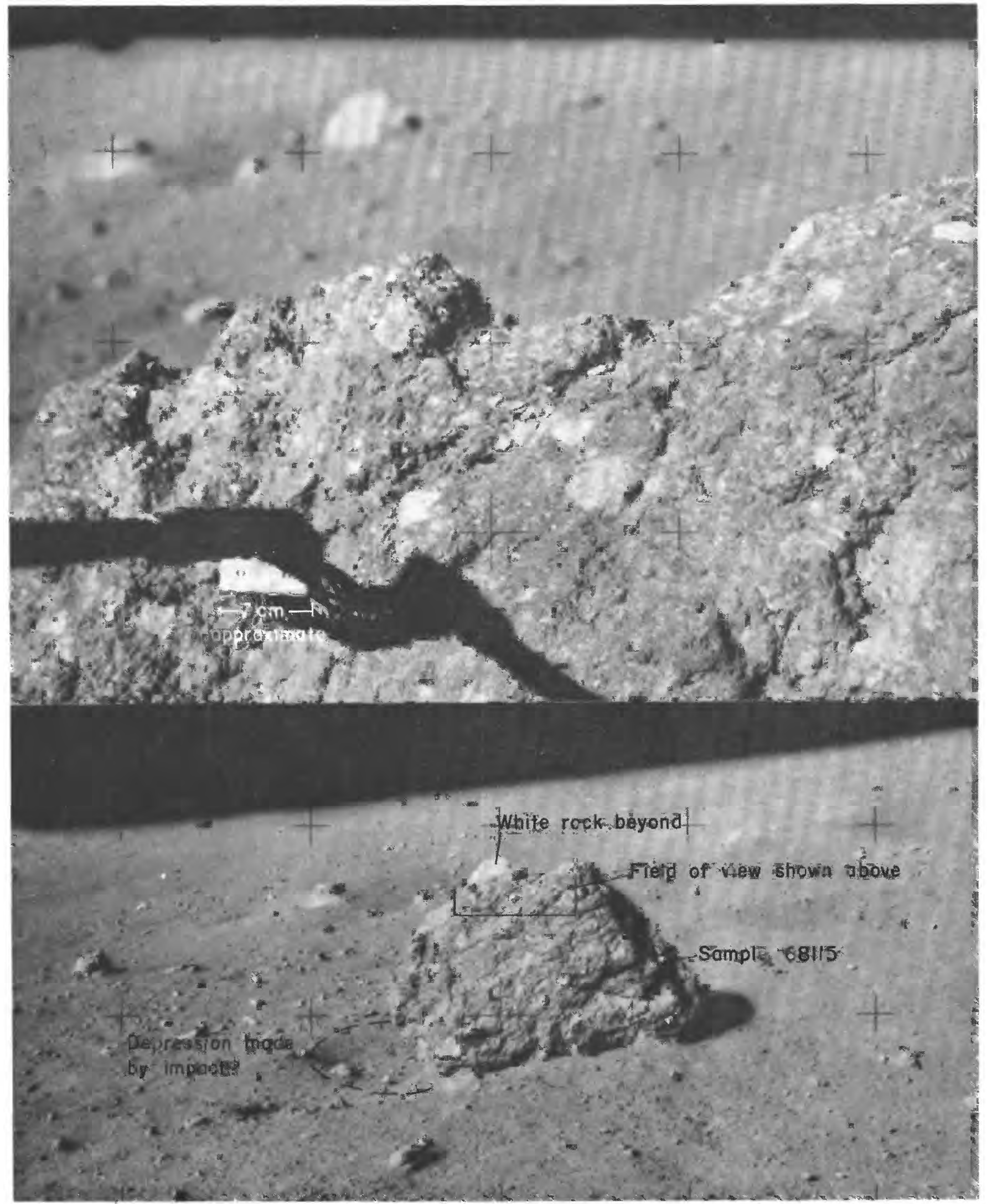

FIGURE 2.-Dark-matrix breccia boulder at station 8. From Hodges and others (1973). Note shallow moat at base and white rock of figure 3 beyond. Dark rocks amount to 75 percent of the fragments at station 8 (Reed, this volume). (AS16-108-17689 bottom; AS16-10817693 close-up). Reprinted with permission of Pergamon Press. 
Inherent in the impact process is the deposition of ejecta, thinning radially away from the crater rim and becoming laterally discontinuous beyond about one crater diameter. Because craters of all sizes, to hundreds of kilometers across, occur on the Moon, the re- sultant ejecta blankets must form layers at many scales. Intertonguing and redistribution of ejecta layers by smaller craters complicate interpretation greatly but can best be studied by relating the rocks around the largest and freshest craters directly to

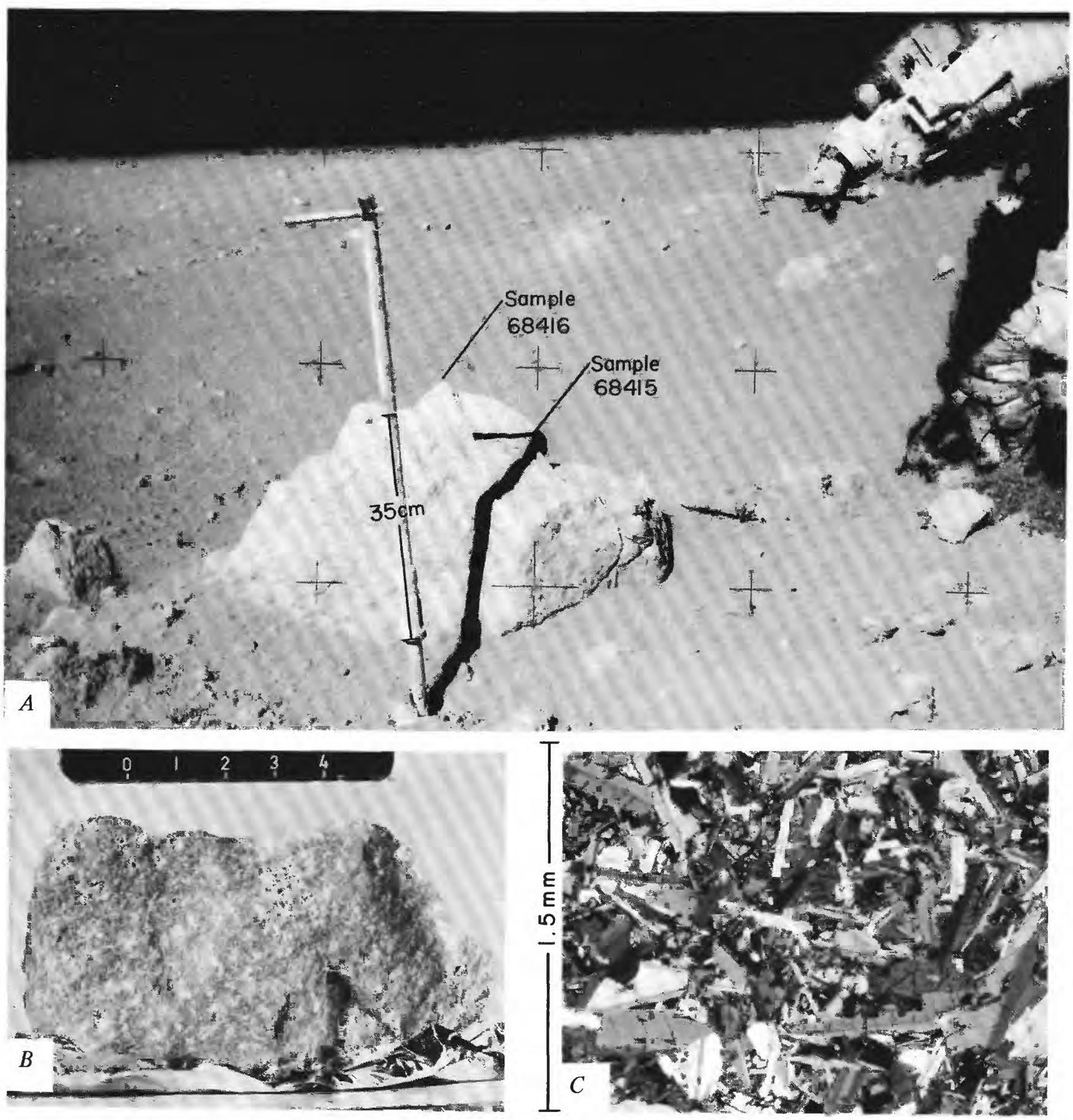

FIGURE 3.-White angular boulder at station 8. Note scattering of other light-colored rocks in area in $A$ (AS16-108-17697). B, Fresh surface of 68415 illustrating fine-grained igneous texture with local vug-filling plagioclase (arrow), indicating slow cooling. Scale is in centimeters. (S-73-39590). $C$, Subophitic texture of seriate plagioclase (75 percent) and pyroxene in crosspolarized light. Note lack of brecciated or quenched glass matrix. $A$ and $C$ from Hodges and others (1973) reprinted with permission of Pergamon Press. 
those craters on the basis of impact-crater mechanics. Although our understanding of the cratering process is far from complete, some principles of ejecta distribution are becoming well established as a result of many studies fostered by lunar exploration. We have utilized these principles in reconstructing the stratigraphic picture at Descartes.

\section{NORTH RAY CRATER}

The surface in the North Bay area has many fewer blocks than had been anticipated prior to the mission. On plate 8 (pan 19), taken to show the types and abundance of fragments present on the rim crest and walls of North Ray, it can be seen that most of the boulders present are LMB's, having rounded profiles and local filleting at their bases. Telephotographs of the northeast wall (Ulrich, this volume) show that most of the 5to 10-m-high blocks there are probably LMB's occurring in roughly horizontal arrangement indicative of outcrop. In addition to the abundance of LMB's on the rim and exposed in the middle and upper wall, the gentle upper slopes reflect the low coherence of these friable rocks. Stoffler and others (1975) show from experimental work that most of the ejecta in an impact or explosion crater is derived from the upper 50 percent of the existing crater wall. This is consistent with photogeologic evidence that the continuous ejecta blanket of North Ray crater consists mainly of light-colored rocks and soils whose source is probably high in the crater.

Only 10 to 30 percent of the fragments on the rim of North Ray are DMB's. The returned samples in this category are primarily from Outhouse rock on the rim crest and from Shadow rock, $750 \mathrm{~m}$ southeast of the crater. DMB's collected elsewhere at North Ray are mainly clasts from within the dominant light-matrix rocks (Ulrich, this volume).

The large coherent boulders of DMB (House and Outhouse rocks and Shadow rock) probably were derived from the lower part of North Ray crater. Photographic evidence permits an interpretation of either a high source, such as the dark mass on the north wall (pl. 8, pan 19) or a deeper source such as the mound of large dark blocks on the crater floor (fig. 4). The lower source is considered likelier for most of the DMB's from stations 11 and 13 for these reasons:

1. The dark-matrix blocks are perched on the rim, within their secondary craters, and show no evidence of burial by subsequent, and therefore deeper, ejecta. These conditions imply that they were the ejecta last deposited on the rim.

2. The dark color and large size of House rock $(25 \mathrm{~m}$ long and about $12 \mathrm{~m}$ high) are tentatively correlated with the blocks on the crater floor of similar size, seen on pre- and post-mission orbital photography and shown in figure 4 . None of the observable blocks higher in the crater wall are as large. Stoffler and others (1974, p. 146-8) conclude that House Rock, because of its large size, has a source high in the wall of North Ray crater. Alternatively, we believe that the size of ejecta blocks depends more on the coherence and fracture spacing of the source rock than on its vertical position in the target material. Support for this is found at Meteor Crater, Ariz., and Shorty crater at TaurusLittrow valley on the Moon. The largest blocks (5-10 m diameter) on the rim of Meteor Crater (fig. $5 A$ ) are from the very resistant and well-bedded Kaibab Formation albeit in the upper wall of the crater. The thick beds of dolomite from which the large blocks are most likely to be derived occur in the bottom two-thirds of the 85-m-thick formation. The deeper Coconino Sandstone occurs in substantial quantities locally on the rim but not as large blocks because of its friable nature. At Shorty crater, 15 to $20 \mathrm{~m}$ of unconsolidated material overlies coherent basalt flows that were barely penetrated at the crater floor (fig. $5 B$ ). The $4-\mathrm{m}$ basalt boulder on the west rim of Shorty probably came from this lowest horizon, although the regolith above cannot be excluded as a possible source for this highly fractured rock.

3. Glass splashes are common as thin veneers on the surface of Outhouse rock and are a likely product of the North Ray event (Ulrich, this volume). Similarly, the vesicle pipes described by the astronauts on Shadow rock are evidence of melting. The greatest melting of target material by the impact process occurs where the greatest heat is generated; in many craters, this zone is found in the lowermost units. For example, Coconino Sandstone is fused to lechatelierite, whereas melting did not occur in the overlying Kaibab and Moenkopi Formations, at Meteor Crater (Shoemaker, 1960), and crystalline basement rocks are dominant in the suevite

NORTH RAY CRATER SE

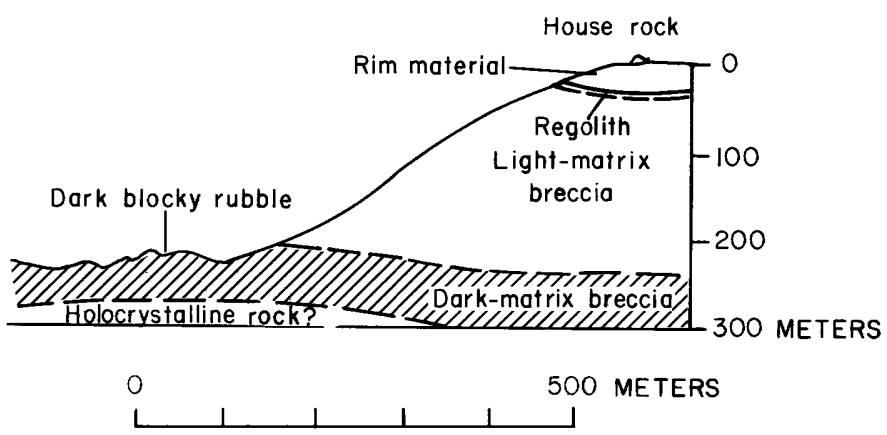

Figure 4.-Partial profile of the southeast wall of North Ray crater showing the stratigraphic sequence as interpreted in this discussion. Profile by G. M. Nakata (USGS) using Apollo 16 panoramic camera frames 4618-4623. 
METEOR CRATER

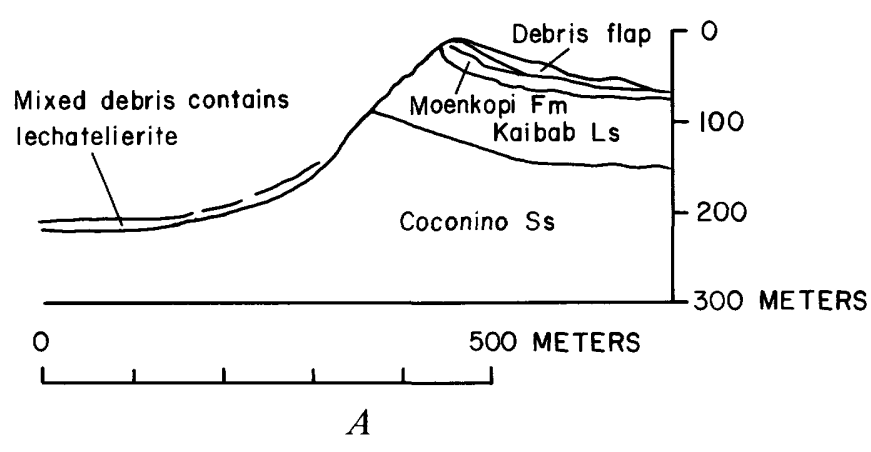

SHORTY CRATER

SW

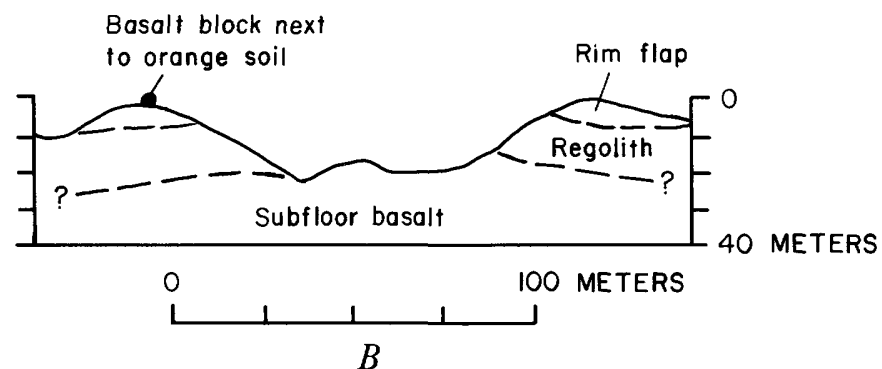

Figure 5.-Cross-section of terrestrial and lunar impact craters. $A$, Meteor Crater, Ariz., after Shoemaker (1960). B, Shorty crater, Taurus-Littrow valley, Apollo 17. (Profile by R. M. Jordan, USGS).

at the Ries crater (Engelhardt and Stoffler, 1968). Melting in the impacted sequence is described at the Rochechouart structure in France (Kraut and French, 1971) and the Carlevoix structure in Canada (Rondot, 1971). The abundant glass on Outhouse rock, which probably was broken from House rock, is additional evidence for the deep source of these boulders.

4. Finally, the subophitic holocrystalline rocks like 67948 and 67956 that crystallized from a melt sufficiently insulated for this texture to develop occur as inclusions mainly in the large dark-matrix boulders. The LMB's contain small inclusions (or interstitial "nuggets") of partly crystallized material (as in the rake samples in the White breccia boulder area); but to our knowledge, the distinctly igneous textures exemplified by 68415 do not occur in those rocks. Our conclusion, therefore, is that LMB's are melt-poor rocks that in the area of North Ray crater appear to overlie and locally enclose the glass-rich DMB's, which in turn are gradational with the completely recrystallized rocks that formed where melt rock cooled slowly enough for coarser igneous textures to develop.

Based on these arguments, a crude geologic model of layering at North Ray crater and possibly elsewhere at the Apollo 16 site is proposed. Beneath the pre-North
Ray regolith is approximately 100 to $200 \mathrm{~m}$ of rocks that are predominantly LMB's. The lowest 75-100 m in the crater wall is largely mass-wasted debris from above, characterized by few large blocks. A mound of coarse dark blocks on the floor of the crater may represent an underlying resistant mass of melt-rich rocks (DMB's) at a depth of about $200 \mathrm{~m}$ below the crater rim. These melt-rich rocks, which may grade downward into rocks with coarse igneous textures, are probably not continuous laterally across the site, although they may occur over extensive areas within the plains.

\section{SOUTH AND BABY RAY CRATERS}

The field geology of the sample locations in the southern part of the landing site, closest to South Ray crater, is discussed by Reed (stations 8 and 9, this volume) and Sanchez (stations 4, 5, and 6, this volume). All but a few of the blocks and fragments perched on the surface, are probably ejecta from the very fresh and blocky South Ray crater. Examination of the types and relative abundance of blocks on the walls, rims, and rays of South Ray crater and of the smaller, younger Baby Ray crater suggests a simple two-layer stratigraphic sequence as shown in figure 6 . The rim ejecta and regolith above this sequence are inferred to be 30 to $40 \mathrm{~m}$ thick. A dark-colored zone of DMB is inferred in the crater wall below the rim and down to a terrace at about 70-m depth. Allowance for rim uplift makes this zone approximately $60 \mathrm{~m}$ thick. Below this bench, the wall is steep and blocky; in orbital photographs, the blocks appear as very light colored debris to the bottom at a depth of about $140 \mathrm{~m}$. A small accumulation of dark rubble at the bottom is interpreted as masswasted debris from higher on the crater wall.

Astronaut Duke commented, as he viewed South Ray crater from station 4 on Stone mountain, that he could see the wall of the crater and that both black and white streaks crossed the rim, indicating two types of rocks (fig. 7A). This observation was substantiated by the rocks collected at stations 8 and 9 , on or near rays. Both DMB's $(68115,68815,69935)$ and light-gray igneous rocks (68415 and 68416) were collected (see Reed, this volume).

The sequence of DMB's overlying light-gray rocks is further supported by the relative abundances of these rock types. in the southern part of the Cayley plain. Block and ejecta maps (fig. $7 B, C$ ) show that the ratio of light to dark rocks on South Ray crater is near unity (53 percent light, 47 percent dark), whereas Baby Ray ejecta are mainly dark (74 to 26 percent). The shallower depth of Baby Ray crater (about $30 \mathrm{~m}$ ) relative to South Ray $(140 \mathrm{~m})$ leads to the conclusion that the DMB's occur near the surface in this area and that the impact of South Ray crater penetrated through a simi- 
lar unit and well into a subjacent layer of coherent light-colored material that we correlate with the igneous-textured blocks at station 8 .

The relative abundance of dark and light rocks in the South Ray rays (station 8 and 9 areas) provide additional evidence for the superposition of dark and light units in South Ray crater. Rocks ejected from deep in the crater are likely to be deposited closer to the rim than rocks derived from shallow depth. The ratio of dark to light rocks (3:1) at stations 8 and 9 suggests that the source of the dark rocks is closer to the surface than the light-rock layer.

That there was little or no deposition of fine-grained materials from South Ray crater at stations 8 and 9 has been shown by McKay and Heiken (1973). There may be very little friable material (light-matrix breccias) present in South Ray ejecta at these locations. It can be further inferred that the predominant rock types penetrated by South Ray are coherent rocks and that these are represented by the dark-matrix breccias and lightcolored holocrystalline rocks collected at these stations.

It appears therefore, that at least locally, there is an upper layer, predominantly DMB, overlying a coherent light-gray unit from which rocks like 68415 are derived. We believe the evidence indicates some continuity of this layering between South Ray and Baby Ray craters, but it is not possible to establish con- tinuity across the entire site. In the central part of the landing site, where the active seismic data were recorded over a distance of $445 \mathrm{~m}$, there is no seismic evidence for a major lithologic break below the regolith in the upper $220 \mathrm{~m}$ (Kovach and Watkins, 1973). The similarity between the DMB's collected at North Ray to those collected at stations 8 and 9 suggests that such a unit exists at shallower depths toward the south. We infer that this unit occurs in several areas of the site and may be the product of a single large impact event.

\section{REGIONAL EVIDENGE FOR STRATIGRAPHIC SEQUENCE}

Irregular mounds on the floor of several kilometersize craters in the Apollo 16 site were tentatively interpreted by Hodges (1972a) prior to the mission as indicative of a stratigraphic discontinuity at depth. Earlier examination of crater morphology by laboratory experiments and lunar regolith studies showed that the boundary between materials of low cohesion and a coherent substrate is reflected by floor mounds in craters when crater depth is approximately the same as the thickness of the upper, low-strength unit (Quaide and Oberbeck, 1968). Table 1 gives measurements of crater parameters from the best available topographic maps in the Apollo 16 region.

These craters and others in the same size range that lack floor mounds are clearly seen in orbital photo-
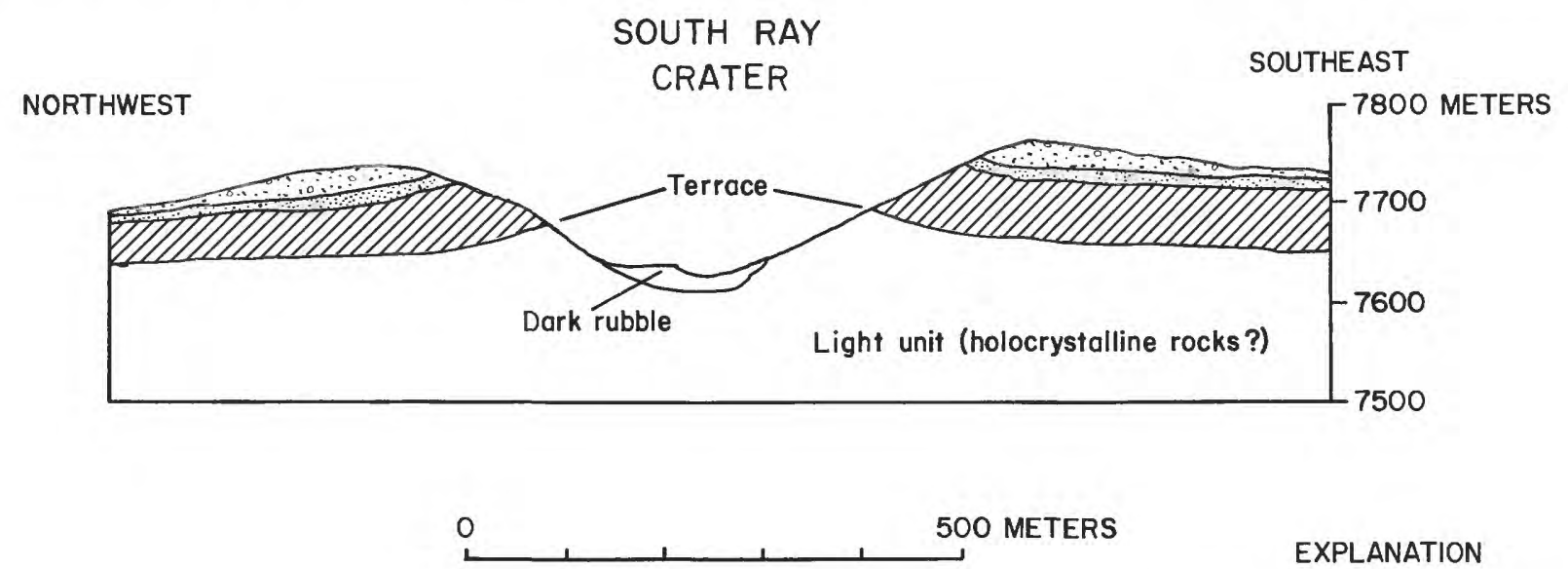

EXPLANATION

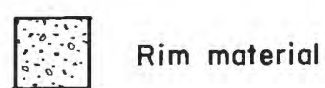

Regolith

Dark breccia 

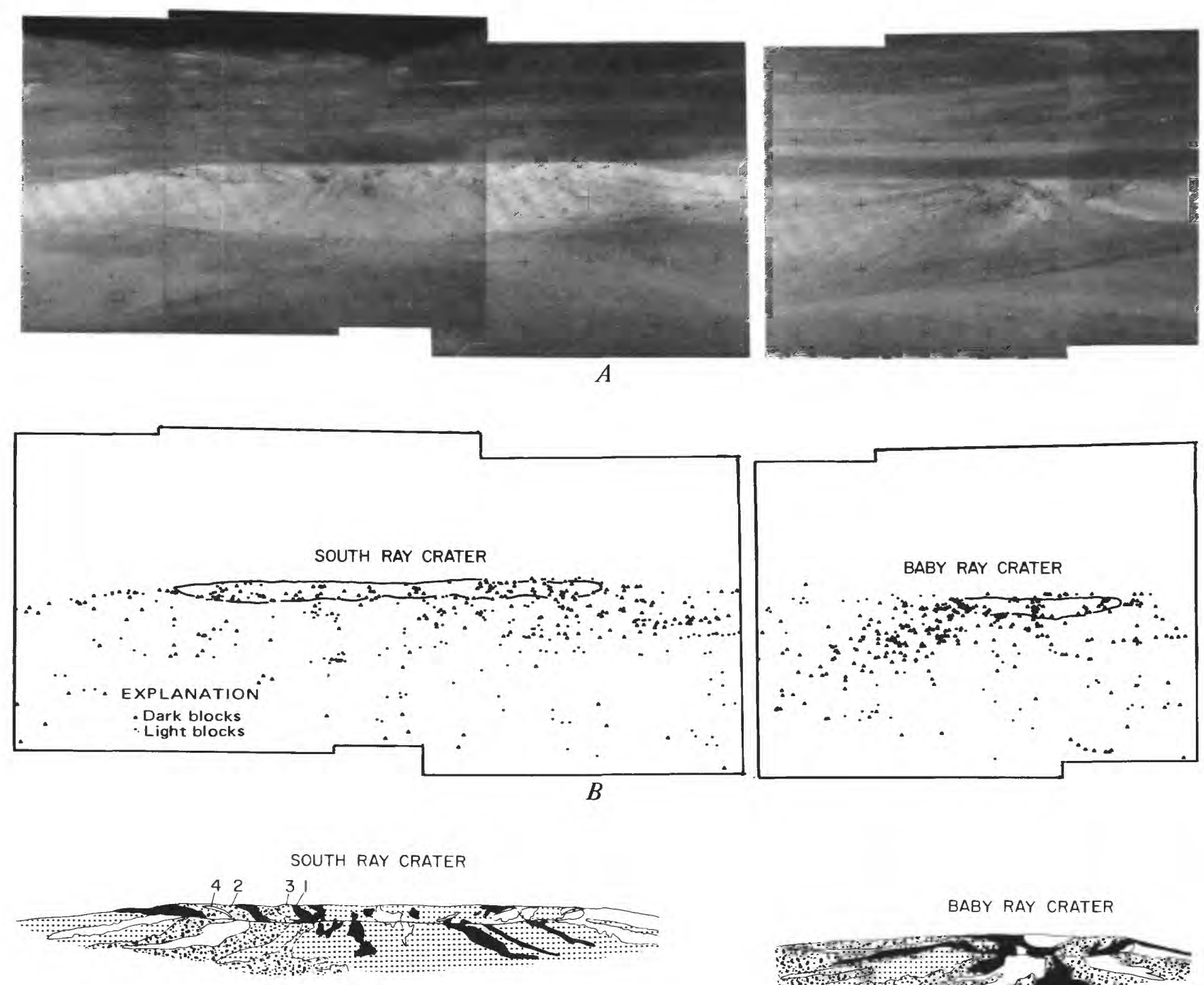

BABY RAY CRATER

\section{EXPLANATION}

Dark ejecta

27 Moderately dark ejecta

3oderately light ejecto

$\frac{4}{C}$ Light ejecta

Figure 7.-Partial panoramas, block populations, and ejecta patterns of South Ray and Baby Ray craters. A, Telephotographs of South Ray crater (left) and Baby Ray crater (right) taken from station 4 on Stone mountain. (AS16-112-18246, 18247, and 18256, South Ray, and AS16-112-18253 and 18254, Baby Ray). Note streaks of ray materials across Cayley plains. B, Block populations on South Ray and Baby Ray craters. C, Light and dark ejecta on South Ray and Baby Ray craters. 
TABLE 1.-Physical parameters (in meters) of craters with floor mounds within the Apollo 16 area (shown in fig. 8)

\begin{tabular}{|c|c|c|c|c|c|}
\hline Crater & $\underset{\text { diameter }}{\operatorname{Rim}}$ & $\begin{array}{c}\text { Rim-to-floor } \\
\text { depth }\end{array}$ & $\begin{array}{l}\text { Mound } \\
\text { height }\end{array}$ & $\begin{array}{l}\text { Depth to } \\
\text { cohesive } \\
\text { substrate }^{1}\end{array}$ & $\begin{array}{c}\text { Source of } \\
\text { topographic } \\
\text { data }\end{array}$ \\
\hline North Ray & 1000 & 230 & 30 & $150-165$ & $\left({ }^{2}\right)$ \\
\hline Kiva & 950 & 135 & 35 & 150 & (2) \\
\hline Palmetto & 900 & 110 & 15 & $140-150$ & (3) \\
\hline Haystack NE & 1200 & 150 & 35 & 190 & $(3)$ \\
\hline Haystack S & 900 & 130 & 15 & $130-160$ & $\left({ }^{3}\right)$ \\
\hline South Ray & 680 & 135 & 20 & 4110 & (5) \\
\hline
\end{tabular}

'Estimated from crater parameters in accordance with Quaide and Oberbeck (1968, fig. 11) ${ }^{2}$ Figure 3 , Ulrich, this volume.

${ }^{3}$ U.S. Army Topographic Command (1972)

We believe the first cohesive substrate in South Ray crater is approximately $90 \mathrm{~m}$ higher. ${ }^{5}$ Figure 4, Ulrich and others, this volume.

graphs (fig. 8). The mounds range in height from 15 to $35 \mathrm{~m}$ and vary from smooth in seven craters of Eratosthenian age (Hodges, 1972a) to blocky in two craters of Copernican age (North and South Ray craters). Craters having conspicuous mounds lie entirely within the diameter range $0.5 \mathrm{~km}$ to $1.8 \mathrm{~km}$ (Hodges, pl. 1, this volume) and occur exclusively within the Cayley plains.

Using the relation of mound height to crater diameter derived by Quaide and Oberbeck (1968) to determine the thickness of a surficial layer from the data of table 1 , we calculate roughly a mean value of about 155 $m$ with a range from $130 \mathrm{~m}$ in Haystack SW crater to $190 \mathrm{~m}$ in Haystack NE crater. Several craters within the approximate size range of craters with mounds and comparable in erosional age, for example, Gator (fig. 8), do not have floor mounds. It may be significant that no craters with floor mounds are found on the Descartes mountains. Because many craters in the same size range and erosional state do not exhibit floor mounds, we believe that mounds are not produced simply by impact mechanics in homogeneous target material but rather reflect a discontinuous coherent substrate in several areas within the site. The rock types that may represent such a substrate might be DMB's, as interpreted for North Ray crater, or light-gray igneoustextured rocks like the boulders at station 8 . A third possibility, unfractured coarse-grained anorthosite basement, might be proposed, but the samples collected in this category were too few to suggest a plutonic mass this near the surface.

A phenomenon possibly related to the occurrence of floor mounds is the dark color of floor material in a few fresh craters ranging in diameter from $150 \mathrm{~m}$, for example, Baby Ray, to 1,000 m, North Ray. Formation of dark glass by local impact melting may be an explanation in some cases, but we prefer the interpretation of stratigraphic discontinuity in North Ray crater. This preference is based on the occurrence of large DMB boulders like House and Outhouse rocks, whose dark matrix is an earlier generation of glass than the surface glass coating and veining expected as products of the North Ray impact event. We believe a similar unit occurs at 10 to $20 \mathrm{~m}$ beneath the surface in the South Ray-Baby Ray area.

It appears possible, therefore, that discontinuous masses of melt-rich material may occur at various depths in the Cayley plains at the Apollo 16 site. The upper surface of this cohesive material may be the controlling basement for the present topographic surface. The bulk of these materials may have originated as ejecta from the Imbrium basin, (Hodges and Muehlberger, this volume) consisting of large masses of molten to partly molten material that arrived early and settled into topographic lows or were transported simultaneously with unmelted feldspathic breccias and became segregated gravitationally to a depth of 10 to nearly $200 \mathrm{~m}$.

\section{STRATIGRAPHY OF THE MOUNTAINS}

The evidence for stratigraphic sequence in the Descartes mountains in and near the Apollo 16 traverse area is rather inconclusive. Stations intended to provide highlands samples include 4,5 , and 6 on Stone mountain and station 14 on Smoky mountain. When it became necessary during the mission to shorten the third EVA (Muehlberger, this volume), station 14 was omitted from this traverse. However, North Ray crater penetrated deeply into a topographic ridge whose morphology is more like that of the adjacent Smoky mountain than was recognized before the mission (Ulrich, 1973; Wilshire and others, 1974), and thus station 11 samples may have offset the loss of station 14. Stations 4 and 5 are well up on Stone mountain; station $4 \mathrm{a}$, in particular, is important because its location is within $40 \mathrm{~m}$ of the rim of Cinco $a$, a $65-\mathrm{m}$ diameter crater approximately $15 \mathrm{~m}$ deep (Sanchez, this volume). Station 6, at the foot of Stone mountain, probably provided samples from both the mountains and the plains, and stratigraphic interpretations from rocks in that area are very uncertain.

The Descartes mountains may have a higher proportion of melt-poor feldspathic breccias than the Cayley plains. LMB's are predominant in the rock samples returned from stations 4 and 11 . Together with the intermediate $B_{3}$ breccias, they are predominant at station 5 (Wilshire and others, fig. 5 , this volume). Of the eight rocks weighing more than $25 \mathrm{~g}$ collected near Cinco $a$ crater (station 4a), seven are LMB's; the eighth is metaclastic, and the remaining small fragments are about equally LMB's and DMB's. At station $4 \mathrm{~b}$, where a possible ray of blocks from South Ray crater was photographed, the 11 rocks returned are all under $25 \mathrm{~g}$. They are a mixture of rock types, and because of their small size, difficult to interpret with respect to local stratigraphy. The rocks most representative of Stone 


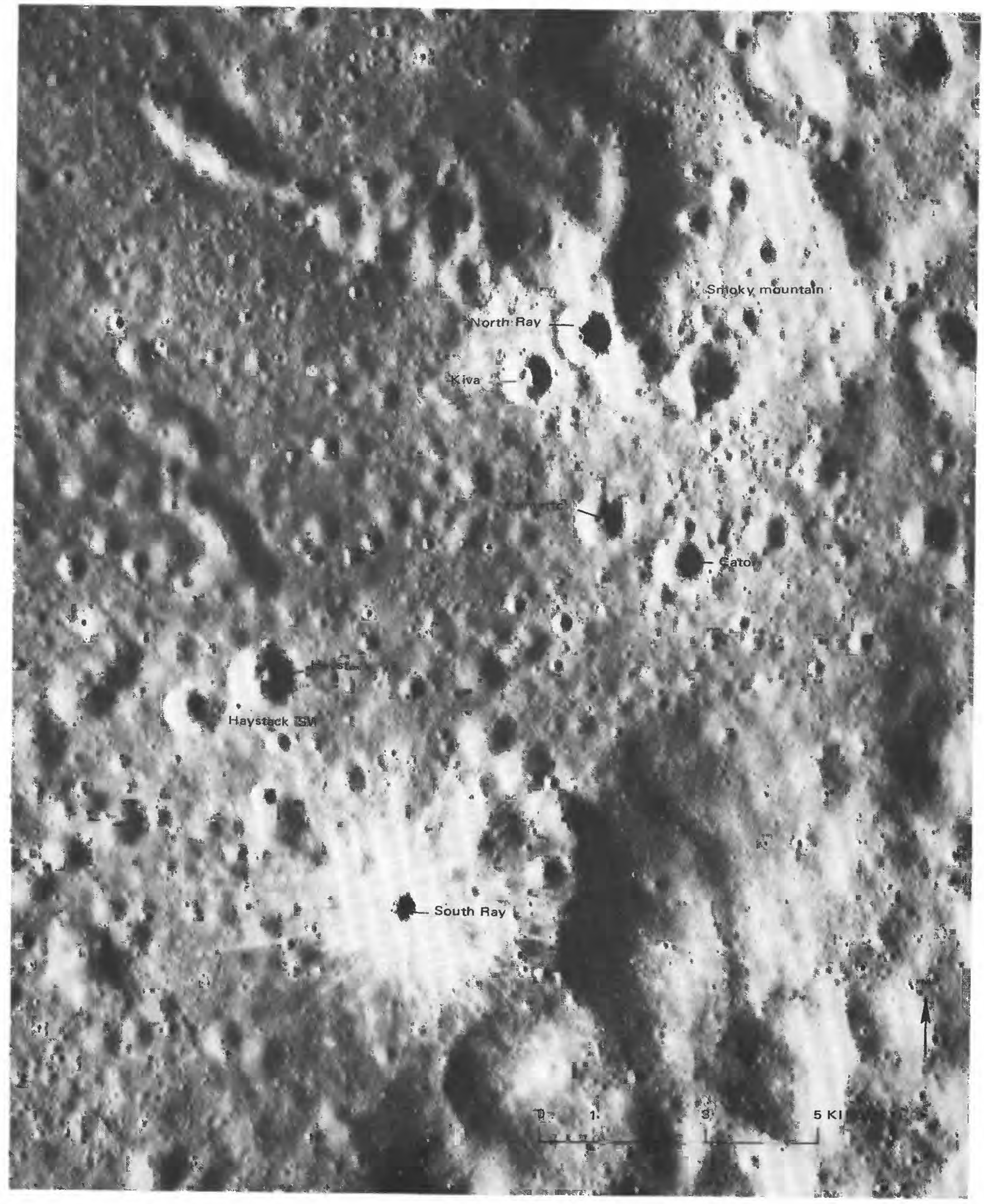

Figure 8.-Photomap of the Apollo 16 region showing craters having floor mounds and those in same size range (0.5-1.5 km) without mounds. (Apollo 16 panoramic camera frame 4618). 
mountain and most likely to be from below the regolith are the larger samples at station $4 \mathrm{a}$; these are LMB's.

Similar LMB's predominate at North Ray crater and possibly indicate the composition of Smoky mountain (Ulrich, 1973). Telescopic spectral reflectance data for 20-km-diameter areas compared with values from the returned samples suggested to Adams and McCord (1973, p 175) that Descartes "is characterized by a relative abundance of white breccias, whereas the Cayley Formation contains more of the darker breccias." Support for this interpretation is the small number of large blocks (several meters and larger) on the very fresh Copernican crater Dollond E, approximately $1 \mathrm{~km}$ deep (fig. 9). Assuming this crater excavated a representative area within the mountains $35 \mathrm{~km}$ south of Stone mountain, we infer that the upper kilometer of material consists of friable LMB-like rocks and soil.

\section{SUMMARY OF PREVIOUS STRATIGRAPHIC INTERPRETATIONS}

Stratigraphic discussions published since the Apollo
16 mission reflect the chronologic evolution of concepts as more data became available from the photographs and the early and very limited distribution of returned samples. Although conclusions of many workers have been drawn more on intuition than on facts and with little regard for field relations (ambiguous as they often are), we have attempted, for the sake of completeness, to include them all. In each case, workers have attempted to explain the origin and history of the lunar highlands in light of their apparent chemical homogeneity and morphologic heterogeneity, based on their own research and often on selected data from the research of others.

In a preliminary evaluation of the mission results, Muehlberger and others (1972) described the Cayley Formation as a crudely stratified debris unit, $200 \mathrm{~m}$ to possibly more than $300 \mathrm{~m}$ thick. Lithologically, it was characterized by materials derived from plutonic anorthosites and feldspathic gabbros and their metamorphic equivalents. The unit was subdivided, from the top down, into $10-15 \mathrm{~m}$ of regolith, a few meters of medium-gray breccia, LMB, and DMB at North Ray

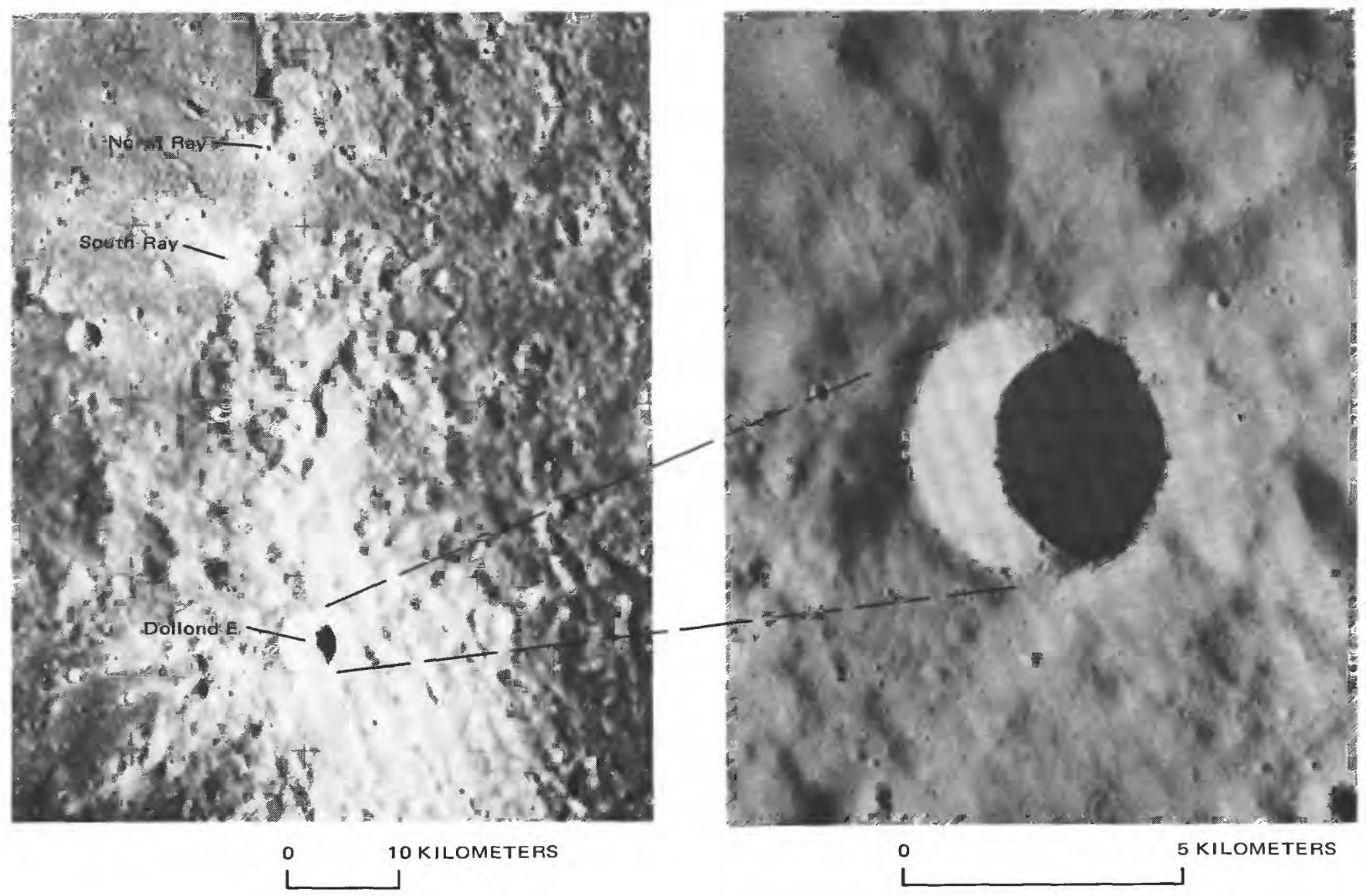

Figure 9.-Descartes highlands, showing bright reflectance area surrounding Dollond south of the Apollo 16 site. Apollo 16 mapping camera frame 1954 and close-up of Dollond E, a Copernican age crater that penetrated a kilometer of highlands material but excavated few coherent blocks $5 \mathrm{~m}$ and larger. Apollo 16 panoramic camera frame 4558 . 
crater. In the area of South Ray and Baby Ray craters, the sequence of LMB and DMB was reversed. No stratigraphic succession underlying the adjacent mountains was proposed.

In a modified interpretation (AFGIT, 1973), four recognizable units based on rock-type distribution at or near North Ray and South Ray craters (fig. 10) were suggested. From the top down these units were: 90 to $100 \mathrm{~m}$ of LMB, $50-100 \mathrm{~m}$ of friable light-colored material, an unknown thickness of coherent DMB in North Ray crater, and, at South Ray crater, about $30 \mathrm{~m}$ of DMB overlying an undetermined thickness of anorthositic gabbroic and metaclastic rocks.

Hodges and others (1973, p. 16-20) redefined the Cayley Formation as the uppermost plains unit beneath the $10-15 \mathrm{~m}$ regolith. On the basis of superposed crater densities and the erosional stage of the largest craters, the plains are equivalent in age to Orientale basin plains units (Soderblom and Boyce, 1972) and were thought possibly to be derived from that basin. A thickness of $50 \mathrm{~m}$ or more at this site was postulated for the Cayley, the base of which was inferred to coincide approximately with a bench on the east wall of North Ray crater (fig. 11). About $100 \mathrm{~m}$ of Imbrium ejecta was inferred to lie beneath the Cayley and an additional $100 \mathrm{~m}$ (minimum) of Imbrium or Nectaris ejecta was shown at the base of their hypothetical cross-section. The Descartes mountains were tentatively considered a ridgey unit of breccias ejected from either or both the Imbrium and Nectaris basins. Ulrich (1973, p. 34) interpreted this same cross-section on the basis of rock types observed in the ejecta blanket, pointing up a resistant unit of dark-looking rocks that form the central mound on the floor of the crater. He referred to all units below the North Ray bench as sub-Cayley materials crudely stratified by gravitational segregation into
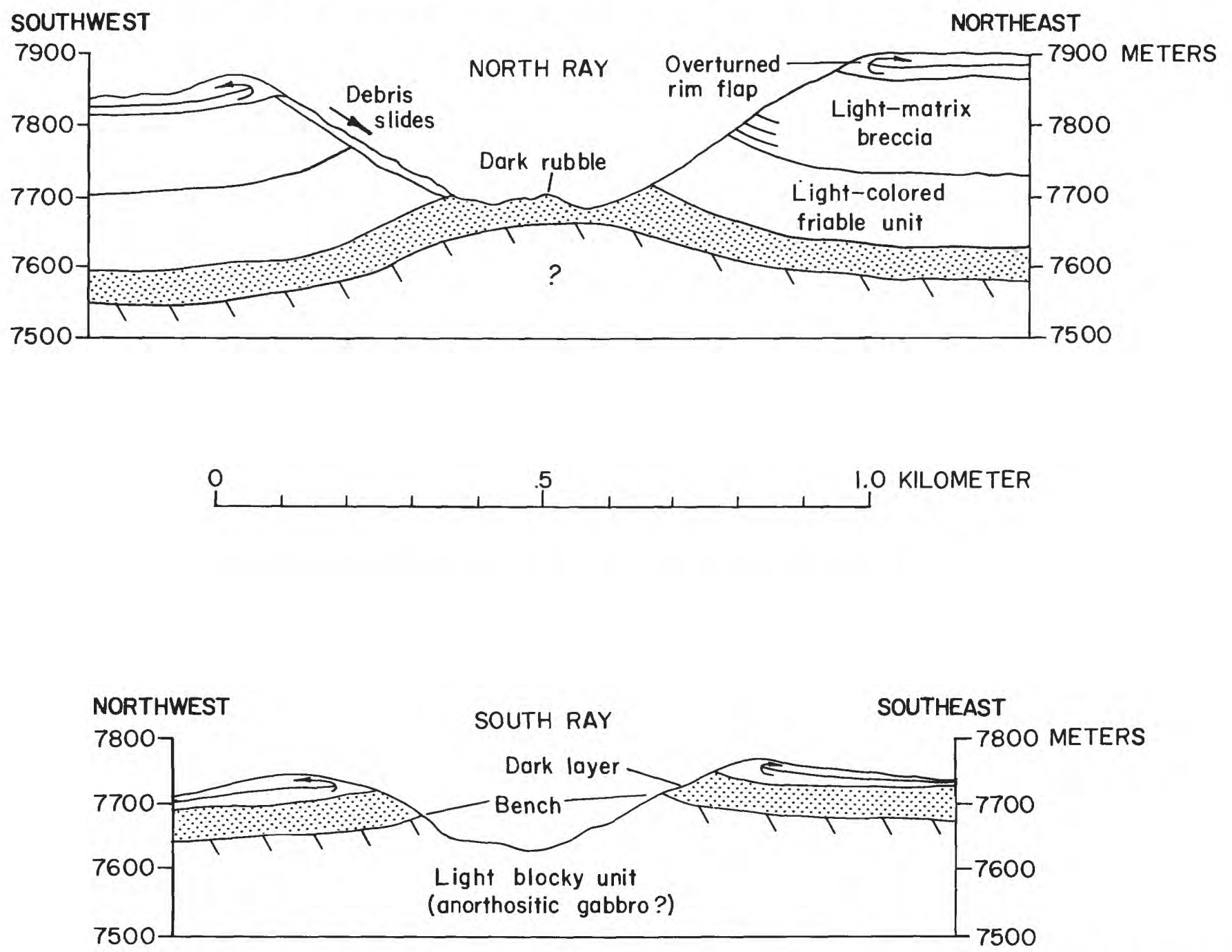

FIGURE 10.- Stratigraphy of North and South Ray craters proposed by AFGIT (1973). Reprinted with permission of the American Association for the Advancement of Science. 
"dry" light-matrix breccias above and dark melt-rich breccias below, grading locally into holocrystalline rock masses that underwent slower cooling (fig. 12).

The dark-colored layer at the bottom of North Ray was recognized by Delano and others (1973, p. 548) but was interpreted as consisting mainly of volcanic rock debris (brecciated feldspathic intersertal igneous rocks, "FIIR"), approximately 4.0 b.y. old (fig. 13). Their model was based on observations of 342 thin sections of 2 - to 4-mm fragments from 8 soil samples collected from all stations except 2 and 5 . The overlying units were unfortunately misinterpreted from Muehlberger and others (1972) as "regolith units" derived from one or more base surges generated by impact and deposited on top of the volcanic layer.

G. J. Taylor and others (1973) postulated an ancient pre-Imbrian regolith of LMB's developed on a deeper, and therefore older, anorthositic bedrock (ANT). Using
${ }^{40} \mathrm{Ar}-{ }^{39} \mathrm{Ar}$ ages from Schaeffer and Husain (1973, p. 1847) for a 2-4-mm fraction of soil on the rim of North Ray crater, together with their petrologic data on 645 1- to 2-mm particles from 5 soil samples (stations LM, $1,6,9$, and 11), they constructed the schematic model shown in figure 14. The ancient regolith is largely overlain by recrystallized anorthositic rocks (METAANT) deposited as mountains by one or several large impact events. Overlying these rocks, and at places the regolith, is the Cayley Formation, largely poikiloblastic rocks (3.8-3.9 b.y. old) filling in the low areas as a result of base-surge deposition from undefined sources. Overlying all units at the surface is the present-day regolith, about to be struck by the North Ray projectile. Neither dark-matrix breccias nor feldspathic basalts like 68415 are mentioned in their stratigraphic model.

More recent interpretations have incorporated other data into new or revised stratigraphic models. Head
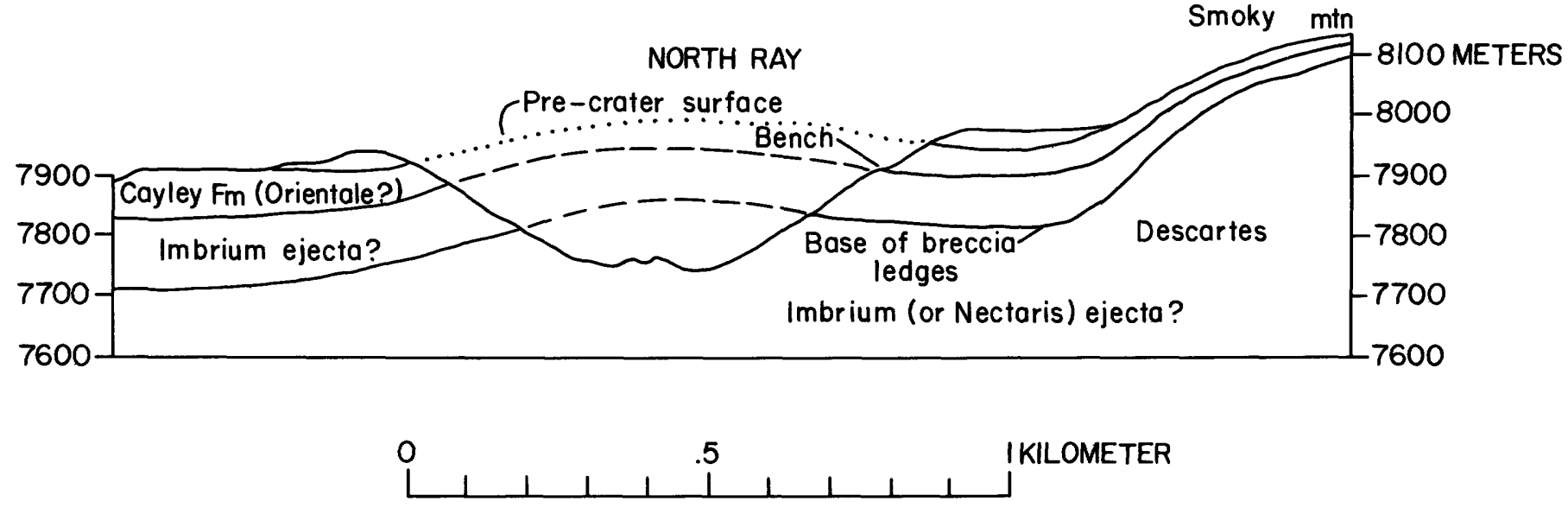

FiguRe 11.-Stratigraphy of North Ray crater proposed by Hodges and others (1973). Reprinted with permission of Pergamon Press.

SMOKY MOUNTAIN
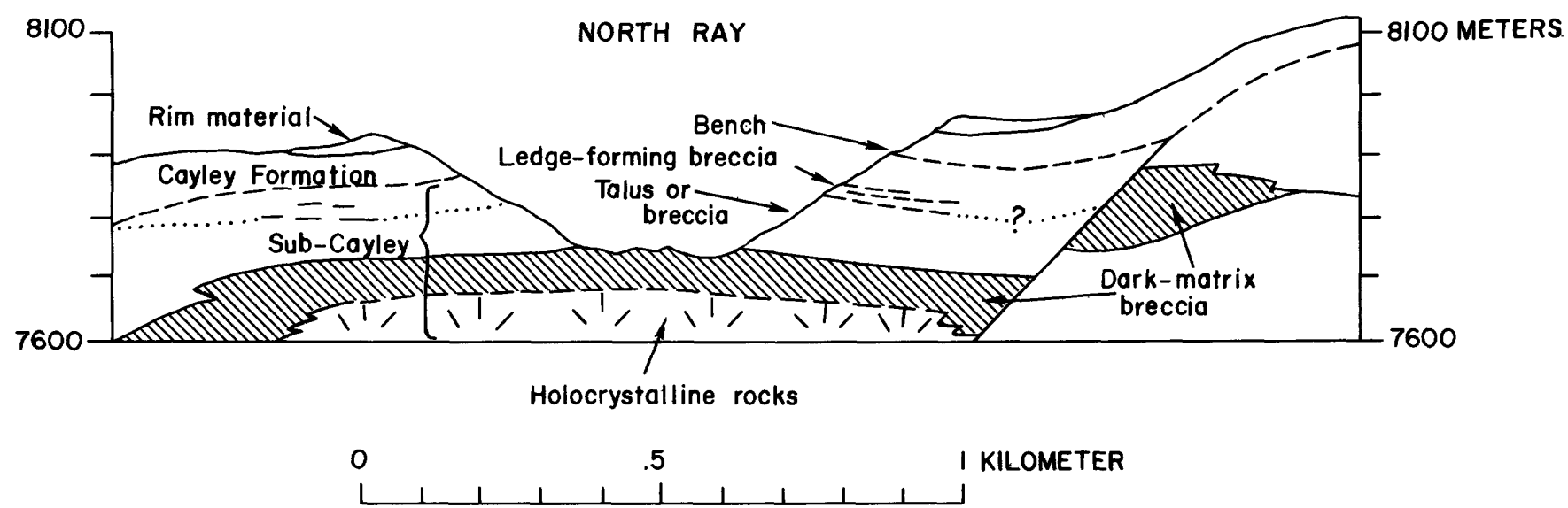

FIgURE 12.-Stratigraphy of North Ray crater proposed by Ulrich (1973). Reprinted with permission of Pergamon Press. 
(1974) has argued that the several breccia types described by LSPET (1972) and by Wilshire and others (1973) represent distinct layers in a stratigraphic sequence that is continuous across the landing site (fig. 15). He interpreted these units as ejecta blankets from, and fallback in, a succession of pre-Imbrium impact craters ranging from 40 to $150 \mathrm{~km}$ in diameter. Using essentially the sequence presented by AFGIT (1973) and Ulrich (1973), Head attributed the layers to local breccias and melt rocks from these craters. The Descartes mountains were considered to be Nectaris ejecta reworked by local impact events. The contributions from Imbrium and Orientale together are taken to be less than $30 \mathrm{~m}$. Inconsistencies in the relative age relations of this model are discussed by Hodges and Muehlberger (this volume).

Oberbeck and others (1974a, b, 1975) cited their studies of laboratory and Nevada Test Site craters as evidence that most of the materials forming upland plains must be locally derived. Their calculations are used to argue that most deposits are secondary ejecta and mass-wasted debris transported from the local highlands onto nearby lowlands. This model implies that nearly all materials in the uplands are chaotically mixed with very minor amounts of primary ejecta and produce no regionally consistent stratigraphic succession. It does not account for the degree of melting and differences in cooling rate reflected in the rather common thermally metamorposed and recrystallized rocks collected and photographed at both the Fra Mauro and Descartes sites.

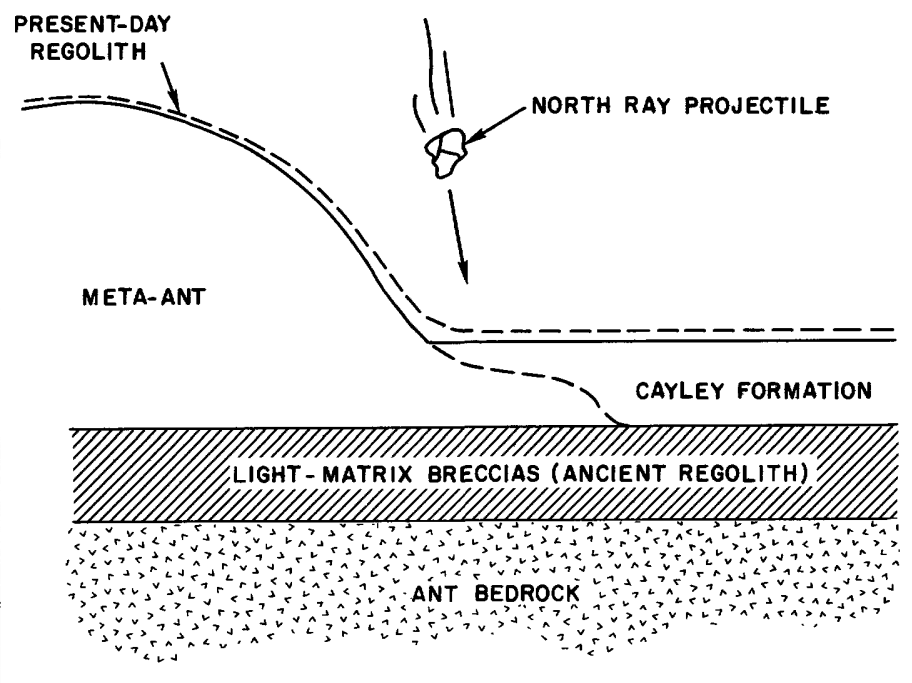

FIGURE 14.-Schematic stratigraphy of the landing site proposed by G. J. Taylor and others (1973). Light-matrix breccias are derived from older anorthositic bedrock (ANT) and overlain by recrystallized anorthositic rocks (META-ANT). Reprinted with permission of Pergamon Press.

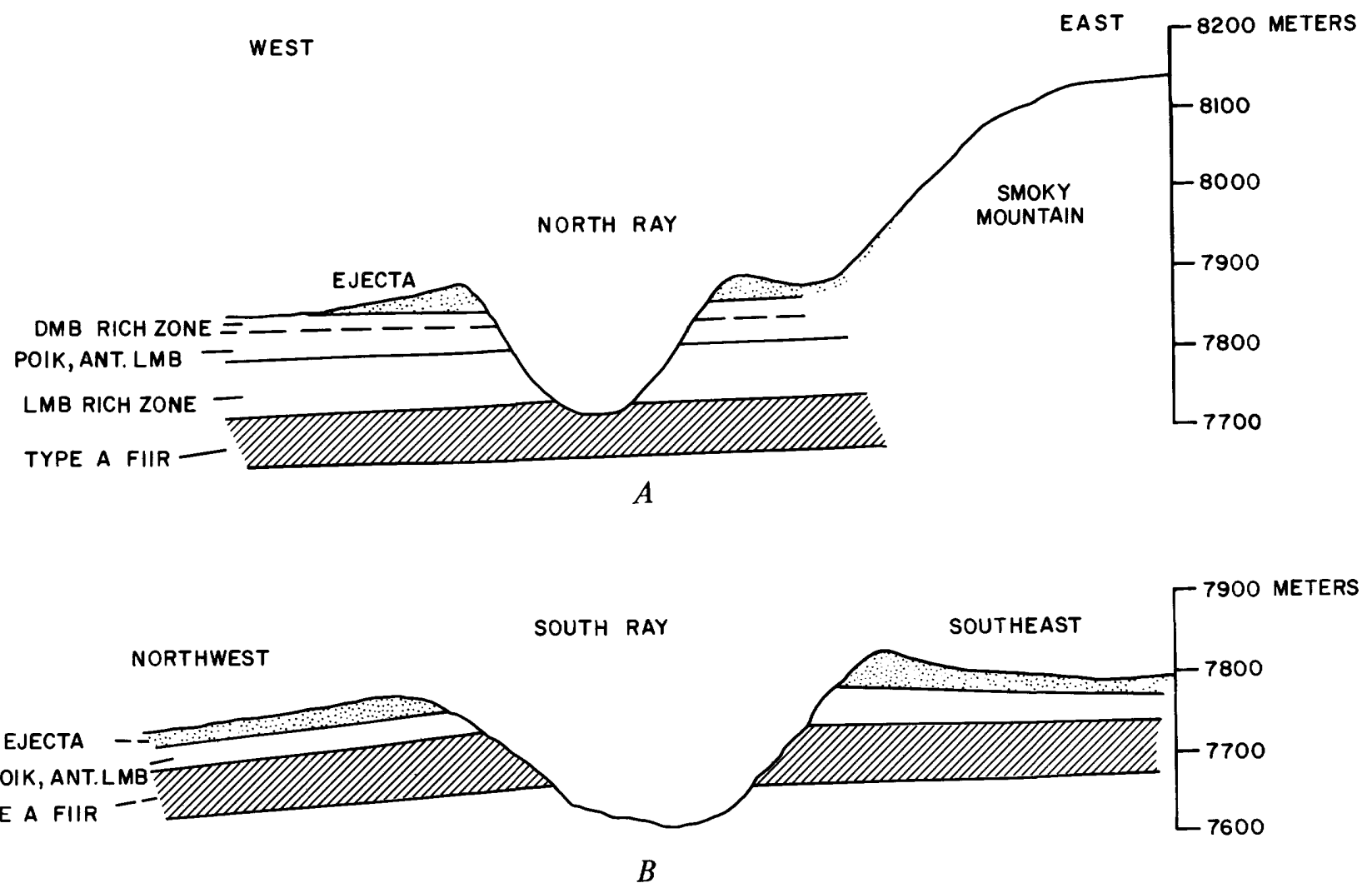

FIgURE 13.-Stratigraphy of North Ray $(A)$ and South Ray $(B)$ craters proposed by Delano and others (1973). Not to scale. Reprinted with permission of Pergamon Press. 
Analysis of meteoritic and volatile elements in rocks and soil samples by Ganapathy and others (1974) led them to assign three layers to a sequence of basin ejecta at the Apollo 16 site. According to these workers, an uppermost unit in North Ray crater consisting of LMB's covers much of the site; it is assigned to ejecta from the Imbrium basin. A middle unit in North Ray, cataclastic anorthosite devoid of meteoritic material, is regarded as ejecta from deep within the Nectaris ejecta. Their lowest unit, DMB, is interpreted as shallow Nectaris basin.

Recent discussions by McGetchin and others (1973) and by Moore and others (1974) have predicted gross stratigraphic models for the Apollo 16 site based on estimates of basin ejecta volumes and theoretical ejecta-distribution models. McGetchin and others (1973) gave the following calculated thicknesses for their preferred basin-rim and ejecta distribution model, from the top down (youngest to oldest basins): Orientale $1.4 \mathrm{~m}$, Imbrium $49.7 \mathrm{~m}$, Crisium $17.5 \mathrm{~m}$, Humorum $7.1 \mathrm{~m}$, Nectaris $201.5 \mathrm{~m}$, Serenitatis $54.3 \mathrm{~m}$, and all other recognized basins less than $10 \mathrm{~m}$ each, adding up to a total predicted thickness at the Apollo 16 site of $350 \mathrm{~m}$ from 10 basins on the Moon's earth side. Moore and others (1974) calculated basin volumes for Orientale and Imbrium; in addition, they made photogeologic estimates of ejecta thicknesses around these basins by measuring the thicknesses of the margins of distinct depositional lobes and the thicknesses of material filling preexisting craters. They estimated at least several hundred meters of Imbrium-related ejecta at Descartes on the basis of the relief of Stone mountain $(500 \mathrm{~m})$ and the depth of fill in crater Andel
M $(100 \mathrm{~m}) 130 \mathrm{~km}$ west of the landing site. The maximum contribution from Orientale was postulated to be $20 \mathrm{~m}$ thick.

Finally, our concept of the stratigraphic sequence within the landing site area incorporates the three fundamental rock units described earlier. The generalized interpretation preferred by us is illustrated in figure 16. While it does not answer the problem of which lunar basins, if any, are source areas for the materials (see also Hodges and Muehlberger, fig. 9, this volume), it fits the distribution of rock types and the photographic evidence as interpreted here.

\section{CONGLUSIONS}

The ejecta from craters in the Apollo 16 area, together with the morphologic characteristics of the craters themselves, provide a basis for a stratigraphic interpretation of the region. The Cayley Formation consists of several rock units having characteristic textural and color properties. These materials are locally mixed but form a gradational assemblage compatible with a crudely layered sequence of rocks whose chemical composition is essentially homogeneous. Samples from North Ray crater, at the northern end of the traverse area, are predominantly friable light-matrix breccias, so easily eroded as to form the convex upper slopes of the crater wall and the rounded and deeply filleted boulders on the rim and ejecta blanket. Field evidence suggests that these rocks are representative of both the mountains and the plains, but they appear more mixed with melt-rich materials in the plains, as shown schematically in figure 16 . The lowermost ma-

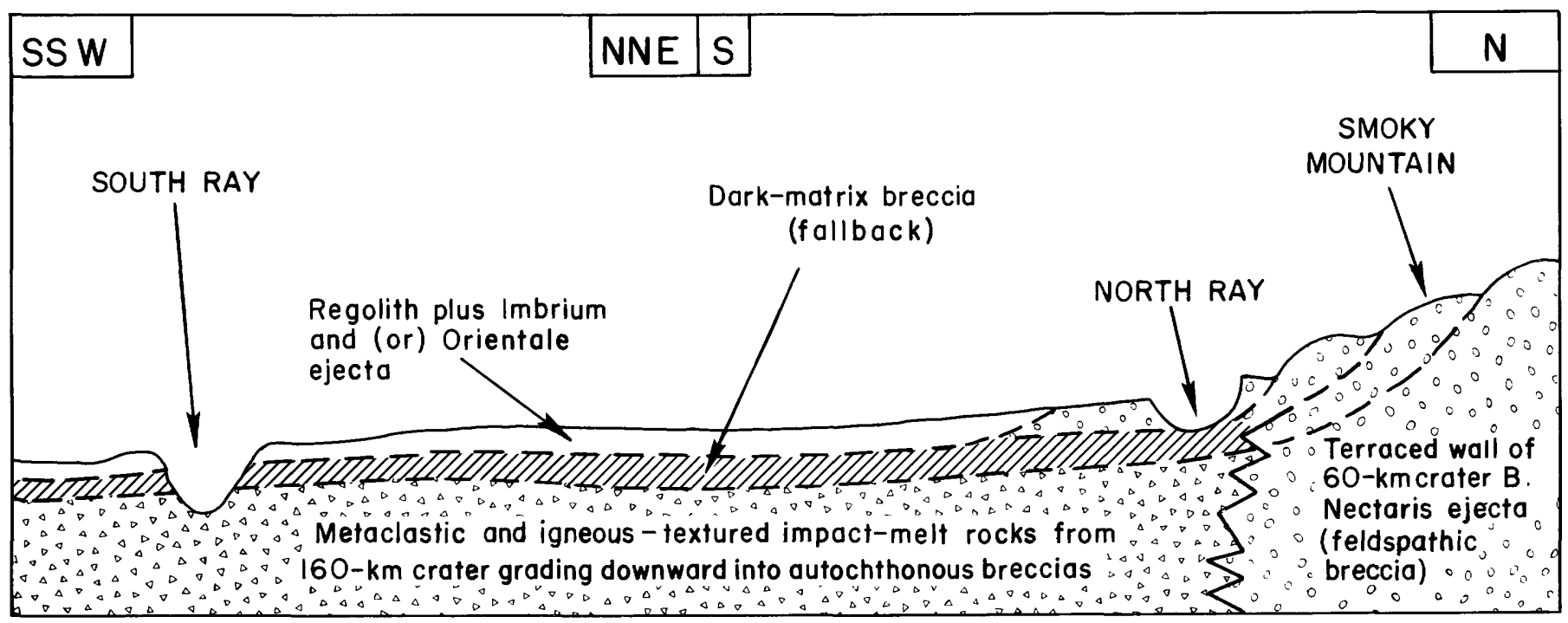

FIGURE 15.-Stratigraphy of the landing site proposed by Head (1974). Not to scale. Modified and reprinted with permission of J. W. Head and D. Reidel Publishing Co. 


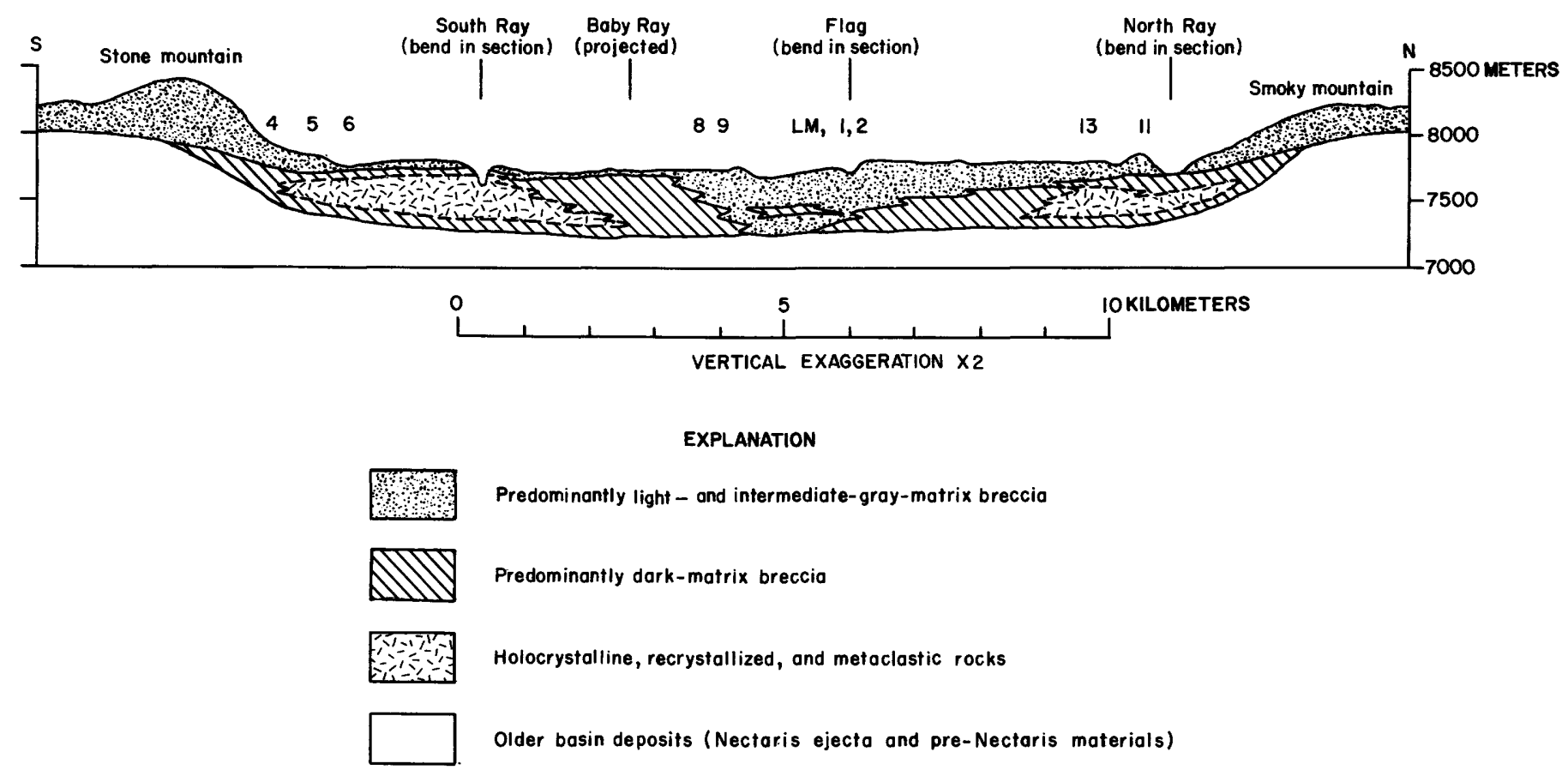

Figure 16.-Geologic cross-section of the Apollo 16 traverse area as interpreted in this discussion. Regolith not shown. Locations of stations 1 and 11 are as shown; 4, 5, and 6 are projected on Stone mountain by approximate elevation; other stations are projected on section by horizontal distance. (Profile from topographic map on plate 1 (this volume) with slight changes to interiors of North and South Ray craters).

terials in the crater's central floor mound are most likely the coherent glass-rich dark-matrix rocks that occur as sparse unfilleted blocks on the rim. The third main lithologic type is a hard white holocrystalline igneous-textured rock, best represented at station 8 within South Ray ejecta. It occurs as inclusions within dark-matrix breccias and interstitially in light-matrix breccias at North Ray. These occurrences together with the relative abundances of the melt rock and darkmatrix breccias in ray materials from South Ray crater and the photographic evidence for stratigraphic layering within South Ray and Baby Ray craters, suggest that the crystalline rocks underlie and may grade upward into the dark melt-rich breccias over much of the site. A local resistant layer at depths ranging from 10 to nearly $200 \mathrm{~m}$ may be reflected by floor mounds in craters '(diameter 0.5 to $1.8 \mathrm{~km}$ ) within the Cayley plains.

The materials of the Descartes highlands adjacent to the traverse area show no evidence of layering. The dominant rock type beneath the regolith at the highest point sampled on Stone mountain is most likely light-matrix breccia. The upper $100 \mathrm{~m}$ or so of the North Ray crater wall appears to consist of similar materials that may represent Smoky mountain. The paucity of coherent blocks in the ejecta of a fresh Copernican crater a kilometer deep and the high reflectance of the Descartes mountains indicates that they consist primarily of friable light-matrix breccias. For most of the Apollo 16 sample suite, the coarse anorthositic fragments within these breccias, whatever their source area (as pointed out by Wilshire and others, this volume), are candidates for the least modified crustal rocks.

\section{ACKNOWLEDGMENTS}

For numerous discussions and very helpful suggestions, C. A. Hodges, E. W. Wolfe, and W. R. Muehlberger are gratefully acknowledged. 


\title{
K. A SUMMARY AND CRITIQUE OF GEOLOGIC HYPOTHESES
}

\author{
By Carroll Ann Hodges and William R. Muehlberger
}

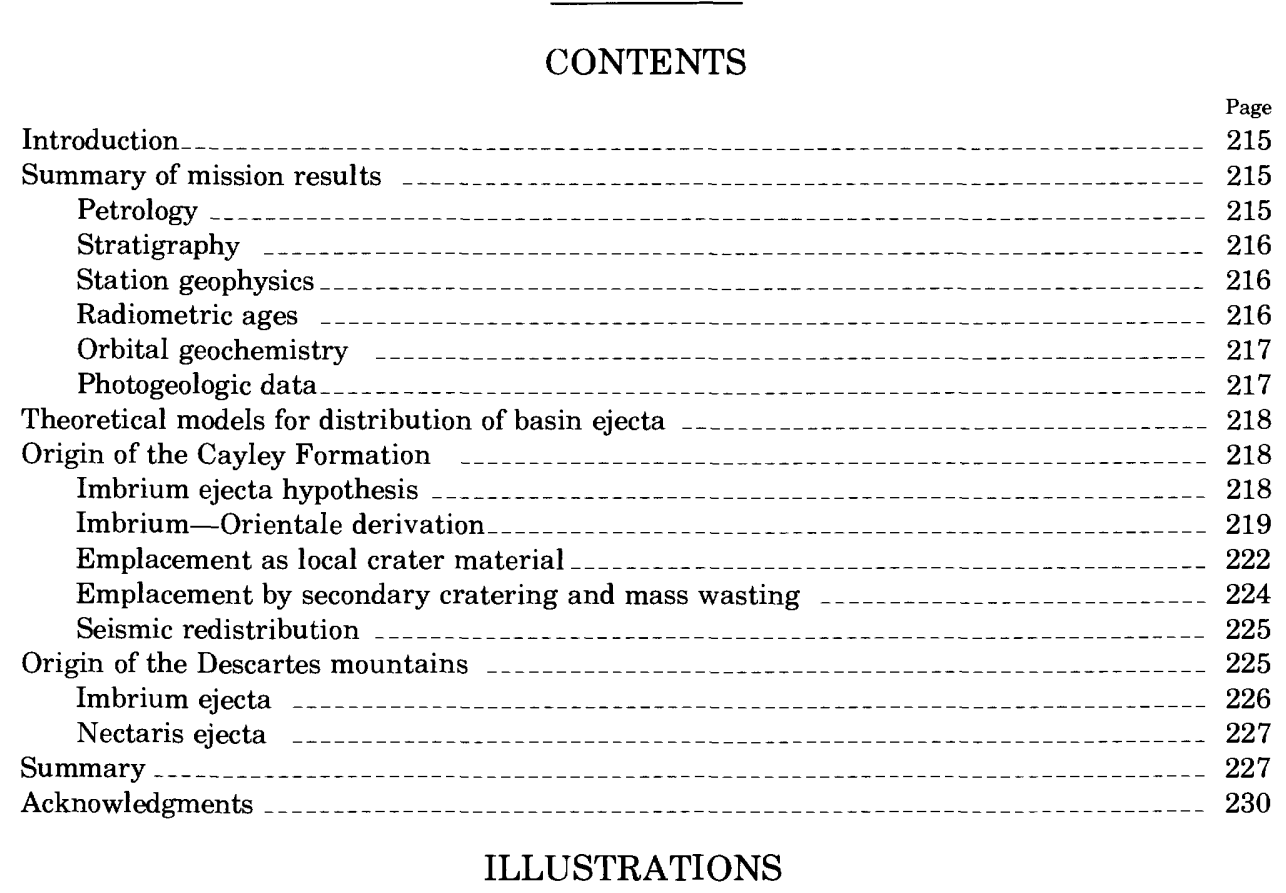

Page

Figure 1. Photograph of ghost craters in Cayley Formation in crater Ptolemaeus _...

2. Lunar Orbiter photograph of Orientale basin showing locations of figures 3 , 4, and 8

3. Lunar Orbiter photograph showing distal end of lineated Hevelius Formation

4. Lunar Orbiter photograph showing Cayley-like smooth plains material at base of leveed channel

5. Map showing large craters of various ages in vicinity of Apollo 16 landing site, from Head (1974)

6. Photograph of Apollo 16 landing site, showing deflection of lineated Imbrium ejecta patterns by the Kant plateau ------ 226

7. Lunar Orbiter photograph showing regional setting of Descartes area and probable deposits of Imbrium ejecta

8. Lunar Orbiter photographs showing relation of Orientale ejecta to preexisting craters

9. Hypothetical cross section of the Apollo 16 landing site

\section{INTRODUCTION}

Apollo 16 was perhaps the most scientifically provocative of the lunar missions. Widely held theories of volcanic origin for two major lunar photogeologic units, the Cayley plains and Descartes mountains, failed to withstand field inspection, and therefore investigators from many disciplines launched an intensive effort to determine the proper geologic context for the samples returned. The ubiquitous impact breccias in the samples required a reexamination of the origin of lunar landforms, particularly with respect to the significance of the enormous multiring basins. The areal distribution of ejecta from large crater- and basin-forming impacts in the lunar environment, and processes of mass wasting became immediate topics of debate. Geologic interpretations of morphologic characteristics are now modified and augmented by the field and orbital data obtained during the Apollo 16 mission.

In order to decipher the geologic history of the Apollo 16 site, results of the various mission experiments must be evaluated and combined. Outlined here are data and related implications critical to genetic theories for the Cayley plains, Descartes mountains, and similar geomorphic units elsewhere on the Moon.

\section{SUMMARY OF MISSION RESULTS PETROLOGY}

The mineralogy and textures of most samples re- 
turned by the Apollo 16 mission indicate an origin from a plutonic source region of gabbroic-anorthosite composition. Nearly all samples show evidence of modification by single or multiple impacts that produced a range of textures resulting from brecciation, recrystallization, and melting (Wilshire and others, this volume). High temperatures must have been generated during impact, and, dependent on rates of cooling, fineto medium-grained igneous textures developed (Grieve and others, 1974; Warner and others, 1974). The sample collections obtained at each station indicate that the various rock types are distributed homogeneously across the area (Wilshire and others, this volume) with the possible exception that breccias from the plains may be slightly richer in glassy to fine-grained matrix than those from the highlands. Rake samples are predictably biased toward resistant rock types, which predominate over the friable breccias. Many Apollo 16 samples have high concentrations of KREEP elements (potassium, rare earth elements, phosphorous), although in general they are not as KREEPy as those from Apollo 14 (Wanke and others, 1974).

The metallic iron content of the crystalline melt rocks, higher than in samples from any other site, implies reduction during melt formation at temperatures of at least $1,3000^{\circ} \mathrm{C}$, and slow cooling (Pearce and Simonds, 1974).

\section{STRATIGRAPHY}

Petrologic data, together with surface and orbital photographs, suggest a stratigraphic sequence of light and dark units in the plains materials at South Ray, Baby Ray, and North Ray craters (Ulrich and Reed, this volume). These units are probably discontinuous and irregular but the collection of light- and darkmatrix breccias at nearly all stations indicates their broad distribution. Subdued but hummocky topography around the margins of the plains southwest of Stone mountain and west of Smoky mountain (pl. 1) suggests that Descartes materials underlie the Cayley Formation in these regions.

Discontinuities within Cayley plains materials are shown by crater morphologies at the Apollo 16 site. Quaide and Oberbeck (1968) demonstrated that morphologic characteristics of impact craters are related to strength discontinuities in layered materials. Craters with mounds, central peaks, and flat floors are produced by experimental impacts on layered sand targets overlying an indurated substrate. Craters in relatively thin layers of sand have concentric structures such as terraces and benches formed at the discontinuities. Mounds on the floors of many 5001000-m-diameter craters at the Apollo 16 site (pl. 1) are, by analogy with the small laboratory craters, in- dicative of a resistant substrate at depths of approximately 100 to $200 \mathrm{~m}$. These lunar craters with floor mounds and other craters with benches suggest that the Cayley materials include both weak and resistant units. The depth of the shallowest discontinuity recognized ranges from 3 to 10 (averaging about $7 \mathrm{~m}$ ) and is interpreted as the base of the regolith at those points (Oberbeck, 1971a; Freeman, this volume). Crater morphologies on the Descartes mountains indicate a regolith thickness of 5 to $10 \mathrm{~m}$ (Freeman, this volume).

\section{STATION GEOPHYSICS}

Seismic experiments revealed only one identifiable velocity boundary, at $12.2 \mathrm{~m}$, interpreted as the base of the regolith in the ALSEP area (Cooper and others, 1974). The maximum potential depth of detection was $220 \mathrm{~m}$.

The portable magnetometer registered magnetic fields higher than at any other landing site, values ranging from 121 gammas near the lunar module to 313 gammas at station 13 on the continuous ejecta blanket of North Ray crater (Dyal and others, 1972). The magnetic field vector on Stone mountain is opposite that on the plains and at North Ray. The unusually high magnetic fields indicate that a substantial body of rock was emplaced in a strong magnetic field at a temperature above the Curie point of iron, approximately $770^{\circ} \mathrm{C}$. Breccias within a hot ejecta blanket several hundred meters thick could have acquired remanent magnetism during cooling (Strangway and others, 1973). The Descartes material is apparently less magnetized and could have been emplaced as a relatively cool mass of ejecta approximately contemporaneous with the hotter planar (Cayley) facies. A possible though less likely alternative is that the reversal in direction of field or Stone mountain implies difference in time of deposition of Stone mountain materials with respect to the plains.

\section{RADIOMETRIC AGES}

Isotope analyses of both rock and soil samples show a broad spectrum of ages-in some cases for one specimen, depending on method used and (or) laboratory involved (Wilshire and others, this volume). Most of the data available are from samples collected at North Ray crater (stations 11 and 13), the LM site, and station 8; two rocks from station 5 on Stone mountain and several from stations 1,2 , and 6 on the plains have been dated. Ages of rocks and crystals range from approximately 3.5 to $4.5 \mathrm{~b} . \mathrm{y}$.; most cluster around 3.8 to 4.0 b.y. The ages of individual grains of coarse fines from soil samples have a wider range but generally are older, clustering at about 4.0 b.y., with some samples as old as 4.26 b.y. (Schaeffer and Husain, 1973). 
The relatively narrow range in ages of highlands rocks from different Apollo sites may result from pervasive blanketing by a single event, such as the Imbrium impact, or the formation of many basins during a very brief time interval (Tera and Wasserburg, 1973).

A stratigraphic sequence based on sample ages has yet to be determined because the immediate source craters of individual rocks are not readily identified except for those samples from station 11 on the rim of North Ray. The original depths of the returned samples are largely unknown. Some radiometric ages of breccia fragments probably reflect neither time of crystallization nor time of shock metamorphism (Wilshire and others, this volume); whole-rock ${ }^{40} \mathrm{Ar}-{ }^{39} \mathrm{Ar}$ analyses probably produce composite ages. Some single-crystal determinations yield dates as old as 4.5 b.y. that may be inherited from original plutonic source rocks. The radiometric data available have yet to confirm a stratigraphic sequence, much less identify local individual layers or distant sources.

\section{ORBITAL GEOCHEMISTRY}

Gamma-ray spectrometer data from the orbiting command module, resolved in $2^{\circ} \times 2^{\circ}$ cells, show higher concentration of radioactive elements in the maria, particularly the western maria, than in the highlands. Anomalous radioactivity was recorded for the highlands near Aristarchus, south of Archimedes, and south of the Apollo 14 landing site near Fra Mauro, but there is no unique geologic feature or unit identifiable in photographs to which the radioactivity can be attributed. KREEP-rich material, abundant at the Apollo 14 site, may be the source of the anomalous radioactivity there (Metzger and others, 1973). Although KREEP material has been identified in Apollo 16 samples, no radioactive anomaly occurs in the orbital data.

Orbital X-ray fluorescence data show good correlation between the two major lunar terrain types and chemical composition. Despite local variations, the highlands, of moderately high albedo, have a consistently higher $\mathrm{Al} / \mathrm{Si}$ ratio than the dark maria, although at any given point detection is limited to a depth of less than $0.1 \mathrm{~mm}$ (Adler and others, 1973). Consistent or well-defined correlations are not otherwide apparent between chemical signature and topography.

\section{PHOTOGEOLOGIC DATA}

Interpretation of the geologic environments of the Apollo landing sites remains dependent to a large extent on the photographic record. Photogeologic units over the entire lunar surface have been delineated according to morphologic characteristics. Genetic hypotheses must account for the characteristic ponding of Cayley Formation in topographic lows at the Apollo 16 site and elsewhere and for the rugged sculptured appearance of the adjacent Descartes mountains. Apollo metric and panoramic photographs show clearly the details of lunar topography, but at their high resolutions (about $20 \mathrm{~m}$ and $2 \mathrm{~m}$, respectively), contacts between geologic units (or at least between regoliths formed on different units) that looked sharp on premission photographs now appear gradational. The prominent breaks in slope at which contacts are drawn, however, are presumed to mark genetic, as well as morphologic, differences (pl. 1).

The preservation of large, subdued, and apparently mantled craters in some areas of Cayley plains, such as in the craters Ptolemaeus and Albategnius, suggests at least two successive events or stages of deposition. Similarly, a flexure in the cumulative frequency distribution curve for craters several kilometers in diameter in Albategnius indicates that two distinct populations occur, possibly as a result of mantling or reworking of a preexisting cratered surface (Boyce and others, 1974). If a mantling deposit exists, its thickness may be estimated by using the equations of Pike (1972) for fresh craters. The original rim height of a $4.5-\mathrm{km}$ crater, barely discernible under low lighting conditions, was about $200 \mathrm{~m}$; the thickness of the mantle in this area, therefore, is of the order of $200 \mathrm{~m}$ or less, depending on the amount of rim erosion prior to and concurrent with deposition of the mantling debris.

Crater size-frequency distributions and relative ages determined using crater degradation models indicate that the morphologic ages of the surfaces of Cayley plains are essentially the same and contemporaneous with those of the Orientale basin and its ejecta; they are younger than Imbrium basin ejecta for which the net accumulated flux is 2.5 to 3 times greater (Trask, 1966; Ulrich and Saunders, 1968; Greeley and Gault, 1970; Soderblom and Boyce, 1972; Boyce and others, 1974). Although there are uncertainties inherent in the methods of determining ages of surfaces using crater morphologies and crater frequency distributions, both techniques imply that two separate events affected widespread areas of the Moon early in lunar history.

The apparently uniform age of the Cayley plains surfaces could have been produced in several ways: (1) widespread deposition of ejecta from a basin (Orientale) that obliterated small preexisting craters and mantled large ones; (2) extensive erosion and reworking of the preexisting cratered surface by basin ejecta, forming secondary craters with little accumulation of primary material; (3) obliteration of craters by settling of unconsolidated debris in response to the seismic 
shock generated by a large basin-forming impact (Schultz and Gault, 1974); (4) a pervasive exogenic event such as a large influx of debris from space. The last alternative is improbable according to the analyses of the meteoritic elements in breccias, which indicate that the large basin-forming impacts predominate over the small, more numerous crater-forming events (Morgan and others, 1974). Each of the first three possibilities, however, is plausible, and all may have significantly influenced the modification of light plains surfaces.

The surface of Stone mountain locally appears less cratered than the Cayley Formation, and the mantled crater population is not apparent on the adjacent Descartes mountains. These differences might indicate that more friable bedrock materials occur in the highlands, enhancing erosion and mass-wasting, and (or) that mass wasting is a more effective modifying process on rugged topography than on plains. Whatever the cause, the process that mantled or modified the plains surfaces must also have affected the highland materials of similar age.

An acceptable hypothesis of origin for the Cayley and Descartes units must account for the data outlined above. Ideally, interpretations of the gelogy at the Apollo 16 site will permit extrapolation to similar photogeologic units elsewhere.

\section{THEORETICAL MODELS FOR DISTRIBUTION OF BASIN EJECTA}

Several models for the volume and distribution of ejecta from multiring basins have been proposed in order to determine the significance of specific basins at specific points on the lunar surface. Short and Forman (1972) estimated the average thickness of ejecta blankets from all craters and basins 3.5 to $400 \mathrm{~km}$ in diameter on the lunar near side; they concluded that the surficial highlands materials (including those at the Apollo 16 site) were derived mainly from basins and averaged about 1 to $2 \mathrm{~km}$ thick. Assuming uniform azimuthal distribution of ejecta and a linear decrease of ejecta thickness from the crater, isopach maps of ejecta blankets around basins were contoured outward to $1 \mathrm{~km}$ thickness; by extrapolation from their model to the Apollo 16 site, as much as $0.5 \mathrm{~km}$ of ejecta from Imbrium and $1.5 \mathrm{~km}$ from Nectaris should occur there (as well as ejecta from Nubium).

McGetchin and others (1973) predicted the thickness of ejecta from various basins at the Apollo 16 landing site as a function of distance from basin centers. The critical factors in their calculations are basin radius, thickness of ejecta at the rim, and the variation in thickness of ejecta as a function of distance from the basin on a flat Moon. At the Apollo 16 site, they pre- dicted a maximum of about $1.4 \mathrm{~m}$ of ejecta from Orientale, about $50 \mathrm{~m}$ from Imbrium, and $200 \mathrm{~m}$ from Nectaris.

Photogeologic evidence (Moore and others, 1974) indicates that the thickness of ejecta at the Cordilleran rim of Orientale is much greater than that assumed by McGetchin and others (1973), and the thickness therefore is probably greater at the Imbrium rim. The total volume of ejecta from the Orientale and Imbrium basins may be as great as 5 to 7 and 15 to 20 million $\mathrm{km}^{3}$, respectively (Moore and others, 1974). The equations of McGetchin and others (1973) for small craters applied to the Orientale basin with a transient cavity $600 \mathrm{~km}$ across predict a uniform thickness on a spherical Moon of $20 \mathrm{~m}$ of Orientale ejecta as far away as the Apollo 16 site (Moore and others, 1974). It seems possible that a substantial amount of relatively fine debris, ejected at velocities of 1.6 to $2.3 \mathrm{~km} / \mathrm{sec}$ and angles of $60^{\circ}$ or less (Chao and others, 1975), could produce a deposit of primary ejecta as distant as several thousand kilometers from its source. Mixing certainly must occur in such a deposit, but if sufficient numbers of particles are introduced, net deposition must also occur. The rays of small Copernican craters demonstrate that ejecta can travel thousands of kilometers (Baldwin, 1963; Moore and others, 1974). By analogy with Orientale, as much as $500 \mathrm{~m}$ of ejecta from Imbrium theoretically could occur at the Apollo 16 site (Moore and others, 1974), and photogeologic evidence in the region indicates that it does.

In all of these theoretical models, the ejecta is distributed symmetrically outward across the entire Moon with uniformly decreasing thickness. Observational evidence, however, clearly indicates that the continuous ejecta blanket extends about one and a half crater radii from the rim (Moore and others, 1974) and that beyond it are only discontinuous rays composed of clots of ejecta and disturbed local debris. Actual thickness of primary ejecta at any given point differs considerably from thickness predicted by these mathematical models (see also Moore and others, 1974).

\section{ORIGIN OF THE CAYLEY FORMATION}

The hypotheses proposed by various investigators to explain the emplacement of the Cayley plains fall into two major categories: (1) basin related and (2) locally derived.

\section{IMBRIUM EJECTA HYPOTHESIS}

Perhaps the earliest comments on the extent of Imbrium ejecta were by Gilbert (1893), who noted on the basis of telescopic observations, that a "deluge of material-solid, pasty, and liquid" was disgorged from the Imbrium basin and "reached nearly to the crater 
Theophilus." The Descartes region was presumably included in this broad flooded area, and indeed, Gilbert attributed the morphologic aspects of much of the lunar surface to deposition of ejecta from Imbrium: "A part [of the surface] was buried by liquid matter whose congelation produced smooth plains. Another part was overrun by a flood of solid and pasty matter which sculptured and disguised its former details."

Eggleton and Schaber (1972) added a different twist to the concept, proposing a fluidized debris cloud of ejecta from Imbrium that contained entrapped gases (such as silicate vapor). Although no adequate terrestrial or experimental analogs for lunar basins exist, this hypothesis does seem to offer a plausible mechanism of emplacement (pl. 12). Some breccia samples are distinctly vuggy, and the ghost craters visible in Ptolemaeus and Albategnius suggest differential compaction of the surficial materials, as would be expected in a fluidized unit deposited on a preexisting cratered surface (fig. 1). The apparent contemporaneity of the present surface with Orientale ejecta rather than with the Fra Mauro Formation (Boyce and others, 1974) requires a subsequent modifying process, although the

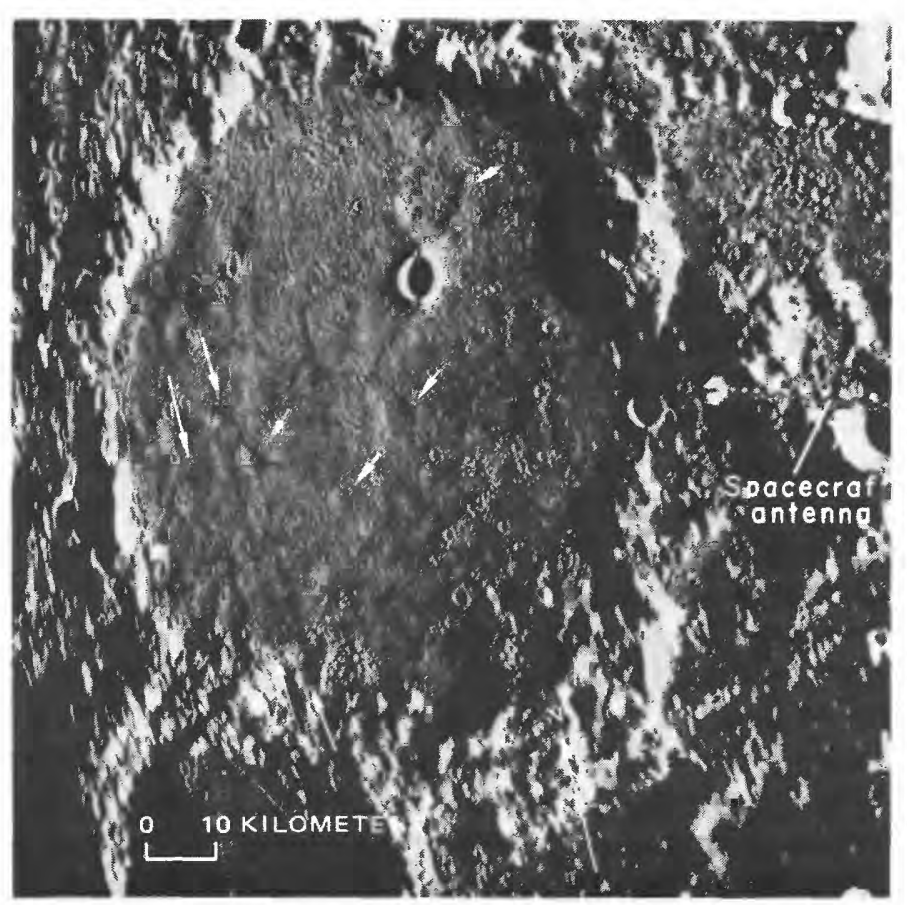

Figure 1.-Ghost craters in Cayley Formation in crater Ptolemaeus. Subdued troughs (long arrows) trending northnorthwest may be buried Imbrium sculpture. Subdued appearance of ghost craters (short arrows) may result from degradation and mantling of initially sharp craters on Imbrium planar ejecta by later Orientale ballistic ejecta. Buried elongate crater couplet (above fresh crater) is Imbrium secondary "chain." Apollo 16 mapping camera frame 0578 . intrinsic relief of the plains could still be attributed to Imbrium-related debris.

The samples from Apollo 16, being more feldspathic and lower in KREEP component than the Imbrium ejecta identified at Apollo 14 (Wilshire and Jackson, 1972a; Chao, 1973; Wanke and others, 1974), probably were not derived from the same local source area, although homogeneity of ejecta from basins the size of Imbrium is unlikely. Inasmuch as ejecta from terrestrial impact and laboratory craters are zoned in texture and composition both vertically and horizontally (Moore, 1971; Oberbeck, 1971b; Shoemaker, 1974), a basin conceivably 130-200 km deep (Moore and others, 1974; Dence and others, 1974) must have intersected heterogeneous crustal materials. The petrologic differences can be accommodated in the hypothesis of Imbrium origin for both the Cayley Formation and the Fra Mauro Formation. Zonation of ejecta from large basins into KREEP-poor and KREEP-rich facies would be expected for some models of the lunar crust and mantle (Taylor and Jakes, 1974).

\section{IMBRIUM-ORIENTALE DERIVATION}

Orientale is the youngest of the multiring basins. Unlike other basins on the lunar near side, it is only partly flooded by mare lava; its internal structure, therefore, as well as the morphology of its ejecta blanket, is largely preserved (fig. 2). The hummocky, textured Hevelius Formation (McCauley, 1967), the most conspicuous unit of the ejecta blanket, grades outward into a planar facies of ejecta (fig. 3) that flowed into topographic lows (Eggleton and Schaber, 1972; Hodges and others, 1973; Moore and others, 1974). Prominent lobate escarpments (figs. 3 and 4 ) occur in plains material as far as $1,470 \mathrm{~km}$ from the basin center. These plains are formed by a smooth facies of basin ejecta, intermingled with the grooved and secondary-crater erosional facies (Moore and others, 1974). It is therefore probable that a similar facies of Imbrium ejecta formed at the periphery of the hummocky, textured Fra Mauro Formation, producing an extensive but discontinuous planar unit (Eggleton and Schaber, 1972); such planar deposits may constitute a major proportion of Cayley-type plains materials peripheral to the Imbrium basin. Because the apparent ages of these plains surfaces are contemporaneous with the plains at Orientale, which are post-Imbrium, it has been suggested (Hodges and others, 1973; Chao and others, 1973) that the surficial materials of such plains may be partly ballistic ejecta from Orientale.

According to this hypothesis, the Cayley plains at the Apollo 16 site and similar plains elsewhere adjacent to the Fra Mauro Formation were formed by ma- 


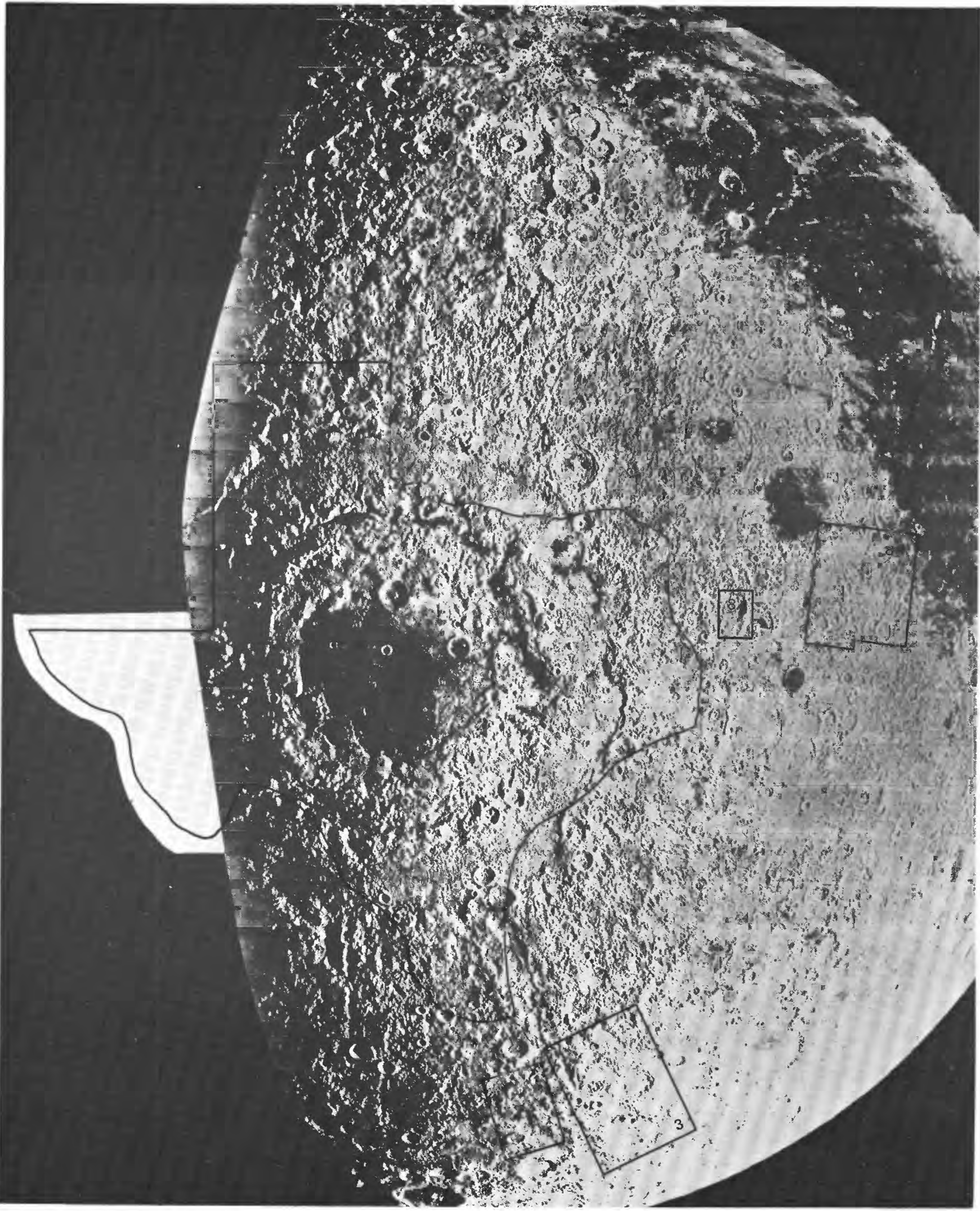

Figure 2.-Orientale basin. Diameter of outermost Cordillera ring, $930 \mathrm{~km}$. Areas shown in figures $3,4,8 A$, and $8 B$ (outlined) lie within ejecta blanket. Lunar Orbiter IV, frame $187 \mathrm{M}$. 
terials derived from at least two different basins. The deposits are composed largely of a hot-ejecta facies from Imbrium that flowed as part of the continuous ejecta blanket and that may have been lubricated by entrained gases or possibly by inclusions of impact melt; topographic and embayment relations require that it be relatively late in the ejecta sequence. The plains thus formed were cratered and subsequently veneered by ballistic ejecta from Orientale with variable thickness and asymmetric distribution. Incoming particles from Orientale must have eroded and sub-

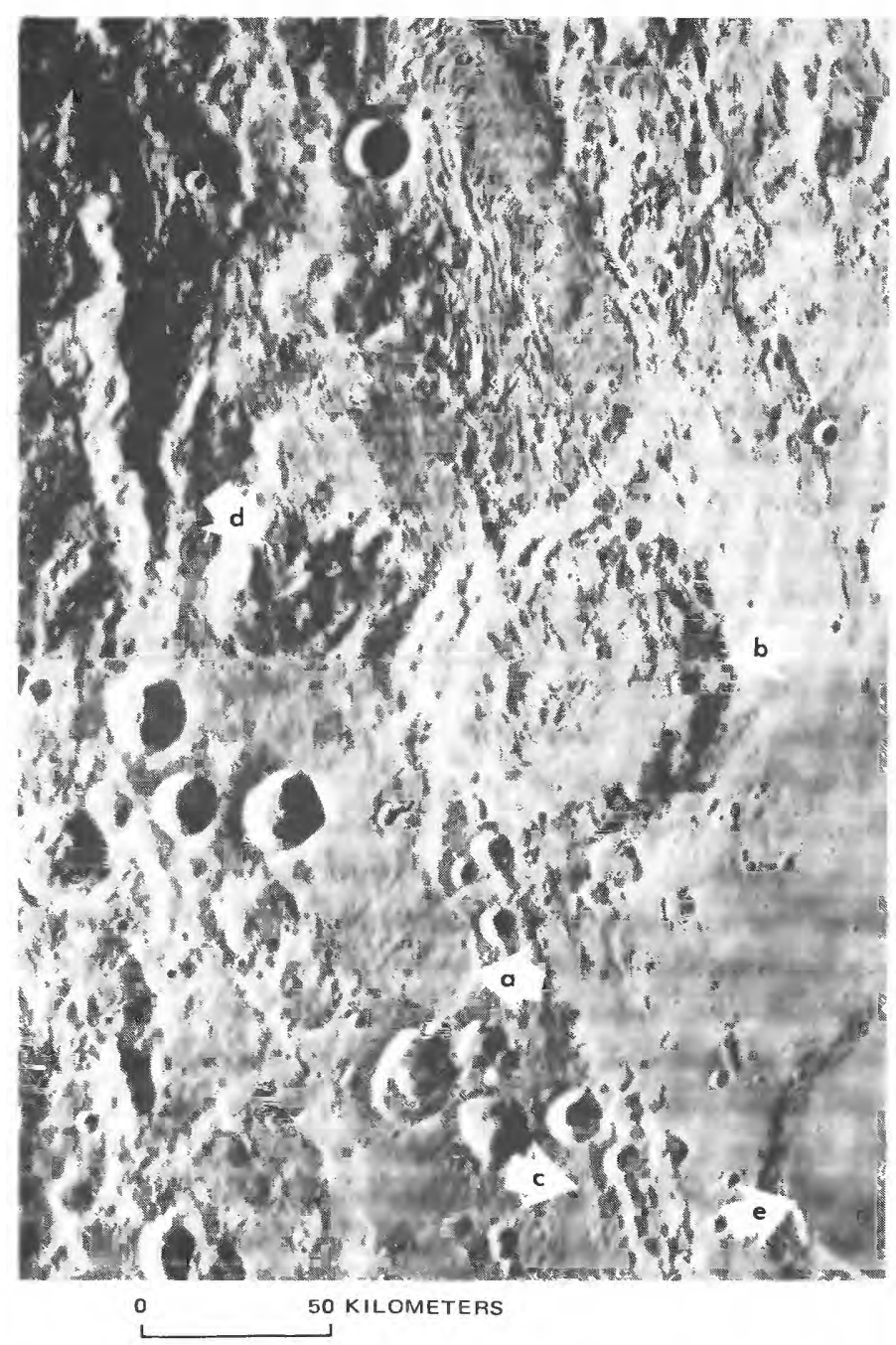

Figure 3.-Distal end of lineated Hevelius Formation (Orientale ejecta) showing gradation into Cayley-like, planar, nontextured facies, about $1,050 \mathrm{~km}$ southeast of center of Orientale basin. Flow lobe (a) is about $400 \mathrm{~m}$ thick; concentric ridges within Inghirami (b) are dunes attributed to deceleration of ejecta. Secondary craters produced by impact of Orientale ejecta form crater chains (c) with chevron ridges below Inghirami. Crater (d) to left of Inghirami is partly filled with ejecta. Half of crater Wargentin (e) is at lower right. Lunar Orbiter IV, frame $180 \mathrm{H}$. (From Moore and others, 1974, fig. 7). Reprinted with permission from H. J. Moore (copyright 1974) Pergamon Press. dued the preexisting terrain (Oberbeck and others, $1974 \mathrm{~b}, 1975)$ so that at least the lower part of such a mantle would be partly mixed with local debris. The assumption inherent in this concept is that the particle-size-frequency distribution is such that net influx of ejecta is great enough for a deposit to accumulate, despite the erosive action of first arrivals. Such ejecta from Orientale must have been deposited concurrently on the highlands, but where preexisting topography is rugged, mantling deposits are less easily recognized.

This hypothesis accounts for the apparent age of the Cayley surfaces as well as for their planar aspect. The high remanent magnetism could have been induced in the hot facies of Imbrium ejecta as that planar unit cooled through the Curie point. The conspicuous impact-melt textures in Apollo 16 samples are compatible with their interpretation as constituents of partly molten ejecta from a large basin. Both the abundance

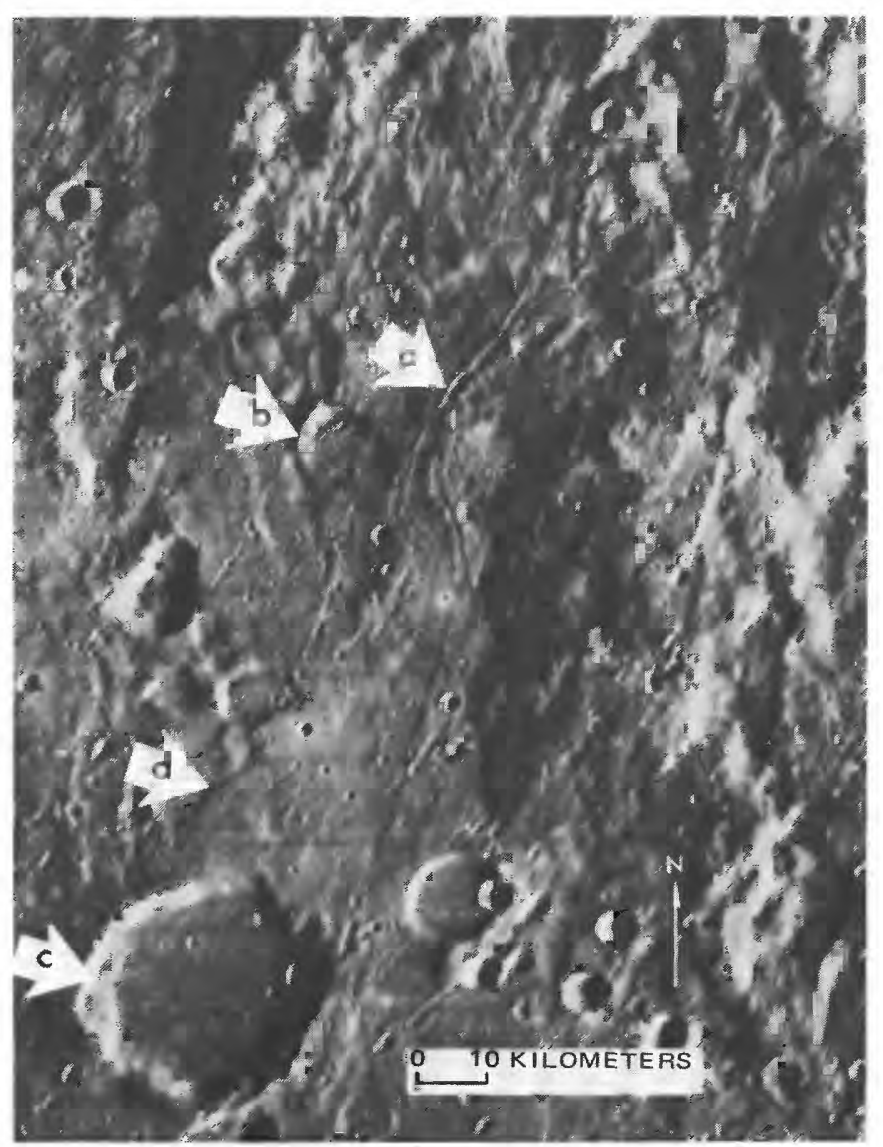

Figure 4.-Cayley-like smooth plains material at base of leveed channel (a), about $1,100 \mathrm{~km}$ south of center of Orientale; radially ridged Hevelius Formation (Orientale ejecta) at top. Smooth plains unit fills craters $b$ and $c$. Flow margin visible at $d$. Lunar Orbiter IV, frame 186 H. (From Moore and others, 1974, fig. 6). Reprinted with permission from H. J. Moore (copyright 1974) Pergamon Press. 
of metallic iron and its coarse grain size in the melt rocks, as compared with the breccias and soils, have been interpreted as evidence for reduction of iron during the formation of the crystalline rocks as impact melts, cooled slowly in an ejecta deposit (Pearce and Simonds, 1974). Photogeologic evidence described earlier supports the presence of a substantial thickness of rugged Imbrium ejecta at Andel M (Moore and others, 1974) near Apollo 16 and in the crater Descartes to the south (Hodges, fig. 2, this volume), and a distal planar facies analogous to the plains of the Orientale ejecta blanket should logically occur.

The presence of several craters 0.5 to $1.0 \mathrm{~km}$ across with central mounds (pl. 1) suggests that a discontinuous interface with a resistant layer may occur at depths of 100 to $200 \mathrm{~m}$. The mound craters are not everywhere the same depth, and thus irregular "pods" of rock cemented by impact melt within the Imbrium planar facies could account for this morphologic feature.

Cayley-type plains occur within the Orientale basin marginal to the central mare material and are most likely analogous to the plains materials within young craters such as Arzachel (Wilhelms and McCauley, 1971), Theophilus (Milton, 1968), and Langrenus (Hodges, 1973). Such craters have relatively smooth floors and "pools" of smooth material on their rims and flanks that may have been fall-back and fallout ejecta or melt produced by the crater-forming impact (Howard and Wilshire, 1975).

The principal problems inherent in this hypothetical origin for Cayley-type plains involve estimates of ejecta volume for the large basins, mechanisms of transport and deposition, and determinations of relative ages of surfaces.

As discussed earlier, the model of McGetchin and others (1973) permits a thickness of only $50 \mathrm{~m}$ of ejecta from Imbrium at the Apollo 16 site and virtually none from Orientale. The hypothesis of Oberbeck and others $(1974 b, 1975)$ requires local derivation of the plains materials, largely as ejecta from secondary craters, but allows as much as 20 percent of that ejecta to be primary debris from Imbrium and 12 percent to be primary from Orientale. Moore and others (1974) estimated much greater potential thicknesses of Imbrium and Orientale ejecta.

If the surfaces of the Imbrium plains deposits were smoothed and the crater age clocks reset by the Orientale event, then some deposits of the Fra Mauro Formation also should have been reset. Apparent age differences could be retained at any given place because of the asymmetric distribution of Orientale ejecta and the ruggedness of the underlying Fra Mauro topography (whereby even a thick mantle would not obscure that topography). There are light plains surfaces that have Imbrium basin ages (Boyce and others, 1974) and preImbrian ages (Wilhelms and McCauley, 1971), indicating that whatever post-Imbrium modification occurred was irregularly distributed. Because the crater erosion model for determining the age of a unit is not applicable to rugged deposits like the Fra Mauro Formation, crater-frequency distributions are the basis for interpreting the age of that ejecta blanket (Soderblom and Boyce, 1972). If craters disappear more rapidly on rugged surfaces, as has commonly been asserted, a greater number of them on the Fra Mauro Formation is additional evidence that age differences are real. If, on the other hand, these analyses of crater populations failed to eliminate craters that, though circular, may actually be Imbrium secondary craters rather than part of the post-Imbrium flux, then the age so determined would be erroneously old. This potential error, however, would not explain the apparent contemporaneity of the younger Orientale plains with Cayley plains if the Cayley were made up entirely of Imbrium ejecta. The much fresher appearance of the Hevelius Formation as compared with the Fra Mauro Formation shows either that a significant time interval did elapse between formation of the two basins or that the Orientale ejecta was dispersed widely enough to mantle or erode preexisting Imbrium morphologic features, or possibly that the seismic effects of the Orientale impact were great enough to subdue the Imbrium topography.

If Orientale ejecta is as widely distributed as postulated herein, then most of the secondary projectiles must have been nearly uniform in size for stirring and mixing of the upper preexisting material to produce a relatively smooth surface. The last ejecta from Orientale must have restructured mainly earlier deposits from the same source. Secondary crater clusters conclusively related to Orientale, which would be persuasive evidence for deposition of Orientale ejecta, are notably lacking in the central highlands region, but the conspicuous Davy crater chain is a possible candidate. Oberbeck and Morrison (1973) pointed out the likelihood that it is of secondary origin with a source of projectiles to the west. They also state, however, that the size of the primary crater need not be larger than Copernicus. The alinement of the chain, its degraded appearance, and its occurrence in Cayley materials are compatible with an Orientale origin, although none of these characteristics is diagnostic.

\section{EMPLACEMENT AS LOGAL CRATER MATERIAL}

Head (1974) proposed that the Cayley Formation at the Apollo 16 site was locally derived, essentially from impact melt and brecciated crater fallback. He sug- 
gested that the Descartes mountains were composed of Nectaris ejecta deposited in a preexisting crater 150 $\mathrm{km}$ in diameter (fig. 5); these materials were subsequently disrupted by the "unnamed Crater B," $60 \mathrm{~km}$ in diameter, which reexcavated the older crater-floor deposits. The melt and fallback breccia from this impact formed the Cayley plains, deposited prior to formation of Dolland B. Samples from the Apollo 16 site would therefore represent mainly floor materials from the $60-\mathrm{km}$ crater; subsequent contributions from the Imbrium and Orientale impact basins were considered minor to negligible.

Head's hypothesis is inconsistent with photogeologic observations at the landing site. As discussed below, the Descartes mountains morphologically grade northwestward into textures distinctly radial to Im- brium; the furrowed fabric of the mountains, therefore, cannot be attributed to Nectaris ejecta. Furthermore, the superposed crater population is even younger than that of the Cayley Formation, certainly not equivalent to the age of Nectaris. Photographic evidence for the old $150-\mathrm{km}$ crater (Milton, 1972) suggests that a depression existed in the area before deposition of the Descartes materials (Hodges, fig. 2, this volume). If a 60-km crater, "unnamed Crater B," also formed, it too must have predated the Descartes mountains. There is no evidence of superposed crater-rim materials or rimcrest morphology on the Descartes escarpments, and this hilly unit with its distinctive morphology is laterally continuous for nearly $100 \mathrm{~km}$ south, filling the crater Descartes. Moreover, the hill representing "Crater B's" central peak is more than $100 \mathrm{~m}$ higher than

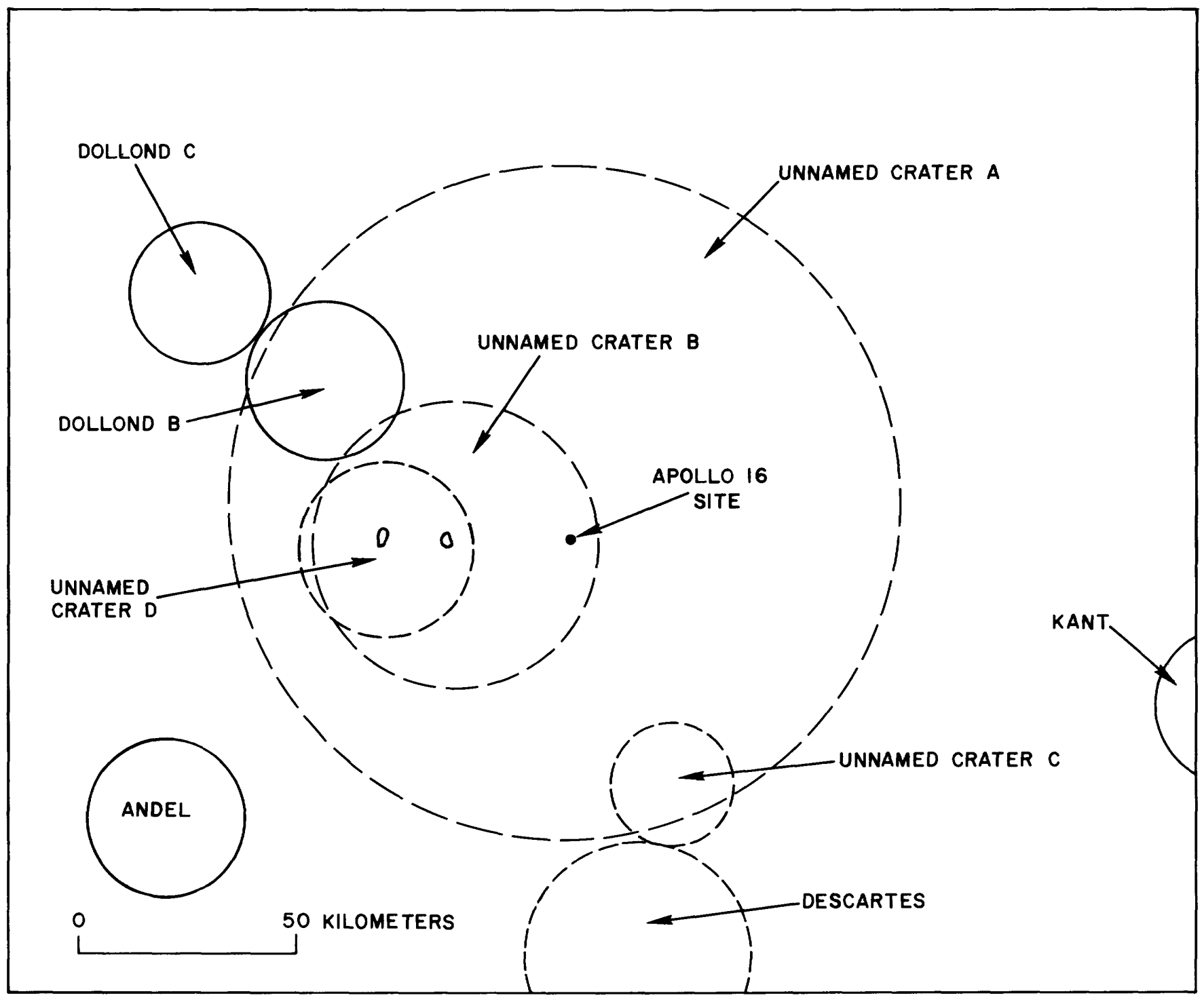

FIGURE 5.-Craters of various ages in vicinity of Apollo 16 landing site, as postulated by Head. Compare with Hodges (this volume, fig. 2). Reprinted with permission from J. W. Head (copyright 1974),D. Reidel Publishing Co. 
its proposed rim crest on Smoky mountain and Stone mountain (pl. 1), an improbable relation.

There is no evidence to suggest that fresh craters fill themselves to the extent called for by Head (1974) in "unnamed Crater B." According to the data of Pike (1974), a $60-\mathrm{km}$ crater should be about $3.4 \mathrm{~km}$ deep after the fallback deposition. Yet, the Descartes mountains rim of the postulated "Crater B" is only 500 $\mathrm{m}$ to $600 \mathrm{~m}$ above the Cayley plains. Craters do become progressively filled through time, but fresh craters that have smooth floors are not filled above the level of the interior wall terraces, nor do these floor materials invade gaps in the rim, as required at the Apollo 16 site. Because samples returned were from depths no greater than the $200 \mathrm{~m}$ of North Ray Crater, impact melts cannot have been derived from the floor of "Crater B," and therefore most returned samples, must, according to Head, be pre-Imbrian. If the plains existed (as crater floor materials) before formation of the Imbrium basin, the surface should be scored by Imbrium secondary craters and sculpture, which are clearly absent. Additionally, many of the dated samples have ages (3.94.0 b.y.) approximately equivalent to those of feldspathic rocks from the Apollo 14 Fra Mauro site, interpreted as Imbrium basin ejecta (Wilshire and Jackson, 1972b). According to Head's hypothesis, the smooth appearance of the Cayley surface is attributable to the floor materials of the pre-Imbrian "Crater B." Analyses of crater morphologies on the plains surface, however, indicate a post-Imbrium age (Soderblom and Boyce, 1972; Boyce and others, 1974).

This explanation cannot be extrapolated to the many occurrences of plains not bounded by crater walls, yet contemporaneous in terms of cratering model ages, such as the type area near the crater Cayley, the Apennine Bench Formation (Hackman, 1966), and other localities. In those cases where the Imbrian light plains are confined to craters, the craters are generally considerably older (Wilhelms and McCauley, 1971).

\section{EMPLACEMENT BY SECONDARY CRATERING AND MASS WASTING}

Oberbeck and others $(1974 b, 1975)$ proposed that the Cayley plains are derived by redistribution of ejecta from secondary craters formed by projectiles ejected from primary craters and basins and by mass wasting. According to their hypothesis, the plains materials represent local highlands material with minor dilution by distant ejecta. At the Apollo 16 site, the plains materials would constitute 20 percent Imbrium ejecta at most, 80 percent being locally derived. Maximum possible contribution of primary ejecta from Orientale is 12 percent. This hypothesis is based on calculations demonstrating that the mass of ejecta from a secondary crater is considerably greater than the mass of the projectile producing it; the ratio of these masses is greater than 1 beyond the continuous ejecta blanket, or "continuous deposits" (Oberbeck and others, 1974b, 1975). The outer limit of rim deposits around Imbrium is about $200 \mathrm{~km}$ from the basin center. Beyond this limit, locally derived secondary ejecta is increasingly dominant and distributed in plains-forming units within depressions by avalanching from the surrounding highlands.

According to the above hypothesis, an extensive "drainage basin" seems required as the source area of the materials, yet some occurrences of Cayley plains are not surrounded by highlands, for example, in Oceanus Procellarum northeast of the crater Bullialdus. Moreover, the only adequate sources of secondary ejecta in the central highlands are the Imbrium secondary craters. The major part of the fill in such large craters as Ptolemaeus and Albategnius would have to have been derived from the battered "uprange" north rims of these larger craters. According to equations of Pike (1972; written commun., 1974), the volume of the entire original uplifted rim of the crater Ptolemaneus is approximately $11,200 \mathrm{~km}^{3}$ (rim diameter $=150 \mathrm{~km}$, rim height $=1.5 \mathrm{~km}$, exterior rim width $=25.5 \mathrm{~km}$ ). Minimum thickness of the plains-forming fill within the crater is $2.5 \mathrm{~km}$, assuming Ptolemaeus had a central peak (now completely obscured) with a predicted height of $2.5 \mathrm{~km}$. Thus the volume of the fill is of the order of $32,000 \mathrm{~km}^{3}$. Based on these estimates, the volume of the entire uplifted rim, eroded across its exterior width to the level of the surrounding terrain, could not account for the interior plains deposits, even assuming debris from all sides (not just the rim uprange toward Imbrium) was added to the crater. Apparently, it must have been partly filled by unrelated material. A large negative gravity anomaly at Ptolemaeus indicates that the crater was not filled by marelike lavas and may contain material less dense than its surroundings (Sjogren and others, 1974). Addition of bulked primary ejecta seems required for the fill of Ptolemaeus; basal deposits may have been derived from Nectaris. The approximate contemporaneity of plains surfaces with Orientale ejecta (Soderblom and Boyce, 1972; Boyce and others, 1974) seems inexplicable by the secondary crater hypothesis, according to which a gradational sequence of plains ages would be expected.

The severe thermal metamorphic effects observed in some rock samples from the Apollo 16 site must have been produced by primary impacts. Secondary craters are formed by relatively low velocity projectiles $(<2.4$ $\mathrm{km} / \mathrm{sec}$ ) that do not produce the shock pressures required for incipient and complete melting (Ahrens and 
others, 1973). Oberbeck and others $(1974 \mathrm{~b}, 1975)$ incorporated in their hypothesis the explanation of Head (1974) for the presence of shock-melted rocks, but as discussed above, such rocks formed in the floor of the postulated "Crater B" would be at depths greater than $3 \mathrm{~km}$-well below the depths penetrated by North and South Ray craters. Furthermore, if the melt-textured rocks were preexisting in the surrounding terrain, the expected ages would be uniformly pre-Imbrian, for the velocity of secondary projectiles is too low to reset radiometric ages.

The field magnetic data also seem inconsistent with this hypothesis. The high remanent magnetism observed indicates material of substantial thickness at some depth within the plains deposits was emplaced in a magnetic field at a temperature above the Curie point. Secondary impacts, however, would tend to randomize a preexisting field. Oberbeck and others (1974b, 1975) adopted the hypothesis of Head (1974) to explain the presence of magnetized impact melt at depth, but the problems of sample ages and the post-Imbrium age of both mountains and plains remain.

The significance of secondary cratering as an adjunct to the formation of craters and basins is demonstrable, and erosion and mixing of preexisting materials with primary ejecta is an obvious corollary, but extensive plains deposits seem generally to be a product more of primary than secondary cratering. At Orientale, planar units are a recognizable major facies of basin ejecta (Eggleton and Schaber, 1972; Hodges and others, 1973; Moore and others, 1974) that flowed outward beyond the thick hummocky and lineated deposits of continuous ejecta. The primary ejecta may be mixed within itself as well as with substrate materials such that the same preexisting rocks are present in deposits of primary ejecta as well as in locally derived secondary ejecta.

If mass wasting from the surrounding escarpments were responsible for such broad expanses of Cayley plains as in Ptolemaeus, then distribution of a uniform sheet many meters thick across a lateral distance of nearly $150 \mathrm{~km}$ is required, assuming that the greater part of the debris came from the north rim, uprange toward Imbrium. The expected morphology would be a wedge-shaped accumulation across this distance with talus aprons around the periphery, and this is contrary to the photogeologic evidence.

Other problems not addressed by this hypothesis include the matter of basin ejecta volume, which could have been much larger and more broadly distributed than estimated by Oberbeck and others (1974b, 1975), as well as the crater morphology data that show the apparent contemporaneity of the plains with Orientale.

\section{SEISMIC REDISTRIBUTION}

Moonwide seismic effects probably resulted from all basin impacts, and that which created the Orientale basin may have shocked the Moon to such an extent that seismic waves caused a reorganization of loosely consolidated materials such as brecciated ejecta (Schultz and Gault, 1974); preexisting deposits might have assumed a contemporaneous age with respect to the subsequent crater flux. Schultz and Gault (1974) predicted $10-\mathrm{m}$ surface displacements induced by $P$-waves at the antipode of the major basins, assuming a solid homogeneous Moon. Lower velocity surface waves with an amplitude of $\sim 10 \mathrm{~m}$ would arrive after the ejecta beyond approximately $1,000 \mathrm{~km}$ from the basin center and increase in magnitude with convergence at the antipode. Schultz and Gault (1974) suggested that "emplacement and leveling of light plains units occurred when contemporaneous arrival of basin-related ejecta and surface waves resulted in mass transfer to topographic lows and 'fluidizing' [of] the slide materials." At the Apollo 16 site $(\sim 3,500 \mathrm{~km}$ from the center of Oriental), debris ejected at angles greater than $30^{\circ}$ (at less than escape velocity) would arrive before the surface wave, which then might reorganize both the Orientale and previously deposited Imbrium ejecta.

The existence of older planar surfaces (Boyce and others, 1974) indicates that some areas survived this seismic effect, however; if modification by seismic waves occurred, the extent may have been governed by the terrain through which the waves passed. As discussed, the avalanching mechanism alone is inadequate to explain the localization of all Cayley plains. The subdued appearance of the Fra Mauro Formation as compared with the Hevelius Formation may have been partly produced by seismic effects of the Orientale impact.

\section{ORIGIN OF THE DESCARTES MOUNTAINS}

If the Orientale impact had depositional and (or) seismic influence on the surficial Cayley plains deposits, then the preexiting rugged Descartes mountains must have been similarly affected. The petrologic similarities between plains and mountains are supportive, though not definitive evidence for a frosting of Orientale ejecta over these preexisting deposits. Additional analyses of the core samples from Station 4 on Stone mountain may eventually produce more diagnostic information. The rugged topography, however, requires explanation regardless of whether or not it is mantled by Orientale ejecta. 


\section{IMBRIUM EJECTA}

Eggleton and Marshall proposed (1962) that the materials of the Descartes mountains may be largely ejecta from Imbrium deposited as a distal part of the Fra Mauro Foundation, trapped against the escarpment of the Kant plateau (fig. 6). This hypothesis, res- urrected after the Apollo 16 mission, is now based on the gradational relation of the materials with ridged deposits to the north and west, lineated radial to the Imbrium basin, that resemble the Fra Mauro Formation. Because of this gradational aspect, a Descartes "Formation" has not been proposed. Although secondary cratering (sculpturing) by Imbrium ejecta is evi-

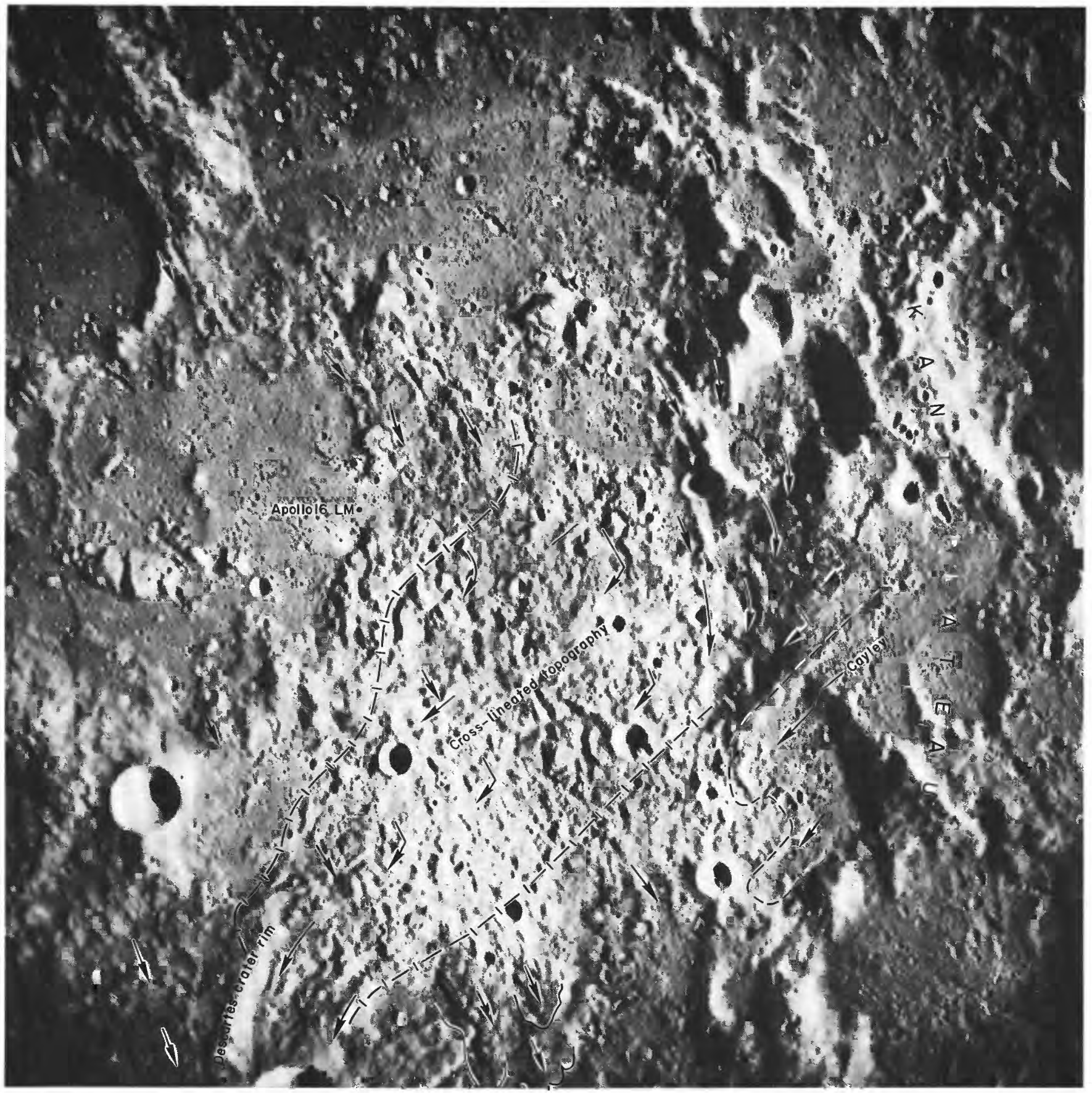

FIGURE 6.-Apollo 16 landing site, showing relation to Kant plateau. Arrows indicate dominant texture of cross-lineated topography that interrupts the southeast radial trend of Imbrium ejecta. The pattern may have been produced by a surge of ejecta up the flanks of the Kant plateau and subsequent deflection southwestward. Apollo 16 mapping camera frame 0439. 
dent in the Apollo 16 vicinity, and therefore mixing with preexisting material must have occurred, there is evidence of primary ejecta deposition in the crater Andel M., in the prominent flow lobe between Descartes and Abulfeda, and north of the landing site in Taylor B (fig. 7). Andel M, $130 \mathrm{~km}$ to the west (Hodges, this volume, fig. 2), provides evidence for an Imbrium origin for much of this debris. The crater is filled to a depth of perhaps a kilometer with debris that apparently came from the north and overran the north rim of the crater, incorporating the rim materials (Moore and others, 1974). Taylor B appears to have been overrun by debris from the northwest that broke through its south rim and continued southward (fig. 7). At several places around Orientale, ridges of ejecta associated with plains occur within the continuous ejecta blanket, trapped against and parallel to preexisting crater walls (fig. 8). The distances to which ejecta can be mapped around Orientale suggest that Imbrium-related ejecta should occur at the Apollo 16 site, accounting for the relief of Stone mountain as well as for much of the kilometer or more of material apparently dumped in the crater Descartes (Moore and others, 1974). The broad trough trending northwest from the site provided a likely conduit for transport of the Imbrium debris.

\section{NECTARIS EJECTA}

Wilhelms (1972) advocated a Nectaris origin for the Descartes materials with subsequent reworking by secondary impact (Imbrium sculpture) and regional fracturing to explain the apparent Imbrian age. A Nectaris origin was,also proposed by Head (1974). Yet there is compelling evidence for a post-Nectaris age: the gradational relations with probable Imbrium deposits north and west, the absence of similar topographic features elsewhere around the Nectaris basin, and, most important, the very fresh looking, rugged topography of the Descartes highlands.

Nectaris ejecta (Janssen Formation, StuartAlexander, 1971) must occur in this area at some depth and could have been penetrated by North Ray crater. Radiometric ages as old as 4.26 b.y. (Schaeffer and Husain, 1973) were obtained on light-matrix-breccia fragments collected from the rim of North Ray and are compatible with such an interpretation. Alternatively, these fragments may simply be Imbrium ejecta not sufficiently shocked for radiometric clocks to have been reset.

\section{SUMMARY}

Clearly many geologic problems raised by the Apollo 16 mission are yet to be solved. The brecciated samples refuted the premission concept of a postbasin, premare period of volcanism in lunar history, and therefore the significance of the gigantic impact basins was reassessed. Apparently basins formed throughout the first 800 million years of lunar history; neither the landforms resulting therefrom nor the distribution of their ejecta had been sufficiently investigated before Apollo 16. Primary craters in the vicinity of the landing site are inadequate to explain the morphologic characteristics of the mappable geologic units.

Orbital and surface results of the Apollo 16 mission, together with postmission photogeologic investigations, support the postulate that ejecta from the Imbrium basin constitutes a major part of both plains and mouritains at this landing site. Around Orientale, both erosional and depositional landforms occur in the ejecta blanket, and conspicuous lineations, together with lobate escarpments, strongly indicate lateral flow. Pitting and grooving by secondary impact occured contemporaneously with deposition of primary hummocky ejecta. Smooth plains deposits appear to be allate-stage fluid facies which ponded in topographic lows within and largely distal to the Hevelius Formation. Extrapolation from this young, well-preserved basin to the older and larger Imbrium basin, suggests that similar morphologic features should occur there. Hummocky ejecta, plains, and secondary craters are all recognizable around Imbrium. The close spatial association of Cayley-type plains with the Fra Mauro Formation is strong evidence for a genetic relation to Imbrium. Moreover, ridged Fra Mauro-type materials appear on Apollo orbital photographs to extend as far as the Kant plateau, forming a depositional unit that partly fills the crater Descartes.

The hypothesis considered most defensible at this time (Dec. 1974) is that primary ejecta from the Imbrium basin, which itself must have included a mixture of preexisting crustal materials, and probably debris incorporated en route, formed rugged deposits as far as the Kant plateau. These relatively thick deposits, in turn, sculptured penecontemporaneously by secondary projectiles from Imbrium, must have been hurled outward at low angles, forming churning, rapidly moving debris flows. Fluid ejecta, perhaps partly molten, succeeding these debris flows or entrained in them, pooled in topographic lows. The morphology of plains within the belt circumferential to Imbrium is a product of planar facies of ejecta from Imbrium. Because the ages of the Cayley-type planar surfaces, as determined by crater-erosion models and crater frequency distributions, are equivalent to those of Orientale ejecta, the "crater clocks" appear to have been locally reset in some way by the Orientale event. Particles of nearly uniform size may have been ejected from Orientale in volume sufficient to both erode and add to the preexisting Imbrium deposits without de- 


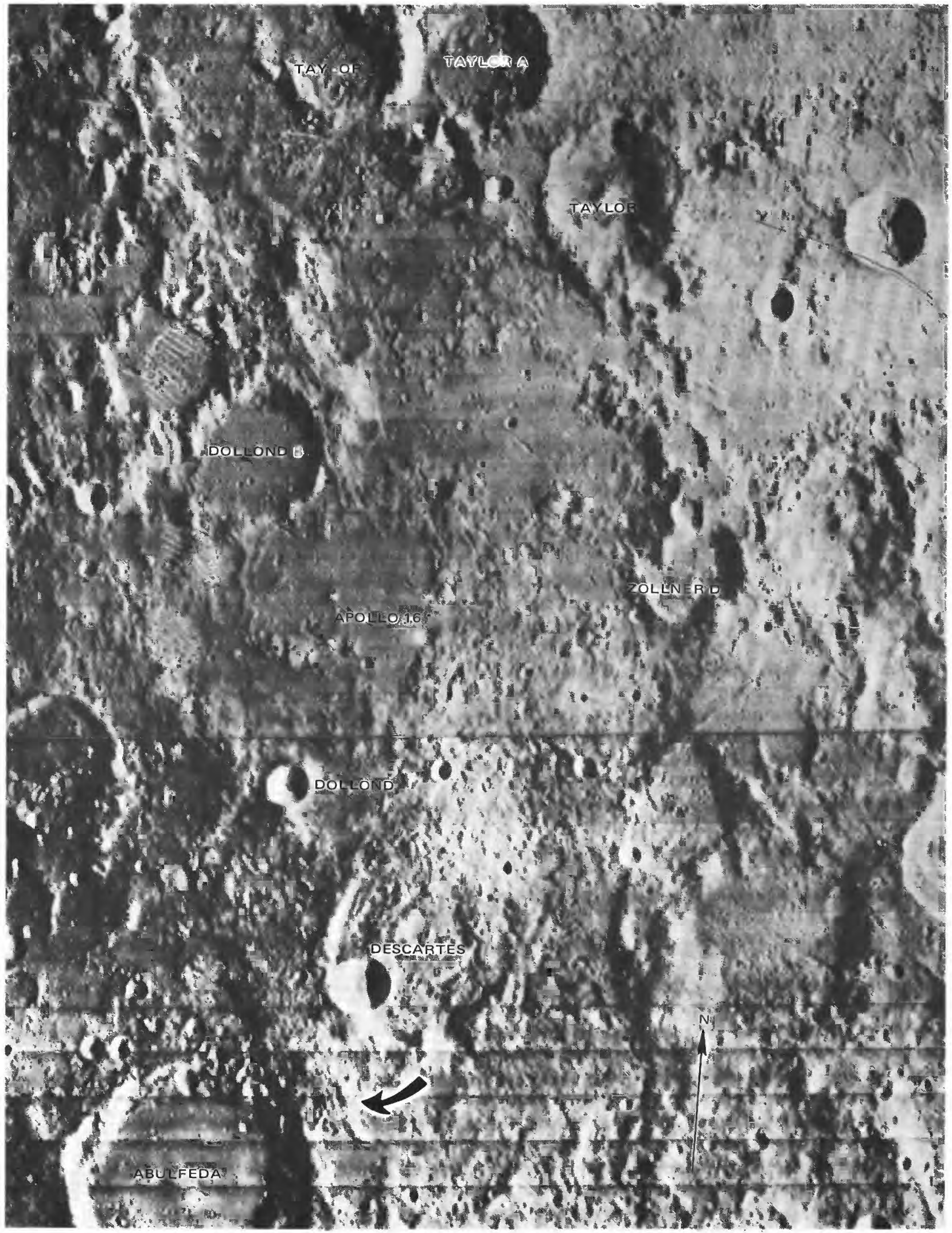

Figure 7.-Regional setting of Descartes area. Probable deposits of Imbrium ejecta occur west and south of Taylor B, in crater Descartes, and as thick "flow lobe" (arrow) between crater rims of Descartes ( $50 \mathrm{~km}$ diameter) and Abulfeda. Lunar Orbiter IV, frame $89 \mathrm{H}$. 
stroying the gross morphology, and (or) the seismic effect of the Orientale impact may have modified much of the preexisting Imbrium surface with the addition of little or no Orientale ejecta.

The Cayley Formation may have been somewhat analogous to a gigantic ignimbrite: lenses or pods of molten material in a matrix of cooler debris that flowed into topographic lows, producing planar deposits. The resulting stratigraphic unit may resemble on a grand scale the unusual suevite outcrop described by Dennis (1971) at the Ries basin, in which a vesicular groundmass indicates that wholesale melting occurred. This material, unlike most suevite, includes no aerodynamically shaped bombs; the last modifier appears to have been flow rather than ballistic transport. If the Cayley Formation is analogous, the molten blobs must have retained heat long enough and been of sufficient magnitude to mobilize the debris. These molten

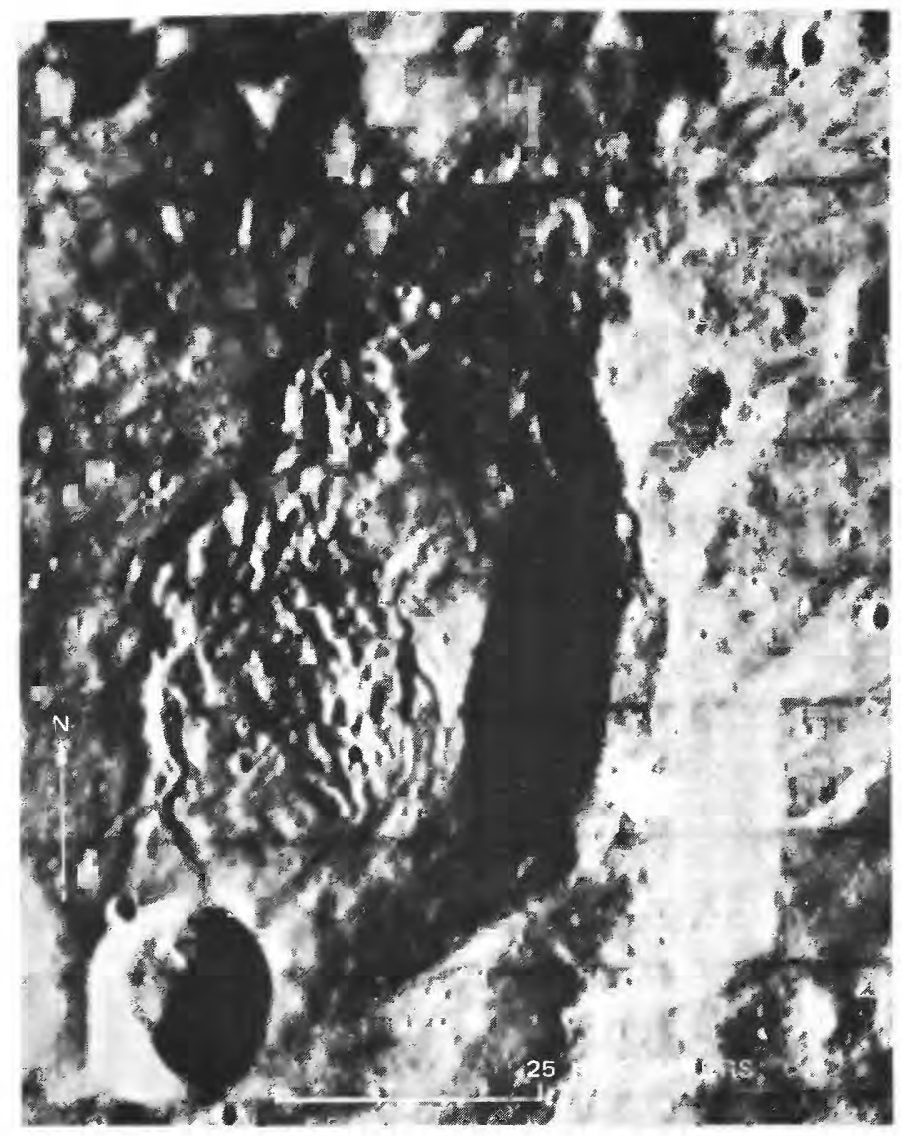

A

Figure 8.-Relation of Orientale ejecta to preexisting craters. A, Deceleration ridges of Orientale ejecta trapped against downrange wall of pre-Orientale crater Rocca (arrow). Similar deposits in other craters on left and bottom margins of photograph. See fig. 2 for location. Lunar Orbiter IV, frame 168 H. B, Ridges of Orientale ejecta (arrow) banked against downrange wall of Sirsalis $\mathrm{Z}$ (out- pods could have thermally metamorphosed the surrounding material, thereby adding to the variety of breccia types sampled. Because igneous textures developed, cooling must have been relatively slow. Like the suevite at the Ries basin (Dennis, 1971), this partly molten material could have acquired, and thereby explain, the anomalous remanent magnetism at the Apollo 16 site.

The brecciated material of the Descartes mountains must have been relatively cool and less fluid in order to have retained its high relief. The smoother, less cratered appearance of Stone mountain, as compared with the plains, may be accounted for mainly by differences in textures of the samples. Crater rims should disappear more readily on the highlands if the rocks are, in general, more friable than those of the plains, in which glassy matrices are more common.

According to our interpretation, schematically represented in figure 9, the Cayley Formation and the materials of the Descartes mountains are ejecta, mainly from the Imbrium basin, as implied by Gilbert

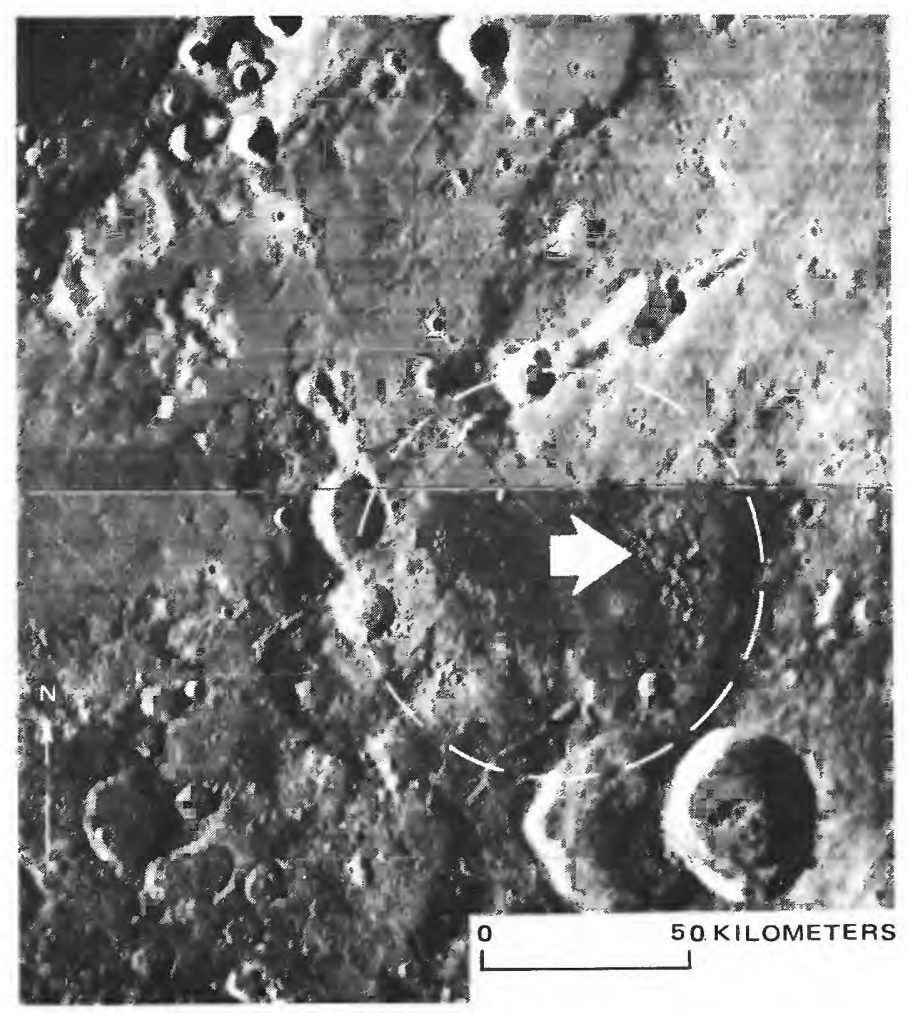

B

lined), $970 \mathrm{~km}$ from center of Orientale. Ridges are transected by at least one graben but otherwise strongly resemble Descartes mountains. Plains west of ridges are smooth facies of basin ejecta. Lunar Orbiter IV, frame $161 \mathrm{H}$. (From Moore and others, 1974, fig. 10.) Reprinted with permission from H. J. Moore (copyright 1974) Pergamon Press. 
(1893), who was probably the first to recognize the significance of that gigantic impact. The deposits may be veneered by debris from the Orientale basin. Nectaris ejecta (Janssen Formation) is undoubtedly present at depth. Conclusive identification of the basin deposits in the samples returned from the Apollo 16 site is unlikely, however, because of the ambiguities in radiometric ages and uncertainties in depths of derivation from local small craters The present landscape records the continued, though decreasing, bombardment by post-Imbrium impacts, climaxed by secondary craters from Theophilus and the bright young Coperni- can craters, North Ray $(-50$ m.y. old) and South Ray $(-2$ m.y. old).

\section{ACKNOWLEDGMENTS}

The authors are particularly indebted to Henry J. Moore for many useful suggestions in his critical review of the manuscript and to several other colleagues-notably George E. Ulrich, Don E. Wilhelms, and Howard G. Wilshire-for innumerable hours of discussion and debate on the perplexities of the Apollo 16 mission.

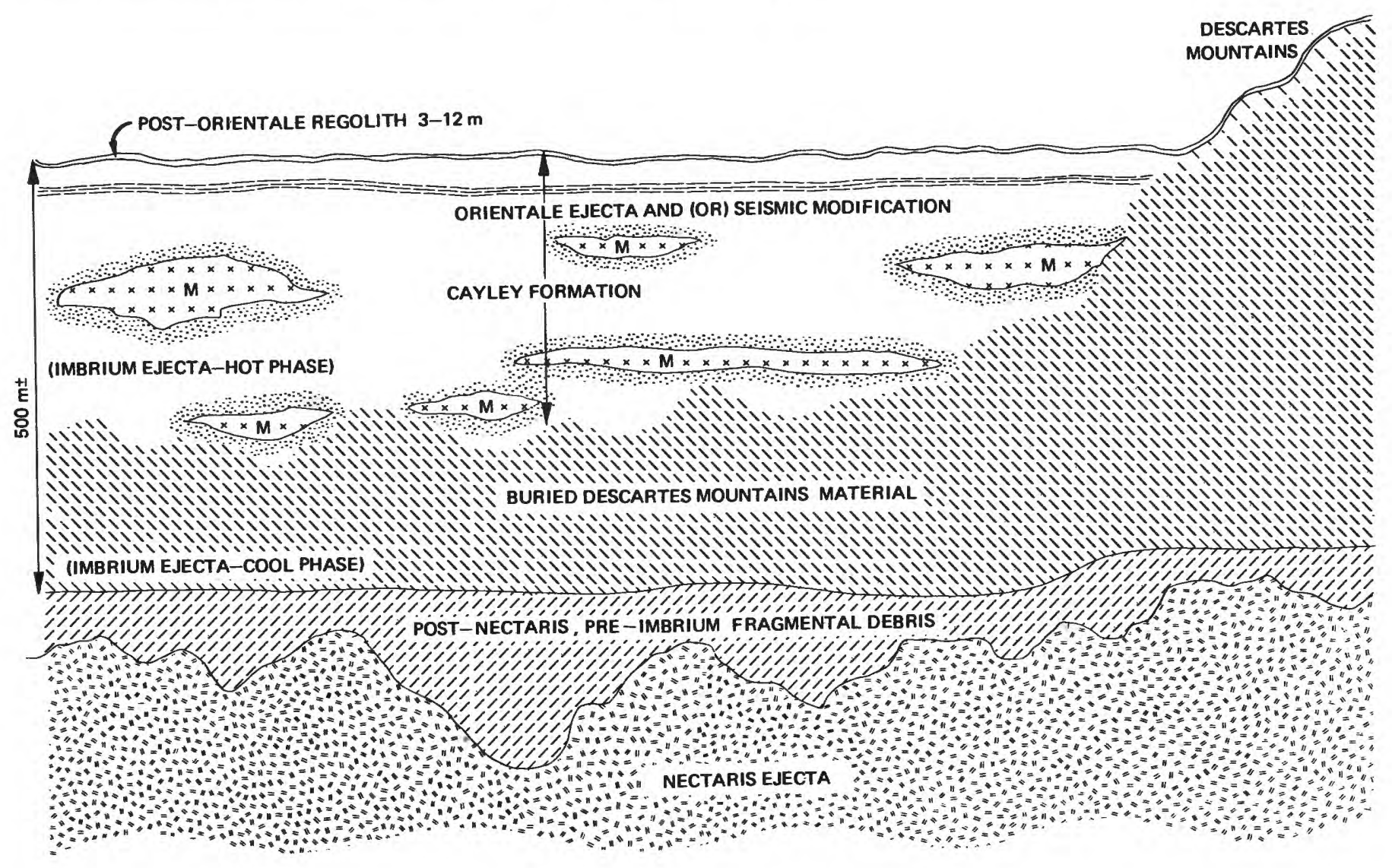

Figure 9.-Hypothetical cross section of the Apollo 16 landing site. Neither depth to Nectaris ejecta nor its thickness is known. Brecciated ejecta, mainly from Imbrium, probably emplaced below the Curie temperature, produced the ridgy surface, characteristic of the Descartes mountains. Hot fluidized Imbrium ejecta formed the greater part of the Cayley Formation, which acquired remanent magnetism during cooling. Lenses and pods of melt $(\mathrm{M})$ scattered within the pooled breccia debris are surrounded by thermal metamorphic envelopes (stipple). Debris from Orientale and (or) seismic smoothing is postulated to explain the apparent contemporaneity of the surface with that basin. Imbrium material is mixed with the Orientale ejecta at their contact. 


\title{
L1. DOCUMENTATION OF APOLLO 16 SAMPLES
}

\author{
By Robert L. Sutton \\ CONTENTS
}

Introduction

Explanation of headings in table 3

Page

234

236

\section{ILLUSTRATIONS}

Figures 1-95 Photographs of:

1. Apollo 16 landing site showing traverse stations

2. Area of deep core sample 60001-60007

3. Double drive-tube sample 60010/60009 at station 10

4. Double drive-tube sample 60014/60013 at station 10

5. Area of sample 60015 as seen from the LM window and stereopair of sample 60015 in the LRL

6. Samples 60016 and 60025 as seen from the LM window, sample 60016 showing reconstructed lunar orientation, and orthogonal views of sample 60016

7. Sample 60018 showing reconstructed lunar orientation, sample 60018 location, after sampling, and orthogonal views of sample 60018 ......... 250

8. Sample 60019 before sampling, sample 60019 showing reconstructed lunar orientation, and orthogonal views of sample 60019

9. Sample 60025 before sampling, sample 60025 showing reconstructed lunar orientation, and orthogonal views of sample 60025 -

10. Sample 60035 showing reconstructed lunar orientation and orthogonal views of sample 60035

11. Location of samples 60050-59 and 60075, area of samples 60050-59 and 60075 before sampling, sample 60055 in the LRL, sample 60056 in the LRL, samples 60057-59 in the LRL, and sample 60075 in the LRL 262

12. Location of sample 60095 and the deep core (60001-60007), area of sample 60095 and the deep core (6000160007), and sample 60095 in the LRL _._. 66

13. Location of sample 60115 with respect to the LM, sample 60115 location after sampling, sample 60115 showing reconstructed lunar orientation, and orthogonal views of sample 60115

14. Sample 60135 before sampling, and stereopair of sample 60135 in the LRL

15. Sample 60215 showing reconstructed lunar orientation and orthogonal views of sample 60215

16. Sample 60235 before sampling and stereopair of sample 60235 in the LRL

17. Sample 60255 showing reconstructed lunar orientation and orthogonal views of sample 60255

18. Sample 60275 showing reconstructed lunar orientation and orthogonal views of sample 60275

19. Sample 60315 showing reconstructed lunar orientation and orthogonal views of sample 60315

20. Sample 60335 before sampling, sample 60335 on the Lunar Portable Magnetometer, sample 60335 showing reconstructed lunar orientation, and orthogonal views of sample 60335

21. Area of rake samples 60500-04 and 60515-35 before sampling, area of samples 60500-04 and 60515-35 after sampling, and rake fragments 60515-19, 60525-29, and 60535 in the LRL

22. Location of rake samples 60600-04 and 60615-79, area of samples 60600-04 and 60615-79 before sampling, area of samples 60600-04 and 60615-79 after sampling, rake fragments 60615-19, 60625-29, and 60635-39 in the LRL, rake fragment 60615 in the LRL, rake fragment 60619 in the LRL, stereopair of rake fragment 60625 in the LRL, rake fragment 60636 in the LRL, stereopair of rake fragment 60639 in the LRL, rake fragments 60645-49,60655-59, 60665-69, and 60675-79 in the LRL, and rake fragment 60645 in the LRL

23. Sample 61015 before sampling, sample 61015 showing reconstructed Iunar orientation, and orthogonal views of sample 61015

24. Television picture of sample 61016 before sampling, sample 61016 showing reconstructed lunar orientation, and orthogonal views of sample 61016

25. Location of samples 61135,61195 , and 61180-84, samples 61135, 61195, and 61180-84 before sampling, looking west, samples 61135,61195 , and 61180-84 before sampling, looking south, samples 61135 and 61195 showing reconstructed Iunar orientations, orthogonal views of sample 61135 , and orthogonal views of sample 61195

26. Location of samples $61140-44$ and $61155-58$, samples $61140-44$ and $61155-58$ before sampling, looking west, samples 61140-44 nd 61155-58 before sampling, looking north, area of samples 61140-44 and 61155-58 after sampling, samples 61155 and 61156 showing reconstructed lunar orientations, orthogonal views of sample 61155, and orthogonal views of sample 61156 
Figures 1-95 Photographs of:

27. Samples $61160-64$ and 61175 before sampling, sample 61175 showing reconstucted lunar orientation, looking west-northwest, sample 61175 showing reconstructed lunar orientations, looking north, and orthogonal views of sample 61175 .

28. Area of trench samples $61220-26$ and $61240-49,61255$ before sampling, trench from which samples 61220 $26,61240-49$, and 61255 were collected, and samples 61225 and 61226 in the LRL

29. Location of samples 61280-84 and 61295, samples 61280-84 and 61295 before sampling, sample 61295 showing reconstructed lunar orientation, area of samples $61280-84$ and 61295 after sampling, and orthogonal views of sample 61295

30. Location of rake samples $61500-05$ and $61615-77$, area of rake samples $61500-05$ and $61515-77$ before sampling, looking west, area of rake samples $61500-05$ and $61515-77$ before sampling, looking north, rake fragments $61515-19,61525-29,61535-39$, and 61545 in the LRL, rake fragment 61536 in the LRL, rake fragments 61546-49, 61555-59, and 61565-67 in the LRL, rake fragment 61546 in the LRL,rake fragments 61568,61569 , and 61575 in the LRL, and rake fragments 61576 and 61577 in the LRL

ation of samples $62230-38,62240-49$ and 62315,62275 , and 62295 , samples $62230-38$ and $62240-49$,

62315 before sampling, samples 62235,62236 , and 62237 showing reconstructed lunar orientations,
orthogonal views of sample 62235 , orthogonal views of sample 62236 , orthogonal views of sample 62237 ,

62315 before sampling, samples 62235,62236 , and 62237 showing reconstructed lunar orientations,
orthogonal views of sample 62235 , orthogonal views of sample 62236 , orthogonal views of sample 62237 , and scooped fragments $62245-49$ and 62315 in the LRL ample 62255 before sampling, sample 62255 showing reconstructed lunar orientation, and orthogonal views of sample 62255

33. Sample 62275 before sampling, sample 62275 showing reconstructed lunar orientation, and orthogonal views of sample 62275

34. Samples $62280-89,62305$, and 62295 before sampling, sample 62295 showing reconstructed lunar orientation, and orthogonal views of sample 62295

35. Partial panorama showing general setting of samples at station 13 , locations of samples collected at Shadow Rock, sample 60017 in the LRL, sample 63335 in the LRL, and sample 63355 in the LRL

36. Area of rake samples $63500-09,63515$, and 63525-98 before sampling, samples $63505-09$ and 63515 in the LRL, rake fragments $63525-29,63535-39,63545-49$, and $63555-58$ in the LRL, rake fragment 63538 in the LRL, rake fragment 63549 in the LRL, rake fragments $63559,63565-69$, and $63575-76$ in the LRL, rake fragments $63577-79,63585-89$, and 63595 in the LRL, rake fragment 63585 in the $L R L$, and rake fragments $63596-98$ in the LRL

7. Double drive tube sample 64002/64001 at station 4

38. Sample 64425 in the LRL

39. Location of sample 64435 shown before sampling, sample 64435 showing reconstructed lunar orientation, and orthogonal views of sample 64435 - 365

40. Locations of samples 64435 and 64455 shown after sampling, area of sample 64455 before sampling, and stereopair of sample 64455 in the LRL

41. Locations of samples $64475-78$ and $64420-25$, area of samples $64475-78$ and $64420-25$ before sampling, sample 64475 showing reconstructed Iunar orientation, looking west-northwest, samples 64475-78 and the area of trench before sampling, area of samples $64475-78$ and $64420-25$ after sampling, samples 64475 and 64476 showing reconstructed lunar orientations, and samples, 64477 and 64478 before sampling, looking south, orthogonal views of sample 64475, orthogonal views of sample 64476, sample 64477 in the LRL, and sample 64478 in the LRL

42. Location of rake samples $64500-25$ and $64535-89$, area of rake samples $64500-25$ and $64535-89$ before sampling, rake fragments $64535-39,64545-49$, and 64555-58 in the LRL, rake fragment 64535 in the LRL, stereopair of rake fragment 64536 in the LRL, stereopair of rake fragment 64537 in the LRL, rake fragment 64538 in the LRL, rake fragments $64559,64565-69,64575-79$, and 64585-86 in the LRL, rake fragments 64587 and 64588 in the LRL, and rake fragment 64589 in the LRL

43. Location of samples 64800-04 and 64810-37 (rake), area of samples 64800-04 (after scooping) and 64810-37 (before raking), rake fragment 64815 in the LRL, rake fragments 64816 and 64817 in the LRL, rake fragment 64818 in the LRL, rake fragment 64819 in the LRL, and rake fragments 64825-29 and 64835-

37 in the LRL
44. Stereopair of sample 65015 in the LRL

45. Sample 65016 in the LRL

46. Location of samples 65035,65315 and $65325-66$ (rake), sample 65035 showing reconstructed lunar orientation, and orthogonal views of sample 65035 -

47. Locations of samples 65055,65056 and 65095 , area of samples 65055 and 65056 before sampling, sample 65055 showing reconstructed lunar orientation, orthogonal views of sample 65055 , and sample 65056 in the LRL

48. Location of sample 65075 in relation to other samples, sample 65075 before sampling, and sample 65075 in

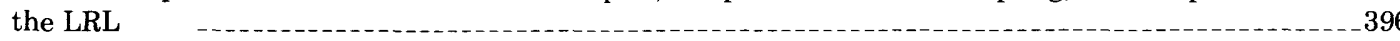

49. Location of sample 65095 in relation to other samples, sample 65095 showing reconstructed (tentative) lunar orientation, and orthogonal views of sample 65095

50. Area of rake samples 65315 and $65325-66$ before sampling, area of rake samples 65315 and $65325-66$ after sampling, stereopair of sample 65315 in the LRL, rake fragments $65325-29$ and $65335-36$ in the LRL, rake fragments $65337-39$ and $65345-47$ in the LRL, rake fragments $65348-49$ and $65355-56$ in the LRL, rake fragments $65357-59$ and 65365 in the LRL, and rake fragment 65366 in the LRL 
51. Location of rake samples $65500-04$ and $65510-88$ in relation to other samples, area of rake samples $65500-04$ and 65510-88 during sampling, location of rake samples $65500-04$ and $65510-88$, rake fragments $65515-19,65525-29,65535-39$, and 65545-49 in the LRL, rake fragments 65555-59, 65565-69, and $65575-79$ in the LRL, and rake fragments $65585-88$ in the LRL

52. Area of rake samples 65700-04 and 65715-95 before sampling, rake fragments 65715-19, 65725-29, 65735-39, 65745-49 and, 65755-56 in the LRL, rake fragment 65715 in the LRL, rake fragments 65757-59 and 65765-66 in the LRL, rake fragment 65757 in the LRL, rake fragments $65767-69$ and 65775-76 in the LRL, rake fragments $65777-79$ and 65785 in the LRL, rake fragment 65786 in the LRL, rake fragments $65786-88$ in the LRL, rake fragment 65789 in the LRL, and rake fragment 65795 in the LRL

53. Area of samples $65900-16$ and $65925-27$ after

5. Area of samples 65900-16 and 65925-27 after sampling, and rake fragments 65925-27 in the LRL --419

54. Area of samples $66030-37,66040-44$, and 66055 before sampling, samples 66035 , 66055, and $66040-44$ before sampling, samples 66035 and 66055 showing reconstructed lunar orientations, orthogonal views of sample 66035, sample 66036 in the LRL, sample 66037 in the LRL, sample 66055 showing reconstructed lunar orientation, and orthogonal views of sample 66055

55. Location of sample 66075 , sample 66075 before sampling, sample 66075 showing reconstructed lunar orientation, and orthogonal views of sample 66075

56. Location of samples $66080-86$, and samples $66080-86$ before sampling

57. Location of sample 66095 , sample 66095 shown during sampling, sample 66095 showing reconstructed lunar orientation, and orthogonal views of sample 66095

58. Map of station 11

59. Sample 67015 before sampling, and sample 67015,01 in the LRL

60. Sample 67016 before sampling, sample 67016 showing reconstucted lunar orientation, sample 67016,01 in the LRL, and sample 67016,04 in the LRL

61. Sample 67025 in the LRL

62. Area of sample $67030-35$ before sampling, and sample 67035 in the LRL

63. Sample 67055 before sampling, area of sample 67055 after sampling, sample 67055 showing reconstructed lunar orientation, and orthogonal views of sample 67055

64. Sample 67075 before sampling, and sample 67075 in the LRL

65. Samples 67095 and 67115 before sampling, stereopair of sample 67095 in the LRL, and sample 67115 in the LRL -

66. Location of sample 67215 shown in television picture, sample 67215 before sampling, and sample 67215 in the LRL, inside padded bag \#1 1

67. Location of sample 67235 shown in television picture, sample 67235 before sampling, and sample 67235 in the LRL, inside padded bag \#2 2

68. White breccia boulders and locations of samples $67415,67455,67475,67460-64,67480-89,67495$, and 67510-76 - 76

69. Sample 67415 before sampling, and sample 67415 in the LRL

70. Location of sample 67435 shown in television picture, sample 67435 before sampling, sample 67435 showing reconstructed lunar orientation, and orthogonal views of sample 67435

71. Sample 67455 before sampling, and sample 67455 in the LRL

72. Location of sample 67460-64, and close-up view of area of sample 67460-64 after sampling

73. Sample 67475 after sampling, sample 67475 showing reconstructed lunar orientation, and orthogonal views of sample 67475

74. Area of samples $67480-89,67495$ (after scooping), and 67510-76, (before raking), samples 67485-89 and 67495 in the LRL, rake fragments $67515-19,67525-29,67535-39$, and $67545-48$ in the LRL, rake fragment 67515 in the $\mathrm{LRL}$, rake fragments $67549,67555-59,67565-69$, and $67575-76$ in the LRL, rake fragment 67556 in the LRL, and rake fragment 67559 in the LRL of rake samples $67600-05$ and $67615-76$ before sampling, area of rake samples $67600-05$ and $67615-76$ after sampling, sample 67605 in the LRL, rake fragments $67615-19,67625-29,67635-39$, and 67645-49 in the LRL, rake fragment 67647 in the LRL, and rake fragments $67655-59,67665-69$, and 67675-76 in the LRL

76. Location of rake samples $67700-08$ and $67710-76$, area of rake samples $67700-08$ and $67710-76$ before sampling, rake fragments $67715-19$ and $67725-26$ in the LRL, rake fragments $67727-29,67735-39$, and $67745-48$ in the LRL, rake fragment 67729 in the LRL, and rake fragments $67749,67755-59,67765-69$, and $67775-76$ in the LRL

77. Partial panorama of House rock and Outhouse rock showing sample locations

78. Sample 67915 showing reconstructed lunar orientation and orthogonal views of sample 67915

79. Areas of samples 67935-37 and 67955-57 before sampling, samples 67955-57 during sampling, sample 67935 in the LRL, sample 67936 in the LRL, and sample 67937 in the LRL

80. Sample 67955 in the LRL, sample 67956 in the LRL, and sample 67957 in the LRL

81. Location of samples $67940-48$ and samples $67945-48$ in the LRL

82. Area of samples 67960 and 67975 before sampling, sample 67960 before sampling, and stereopair of sample 67975 in the LRL

83. Location of double drive tube sample 68002/68001, double drive tube 68002/68001, first (unsuccessful) attempt, and double drive tube 68002/68001, second (successful) attempt 
Figures 1-95 Photographs of:

84. Sample 68035 before sampling, location of sample 68035, sample 68035 showing approximate lunar orientation, and orthogonal views of sample 68035

85. Locations of samples 68115 and $68120-24$ at boulder \#1, samples 68115 and 68120-24 before sampling, looking southwest, samples 68115 and $68120-24$ before sampling, looking southeast, locations of samples 68115 and $68120-24$ after sampling, sample 68115 showing reconstructed lunar orientation, and orthogonal views of sample 68115

86. Locations of samples 68415 and 68416 at boulder \#2, sample 68415 showing reconstucted lunar orientation, locations of samples 68415 and 68416 after sampling, orthogonal views of sample 68415, sample 68416 showing reconstructed lunar orientation, and orthogonal views of sample 68416

87. Area of rake samples $68500-05$ and $68515-37$ before sampling, sample 68505 in the LRL, rake fragments
$68515-19,28$, and 29 in the LRL, stereopair of rake fragment 68515 in the LRL, and rake fragments

87. Area of rake samples $68500-05$ and $68515-37$ before sampling, sample 68505 in the LRL, rake fragments
$68515-19,28$, and 29 in the LRL, stereopair of rake fragment 68515 in the LRL, and rake fragments 68525-27 and 68535-37 in the LRL ation of samples $68815,68820-25,68840-48$, and boulder \#3, sample 68815 during sampling, sample

88. Location of samples $68815,68820-25,68840-48$, and boulder \#3, sample 68815 during sampling, sample
68815 showing reconstructed lunar orientation, and orthogonal views of sample 68815

89. Location of samples $68840-48$ and area of samples $68840-48$ after sampling

90. Locations of all samples at station 9

91. Drive tube sample 69001 during sampling

92. Contact soil sampling devices used to collect samples 69003 and 69004 and collection plates draped with nylon fabrics

93. Sample 69935 in stereopair before and after sampling, sample 69935 shown before and after sampling, and orthogonal views of sample 69935

94. Sample 69945 in the LRL

95. Samples 69955 and 69960-65 before sampling, sample 69955 shown before and after sampling, and orthogonal views of sample 69955

\section{TABLES}

TABLE 1. Summary of Apollo 16 sample weights and the number of rock and soil samples at traverse stations

2. Dimensions of selected lunar and laboratory (LRL) hardware

3. Cross-reference of Apollo 16 lunar samples with locations, lunar-surface photographs, Apollo elapsed times, and excerpts from the air-to-ground transcript of astronauts' comments

4. Index of samples showing classifications, figure illustrations, and page references in table 3

\section{INTRODUCTION AND EXPLANATION}

The Apollo 16 mission returned $95.7 \mathrm{~kg}$ of rock and soil samples collected by astronauts John W. Young and Charles M. Duke on the surface of the Moon. This chapter is primarily a reference catalog of Apollo 16 samples, with emphasis on the local environmental context of each sample as it was documented by astronauts Young and Duke on the lunar surface. It includes two sections:

1. "Photographic Documentation of Apollo 16 Samples"-A photographic documentation of samples and their lunar environments, including, for most rock samples larger than about $1 \mathrm{~cm}$ diameter, pictures taken in the Lunar Receiving Laboratory (LRL "mugshots").

2. "Cross-Reference of Apollo 16 Lunar Samples" (table 3)-A table of cross-reference between traverse locations and sample numbers, their weights and type classification, lunar-surface documentation photographs, time during the mission at which the samples were collected, and comments by the crew relating to the geologic setting or description of each sample.

The photographic documentation of samples and their lunar environments includes a brief descriptive outline of the lunar setting within a few meters of each sample, taken largely from ALGIT (1972b), as well as photographic documentation of the sample on the lunar surface and in the Lunar Receiving Laboratory. Samples are listed in sequence by ascending LRL number, except for the few cases in which samples with widely separated numbers were collected at the same location. In these instances, the reader is referred to the pages or figures. Sample-bag residues and residue fines collected incidentally with rock samples are generally omitted in this section, unless identified as soil samples in the LRL catalog (see below).

From weights and sizes given in the Apollo 16 Sample Information Catalog (LRL, 1972), a summary was prepared of total sample weights for all traverse stations (fig. 1), including the number of rocks and soil samples collected at each station (table 1).

Most measurements that refer to documentary lunar-surface photographs (size, distance, slope, and percentages) are qualitative visual estimates, based wherever possible on the known dimensions of features shown in the photographs. Scales can be estimated in pictures that include features such as identifed sam- 
TABLE 1. Summary of Apollo 16 sample weights (in grams) and the number of rock and soil samples at traverse stations

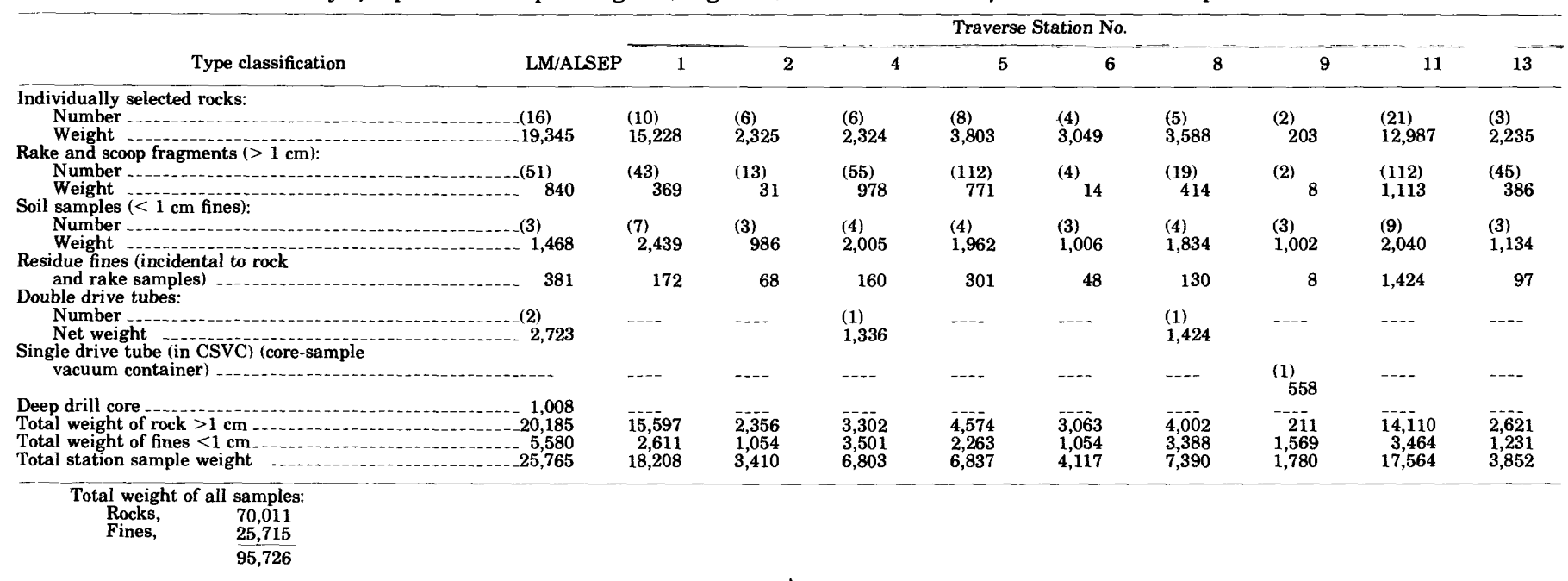

ples, the gnomon, tools for sampling, an astronaut or his footprints, the LRV, the Lunar Module, or even a crater or large boulder that can be identified and measured on orbital photographs. A perspective grid of the type illustrated in chapter L2, figure 3, can be of assistance in determining comparative sizes with respect to objects of known dimensions within the field of view.

Dimensions given in table 2 will assist the reader in determining scale (the size of objects) in both lunar and LRL photographs of lunar and laboratory hardware items. Most lunar-surface photographs of samples include at least one feature of known size listed in part A of table 2. Most laboratory photographs of samples include a scale divided into centimeters. A bar scale is drawn on pictures in which the LRL scale has been omitted for reasons of format or photo reproduction. Some pictures, including those of rake samples, are oblique views in which the scale changes from one side of a picture to the other. Part B, table 2, lists the dimensions of some laboratory hardware useful in determining the sizes of samples shown in oblique views.

Rock samples that weigh 2 grams or more are classified according to the scheme of Wilshire, StuartAlexander, and Schwarzman (this volume). The composition of soil samples is not included.

Lunar-surface orientations were determined for 47 of the 111 Apollo 16 rock samples larger than $25 \mathrm{~g}$. Of these, forty three were determined by correlating shapes and shadow characteristics evident in presampling lunar-surface photographs with similar details of these samples when illuminated by collimated light in the Lunar Receiving Laboratory. Directions of sun and shadow thus determined were transferred to models and LRL photographs of the same rocks and are shown in the top views of orthogonal photographic layouts of the oriented samples (described below). Orientations of four rocks $(67475,68035,69935$, and 69955$)$ were estimated using models and photographs only. Because of changes in sun azimuth at the landing site during the mission, sun-shadow directions required corrections to obtain true lunar azimuths. The sun azimuth varied from $084^{\circ}$ during EVA 1 to averages of $081 \frac{1 / 2^{\circ}}{}$ and $078^{\circ}$ during EVA's 2 and 3, respectively. In other words, the

TABLE 2.-Dimensions of selected lunar and laboratory (LRL) hardware

\section{A. Lunar-surface hardware}

Lunar module:

Height, from top of footpad, excluding antennas __. $6.1 \mathrm{~m}$

Leg-to leg (diagonal) from outer edge of footpads ...... $9.45 \mathrm{~m}$

Leg-to-leg (peripheral) _._-_._-_._- $6.7 \mathrm{~m}$

Lunar roving vehicle (LRV):

Length (including wheels) _._._._. $3.1 \mathrm{~m}$

Width (wheel-to-wheel centers)

Width of wheel track

Helmet of an astronaut's pressure suit:

Average lateral diameter

Hand tools used in sampling:

Rake width

Scoop width

Tongs width (tines)

Tongs handle length (to top of tines)

Extension handle for scoop and rake _._._. $76.0 \mathrm{~cm}$ (dark band on handle: distance from end of

connection) - $40.0 \mathrm{~cm}$

Drive tube (length)

Gnomon:

Wand length

Leg length

Photometric scale divisions (width) _..._. $2.0 \mathrm{~cm}$

(Astronaut's footprint, width, maximum)

(Astronaut's footprint, length, approx.)

B. Laboratory (LRL) hardware used in sample processing

Large cube with letters for photoorientation (used mostly

in laboratory trays with broken and loose samples)

Small cube with letters for photoorientation (used in $(\sim 1.0 \mathrm{~cm})$ most pictures of individual rock samples)

Aluminum cups used for separation rake fragments

(inside diameter) _........ $5.4 \mathrm{~cm}$

Rod dividers in rake-sample trays (center-to-center of rods) $6.7 \mathrm{~cm}$

(square) 
sun was north of true lunar east by average amounts of

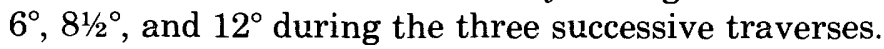
These corrections have been made in sample orientations as well as in the photographic panoramas (pls. $3-11$, this volume).

Following each photograph that shows the lunar orientation of a rock, as it was reconstructed in the laboratory, is an orthogonal "foldout" portrayal of the same sample made from selected LRL mugshots, designed to show the lunar top, bottom, and four sides of the samples as it lay at the time of collection. Directions to the sun and the lunar ordinates are shown on the top view, and lines portraying breakage or the approximate depth of burial are shown on all appropriate views of the samples. The orthogonal layouts were carefully made in order to help the reader in mental transition from the lunar-orientation photographs to the mugshot photographs. The "front," or occasionally, the "top," view was chosen to match (as nearly as possible) the presampling view shown in lunar-surface photographs.

Photographic procedures in the laboratory did not always result in all pictures of a given sample being taken from exactly the same camera distance; therefore average scales are shown in the orthogonal layouts. In addition, because of the difficulty in the laboratory of supporting odd-shaped rock samples in truly orthogonal attitudes, "orthogonal" views are not actually $90^{\circ}$ apart, except for the pictures taken of a sample in one position on the turn-table stage throughout a complete rotation. In constructing the layouts used here, photographs were selected that most nearly show truly orthogonal relations. Infrequently, not all orthogonal views of a sample were photographed; these were either left blank in the layouts or the closest alternate view was substituted.

Table 3 is a cross-reference of Apollo 16 samples with locations, weights and sample types, lunar-surface photographs, Apollo-Elapsed Times (AET), and excerpts from the air-to-ground voice transcription. Samples are placed in chronological sequence by the time (AET) at which they were collected during the three EVA's. In several cases where the two astronauts collected samples separately but at the same time, which sample was listed first in the table.was somewhat arbitrary. In general, all crew comments relating to a specific sample are combined under the sample heading, even though pertinent comments were, in several cases, widely separated in time.

EXPLANATION OF HEADINGS IN TABLE 3 [Note: The microfiche copy of table 3 (chapter L1) is mislabeled as "table 3, chapter 3."]

Sample number.-Samples are referred to by the numbers of both the lunar containers into which they were first collected (prenumbered sample bags and core tubes) and the five-digit numbers assigned to them in the Lunar Receiving Laboratory, now the official designation for all samples. Because the sequence of samples in table 3 is in the order of their time of collection rather than ascending sample number, an index of all samples is included (table 4) for easy reference to table 3 . The index lists all illustrations relevant to each sample throughout the report and the classification of Wilshire and others (this volume) of all samples $2 \mathrm{~g}$ or larger.

The LRL sample numbering scheme was designed to convey information about the samples. The prefix digit 6 designates all samples from Apollo 16 (likewise, Apollo 17 sample numbers begin with 7). The second digit of the sample number indicates the station from which the sample was collected: $0=\mathrm{LM}$, ALSEP, and station 10 and 10 prime; digits 1 through 9 are equivalent to stations with the same numbers except for 3 , which indicates station 13 , and 7 , which indicates station 11. By convention, sample numbers that end with digits 0 (zero) through 4 are soil samples, and final digits 5 through 9 denote sample fragments larger than $1 \mathrm{~cm}$ in diameter. An exception is the deep-drillcore sample, whose top three sections end in digits 5-7. In table 3 , fragments weighing $<12 \mathrm{~g}$ are arbitrarily called "chip"; those $>12 \mathrm{~g}$ are shown as "rock." The terms are not meant to imply difference in composition.

Weight.-Sample weight, in grams, shown in column 2, is taken from the Apollo 16 Sample Information Catalog (LRL, 1972). Values of small samples have been rounded to the nearest 0.01 gram.

Sample type.-Rocks and fragments $>2 \mathrm{~g}$ are classified by type according to Wilshire and others this volume) in column 3 . Chips $<2 \mathrm{~g}$ are not classified.

Lunar surface photographs. -Documentary lunarsurface photographs are listed by NASA photograph number, including the film magazine ( 3 digits) and frame number (5 digits). A prefix of AS16- on all photograph numbers has been omitted for brevity. Acronyms following photograph numbers are explained in the glossary at the end of this volume.

Apollo-elapsed-time (AET).-AET is the true elapsed time, shown in days: hours: minutes: seconds (for example, 05012536 ) after the mission began at launch from Kennedy Space Center. Times are taken from the Apollo 16 Technical Air-to-Ground Voice Transcription (MSC-06802) prepared by the Test Division, Apollo. Spacecraft Program Office, NASA, Houston, Texas.

Crew comments. - Crew comments are excerpts from the Technical Air-to-Ground Voice Transcription, selected for geologically descriptive content with specific or general reference to samples. The speakers, 
all of them astronauts, are identified as follows:

CDR (Commander) John W. Young

LMP (Lunar Module Pilot) Charles M. Duke, Jr.

CC (Capsule Communicator, "Capcom," Mission Control, Houston) Anthony W. England

TABLE 4.-Index of samples showing classifications, figure illustrations, and page references in table 3

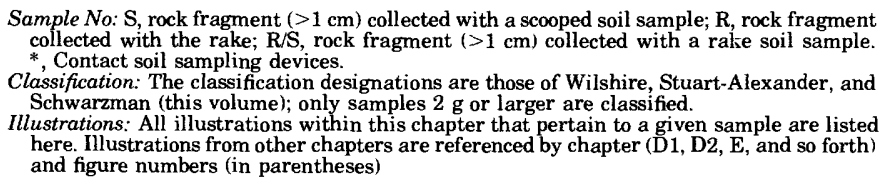

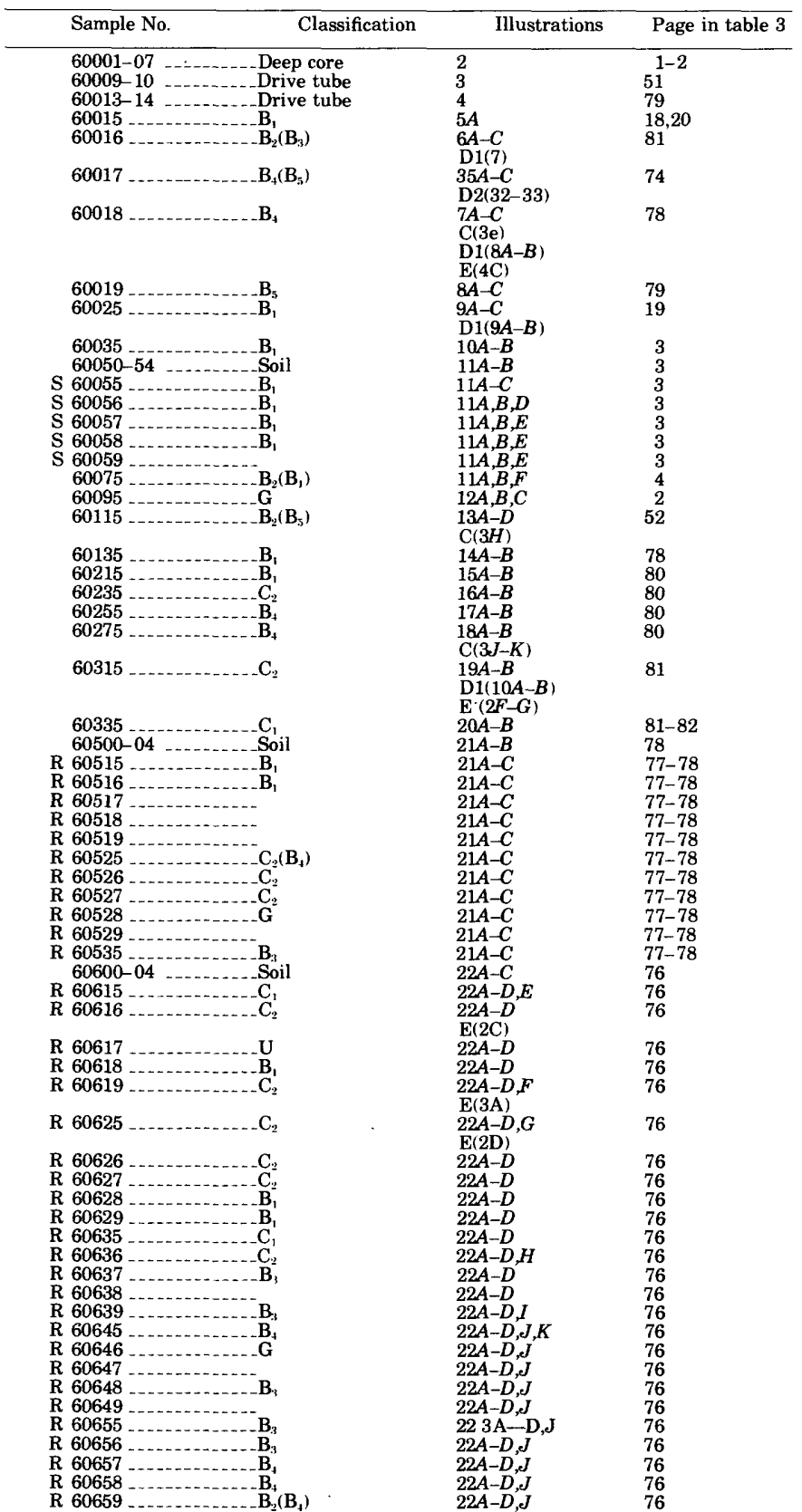

TABLE 4.-Index of samples showing classifications, figure illustrations, and page references in table 3-continued

\begin{tabular}{|c|c|c|}
\hline Classification & Illustrations & Page in table 3 \\
\hline R $60665 \ldots$ & $22 A-D, J$ & 76 \\
\hline $\begin{array}{l}\mathrm{R} \\
\mathrm{R} 606667\end{array}$ & $22 A-D, J$ & 76 \\
\hline $\begin{array}{l}\text { R } 60667 \ldots \\
\text { R } 60668 \ldots\end{array}$ & $\begin{array}{l}22 A-D, J \\
22 A-D, J\end{array}$ & $\begin{array}{l}76 \\
76\end{array}$ \\
\hline $\begin{array}{l}\text { R 60669 } \\
\text { R } 60675\end{array}$ & $22 A-D, J$ & 76 \\
\hline R 60676 & $\begin{array}{l}22 A-D, J \\
22 A-D, J\end{array}$ & $\begin{array}{l}76 \\
76\end{array}$ \\
\hline $\begin{array}{l}\text { R } 60677 \ldots \\
\text { R } 60678\end{array}$ & $22 A-D, J$ & 76 \\
\hline${ }_{R}^{R} 60679 \ldots$ & $\begin{array}{l}22 A-D, D, J \\
22 A-J\end{array}$ & 76 \\
\hline 61015 & $\begin{array}{l}23 A-C \\
\mathrm{D} 1(16)\end{array}$ & $\begin{array}{l}76 \\
13\end{array}$ \\
\hline $61016 \ldots B_{4}$ & $24 A-C ; 28 A$ & $13-14$ \\
\hline 61017 & $\begin{array}{l}\text { (none) } \\
25 A-D, E\end{array}$ & 9 \\
\hline $\begin{array}{l}61140-44 \\
61155 \\
61156 \\
61157 \\
61158 \\
61160-64\end{array}$ & $\begin{array}{l}\text { D1(14) } \\
26 A-D \\
26 A-D, E, F \\
26 A-D, E, G \\
26 A-D \\
26 A-D \\
27 A \\
27 A-D\end{array}$ & $\begin{array}{l}7 \\
7 \\
7 \\
7 \\
7 \\
8 \\
8\end{array}$ \\
\hline $61180-84 \ldots$ & $25 A-C$ & 10 \\
\hline $\begin{array}{l}61195- \\
61220-24\end{array}$ & $\begin{array}{l}25 A-C, D, F \\
28 A-B\end{array}$ & $\begin{array}{r}9 \\
10\end{array}$ \\
\hline $\mathrm{S}_{\mathrm{S}} 61225 \ldots$ & $28 A-C$ & 10 \\
\hline $\begin{array}{l}\mathrm{S} \underset{61240-44}{6126} \text { Soil } \\
\end{array}$ & $\begin{array}{l}28 A-C \\
28 A-B\end{array}$ & $\begin{array}{l}10 \\
10\end{array}$ \\
\hline $\mathrm{S} 61245$ & $28 A-B$ & 10 \\
\hline $\begin{array}{l}S \\
S\end{array} 61246 \ldots$ & ${ }_{28 A-B}^{28 A-B}$ & $\begin{array}{l}10 \\
10\end{array}$ \\
\hline S 61248 & $28 A-B$ & 10 \\
\hline $\begin{array}{l}\text { S } 61249 \\
\text { S } 61255\end{array}$ & $\begin{array}{l}28 A-B \\
28 A-B\end{array}$ & $\begin{array}{l}10 \\
10\end{array}$ \\
\hline $\begin{array}{l}61280-84 \\
61295\end{array}$ & $\begin{array}{l}29 A-B, D \\
29 A-E\end{array}$ & $\begin{array}{l}12 \\
11-12\end{array}$ \\
\hline & $\begin{array}{l}\text { C(3A) } \\
\text { D1(15A-B) }\end{array}$ & \\
\hline $61500-04$ & $30 A-C$ & 6 \\
\hline R/S $61505 \ldots$ & $30 A-C$ & 6 \\
\hline 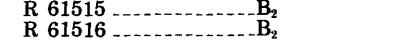 & $\begin{array}{l}30 A-D \\
30 A-D\end{array}$ & $\begin{array}{l}5-6 \\
5-6\end{array}$ \\
\hline $\mathrm{R} 61517$ & $30 A-D$ & $5-6$ \\
\hline $\begin{array}{l}\mathrm{R} \\
\mathrm{R} 61519\end{array}$ & $\begin{array}{l}30 A-D \\
30 A-D\end{array}$ & 年-6 \\
\hline $\begin{array}{l}\mathrm{R} 61525 \\
\mathrm{R} 61526\end{array}$ & $\begin{array}{l}30 A-D \\
30 A-D\end{array}$ & $\begin{array}{l}5-6 \\
5-6\end{array}$ \\
\hline R $61527-\ldots$ & $30 A-D$ & $5-6$ \\
\hline $\begin{array}{l}\mathrm{R} \\
\mathrm{R} 61529\end{array}$ & $\begin{array}{l}30 A-D \\
30 A-D\end{array}$ & $\begin{array}{l}5-6 \\
5-6\end{array}$ \\
\hline R 61535 & $30 A-D$ & $5-6$ \\
\hline $\begin{array}{l}R \quad 61536 \\
R \\
R\end{array}$ & $\begin{array}{l}30 A-D, E \\
30 A-D\end{array}$ & $\begin{array}{l}5-6 \\
5-6\end{array}$ \\
\hline$R_{R} 61538$ & $30 A-D$ & $\begin{array}{l}5-6 \\
5-6\end{array}$ \\
\hline $\begin{array}{l}\text { R } 61539 \ldots \ldots \\
\text { R } 61545 \ldots \ldots\end{array}$ & $\begin{array}{l}30 A-D \\
30 A-C F\end{array}$ & $\begin{array}{l}5-6 \\
5-6\end{array}$ \\
\hline $\mathrm{R} 61546$ & $30 A-C, F, G$ & $5-6$ \\
\hline $\begin{array}{l}R \\
R \\
R\end{array} 61548$ & $\begin{array}{l}30 A-C, F \\
30 A-C F\end{array}$ & $\begin{array}{l}5-6 \\
5-6\end{array}$ \\
\hline $\mathrm{R} 61549$ & $30 A-C, F$ & $5-6$ \\
\hline $\begin{array}{l}R \\
R \\
6\end{array} 61555 \ldots$ & $\begin{array}{l}30 A-C, F \\
30 A-C F\end{array}$ & $\begin{array}{l}5-6 \\
5-6\end{array}$ \\
\hline R $61557 \ldots$ & $30 A-C, F$ & $5-6$ \\
\hline $\begin{array}{l}\mathrm{R} 61558 \ldots \ldots \ldots \\
\mathrm{R} 61559 \ldots \ldots\end{array}$ & $\begin{array}{l}30 A-C, F \\
30 A C F\end{array}$ & ${ }_{5-6}^{5-6}$ \\
\hline $\begin{array}{l}\mathrm{R} 61559-1 \\
\mathrm{R} 61565\end{array}$ & $30 A-C, F$ & $\begin{array}{l}5-6 \\
5-6\end{array}$ \\
\hline $\begin{array}{l}\text { R } 61566 \ldots \\
\text { R } 61567 \ldots\end{array}$ & $\begin{array}{l}30 A-C, F \\
30 A-C, F\end{array}$ & $\begin{array}{l}5-6 \\
5-6\end{array}$ \\
\hline $\mathrm{R} 61568$ & $30 A-C, H$ & $5-6$ \\
\hline $\begin{array}{l}R 61569 \ldots \ldots \ldots \\
R 61575\end{array}$ & $\begin{array}{l}30 A-C, H \\
30 A-C H\end{array}$ & ${ }_{5-6}^{5-6}$ \\
\hline $\mathrm{R} 61576$ & 30A-C,I & $5-6$ \\
\hline R $615770-34$ & $\begin{array}{l}30 A-C, I \\
31 A-B\end{array}$ & $\begin{array}{c}5-6 \\
15-16\end{array}$ \\
\hline $62235 \ldots \ldots$ & $31 A-D$ & $15-16$ \\
\hline $62236 \ldots \ldots \ldots B_{1}$ & $31 A-C, E$ & $15-16$ \\
\hline & $\begin{array}{l}\mathrm{D} 1(21 B) \\
\mathrm{E}(4 H)\end{array}$ & \\
\hline $62237 \ldots \ldots$ & $31 A-C, F$ & $15-16$ \\
\hline S $62238 \ldots$ & $31 A-B$ & $15-16$ \\
\hline $62240-44 \quad \ldots$ & $31 A-B$ & 16 \\
\hline $\mathrm{S} 62245 \ldots$ & $31 A-B, G$ & 16 \\
\hline 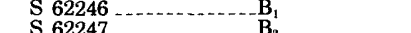 & $31 A-B, G$ & 16 \\
\hline $\begin{array}{l}\mathrm{S} 62247 \\
\mathrm{~S} 62248\end{array}$ & $\begin{array}{l}31 A-B, G \\
31 A-B, G\end{array}$ & $\begin{array}{l}16 \\
16\end{array}$ \\
\hline S 62249 & $31 A-B, G$ & 16 \\
\hline 62255 & $32 A-C$ & 16 \\
\hline $62275 \ldots \ldots$ & $33 A-C$ & 17 \\
\hline $62080-84$ & $\mathrm{D} 1(23 A-B)$ & 17 \\
\hline $\mathrm{s} 62285$ & $\begin{array}{l}34 A \\
34 A\end{array}$ & 17 \\
\hline S 62286 & $34 A$ & 17 \\
\hline $\begin{array}{l}\text { S } 62287- \\
\text { S } 62288 \text { - }\end{array}$ & $\begin{array}{l}34 A \\
34 A\end{array}$ & $17-18$ \\
\hline
\end{tabular}


TABLE 4.-Index of samples showing classifications, figure illustrations, and page references in table 3 -continued

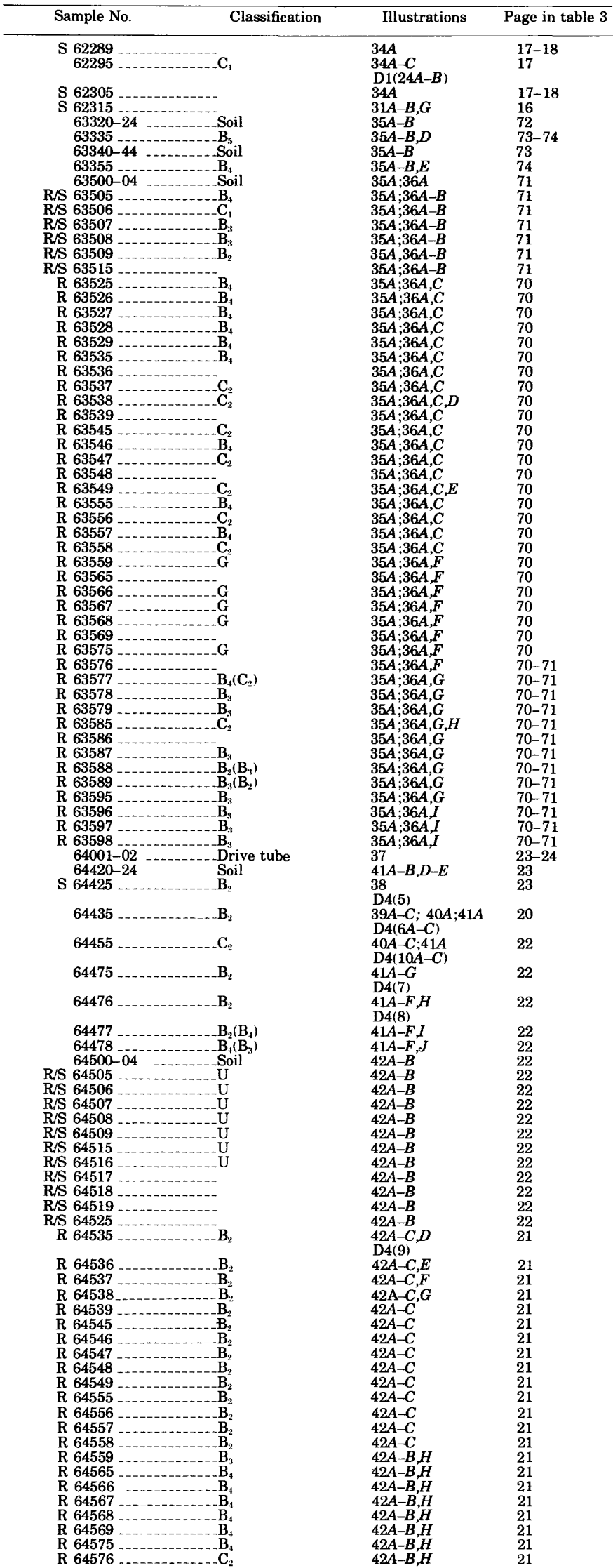

TABLE 4.-Index of samples showing classifications, figure illustrations, and page references in table 3-continued

\begin{tabular}{|c|c|c|c|}
\hline Sample No. & Classification & Illustrations & Page in table 3 \\
\hline 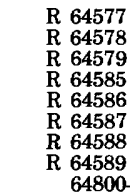 & $\begin{array}{l}-B_{4} \\
-B_{4} \\
-B_{4} \\
-B_{4} \\
-B_{4} \\
-B_{2} \\
-B_{3} \\
-B_{1} \\
- \text { Soil }\end{array}$ & $\begin{array}{l}42 A-B, H \\
42 A-B, H \\
42 A-B, H \\
42 A-B, H \\
42 A-B, H \\
42 A-B, I \\
42 A-B, I \\
42 A-B, J \\
43 A-B\end{array}$ & $\begin{array}{l}21 \\
21 \\
21 \\
21 \\
21 \\
21 \\
21 \\
21 \\
24\end{array}$ \\
\hline
\end{tabular}

64810-14 _..-..-Soil

R 64815

$\mathrm{R} 64816$ - $\mathrm{B}_{4}\left(\mathrm{C}_{2}\right)$

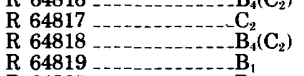

64825

R 64826

R 64827

64828

R 64835

R 64837 .

65016

65055

65056

$65095 \ldots . . . . . . . . . .3\left(B_{1}\right)$

65315

B.

R 65325 -

R $65326 \ldots$

R 65328

R 65335

$R$
$R$
$R$ $653367 \ldots$

R 65339

R 65345

R 65346

R 65347

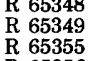

R 65355

R 65357

R 65358

R 65365

65366 -G

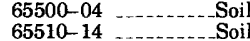

R 65515
R 65516
R 65517

R 65517

R 65519

R 65525
R 65526
65527

R 65527

R 65528

(3A

$43 A-B$
$C(3 L)$

$43 A-B, C$

24-25

$\mathrm{C}(3 L)$

43A-B,D

$43 A-B, D$
$43 A-B, E$

$43 A-B, E$
$43 A-B, F$

$43 A-B, G$

$43 A-B, G$

$43 A-B, G$

$43 A-B, G$
$43 A-B, G$

$43 A-B, G$
$43 A-B, G$

44

D4(21)

$45 A-C ; 48 A$

$\mathrm{C}(3 B-C)$

D4(16)

$47 A-D ; 49 A$

D4(20A-C)

$47 A-B, E$

$47 A-B, E$
$48 A-C$

47A;49A-

47A;49A
D4(18)

$50 A-C ; 46 A ; 48 A$

D4 $(19 A-C)$

$50 A-B, D ; 46 A ; 48 A$

C(3D)

$50 A-B, D ; 46 A ; 48 A$

$5 A A-B, D ; 46 A ; 48 A$

$50 A-B, D ; 46 A ; 48 A$

$50 A-B, D ; 46 A ; 48 A$

50A-B,D46A;48A

$50 A-B, E ; 46 A ; 48 A$
$50 A-B, E ; 46 A ; 48 A$

$50 A-B, E ; 46 A ; 48 A$

$0 A-B, E ; 46 A ; 48 A$

OA-B,E;46A;48A

$50 A-B, F ; 46 A ; 48 A$

(

(1)

$50 A-B, F ; 46 A ; 48 A$

$50 A-B, G ; 46 A ; 48 A$

$50 A-B, G ; 46 A ; 48 A$

$50 A-B, G ; 46 A ; 48 A$

$50 A-B, G ; 46 A ; 48 A$

$51 A-C$

$51 A-C$

$51 A-C, D$

$51 A-C, D$
$51 A-C, D$

$51 A-C, D$
$51 A-C D$

$51 A-C, D$
$51 A-C, D$

$51 A-C, D$
$51 A-C, D$

$51 A-C, D$
$51 A-C, D$

$51 A-C, D$
$51 A-C, D$

$1 A-C, D$

$51 A-C, D$

51A-C,D

$51 A-C, D$

$51 A-C, D$

$51 A-C, D$

$51 A-C, D$

$51 A-C, D$

$51 A-C, D$

$51 A-C, D$

$51 A-C, E$

$51 A-C, E$

$51 A-C, E$

$51 A-C, E$

$51 A-C, E$

51A-C,E

51A-C, $E$

$51 A-C, E$

$51 A-C, E$
$51 A-C, E$

$51 A-C, E$

$51 A-C, E$

$51 A-C, E$

$51 A-C, E$

24-25

24-25 
TABLE 4.-Index of samples showing classifications, figure illustrations, and page references in table 3-continued

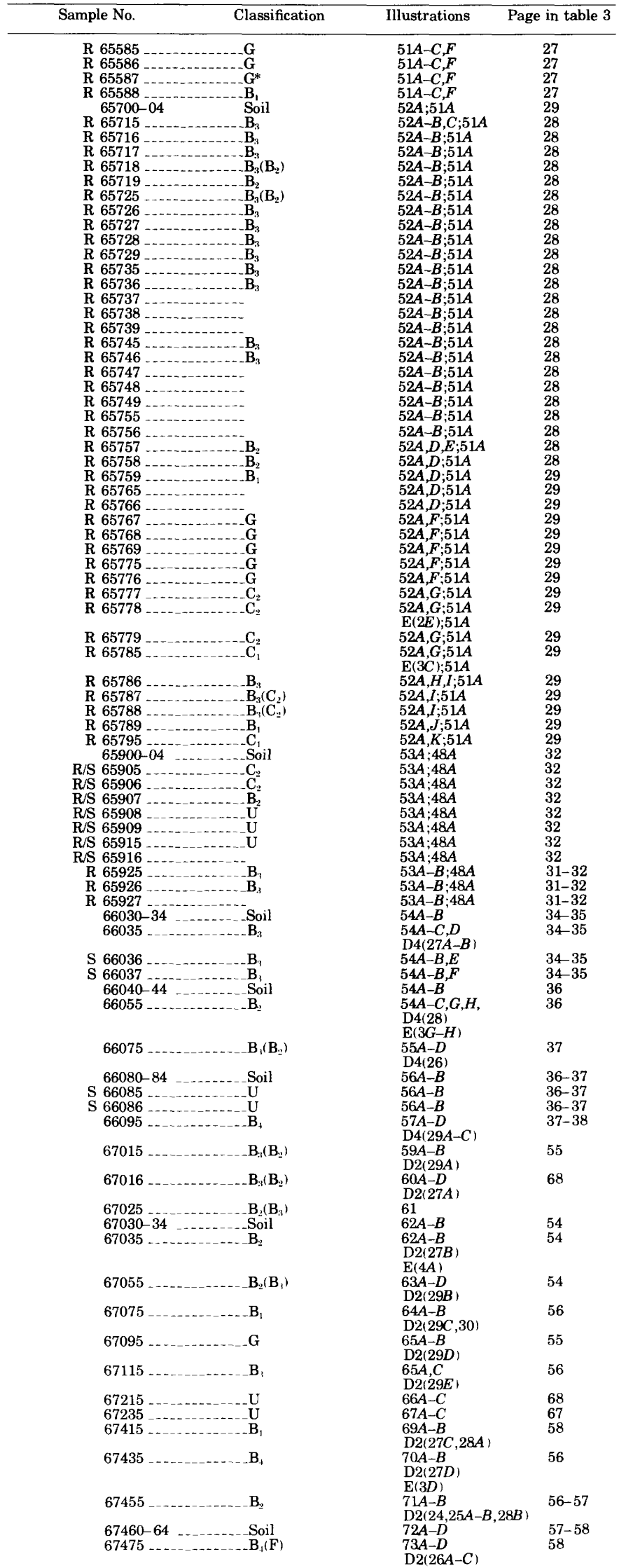

TABLE 4.-Index of samples showing classifications, figure illustrations, and page references in table 3-continued

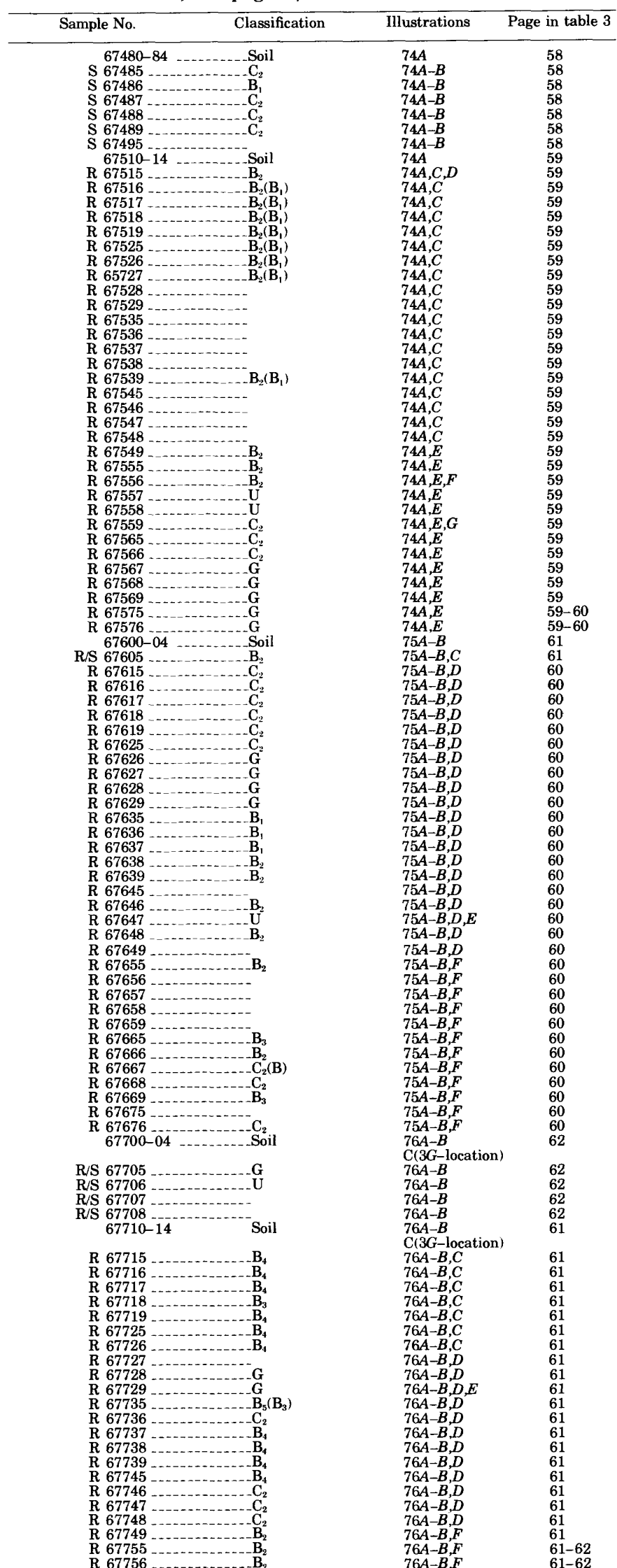


TABLE 4.-Index of samples showing classifications, figure illustrations, and page references in table 3-continued

\begin{tabular}{|c|c|c|}
\hline Classification & Illustrations & Page in table 3 \\
\hline 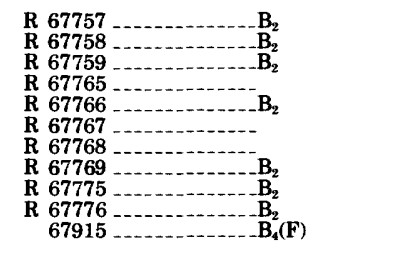 & $\begin{array}{l}76 A-B, F \\
76 A-B, F \\
76 A-B, F \\
76 A-B, F \\
76 A-B, F \\
76 A-B, F \\
76 A-B, F \\
76 A-B, F \\
76 A-B, F \\
76 A-B, F \\
77 ; 78 A-B \\
\text { D2(15) }\end{array}$ & $\begin{array}{l}61-62 \\
61-62 \\
61-62 \\
61-62 \\
61-62 \\
61-62 \\
61-62 \\
61-62 \\
61-62 \\
61-62 \\
64\end{array}$ \\
\hline 67935 & $\begin{array}{l}77 ; 79 A-B, C \\
\text { C }(3 F) \\
\text { D2(17;18) }\end{array}$ & $63-64$ \\
\hline 67936 & $\begin{array}{l}77 ; 79 A-B, D \\
\mathrm{C}(3 F) \\
\mathrm{D} 2(17)\end{array}$ & $63-64$ \\
\hline 67937 & $\begin{array}{l}77 ; 79 A-B, E \\
C(3 F) \\
\text { D2 }(17 ; 19)\end{array}$ & $63-64$ \\
\hline R/S 67945 & $\begin{array}{l}77 ; 81 A-B \\
77 ; 81 A-B \\
\text { D2(21) }\end{array}$ & $\begin{array}{l}65-66 \\
65-66 \\
65-66\end{array}$ \\
\hline $\begin{array}{l}\text { R/S } 67946 \\
\text { R/S } 67947 \\
\text { R/S } 67948\end{array}$ & $\begin{array}{l}77 ; 81 A-B \\
77 ; 81 A-B \\
77 ; 81 A-B \\
\text { D2 }(22 A-C)\end{array}$ & $\begin{array}{l}65-66 \\
65-66 \\
65-66\end{array}$ \\
\hline 67955 & $\begin{array}{l}77 ; 79 A-B ; 80 A \\
\text { C(3F) } \\
\text { D2(16;17) }\end{array}$ & 65 \\
\hline 67956 & $\begin{array}{l}\text { D2(16;17) } \\
77 ; 79 A-B ; 80 B \\
\text { C }(3 F) \\
\text { D2 }(17 ; 20)\end{array}$ & 65 \\
\hline 67957 & $\begin{array}{l}77 ; 79 A-B, 80 C \\
C(3 F)\end{array}$ & 65 \\
\hline $\begin{array}{l}67960 \\
67975 \\
68001-02-B_{2}-B_{2}\end{array}$ & $\begin{array}{l}81 A ; 82 A-B \\
81 A ; 82 A-C \\
83 A-C \\
C(3 M-N)\end{array}$ & $\begin{array}{l}66 \\
66 \\
40\end{array}$ \\
\hline 68035 & $\begin{array}{l}84 A-D \\
85 A-F \\
\text { D3 }(8 A-B ; 9 A)\end{array}$ & $\begin{array}{l}41 \\
41-42\end{array}$ \\
\hline
\end{tabular}

TABLE 4.-Index of samples showing classifications, figure illustrations, and page references in table 3-continued

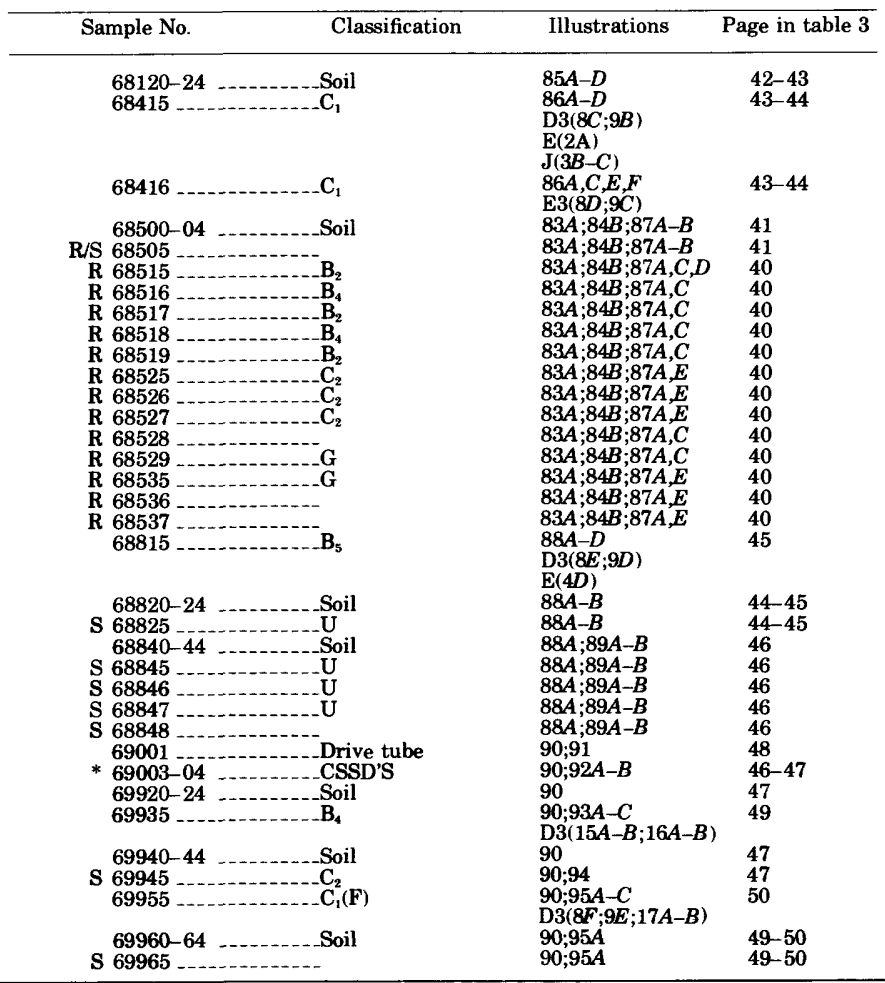

PHOTOGRAPHIC DOCUMENTATION OF APOLLO 16 SAMPLES

[Figures 1-95; p. 241-525] 


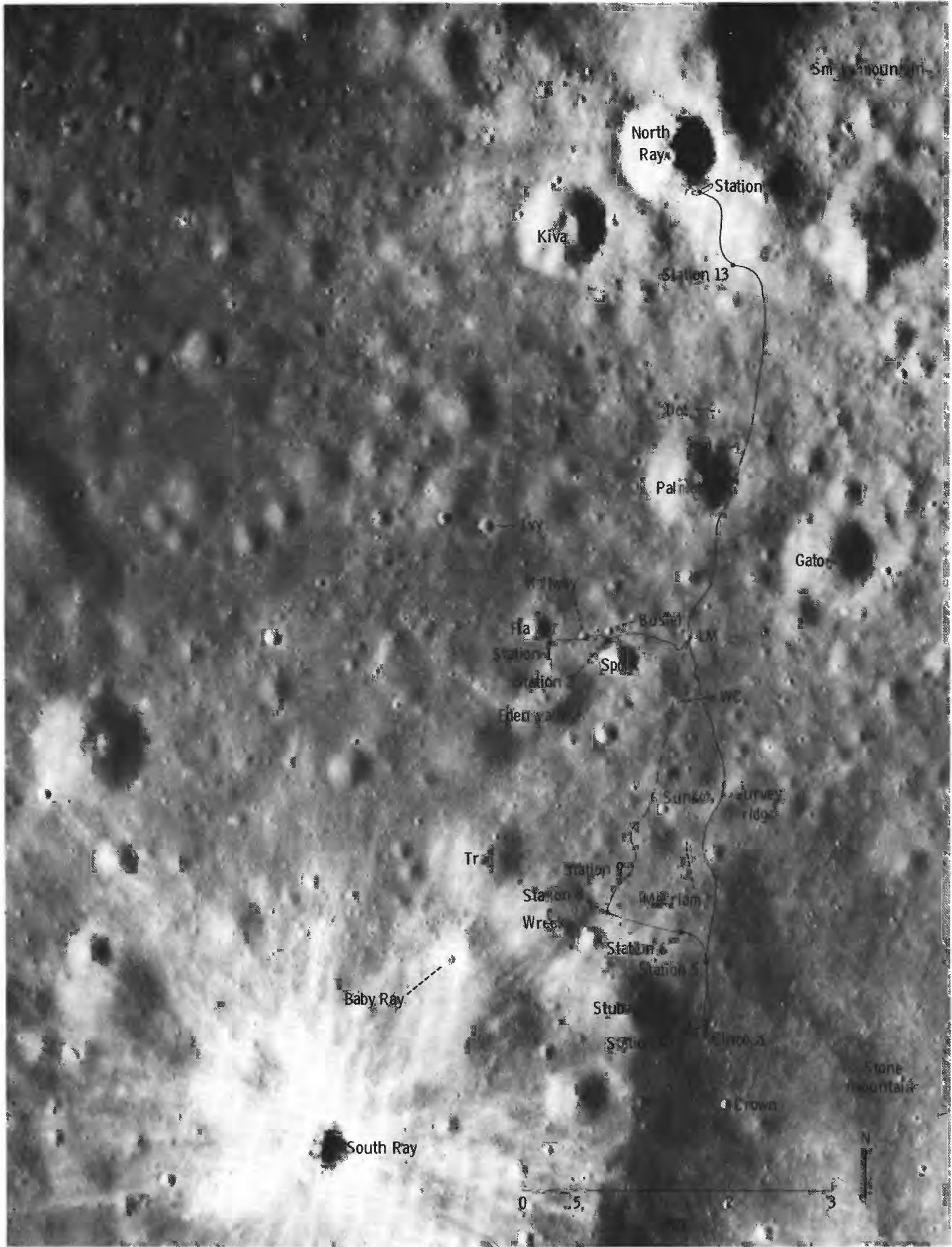

FigURE 1.-Apollo 16 landing site showing the location of the LM/ALSEP and nine traverse stations. Apollo 16 panoramic camera frame 4618 , taken from lunar orbit. 


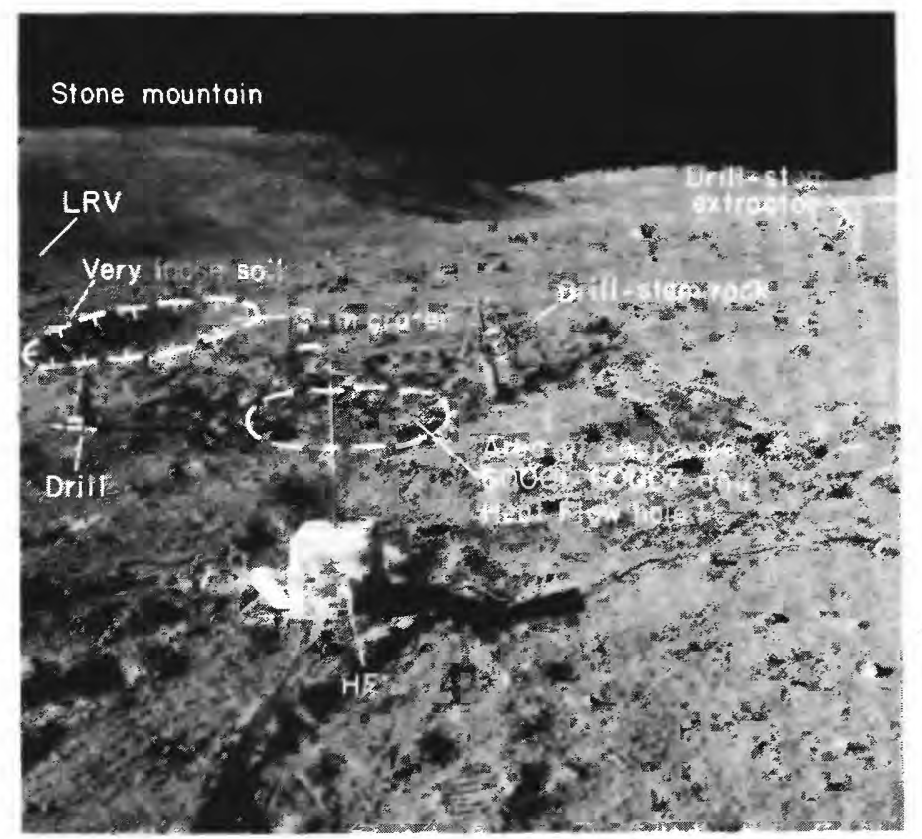

Figure 2.-Area of deep core sample 60001-60007, south side of the ALSEP site, shown after sampling in panorama photograph AS16-113-18367; view is south. Sample 60095 was collected between the deep core and the drill-stem rack (see fig. 12). Drill-stem extractor, thrown away after it was used, landed upright where it is seen in the picture.

SAMPLE: 60001-60007 (deep core)

Station: LM/ALSEP

Landmark: About $125 \mathrm{~m}$ southwest of LM and $25 \mathrm{~m}$ south of ALSEP central station.

Sample type: Deep core.

SURFACE CHARACTERISTICS OF SAMPLE AREA

Slopes: Generally flat spot in an area of rolling topography.

Fragment population

Size rang and distribution: Blocks up to $10-15 \mathrm{~cm}$ abundant

(10-15\%).

Color: Light gray to whitish.

Shapes: Angular to subrounded.

Fillets: Poorly developed.

Apparent burial: Little; mostly perched.

\section{Fines}

Color: Medium gray with white soil at $3 \mathrm{~cm}$ depth in 3-m crater $6 \mathrm{~m}$ southeast of drill core site.

Compaction: Generally very loose in entire ALSEP area; very dusty.

Craters

Size range and distribution: Craters up to $6 \mathrm{~m}$ abundant.

Shape: Majority subdued.

Ejecta: Only on fresher 1-2 m craters.

SAMPLE CHARACTERISTICS

Size: 2.25-m core; $1.8 \mathrm{~m}$ recovered; total weight, 1007.6 grams. Comparison with other soil in area: Soil probably typical of LM/ALSEP area.

Probable origin: Deep drill core should contain South Ray crater ejecta and perhaps North Ray and pre-North Ray ejecta. The core probably contains overlapping ejecta from hearby craters.

COMMENTS: Important to note that the ALSEP deep drill area appears to have the least compacted soil and most 2-6 $\mathrm{m}$ sized craters in the LM/ALSEP area. Core stems went easily into surface. 


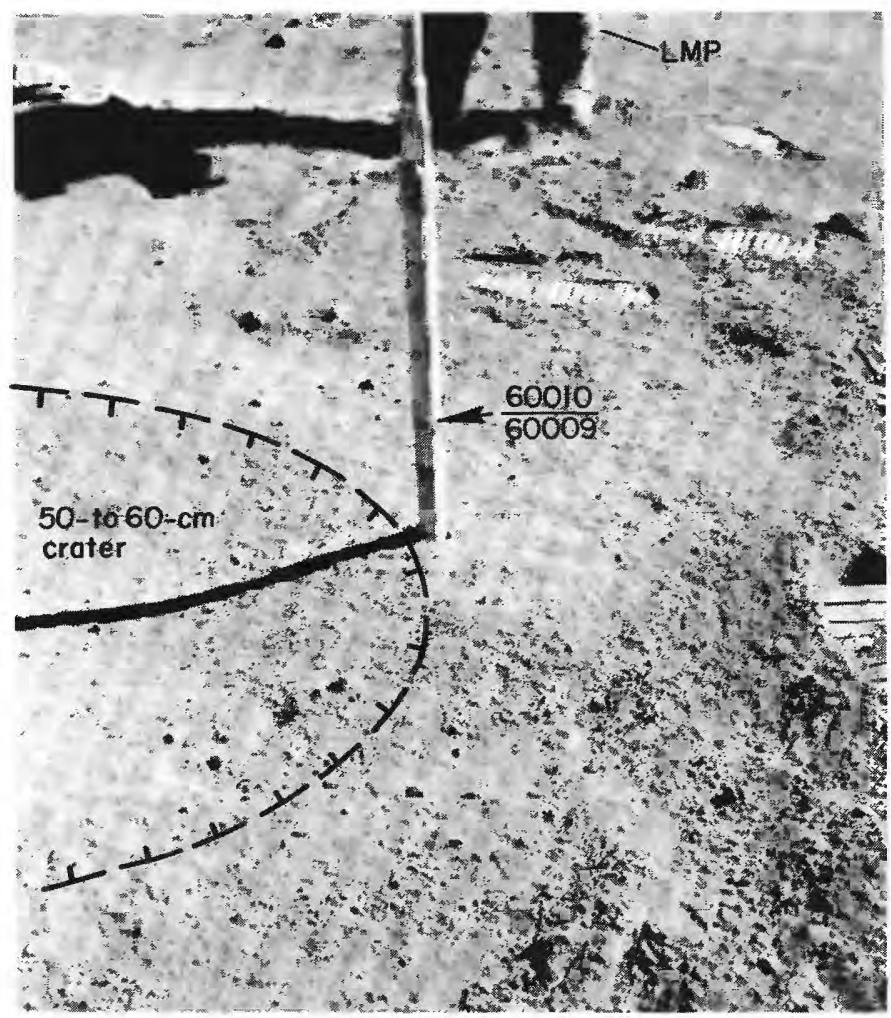

Figure 3.-Double drive-tube sample 60010/60009, at station 10 about $60 \mathrm{~m}$ southwest of the LM, shown during sampling in photograph AS16-115-18557; view is north.

SAMPLE: 60010/60009

Station: 10 (LM/ALSEP)

Landmark: Taken about $6 \mathrm{~m}$ south-southeast of station 10 (see panorama 16, plate 4) and approximately $60 \mathrm{~m}$ southwest of LM.

Sample type: Double drive tube.

SURFACE CHARACTERISTICS OF SAMPLE AREA

Slopes: Generally flat spot in area of rolling topography. Fragment population

Size range and distribution: Mostly cm-sized; none larger than several cm.

Color: Light gray to whitish.

Shapes: Subangular to subrounded.

Fillets: None.

Fines

Color: Medium gray.

Compaction: Moderate.

\section{Craters}

Size range and distribution: $50-60 \mathrm{~cm}$ crater just west of core tube. Core taken on rim crest.

Shape: Round, subdued.

Ejecta: Not visible.

COMMENTS: Core tubes may reveal stratification reflecting ejecta from 50-60 m crater. 


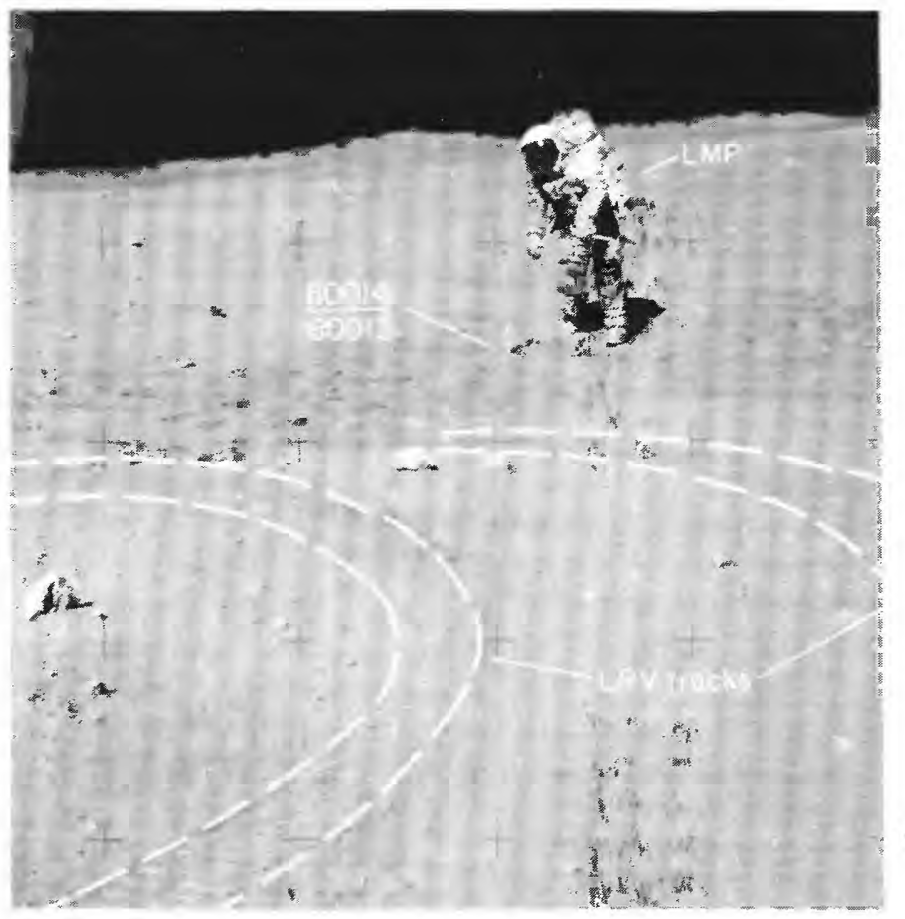

SAMPLE: 60014/60013

Station: 10' (LM/ALSEP)

Landmark: Approximately $70 \mathrm{~m}$ west-southwest of LM. Rock type: Double drive tube.

SURFACE CHARACTERISTICS OF SAMPLE AREA

Slopes: Level.

Fragment population

Size range and distribution: $5-20 \mathrm{~cm}$ blocks moderately abundant; scattered $1-4 \mathrm{~cm}$ rocks.

Color: Many whitish rocks observed in down-sun photo; some moderately gray.

Shapes: Subrounded to irregular.

Fillets: Poorly developed.

Apparent burial: < $1 / 8$

Dust cover: Low-moderate.

Fines

Color: Medium gray.

Compaction: Moderate.

Craters

Size range and distribution: Very sparse 10-20 m craters;

relatively crater free area.

Shape: Subdued.

Ejecta: None visible.

SAMPLE CHARACTERISTICS

Color: LMP noted bottom of core whitish, coarse grained.

Comparison with other soil in area: The white coarse soil noted in the bottom of the core tube was not noted on surface at station 10' but was noted at deep drill site.

Probable origin: Core tube material including white soil probably represents South Ray crater ejecta.

COMMENTS: Bottom of core may include North Ray crater ejecta as well. 


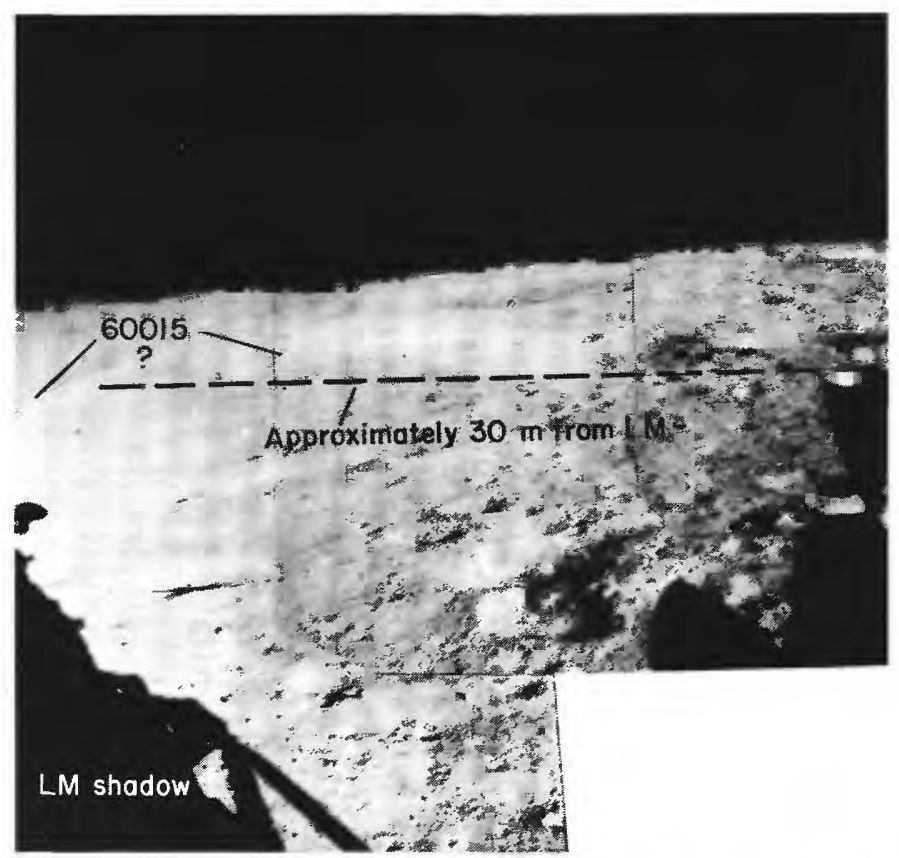

Figure 5A.-Partial pan taken from the right LM window before EVA 1 showing the area of sample 60015 , collected about $30 \mathrm{~m}$ in front (west) of LM at the end of EVA 1. Sample not identified, but two rocks of about the correct size are indicated as the possible sample. Mosaic of photographs AS16-113-18304,-18307,-18308, and -18310 , looking west to northwest.
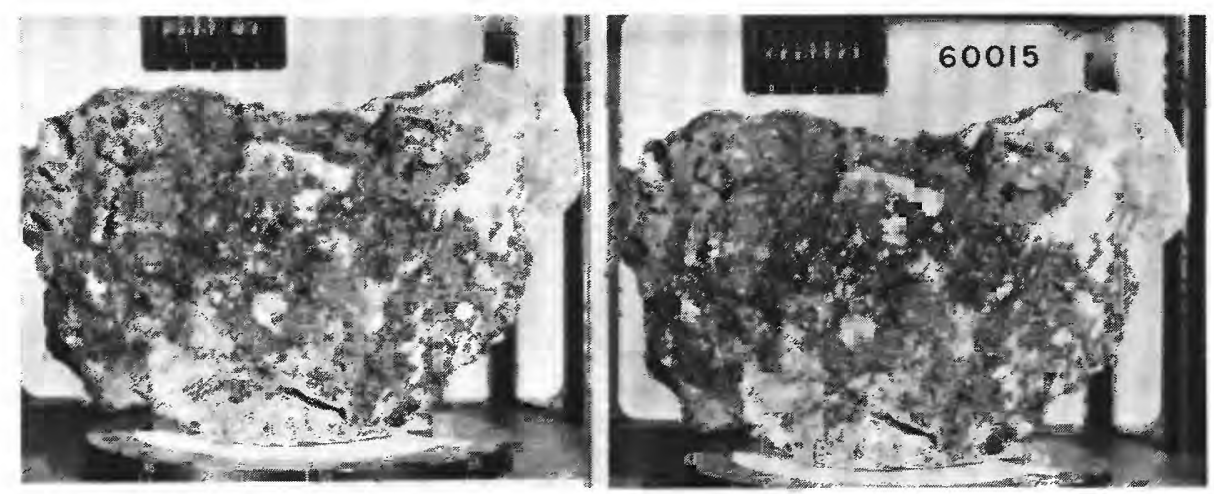

Figure $5 B$.-Stereopair of sample 60015 taken in LRL; photographs S-72-42706 (right) and $-42706 \mathrm{~B}$ (left). Other sides of this $\mathrm{B}_{1}$ breccia mostly glass coated. 
SAMPLE: $\quad 60015$

Station: LM/ALSEP

Landmark: Probably collected about $30 \mathrm{~m}$ west-northwest of LM within view out right window. Sample not recognized in photographs. Rock type: Glass-coated crystalline rock, Bl.

SURFACE CHARACTERISTICS OF SAMPLE AREA

Slopes: Broadly rolling.

Fragment population*

Size range and distribution: $5-15 \mathrm{~cm}$ cobbles abundant; $20-30 \mathrm{~cm}$ blocks common.

Color: Gray to white; very few dark gray.

Shapes: Angular to subrounded.

Fillets: Not visible.

Apparent burial: Some partially buried. Dust cover: Not visible.

Fines

Color: Medium gray.

Craters

Size range and distribution: Scattered 1-3 m craters; some

fresh secondaries.

Shape: Mostly subdued.

Ejecta: Not discernible.

SAMPLE CHARACTERISTICS

Size: $28 \times 15 \times 10 \mathrm{~cm} ; 5,574$ grams.

Color: Bluish as seen from LM (see Table 3, p. 18); glass is medium dark gray.

Shape: Blocky, elongate, one side rounded.

Fillet: Not recognized in photographs.

Apparent Burial: Not recognized in photographs. Dust cover: Not recognized in photographs.

Comparison with other fragments in area: Crystalline rocks sparse in LM/ALSEP area; nearly absent at most other stations.

Probable origin: Ejecta from South Ray.

* Fragment description refers to area shown in LM window pan; not immediate sample area. 


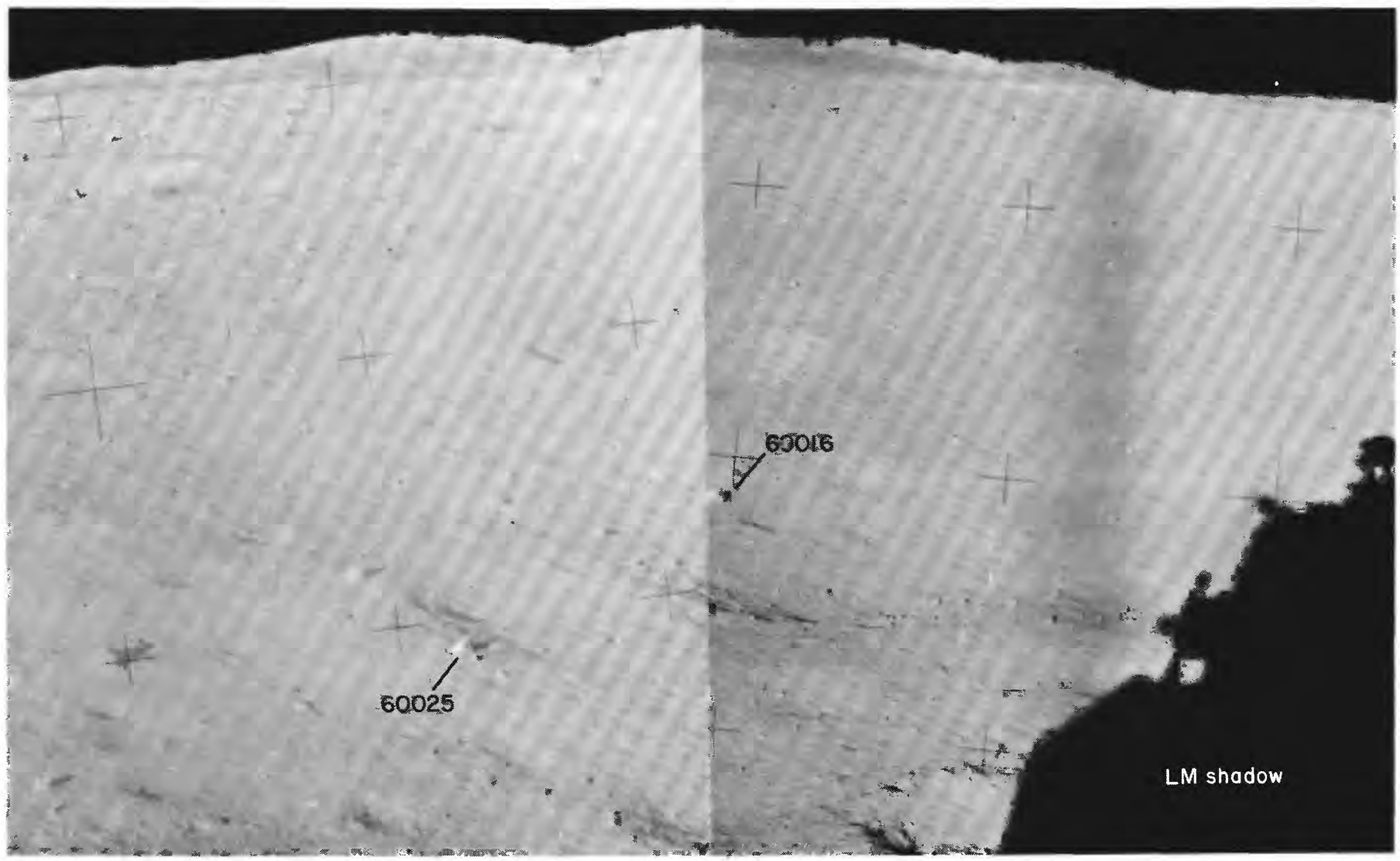

Figure 6A.-Partial pan taken from left LM window before EVA 1, showing samples 60016 and 60025 (collected at end of EVA 3 and beginning of EVA 2, respectively). Both are light-matrix breccias as suggested by their very light color in the photograph. (Photographs AS16-113-18301 and -18302)

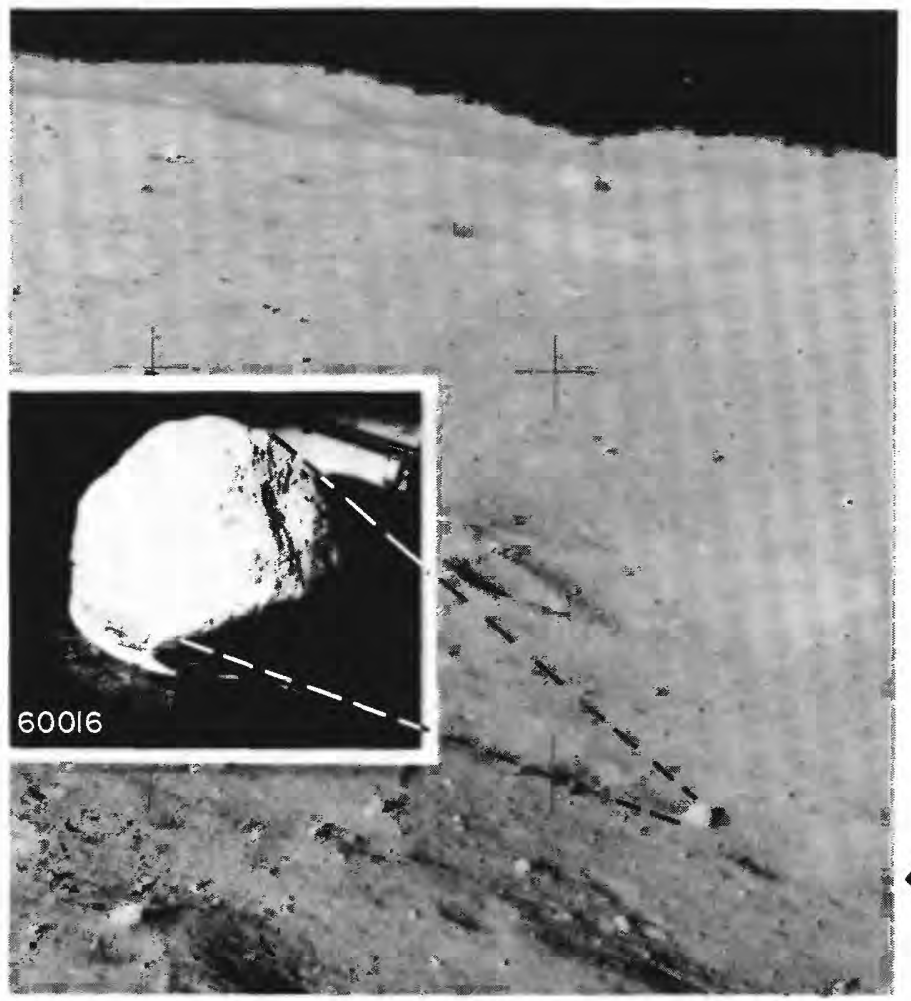

4 Figure 6B.-Sample 60016, showing approximate lunar orientation reconstructed in LRL compared to an enlarged part of photograph AS16-113-18298 taken from LM window before EVA 1. View is southwest (inset photograph, S-72-44510). 


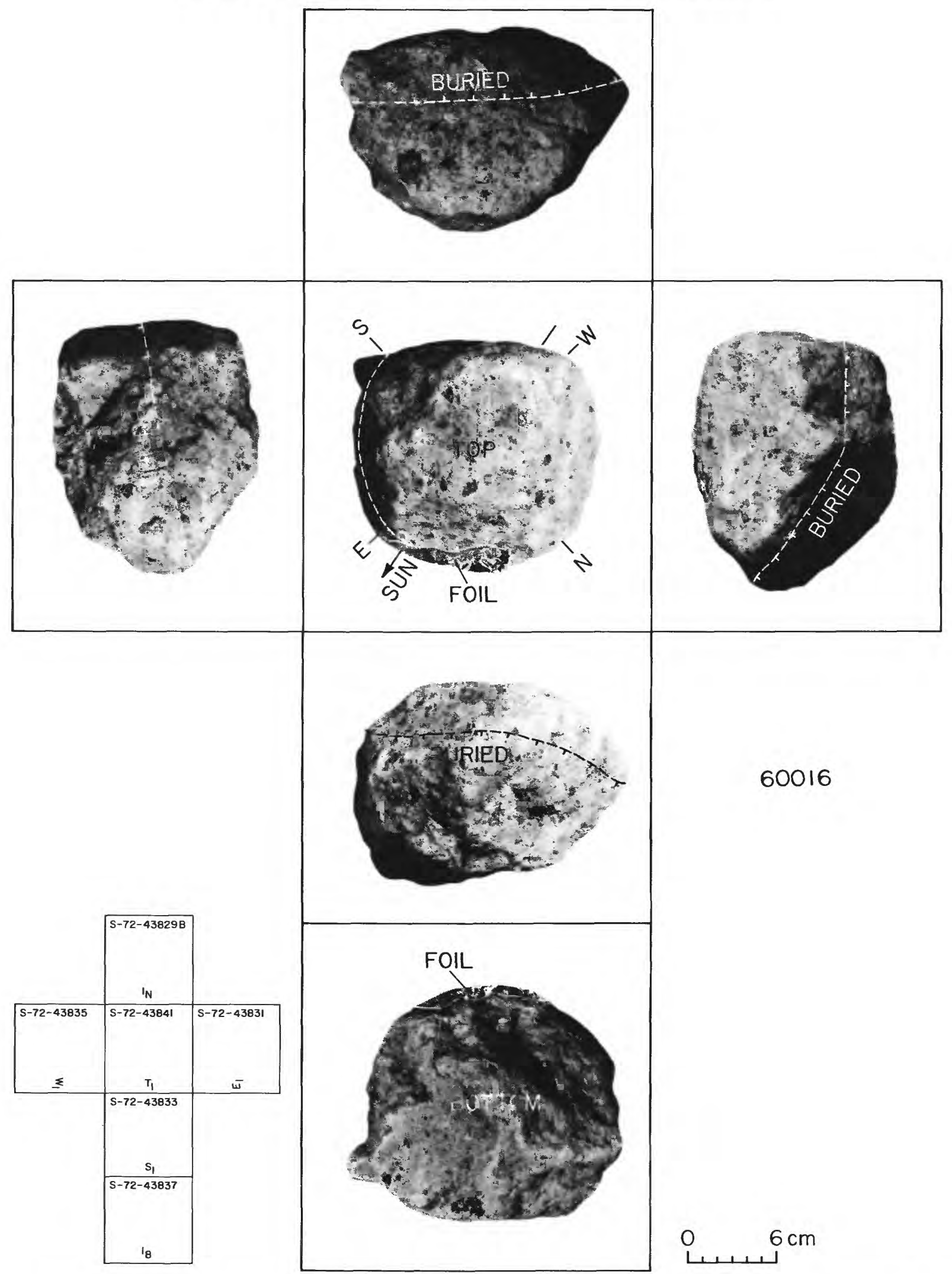

FigURE 6C.-Orthogonal views of sample 60016 related to its lunar orientation at time of sampling. See chapter E, figure 7 , for $B_{1}$ photographic view of this type $B_{2}\left(B_{3}\right)$ breccia. 
SAMPLE: 60016

Station: LM/ALSEP

Landmark: 14-15 $\mathrm{m}$ southwest of LM

Rock type: Breccia, white matrix, small dark clasts; moderately coherent. B2(B3).

SURFACE CHARACTERISTICS OF SAMPLE AREA

Slopes: Nearly flat in immediate vicinity of sample.

Fragment population

Size range and distribution: Up to $20 \mathrm{~cm}$ size; up to $1 \mathrm{~cm}$

fairly abundant; 1 to $5 \mathrm{~cm}$ sparse; sample 60016 one of largest

fragments in vicinity.

Color: Primarily light gray to white, dark fragments sparse.

Shapes: Angular to rounded. Sample 60016 is well rounded.

Fillets: Poorly developed.

Apparent burial: Most fragments $>3-4 \mathrm{~cm}$ buried $1 / 8$ or less.

Dust cover: Moderate to heavy.

Fines

Color: Light gray.

Compaction: Moderately firm.

Craters

Size range and distribution: Up to $3 \mathrm{~m}$ craters sparse in

near sample environment. Surface relatively unpitted and

smooth. LM window view of sample (figure 6a) show general crater distribution.

SAMPLE CHARACTERISTICS

Size: $20 \times 16 \times 13 \mathrm{~cm} ; 4,307$ grams.

Color: White and gray; tan.

Shape: Rounded, equidimensional.

Fillet: Poorly developed.

Apparent burial: < 1/4 of height (relatively perched).

Dust cover: Moderate to heavy.

Comparison with other fragments in area: Size of 60016 appears unique

for a white rock in the LM-ALSEP area.

Probable origin: Most likely representative of South Ray crater ejecta. Sample 60016 rested on the east rim of a 3-m crater from which it may have been excavated

SAMPLE: 60017 Collected at station 13. See 63320 

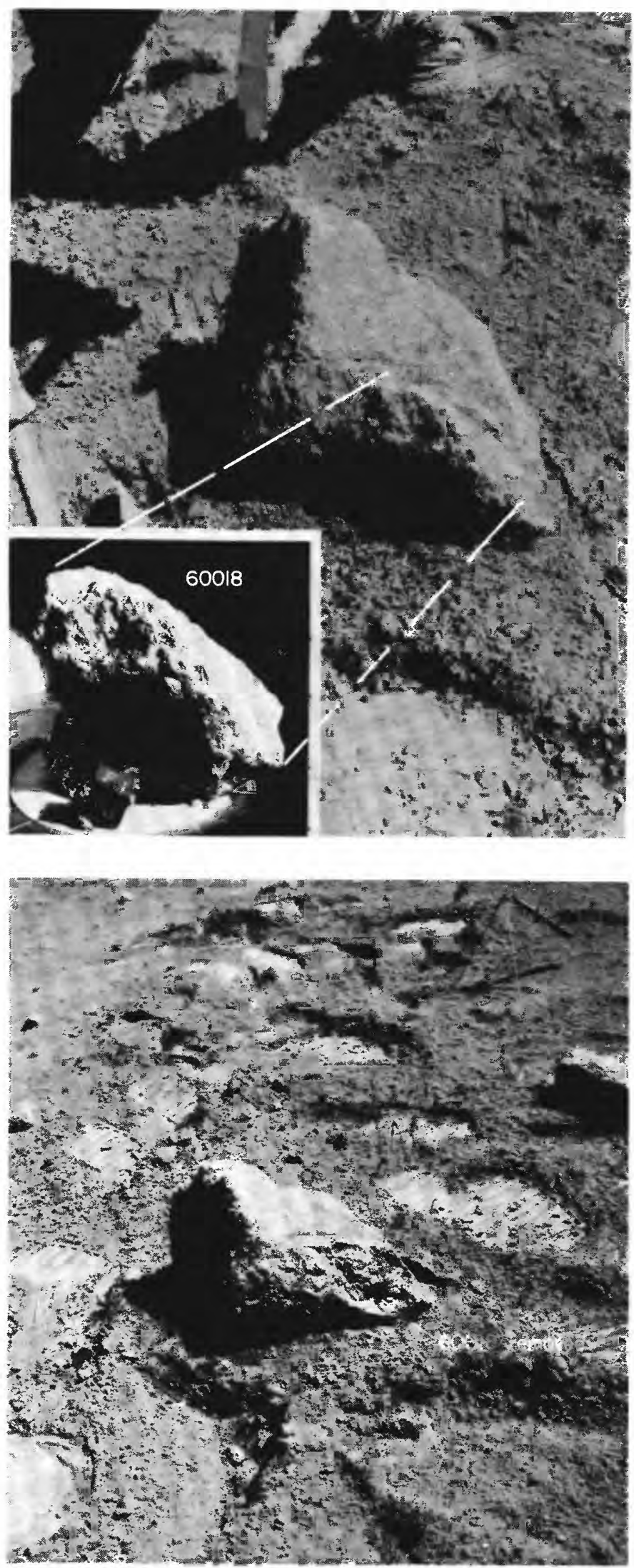

AFigure 7A.-Sample 60018 showing approximate lunar orientation reconstructed in the $\mathrm{LRL}$ compared to an enlarged part of photograph AS16-116-18689 taken before sampling. View is north (inset photograph, S-72-41840).
Figure 7B.-Photograph AS16-116-18691, taken after sample 60018 was broken from the boulder; view is northeast. 


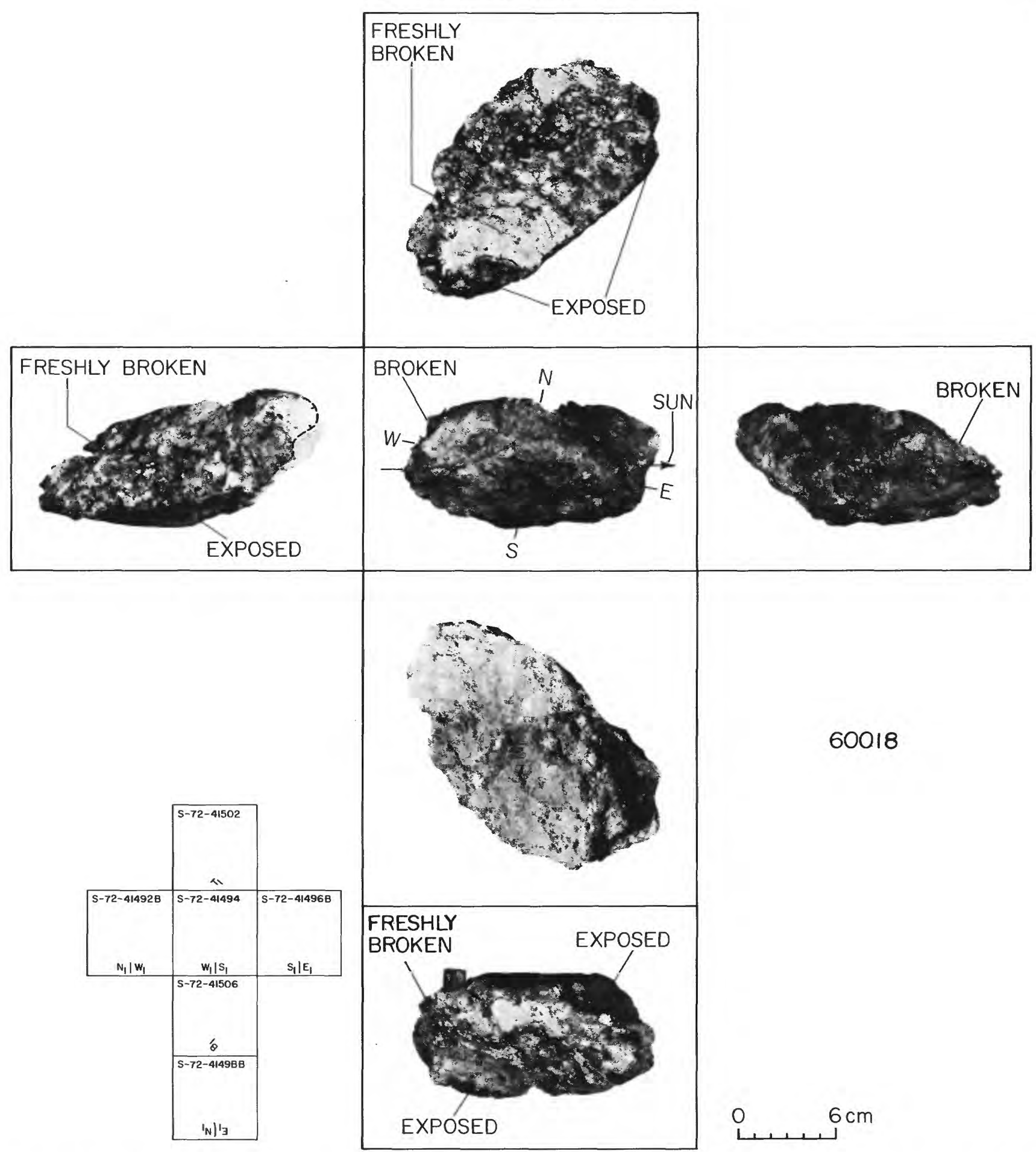

Figure 7C.-Orthogonal views of sample 60018 related to its lunar orientation at time of sampling. See Chapter D1, figure $8 A$, for $N_{1}$ photographic view; chapter $\mathrm{E}$, figure $4 C$, for photomicrograph of this type $\mathrm{B}_{4}$ breccia. 
SAMPLE: 60018

Station: 10 (LM/ALSEP)

Landmark: $60 \mathrm{~m}$ southwest of $L M$ at station 10 pan site. Rock type: Breccia, dark matrix, light clasts; glassy. B4

SURFACE CHARACTERISTICS OF SAMPLE AREA

Slopes: Level.

Fragment population

Size range and distribution: Two 40 or $50 \mathrm{~cm}$ fragments in area; up to $0.5 \mathrm{~cm}$ common; up to $10 \mathrm{~cm}$ sparse; small fragments not as common as in most areas.

Color: Whitish-tan to gray.

Shapes: Subrounded, irregular.

Fillets: Absent.

Apparent burial: $1 / 8$ on large boulders; up to $1 / 3$ on smaller, fist-sized rocks.

Dust cover: Low to moderate.

Fines

Color: Medium gray.

Craters

Compaction: Moderate, soil cakes easily.

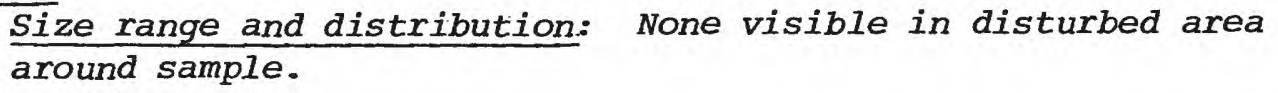

Size: $19 \times 11 \times 6.5 \mathrm{~cm}$; 1,501 grams.

Color: Gray-tan to whitish weathered surface; gray black on broken surface; white clasts.

Shape: Very irregular on broken surface; subrounded but rough on eroded surfaces.

Fillet: None.

Apparent burial: Perched.

Dust cover: Appears light to moderate.

Comparison with other fragments in area: Rock from which 60018 was broken is one of two large rocks that may be of a similar type.

Area too disturbed to evaluate nature of smaller fragments in vicinity. Probable origin: South Ray crater ejecta most probable source as indicated by the number of boulders and the general lack of burial. 


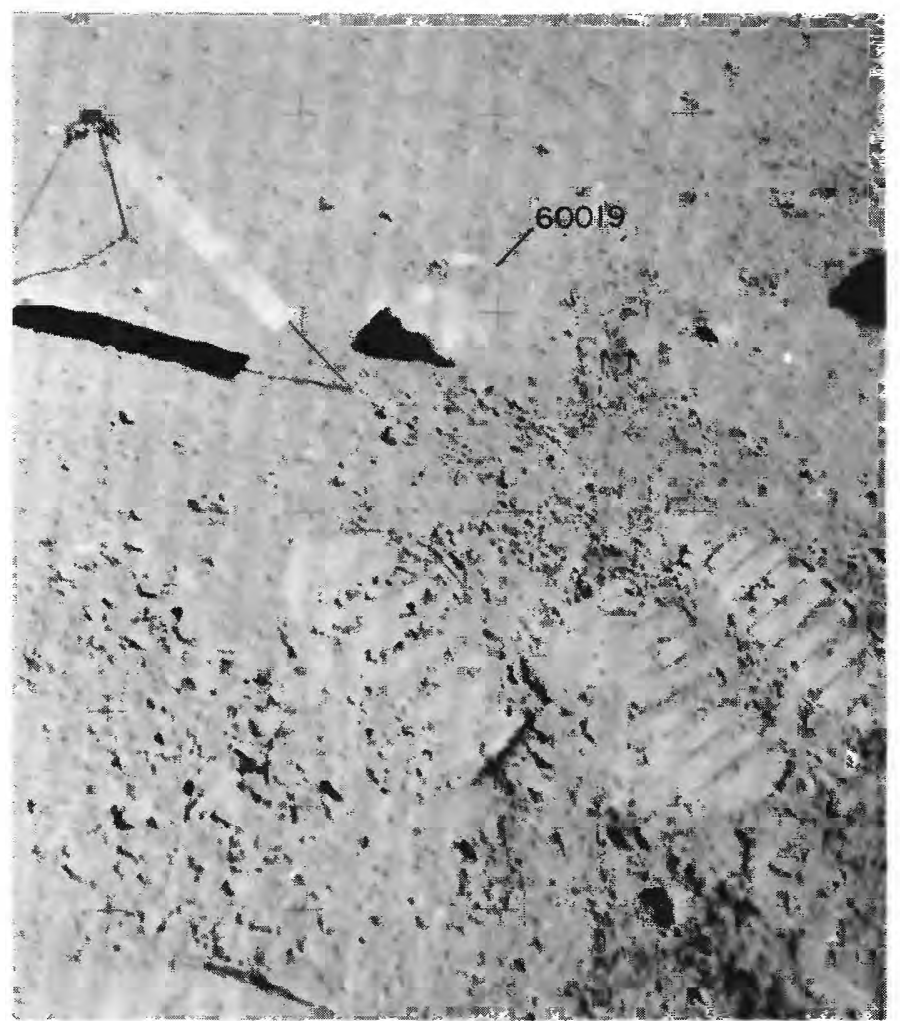

Figure 8A.-Sample 60019 shown before sampling in photograph AS16-116-18702; view is northwest. Note light-colored clasts in breccia sample. Vertical wand of gnomon broken from leg assembly before this picture was taken.

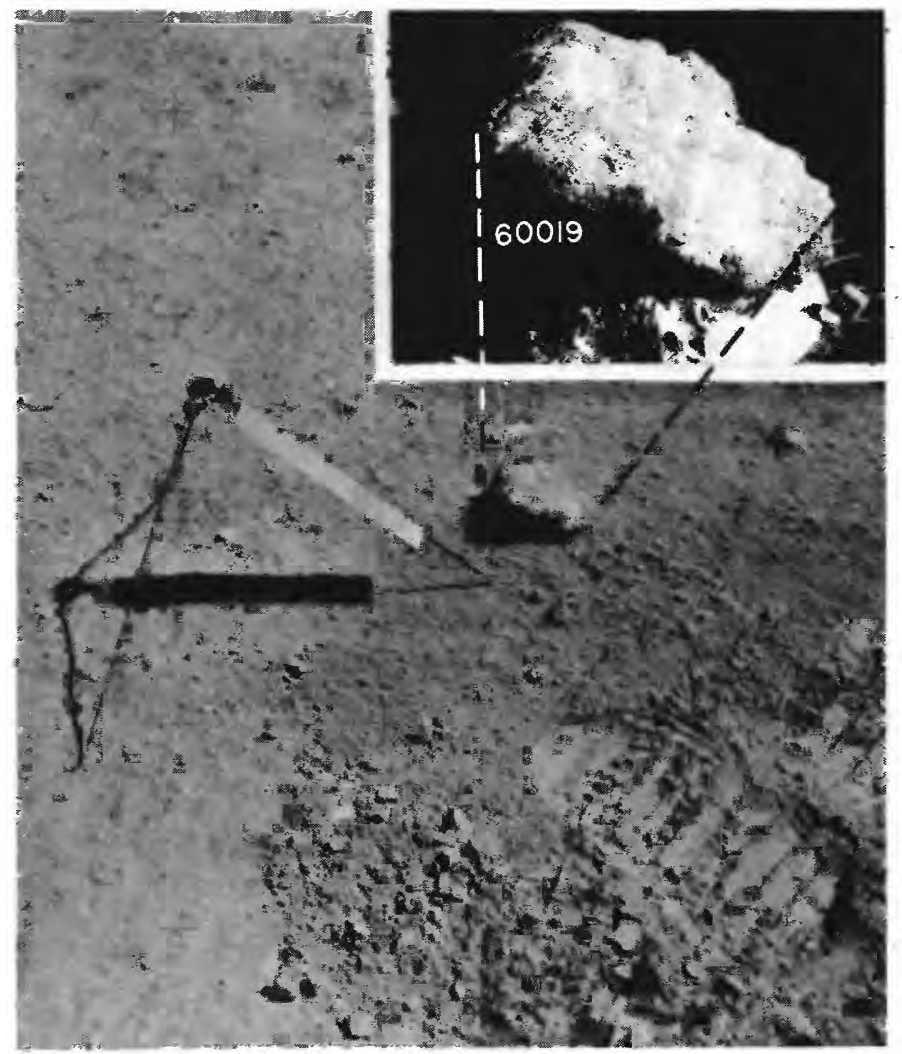

4 Figure 8B.-Sample 60019 showing approximate lunar orientation reconstructed in LRL compared to an enlarged part of photograph AS16-116-18701 taken before sampling. View is north (inset photograph, S-72-42838). 


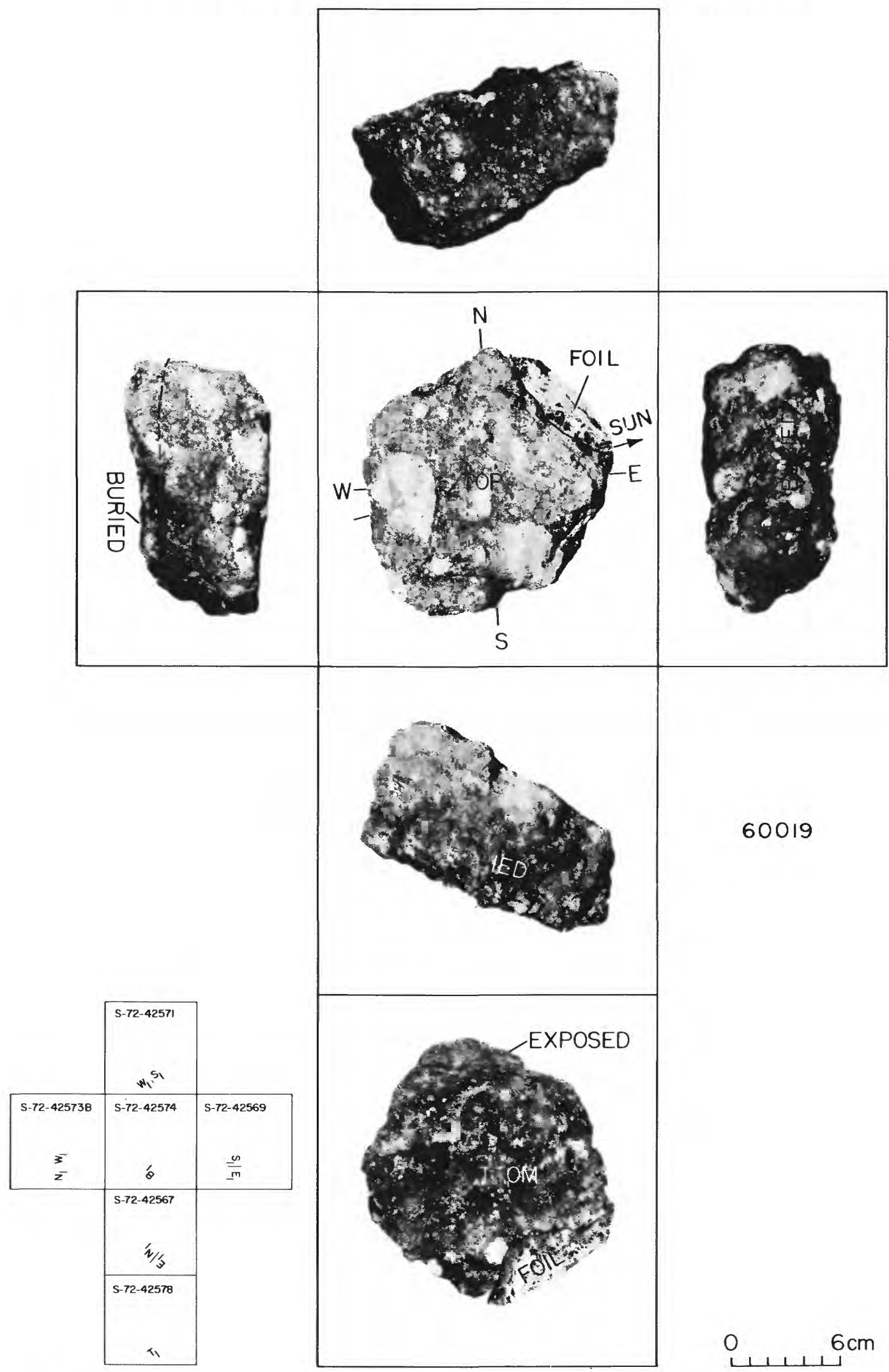

Figure $8 C$.- Orthogonal views of sample 60019 related to its lunar orientation at time of sampling. Sample classified as type $B_{5}$ breccia. 
SAMPLE: 60019

Station: 10' (LM/ALSEP)

Landmark: Probably collected near station 10'. Approximately $70 \mathrm{~m}$ west-southwest of $L M$.

Rock type: Dark breccia with white clasts; glassy coating, B5.

SURFACE CHARACTERISTICS OF SAMPLE AREA

Slopes: Level.

Fragment population

Size range and distribution: $U p$ to $15 \mathrm{~cm} ; 3 \mathrm{~cm}$ to $15 \mathrm{~cm}$ very sparse.

Color: Medium gray to whitish.

Shapes: Subrounded to angular.

Fillets: Very poorly developed.

Apparent burial: $1 / 8$ to $1 / 4$.

Dust cover: Moderate.

Fines

Color: Light to medium gray.

Craters

Compaction: Relatively high.

Size range and distribution: 10-15 cm diameter craters sparse. Shape: Subdued.

Ejecta: Not visible.

SAMPLE CHARACTERISTICS

Size: $15 \times 15 \times 7.5 \mathrm{~cm} ; 1,887$ grams.

Color: Medium gray with white clasts.

Shape: Subrounded with knobby surface.

Fillet: Poorly developed.

Apparent burial: < $1 / 4$ of height.

Dust cover: Moderate.

Comparison with other fragments in area: Appears to be typical of many glass-coated breccias in LM-ALSEP area.

Probable origin: Ejecta from South Ray crater. 

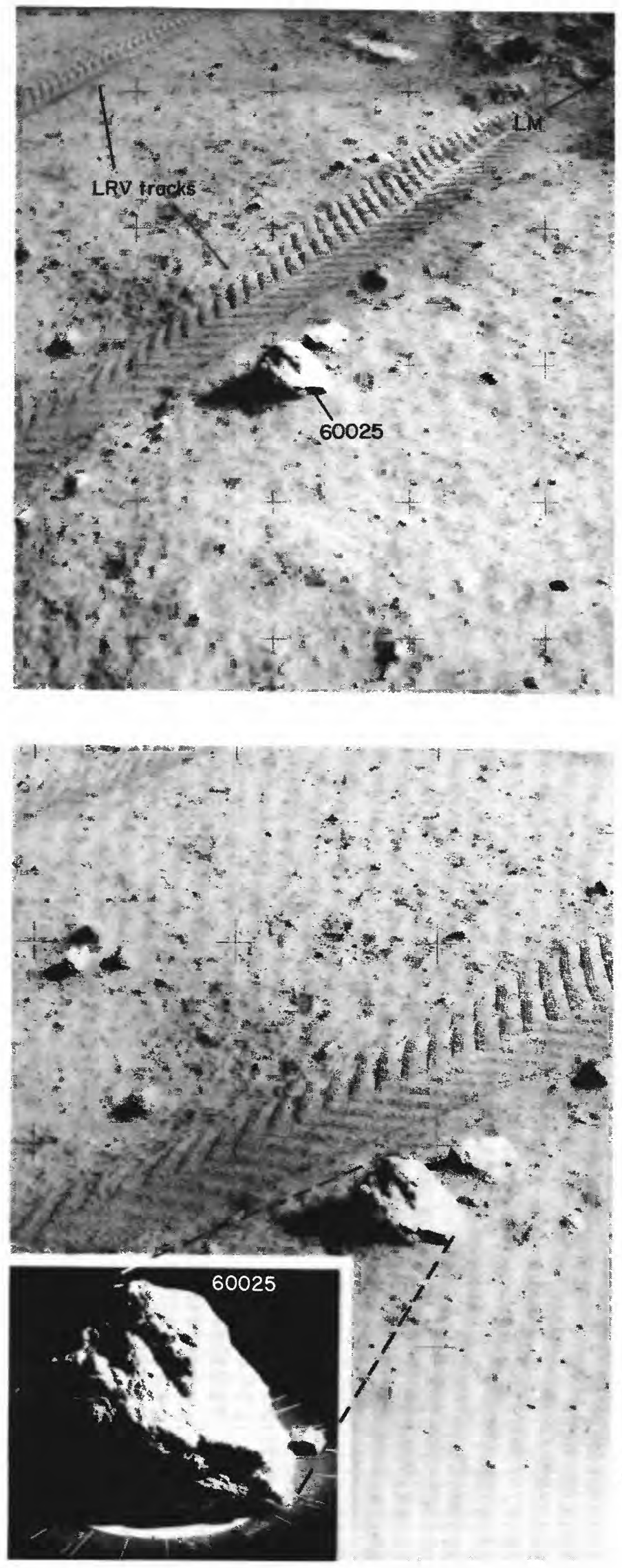

Figure 9A.-Sample 60025 shown before sampling in photograph AS16-110-17867. View is north. See also figure $6 A$ for presampling view from LM window.
\Figure 9B.-Sample 60025 showing approximate lunar orientation reconstructed in LRL compared to an enlarged part of photograph AS16-110-17866 taken before sampling. View is north (inset photograph S-72-44019). 


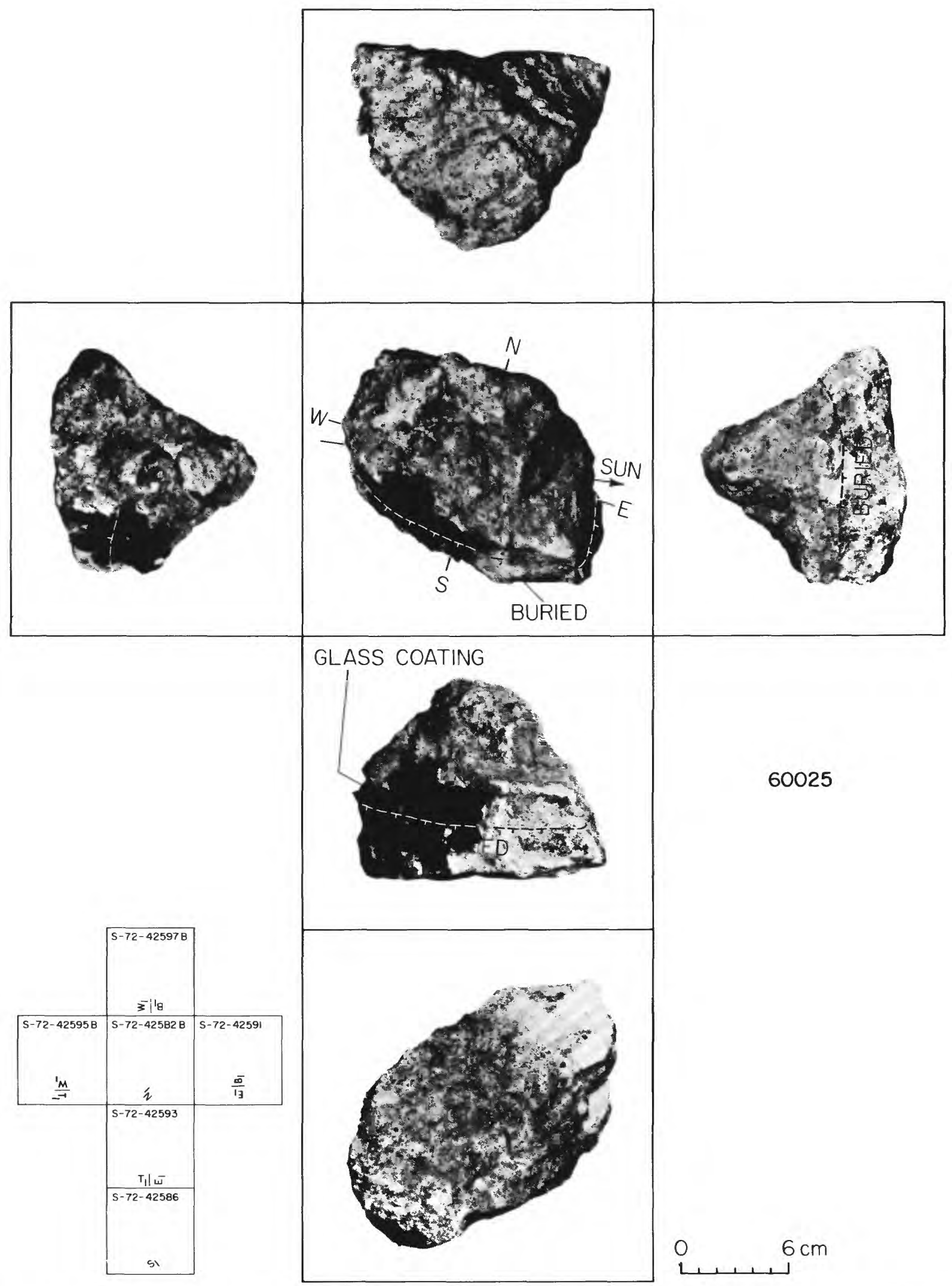

FIGURE 9 C.-Orthogonal views of sample 60025 related to its lunar orientation at time of sampling. See chapter D1, figure $9 A$, for $T_{1} / 5$ photographic view of this type $B_{1}$ breccia. 
SAMPLE: 60025

Station: LM/ALSEP

Landmark: 12-14 $\mathrm{m}$ southwest of $L M$

Rock type: Breccia, white matrix, with partial coating of black

glass, BI

SURFACE CHARACTERISTICS OF SAMPLE AREA

Slopes: Broadly rolling. Nearly flat in immediate vicinity of sample. Fragment population

Size range and distribution: Up to $20 \mathrm{~cm}$ size; up to $1 \mathrm{~cm}$ fairly

abundant; 1 to $5 \mathrm{~cm}$ sparse; sample 60025 one of largest fragments in vicinity.

Color: Primarily ijght gray to white, dark fragments sparse.

Shapes: Angular to rounded. Sample 60025 is angular.

Fillets: Generally poorly developed.

Apparent burial: Most fragments $>3-4 \mathrm{~cm}$ are buried $1 / 8$ or less. Dust cover: Moderate to heavy.

Fines

Color: Light gray.

Compaction: Moderately firm.

Craters

Size range and distribution: Scattered $1-3 \mathrm{~m}$ craters; larger

craters up to $30 \mathrm{~m}$. LM window view of sample (figure 6a) shows

general crater distribution.

Shape: Mostly subdued.

Ejecta: Not discernible.

SAMPLE CHARACTERISTICS

Size: $14 \times 10 \times 10 \mathrm{~cm}$; 1,836 grams

Color: white

Shape: Blocky, pyramidal.

Fillet: Poorly developed.

Apparent burial: < $1 / 4$ of height

Dust cover: Moderate; probably sprayed by dust from LRV track (figure 9A). Comparison with other fragments in area: Part of population of partially glass-covered rocks near $L M$.

Probable origin: South Ray crater ejecta. 


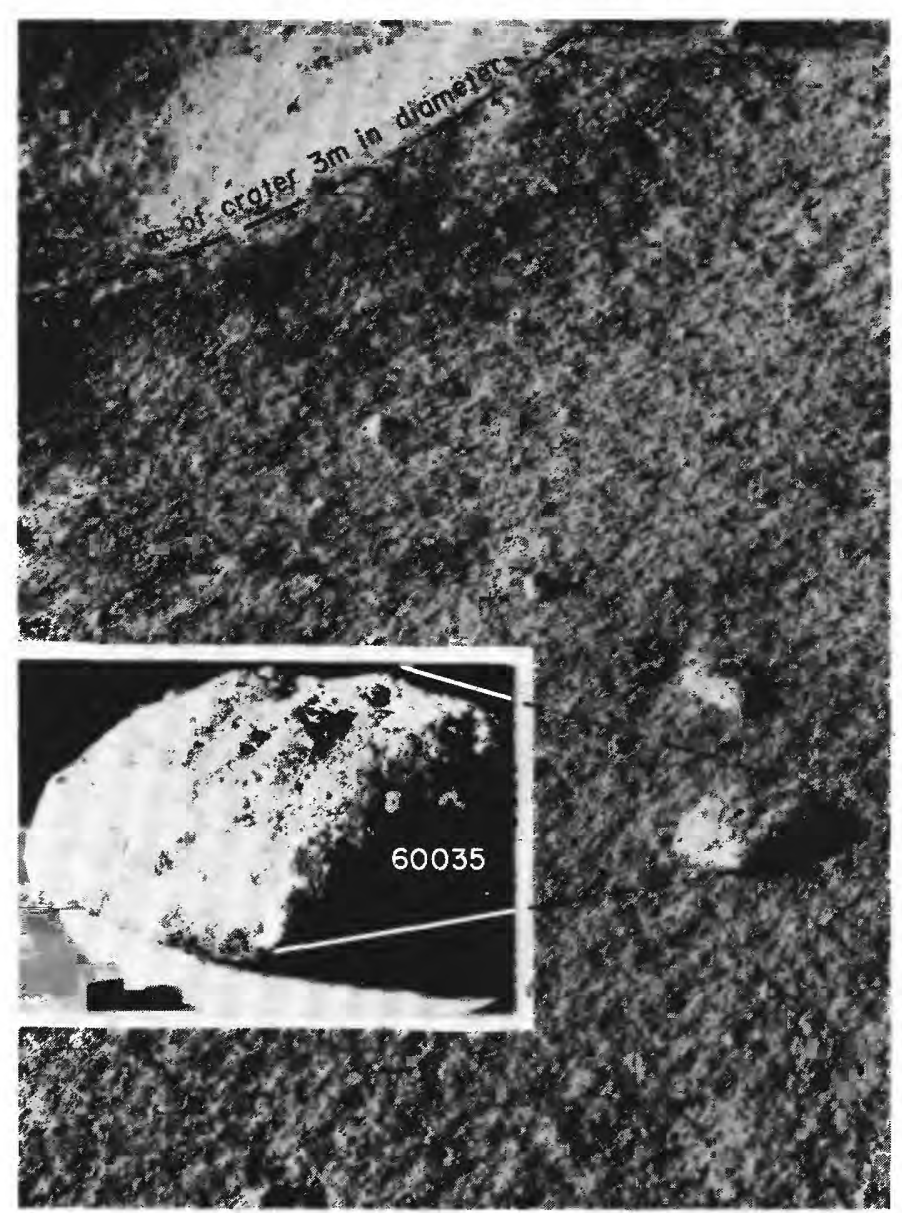

Figure 10A.-Sample 60035 showing approximate lunar orientation reconstructed in LRL compared to an enlarged part of photograph AS16-114-18384 taken before sampling. View is south (inset photograph, S-72-41610). 


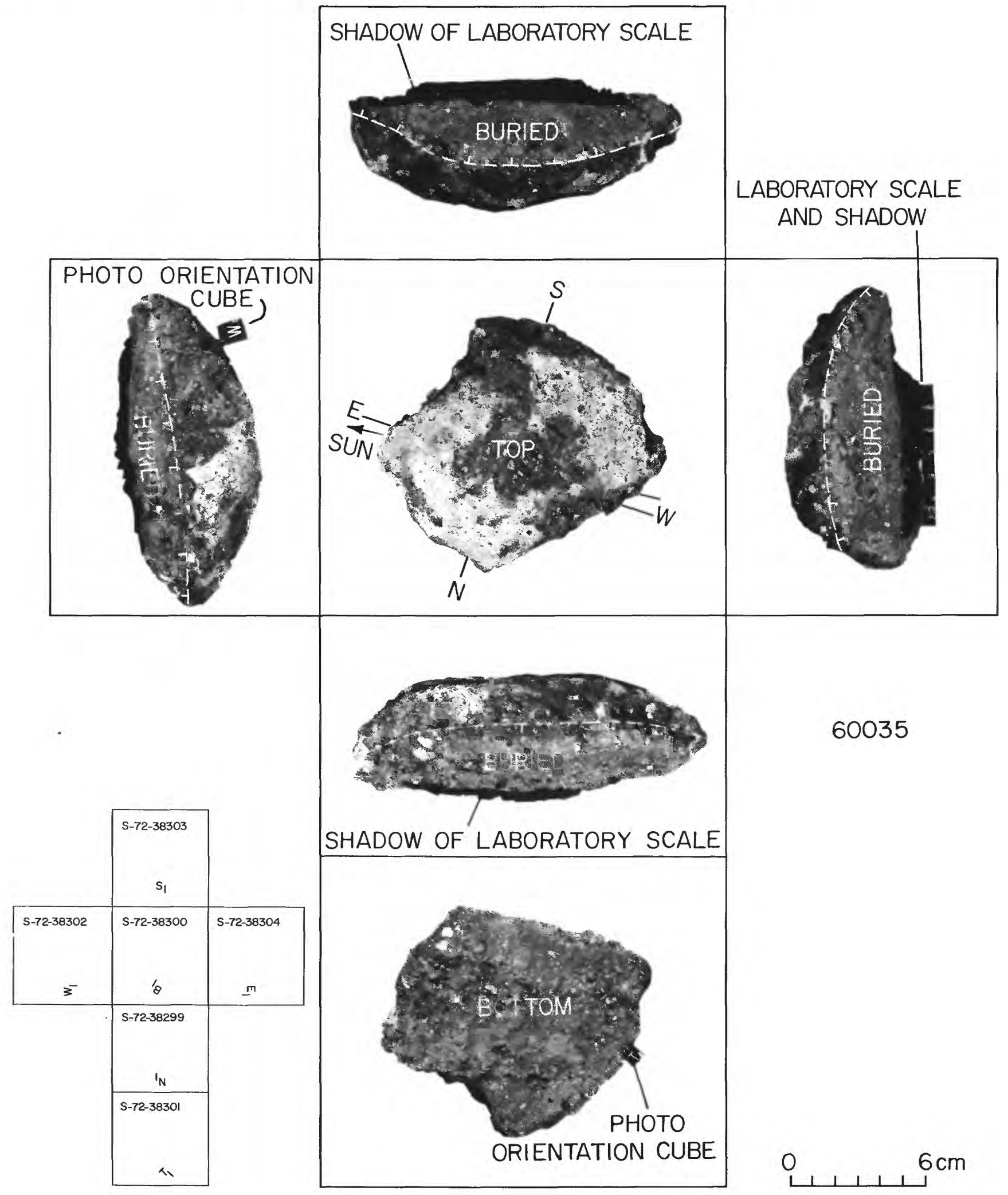

Figure 10B.-Orthogonal views of sample 60035 related to its lunar orientation at time of sampling. Sample is classified as $B_{1}$ breccia. 
SAMPLE: 60035

Station: LM/ALSEP

Landmark: Approximately $110 \mathrm{~m}$ south-southwest of $L M$ and $40 \mathrm{~m}$ south-southeast of ALSEP central station.

Rock type: Breccia, white matrix, B1.

SURFACE CHARACTERISTICS OF SAMPLE AREA

Slopes: Level.

Fragment population

Size range and distribution: Limit of resolution to the size of sample $60035(14 \mathrm{~cm})$; pea-sized frags very abundant; > 3-4 cm frags sparse.

Color: Light gray "whitish".

Shapes: Larger fragments semi-rounded but tabular; smaller

$<2 \mathrm{~cm}$ fragments irregular to tabular.

Fillets: Poorly developed.

Apparent burial: Unusually little; larger fragments 1/8-1/4. Dust cover: Crew reported mostly dust covered.

Fines

Color: Light gray; raindrop pattern on surface well developed.

Compaction: Low to moderate.

Craters

Size range and distribution: 5-20 cm craters moderately

abundant-subdued; $3 \mathrm{~m}$ diameter crater approximately $2 \mathrm{~m}$ south of 60035 .

Shape: Subdued.

Ejecta: None visible.

SAMPEL CHARACTERISTICS

Size: $14 \times 11 \times 5 \mathrm{~cm} ; 1,052$ grams.

Color: Whitish, mottled gray.

Shape: Subrounded edges but tabular.

Fillet: Poorly developed.

Apparent burial: 1/8-1/4.

Dust cover: Heavy.

Comparison with other fragments in area: Crew stated "looks like

typical rocks that are in this area" (see table 3, p.3).

Probable origin: Probably most recently excavated from approximately

$3 \mathrm{~m}$ diameter crater approximately $2 \mathrm{~m}$ south of the sample. Sample

could have previously been part of South Ray ejecta. 

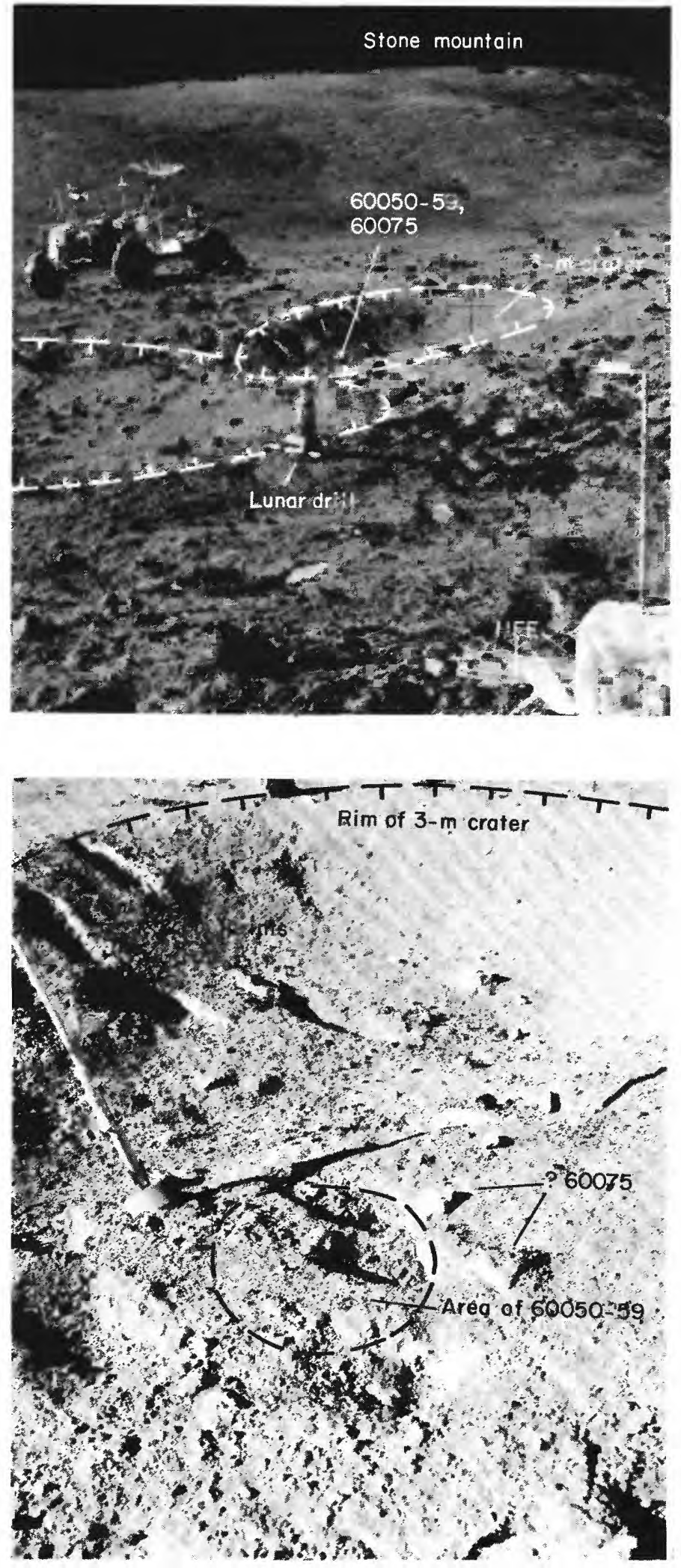

Figure 11A.-Samples 60050-59 and 60075 were collected from bottom of relatively young, soft-rimmed 3-m crater near site of deep drill core (see fig. 2) at ALSEP site. Enlarged part of AS16113-18366 taken as part of panorama 3 at ALSEP before sampling. View is south.
LFigure 11B.-Area of samples 60050-60059 and 60075 shown before sampling in photograph AS16-114-18386; view is south. Crew was attracted to sample because of white "calichelike" appearance of materials at a depth of about $3 \mathrm{~cm}$. 


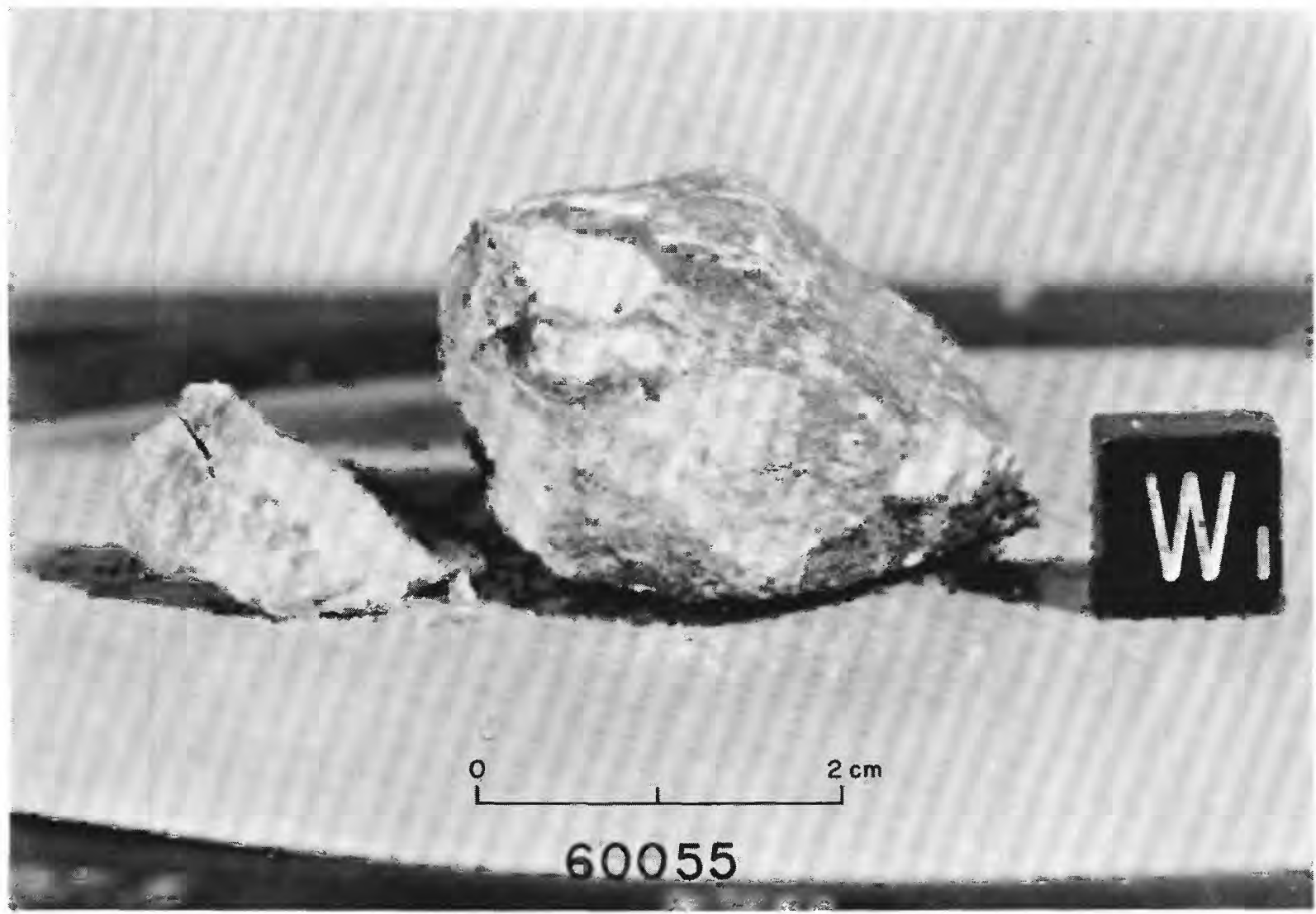

FIGURE 11C.-Sample 60055 in LRL (photograph S-72-41416). Sample is a type $\mathrm{B}_{1}$ breccia that is both fragile and friable, as the picture illustrates.

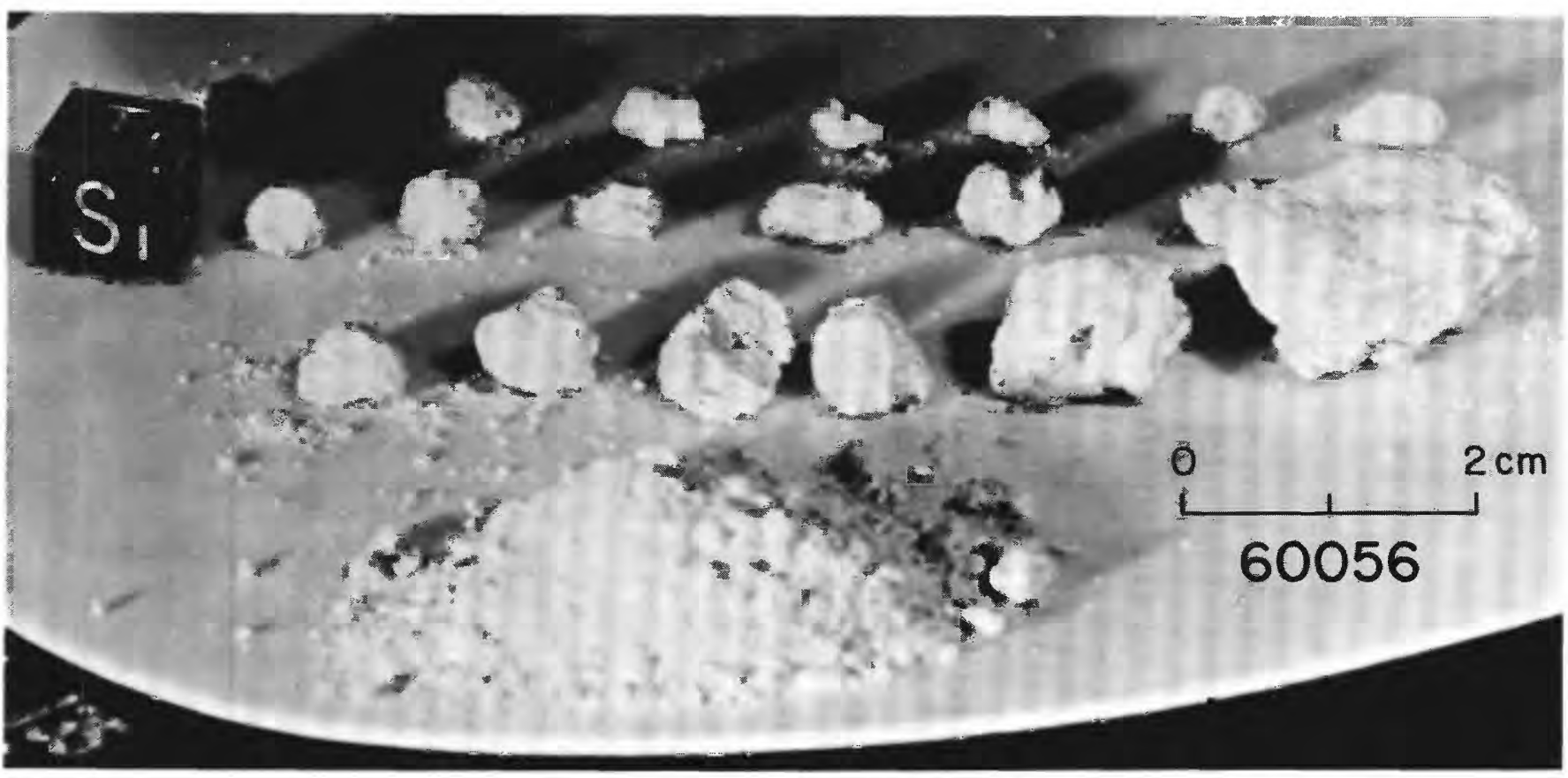

FIGURE $11 D$.- Sample 60056 in LRL (photograph S-72-41419). Type $\mathrm{B}_{1}$ breccia. 


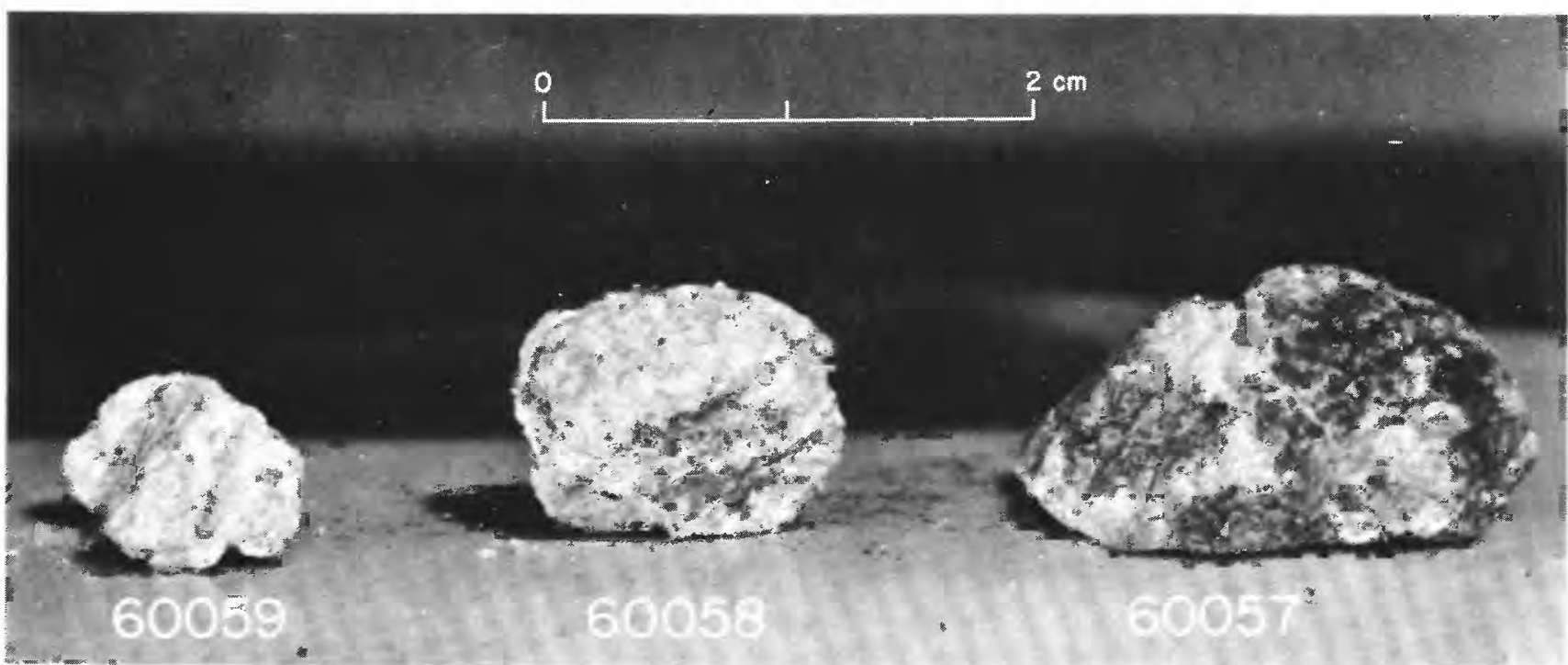

FigURE 11E.-Samples 60057-59 in LRL (photograph S-72-41309, $\mathrm{S}_{1}$ view); 60057 and 60058 are $\mathrm{B}_{1}$ breccias; fragment 60059 appears to be a breccia.

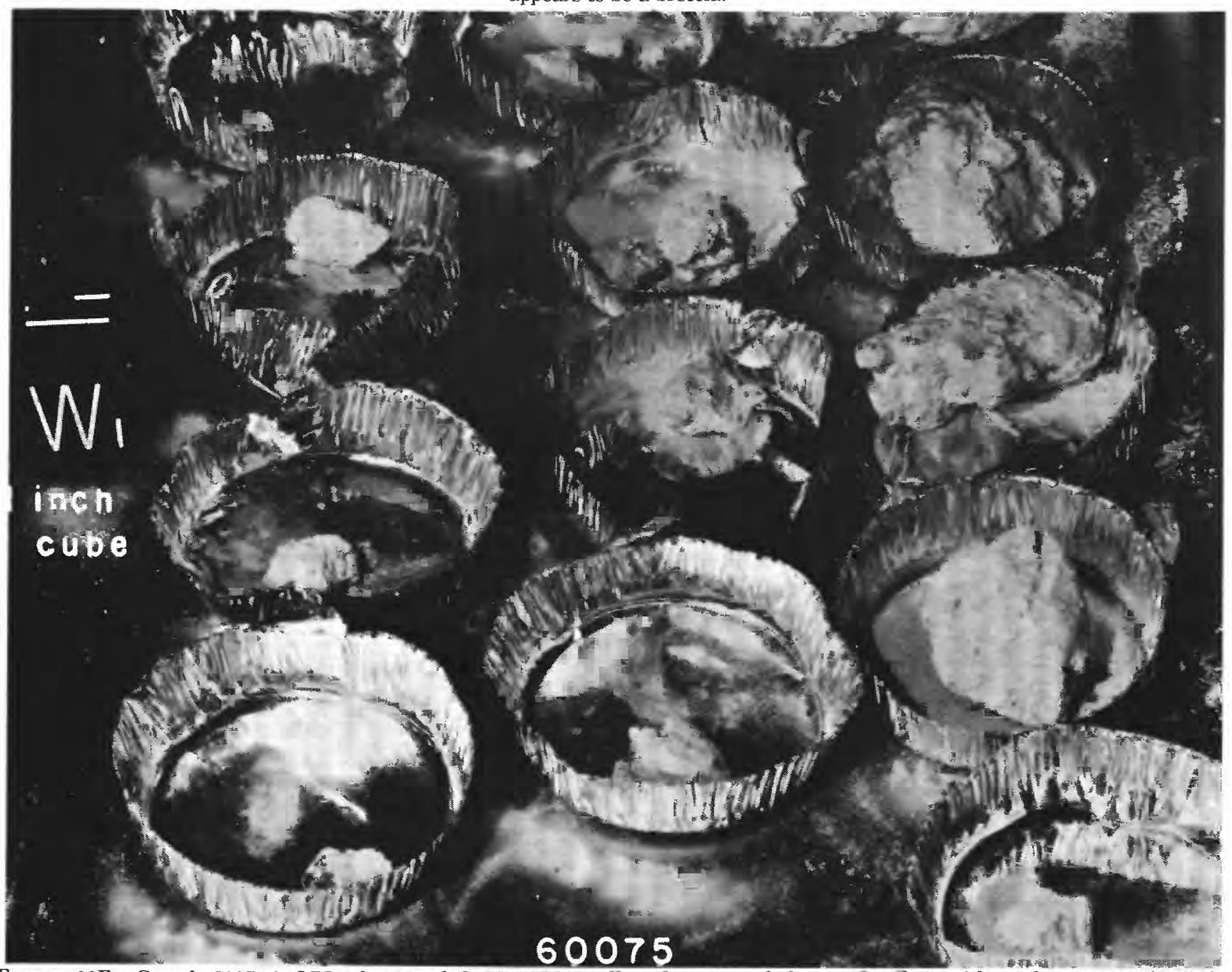

FIGURE 11F.-Sample 60075 in LRL (photograph S-72-40761), collected as one rock, but too fragile to withstand transportation in its collection bag. $\mathrm{A} \mathrm{B}_{2}\left(\mathrm{~B}_{1}\right)$ breccia. 
SAMPLE: $60050-59 ; 60075$

Station: LM/ALSEP

Landmark: Approximately $100 \mathrm{~m}$ south-southwest of LM and $25 \mathrm{~m}$ southsoutheast of ALSEP central station.

Rock type: Breccia with white "caliche-1ike" matrix (60050-59), B1; friable white rocks (60075), B2(B1)

SURFACE CHARACTERISTICS OF SAMPLE AREA

Slopes: Surface slopes down $3-4^{\circ}$ to south-southwest toward floor

of approximately $3 \mathrm{~m}$ subdued crater which is one of a doublet. Fragment population

Size range and distribution: Up to $15 \mathrm{~cm}$ or greater; 0.5 to several cm fragments very abundant; larger fragments moderately abundant.

Color: Whitish rocks and "caliche-like" soil predominate.

Shapes: Semi-rounded to angular and knobby.

Fillets: Difficult to resolve; area disturbed.

Apparent burial: Difficult to resolve; area disturbed.

Fines Dust cover: Probably high.

Color: Light gray.

Compaction: Loose in crater wall and floor. Craters

Size range and distribution: Area photographed too disturbed

to recognize $10 \mathrm{~cm}$ sized craters; samples from bottom of approximately $3 \mathrm{~m}$ diameter subdued crater.

SAMPLE CHARACTERISTICS FOR 60050-59 (soil and small fragments)

Size: $\quad<1 \mathrm{~cm}$ fines, 225.81 grams; 5 fragments, 57.82 grams.

Color: White, "caliche-like" (Table 3, p. 3).

Apparent burial: White fragments apparently lying on surface.

Dust cover: Not visible.

Comparison with other fragments in area: Probably representative

of most fragments in the area of the crater rim.

Probable origin: Probably material excavated from $3 \mathrm{~m}$ down

to $1 \mathrm{~m}$ depth. Could also represent reexcavated South Ray ejecta.

SAMPLE CHARACTERISTICS FOR 60075

Size: Fragile sample broken into 16 pieces; 183.8 grams, total weight Color: White, friable.

Shape: Irregular, knobby.

Fillet: Unknown; sample was disturbed before pre-sample photo.

Apparent burial: Most likely candidate appears disturbed prior to pre-sample photo. Burial line indicates about 1/2 buried.

Dust cover: Heavy.

Comparison with other fragments in area: Apparently characteristic of many white rocks on the rim of this crater.

Probable origin: White clast from a cayley breccia; recently excavated from the 3-m crater, and may represent reworked south Ray ejecta. 


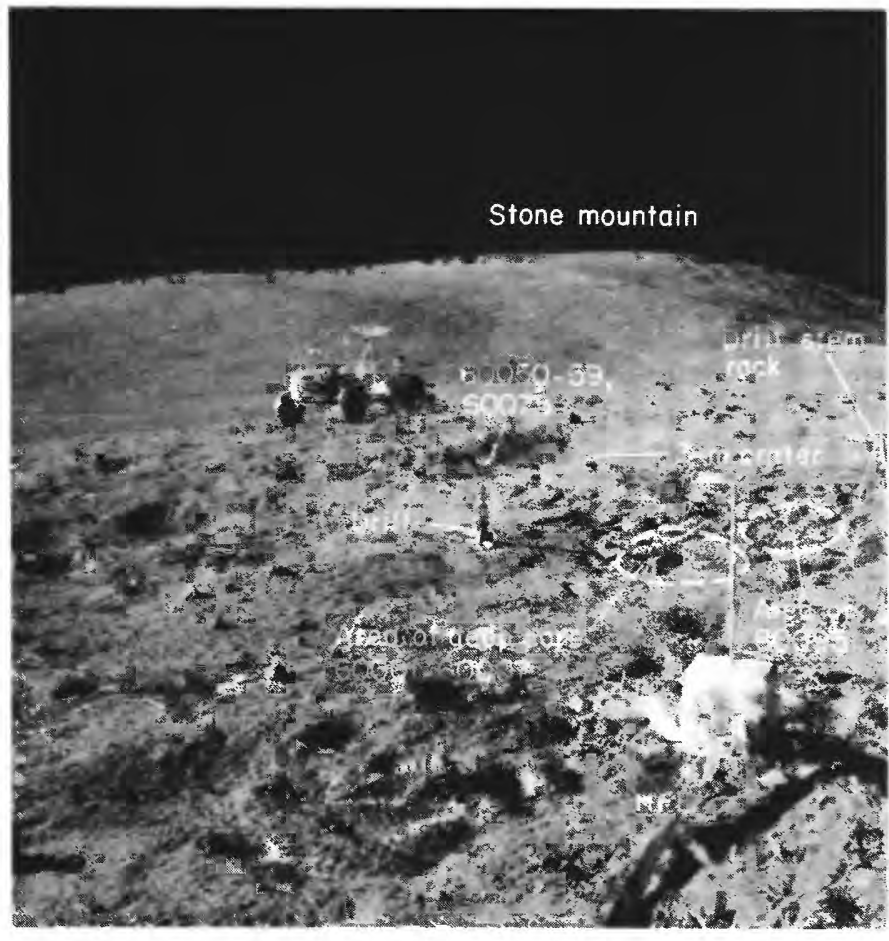

Figure 12A.- Sample 60095, collected between the deep core hole and the drill-stem rack, shown after sampling in panorama photograph AS16-113-18366. View is south.

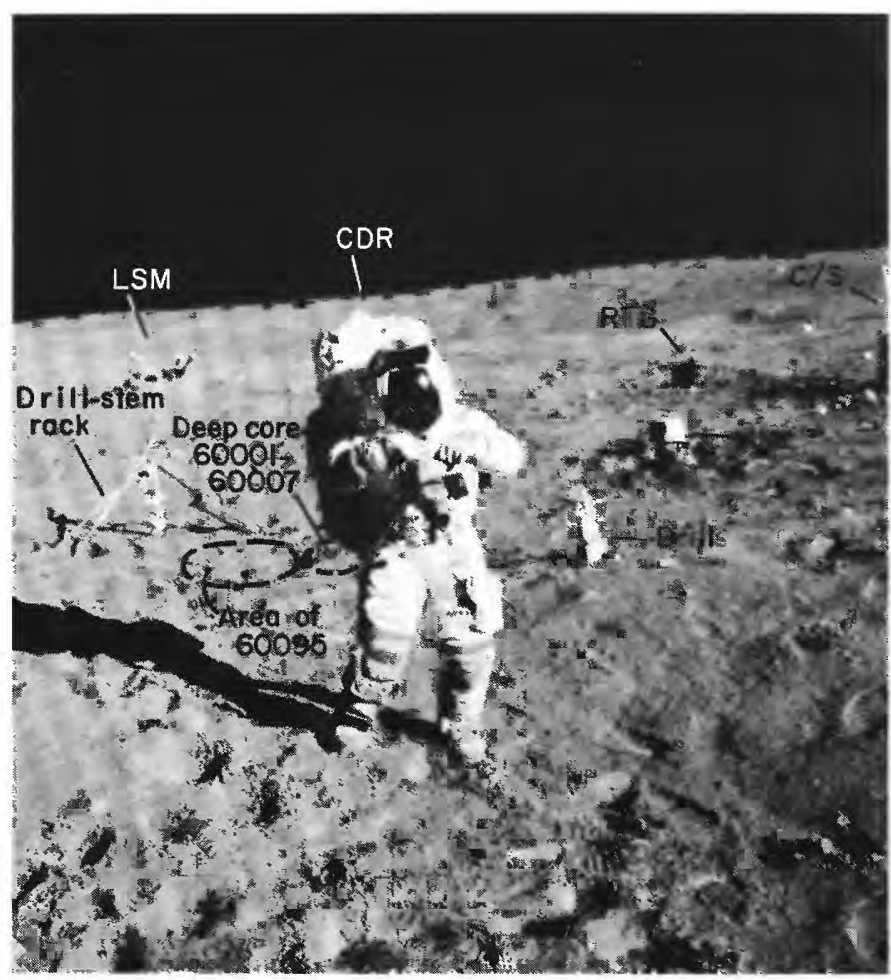

Figure 12B. - Area of samples 60095 and deep core (60001-60007) from site of samples $60050-59$ and 60075 , shown after sampling in photograph AS16-114-18388. View is northwest toward the ALSEP.

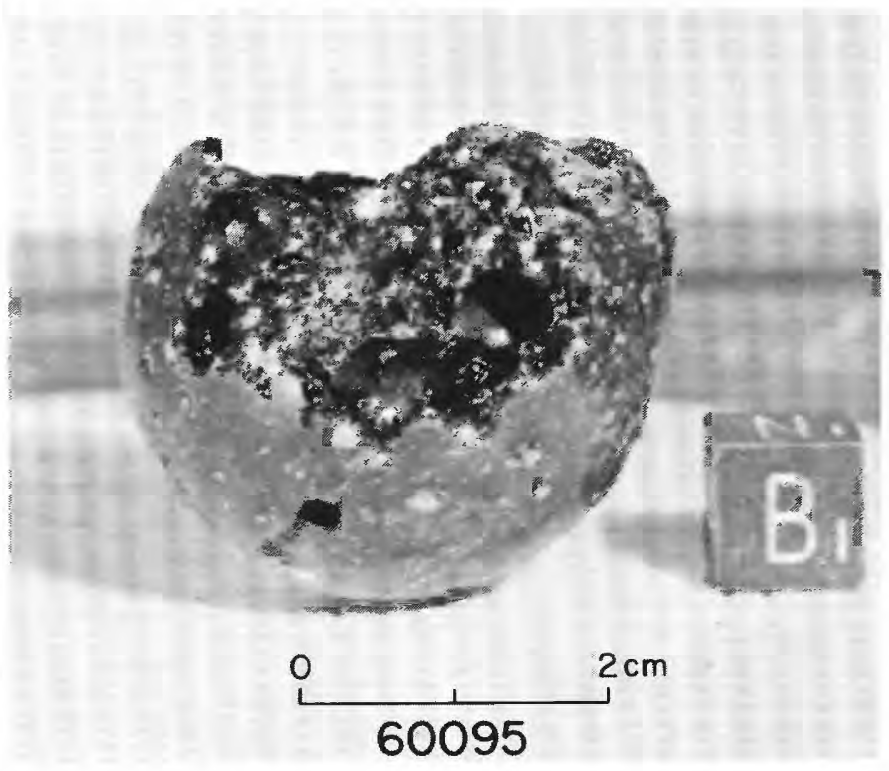

Figure 12C.- Sample 60095, a broken glass sphere, in LRL (photograph S-72-39426). 
SAMPLE: 60095

Station: LM/ALSEP

Landmark: Collected at the deep core site about $125 \mathrm{~m}$ southwest of $L M$.

Rock type: Glass ball, $G$. SURFACE CHARACTERISTICS OF SAMPLE AREA

Slopes: Level spot near two subdued $3 \mathrm{~m}$ and $5 \mathrm{~m}$ craters. Region generally rolling, hummocky.

Fragment population

Size range and distribution: ALSEP area generally blocky with

5-15 cm fragments; area of deep core and sample 60095

much less so; few rocks > 5-7 cm in near vicinity.

Color: Medium gray.

Shapes: Subangular to round.

Fillets: Minor.

Apparent burial: Slight.

Fines Dust cover: Probably high.

Color: Medium gray generally; white soil ( $3 \mathrm{~cm}$ down) kicked up in nearby crater.

Compaction: Loose in all of ALSEP-deep drill area; especially

Craters on small crater rims.

Size range and distribution: Heavily cratered area. Craters up to $5 \mathrm{~m}$ abundant; forms very rolling terrain.

Shape: Subdued.

Ejecta: Present around freshest 1-2 $\mathrm{m}$ sizes.

SAMPLE CHARACTERISTICS

Size: $3.8 \times 3.4 \times 3.4 \mathrm{~cm} ; 46.6$ grams.

Color: Grayish black.

Shape: Spherical.

Fillet: Not recognized in photograph.

Apparent burial: Unknown, probably kicked up during drilling.

Dust cover: Not recognized in photograph.

Comparison with other fragments in area: Not common but several

sampled in LA area.

Probable origin: Splash glass from South Ray crater.

COMMENTS: 60095 observed while placing heat flow probe in only heat flow hole drilled. 


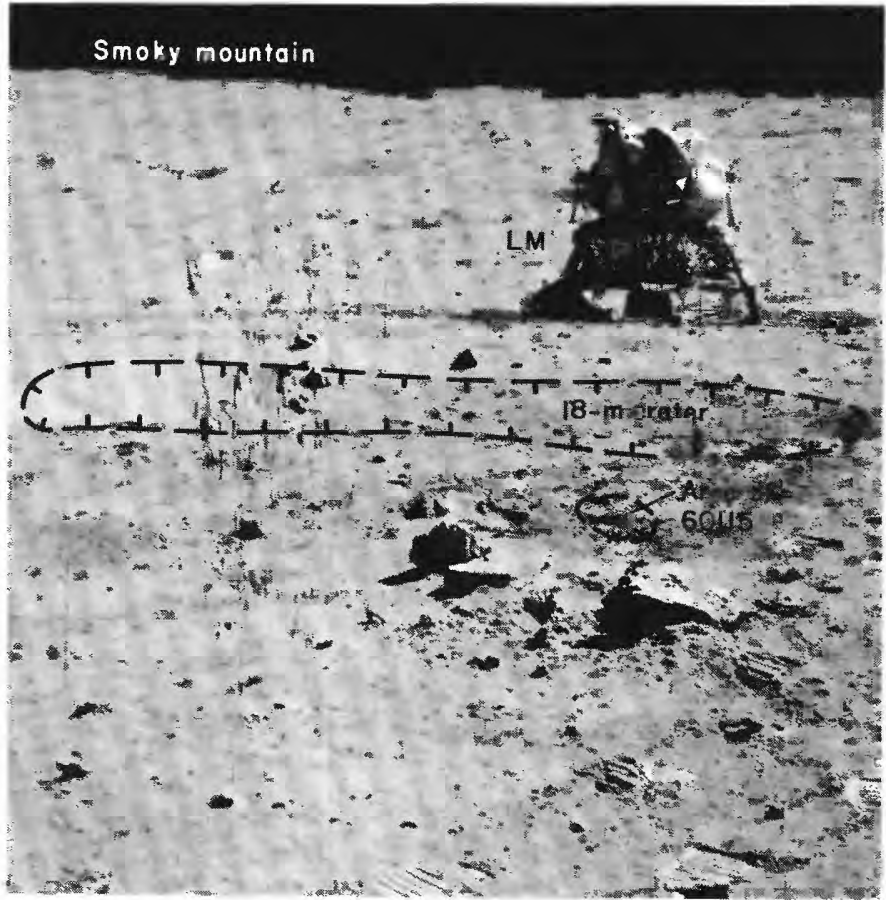

Figure 13A.-Sample 60115, collected about $60 \mathrm{~m}$ southwest of LM near a group of relatively large $(20-40 \mathrm{~cm})$ angular blocks that may be of the same type, $B_{2}\left(B_{5}\right)$, as sample. Blocks may represent ejecta from 18-m crater that has other angular rocks on its rim and inner wall. Photograph is an enlarged part of AS16-114-18455 taken as part of panorama 16 at Station 10 after sampling. View is northeast.

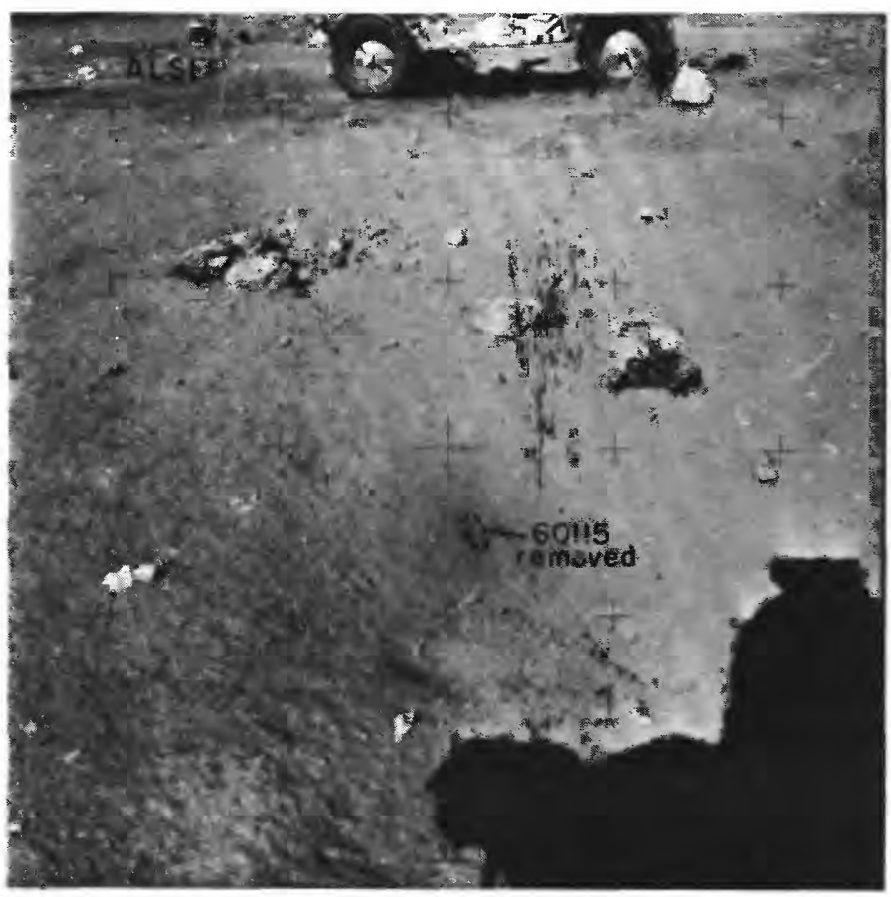

Figure 13B.-Postsampling picture of site of 60115 , showing proximity of broken, angular blocks that appear to be perched on surface, suggesting relatively recent emplacement. (Photograph AS16-114-18448, looking west-southwest.)

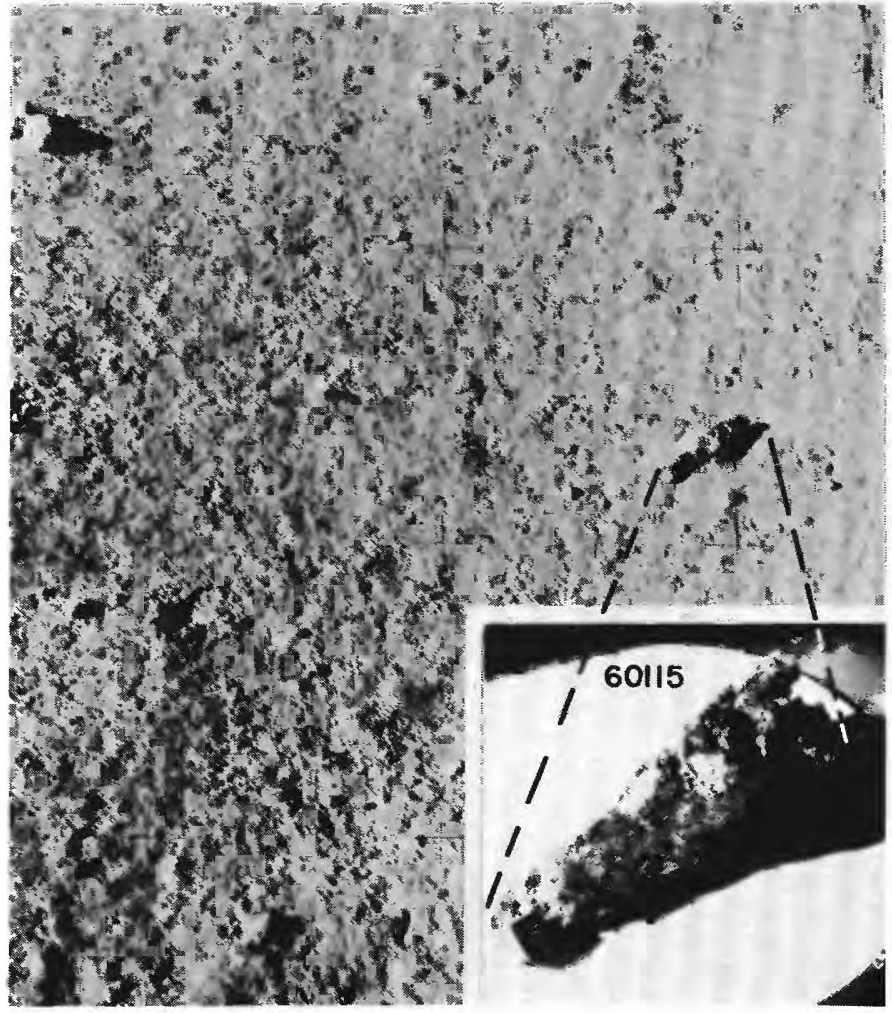

Figure 13C.-Sample 60115, showing approximate lunar orientation reconstructed in LRL compared to an enlarged part of photograph AS16-114-18446 taken before sampling. View is south (inset photograph, S-72-42559). 


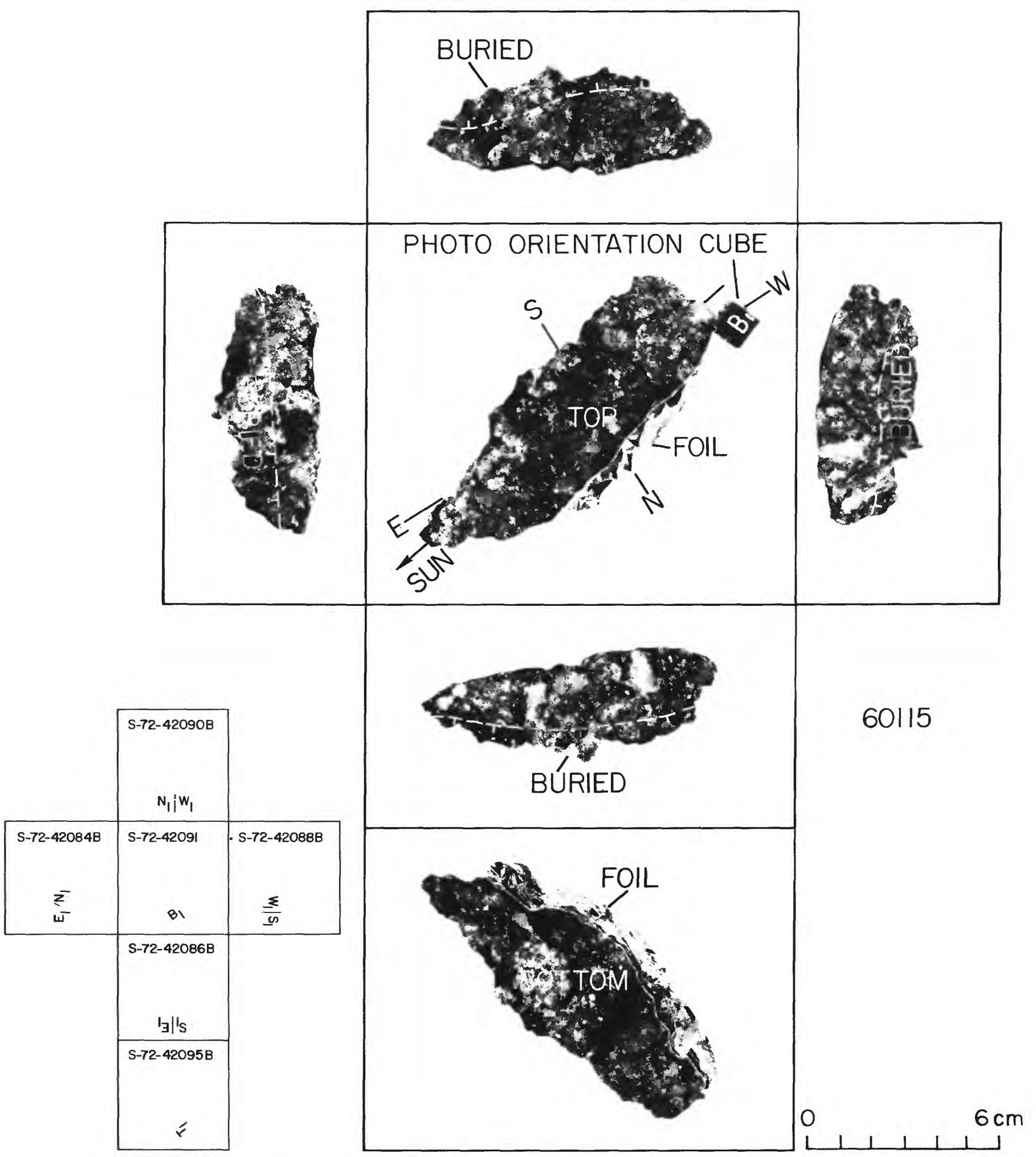

FiguRE $13 D$-Orthogonal views of sample 60115 related to its lunar orientation at time of sampling. Sample classified as $B_{2}\left(B_{5}\right)$ breccia. 
SAMPLE: 60115

Station: 10 (LM/ALSEP)

Landmark: Location approximately $60 \mathrm{~m}$ southwest of LM. Rock type: Dark breccia, B2(B5).

SURFACE CHARACTERISTICS OF SAMPLE AREA

Slopes: $2-3^{\circ}$ to north-northeast into subdued $18-m$ crater.

Fragment population

Size range and distribution: $U p$ to $~ 50 \mathrm{~cm}$; fragments $>3-4 \mathrm{~cm}$ unusually sparse; pea-sized fragments low to moderately abundant.

Color: Two distinct colors: (1) dark gray (2) whitish. Shapes: Tabular-subangular (darker fragments) to subrounded (whitish fragments).

Fillets: Poorly developed.

Apparent burial: Larger fragments less than 1/3.

Fines Dust cover: Moderate.

Color: Medium gray to light gray.

Compaction: Moderately high in sample area. Craters

Size range and distribution: Very. few centimeter-sized craters in the immediate sample vicinity. Local region of station 10 rather heavily cratered including a probable South Ray crater secondary with projectiles on rim (see figure 13A).

Shape: Larger craters subdued. Ejecta: None except from secondary (figure 13A).

SAMPLE CHARACTERISTICS

Size: $11 \times 3.5 \times 2 \mathrm{~cm} ; 132.5$ grams.

Color: Medium gray.

Shape: Semi-tabular to angular, elongate.

Fillet: Poorly developed.

Apparent burial: Less than $1 / 4$ to $1 / 3$.

Dust cover: Low to moderate.

Comparison with other fragments in area: Uniquely darker, more tabular and angular. Nearest fragments of similar size are whitechalky, irregularly shaped with knobby surfaces.

Probable origin: 60115 may have been most recently excavated from the $18 \mathrm{~m}$ crater northeast of the sample location. (Depth of maximum penetration about $4 \mathrm{~m}$ ). Sample may also represent South Ray or North Ray crater ejecta. 


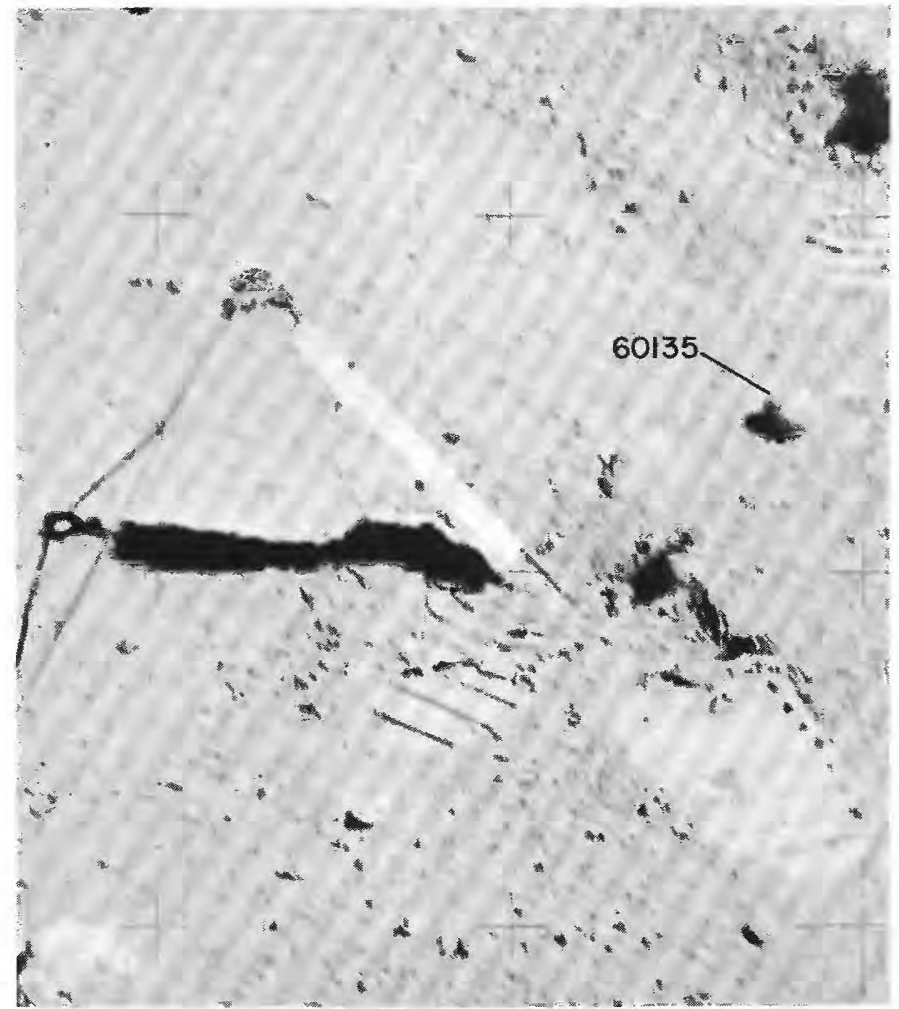

FigURE 14A.-Sample 60135 shown before sampling in photograph AS16-116-18695; view is north. Nearly spherical glass-coated breccia of $\mathrm{B}_{1}$ type collected during EVA 3 at Station 10 (LM/ ALSEP), about $60 \mathrm{~m}$ southwest of LM.

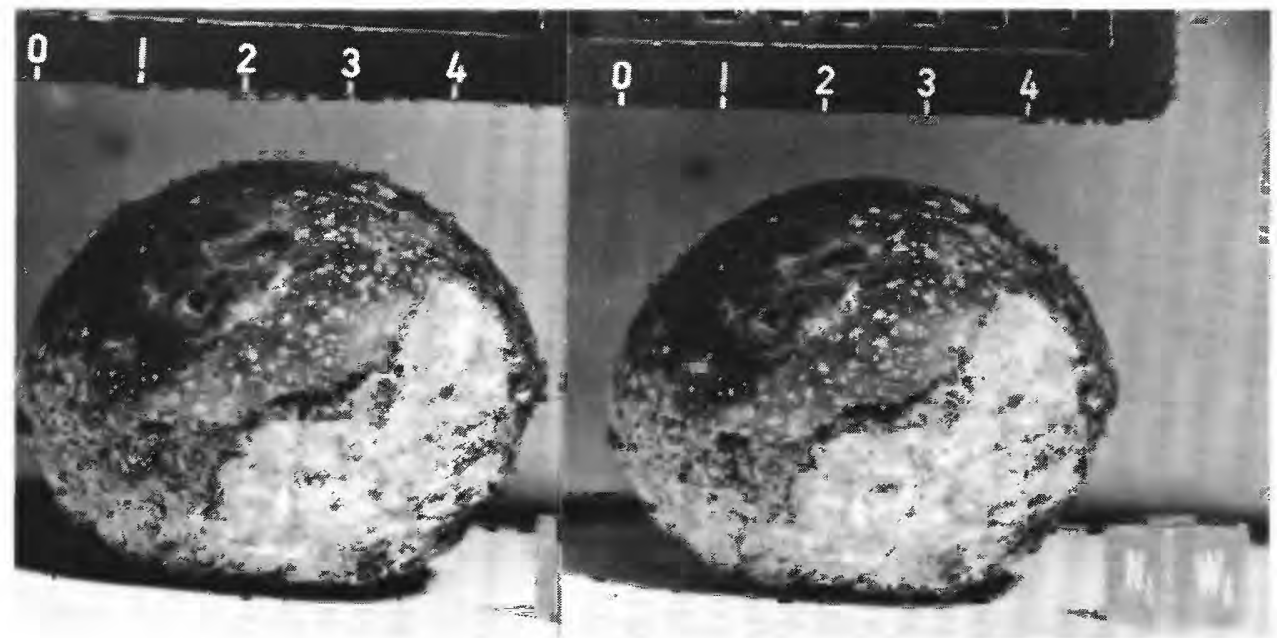

Figure 14B.- Stereopair of sample 60135 taken in the LRL; photographs S-72-46035 (right) and $-46035 \mathrm{~B}$ (left). Classified type $\mathrm{B}_{1}$ breccia. 
SAMPLE: 60135

Station: 10 (LM/ALSEP)

Landmark: $4 \mathrm{~m}$ west of station 10 pan site; $60 \mathrm{~m}$ southwest of $L M$.

Rock type: Round glass-coated breccia, B1.

SURFACE CHARACTERISTICS OF SAMPLE AREA

Slopes: Level.

Fragment population

Size range and distribution: Limit of resolution to $8-10 \mathrm{~cm}$; pea-sized fragments abundant; few $>3 \mathrm{~cm}$.

Color: Light gray to whitish.

Shapes: Subrounded to subangular.

Fillets: Moderately well developed.

Apparent burial: Some of larger fragments as much as $1 / 4$ buried; smaller fragments mostly perched.

Dust cover: High on most fragments.

Fines

Color: Light to medium gray.

Compaction: Moderately high.

Craters

Size range and distribution: None in immediate area; photographed area disturbed, however.

SAMPLE CHARACTERISTICS

Size: $5.5 \times 4.5 \times 4 \mathrm{~cm} ; 137.7$ grams.

Color: Dark gray glass coating on light gray breccia (see figure 14 b) .

Shape: Round.

Fillet: None.

Apparent burial: Perched in figure 14a but may have been kicked up.

Dust cover: Appears high in pre-sampling photos.

Comparision with other fragments in area: Appears unique in the

immediate sample area but glassy fragments apparently not uncommon

in the LM/ALSEP vicinity.

Probable origin: Glass coating may be impact-generated splash on rock fragment. Possible source is South Ray crater. 


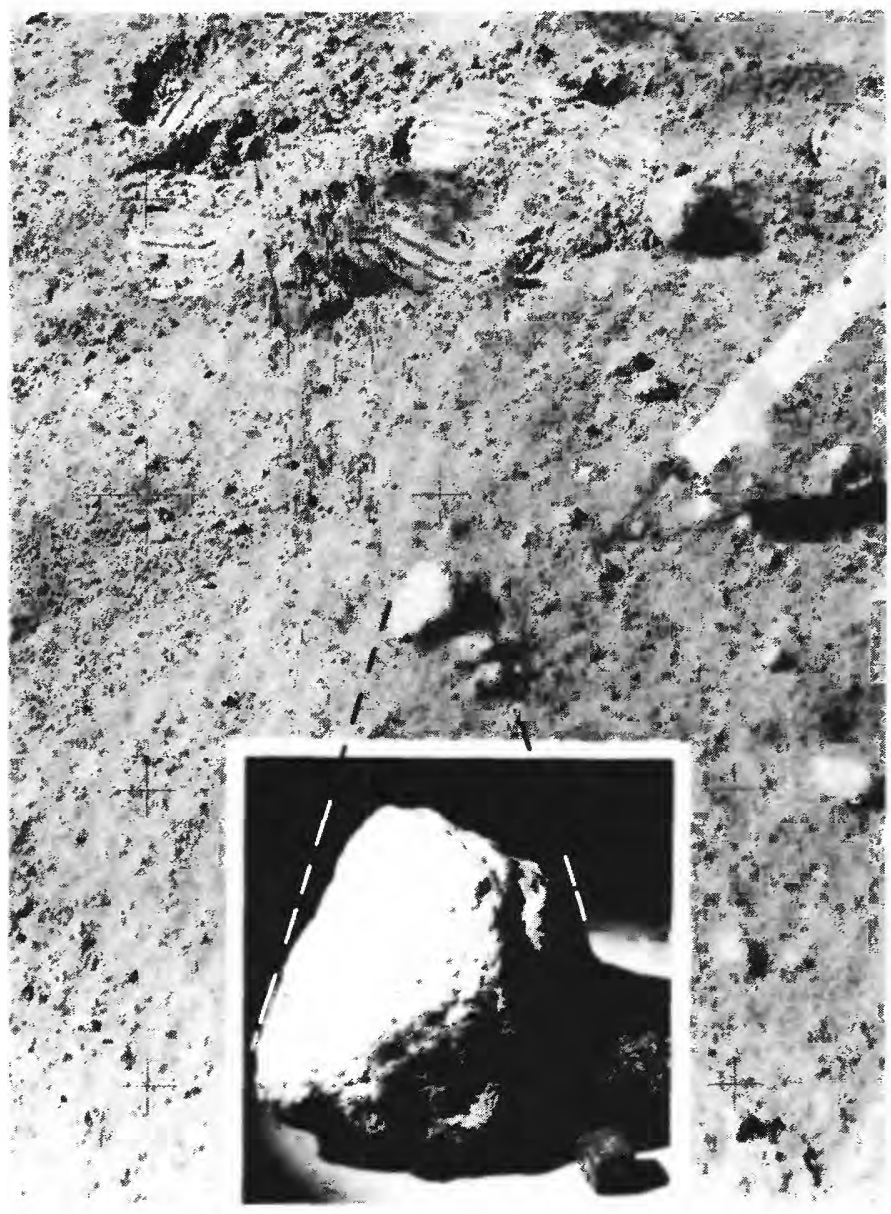

Figure 15A.-Sample 60215 showing approximate lunar orientation reconstructed in LRL compared to an enlarged part of photographic AS16-116-18705 taken before sampling. View is south (inset photograph, S-72-42836). Collected during EVA 3 at station 10' (LM/ALSEP), about $70 \mathrm{~m}$ west-southwest of LM. 


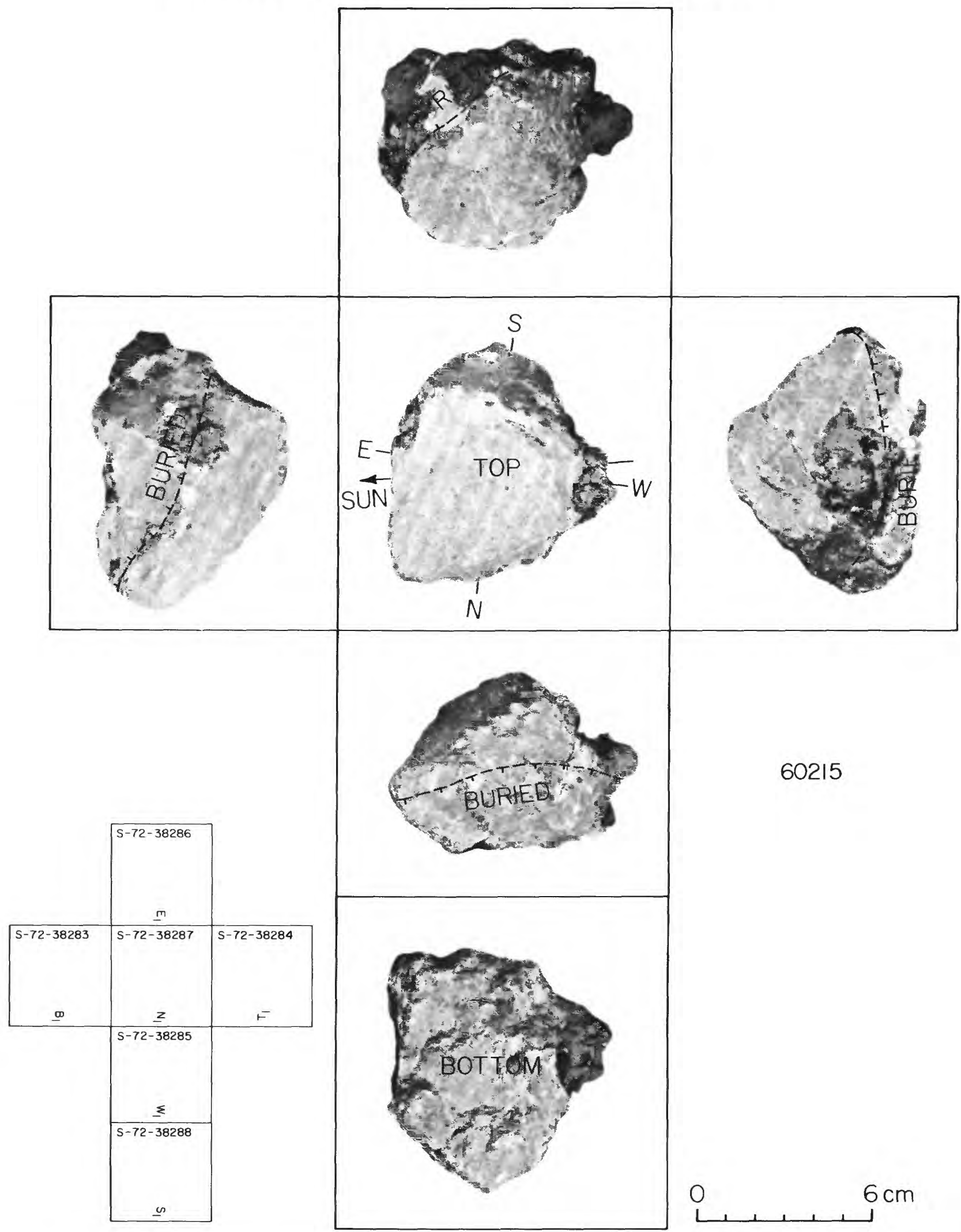

Figure $15 B$. - Orthogonal views of sample 60215 related to its lunar orientation at times of sampling. Classified type $B_{1}$ breccia. 
SAMPLE: 60215

Station: $10^{\prime}$ (LM/ALSEP)

Landmark: In vicinity of $10^{\prime}$ station, approximately $70 \mathrm{~m}$ west-southwest. of LM; exact location unknown but thought to be near LRV station 10' park position.

Rock type: Blocky, subangular, white breccia, BI.

SURFACE CHARACTERISTICS OF SAMPLE AREA

Slopes: Level.

Fragment population

Size range and distribution: $U p$ to $1 \mathrm{~cm}$ abundant; up to $10 \mathrm{~cm}$ commmon.

Color: Medium gray to distinct whitish rocks common.

Shapes: Subrounded to irregular, knobby.

Fillets: Poorly developed on all sizes.

Apparent burial: Very little on most $5-10 \mathrm{~cm}$ rocks; $1 / 4-1 / 2$ on $0.5 \mathrm{~m} \mathrm{block}$ just west of 60215 . Dust cover: Moderately high.

Fines

Color: Light gray.

Compaction: Moderately firm.

Craters

Size range and distribution: None in field of view of presampling photo.

SAMPLE CHARACTERISTICS

Size: $8 \times 7 \times 6 \mathrm{~cm} ; 385.8$ grams.

Color: White.

Shape: Blocky, subangular.

Fillet: None on photographed face.

Apparent burial: Almost perched.

Dust cover: Crew reported moderate.

Comparison with other fragments in area: Probably typical (except

in size) to other light-colored rocks in vicinity; darker fragments more knobby; irregular shaped.

Probable origin: Proibabiy South Ray ejecta. 


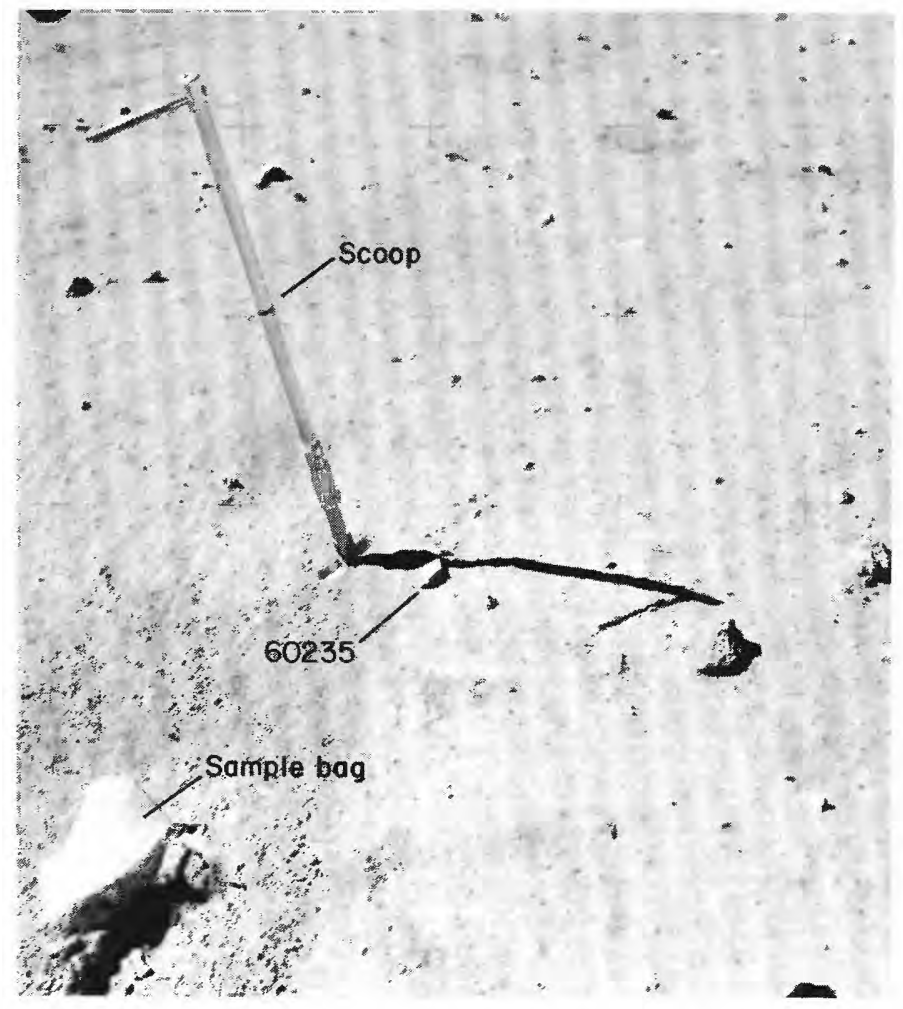

Figure 16A.-Sample 60235 shown before sampling in photograph AS16-117-18829; view is southeast. Metaclastic $\left(\mathrm{C}_{2}\right)$ rock collected near end of EVA 3 a few meters southeast of LM, on rim of 27-m crater located behind LM.
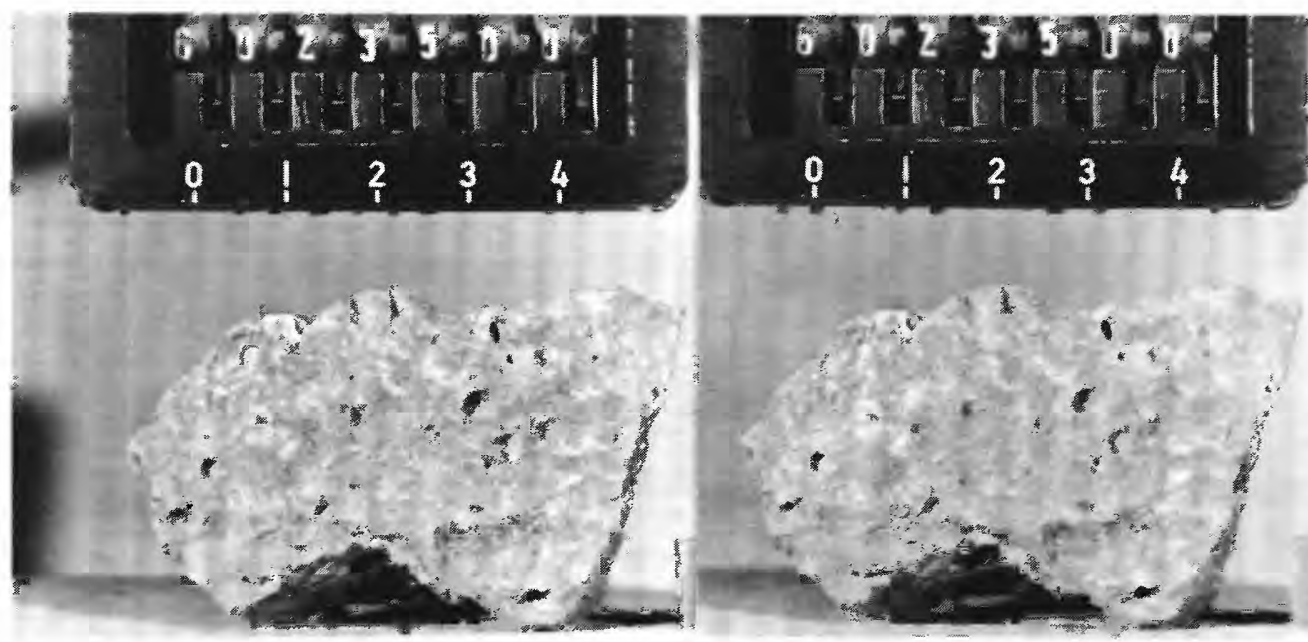

FigURE 16B. - Stereopair of sample 60235 taken in LRL; photographs S-72-43748 (right) and -43748B (left). Classified type $\mathrm{C}_{2}$ (metaclastic). 
SAMPLE: 60235

Station: LM/ALSEP

Landmark: Approximately $10 \mathrm{~m}$ southeast of $L M$.

Rock type: Probably breccia with bluish-black matrix and light-

colored crystalline clasts; subangular, C2.

SURFACE CHARACTERISTICS OF SAMPLE AREA

Slopes: Locally gentle, immediate vicinity of sample, slope is

several degrees to northeast into $1.5 \mathrm{~m}$ subdued crater.

Fragment population

Size range and distribution: Up to $20 \mathrm{~cm}$; pea size very

abundant; up to $10 \mathrm{~cm}$ moderately abundant.

Color: Moderate dark gray to light gray; two types distinct

in sample area.

Shapes: Semi-angular to knobby-irregular; semi-angular frags

tend to be lighter with smoother surface.

Fillets: Very little on fist-sized frags.

Apparent burial: 60235 and larger rock nearby appear to be perched-mest of fist-sized and smaller are moderately well

buried.

Dust cover: Appears to be moderately heavy on unperched frags.

Fines

Color: Darker fragments are medium gray; lighter frags lighter

than soil

Compaction: Loose to moderate in immediate sample area on rim

Craters

of $1.5 \mathrm{~m}$ diameter crater.

Size range and distribution: $S i x 8 \mathrm{~cm}$ to $1.5 \mathrm{~m}$ diameter craters

in immediate sample area. 27-m crater behind LM dominates the $10 c a l$ area.

Shape: Small 20-cm sized craters appear to be very fresh, pos-

sibly secondaries; larger craters moderately subdued.

Ejecta: Present as clods in floor and on rims of two 20-cm

craters.

SAMPLE CHARACTERISTICS

Size: $6 \times 3.5 \times 3.3 \mathrm{~cm} ; 70.13$ grams.

Color: Medium gray.

Shape: Angular.

Fillet: None.

Apparent burial: Perched.

Dust cover: Not visible.

Comparison with other fragments in area: 60235 typical of the 1 ighter

colored, smaller, more subangular frags in vicinity. Other class of

frags larger, darker gray with knobby surfaces.

Probable origin: 60235 probably came into this position as a secondary

projectile from a nearby primary (probably not. South Ray) due to

extreme freshness of small 20-cm crater. Sample however may represent South Ray ejecta that has been reexcavated.

COMMENTS: General area appears to have generally equal distribution of light (smooth) and darker gray (knobby) fragments. 


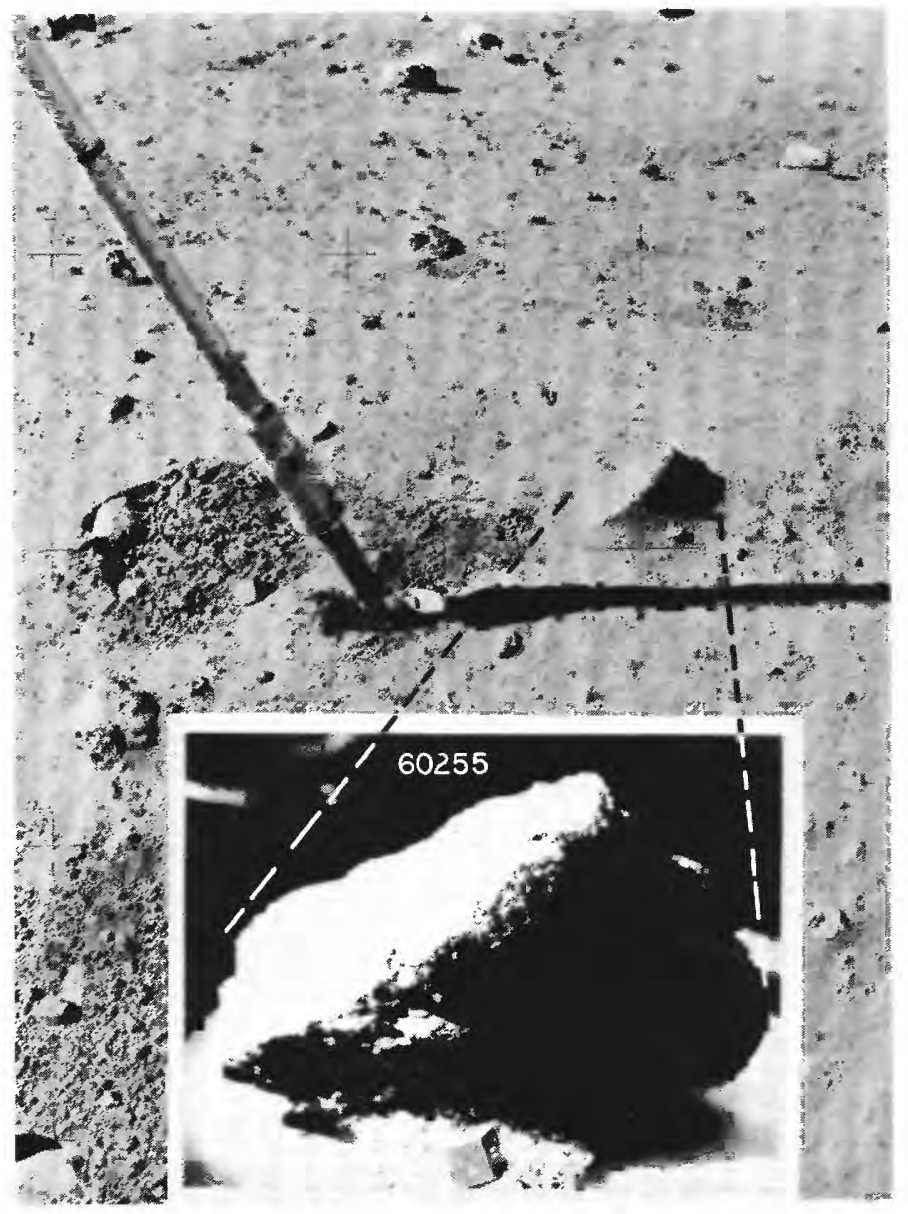

FIGURE 17A.-Sample 60255 showing approximate lunar orientation reconstructed in LRL compared to an enlarged part of photograph AS16-117-18832 taken before sampling. View is south (inset photograph, $\mathrm{S}-72-42837) . \mathrm{B}_{4}$ breccia collected east of sample 60235 , on inner rim area or upper wall of $27-\mathrm{m}$ crater located behind LM. 


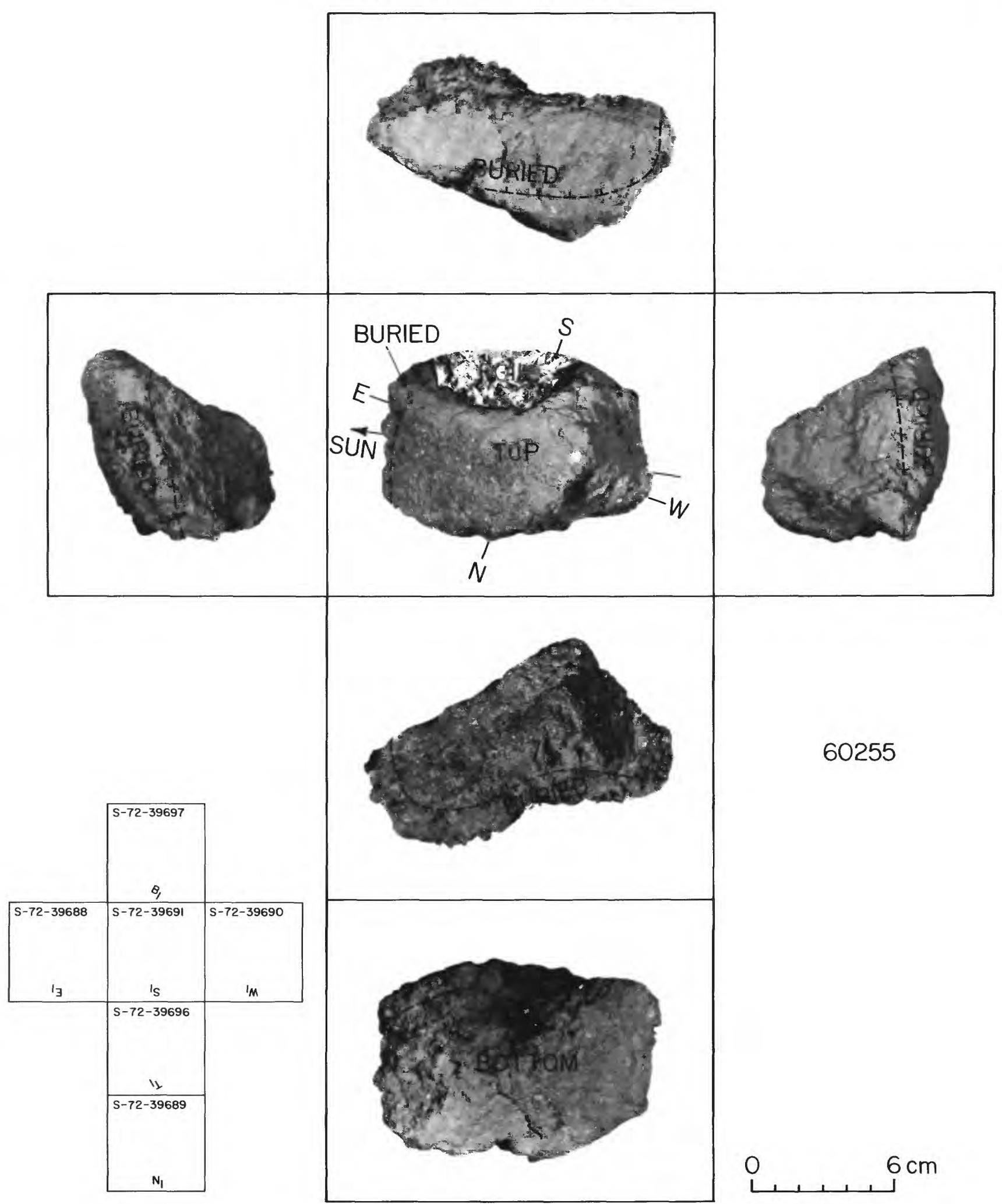

FigURE 17B.-Orthogonal views of sample 60255 related to its lunar orientation at time of sampling. Classified type $\mathrm{B}_{4}$ breccia. 
SAMPLE: 60255

Station: LM/ALSEP

Landmark: Television from the LRV showed the sample area to be southeast of the $L M$, near the rim of a 27-m crater 1ocated behind the $I M$.

Rock type: Breccia with a dark aphanitic matrix and small white clasts, $B 4$.

SURFACE CHARACTERISTICS OF SAMPLE AREA

Slopes: Slope several degrees downward to east-northeast in immediate sample area. This appears to be the inner rim or uppper wall of a 27 m crater (see chapter E, fig. 1).

Fragment population

Size range and distribution: Limit of resolution up to 20-cm

size; pea-size fragments very abundant; 2-cm to 20-cm size moderately abundant.

Color: Two distinct types: 1) medium gray and 2) light gray (whitish); type 2 in near-sample area are the smaller $(<5 \mathrm{~cm}$ ) fragments.

Shapes: Subangular with planar surfaces to subrounded with knobby surfaces.

Fillets: Moderately developed on 10-cm size fragments; many pea-sized fragments appear perched (possibly disturbed by DPS engine).

Apparent burial: Larger fragments range from $1 / 4$ to $1 / 2$ burial. Dust cover: Appears moderate to heavy.

Fines

Color: Medium to light gray.

Craters

Compaction: Low to moderate.

Size range and distribution: $8-\mathrm{cm}$ to $30-\mathrm{cm}$ craters present

but not abundant; no sharp fresh craters in near sample area. SAMPLE CHARACTERISTICS

Size: $12 \times 9 \times 7 \mathrm{~cm} ; 871$ grams.

Color: Dark aphanitic matrix with about $30 \%$ white clasts, glassy coating.

Shape: Subrounded with some planar surfaces.

Fillet: Moderately well developed.

Apparent burial: $1 / 3$ to $1 / 2$ buried.

Dust cover: Appears to be heavy.

Comparison with other fragments in area: 60255 is distinct in the immediate vicinity of sample by its subrounded knobby appearance; glass coating and advanced burial. It is, however, typical of many such rocks in the general area.

Probable origin: Ejecta from 27-m crater east of $L M$.

COMMENTS: Documentation not completed by location photo. Referred to as "half a grapefruit" size sample. May represent reworked South Ray material. 


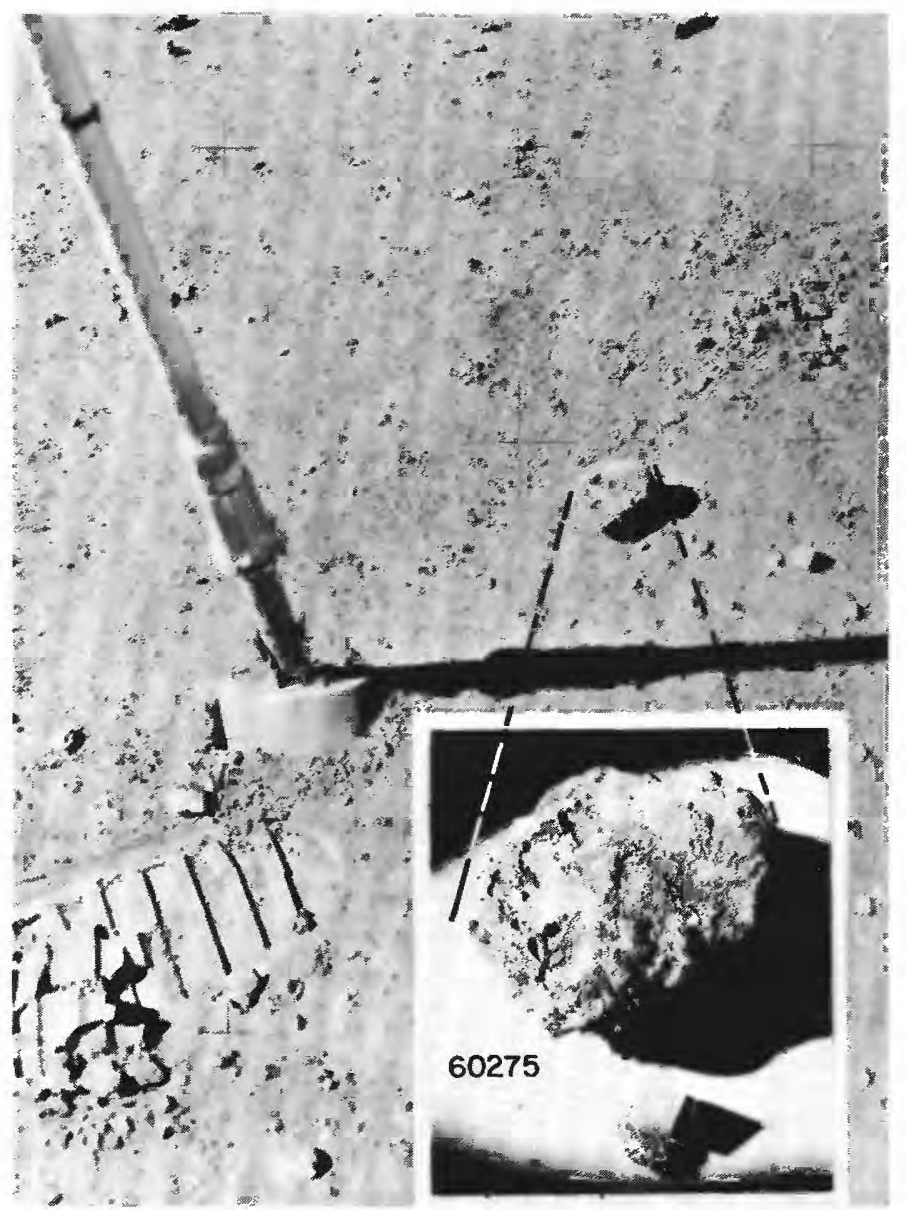

Figure 18A.-Sample 60275 showing approximate lunar orientation reconstructed in LRL compared to an enlarged part of photograph AS16-117-18833 taken before sampling. View is south (inset photograph, S-72-43115). $B_{4}$ breccia collected near end of EVA 3 a few meters north of LM. See chapter C, figures $3 J$ and $3 K$ for pre- and post-sampling photographs. 


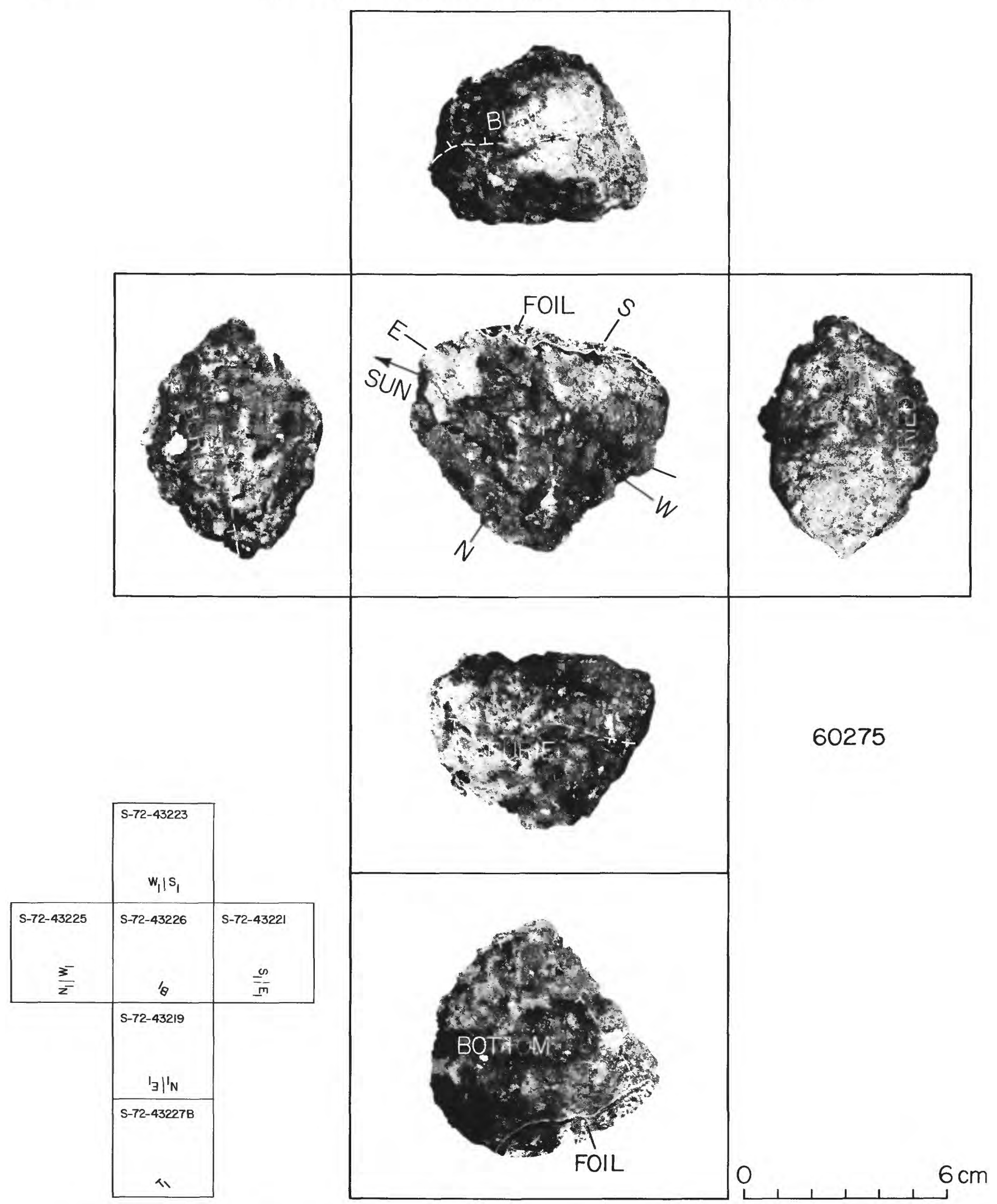

Figure 18B.-Orthogonal views of sample 60275 related to its lunar orientation at time of sampling. Classified type $B_{4}$ breccia. 
SAMPLE: 60275

Station: LM/ALSEP

Landmark: $4 \mathrm{~m} N N E$ of $L M+Y$ (right side) footpad.

Rock type: Glass coated breccia with white clasts, $B 4$. SURFACE CHARACTERISTICS OF SAMPLE AREA

Slopes: Low; surface unusually flat.

Fragment population

Size range and distribution: Limit of resolution to $\approx 12 \mathrm{~cm}$;

pea size abundant.

Color: Light gray to chalky.

Shapes: Subangular to subrounded to irregular.

Fillets: Few on larger frags; smaller frags range from

filleted to perched.

Apparent burial: Little on $2 \mathrm{~cm}$ to $12 \mathrm{~cm}$ sized frags.

Fines

Dust cover: Moderate to heavy on all sizes.

Color: Medium gray.

Compaction: Moderate to moderately high.

Craters

Size range and distribution: None in near environment.

SAMPLE CHARACTERISTICS

Size: $8 \times 7 \times 5 \mathrm{~cm} ; 255.2$ grams.

Color: Medium gray to white with dark glass coat.

Shape: Subrounded, lumpy.

Fillet: None.

Apparent burial: 1/3-1/2 (relatively perched). Dust cover: Light to moderate.

Comparison with other fragments in area: Appears to be typical of other perched 10-cm sized fragments in local area.

Probable origin: Perched, nature indicates relatively recent deposition; location of 60275 near rim of $27-m$ crater east of LM (fig.

1. Chapter DI)indicates it may have been excavated from a maximum of $6 \mathrm{~m}$ depth in the Cayley.

COMMENTS: May represent reworked South Ray material. 


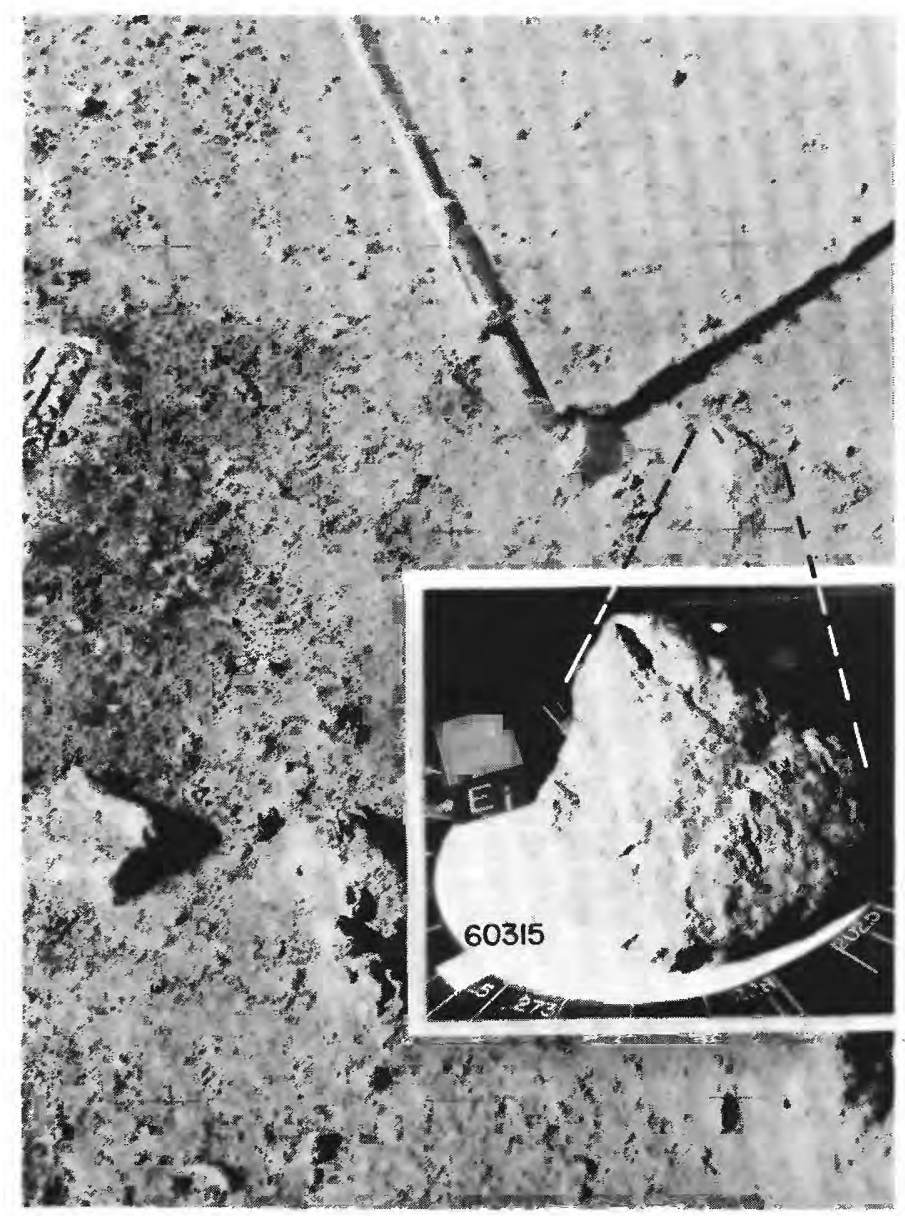

FigURE 19A.-Sample 60315 showing approximate lunar orientation reconstructed in LRL compared to an enlarged part of photograph AS16-117-18836 taken before sampling. View is southwest (inset photograph, S-72-41842). Metaclastic $\left(\mathrm{C}_{2}\right)$ rock collected near sample 60275 , north of LM. 


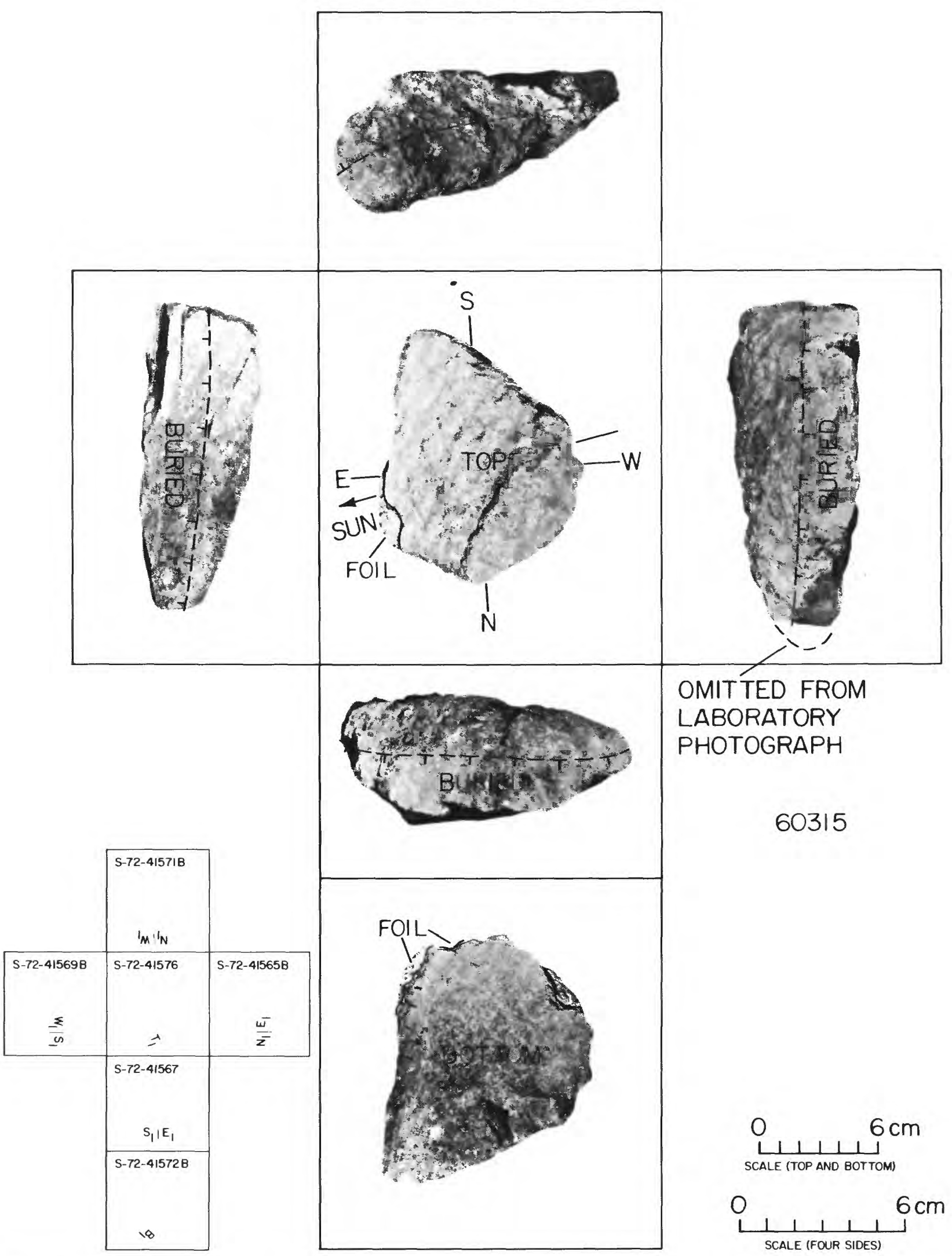

FIGURE 19B.-Orthogonal views of sample 60315 related to its lunar orientation at time of sampling. See chapter D1, figure 10A, for $\mathrm{B}_{1}$ photographic view; and chapter $\mathrm{E}$, figures $2 F$ and $2 G$, for photomicrographs of this type $\mathrm{C}_{2}$ rock. 
SAMPLE: 60315

Station: LM/ALSEP

Landmark: $5 \mathrm{~m}$ north of $L M+Y$ (right side) footpad

Rock type: Crystalline rock, white crystals or small clasts, C2

SURFACE CHARACTERISTICS OF SAMPLE AREA

Slopes: None

Fragment population

Size range and distribution: Limit of resolution to $17-18 \mathrm{~cm}$;

6-18 cm frags moderately abundant; < $5 \mathrm{~cm}$ very abundant

Color: Light to medium gray

Shapes: Primarily irregular to subrounded, knobby

Fillets: Moderately well developed

Apparent burial: Extensive on majority of larger fragments;

$1 / 8-3 / 4$ burial range

Fines

Dust cover: Heavy

Color: Light gray

Compaction: Moderately firm as indicated by footprints Craters

Size range and distribution: Very sparse for all sizes

SAMPLE CHARACTERISTICS

Size: $14 \times 10.5 \times 4 \mathrm{~cm} ; 787.7$ grams

Color: Medium light gray

Shape: Tabular, with rounded top and flat bottom

Fillet: slight

Apparent burial: Aproximately $1 / 2$

Dust cover: Appears to be heavy, but not heavy enough to eliminate all shadows from minor irregularities on the exposed surface.

Comparison with other fragments in area: Sample 60315 is more rounded, with smoother surface than nearby rocks. It also appears to be lighter colored than most other fragments.

Probable origin: Sample may represent part of South Ray ejecta, or material comprising Cayley down to $6 \mathrm{~m}$ below $L M$ site if it was excavated by 27-m diameter crater east of LM. (See Chapter DI, figure 1). 

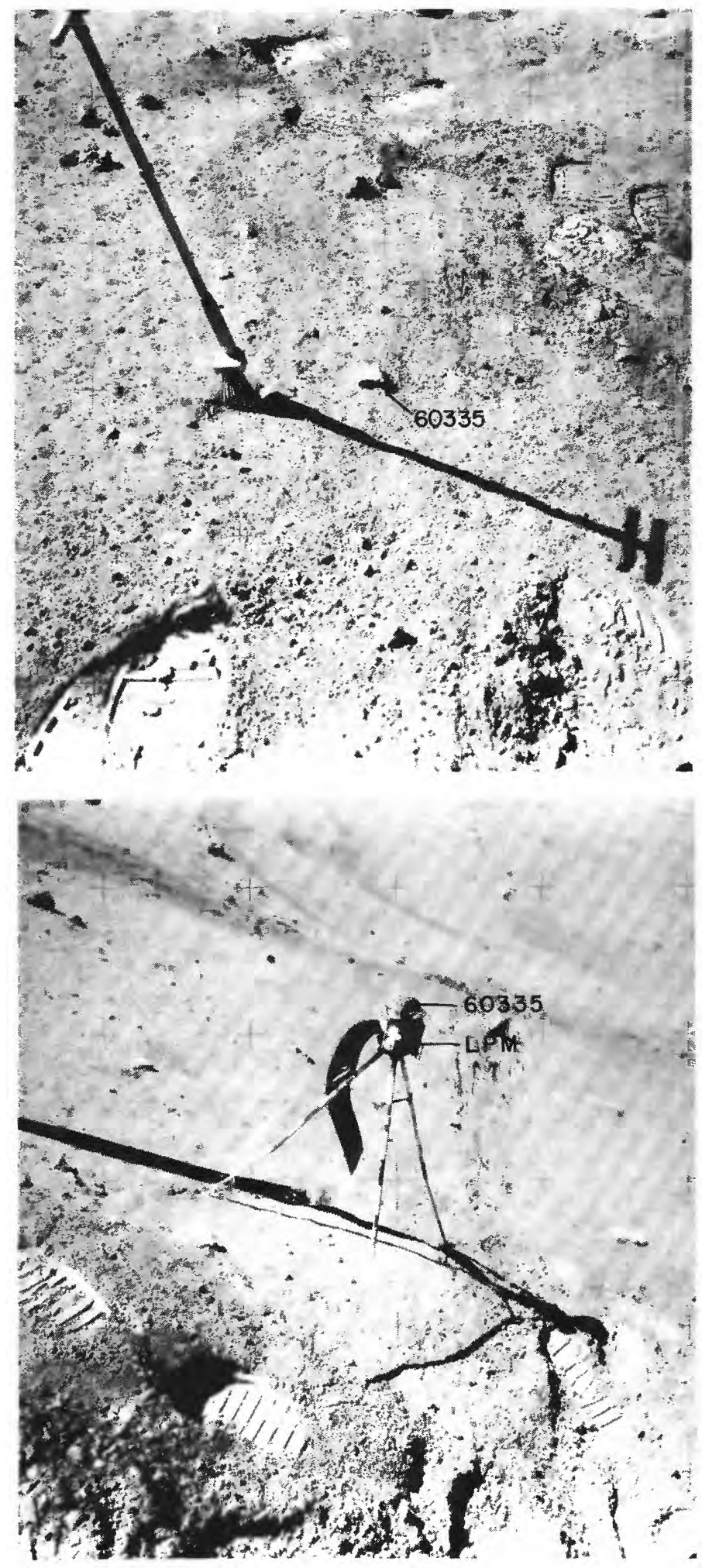

4 Figure 20A.--Sample 60335 shown before sampling in photograph AS16-116-18713; view is southeast. Crystalline $\left(C_{1}\right)$ rock. Last sample collected.

4 Figure 20B.-Sample 60335 placed on top of Lunar Portable Magnetometer (photograph AS16-116-18721) to test the remanent magnetization of a single rock in lunar environment. Magnetic field of the rock was too small to be detected by instrument (Dyal and others, 1972). 


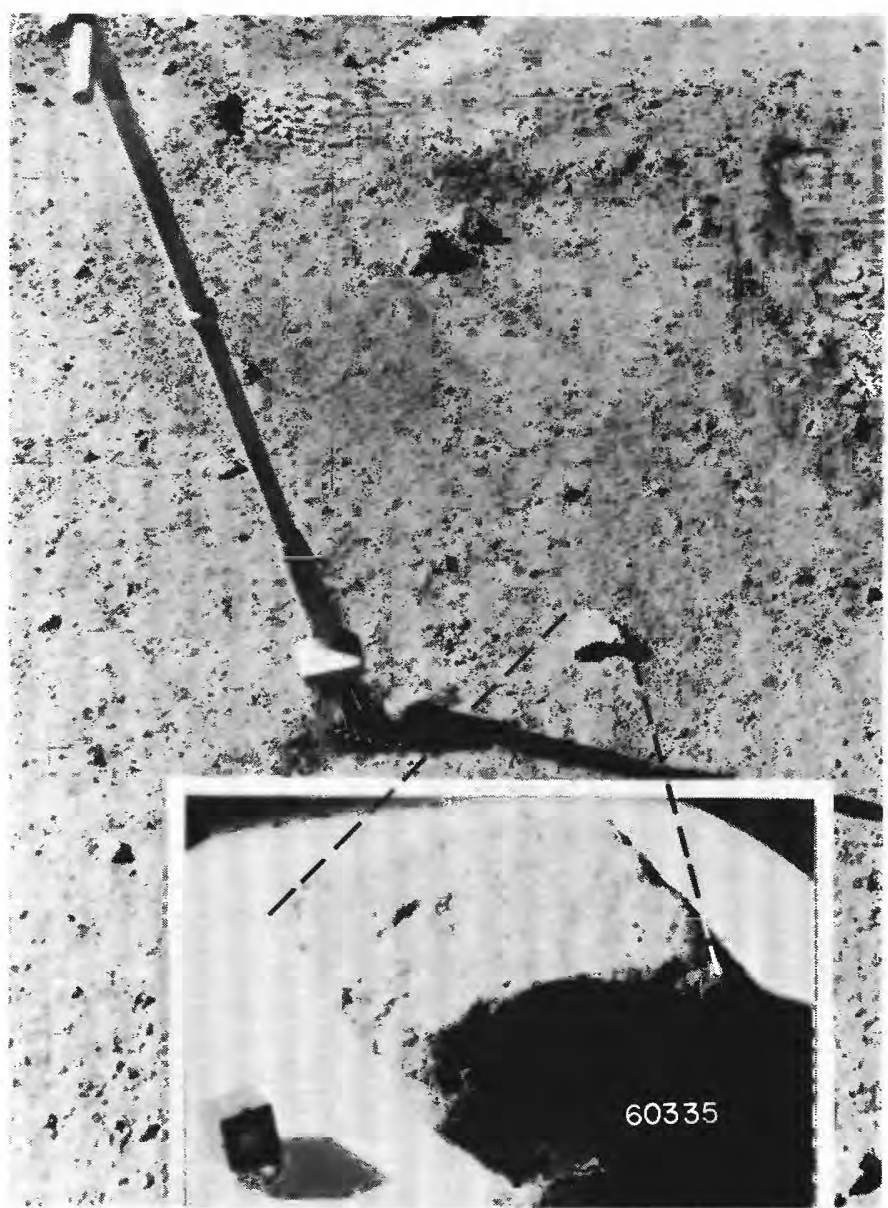

Figure 20C.-Sample 60335 showing approximate lunar orientation reconstructed in LRL compared to an enlarged part of photograph AS16-116-18712 taken before sampling. View is south (inset photograph, S-72-41335). 
DOCUMENTATION OF SAMPLES

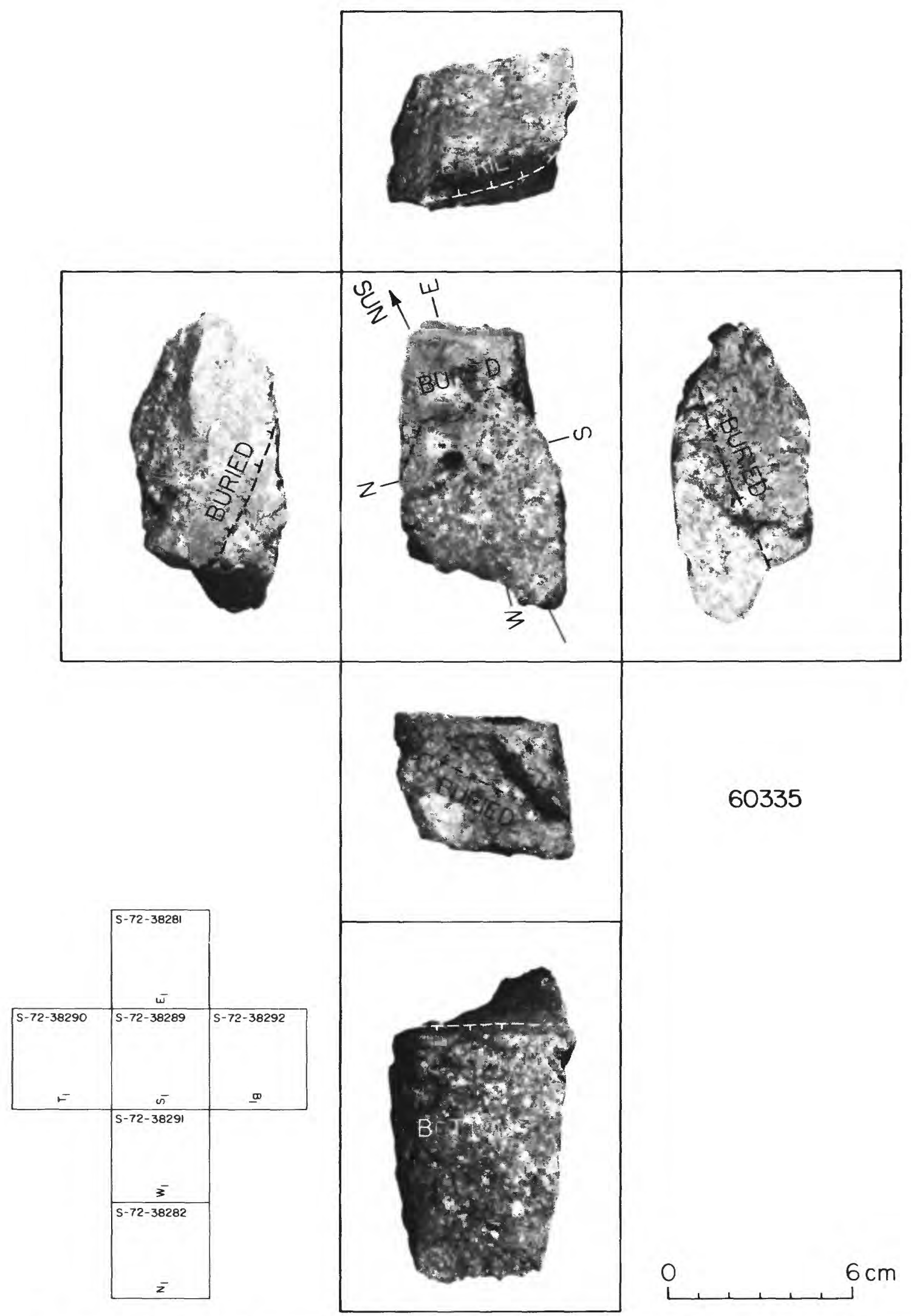

FigURE 20D.-Orthogonal views of sample 60335 related to its lunar orientation at time of sampling. Classified crystalline, type $\mathrm{C}_{1}$. 
SAMPLE: 60335

Station: LM/ALSEP

Landmark: Approximately $50 \mathrm{~m}$ east-northeast of $L M$ and $25 \mathrm{~m}$ northwest of LRV final park position.

Rock type: Hard, sugary crystalline rock, Cl. SURFACE CHARACTERISTICS OF SAMPLE

Slopes: Level.

Fragment population

Size range and distribution: Limit of resolution to $10 \mathrm{~cm}$; pea-sized fragments abundant; very few rocks $>2-3 \mathrm{~cm}$ in immediate area.

Color: Medium gray to whitish.

Shapes: Tabular and angular to irregular and knobby.

Fillets: Poor to moderately developed.

Apparent burial: Most larger fragments $1 / 8$ to $1 / 3$. Dust cover: Moderately high.

Fines

Color: Light gray.

Compaction: Moderately firm

Craters
Size range and distribution: None present $>3-4 \mathrm{~cm}$ in
immediate sample area.

SAMPLE CHARACTERISTICS

Size: $10 \times 6 \times 5 \mathrm{~cm} ; 317.8$ grams.

Color: Medium gray.

Shape: Tabular, angular.

Fillet: Moderately well developed on east side.

Apparent burial: 1/3-1/2.

Dust cover: Moderately heavy.

Comparison with other fragments in area: 60335 is distinct in the sample area by virtue of its blocky and angular shape. Closest

similar sized fragments just to the south of 60.335 are darker and irregular (knobby) in shape.

Probable origin: Most likely represents South Ray crater ejecta. COMMENTS: This rock used for LPM measurement. 

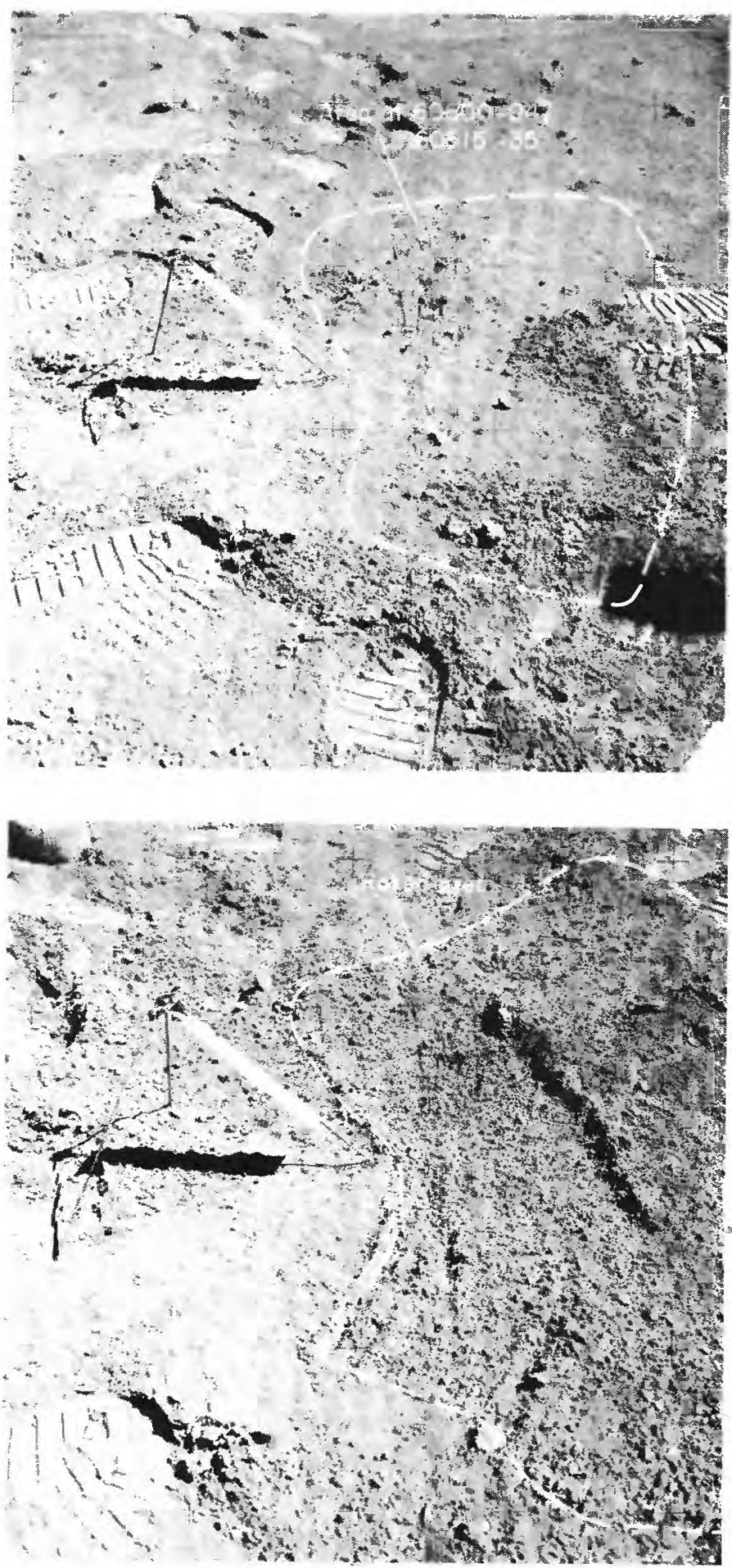

TFigure 21A.-Area of rake samples 60500-04 and 60515-35 shown before sampling in photograph AS16-116-18686; view is north. Vertical wand of gnomon had broken from leg assembly before this picture was taken. Sample collected at station 10 (LM/ALSEP) during EVA 3.
Figure 21B.-Area of rake samples 60500-04 and 60515-35 shown after sampling in photograph AS16-116-18687; view is north. 


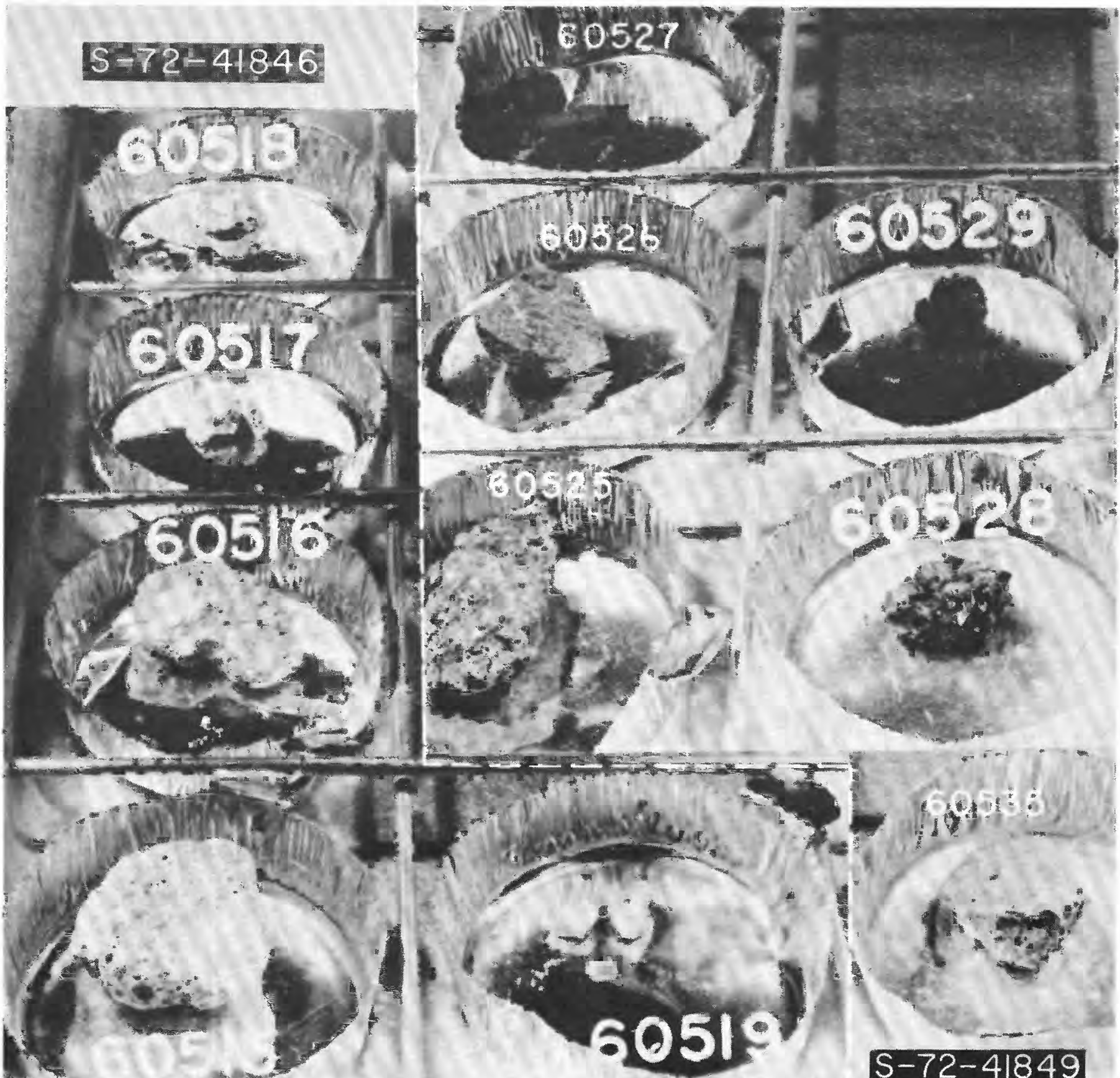

Figure 21C.-Rake fragments 60515-19, 60525-29, and 60535 in LRL (composite of photographs S-72-41846 and S-72-41849). Fragments 15 and 16 , type $B_{1}$ breccia; fragments $17-19,<2 \mathrm{~g}$ and not classified, but look like $B_{1}$ breccia; fragments $25-27$, metaclastic $\left(C_{2}\right)$; fragment 28 and probably 29 , glassy $(\mathrm{G}) ; 60535, \mathrm{~B}_{3}$ breccia. 
SAMPLE: 60500-04 (soil); 60515-19, 60525-29, 60535 (rake fragments)

Station: 10 (LM/ALSEP)

Landmark: Collected about $5 \mathrm{~m}$ southeast of station 10 pan site approximately $60 \mathrm{~m}$ southwest of $\mathrm{LM}$.

Rock type: Soil and fragments collected with the rake.

SURFACE CHARACTERISTICS OF SAMPLE AREA

Slopes: Level

Fragment population

Size range and distribution: Up to $2-3 \mathrm{~cm}$; very few pebble-sized fragments (much less than average in LM/ALSEP area).

Color: Whitish to light gray.

Shapes: Generally equidimensional; subangular to subrounded.

Fillets: Very poorly developed.

Apparent burial: $1 / 3-1 / 4$ on $2-3 \mathrm{~cm}$ fragments.

Dust cover: Not visible.

Fines

Color: Light gray.

Compaction: Moderate.

Craters: None in vicinity.

SAMPLE CHARACTERISTTCS FOR 60500-04 (SOII)

Size: < $1 \mathrm{~cm}$ fines; 710.13 grams total weight.

Color: Light to medium gray.

Comparison with other soil in area: Texture and color appear typical.

SAMPLE CHARACTERISTICS FOR 60515-19, 25-29, 35 (11 fragments)

Size: 1-3 cm; 67.53 grams total weight.

Color: Light gray to whitish.

Shape: Subangular.

Fillets: Absent to poorly developed.

Apparent burial: Perched to slight.

Dust cover: Not visible.

Comparison with other fragments in area: Probably rake fragments are typical of the relatively few rocks in area.

Probable origin: Mostly South Ray crater ejecta and local Cayley

material. 


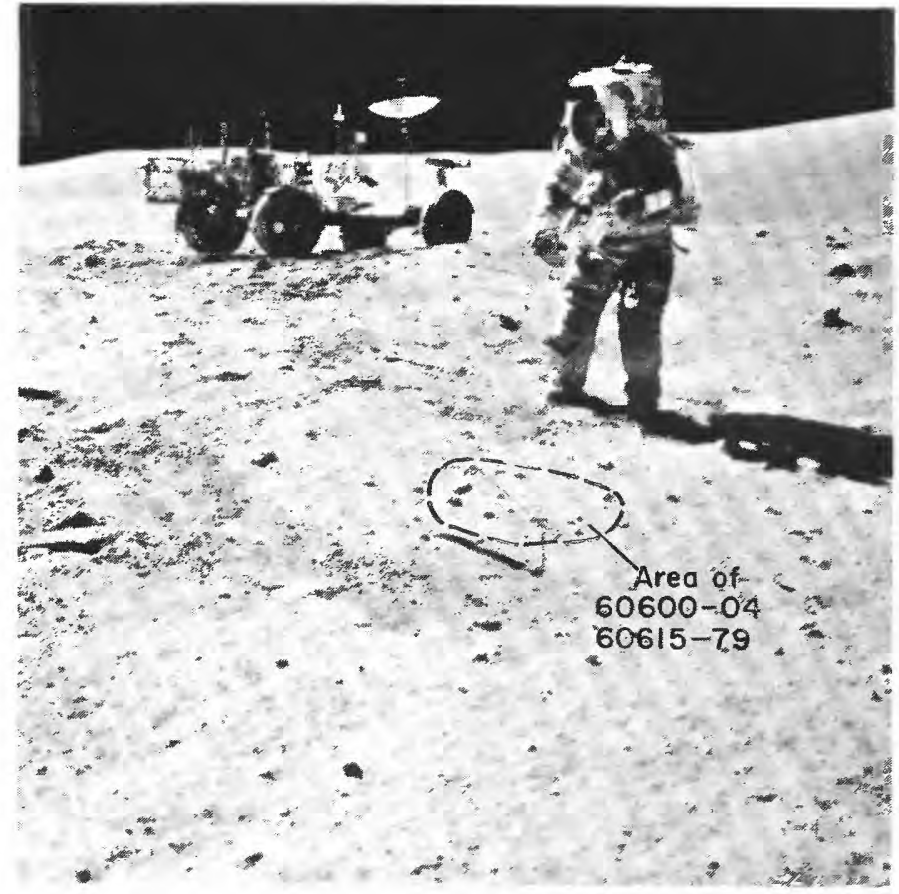

Figure 22A.-Location of rake samples 60600-04 and 60615-79 in relation to LRV at station $10^{\prime}$ during EVA 3, shown before sampling in photograph AS16-117-18825. View is southeast.

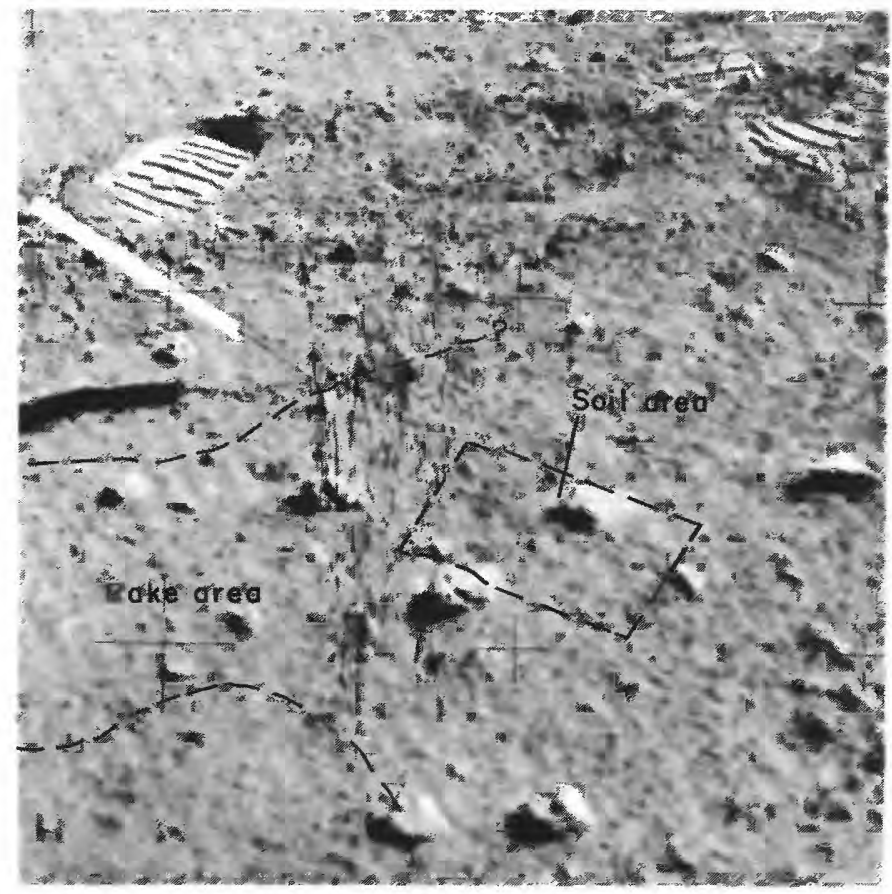

FIGURE 22B.-Area of rake samples 60600-04 and 60615-79 shown before sampling in photograph AS16-116-18681; view is north.

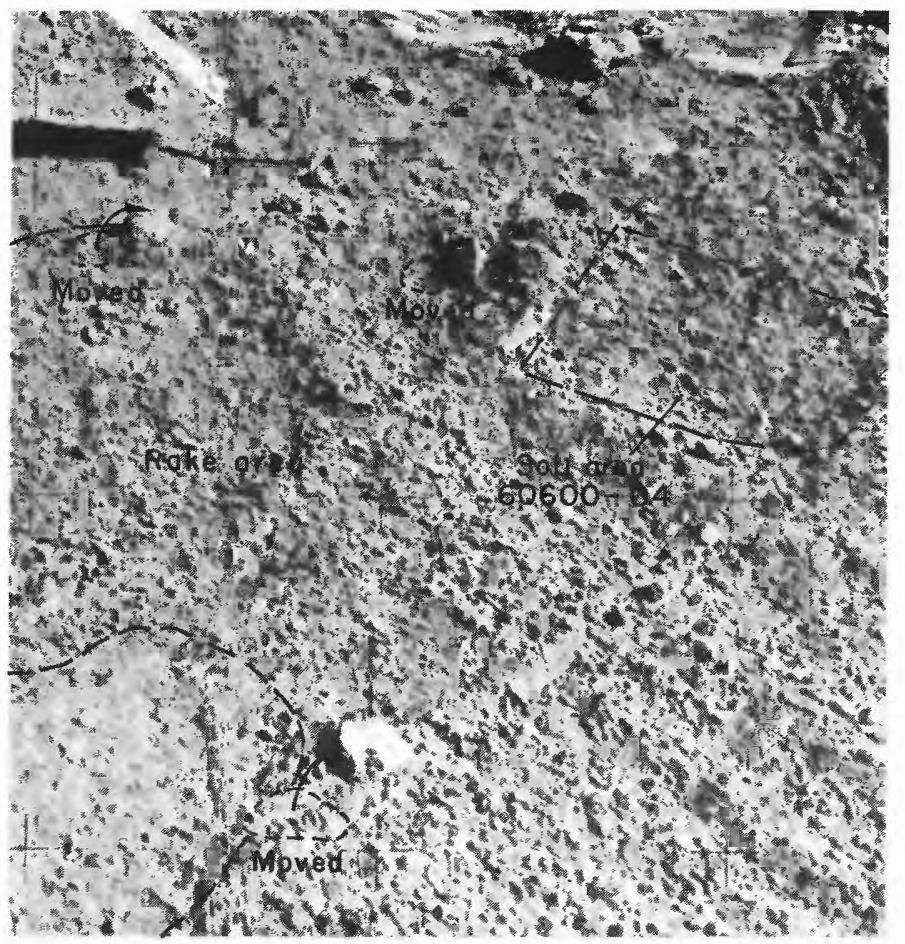

Figure 22C.-Area of rake samples $60600-04$ and 60615-79 shown after sampling in photograph AS16-116-18683; view is north. 

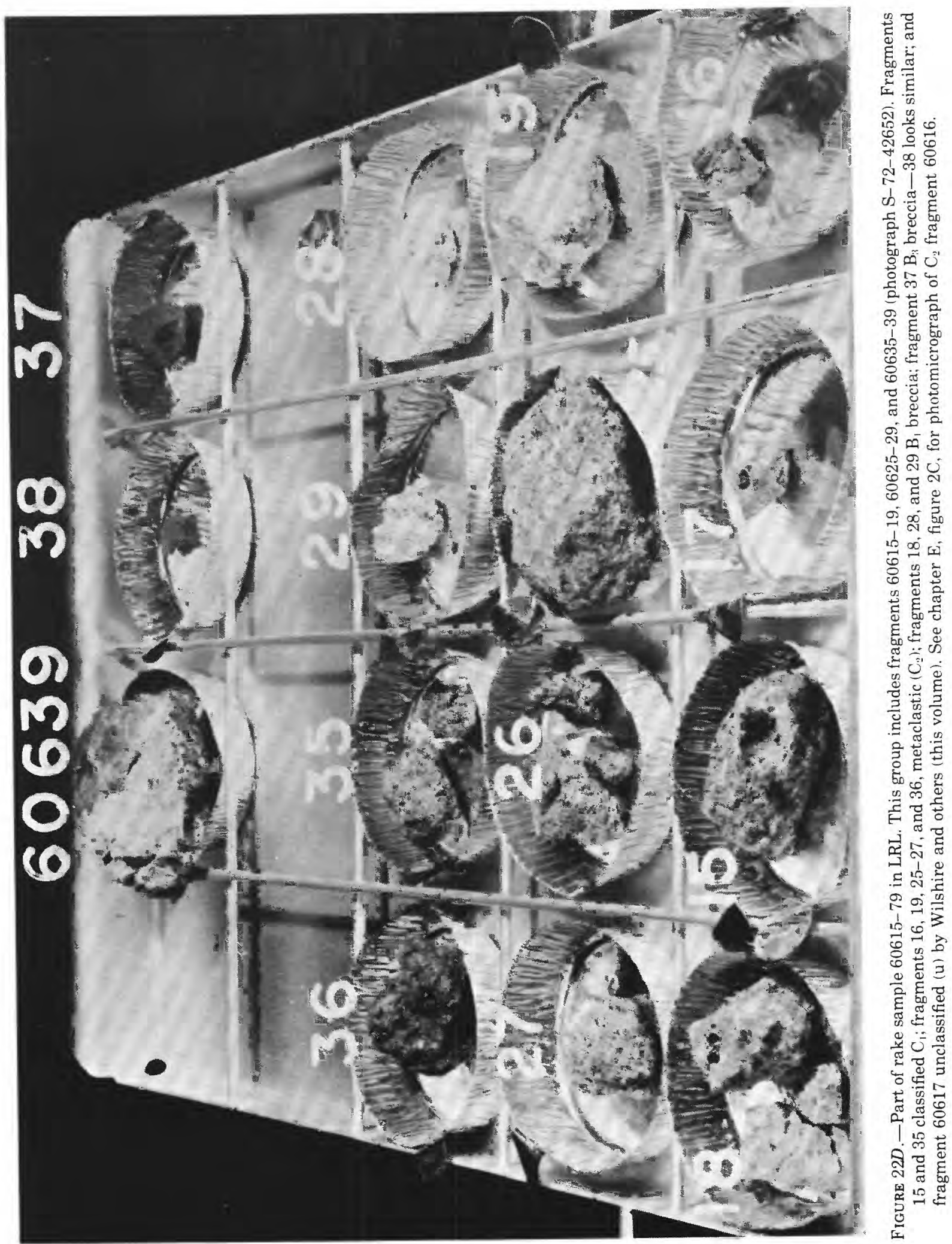


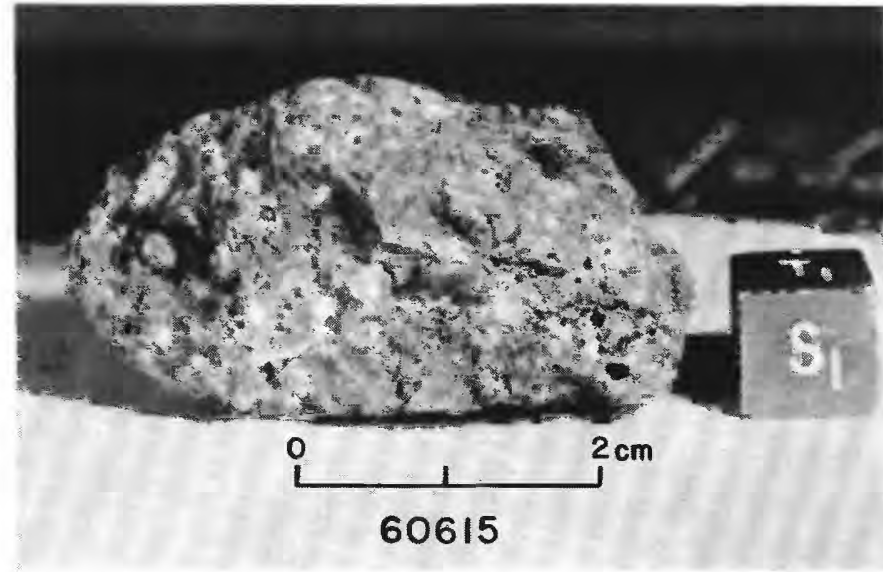

Figure 22E.--Rake fragment 60615 in LRL (photograph S72-43512). Crystalline $\left(C_{1}\right)$ rock.

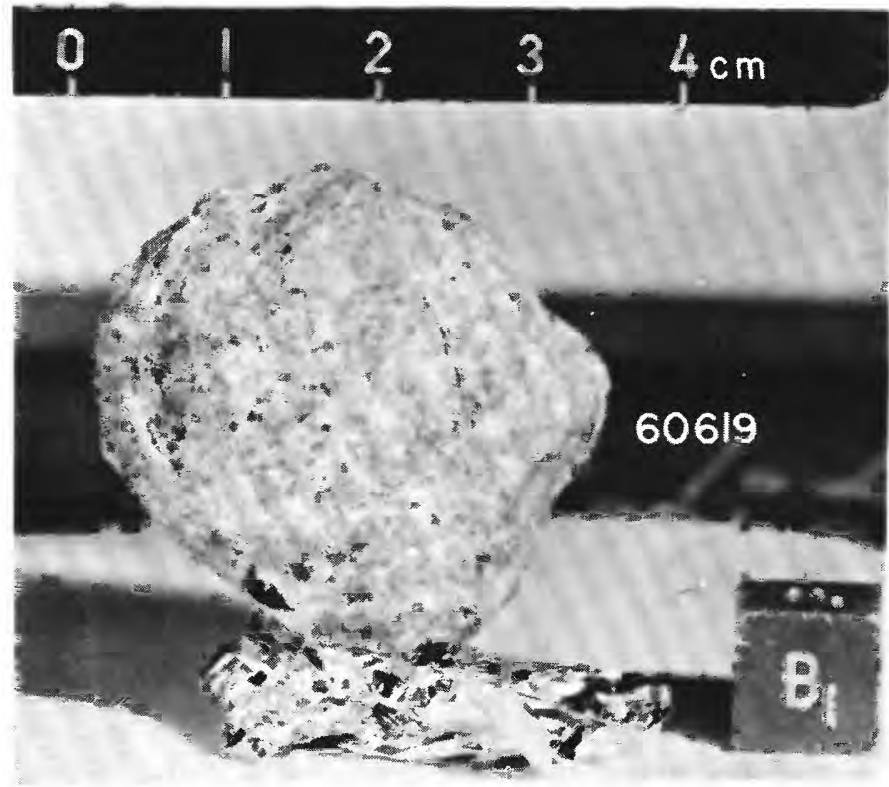

FIgUre 22F.-Rake fragment 60619 in LRL (photograph S72-43474). Metaclastic $\left(\mathrm{C}_{2}\right)$ rock. (See photomicrograph, chapter E, fig. $3 A$.)

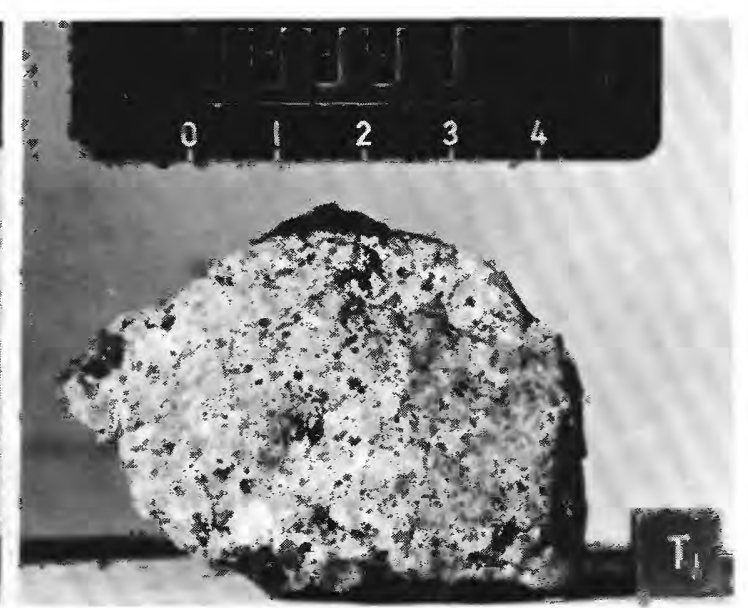

FIGURE 22G.- Stereopair of rake fragment 60625 taken in LRL; photographs S-72-44915 (right) and $-44915 \mathrm{~B}$ (left). Metaclastic $\left(\mathrm{C}_{2}\right)$ rock (see photomicrograph, chapter $\mathrm{E}$, fig. $2 \mathrm{D}$ ). 


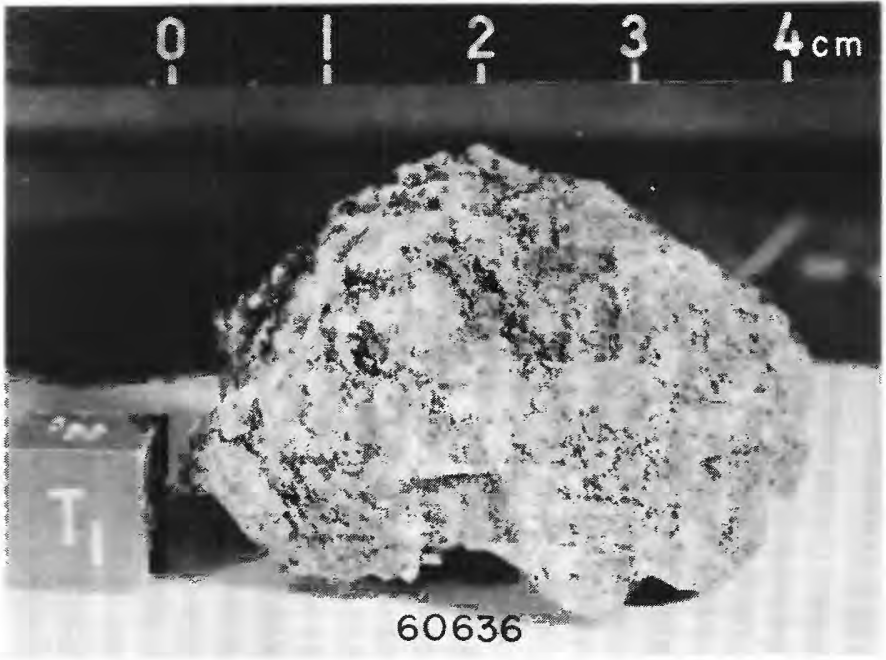

Figure 22H.-Rake fragment 60636 in LRL (photograph S72-43472). Metaclastic $\left(\mathrm{C}_{2}\right)$ rock.

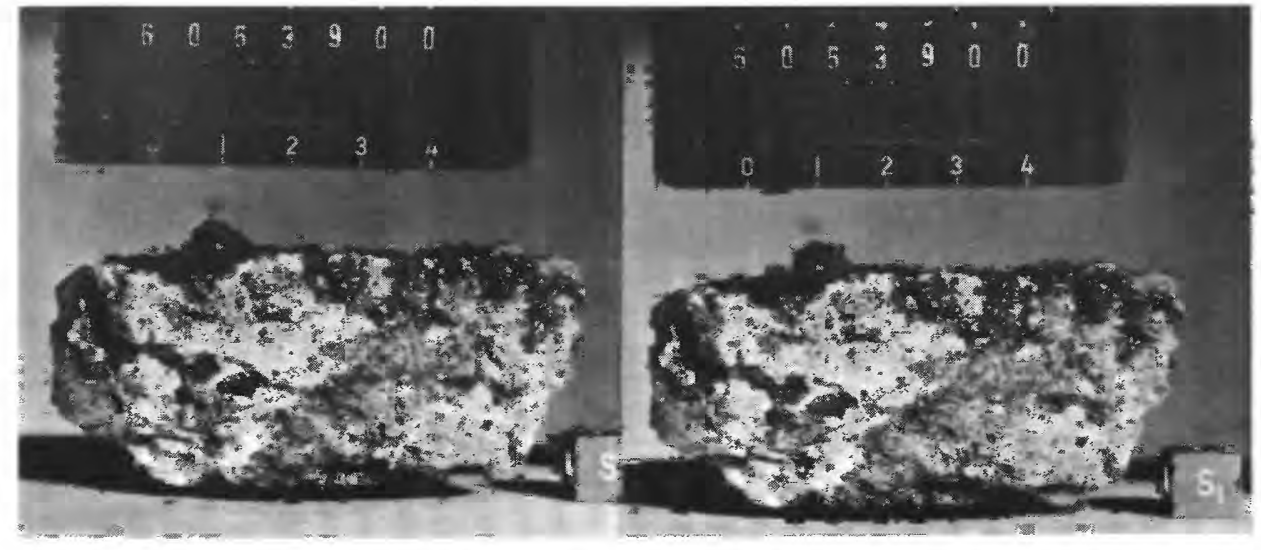

FIGURE 22I. - Stereopair of rake fragment 60639 taken in LRL; photographs S-72-44899 (left) and $-44899 \mathrm{~B}$ (right). $\mathrm{B}_{3}$ breccia, partly coated with black glass. 


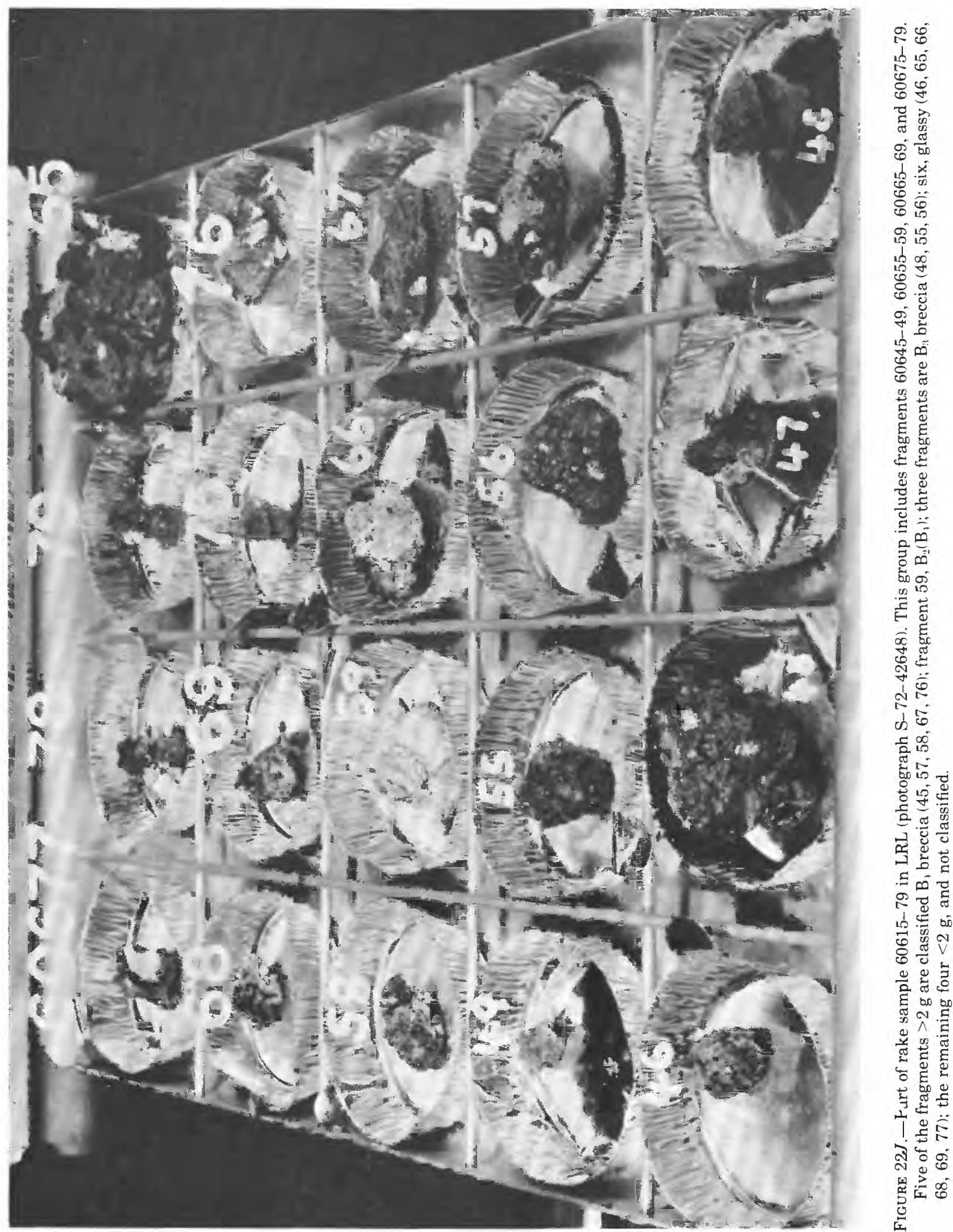




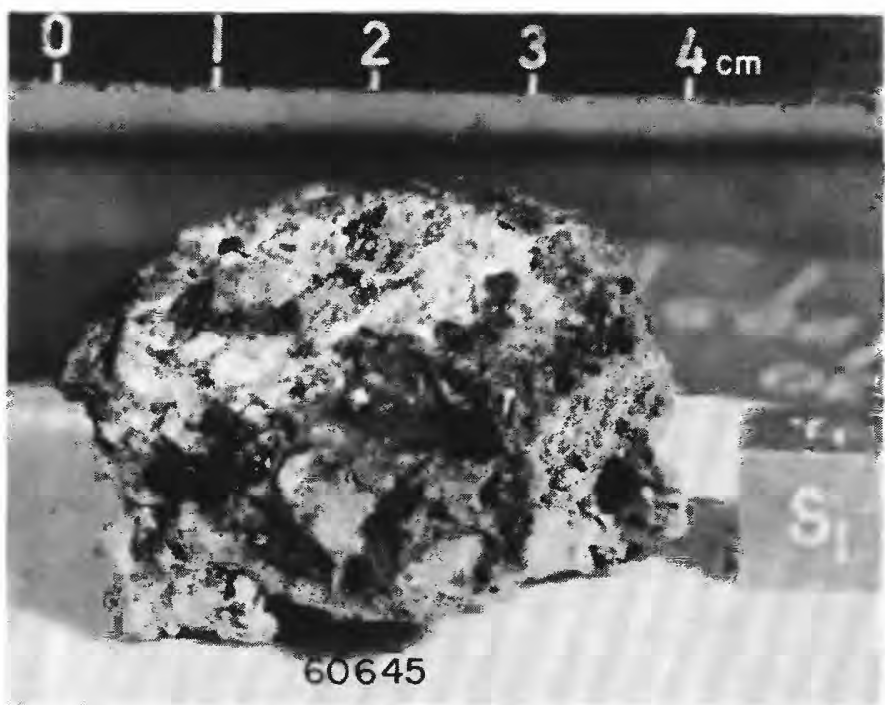

Figure 22K.-Rake fragment 60645 in LRL (photograph S72-43494). $\mathrm{B}_{4}$ breccia.

SAMPLE: 60600-04 (soi1); 60615-19, 60625-29, 60635-39, 60645-49, 60655-59,. 60665-69, 60675-79 (rake fragments)

Station: 10' (LM/ALSEP)

Landmark: About $10 \mathrm{~m}$ northwest of $L R V$ and $70 \mathrm{~m}$ west-southwest of $L M$.

Rock type: Soil and fragments collected with the rake (see figures $22 \mathrm{D}$ and SURFACE CHARACTERISTICS OF SAMPLE AREA

$22 \mathrm{~J}$ for rock

Slopes: Level. classification).

Fragment population

Size range and distribution: Up to $7-8 \mathrm{~cm} ; 3-6 \mathrm{~cm}$ fragments usually abundant.

Color: Light gray to whitish.

Shapes: Subrounded.

Fillets: None.

Apparent burial: $1 / 8$

Dust cover: Moderate to high.

Fines

Color: Medium gray.

Compaction: Moderate to high.

Craters: None in immediate vicinity.

SAMPLE CHARACTERISTICS FOR 60600-04 (soil)

Size: <1 cm fines; 540-24 grams total weight

Color: Light gray on surface.

Comparison with other soil in area: Typical in color and texture.

Probable origin: Contains material from South Ray and North Ray craters. COMMENTS: Sampled to depth of $5-8 \mathrm{~cm}$.

SAMPLE CHARACTERISTICS FOR 60615-19, 25-29, 35-39, 45-49, 55-59, 65-69, 75-79

(35 fragments)

Size: 1-8 cm in diameter; 714.97 grams total weight.

Color: Light gray to whitish.

Shape: Primarily subrounded and irregular.

Fillet: None.

Apparent burial: $1 / 8$ of fragment.

Dust cover: Moderately high.

Comparison with other fragments in area: Whitish rake fragments appear typical of fist-sized rocks in local area. Some white clasts visible.

Probable origin: South Ray crater ejecta. 

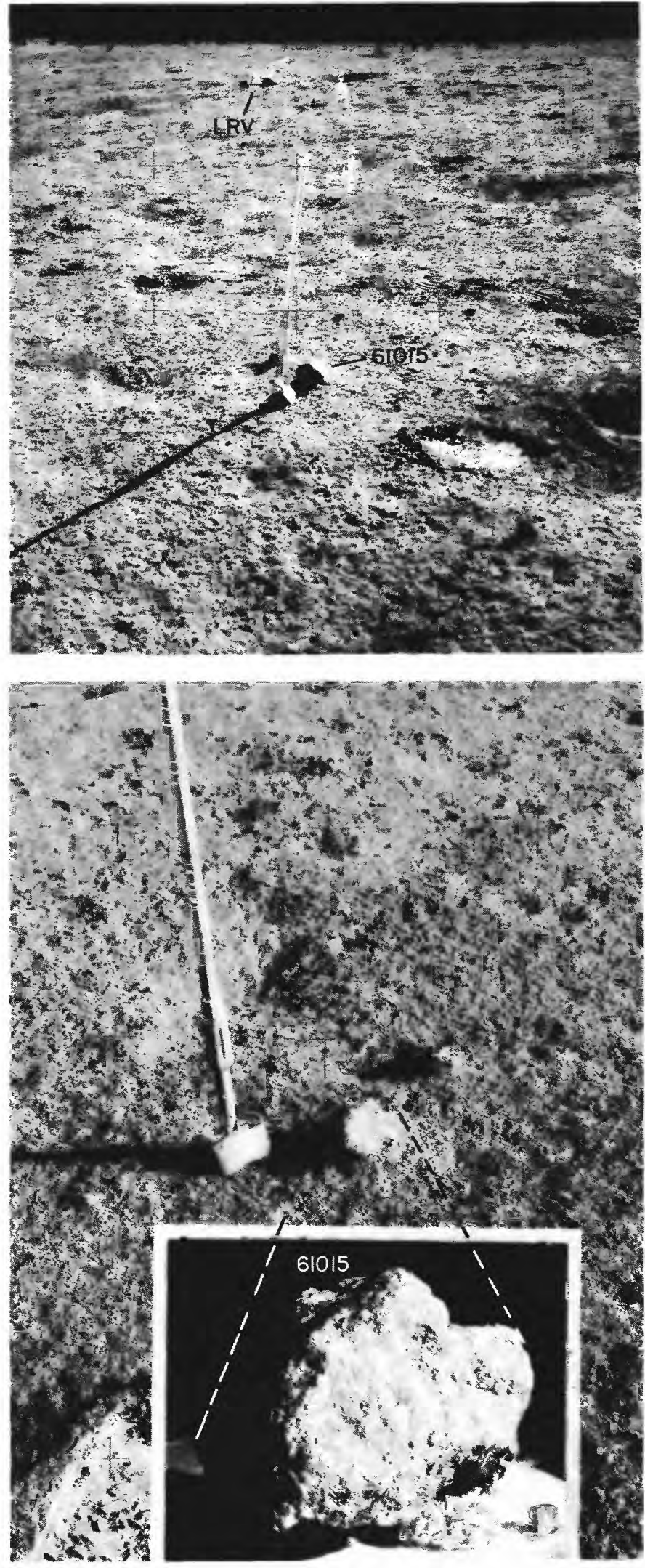

Figure 23A.-Sample 61015 shown before sampling in photograph AS16-109-17810; view is northeast toward LRV at station 1.

Figure 23B.-Sample 61015 showing approximate lunar orientation reconstructed in LRL compared to an enlarged part of photograph AS16-109-17808 taken before sampling; view is north (inset photograph S-72-41058). Scoop is $17 \mathrm{~cm}$ wide. Rock is B. breccia. 


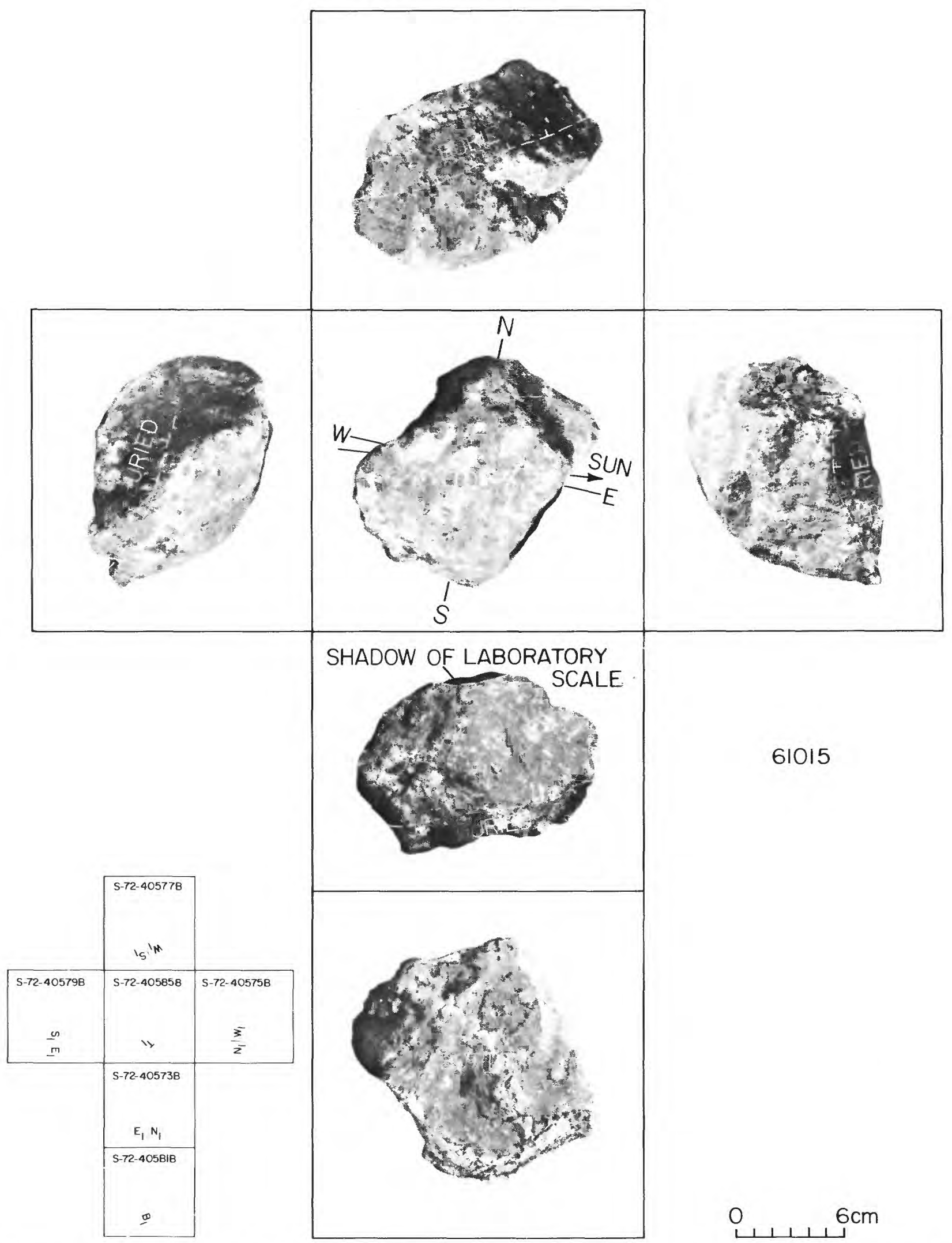

FigURE 23C.-Orthogonal views of sample 61015 related to its Iunar orientation at time of sampling. See chapter $\mathrm{E}$, figs. $3 E$ and $3 F$ for ${ }^{\top} \mathrm{T}_{1}$ photographic view and photomicrograph, respectively, of this $\mathrm{B}_{2}$ breccia. 


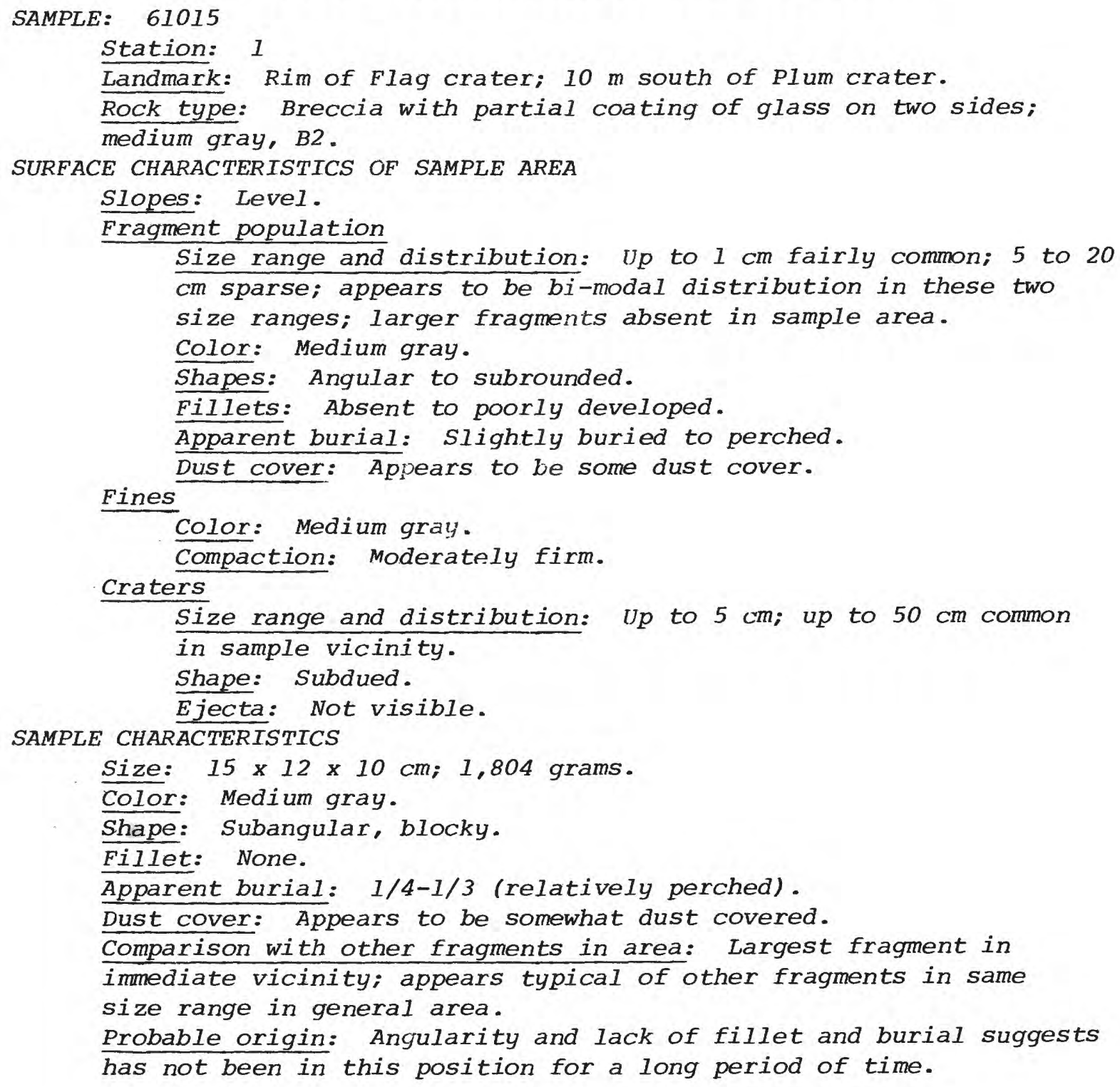



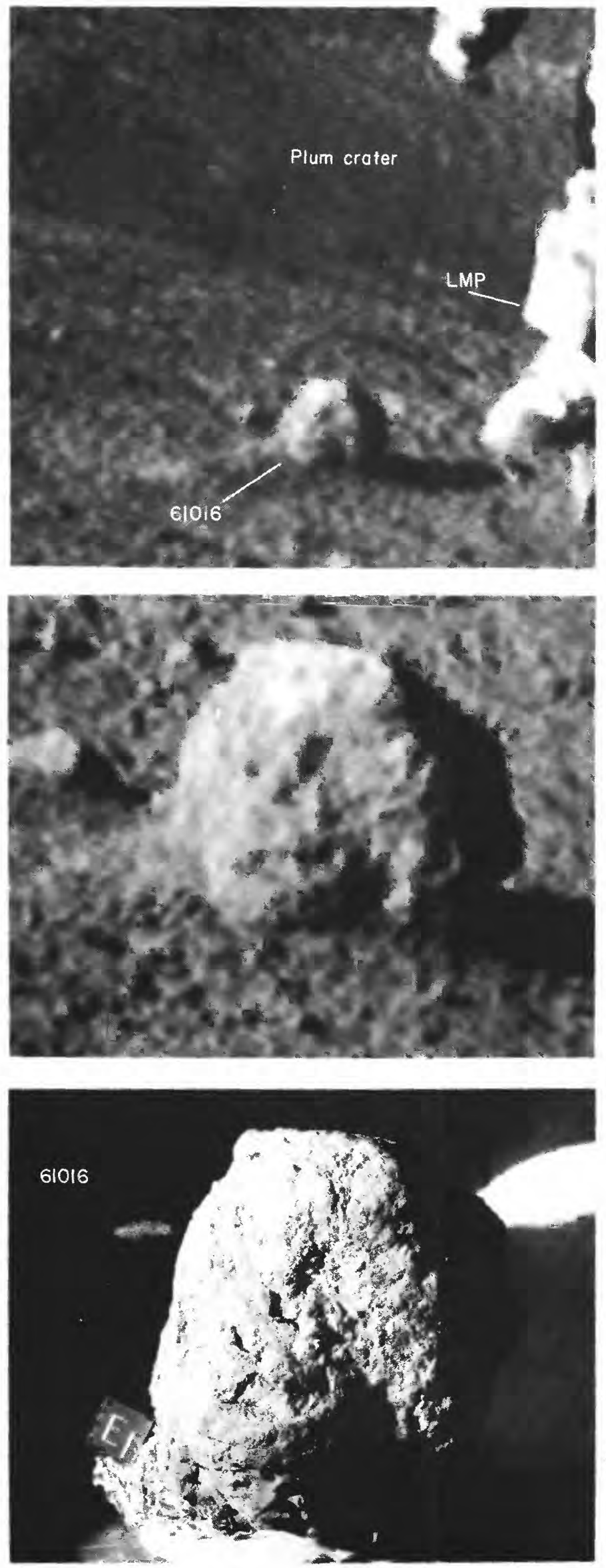

Figure 24A.-Television picture from LRV of sample 61016 and part of astronaut Charles M. Duke, shown before LMP picked up largest single rock to be returned from Moon in all of the Apollo missions. Figure $28 A$ shows setting of sample 61016 on rim of Plum crater.

Figure 24B.-Sample 61016 (so-called "Big Muley") showing approximate lunar orientation reconstructed in LRL. Compare with television picture taken before sampling from LRV. View is southwest (inset photograph S-72-41841). B breccia, partly glass coated (see fig. $24 \mathrm{C}$ ). 


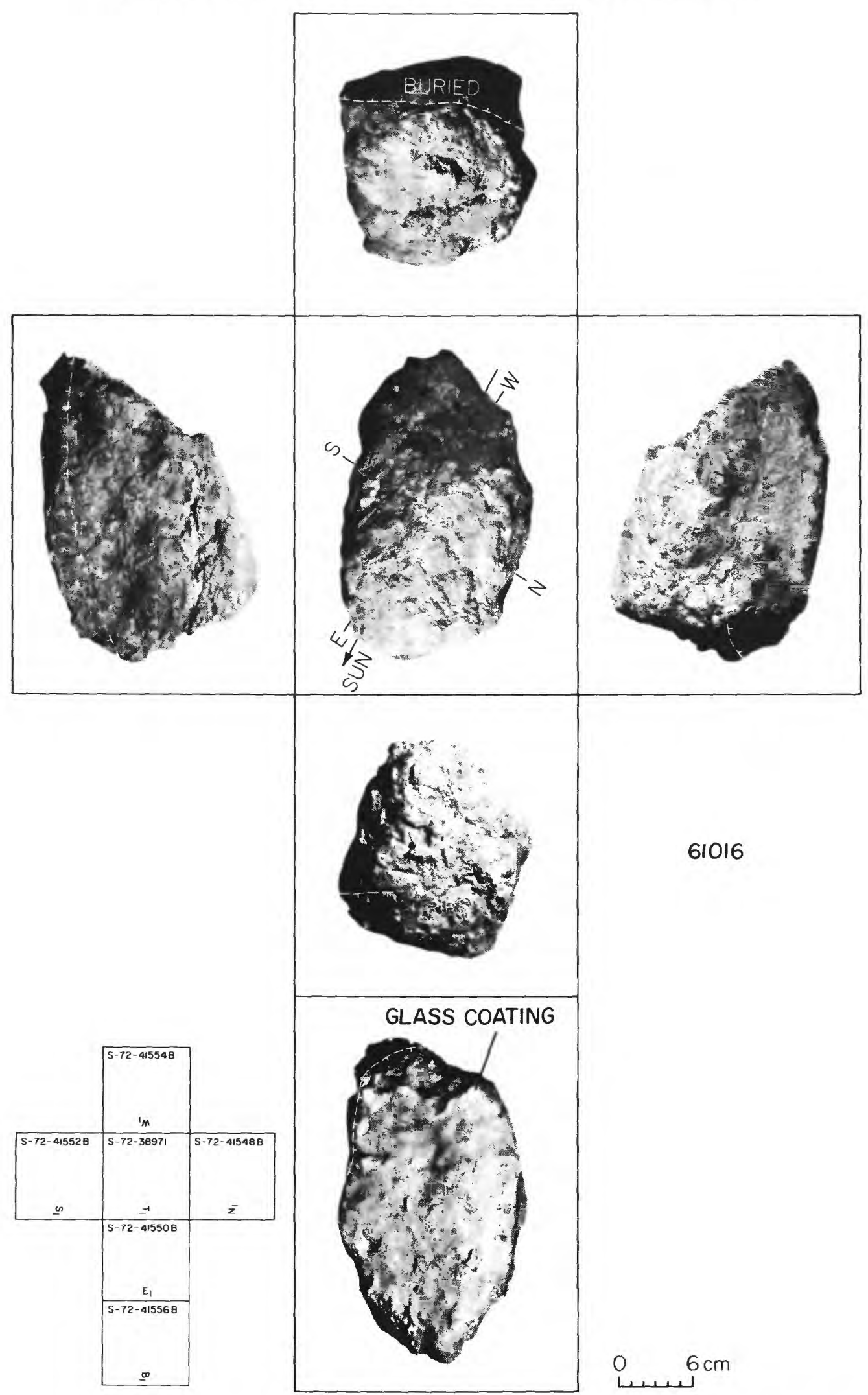

Figure 24C.-Orthogonal views of sample 61016 related to its lunar orientation at time of sampling. See chapter D1, figure $13 \mathrm{~A}$ for the $N_{1}$ photographic view. 


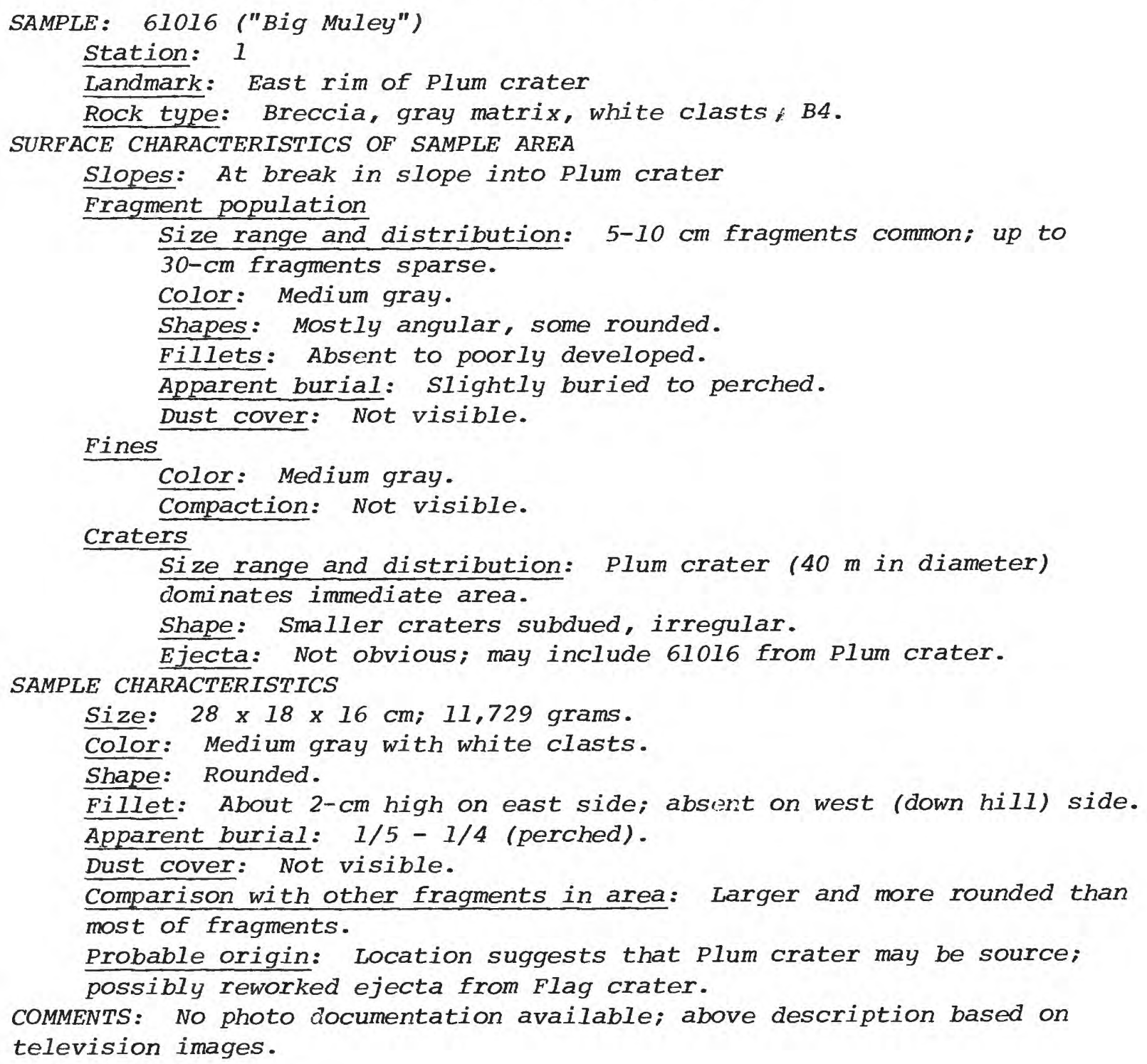




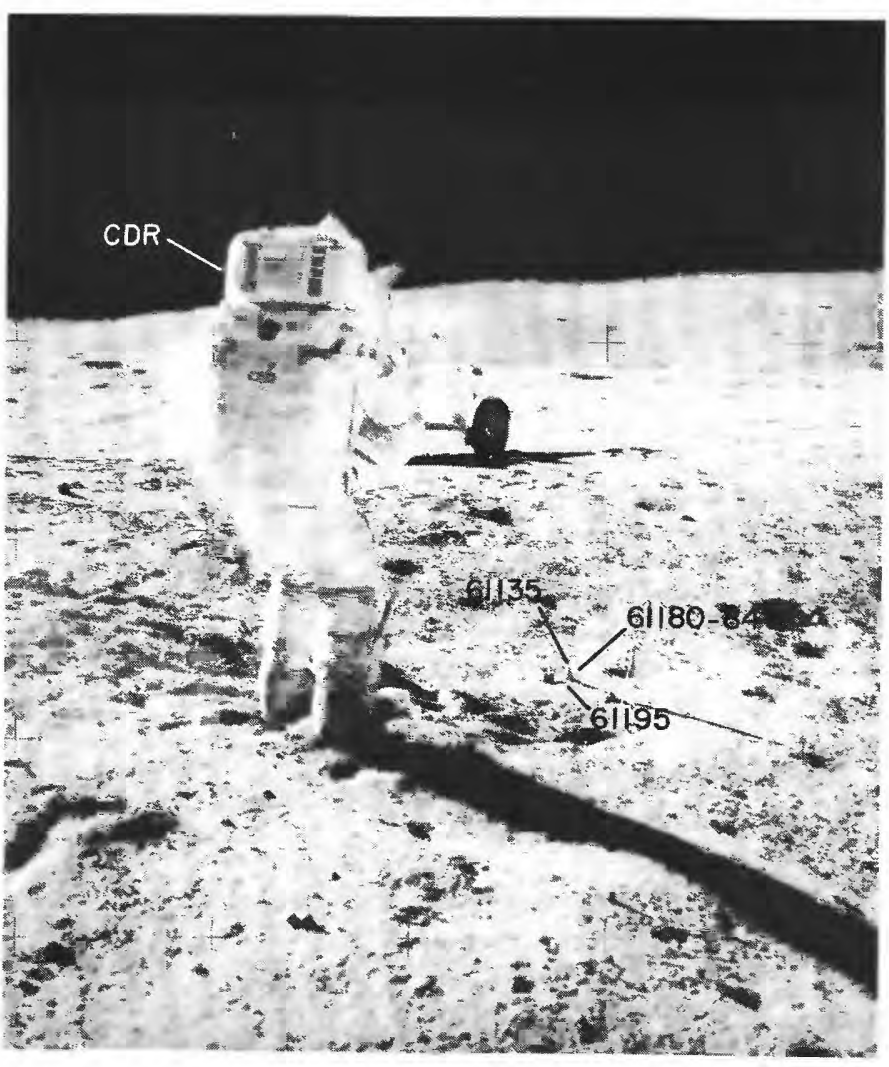

FIGURE 25A.-Location of rock samples 61135 and 61195 and soil samples 61180-84 in relation to LRV at station 1, shown before sampling in photograph AS16-109-17800. View is southeast.

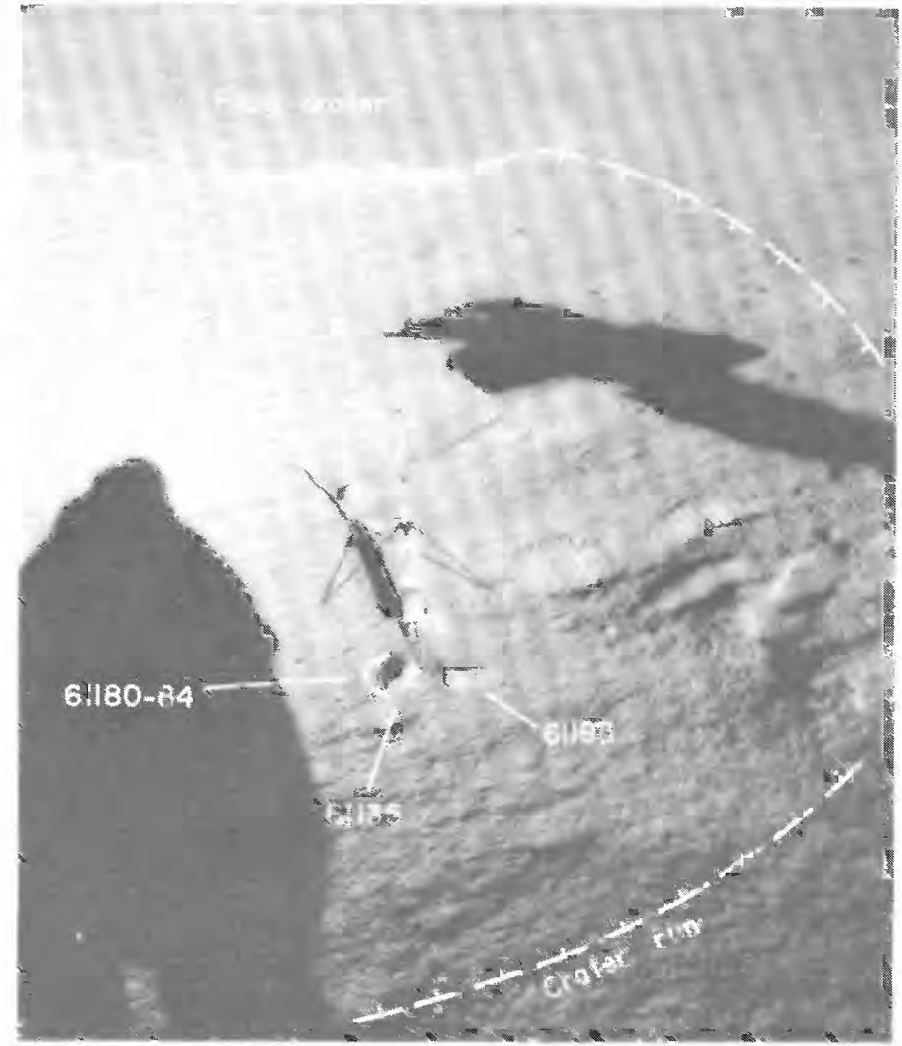

Figure 25B.-Sample 61135 and 61195 shown before sampling in photograph AS16-109-17799; view is down-sun. Soil sample $61180-84$ was collected from beneath 61135 . View is west toward Flag crater from northeast rim of Plum crater (see map of station 1, chapter D1, fig. 11). 


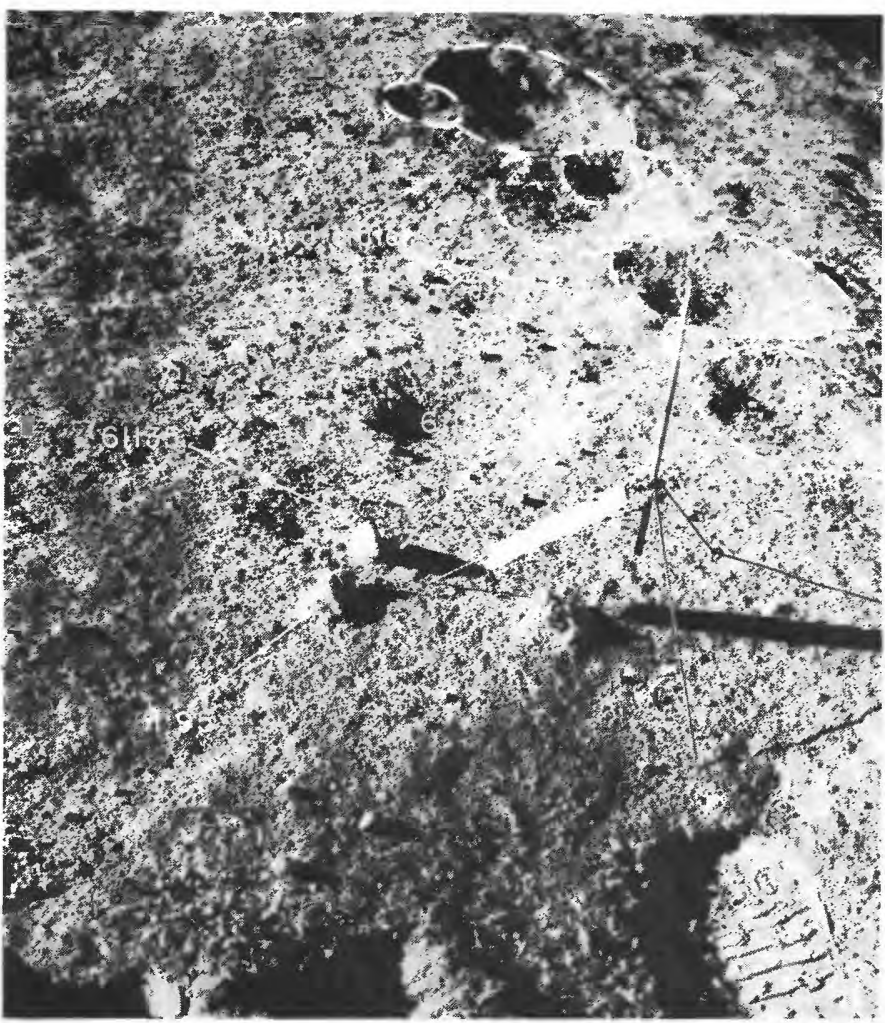

Figure 25C.-Samples 61135,61195 , and $61180-84$ shown before sampling in photograph AS16-114-18405; view is south.

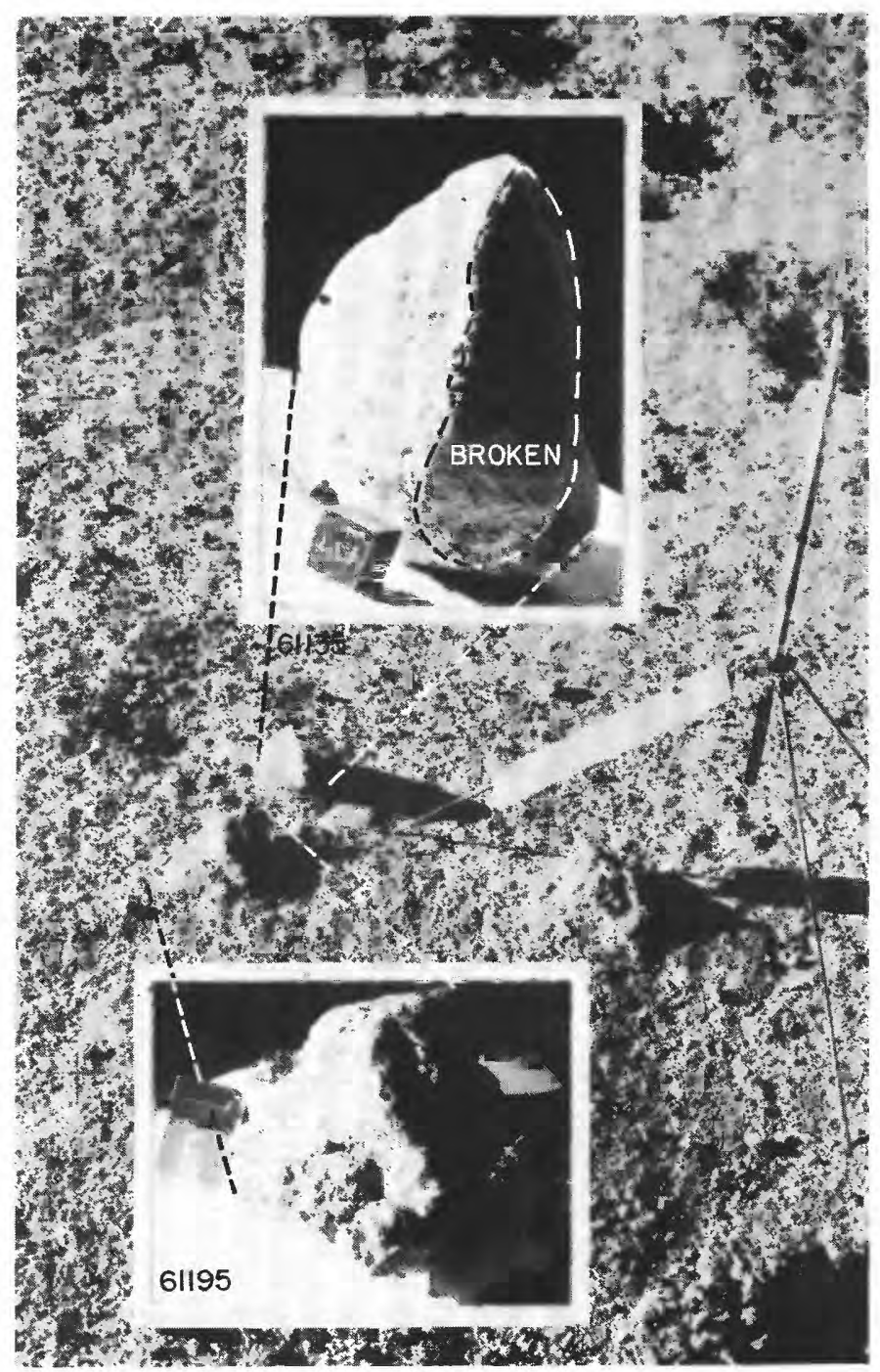

Figure 25D.-Samples 61135 and 61195 showing approximate lunar orientations reconstructed in the LRL compared to enlarged part of photograph AS16-114-18405 taken before sampling. View is south (inset photographs, S-72-41609 and 43315, respectively). 


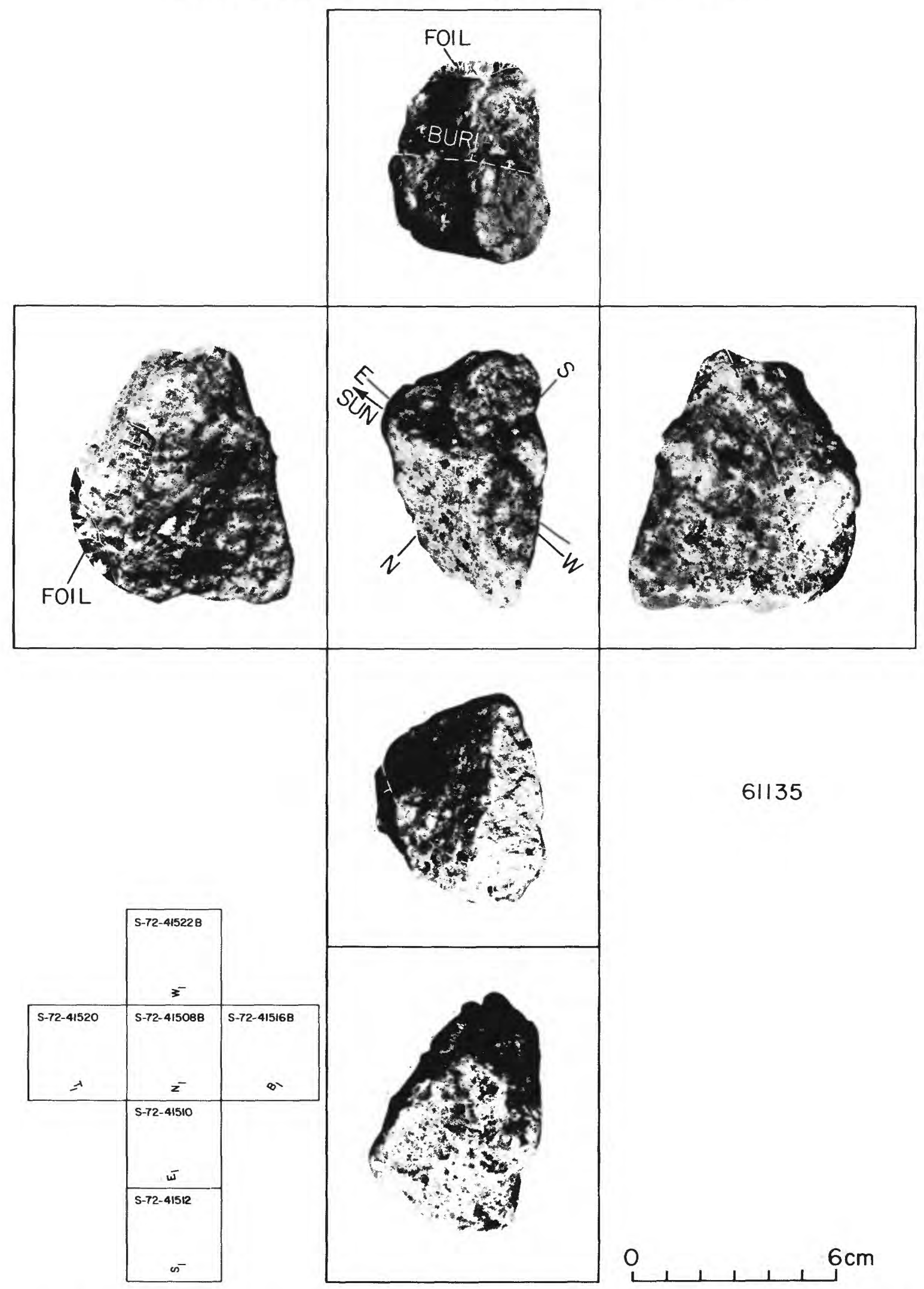

FIGURE 25E.-Orthogonal views of sample 61135 related to its lunar orientation at the time of sampling. The sample is classified as a $\mathrm{B}_{3}$ breccia. 


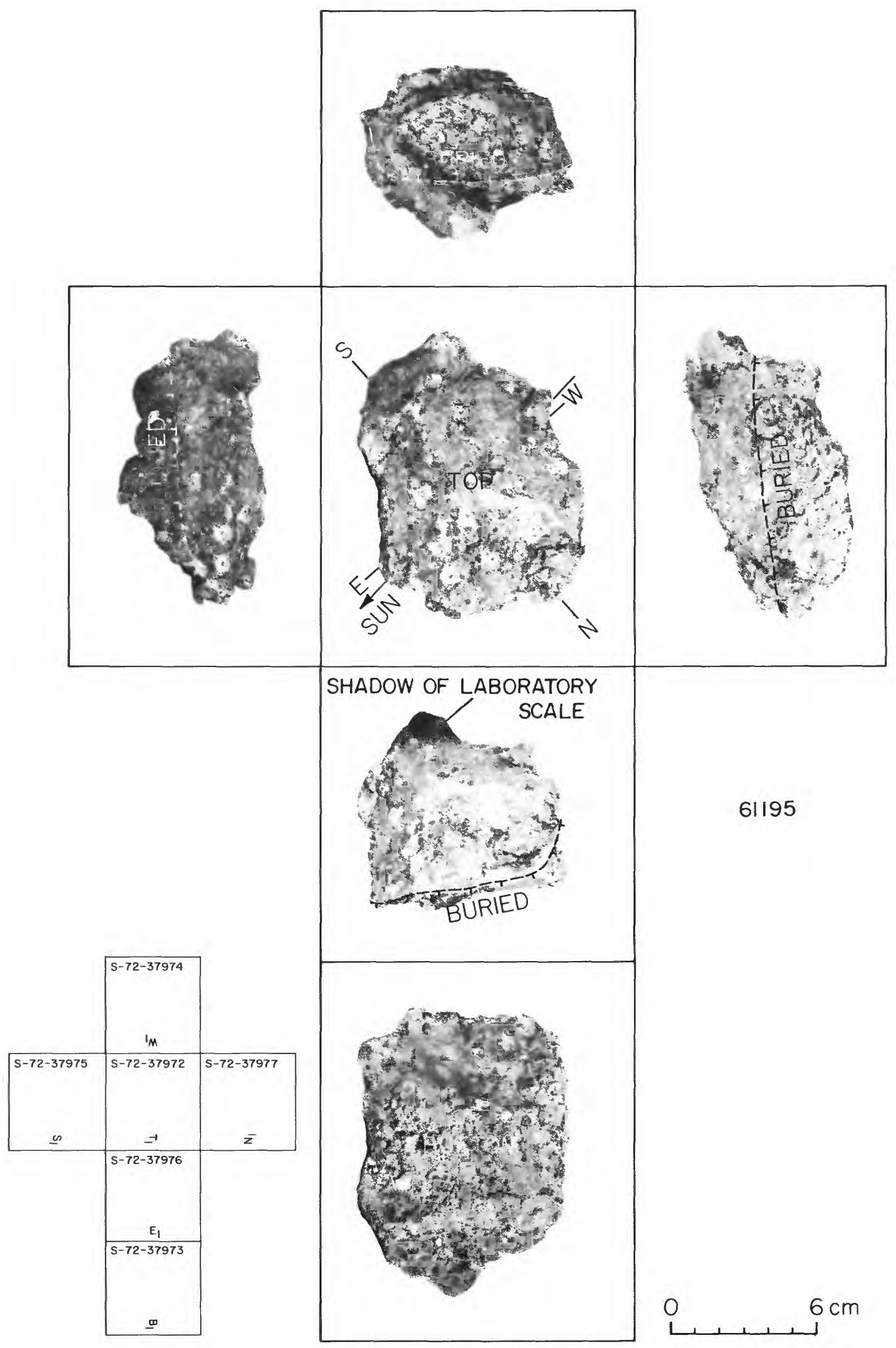

FIGURE 25F.--Orthogonal views of sample 61195 related to its lunar orientation at time of sampling, Classified G (glassy). 


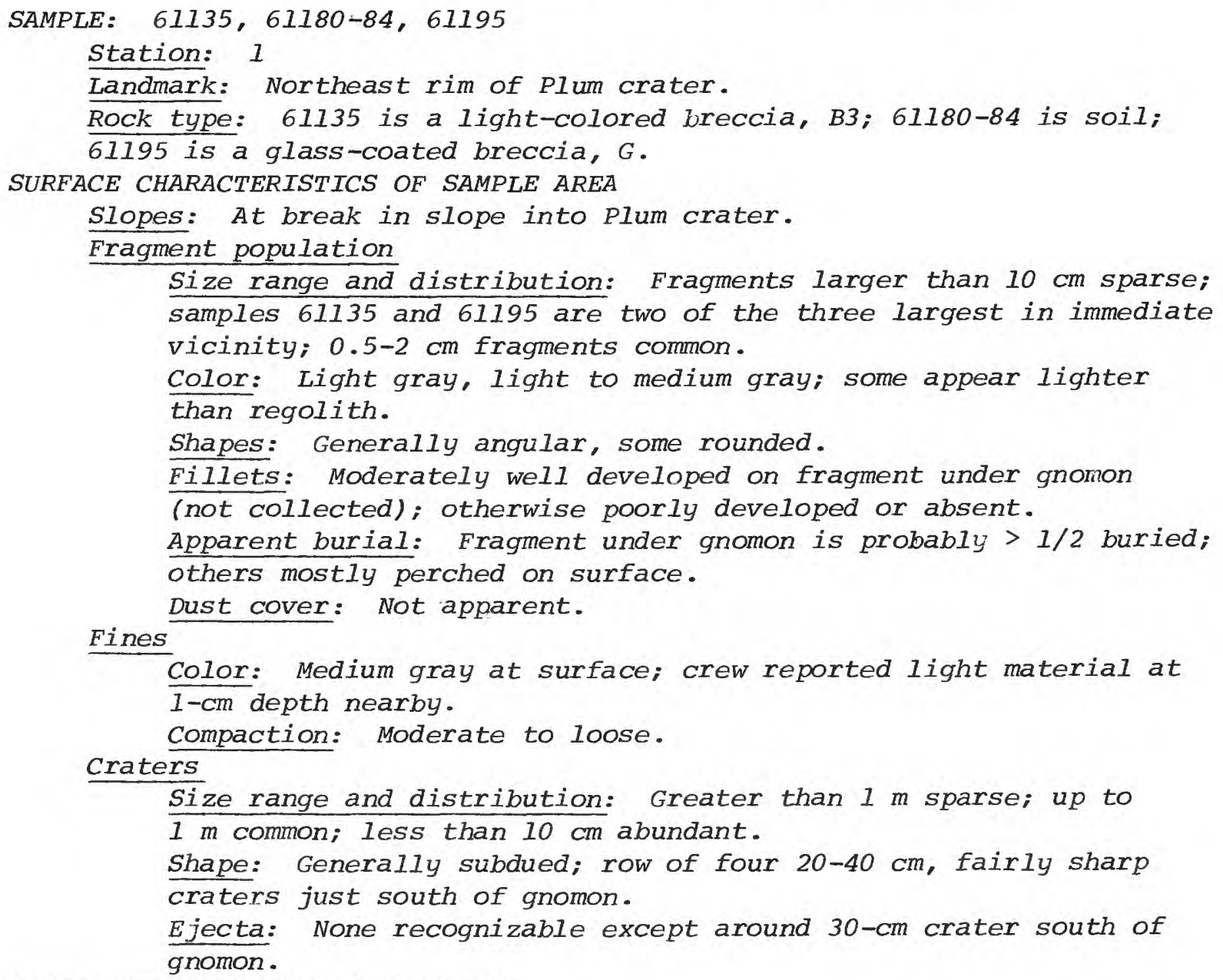


SAMPLE CHARACTERISTICS: 61180-84 (sOi1)

Size: < $1 \mathrm{~cm}$ fines; 271.35 grams total weight.

Color: Medium gray.

Comparison with other soil in area: Appears typical in color and granularity.

Probable origin: Largely a mixture of ejecta from North Ray, South

Ray, Flag, and Plum craters.

COMMENTS: On rim of Plum crater; part of 4-part radial sample.

SAMPLE CHARACTERISTICS: 61195

Size: $12 \times 9 \times 6.5 \mathrm{~cm} ; 587.9$ grams.

Color: Medium gray.

Shape: Angular, irregular.

Fillet: None visible.

Apparent burial: 1/4 - 1/2 of sample.

Dust cover: None visible.

Comparison with other fragments in area: Second largest of three

largest in vicinity; less irregular than largest (not collected);

otherwise appears similar to these and most smaller fragments in area.

Probable origin: Lack of filleting and burial, and angularity, suggest relatively short period of exposure.

COMMENTS: On rim of Plum crater; part of 4-part radial sample.

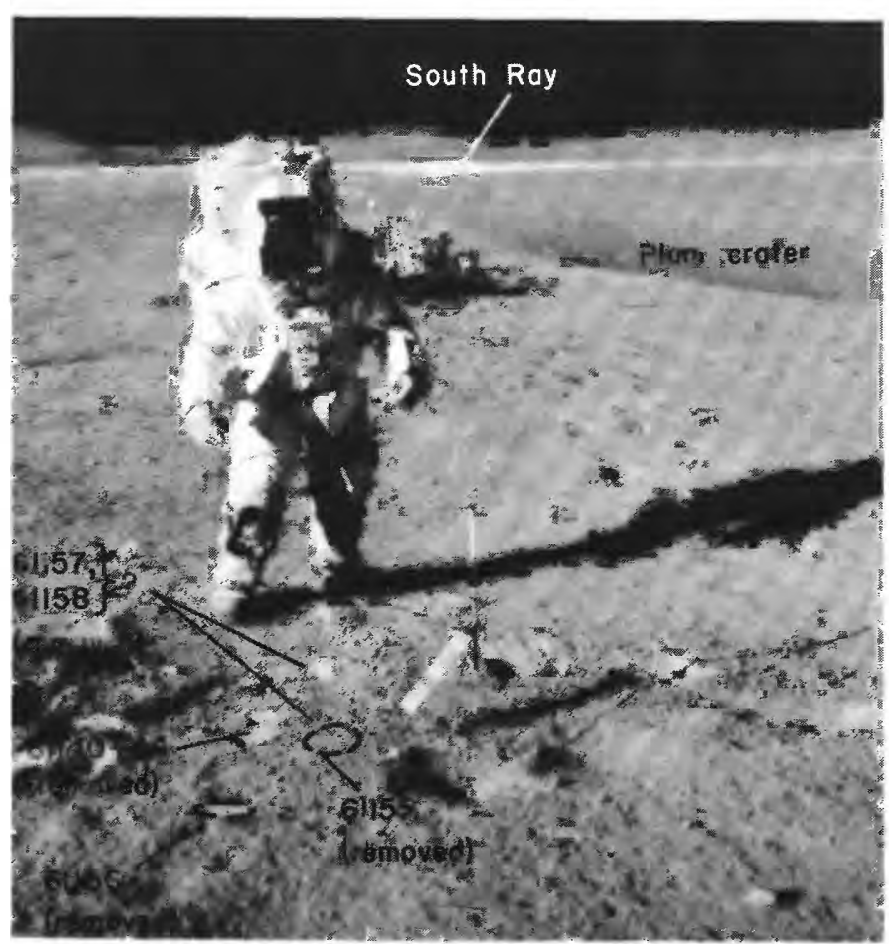

Figure 26A.-Location of soil samples $61140-44$ and rock samples 61155-58 in relation to LRV and Plum crater at station 1, shown after sampling. Photograph AS16-109-17797; view is southwest.

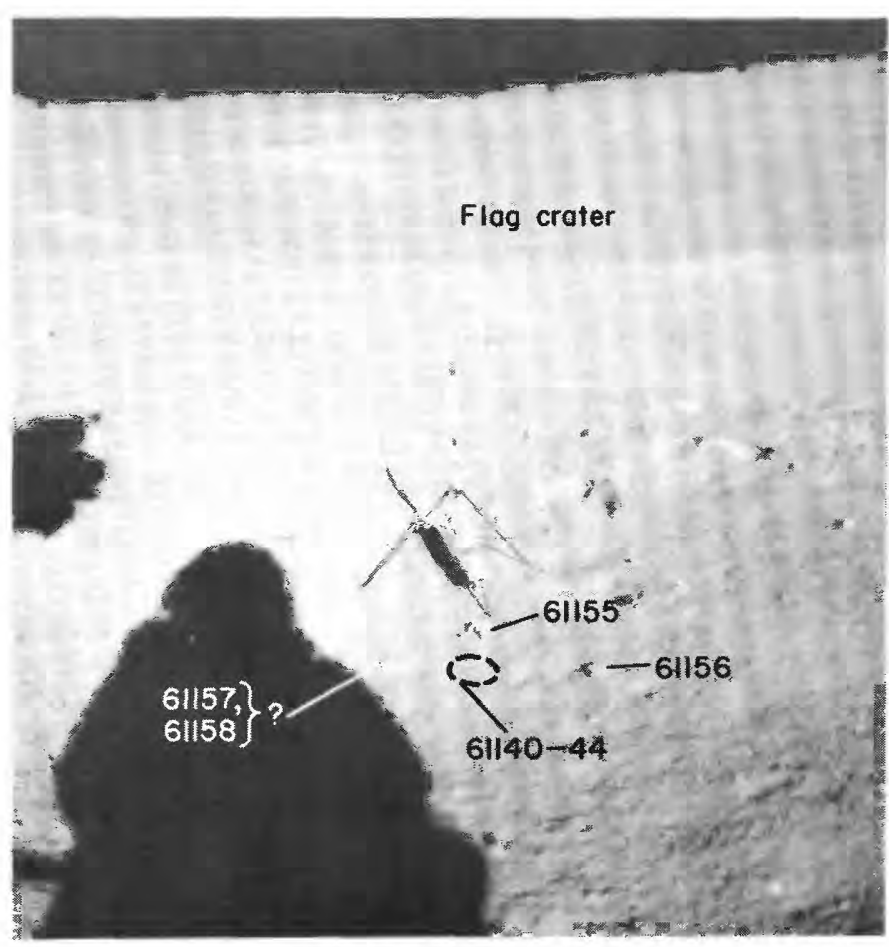

Figure 26B.-Samples 61140-44 and 61155-58 shown before sampling in photograph AS16-109-17796; view is west toward Flag crater. 


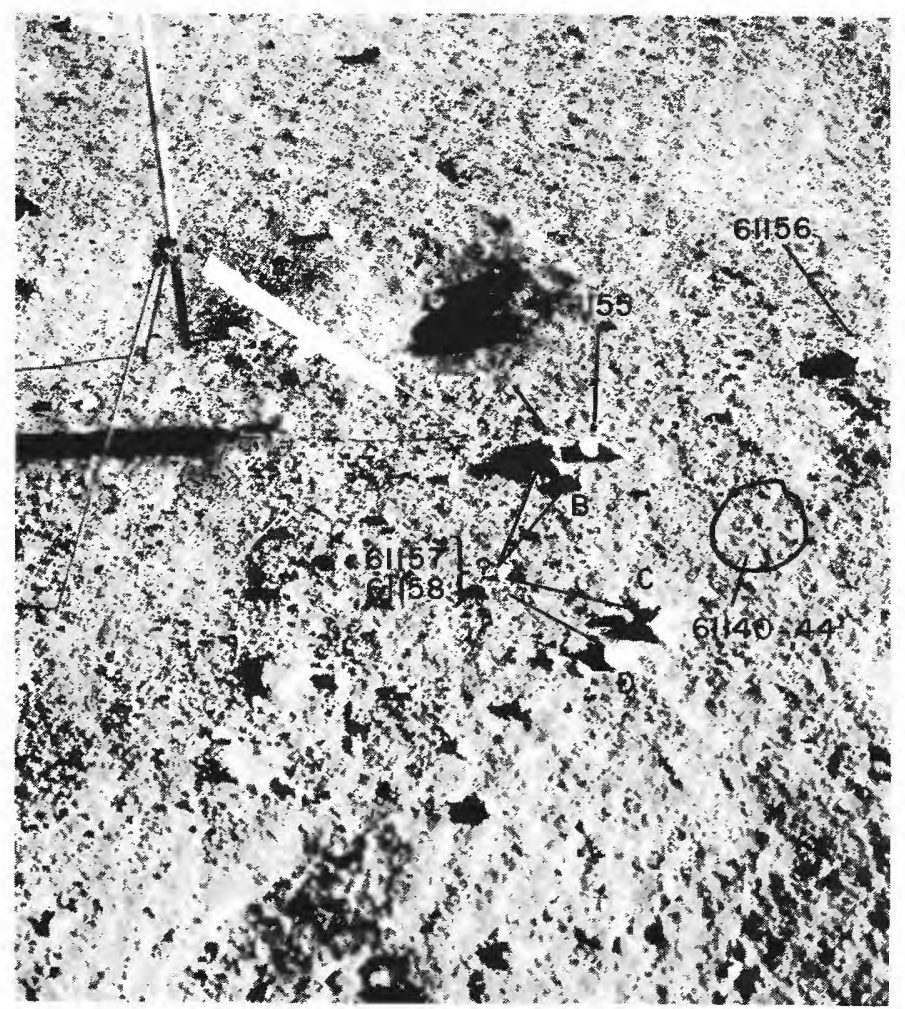

Figure 26C.--Samples 61140-44 and 61155-58 shown before sampling in photograph AS16-114-18396; view is north. Samples 61157 and 61158 (both glassy) have not been identified in the photograph; absence of the four queried and lettered fragments from the postsampling photograph (fig. $26 D$ ) suggests that one of them probably accounts for the two samples because of breakage. Fragment B is the most likely candidate because A appears to have been moved, and fragments $\mathrm{C}$ and $\mathrm{D}$ look like nonglassy breccias (see fig. 26E).

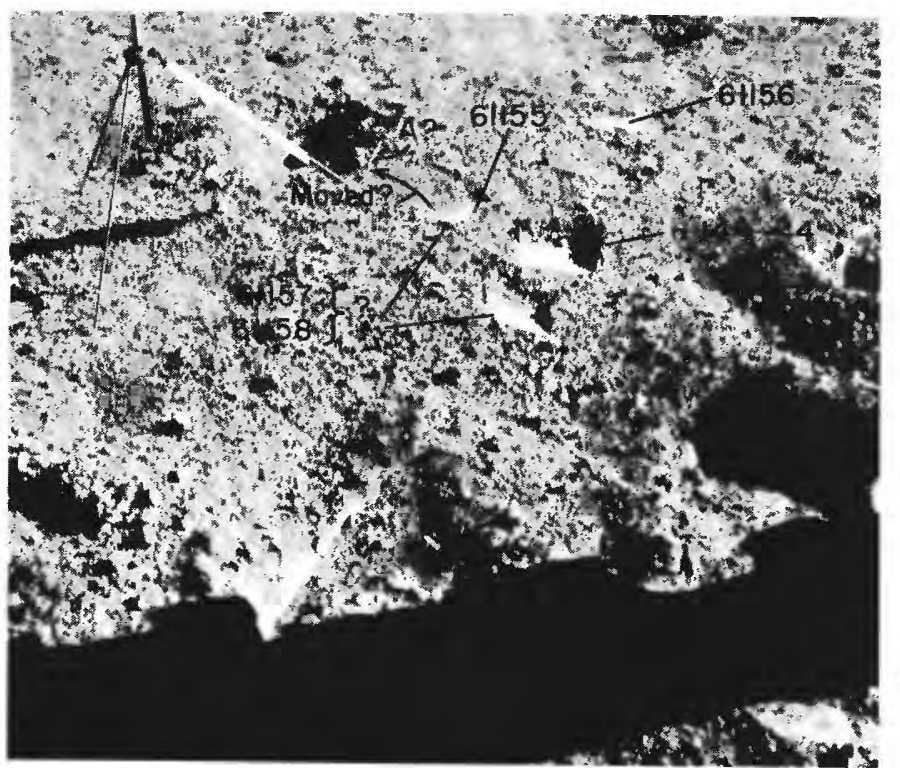

Figure 26D.-Area of samples 61140-44 and 61155-58 shown after sampling in an enlarged part of photograph AS16-114-18398; view is north. 


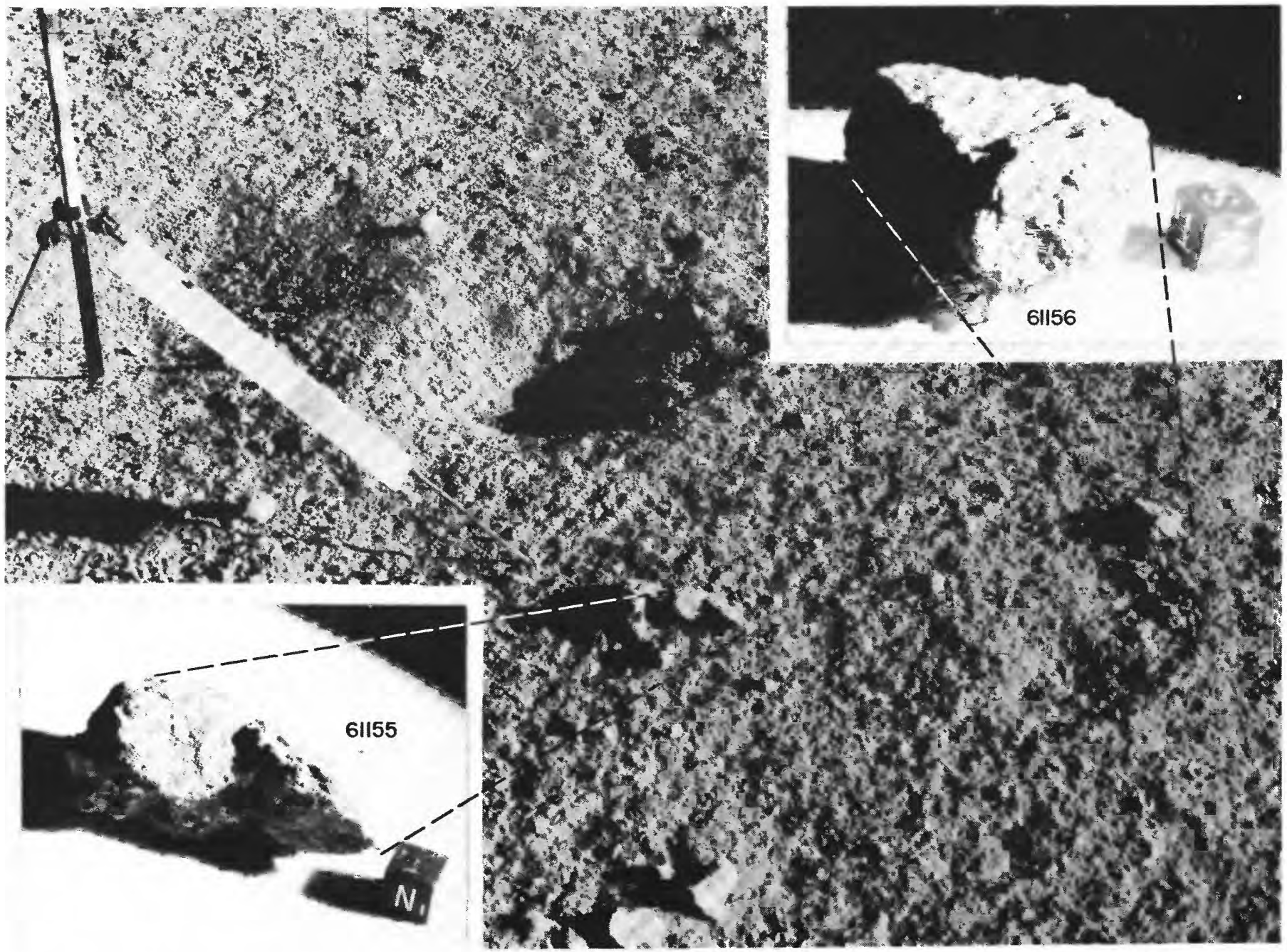

FIGURE 26E.-Samples 61155 and 61156 showing approximate lunar orientations reconstructed in LRL compared to an enlarged part of photograph AS16-114-18397 taken before sampling. View is north (inset photographs, S-72-41613 and 41544, respectively). 


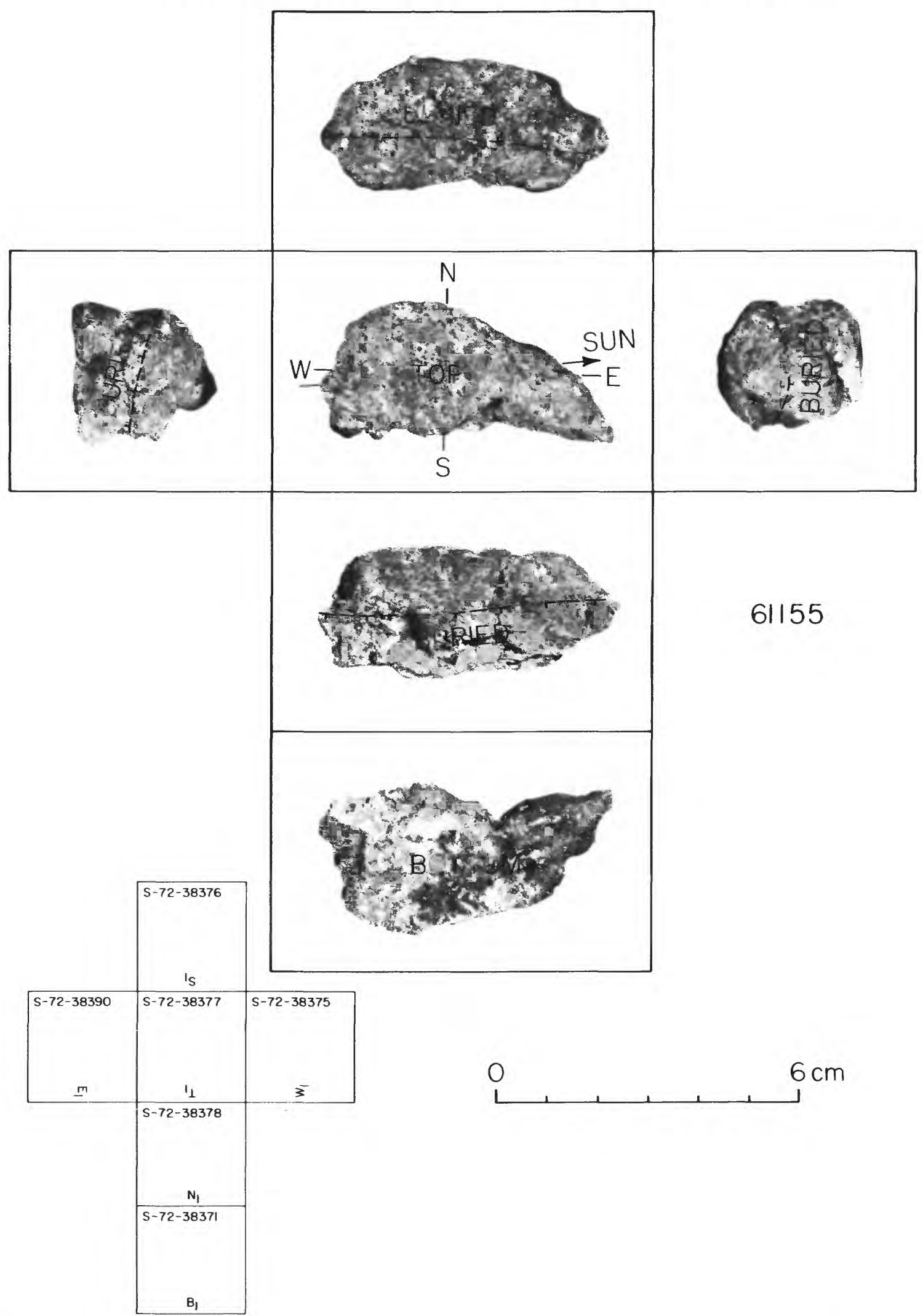

Figure $26 F$. - Orthogonal views of sample 61155 related to its lunar orientation at time of sampling. Classif $\mathrm{B}_{2}\left(\mathrm{~B}_{4}\right)$ breccia. 


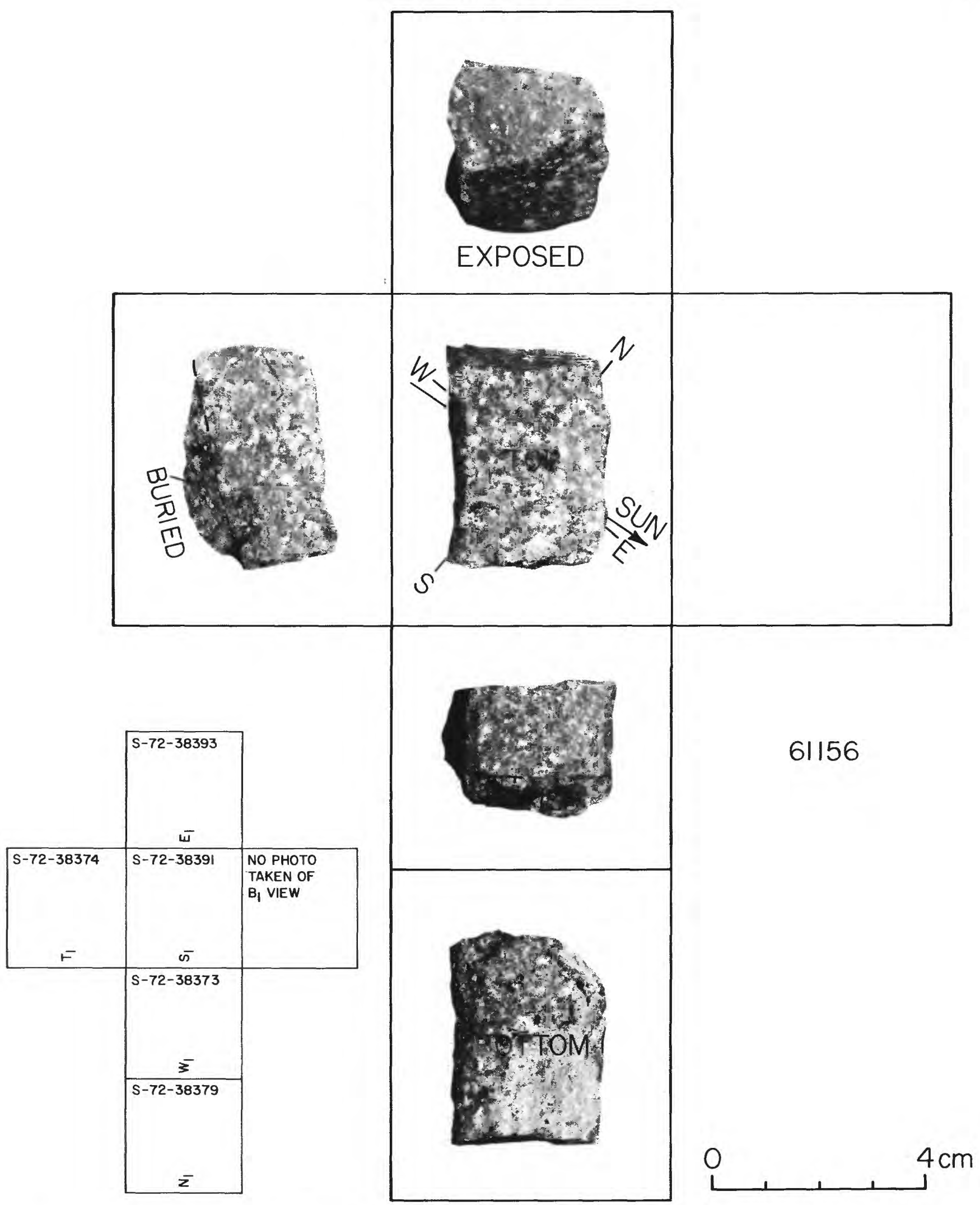

Figure 26G.-Orthogonal views of sample 61156 related to its lunar orientation at time of sampling. Metaclastic $\left(\mathrm{C}_{2}\right)$ rock. 
SAMPLE: $61140-44 ; 61155-58$

Station: 1

Landmark: Approximately $35 \mathrm{~m}$ northeast of Plum crater. Rock type: 61140-44 is soil; 61155 is breccia B2(B4); 61156 is metaclastic $C 2$; and 61157-58 are glassy fragments $G$.

SURFACE CHARACTERISTICS OF SAMPLE AREA

Slopes: Leve1

Fragment population

Size range and distribution: Less than $1 \mathrm{~cm}$ abundant; 1 to 6 cm common; larger fragments absent in sample area. Color: Light gray.

Shapes: Angular to rounded.

Fillets: Absent to poorly developed.

Apparent burial: Most fragments perched; a few slightly buried except for some that look like indurated regolith, which may be up to $1 / 2$ buried.

Fines Dust cover: Crew reported everything covered (see Table 3, p. 7).

Color: Medium gray.

Compaction: Moderate.

Craters

Size range and distribution: Up to $5 \mathrm{~cm}$ abundant; up to $50 \mathrm{~m}$ common; larger are sparse.

Shape: Subdued, except for 15-cm crater just north of photometric chart, which is sharp with moderately raised rim. Ejecta: Not visible.

SAMPLE CHARACTERISTTCS FOR 61140-44 (SOI1)

Size: < I cm fines; 229.35 grams total weight.

Color: Medium gray.

Comparison with other soil in area: Appears typical of other soil

in area.

Probable origin: Includes material ejected from North Ray, South Ray, Flag, and Plum craters.

COMMENTS: About one crater diameter away from Plum crater; third farthest out in 4-part radial sample of Plum crater.

SAMPLE CHARACTERISTICS FOR 61155

Size: $6 \times 3 \times 2.5 \mathrm{~cm} ; 47.59$ grams.

Color: Medium light gray.

Shape: Angular, elongate.

Fillet: None

Apparent burial: Perched.

Dust cover: Crew reported dust cover; not visible in photos.

Comparison with other fragments in area: Typical of the more angular

fragments in area; one fragment in cluster by gnomon leg is rounded, but was not collected.

Probable origin: Angularity, and lack of fillets and burial, suggests that fragments have been in this position for a short period of time. 
SAMPLE CHARACTERISTICS FOR 61156

Size: $4 \times 2.7 \times 2.5 \mathrm{~cm} ; 58.46$ grams.

Color: Medium gray.

Shape: Angular, blocky.

Fillet: None.

Apparent burial: Perched.

Dust cover: Crew reported dust cover; not visible in photos.

Comparison with other fragments in area: Appears typical.

Probable origin: (Same as for sample 61155)

SAMPLE CHARACTERISTICS FOR 61157 and 61158 (Combined)

Size: < $4 \mathrm{~cm} ; 26.05$ grams total weight.

Other characteristics probably typical of glassy fragments.

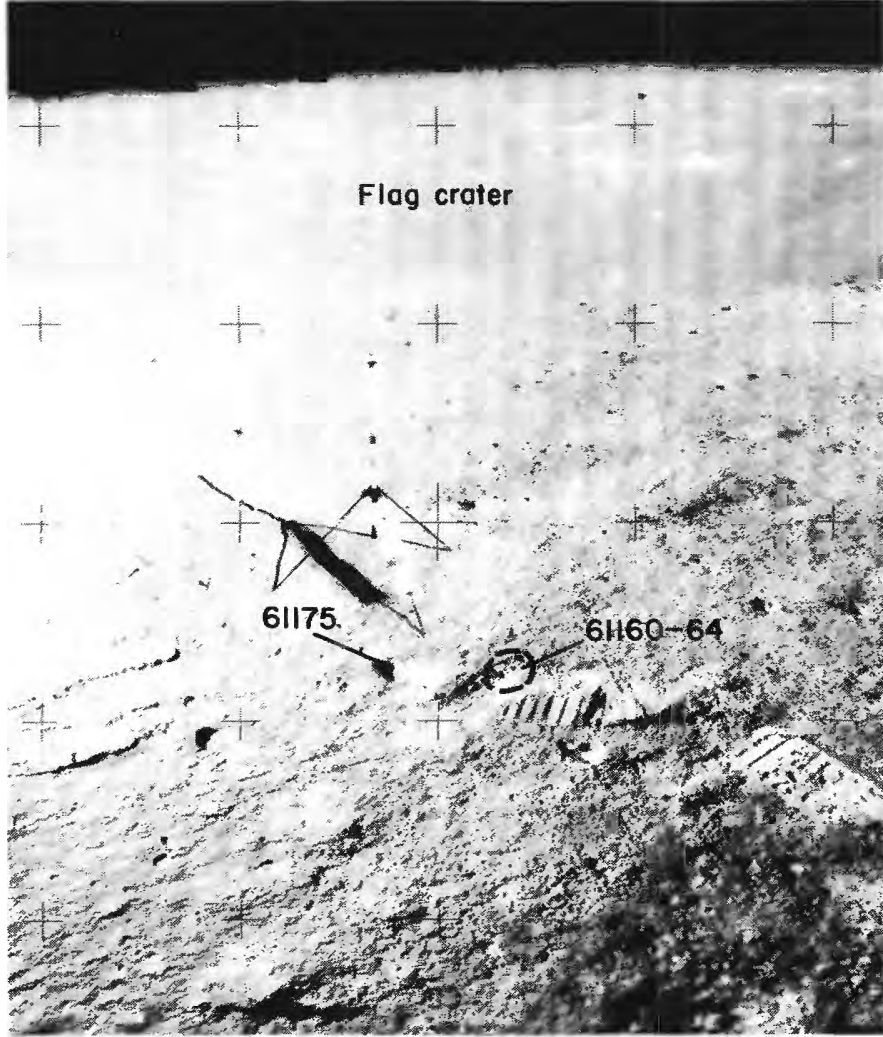

Figure 27A.-Samples 61160-64 and 61175 shown before sampling in photograph AS16-109-17798; view is west-northwest.

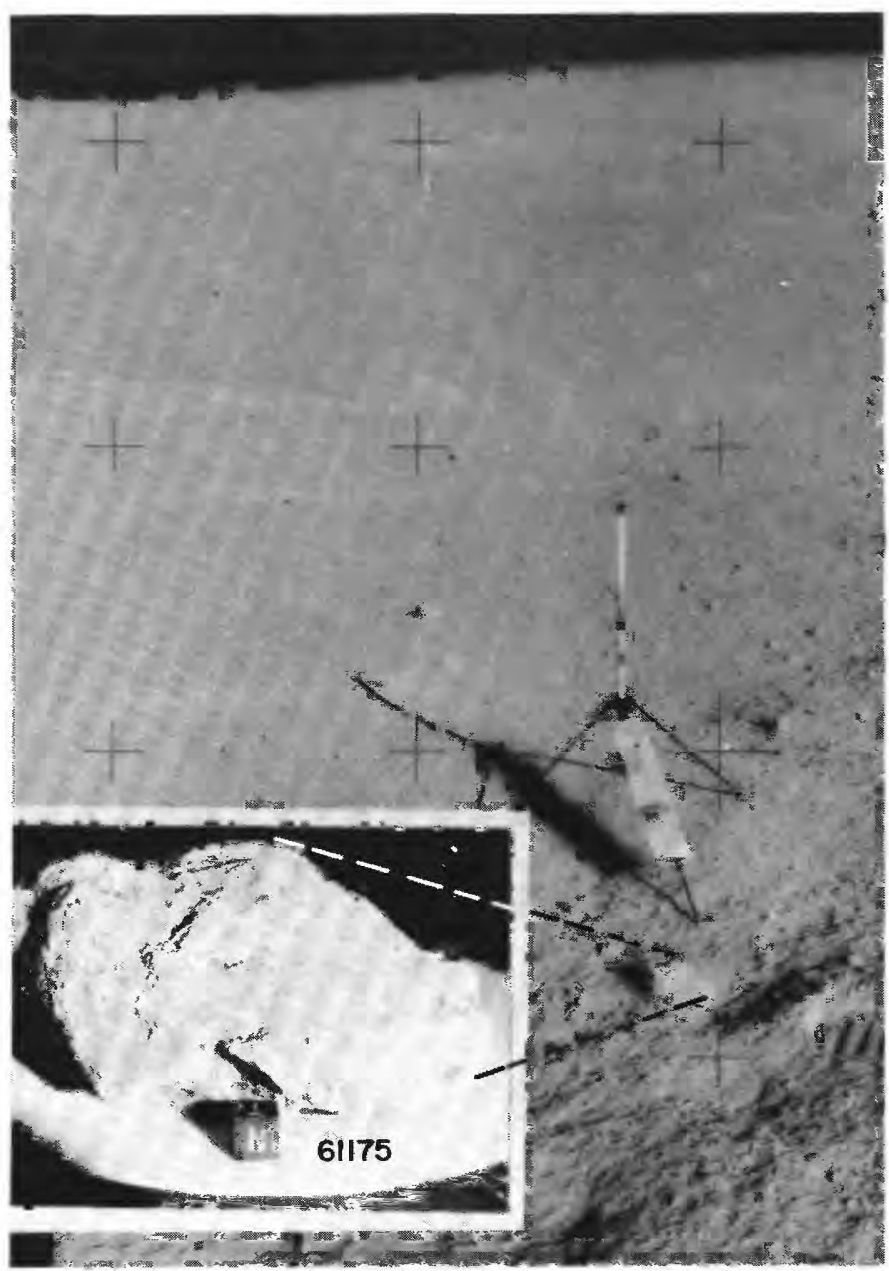

Figure 27B.-Sample 61175 showing approximate lunar orientation reconstructed in LRL compared to an enlarged part of photograph AS16-109-17798 taken before sampling: View is westnorthwest (inset photograph S-72-40966). 


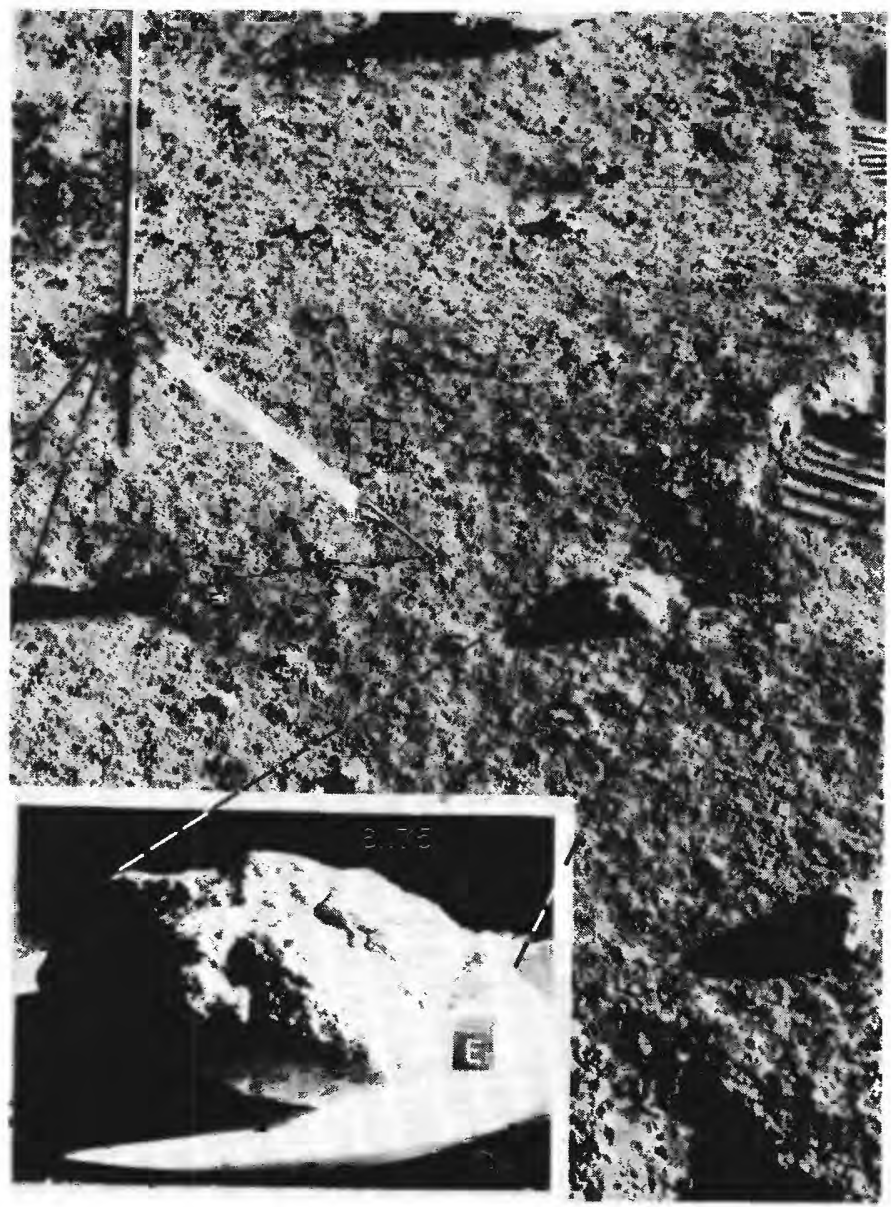

FIGURE 27C.-Sample 61175 showing approximate lunar orientation reconstructed in LRL compared to an enlarged part of photograph AS16-114-18400 taken before sampling. View is north (inset photograph S-72-40965). 


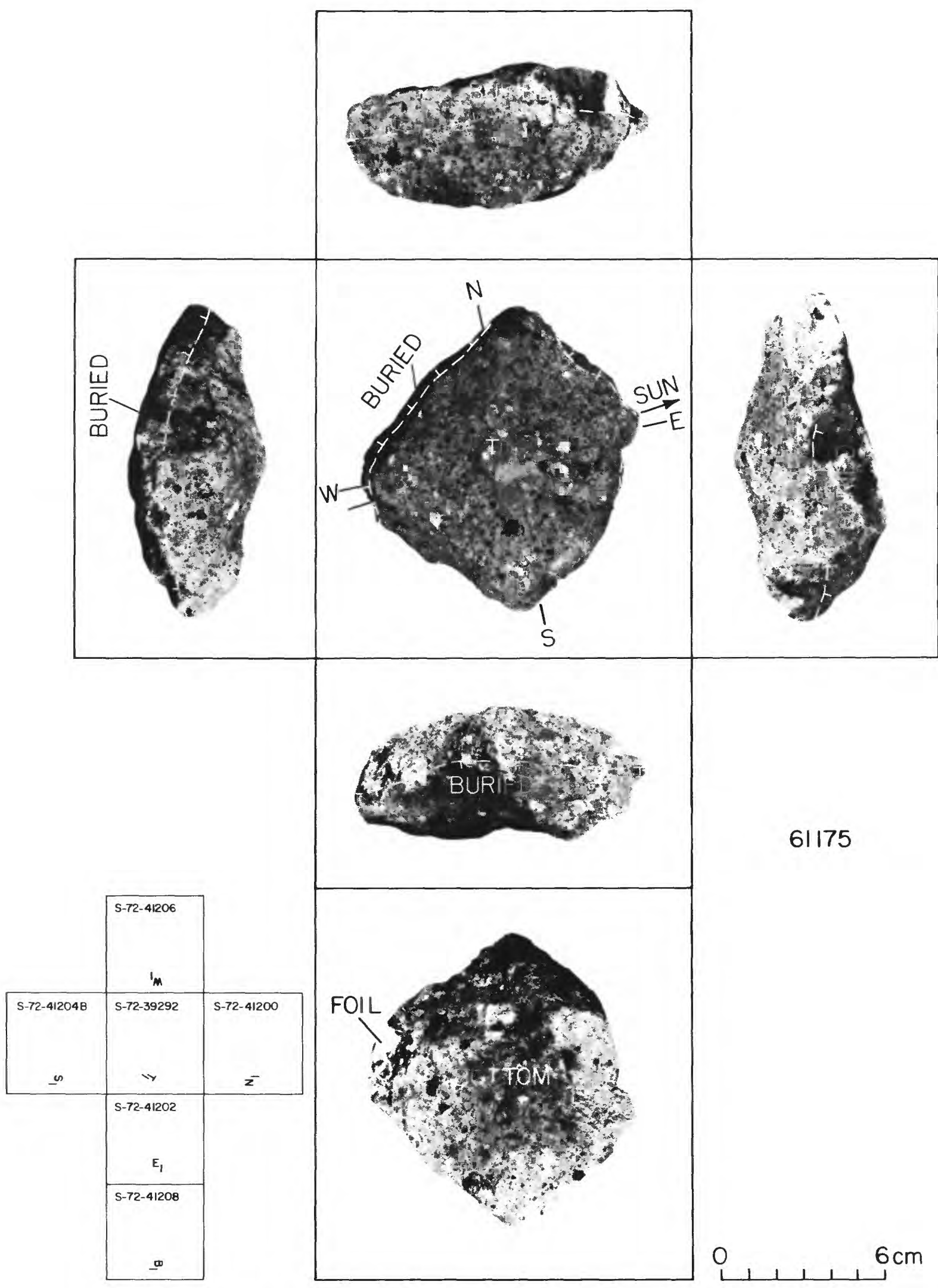

FIGURE 27D.-Orthogonal views of sample 61175 related to its lunar orientation at time of sampling, as shown in figure $27 C$. See chapter D1, figure $17 A$, for a stereopair. Type $B_{3}$ breccia. 


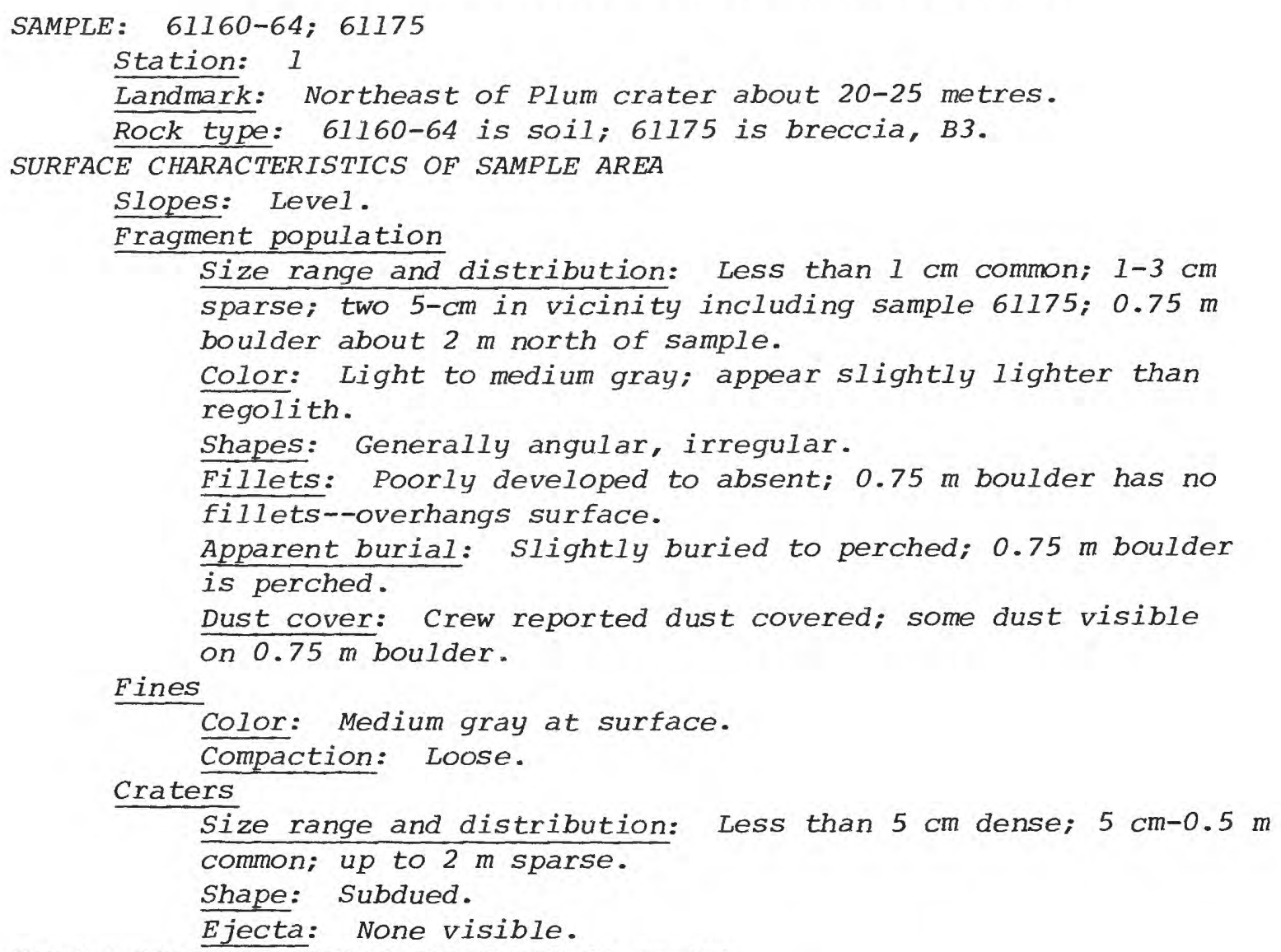




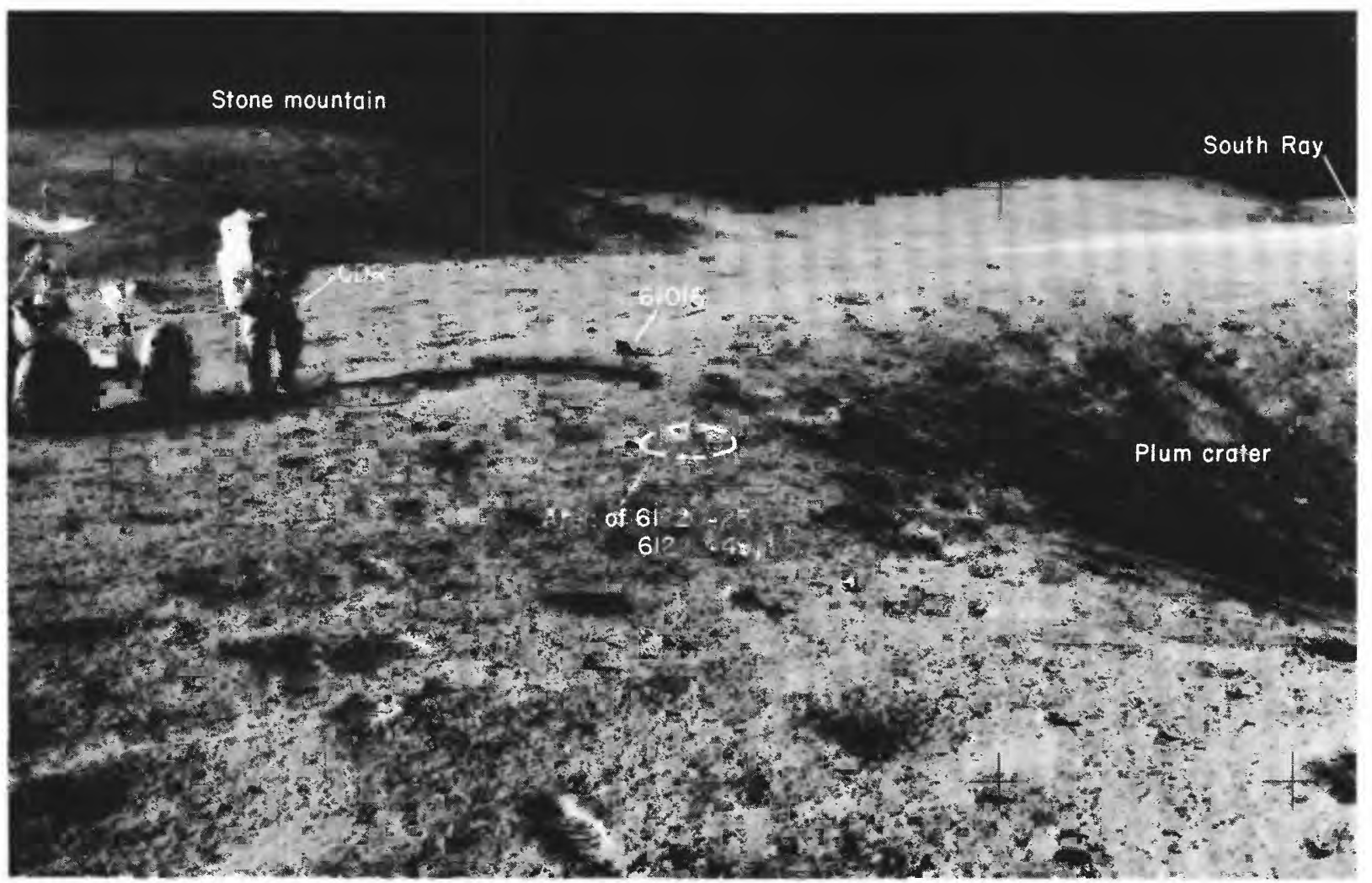

Figure 28A.-Area of trench samples 61220-26 (bottom) and 61240-49, 61255 (top) shown before sampling in photograph AS16-109-17789. View is south on rim of Plum crater. This photograph provides another view of sample 61016 ("Big Muley").
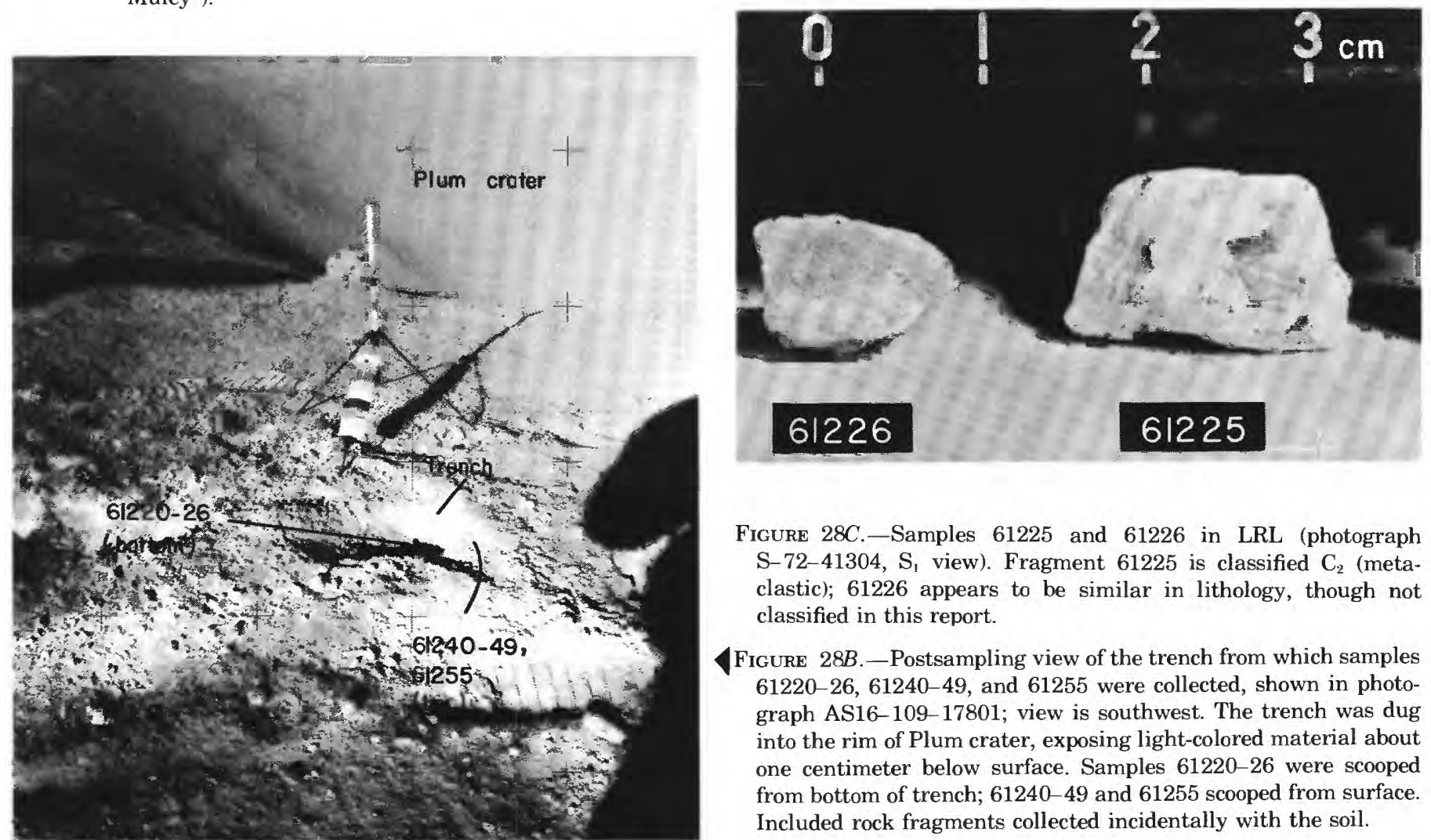

FIGURE 28C.-Samples 61225 and 61226 in LRL (photograph $\mathrm{S}-72-41304, \mathrm{~S}_{1}$ view). Fragment 61225 is classified $\mathrm{C}_{2}$ (metaclastic); 61226 appears to be similar in lithology, though not classified in this report.

Figure 28B.-Postsampling view of the trench from which samples $61220-26,61240-49$, and 61255 were collected, shown in photograph AS16-109-17801; view is southwest. The trench was dug into the rim of Plum crater, exposing light-colored material about one centimeter below surface. Samples $61220-26$ were scooped from bottom of trench; $61240-49$ and 61255 scooped from surface. Included rock fragments collected incidentally with the soil. 
SAMPLE: $61220-24,25-26 ; 61240-44,45-49,55$

Station: 1

Landmark: East rim of Plum crater.

Rock type: 61220-26 is scoop sample from bottom of trench including soil and two fragments > $1 \mathrm{~cm}(61225-26) ; 61240-49$ is scoop sample from top of trench including soil and 5 fragments $>1$ cm (61245-49). SURFACE CHARACTERISTICS OF SAMPLE AREA

Slopes: At break in slope into Plum crater.

Fragment population

Size range and distribution: Fragments larger than $10 \mathrm{~cm}$ sparse in general area; vicinity of sample 0.5-2 chil common, larger are absent.

Color: Medium gray.

Shapes: Generally angular; some rounded.

Fillets: Poorly developed.

Apparent burial: Generally perched.

Fines Dust cover: Not visible.

Color: Medium gray at surface, light gray just below surface. Compaction: Loose.

Craters

Size range and distribution: Greater than $1 \mathrm{~m}$ sparse; up to

$1 \mathrm{~m}$ common; less than $10 \mathrm{~cm}$ dense.

Shape: Generally subdued.

Ejecta: None recognizable.

S. MPLE CHARACTERISTICS OF SOILS 61220-24 and 61240-44

Size: < $1 \mathrm{~cm}$ fines; 61220-24 total weight 279.15 grams; 61240-44

total weight 452.21 grams.

Color: 61220-24 is light gray; 61240-44 is medium gray.

Comparison with other soil in area: Texture and albedo of soil where 61240-44 taken appears typical of area; cannot tell from present data if lighter material such as 61220-24 is continuous in subsurface. Probable origin: Ejecta from Plum crater; likely originally North Ray ejecta that has darkened at surface; probably small amount of South Ray ejecta at surface but not enough to lighten the surface appreciably.

SAMPLE CHARACTERISTICS FOR FRAGMENTS 61225-26

Size: $61225-1.7 \times 1.4 \times 1.0 \mathrm{~cm} ; 3.52$ grams (type C2)

$61226-1.2 \times 1.1 \times 6.8 \mathrm{~cm} ; 1.53$ grams

Color: 61225 -- medium dark gray. 61226 -- white.

Shape: Subangular (both)

SAMPLE CHARACTERISTICS FOR FRAGMENTS 61245-49, 55

Size: Approximately $1-3 \mathrm{~cm}$ (no photographs); 20.79 grams total weight. Fragments not described. 


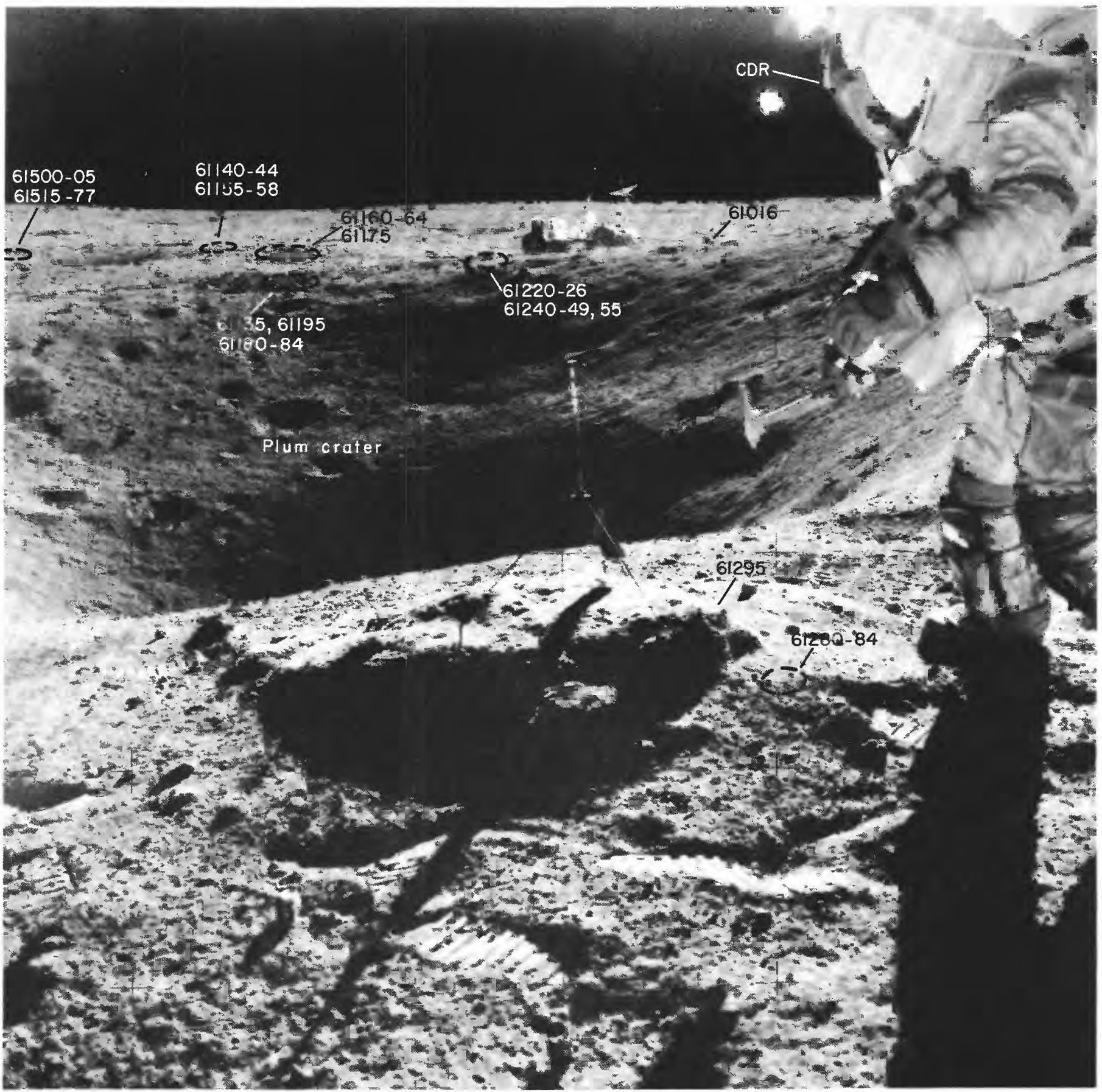

FIGURE 29A.-Location of samples $61280-84$ and 61295 on southwest rim of Plum crater, shown before sampling in photograph AS16109-17804; view is northeast. Sample 61295, a type $B_{3}$ breccia, broken from a rounded 2-m boulder that appears to be mostly buried by fine material on crater rim. Sample 61016 identified in front of LRV on far rim of crater; areas shown where all other samples except 61015 and 61017 were collected at station 1. 


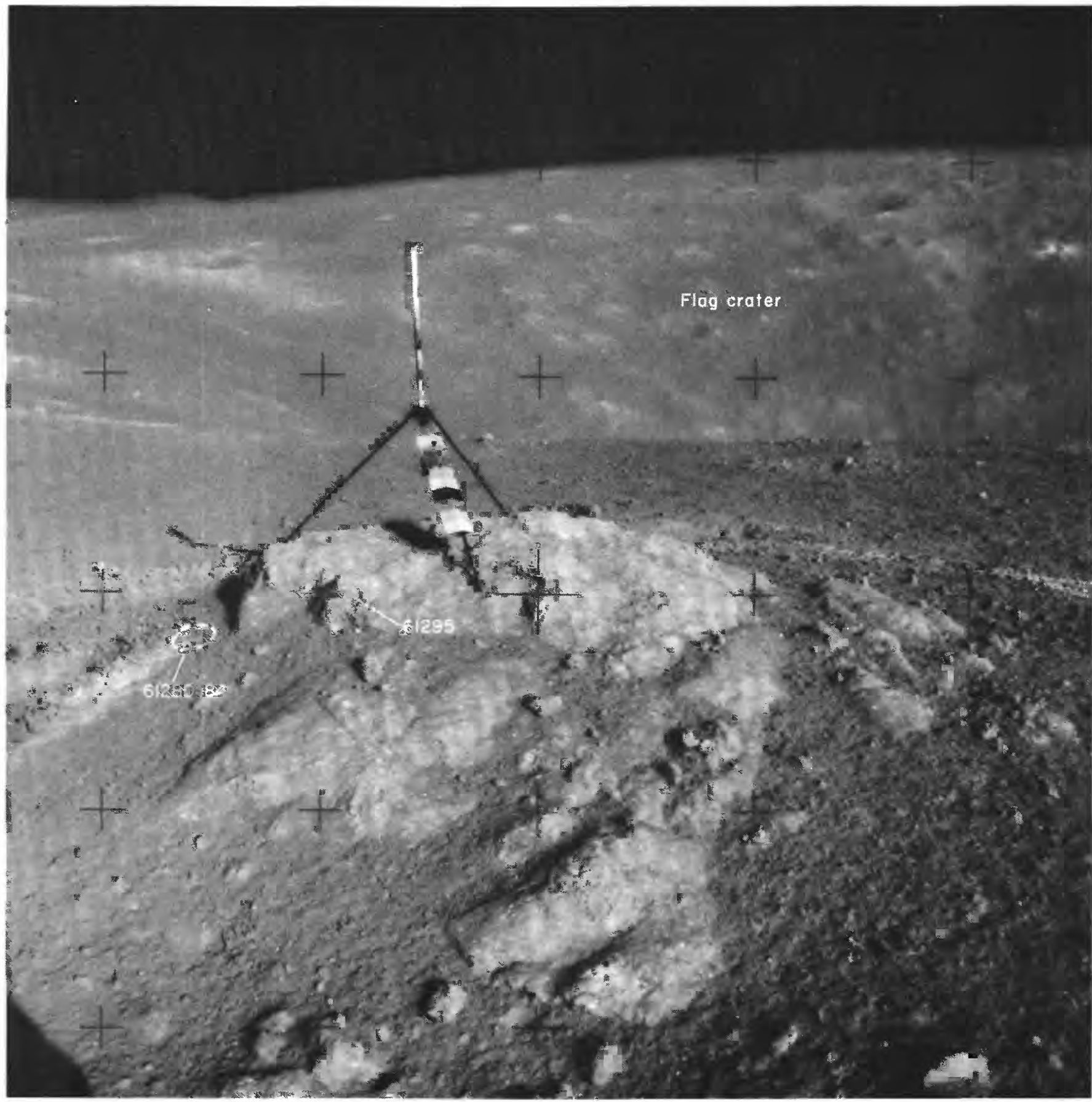

Figure 29B.- Samples 61280-84 and 61295 shown before sampling in photograph AS16-109-17802; view is west-northwest toward Flag crater. Several outcrops of rounded rock beneath gnomon are probably parts of one large buried boulder. Note light-colored soil where surface has been disturbed, left of the boulder. 


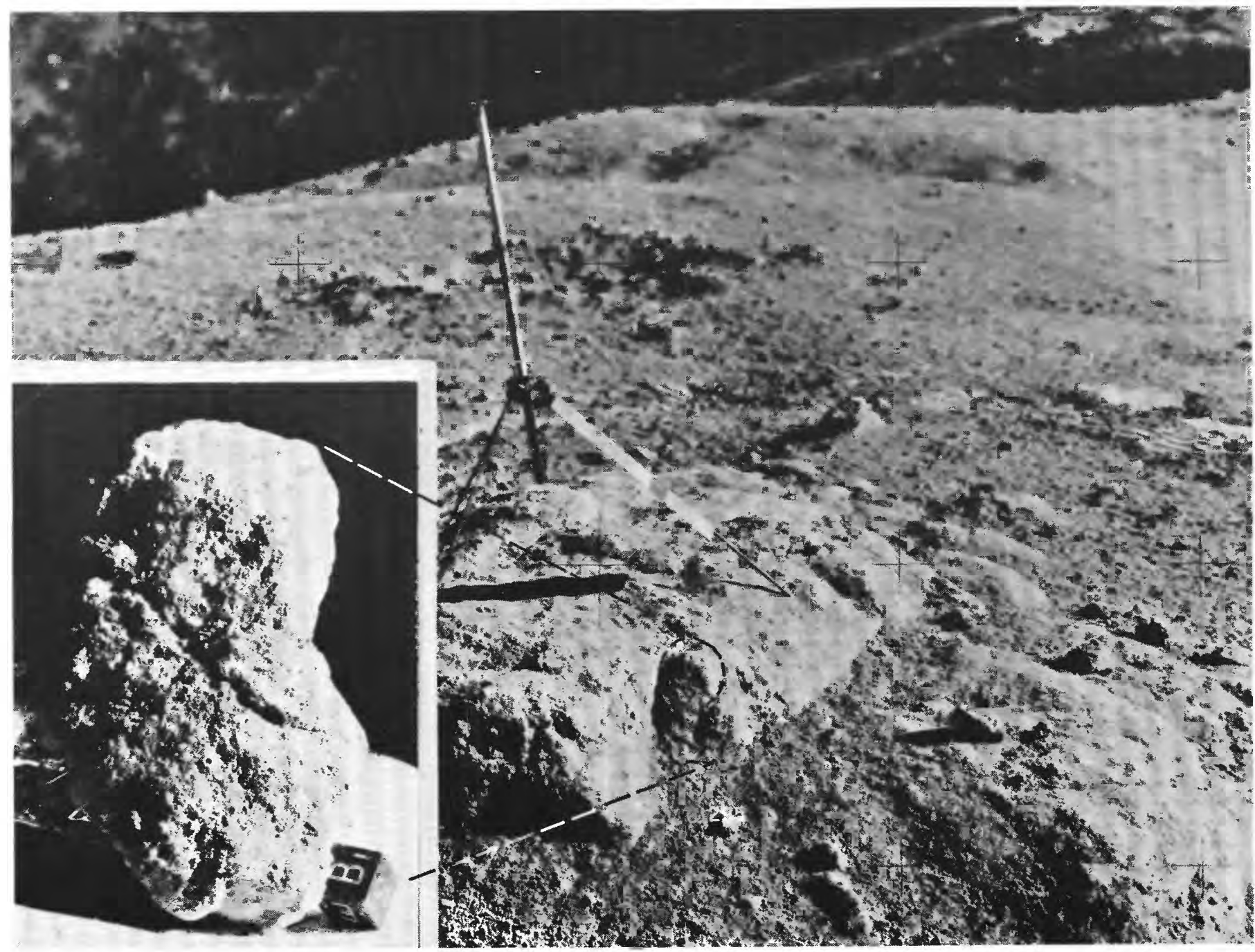

FIGURE 29C.-Sample 61295 showing approximate lunar orientation reconstructed in LRL compared to an enlarged part of photograph AS16-114-18412 taken before sampling. View is north (inset photograph, S-72-40967). 


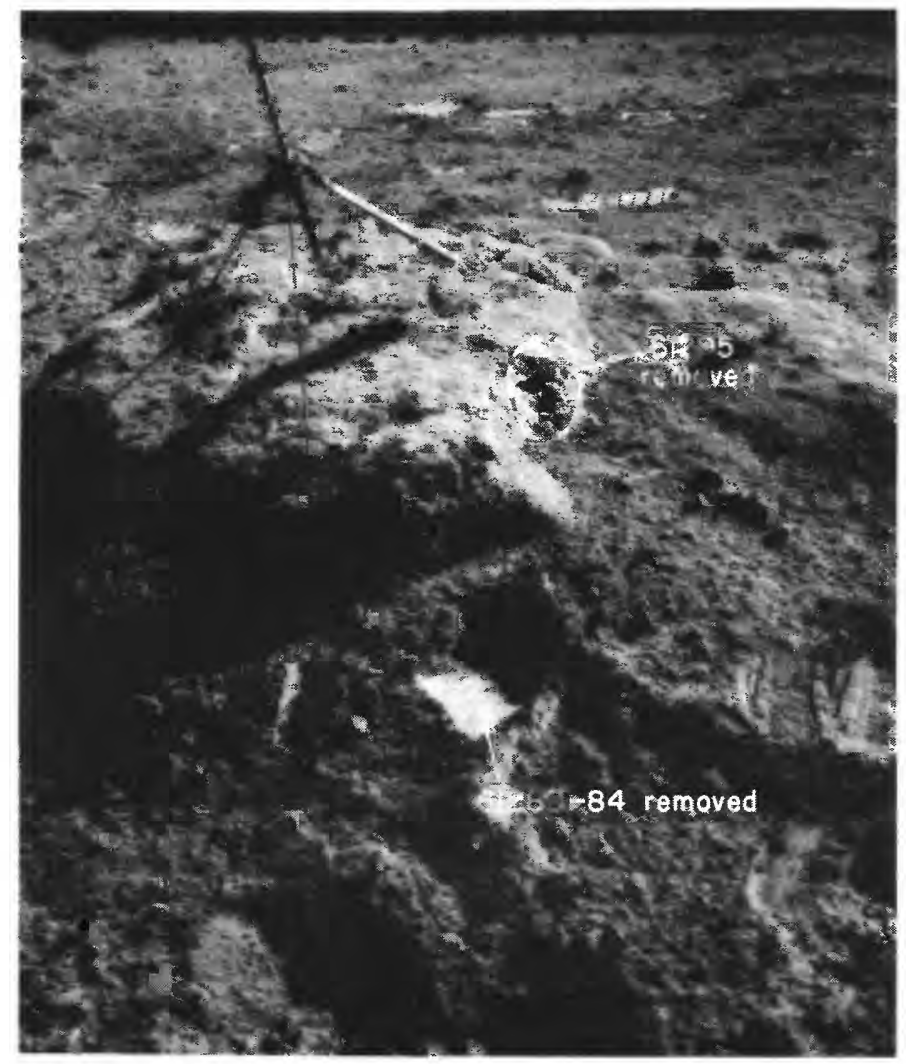

Figure 29D.-Area of samples $61280-84$ and 61295 shown after sampling in photograph AS16-109-17805; view is north. 


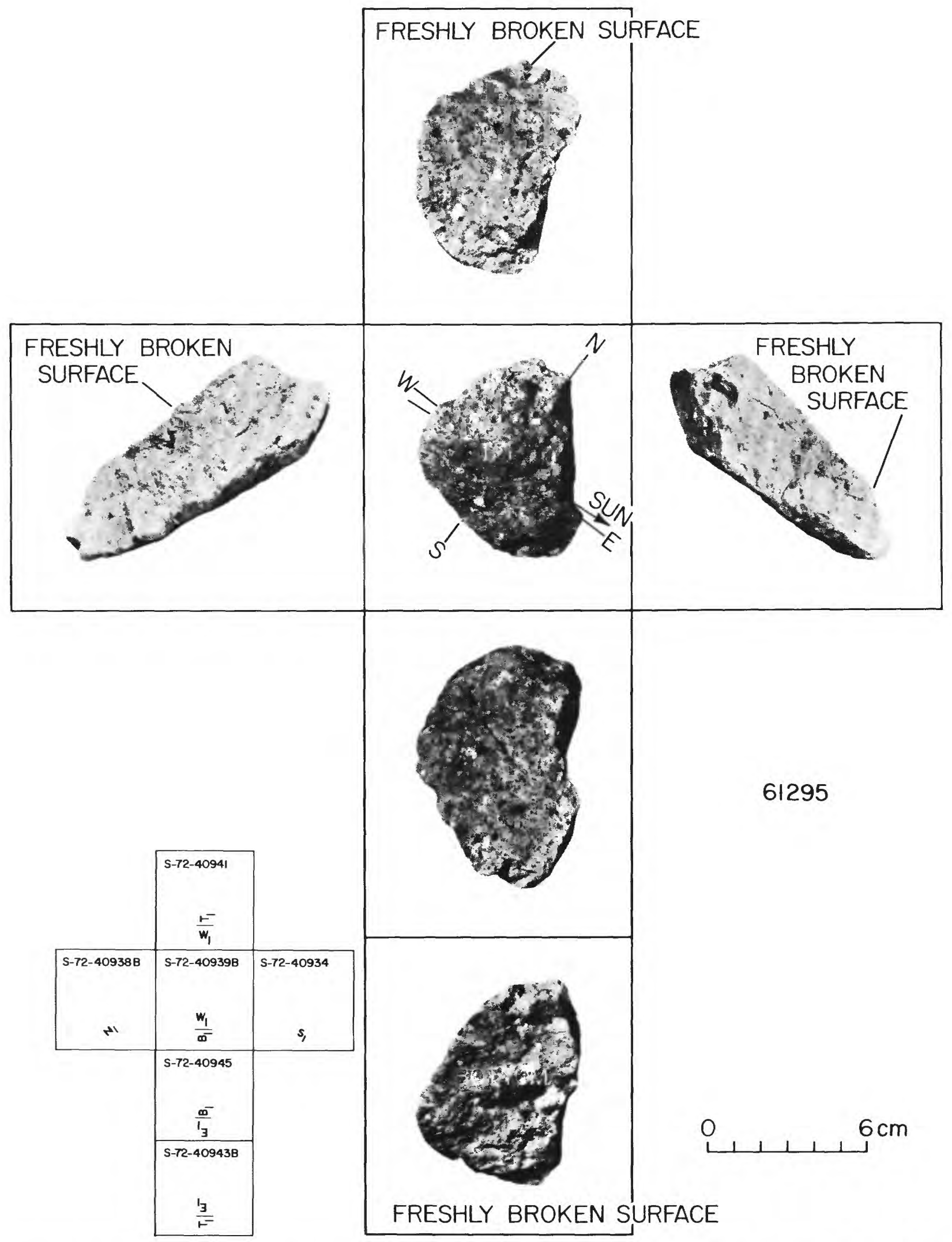

FIGURE 29E.-Orthogonal views of sample 61295 related to its lunar orientation at time of sampling. See chapter D1, figure $15 A$, for a stereopair and chapter $\mathrm{E}$, fig. $4 B$, for $a$ photomicrograph of this $\mathrm{B}_{3}$ breccia. 
SAMPLE: $61280-84 ; 61295$

Station: 1

Landmark: Southwest rim of Plum crater; southeast rim of Flag crater.

Rock type: 61295 is from breccia boulder, B3; 61280-84 is soil

sample of fillet around boulder.

SURFACE CHARACTERISTICS OF SAMPLE AREA

Slopes: At break in slope into Plum crater.

Fragment population

Size range and distribution: Sample 61295 is from 2-m (largest

in area) boulder; < I-cm fragments abundant; 1 to 5-cm fragments

common; larger are sparse.

Color: Light to medium gray.

Shapes: Generally angular; 2-m boulder rounded.

Fillets: Absent to poorly developed, except well developed, about $10 \mathrm{~cm}$ high, fillet on boulder.

Apparent burial: Generally perched, except for boulder that is

$4 / 5$ buried.

Dust cover: Not apparent, except boulder appears to be mostly

covered.

Fines

Color: Medium gray at surface; light gray in subsurface, at

least in some spots.

Craters

Compaction: Moderate to 1oose.

Size range and distribution: Sparse in immediate vicinity of

sample. Plum crater (40m) and Flag crater (400m) dominate sample area. Shape: One 2-m fresh, blocky (cloddy?) irregular and

sharp-rimmed crater $5 \mathrm{~m}$ north of boulder.

Ejecta: Some of perched angular fragments in vicinity of sample

site possibly from sharp 2-m crater. Sampled boulder probably ejected

SAMPLE CHARACTERISTICS FOR 61295

from Plum or Flag crater.

Size: $11 \times 6 \times 3 \mathrm{~cm}$; 187 grams.

Color: Medium gray.

Shape: Rounded on exposed surface.

Fillet: Well developed around boulder.

Apparent burial: None of sampled portion of boulder buried.

Dust cover: Probably moderate on upper part of sample.

Comparison with other fragments in area: Boulder more rounded

than most of the smaller fragments in area.

Probable origin: Too rounded to be from South Ray crater; from Plum or

Flag craters.

SAMPLE CHARACTERISTICS FOR 61280-84

Size: < $1 \mathrm{~cm}$ fines; 258.51 grams total weight.

Color: Medium gray.

Comparison with other soil in area: From fillet on 2-m boulder; looks

similar to other soil in area; cannot tell from photos or transcript

if it is lighter in the subsurface at the spot sampled.

Probable origin: Mixture of ejecta from North Ray, South Ray,

Flag, and Plum craters, plus material eroded from sampled boulder. 


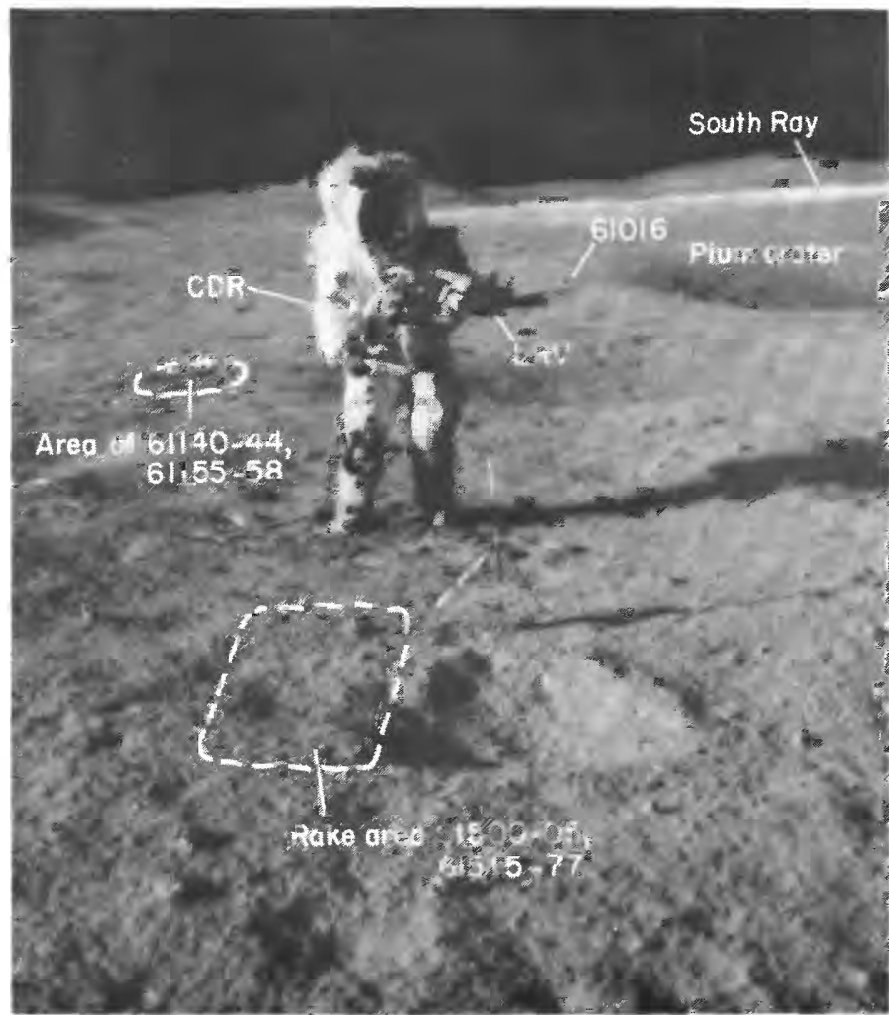

Figure 30A.--Location of rake samples $61500-05$ and $61515-77$ shown before sampling. Photograph AS16-109-17795; view is south toward the LRV and also shows the area where samples $61140-44,61155-58$, and 61016 were later collected.

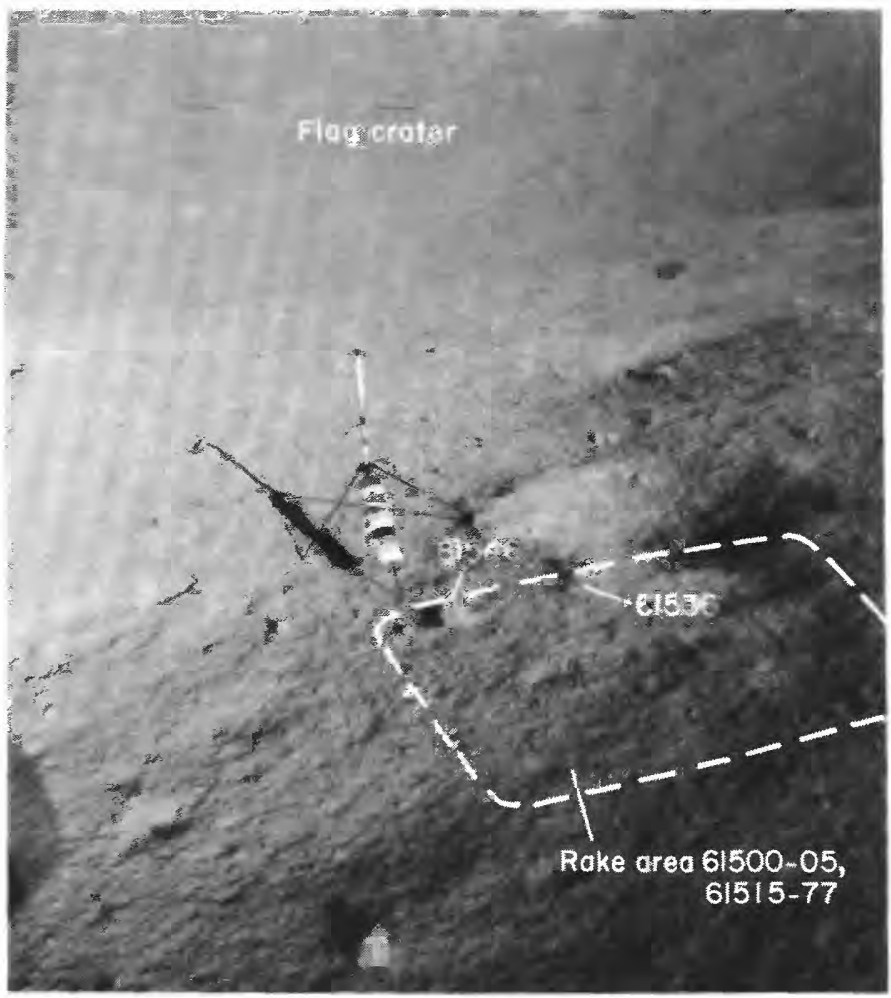

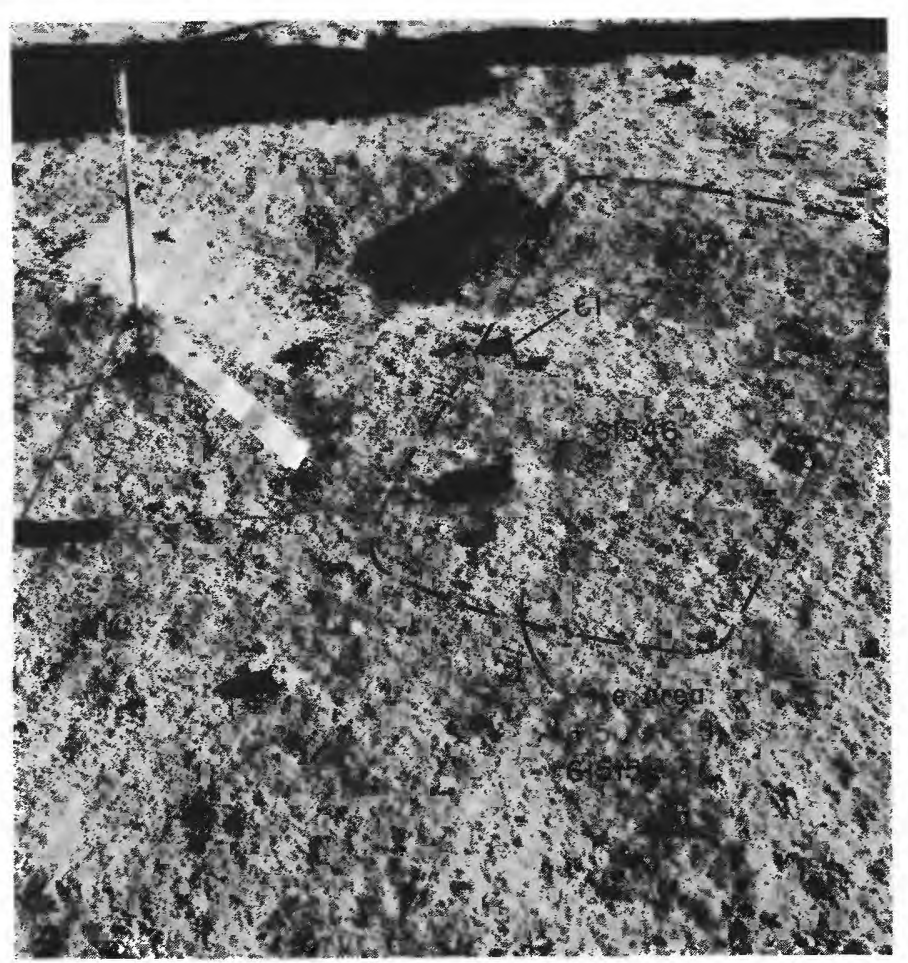

Figure 30C.-Area of rake samples 61500-05 and 61515-77 shown before sampling. Photograph AS16-114-18390; view is north.

Figure 30B.-Area of rake samples 61500-05 and 61515-77 shown before sampling in photograph AS16-109-17795; view is west toward Flag crater. Samples 61536 and 61546 are the largest rake fragments. 


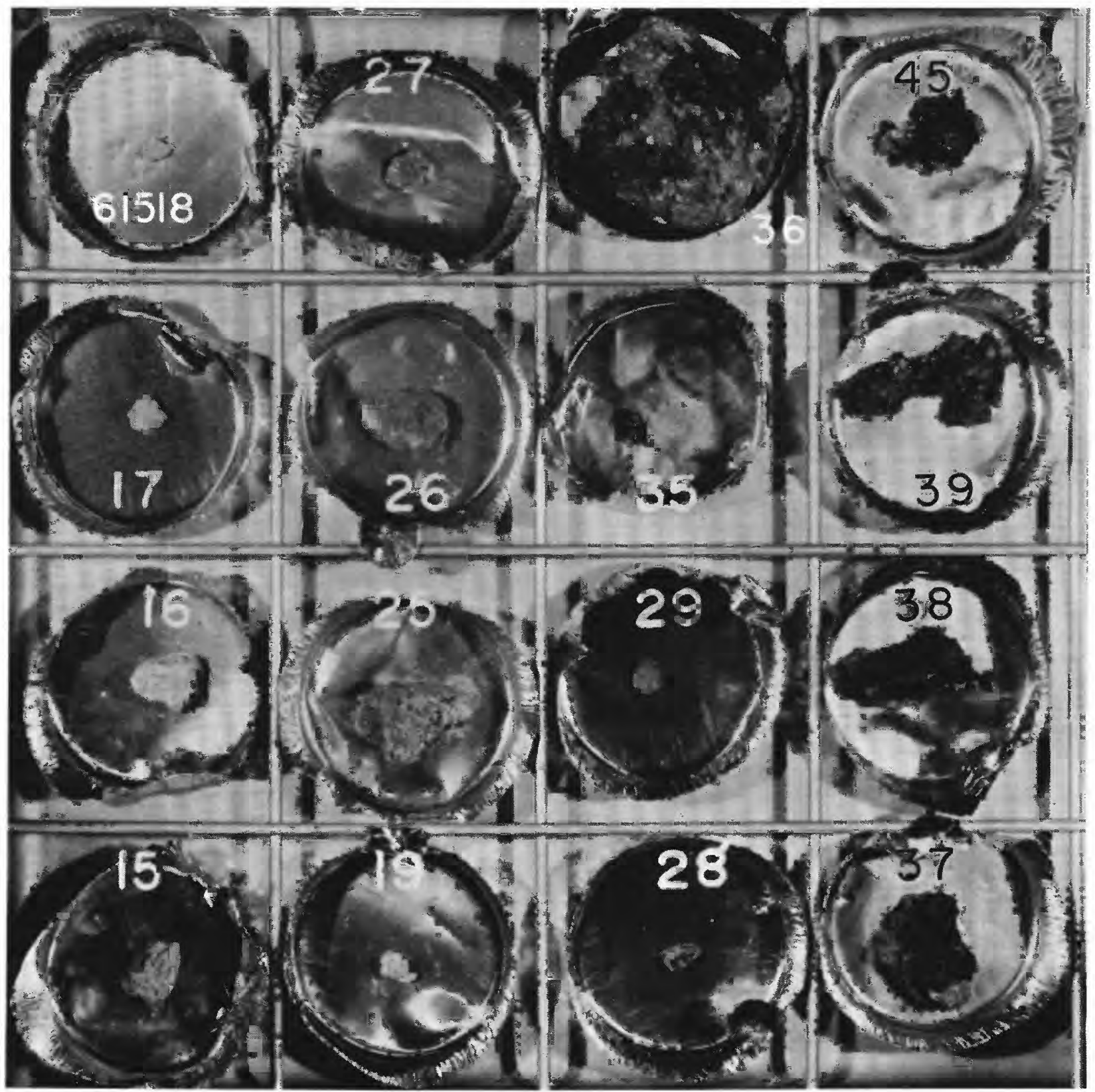

Figure 30D.-Part of rake sample 61515-77 in LRL (photograph S-72-43347). Includes samples 61515-19, 61525-29, 61535-39, and 61545. Fragments 15 and 16 classified $B_{2}$ breccia (smaller fragments 17-19 look similar in lithology); the other 7 fragments $>2 \mathrm{~g}(25-26,36-39$, and 45$)$ are type $B_{3}$, several with glass coatings.

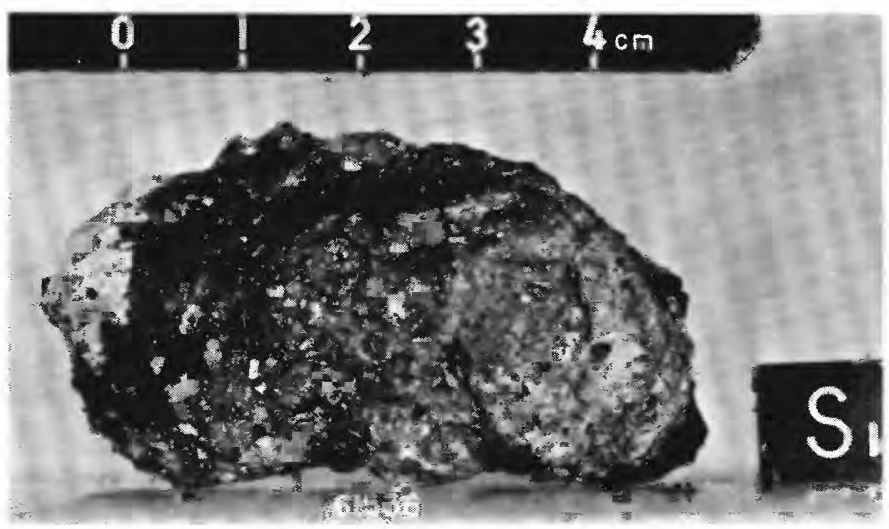



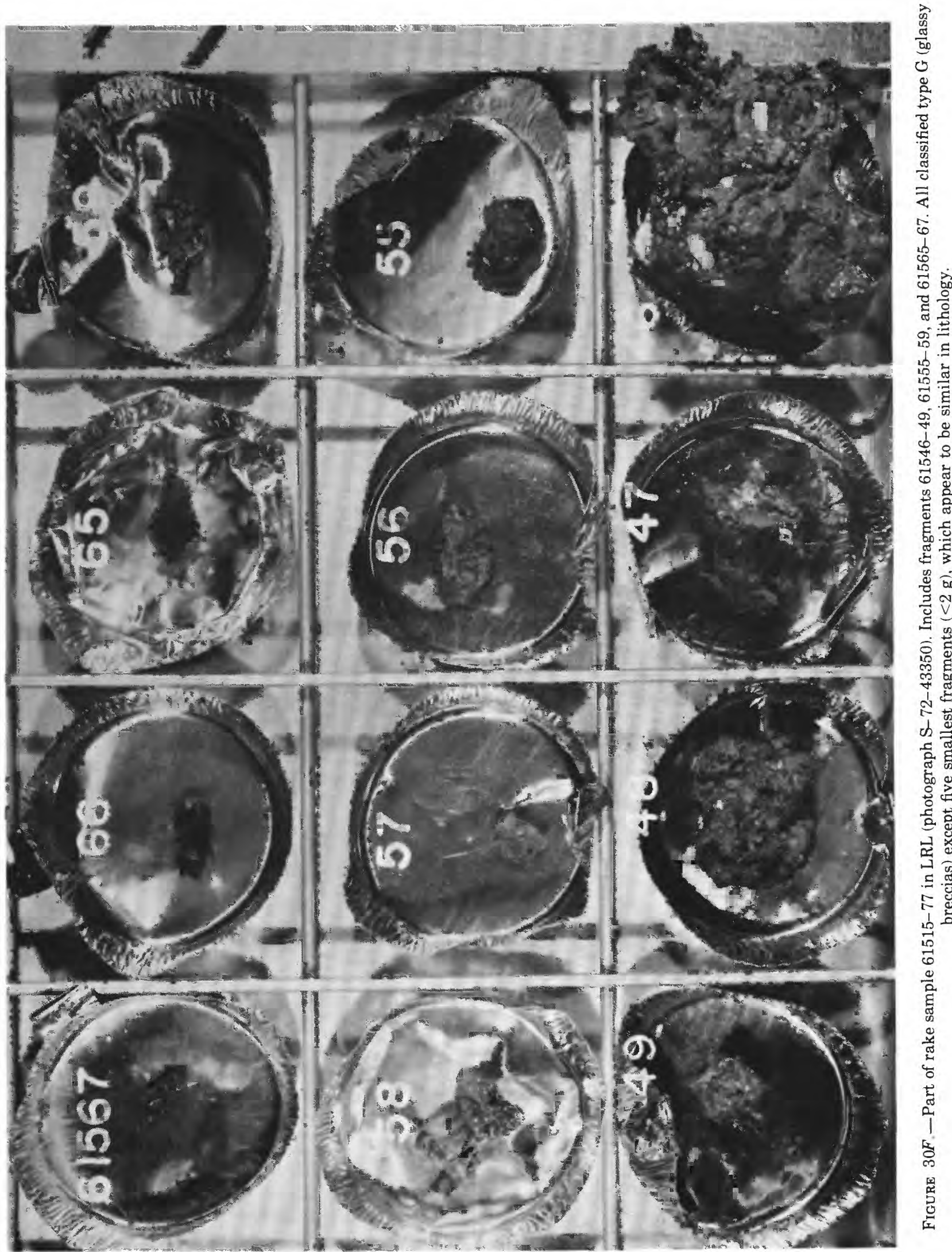


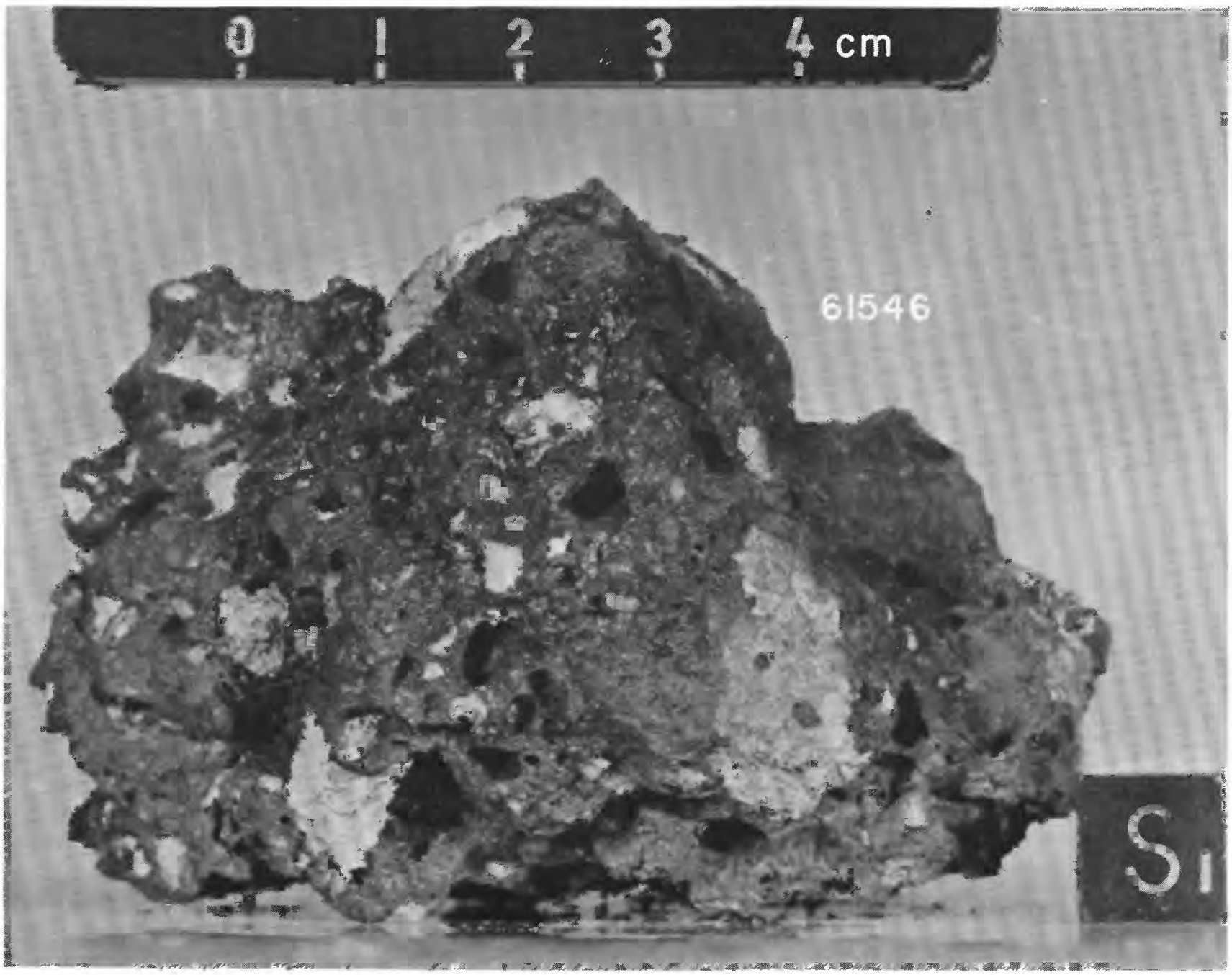

FigURE 30G.- Rake fragment 61546 in LRL (photograph S-72-43422). Glassy-matrix breccia (type G). 


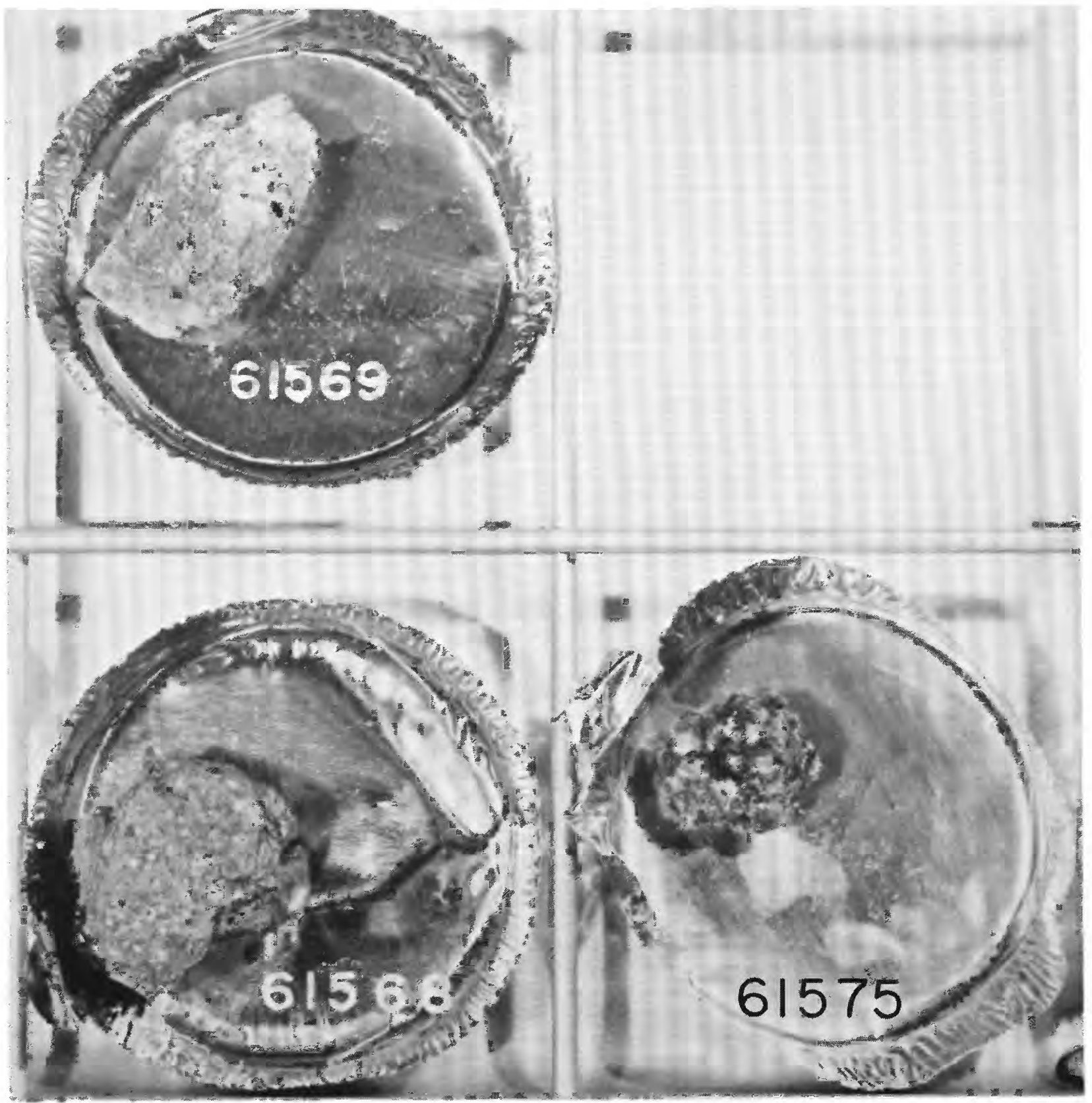

FigURE $30 H$.-Fragments 61568,61569 , and 61575 in the LRL (photograph S-72-43355). All are classified type $\mathrm{B}_{4}$ breccia. 

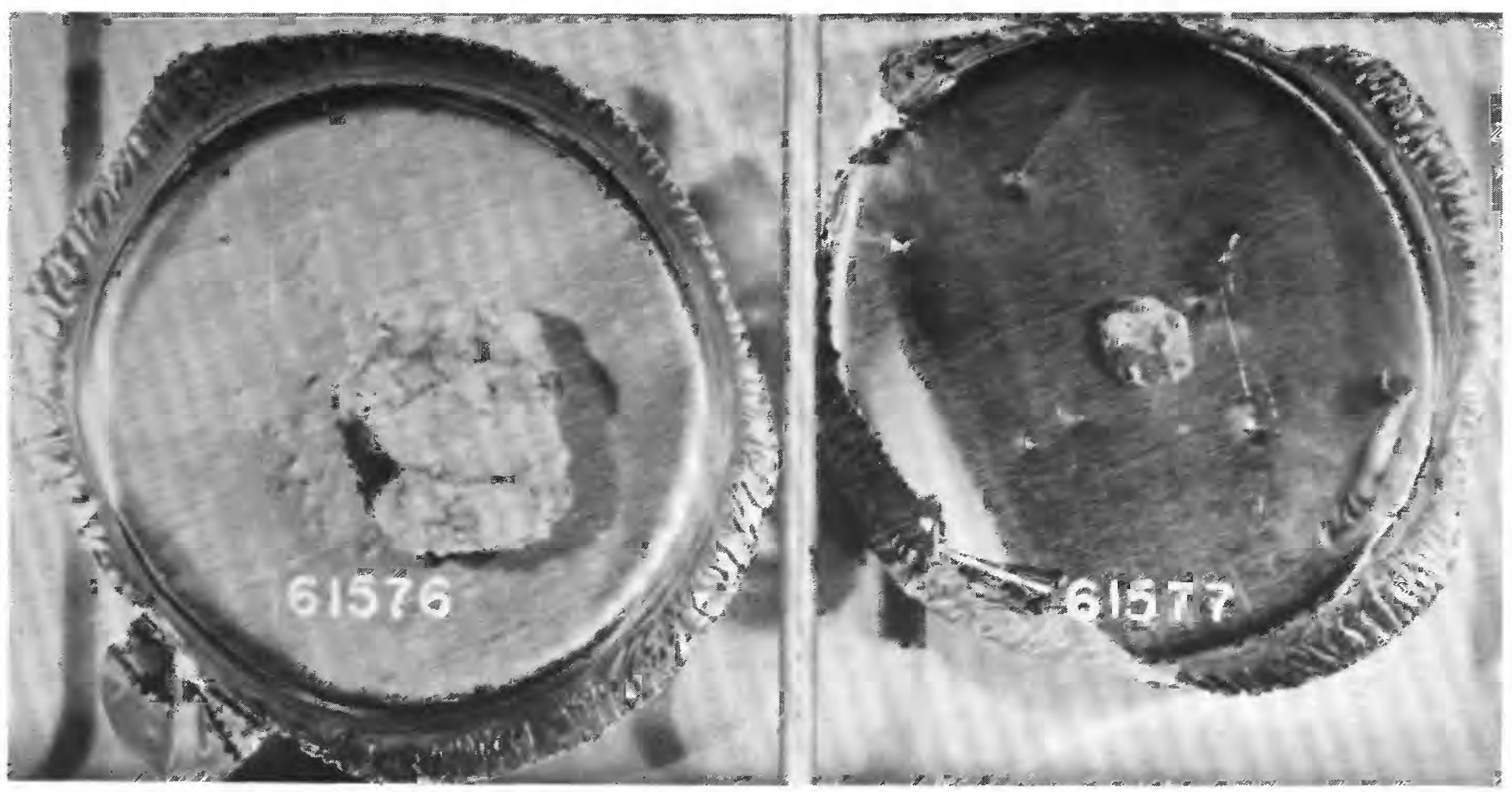

FIGURE 30I._Fragments 61576 and 61577 in the LRL (photograph S-72-43343). Fragment 76 is classified $\mathrm{C}_{1}$ (crystalline); fragment 77 appears to be similar in lithology. 
SAMPLE: 61500-05; 61515-19, 25-29, 35-39, 45-49, 55-59, 65-69, 75-77 (rake samples)

Station: 1

Landmark: About 1 crater diameter $(40-50 \mathrm{~m})$ NE of plum crater.

Rock type: 61500-05 is soil with one fragment; 61515-77 are rake

fragments $>1 \mathrm{~cm}$. See figures $30 \mathrm{D}, F, H$, and $I$ for rock classifications.

SURFACE CHARACTERISTICS OF SAMPLE AREA

Slopes: Level

Fragment population

Size range and distribution: Less than $1 \mathrm{~cm}$ common; 1 to $10 \mathrm{~cm}$

sparse; none larger in immediate area.

Color: Medium gray.

Shapes: Angular to rounded.

Fillets: Poorly developed to absent.

Apparent burial: Slightly buried to perched; several 2-cm angular

fragments in and near 1-m crater north of gnomon markedly perched.

Fines

Dust cover: Not visible.

Color: Medium gray.

Compaction: Moderate.

Craters

Size range and distribution: Less than $5 \mathrm{~cm}$ dense; $5 \mathrm{~cm}$ to $3 \mathrm{~m}$

fairly common.

Shape: Generally subdued; one 1-m crater just north of gnomon

with sharp, raised rim.

Ejecta: None visible.

SAMPLE CHARACTERISTICS FOR 61500-04 (rake soil)

Size: < $1 \mathrm{~cm}$ fines; 794.91 grams total weight $(61505$ is > $1 \mathrm{~cm} ; 1.65$

grams).

Color: Medium gray.

Comparison with other soil in area: Appears typical in color and granularity.

Probable origin: Includes contributions from North Ray, South Ray,

Flag, and Plum craters.

COMMENTS: About 1 crater diameter away from Plum crater; farthest from

the rim in 4-part radial sample.

SAMPLE CHARACTERISTICS FOR 61515-77 (33 rake fragments)

Size: About 1 to $8 \mathrm{~cm}$; 339.02 grams total weight.

Shape: Angular to rounded.

Fillets: Poorly developed to absent.

Apparent burial: Slightly buried to perched.

Dust cover: Not visible.

Comparison with other fragments in area: Appears typical of smaller

fragments outside rake area.

probable origin: Includes contributions from North Ray, South Ray,

Flag, and Plum craters.

COMMENTS: About 1 crater diameter away from Plum crater; farthest from the

rim in 4-part radial sample. 


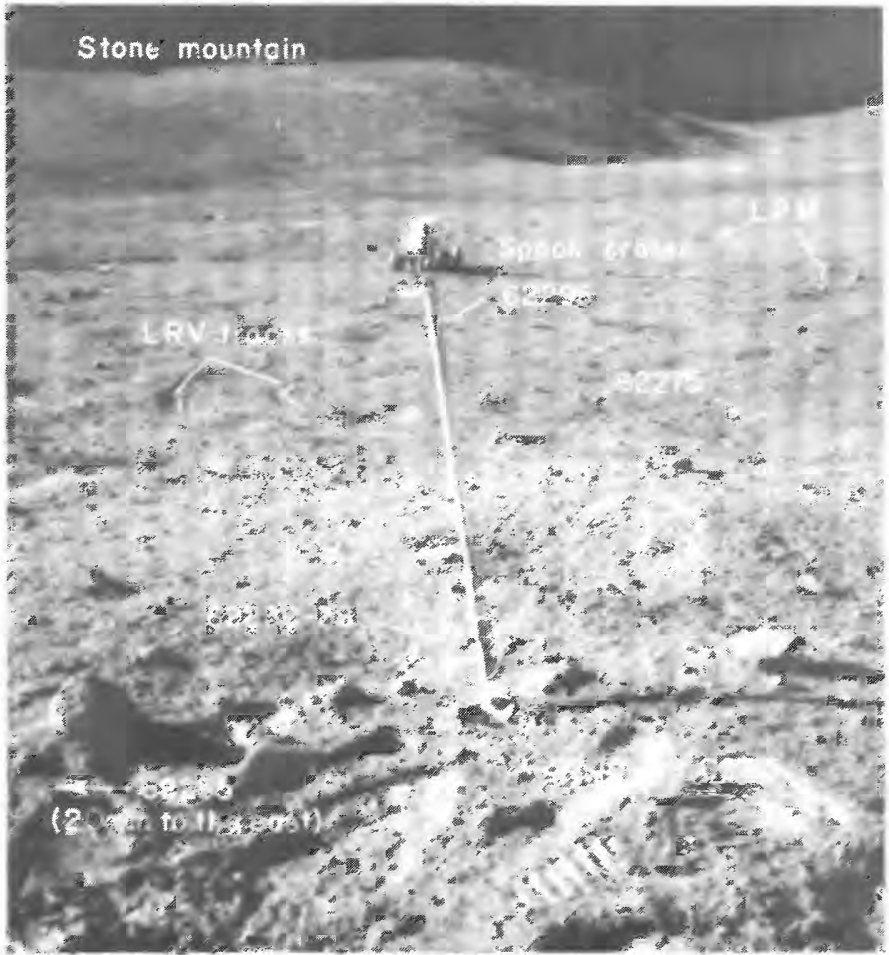

Figure $31 A$.-Location of samples $62230-38,62240-49$ and 62315 , on south rim of Buster crater at station 2, shown in photograph AS16-109-17840. View is south toward LRV, Spook crater, and Stone mountain. Commander Young is at the Rover reading measurements from the Lunar Portable Magnetometer (LPM).

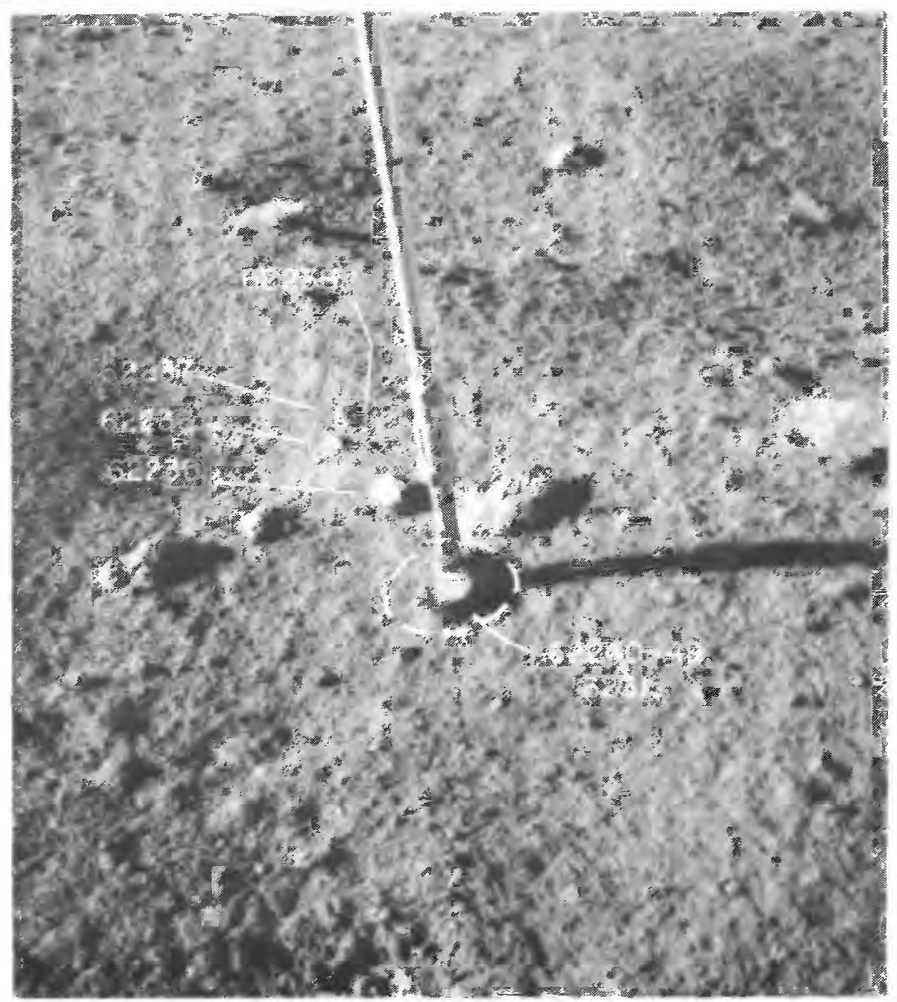

Figure 31B.-Samples 62230-38 and 62240-49, 62315 (scooped soil and fragments) shown before sampling in photograph AS16109-17838, looking south. Only the three largest rocks (62235-37) are identified in the picture. The smaller fragments were collected incidentally with the scooped samples. Fragment 62238 questionably identified. 


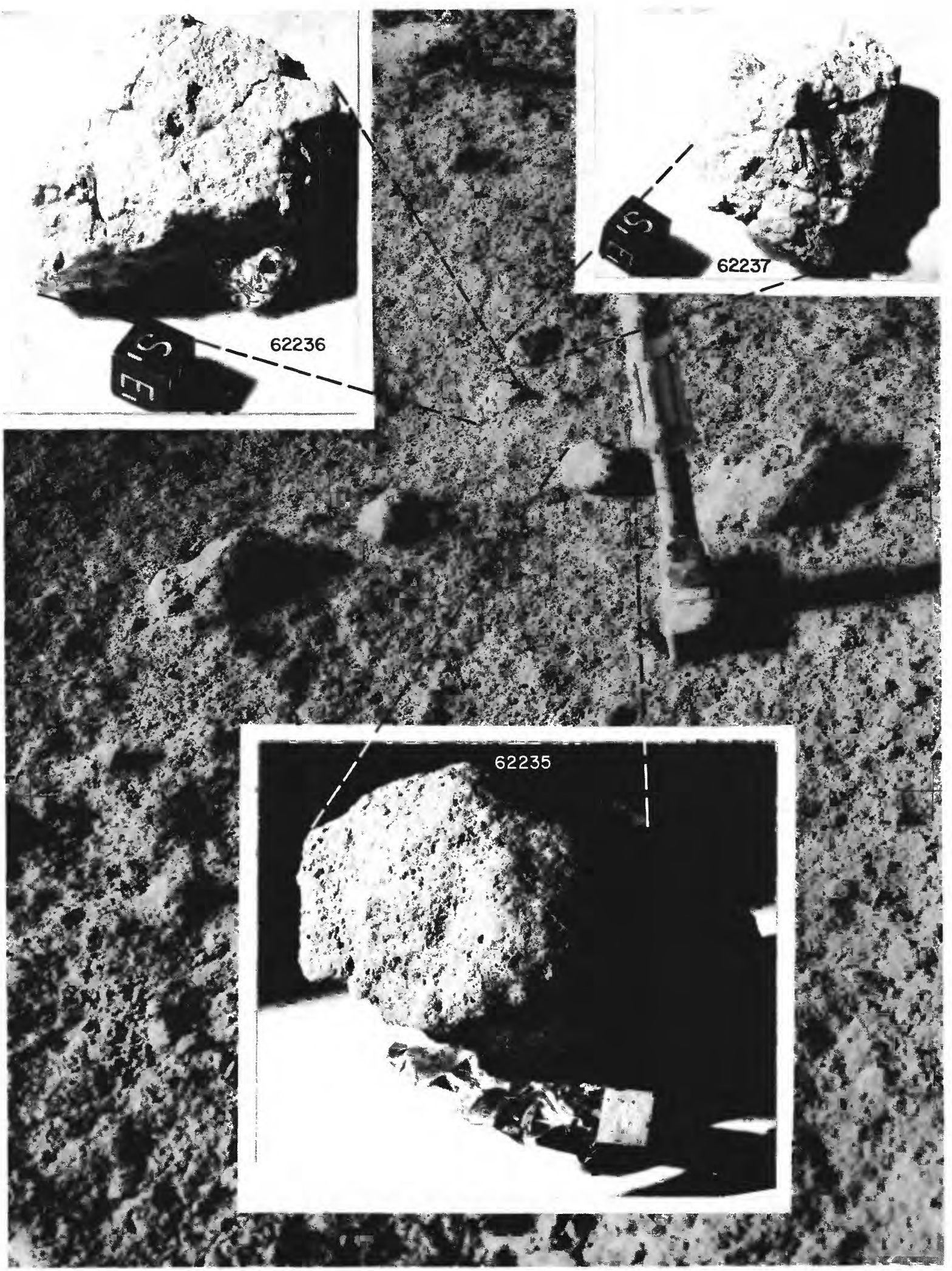

FIGURE 31C.-Samples 62235, 62236, and 62237 showing approximate lunar orientations reconstructed in LRL compared to an enlarged part of photograph AS16-109-17838 taken before sampling; view is south (inset photographs, S-72-41424, 41837, and 41838, respectively). Sample 62235 is a metaclastic $\left(C_{2}\right)$ rock; the other two, $B_{1}$ breccias. 


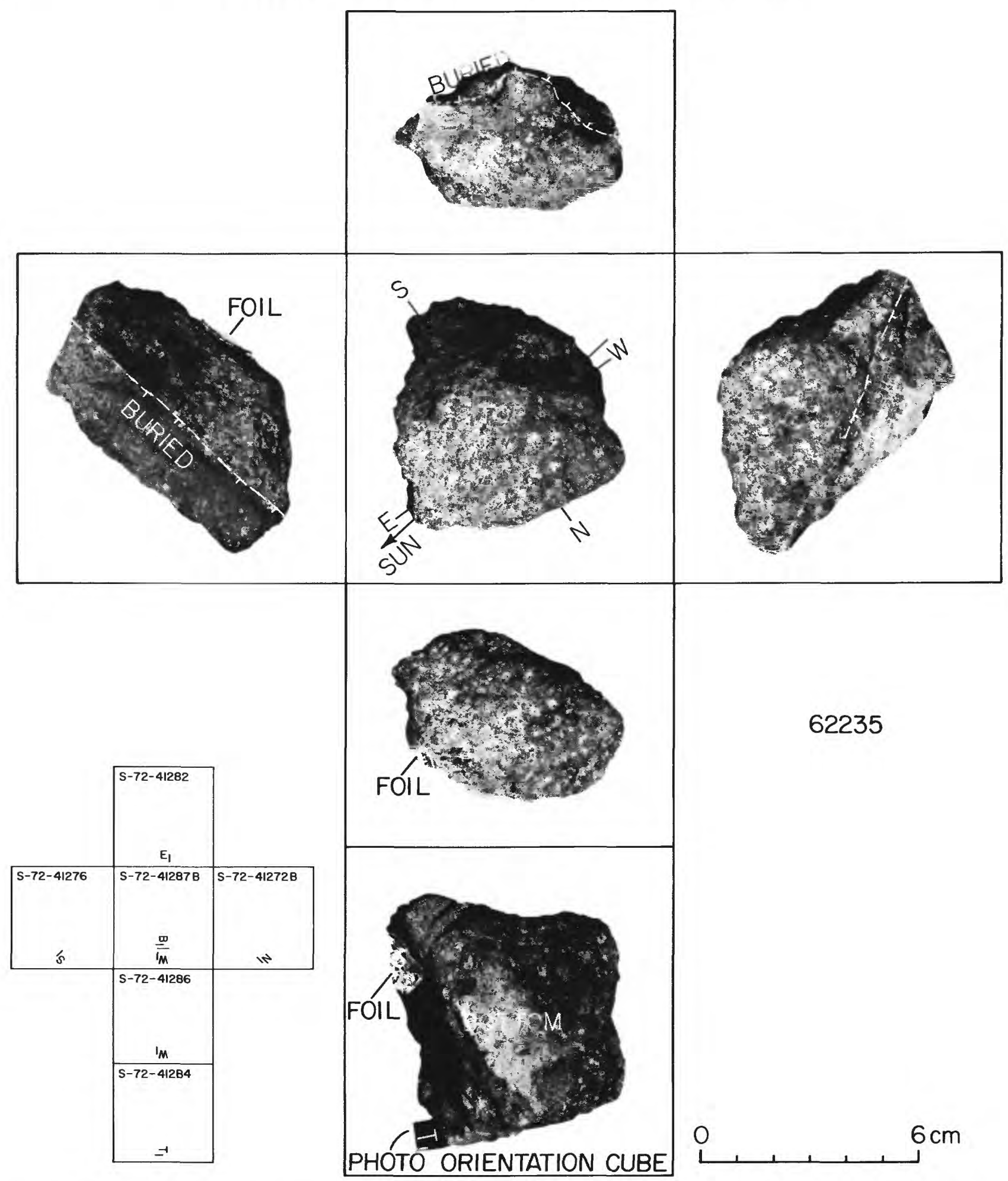

FIGURE 31D.-Orthogonal views of sample 62235 related to its lunar orientation at the time of sampling. See chapter D1, fig. 21A, for a stereopair of this type $C_{2}$ sample. 


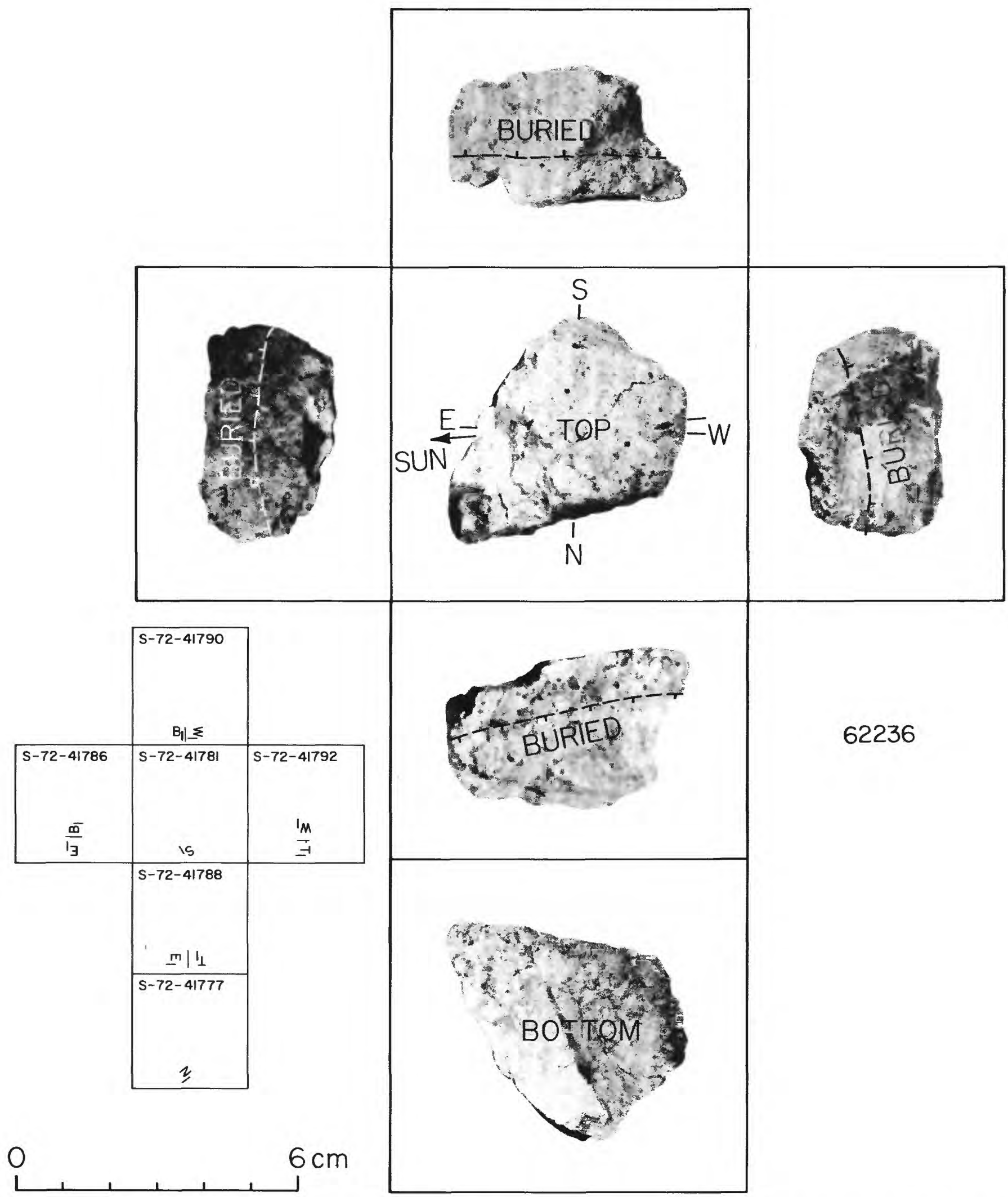

Figure 31E.-Orthogonal views of sample 62236 related to its lunar orientation at time of sampling. See chapter $\mathbf{E}$, fig. $4 H$, for photomicrograph of this type $B_{1}$ breccia. 


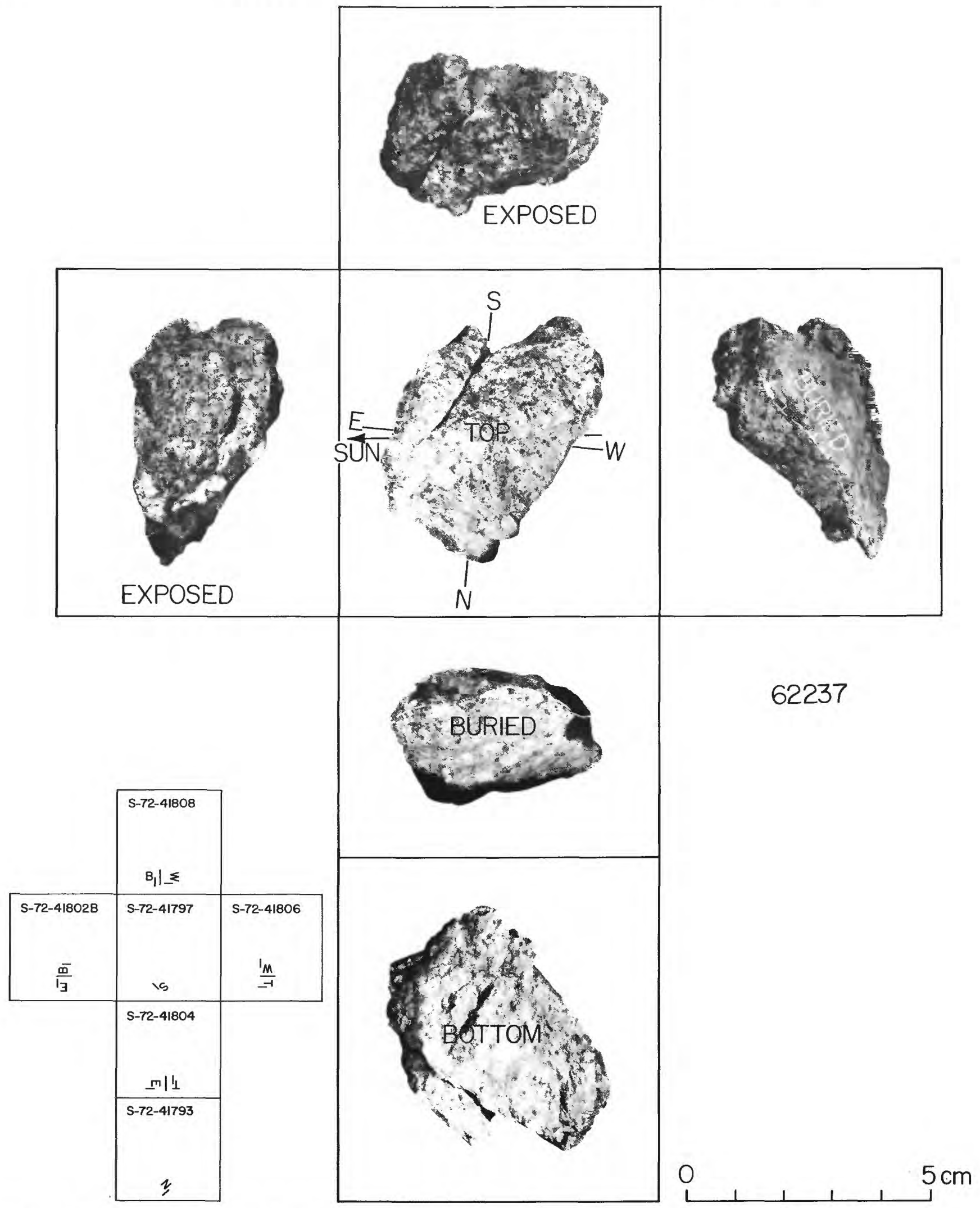

Figure $31 F$.- Orthogonal views of sample 62237 related to its lunar orientation at time of sampling. See chapter E, figure $3 B$, for photomicrograph of this type $B_{1}$ breccia. 


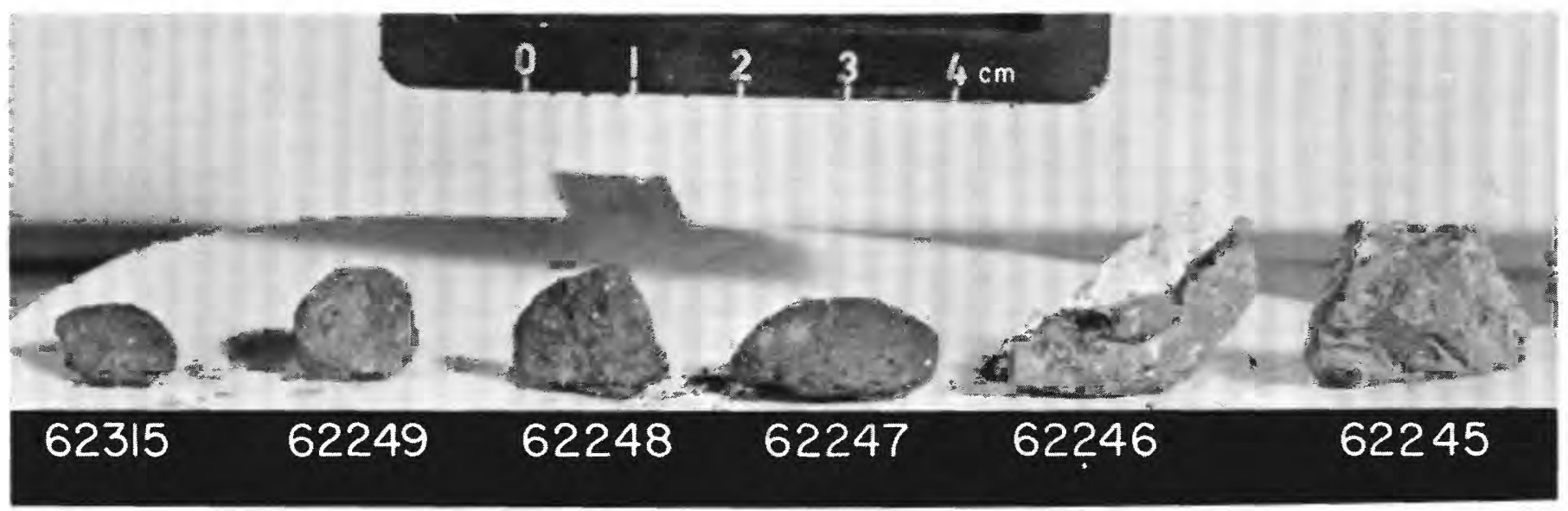

Figure $31 G$.- Scooped fragments $62245-49$ and 62315 in the LRL (photograph S-72-41307). Fragment 45 is classified metaclastic $\left(C_{2}\right)$; fragment $46, B_{1}$ breccia (partly coated by glass); fragment $47, B_{3}$, and the three smaller fragments resemble type $B_{3}$ breccia.

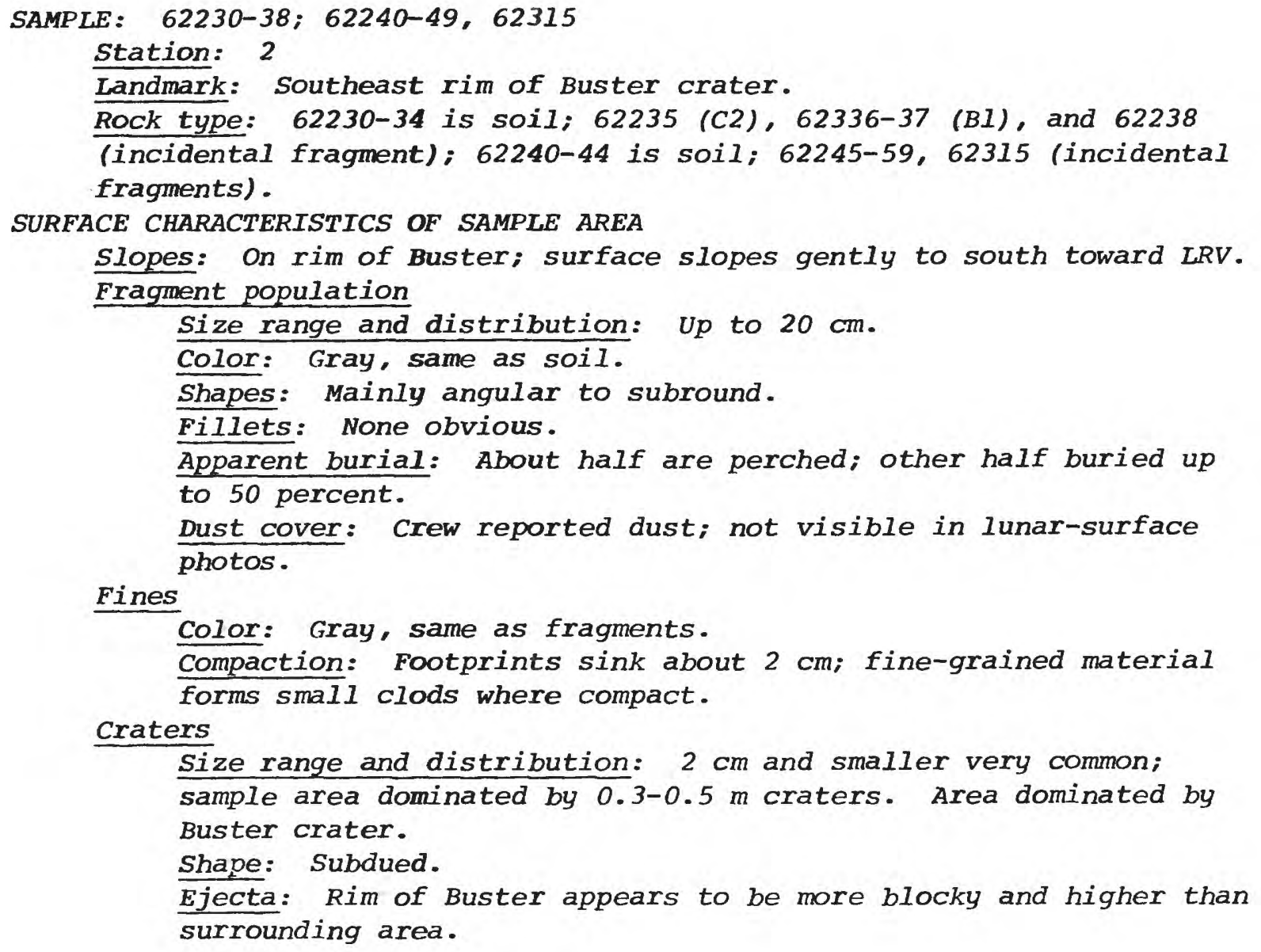


SAMPLE CHARACTERISTICS FOR 62230-34 (incidental soil) and 62238 (incidental fragment), collected with rocks samples 62235-37

Size: < $1 \mathrm{~cm}$ fines; 112.12 grams total weight. $62238,>1 \mathrm{~cm}$

fragment; 1.56 grams.

SAMPLE CHARACTERISTICS FOR 62235 (C2)

Size: $8 \times 7 \times 5.5 \mathrm{~cm} ; 319.6$ grams.

Color: Medium dark gray.

Shape: Subangular, blocky, smooth surface.

Fillet: None visible.

Apparent burial: Perched; about $1 / 4$ buried.

Dust cover: Heavy (see Table 3, p. 15-16).

Comparison with other fragments in area: Angularity and surface texture are similar to other fragments.

Probable origin: Ejecta from Buster crater.

SAMPLE CHARACTERISTICS FOR 62236-37 (BI)

Size: $62236--6 \times 4 \times 3 \mathrm{~cm} ; 57.27$ grams

$62237-5 \times 4 \times 3 \mathrm{~cm} ; 62.35$ grams

Color: Very light gray.

Shape: Subangular.

Fillet: None visible.

Apparent burial: About 1/2 buried.

Dust cover: Moderately heavy.

Comparison with other fragments in area: Probably representative of a. large proportion of fragments in the area.

Probable origin: Ejecta from Buster crater.

SAMPLE CHARACTERISTICS FOR 62240-44 (soil)

Size: < $1 \mathrm{~cm}$ fines; 463.51 grams.

Color: Medium gray.

Comparison with other soil in area: Appears typical of soil on $r i m$ of Buster crater.

Probable origin: Ejecta from Buster crater.

SAMPLE CHARACTERISTICS FOR 62245-49, 62315 (6 fragments collected incidentally with soil sample)

Size: About 1-3 cm; 16.52 grams total weight.

Color: Medium dark gray (62245, C2); olive gray (62247, B3); and

white $(62246, B 1)$. See figure $31 G$. 


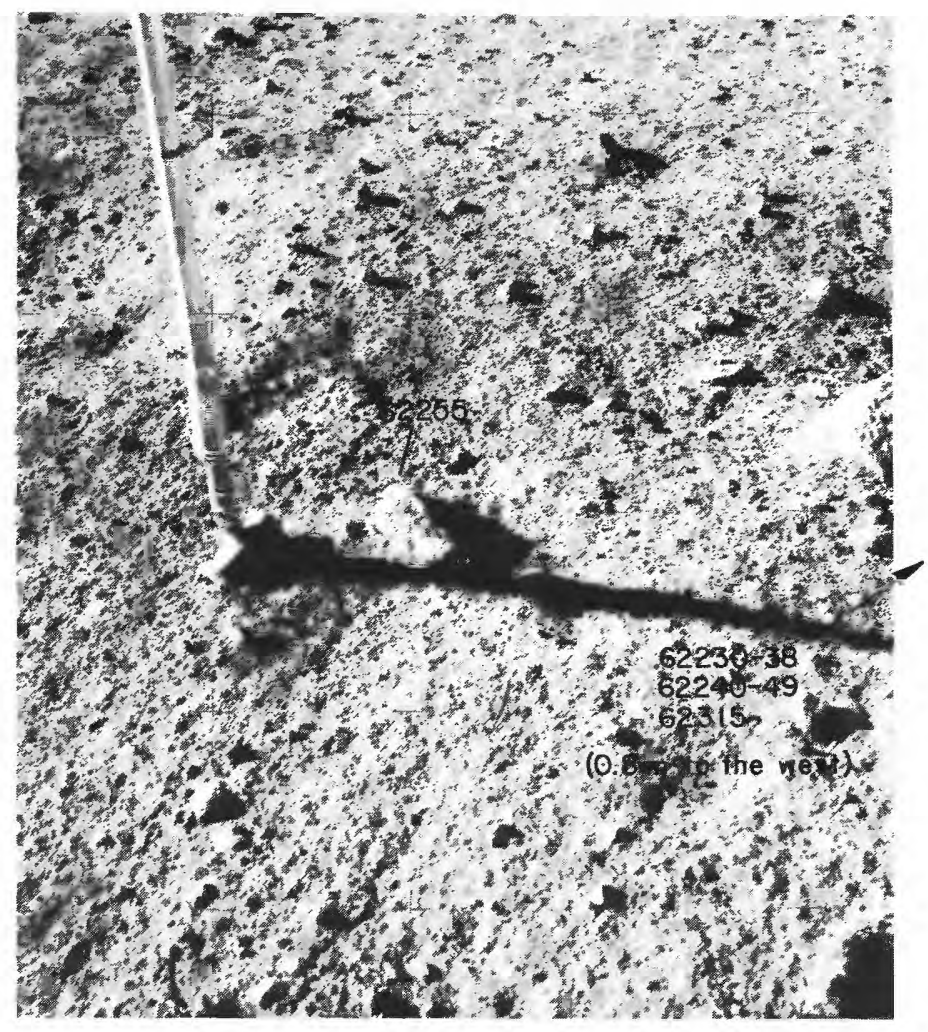

FIGURE 32A.-Sample 62255 shown before sampling in photograph AS16-109-17844; view is south. Type $B_{2}$ breccia collected from the south rim of Buster crater, about $1.5 \mathrm{~m}$ away from samples $62230-38$ and $62240-49,62315$ (see fig. $31 A$ ). 


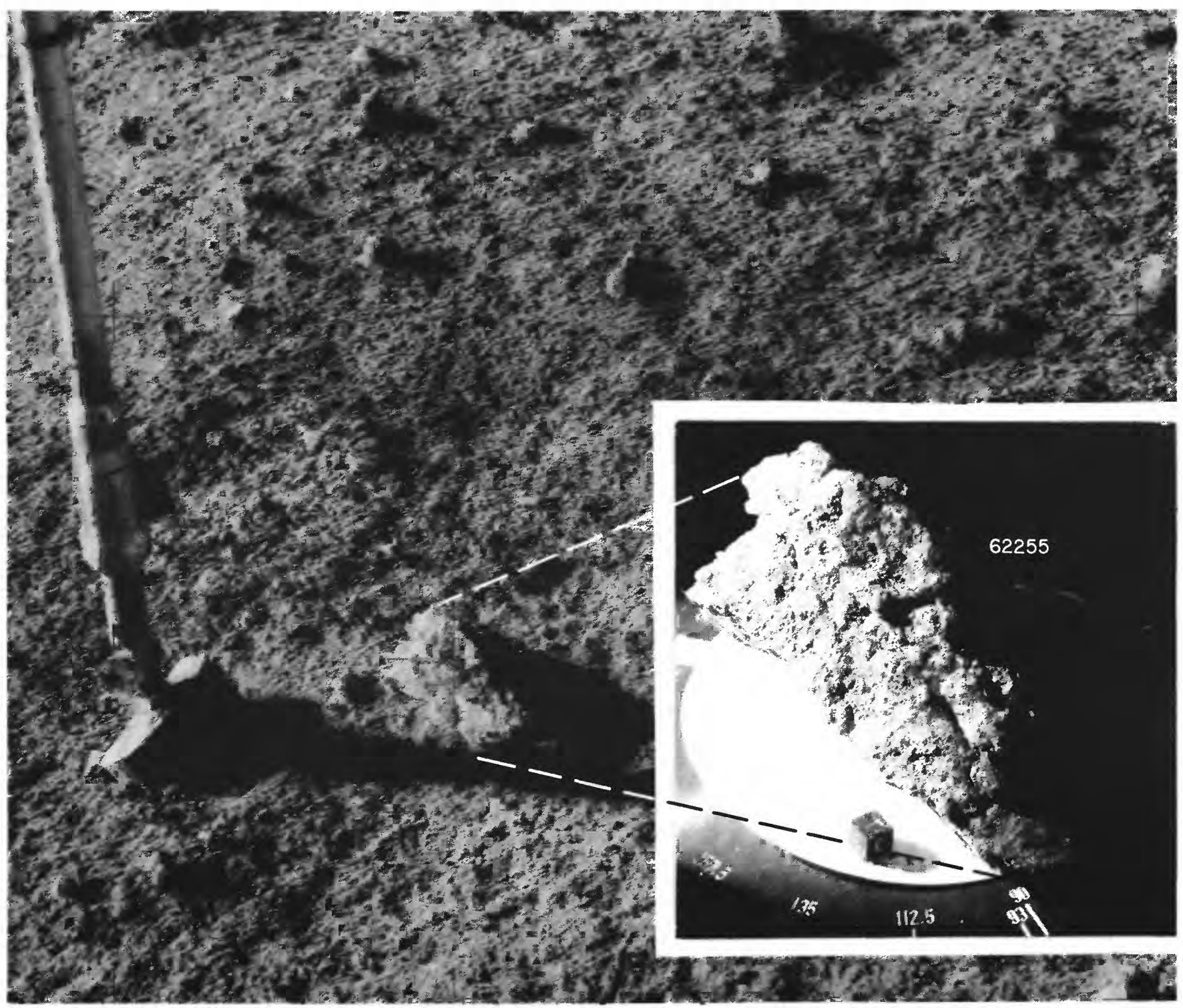

FIGURE 32B.- Sample 62255 showing approximate lunar orientation reconstructed in LRL compared to an enlarged part of photograph AS16-109-17844 taken before sampling. View is south (inset photograph, S-72-41834). 


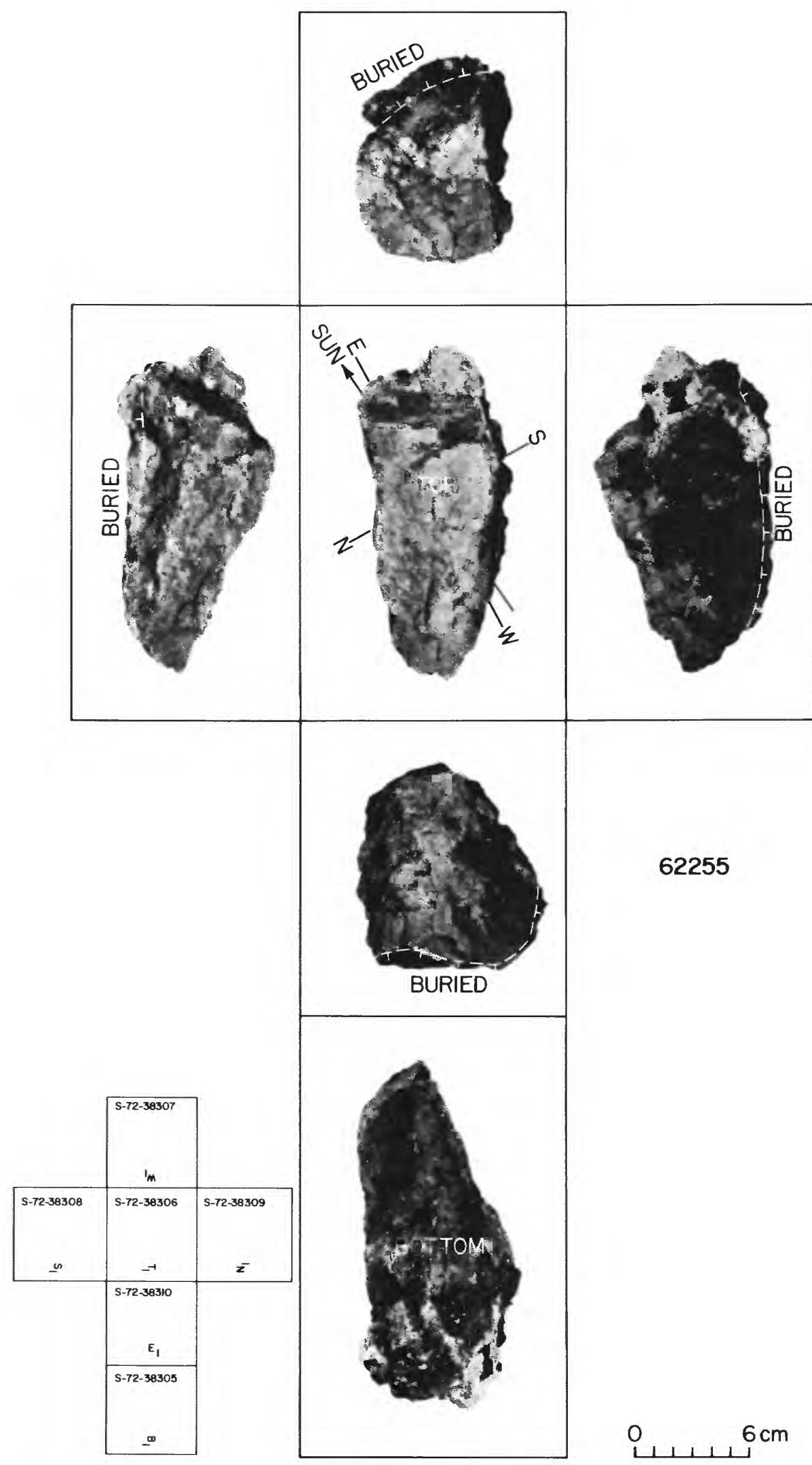

Figure $32 C$.- Orthogonal views of sample 62255 related to its lunar orientation at time of sampling. See chapter D1, fig. $22 A$, for a stereopair of this $B_{2}$ breccia in LRL. 
SAMPLE: 62255

Station: 2

Landmark: Rim of Buster crater.

Rock type: Breccia, $B 2$.

SURFACE CHARACTERISTICS OF SAMPLE AREA

Slopes: On rim of Buster, surface slopes gently to south.

Fragment population

Size range and distribution: Up to $20 \mathrm{~cm}$; mainly $1-2 \mathrm{~cm}$.

Color: Gray, lighter than soil.

Shapes: Very angular.

Fillets: None visible.

Apparent burial: Two largest fragments about $1 / 4-1 / 3$ buried, burial of small fragments not visible.

Dust cover: Not visible.

Fines

Color: Gray.

Compaction: None.

Craters

Size range and distribution: Up to $0.5 \mathrm{~m}$, but mainly less than

$5 \mathrm{~cm}$.

Shape: All subdued except one fresh crater about $0.25 \mathrm{~m}$ south

of scoop.

Ejecta: None visible except around fresh crater $0.25 \mathrm{~m}$ south

of scoop. On ejecta rim of Buster crater, which dominates

sample area.

SAMPLE CHARACTERISTICS

Size: $16 \times 9 \times 6 \mathrm{~cm}$; 1192 grams.

Color: Patchy white and gray.

Shape: Angular, blocky.

Fillet: None.

Apparent burial: Perched.

Dust cover: Heavy (see Table 3, p. 16).

Comparison with other fragments in area: Appears similar in shape to other, smaller rocks.

Probable origin: Angularity suggests the sample was recently exposed or freshly broken from larger block; probably ejecta from Buster crater. 

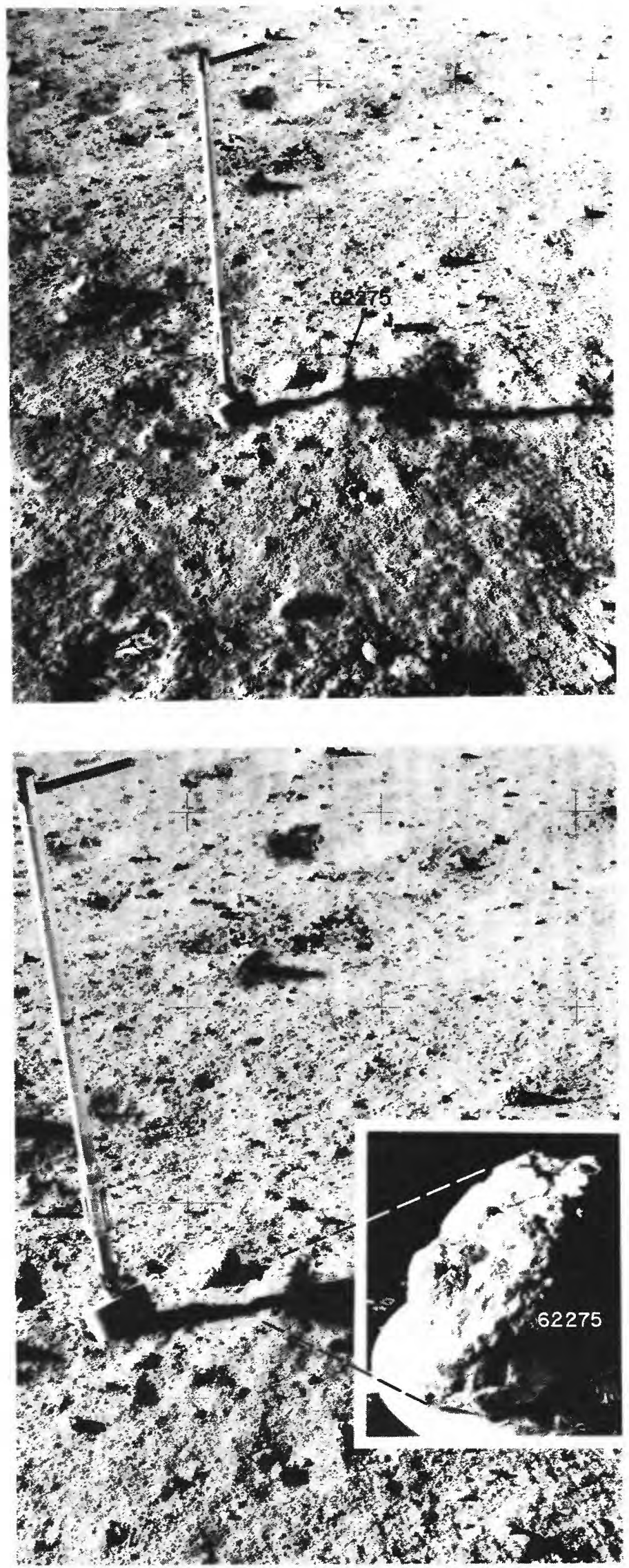

Figure 33A.-Sample 62275 shown before sampling in photograph AS16-109-17845; view is south. Type $B_{2}$ breccia collected from intercrater area between Buster and Spook craters (see map of station 2, chap. D1, fig. 19).
Figure 33B.-Sample 62275 showing approximate lunar orientation reconstructed in LRL compared to an enlarged part of photograph AS16-109-17846 taken before sampling; view is south. The sample is fragile and minor breakage has occurred, making shadow details impossible to duplicate accurately in the laboratory (inset photograph, S-72-41426). 


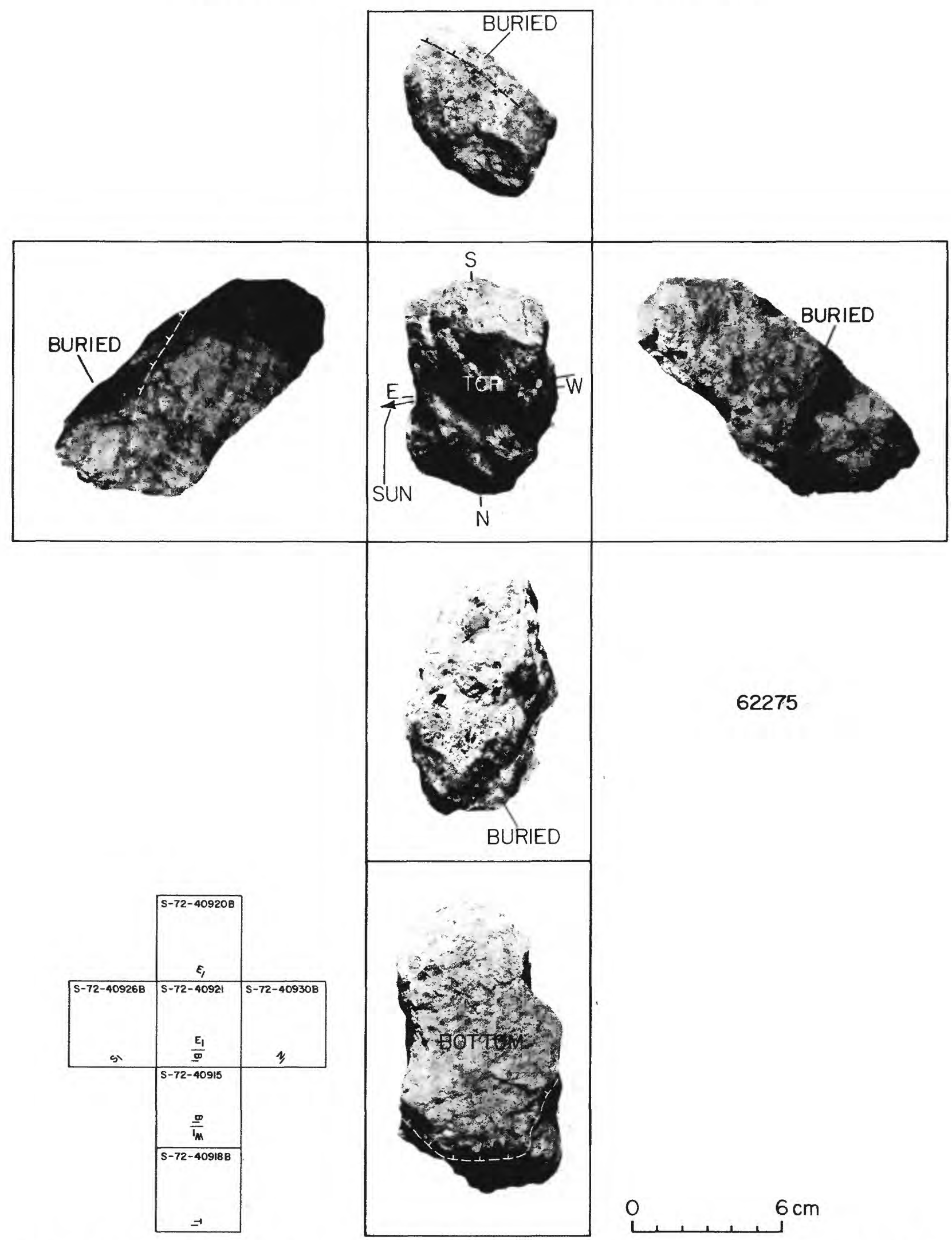

Figure 33C.-Orthogonal views of sample 62275 related to its lunar orientation at time of sampling. See chapter D1, fig. 23A, for a stereopair of this $B_{2}$ breccia. 
SAMPLE: 62275

Station: 2

Landmark: Southeast flank of Buster crater midway between LRV and Buster rim.

Rock type: Breccia with friable white matrix, B2. SURFACE CHARACTERISTICS OF SAMPLE AREA

Slopes: On slope south of Buster.

Fragment population

Size range and distribution: $U p$ to $10-20 \mathrm{~cm} ; 2-5 \mathrm{~cm}$ fragments common.

Color: Gray; some blocks appear to be lighter colored than

the local soil.

Shapes: Angular to subangular.

Fillets: Absent.

Apparent burial: Smaller fragments perched to slightly buried;

larger fragments generally about 1/10-1/5 buried.

Dust cover: None visible.

Fines

Color: Gray.

Compaction: Fairly compact; footprints lightly impressed.

\section{Craters}

Size range and distribution: Up to $0.5 \mathrm{~m}$.

Shape: Subdued.

Ejecta: Not visible.

SAMPLE CHARACTERISTICS

Size: $11 \times 7.5 \times 5 \mathrm{~cm} ; 443.0$ grams.

Color: White.

Shape: Blocky; angular; friable.

Fillet: None.

Apparent burial: $1 / 4$ or less (perched).

Dust cover: None reported by astronaut crew.

Comparison with other fragments in area: Appears similar in lunar surface photo. Probably was collected because it was whiter than other rocks nearby.

Probaije origin: Most likely related to ejecta from Buster crater. COMMENTS: Sample was collected from an area of fine-surface texture that may be dust spray kicked by a boot. 

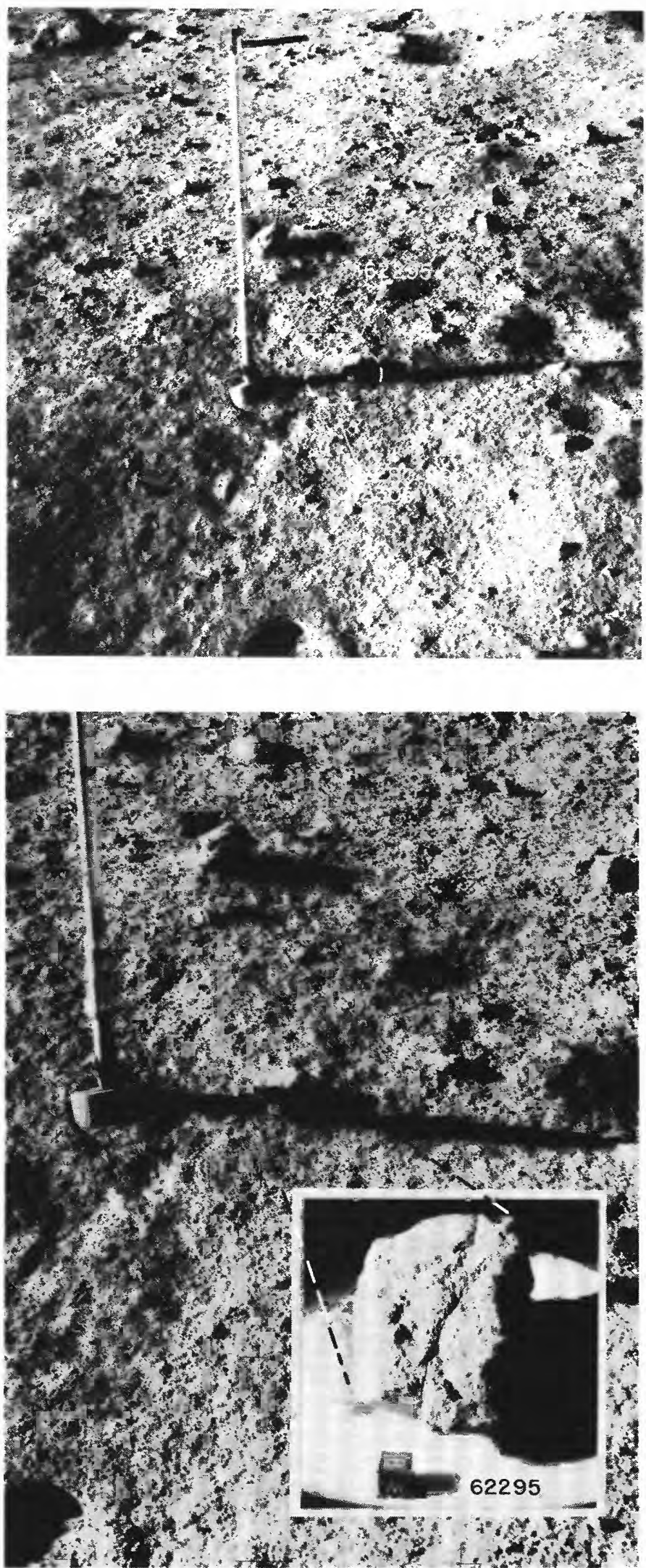

TFigure 34A.-Samples 62280-89, 62305 (scooped soil and fragments) and rock sample 62295 shown before sampling. Photograph AS16-109-17847, looking south. In the absence of a postsampling photograph, the precise location of soil sample is not known; probably taken from beneath 62295 , judged from television videotape recording of sampling activity.
4Figure 34B.-Sample 62295 showing approximate lunar orientation reconstructed in LRL compared to an enlarged part of photograph AS16-109-17848 taken before sampling. View is south (inset photograph, S-72-42563). 


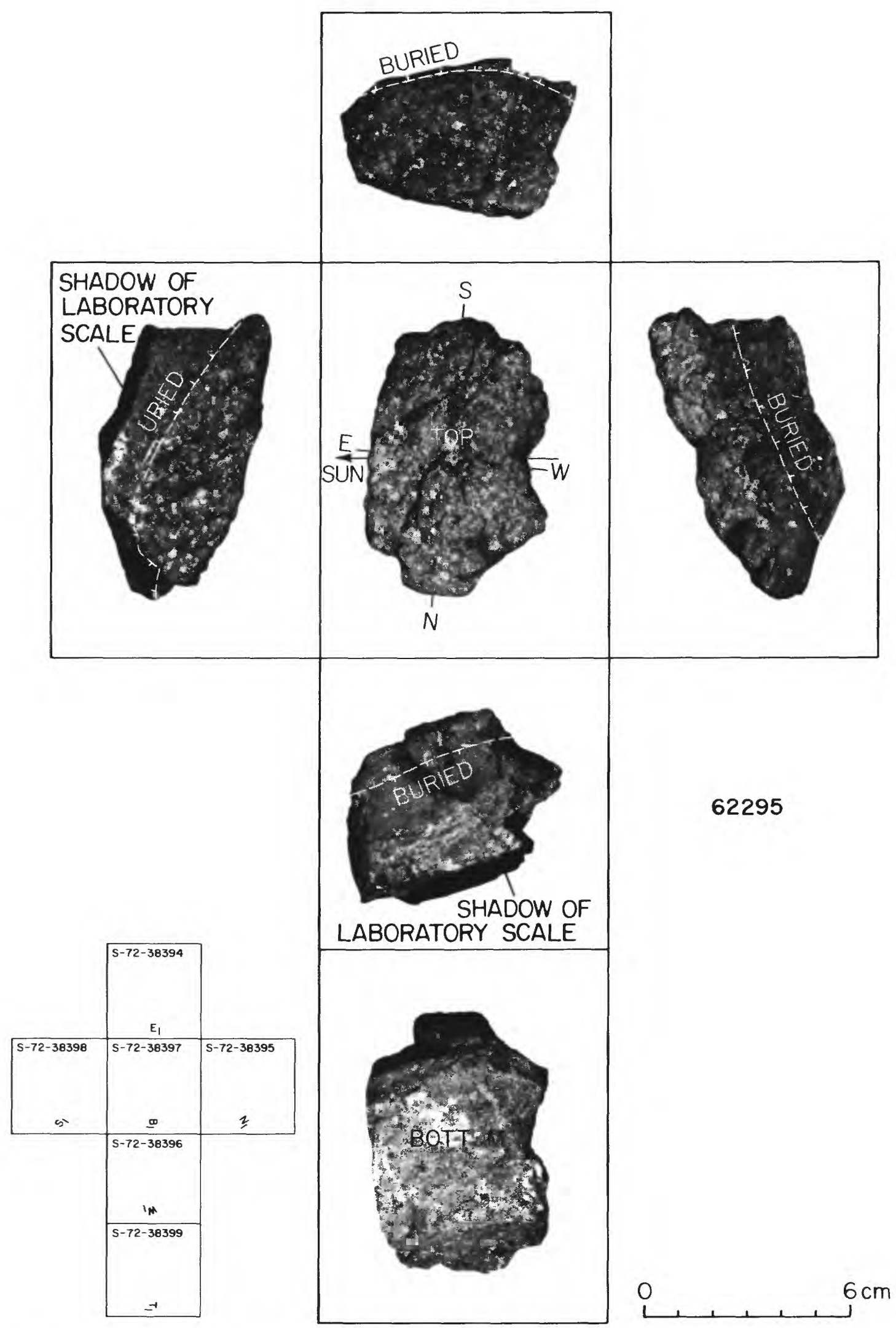

Figure 34C.-Orthogonal views of sample 62295 related to its lunar orientation at time of sampling. See chapter D1, fig. 24A, for stereopair of this crystalline $\left(\mathrm{C}_{1}\right)$ rock in LRL showing lunar top of sample pitted by numerous microcraters. 
SAMPLE: 62280-89, 62305; 62295

Station: 2

Landmark: About $20 \mathrm{~m}$ north-northwest of $L R V$. Rock type: Soil (62280-84) with incidental fragments (62285-89, 62305); 62295 is crystalline, C1.

SURFACE CHARACTERISTICS OF SAMPLE AREA

Slopes: On slope south of Buster crater.

Fragment population

Size range and distribution: Up to $10 \mathrm{~cm}$; mostly $5 \mathrm{~cm}$ or less. Color: Same as fine-grained material. Shapes: Most are angular.

Fillets: Fragments too small to observe filleting.

Apparent burial: Most fragments appear perched or just slightly buried.

Dust cover: None visible.

Fines

Color: Gray.

Compaction: Soil at this station appears less compact than elsewhere; bootprints are about twice as deep.

Craters

Size range and distribution: Up to $0.3 \mathrm{~m}$, mostly $5-10 \mathrm{~cm}$.

Shape: Subdued; a few well defined.

Ejecta: None visible.

SAMPLE CHARACTERISTICS FOR 62280-84 (soi1)

Size: < $1 \mathrm{~cm}$ fines; 410.62 grams.

Color: Gray, no high-albedo soil below surface.

Probable origin: Most likely a mixture of material from North Ray,

South Ray, Spook, and Buster craters. Lack of high-albedo material

suggests South Ray crater contribution is small.

COMMENTS: Not located on photographs of sample 62295.

SAMPLE CHARACTERISTICS FOR 62285-89, 62305 (6 incidental fragments collected

with soil 62280-84)

Size: $1-2 \mathrm{~cm} ; 12.79$ grams total weight.

SAMPLE CHARACTERISTICS FOR 62295

Size: $8.5 \times 6.5 \times 4 \mathrm{~cm} ; 250.8$ grams

Color: Medium gray.

Shape: Angular; blocky with sharp edges.

Fillet: None.

Apparent burial: Perched.

Dust cover: Not visible.

Comparison with other fragments in area: Smooth surface texture and

angularity unlike the other large fragment just to south.

Probable origin: Has not been on surface very long; lacks a fillet,

is not buried, and is very angular. May be from South Ray crater.

COMMENTS: 62295 is the only rock classified as crystalline from station 2 . 


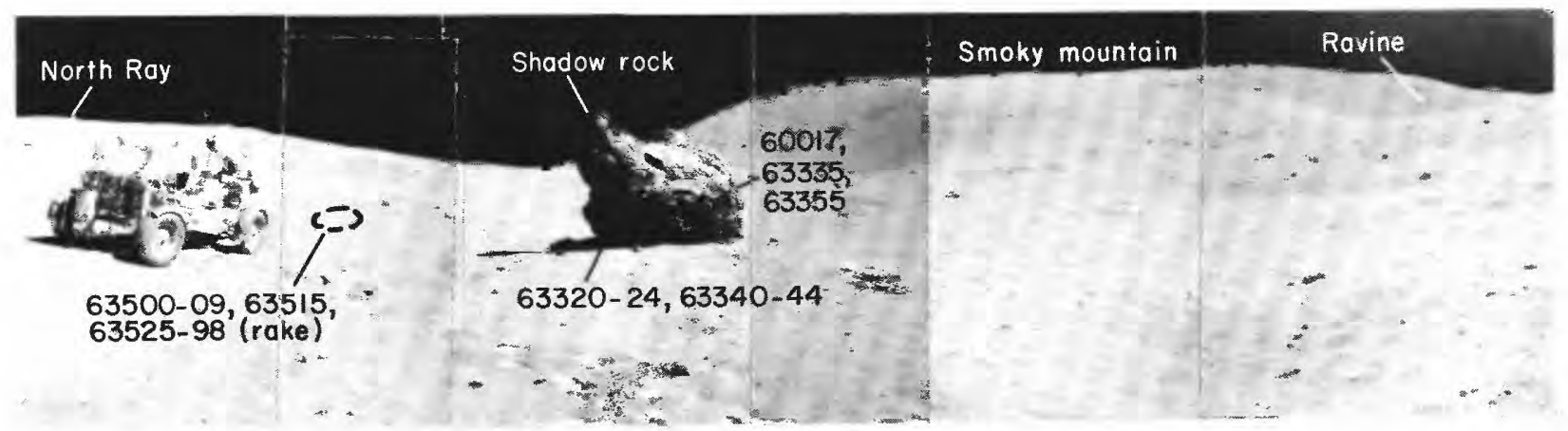

FIGURE 35A.-Partial panorama at station 13 (located about $750 \mathrm{~m}$ south of rim of North Ray crater), showing Shadow rock and general setting of samples from station (photographs AS16-106-17390 to 17397). See figures $35 B-E$ for illustrations of Shadow rock samples, and figures $36 A-I$ for illustrations of rake samples.

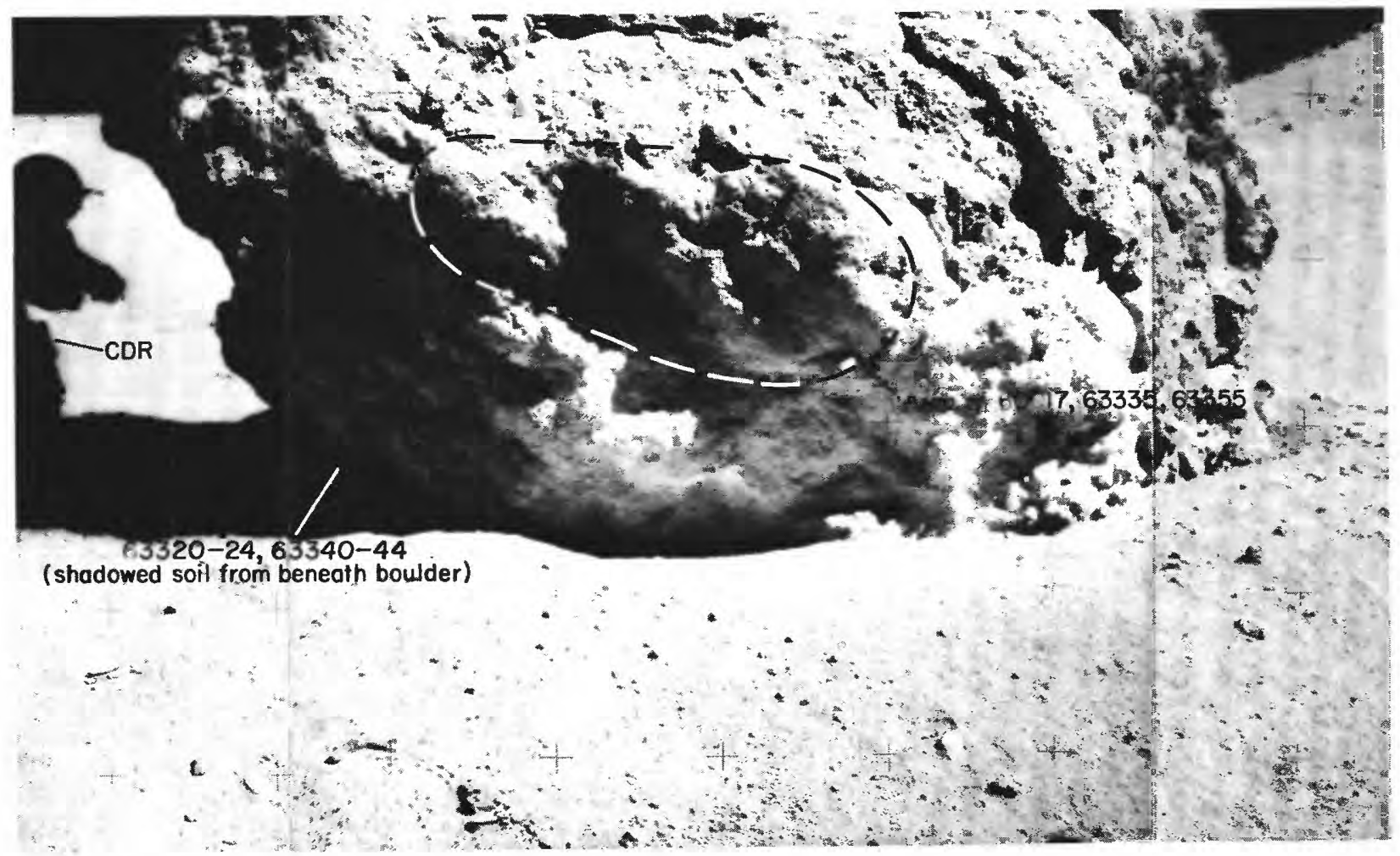

FigURE 35B.- Shadow rock, at station 13, showing approximate locations of soil samples 63320-24 and 63340-44 collected from beneath the shadowed part of boulder, and rock samples 60017,63335 , and 63355 , broken from south face of 5 -m boulder (photographs AS16-106-17413 to 17415). 


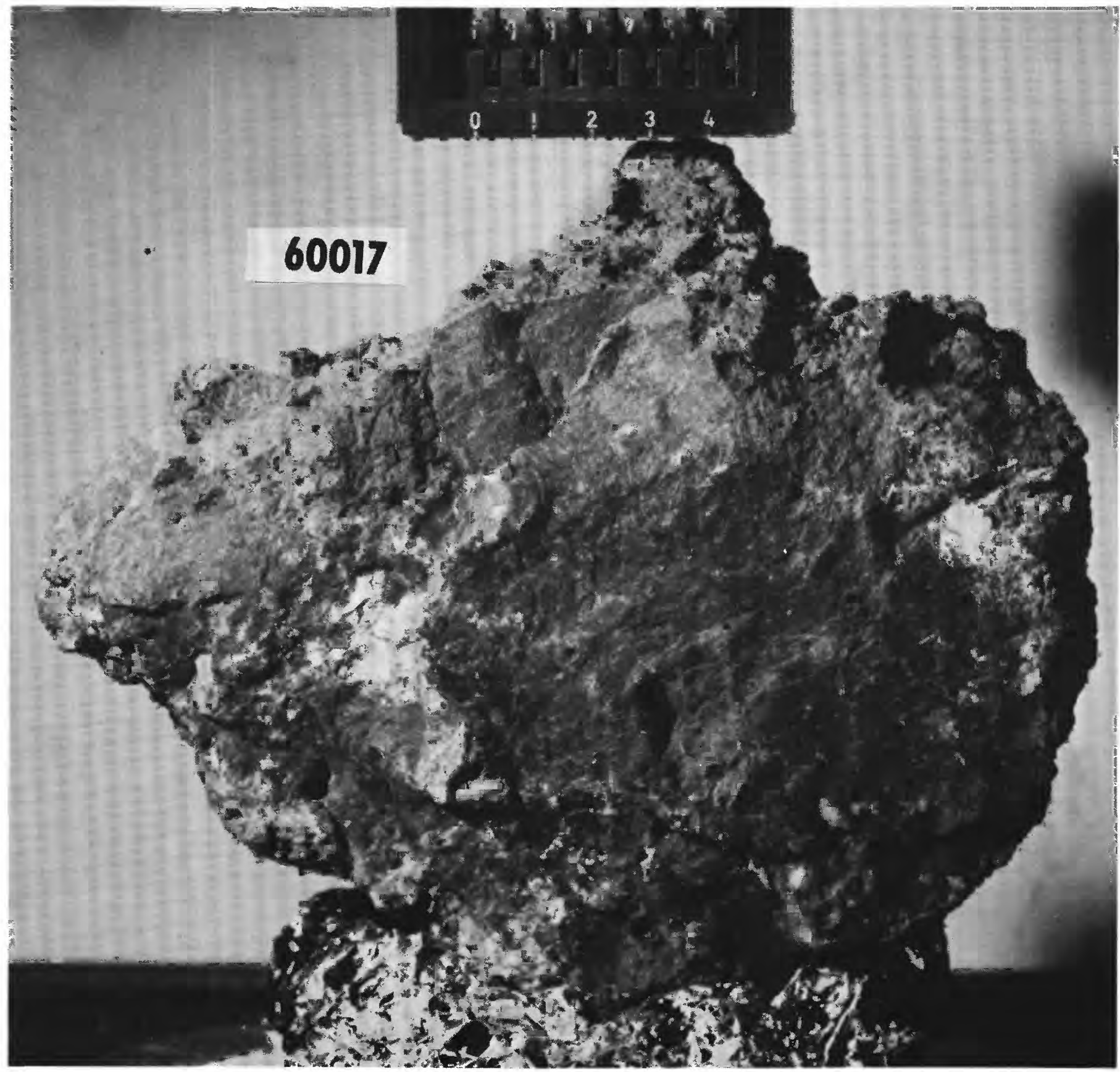

Figure 35C.-Sample 60017 in LRL showing fresh surface of this type $\mathrm{B}_{4}\left(\mathrm{~B}_{\overline{5}}\right.$ ) breccia as broken from the side of Shadow rock (photograph S-72-36943). See chapter D2, fig. 33, for photomicrograph. 

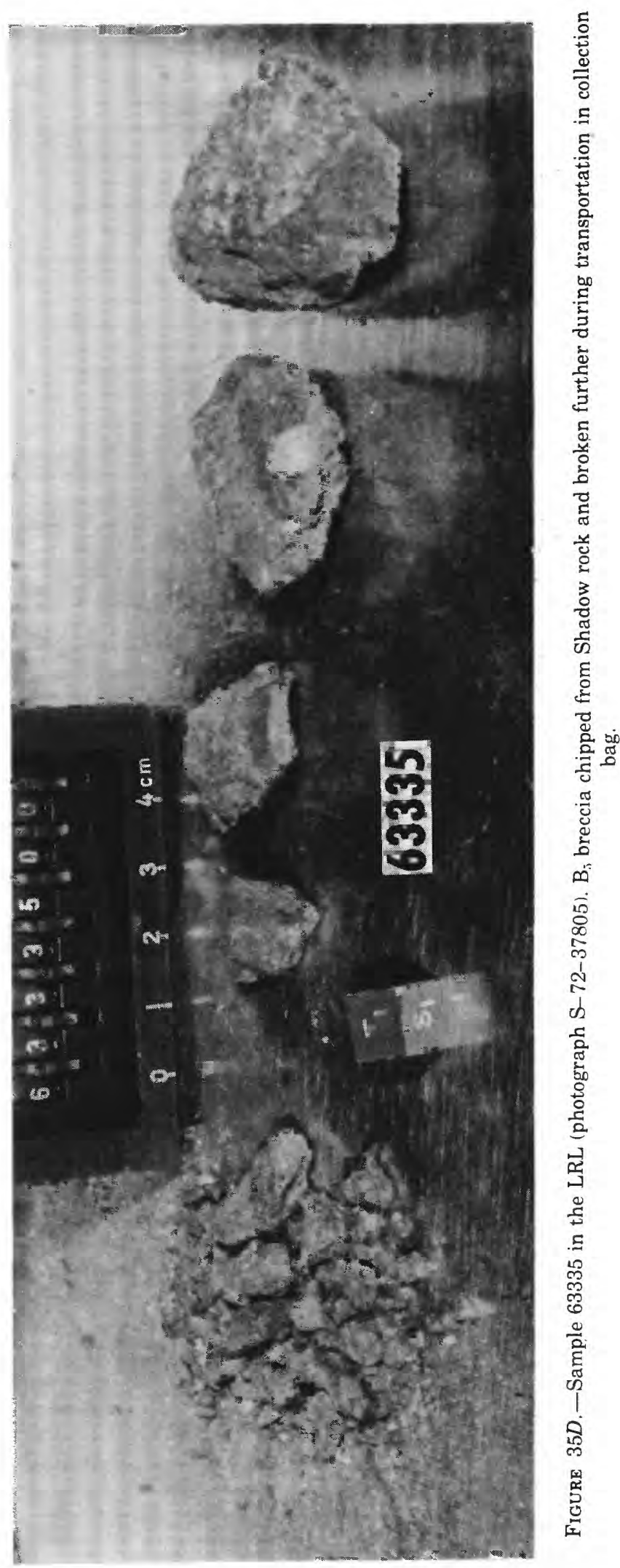

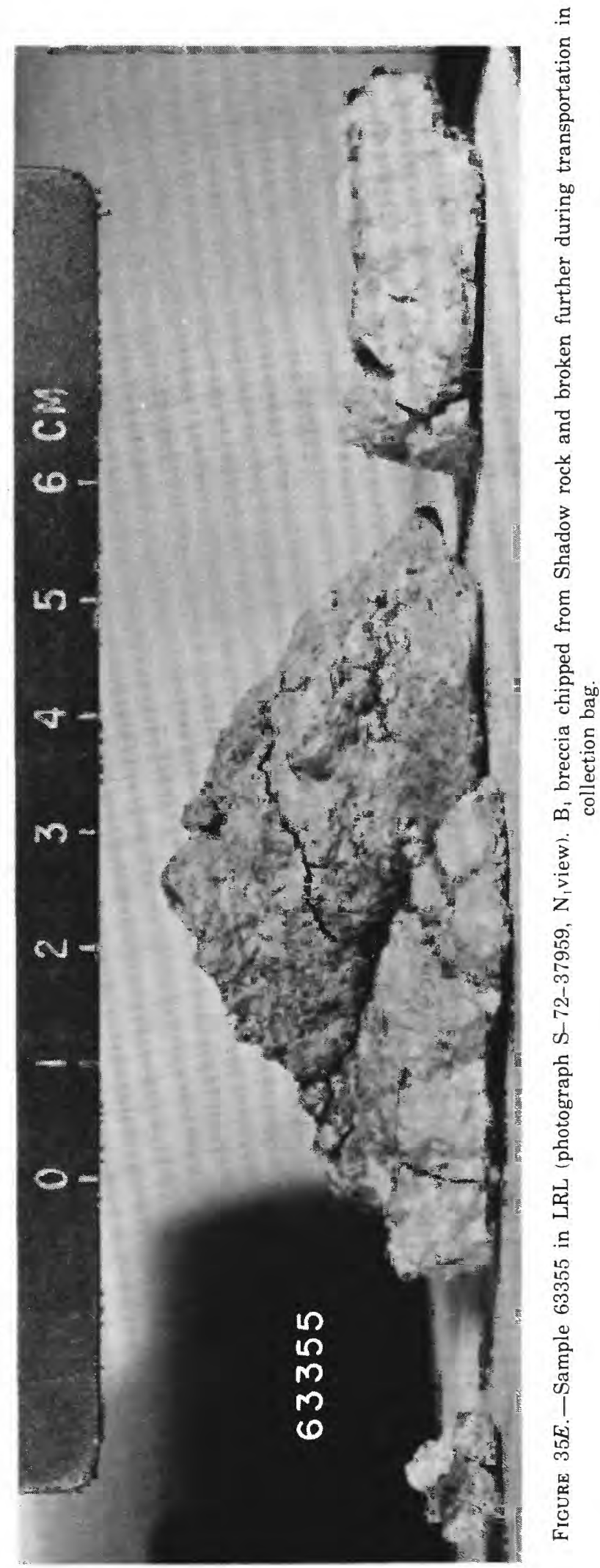
SAMPLE: $63320-24 ; 63335 ; 63340-44 ; 63355 ; 60017 *$

Station: 13

Landmark: Shadow Rock, located on southeast part of North Ray crater ejecta blanket, approximately $750 \mathrm{~m}$ from crater rim crest. Rock type: Breccia with black matrix and dark and white clasts (60017, B4(B5); 63335, B5; 63355, B4); soil samples 63320-24 and 63340-44 from beneath Shadow Rock overhang.

SURFACE CHARACTERISTICS OF SAMPLE AREA

Slopes: Southeast slope on flank of North Ray crater, about 5 degrees. Fragment population

Size range and distribution: Abundant 5-10 cm fragments

scattered on surface. Scattered blocks up to about $5 \mathrm{~m}$.

Color: Light to medium gray.

Shapes: Generally subangular, many rocks are tabular; larger

blocks are hackly and irregular with crudely developed layering.

Fillets: Notably absent from shadow Rock; some other rocks are

filleted.

Apparent burial: Cobbles largely perched. Large blocks range

from perched (Shadow Rock) to nearly completely buried.

Dust cover: Negligible.

Fines

Color: Medium gray, white below surface by LRV.

Compaction: Firm; boots leave distinct but shallow impression. Craters

Size range and distribution: Abundant $0.5-1 \mathrm{~m}$ craters in imme-

diate station area.

Shape: Subdued.

Ejecta: Indistinct.

SAMPLE CHARACTERISTICS FOR 60017, 63335, 63355 (chips broken from Shadow Rock)

Size: $60017-18 \times 14 \times 9$ cm; 2102 grams.

63335 -- broken into pieces; 65.4 grams

$63355--6 \times 3 \times 3 \mathrm{~cm} ; 68.24$ grams

Color: Medium dark gray.

Shape: Irregular, hackly to crudely layered, angular to subangular. Dust Cover: None.

Comparison with other fragments in area: Shadow Rock is the largest boulder in immediate area. Like other large rocks it is irregularly shaped, coarsely clastic, and crudely layered.

Probable origin: Breccia block ejected from North Ray crater.

Breccia emplaced in North Ray crater area prior to North Ray event.

SAMPLE CHARACTERISTICS FOR 63320-24 and 63340-44 (sOiIs)

Size: < 1 cm fines; 351.48 grams (63320-24); 181.19 grams (63340-44).

Probable origin: Fine-grained ejecta from North Ray crater. If

Shadow Rock was ejected from North Ray crater, these samples have been virtually undisturbed since the North Ray event.

* Sample 60017 was assigned a LM/ALSEP number before its source location at station 13 was recognized with assurance. 


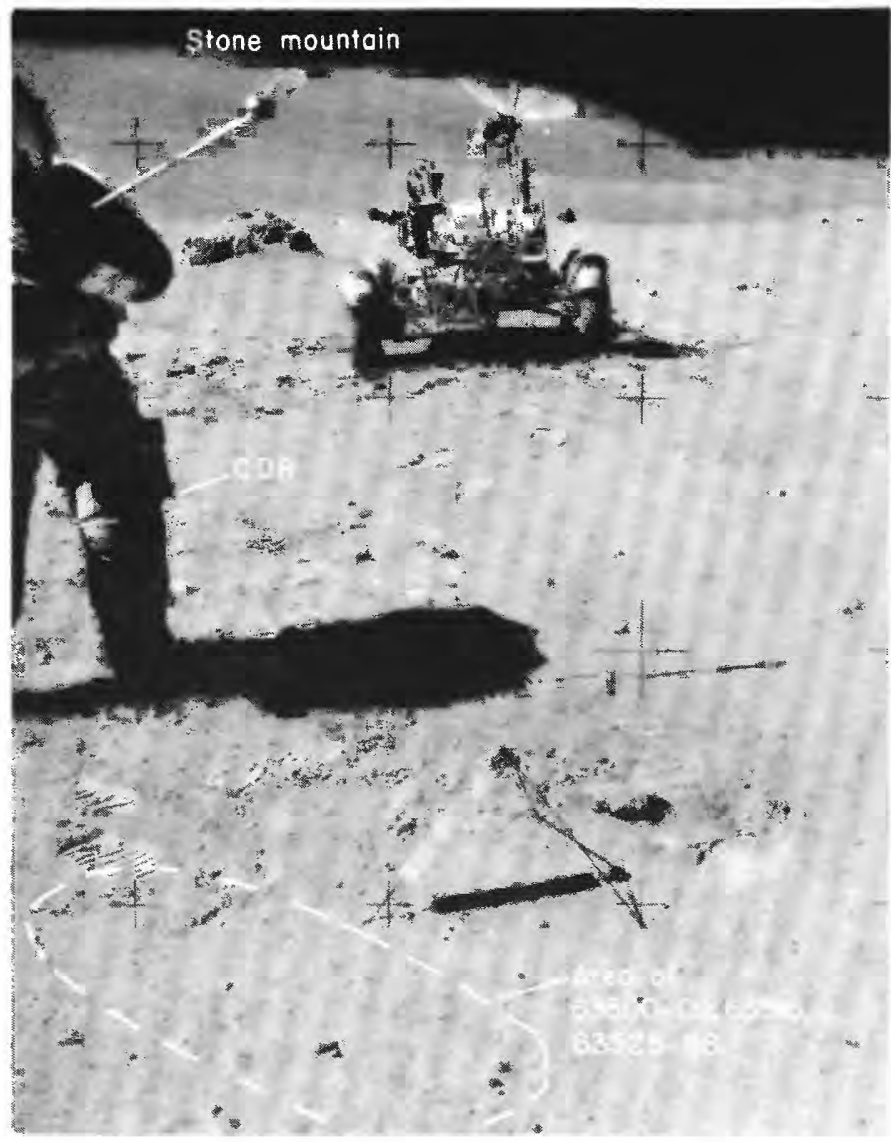

Figure 36A.-Area of rake samples 63500-09, 63515, and 6352598, shown before sampling in an enlarged part of photograph AS16-106-17409; view is south. Vertical wand of gnomon was inadvertently removed before this picture was taken.

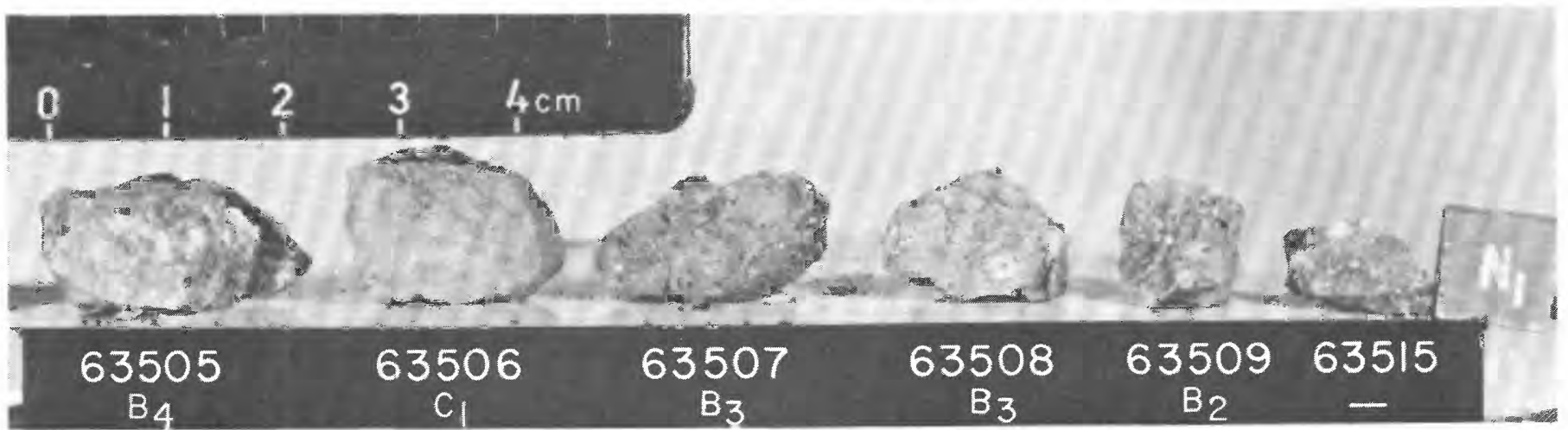

Figure 36B.--Samples 63505-09 and 63515 in LRL (photograph S-72-38968). Collected incidentally with soil from same area that yielded rake fragments 63525-98. Rock classification of Wilshire and others (this volume) is given below each fragment. 


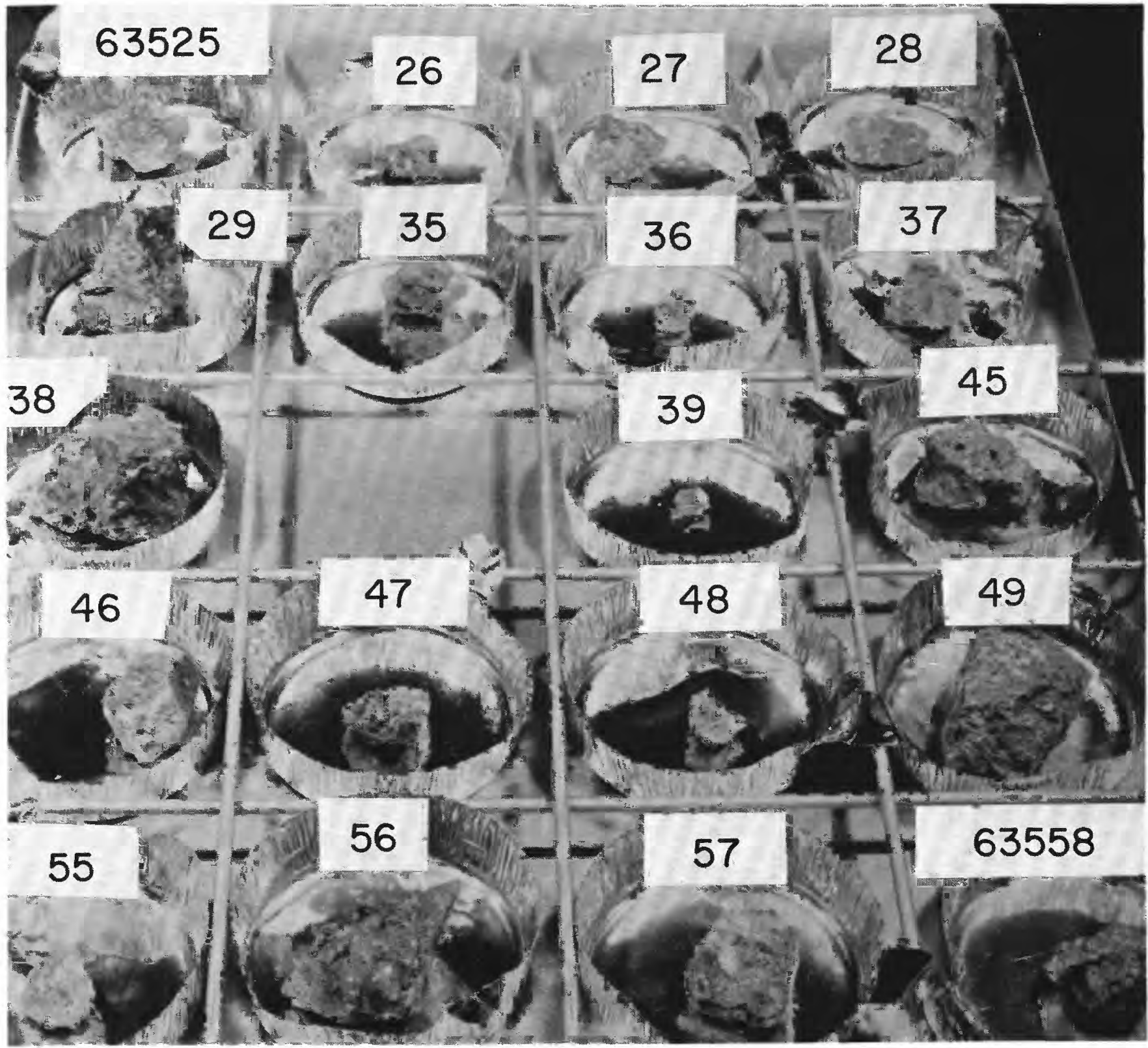

Figure 36C.-Part of rake sample 63525-98 in LRL (photograph S-72-42072). This group includes fragments 63525-29, 63535-39, $63545-49$, and $63555-58$. Nine are classified type $\mathrm{B}_{4}(25-29,35,46,55$, and 57$)$; seven, $\mathrm{C}_{2}$ metaclastic $(37,38,45,47,49,56$, and 58$)$; and three $<2 \mathrm{~g}$, not classified $(36,39$, and 48 ). Note similar appearance of all fragments in the group. 


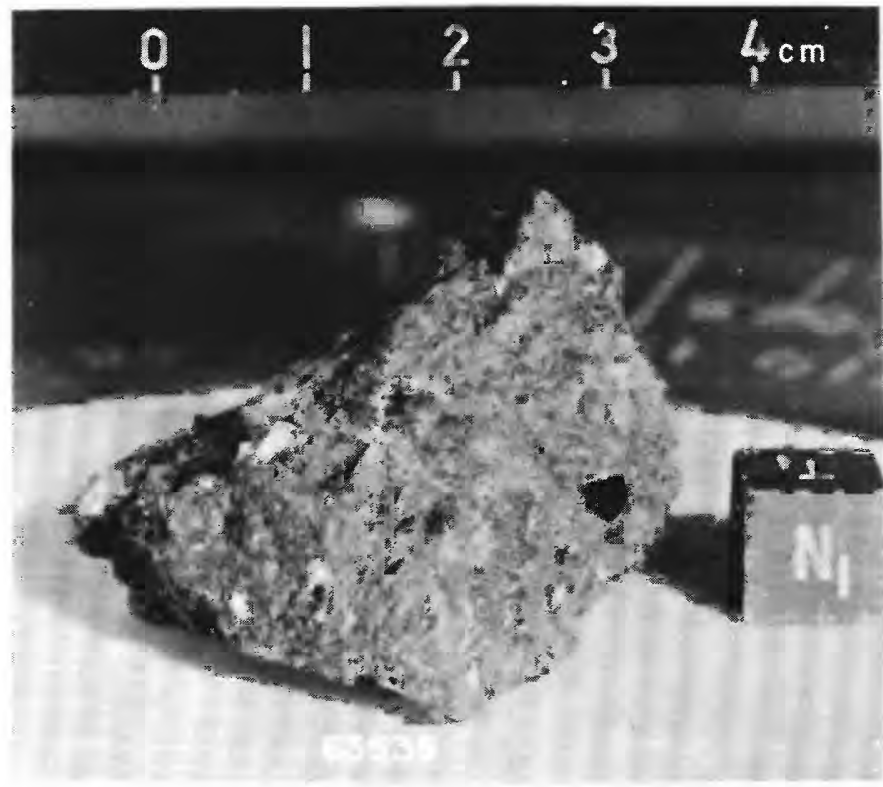

Figure 36D. - Rake fragment 63538 in LRL (photograph S72-43502). Metaclastic $\left(\mathrm{C}_{2}\right)$ rock.

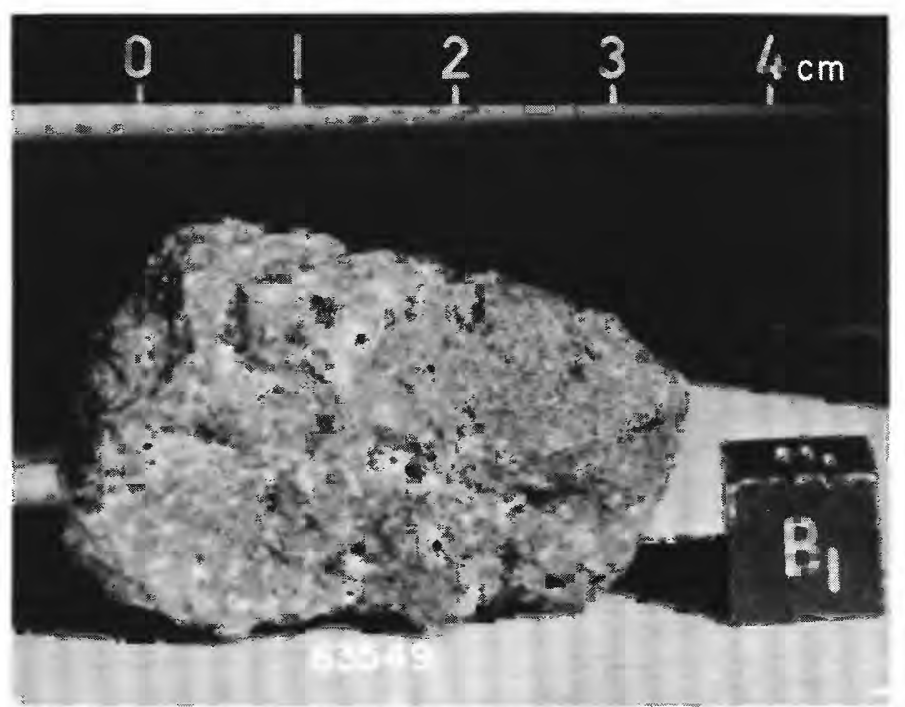

Figure $36 E$.- Rake fragments 63549 in LRL (photograph S$72-43508)$. Metaclastic $\left(\mathrm{C}_{2}\right)$ rock.

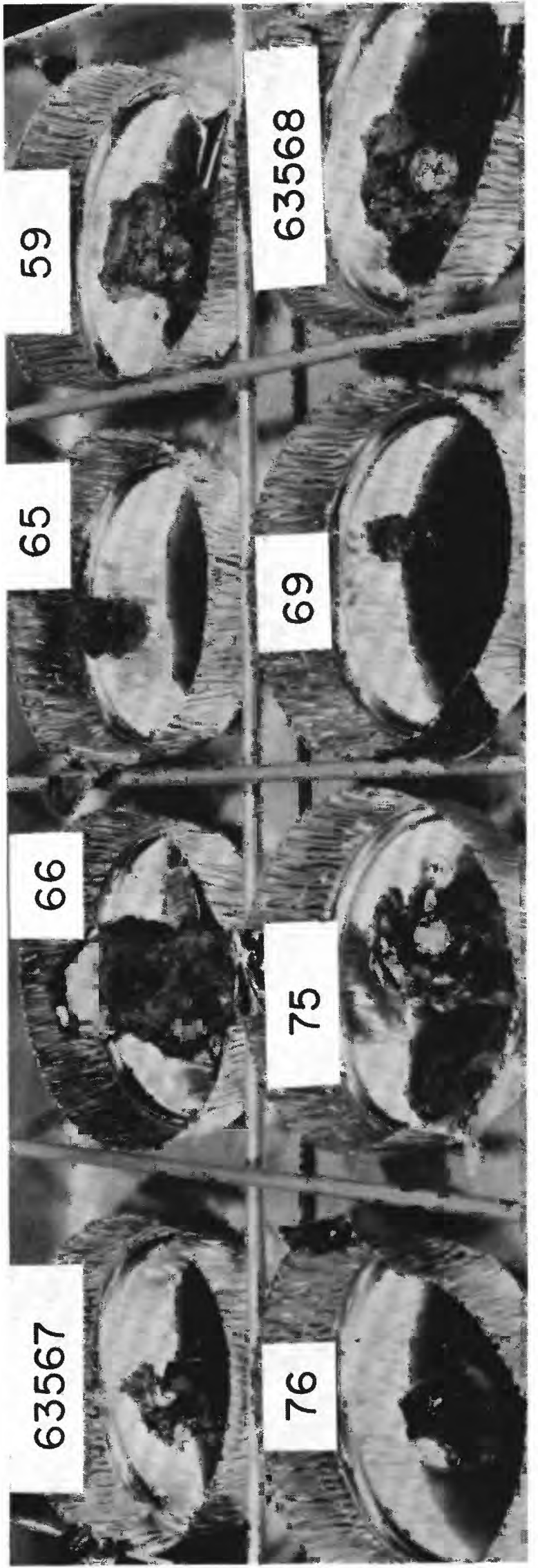

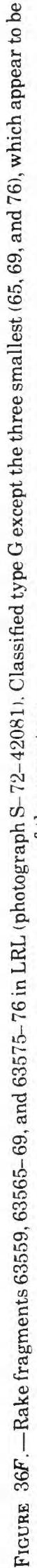




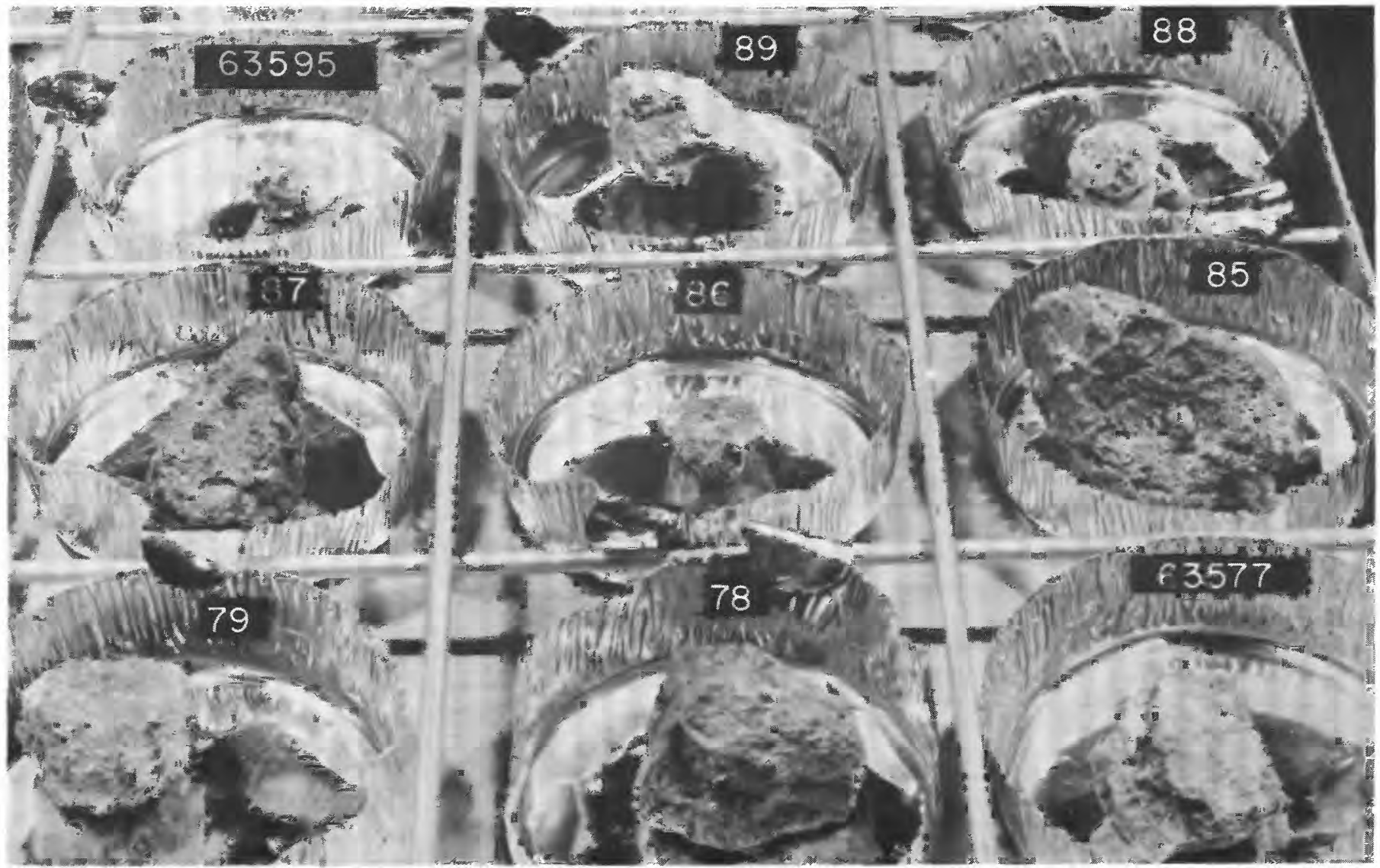

FiguRe 36G.-Part of rake sample 63525-98 in LRL (photograph S-72-42071). This group includes fragments 63577-79, 63585-89, and 63595. Classified as follows: fragment $77, \mathrm{~B}_{4}\left(\mathrm{C}_{2}\right)$; fragments $78,79,87,89$, and $95, \mathrm{~B}_{3}$, and fragment $88, \mathrm{~B}_{2}\left(\mathrm{~B}_{3}\right)$; fragment $85, \mathrm{C}_{2}$, metaclastic; 86, <2 g not classified.
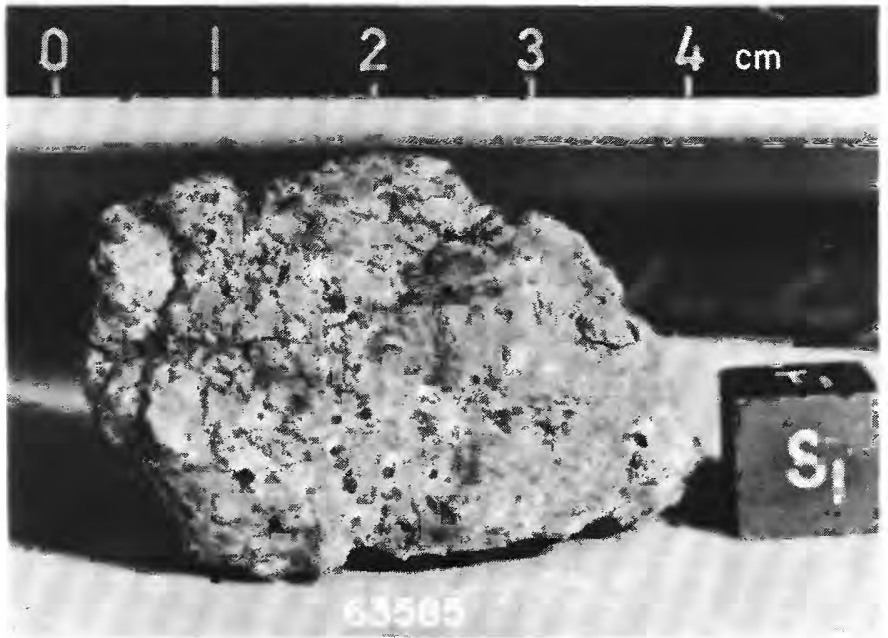

FIGURE $36 H$.- Rake fragment 63585 in LRL (photograph S72-43492). Metaclastic $\left(\mathrm{C}_{2}\right)$ rock. 


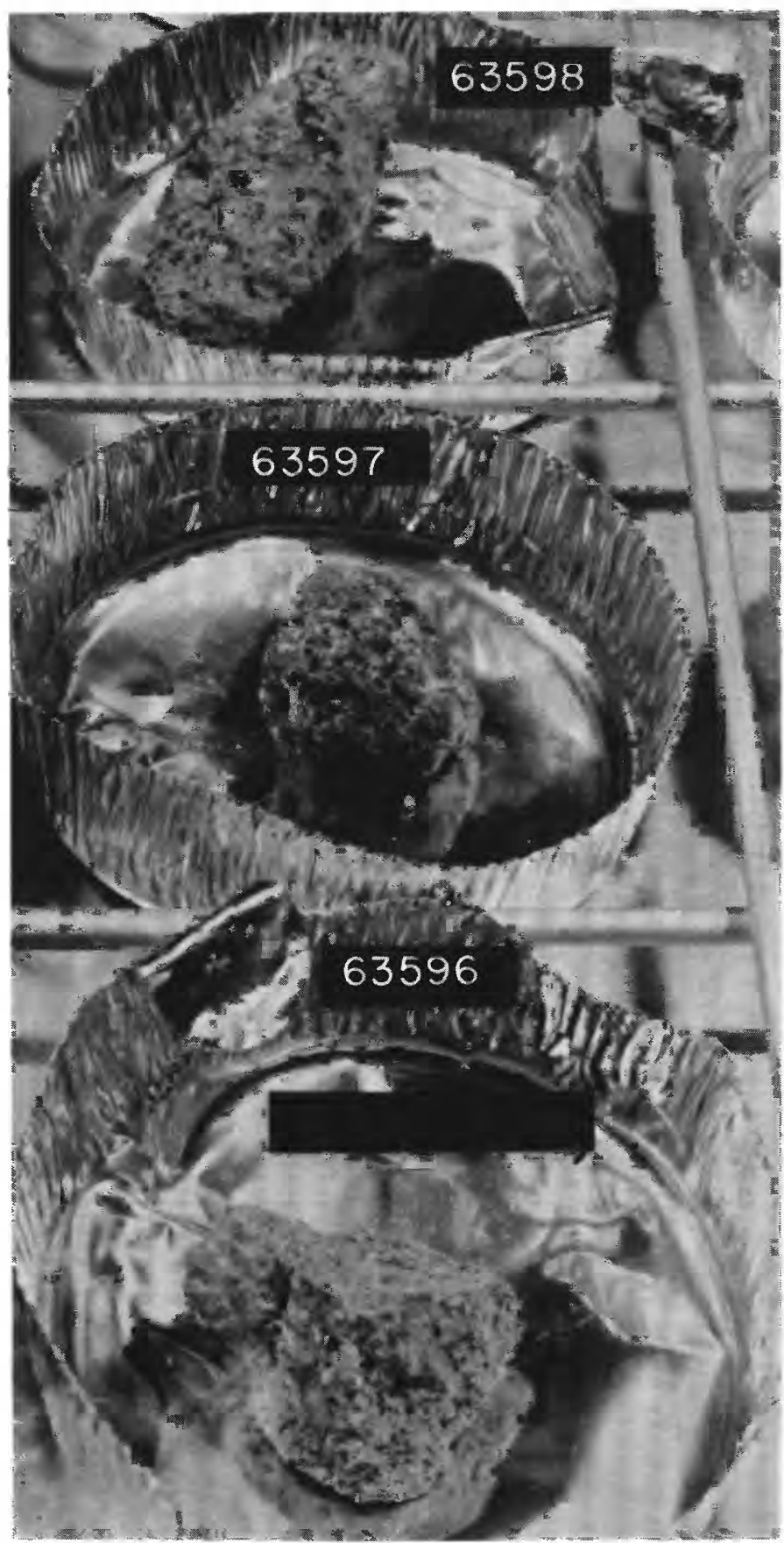

Figure 36I.-Part of rake sample $73525-98$ in LRL (photograph S-72-42082). This group includes fragments 63596-98, all classified as $\mathrm{B}_{3}$ breccia. 
SAMPLE: 63500-09, 63515; 63525-29, 35-39, 45-49, 55-59, 65-69, 75-79, 85-89, 95-98 (rake samples)

Station: 13

Landmark: $5 \mathrm{~m}$ west-northwest of Shadow Rock.

Rock type: Soil and fragments collected with the rake, types B4, C2, and $B 3$ predominant.

SURFACE CHARACTERISTICS OF SAMPLE AREA

Slopes: Regional slope to southeast off North Ray crater. Local

slopes undulating but averaging about $5^{\circ}$.

Fragment population

Size range and distribution: Small rocks $(2-10 \mathrm{~cm})$ covering

5 percent of surface; clotting of soil by bootprints makes the surface appear to have a higher rock percentage than in undisturbed areas.

Color: In immediate area of sample, all are of same dull gray.

Shapes: Fragments are all subrounded if at $10 \mathrm{~cm}$ end of size

range and subangular at 2-3 cm end of size range.

Fillets: Not visible.

Apparent burial: None.

Fines

Dust cover: None identifiable.

Color: Same as rocks.

Compaction: Less compacted than soil at North Ray crater.

Craters

Size range and distribution: Random 1-2 $\mathrm{m}$ fresh to subdued

craters in local area. None recognizable within 2 ril of sample

area.

Shape: Circular with low rims.

Ejecta: Slightly raised rims, material expected to be part of North Ray crater ejecta blanket.

SAMPLE CHARACTERISTICS FOR 63500-04 (rake soil)

Size: < $1 \mathrm{~cm}$ fines; 601.46 grams.

Color: Gray.

Comparison with other soil in area: Probably typical regolith.

Probable origin: Regolith derived from North Ray crater ejecta.

SAMPLE CHARACTERISTICS FOR 63505-09, 63515 (six incidental fragments collected with soil sample 63500-04).

Size: 1-2 cm; 19.07 grams total weight.

Color: Gray.

Shape: Angular and subangular (see figure 36B)

SAMPLE CHARACTERISTICS FOR 63525-98 (39 fragments)

Size: 1-4 cm; 366.72 grams total weight (see figures $36 \mathrm{C}$ and $36 \mathrm{I}$ ).

Probable origin: Regolith derived from North Ray crater ejecta. 


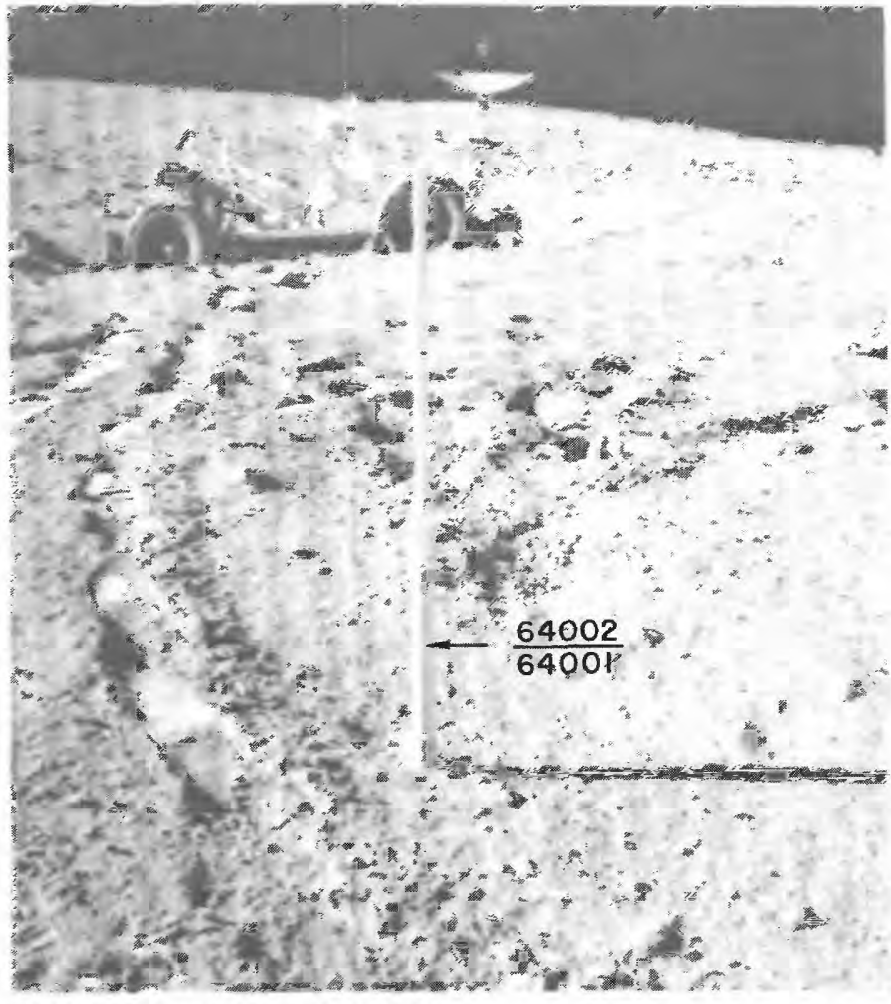

SAMPLE: $64002 / 64001$
Figure 37-Location of double drive-tube sample 64002/64001 about $5 \mathrm{~m}$ north of LRV at station $4 \mathrm{a}$, shown during sampling in photograph AS16-110-17951; view is south. Location of station 4a is shown in chap. D4, figures $1-3$.

Station: $4 a$ (for location, see Chapter $D 4$ figures 1-3).

Landmark: Vicinity of Cinco a crater, downslope from rim of 15-m

crater (LRV parking area), $\simeq 5 \mathrm{~m}$ north of $L R V$.

Rock type: Double drive tube, soil sample.

SURPACE CHARACTERISTICS OF SAMPLE AREA

Slopes: Regional slope $\simeq 10^{\circ}-15^{\circ}$ northwest.

Fragment population

Size range and distribution: Few scattered cobbles $5-10 \mathrm{~cm}$;

fragments < $5 \mathrm{~cm}$ common; most fragments are $<1 \mathrm{~cm}$.

Color: Gray.

Shapes: Small fragments mainly angular and platy; well-rounded

10-cm rock west of drive tube; few small subrounded fragments.

Fillets: Apparent on rounded fragments, mostly on uphill sides.

Apparent burial: Moderately deep, mostly by filleting.

Dust Cover: Appears heavy, probably from kicked material.

Fines

Color: Gray.

Compaction: Loose.

\section{Craters}

Size range and distribution: Cinco a crater (60-70 m diameter) is less than 1 crater diameter to the $N E$; the LRV is parked on rim of 15-m crater; smaller ones include $1 / 2 \mathrm{~m}$ concentric crater SW of drive tube.

Shape: Cinco a is sharp-rimmed; smaller ones are more subdued; I/2 $\mathrm{m}$ concentric crater appears relatively fresh, though shallow. Ejecta: Possibly on ejecta blanket of Cinco a. Blocks south of LRV may be part of ray from South Ray crater.

SAMPLE CHARACTERISTICS

Size: Upper drive tube (64002), 584.1 grams; lower (64001) 752.3 grams. Probable origin: Regolith, possibly including Descartes material at depth. Possibly ejecta from Cinco a crater. 


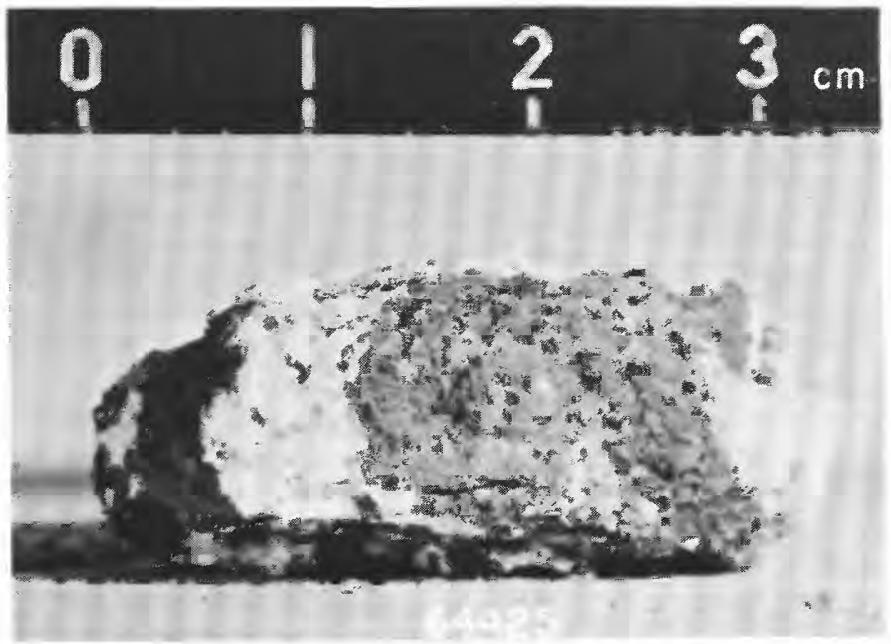

FigURE 38-Sample 64425 in LRL (photograph S-72-41585, S, view). $B_{2}$ breccia collected incidentally with soil sample $64420-24$ at the same location as rock sample 64475 , also a $B_{2}$ breccia. See figs. $41 A, B, D, E$ for lunar-surface photographs and accompanying description of the sample area. Also see chap. D4, fig. 5, for N1 photographic view of sample 64425 in LRL.

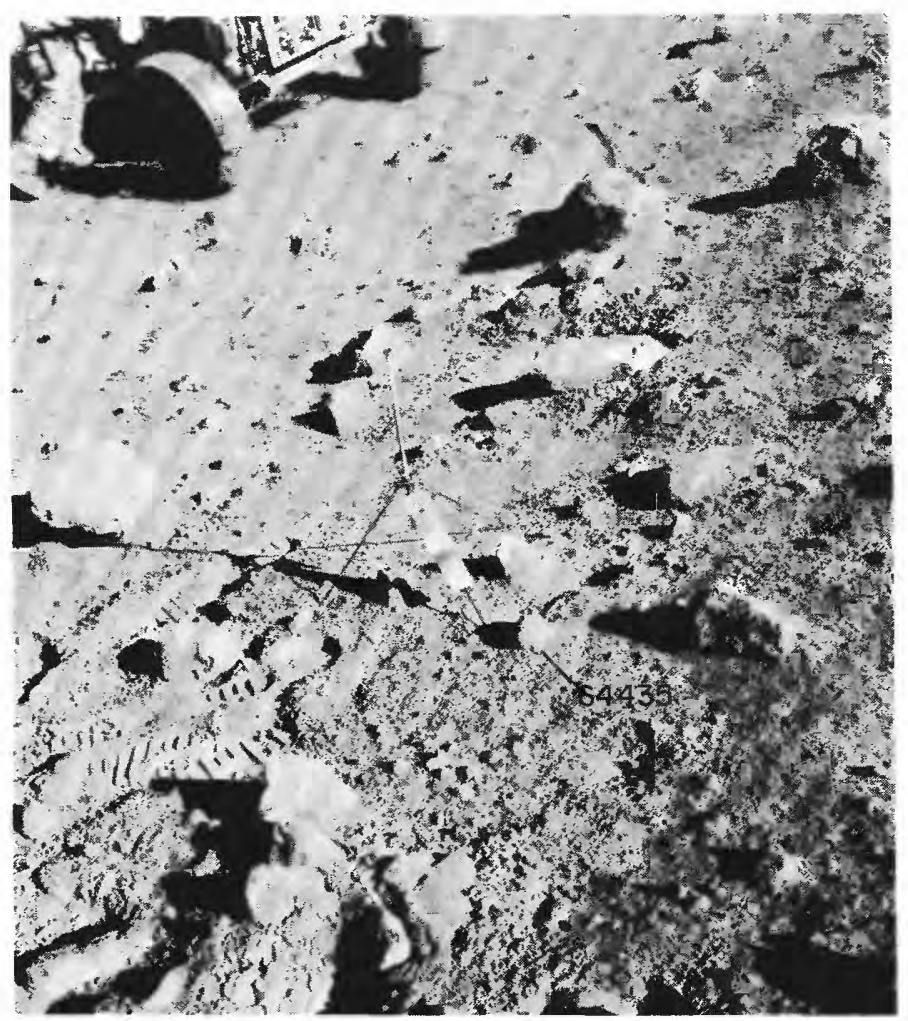

Figure 39A.-Location of sample 64435 shown before sampling in photograph AS16-107-17445; view is northwest toward Rover parked at station 4a. The sample, a $\mathrm{B}_{2}$ breccia, looks similar in shape and reflectance to rocks nearby. Location also shown in figures $40 A$ and $41 A$.

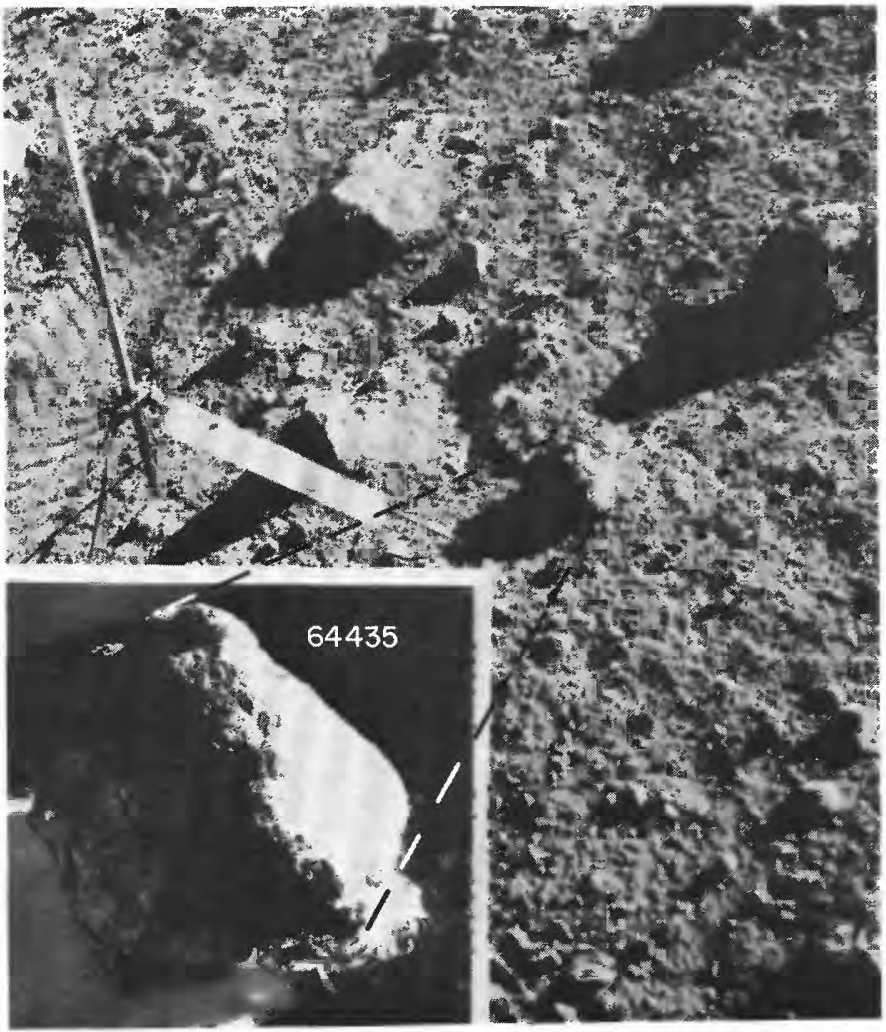

Figure 39B.-Sample 64435 showing approximate lunar orientation reconstructed in LRL compared to photograph AS16-10717444 taken before sampling; view is northeast (inset photograph, S-72-41423). 


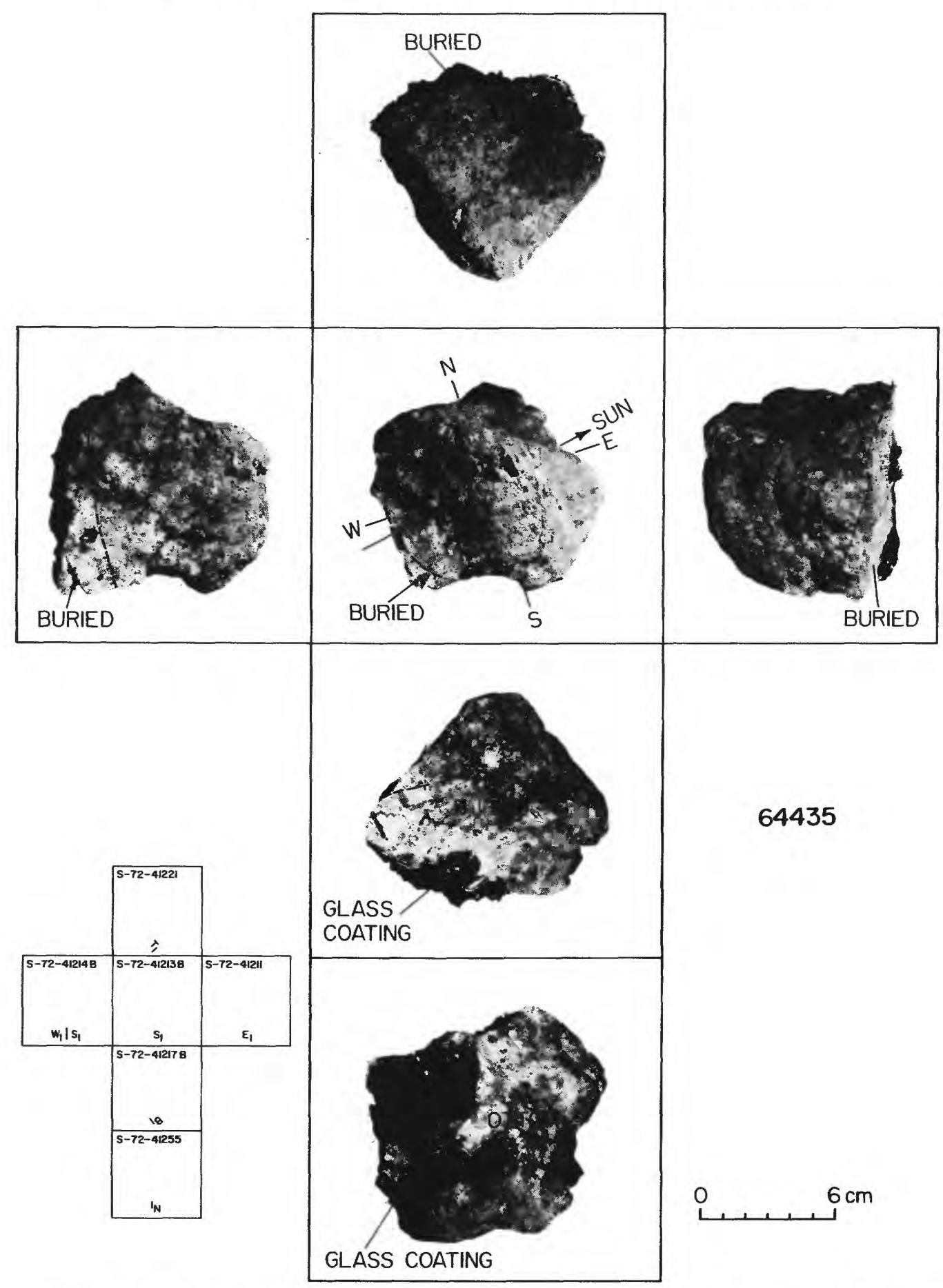

FigURE 39C.-Orthogonal views of sample 64435 related to its lunar orientation at time of sampling. See chapter D4, figs. $6 A-C$, for $N_{1}$ photographic view and two photomicrographs of this $B_{2}$ breccia. 
SAMPLE : 64435

Station: $4 a$ (for location, see Chapter D4 figures 1-3).

Landmark: Vicinity of Cinco a crater, $\simeq 3 \mathrm{~m}$ from $L R V$, on wall of subdued 15-m crater.

Rock type: Light-gray breccia, B2, partly glass coated.

SURFACE CHARACTERISTICS OF SAMPLE AREA

Slopes: Regional slope $\simeq 10^{\circ}-15^{\circ}$ downward to the northwest off

Stone Mountain; local crater slope about the same.

Fragment population

Size range and distribution: Less than $10 \mathrm{~cm}$ abundant; 10-40

cm common; $40 \mathrm{~cm}-1 \mathrm{~m}$ sparse.

Color: Whitish cast on most rocks.

Shapes: Majority very angular.

Fillets: Moderately vell developed around most blocks and

cobbles.

Apparent burial: Not visible.

Dust cover: Most do not have dust; many are covered (see Table

3, . 20).

Fines

Color: Gray.

Compaction: Loose.

\section{Craters}

Size range and distribution: Cinco a crater (60-70 $\mathrm{km}$ diameter)

is less than 1 crater diameter to the $N E$; sample collected from

$E$ wall of 15-m crater; smaller craters occur among blocks indistinctly.

Shape: Large craters sharp, circular; smaller craters irregular, subdued.

Ejecta: Probably on blocky ray from South Ray crater and ejecta from $C$ inco a crater.

SAMPLE CHARACTERISTICS FOR 64435

Size: $12 \times 11 \times 10 \mathrm{~cm} ; 1079$ grams.

Color: Very light gray.

Shape: Subangular to subrounded.

Fillet: slight, on uphill (east) side.

Apparent burial: < $1 / 4$ (perched).

Dust cover: Present.

Comparison with other fragments in area: Apparently is typical of the predominant $B 2$ breccia population at station $4 a$.

Probable origin: Ejecta from South Ray crater, although may be derived from Cinco a crater. 


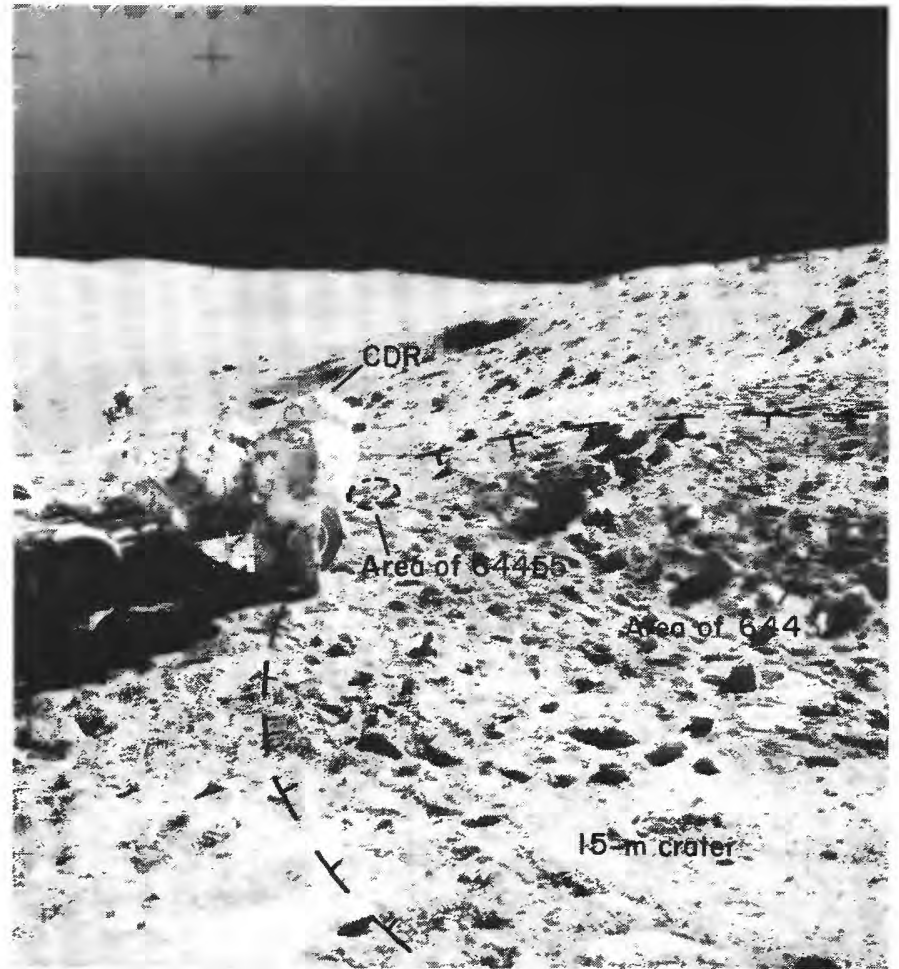

Figure 40A.-Location of samples 64435 and 64455 shown after sampling in panorama photograph AS16-110-17961; view is northeast. See also fig. $41 A$ for locations of the samples.

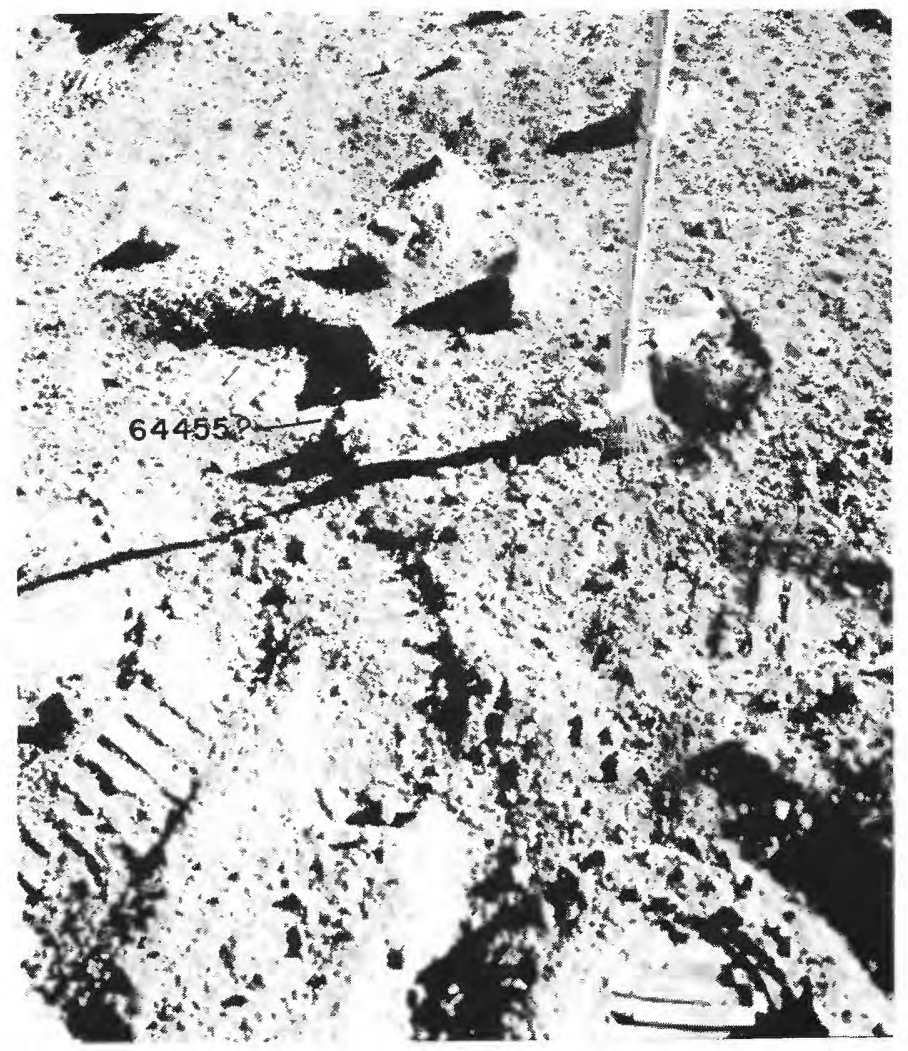

Figure $40 B$.- Area of sample 64455 shown before sampling in photograph AS16-107-17456; view is north. The "bubble of glass splatter" collected from beneath a rock in this area (crew comments, table 3, p. 22). Sample not positively identified in picture.

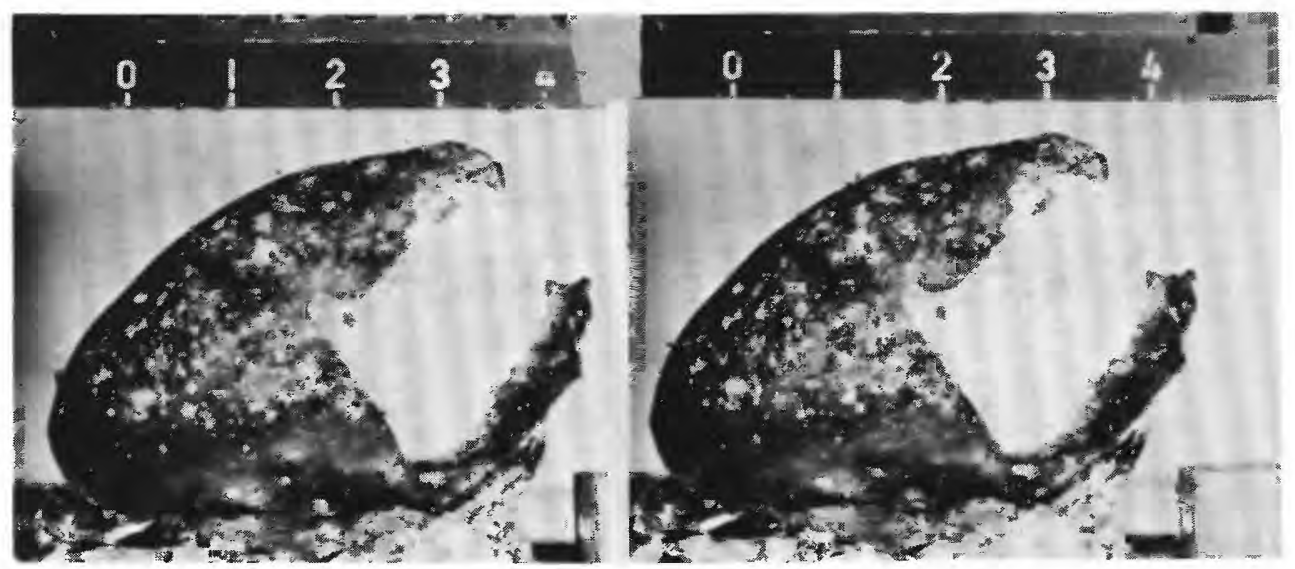

FIGURE 40C.- Stereopair of sample 64455, a glass-coated $C_{2}$ metaclastic rock in LRL; photographs S-72-43258 (right) and $-43258 \mathrm{~B}$ (left). Breakage may have occurred during sampling. Note difference in number of microcraters in glass indicating the exposed relative to the buried (or protected) surfaces. See chap. D4, figs. $10 \mathrm{~A}-\mathrm{C}$, for the $\mathrm{N}_{1}$ photographic view and two photomicrographs. 
SAMPLE: 64455

Station: $4 a$ (for location, see Chapter D4 figures 1-3).

Landmark: Vicinity of Cinco a crater, on rim of subdued 15-m crater. Rock type: Glass-coated metaclastic rock, C2.

SURFACE CHARACTERISTICS OF SAMPLE AREA

Slopes: Regional slope $\simeq 10^{\circ}-15^{\circ}$ downward to the northwest off stone mountain.

Fragment population

Size range and distribution: Less than $10 \mathrm{~cm}$ abundant; $10-40 \mathrm{~cm}$ common; $40 \mathrm{~cm}-1 \mathrm{~m}$ sparse. Few scattered blocks $(10-20 \mathrm{~cm})$ within $1 / 2$ meter radius of sample area.

Color: Whitish cast.

Shapes: Blocks angular to subangular; cobble size and smaller mainly subround.

Fillets: Well developed around large blocks (15-20 cm); minor around cobbles.

Apparent burial: Mostly perched

Dust cover: Variable; crew reported most rocks without dust cover.

Fines

Color: Gray surface.

Compaction: Loose.

Craters

Size range and distribution: Cinco a crater (60-70 $\mathrm{m}$ diameter)

is less than 1 crater dlameter to the $N E$. The 15-m crater where sample collected is packed by craters $\simeq 1 / 2 \mathrm{~m}$ diameter.

Shape: Cinco a is sharp; 15-m crater is subdued; most craters circular.

Ejecta: Blocks may be part of ray from South Ray; possibly includes Cinco a ejecta.

SAMPLE CHARACTERISTICS FOR 64455

Size: $5.6 \times 4 \times 2.5 \mathrm{~cm} ; 56.68$ grams.

Color: Grayish-black glass coating; white interior.

Shape: Ovoid, rounded.

Fillet: Not recognized.

Apparent burial: Not recognized in lunar-surface photo; sample was covered by another rock (see Table 3, p. 22).

Dust cover: Unknown.

Comparison with other fragments in area: C2 rock type is relatively sparse among samples from station $4 a$.

Probable origin: Rounded regolith fragment coated by impact-melt glass

from a large cratering event -- probably South Ray. 

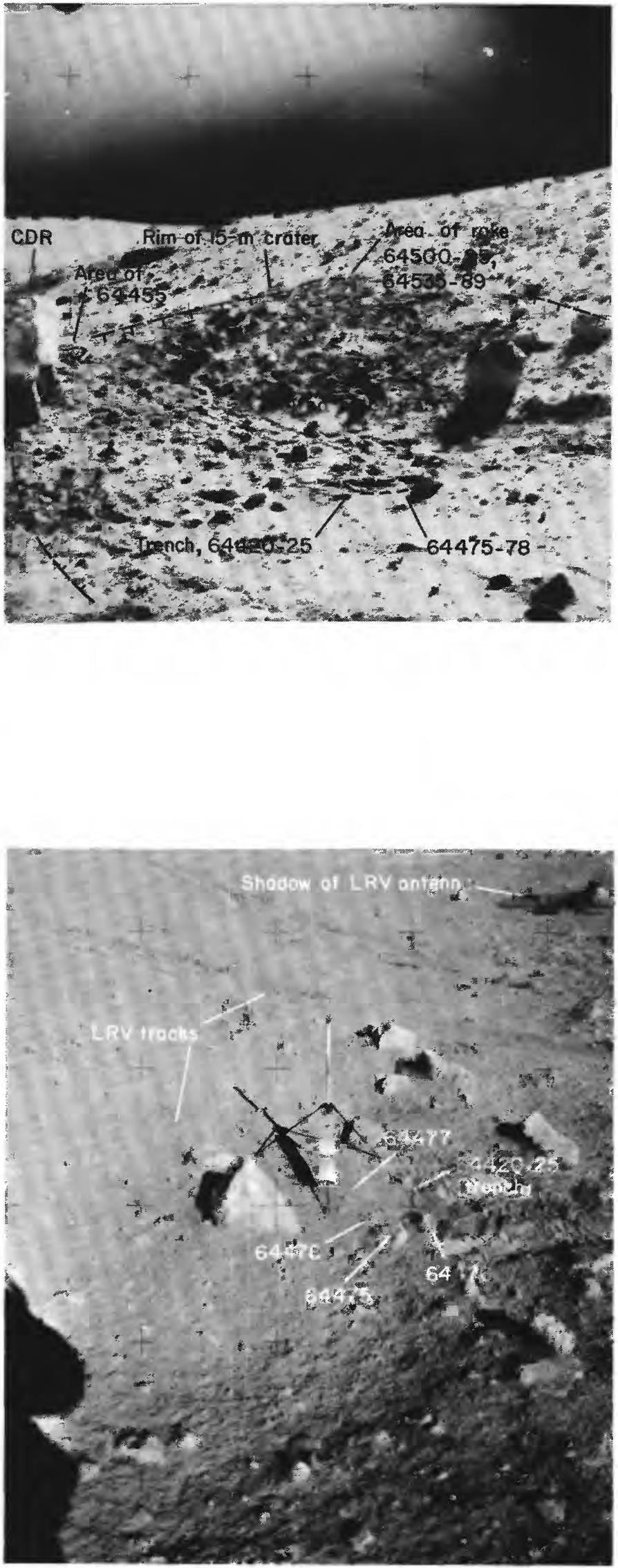

Figure 41A.-Location of samples 64475-78 and 64420-25 (soil and incidental fragment from bottom of trench, $\sim 20 \mathrm{~cm}$ deep, collected near center of 15-m crater on whose rim LRV was parked, shown after sampling in panorama photograph AS16-110-17962. View is northeast and also shows location of all samples (except the double drive tube) collected near the LRV at station 4a.

Figure 41B.-Area of samples 64475-78 and 64420-25 shown before sampling in part of photograph AS16-107-17454; view is west-northwest. See fig. 38 for photograph of sample 64425 in LRL. 


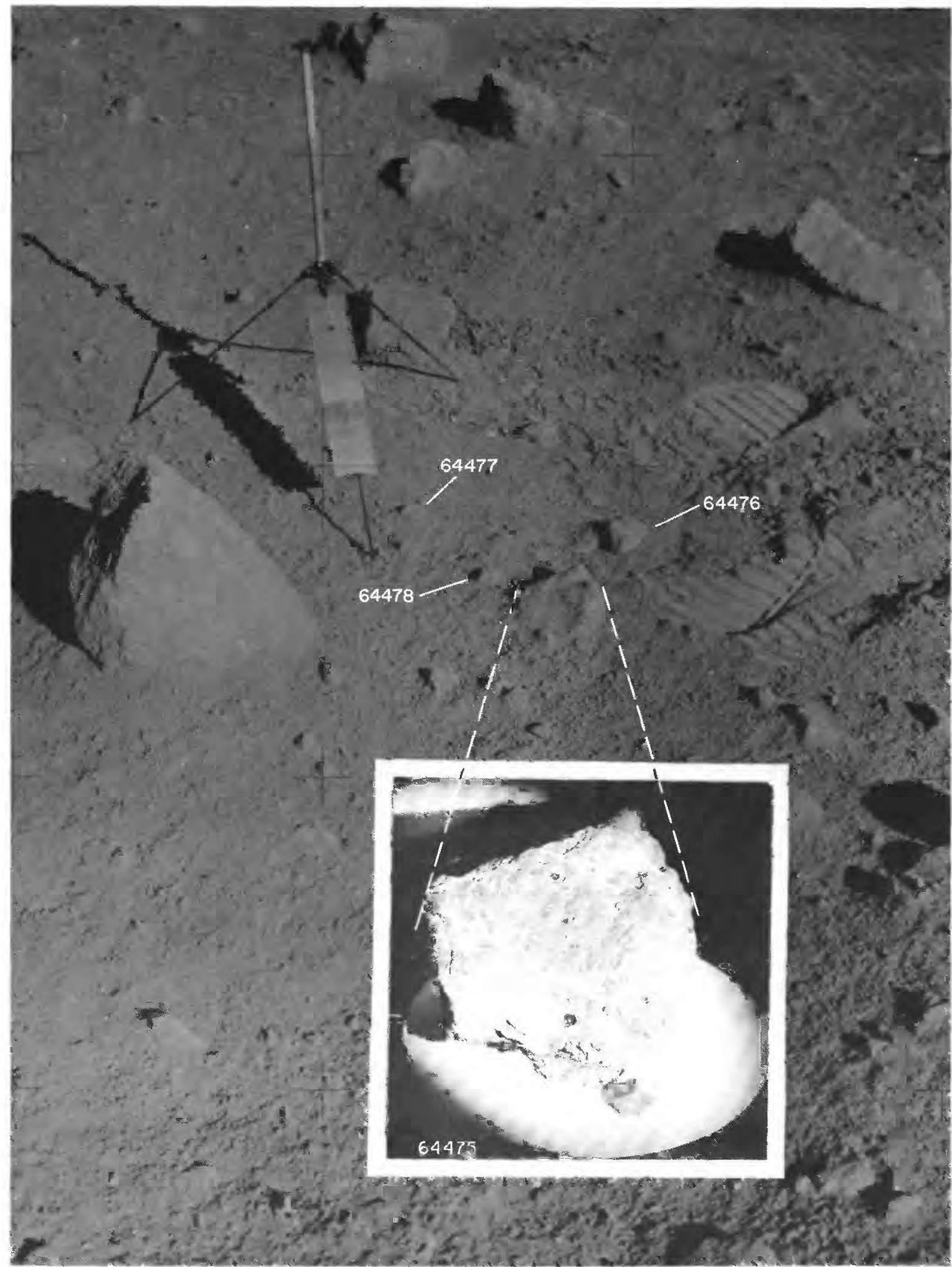

FIGURE 41C.-Sample 64475 showing approximate lunar orientation reconstructed in LRL compared to an enlarged part of photograph AS16-107-17453 taken before sampling. View is west-northwest and samples $64476-78$ are also identified. Note large glass-lined micrometeorite pit on rock 64475 just above soil level (inset photograph, S$72-43116)$. 


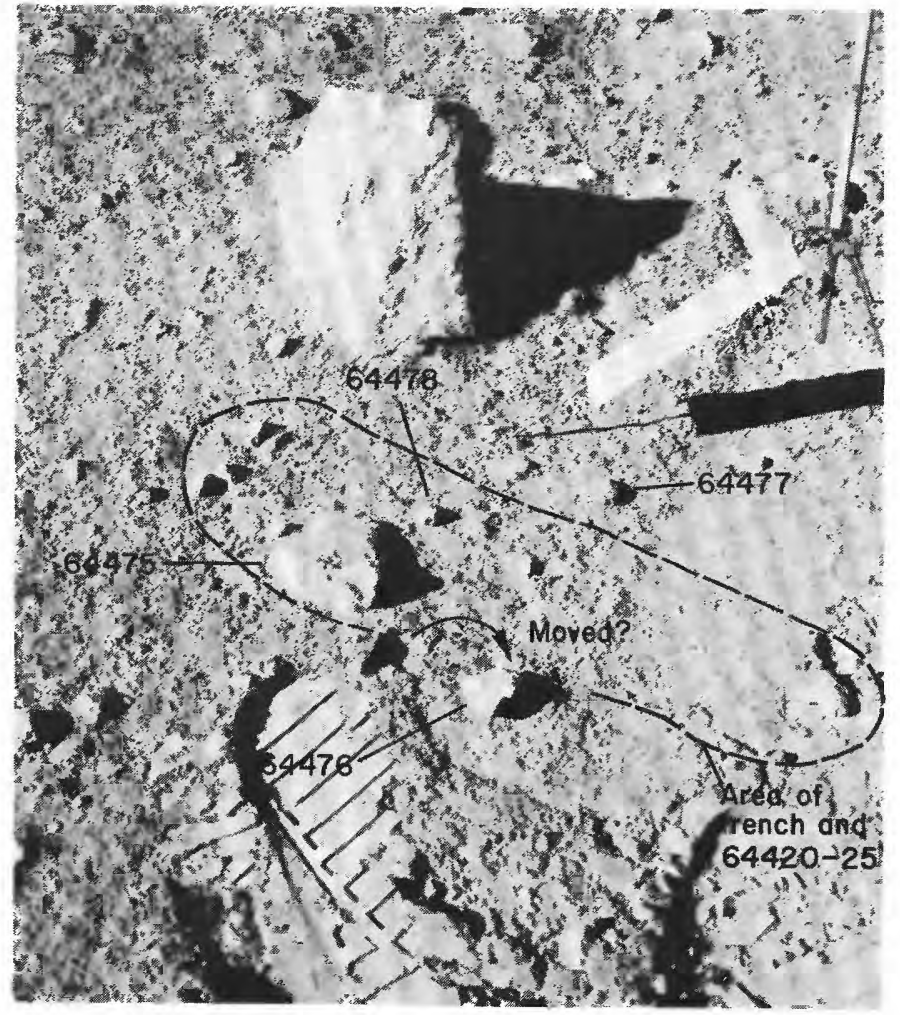

Figure 41D.--Samples 64475-78 and area of trench samples 64420-25 shown before sampling in photograph AS16-107-17452; view is south.

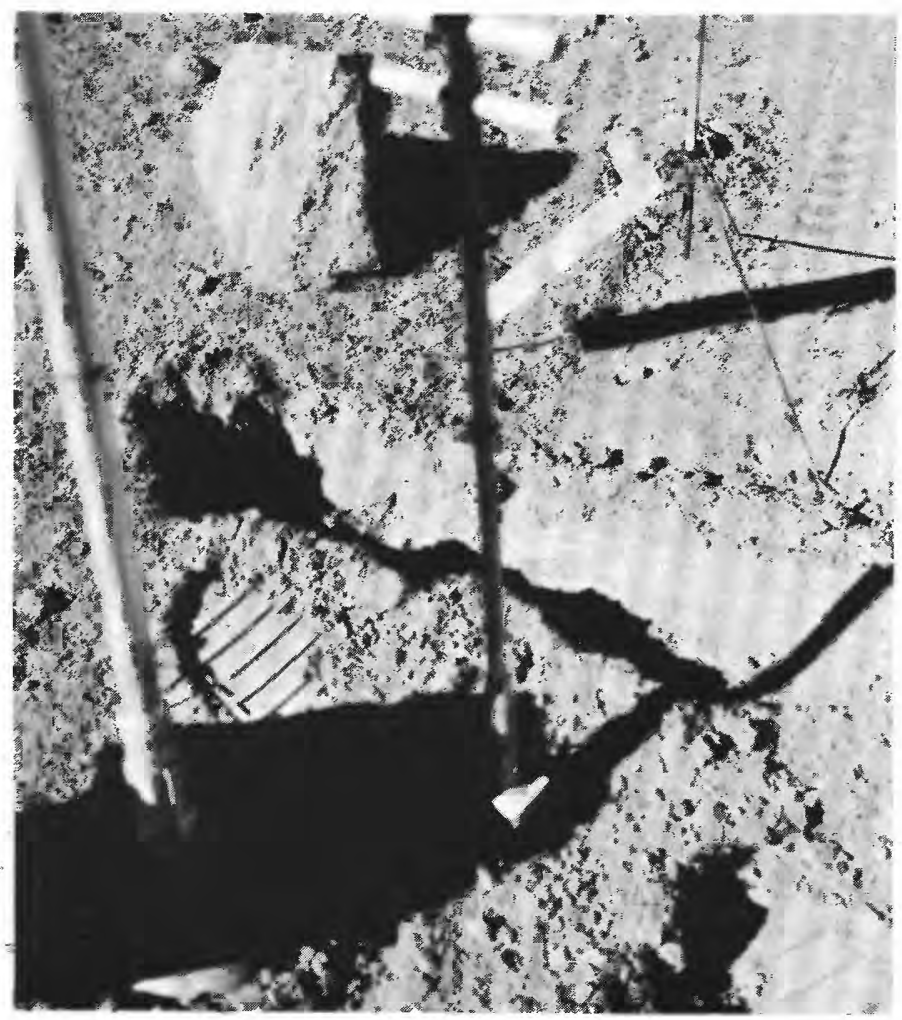

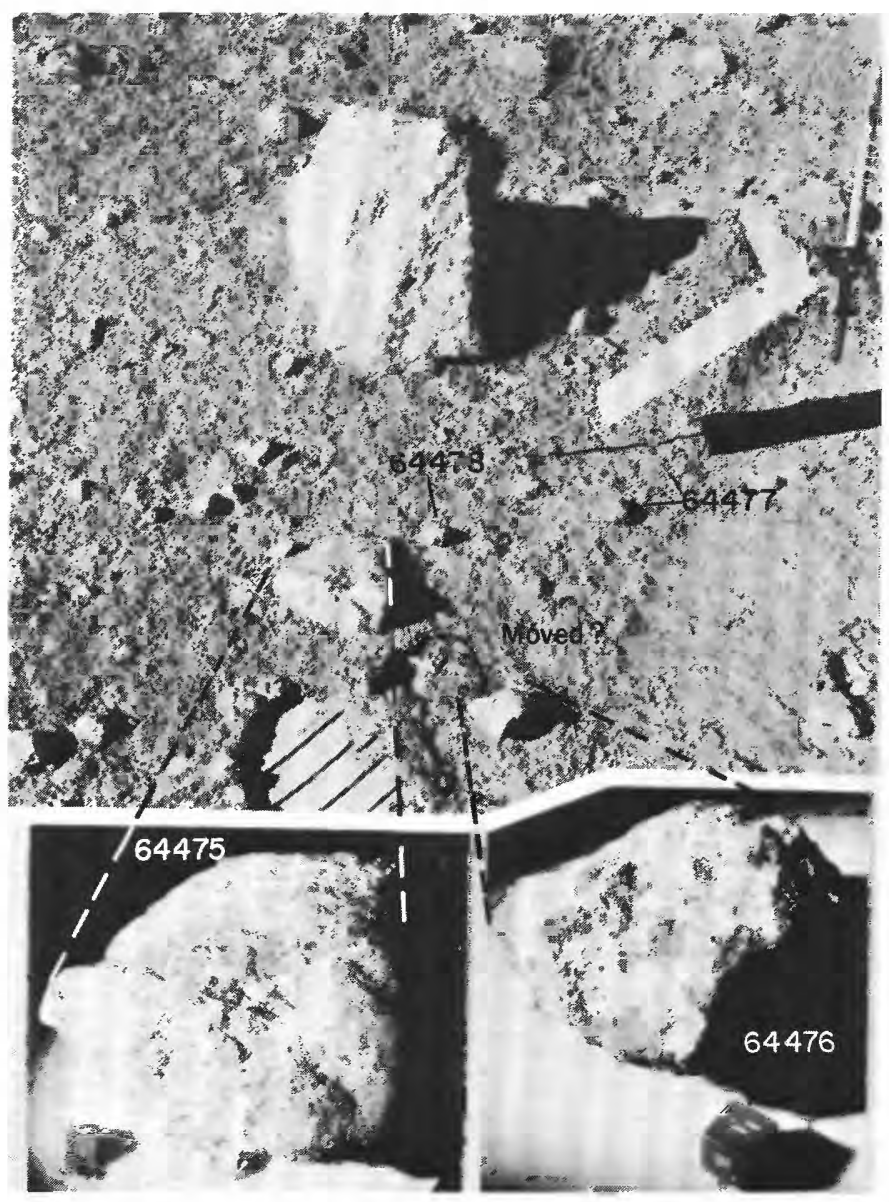

FIGURE $41 F$.-Samples 64475 and 64476 showing approximate lunar orientations reconstructed in LRL compared to an enlarged part of photograph AS16-107-17452 taken before sampling; view is south. Sample 64476 appears to have been moved prior to lunar photography (inset photographs, S- $72-43117$ and 43118, respectively). Samples 64477 and 64478 also identified.

Figure 41E.-Area of samples 64475-78 and 64420-25 shown after sampling in photograph AS16-107-17561; view is south. See fig. 38 for photograph of sample 64425 in LRL. 


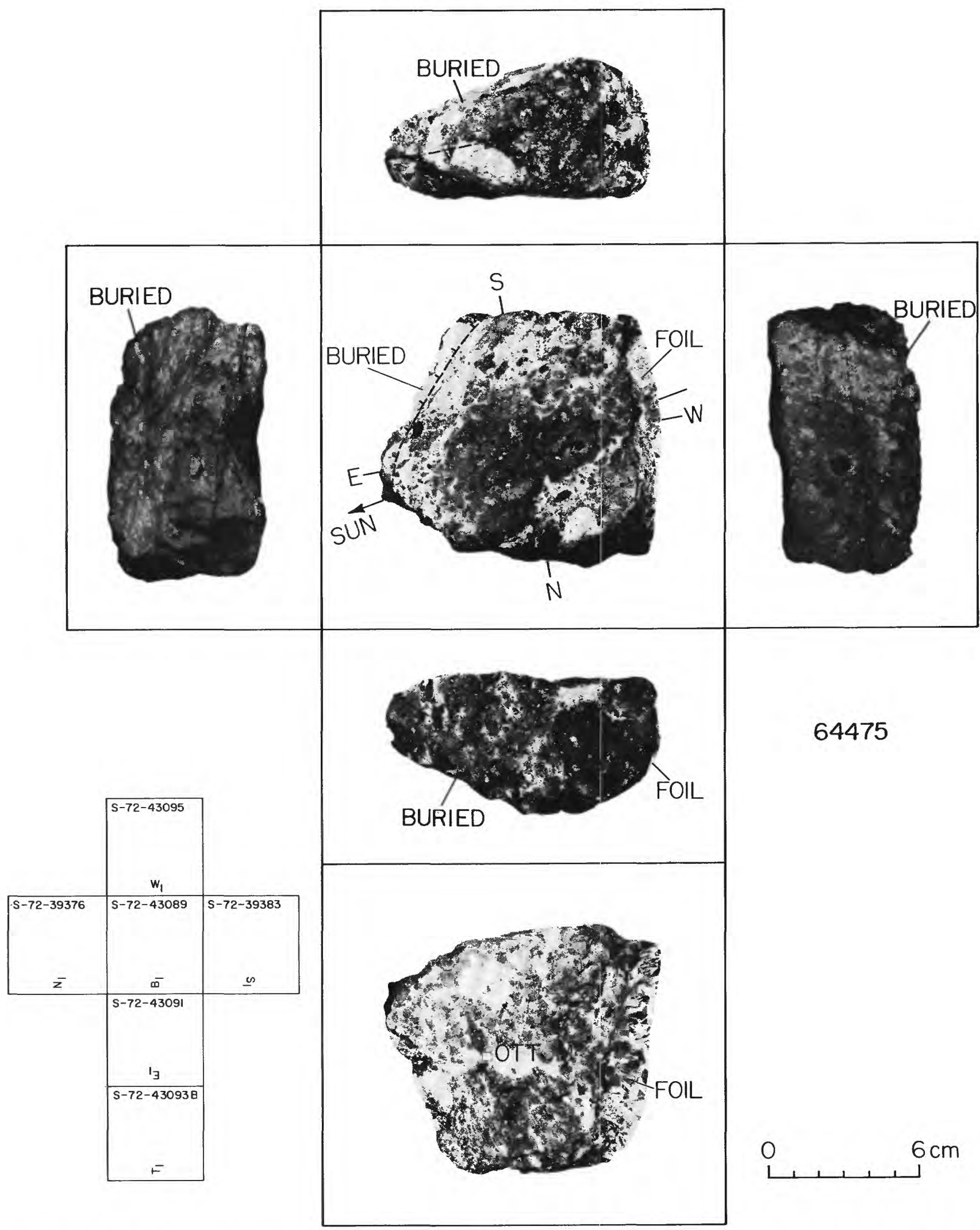

Figure $41 G$.- Orthogonal views of sample 64475 related to its lunar orientation at time of sampling. See chaper D4, fig. 7, for a stereopair of this type $B_{2}$ breccia. 


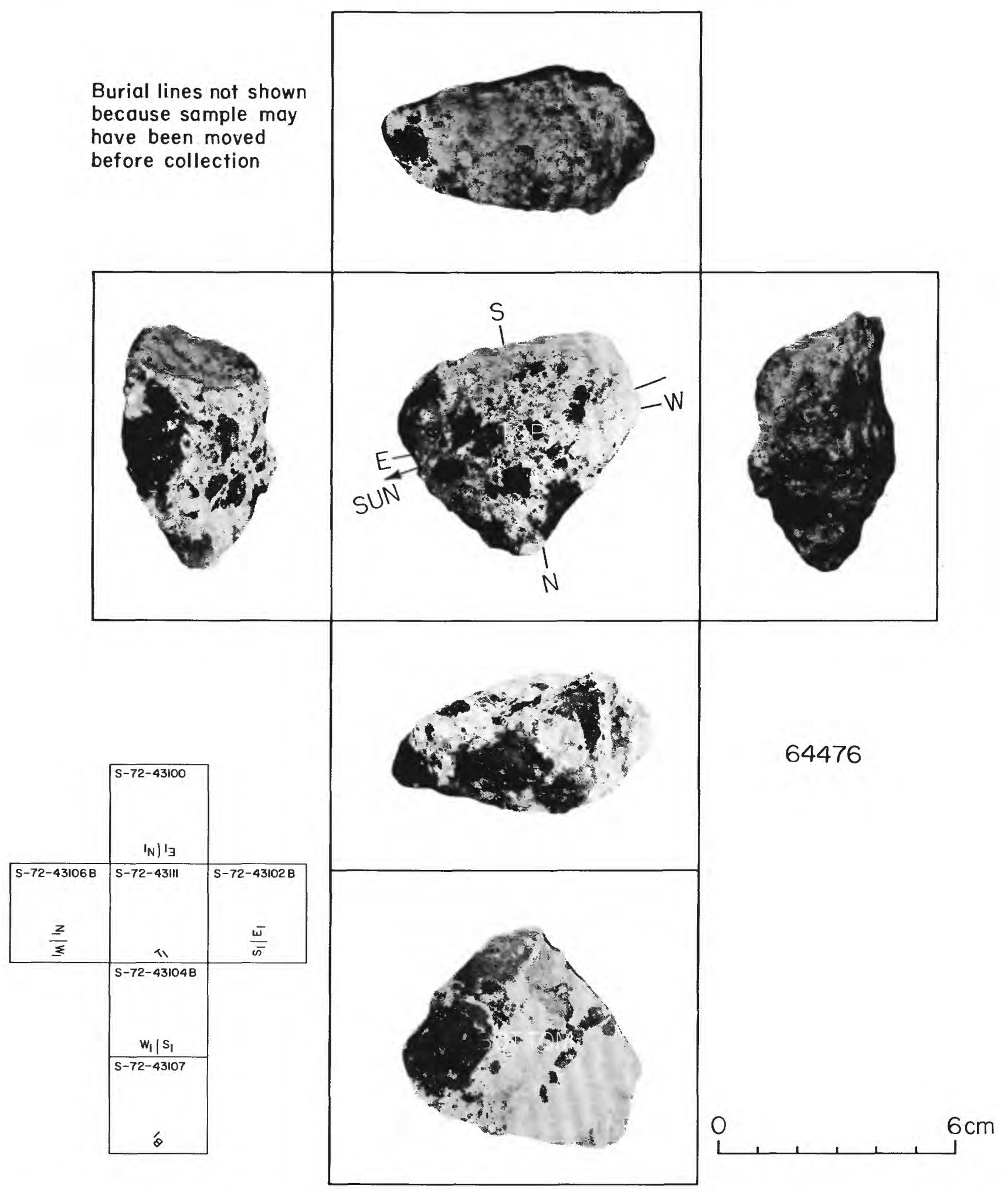

FIGURE $41 H$.-Orthogonal views of sample 64476 related to its lunar orientation (after being moved) at time of sampling. See chapter D4, fig. 8 , for a stereopair of this type $\mathrm{B}_{2}$ breccia. 


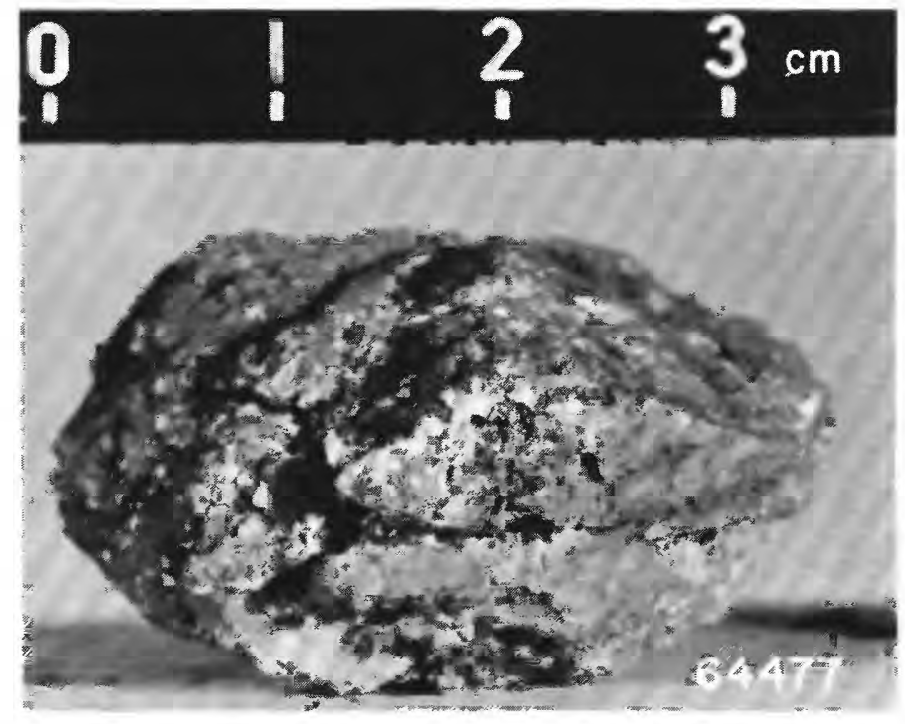

Figure 41I.-Sample 64477 in LRL (photograph S-72-40143), $\mathrm{N}_{1}$ view). $B_{2}\left(B_{4}\right)$ breccia.
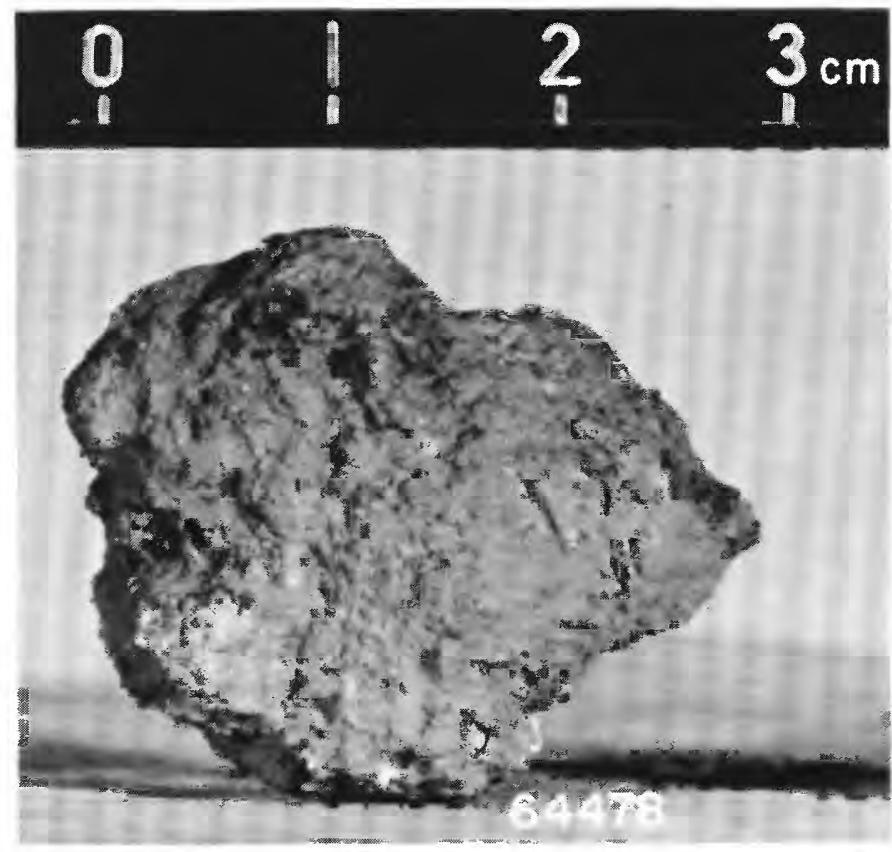

FIGURE 41J.-Sample 64478 in LRL (photograph S-72-40139, $\mathrm{N}_{1}$ view). $\mathrm{B}_{4}\left(\mathrm{~B}_{3}\right)$ breccia.

SAMPLE: $64420-25 ; 64475-78$

Station: 4a (for location, see Chapter D4 figures 1-3).

Landmark: Near Cinco a crater, $\simeq 5 \mathrm{~m}$ from $L R V$, on floor of subdued

15-m crater.

Rock type: 64420-25 soil with incidental fragment; 64475-78 four

breccia fragments, types $B 2, B 2, B 2(B 4)$, and $B 4(B 3)$, respectively.

SAMPLE CHARACTERISITICS OF SAMPLE AREA

Slopes: Regional slope downward to northwest off Stone Mountain;

locally nearly horizontal because of craters in the slope.

Fragment population

Size range and distribution: $5-10 \mathrm{~cm}$ (and less) abundant;

20-40 cm common; meter-size blocks sparsely scattered (majority

$<30 \mathrm{~cm}$ ).

Color: Light gray; whitish clasts where visible in large rocks.

Shapes: Mainly angular; some small rounded rocks.

Fillets: Practically nil around large blocks, slight around

small rocks.

Apparent burial: Mostly perched.

Dust cover: Generally widespread.

Fines

Color: Gray; no subsurface layering reported.

Compaction: Loose.

\section{Craters}

Size range and distribution: Cinco a crater (60-70 m diameter)

is less than I crater diameter to the $N E$; the 15-m crater where sample collected is pocked by a few craters $\simeq 1 / 2 \mathrm{~m}$ in diameter. Shape: Cinco a is sharp rimmed; smaller ones subdued, circular. Ejecta: Possibly on ejecta blanket of Cinco a; blocks may be locally derived or part of ray from South Ray crater. 
SAMPLE CHARACTERISTICS FOR 64420-24

Size: < I cm fines; 331.09 grams total weight.

Color: Gray (no white layer).

Comparison with other soil in area: Apparently typical regolith.

Probable origin: Regolith probably derived mainly from Cinco a crater with contribution from South Ray crater ray.

SAMPLE CHARACTERISTICS FOR 64425 (incidental fragment collected with soil

64420-24) See figure 38 for illustration of sample 64425 in the LRL.

Size: $3.5 \times 2.5 \times 2 \mathrm{~cm} ; 14.62$ grams.

Color: Medium light gray with white areas.

Shape: Blocky, subangular.

Probable origin: Part of blocky ray from South Ray crater; possibly

ejecta from Cinco a crater.

SAMPLE CHARACTERISTICS FOR 64475, B2

Size: $12 \times 10.5 \times 6 \mathrm{~cm} ; 1032$ grams.

Color: Medium light gray.

Shape: Blocky, subangular.

Fillets: None.

Apparent burial: $1 / 3-1 / 2$

Dust cover: Prominent (as reported by crew, see Table 3, p. 22).

Comparison with other fragments in area: The type $B 2$ breccia is predominant among fragments collected at station 4a; possibly represents larger block broken into numerous pieces upon impact.

Probable origin: Part of blocky ray from South Ray crater; or ejecta from Cinco a crater.

SAMPLE CHARACTERISTICS FOR 64476, B2

Size: $7 \times 5 \times 4 \mathrm{~cm}$; 125.1 grams

Color: Matrix white, clasts dark gray

Shape: Subangular

Apparent burial: Perched; probably kicked up before lunar surface

photographs were taken (see figures $4 I D$ and $4 I F$ )

Comparison with other fragments in area: See comments for 64475 .

Probably origin: See comments for 64475

SAMPLE CHARACTERISTICS FOR 64477, B2(B4)

Size: $3.5 \times 2.3 \times 1.1 \mathrm{~cm}$; 19.32 grams

Color: Medium gray

Shape: Subrounded, blocky

Apparent burial: 1/3-1/2

Comparison with other fragments in area: See comments for 64475 .

Probable origin: See comments for 64475

SAMPLE CHARACTERISTICS FOR 64478, B4(B3)

Size: $2.5 \times 2 \times 1 \mathrm{~cm} ; 12.34$ grams

Color: Medium dark gray

Shape: Subangular

Apparent burial: 1/3-1/2

Comparison with other fragments in area: The type $B 4$ breccia is second most common type of rock found at station 4, but not a common type among South Ray ejecta presumably sampled at station 8.

Probably origin: The abundance of breccia types $B 3$ at station 5 and

B4 at station 11 suggest that the source was from the Descartes highlands, possibly Clnco al crater, or from North Ray crater. 

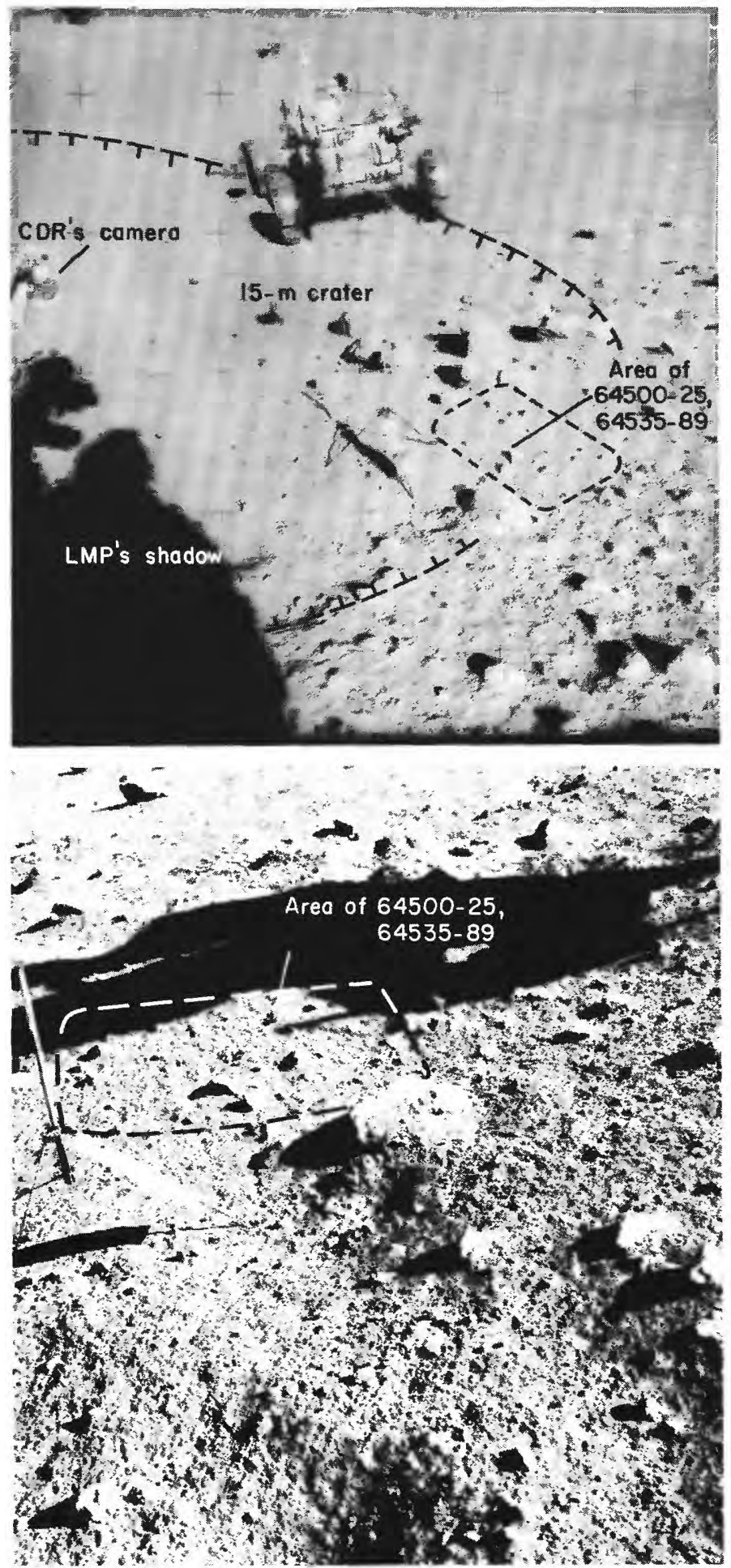

FigURE 42A.-Location of rake samples 64500-25 (soil and incidental fragments), and 64535-89 (rake fragments) shown before sampling in photograph AS16-110-17948. View is west toward LRV on rim of a $15-\mathrm{m}$ crater.
LFigure 42B.-Area of rake samples 64500-25 (soil and incidental fragments) and 64535-89 (rake fragments) shown before sampling in photograph AS16-107-17449; view is north. Individual rake fragments not identified. Fragments collected with rake soil (64505-09, 15-25) not illustrated or classified. 

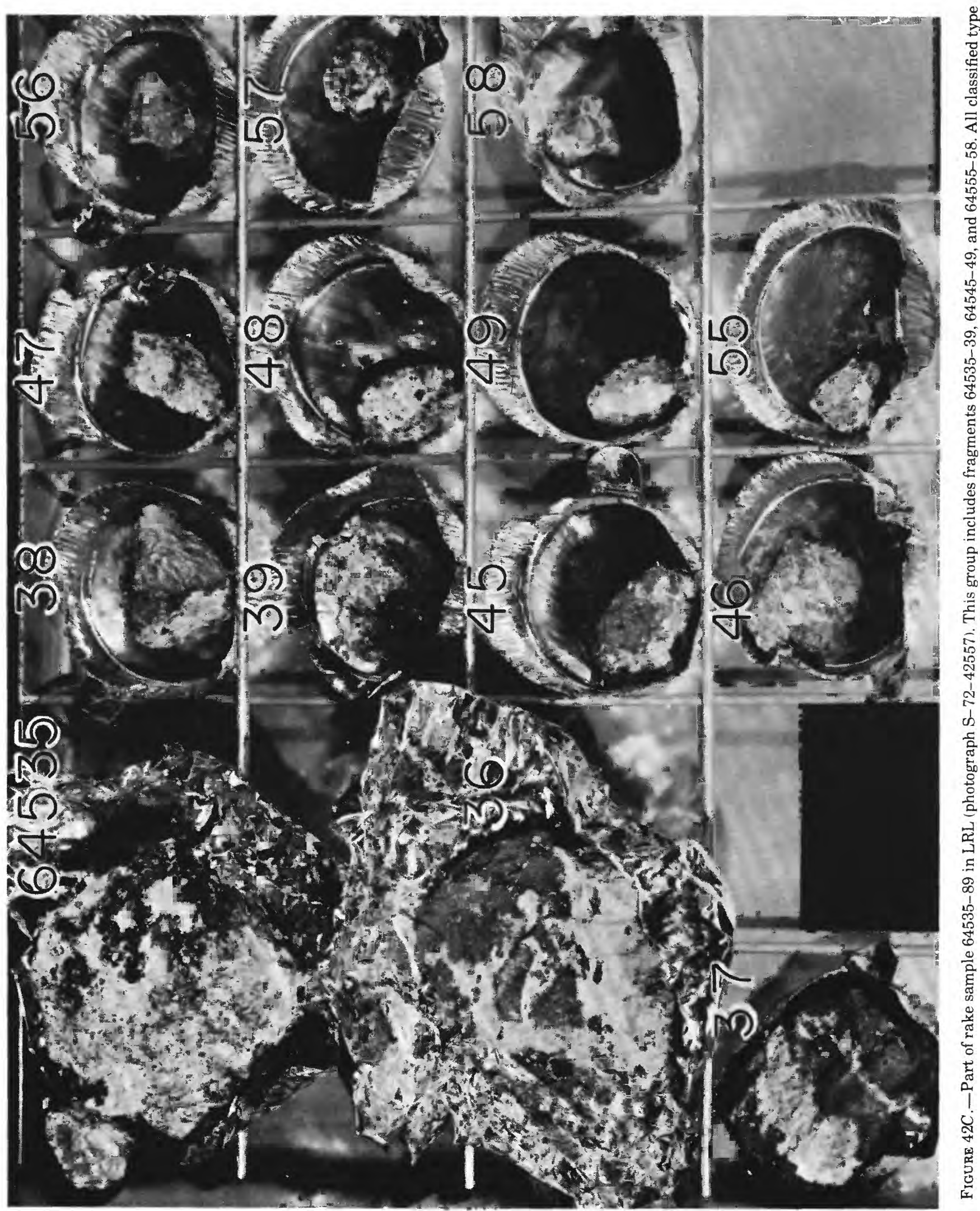


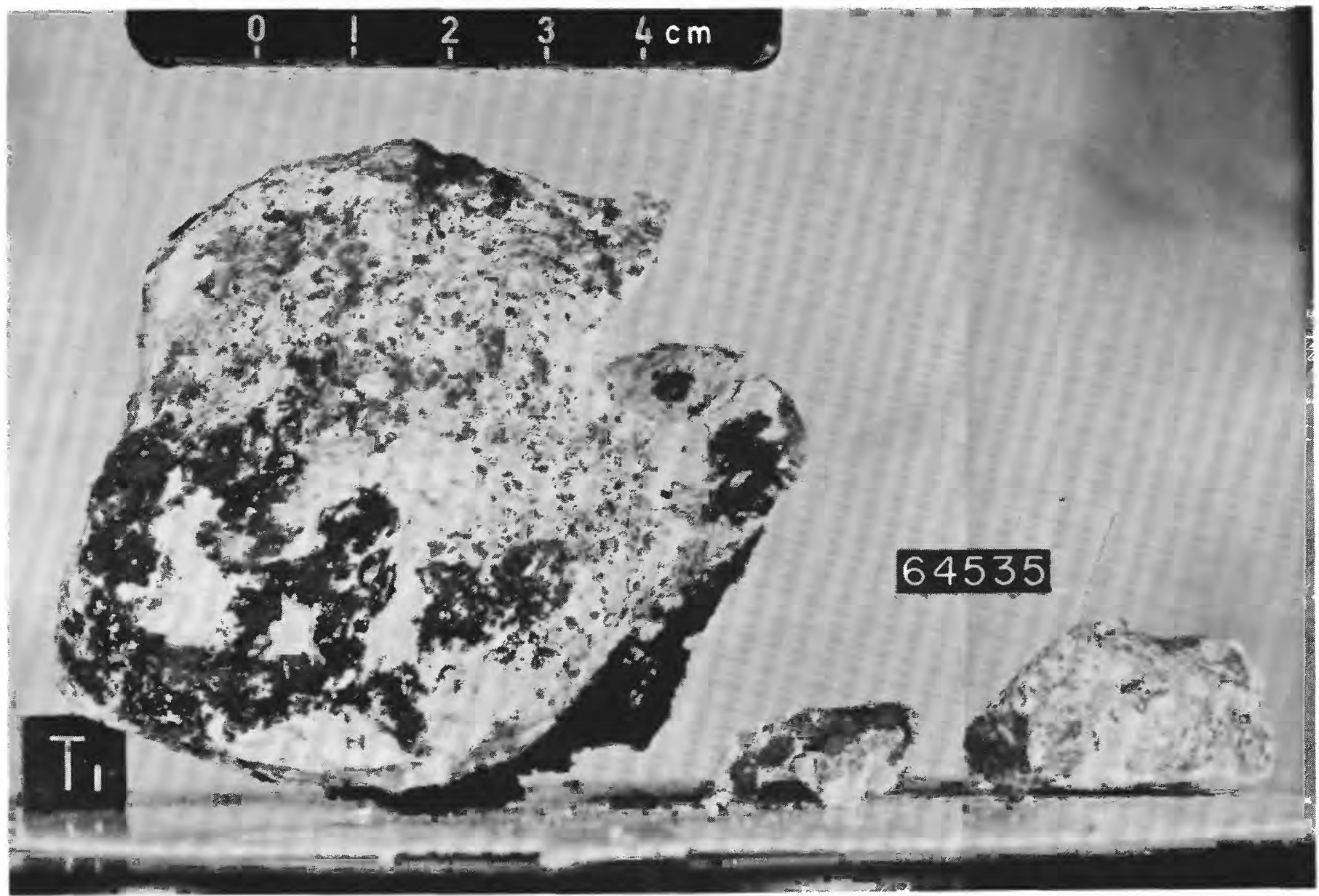

Figure 42D.--Rake fragment 64535 in LRL (photograph S-72-43421). See chapter D4, fig. 9, for $B_{1}$ photographic view of this type $B_{2}$ breccia.

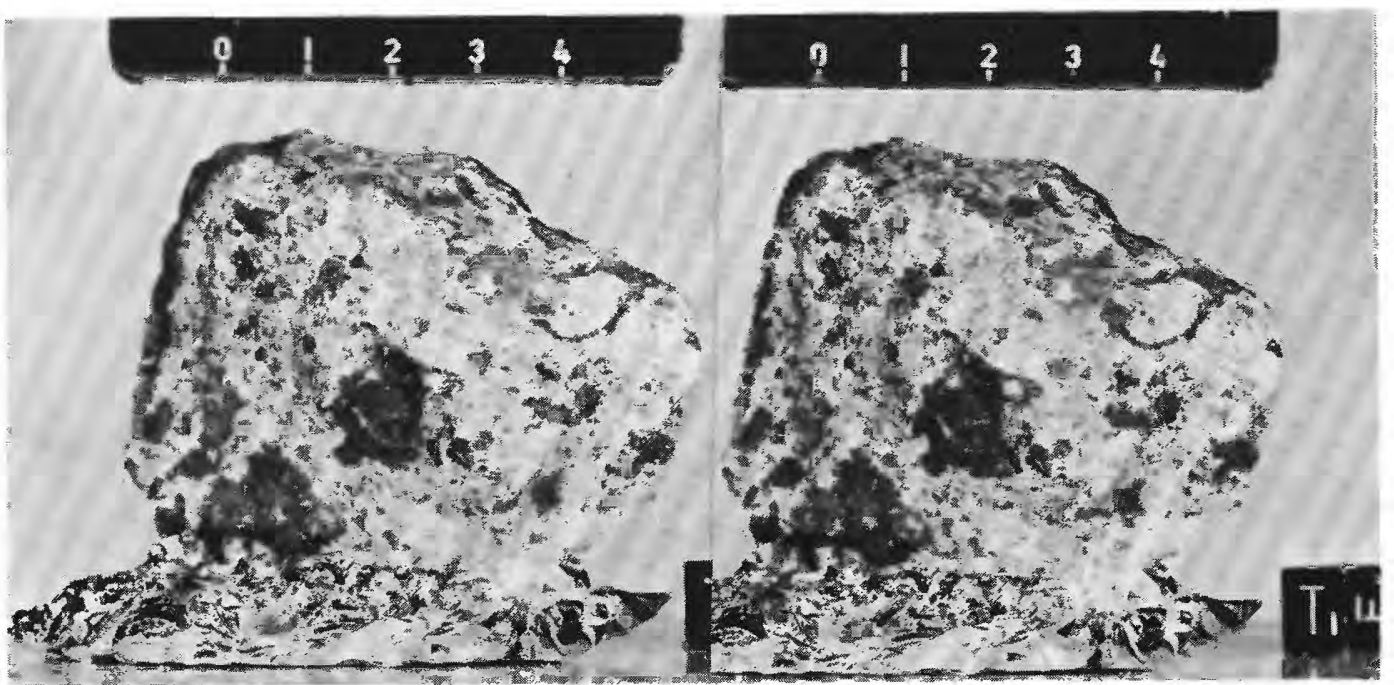

Figure 42E.-Stereopair of rake fragment 64536 in LRL; photographs S-72-43952 (right) and -43952B (left). $B_{2}$ breccia. 


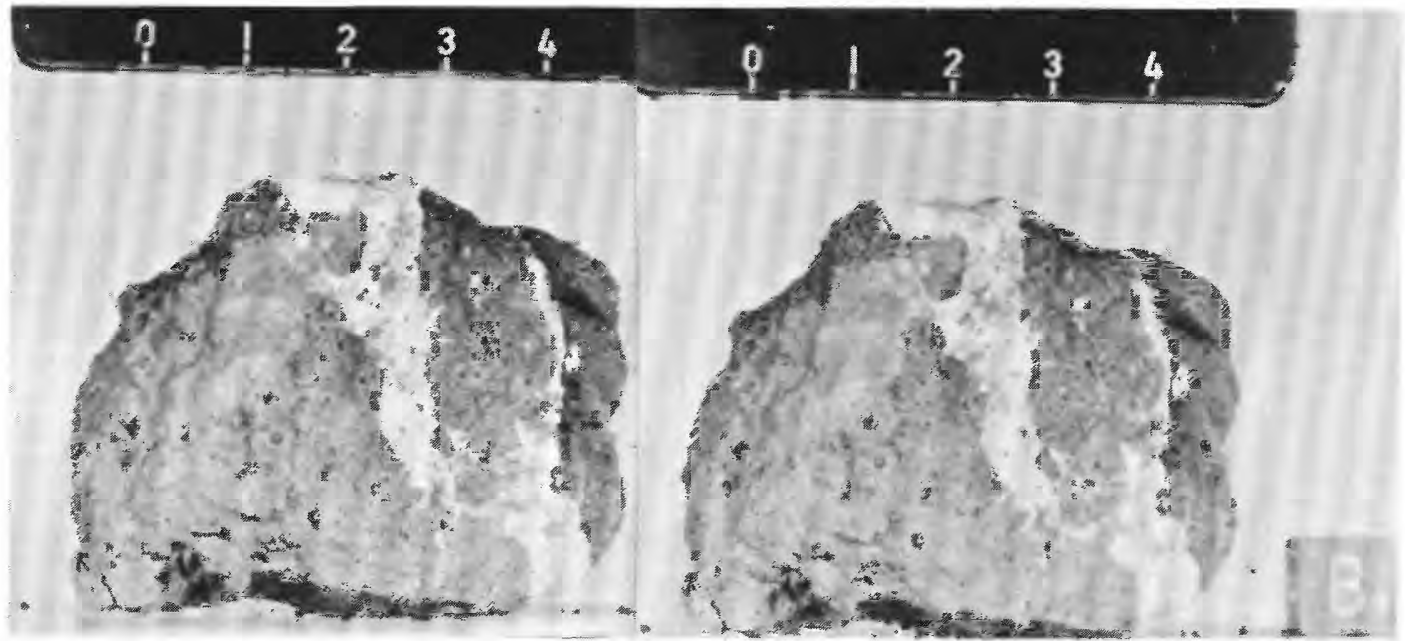

FIGURE 42F.-Stereopair of rake fragment 64537 in LRL; photograph S-72-44444 (right) and -44444B (left). $\mathrm{B}_{2}$ breccia.

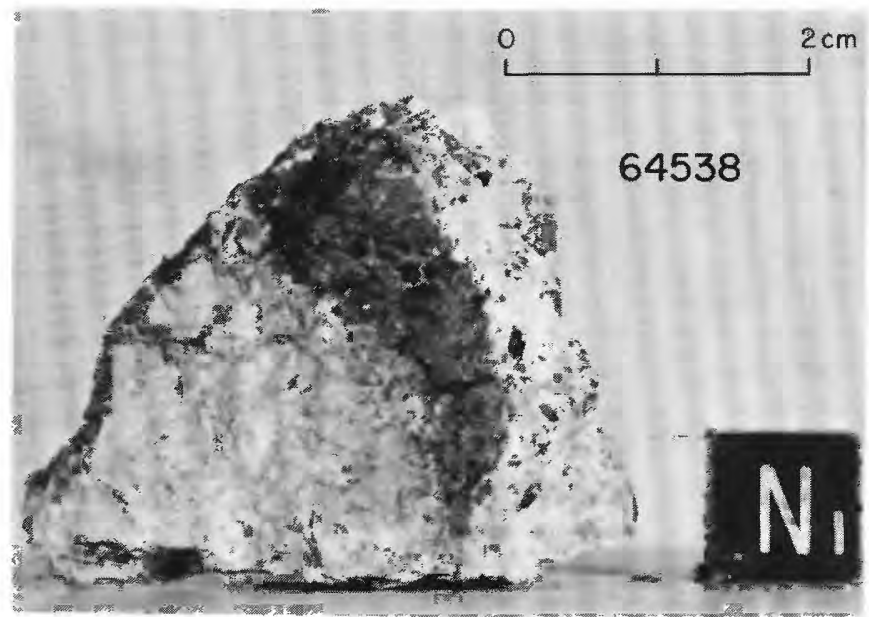

Figure $42 G$.-Rake fragment 64538 in LRL (photograph S72-43418). B. breccia. 


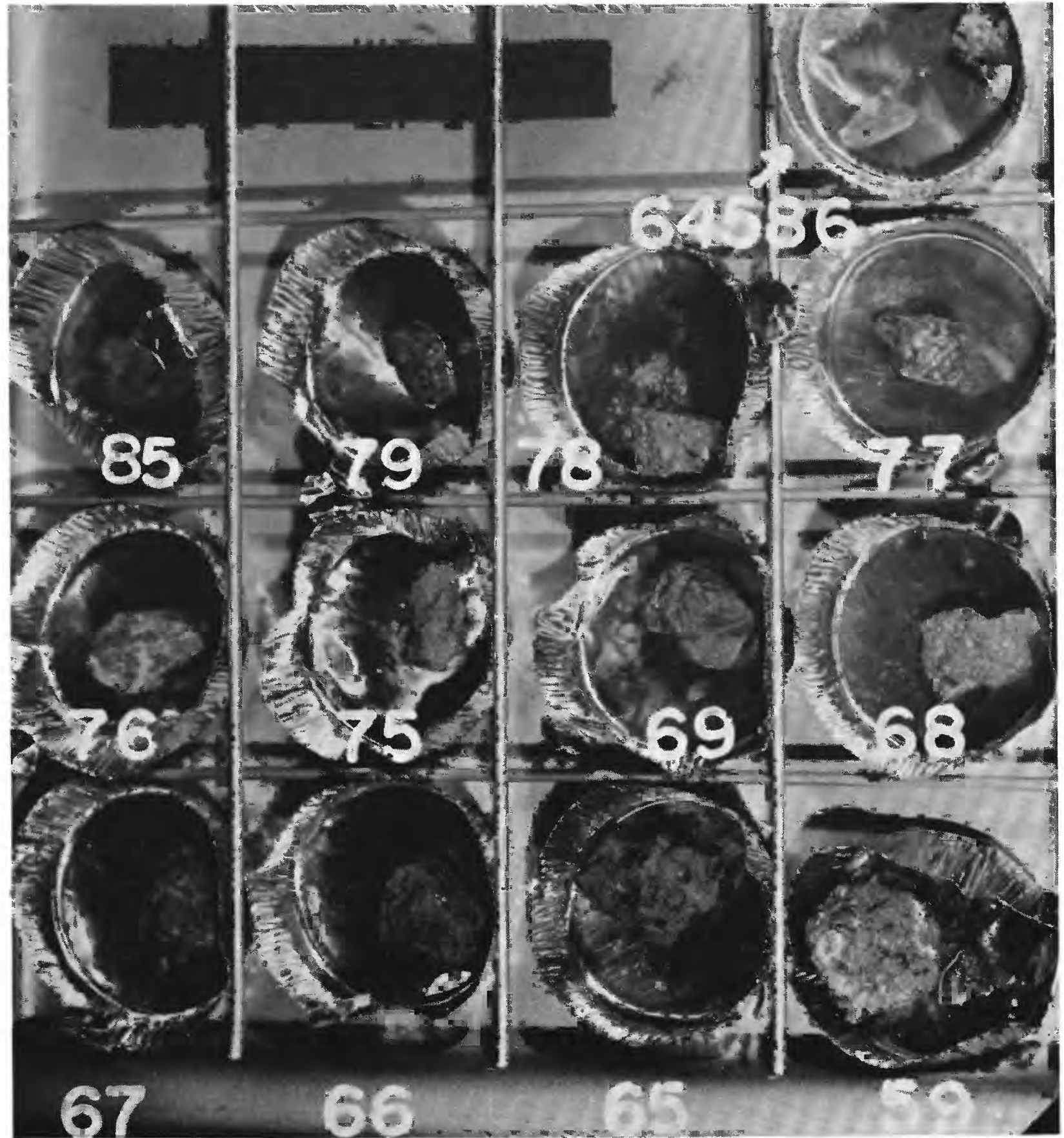

Figure 42H.-Part of rake sample 64535-89 in LRL (photograph S-72-42556). This group includes fragments 64559, 64565$69,64575-79$, and 64585-86. All classified as type $\mathrm{B}_{4}$ breccia except 64559 (a $\mathrm{B}_{3}$ breccia) and 64576 (a $\mathrm{C}_{2}$ metaclastic fragment). 


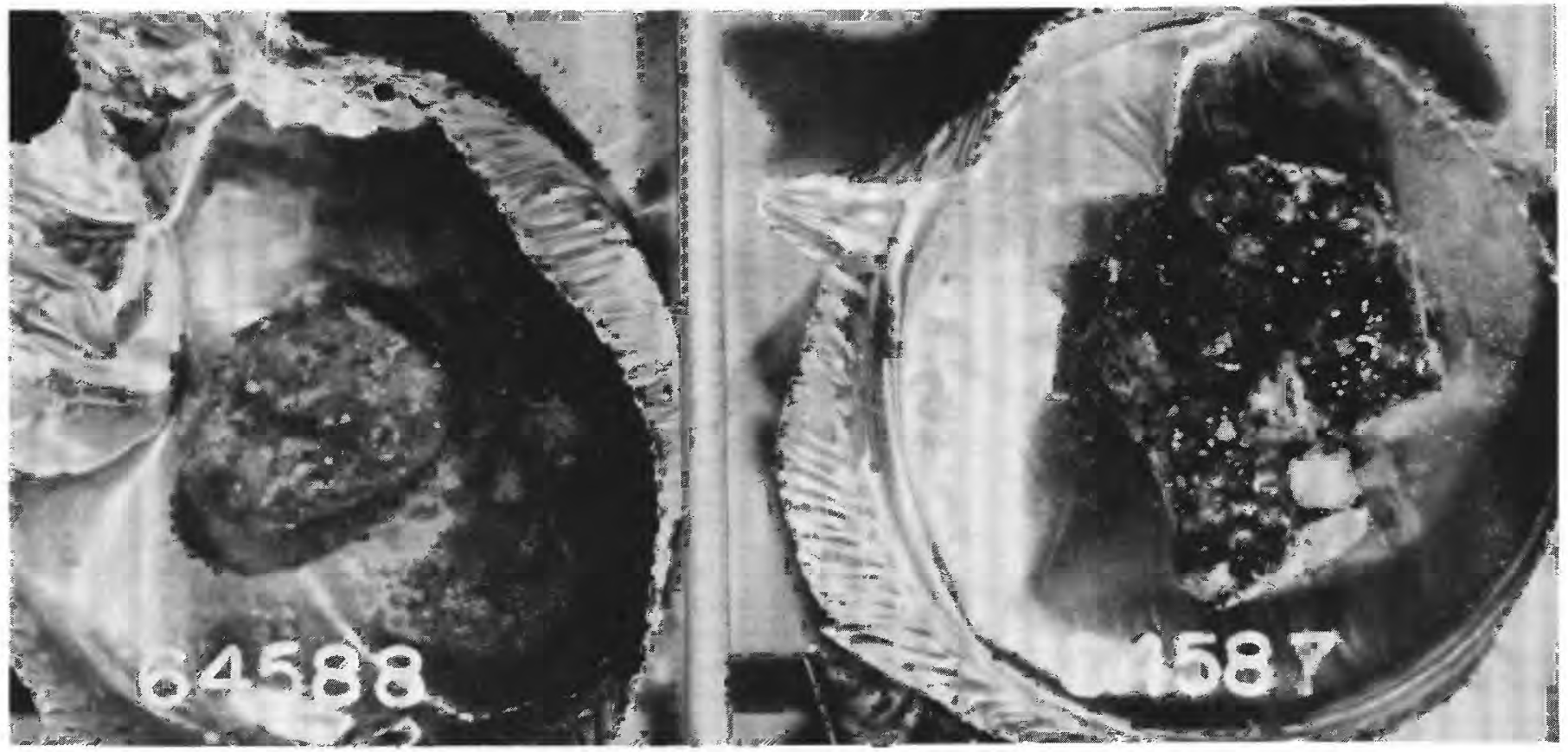

FIGURE 42I.-Part of rake sample 64535-89 in LRL (photograph S-72-42551). This group includes fragments 64587 and 64588 , breccias of types $B_{2}$ and $B_{3}$, respectively.

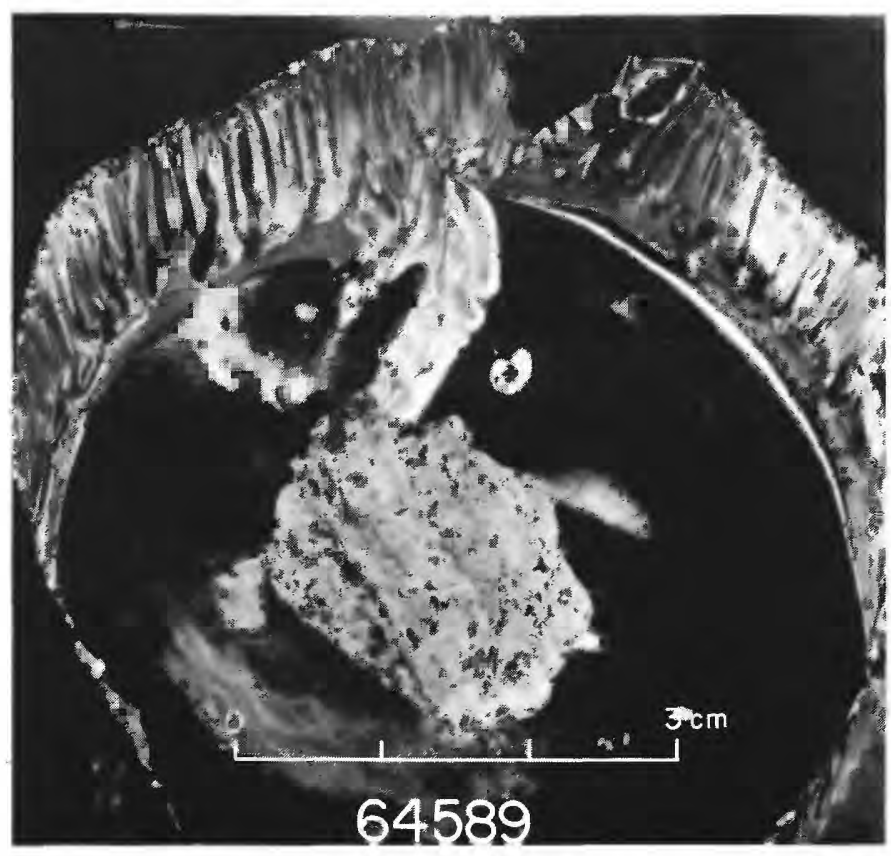

Figure 42J.-Rake fragment 64589 in LRL (photograph S72-42554). B, breccia. 
SAMPLE: 64500-09, 15-19, 25; 64535-39, 45-49, 55-59, 65-69, 75-79, 85-89 (rake samples)

Station: $4 a$ (for location, see Chapter D4, figures 1-3).

Landmark: Vicinity of Cinco a crater, near rim of subdued 15-m crater. Rock type: 64500-25, soil with 11 incidental fragments; 64535-89, 30 fragments $(15 \mathrm{B2}, 11 \mathrm{~B} 4,2 \mathrm{B3}, 1 \mathrm{B1}, 1 \mathrm{C2})$.

SURFACE CHARACTERISTICS OF SAMPLE AREA

Slopes: Regional slope about $10^{\circ}-15^{\circ}$ downward to the northwest off Stone Mountain.

Fragment population

Size range and distribution: Less than $10 \mathrm{~cm}$ abundant, $10-40 \mathrm{~cm}$

common; $40 \mathrm{~cm}-1 \mathrm{~m}$ sparse.

Color: Whitish cast.

Shapes: Large blocks very angular; cobble size and smaller mainly

subangular; few small rocks $(<10 \mathrm{~cm})$ subrounded.

Fillet: Moderately well developed.

Apparent burial: Small rocks slightly buried.

Fines Dust cover: Variable; not apparent on large blocks.

Color: Gray surface layers (about $1 \mathrm{~cm}$ ) underlain by white material. Craters Compaction: Loose.

Size range and distribution: Cinco a crater (60-70 m diameter)

is less than 1 crater diameter to the NE. The 15-m crater where sample collected is pocked by a few craters $1 / 2 \mathrm{~m}$ diameter.

Shape: Circular, subdued, shallow. Cinco a is sharp rimmed.

Ejecta: Probably in area of Cinco a ejecta and South Ray ray.

SAMPLE CHARACTERISTICS FOR 64500-04 (rake soil)

Size: <1 cm fines; 892.94 grams total weight.

Color: Gray surface, underlain by white.

Comparison with other soil in area: Probably typical of local soil. Probable origin: Regolith, probably derived from Cinco a or the local 15-m crater at station $4 a$.

SAMPLE CHARACTERISTICS FOR 64505-09, 15-19, 25 (incidental fragments with

soil sample 64500-04)

Size: 1-2- cm fragments; 34.22 grams total.

Color: Not described.

Shape: Subangular to subrounded.

Comparison with other fragments in area: Probably similar to rake

fragments 64535-89 (see below, and figures 42C-42J).

Probable origin: Mixture of South Ray and Cinco a ejecta.

SAMPLE CHARACTERISTICS FOR 64535-89 (30 rake fragments) See figures 42C-42J). Size: $1-8 \mathrm{~cm}$ fragments; 817.2 grams total weight.

Color: Mixed white and dark gray

Shape: Subangular to angular Comparison with other fragments in area: Probably typical of the types of fragments in the smaller size range derived partly from South Ray ejecta and partly for local (Cinco a) sources. 


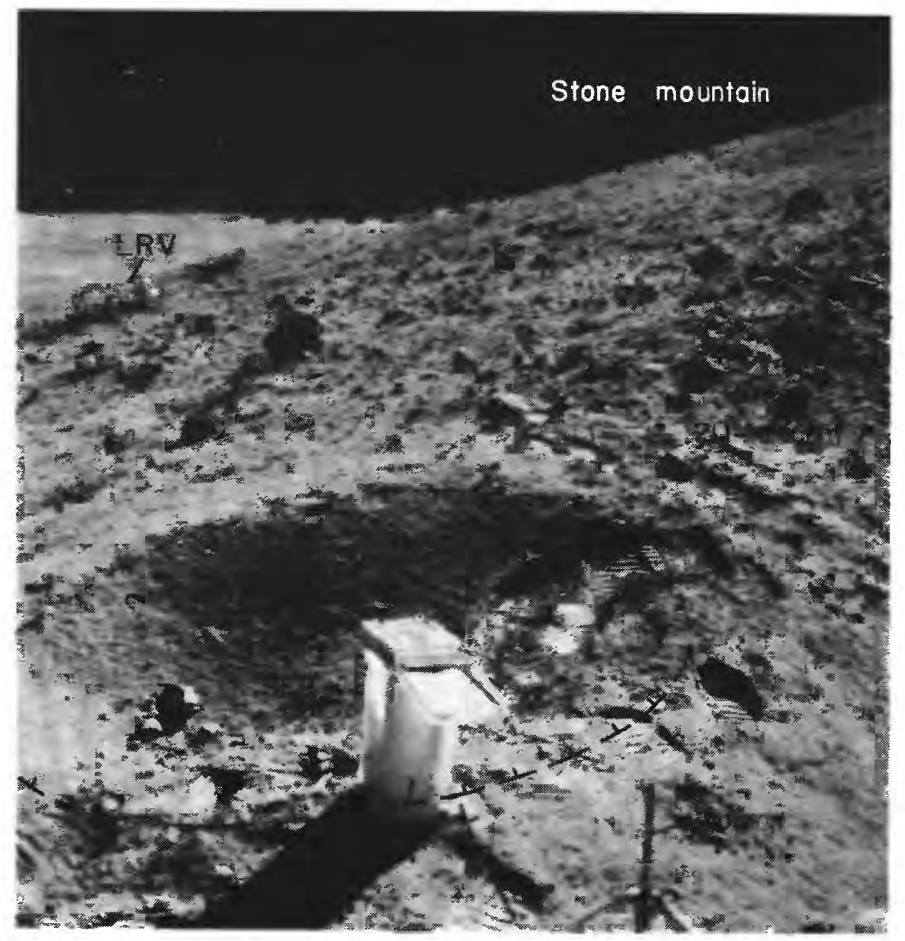

Figure 43A.-Samples 64800-04 (scooped soil), 64810-14 (rake soil), and 64815-37 (rake fragments) were collected from the area just below foreground rim of 20-m crater. Photograph AS16-10717474 taken after sampling; view is northeast toward LRV.

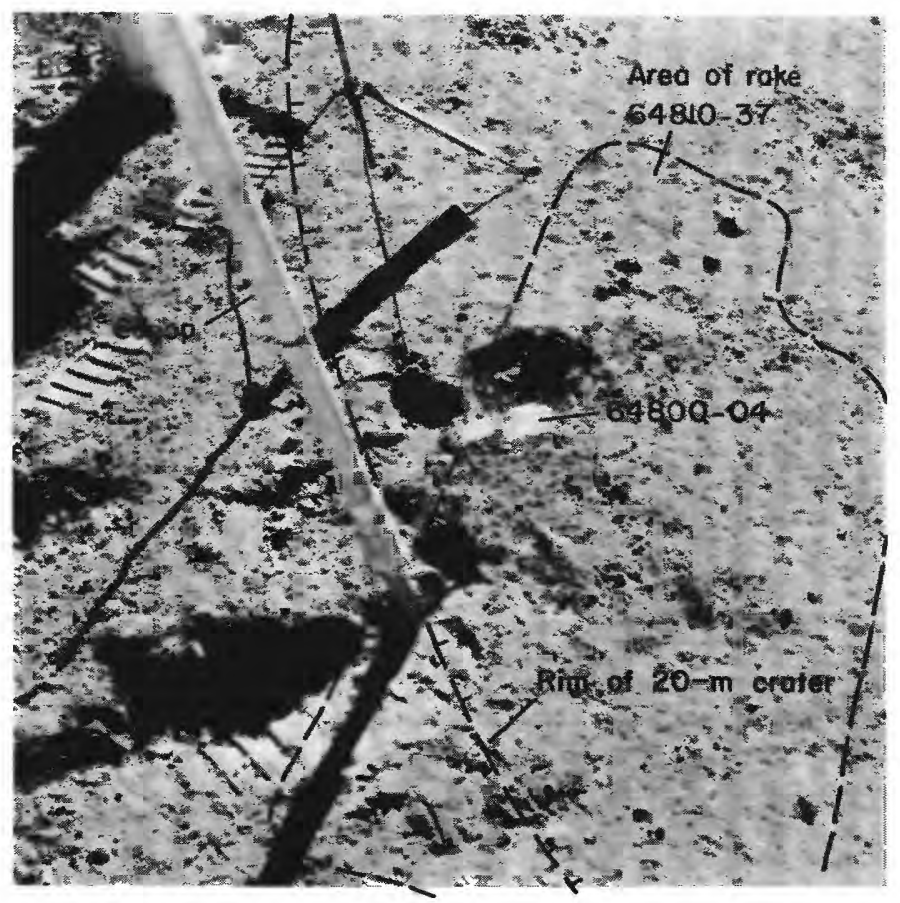

Figure $43 B$.- Area of scooped soil sample $64800-04$ and rake samples 64810-37 shown after scoop and before rake in photograph AS16-107-17465; view is northeast. See chapter C, fig. 3L, for the presampling down-sun view of sample site.

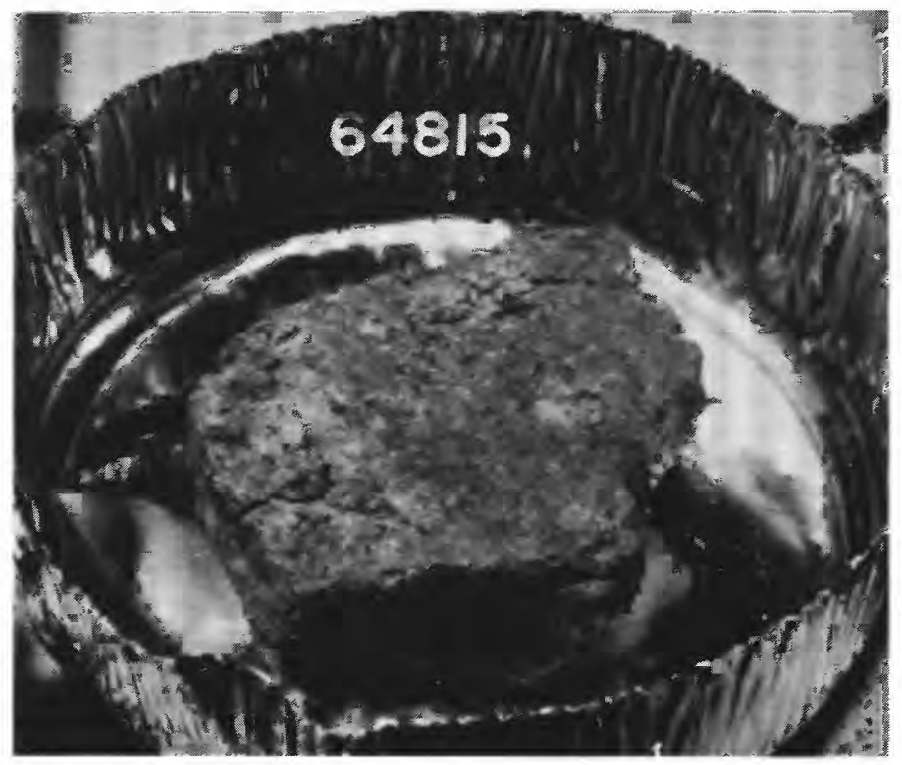

Figure 43C.-Rake fragment 64815 in LRL (photograph S$72-42664$ ). See chapter D4, fig. 11, for another view of this rock, classified as type $\mathrm{C}_{2}(\mathrm{~B})$. 
DOCUMENTATION OF SAMPLES

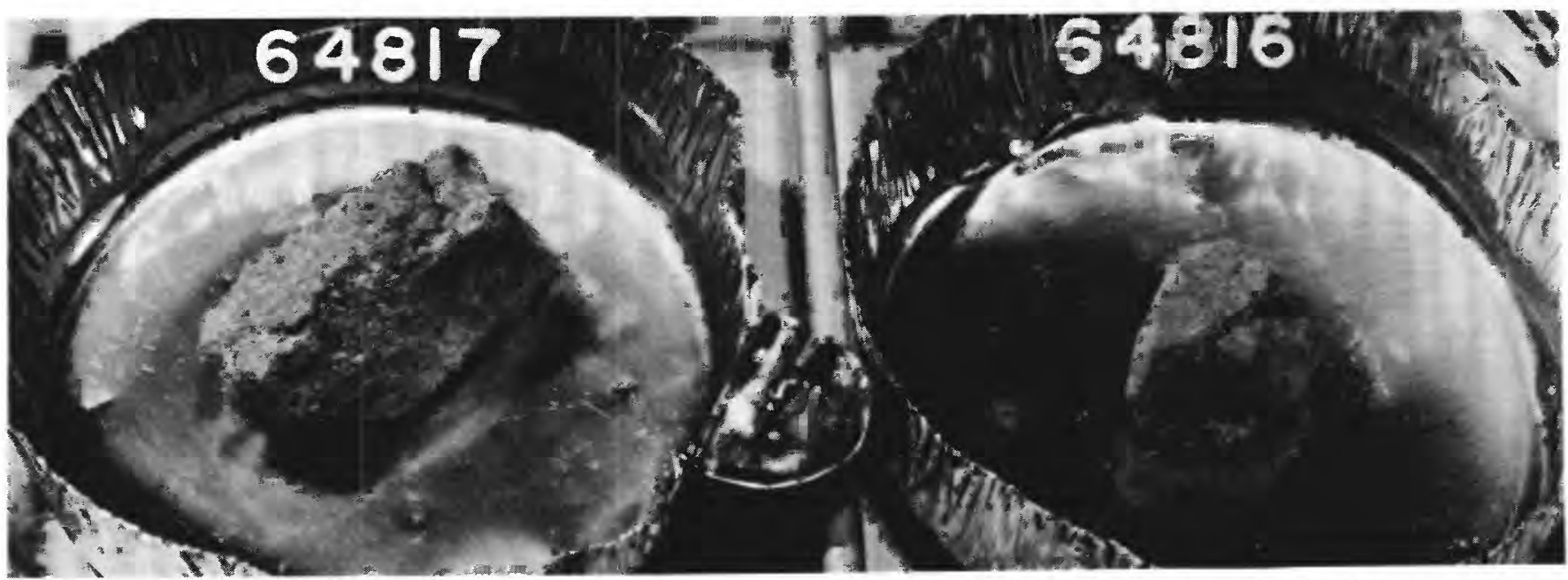

Figure $43 D$.-Rake fragments 64816 and 64817 in LRL (photograph S-72-42663). Classified as types $B_{4}\left(C_{2}\right)$ and $C_{2}$, respectively.

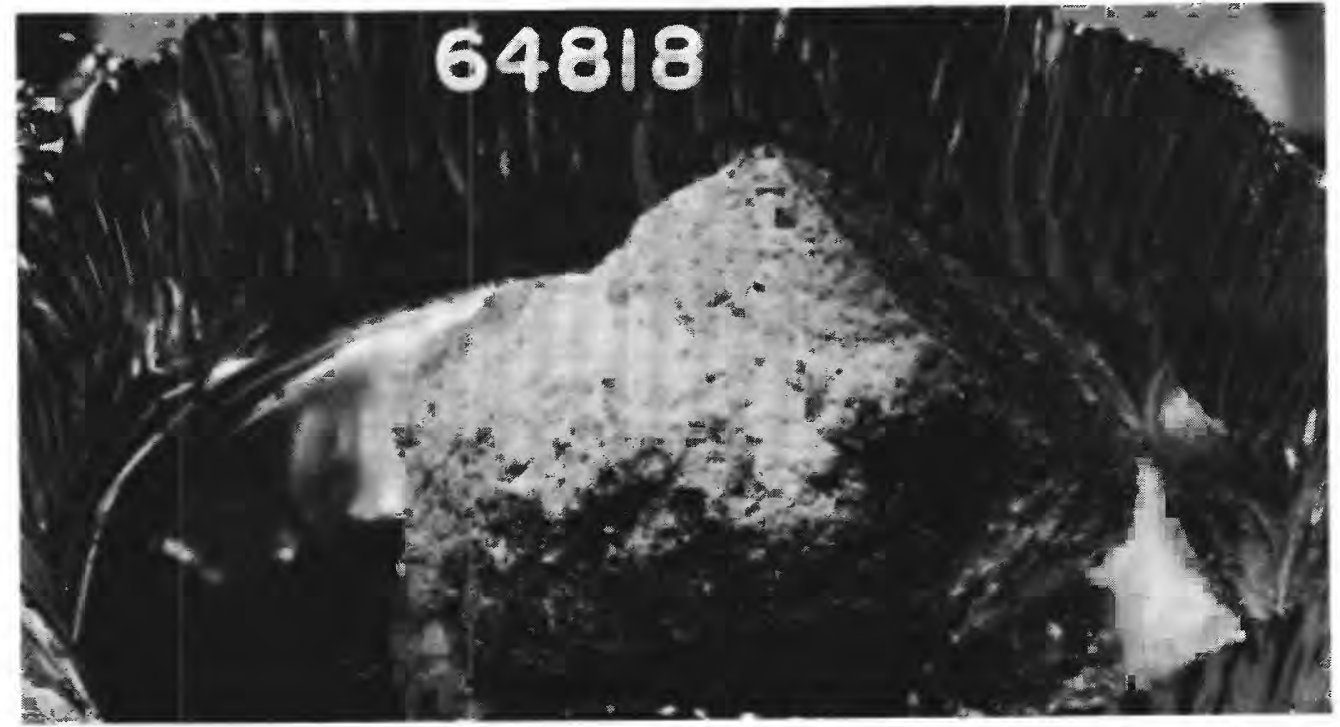

FIGURE 43E.-Rake fragment 64818 in LRL (photograph S-72-42662). Classified as type $\mathrm{B}_{4}\left(\mathrm{C}_{2}\right)$.

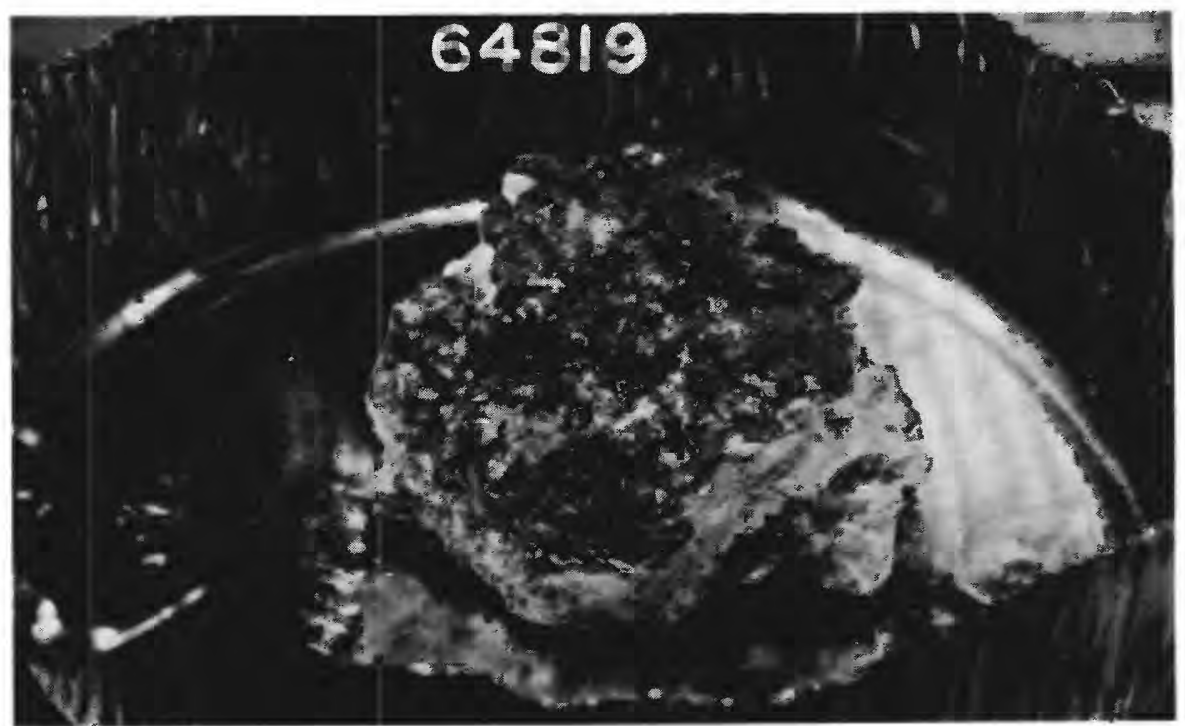

FIGURE 43F.-Rake fragment 64819 in LRL (photograph S-72-42661). B breccia. 


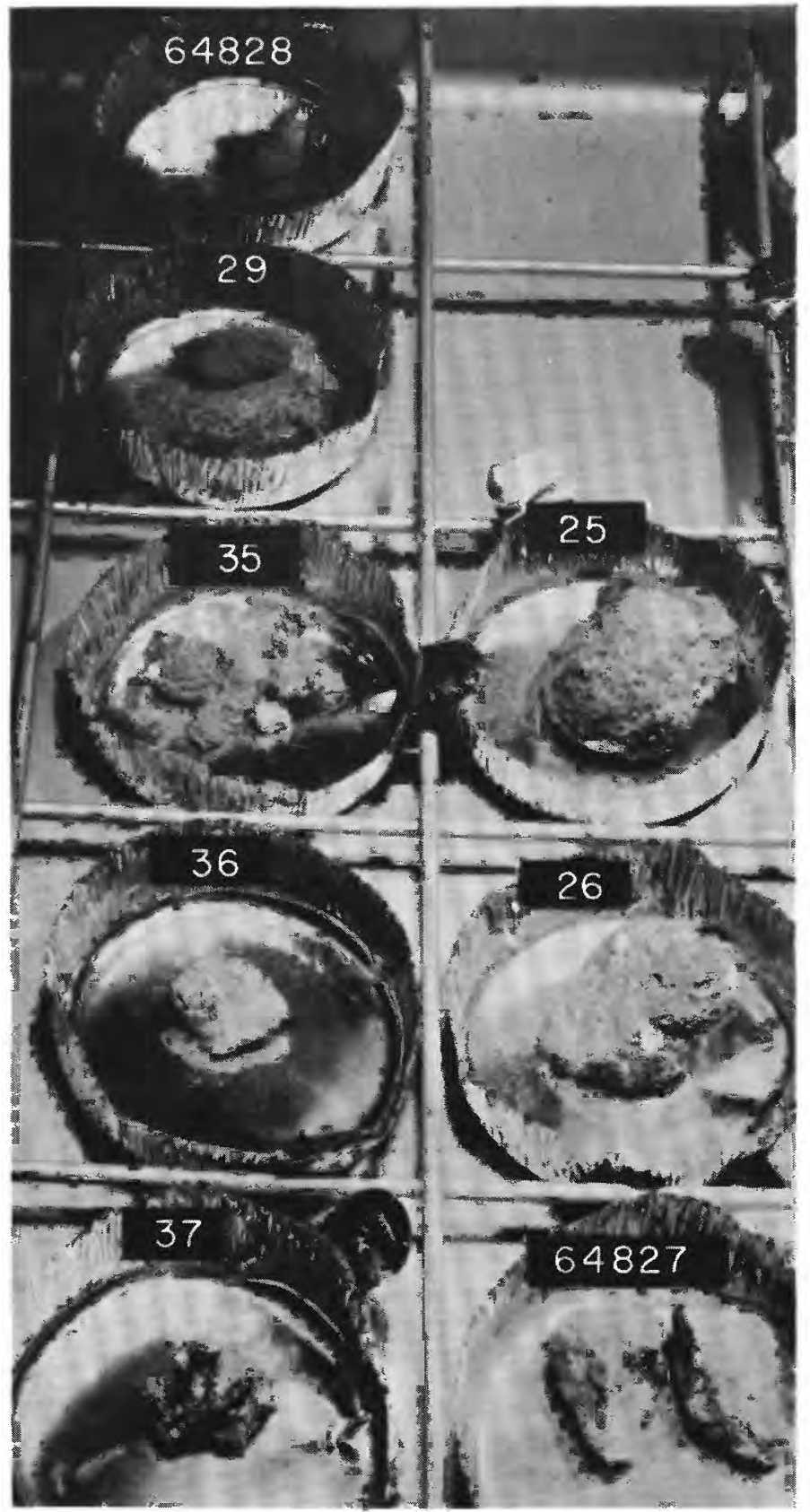

FigURE 43G.-Part of rake sample 64815-37 in LRL (photograph S-72-42070). This group includes fragments 64825-29 and $64835-37$, all classified as type $B_{3}$ breccia except fragments 28 and 36 , which are $<2 \mathrm{~g}$ but appear to be of $\mathrm{B}_{3}$ lithology. 
SAMPLE: 64800-04; 64810-14, 15-19, 25-29, 35-37 (Rake samples)

Station: $4 b$ (for location, see Chapter $D 4$ figures 1-3)

Landmark: Rim of $20 \mathrm{~m}$ crater

Rock type: 64800-04, 64800-14, soil; 64815-37, 13 fragments $6-8$ B3,2-4 C2,B4,B1)

SURFACE CHARACTERISTICS OF SAMPLE AREA.

Slopes: Regional slope WNW downward from stone Mountain; probably about $10^{\circ}$ in local sample area.

Fragment population

Size range and distribution: Local concentration of blocks

and cobbles covering $80-90 \%$ of $N E$ wall of main crater, continuing

on surface to $E ; \quad 20-50 \mathrm{~cm}$ blocks common, $<20 \mathrm{~cm}$ abundant; else-

where, regolith surface relatively smooth except for scattered

cobbles

Color: Mainly gray, but large white clasts apparent in blocks

on $N E$ wall of crater.

Shapes: Angular

Fillets: None apparent.

Apparent burial: Nil; some blocks obviously perched.

Dust cover: Not evident.

Fines

Color: Gray

Craters

Compaction: Loose

Size range and distribution: Apparently random distribution

of various size craters; in sample area, small rounded $\simeq 1-2 \mathrm{~m}$

crater superposed on prominent $20 \mathrm{~m}$ crater; numerous small

$\simeq 1 / 2 \mathrm{~m}$ craters.

Shape: Mainly circular and subdued.

Ejecta: Slightly raised rims; concentrated blocks probably

ejecta from South Ray.

SAMPLE CHARACTERISTICS FOR 64800-04 and 64810-14 (rake soils)

Size: <1 cm fines; 780.85 grams total weight

Color: Gray

Comparison with other soil in area: Probably typical local regolith. Probable origin: Regolith, possibly derived mainly from underlying Descartes materials, but possibly also including fine ejecta from South Ray.

COMMENTS: Sample taken from block-free area of crater (west rim);

blocks concentrated on NE wall probably South Ray ejecta.

SAMPLE CHARACTERISTICS FOR 64815-37 (13 rake fragments)

Size: $1-3.5 \mathrm{~cm} ; 111.82$ grams total weight

Color: Dark gray predominant; white minor

Shape: Angular, slabby, and subrounded.

Comparison with other fragments in area: Not similar to majority of

fragments collected at station $4 a$.

Probable origin: Type B3 breccias and metaclastic (C2) rocks are most

like station 5 samples, suggesting local source from the Descartes

highlands. 

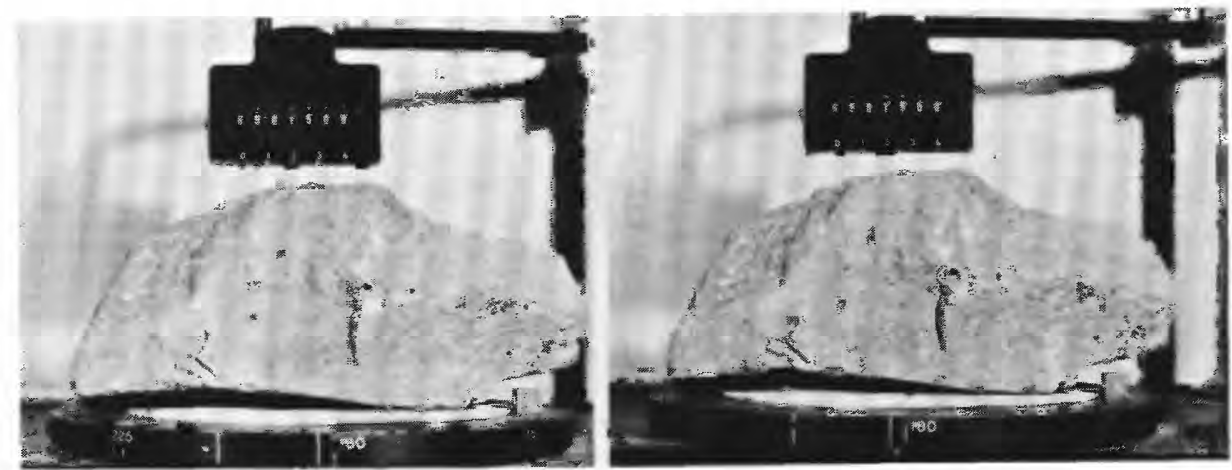

Figure 44.-Stereopair of sample 65015 in LRL; photographs S-72-43929 (right) and $-43929 \mathrm{~B}$ (left). See chap. D4, fig. 21, for stereopair of this type $\mathrm{C}_{2}$ metaclastic rock. Sample was an undocumented grab sample at station 5 (see table 3, pages 33-34).

SAMPLE: 65015

Station: 5

Landmark: Probably within $15 \mathrm{~m}$ of LRV during station activities, and outside of $20-m$ crater at station.

Rock type: Metacrystalline rock, C2.

SURFACE CHARACTERISTICS OF SAMPLE AREA

Slopes: Regional slope $\simeq 10^{\circ}$ northwest off Stone Mountain.

Fragment population

Size range and distribution: Fragments < $5 \mathrm{~cm}$ abundant; $5-15 \mathrm{~cm}$ cobbles common, widely distributed; > $15 \mathrm{~cm}$ blocks sparsely scattered.

Color: Gray.

Shapes: Fragments $<5 \mathrm{~cm}$ round to angular; some cobbles $(\simeq 5-15 \mathrm{~cm}$ ) round, but mainly subround; large blocks subangular to subround. Fillets: Common around most cobbles and fragments.

Apparent burial: Some fragments partially buried, some perched. Dust cover: Prevalent.

Fines

Color: Gray.

Compaction: Loose.

\section{Craters}

Size range and distribution: 1/2-2 m craters abundant; widely

distributed; 3-5 m craters common; larger craters visible in

landscape.

Shape: Mainly rounded and subdued; few small craters with

raised rims still visible.

Ejecta: Rim deposits generally subdued.

SAMPLE CHARACTERISTICS FOR 65015

Size: $19 \times 10 \times 9 \mathrm{~cm}$; 1802 grams.

Color: Light olive gray.

Shape: Angular, blocky, elongate; likened to a "viper's head" (see Table 3, p. 33-34).

Probable origin: Angularity suggests rock may be fragment of South Ray crater ejecta, although smaller fragments of $\mathrm{C} 2$ rocks occur in rake samples collected specificially to avoid South Ray material.

COMMENTS: No photographic or television documentation. 


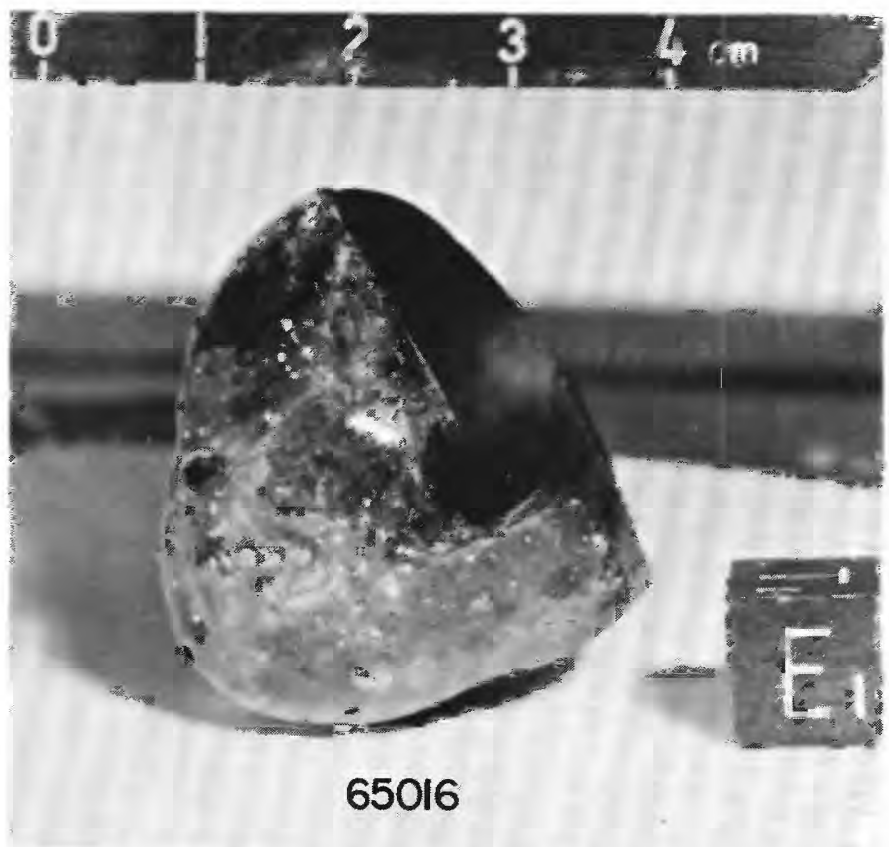

Figure 45.-Sample 65016 in LRL (photograph S- 72-39403). Hollow glass hemisphere collected as an undocumented grab sample at station 5 (see crew comments in table 3 , page 28 ).

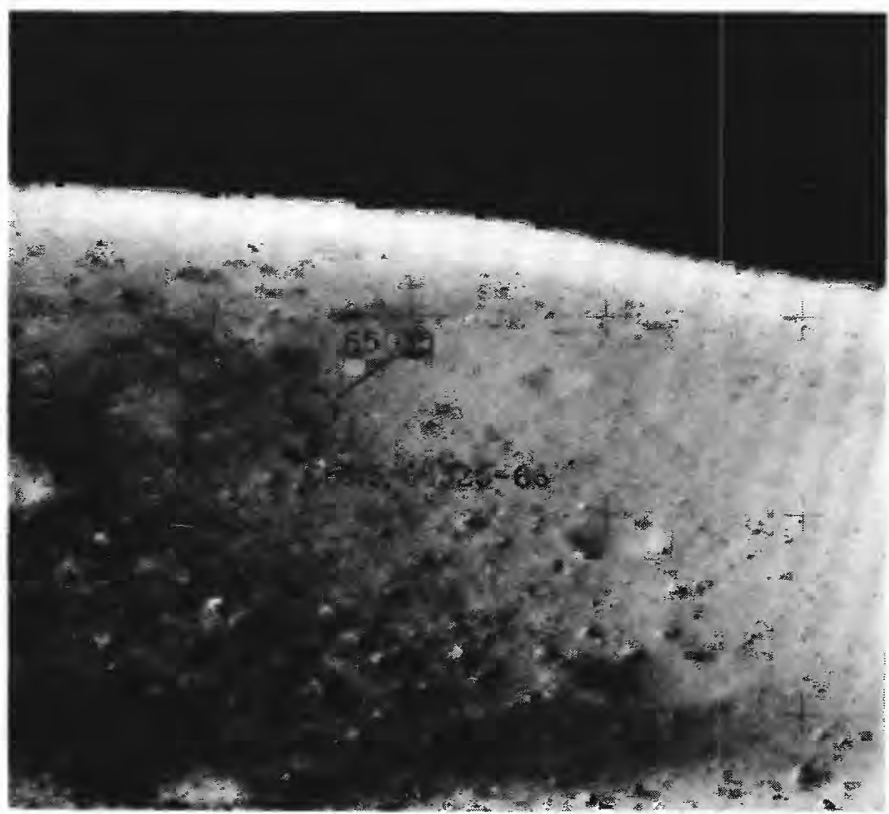

Figure 46A.-Location of samples 65035, 65315, and rake samples 65325-66, shown before sampling in panorama photograph AS16-110-18013; view is south. See fig. 50 for rake sample.

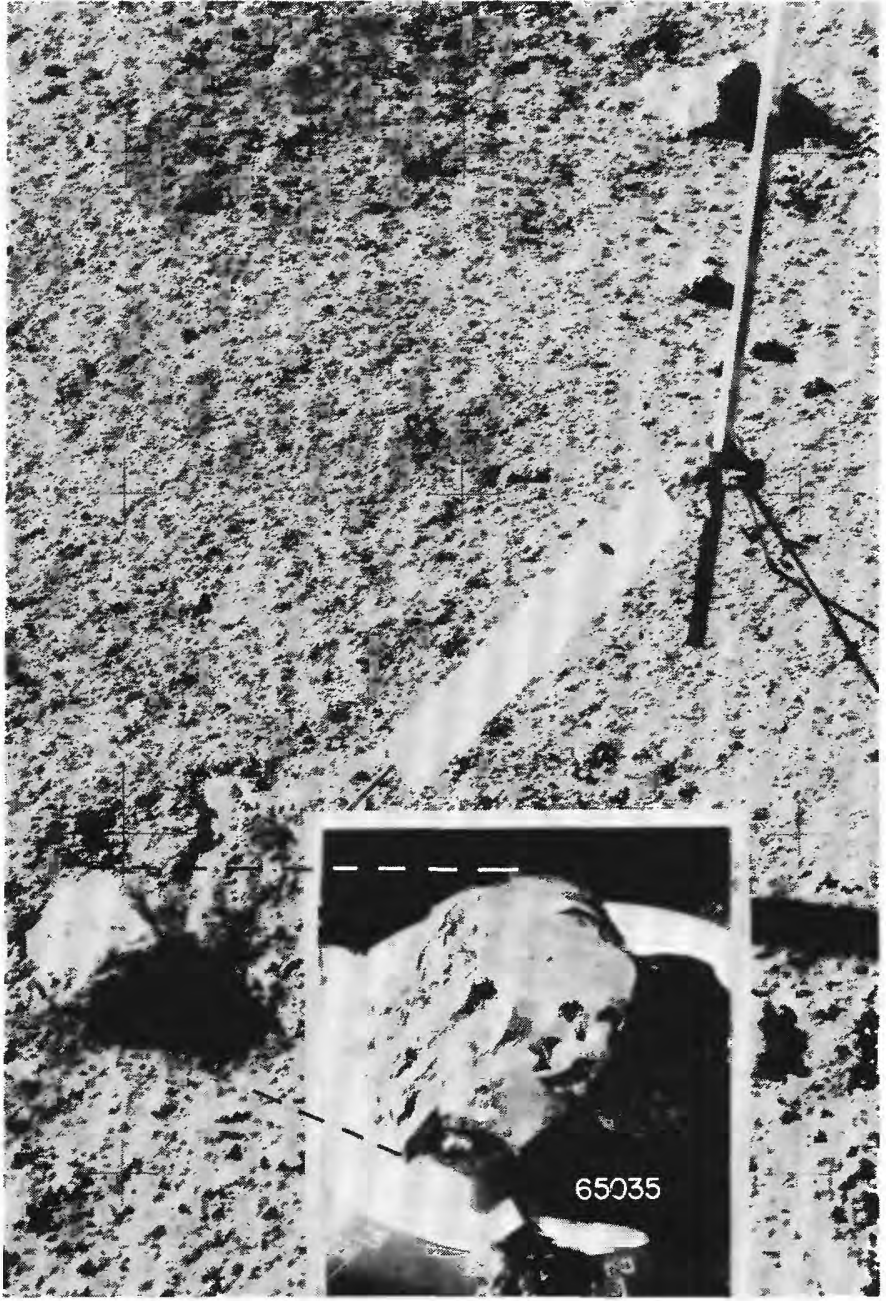

Figure 46B.-Sample 65035 showing approximate lunar orientation reconstructed in LRL compared to an enlarged part of photograph AS16-110-18023 taken before sampling. View is southeast (inset photograph, S-72-43313). Sample 65315, collected with rake sample 65325-66, is not identified but was from same area. 


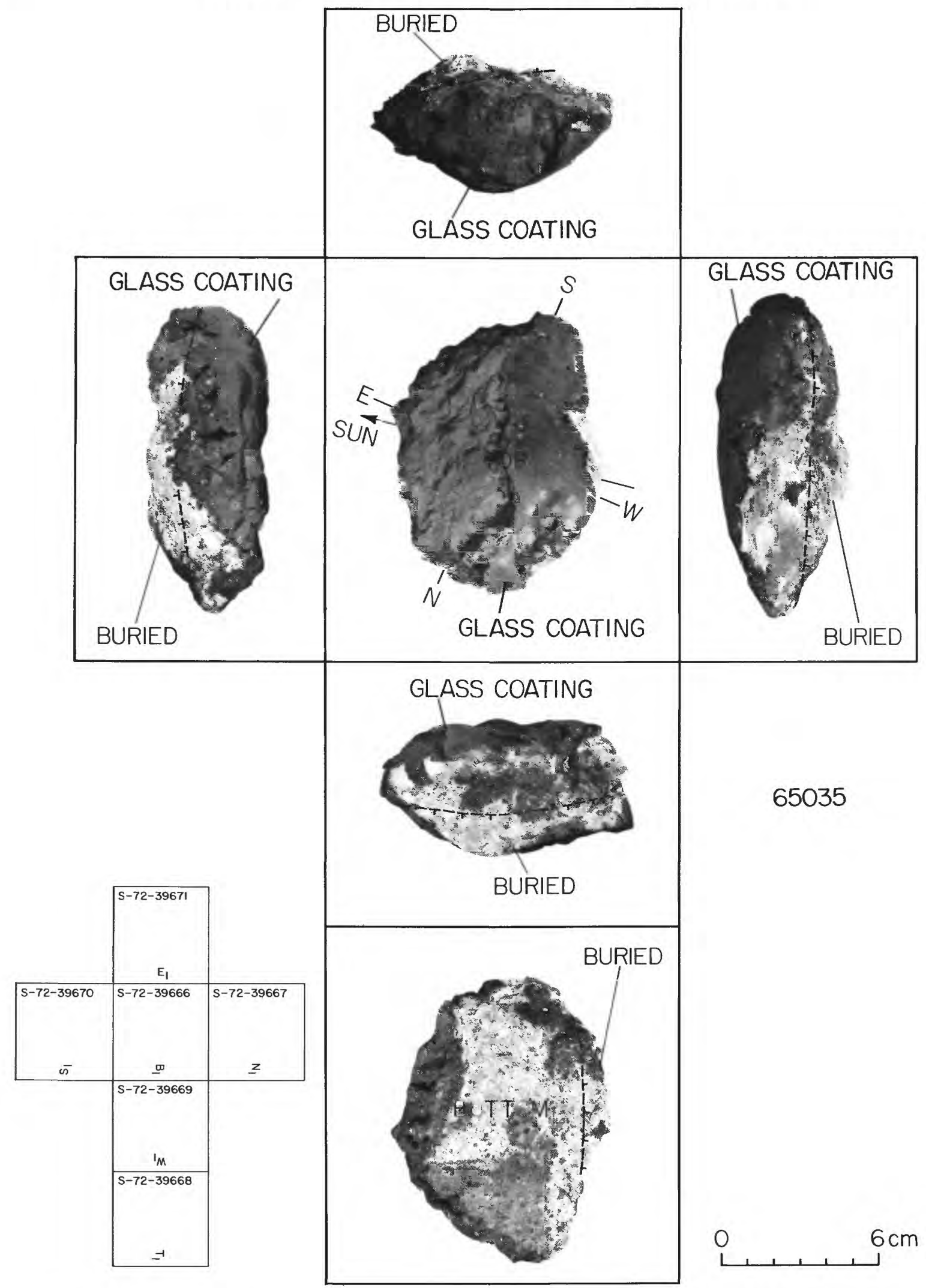

FIGURE 46C.-Orthogonal views of sample 65035 related to its lunar orientation at time of sampling. See chapter D4, fig. 16, for a stereopair of this partly glass-coated $B_{2}$ breccia. 
SAMPLE : $65035 ; 65315,25-29,35-39,45-49,55-59,65-66$

Station: 5

Landmark: Interior wall of $20 \mathrm{~m}$ crater, near rim of superposed 2 m crater.

Rock type: 65035 and 65315 are B2 breccia; see figures 5OD-H

for type classifications of rake fragments.

\section{SURFACE CHARACTERISTICS OF SAMPLE AREA}

Slopes: Crater wall sloping $20^{\circ} \mathrm{N}$ into $20 \mathrm{~m}$ crater.

Fragment population

Size range and distribution: Scattered cobbles, very few

blocks as large as 20-30 cm; surface covered mainly by

fragments and clods approximately $2 \mathrm{~cm}$ or less.

Color: Gray.

Shapes: Mainly subangular to subround.

Fillets: Not apparent.

Apparent burial: Slight.

Dust cover: Prevalent.

Fines

Color: Gray.

Compaction: Extremely loose.

Craters

Size range and distribution: Numerous $1 / 2-2 \mathrm{~m}$ craters superposed on interior wall of $20 \mathrm{~m}$ crater; sample locality near

(but outside) rim of $\sim 2 \mathrm{~m}$ crater.

Shape: Generally shallow, subdued.

Ejecta: slightly raised rim visible around crater at sample locality.

SAMPLE CHARACTERISTICS OF 65035

Size: $12 \times 8.5 \times 4.5 \mathrm{~cm} ; 446.1$ grams.

Color: White matrix, medium dark gray clasts; dark gray glass coating.

Shape: Rounded.

Fillet: If any, destroyed prior to taking photo.

Apparent burial: None.

Dust cover: Covered (see crew comments, Table 3, p. 30).

Comparison with other fragments in area: Slightly more rounded than most other rocks in area, but a few almost spherical fragments nearby.

Probable origin: Possibly derived from Descartes materials, glass coated by local impact; alternatively, ejecta from distant source deposited on Descartes highlands and subsequently "reworked" by local impacts; round shape not typical of South Ray ejecta.

COMMENTS: Sample disturbed before photo documentation. SAIIPLE CHARACTERISTICS OF 65315, 25-66 (see description with figures

$50 A-H 2$. 


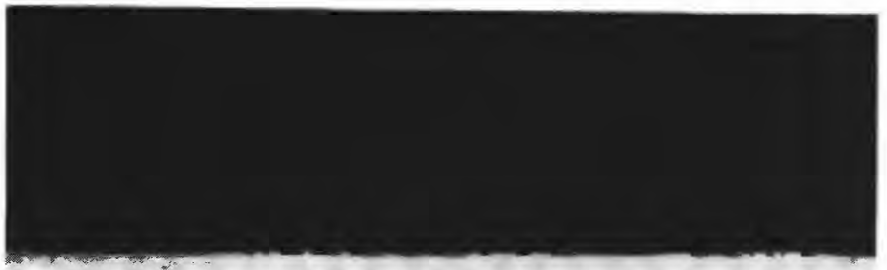

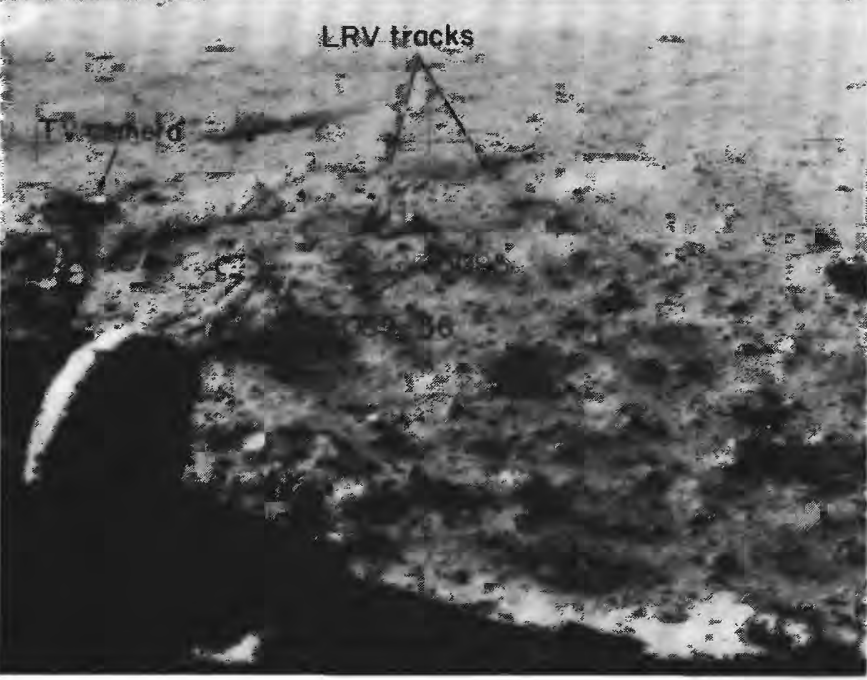

FIGURE 47A.-Locations of samples 65055,65056 , and 65095 shown before sampling in panorama photograph AS16-110-18010; view is southeast.

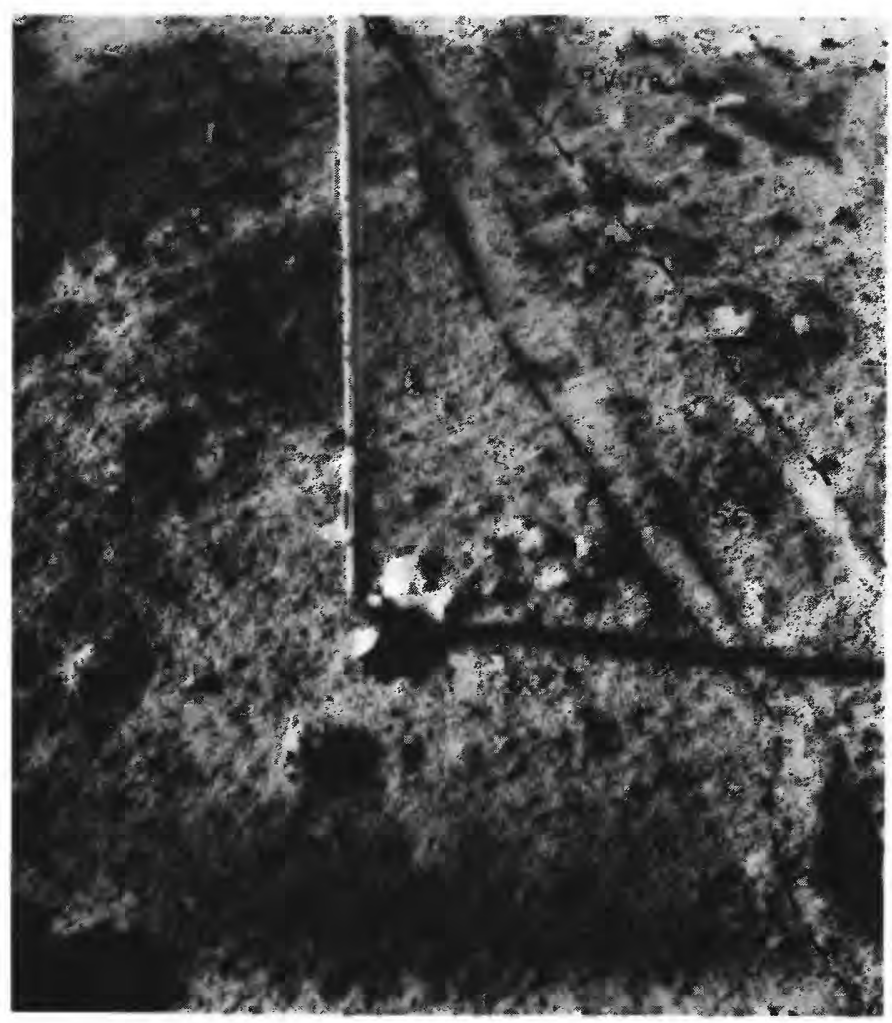

Figure 47B.-Area of samples 65055 (identified) and 65056 (tentatively identified) shown before sampling in photograph AS16$110-18029$; view is south.

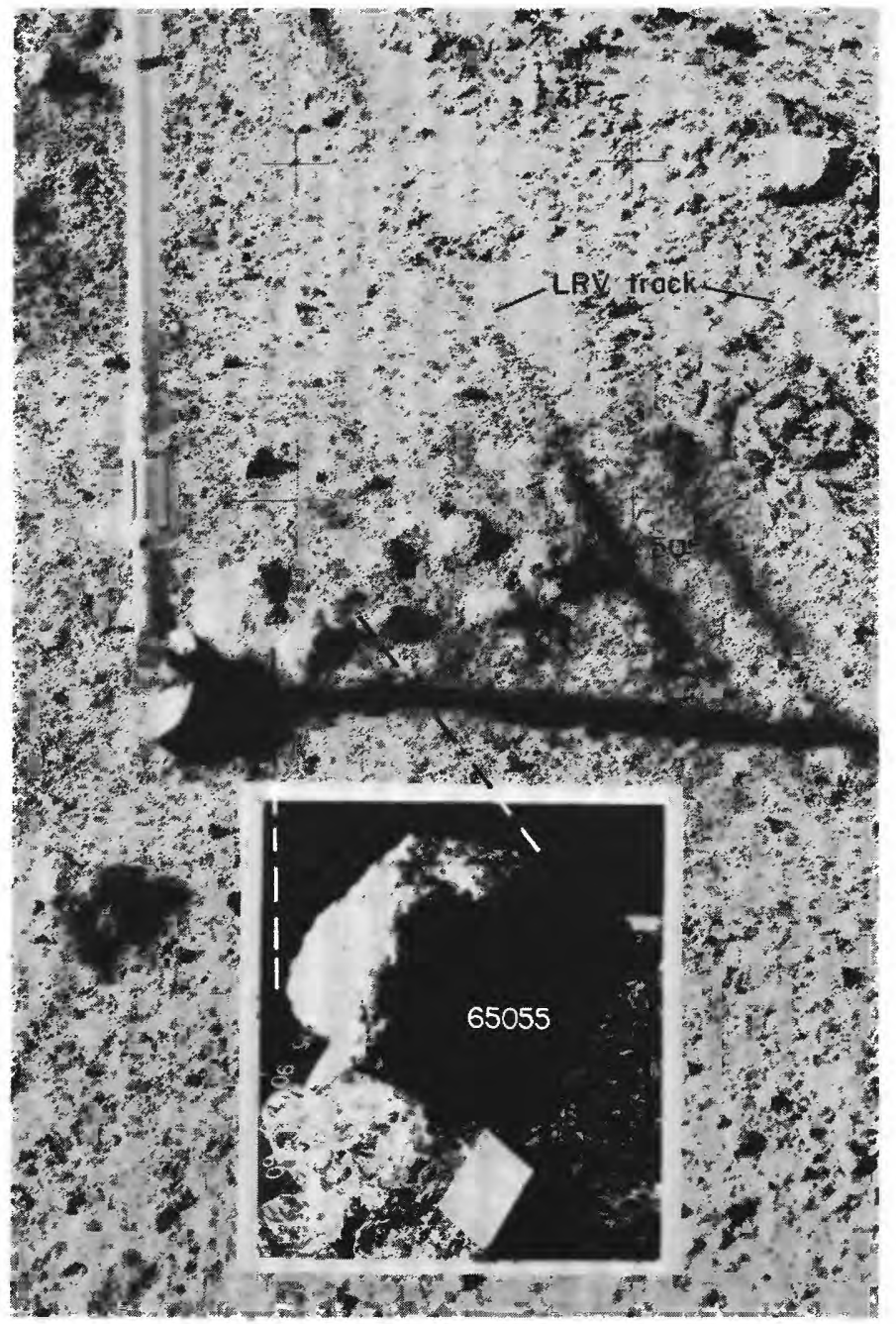

Frgure 47C.—Sample 65055 showing approximate lunar orientation reconstructed in LRL compared to an enlarged part of photograph AS16-110-18029 taken before sampling. View is south (inset photograph, S-72-43314). Sample 65056 tentatively identified by its vesicular appearance, but not oriented in the laboratory because of breakage (see fig. $47 E$ ). 


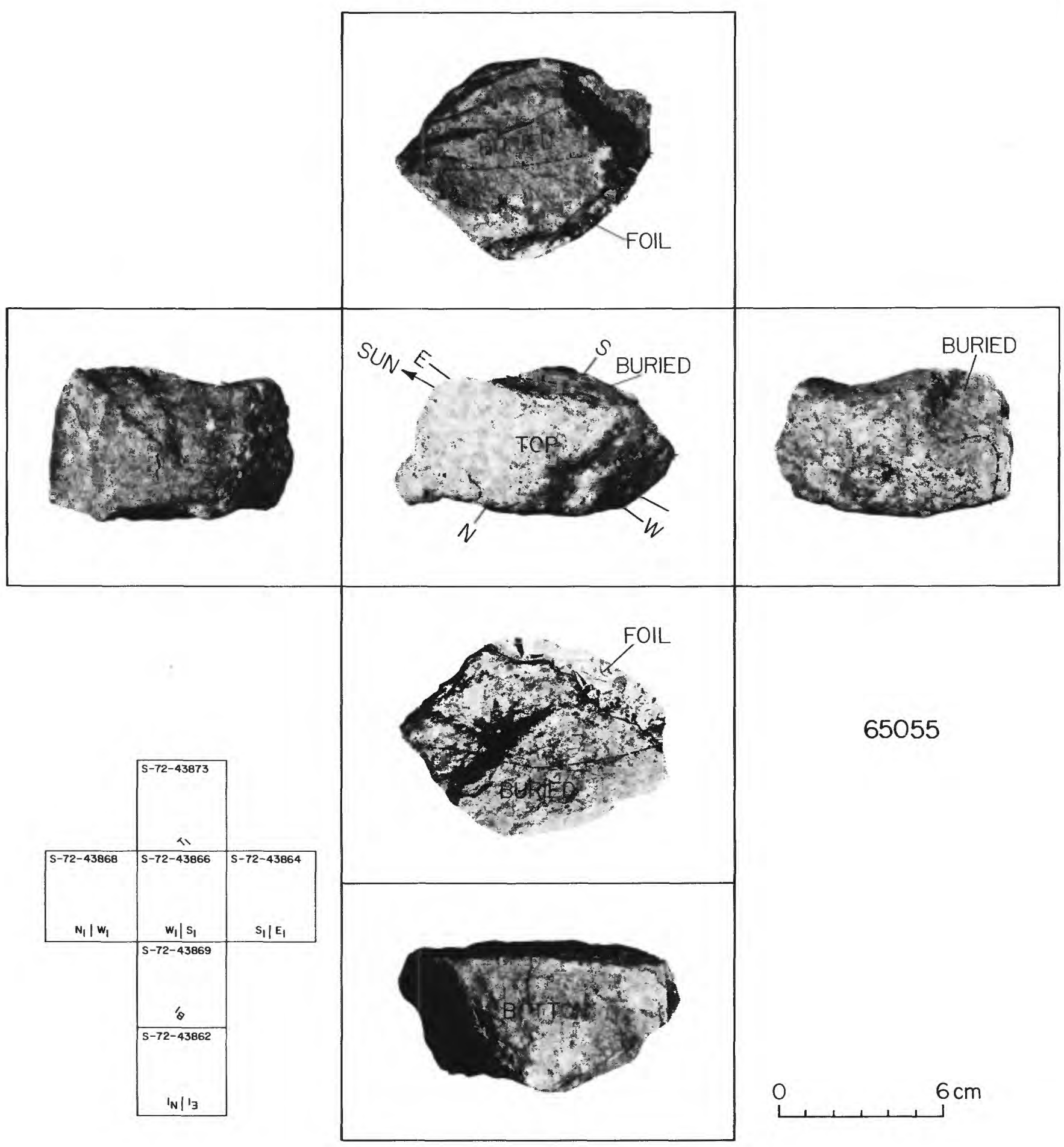

Figure 47D.-Orthogonal views of sample 65055 related to its lunar orientation at time of sampling. See chapter D4, figs. 20 $A-C$, for a stereopair and two photomicrographs of this crystalline $\left(C_{1}\right)$ rock. Another photomicrograph shown in chap. E, fig. $2 B$. 


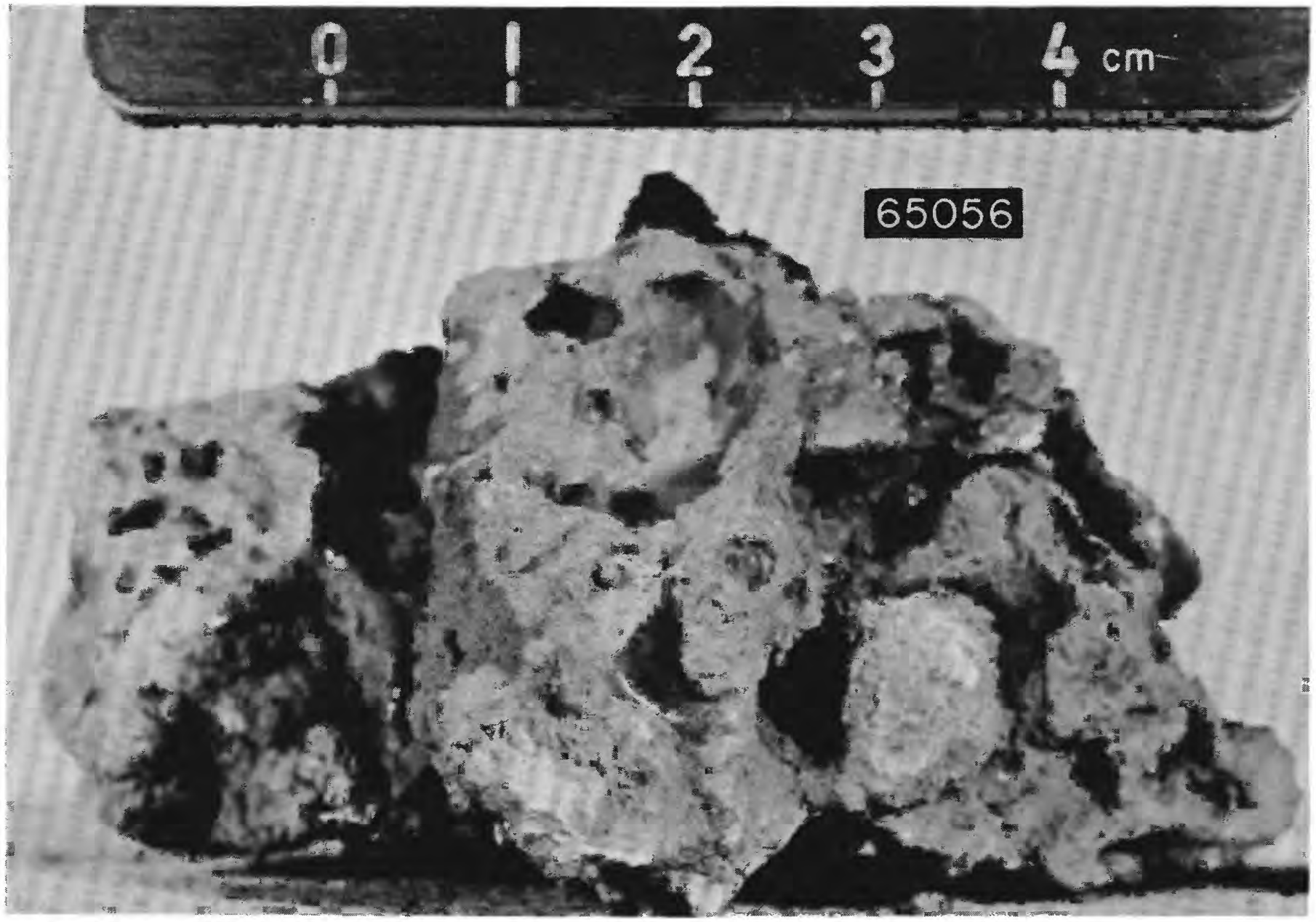

FigURE 47E.-Sample 65056 in LRL (photograph S-72-40136, $\mathrm{S}_{1}$ view). Glassy rock (G) with numerous irregular-shaped vesicles. 
SAMPLE: 65055,65056

Station: 5

Landmark: Rim of $20 \mathrm{~m}$ crater, about $3 \mathrm{~m}$ in front(south) of ILV; Samples at edge of subdued $1 \mathrm{~m}$ crater.

Rock type: 65055 is crystalline, C1; 65056 is glassy (G) with crystalline clasts.

SURFACE CHARACTERISTICS OF SAMPLE AREA

Slopes: Local slope $\simeq 5^{\circ}$, regional slope $\simeq 10^{\circ}$ northwest off Stone Mountain.

Fragment population

Size range and distribution: Fragments < $5 \mathrm{~cm}$ abundant; $5-15 \mathrm{~cm}$ cobbles common, widely distributed; > $15 \mathrm{~cm}$ blocks sparsely scattered.

Color: Gray.

Shapes: Fragments $<5 \mathrm{~cm}$ round to angular; some cobbles ( $\simeq 5-15 \mathrm{~cm})$ round, but mainly subround; large blocks subangular to subround. Fillets: Common around most cobbles and fragments.

Apparent burial: Some fragments partially buried, some perched. Dust cover: Prevalent.

Fines

Color: Gray.

Compaction: Loose.

Craters

Size range and distribution: 1/2-2 m craters abundant, widely

distributed; 3-5 m craters common; larger craters visible in landscape.

Shape: Mainly rounded and subdued; few small craters with raised rims still visible.

Ejecta: Rim deposits generally subdued.

SAMPLE LCHARACTERISITCS FOR 65055

Size: $10 \times 8.5 \times 5.5 \mathrm{~cm} ; 500.8$ grams

Color: Light brownish gray.

Shape: Subangular, blocky.

Fillet: Slight.

Apparent burial: Approximately $I / 2$.

Dust cover: Covered, probably from debris kicked up from LRV track.

Comparison with other fragments in area: Type cl crystalline rock is

in the minority of fragments collected at station 5; glass is not uncommon.

Probable origin: Possibly represents ejecta from South Ray.

SAMPLE CHARACTERISTICS FOR 65056

Size: $7 \times 4 \times 4 \mathrm{~cm} ; 74.78$ grams.

Color: Dark gray, glassy.

Shape: Lumpy, glassy agglutinate with large vesicles.

Comments: Sample not positively identified in Iunar-surface photograph, although characteristics match those of fragment indicated in figures $47 \mathrm{~B}-\mathrm{C}$. 

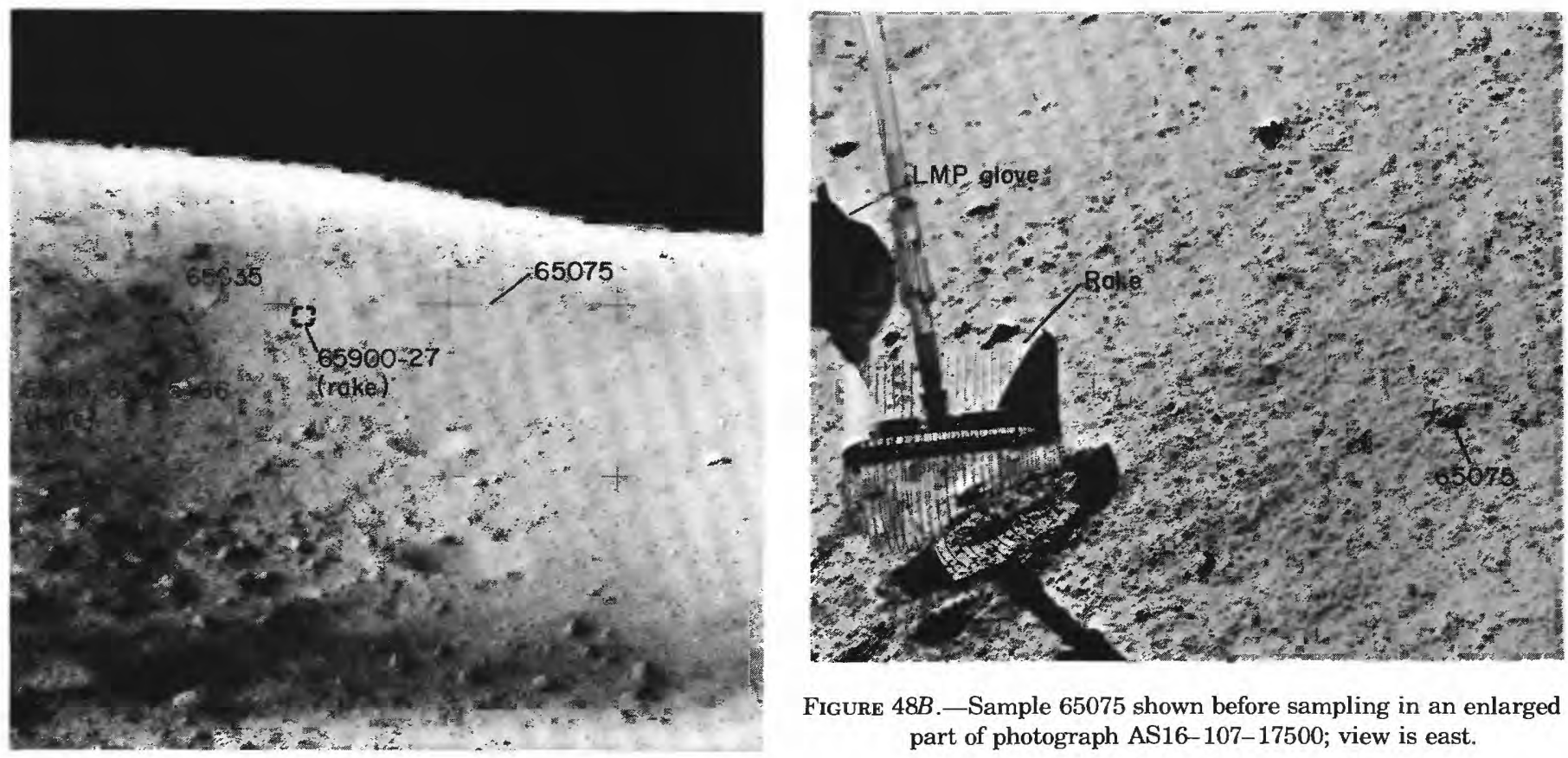

FigURE 48B.-Sample 65075 shown before sampling in an enlarged part of photograph AS16-107-17500; view is east.

Figure 48A.-Location of sample 65075 in relation to nearby samples $65035,65315,65325-66$, and $65900-27$, shown before sampling in panorama photograph AS16-110-18014, looking south.

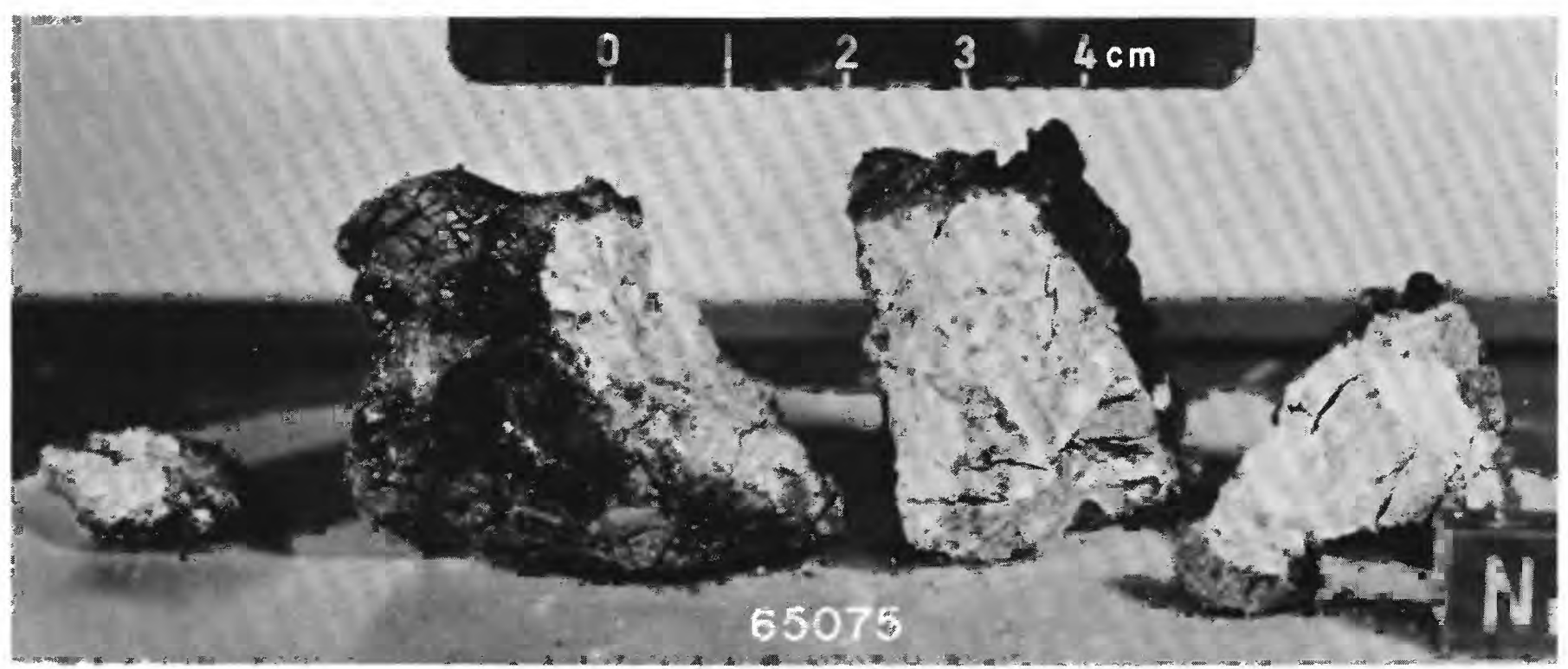

FIgURE 48C.-Sample 65075 in LRL (photograph S-72-39414). Note vesicular and irregularly cracked glass coating. See chap. D4, fig. 17, for $W_{1}$ photographic view of this type $B_{2}\left(B_{4}\right)$ breccia. 
SAMPLE: 65075

Station: 5

Landmark: Interior wall of 20-m crater.

Rock Type: BrecCia, B2(B4, partly glass coated.

SURFACE CHARACTERISTICS OF SAMPLE AREA

Slopes: Crater wall sloping approximately $20^{\circ}$ northeast into $20-m$

crater.

Fragment population

Size range and distribution: Large blocks (up to approximately

$1 / 2 \mathrm{~m})$ sparsely distributed outside $20-\mathrm{m}$ crater rim; cobbles

10-15 cm common in and around crater; in local sample area, cobbles

rare; fragments mainly $<2 \mathrm{~cm}$.

Color: Gray.

Shapes: Large blocks angular; cobbles subangular to round, but

predominatly subrounded in sample area.

Fillets: Minor to none.

Apparent burial: A few blocks are partly buried, but most are

not.

Dust cover: Prevalent.

Fines

Color: Gray.

Compaction: Loose.

Craters

Size range and distribution: Several $1 / 2-1 \mathrm{~m}$ craters on larger

crater wall.

Shape: Generally subdued.

Ejecta: Slightly raised rims visible around some craters.

SAMPLE CHARACTERISTICS FOR 65075

Size: Originally 5-6 cm; largest of 4 broken pieces is $5 \times 4 \times 4^{i} \mathrm{~cm}$; 107.9 grams total weight.

Color: Greenish gray.

Shape: Rounded cobble, highly fractured and friable.

Fillet: Slight.

Apparent burial: Probably about half buried.

Dust cover: Appears to be heavy.

Comparison with other fragments in area: More fractured than any

other rock in local area (see crew comments, Table 3, p. 29-30).

Probable origin: Fragment of Descartes material, fractured by local impact; rounded shape not characteristic of South Ray ejecta. 

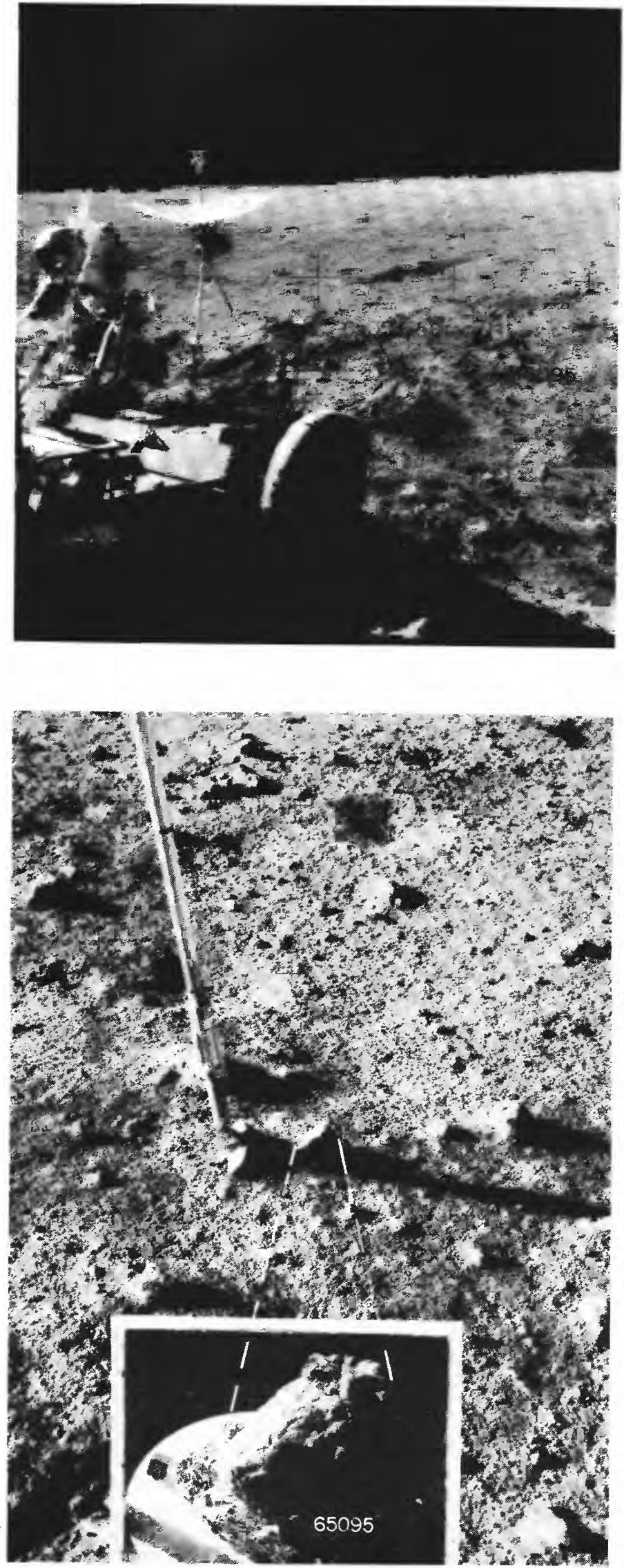

FIGURE 49A.-Location of sample 65095 in relation to nearby samples 65055 and 65056 , shown before sampling in panorama photograph AS16-110-18009; view is east-southeast.
Figure 49B.-Sample 65095 showing tentative lunar orientation reconstructed in LRL compared to photograph AS16-110-18027 taken before sampling; view is south-southeast. Partial breakage of glass coating makes shadow details impossible to duplicate accurately in the LRL (inset polaroid photograph not numbered). 


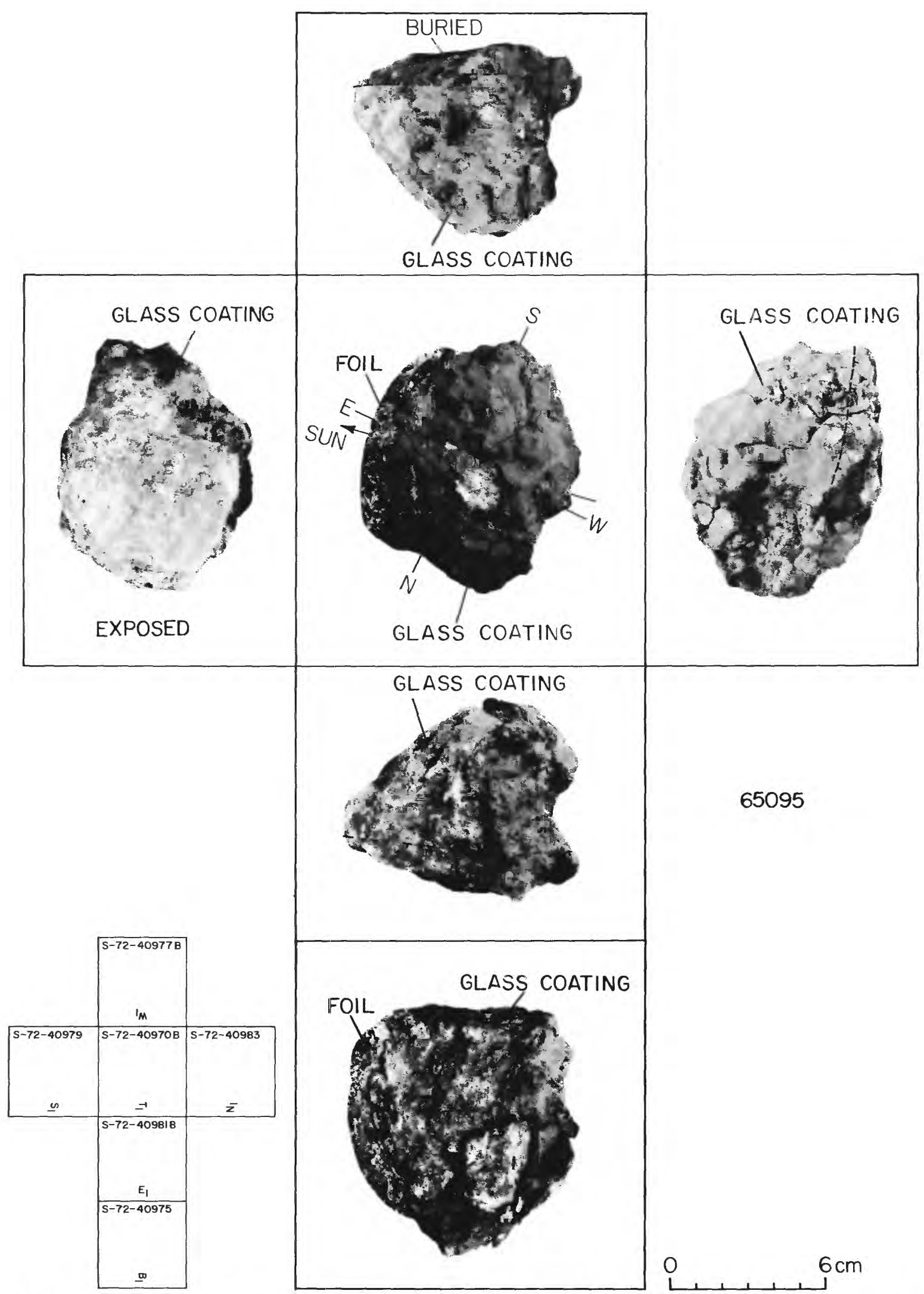

FIGURE $49 C$.- Orthogonal views of sample 65095 related to its tentative lunar orientation at time of sampling. See chap. D4, fig. 18, for a photographic stereopair of this type $B_{2}\left(B_{1}\right)$ rock. 
SAMPLE: 65095

Station: 5

Landmark: Rim of $20 \mathrm{~m}$ crater, $\simeq 3 \mathrm{~m}$ in front (south) of LRV. Rock type: B2(BI) breccia, partly glass coated.

SURFACE CHARACTERISTICS OF SAMPLE AREA

Slopes: Local slope $\simeq 5^{\circ}$, regional slope $\simeq 10^{\circ}$ northwest off stone Mountain.

Fragment population

Size range and distribution: Fragments $>5 \mathrm{~cm}$ abundant; $5-15 \mathrm{~cm}$ cobbles common, widely distributed: < $15 \mathrm{~cm}$ blocks very sparsely scattered.

Color: Gray.

Shapes: Fragments < $5 \mathrm{~cm}$ round to angular; some cobbles ( $~ 5-15$ )

round, but mainly subround; large blocks subangular to subround;

several distinctly platey, angular fragments, 8-10 cm.

Fillets: Common around most cobbles and small fragments.

Apparent burial: Perched to $1 / 4$ of fragment.

Fines Dust cover: Prevalent.

Color: Gray.

Compaction: Loose.

Craters

Size range and distribution: $1 / 2$ to 2 m craters abundant, widely distributed; 3-5 m craters common; larger craters visible in landscape.

Shape: Mainly rounded and subdued; few small craters with raised rims visible.

Ejecta: Rim deposits generally subdued.

SAMPLE CHARACTERISTICS FOR 65095

Size: $8 \times 7 \times 6 \mathrm{~cm}$; 560.1 grams.

Color: White matrix breccia with brownish-black glass coating.

Shape: Subrounded, crudely pyramidal.

Fillet: Poorly developed.

Apparent burial: < 1/4 (perched).

Dust cover: Present.

Comparison with other fragments in area: Appears similar to other near-field fragments in figure $49 B$.

Probable origin: The perched nature of the type B2 sample suggests an affinity with South Ray ejecta similar to samples collected at station $4 a$. 


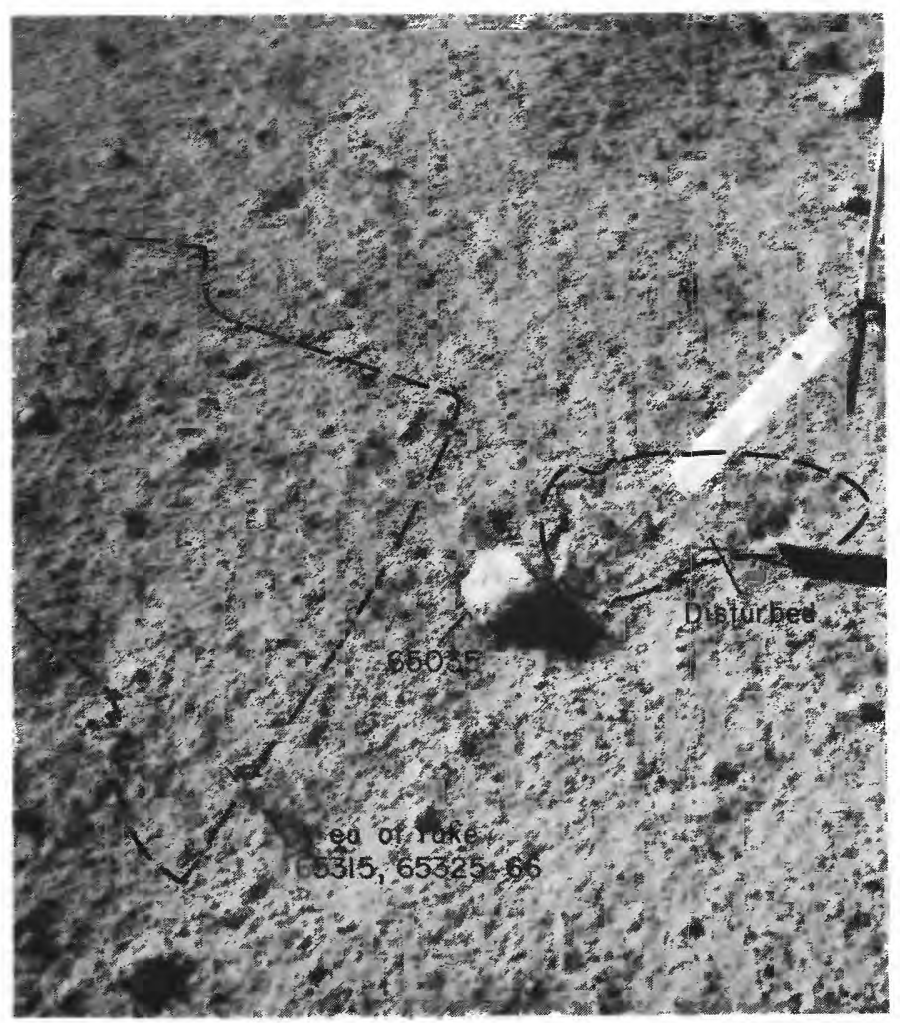

FigURE 50A.-Area of rake samples 65315 and $65325-66$, adjacent to documented sample 65035 , shown before sampling in photograph AS16-110-18023; view is southeast. Sample 65315, not identified in the presampling picture, was picked up individually and included with the rake samples (see figs. $46 \mathrm{~A}$ and $48 \mathrm{~A}$ for location in relation to other samples).

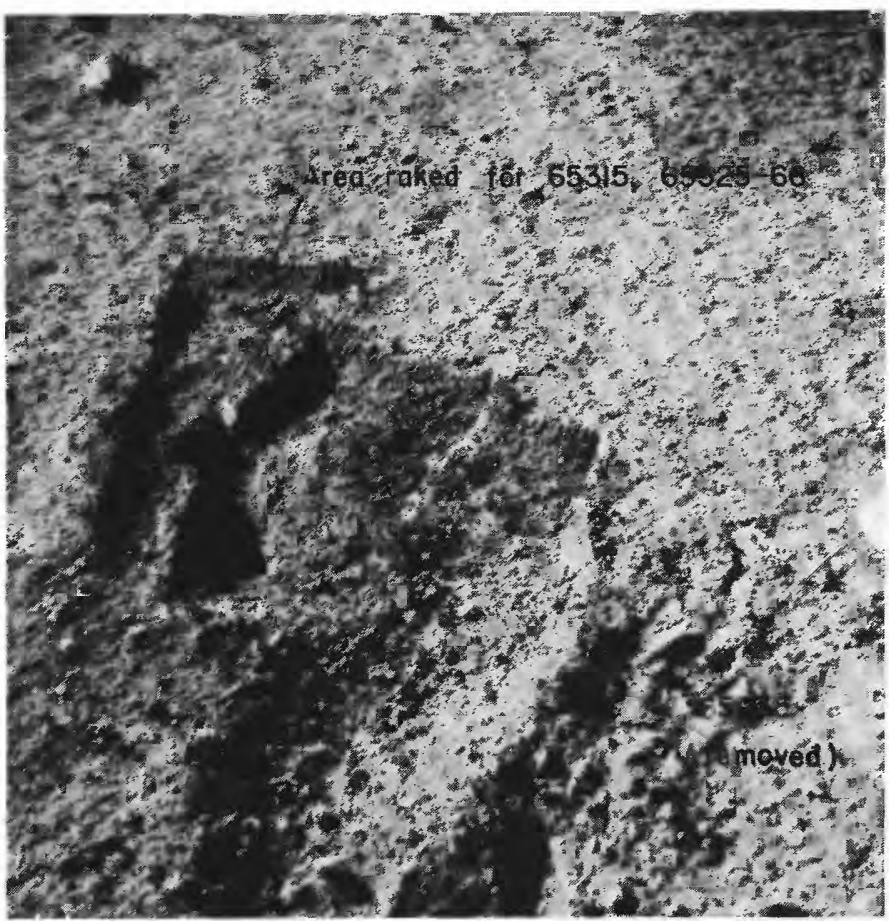

Figure 50B.-Area of rake samples 65315 and 65325-66 shown after sampling in photograph AS16-110-18026; view is south. Also shows place from which sample 65035 had been removed.
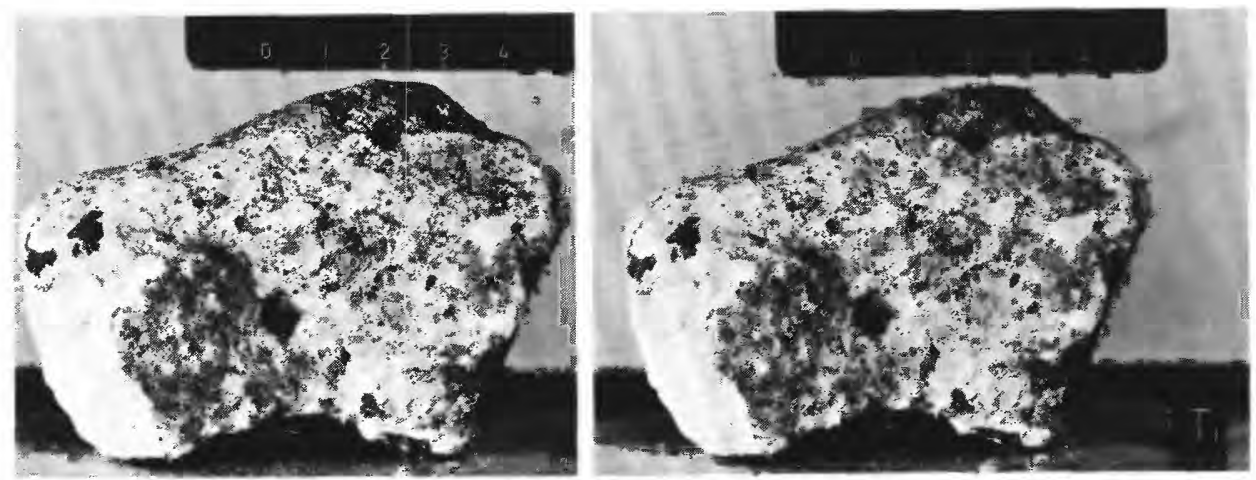

FIGURE 50C.-Stereopair of sample 65315 in LRL; photographs S-72-42111 (right) and $-42111 \mathrm{~B}$ (left). See chap. D4, figs. $19 A-C$, for a stereopair and two photomicrographs of this type $B_{2}$ breccia, collected with rake samples $65325-66$. 


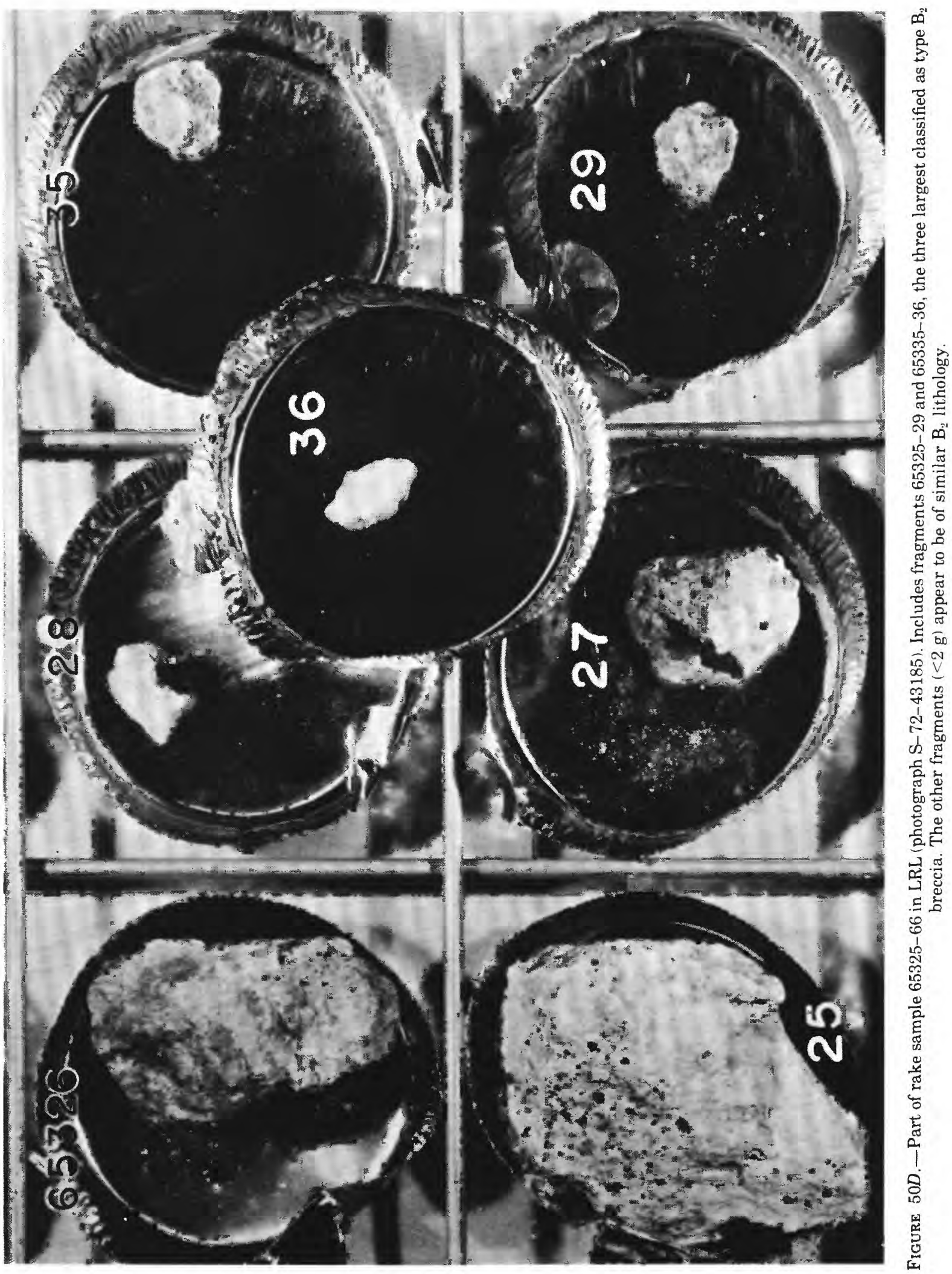



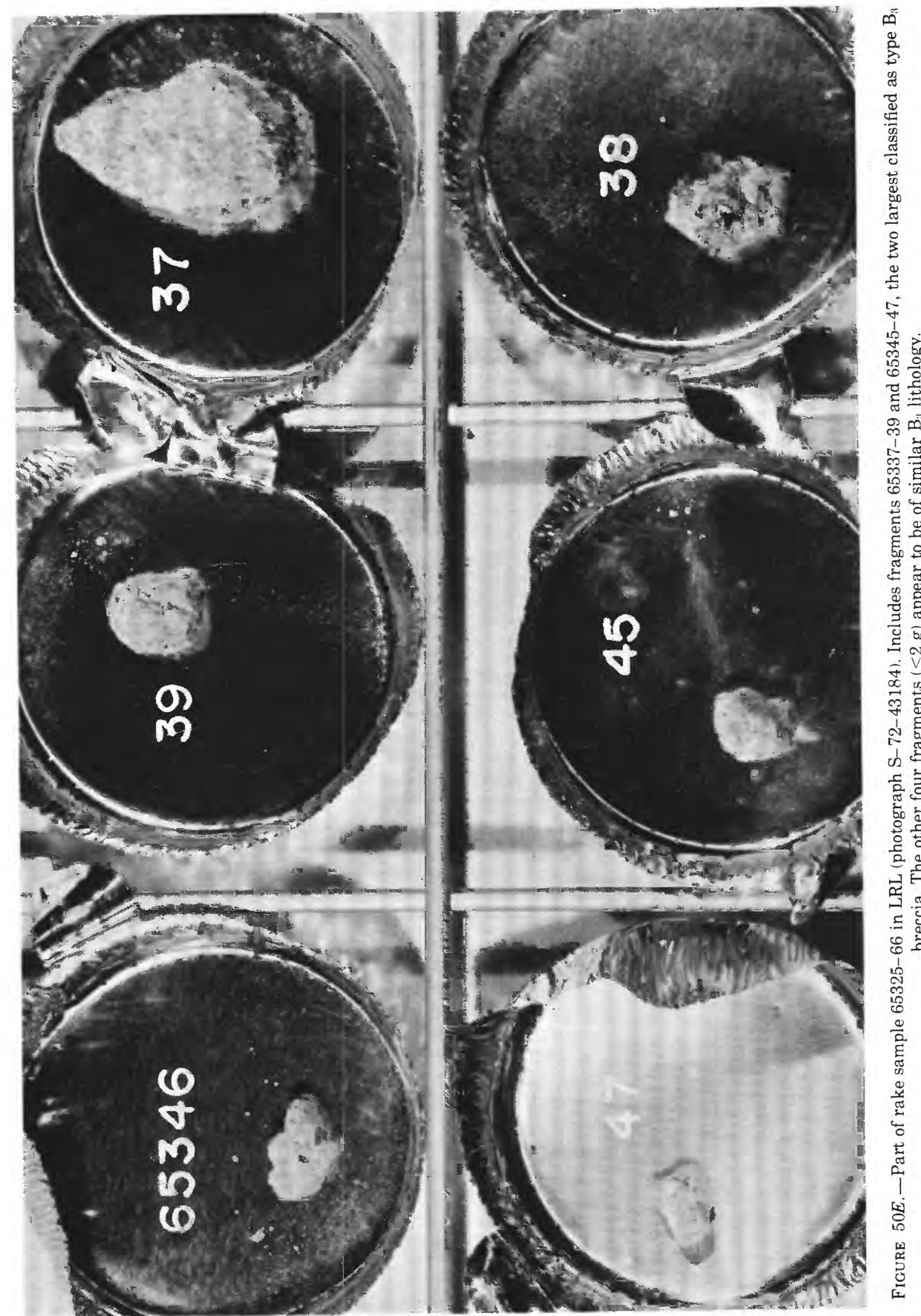


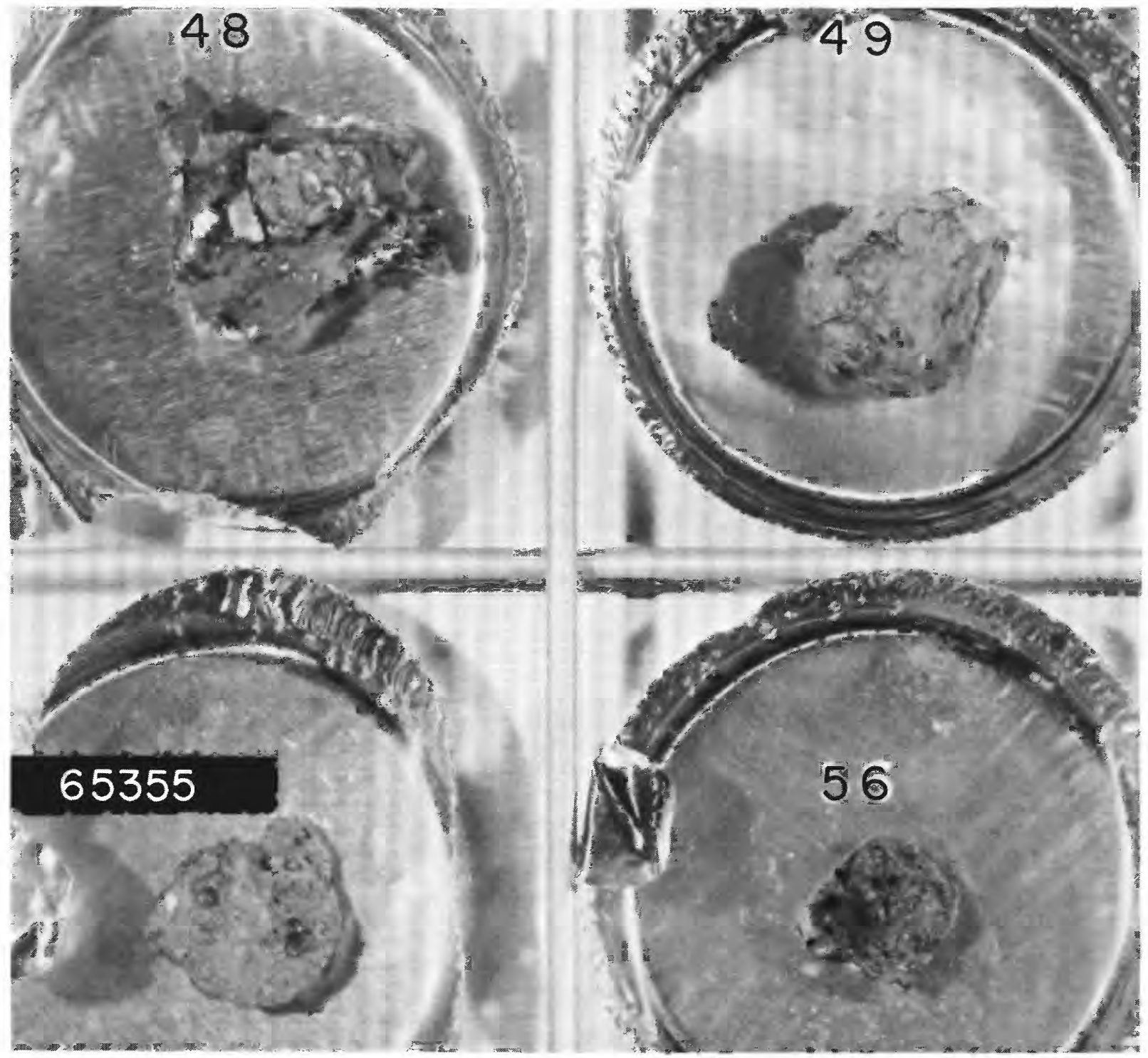

Figure 50F.-Part of rake sample 65325-66 in LRL (photograph S-72-43181). This group includes fragments 65348-49 and $65355-56$, all classified as glassy $(\mathrm{G})$ rocks. 


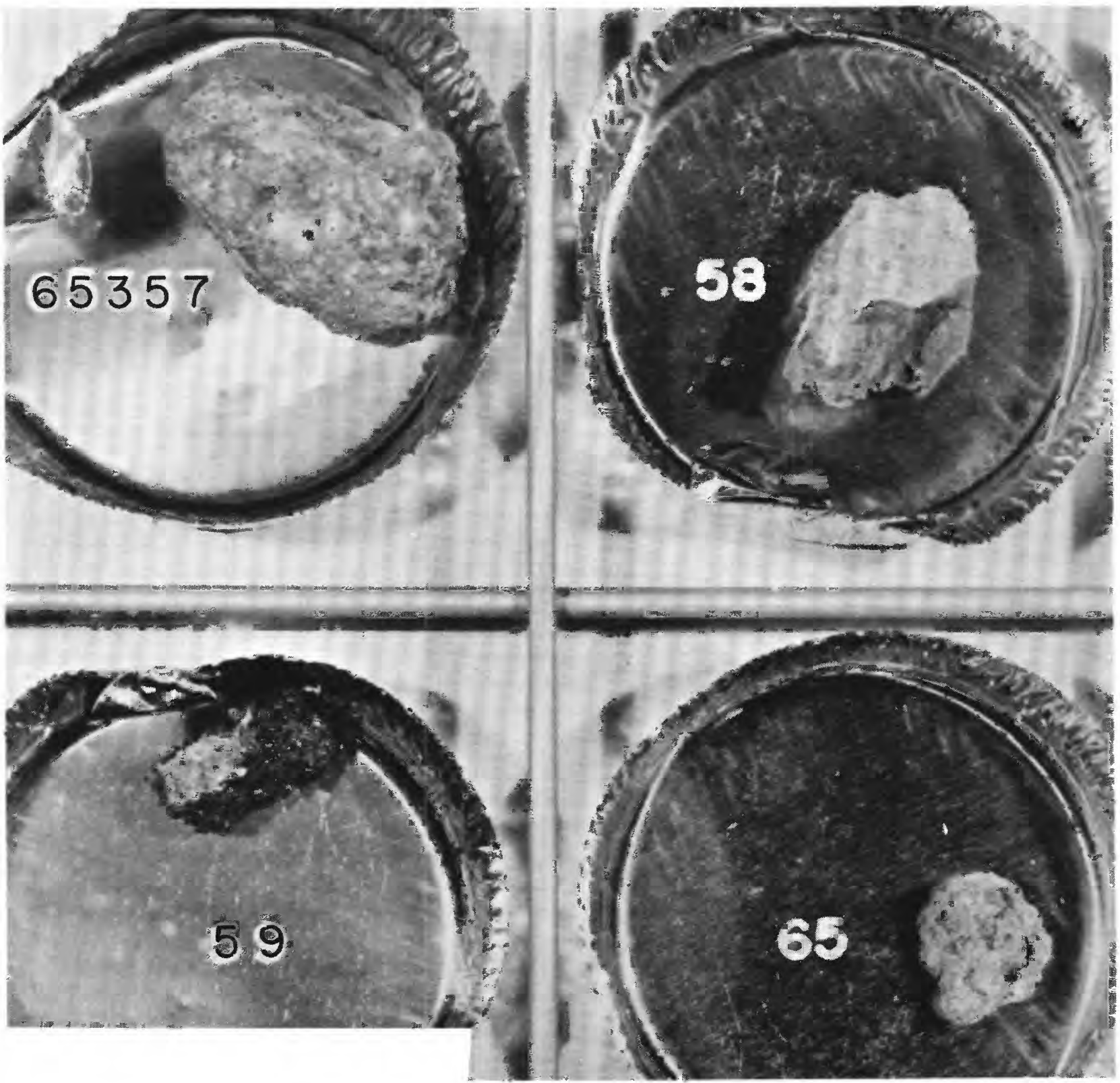

FigURE 50G.-Part of rake sample 65325-66 in LRL (photograph S-72-43180). This group includes fragments 65357-59 and 65365 , all metaclastic $\left(C_{2}\right)$ rocks except sample 65359 , a glass-coated $B_{2}$ breccia. 


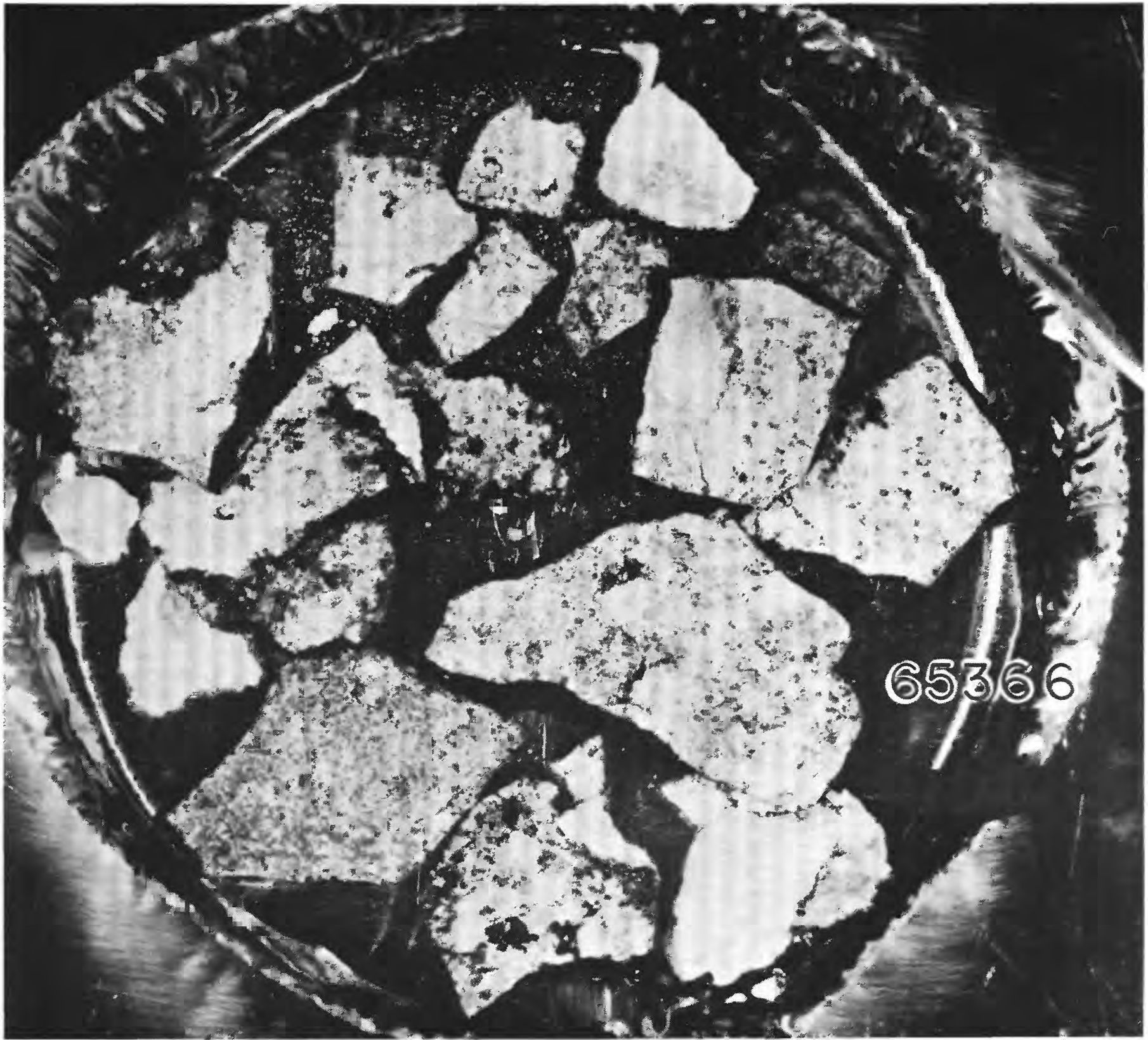

FrgURE 50H.-Rake fragment 65366 in LRL (photograph S-72-43178). The broken sample is classified as a glassy (G) rock.

SAMPLE: 65315, 65325-29, 35-39, 45-49, 55-59, 65-66, (rake sample). See description of sample 65035, and figures 46A and 48A for location.

SAMPLE CHARACTERISTICS OF 65315, 25-66, (27 rake fragments)

Size: 1-10 cm fragments; 65315 is 300.4 grams; remainder total $200.29 \mathrm{grams}$.

Color: White and gray.

Shape: Most fragments rounded, friable.

Dust cover: Covered.

Comparison with other fragments in area: Hard fragments apparently more common in rake sample than in nearby crater wall which contains mainly friable clods.

Probable origin: Crater wall somewhat shadowed from south Ray ejecta, and therefore the regolith fragments may be derived from underlying Descartes materials. 


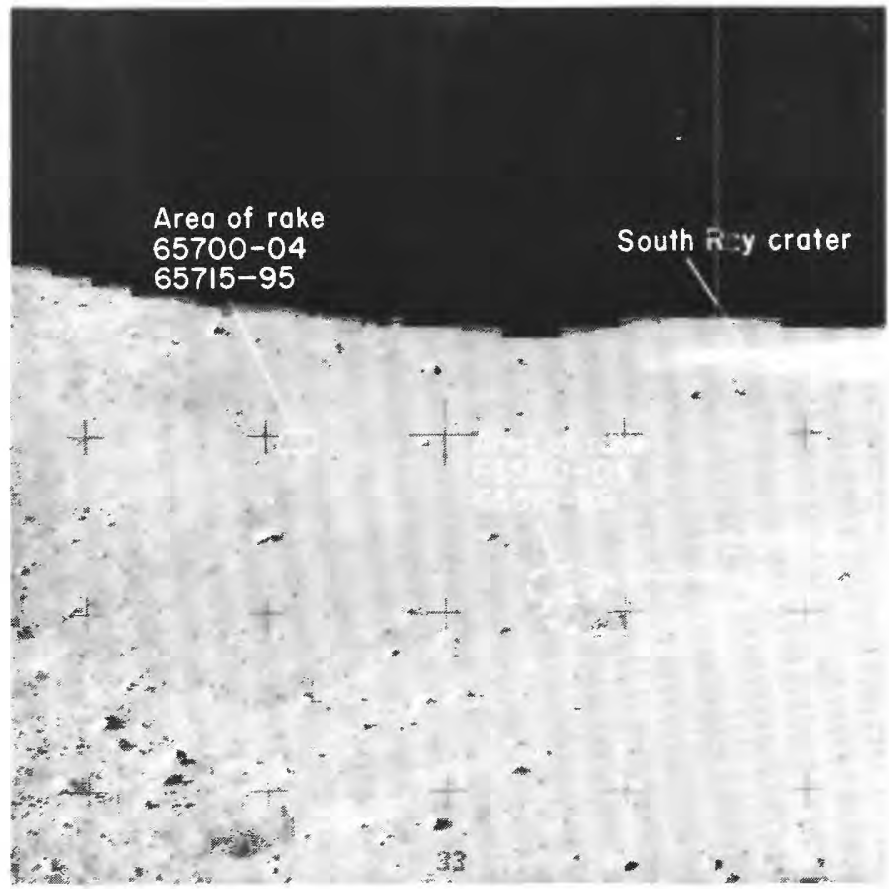

Figure 51A.-Location of rake samples 65500-04 and 65510-88 in relation to nearby samples $65700-04$ and $65715-95$, shown before sampling; panorama photograph AS16-110-18016; view is southwest.

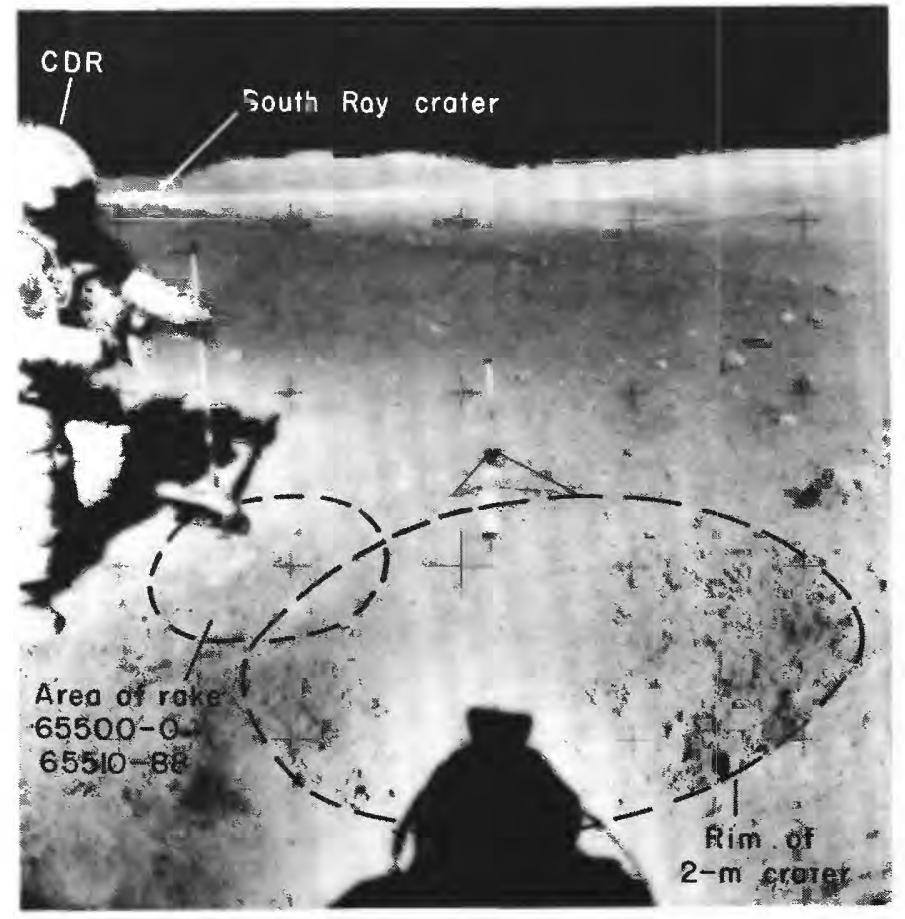

Figure $51 B$.- Area of rake samples $65500-04,65510-14$ (soils), and 65515-88 (fragments) shown during sampling in photograph AS16-110-18019. View is west. Collected from rim of a relatively young 2-m crater.

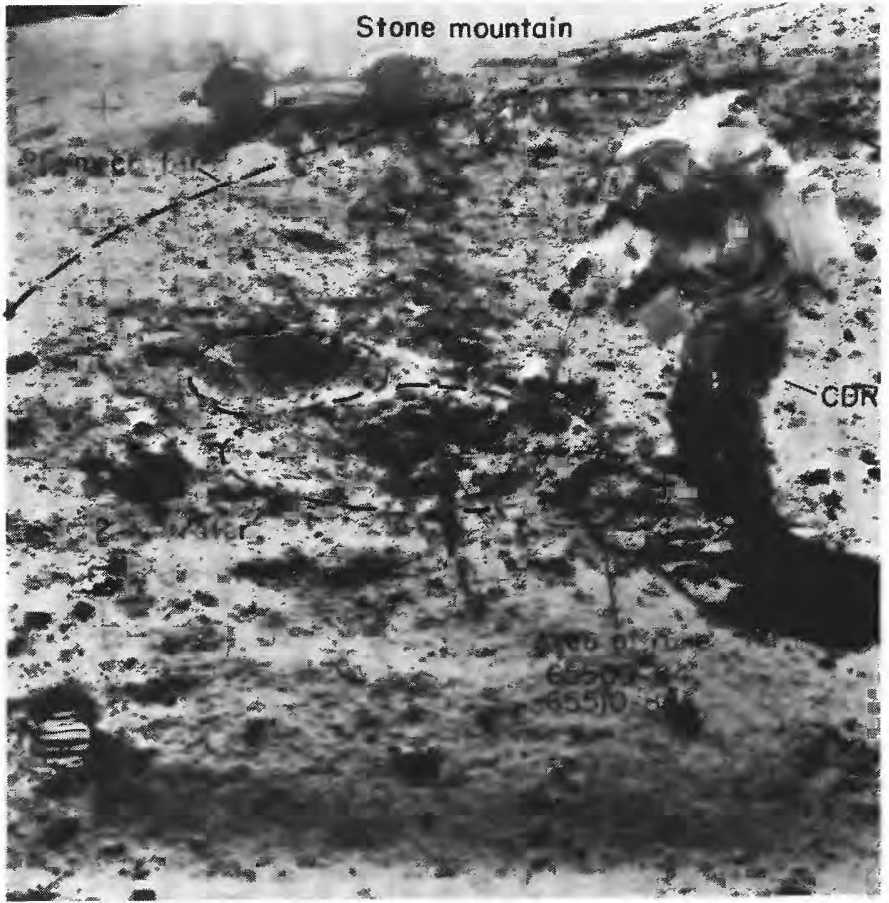

FigURE 51C.-Location of rake samples 65500-04, 65510-14 (soils), and 65515-88 (fragments) shown during sampling in photograph AS16-110-18020. View is east toward LRV and Stone mountain. 


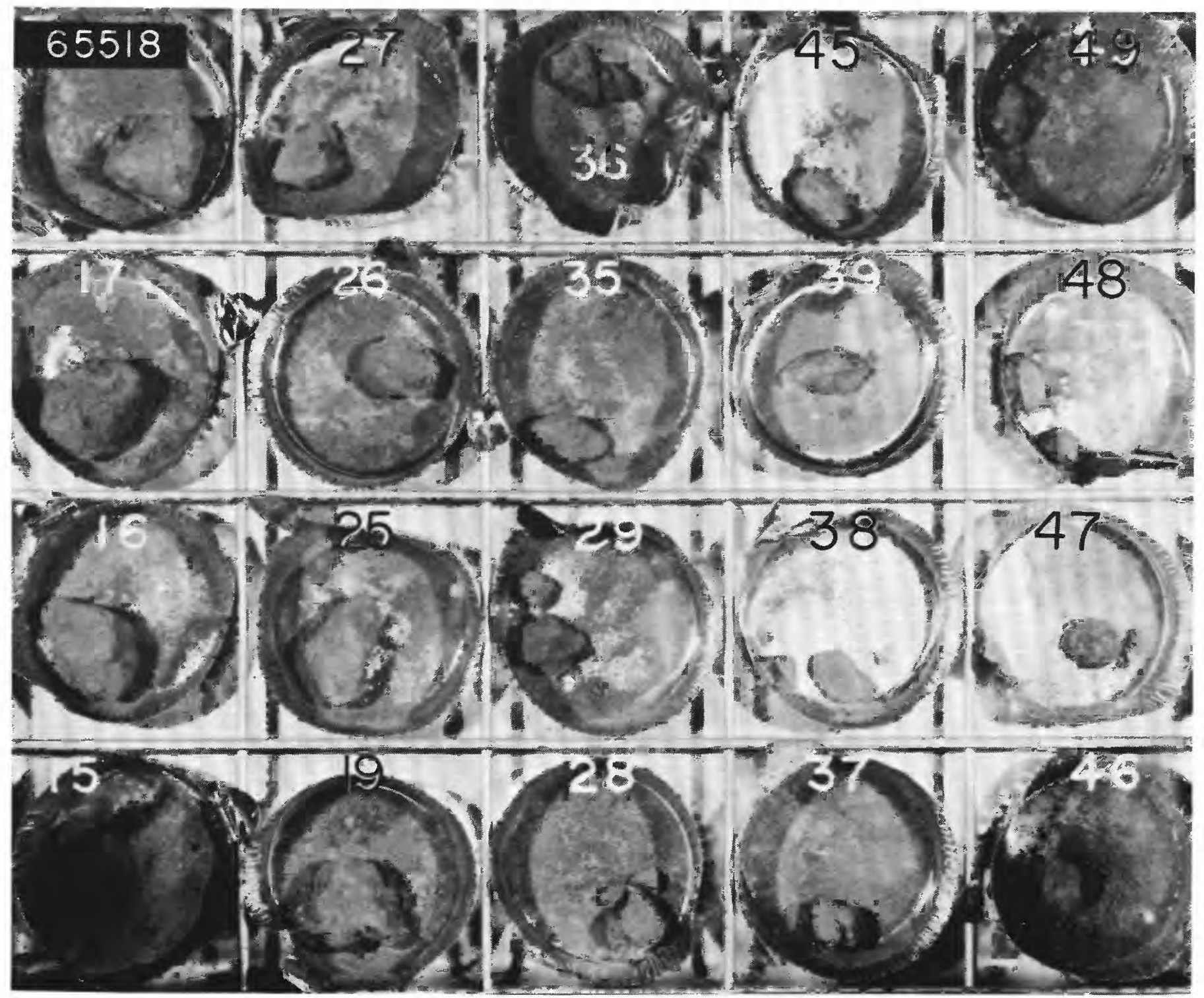

FiguRE 51D.-Part of rake sample 65515-88 in LRL (photograph S-72-43348). This group includes fragments 65515-19, 65525-29, $65535-39$, and $65545-49$. All except the four smallest ( 36 and $45-47$ ) are classified as type $B_{3}$ breccia. The four $<2 \mathrm{~g}$ appear to be of similar $\mathrm{B}_{3}$ lithology. 

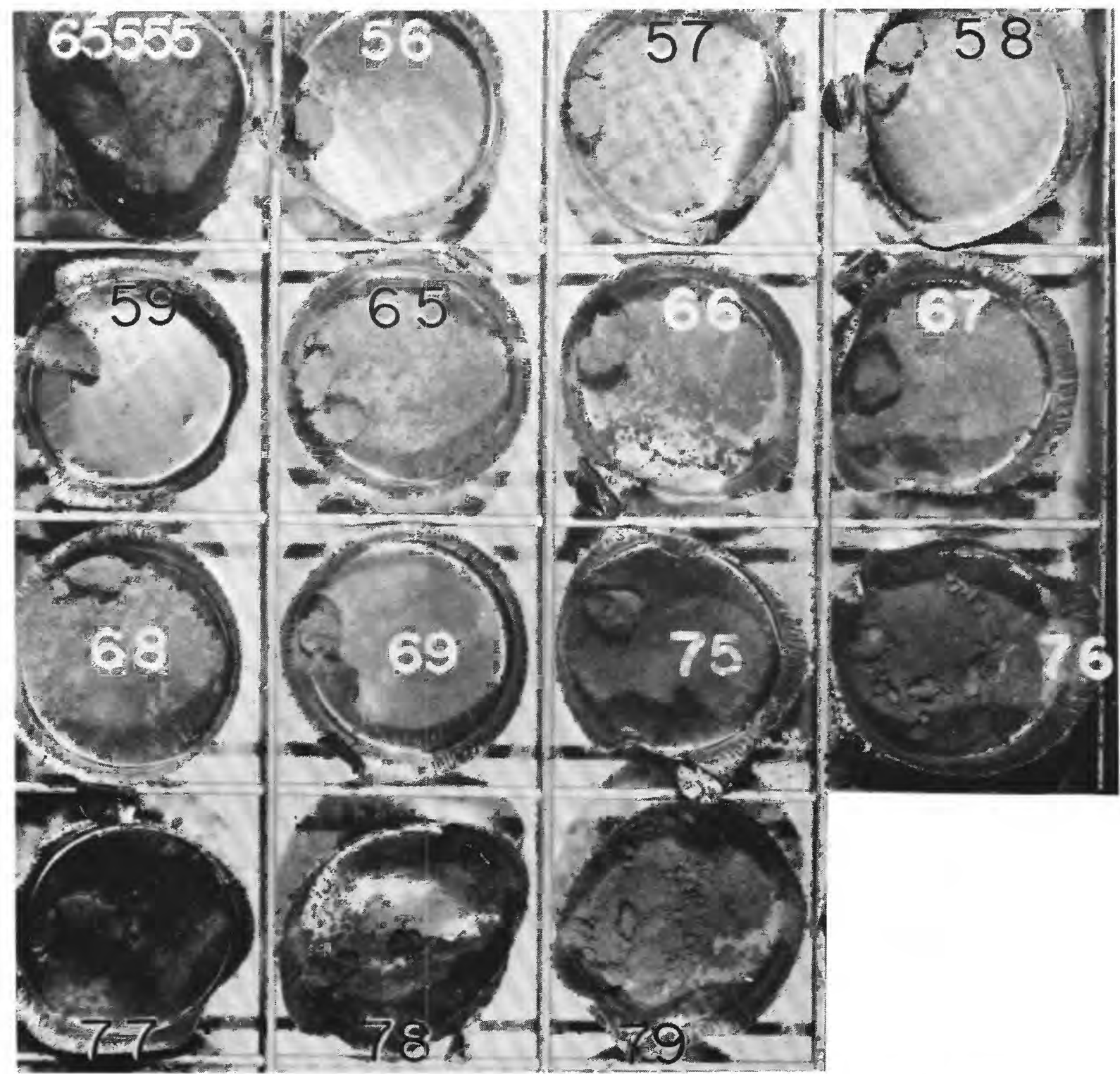

Figure 51E.-Part of rake sample 65515-88 in LRL (photograph S-72-43352). This group includes fragments 65555-59, $65565-69$, and $65575-79$. Fragment 65555 is a $B_{3}$ breccia; the other 14 fragments, $<2 \mathrm{~g}$ and not classified, appear to be of similar $\mathbf{B}_{3}$ lithology. 


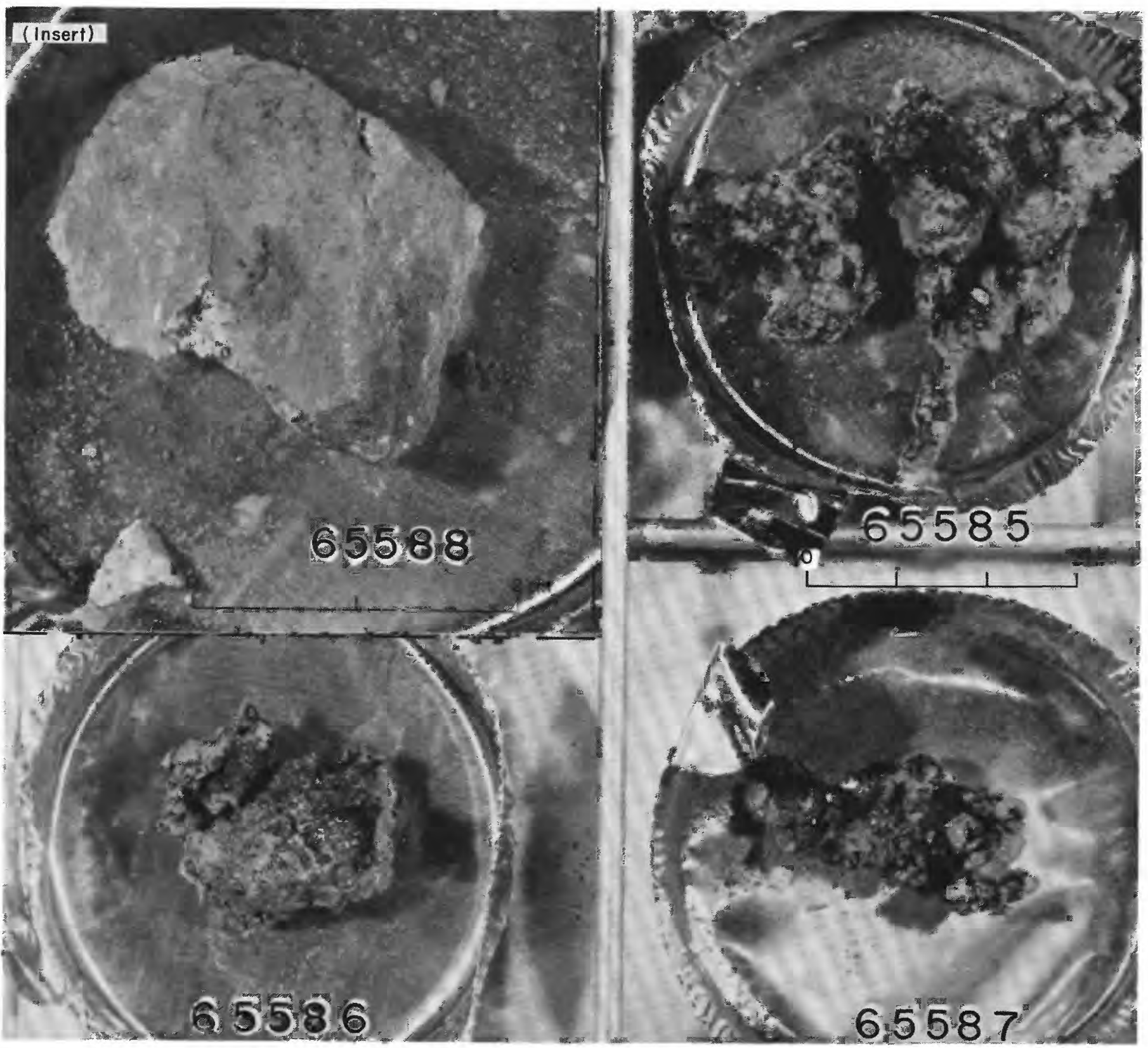

Figure 51F. - Part of rake sample 65515-88 in LRL (photograph S-72-43346 with insert 43357). This group includes fragments 65585-88. Fragment 65588 is a $B_{1}$ breccia; the other three, glassy agglutinates $(G)$. 
SAMPLE: $65500-04 ; 65510-14,65515-19,25-29,35-39,45-49,55-59,65-69$, 75-79, 85-88 (rake samplẹs).

Station: 5

Landmark: Approximately $10 \mathrm{~m}$ west of LRV.

Rock type: 65500-04 and 65510-14, soil; 65515-88, 39 rake fragments (mostly B3 breccia).

SURFACE CHARACTERISTICS OF SAMPLE AREA

Slopes: Local slope $5^{\circ}$; regional slope $10^{\circ}$ to the northwest on

flank of stone Mountain.

Fragment population

Size range and distribution: Meter-size blocks absent; few scattered blocks approximately $30 \mathrm{~cm}$; 10-20 cm cobbles common and widely distributed; surface mainly sand size up to $5 \mathrm{~cm}$; some cobbles highly fractured.

Color: Gray.

Shapes: Large blocks (> $20 \mathrm{~cm}$ ) angular to subangular; cobble size and smaller mainly subround to round.

Fillets: slight to none.

Apparent burial: No burial of large blocks; some rounded cobbled and pebbles partly buried.

Dust cover: Most prevalent on smaller; rounded rocks; probably light on large blocks.

Fines

Color: Gray surface; whitish subsurface.

Compaction: Loose.

Craters

Size range and distribution: Numerous small $1 / 2-1 \mathrm{~m}$ size craters superposed on 20-m crater; sample apparently taken from small (1-1/2 m) crater near rim.

Shape: Small craters relatively distinct with slightly raised rims; larger ( $>2 \mathrm{~m}$ ) craters mainly shallow and subdued.

Ejecta: Clods around small craters probably locally derived;

rounded cobbles probably ejecta from large craters; angular

blocks possibly ejecta from south Ray crater.

SAMPLE CHARACTERISTICS FOR 65500-04 and 65510-14 (rake soil)

Size: < $1 \mathrm{~cm}$ fines; 1028.59 grams total weight.

Color: Gray surface, lighter beneath (not as white as subsurface soil at station 1).

Comparison with other soil in area: Probably typical of local soil composition, but possibly more indurated as result of small impact at sample locality; light color unique among soil samples from station 5 .

Probable origin: Regolith derived primarily from underlying and reworked Descartes highlands materials. 
SAMPLE CHARACTERISTICS FOR 65515-88 (39 rake fragments)

Size: $1-5 \mathrm{~cm}$ fragments; 178.04 grams total weight.

Color: Mostly yellowish gray to light olive gray clods; dark gray glassy agglutinates.

Shape: Subround to subangular clods; very friable.

Comparison with other fragments in area: Typical, but formation of glass and induration of clods possibly caused by local small impact. Probable origin: Regolith derived from underlying reworked Descartes material as well as superposed ejecta from distant impact craters; rounded fragments. Probably not South Ray ejecta.

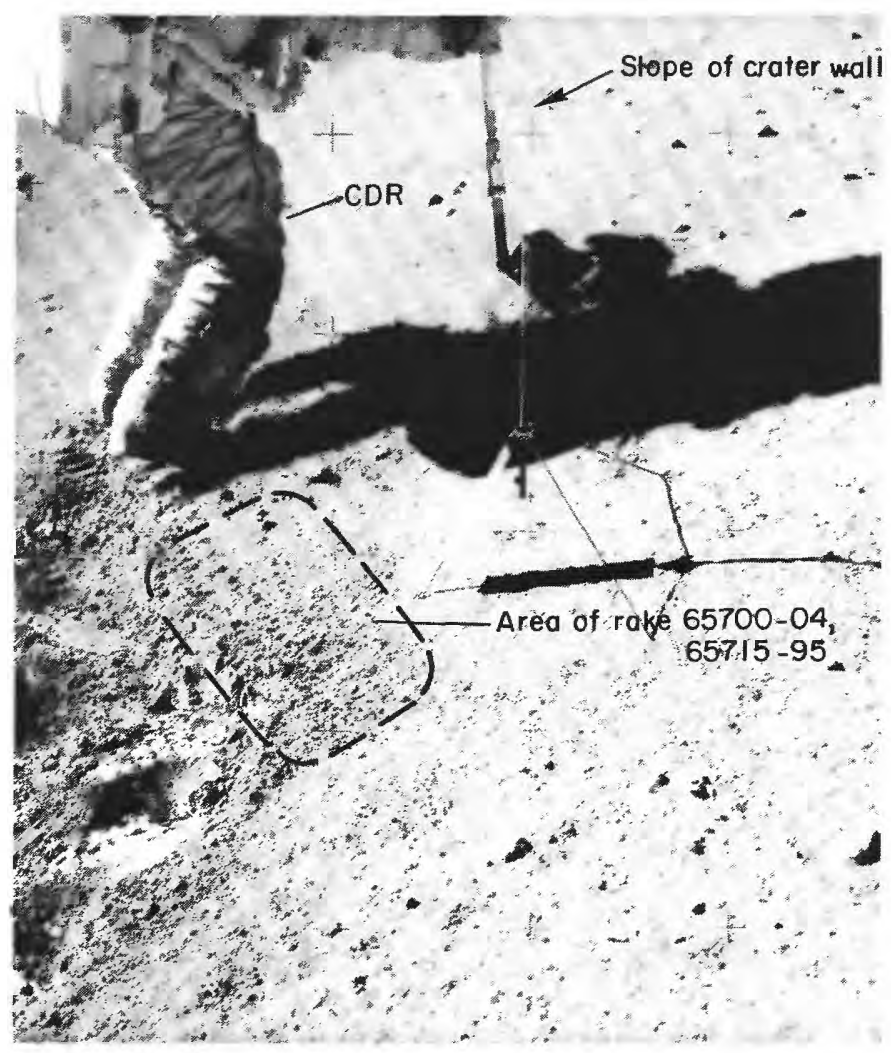

Figure 52A.-Area of rake samples 65700-04 and 65715-95 shown before sampling in photograph AS16-110-18022; view is southeast. Collected from south wall of a $20-\mathrm{m}$ crater-an area believed to have been shielded from South Ray ejecta. See fig. $51 A$ for location of sample in panorama photograph AS16-110-18016. 


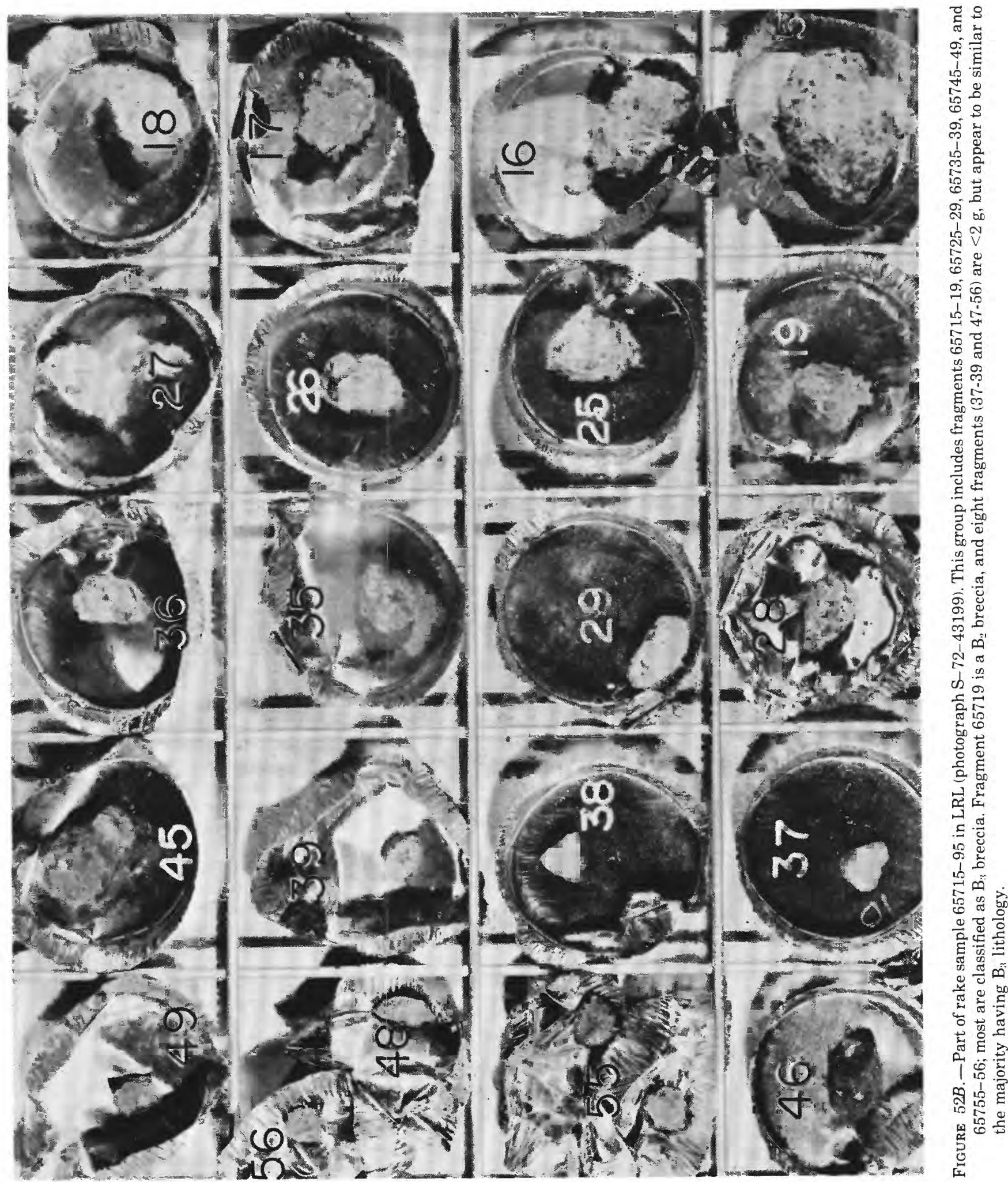



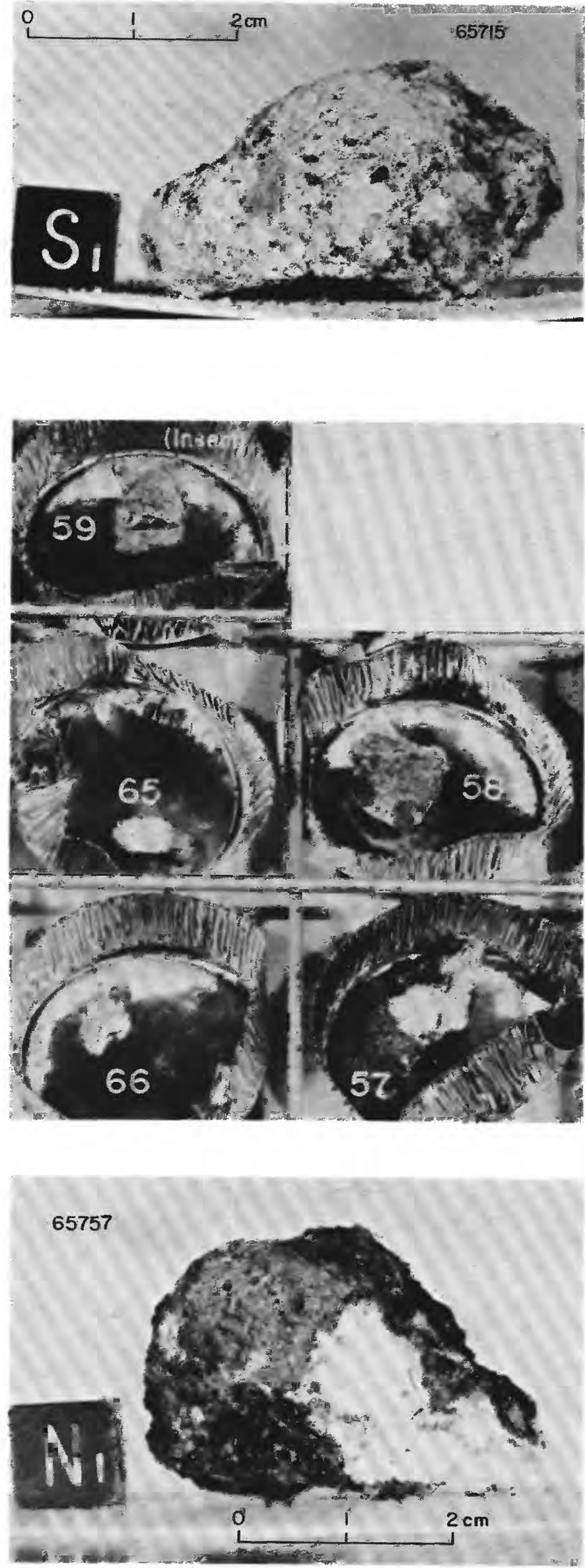

Figure 52C.-Rake fragment 65715 in LRL (photograph S72-43417). $B_{3}$ breccia.
Figure 52D.-Part of rake sample 65715-95 in LRL. This group includes fragments $65757-59$ and 65765-66. Fragments 57 and 58 are type $B_{2}$ breccia; 59 , type $B_{1} ; 65$ and $66(<2 \mathrm{~g})$ not classified (photograph S-72-43198, with an insert of S-72-43197 to give best view of fragments 59 and 65 ).
FIGURE 52E.-Rake fragment 65757 in LRL (photograph S72-43404). $B_{2}$ breccia. 

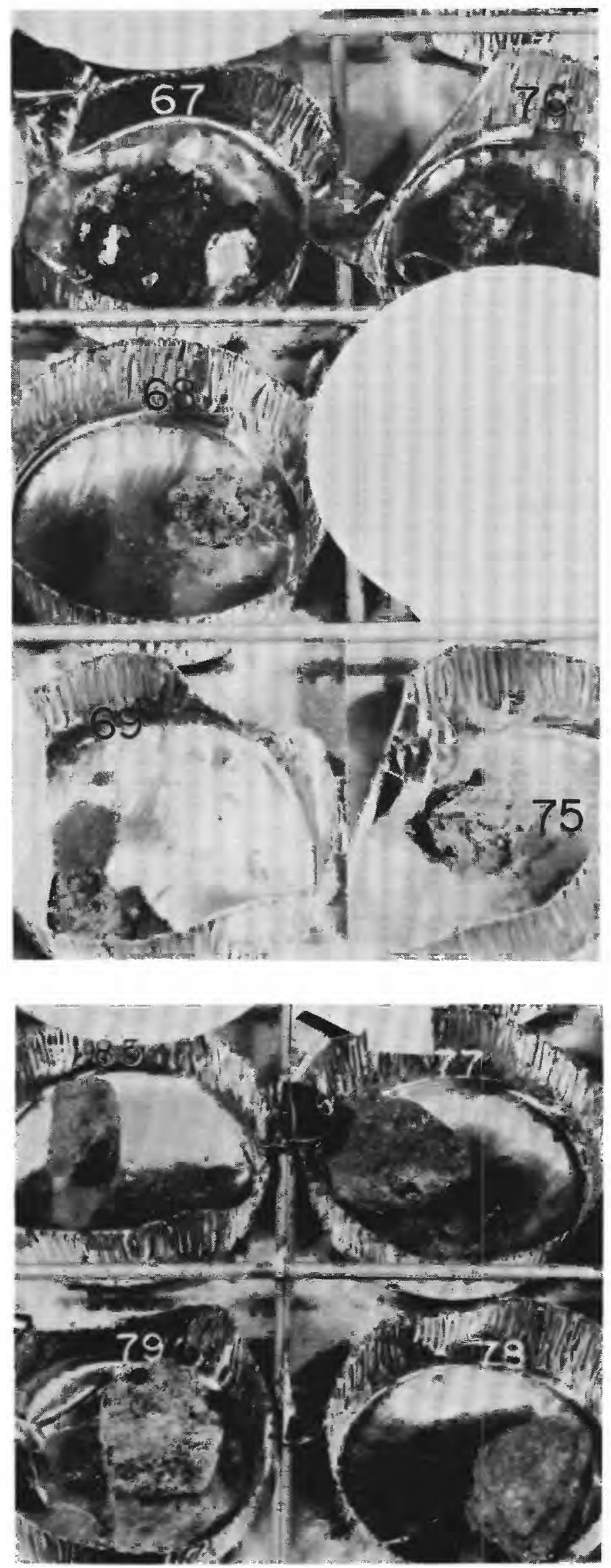

Figure 52F.-Part of rake sample 65715-95 in LRL. This group includes fragments 65767-69 and 65775-76, all classified as type G, glassy agglutinates (photograph S-72-43195 with insert from S-72-43196 of fragment 75 ).

AFigure 52G.-Part of rake sample 65715-95 in LRL. This group includes fragments 65777-79 (type $\mathrm{C}_{2}$ ) and 65785 (type $\mathrm{C}_{1}$ ); composite illustration made from photographs $\mathrm{S}-72-43193$ (fragments 77 and 78 ) and S-72-43194 (fragments 79 and 85). See chap. E, figs. $2 E$ and $3 C$, for photomicrographs of samples 65778 and 65785 , respectively. 


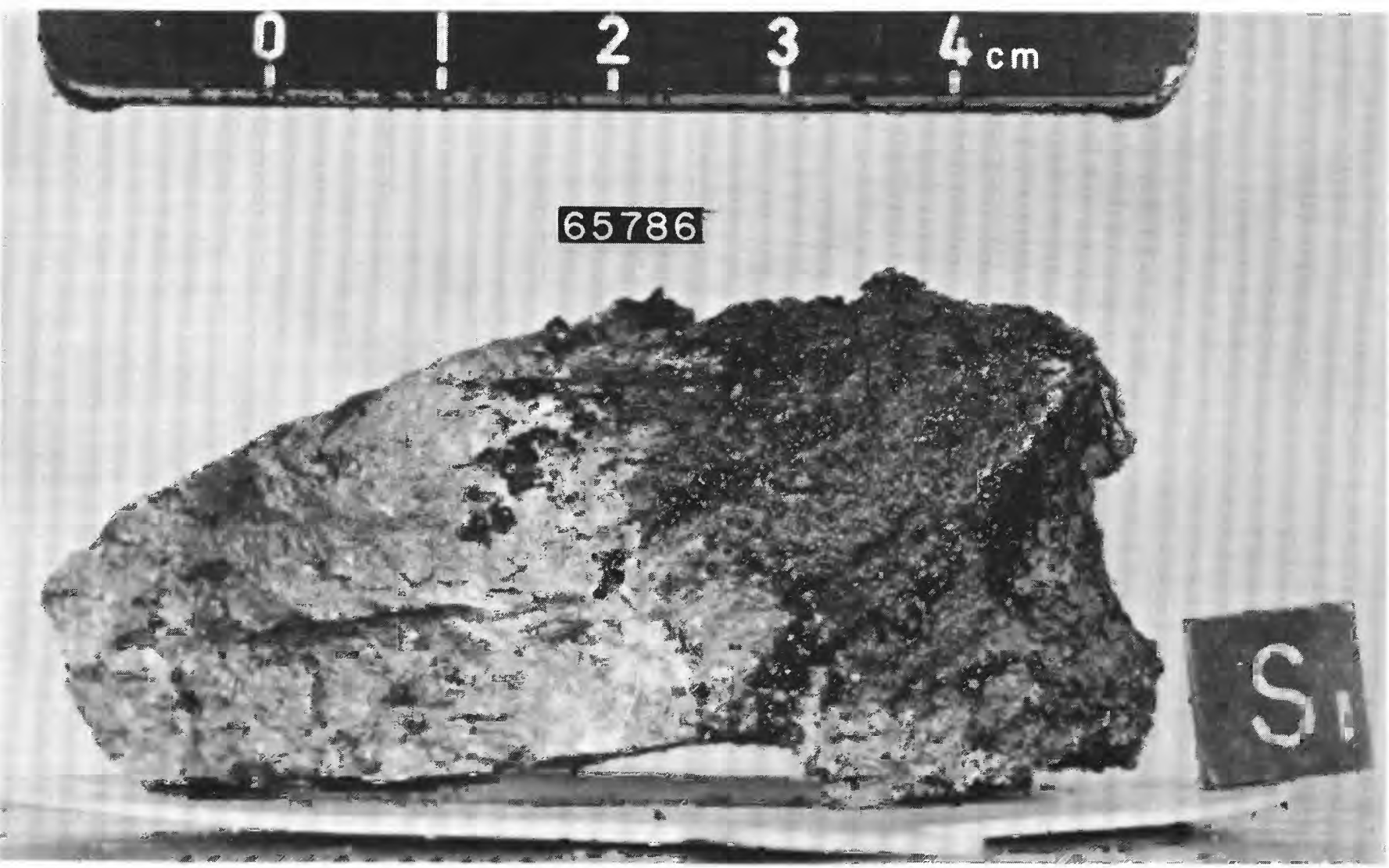

FIGURE 52H.-Rake fragment 65786 in LRL (photograph S-72-43415). Partly glass-coated $B_{3}$ breccia.

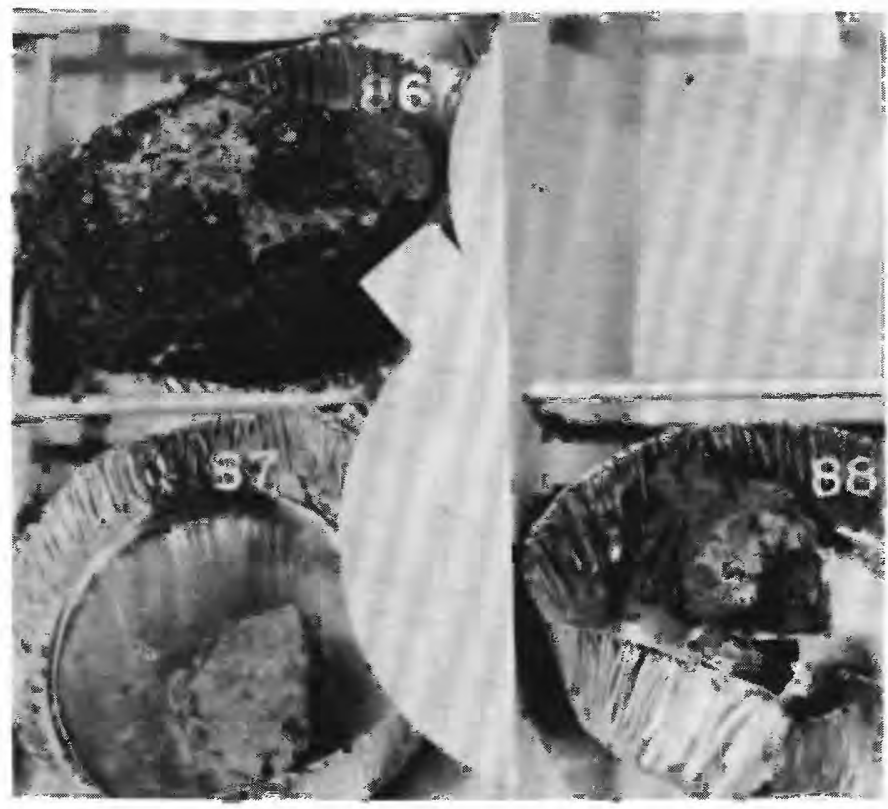

Figure 52I.-Part of rake sample 65715-95 in LRL. This group includes fragments 65786-88, classified as type $\mathrm{B}_{3}$ and $\mathrm{B}_{3}\left(\mathrm{C}_{2}\right)$ breccias (photograph S-72-43191 with insert from S-72-43192 of fragment 88). 

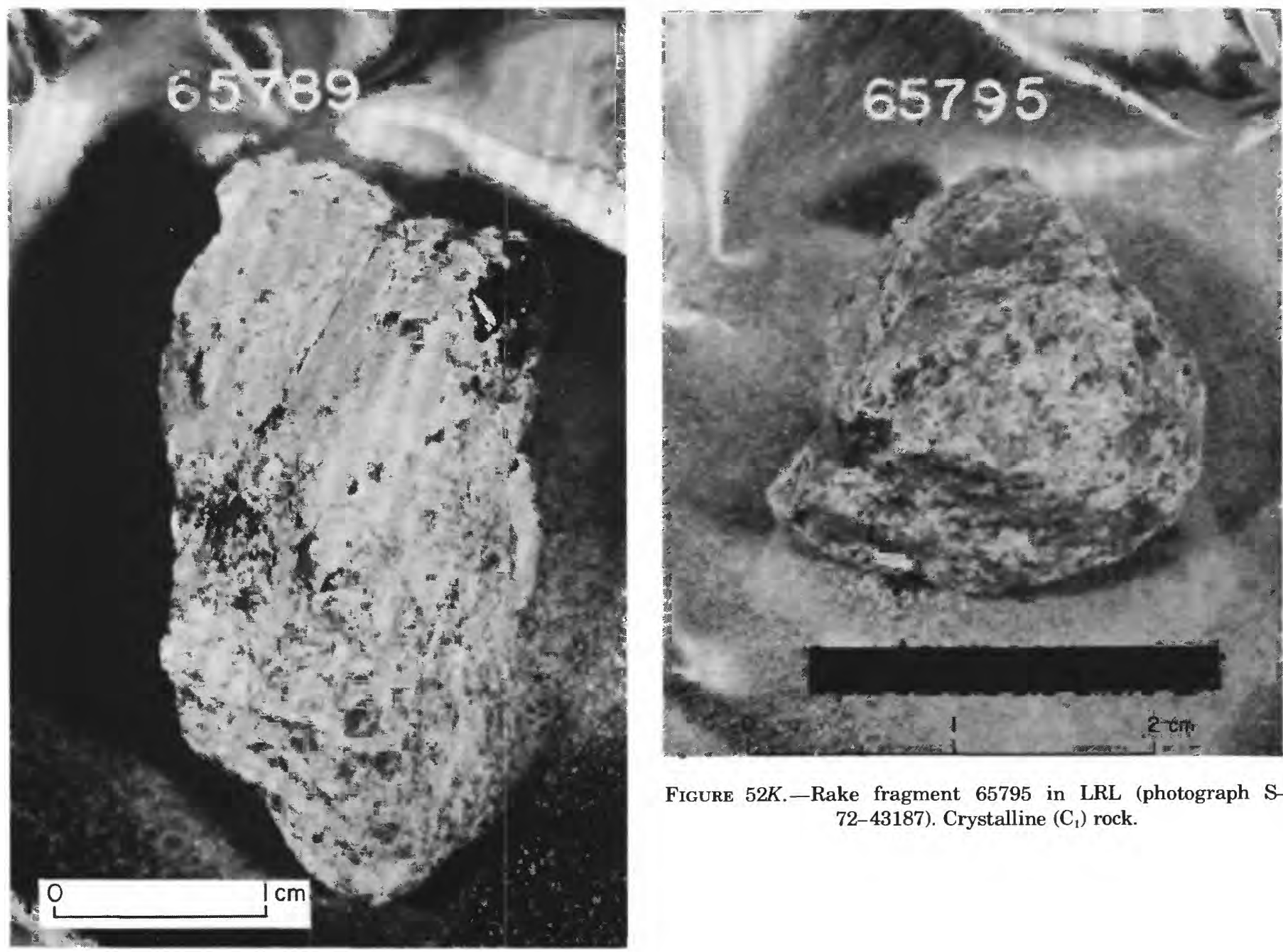

Figure 52K.-Rake fragment 65795 in LRL (photograph S72-43187). Crystalline $\left(C_{1}\right)$ rock.

Figure 52J.-Rake fragment 65789 in the LRL (photograph S-72-43190). $B_{1}$ breccia. 


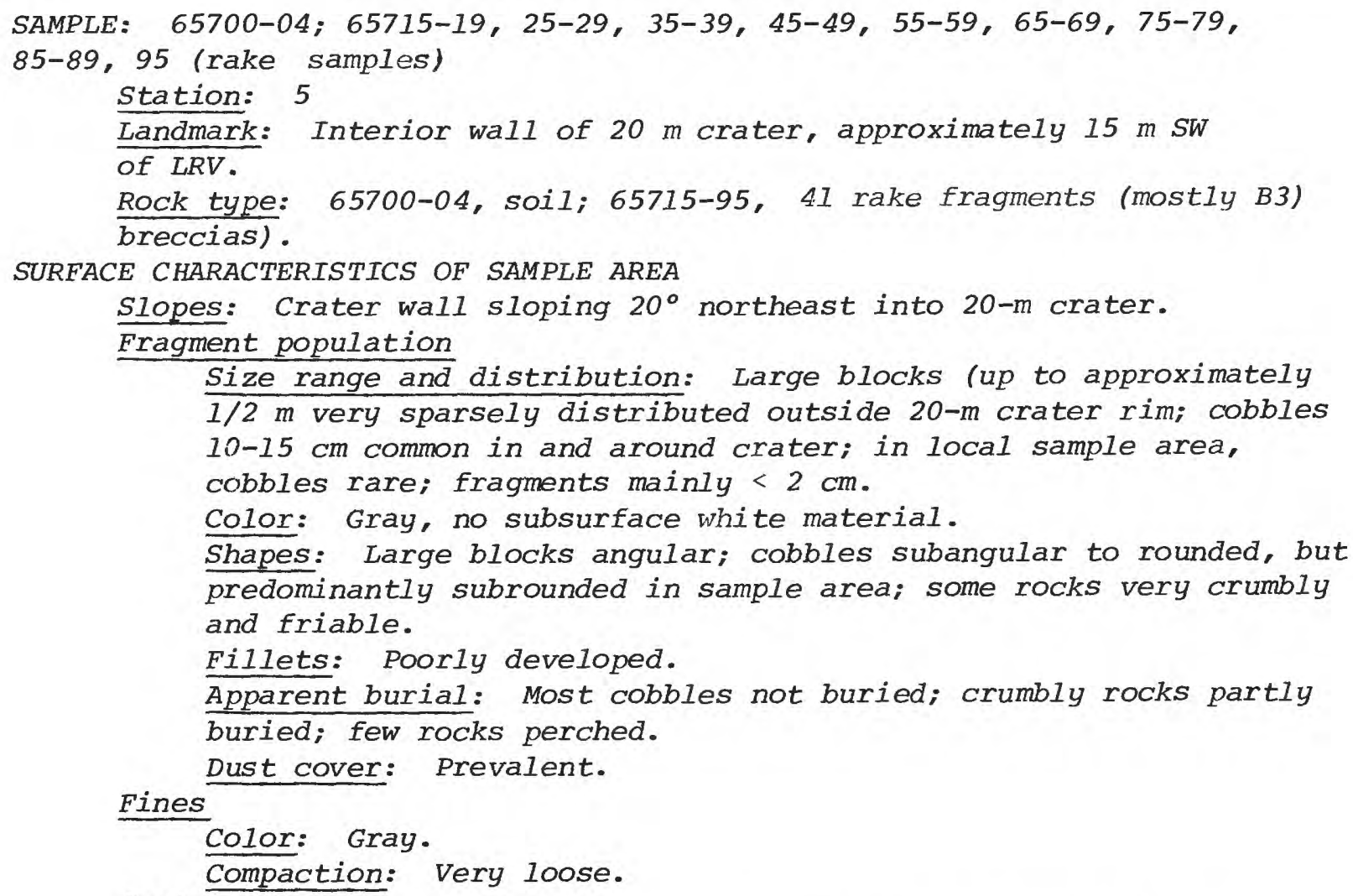




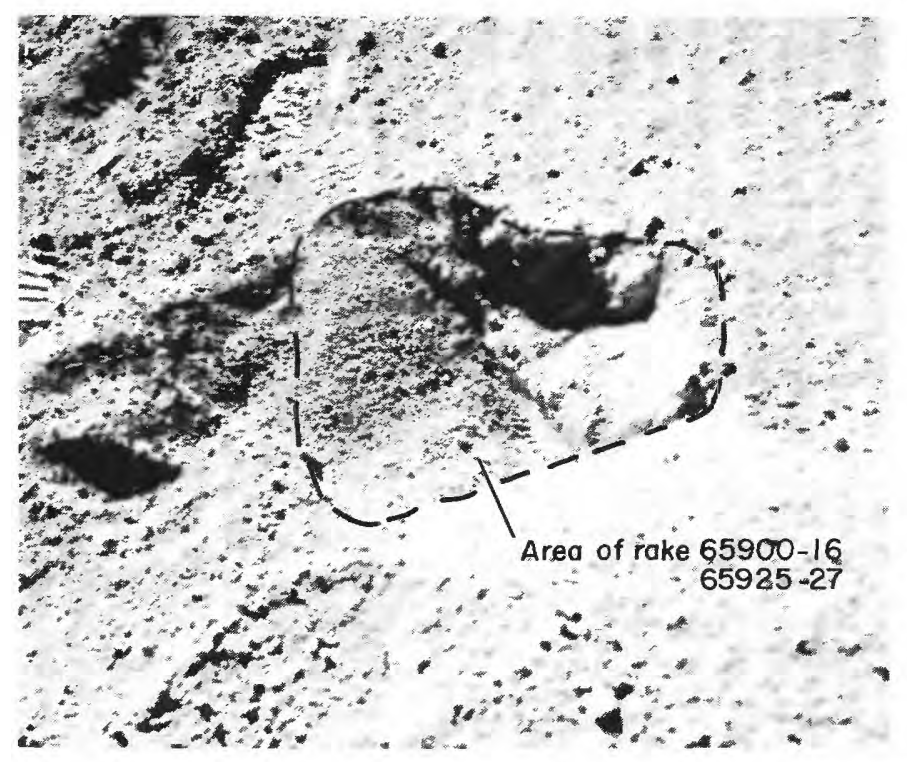

\Figure 53A.-Samples 65900-16 (soil and incidental fragments) and 65925-27 (rake fragments) collected from a trench dug with rake in south wall of 20 -m crater at station 5 . Photograph (AS16107-17509) taken after sampling, looking east approximately parallel to crater wall. See fig. $48 \mathrm{~A}$ for location of samples relative to other samples collected nearby.

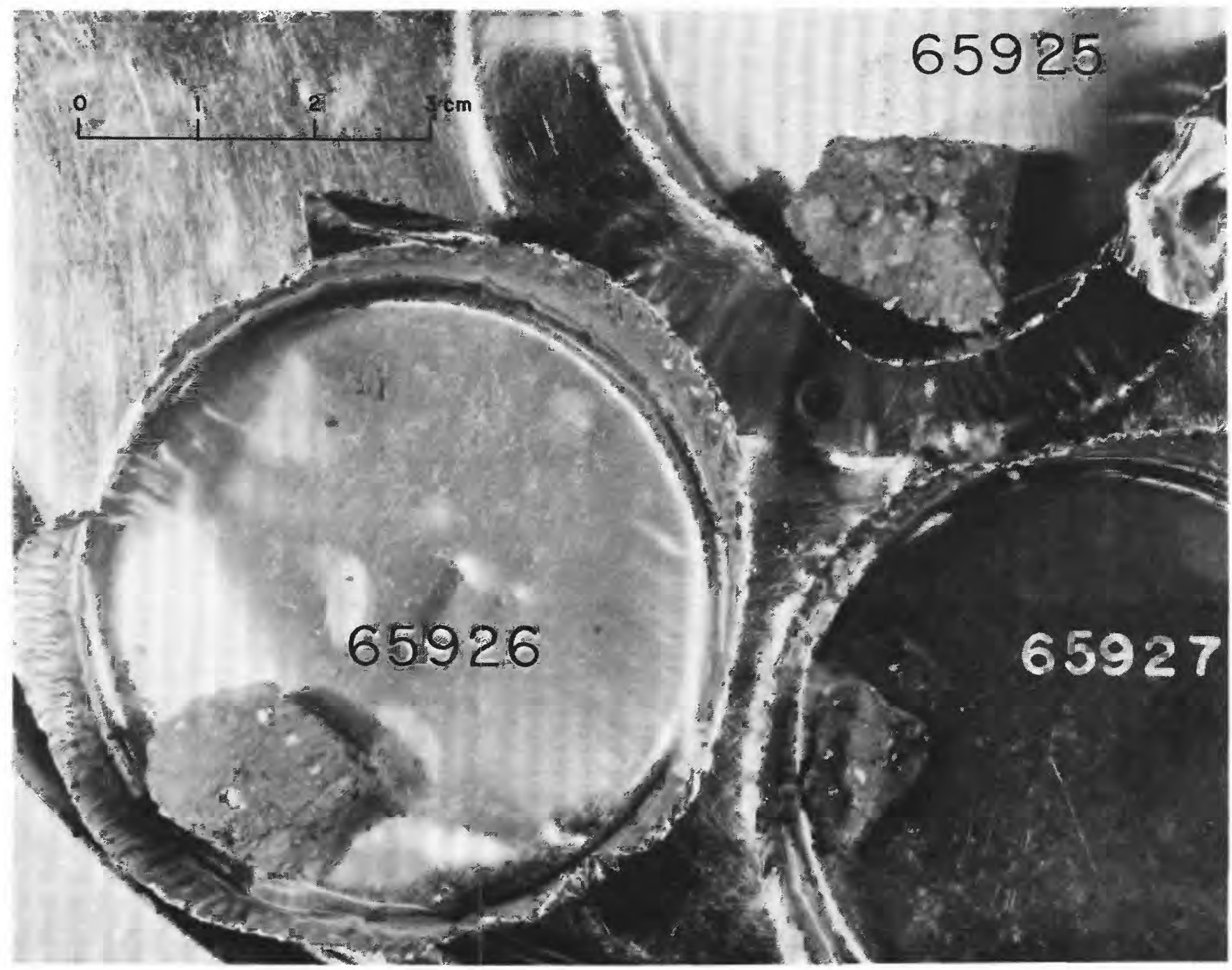

Figure 53B.-Rake samples 65925-27 in LRL (photograph S- 72-43356). Fragments 25 and 26 are type $B_{3}$ breccia; fragment 27 ( $<2$ g) appears to be of similar $B_{3}$ lithology. 
SAMPLE: 65900-04, 05-09, 15-16; 65925-27 (rake samples) Station: 5

Landmark: Interior wall of 20-m crater, just west of small superposed crater $(2 \mathrm{~m}) ; 20 \mathrm{~m}$ south of $L R V$.

Rock type: 65900-04, soil; 65905-16, 65925-27, 10 fragments (types include $C 2, B 3$, and B2). See figure $53 B$ for illustration of 65925-27. SURFACE CHARACTERISTICS OF SAMPLE AREA

Slopes: Steep part of crater wall, probably $20^{\circ}-25^{\circ}$.

Fragment population

Size range and distribution: Few scattered cobbles 5-10 cm on otherwise fine-grained surface; no large blocks near sample locality.

Color: Gray.

Shapes: Subangular.

Fillets: Not apparent.

Apparent burial: None.

Dust cover: Prevalent.

Fines

Color: Gray.

Compaction: Extremely loose.

\section{Craters}

Size range and distribution: Numerous $1 / 2-2 \mathrm{~m}$ craters super-

posed on interior wall of $20-m$ crater; sample locality west

of small ( $\simeq 2 \mathrm{~m})$ crater.

Shape: Generally shallow, subdued.

Ejecta: Slightly raised rims visible around some craters.

SAMPLE CHARACTERISTICS OF 65900-04 (soil, exCluding 7 incidental fragments 65905-16)

Size: < $1 \mathrm{~cm}$ fines; 662.15 grams total weight.

Color: Gray with white splotches (see Table 3, p. 31-32).

Comparison with other soil in area: Apparently typical regolith soil; no white layer reported.

Probable origin: Possibly derived from underlying Descartes

material, "reworked" by numerous local impacts; crater wall at

this locality apparently shielded from South Ray crater ejecta.

SAMPLE CHARACTERISTICS OF 65905-09, 15-16; and 65925-27 (rake fragments)

Size: $1-2.5 \mathrm{~cm} ; 38.12$ grams total weight.

Color: Light gray (B3) and light to medium gray (C2).

Shape: Irregular clods and subangular fragments.

Comparison with other soil in area: Marked scarcity of rocks compared with rake samples 65515-88 and 65715-95.

Probable origin: Indurated regolith, possibly derived initially from underlying Descartes materials, "rew ked" by numerous local impacts; crater wall at this locality apparently shielded from South Ray crater ejecta. 

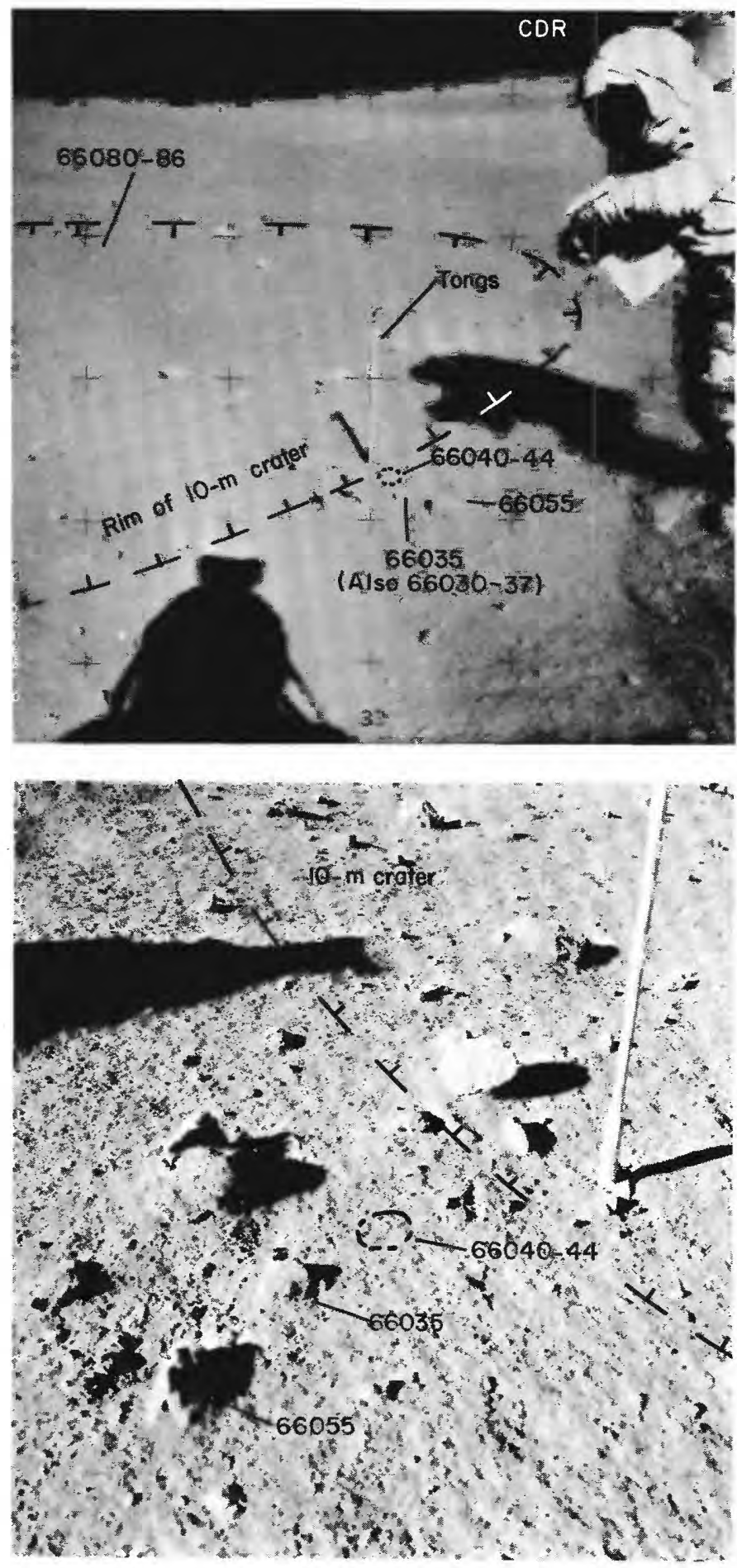

Figure 54A.-Area of samples 66030-37, 66040-44, and 66055 on northeastern rim of a 10 -m crater at station 6 , shown before sampling in photograph AS16-108-17627; view is west. Samples 66080-86 appear as a white spot on far wall of crater.

4 Figure 54B.-Rock samples 66035 and 66055, and soil sample 66040-44 shown before sampling in photograph AS16-107-17512; view is southwest. Samples $66030-34$ and $66036-37$ were collected with 66035 . 


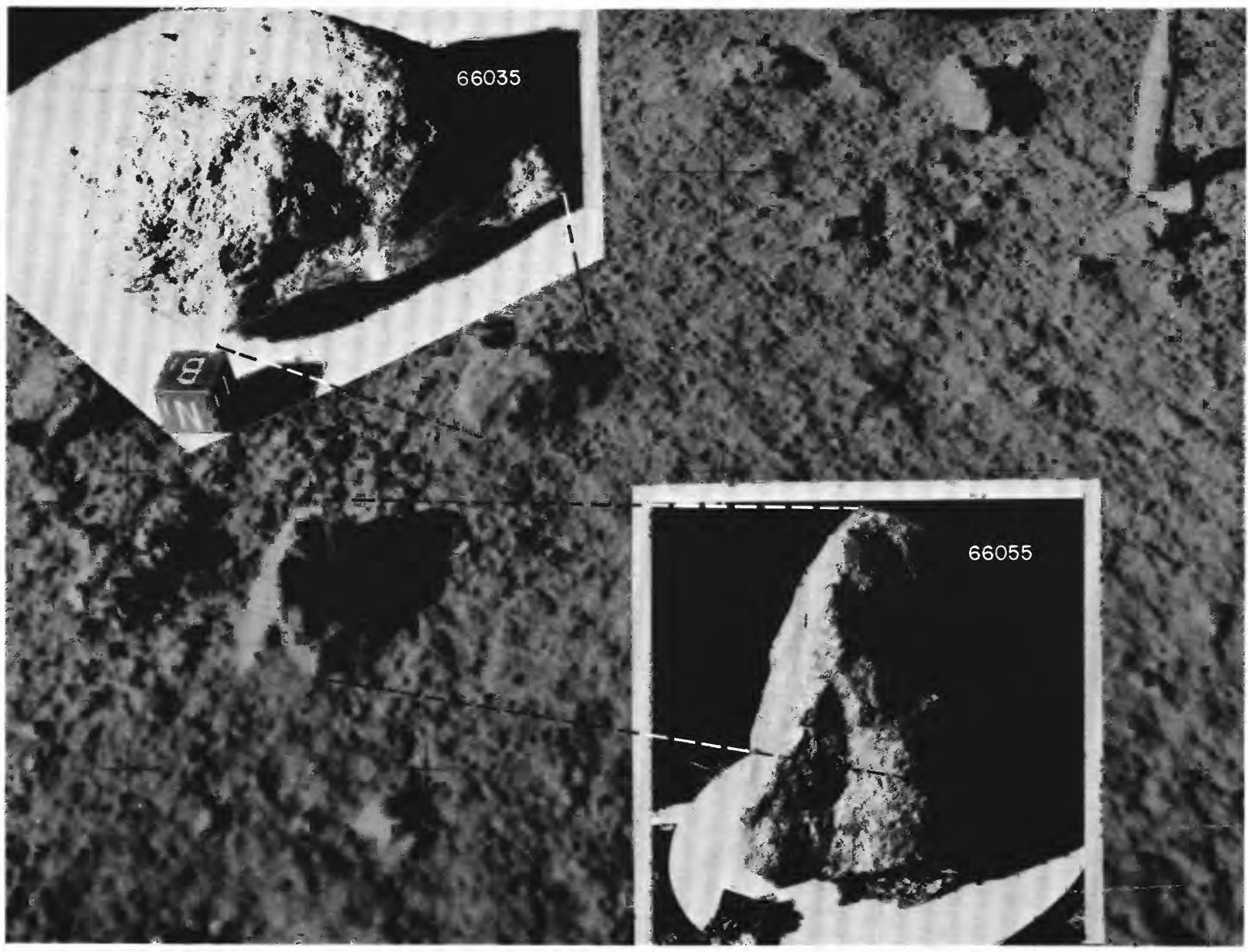

FigURE 54C.-Samples 66035 and 66055 showing approximate lunar orientations reconstructed in LRL compared to an enlarged part of photograph AS16-107-17512 taken before sampling. View is southwest (inset photographs S-72-41427 and 42560, respectively). See fig. $54 G$ for a reconstructed orientation of sample 66055 viewed down-sun (west). 


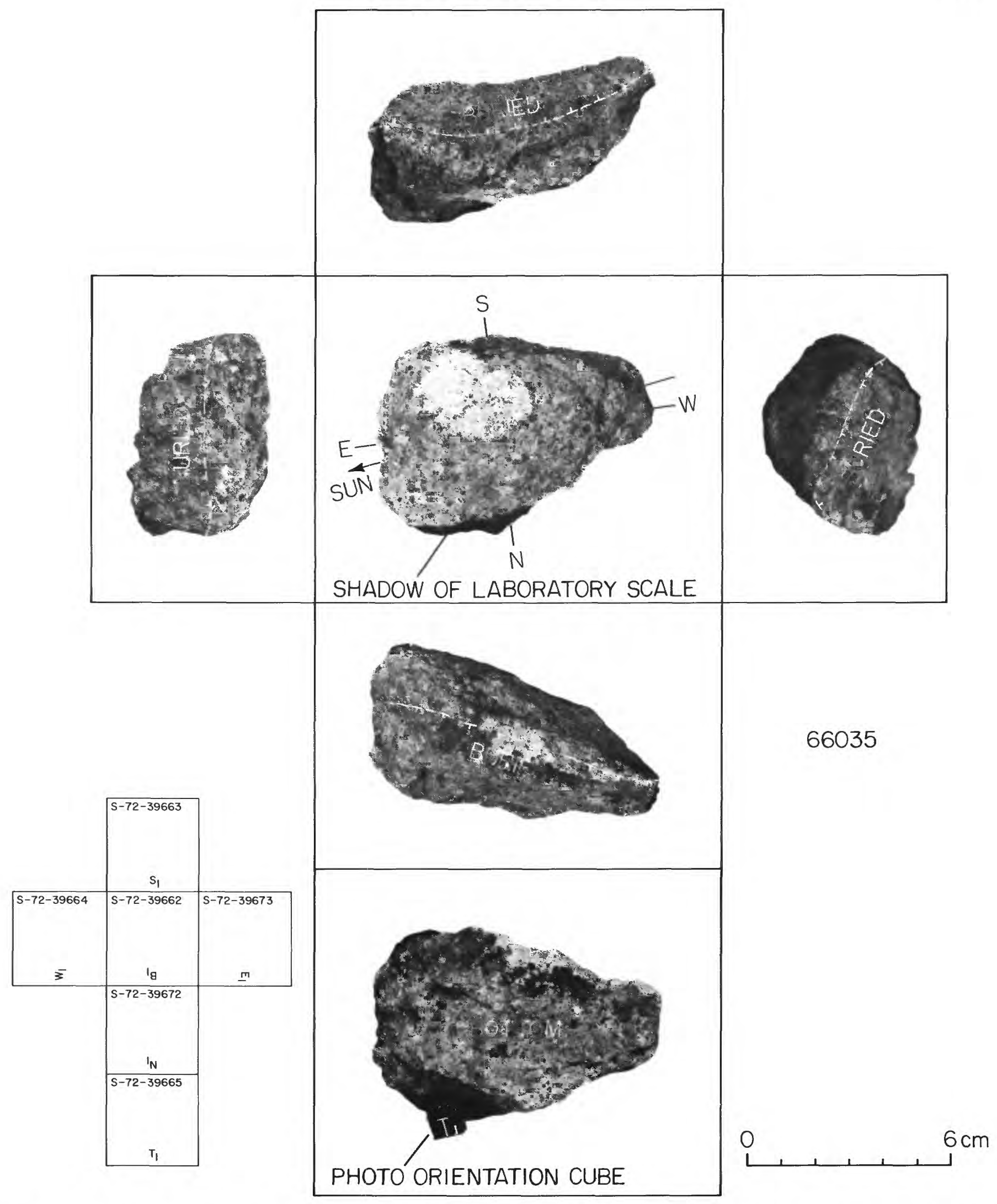

FIGURE 54D.-Orthogonal views of sample 66035 related to its lunar orientation at time of sampling. See chap. E fig. $27 \mathrm{for}$ a stereopair and a photomicrograph of this $B_{3}$ breccia. (Orthogonal views of sample 66055 are shown in fig. $54 \mathrm{H}$.) 


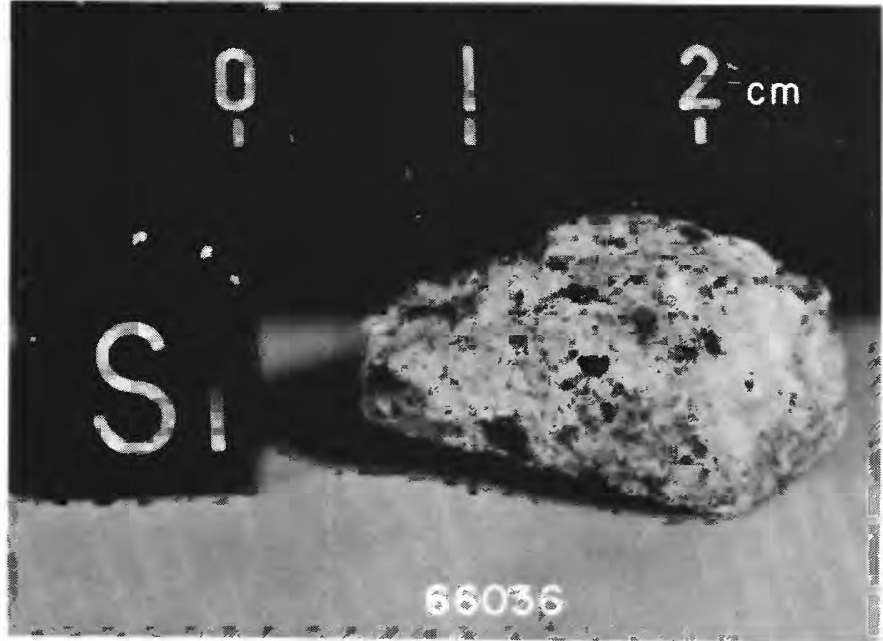

Figure 54E.-Sample 66036 in LRL (photograph S-72-40389). B $_{3}$ breccia collected with documented rock sample 66035 .

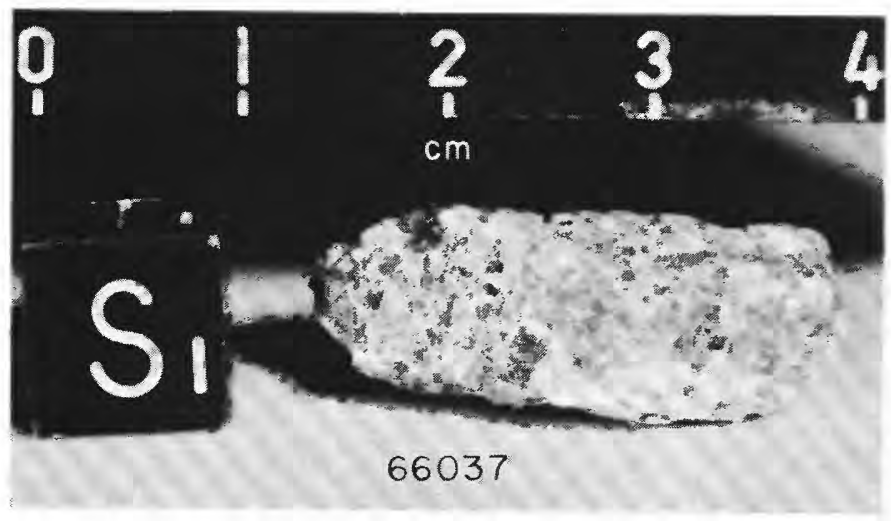

Figure 54F.-Sample 66037 in LRL (photograph S-72-40391). $\mathrm{B}_{3}$ breccia collected with documented rock sample 66035 .

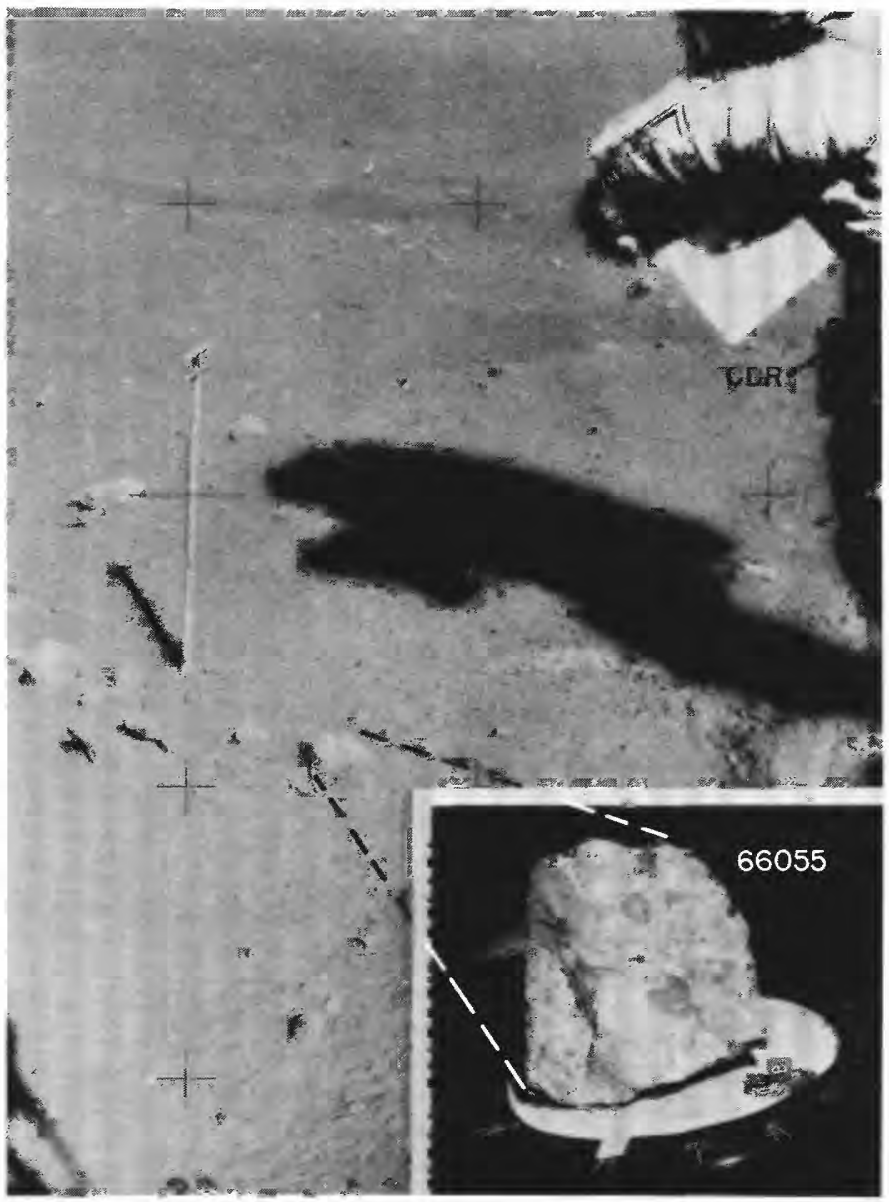

FIGURE 54G.-Sample 66055 showing approximate lunar orientation reconstructed in LRL compared to an enlarged part of photograph AS16-108-17627 taken before sampling. View is west (inset photograph, S-72-43562). See fig. 54C for a reconstructed orientation of sample viewed cross-sun (southwest). 


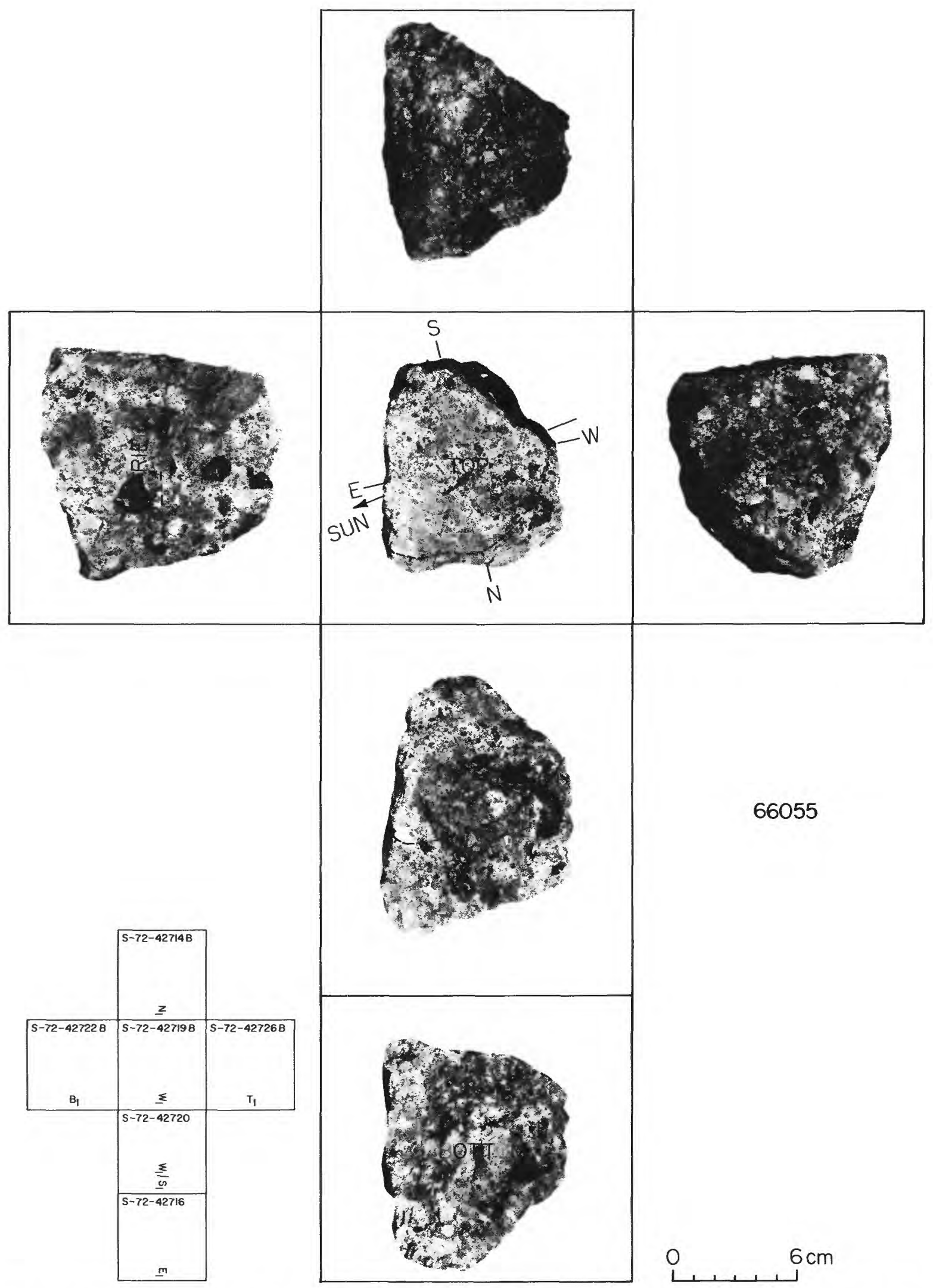

FIGURE 54H.-Orthogonal views of sample 66055 related to its lunar orientation at time of sampling, constructed so that the reader can visually relate to the cross-sun view of sample shown in fig. $54 C$. See chap. D4, fig. 28 , for a stereopair and chap. $\mathrm{E}$, figs. $3 G-H$ for photomicrographs of this type $\mathrm{B}_{2}$ breccia. 
SAMPLE : $66030-37 ; 66040-44 ; 66055$

Station: 6

Landmark: $10 \mathrm{~m}$ crater rim, on lowest "bench" of Stone Mountain;

near base. Samples collected approximately $5 \mathrm{~m}$ north of LRV.

Rock type: 66030-34 and 66040-44, soil; 66035-37, B3 breccia; 66055, B2 breccia.

SURFACE CHARACTERISTICS OF SAMPLE AREA

Slopes: Gentle regional slope northwest off stone Mountain; local slope $2-3^{\circ}$.

Fragment population

Size range and distribution: $\quad>30 \mathrm{~cm}$ blocks very sparse;

15-30 cm blocks relatively common; $5-15 \mathrm{~cm}$ cobbles relatively

abundant; $<5 \mathrm{~cm}$ fragments abundant.

Color: Generally dark with white clasts.

Shapes: All sizes angular to subrounded; few rocks rounded.

Fillets: Few rocks with poorly developed fillets.

Apparent burial: Majority of blocks and cobbles perched; few

large blocks partly buried.

Fines

Dust cover: Probably slight.

Color: Gray.

Compaction: Relatively firm, compared to looser regolith at

Stations 4 and 5 (see crew comments. Table 3, p. 34).

Craters

Size range and distribution: $<5 \mathrm{~m}$ common; $5-10 \mathrm{~m}$ sparse,

$10 \mathrm{~m}$ not visible in general area.

Shape: Generally shallow, subdued.

Ejecta: Not discernible. Crew reported fairly blocky rim on the 10-m crater at station 6.

SAMPLE CHARACTERISTICS FOR 66030-34 (soil collected with 66035)

Size: $\quad<1 \mathrm{~cm}$ fines; 134.6 grams total weight.

Color: Gray.

Comparison with other soil in area: Typical of the firmer regolith

at station 6.

Probable origin: Fines probably derived mostly from local ejecta and underlying Descartes material.

SAMPLE CHARACTERISTICS FOR 66035 and incidental fragments 66036-37

Size: $66035-9 \times 6 \times 3.5 \mathrm{~cm} ; 211.4$ grams

$66036--2.5 \times 2.5 \times 2 \mathrm{~cm} ; 4.38$ grams

$66037--2.5 \times 1.5 \times 0.75 \mathrm{~cm} ; 3.72$ grams

Color: Light gray; dark clasts, and white clasts.

Shape: Subangular to subrounded, elongate.

Fillet: None visible.

Apparent burial: Approximately $1 / 2$ (see figure 54D).

Dust cover: Very little.

Comparison with other fragments in area: Appears typical in the fragment population near the moderately blocky rim of a 10-m crater. Probable origin: Ejecta from 10-m crater at station 6. Possibly broken material from South Ray crater. 
SAMPLE CHARACTERISTICS FOR 66040-44

Size: < $1 \mathrm{~cm}$ fines; 570.2 grams.

Color: Gray (no white subsurface material).

Comparison with other soil in area: Presumably typical of local

regolith.

Probable origin: Degradation of local impact ejecta, probably

mostly derived from underlying Descartes materials.

SAMPLE CHARACTERISTICS FOR 66055

Size: $12 \times 12 \times 9.5 \mathrm{~cm}$; 1306 grams.

Color: Light gray, dark clasts and light clasts.

Shape: Angular, blocky.

Fillets: Poorly developed.

Apparent burial: $>1 / 2$ (see figure $54 \mathrm{~h}$ ).

Dust cover: Not detectable.

Comparison with other fragments in area: Typical of nearby angular

breccias in which light clasts can be seen (figure 54A).

Probable origin: Ejecta from 10-m crater at station 5, possibly

a broken block derived from south Ray crater.

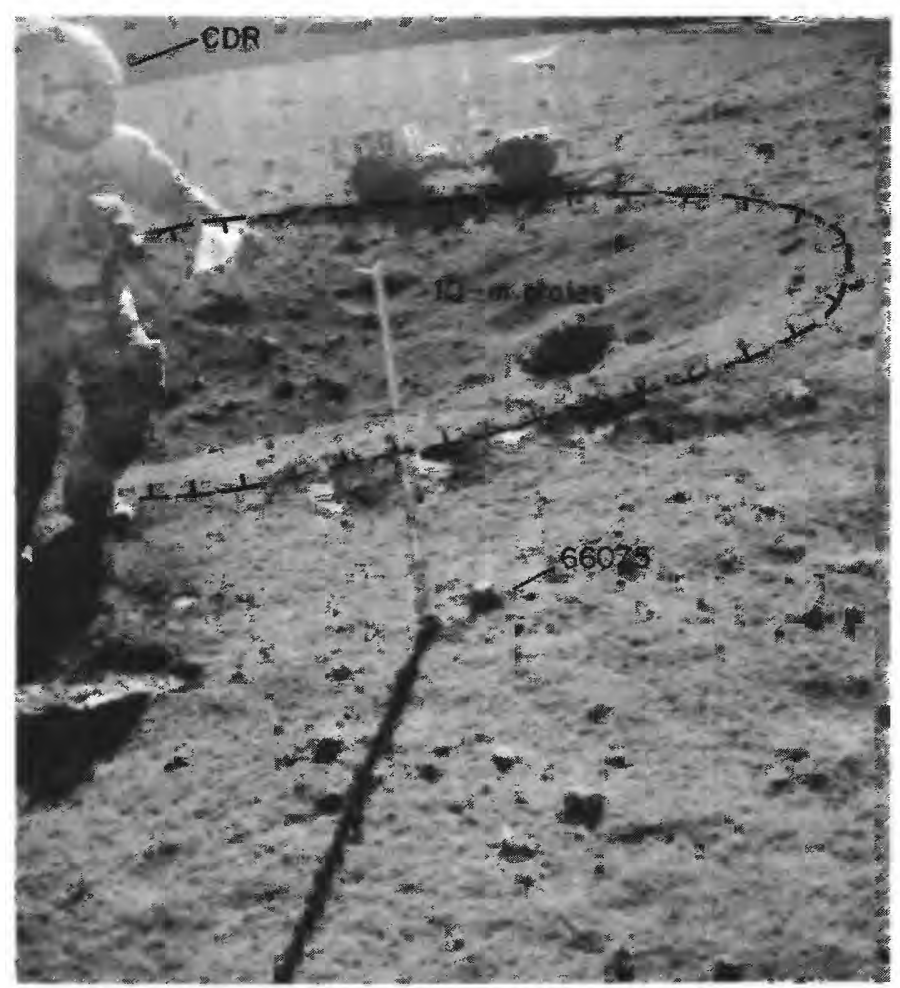

FIGURE 55A,-Location of sample 66075 on southwestern rim of a $10-\mathrm{m}$ crater at station 6 , shown before sampling in photograph AS16-108-17631; view is northeast.

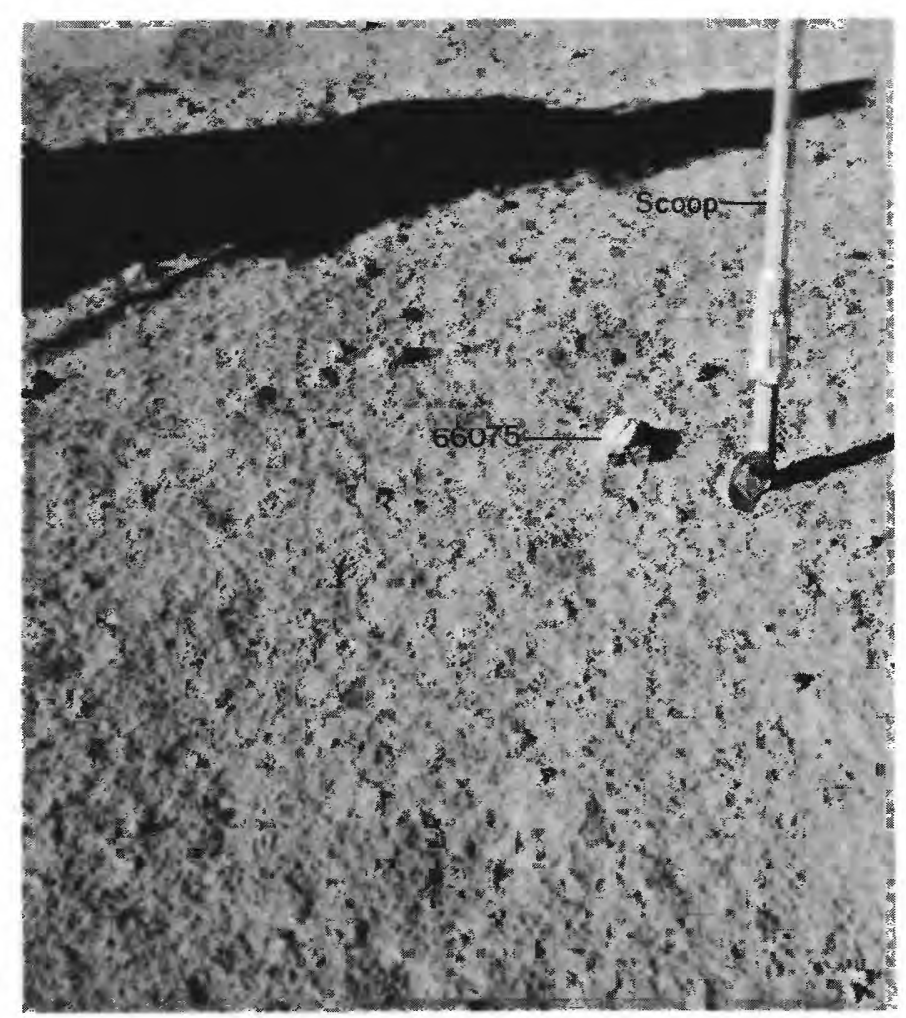

FIgURE $55 B$.- Sample 66075 shown before sampling in photograph AS16-107-17522; view is south. 


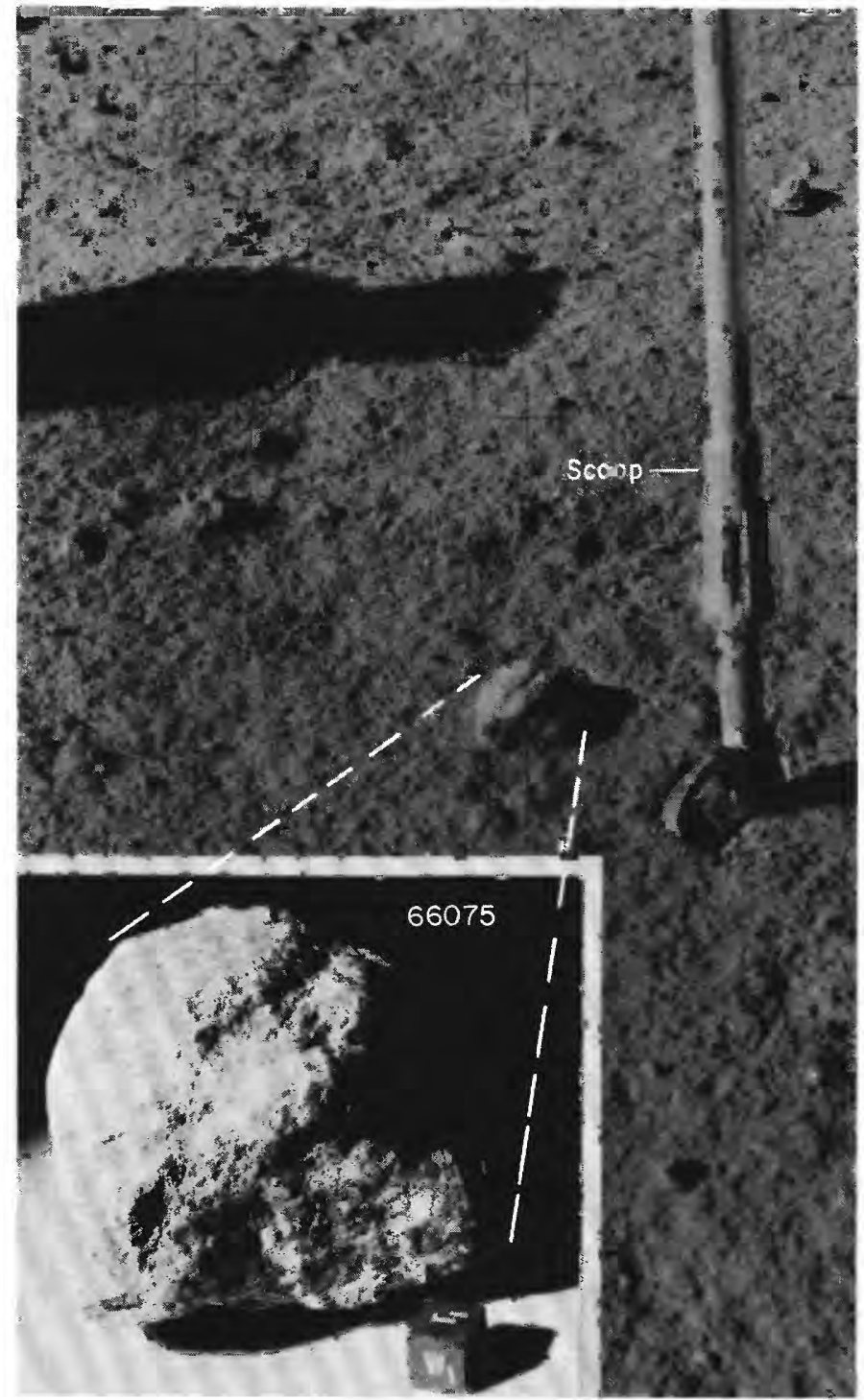

Figure 55C.-Sample 66075 showing approximate lunar orientation reconstructed in LRL compared to an enlarged part of photograph AS16-107-17521 taken before sampling; view is south (inset photograph, S-72-40571). 


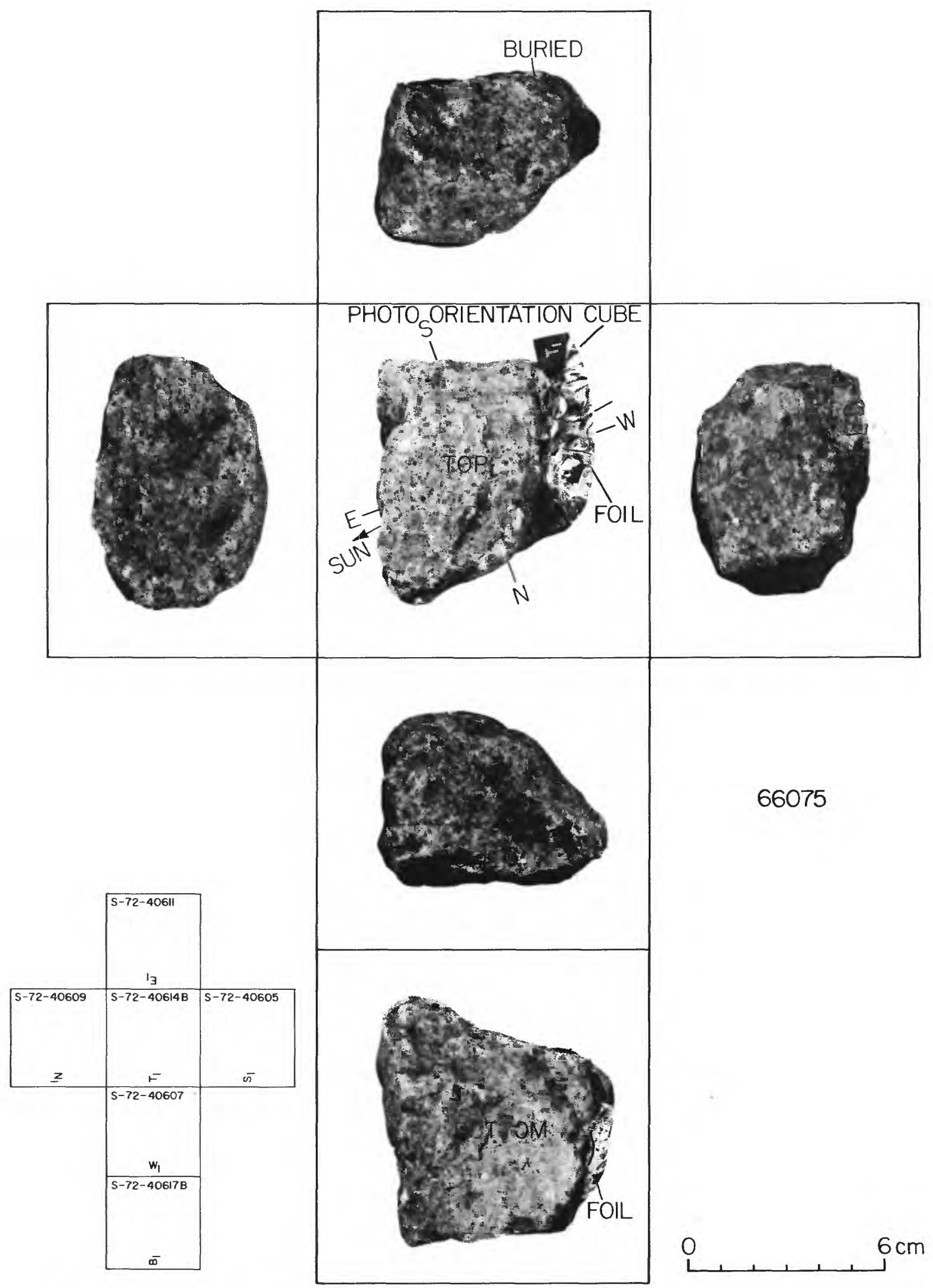

FIGURE $55 D$.- Orthogonal view of sample 66075 related to its lunar orientation at the time of sampling. See chap. D4, fig. 26 , for the $N_{1}$ photographic view of this type $B_{3}\left(B_{2}\right)$ breccia. 


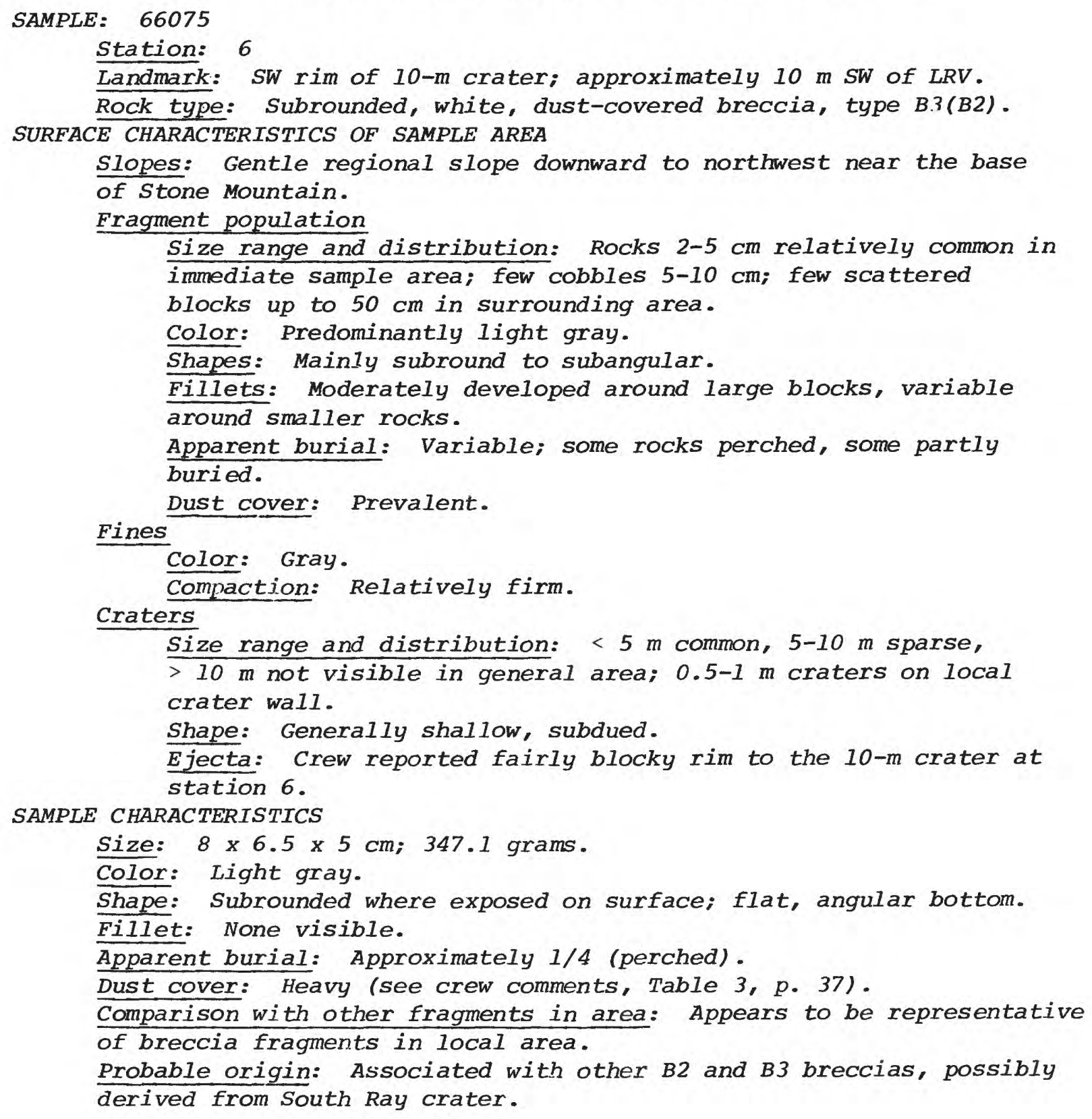



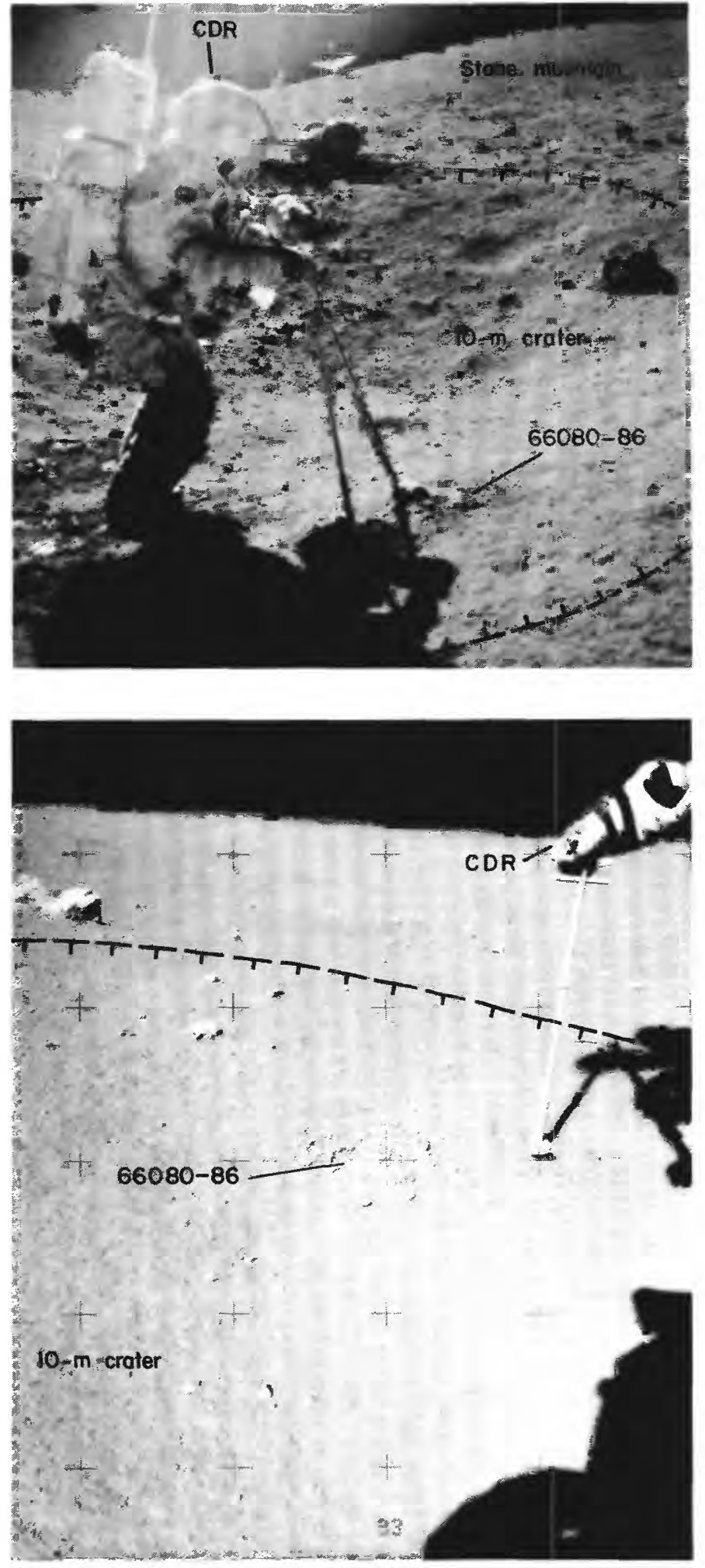

4 Figure 56A.-Location of samples 66080-86 on western wall of a 10-m crater at station 6 , shown before sampling in photograph AS16-108-17629; view is east.
Figure 56B.-Samples 66080-86 shown before sampling in photograph AS16-108-17628; view is west. The crew was attracted to this sample because it looked like a small white patch of indurated regolith (see table 3 , p. $36-37$ ). 
SAMPLE: 66080-86

Station: 6

Landmark: West wall of 10-m crater; approximately $10 \mathrm{~m}$ west of LRV. Rock type: 66080-84, soil; 66085-86 incidental fragments (unclassified). SURFACE CHARACTERISTICS OF SAMPLE AREA

Slopes: Gentle regional slope downward to the northwest; 10-15\%

eastward at sample locality on crater wall.

Fragment population

Size range and distribution: Fragments mainly $<5 \mathrm{~cm}$, very few rocks $>5 \mathrm{~cm}$ in immediate sample area; cobbles $5-15 \mathrm{~cm}$ widely distributed in surrounding area with few scattered blocks up to $50 \mathrm{~cm}$.

Color: Gray.

Shapes: Mainly subrounded, large blocks subangular.

Fillets: Moderately developed around large blocks.

Apparent burial: Probably slight.

Fines Dust cover: Probably present.

Color: Gray.

Compaction: Generally loose.

Craters

Size range and distribution: $\quad 55 \mathrm{~m}$ common, 5-10- $\mathrm{m}$ sparse,

$>10 \mathrm{~m}$ not visible in general area; $0.5-1 \mathrm{~m}$ craters on local

crater wall.

Shape: Generally shallow, subdued.

Ejecta: Not discernible. Crew reported fairly blocky rim to the 10-m crater at station 6.

SAMPLE CHARACTERISTICS FOR 66080-84 (soil) and 66085-86 (fragments or clods)

Size: $\quad<1 \mathrm{~cm}$ fines; 300.91 grams. Two fragments $>_{1} \mathrm{~cm} ; 5.69$ grams

total weight.

Color: White.

Shape: Angular fragments.

Apparent burial: Mostly buried.

Comparison with other soil in area: Apparently unique; an indurated

clod of white material.

Probable origin: Derived locally from 10-m crater; location generally

"shadowed" from south Ray crater ejecta. 


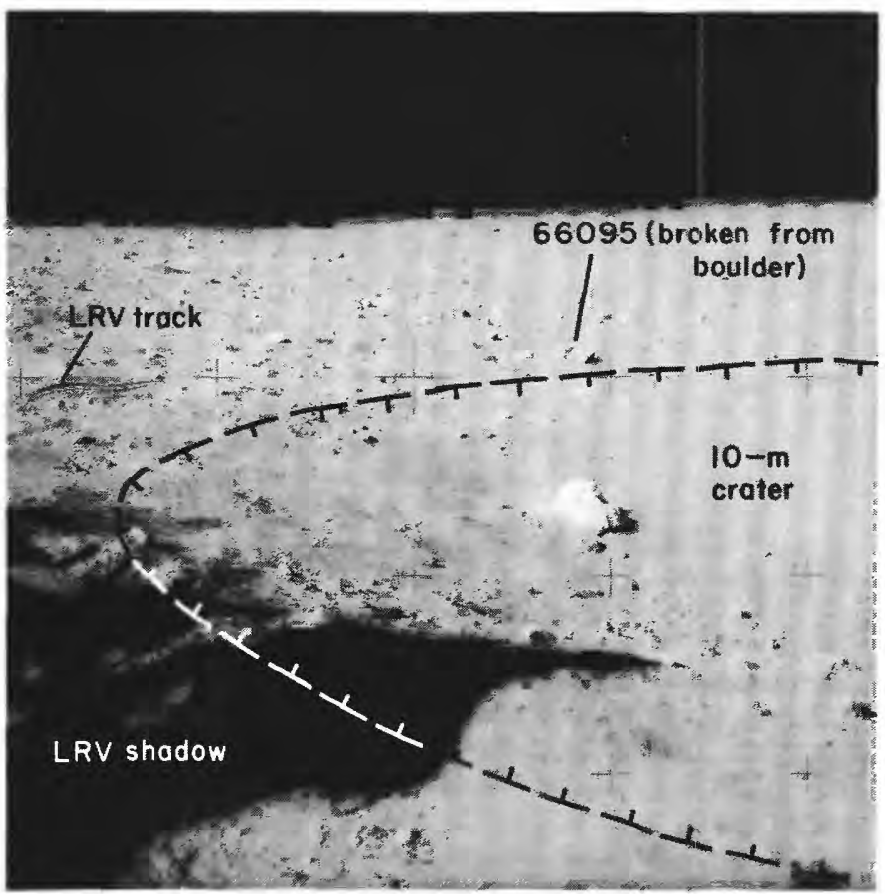

Figure 57A.-Sample 66095 was broken from a half-meter-size boulder located on south rim of a 10 -m crater at station 6 , shown before sampling in panorama photograph AS16-108-17624. View is southwest.

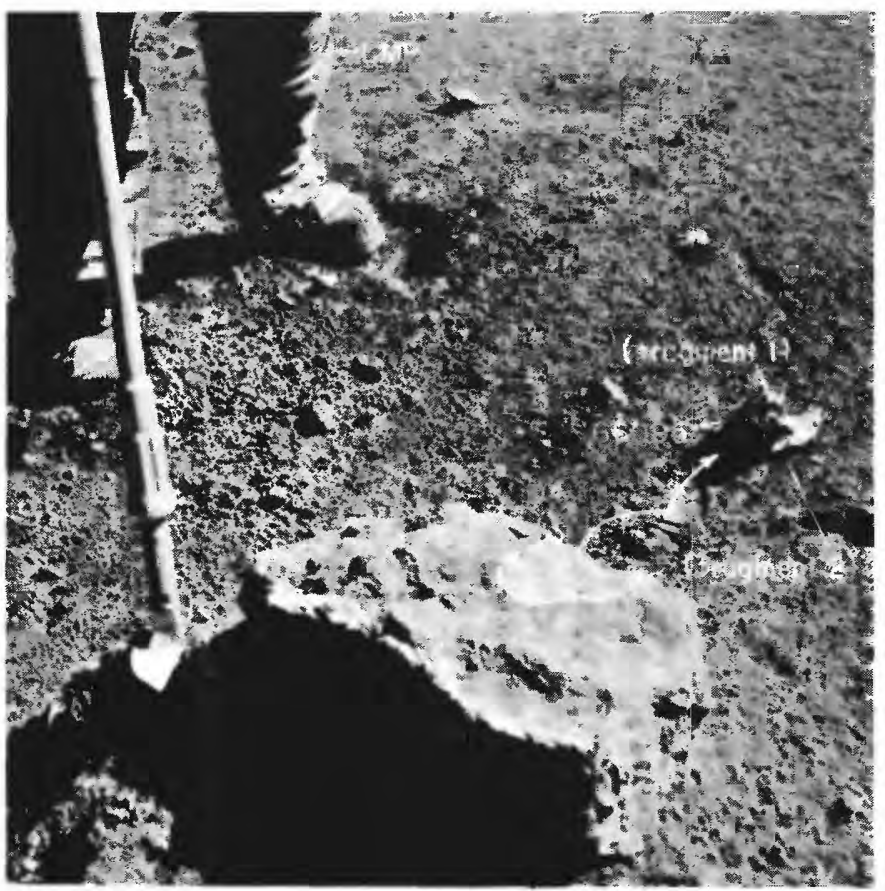

4 Figure 57B.-Sample 66095, chipped from a half-meter boulder, shown where it landed and broke into two pieces during sampling in photograph AS16-107-17523. View is northeast. 


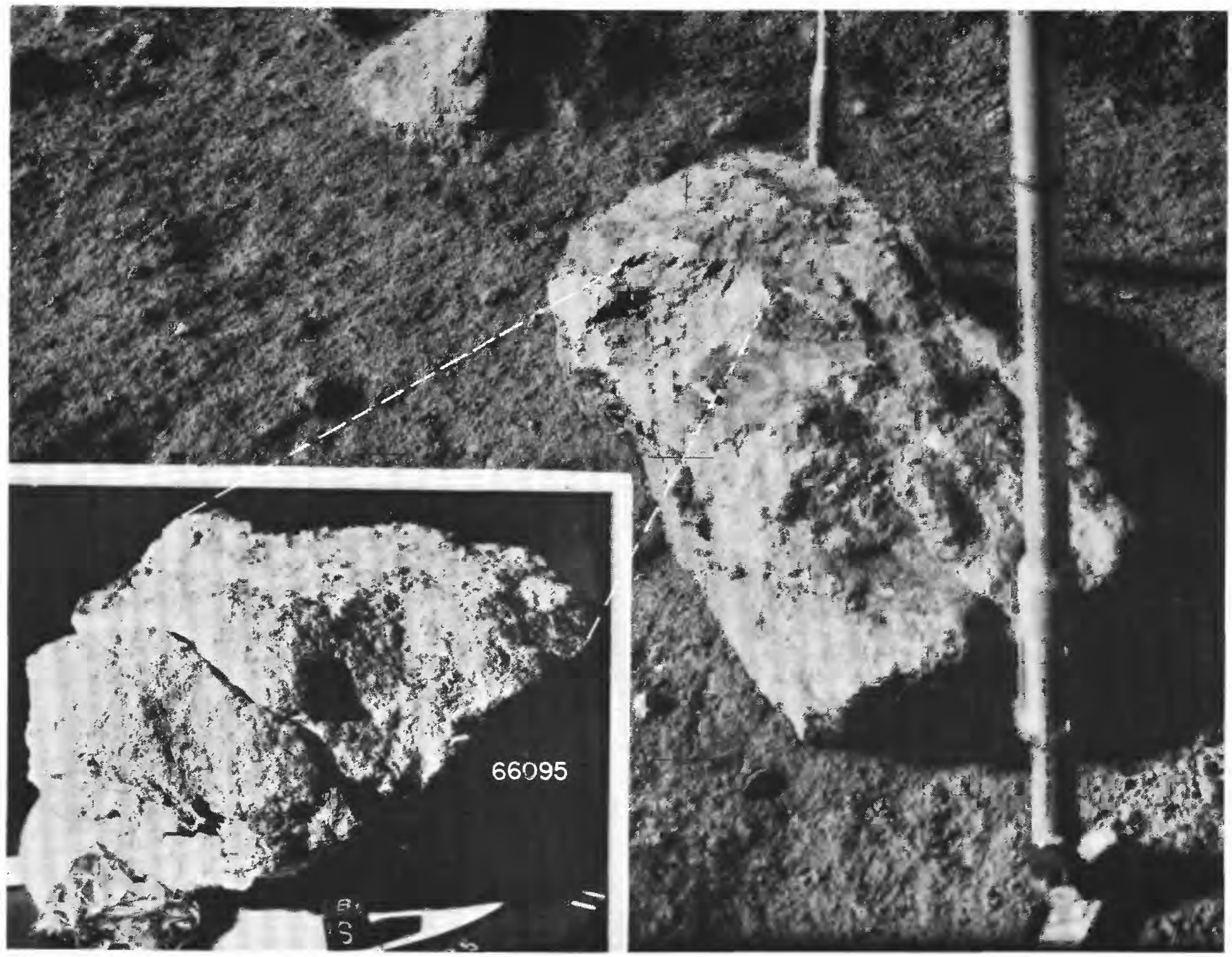

FigURE 57C.-Sample 66095 (broken into two pieces) showing approximate lunar orientation reconstructed in LRL compared to an enlarged part of photograph AS16-108-17632 taken before chipping the sample from the boulder. Reconstrution of orientation done by matching the shapes of sample, in LRL, with the scar on the boulder, in the photograph (inset photograph, S-72-41433). 


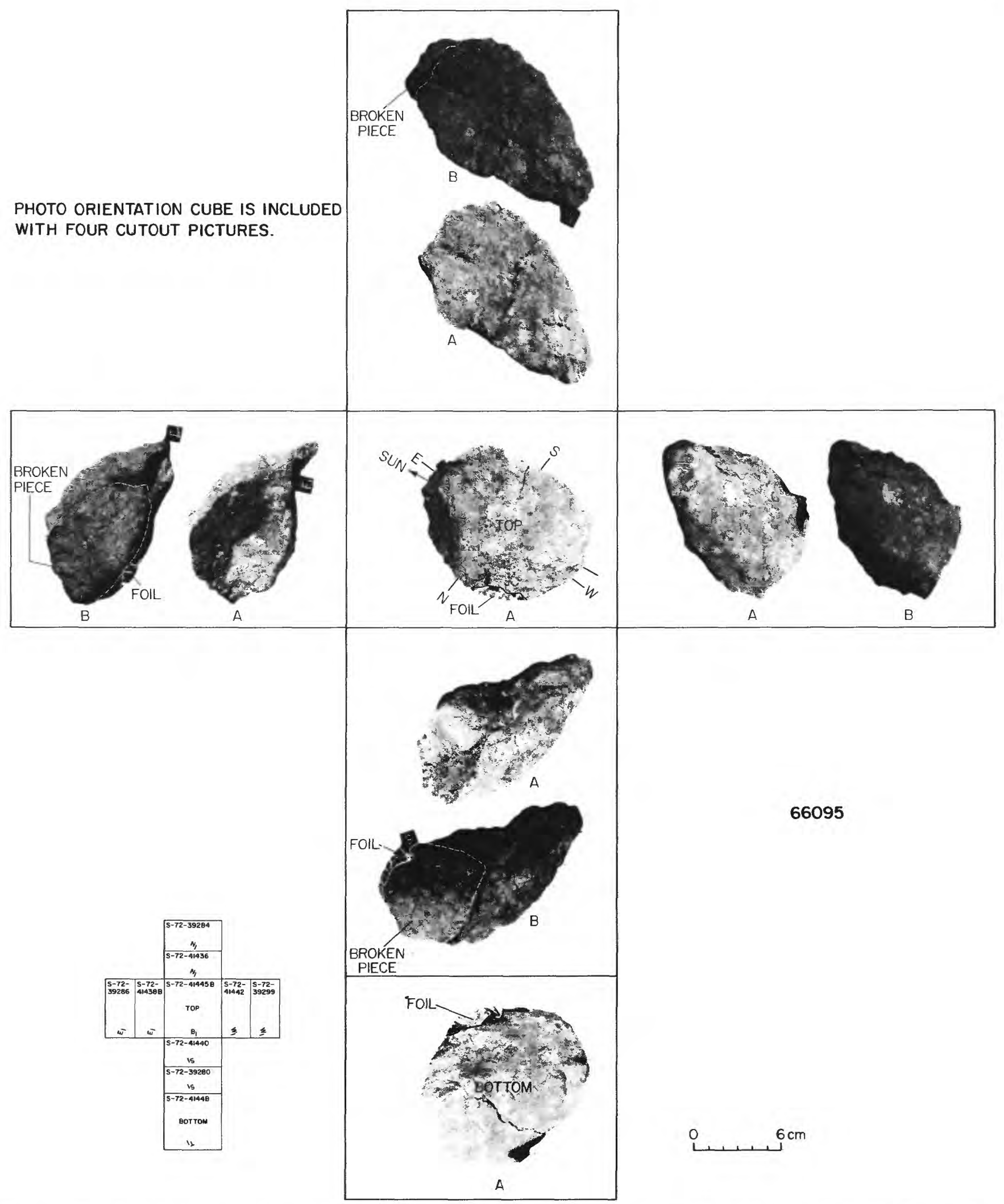

Figure 57D.-Orthogonal views of sample 66095 related to its lunar orientation before it was chipped from top of a boulder for sampling. This layout is made from two sets of photographs taken in LRL: those lettered "B" were taken first, showing the broken sample put together; those labeled " $A$ " are from set of stereoscopic photographs taken of the largest piece of sample 66095. See chap. D4, figs. $29 A-C$, for a stereopair and two photomicrographs of this type $\mathbf{B}_{4}$ breccia. 
SAMPLE: 66095

Station: 6

Landmark: On south rim of $10 \mathrm{~m}$ crater; approximately $10 \mathrm{~m}$ SW of LRV. Rock type: Breccia with white and light gray clasts, type B4. SURFACE CHARACTERISTICS OF SAMPLE AREA

Slopes: Gentle regional slope downward to the northwest; very gentle local slope downward to north.

Fragment population

Size range and distribution: Several blocks $20-50 \mathrm{~cm}$ in local area; cobbles 5-20 cm relatively common; fragments $55 \mathrm{~cm}$ common;

Color: Gray.

Shapes: Angular to rounded in all size ranges.

Fillets: Present around some large blocks.

Apparent burial: Large rounded rock partly buried; none elsewhere.

Dust cover: Prevalent.

Fines

Color: Gray.

Compaction: Firmer than on crater wall (LRV tracks and footprints were more shallow than at stations 4 and 5).

Craters

Size range and distribution: $<5 \mathrm{~m}$ common, 5-10 $\mathrm{m}$ sparse, $>10 \mathrm{~m}$ not visible; small $(<1 \mathrm{~m})$ craters visible in local area.

Shape: Shallow and subdued.

Ejecta: Not discernible. Crew reported fairly blocky rim

to the $10-m$ crater at station 6 .

SAMPLE CHARACTERISTICS

Size: $18 \times 16 \times 7 \mathrm{~cm}$ (broken into 2 pieces); 1185 grams.

Color: Medium light gray.

Shape: Subangular with broadly curved "turtle back" fracture where fragment broke from parent boulder (see figure 57D).

Fillet: Minor around parent block.

Apparent burial:

Dust cover: Prevalent.

Comparison with other fragments in area: This is the only sample collected from station 6 that is classified type B4 breccia; and it is the only chip broken from a larger block. More of the large blocks may be of the same type.

Probable origin: Part of blocky ray from South Ray crater, possibly material broken during secondary impact at $10 \mathrm{~m}$ crater site, station 6 . 
NORTH RAY CRATER

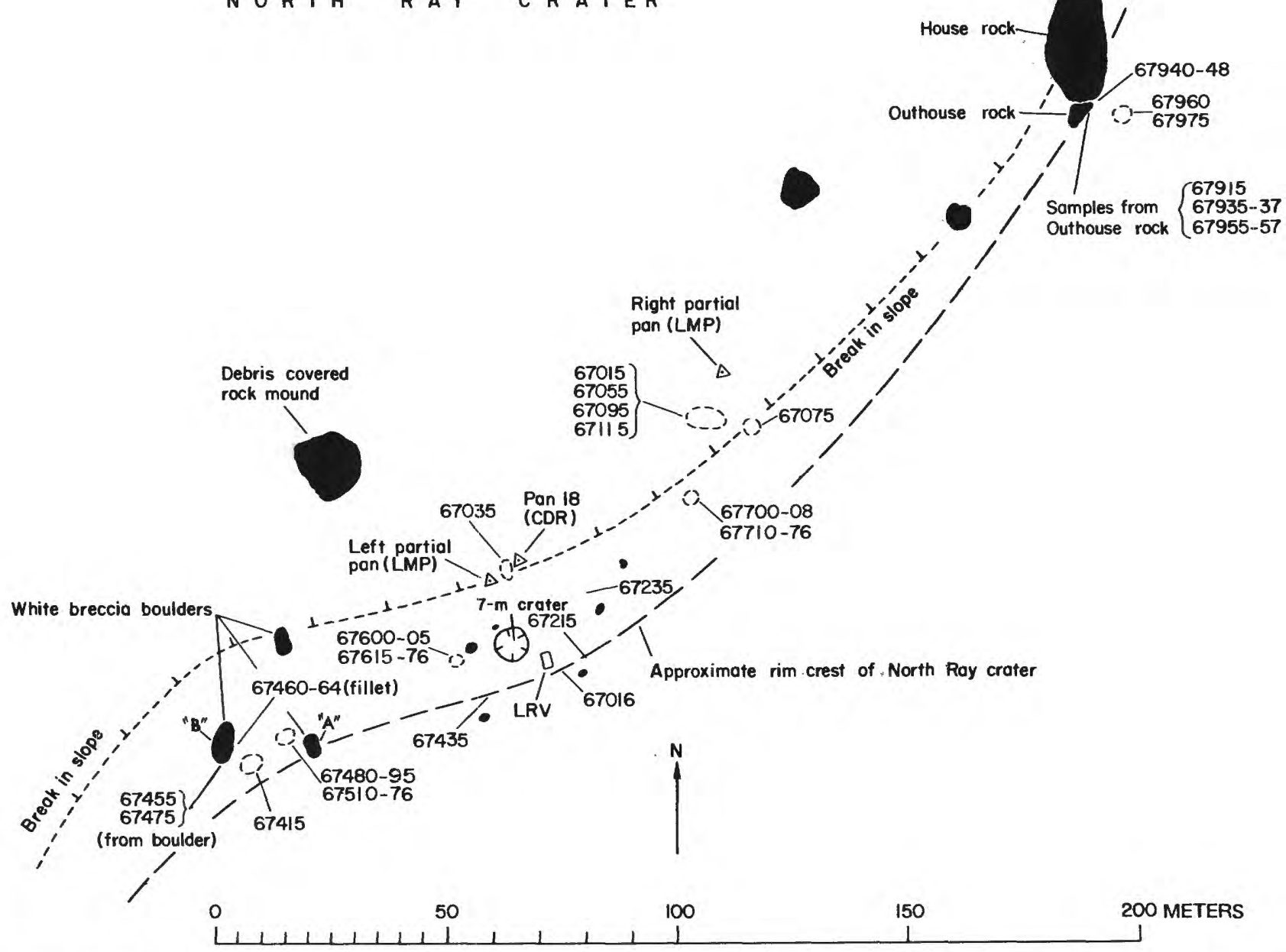

FigURE 58.- Map of station 11, on southeastern rim of North Ray crater, showing location of most prominent boulders and collected samples relative to LRV and photographic panoramas used for control in making the map. North Ray crater is approximately $1 \mathrm{~km}$ in diameter. Boulders lettered " $\mathrm{A}$ " and " $\mathrm{B}$ " are also in figures 68 and $76 \mathrm{~A}$. 


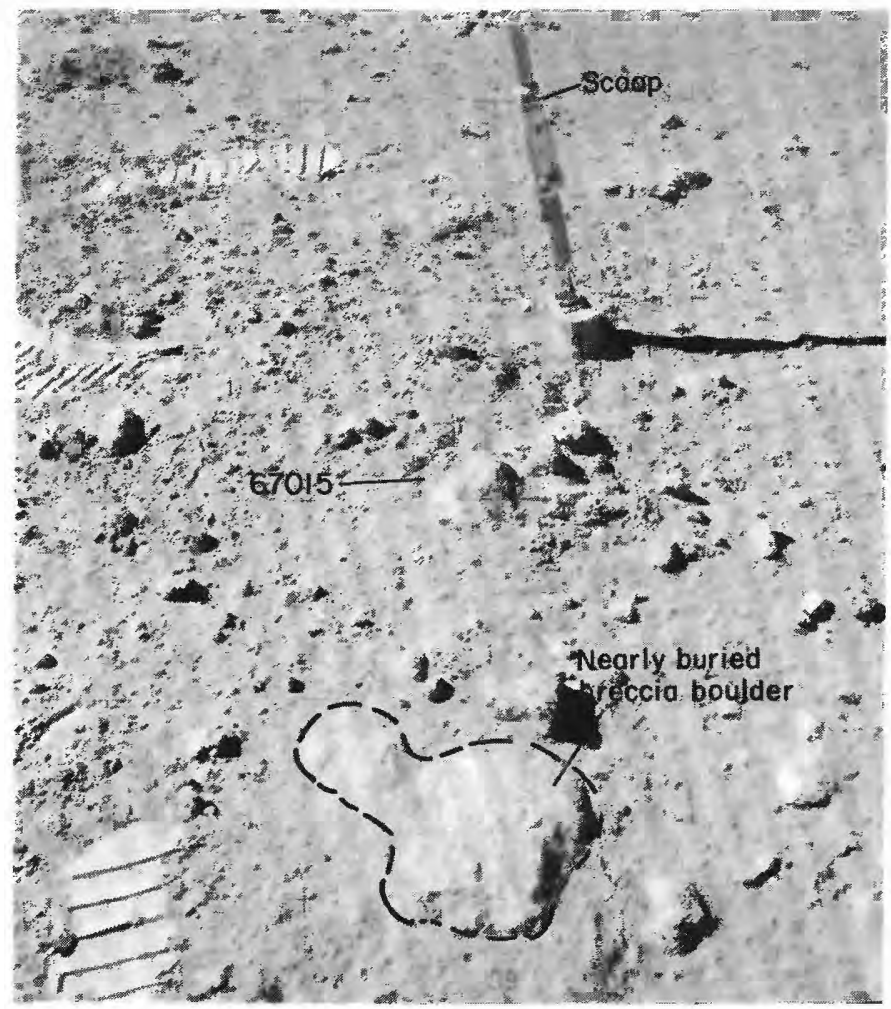

Figure 59A.-Sample 67015 shown before sampling in photograph AS16-116-18621; view is southeast. 


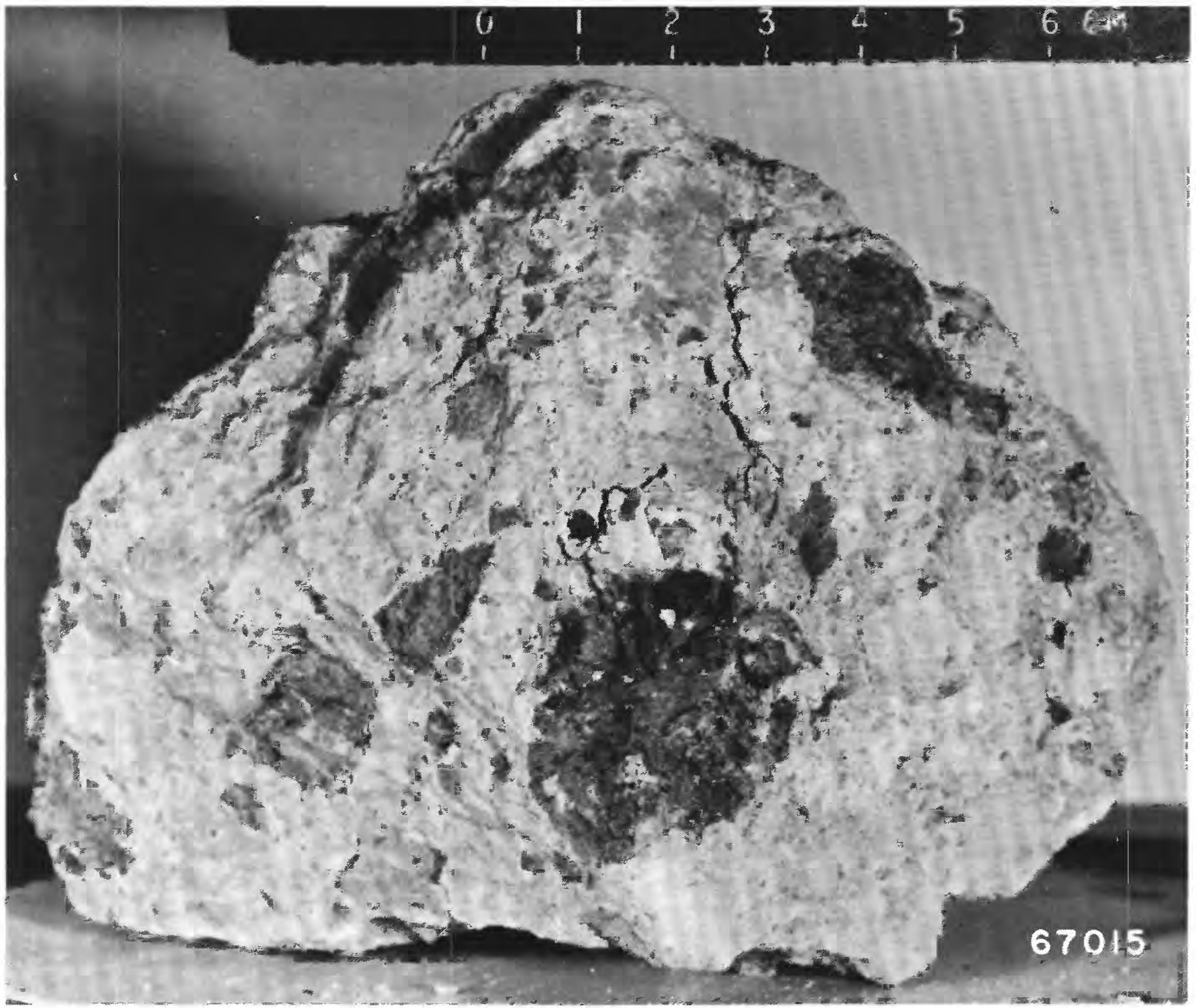

FIGURE 59B.--Largest piece of broken sample 67015 in LRL (photograph S- $72-37214, \mathrm{~N}_{1}$ view). See chap. D2, fig. $29 A$, for another $\mathrm{N}_{1}$ photographic view of partly reconstructed sample. $\mathrm{B}_{3}\left(\mathrm{~B}_{2}\right)$ breccia. 
SAMPLE: 67015

Station: 11

Landmark: Approximately $60 \mathrm{~m} \mathrm{NE}$ of LRV, on upper wall of North Ray crater.

Rock type: Breccia, light matrix, dark clasts; B3(B2).

SURFACE CHARACTERISTICS OF SAMPLE AREA

Slopes: Northwestward into North Ray crater.

Fragment population

Size range and distribution: Greater than $10 \mathrm{~cm}$, sparse; 5-10

cm common; < $5 \mathrm{~cm}$ abundant.

Color: White to medium gray.

Shapes: Subrounded to subangular.

Fillets: Where present, appear to be on up-slope (south) sides of rounded rocks.

Apparent burial: Few larger rocks of 10-25 cm size are $>1 / 2$

buried.

Dust cover: Heavy to moderate.

Fines

Color: Light gray.

Compaction: Fairly firm; bootprints penetrate less than $1 \mathrm{~cm}$. Craters: None observed.

SAMPLE CHARACTERISTICS

Size: $13 \times 10 \times 8 \mathrm{~cm}$; 1194 grams.

Color: Medium light gray matrix with dark gray clasts.

Shape: Subrounded.

Fillet: Not apparent in lunar surface photograph (see figure 59a).

Apparent burial: Approximately half buried.

Dust cover: Appears to be heavy.

Comparison with other fragments in area: Similar in color and shape to other rounded fragments in vicinity.

Probable origin: North Ray crater ejecta. 

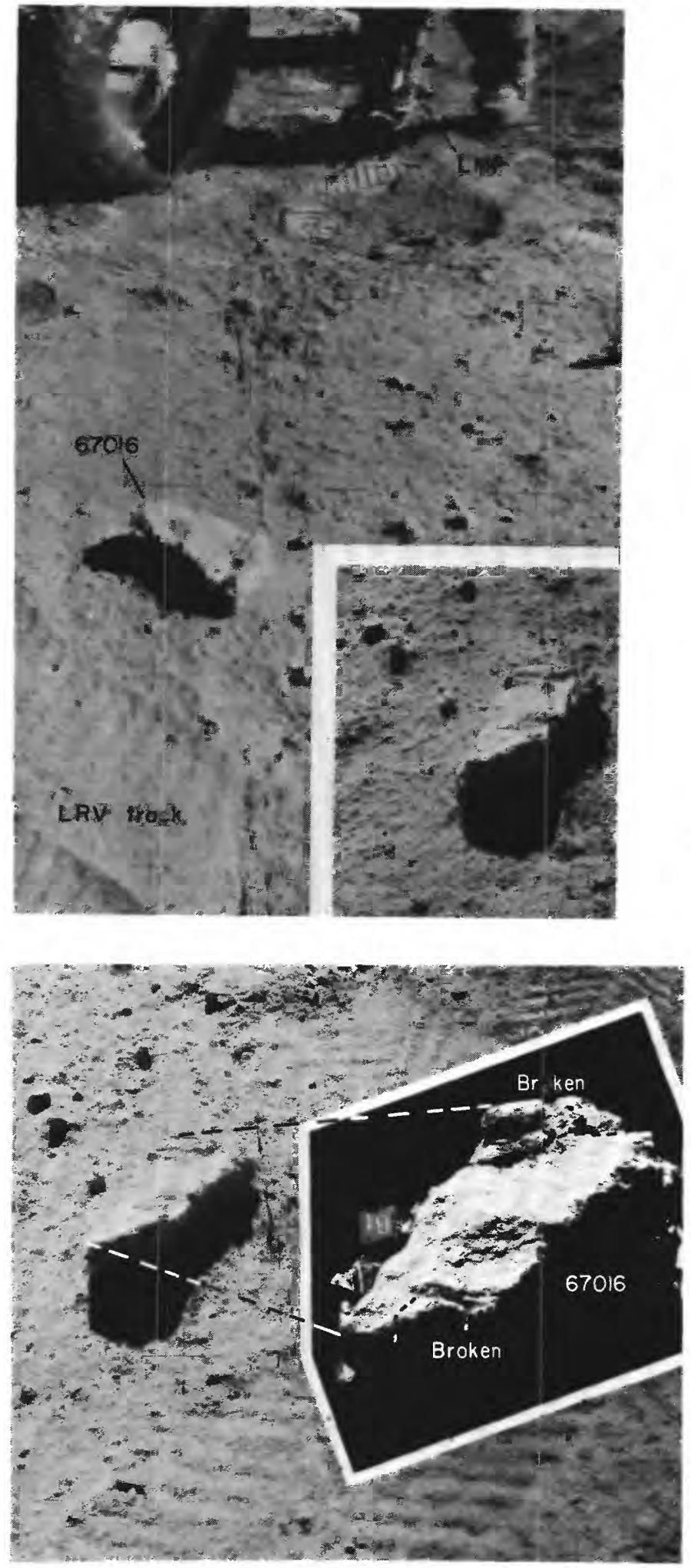

Figure 60A.-Sample 67016 is shown in two views before it was picked up near LRV at station 11 (photograph AS16-116-18658, looking northwest; and inset photograph AS16-116-18660, looking east).
Figure 60B.--Sample 67016 showing approximate lunar orientation reconstructed in LRL compared to an enlarged part of photograph AS16-116-18659 taken before sampling; view is east. Sample partly broken during transport, reconstruction of its lunar or.entation was an aid to fitting the pieces together in the laboratory (inset photograph S-72-44509). 


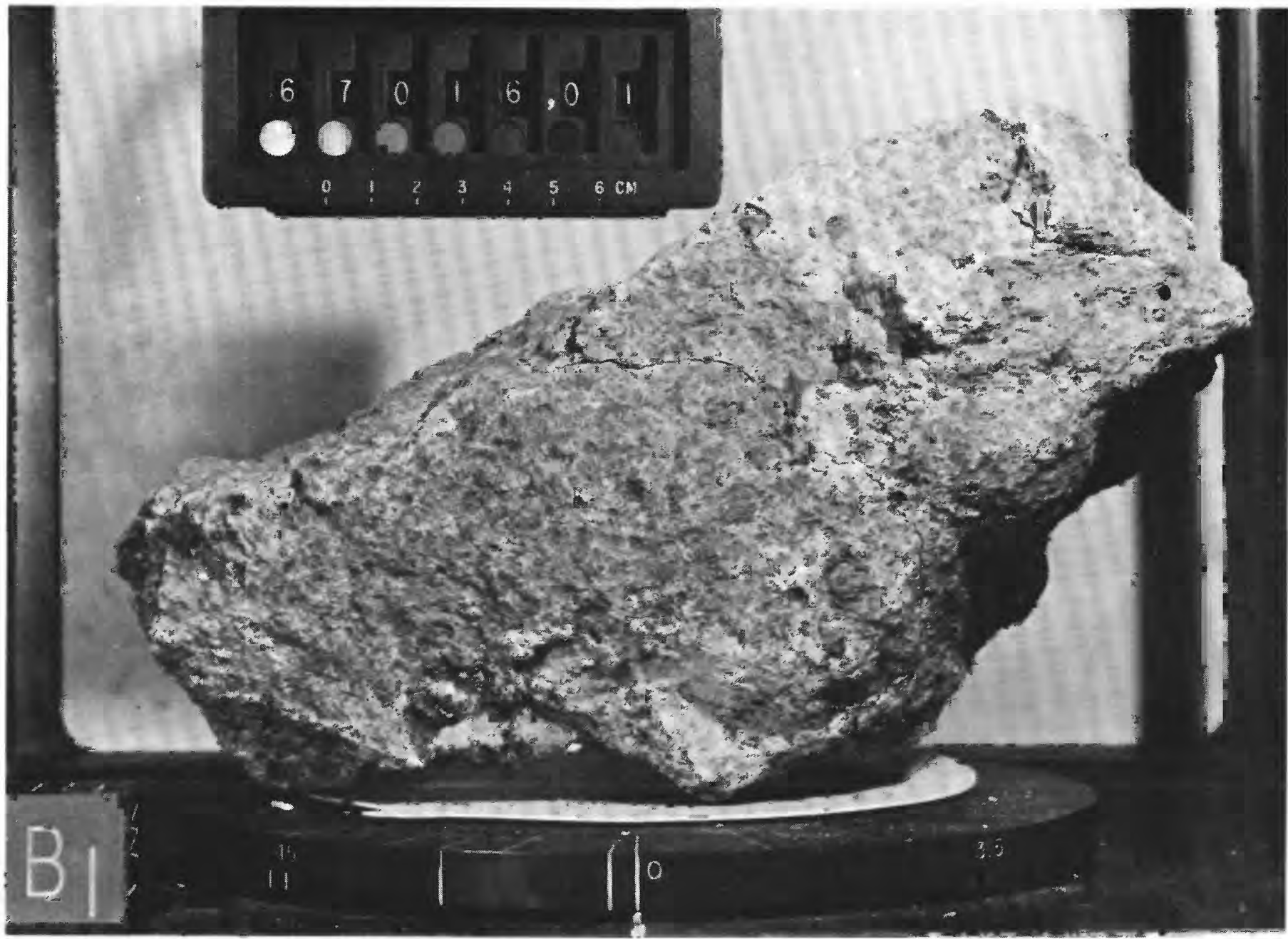

FIGURE 60C.-Largest piece of broken sample $67016(67016,01)$ in LRL showing side that was lunar top at time of sampling (photograph S-72-39230). Compare this view (inverted) with the previous figure. Same $\left(\mathrm{B}_{1}\right)$ photographic view of this type $\mathrm{B}_{3}\left(\mathrm{~B}_{2}\right)$ breccia is shown in chapter D2, fig. 27A. 


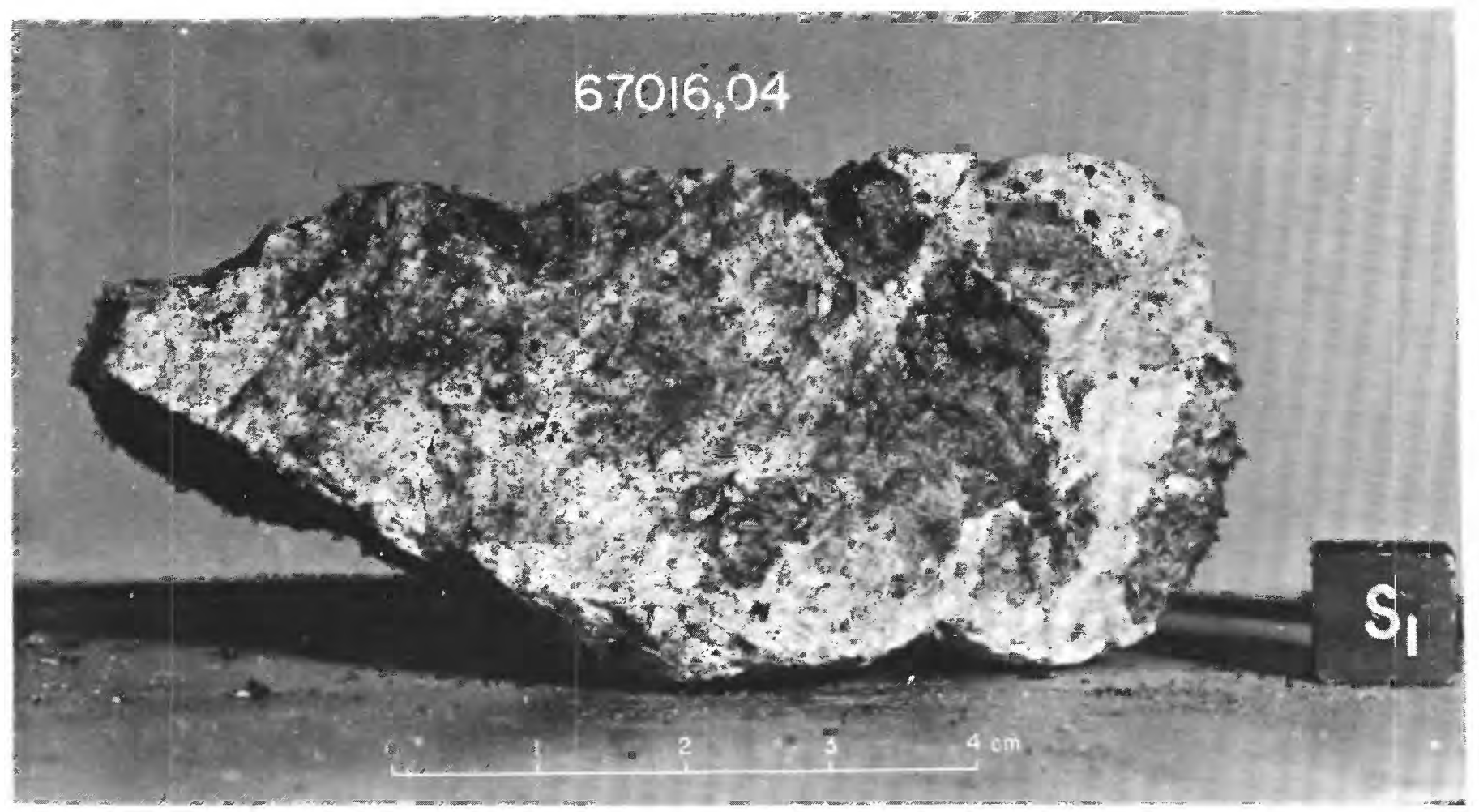

Figure 60D.-Sample 67016,04, a fragment from broken rock 67016 that shows the megascopic character of this type $\mathrm{B}_{3}\left(\mathrm{~B}_{2}\right)$ breccia on a freshly broken surface (photograph S-72-39227).

SAMPLE : 67016

Station: 11

Landmark: $2 \mathrm{~m} S E$ of $L R V$, on rim crest of North Ray crater. Rock type: Breccia, light matrix, dark clasts; B3(B2).

SURFACE CHARACTERISTICS OF SAMPLE AREA

Slopes: Nearly level.

Fragnent population

Size range and distribution: $10-20 \mathrm{~cm}$ fragments are sparse;

2-5 cm fragments common; fragments $<2 \mathrm{~cm}$, abundant.

Color: Light gray.

Shapes: Subangular to subrounded.

Fillets: None.

Apparent burial: None.

Dust cover: None visible.

Fines

Color: Light gray.

Compaction: Hard; depression by bootprints and Rover wheels

are less than $1 \mathrm{~cm}$.

Craters: None in photographs.

SAMPL $\overline{E \text { CHARACTERISTICS }}$

Size: $25 \times 15 \times 10 \mathrm{~cm} ; 4262$ grams (broken during transportation).

Color: Light gray with dark gray clasts.

Shape: Subangular.

Fillet: None.

Apparent burial: Perched.

Dust cover: None visible.

Comparison with other fragments in area: Largest rock in area of photographs and more angular than most.

Probable origin: North Ray crater ejecta. 


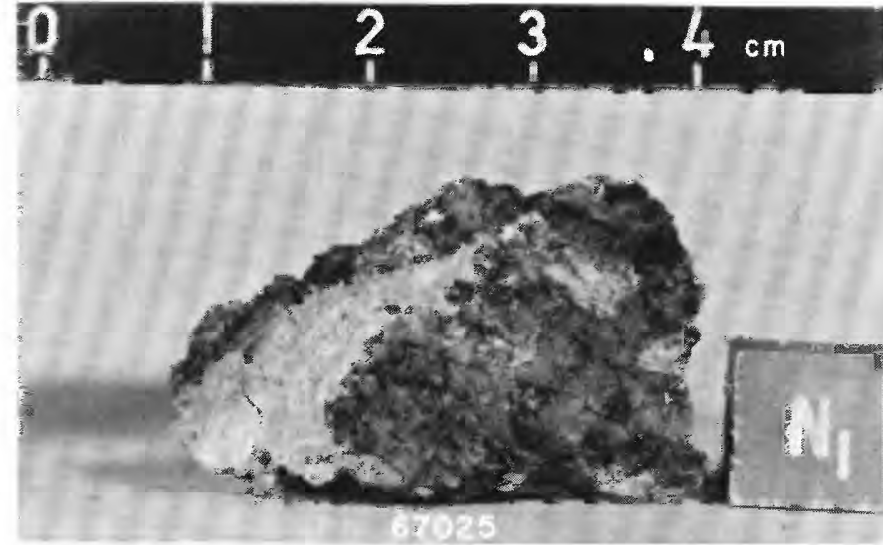

FIGURE 61.-Sample 67025 in LRL (photograph S-72-40525), 16-g fragment of $\mathrm{B}_{2}\left(\mathrm{~B}_{3}\right)$ breccia, part of residue collected in LRL from the same bag in which the large rocks 61016 and 67016 were transported. Lunar source of 67025 unknown. Breakage from sample 67016, type $B_{3}\left(B_{2}\right)$, seems likelier than breakage from 61016 . Sample 67025 classified as $B_{4}$ breccia.

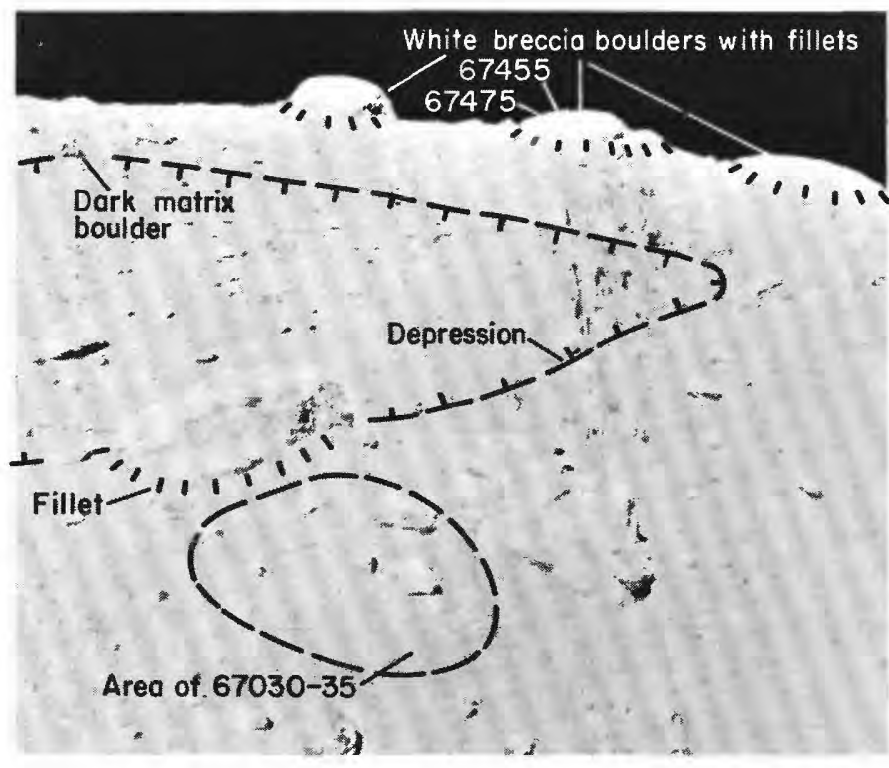

Figure 62A.-Area of sample 67030-35 (soil and fragile breccia) shown before sampling in photograph AS16-116-18610, looking southwest. Location of samples 67455 and 67475 also shown on one of three white breccia boulders on local horizon (see map, fig. 58 , and photograph, fig. 68).

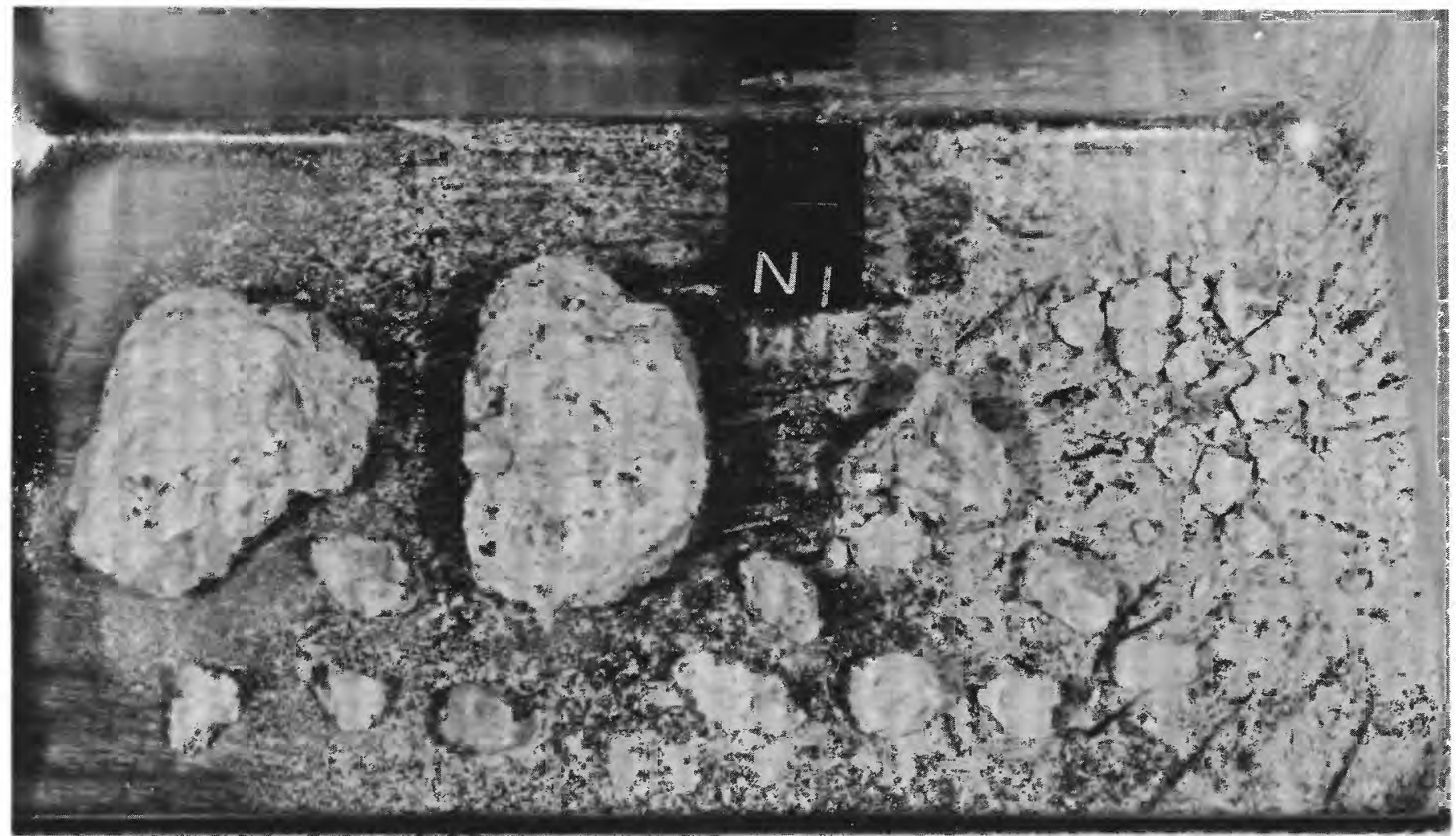

\section{5}

Figure $62 B$.-Sample 67035, a fragile $\mathrm{B}_{2}$ breccia, shown broken in a laboratory pan (photograph $\mathrm{S}-72-37545$ ). Lettered cube is $2.54 \mathrm{~cm}$ on a side. See chap. D2, fig. $27 B$, for another photographic view; and chap. $\mathrm{E}$, fig. $4 A$, for photomicrograph. 
SAMPLE: 67030-35 (rock sample with incidental soil)

Station: 11

Landmark: Approximately $20 \mathrm{~m} \mathrm{NNW}$ of LRV, on upper wall of North Ray crater.

Rock type: 67030-34, soil; 67035, light matrix breccia, B2.

SURFACE CHARACTERISTICS OF SAMPLE AREA

Slopes: Northward into North Ray crater, approximately 10 degrees.

Fragment population

Size range and distribution: $0.5-2 \mathrm{~m}$ boulders common $15-10$

within $10 \mathrm{~m}$ radius); $10-50 \mathrm{~cm}$ rocks also common; $1-10 \mathrm{~cm}$

abundant.

Color: Most fragments are light gray to white; few are dark.

Shapes: Angular to subrounded.

Fillets: Poorly to moderately well developed.

Apparent burial: Generally $<1 / 2$.

Dust cover: Not visible.

Fines

Color: Light gray.

Compaction: Firm; bootprints less than $1 \mathrm{~cm}$ deep.

Craters: None observed.

SAMPLE CHARACTERISTICS

Size: $67030-34,<1 \mathrm{~cm}$ fines; 96.23 grams.

67035, broken during transportation; 245.2 grams (see figure 62b).

Color: Light gray matrix, with dark and white clasts.

Shape: Rounded to subrounded.

Comparison with other fragments in area: Probably typical of

boulders and small fragments in this vicinity.

Probable origin: North Ray crater ejecta. 


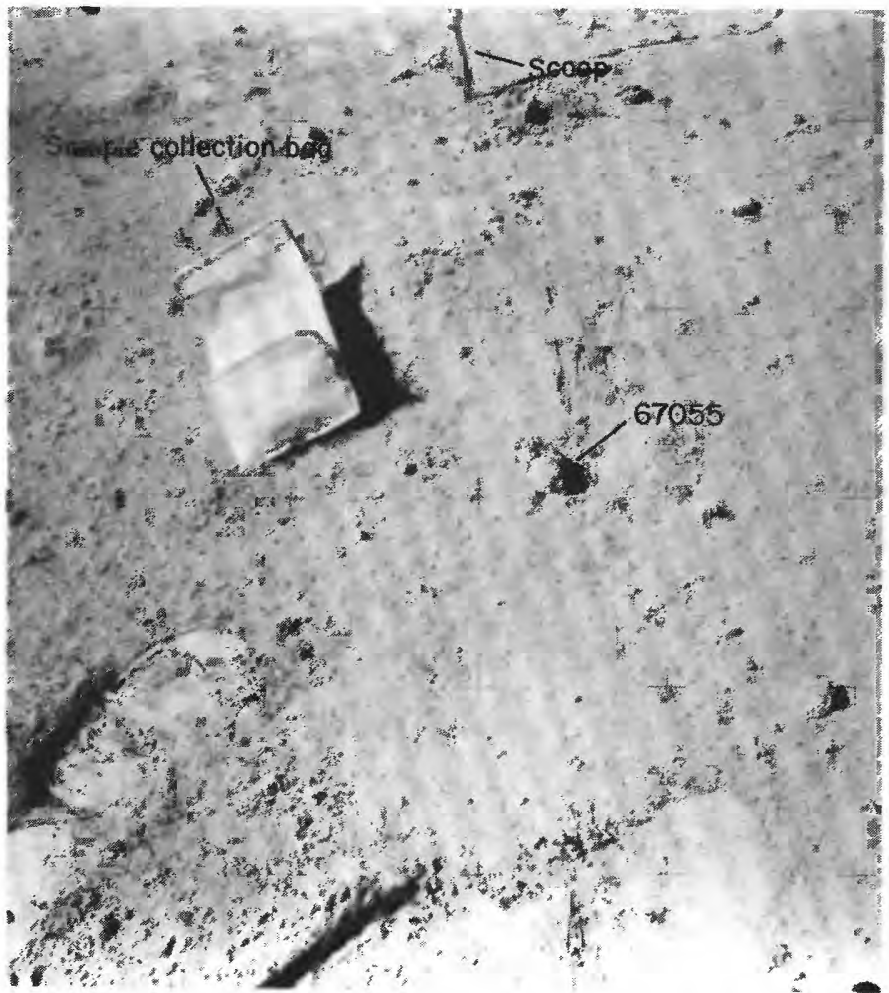

FIGURE 63A.- Sample 67055 shown before sampling in photograph AS16-116-18616; view is south.

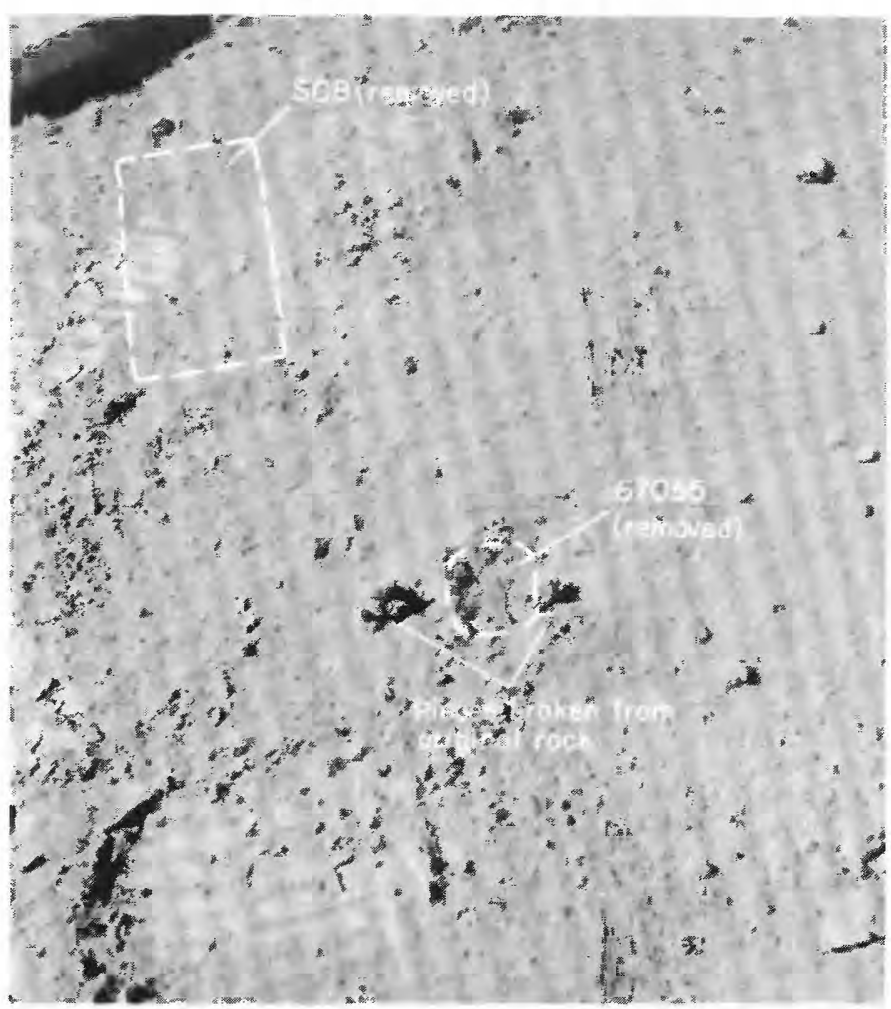

FigURE $63 B$.-Area of sample 67055 shown after sampling in photograph AS16-116-18618; view is south. Note the broken pieces that remained after the fragile sample was collected.

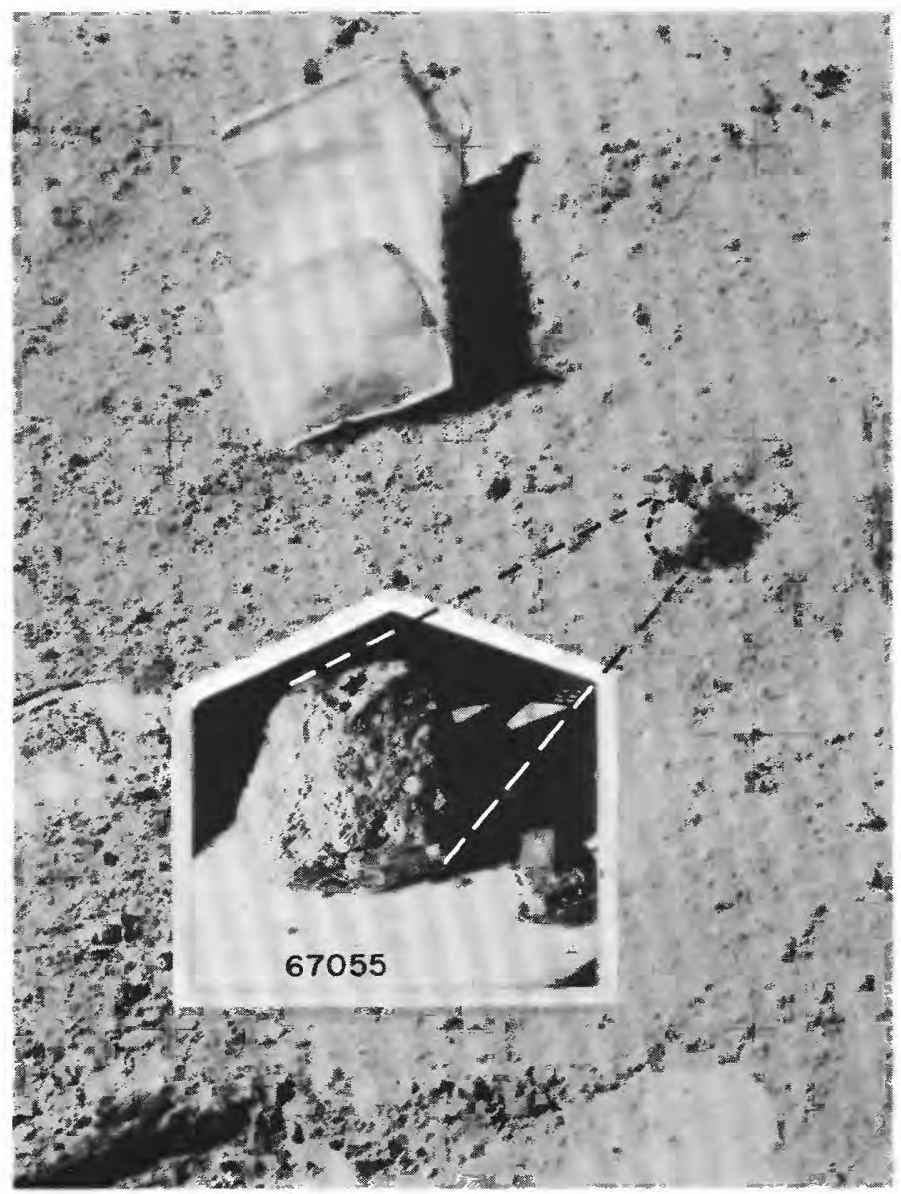

FIGURE $63 C$.- Sample 67055 showing approximate lunar orientation reconstructed in LRL compared to an enlarged part of photograph AS16-116-18617 taken before sampling. View is south. Friable sample broke during collecting; further minor breakage during transport and handling made shadow details impossible to duplicate accurately in the laboratory (inset photograph S72-44550). 


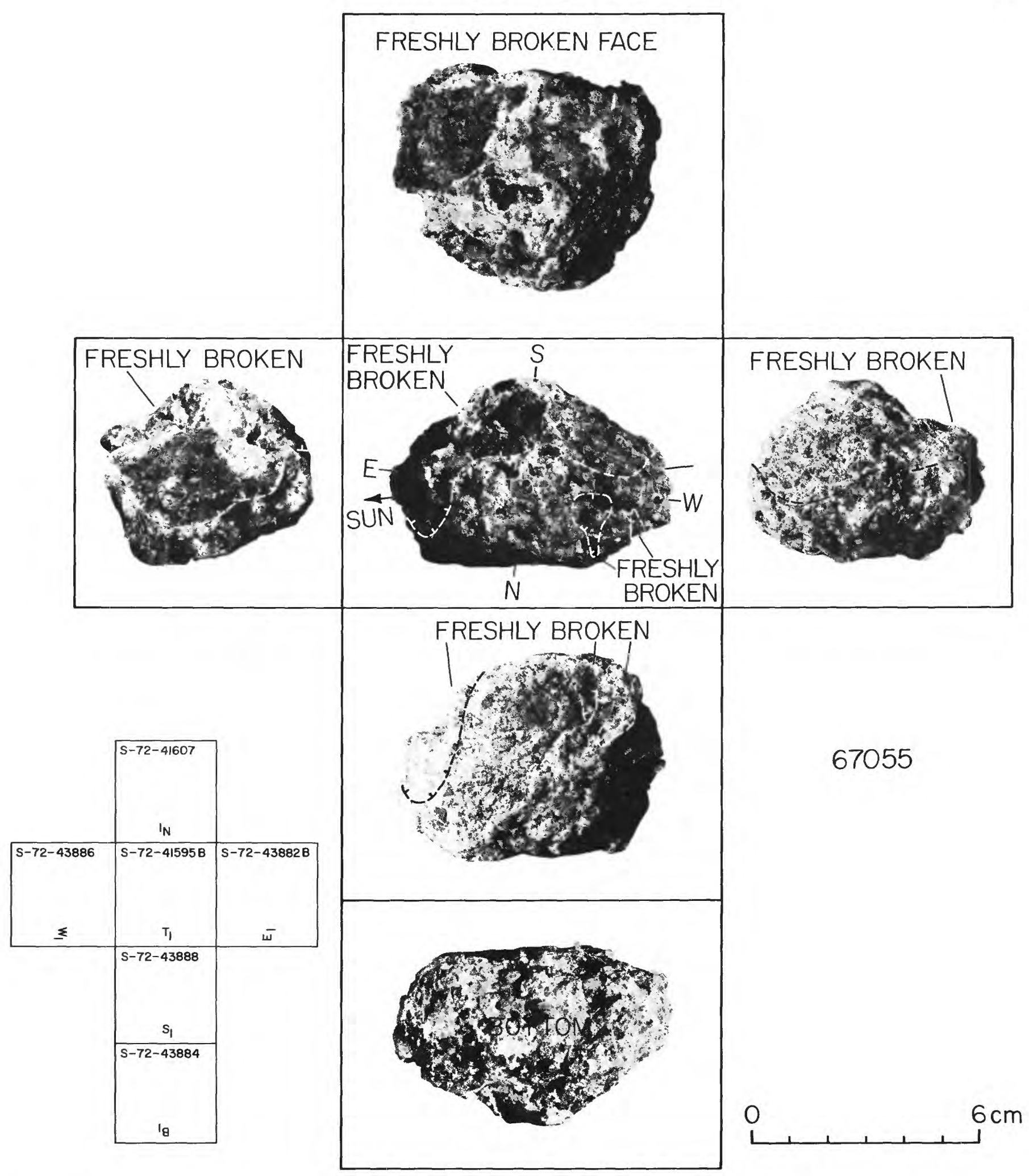

Figure $63 D$.- Orthogonal views of sample 67055 related to its lunar orientation at time of sampling. See chap. D2, fig. $29 B$, for stereopair of this type $B_{2}\left(B_{3}\right)$ breccia. 


\section{SAMPLE: 67055}

Station: 11

Landmark: Approximately $60 \mathrm{~m} \mathrm{NE}$ of LRV, on upper wall of North Ray crater.

Rock type: Breccia with light matrix, dark and light clasts, B2(B3). SURFACE CHARACTERISTICS OF SAMPLE AREA

Slopes: Northwestward into North Ray crater.

Fragment population

Size range and distribution: 3-10 cm fragments are sparse;

$<3 \mathrm{~cm}$, abundant.

Color: Light gray.

Shapes: Subangular (larger clods) to rounded (smaller ones).

Fillets: None visible.

Apparent burial: Generally $<1 / 2$.

Dust cover: Moderate.

Fines

Color: Light gray.

\section{Craters}

Compaction: Relatively firm.

\section{SAMPLE CHARACTERISTICS}

Size range and distribution: None visible in field of photos.

Size: $7 \times 6 \times 6 \mathrm{~cm} ; 221.88$ grams.

Color: White matrix, dark and light gray clasts.

Shape: Subrounded, with loose subangular to subrounded clasts; friable.

Fillet: Not distinctive.

Burial: Approximately 1/2. Sample broken during collection.

Dust cover: Dust covered (see Table 3, p. 54).

Comparison with other fragments in area: Larger than any of 5 or

6 others in vicinity, but appears to be typical in shape and texture.

Probable origin: North Ray crater ejecta.

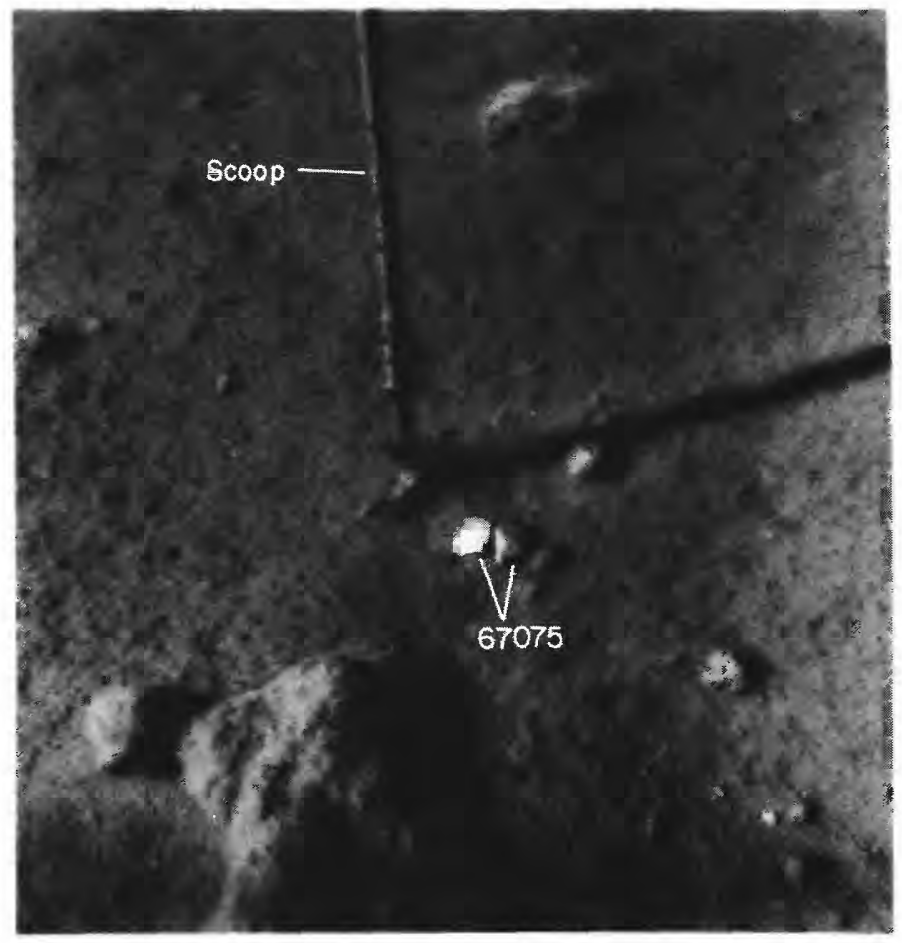

FigURe 64A.-Sample 67075 shown broken on lunar surface before sampling in photograph AS16-106-17319. View is south. Interior of freshly broken breccia fragment is white, in sharp contrast to weathered exterior of this sample and other rocks nearby. 


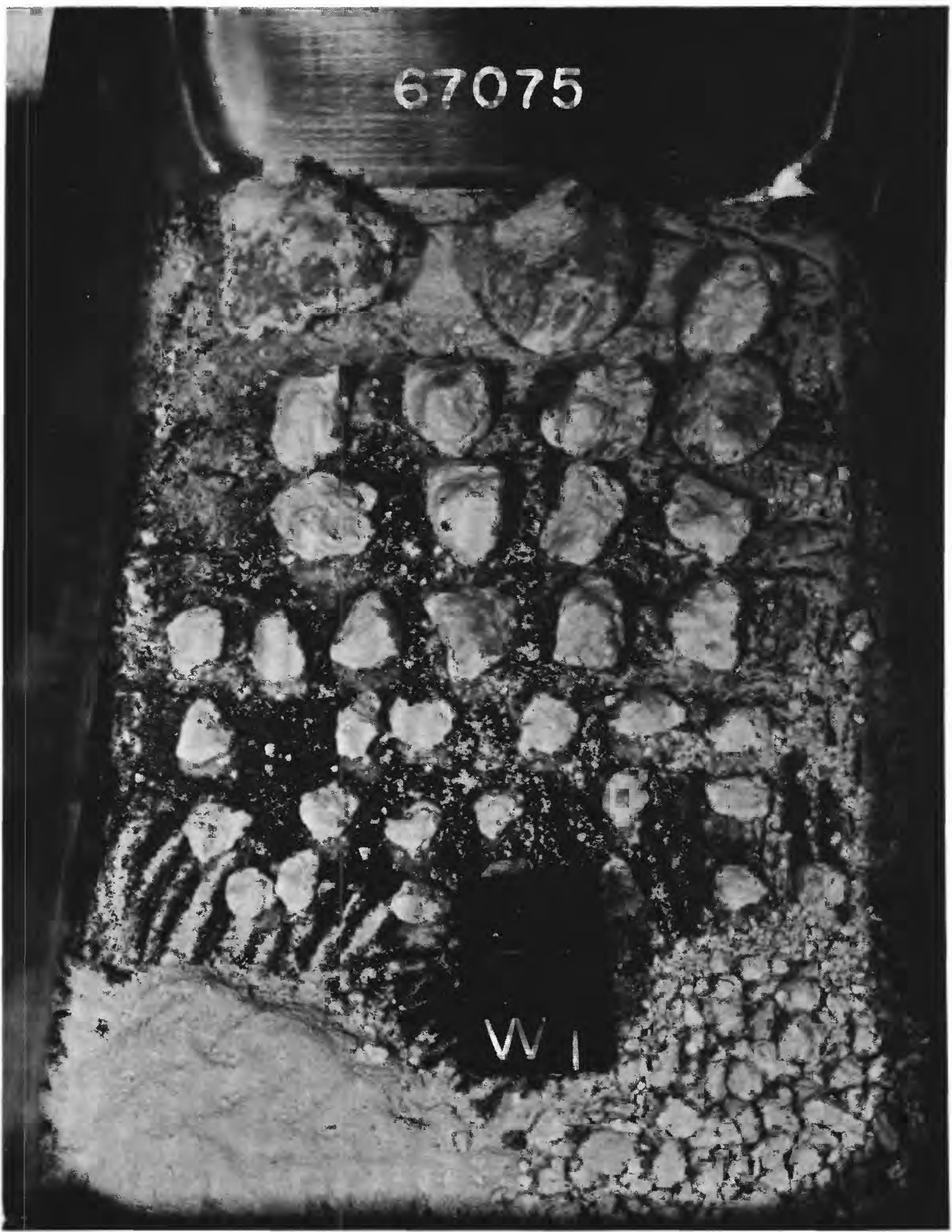

Figure 64B.-Sample 67075, a fragile $\mathrm{B}_{1}$ breccia, shown broken in a laboratory pan (photograph S-72-37538). Lettered cube is $2.54 \mathrm{~cm}$ on a side. See chap. D2, figs. $29 \mathrm{C}$ and 30 , for another photographic view and photomi. crograph respectively. 
SAMPLE: 67075

Station: 11

Landmark: Approximately $65 \mathrm{~m} \mathrm{NE}$ of $L R V$, on upper wall of North Ray crater.

Rock type: Fragile white breccia, Bl.

SURFACE CHARACTERISTICS OF SAMPLE AREA

Slopes: Northwestward into North Ray crater.

Fragment population

Size range and distribution: Two rocks $>25 \mathrm{~cm}$ within field of

view; 1-10 cm fragments sparse; mostly $<1 \mathrm{~cm}$ fines.

Color: Medium gray.

Shapes: Most are rounded to subrounded.

Fillets: Not obvious; may be developed on uphill (south) sides of larger rocks.

Apparent burial: Large rocks > $1 / 2$ - small rocks perched.

Fines Dust cover: Appears moderately heavy.

Color: Medium gray.

Compaction: Cannot determine from documentation photographs.

\section{Craters}

Size range and distribution: None visible in photographs of

immediate area.

SAMPLE CHARACTERISTICS

Size: Originally 2 fragments, further broken during transporation;

Color: White, "chalky" (see table 3, p. 56).

Shape: Subrounded; angular at fracture edges.

Fillet: None.

Apparent burial: Perched (sample was broken before photography).

Dust cover: None reported during sampling.

Comparison with other fragments in area: Whiter than nearby fragments. Similar to white boulders approximately $120 \mathrm{~m}$ to the southwest of sample site.

Probable origin: North Ray crater ejecta.

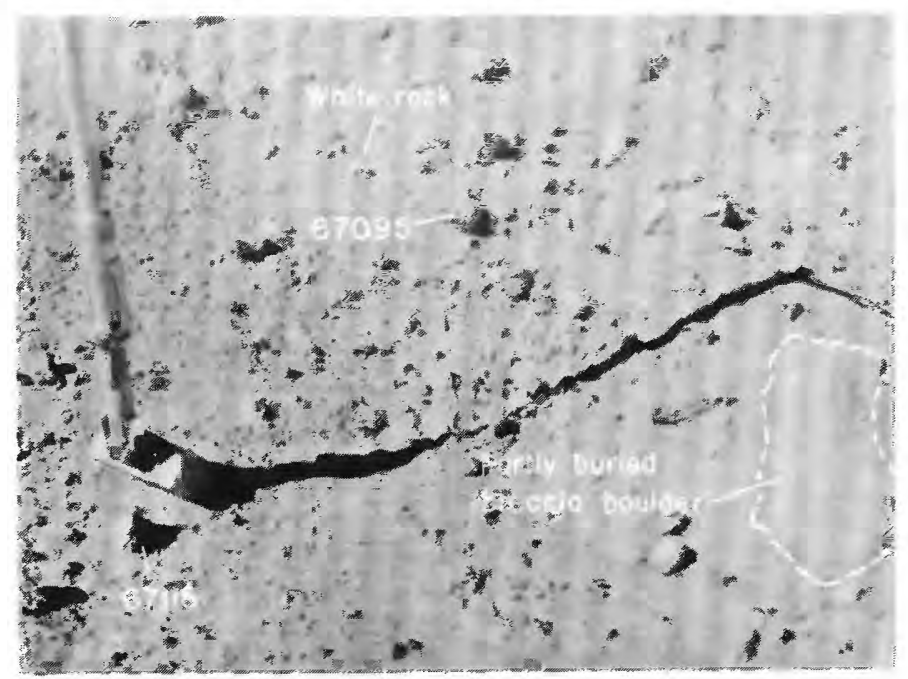

FIGURE 65A.-Samples 67095 and 67115 shown before sampling in photograph AS16-116-18626. View is south. Collected fragments were identified primarily by their relative sizes and their absence from the postsampling photograph (not show) of same area. 

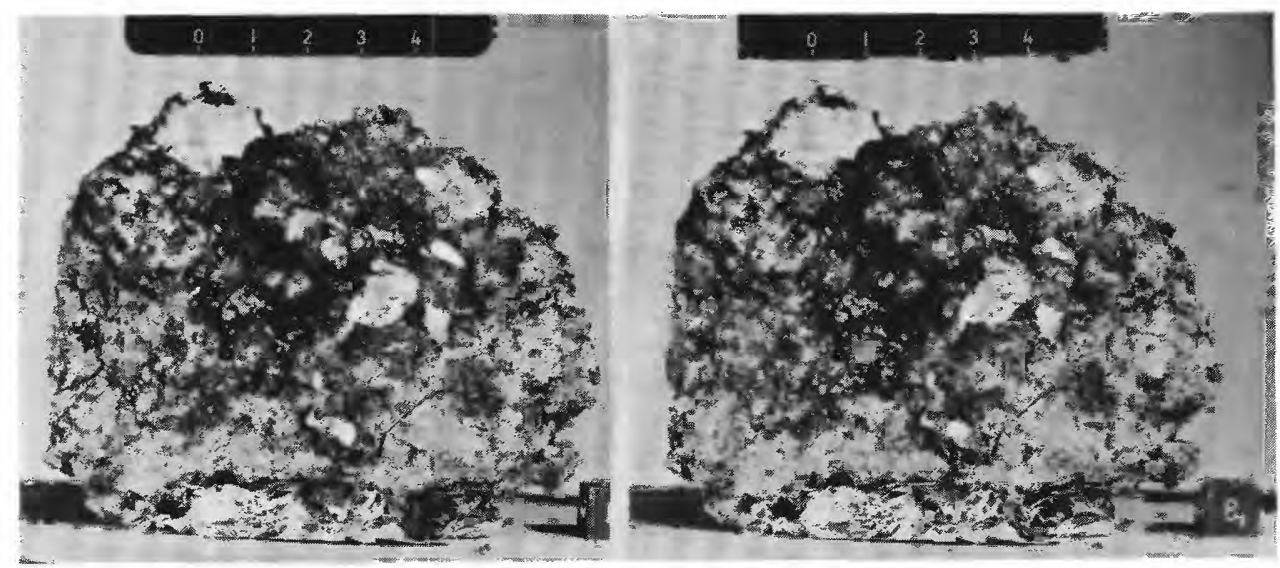

FIGURE 65B.-Stereopair of sample 67095 in LRL; photographs S-72-43072 (right) and -43072B (left). See chap. E, fig. 29D, for stereopair of this glassy (type G) breccia.

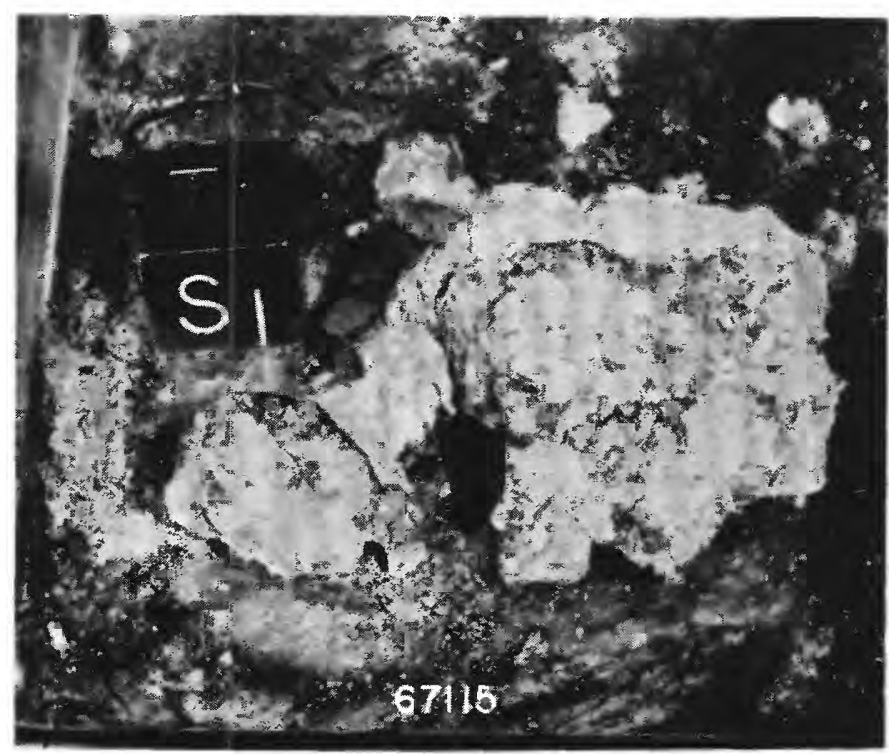

Figure 65C.-Sample 67115, a type $\mathrm{B}_{3}$ breccia, shown broken in a laboratory pan (photograph S-72-37747). Lettered cube is $2.54 \mathrm{~cm}$ on a side. See chap. D2, fig. $29 E$, for enlarged $S_{1}$ photographic view of the biggest fragment: 


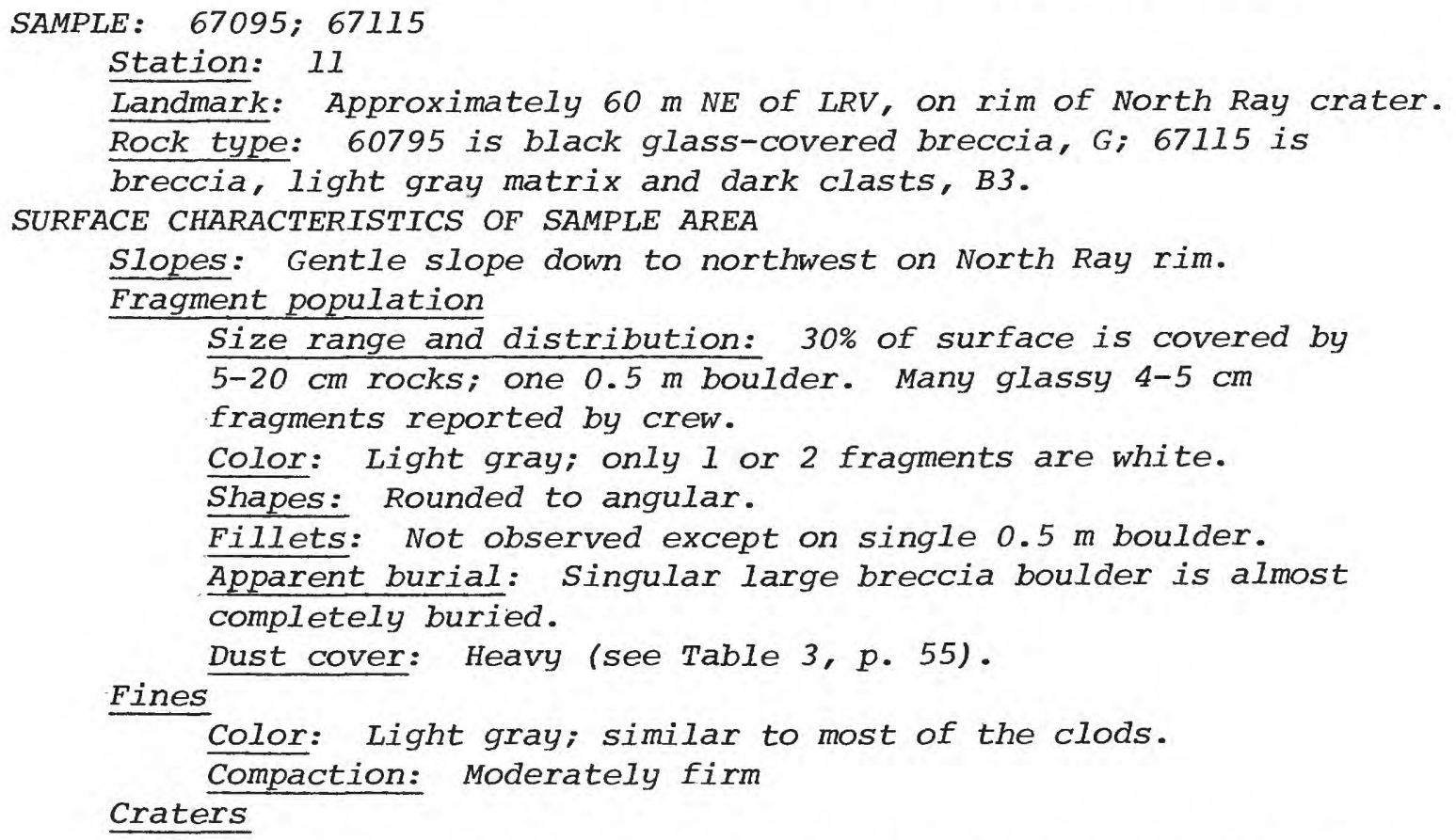




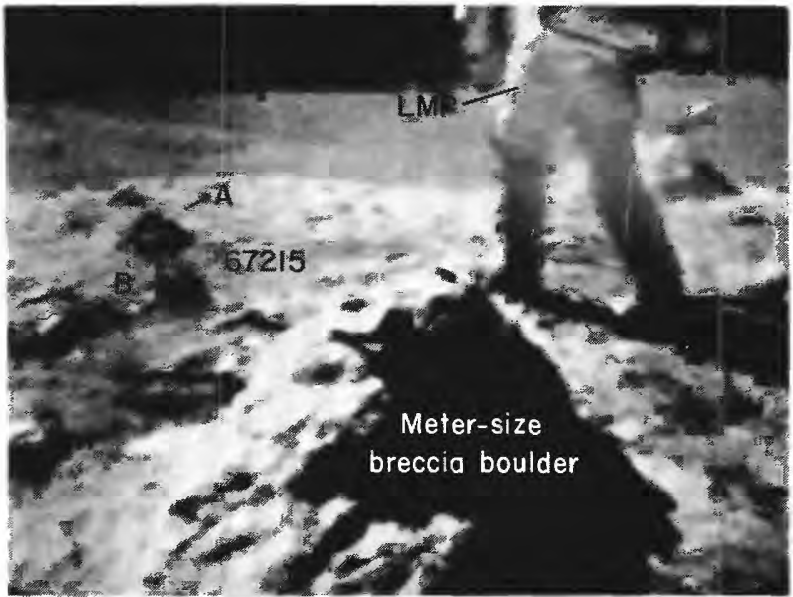

Figure 66A.-Sample 67215, 277-g rock collected as special padded bag sample ( $\mathrm{PB} \# 1$ ), picked up about $7 \mathrm{~m}$ east of LRV at station 11 as shown before sampling in this television picture transmitted from the Rover. Compare rocks " $A$ " and " $B$ " with same rocks shown in fig. $66 B$.

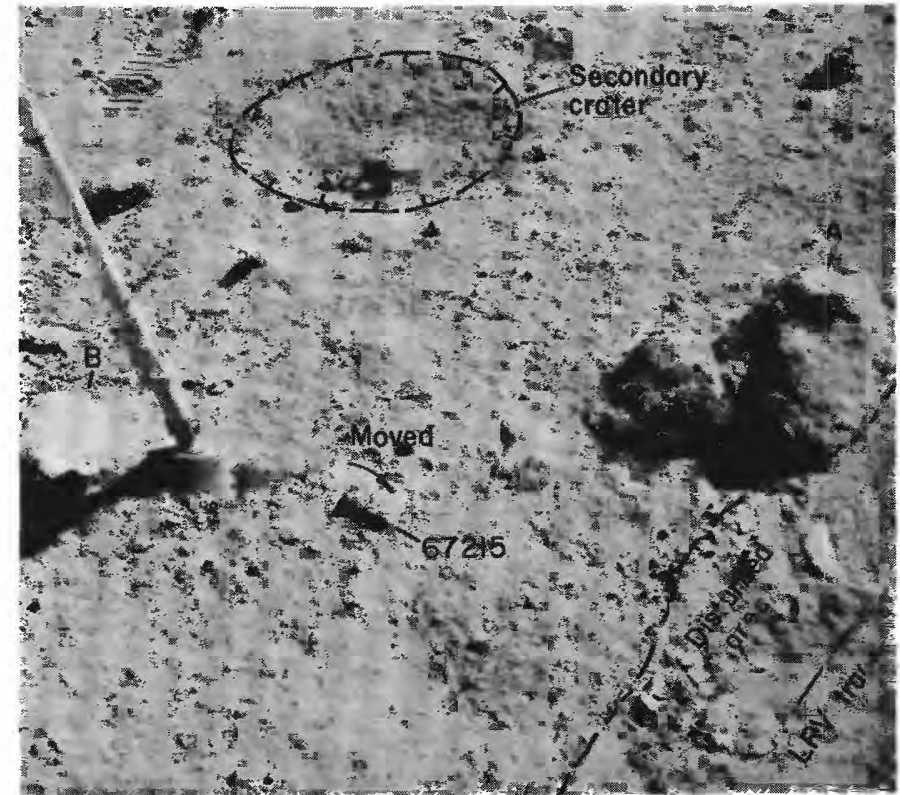

Figure $66 B$.- Sample 67215 shown before sampling in part of photograpin AS16-106-17355; view is northeast. The rock had been moved slightly when it was struck by the scoop to determine the coherence of the proposed sample. Rocks labeled " $A$ " and " $B$ " match those with same labels in fig. $66 \mathrm{~A}$.

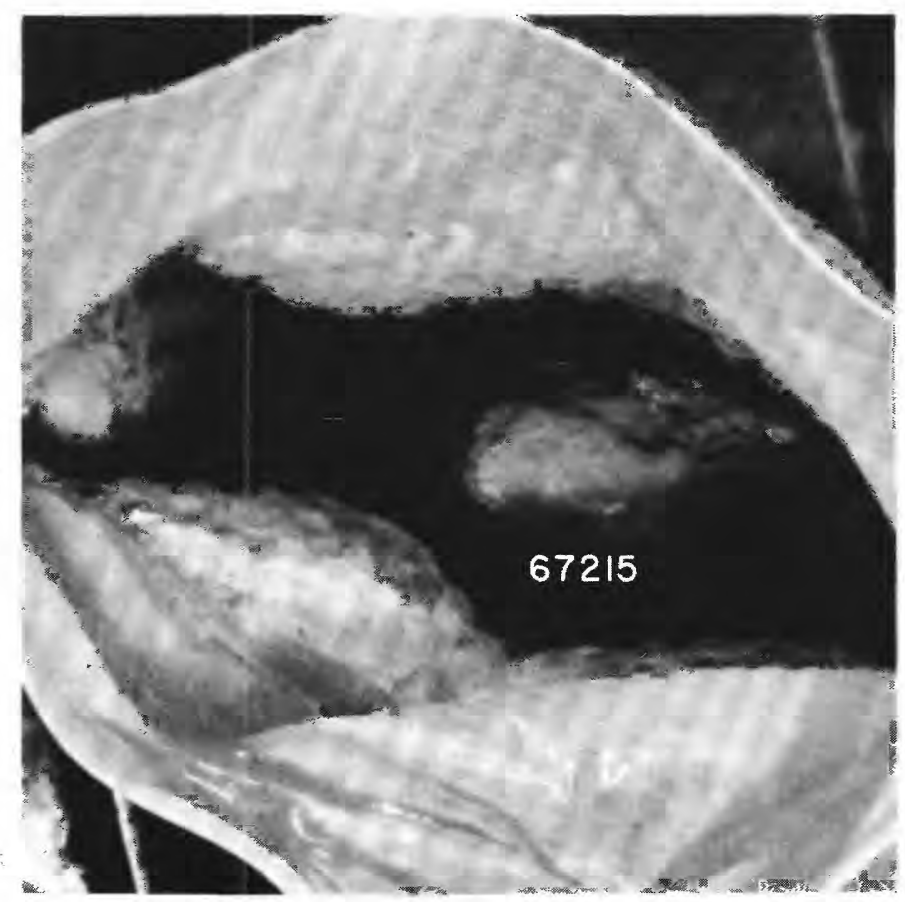

Figure 66C.-Padded bag sample 67215 (PB \#1) shown in LRL (photograph S-72-43811). Rock was left in bag, untouched and dust covered; from cursory inpection in the laboratory, appears to be a moderately tough, polymict breccia (see Horz and others, 1972, fig. 7-21). 

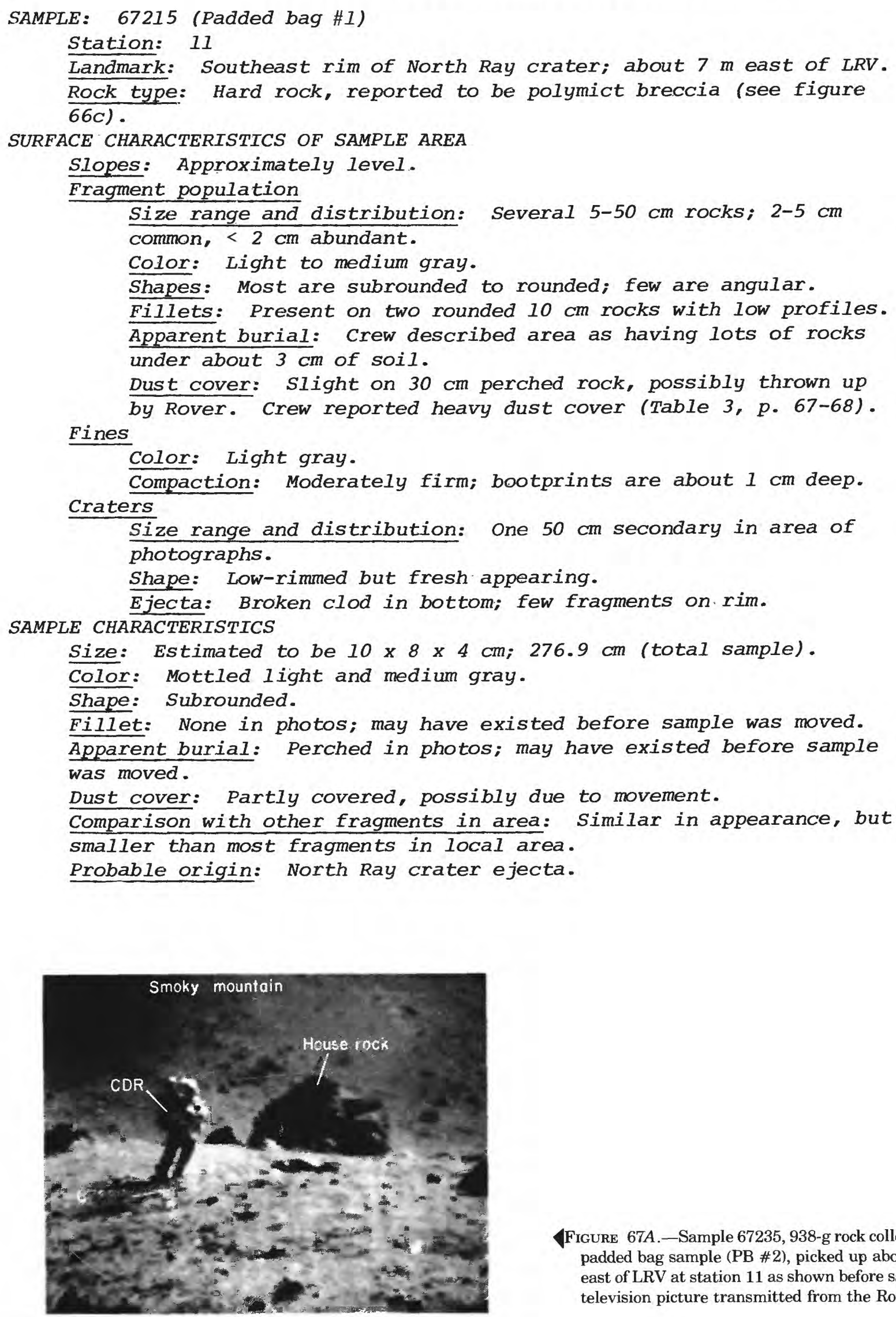

4Figure 67A.--Sample 67235, 938-g rock collected as special padded bag sample (PB \#2), picked up about $15 \mathrm{~m}$ northeast of LRV at station 11 as shown before sampling in this television picture transmitted from the Rover. 


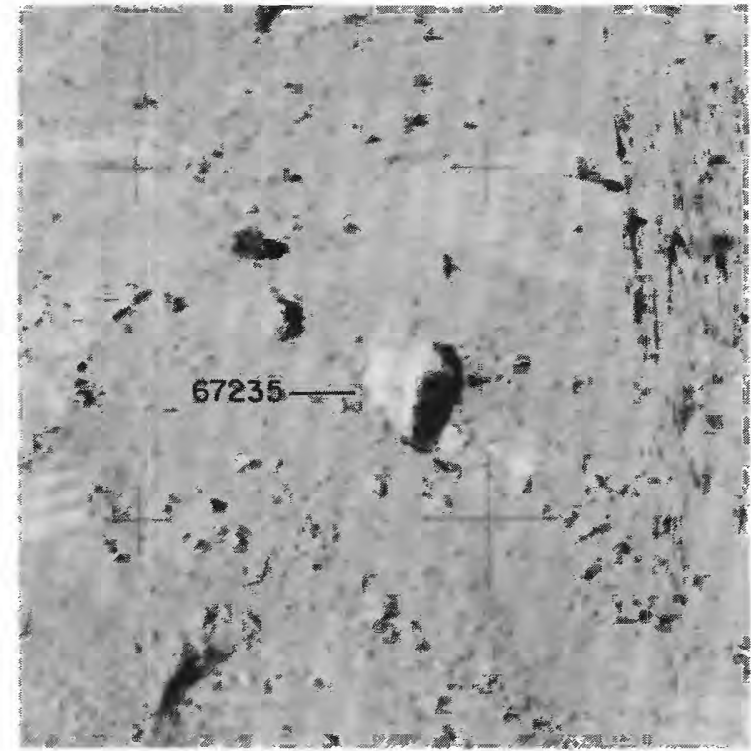

Figure 67B.-Sample 67235 shown before sampling in enlarged part of photograph AS16-116-18656; view is south.

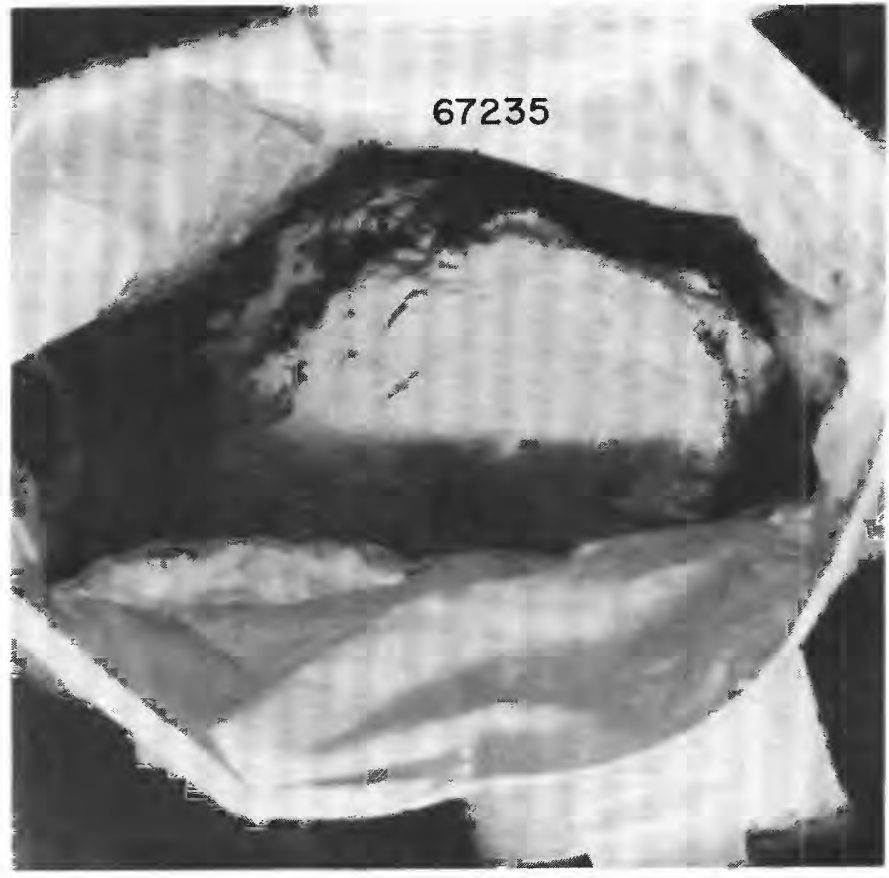

Figure 67C.-Padded bag sample 67235 (PB \#2) shown in LRL (photograph S-72-43811). Rock was left in the bag, untouched and dust covered; from cursory inspection in the laboratory, appears to be a hard, recrystallized dark-matrix breccia (see Horz and others, 1972, fig. 7-21).

SAMPLE: 67235 (Padded bag \#2)

Station: 11

Landmark: Southeast rim of North Ray crater; about $15 \mathrm{~m} \mathrm{NE}$ of LRV.

Rock type: Dark matrix breccia (see figure $67 \mathrm{C}$ ).

SURFACE CHARACTERISTICS OF SAMPLE AREA

Slopes: Gentle slope down to north along North Ray crater rim.

Fragment population

Size range and distribution: $5-20 \mathrm{~cm}$ rocks cover less than

$1 \%$ of area; 2-5 cm, 2-3\%; 0.5-2 cm, 20-30\%.

Color: Light gray.

Shapes: Subangular to subrounded.

Fillets: Present on larger rocks.

Apparent burial: Perched to $>1 / 2$.

Dust cover: Crew reported dust cover (Table 3, p. 67-68).

Fines

Color: Light gray.

Craters

Compaction: Firm; most bootprints less than $1 \mathrm{~cm}$ deep.

SAMPLE CHARACTERISTICS

Size: Estimated to be $15 \times 8 \times 5 \mathrm{~cm} ; 938.34$ grams (total sample).

Color: Light gray to white.

Shape: Elongate, subangular.

Fillet: None.

Apparent burial: Perched.

Dust cover: Reported by crew to be dusty.

Comparison with other fragments in area: More angular and lighter

in color than the majority of larger fragments.

probable origin: North Ray crater ejecta. 


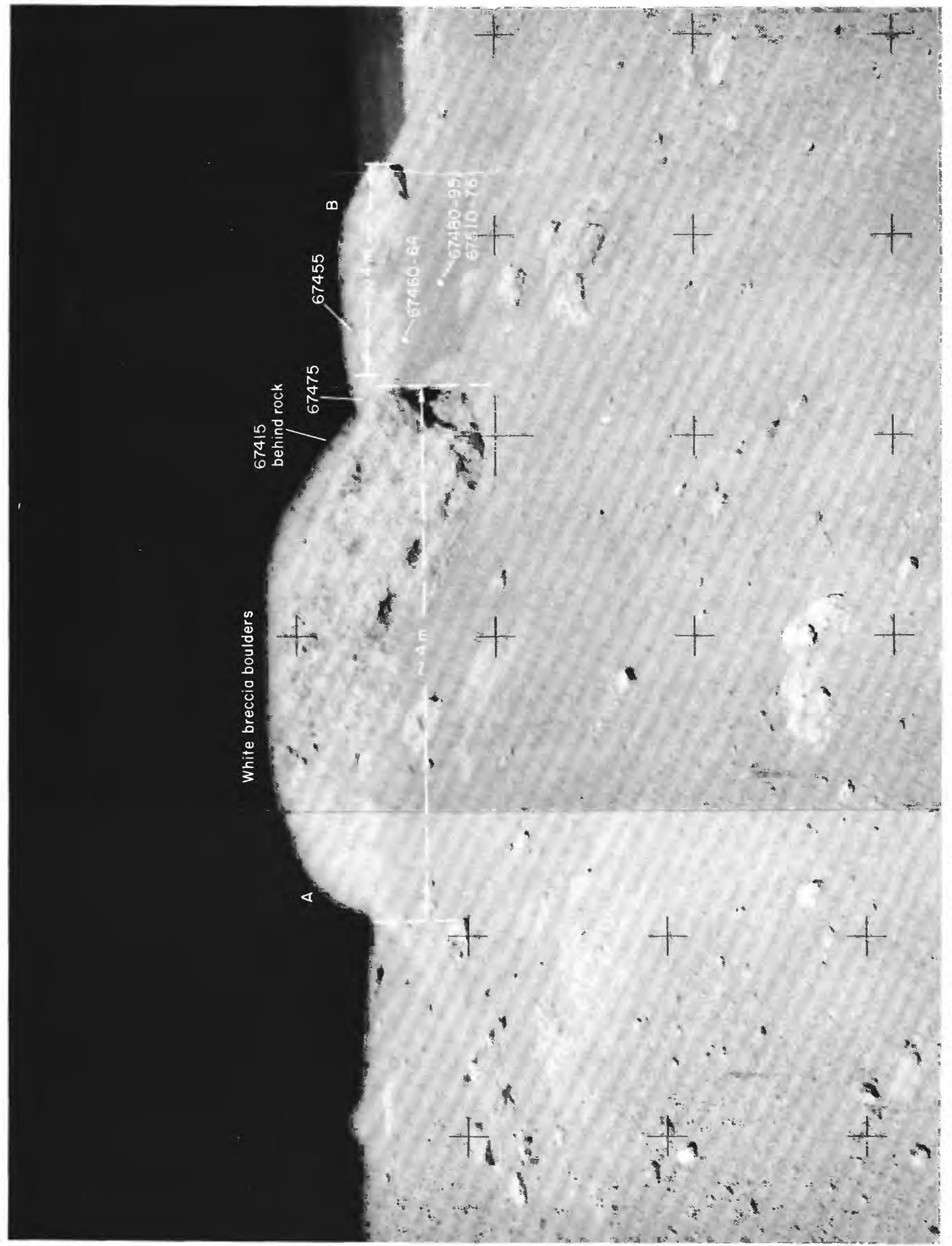

要焉

to

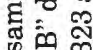
象空 चा

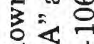
空 है 행 공 ㄷำ 政 t. 这岳 용 要 क. छํํㅇ क 10 ป $3 \frac{0}{6}$ कิ ?ํㅇㅇ ป 5 范 苋 बै : () क 515 일 赵要 등 웅 $=\overline{2}$ ส 苍 氙

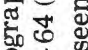
용 空 46

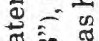
ปั क है 婇 毒 क 응 일 의 튼 눙워 5 동 of $\overline{0}$. ปี 든 용

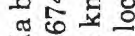
: 造乐 : 牙. 部专 1 . $\infty$ 焉获 동 릉 
SAMPLE: 67415

Station: 11

Landmark: Approximately 65-70 $\mathrm{m}$ WSW of LRV in vicinity of large white breccia boulders (figures 58 and 68).

Rock type: White matrix breccia, Bl.

SURFACE CHARACTERISTICS OF SAMPLE: AREA

Slopes: Nearly horizontal; near rim crest of North Ray crater.

Fragment population

Size range and distribution: $5-10 \mathrm{~cm}$, less than $1 \%$ of surface;

$1-5 \mathrm{~cm}, 30-40 \%$ of surface.

Color: Light gray (may be dust covered) and white.

Shapes: Rounded to subangular.

Fillets: Large boulders have well developed fillets. Small

rocks generally lack them.

Apparent burial: Most appear perched in immediate area of sample. Dust cover: Reported to be covered.

Fines

Color: Light gray.

Compaction: Soft; boot impressions are several centimeters deep.

Craters

None visible.

SAMPLE CHARACTERISTICS

Size: Sample broken into many pieces; 174.9 grams.

Color: Very light gray.

Shape: Rounded on top surface before breakage.

Fillet: None.

Apparent burial: Perched.

Dust cover: Crew described as dust covered (see Table 3, p. 58).

Comparison with other fragments in area: Similar to largest

ones observed.

Probable origin: Ejected from North Ray crater. May have broken

from adjacent large white breccia boulder. 


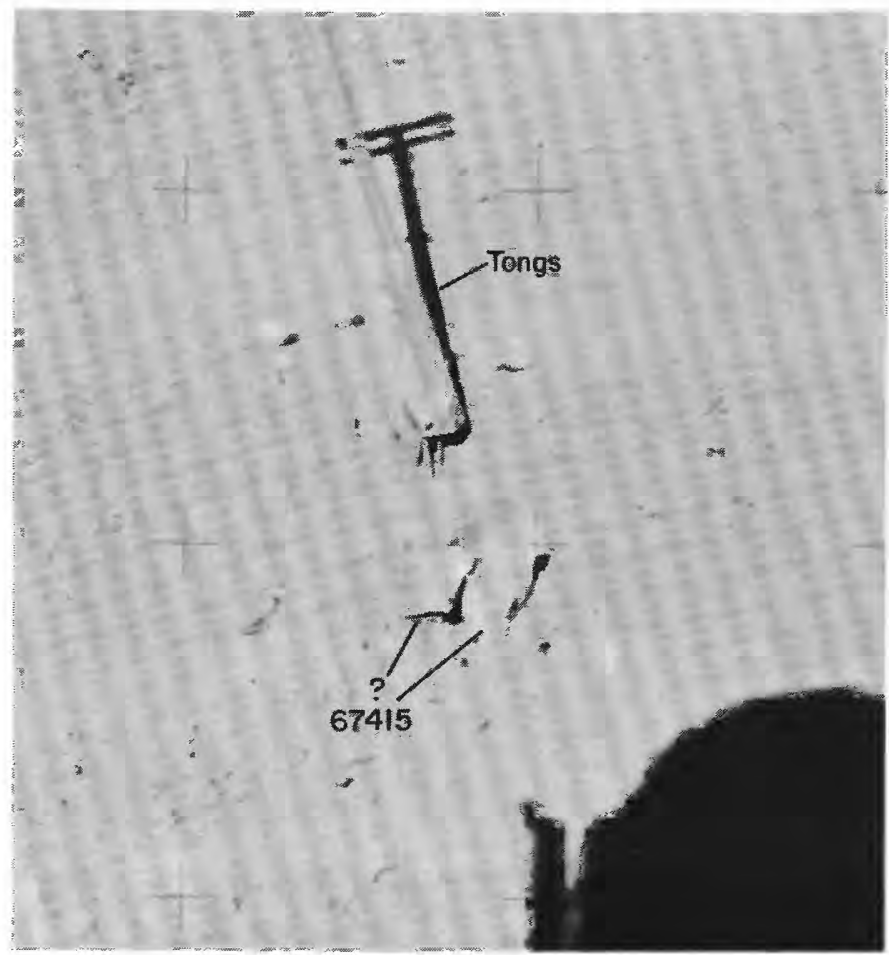

Figure 69A.-Sample 67415 shown before sampling in an enlarged part of photograph AS16-116-18636; view is west. Note that several white clasts can be seen in this down-sun view.

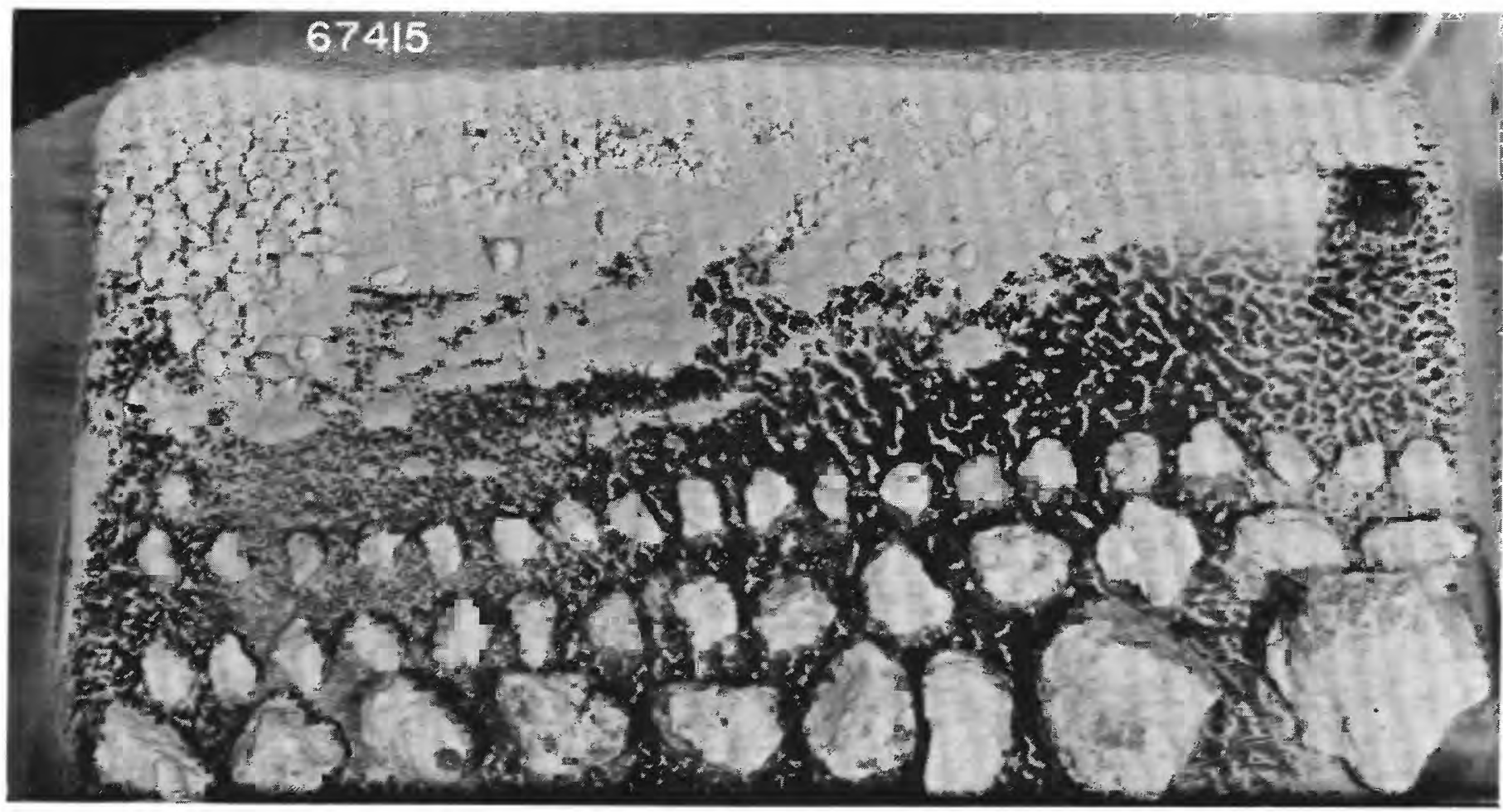

Figure $69 B$.-Sample 67415, a fragile $\mathrm{B}_{1}$ breccia, shown broken in a laboratory pan (photo S-72-39037). Scale at upper left in centimeters. See chap. D2, fig. $27 C$, for another view, and fig. $28 A$ for photomicrograph of sample. 


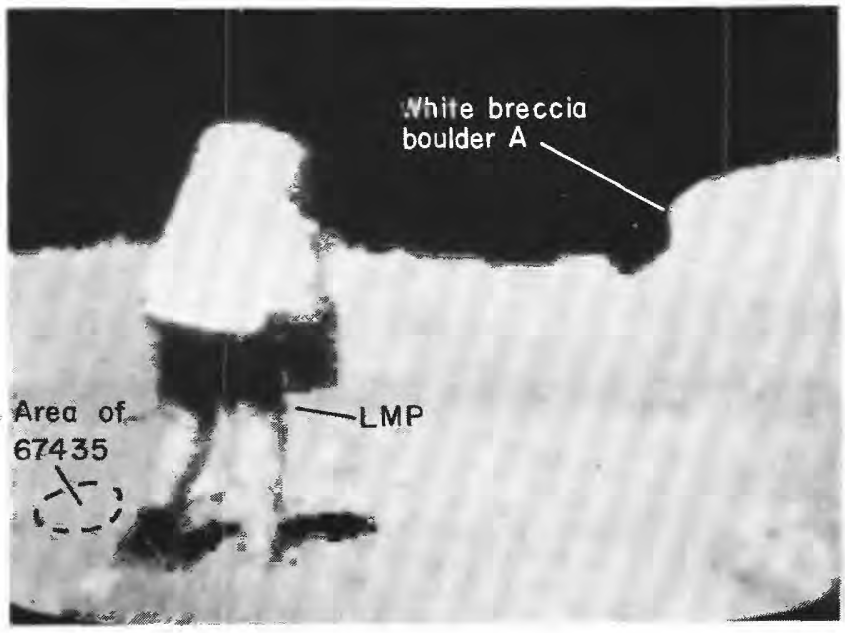

FIGURE 70A.-Location of sample 67435 shown in television picture from LRV just prior to sampling; view is southwest. Note white breccia boulder " $\mathrm{A}$ " is same as boulder in fig. 68 .

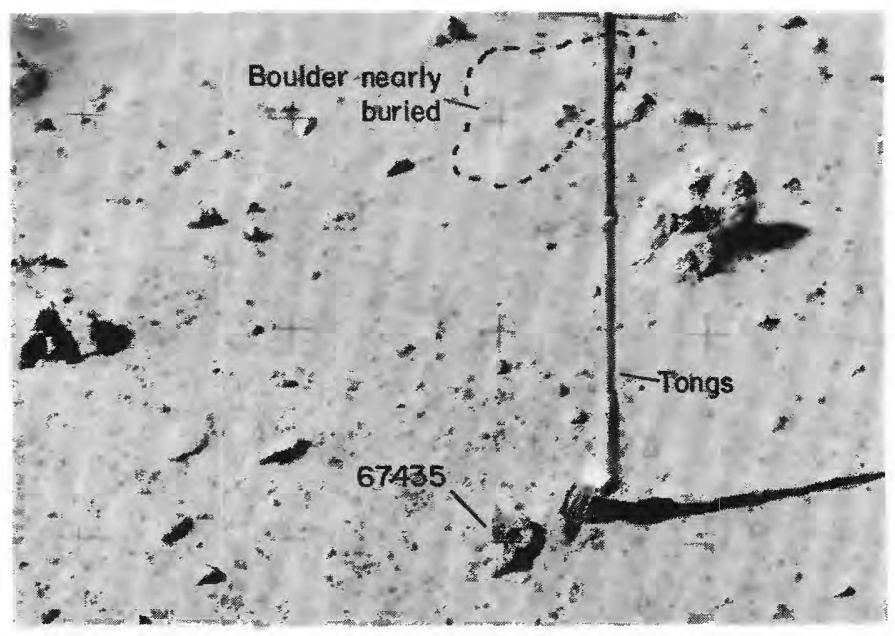

Figure $70 B$.- Sample 67435 shown before sampling in part of photograph AS16-107-17321; view is south.

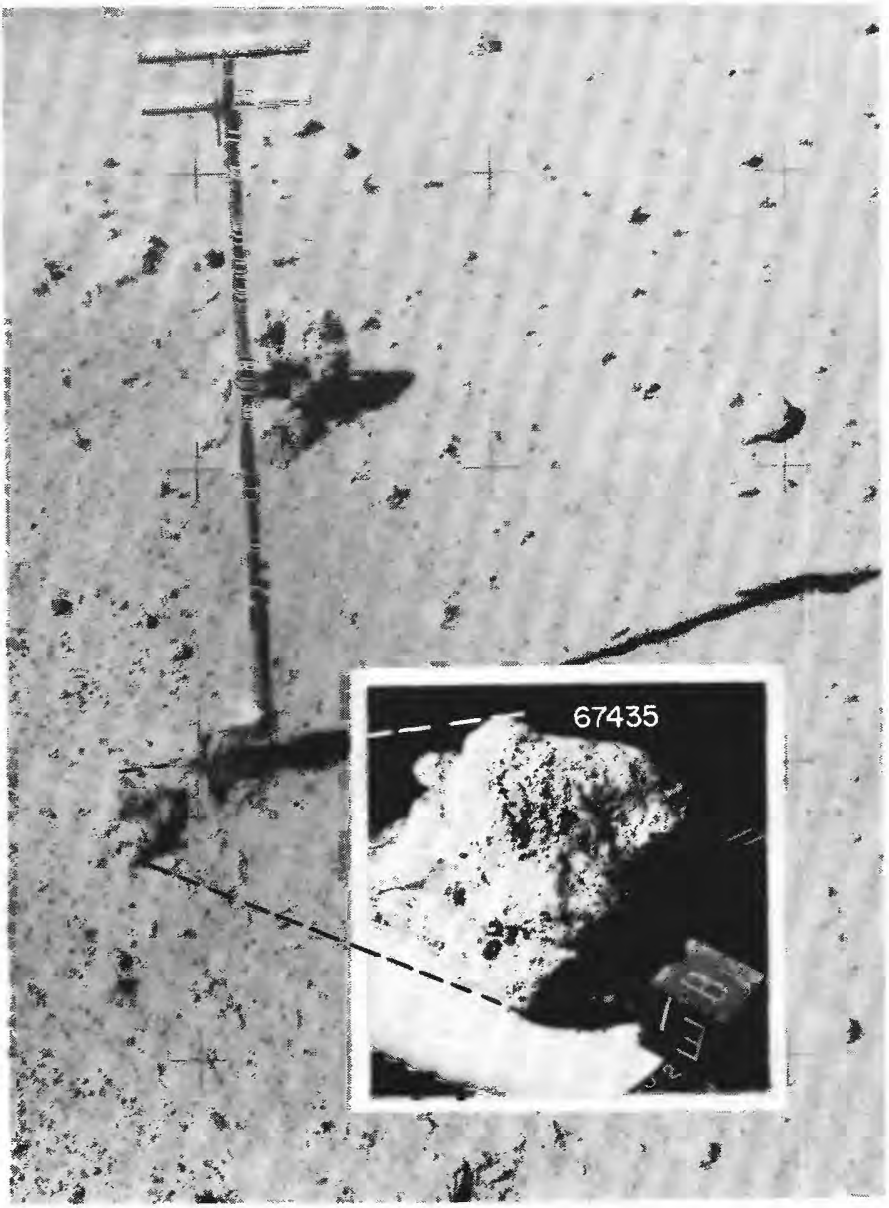

FIGURE 70 C.-Sample 67435 showing approximate lunar orientation reconstructed in LRL compared to an enlarged part of photograph AS16-106-17320 taken before sampling. View is south (inset photograph, S-72-44507). 


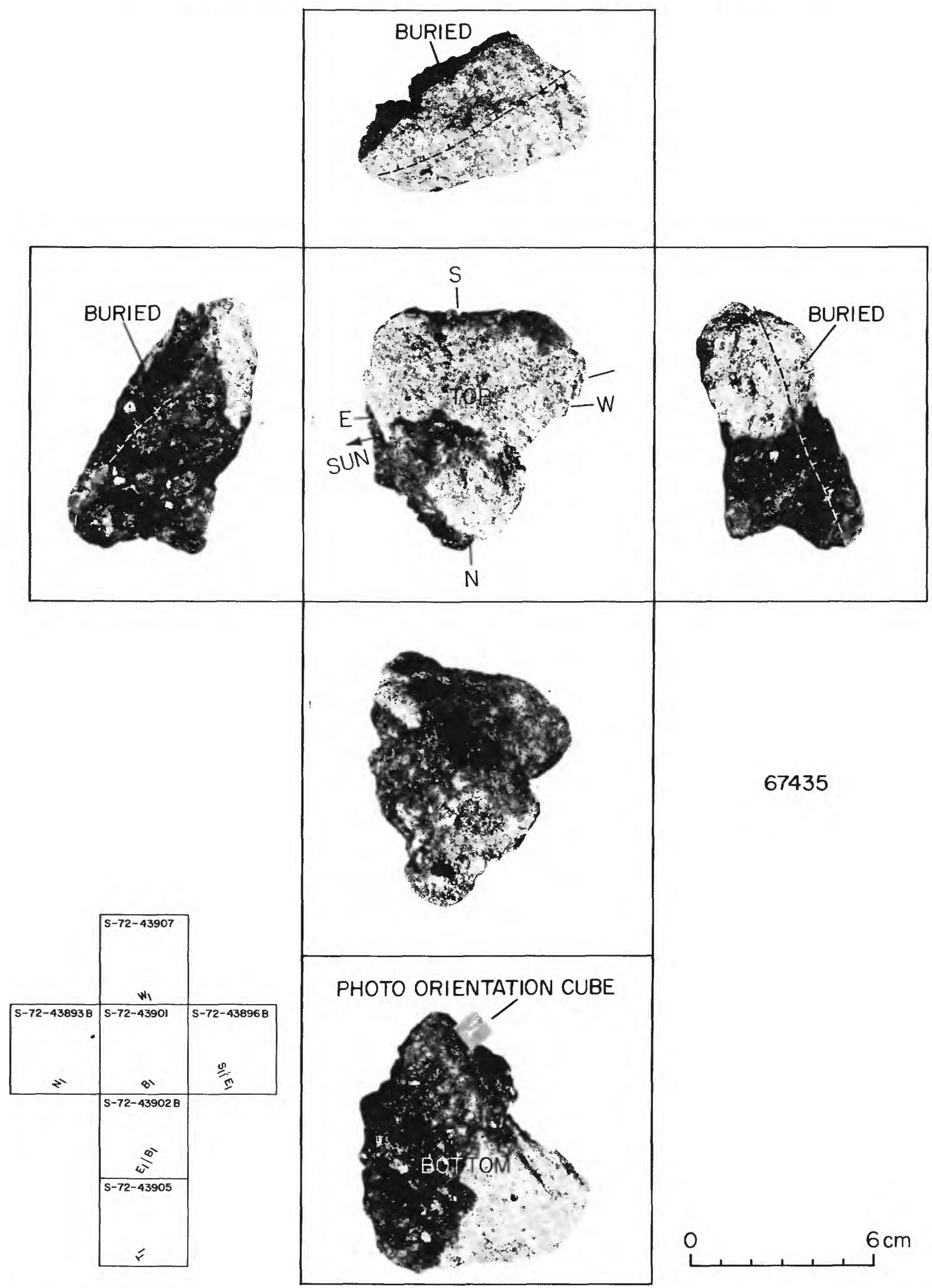

FIGURE 70D.-Orthogonal views of sample 67435 related to its lunar orientation at time of sampling. See chap. D2, fig. $27 D$, for stereopair and chap. E, fig. $3 D$, for photomicrograph of this type $\mathrm{B}_{4}$ breccia. 
SAMPLE: $\quad 67435$

Station: 11

Landmark: Approximately $15 \mathrm{~m}$ SW of LRV; SE rim of North Ray crater. Rock type: Breccia; glass coated, hackled surface, B4. SURFACE CHARACTERISTICS OF SAMPLE AREA

Slopes: Up toward white breccia boulder.

Fragment population

Size range and distribution: $0.5-1 \mathrm{~m}$ boulders sparse; 2-10 $\mathrm{cm}$ fragments common; < 2 cm rocks abundant.

Color: Light gray.

Shapes: Angular to subrounded.

Fillets: Only around rounded $1-2 \mathrm{~m}$ rock to south; not well

developed.

Apparent burial: Substantial burial on larger rocks; smaller ones perched.

Dust cover: Not apparent.

Fines

Color: Light gray.

Compaction: Moderately firm; about 1-cm-deep bootprints.

Craters

Size range and distribution: A few small (< $2 \mathrm{~m})$, probably

secondary craters.

Shape: Round, subdued.

Ejecta: Not clearly related to smaller craters.

SAMPLE CHARACTERISTICS

Size: $9.5 \times 8 \times 5 \mathrm{~cm} ; 353.5$ grams.

Color: Medium gray.

Shape: Blocky, angular, hackly.

Fillet: None.

Apparent burial: < $1 / 2$ (perched).

Dust cover: Not visible; none reported.

Comparison with other fragments in area: The B4 breccia is not common among fragments collected from the white breccia boulder area; may represent a dark clast or a scattered "House Rock" type of ejecta. Probable origin: North Ray crater ejecta. 


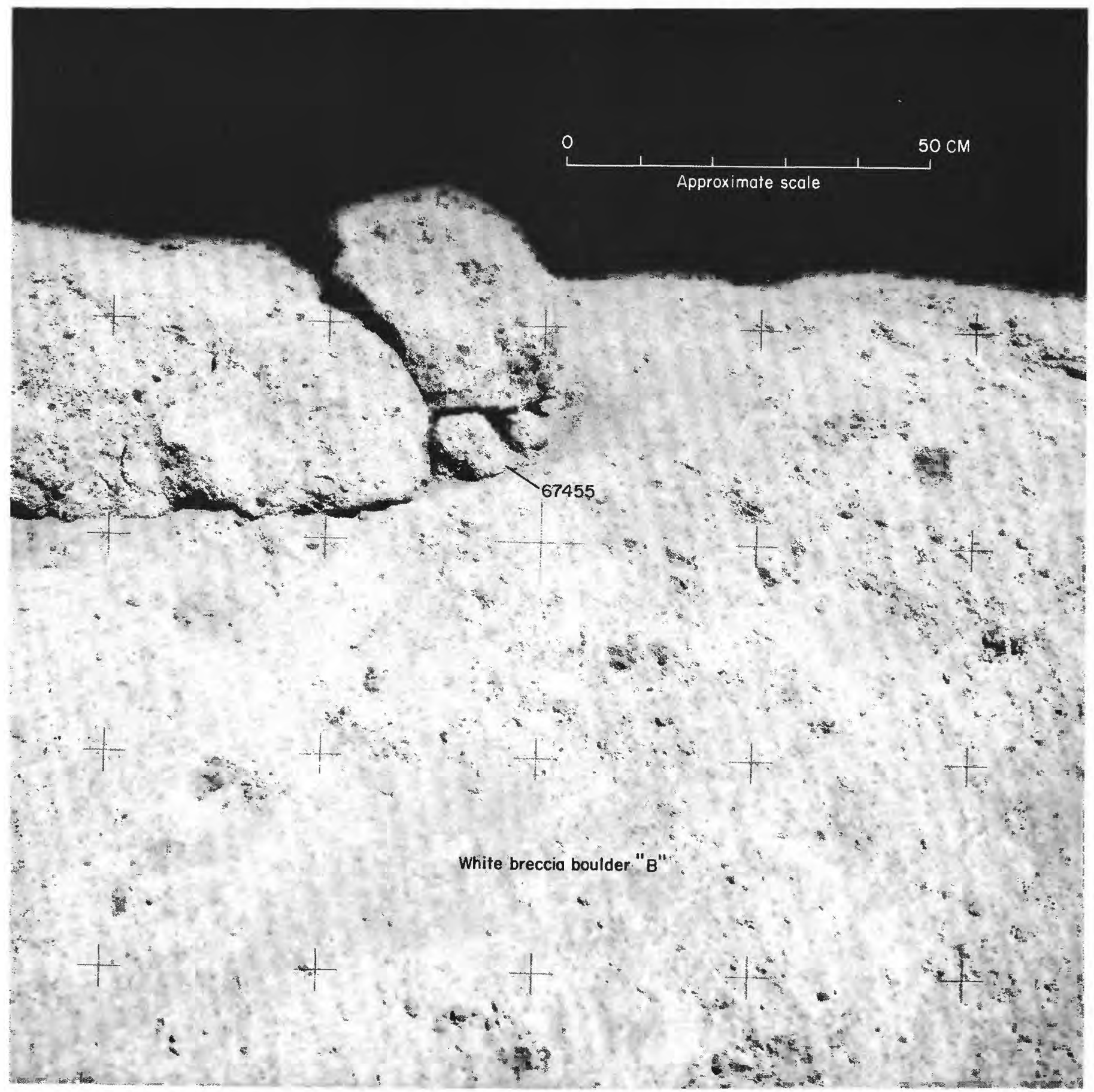

FIGURE 71A.-Sample 67455 shown before sampling in photograph AS16-106-17332; view is northeast. Sample was lying loose on top of white breccia boulder " $B$ " shown in fig. 68. Scale determined by comparing television image of LMP's helmet with larger loose rock immediately above sample. Note dark clasts, one sampled (67475) from another part of same boulder (see fig. 73). See chap. D2, fig. 25A, for stereopair of presampling photographs of 67455 . 


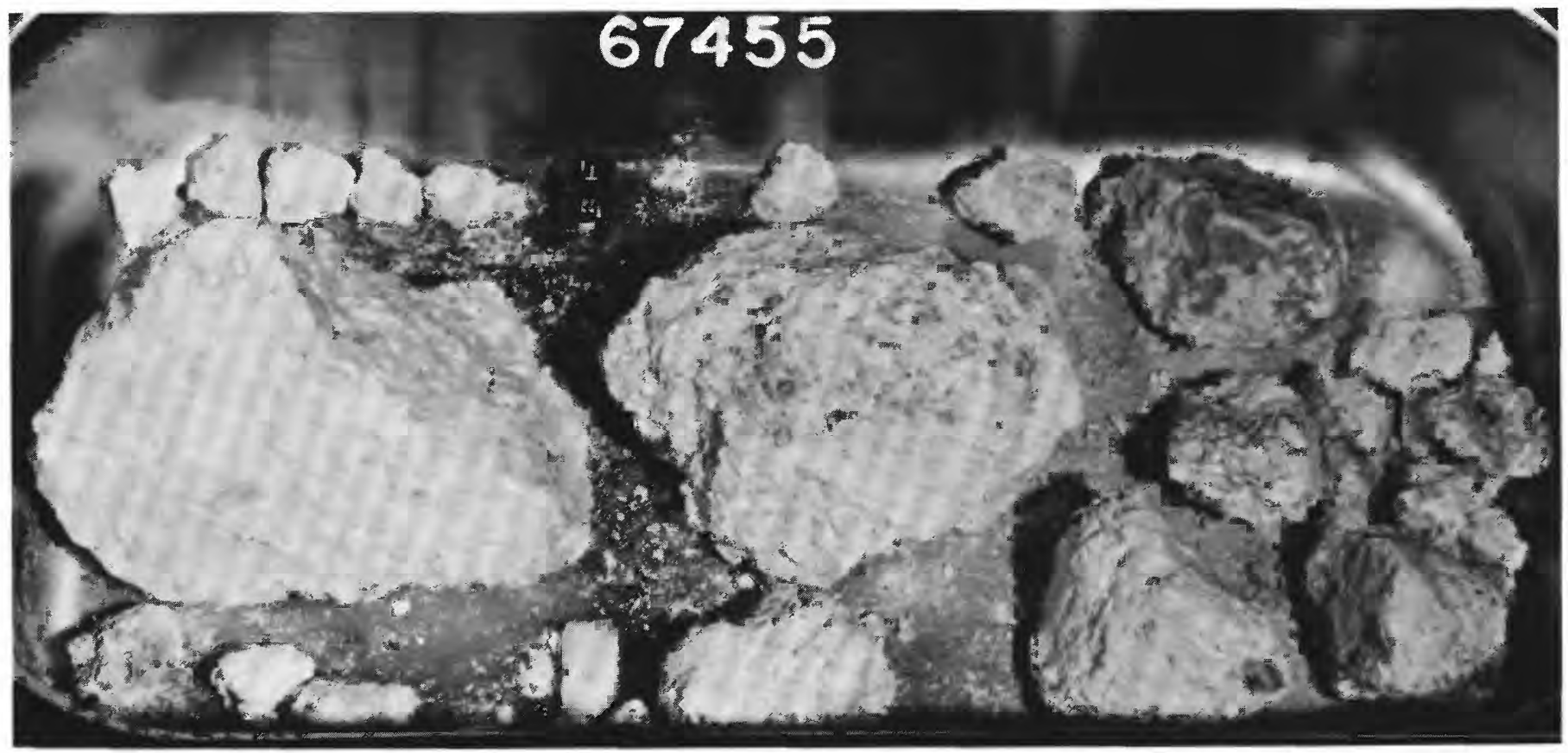

FigURE $71 B$. - Sample 67455 , a fragile $\mathrm{B}_{2}$ breccia, shown broken in a laboratory pan (photograph S-72-38192). Lettered cube is $0.95 \mathrm{~cm}$ on a side. See chap. D2, figs. $24,25 B$, and $28 B$, for another photographic view and two photomicrographs respectively.

SAMPLE: 67455

Station: 11

Landmark: White breccia boulder "B" (see figures 58 and 68); approximately $\overline{70 \mathrm{mWSW}}$ from $L R V$.

Rock type: Breccia, white matrix, dark clasts, B2.

SURFACE CHARACTERISTICS OF SAMPLE AREA

Slopes: Slopes are down in all directions from this local high

point, due partly to fillet around the boulder.

Fragment population

Size range and distribution: $6-8 \mathrm{~m}$ boulder " $B$ " is largest in

local area; smaller loose rocks (about $30 \mathrm{~cm}$ ) present on top of boulder.

Color: Light gray.

Shapes: Subrounded to subangular.

Fillets: steep fillet at base of boulder.

Apparent burial: Partial burial of larger white boulders.

Samples not buried.

Dust cover: None visible; none reported.

Fines

Color: Light to medium gray.

Compaction: Soft. Bootprints are several centimeters deep. Craters

Size range and distribution: None visible.

SAMPLE CHARACTERISTICS

Size: Broken during transportation; originally $10 \mathrm{~cm}$ diameter

(estimated); 942.2 grams total weight.

Color: White to grayish white.

Shape: Subrounded, friable.

Dust cover: Fines occur under rounded edges of sampled fragments.

Comparison with other fragments in area: Typical of larger loose

fragments on top and of the boulder as a whole.

Probable origin: Broken, but nearly in place on larger boulder

which is probable ejecta from the deeper levels of North Ray crater. COMMENTS: This sample represents the largest boulder of the white matrix type from which samples were collected. 

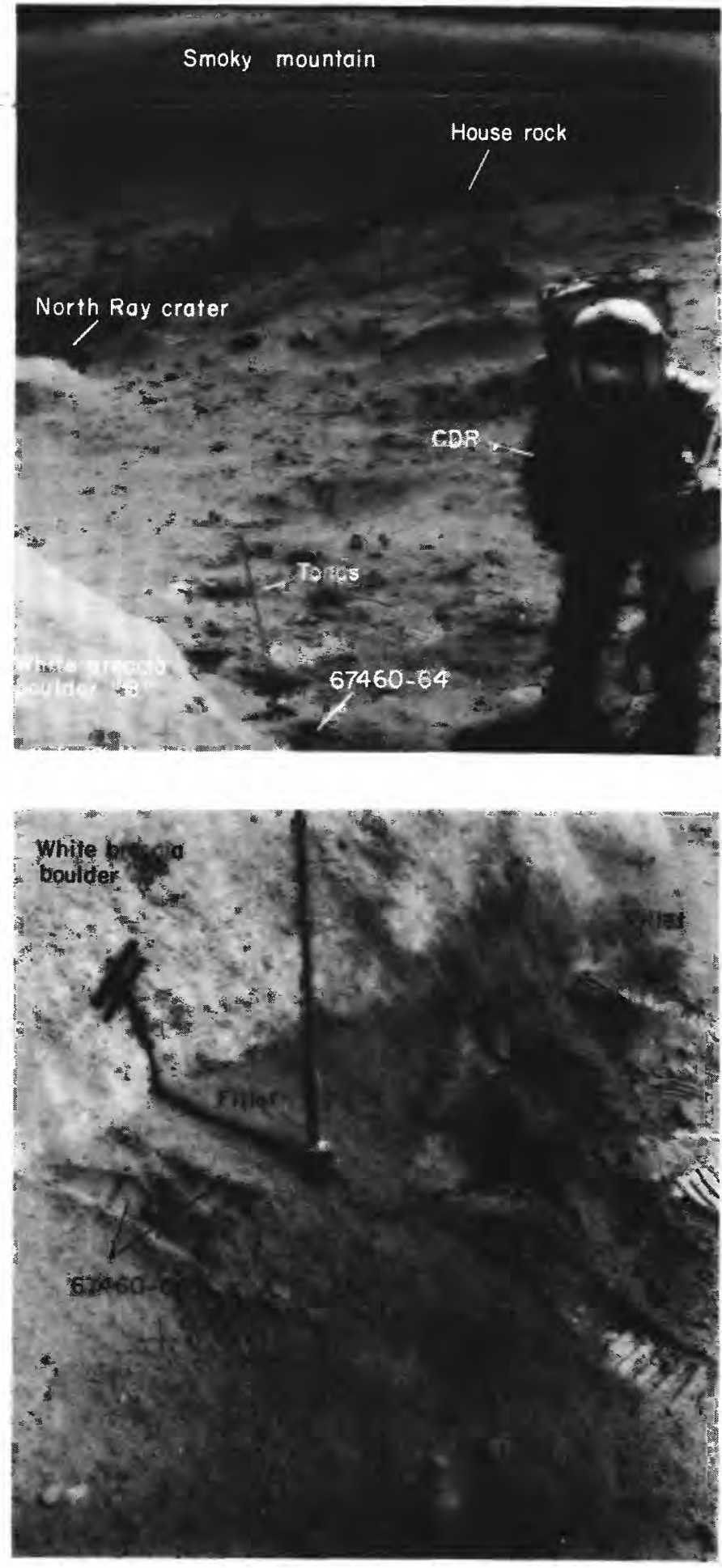

TFigure 72A.-Location of soil sample 67460-64 shown after sampling in photograph AS16-106-17336, looking northeast along rim of North Ray crater. Sample collected from banked fillet beside white breccia boulder " $B$ " (identified in fig. 68 ).

Figure 72B.-Close-up view of fillet which sample 67460-64 was collected, shown after sampling in photograph AS16-106-17335 looking northwest. Note softness of soil near boulder as indicated by depth of footprints to right of tongs. 
SAMPLE : 67460-64

Station: 11

Landmark: Adjacent to large white breccia boulder (" $B$ ") approximately

$70 \mathrm{mWSW}$ from LRV; SE rim of North Ray crater.

Rock type: Soil, from fillet.

SURFACE CHARACTERISTICS OF SAMPLE AREA

Slopes: Down in all directions from this local high point.

Fragment population

Size range and distribution: $2 \mathrm{~cm}$ to 0.5 fragments are

sparse; < cm-size fragments are abundant.

Color: Light gray to white.

Shapes: Subrounded to subangular.

Fillets: Steep fillets on larger white boulders.

Apparent burial: Partial burial of larger white boulders.

Dust cover: Finer debris has settled on shallow sloping

surfaces of large boulder.

Fines

Color: Light to medium gray.

Compaction: Soft; bootprints are several centimeters deep.

Craters

Size range and distribution: A few shallow depressions to the

east.

Shape: Irregular, subdued; may not be craters.

Ejecta: None observed.

SAMPLE CHARACTERISTICS

Size: Color: Light gray.

< $1 \mathrm{~cm}$ fines; 370.24 grams total weight.

Fillet: Well developed, with steep, sharp contact at base of boulder. Comparison with other soil in area: Similar in color and texture to adjacent soil.

Probable origin: Derived from disintegrating white matrix breccias in this area.

COMMENTS: Sample should contain some resistant dark gray clasts, if representative of the breccias.

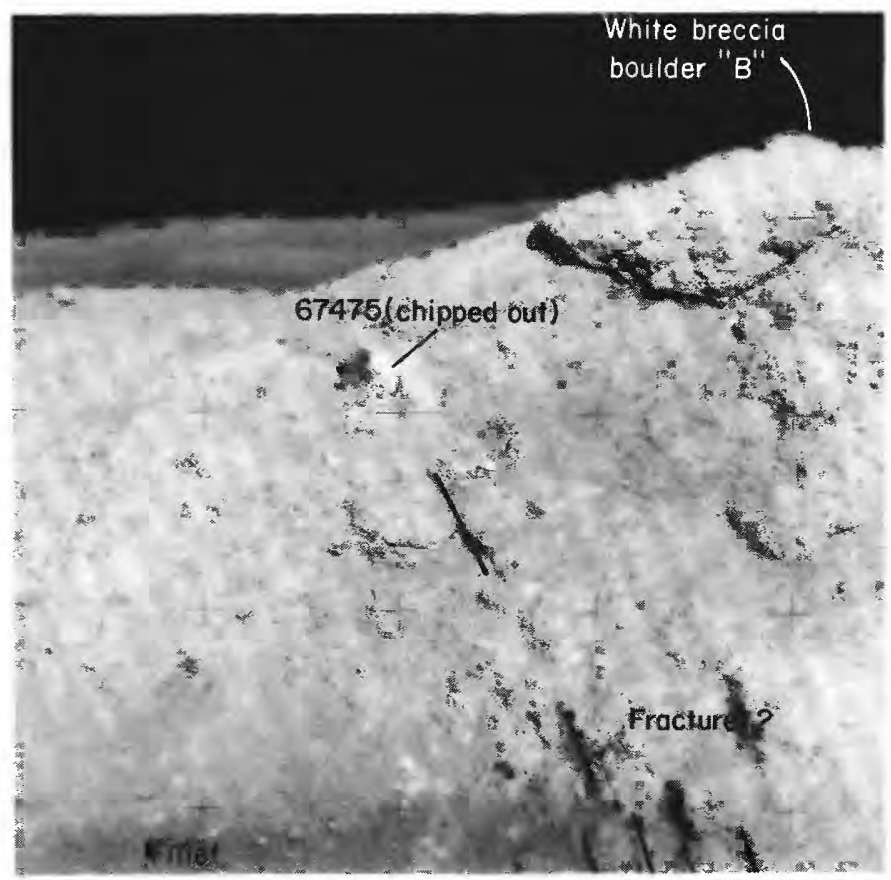

Figure 73A.- Sample 67475 broken from dark clast in large white breccia boulder "B" (see fig. 68) west of LRV. Scar can be seen where the chip was removed, in photograph AS16-106-17337 taken after sampling looking northwest. Note alinement of elongate shadows that suggest the presence of incipient fractures or foliation within the boulder. 


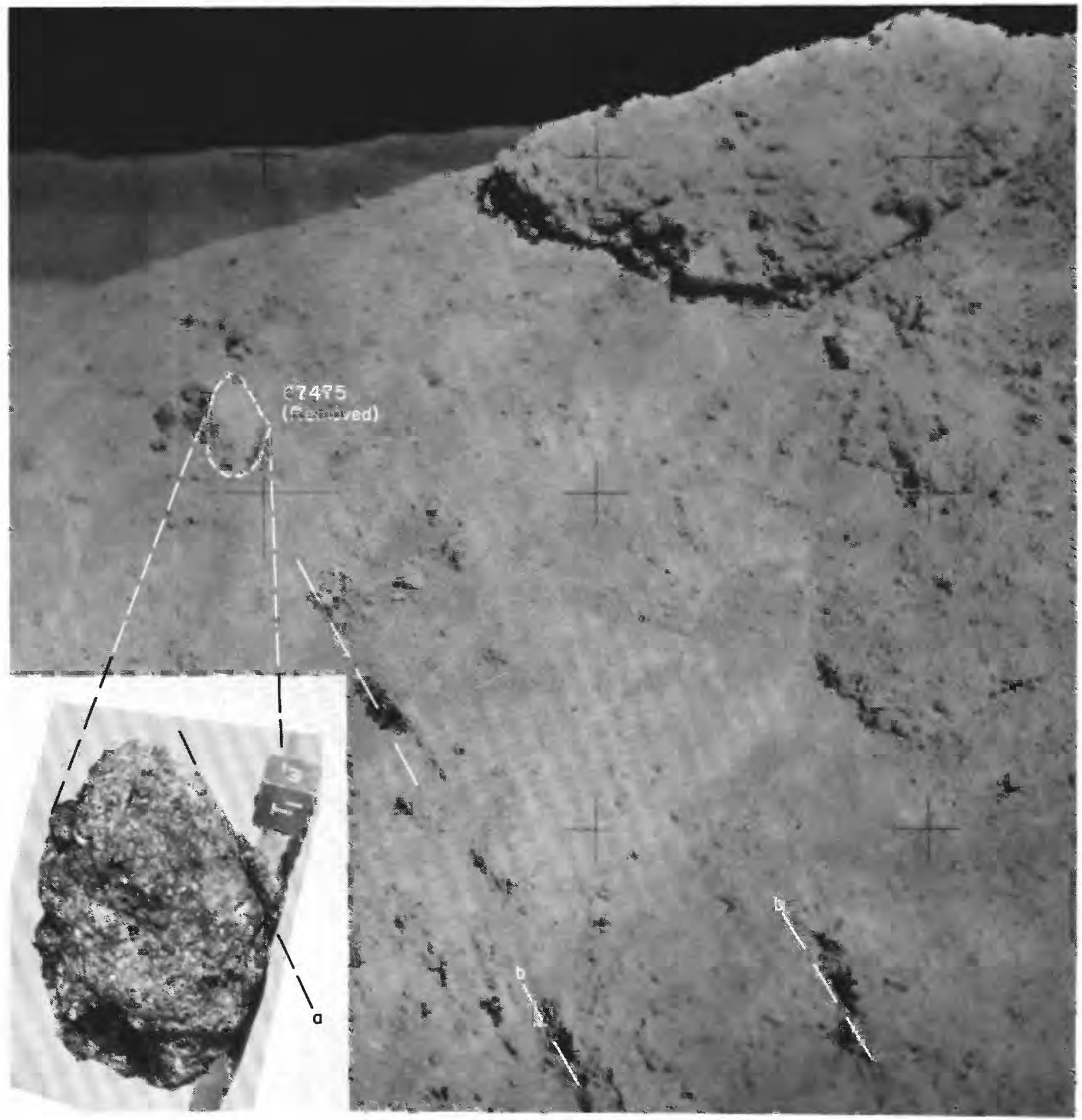

FIGURE 73B.- Sample 67475 showing approximate lunar orientation reconstructed by matching characteristics of scar left on boulder, shown after sampling in enlarged part of photograph AS16-106-17337, with stereophotographs of sample taken in LRL (inset photo, S-72-43245B). No lunar-surface photograph was taken before sampling. In orientation shown, fracture $a$ on exposed surface of sample is parallel to incipient fractures or foliation mapped $b$ in boulder. 


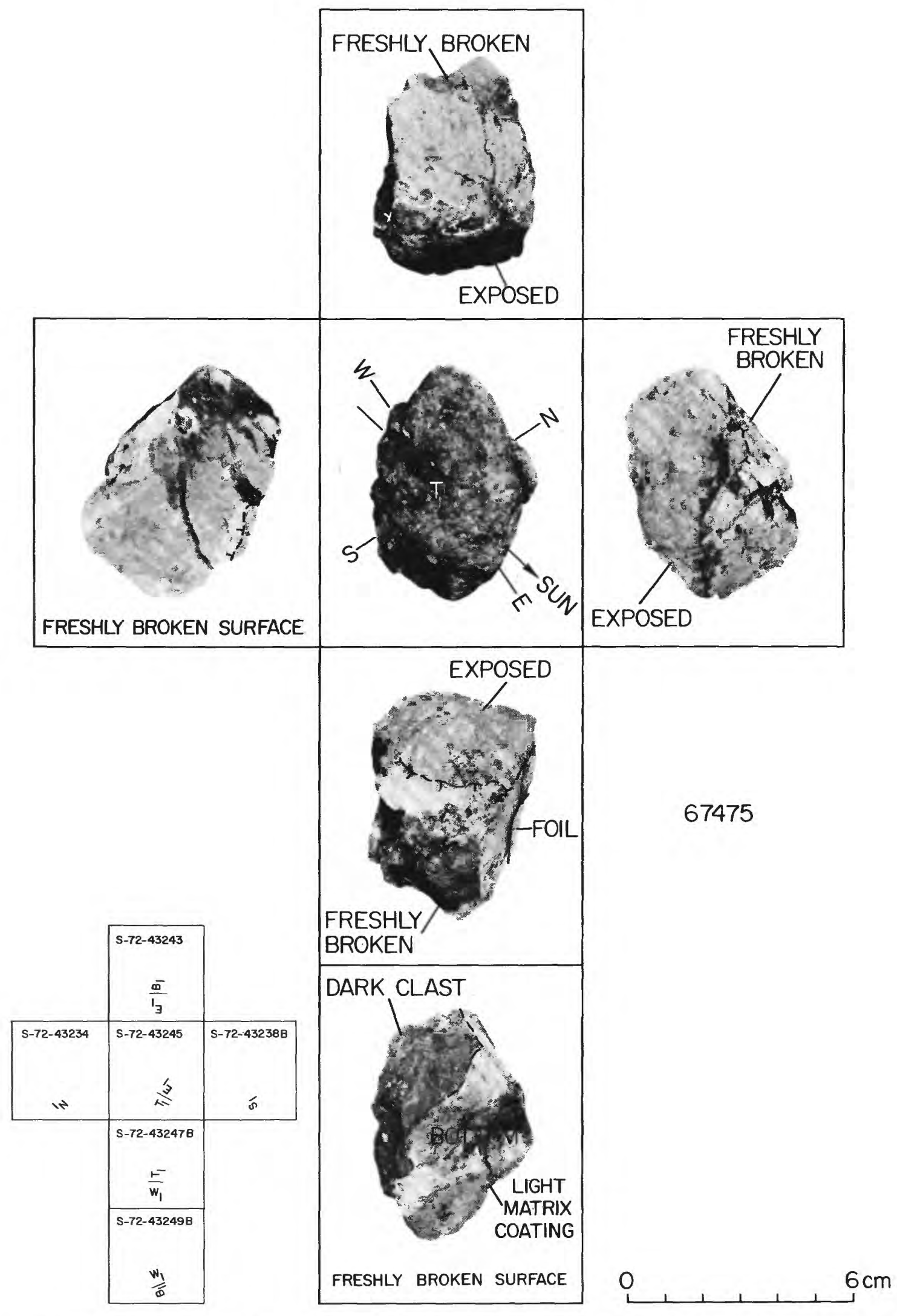

Figure 73C.-Orthogonal views of sample 67475 related to its lunar orientation at time of sampling. See chap. D2, figs. $26 A-C$ for $T_{1}, N_{1}$, and $S_{1}$ photographic views (respectively) of this type $B_{4}(F)$ rock. 
SAMPLE: 67475

Station: 11

Landmark: White breccia boulder " $B$ " (see figure 68); approximately $70 \mathrm{mWSW}$ from LRV.

Rock type: Aphanitic, black clast from white breccia boulder, B4(F). SURFACE CHARACTERISTICS OF SAMPLE AREA

Slopes: Down in all directions from this local high point, due partly to fillet around the boulder.

Fragment population

Size range and distribution: $6-8 \mathrm{~m}$ boulder " $B$ " is largest in local area; smaller loose rocks present on top of boulder and scattered on surrounding surface.

Color: Light gray to white.

Shapes: Subrounded to subangular.

Fillets: Steep fillet at base of boulder.

Apparent burial: Partial burial of larger white boulders.

Dust cover: Finer debris has settled on shallow sloping surfaces of large boulder.

Fines

Color: Light to medium gray on surrounding surface.

Compaction: Soft in fillet beside boulder; bootprints are

Craters several centimeters deep.

Size range and distribution: Abundant "zap pits" on boulder surface.

SAMPLE CHARACTERISTICS

Size: $6 \times 6 \times 4.5 \mathrm{~cm}$; 175.1 grams.

Color: Dark gray with partial white coating.

Shape: Exposed surface rounded; freshly broken faces angular. Comparison with other fragments in area: Unusual; collected to represent dark clasts within white breccia boulder. Probable origin: North Ray crater ejecta. 


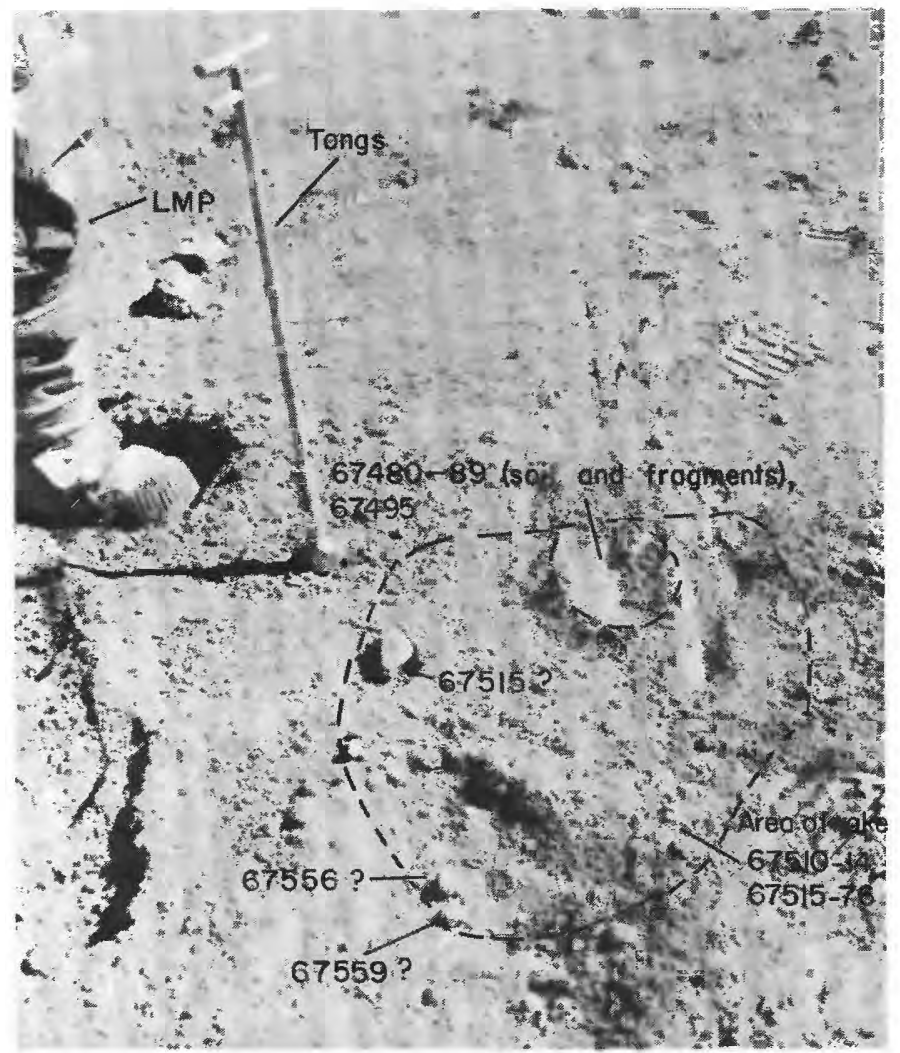

Figure $74 A$.-Area of samples $67480-89,67495$ (soil with fragments), and 67510-14, 67515-76 (rake fragments with incidental soil) shown in photograph AS16-116-18639, taken after collecting soil sample and before raking, looking north. Rake fragments 67515,67556 , and 67559 are tentatively identified.

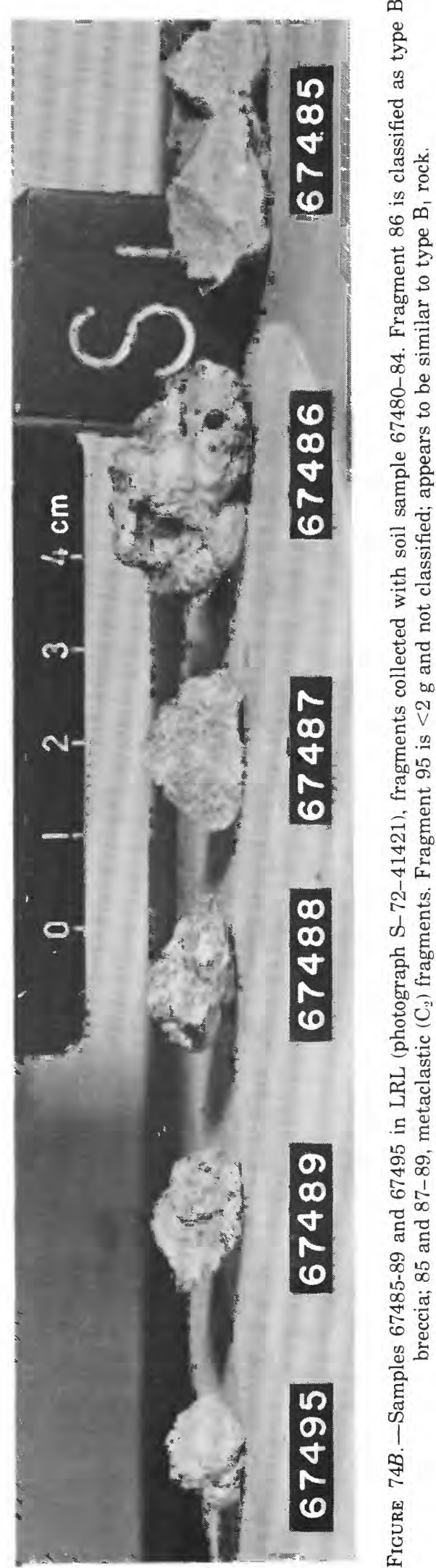




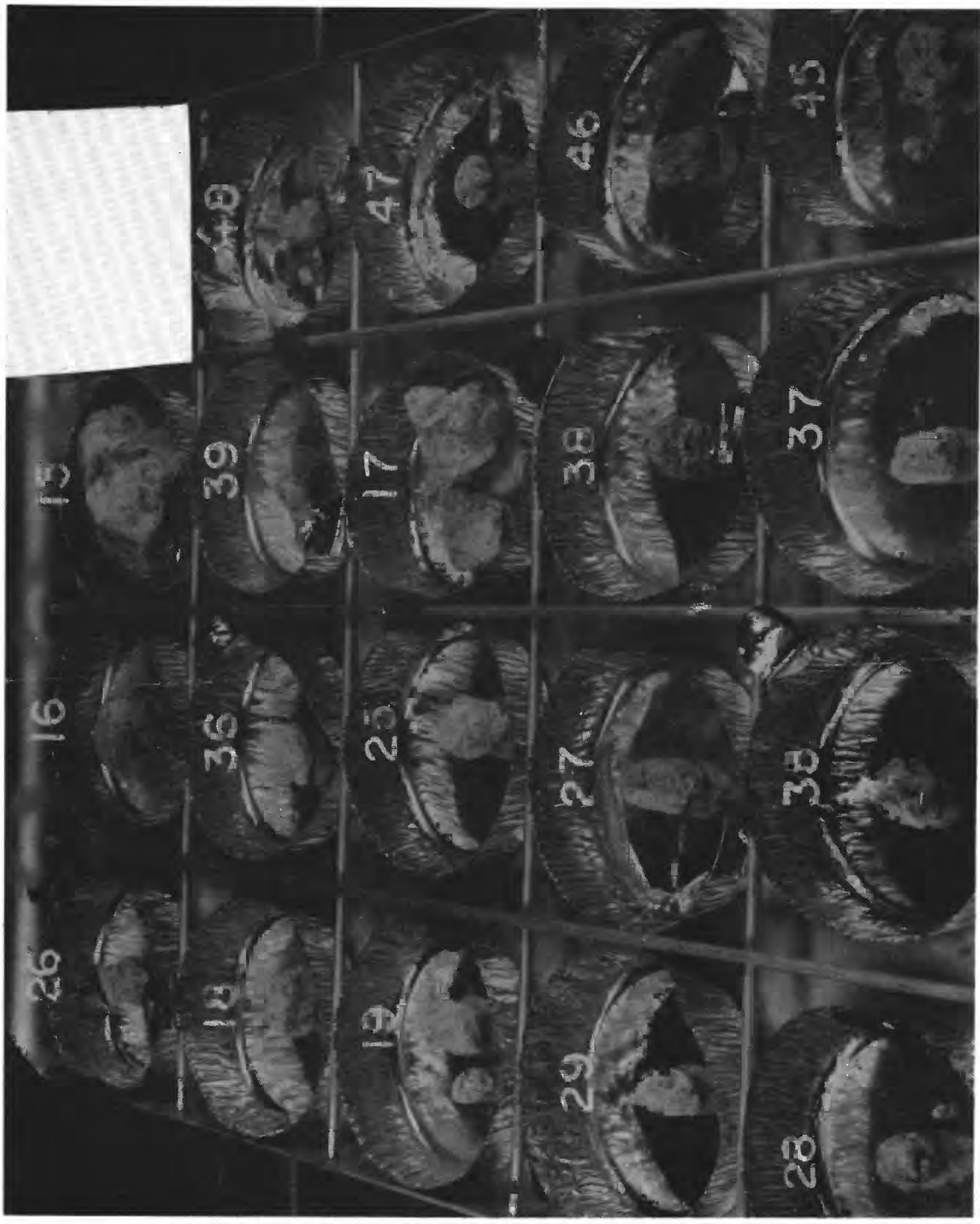




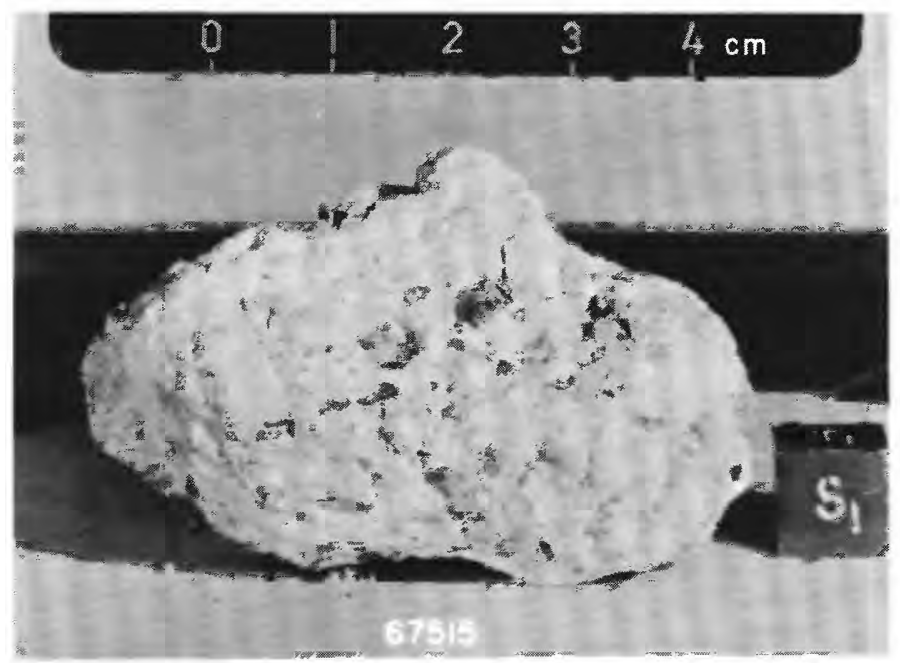

Figure $74 D$.-Rake fragment 67515 in LRL (photograph S$72-43481) . B_{2}$ breccia.

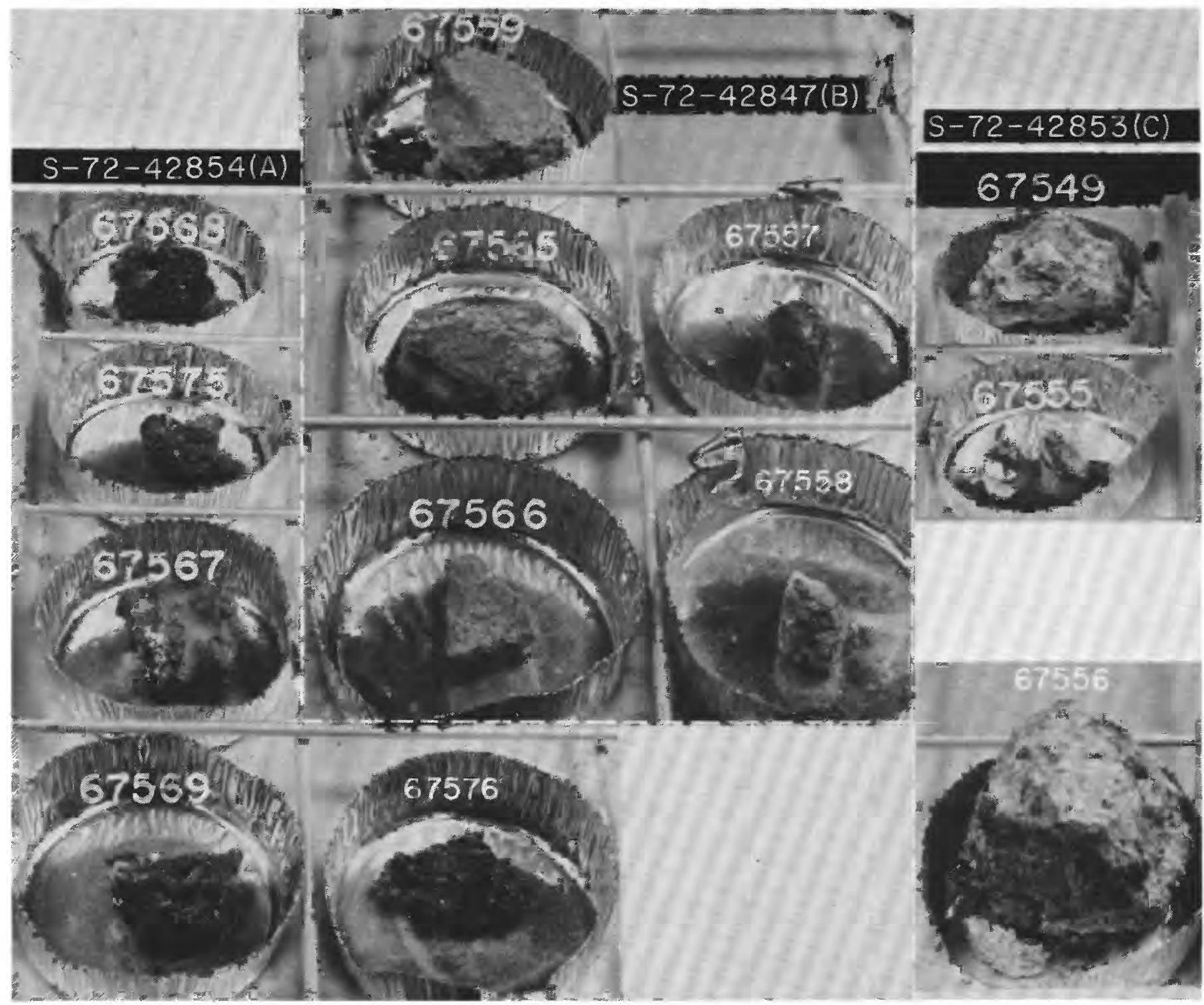

Figure $74 E$._-Part of rake sample $67515-76$ in LRL. This group includes fragments $67549,67555-59,67565-69$, and $67575-76$, in a composite illustration made from three LRL photographs (A, B, C), as indicated. Fragments 67549,55 , and 56 classified as $\mathrm{B}_{2}$ breccia; 57 and 58 unclassified (U); 59, 65, and 66 metaclastic $\left(\mathrm{C}_{2}\right)$ fragments; and 67-76 glassy $(\mathrm{G})$ fragments. 


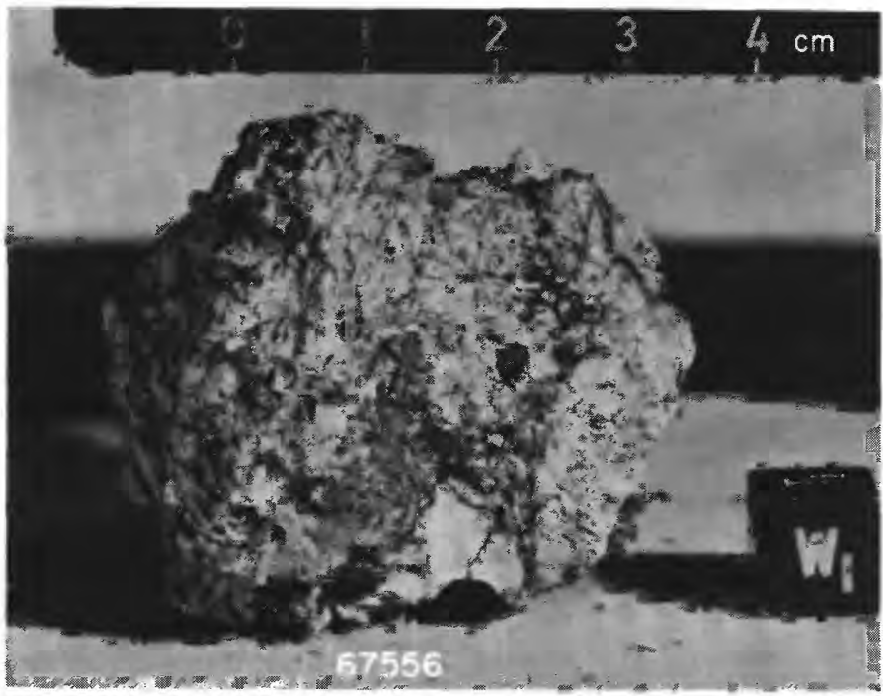

4Figure 74F.-Rake fragment 67556 in LRL (photograph S72-43437). $B_{2}$ breccia.

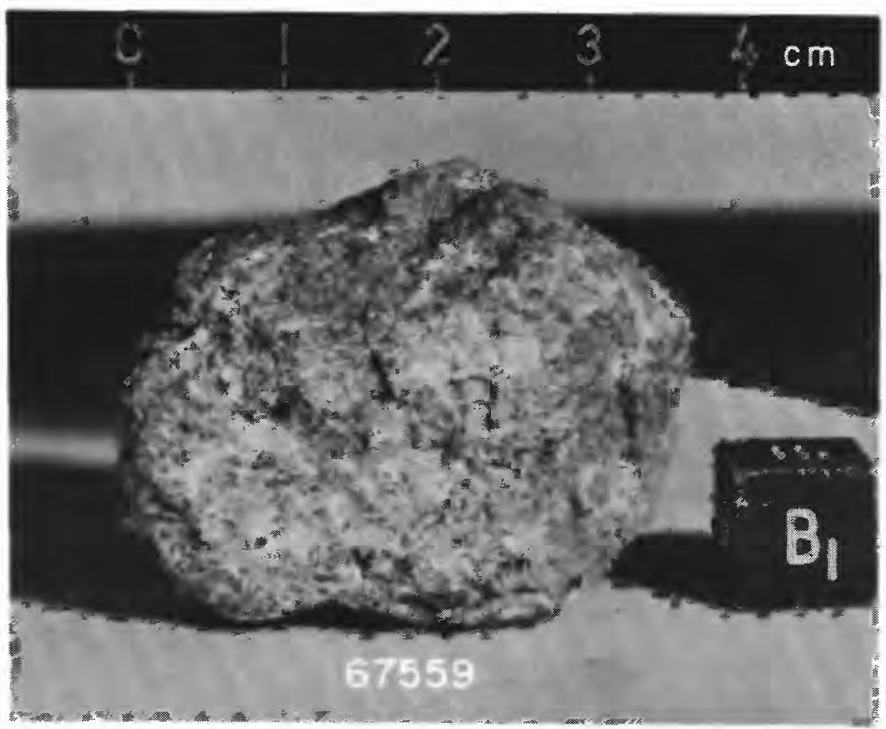

Figure 74G.-Rake fragment 67559 in LRL (photograph S72-43434). Metaclastic $\left(\mathrm{C}_{2}\right)$ rock. 
SAMPLE: $67480-84,85-89,95 ; 67510-14,15-19,25-29,35-39,45-49$, 55-59, 65-69, 75-76 (rake samples)

Station: 11

Landmark: Approximately $60 \mathrm{~m}$ WSW from $L R V$, between white breccia

boulders " $A$ " and " $B$ " (see figures 58 and 68).

Rock type: 67480-95, soil with 6 incidental fragments; 67510-76,

32 rake fragments with incidental soil. Most fragments are of types

$B 2(B I)$ and $C 2$. See figures $74 B-G$ for classifications of specific fragments.

SURFACE CHARACTERISTICS OF SAMPLE AREA

Slopes: Nearly level.

Fragment population

Size range and distribution: Greater than $10 \mathrm{~cm}$ sparse;

2-10 cm common; less than $2 \mathrm{~cm}$ abundant.

Color: Light gray.

Shapes: Subrounded; larger blocks are subangular

Fillets: None visible.

Apparent burial: Some partially buried; most of area too disturbed to tell.

Dust cover: Area largely disturbed; dust cover not visible.

Fines

Color: Light gray.

Compaction: Soft; crew reported "sinking in on the slopes about 6 inches."

Craters: None observed.

SAMPLE CHARACTERISTICS FOR 67480-84 (soil), 85-89, 95 (incidental fragments. see figure 74B).

Size: $\quad<1 \mathrm{~cm}$ fines, 248.79 grams; 6 fragments $\quad>1 \mathrm{~cm} ; 20.65$ grams

total weight.

Color: Light gray.

Comparison with other soil in area: Typical of local soil.

Probable origin: Derived from underlying North Ray crater ejecta, probably white matrix breccia; fragments of $C 2$ type may represent clasts from breccia.

COMMENTS: Soil sample was collected prior to rake; normal procedure was the reverse.

SAMPLE CHARACTERISTICS FOR 67510-14 (soil), 67515-76 (32 rake fragments).

Size: $\quad<1 \mathrm{~cm}$ fines, 133.6 grams; 32 fragments $>1 \mathrm{~cm}, 333.8$ grams total weight.

Color: Light gray.

Shape: Variable, from rounded to angular.

Comparison with other fragments in area: Typical of local fragments

in area.

Probable origin: Derived from underlying North Ray crater ejecta; probably includes white matrix breccias and individual resistant clasts. 


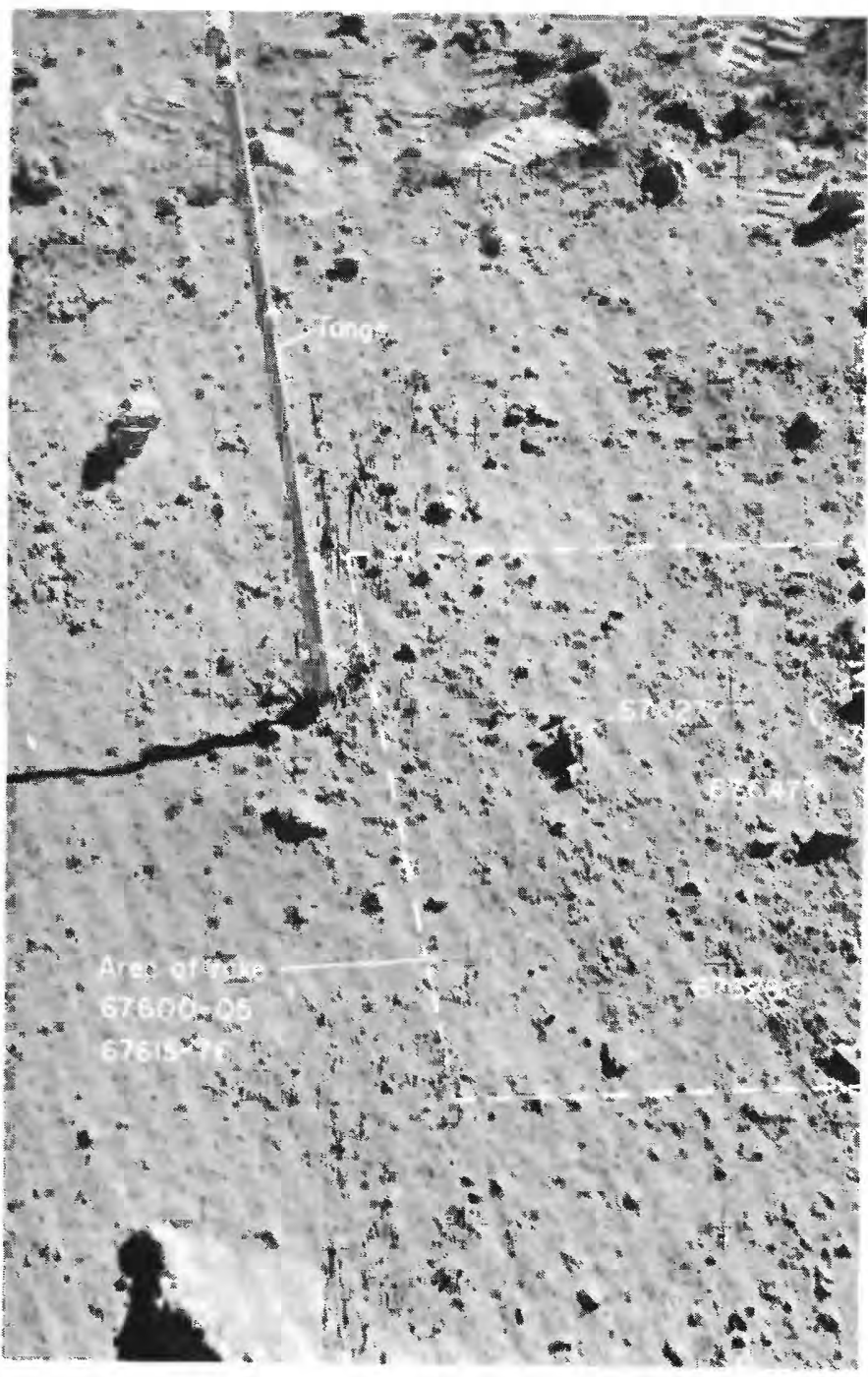

Figure 75A.-Area of samples 67600-05 (rake soil with a fragment) and 67615-76 (rake fragments) shown before sampling in part of photograph AS16-116-18642. View is northeast. Rake fragments 67627,67628 , and 67647 tentatively identified.

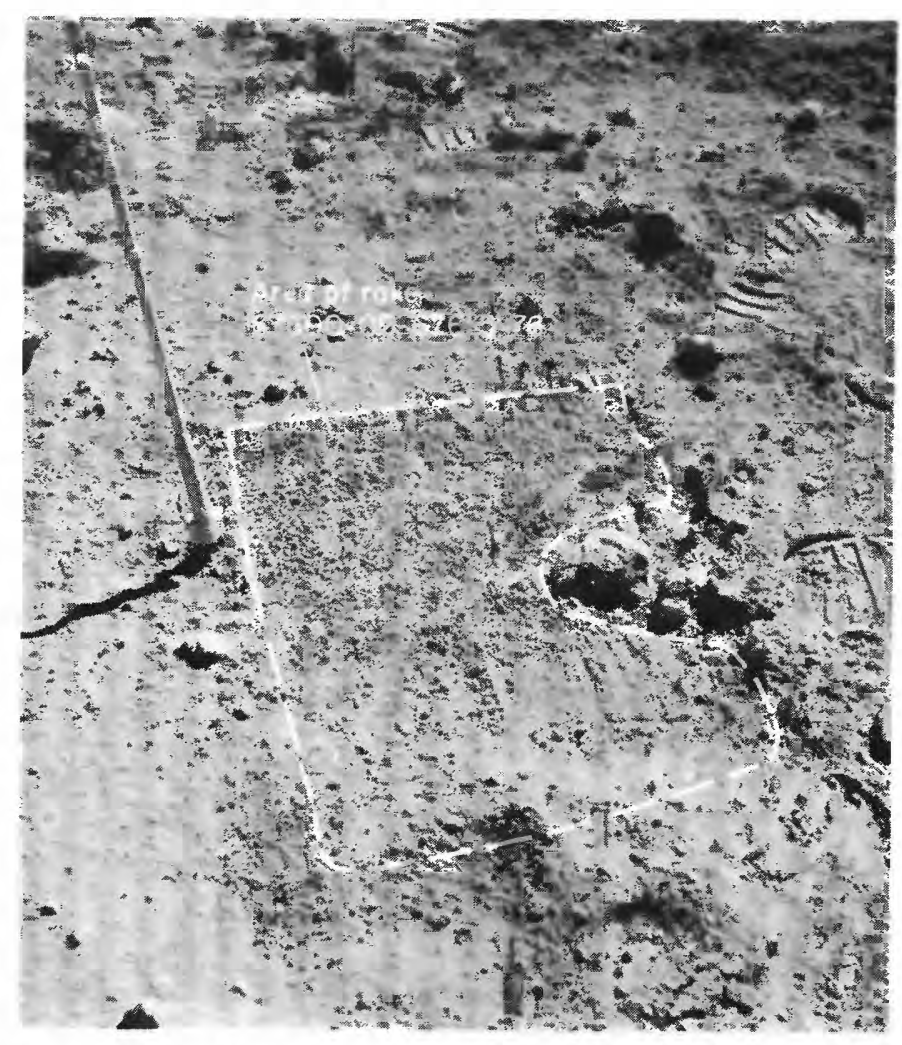

Figure 75B.- Area of samples $67600-05$ and $67615-76$ shown after raking in photograph AS16-116-18643; view is northeast.

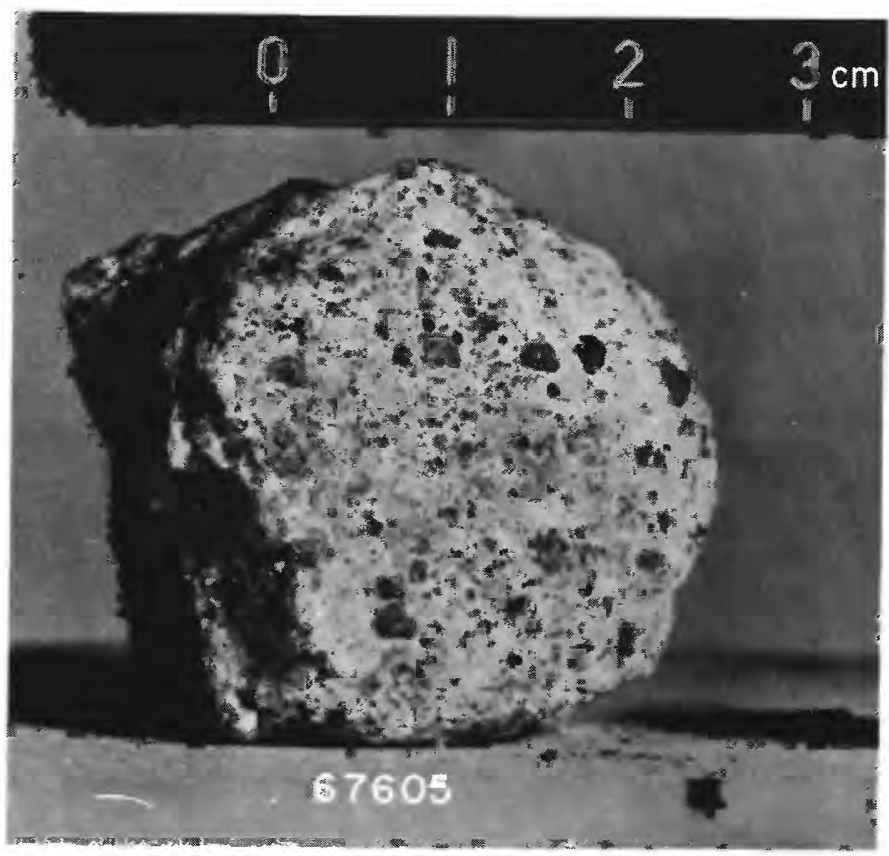

Figure 75C.-Sample 67605 in LRL (photograph S-72-41581, $\mathrm{S}_{1}$ view), 44.5-g fragment of $B_{2}$ breccia collected incidentally with soil sample 67600-04. 


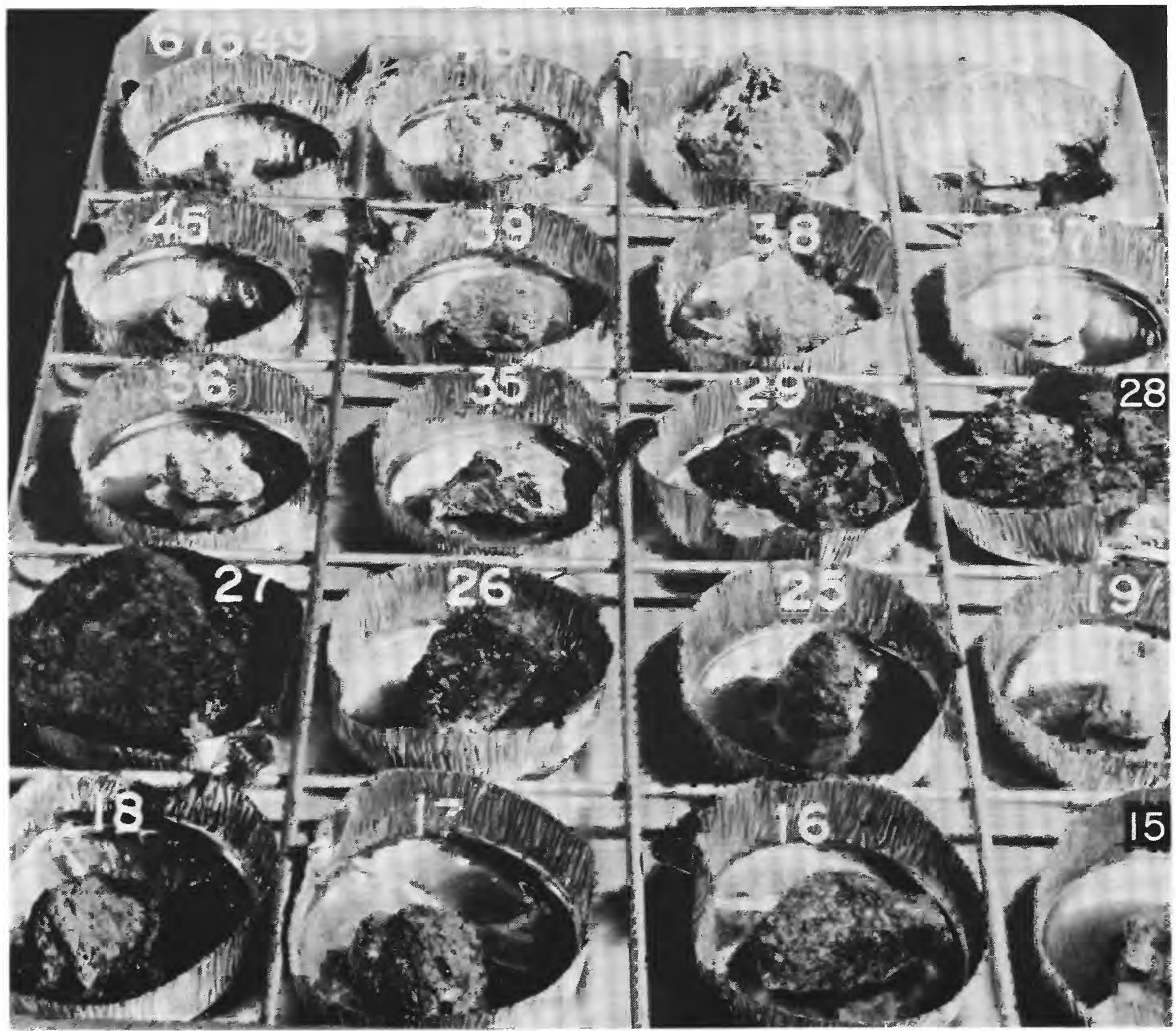

FIgURE 75D.-Part of rake sample 67615-76 in LRL (photograph S-72-43201). This group includes fragments 67615-19, 67625-29, 67635-39, and 67645-49. Fragments 15-25 classified as $C_{2} ; 26-29$ glassy (G); 35-37 $\mathrm{B}_{1}$ breccia; and 38-49 type $\mathrm{B}_{2}$ breccia except for fragments 47 (unclassified) and 45 and $49(<2 \mathrm{~g})$. 


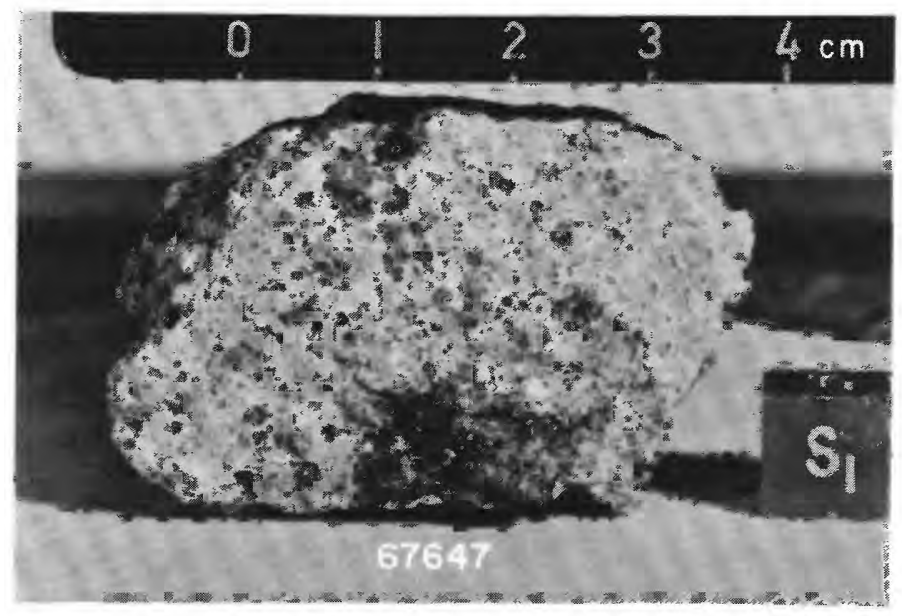

Figure 75E.-Rake fragment 67647 in LRL (photograph S72-43440). This sample is unclassified (U) by Wilshire and others (this volume); looks like $\mathrm{B}_{2}$ breccia sample 67605 (see fig. $75 \mathrm{C}$ ).
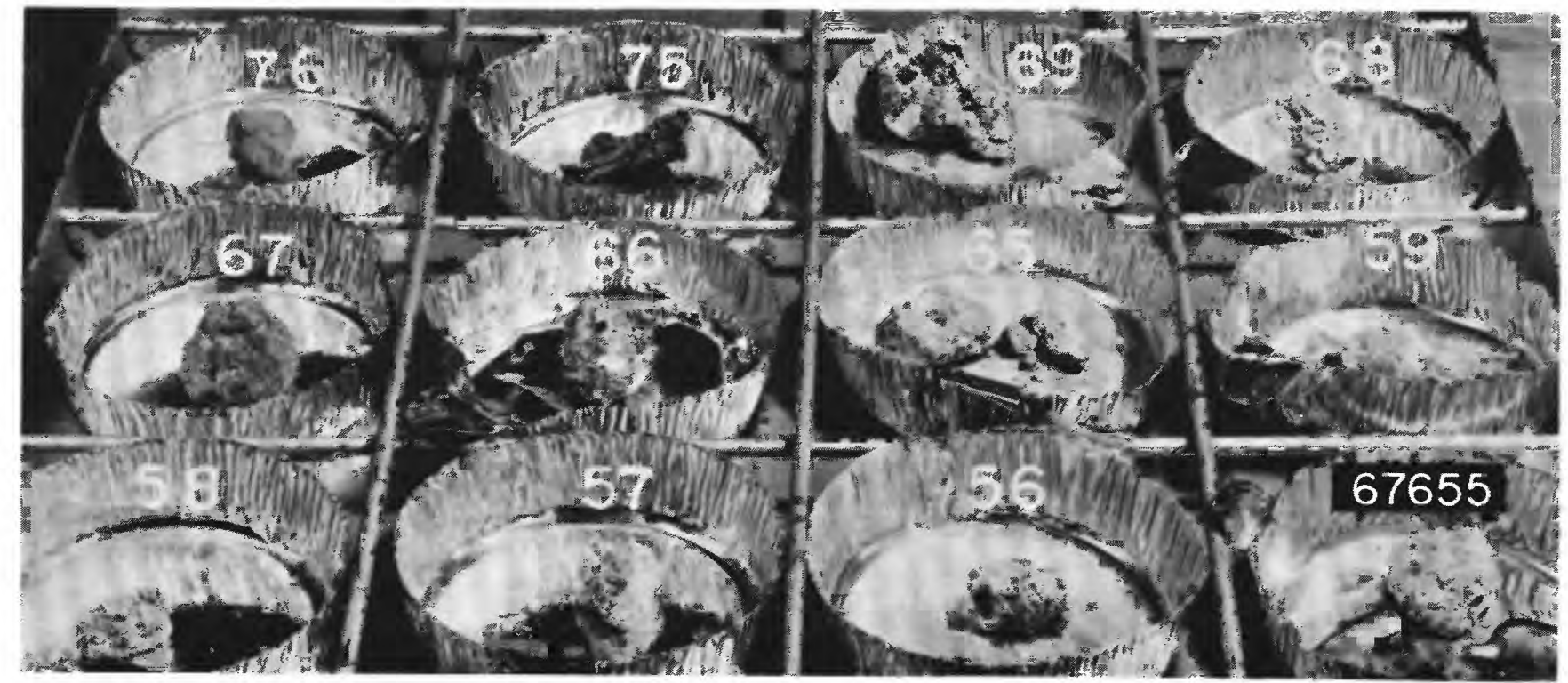

Figure 75F.-Part of rake sample 67615-76 in LRL (photograph S-72-43723). This group includes fragments 67655-59, 67665-69, and $67675-76$. Fragments 55 and 66 classified as $\mathrm{B}_{2}$ breccia; 65 and $69 \mathrm{~B}_{3}$ breccia; 67,68 , and 76 metaclastic $\left(\mathrm{C}_{2}\right)$; and fragments $56-59$ and 75 unclassified $(<2 \mathrm{~g})$. 
SAMPLE: 67600-04, 05; 67615-19, 25-29, 35-39, 45-49, 55-59, 65-69, 75-76

(rake samples)

Station: 11

Landmark: $20 \mathrm{~m}$ west of $L R V$, in area of white breccia boulders; SE rim of North Ray crater.

Rock type: 67600-05, soil with 1 incidental fragment; 67615-76, 32

rake fragments, mostly of types $C 2$ and $B 2$ (see figures $75 D-F$ for

classifications of specific fragments)

SURFACE CHARACTERISTICS OF SAMPLE AREA

Slopes: Nearly level.

Fragment population

Size range and distribution: 10-50 cm rocks are sparse in

area of photos; 2-10 cm common; <2 cm abundant.

Color: Light gray and mottled; a few are white.

Shapes: Subangular to subrounded.

Fillets: Few steep fillets on rounded 5-10- $\mathrm{cm}$ rocks.

Apparent burial: Partial on rounded $20-30 \mathrm{~cm}$ rock to north.

Fines Dust cover: Not apparent.

Color: Light gray.

Compaction: Moderately firm; bootprints about $1 \mathrm{~cm}$ deep. Craters: None visible.

SAMPLE CHARACTERISTICS FOR 67600-04 (soil), 67605 (incidental fragment, B2)

Size: $\quad<1 \mathrm{~cm}$ fines, 186.2 grams; $3.5 \times 3 \times 3,44.52$ gram (see figure)

75 C).

Color: Light gray, very light gray.

Comparison with other soil in area: Typical of local soil and fragments. Probable origin: Derived from North Ray crater ejecta, and probably similar to nearby white-matrix breccia boulders.

SAMPLE CHARACTERISTICS FOR 67615-76 (32 rake fragments, see figures 75D, 75F)

Size: 1-5 cm fragments; 390.51 grams total weight.

Color: Light gray.

Shape: Fragments at surface mostly subangular.

Comparison with other fragments in area: Appear typical of rock population.

Probable origin: Derived from underlying North Ray crater ejecta. 


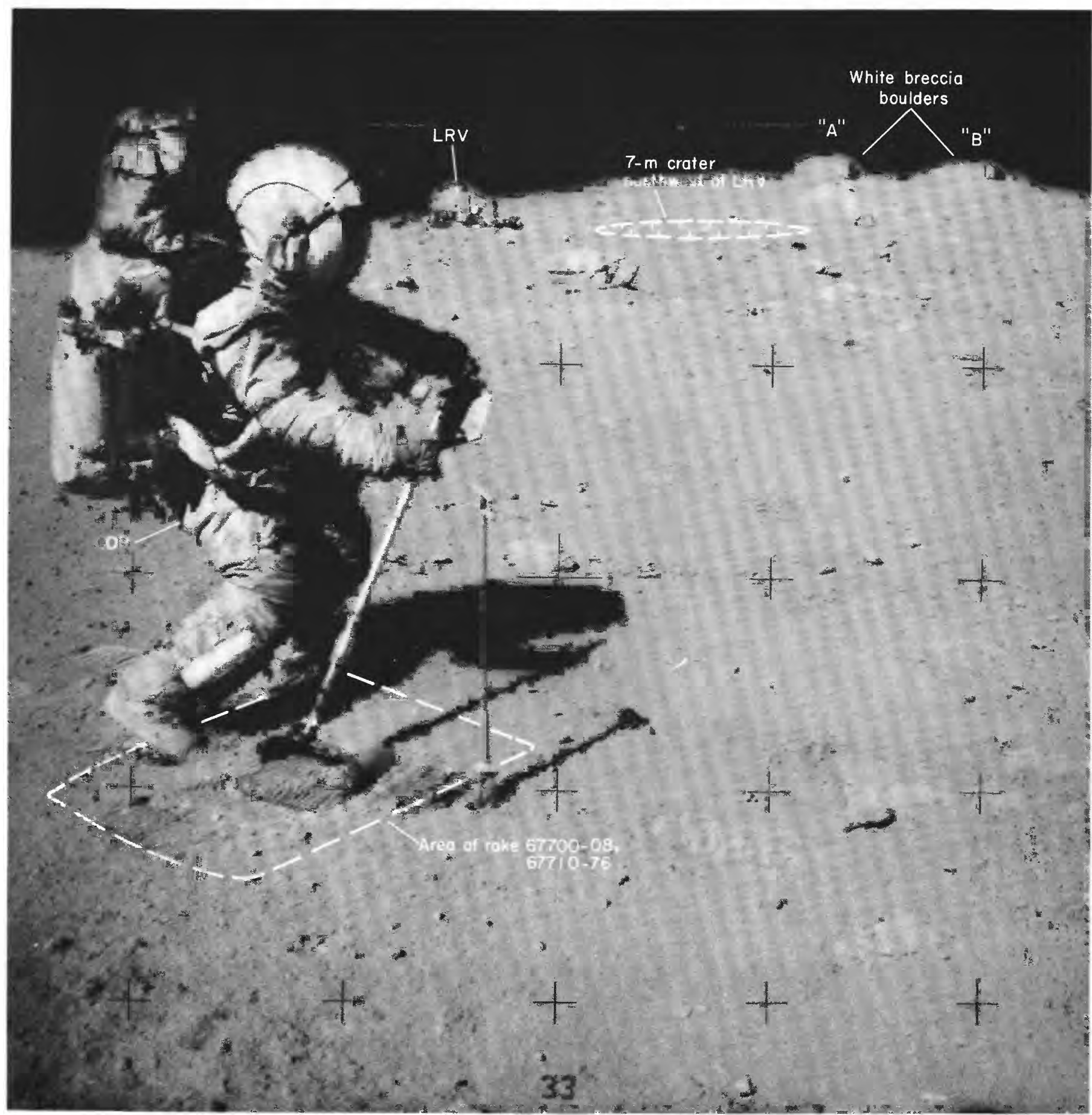

FigUre 76A.-Location of rake samples 67700-08 (soil and fragments), and 67710-76 (primarily fragments, with some soil), shown during raking in photograph AS16-106-17340. View is southwest toward the Rover 45-50 m away. 


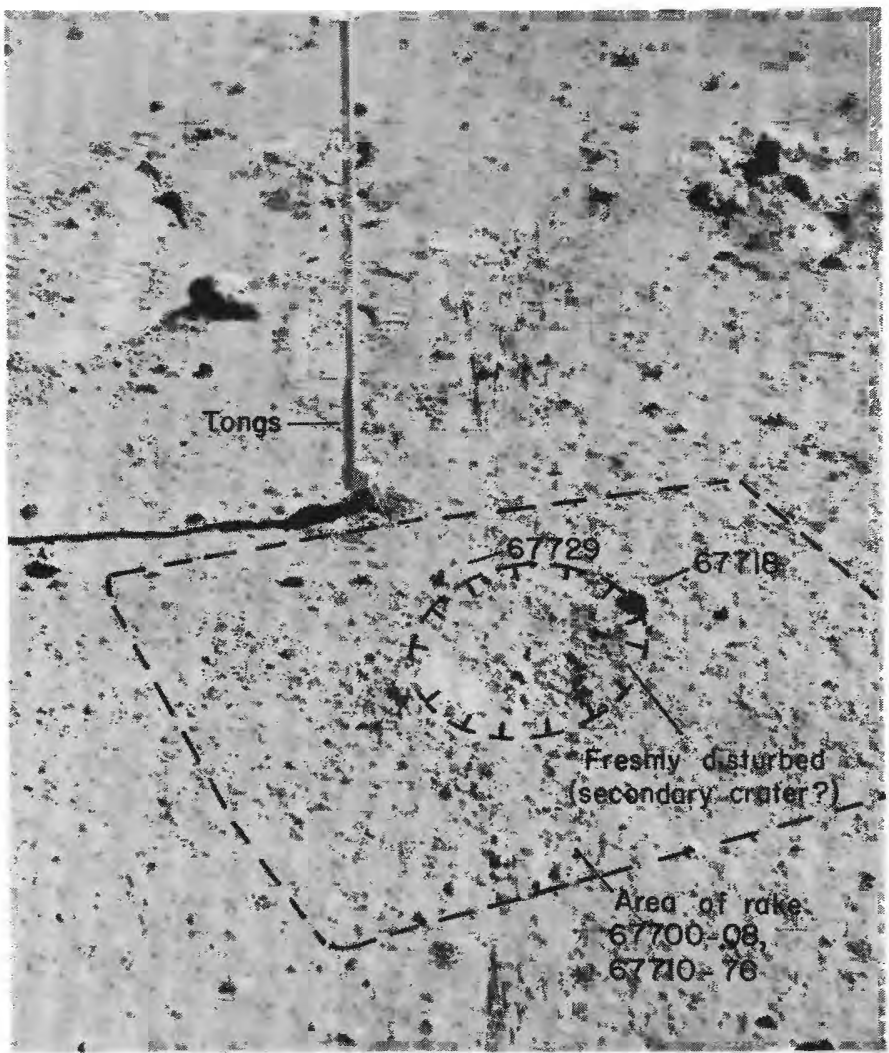

Figure 76B.-A Area of rake samples $67700-08$ and 67710-76 shown before sampling in photograph AS16-116-18645; view is north. Rake fragments 67718 and 67729 identified. Fresh-looking $30-\mathrm{cm}$ crater within rake area may be a very young secondary or point of impact of material kicked by one of the astronauts.

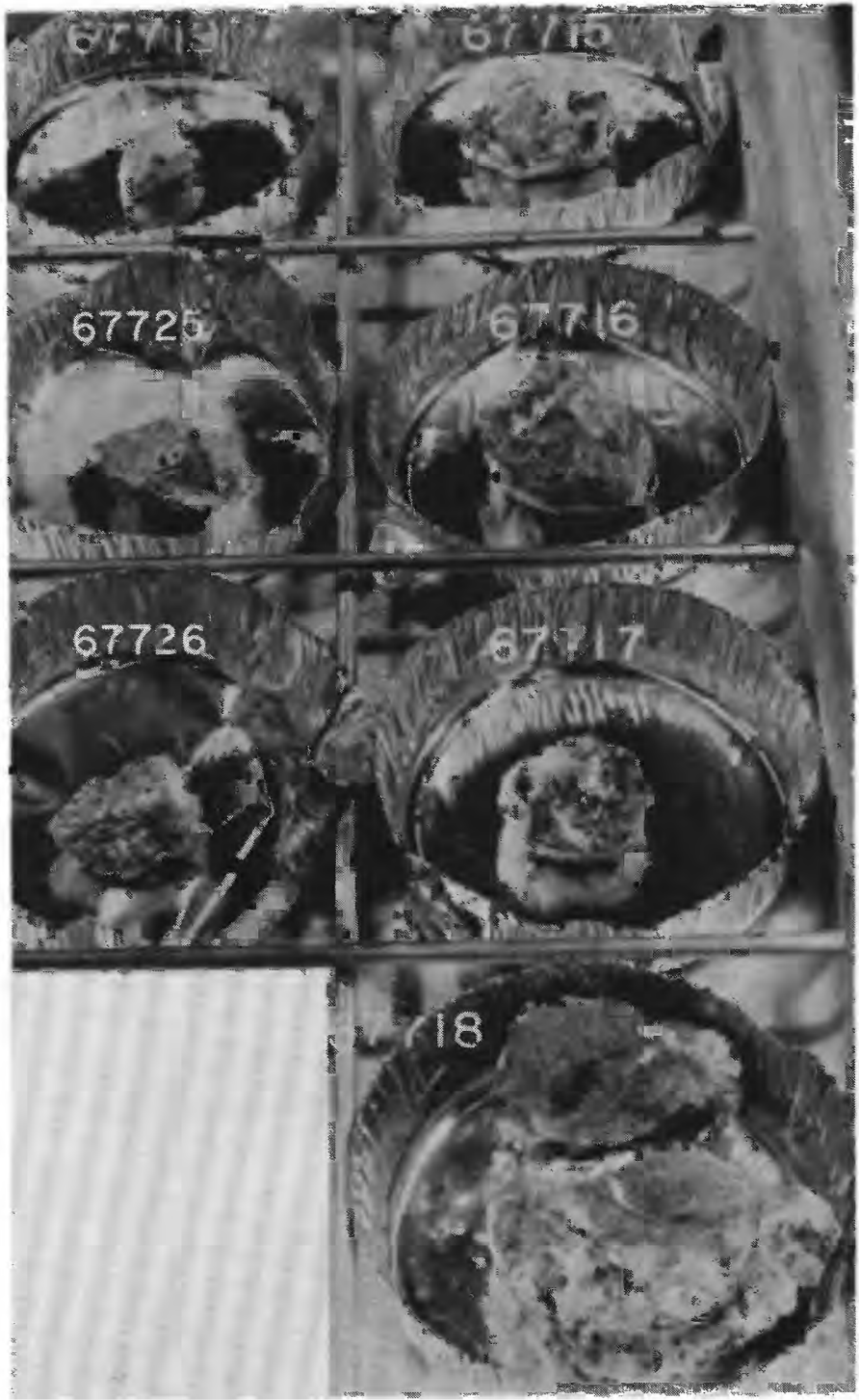

Figure 76C.-Part of rake sample 67710-76 in LRL (photograph S-72-43215). This group includes fragments 67715-19, and $67725-26$, all classified as $B_{4}$ breccia except fragment 18 , a $B_{3}$ breccia. Compare fragment 18 with same rock, identified on the presampling lunar-surface photograph, fig. 76B. Tabular fragment stood on narrow edge at the time of sampling. 


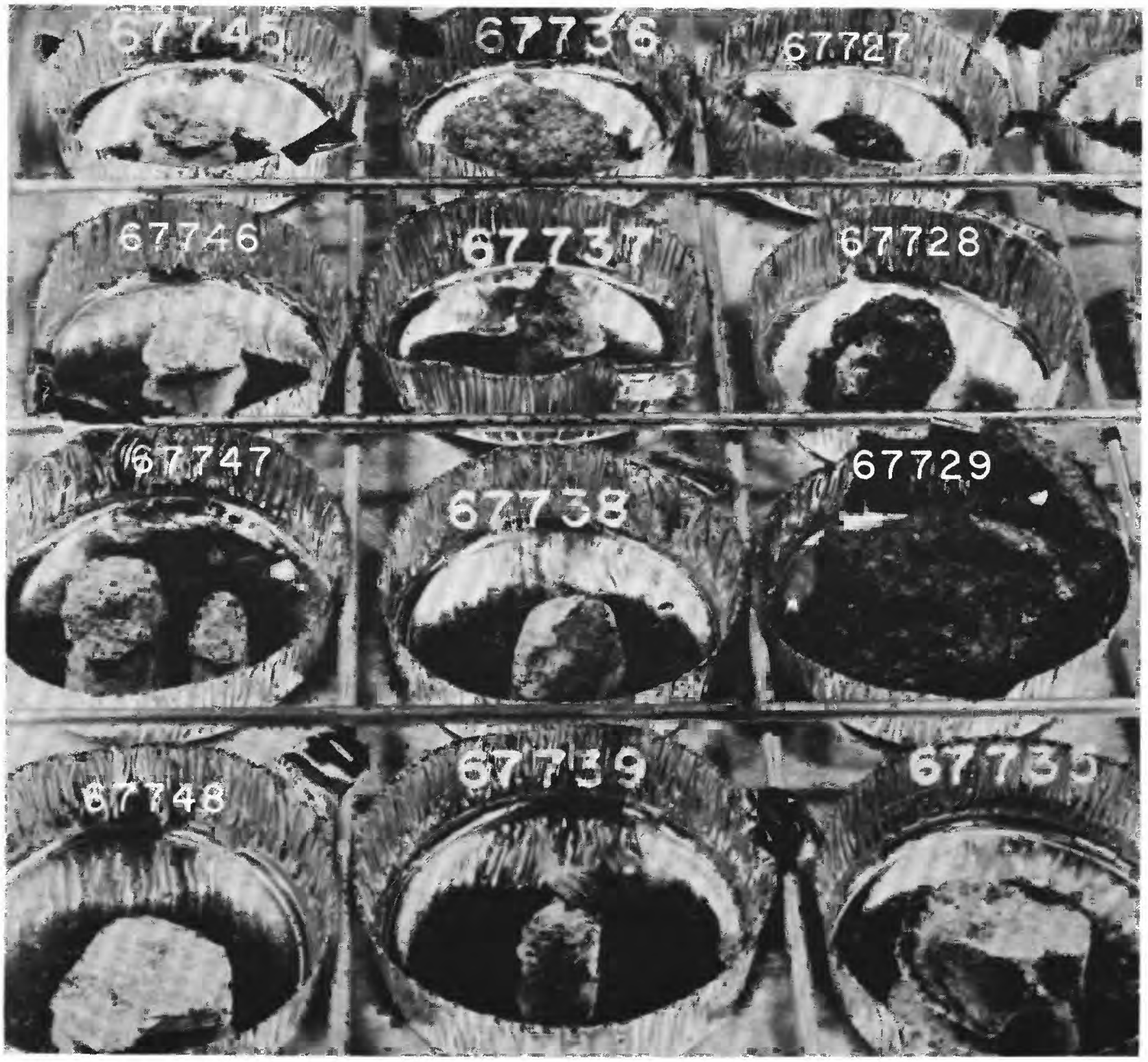

FigURE 76D.-Part of rake sample 67710-76 in LRL (photograph S-72-43207). This group includes fragments 67727-29, 67735-39, and 67745-48. Fragment 27 is $<2 \mathrm{~g}$ and not classified; fragments 28 and 29 glassy $(G)$ breccias; 35 a $B_{5}\left(B_{3}\right)$ breccia; fragments $37-39$ and 45 type $\mathrm{B}_{4}$ breccia; the four remaining fragments ( 36 and 46-48) metaclastic $\left(\mathrm{C}_{2}\right)$. Fragment identified as 67729 shown in presampling orientation on lunar surface in figure $76 B$. 


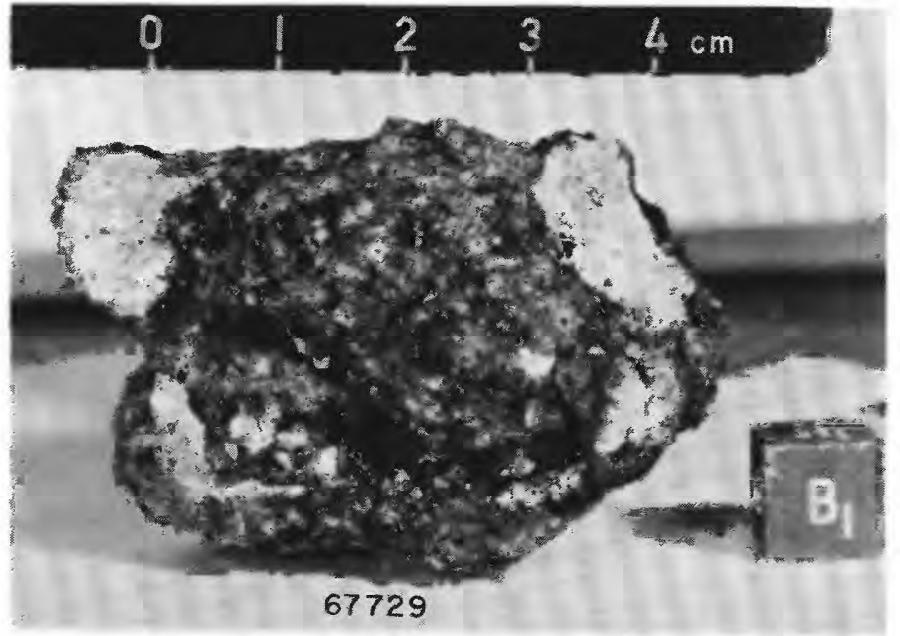

\Figure 76E.-Rake fragment 67729 in LRL (photograph S72-43442), 73-g glassy breccia (G) identified in presampling lunar-surface photograph (fig. $76 B$ ).

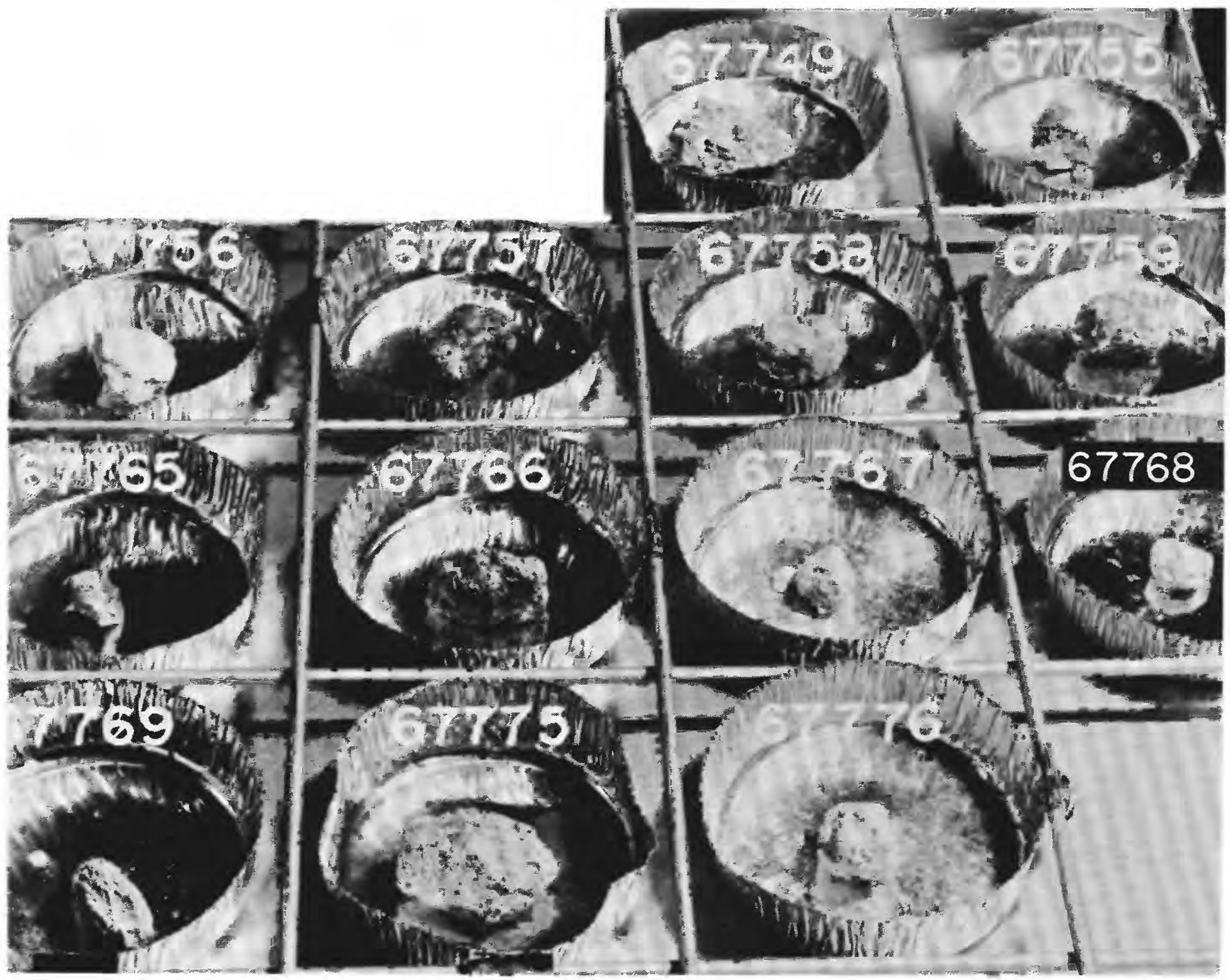

Figure $76 F$,-Part of rake sample 67710-76 in LRL (photograph S-72-43202). This group includes fragments 67749, 67755-59, 67765-69, and 67775-76, all classified as $B_{2}$ breccia except three fragments $(65,67$, and 68$),<2 \mathrm{~g}$ and not classified. 
SAMPLE: 67700-04, 05-08; 67710-14, 15-19, 25-29, 35-39, 45-49, 55-59, 65-69, 75-76 (rake samples)

Station: 11

Landmark: Approximately $45 \mathrm{~m} \mathrm{NE}$ from $L R V$, on $S E$ rim of North Ray crater.

Rock type: 67700-08, soil with 4 incidental fragments; 67710-76, incidental soil with 32 rake fragments. Most fragments are types $B 2$ and $B 4$ (see figures $76 C-F$ for classification of specific fragments). SURFACE CHARACTERISTICS OF SAMPLE AREA

Slopes: Gentle downslope to north.

Fragment population

Size range and distribution: $10-30 \mathrm{~cm}$ fragments, sparse;

2-10 cm common but less than $1 \%$ of surface; $0.5-2 \mathrm{~cm}, 20-30 \%$

of surface.

Color: Light gray; some white.

Shapes: Most larger than several centimeters are subangular.

Fillets: None.

Apparent burial: Mostly perched. Fines

Dust Cover: Not visible, but reported by the crew (Table 3, p. 61).

Color: Light gray.

Compaction: Crew described as hard; possibly on top of a

Craters

large white rock. Rake would not penetrate.

Size range and distribution: One 30-40 cm light colored

secondary (?) in center of rake sample area.

Shape: Raised rim.

Ejecta: Small clods appear localized on floor and west rim of secondary.

SAMPLE CHARACTERISTICS FOR 67700-04 (soil); 67705-08 (4 incidental fragments).

Size: $\quad<1 \mathrm{~cm}$ fines; 420.47 grams total; $1-3 \mathrm{~cm}$ fragments, 11.92

grams total weight.

Color: Light gray.

Probable origin: Regolith on North Ray crater ejecta. In part disaggregated material from nearby or underlying white friable breccia.

SAMPLE CHARACTERISTICS FOR 67710-14 (incidental soil with rake fragments

67715-76).

Size: $\quad<1 \mathrm{~cm}$ fines, 408.64 grams total weight.

Color: Light gray.

Comparison with other soil in area: Probably typical.

SAMPLE CHARACTERISTICS FOR 67715-76 (32 rake fragments)

Size: 1-5 cm fragments; 284.38 grams total weight.

Color: Medium and dark gray (B4) and light gray (B2) breccias

predominant.

Comparison with other fragments in area: Increased number of $B 4$ breccia fragments compared to samples west of the LRV in the areas of large white breccia boulder.

Probable origin: Ejecta from North Ray crater; source similar to House Rock and other dark-matrix breccias, in addition to white matrix breccias. 


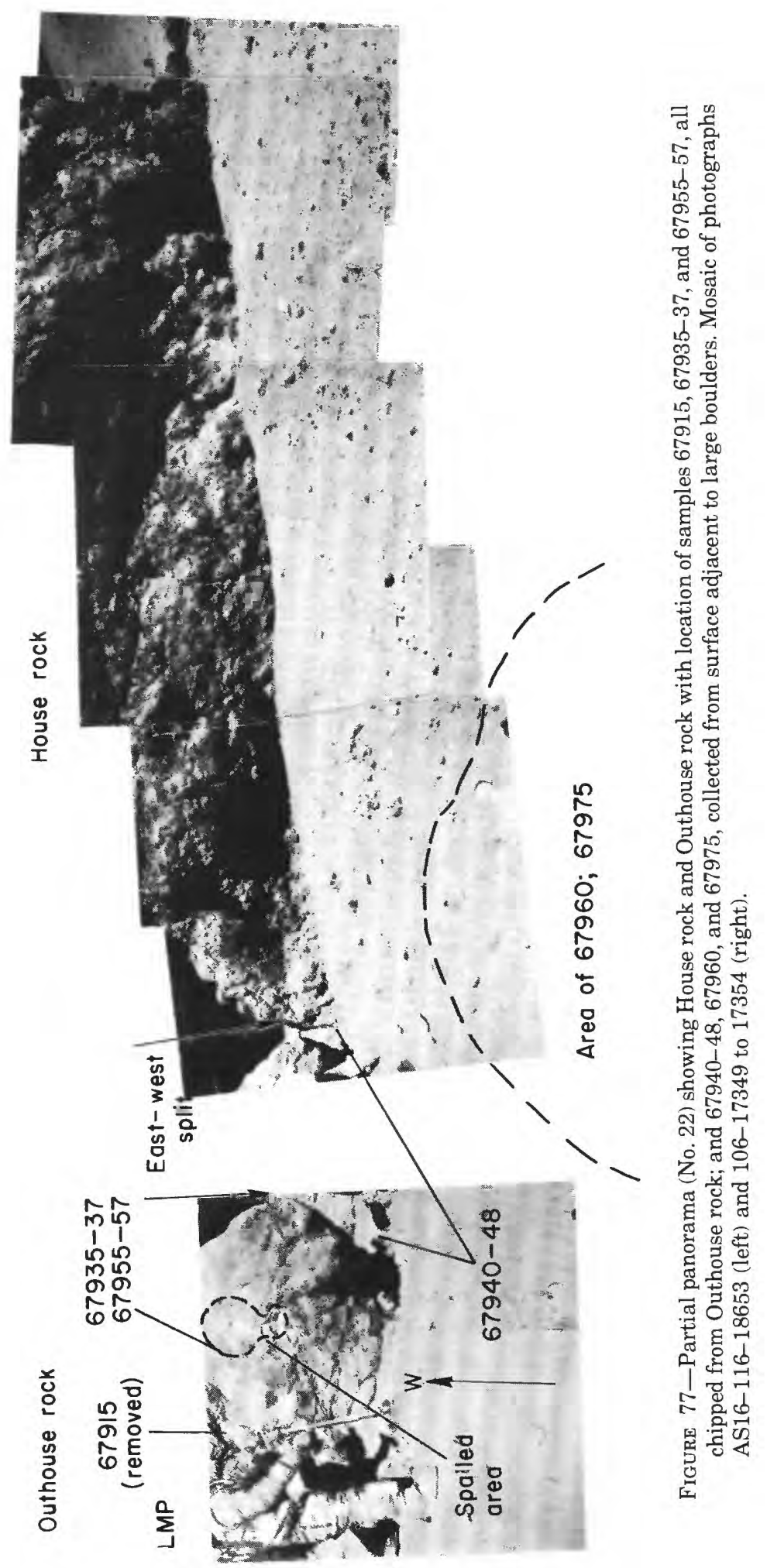




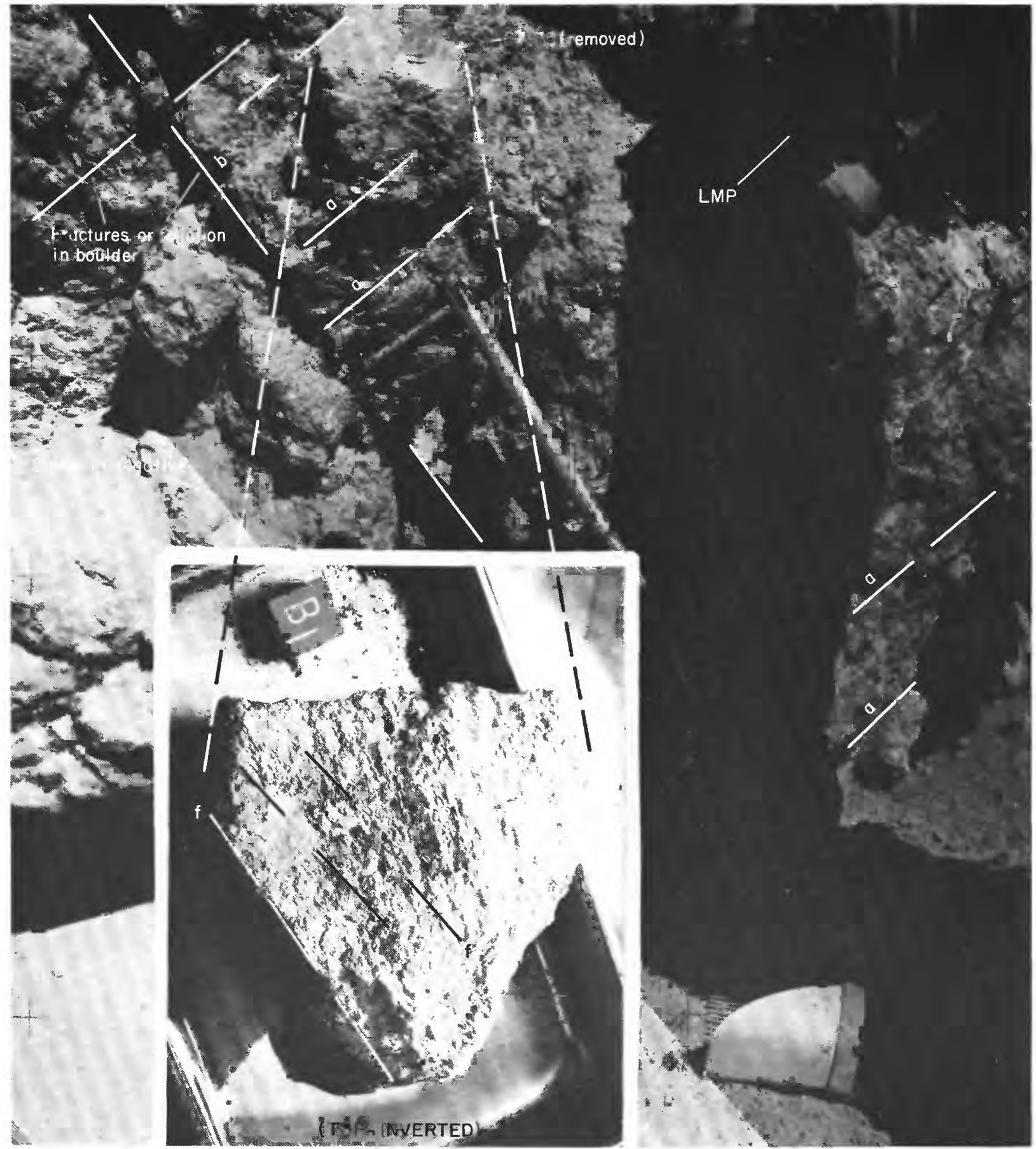

FIGURE 78A.-Sample 67915 showing approximate lunar orientation reconstructed by matching the shape and surface characteristics of the scar left on the boulder as shown in an enlarged part of photograph AS16-116-18652, with freshly broken surface of the sample $\left(B_{1}\right.$ photographic view) in LRL. Note that the inset photograph shows the freshly broken surface of sample whose original orientation has been inverted. Oblique lighting in the laboratory enhances irregular linear fractures on broken face roughly parallel to dashed lines, $f$, also nearly parallel to one side of triangular-shaped sample. If one mentally reverts the sample to its presampling orientation, then lineaments $f$ coincide very closely to lineaments $a$ on the boulder and may represent a pervasive foliation or shear within the rock. Shadowed lineament $b$ on boulder may represent one of a set of conjugate fractures or foliation. 


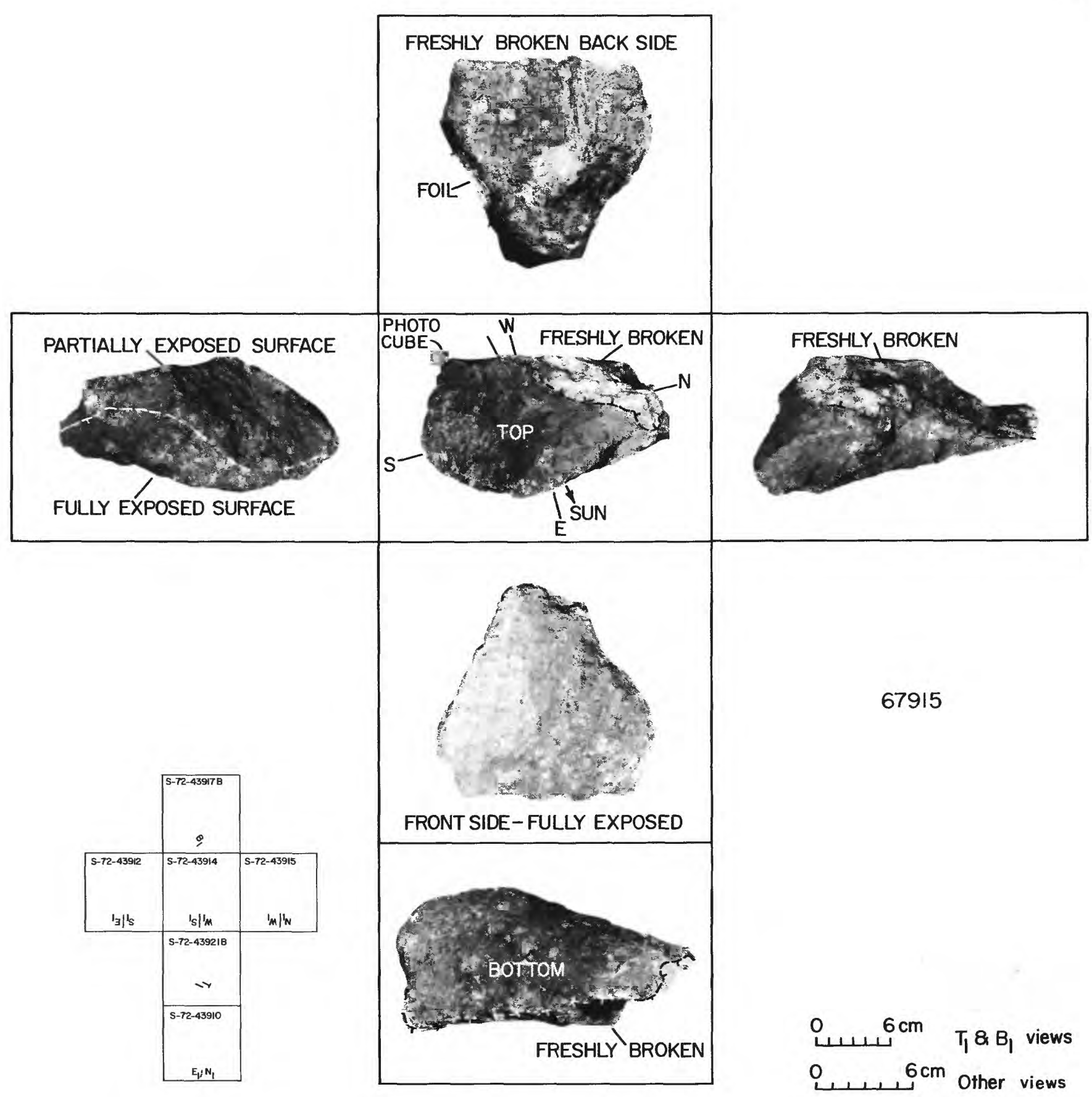

FIGURE $78 B$.- Orthogonal views of sample 67915 related to its lunar orientation at time of sampling. See chap. D2, fig. 15, for stereopair of this type $B_{4}(F)$ rock. 
SAMPLE: $67915 ; 67935-37 ; 67955-57$

Station: 11

Landmark: Approximately $165 \mathrm{~m} \mathrm{NE}$ from LRV at Outhouse Rock; on rim of North Ray crater. (See figures 58 and 77)

Rock type: Breccia, dark matrix, white clasts. 67915, large sample that includes white clasts, $B 4(F) ; 67935-37$, chips from surface adjacent to "shatter cone", types $C 2(F), C 1$, and $B 4(F)$, respectively; 67955-57, chips farther from "shatter cone" than 67935-37, types $B 1, C I(F)$, and $B 4(F)$, respectively.

SURFACE CHARACTERISTICS OF SAMPLE AREA

Slopes: On rim crest of North Ray crater; slope gentle to ESE from Outhouse Rock for about $15 \mathrm{~m}$ before steepening. Samples collected from nearly vertical face of boulder.

Fragment population

Size range and distribution: House Rock (about $25 \mathrm{~m}$ long) is largest boulder in area of station 11, Outhouse Rock is about $5 \mathrm{~m}$ long; smaller sizes increase in abundance.

Color: Large boulder from which samples taken is dark gray with white clasts.

Shapes: Rounded to angular; large boulder from which samples taken rounded except under overhang, knobby.

Fillets: Fillet on large boulder poorly developed--nearly absent.

Dust cover: None visible.

Matrix of sampled boulder

Color: Medium to dark gray.

SAMPLE CHARACTERISTICS FOR 67915 (see figures 78A-B)

Size: $21 \times 16 \times 9 \mathrm{~cm} ; 2559$ grams.

Color: Gray matrix; white and gray clasts.

Shape: Angular where broken off; rounded on exposed surfaces.

Dust cover: None.

Comparison with other fragments in area: Typical of Outhouse Rock and probably of adjacent House Rock.

Probable origin: May represent deepest material ejected from North Ray crater.

COMMENTS: . Lineations or shears probably record multiple shock events in past history of boulder.

SAMPLE CHARACTERISTICS FOR 67935-37 (see figures 79A-E).

Size: Broken fragments up to $7.5 \mathrm{~cm}$ long; 230.39 grams total weight.

Color: Light gray, medium gray, with black glass as coating and penetrative veinlets.

Shape: Angular, slabby.

Dust cover: None.

Comparison with other fragments in area: Probably typical of Outhouse Rock and adjacent House Rock.

Probable origin: Material from deepest part of North Ray crater.

SAMPLE CHARACTERISTICS FOR 67955-57 (see figures 79A-B, 80-A-C)

Size: Broken fragments up to $6 \mathrm{~cm}$ long; 168.03 grams total weight.

Color: 67955 light gray to white; 67956 and 67957 medium light

and medium dark gray, respectively.

Shape: Angular to rounded.

Dust Cover: None.

Comparison with other fragments in area: White pieces probably typical of white clasts in Outhouse Rock and adjacent House Rock. Probable origin: Material from deepest part of North Ray crater. 


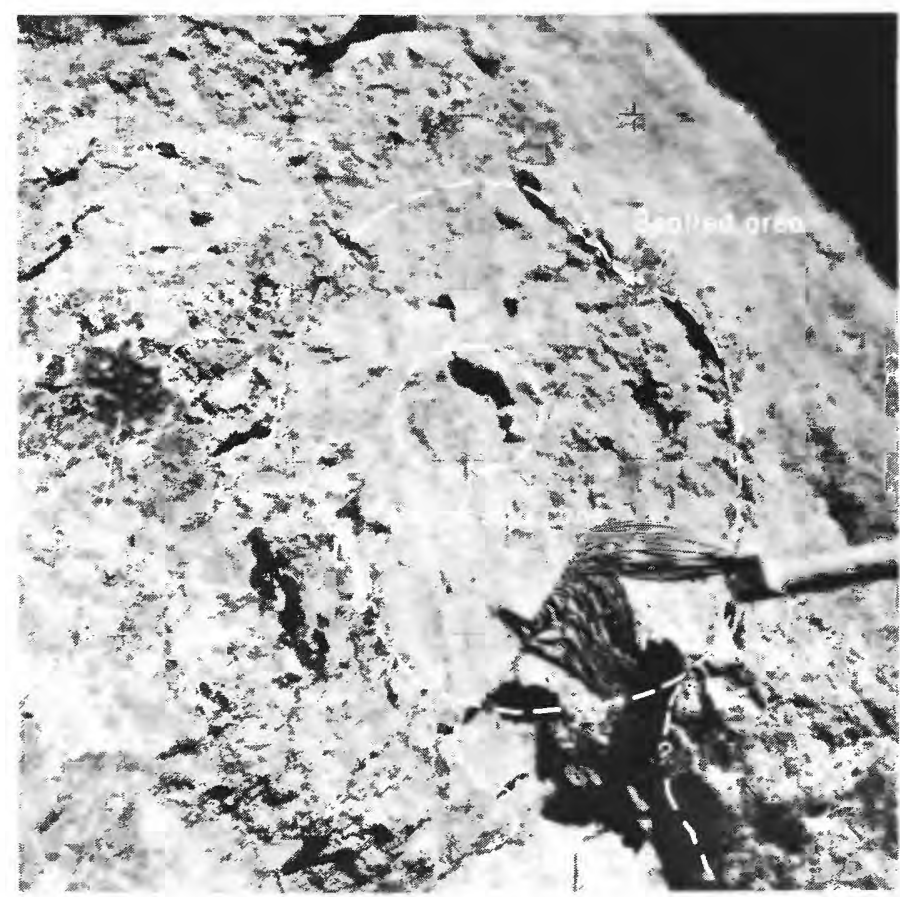

Figure 79A.-Samples 67935-37 and 67955-57 were chipped from two small areas adjacent to percussion spall half a meter in diameter on Outhouse rock, shown before sampling in closeup photograph AS16-106-17345. View is west-northwest. The crew was attracted to the fracture as a possible "shatter cone" (see table 3 , pages 63-64). Thin coating of shiny black glass coats parts of boulder near spall zone. Note area below tongs that appears to be freshly broken. See chap. D2 for similar illustration and discussion of geologic setting.

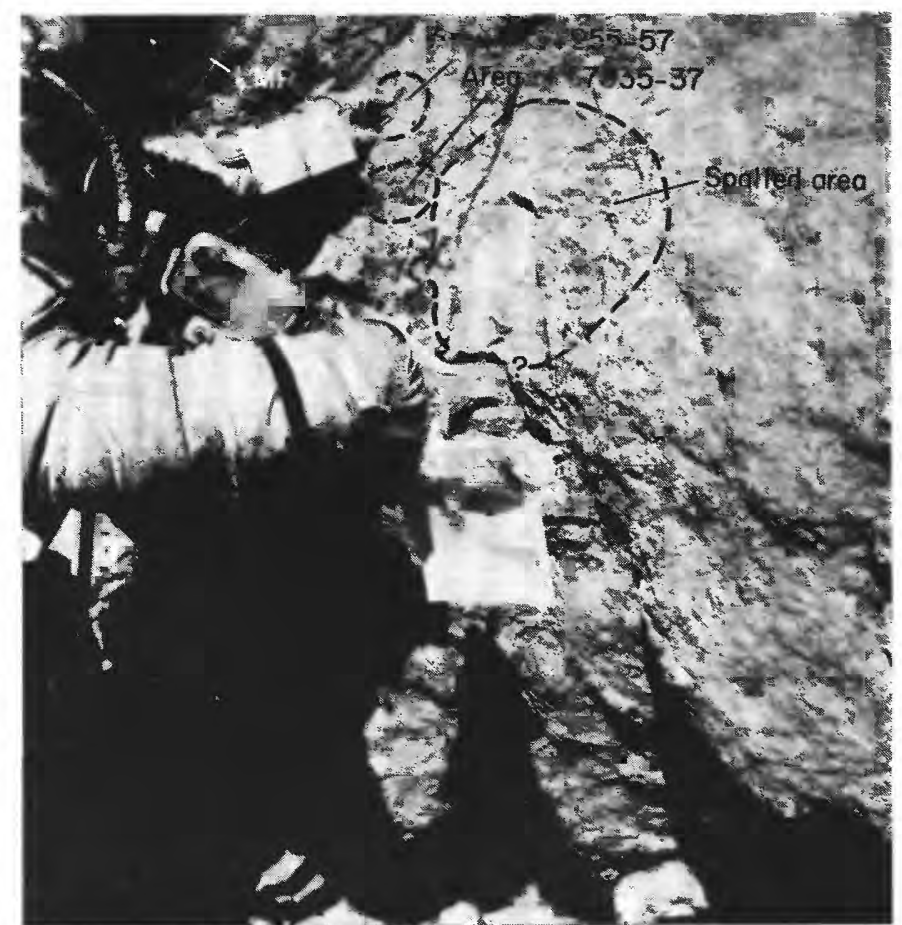

Figure 79B.-Lunar-surface photograph AS16-116-18649 shows astronaut Charles Duke in process of collecting samples 67955-57. Samples 67935-37 already collected.

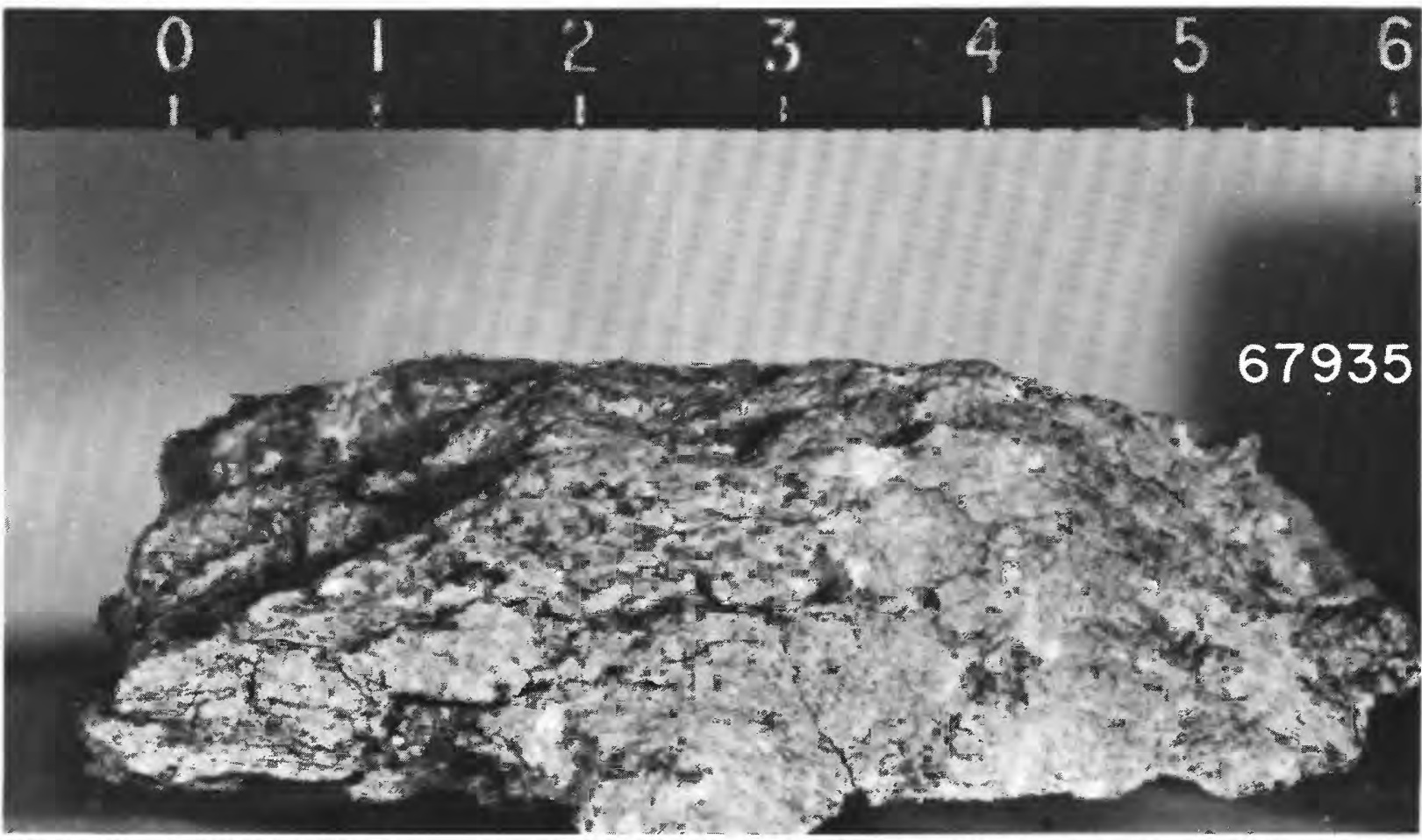

FIGURE 79 C--Sample 67935 in LRL (photograph S-72-37784, $\mathrm{N}_{1}$ view), classified type $\mathrm{C}_{2}(\mathrm{~F})$. Numerous glass veinlets penetrate sample. Also shown in chap. D2, fig. 18 . 


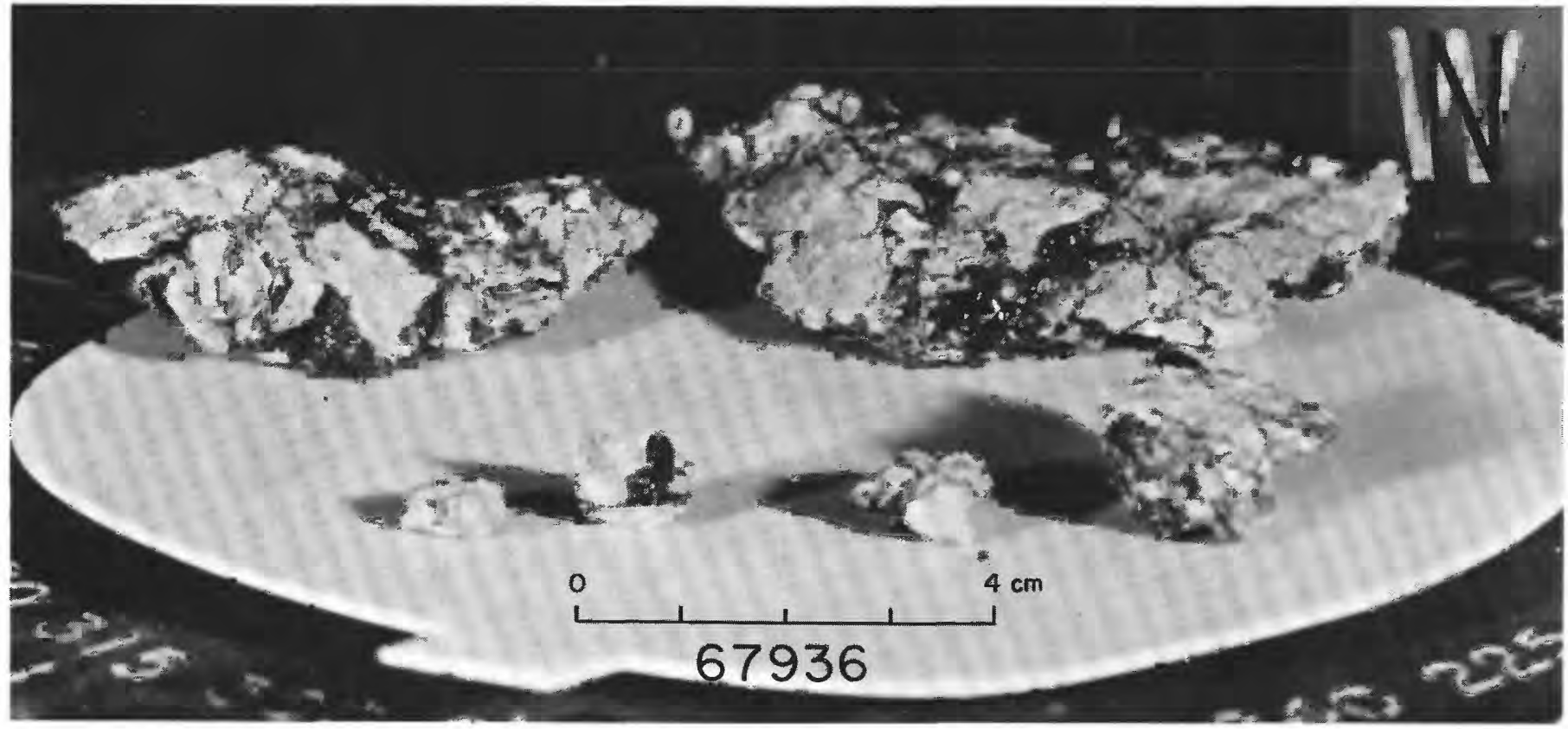

Figure 79D. - Sample 67936 shown broken on a 6-inch diameter white teflon pad in LRL (photograph S-72-37777, N 1 view), collected from an area covered by glass spatter (fig. $79 A$ ); note that glass also intrudes the rock as veinlets along fractures. Crystalline, $\mathrm{C}_{1}$.

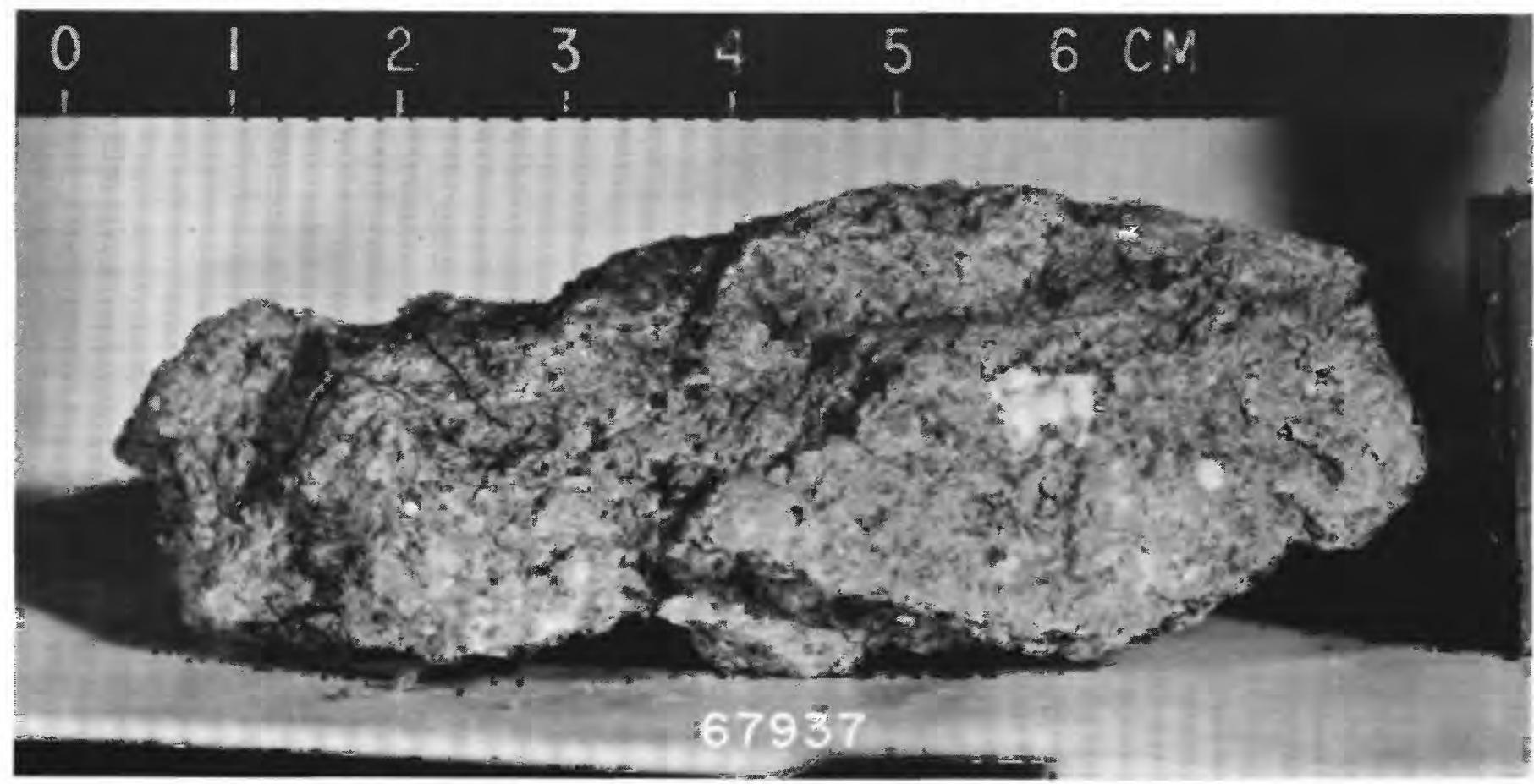

Figure $79 E$. - Sample 67937 in LRL (photograph S-72-37771, $\mathrm{T}_{1}$ view). Classified as type $\mathrm{B}_{4}(\mathrm{~F})$ ), same type as larger fragment 67915 taken from Outhouse rock. Glass abundant as surface spatter and small veinlets in sample 67937. Also shown chap. D2, fig. 19. 


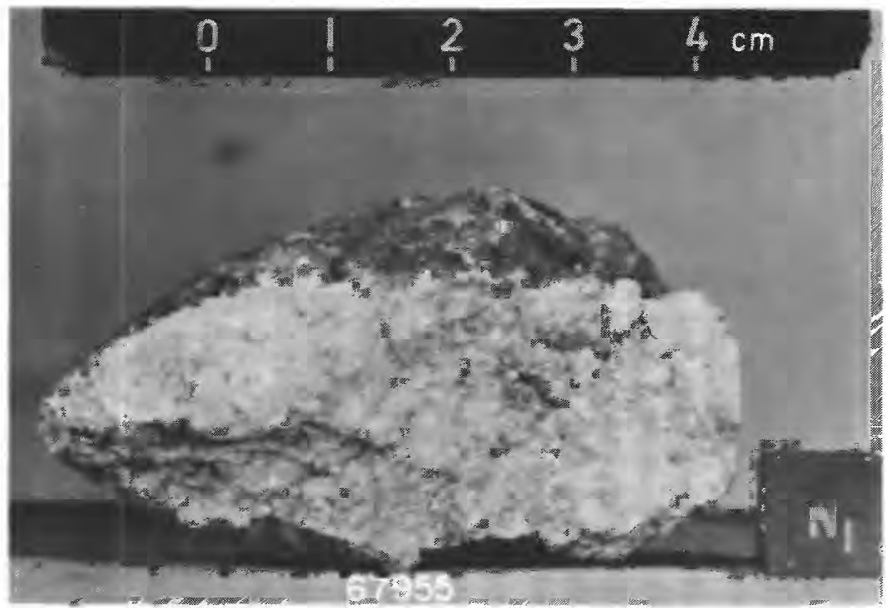

TFigure 80A-Sample 67955 in the LRL (photograph S-72-45682). Fragment chipped from a white clast in Outhouse rock; classified as type $\mathrm{B}_{1}$ breccia (figs. $79 A-B$; table 3 , p. 65). See chap. D2, fig. 16 , for $B_{1}$ photographic view.

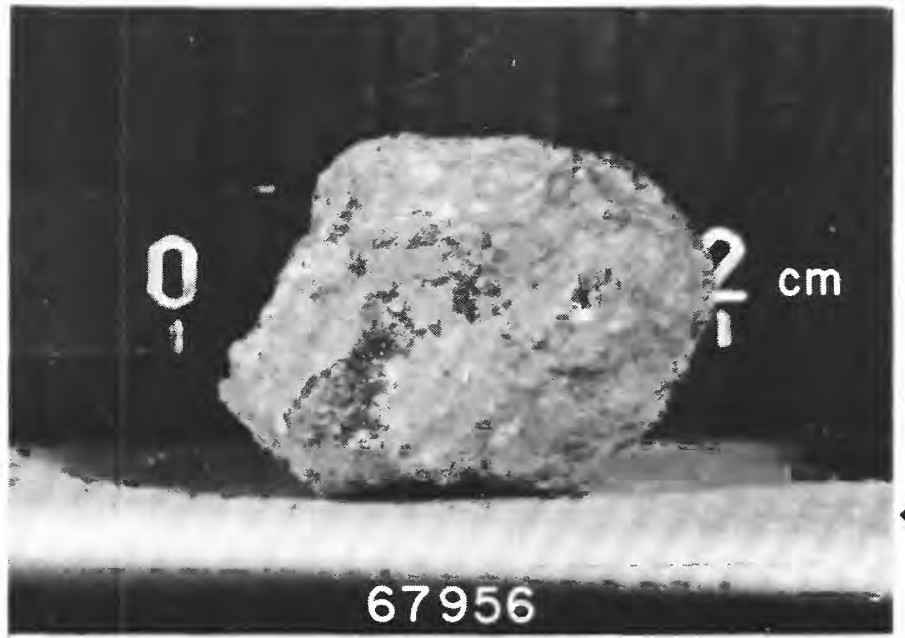

4FIgURe 80B.-Sample 67956 in LRL (photograph S-72-37546, $\mathrm{N}_{1}$ view). Classified as a $C_{1}(F)$ crystalline rock. Small patches of glass splatter adhere to surface. See chap. D2, fig. 20 , for $S_{1}$ photographic view.

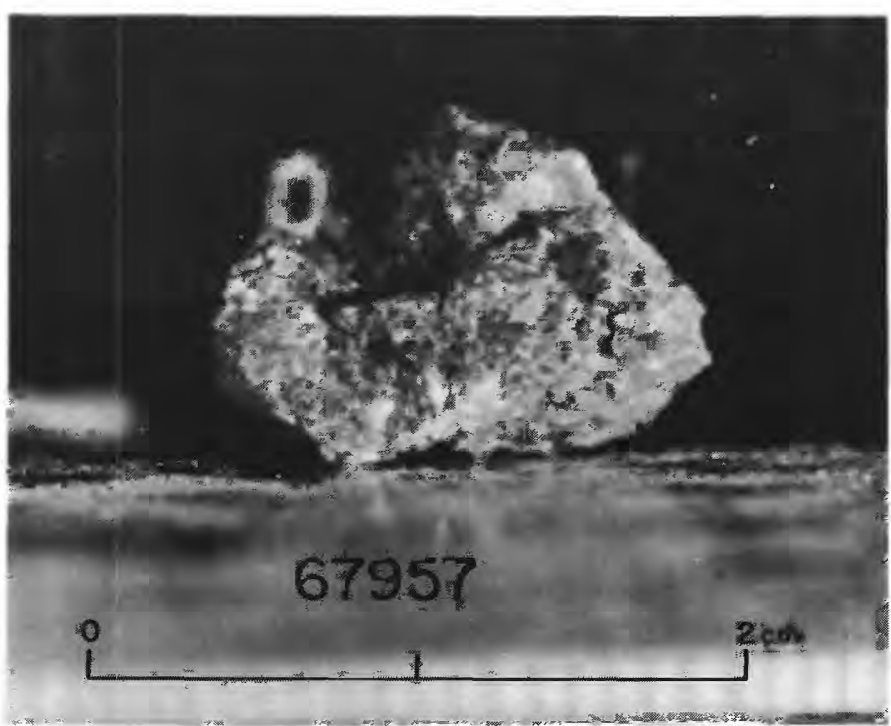

Figure 80C.-Sample 67957 in LRL (photograph S-72-37793, N, view). $\mathrm{B}_{4}(\mathrm{~F})$ breccia. 


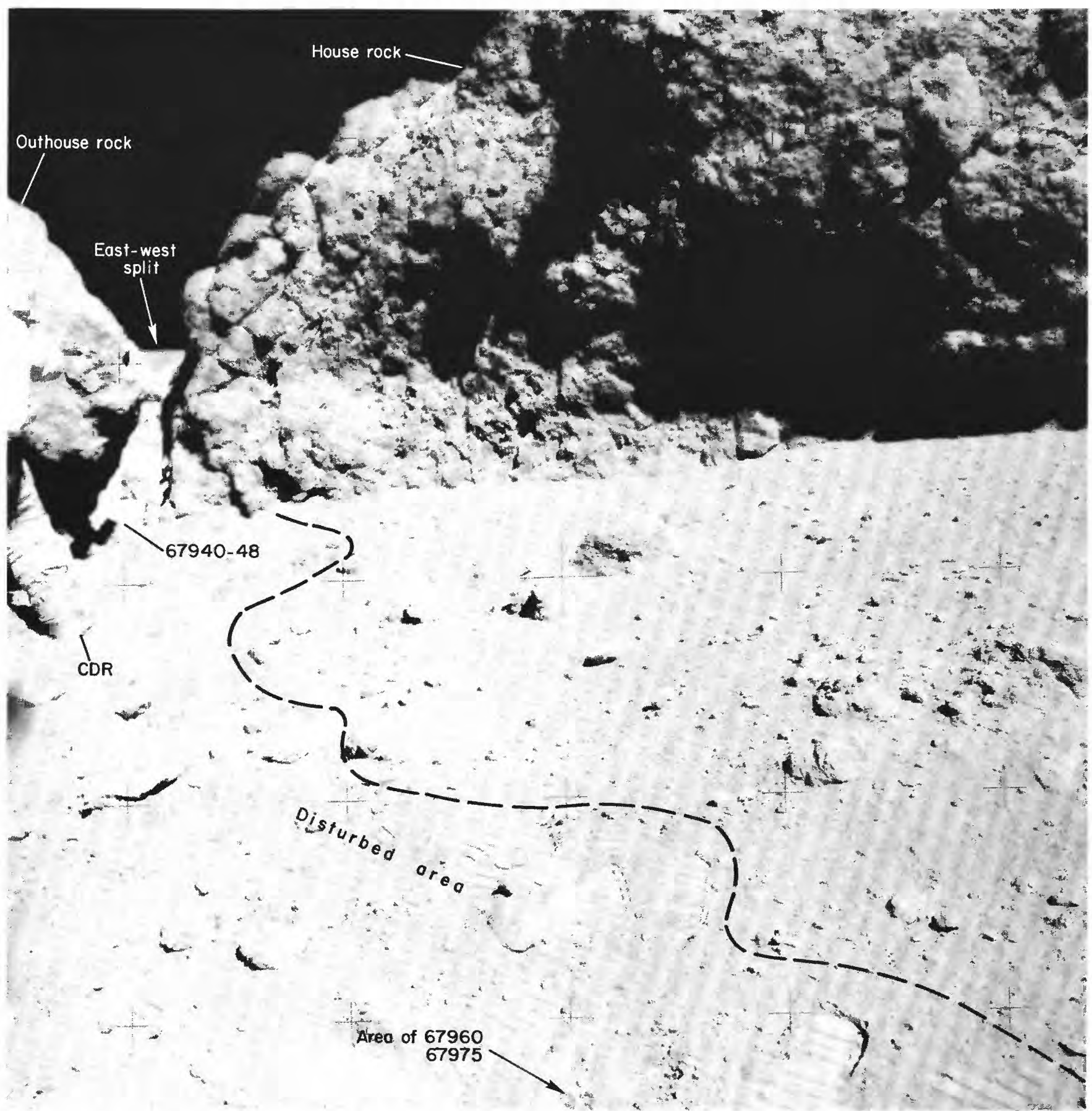

FIGURE 81A.-Samples 67940-48 (soil with incidental fragments) collected from narrow east-west-trending gap between House rock and Outhouse rock, shown after sampling in photograph AS16-106-17354. View is northwest. Part of partial panorama No. 22, taken after samples 67960 and 67975 were collected from an area just out of the picture, in the foreground (see figs. 77 and $82 A$ ).

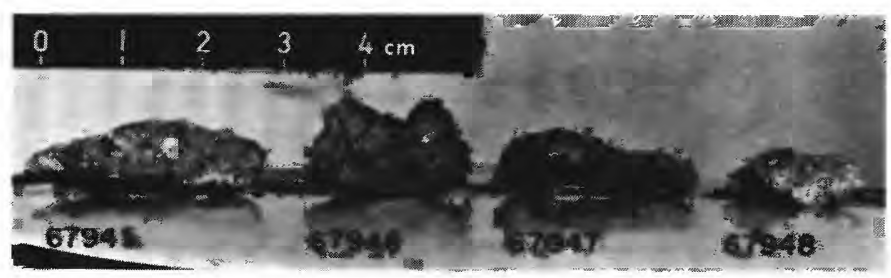

Figure 81B.-Samples 67945-48 in LRL (photograph S-72-38977, $N_{1}$ view). Three larger fragments type $B_{4}$ breccia. These are also illustrated in chap. D2, fig. 21. Although fragment 67948 is $<2 \mathrm{~g}$ and was not classified by Wilshire and others (this volume), it is a crystalline $\left(\mathrm{C}_{1}\right)$ rock, as illustrated in chap. D2, fig. $22 A-C\left(\mathrm{~N}_{1}\right.$ photographic view and two photomicrographs, respectively). 
SAMPLE: $\quad 67940-44,45-48$

Station: 11

Landmark: Approximately $170 \mathrm{~m} \mathrm{NE}$ from $L R V$, at $E-W$ split between House Rock and Outhouse Rock (see figures 77, 81A).

Rock type: 67940-44, soil; 67945-48, 4 incidental fragments (the largest 3 classified B4).

SURFACE CHARACTERISTICS OF SAMPLE AREA

Slopes: On rim crest of North Ray crater; nearly level.

Fragment population: Details of fragment distribution in the immediate sample site not shown by close-up documentation photographs. House Rock ( $25 \mathrm{~m}$ ) and Outhouse Rock ( $5 \mathrm{~m}$ ) dominate the area. Regolith similar to that briefly described under samples 67960 and 67975.

SAMPLE CHARACTERISTICS FOR 67940-44 (soil), 45-48 (> 1 cm fragments) Size: < $1 \mathrm{~cm}$ fines; 106.3 grams total; 4 incidental fragments (see figure 81b) $1.6-3 \mathrm{~cm}$ long, 11.59 grams total weight. Color: Medium light gray to medium dark gray.

Shape: Angular fragments. Comparison with other soil and fragments in area: Probably similar, derived from larger rocks of $B 4$ breccia which appears to predominate in House Rock and Outhouse Rock.

Probable origin: Ejecta from North Ray crater.

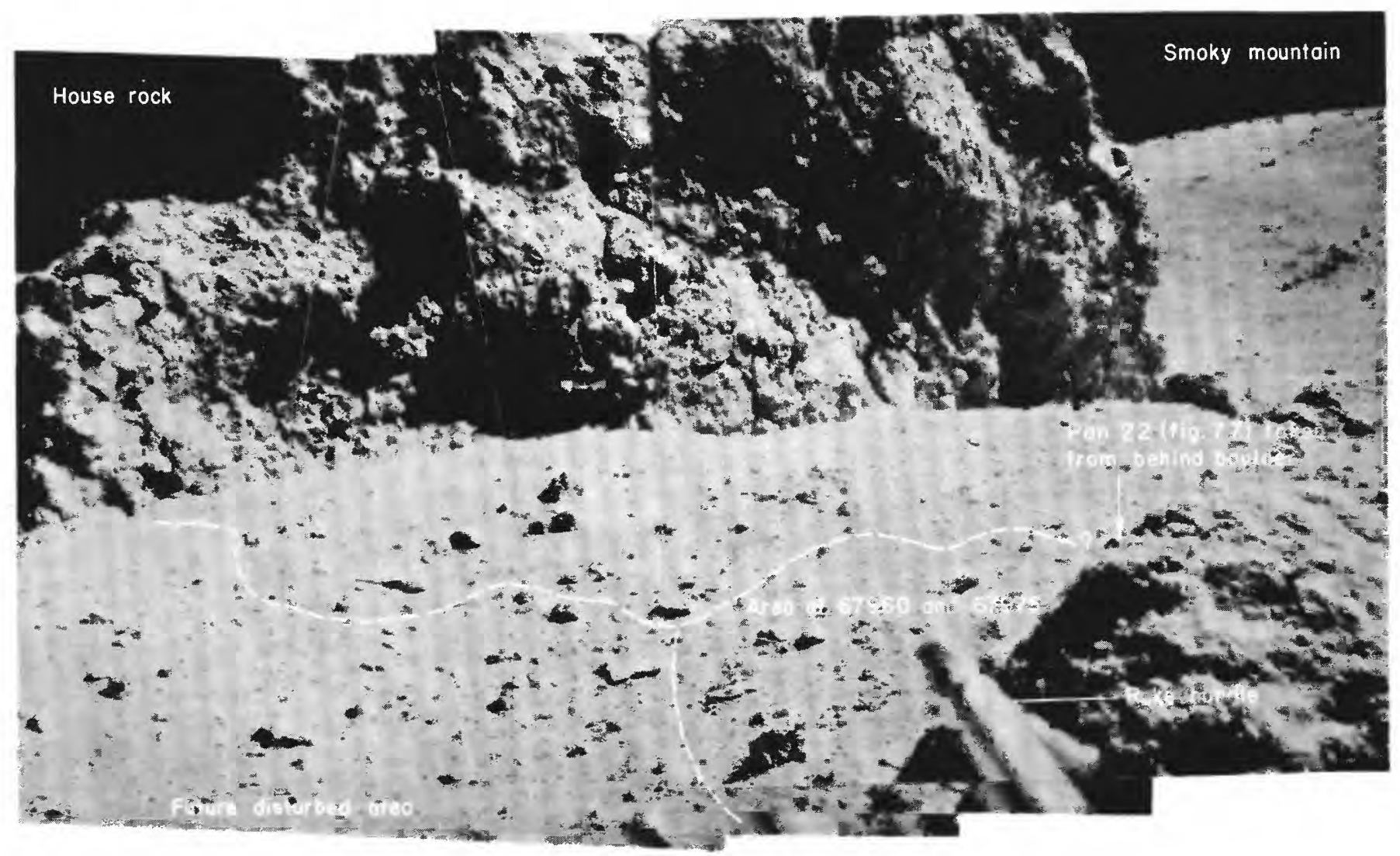

FigURE 82A.-Area of samples 67960 and 67975 shown before sampling in partial panorama No. 21; view is toward House rock (photographs AS16-106-17341 to 17344). Samples not identified in panorama; probably hidden from view by boulder at lower right. Compare with figures 77 and $81 A$. 


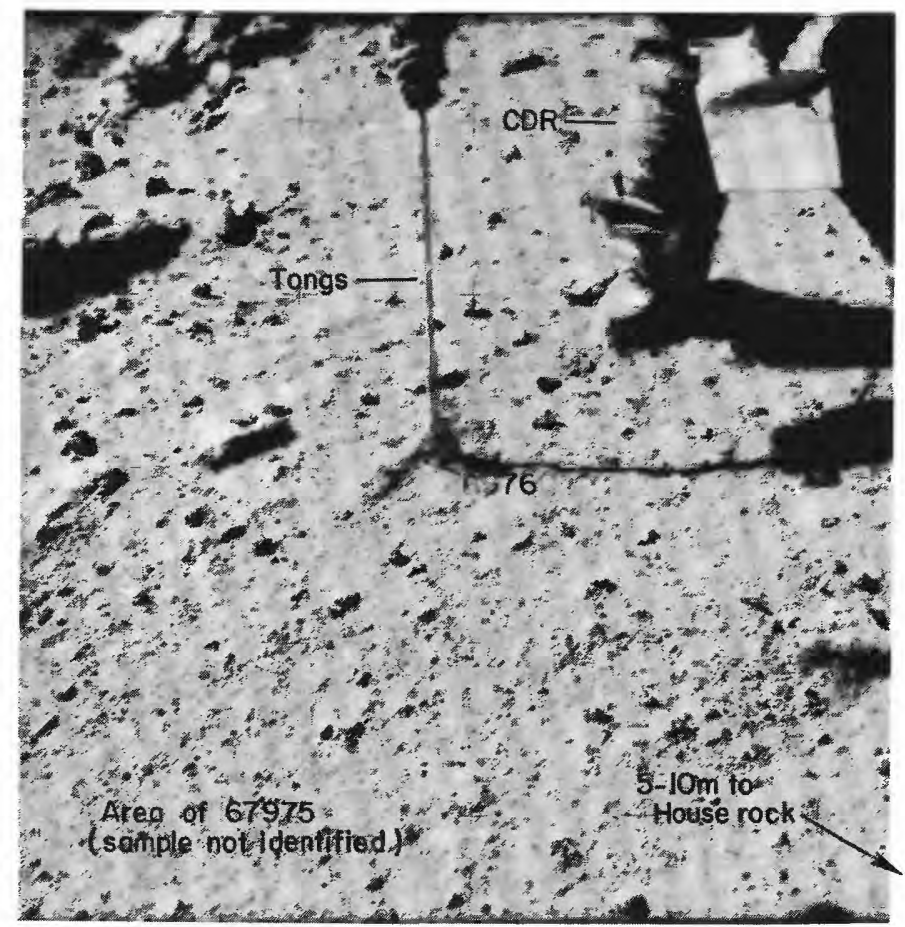

Figure 82B.-Sample 67960 (soil) shown next to tongs before sampling in photograph AS16-106-17347; view is south. Rock sample 67975 collected from this area; not identified in presampling photograph.
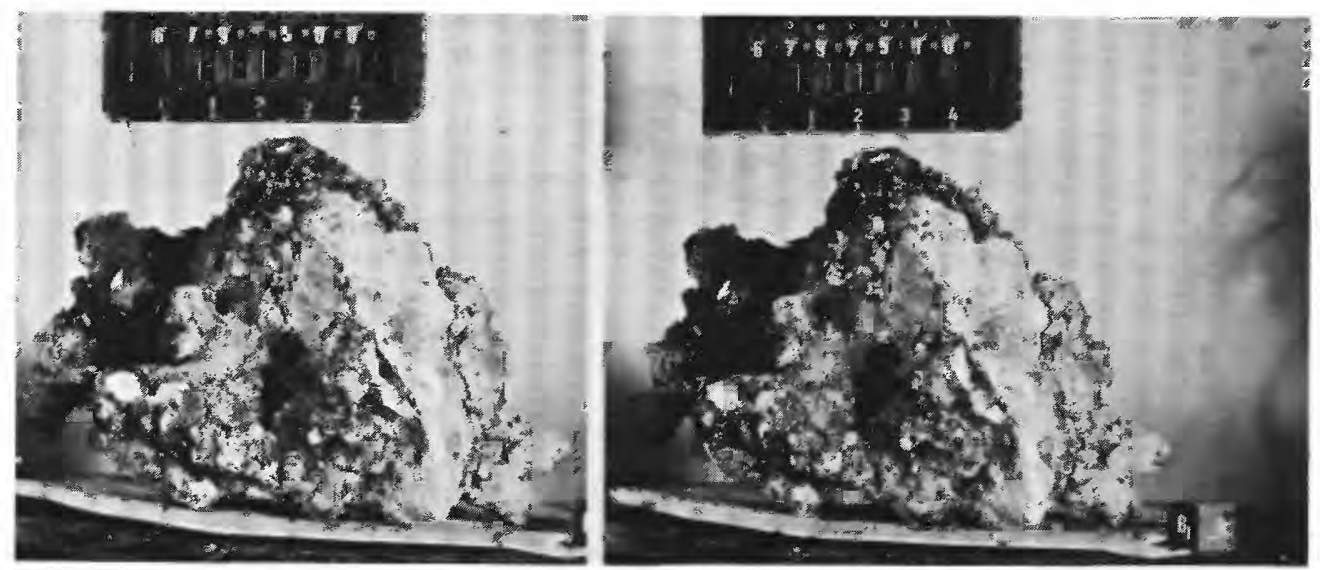

FiguRe $82 C$.- Stereopair of sample 67975 taken in LRL; photographs S-72-43860 (right) and $-43860 \mathrm{~B}$ (left). A glass-coated $\mathrm{B}_{2}$ breccia. Breakage apparently occurred during sampling, exposing fresh surface of breccia beneath the glass as seen in this view. 
SAMPLE: $67960 ; 67975$

Station: 11

Landmark: Approximately $170 \mathrm{~m} \mathrm{NE}$ from $L R V$, and $5-10 \mathrm{~m}$ east of Outhouse rock.

Rock type: 67960 is undivided soil; 67975 is glass-coated, lightmatrix breccia, B2.

SURFACE CHARACTERISTICS OF SAMPLE AREA (for "reference" soil 67960 only)

Slopes: Near crest of North Ray rim; slope toward east, down from rim.

Fragment population: (Excluding House rock and Outhouse rock). Size range and distribution: Sparse $10-30 \mathrm{~cm}$ fragments, abundant 5-10 cm fragments, and abundant centimeter-size fragments (or clods).

Color: Light to medium gray.

Shapes: Angular to rounded.

Fillets: Moderately developed on uphill sides of larger rounded rocks.

Apparent burial: Slight. Dust cover: Not visible.

Fines

Color: Light gray.

Compaction: Very hard just beneath surface.

SAMPLE CHARACTERISTICS FOR 67960 (unsieved sOil)

Size: < $1 \mathrm{~cm}$ fines; 12.11 grams total weight.

Color: Light gray.

Comparison with other soil in area: Typical of very thin soil cover described in much of station area by the crew.

Probable origin: Derived from local rocks of North Ray crater ejecta.

SAMPLE CHARACTERISTICS FOR 67975

Size: $11.5 \times 8 \times 7 \mathrm{~cm} ; 446.6$ grams.

Color: Medium light gray breccia coated with dark gray glass.

Shape: Irregular, hackly.

Comparison with other fragments in area: "Frothy" character implies uniqueness in this area; may be more glassy or vesicular than most

local rocks.

Probable origin: Ejecta from North Ray crater.

COMMENTS: No photographic documentation of this rock sample. 


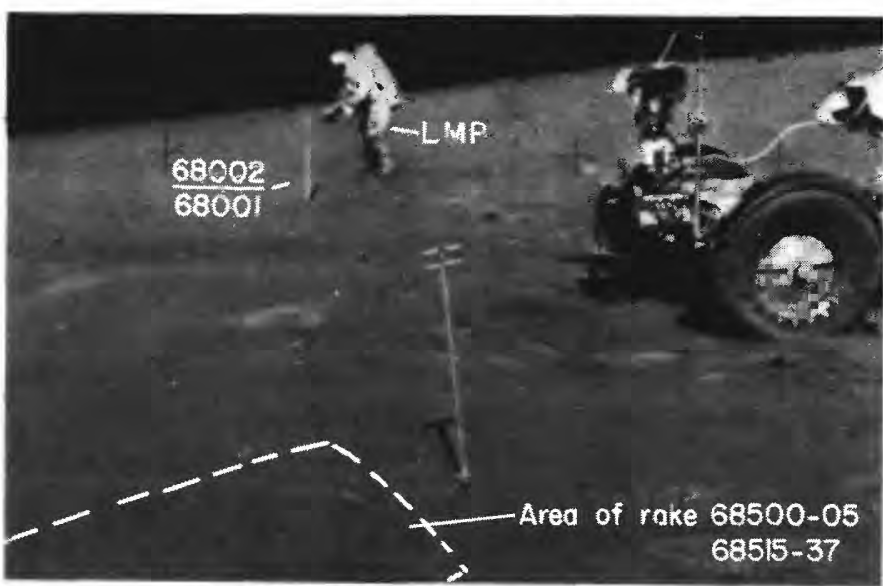

Figure $83 A$.- Location of double-drive tube sample $68002 / 68001$ relative to the Rover at station 8 , shown during sampling in photograph AS16-107-17529, looking west. See fig. 87 for rake samples 68500-05 and 68515-37.

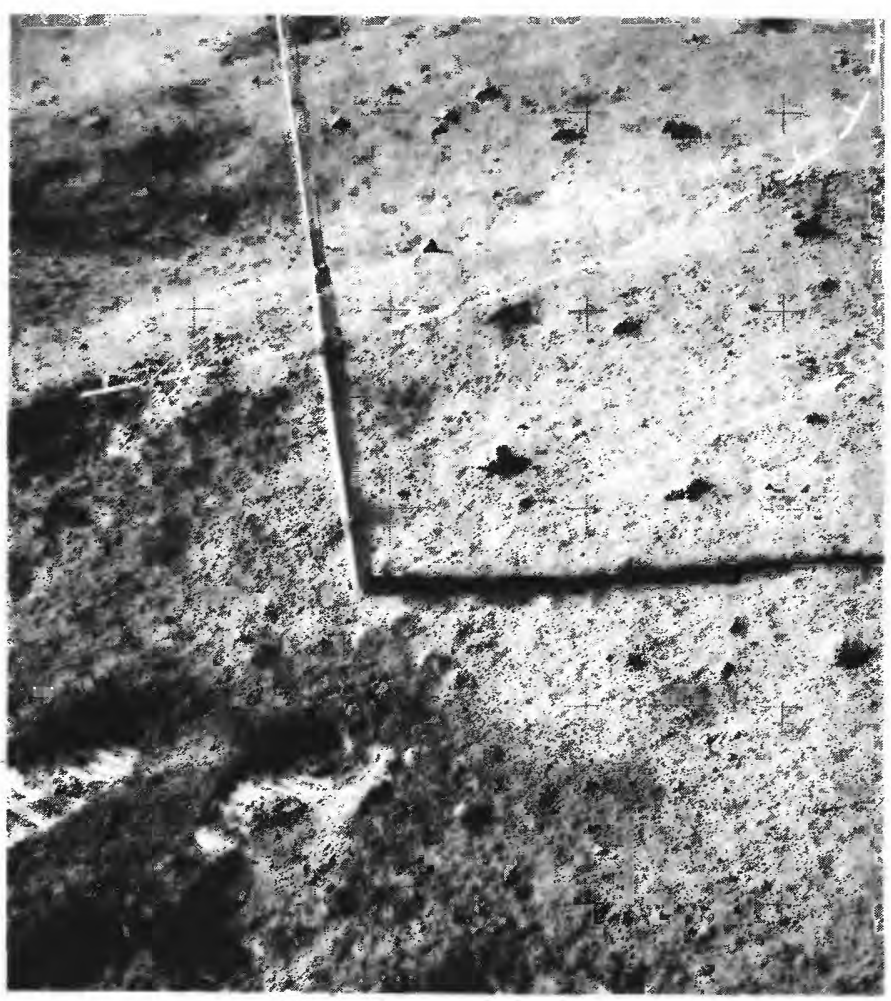

Figure 83B.-Double drive tube shown during the first (unsuccessful) attempt at sampling, in photograph AS16-108-17683. View is south. The drive tube struck something hard beneath the surface, was moved to the spot indicated, and there driven successfully.

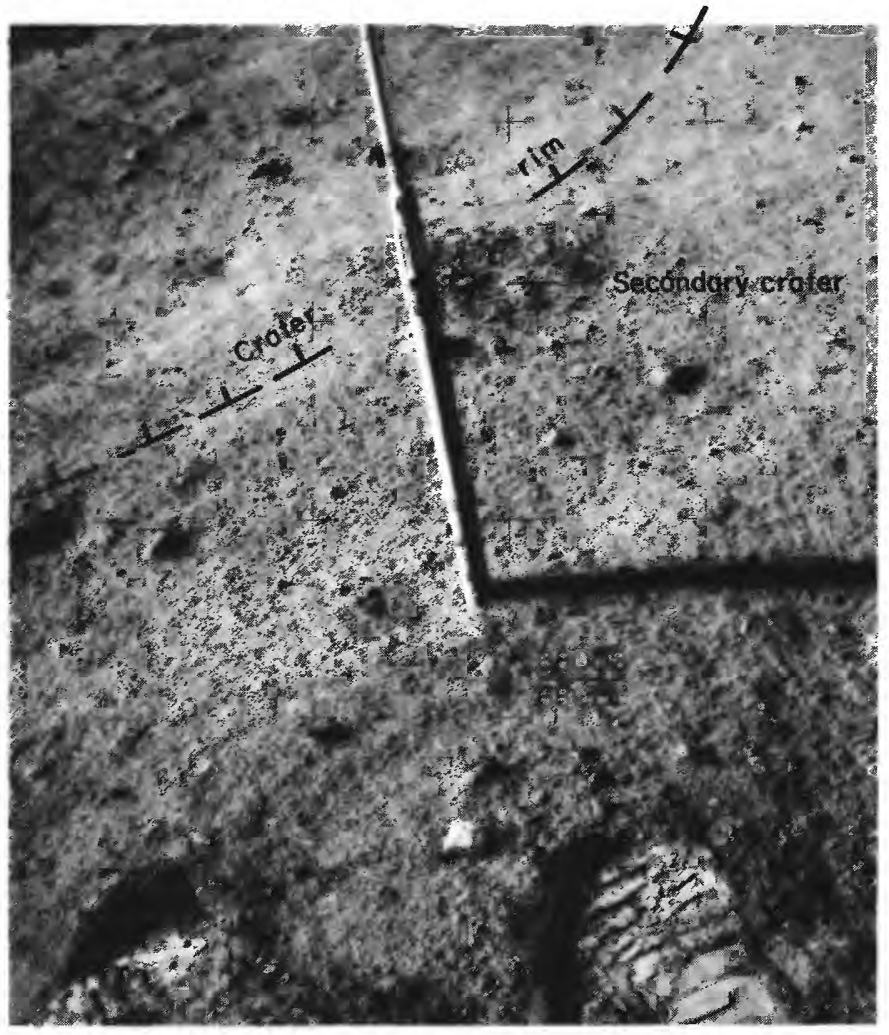

Figure $83 C$.-Double drive tube $68002 / 68001$ shown at new location, in photograph AS16-108-17684. View is south. 
SAMPLE: $\quad 68002 / 68001$

Station: 8

Landmark: West of the LRV 10-15 $\mathrm{m}$.

Rock type: Double drive tube.

SURFACE CHARACTERISTICS OF SAMPLE AREA

Slopes: $3-5^{\circ}$ regional slope downward to the northwest. Locally, nearly level on the rim of a $10-15 \mathrm{~m}$ crater.

Fragment population

Size range and distribution: Up to $1 \mathrm{~cm}$ abundant; $1-3 \mathrm{~cm}$

common; 3-5 cm sparse.

Color: Medium gray.

Shapes: Generally rounded, a few angular.

Fillets: None visible.

Apparent burial: Several fragments appear partially buried. Dust cover: None visible.

Fines

Color: Medium gray.

Compaction: Very soft, as indicated by bootprints.

Craters

Distribution: Up to 4-5 cm common; larger ones sparse.

Shape: Subdued.

Ejecta: None visible.

SAMPLE CHARACTERISTICS

Size: Mostly <1 cm fines; 68002 (upper) -- 583.5 grams

68001 (lower) -- 840.7 grams

Comparison with other soil in area: Surface around the drive tube appears typical of the area.

Probable origin: Locale suggests South Ray ejecta at the surface; the drive tube probably sampled pre-South Ray regolith derived predominatly from the nearby area.

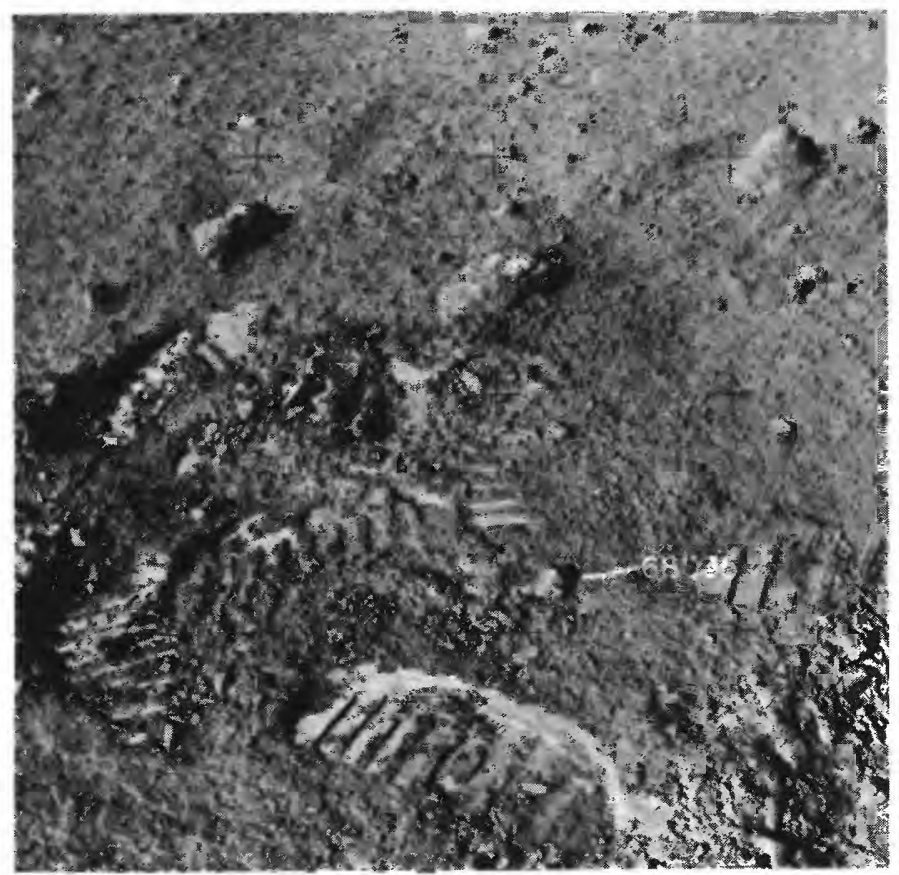

FIGURE $84 A$.- Sample 68035 shown before sampling in part of photograph AS16-107-17532; view is southwest. Bright spots in sample are reflections from glassy surface (see table 3, p. 41). 


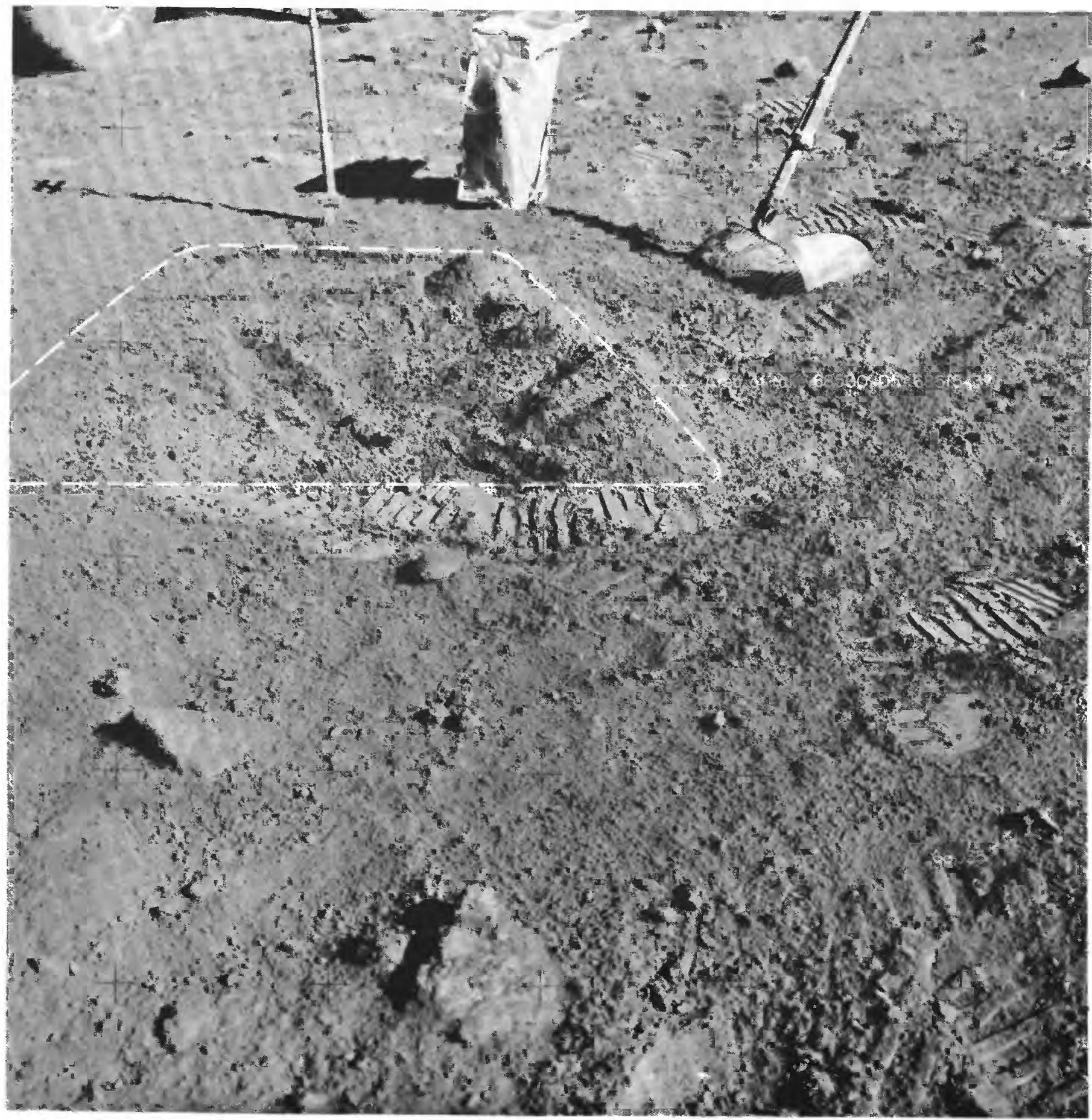

FIGURE $84 B$.- Location of sample 68035 relative to LRV and rake samples $68500-05$ and $68515-37$, shown after raking and before sampling 68035 in photograph AS16-107-17535. View is northwest. See fig. 87 for further documentation of rake samples. 


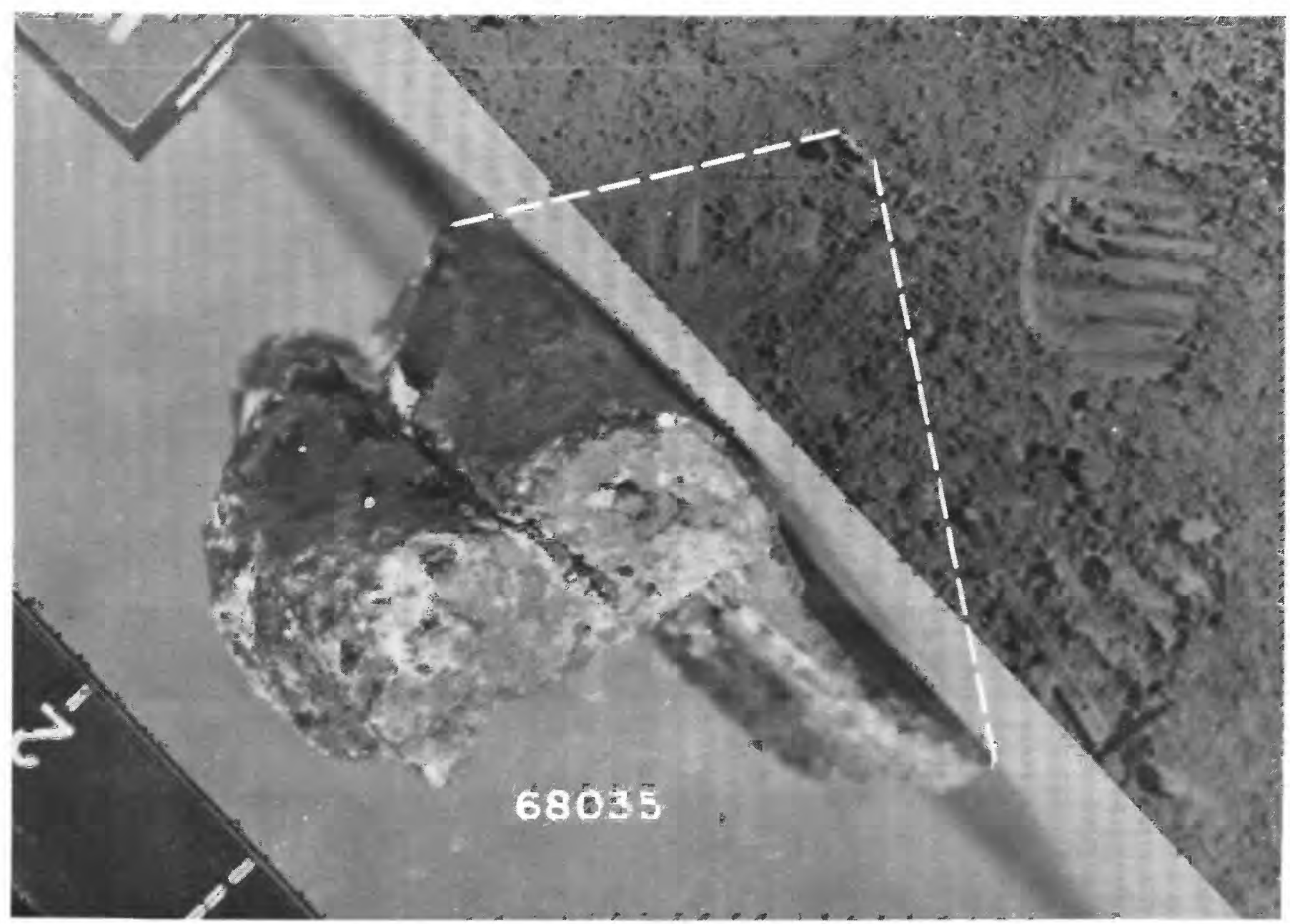

FIGURE $84 C$.- Sample 68035 showing approximate lunar orientation by comparing the $W_{1}$ photographic view in LRL to an enlarged part of lunar-surface photograph AS16-107-17534 taken before sampling. View is north (inset photograph, S-72-40513). Scale at lower left in centimeters. 


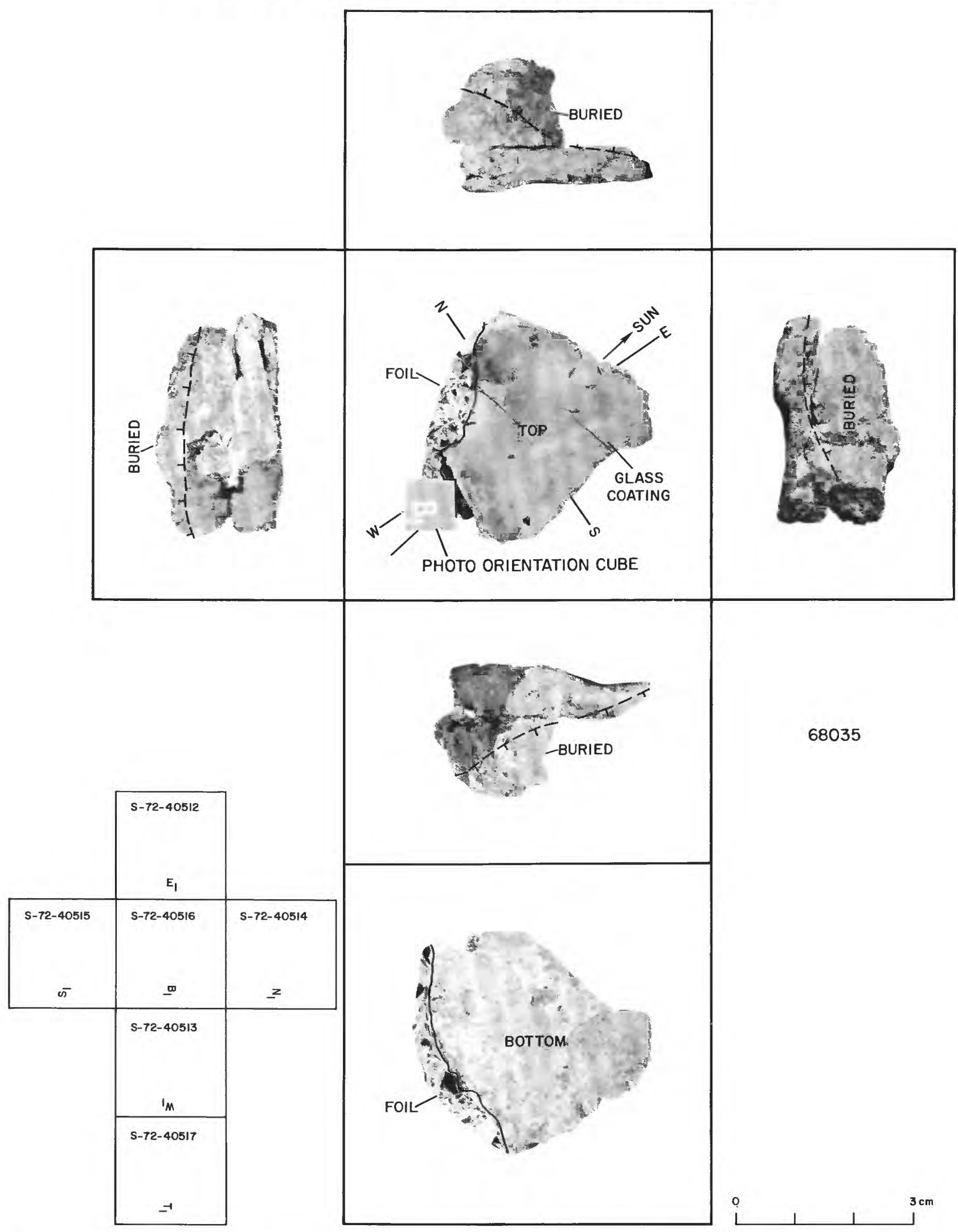

FigURE $84 D$.- Orthogonal views of sample 68035 related to its lunar orientation at time of sampling. Sample is partly glass coated $\mathrm{B}_{2}$ breccia. 
SAMPLE: $68035 ; 68500-04,05 ; 68515-19,25-29,35-37$

Station: 8

Landmark: On north rim of a $10-15 \mathrm{~m}$ crater in vicinity of visible rays from South Ray crater.

Rock type: 68035, partly glass coated B2 breccia; 68500-05, rake soil with 1 incidental fragment; 68515-37, 13 rake fragments types $B 2, B 4, C 2$, and $G$ (see figures $87 A-E$ ).

SURFACE CHARACTERISTICS OF SAMPLE AREA

Slopes: Locally sloping north off rim of $10-15 \mathrm{~m}$ crater.

Fragment population

Size range and distribution: Up to $1 \mathrm{~cm}$ abundant; $1-2 \mathrm{~cm}$

sparse; 2-5 cm rare.

Color: Medium gray.

Shapes: Generally rounded, some angular.

Fillets: None visible.

Apparent burial: Some of the more rounded fragments are partially buried.

Dust cover: None visible.

Fines

Color: Medium gray.

Compaction: Generally firm.

Craters

Size range and distribution: $U p$ to $3 \mathrm{~cm}$ common, larger ones sparse.

Shape: Subdued.

Ejecta: None visible.

SAMPLE CHARACTERISTICS FOR 68035 (see figures $84(A-D)$.

Size: $3 \times 3 \times 3 \mathrm{~cm} ; 20.96$ grams.

Color: White matrix, dark clasts, dark glass coating.

Shape: Slabby, subangular, roughly triangular.

Comparison with other fragments in area: Other glass fragments are scattered over the surface in this area. This one reflected red and green in the sunlight (see Table 3, p. 41).

Probable origin: Ejecta from South Ray crater. 

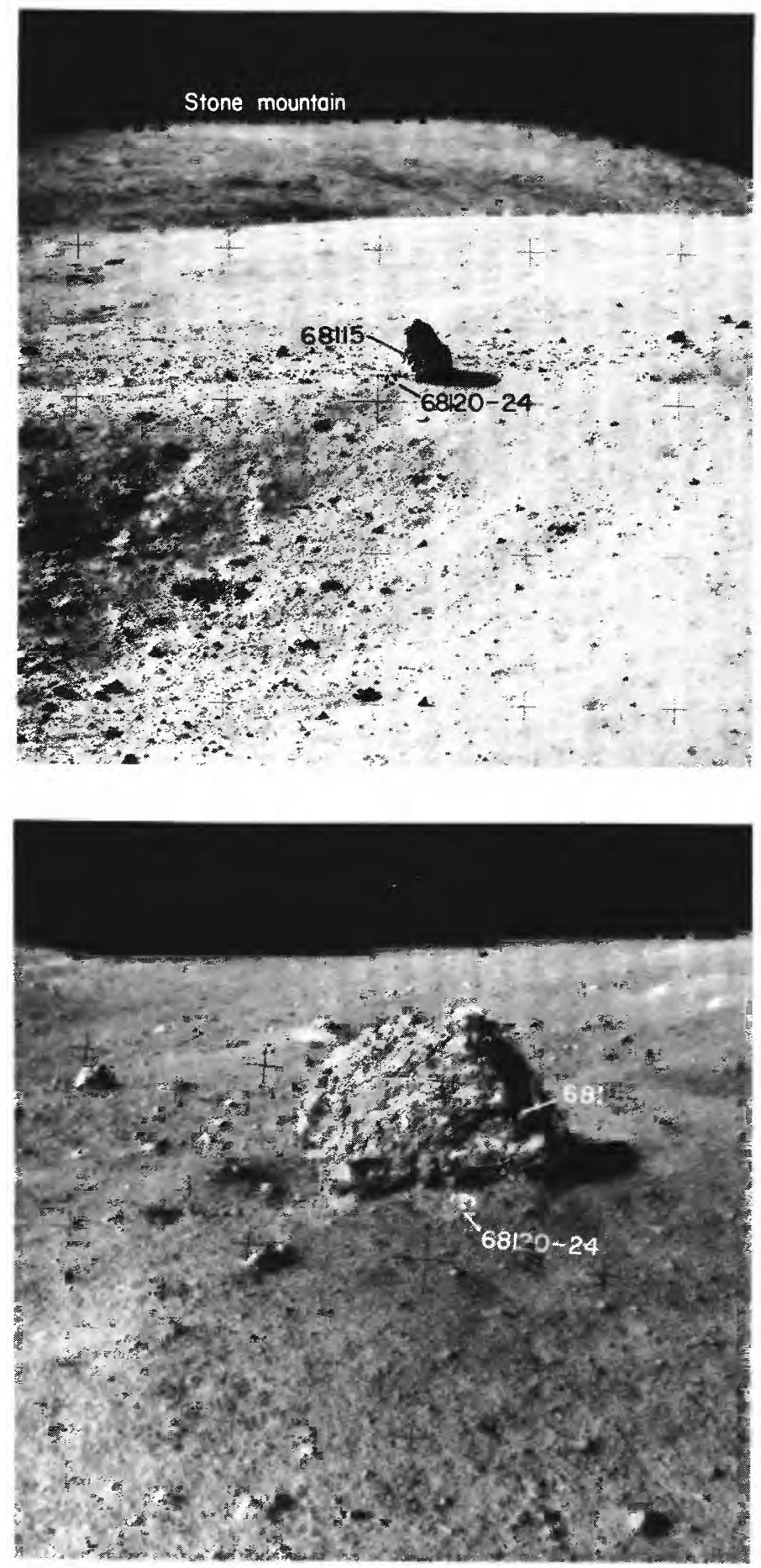

4Figure 85A.-Location of rock sample 68115, chipped from boulder No. 1 (see chap. D3, for discussion of station 8), and soil sample $68120-24$ collected adjacent to boulder, shown before sampling in panorama photograph AS16-108-17676. View is southeast toward Stone mountain. Boulder is believed to be part of blocky ray ejected from South Ray crater.

4Figure 85B.-Samples 68115 and 68120-24, at boulder No. 1, shown before sampling in part of photograph AS16-108-17690; view is southwest. 


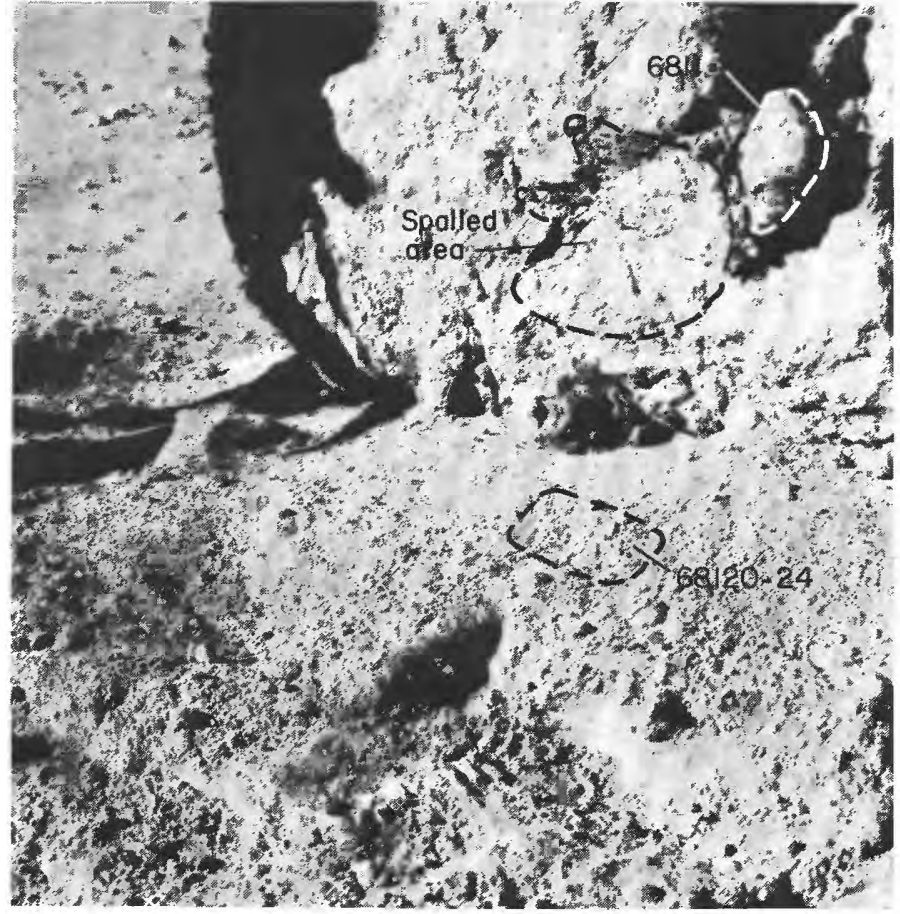

Figure $85 C$ - Samples 68115 and $68120-24$ shown before sampling in photograph AS16-107-17542; view is southeast. Note nearly circular percussion spall $\sim 20 \mathrm{~cm}$ in diameter to left of sample 68115 on the boulder. Compare this spall feature with one photographed by the crew at Outhouse rock (fig. 79A).

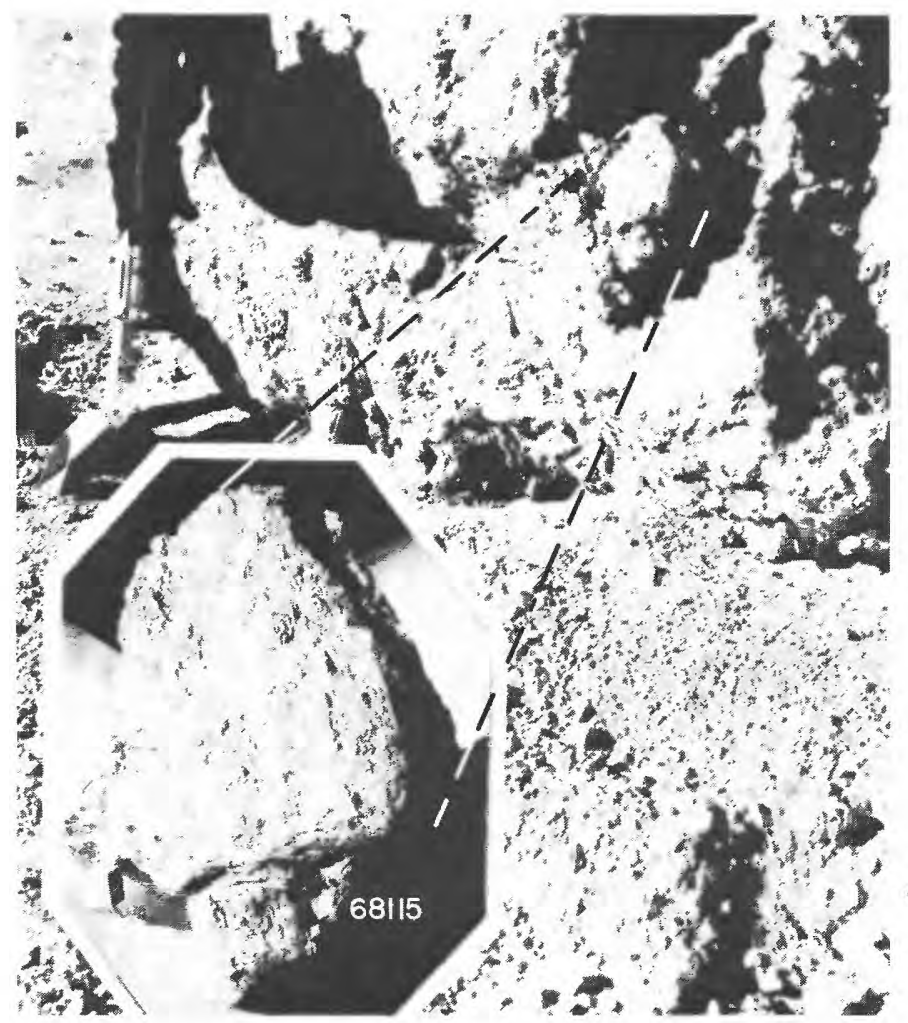

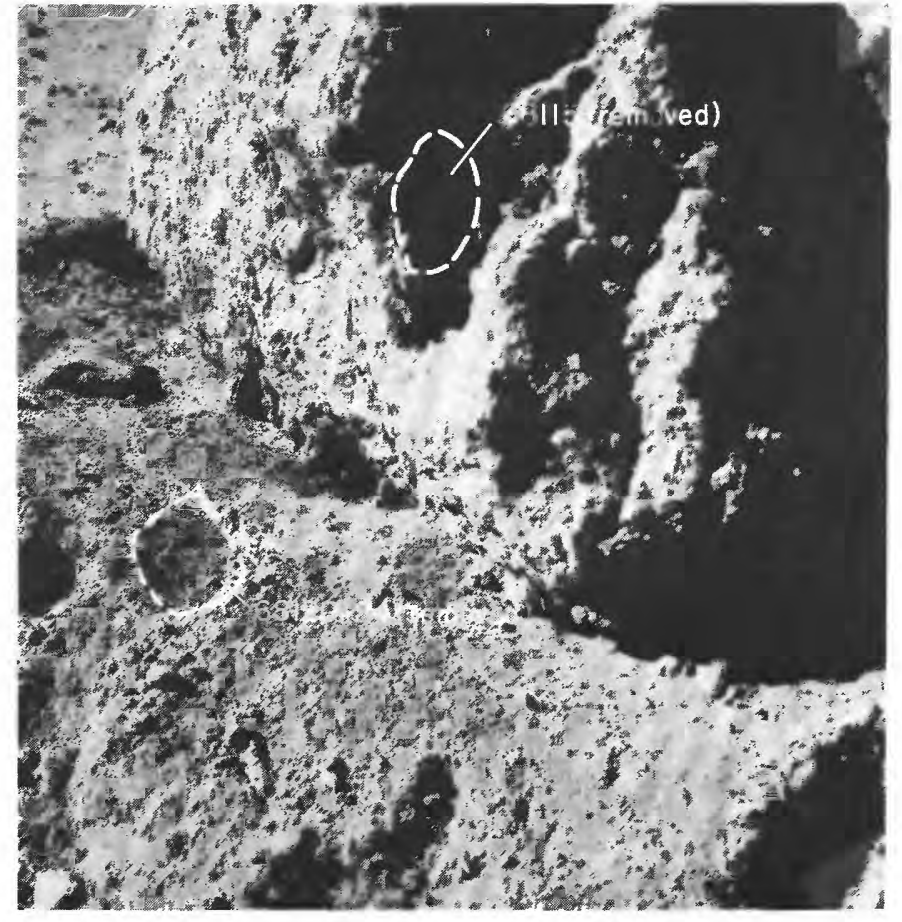

Figure 85D.-Locations of samples 68115 and $68120-24$ shown after sampling in photograph AS16-107-17547; view is east.

Figure 85E.-Sample 68115 showing approximate lunar orientation reconstructed in LRL compared to an enlarged part of photograph AS16-107-17544 taken before sampling. View is southeast (inset photograph, S-72-41056). 


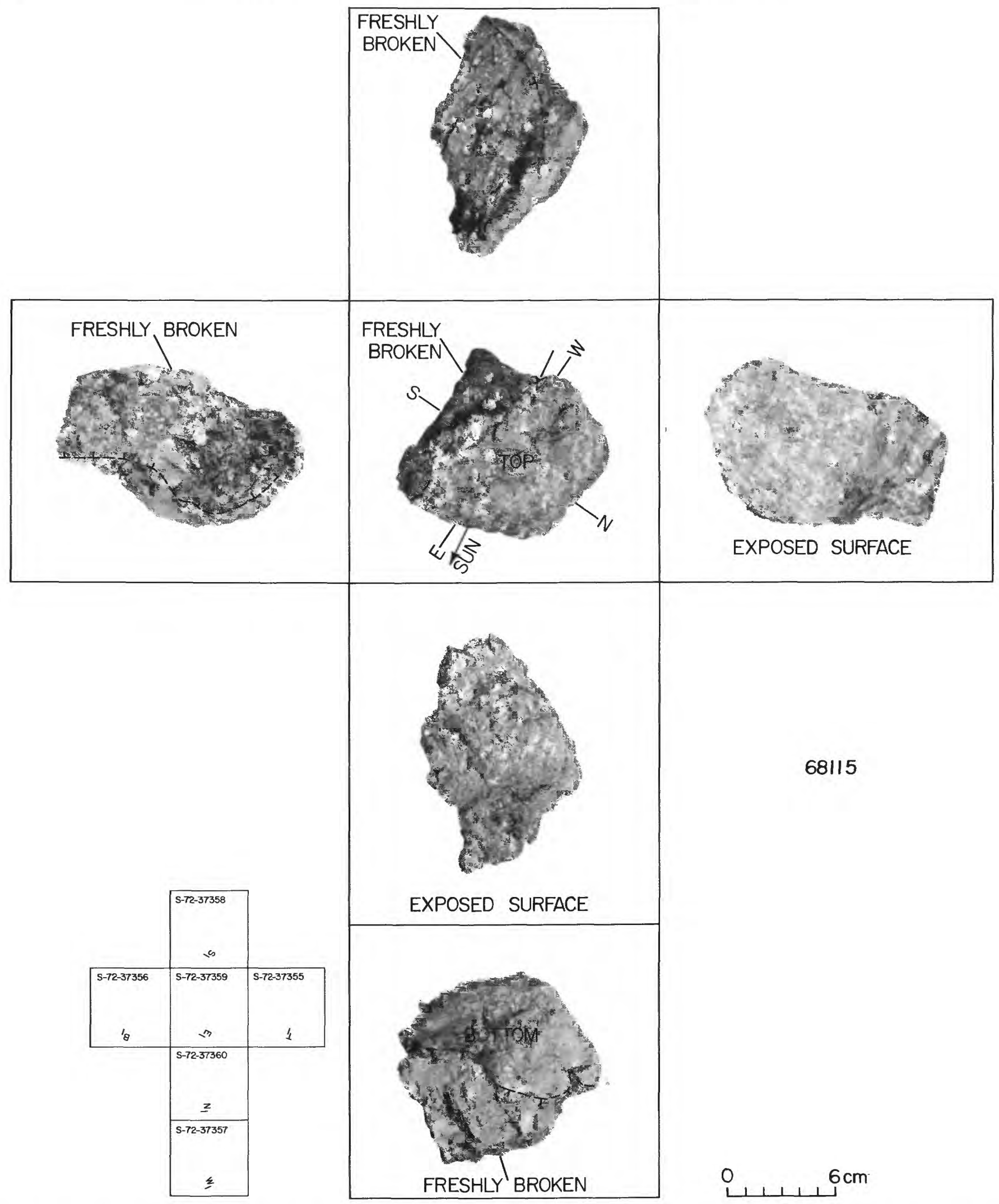

FIGURE $85 F$.-Orthogonal views of sample 68115 related to its lunar orientation at time of sampling. See chap. D3, figs. $9 A$, $9 B$, and $10 A$ for a stereopair of this type $B_{5}$ breccia, a closeup photograph of breccia boulder No. 1, and a photomicrograph of sample, respectively. 
SAMPLE: 68115, 68120-24

Station: 8

Landmark: $1 \mathrm{~m}$ boulder (boulder \#I) on the southeast rim of a 10-15 m crater, approximately $10 \mathrm{~m}$ SE of station 8 panorama site. Rocky type: 68115 is dark matrix breccia, B5; 68120-24 is soil collected from near the base of the boulder.

SURFACE CHARACTERISTICS OF SAMPLE AREA

Slopes: Regionally a $35^{\circ}$ slope downward to the northeast.

$\overline{L o c a l l y}$, a steeper slope northwestward into $10-15 \mathrm{~m}$ crater.

Fragment population

Size range and distribution: Up to $2 \mathrm{~cm}$ abundant. Three cm to $15 \mathrm{~cm}$ common, $15 \mathrm{~cm}$ to $2 \mathrm{~m}$ sparse.

Color: Generally medium gray, a few light gray.

Shapes: Mostly angular, some rounded.

Fillets: Within the $10-15 \mathrm{~m}$ crater most fragments have

well developed fillets on the uphill sides.

Apparent burial: Mostly perched.

Dust cover: None visible except on small fragments

Fines

Color: Medium Gray

Compaction: Moderately firm away from crater rims.

Craters

Distribution: Up to $20 \mathrm{~cm}$ aburdant. Twenty $\mathrm{cm}$ and larger common.

One 10-15 $\mathrm{m}$ and one $15-20 \mathrm{~m}$ crater are in the immediate area.

Shape: Subdued.

Ejecta: Most blocks on surface probably represent south Ray

ejecta.

SAMPLE CHARACTERISTICS FOR 68115 (see figure 85F)

Size: $15 \times 9.5 \times 8.5 \mathrm{~cm}$; 1191 grams.

Color: Medium gray to medium dark gray.

Shape: Subangular, blocky.

Fillets: Possibly a poorly developed fillet at the base of $1 \mathrm{~m}$ boulder.

Burial: Approximately $1 / 3$ of surface of the sample is freshly

broken (from boulder).

Dust cover: None visible.

Comparison with other fragments in area: The boulder is similar in

angularity, color, and burial to many other fragments in the area.

Probable origin: Perched nature; similarity to other fragments in

the area, and location on a mapped ray from South Ray suggest the boulder was ejected from south Ray crater.

SAMPLE CHARACTERISTICS FOR 68120-24

Size: $\quad<1 \mathrm{~cm}$ fines; 259.32 grams total weight.

Color: Medium gray.

Comparison with other soil in area: Soil and small fragments.

Probable origin of fillet: l) soft, fine-grained, crater-rim material

shoved up by the boulder as it came to rest; 2) formed by material

sloughing off the face of the boulder. 


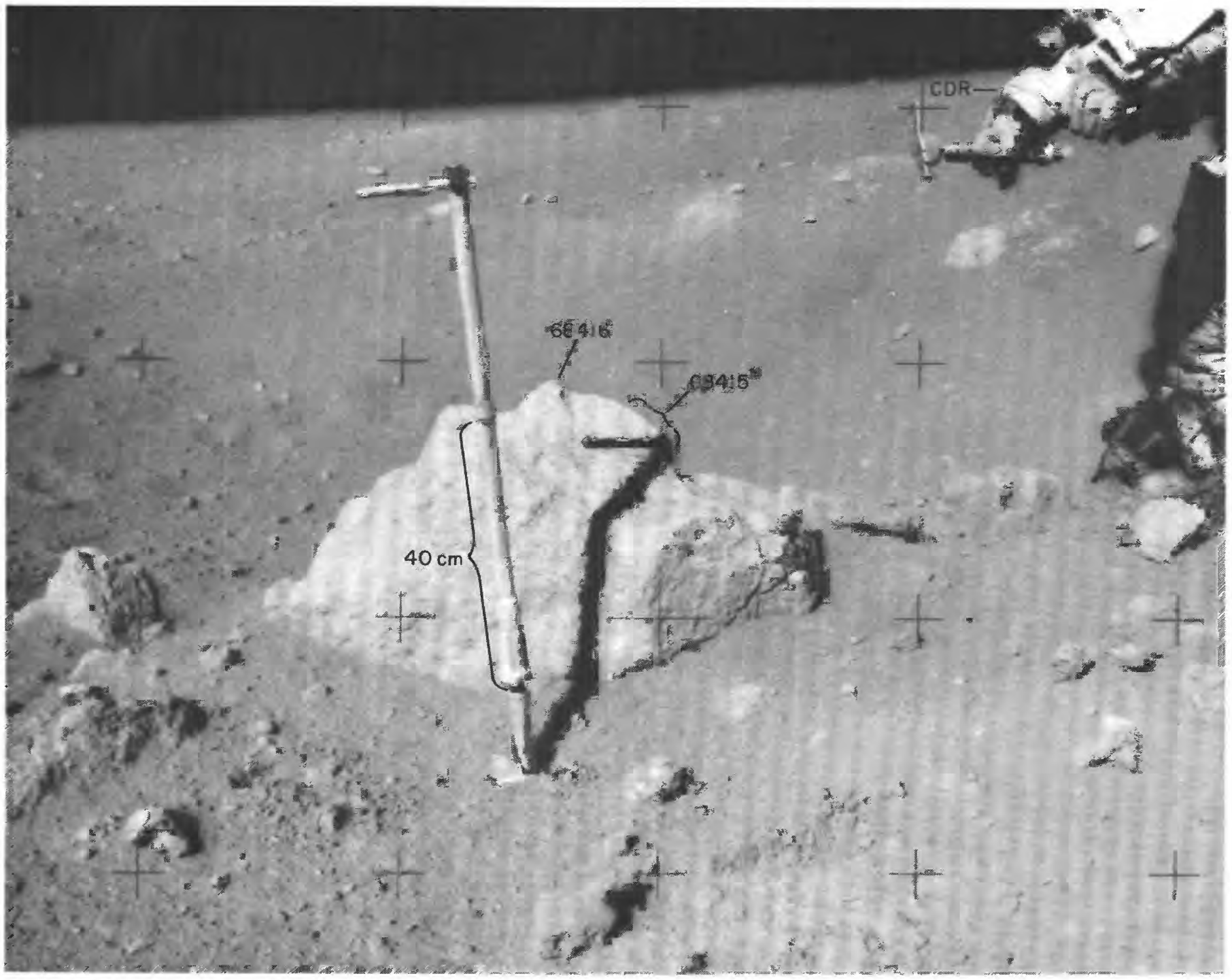

FIGURE 86 A.-Location of samples 68415 and 68416 , in boulder No. 2 at station 8 , shown before sampling in photograph AS16-108-17697. View is southwest. This crystalline rock, one of many in the area that are similar in appearance, is believed to be part of a blocky ray ejected from South Ray crater. 


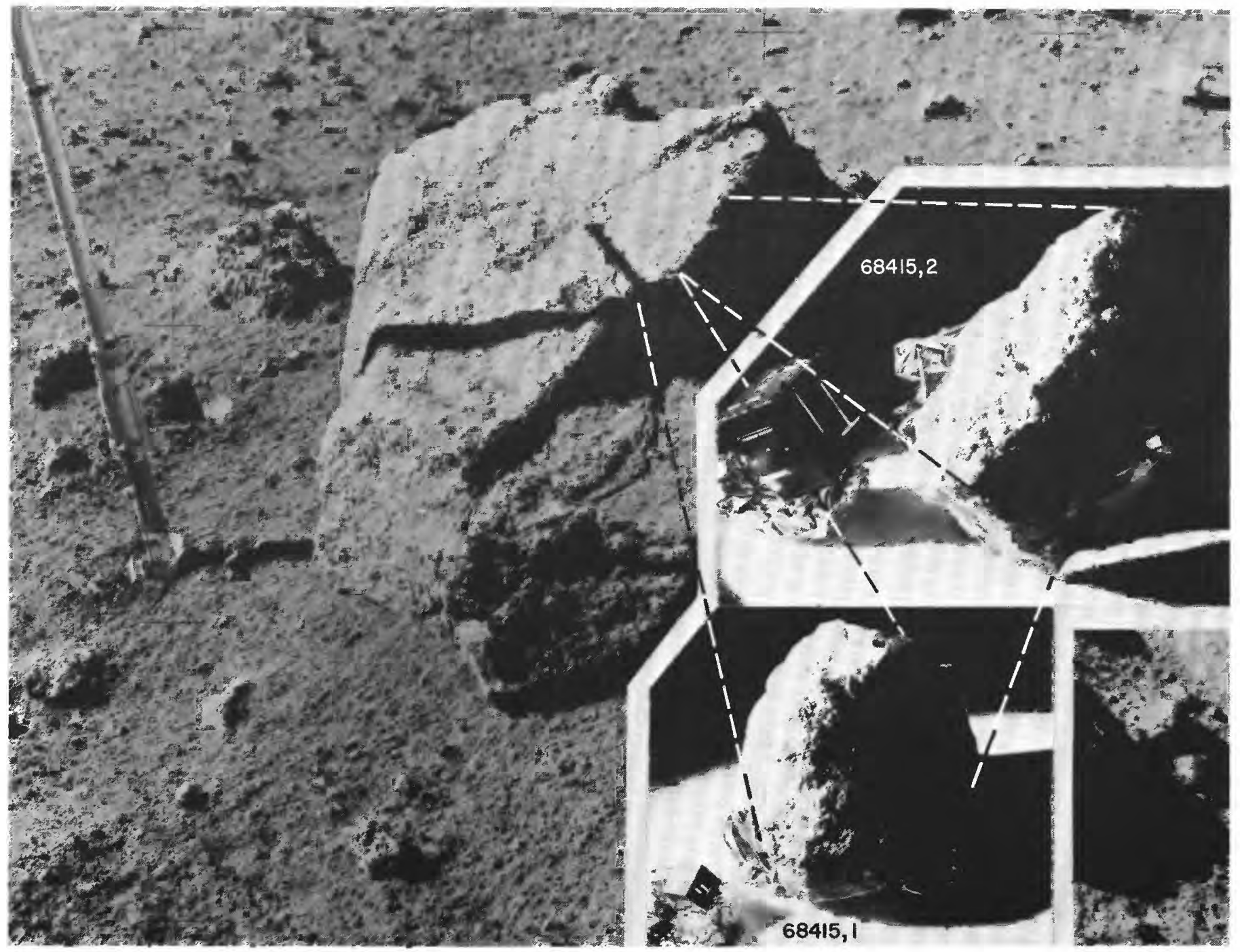

Figure 86B.--Sample 68415, broken from boulder in two parts $(68415,1$ and 68415,2$)$, showing approximate lunar orientation reconstructed in LRL compared to an enlarged part of photograph AS16-107-17549 taken before sampling. View is southeast (inset photographs, S-74-41545 and 42600). Sample 68416 chipped from same boulder.

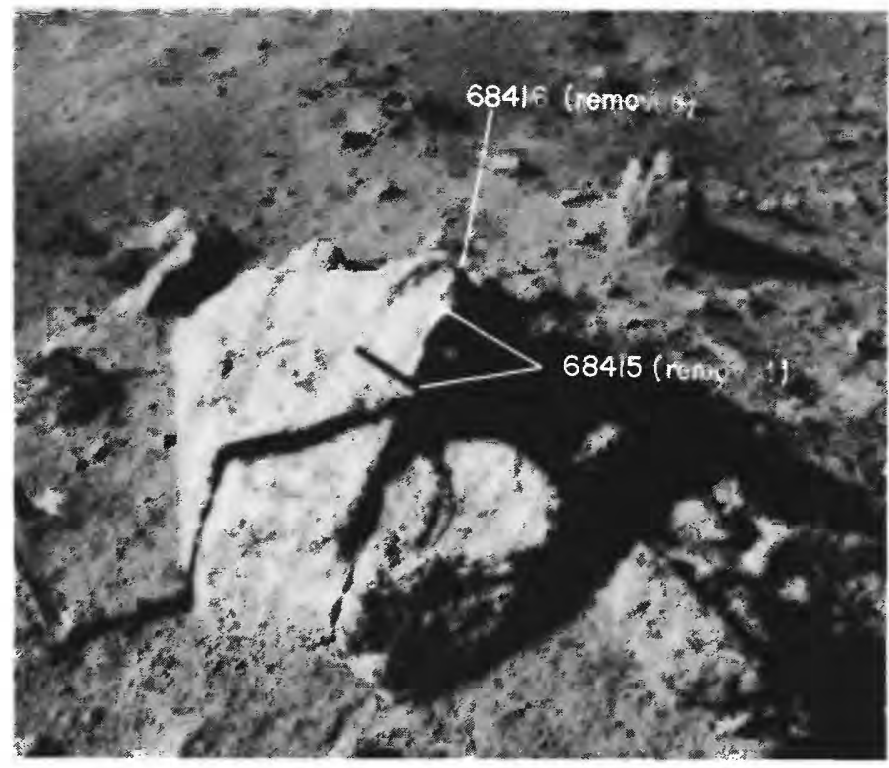

4Figure 86C.-Location of samples 68415 and 68416 shown after sampling in photograph AS16-108-17698; view is southeast. 


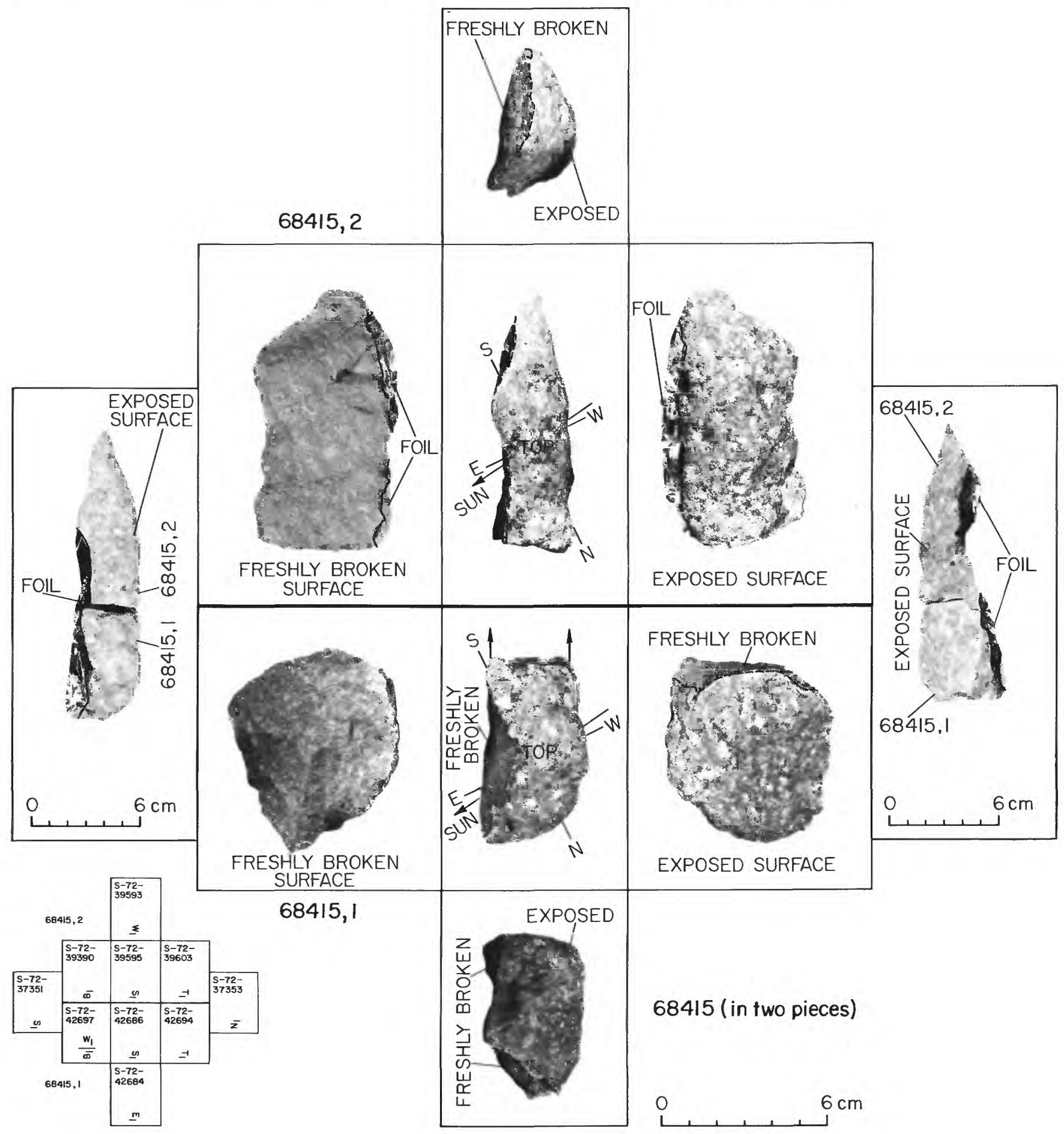

FIGURE $86 D$.- Orthogonal views of sample 68415 (combining two broken pieces) related to its lunar orientation at time of sampling. See chap. D3, figs. $9 C$ and $10 B$, for stereopair and photomicrograph, respectively, of fragment 68415,1 . Other photomicrographs of this crystalline $\left(\mathrm{C}_{1}\right)$ rock shown in frontispiece, chap. E, fig. $2 A$, and chap. J, fig. $3 C$. The $\mathrm{B}_{1}$ photographic view of 68415,2 shown in chap. $J$, fig. $3 B$. 


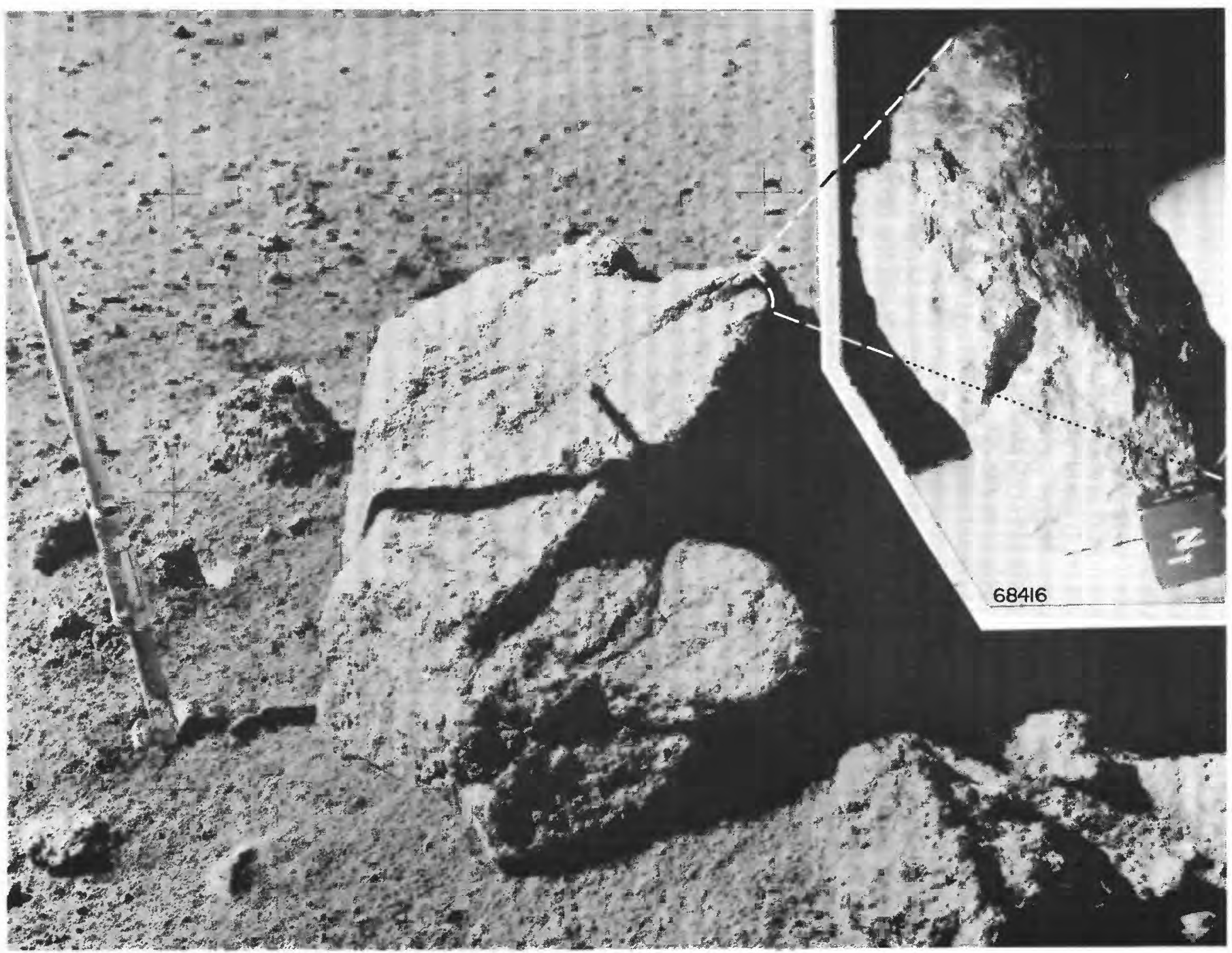

FIGURE $86 E$.- Sample 68416 showing approximate lunar orientation reconstructed in LRL compared to an enlarged part of photograph AS16-107-17549 taken before sampling. View is southeast (inset photograph, S-72-40964). Sample 68415 was chipped from the same boulder. 


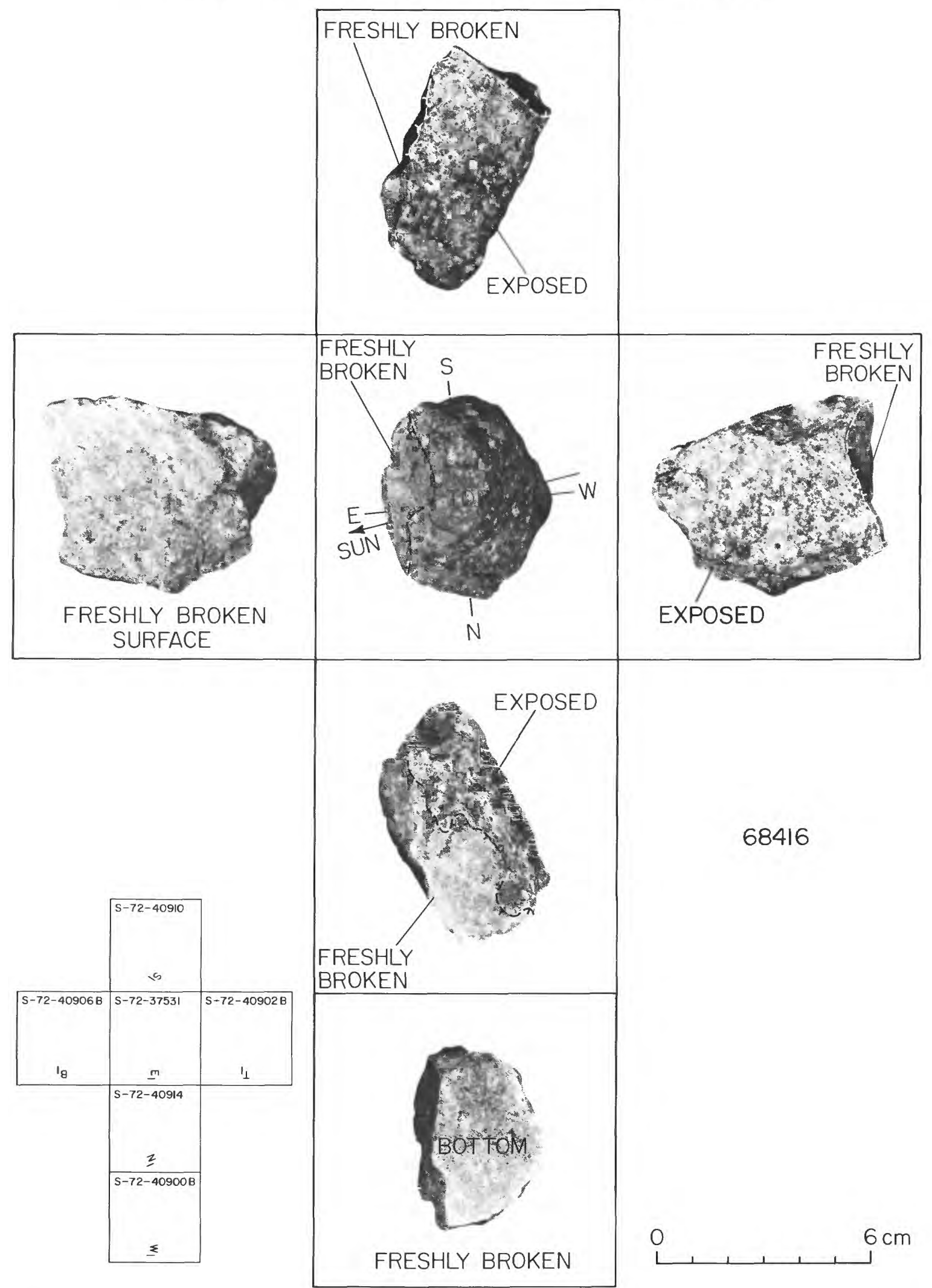

Figure $86 F$. - Orthogonal views of sample 68416 related to its lunar orientation at time of sampling. See chap. D3, figs. $9 D$ and $10 C$, for a stereopair and photomicrograph, respectively, of this crystalline $\left(\mathrm{C}_{1}\right)$ sample. 


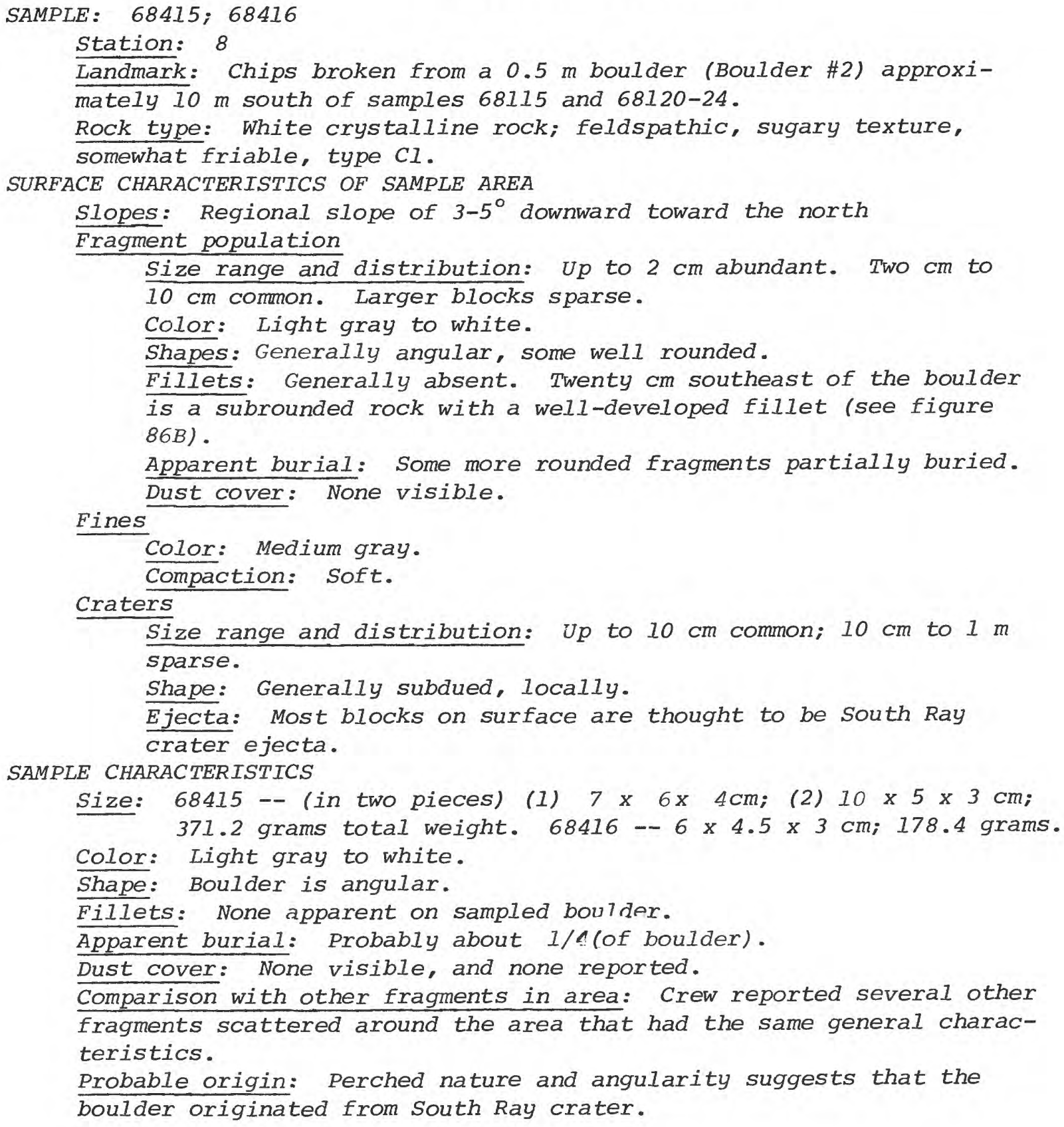




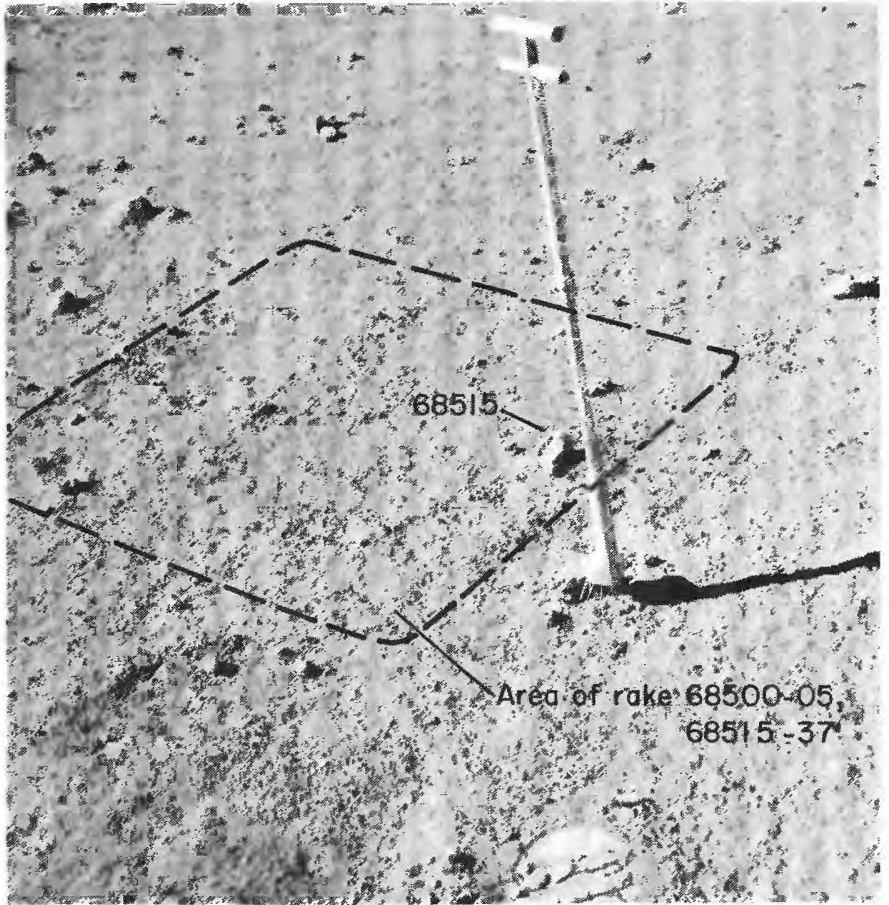

FigURE 87A.-Area of rake samples 68500-05 and 68515-37 shown before sampling in AS16-107-17528; view is south. See figures $83 A$ and $84 B$ for location of the rake area with respect to LRV at station 8 .

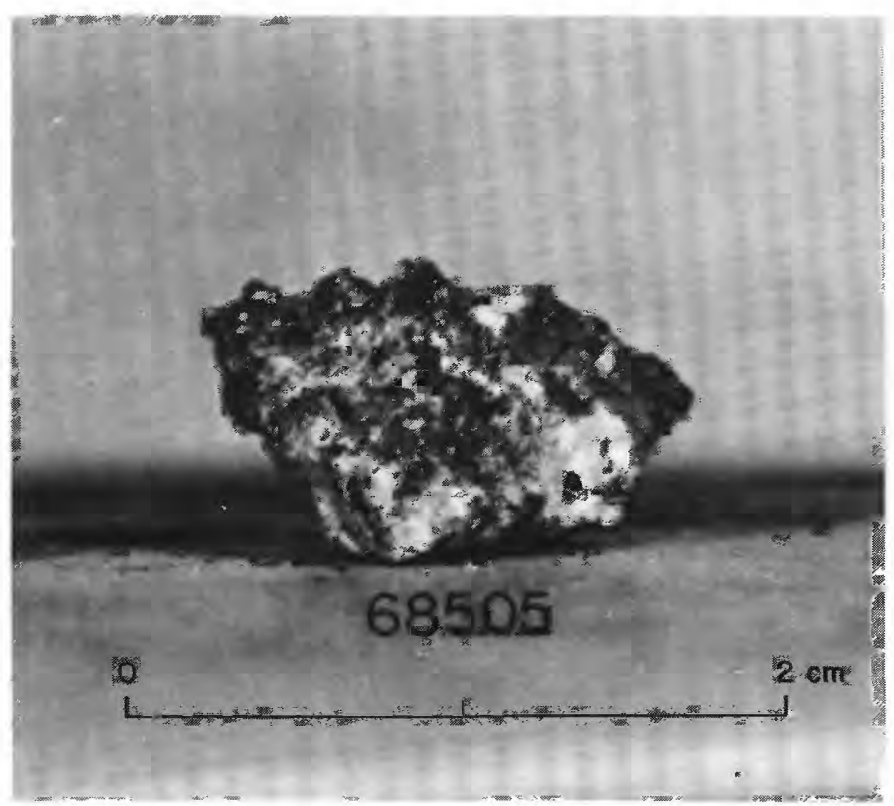

Figure 87B.-Sample 68505, an incidental fragment collected with rake soil sample 68500-04, in LRL (photograph S-72-40520, $\mathrm{S}_{1}$ view). $<2$ g, not classified.

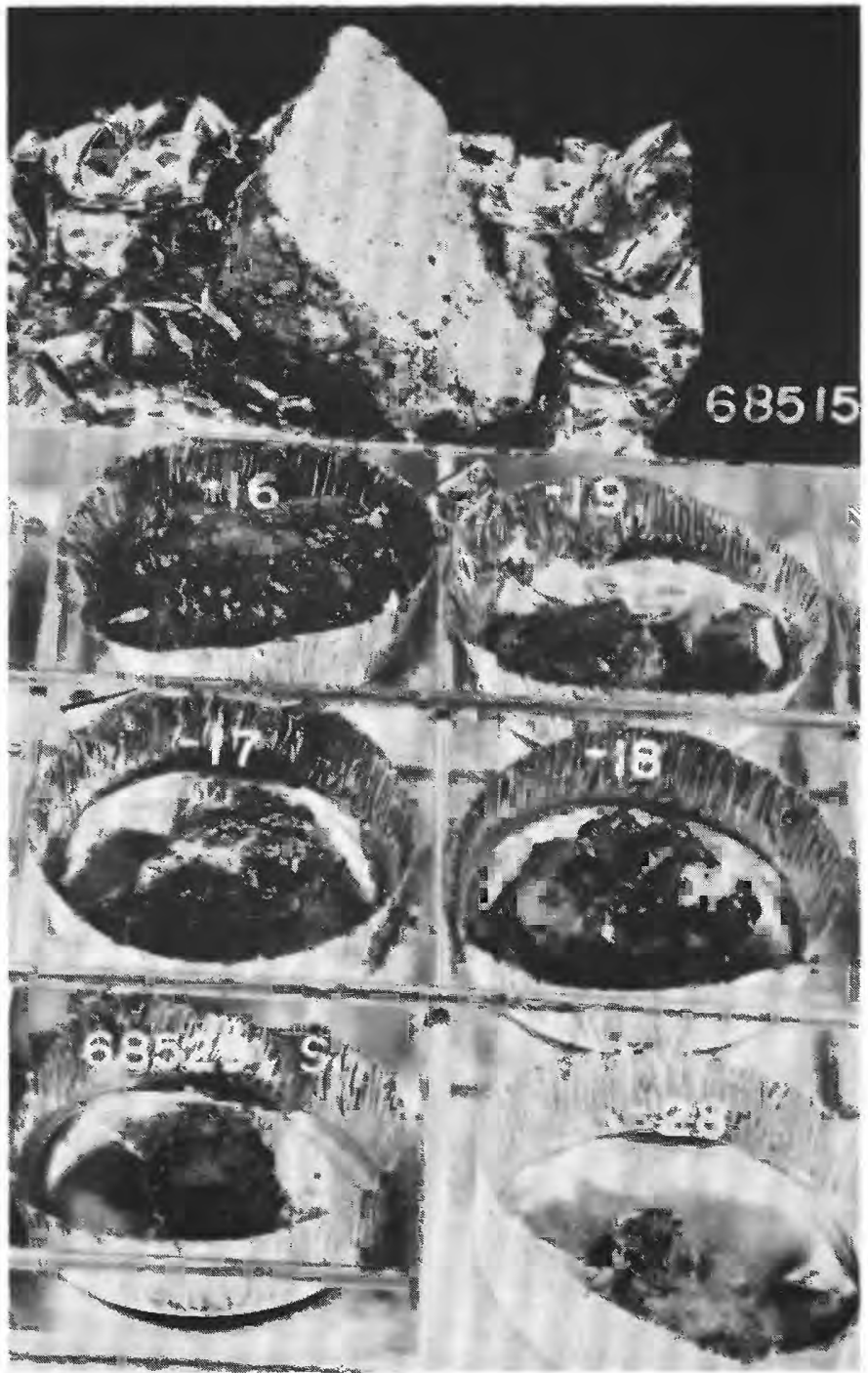

Figure 87C.-Part of rake sample 68515-37 in LRL. This group includes fragments $68515-19,28$, and 29. (Photograph S72-43516, with inset from S-72-43518 that shows fragment 29.) Fragments 15,17 , and 19 classified as $B_{2}$ breccia; fragments 16 and $18, \mathrm{~B}_{4}$ breccia; 28 is $<2 \mathrm{~g}$, not classified; 29 , a glass $(\mathrm{G})$ fragment. All partly coated by glass. 


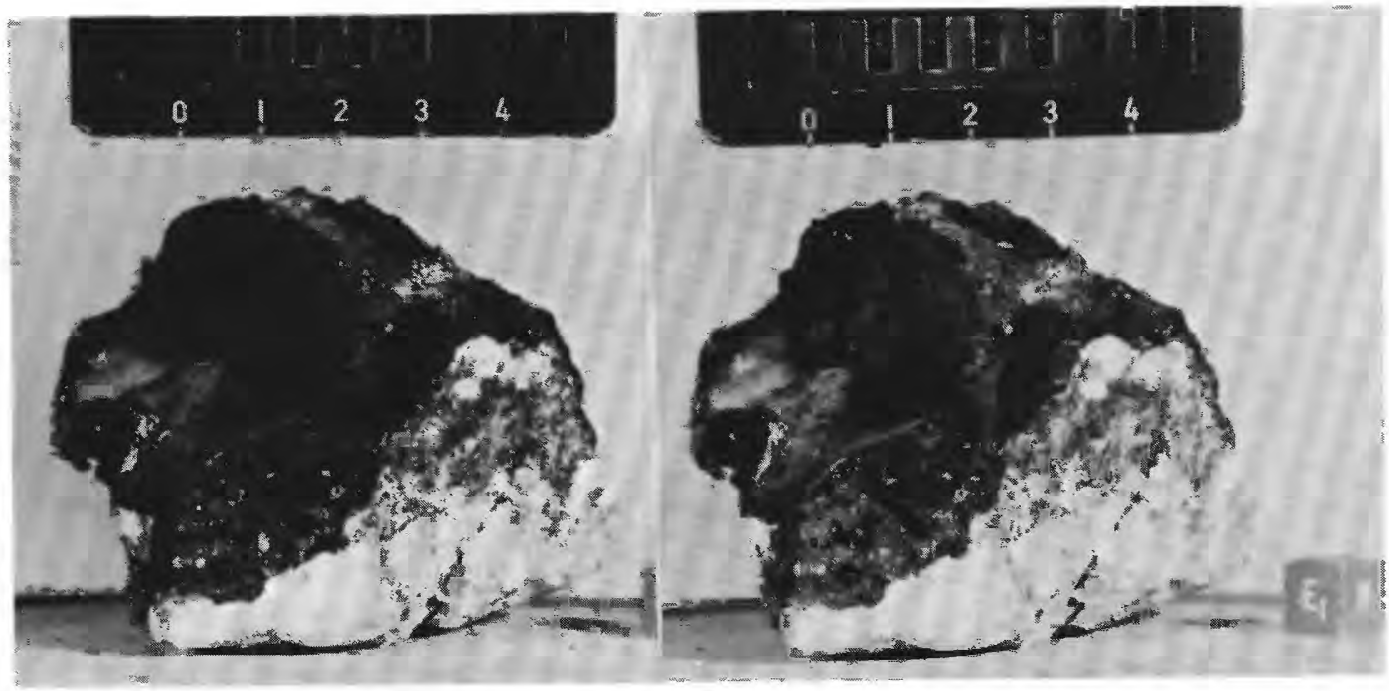

FIgURE 87D. - Stereopair of rake fragment 68515 in LRL; photographs S-72-45263 (right) and -45263B (left). $B_{2}$ breccia partly coated by vesicular black glass.

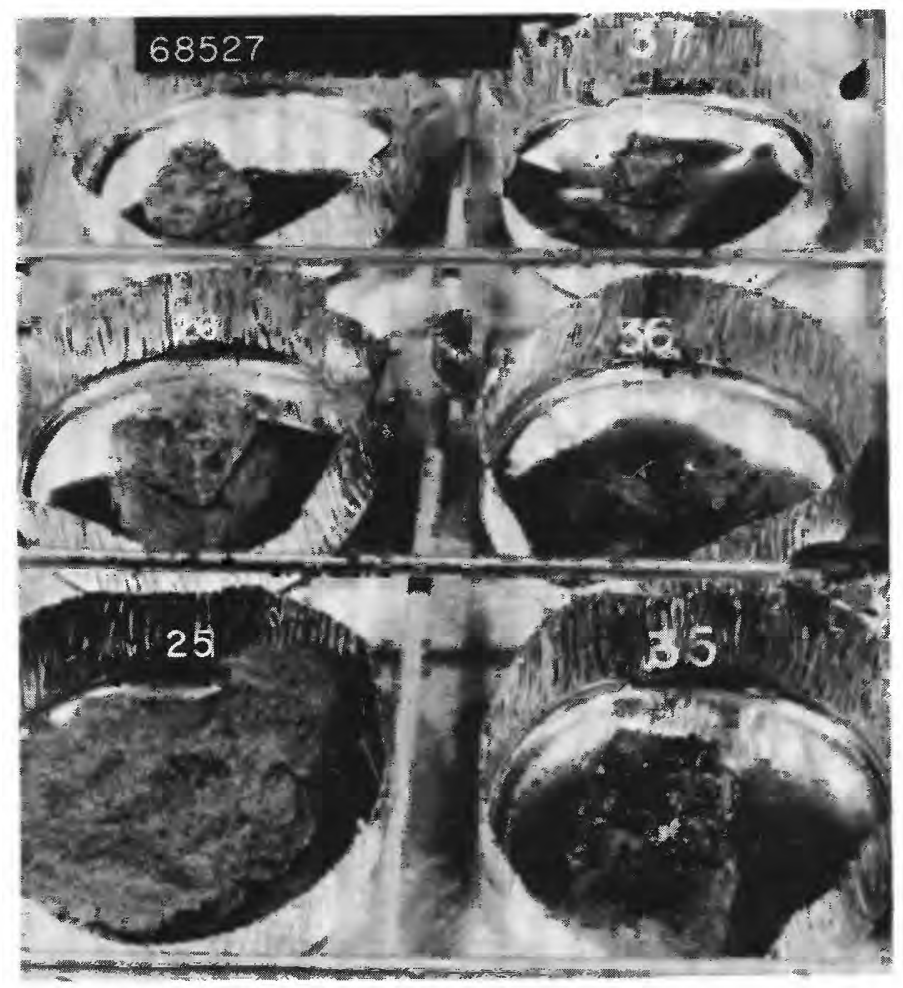

FIGURE 87E.-Part of rake sample $68515-37$ in LRL (photograph S-72-43514). This group includes fragments 68525-27 and 68535-37. Fragments $25-27$ and 35 classified metaclastic $\left(\mathrm{C}_{2}\right)$; fragments 36 and $37(<2 \mathrm{~g})$ not classified; look similar to partly glass coated fragment 35 . 
SAMPLE: 68500-05; 68515-19, 25-29, 35-37, (rake samples)

See description with sample 68035, and figures $83 \mathrm{~A}$ and $84 \mathrm{~B}$ for illustrations showing location of samples.

SAMPLE CHARACTERISTICS FOR 68500-04 (rake soil) and 68605 (incidental

fragment)

Size: $\quad<1 \mathrm{~cm}$ fines; 905.77 grams total weight; $1.5 \mathrm{~cm}$ fragment, 1.3 grams.

Color: Medium gray.

Comparison with other soil in area: Probably typical of station 8. Probable origin: Local regolith probably mixed to some extent with fine ejecta from South Ray.

SAMPLE CHARACTERISTICS FOR 68515-37 (13 rake fragments)

Size: 68515 is approximately $8 \times 6 \times 5 \mathrm{~cm}, 236.1$ grams; other

12 fragments are $1.5-4.5 \mathrm{~cm}$ long, 156.16 grams total weight.

Color: Medium gray.

Shape: Rounded.

Comparison with other fragments in area: Shape and color of material in rake area appears similar to the surrounding area.

Probable origin: Locale, similarity to surrounding surface, suggests ejecta from South Ray. 


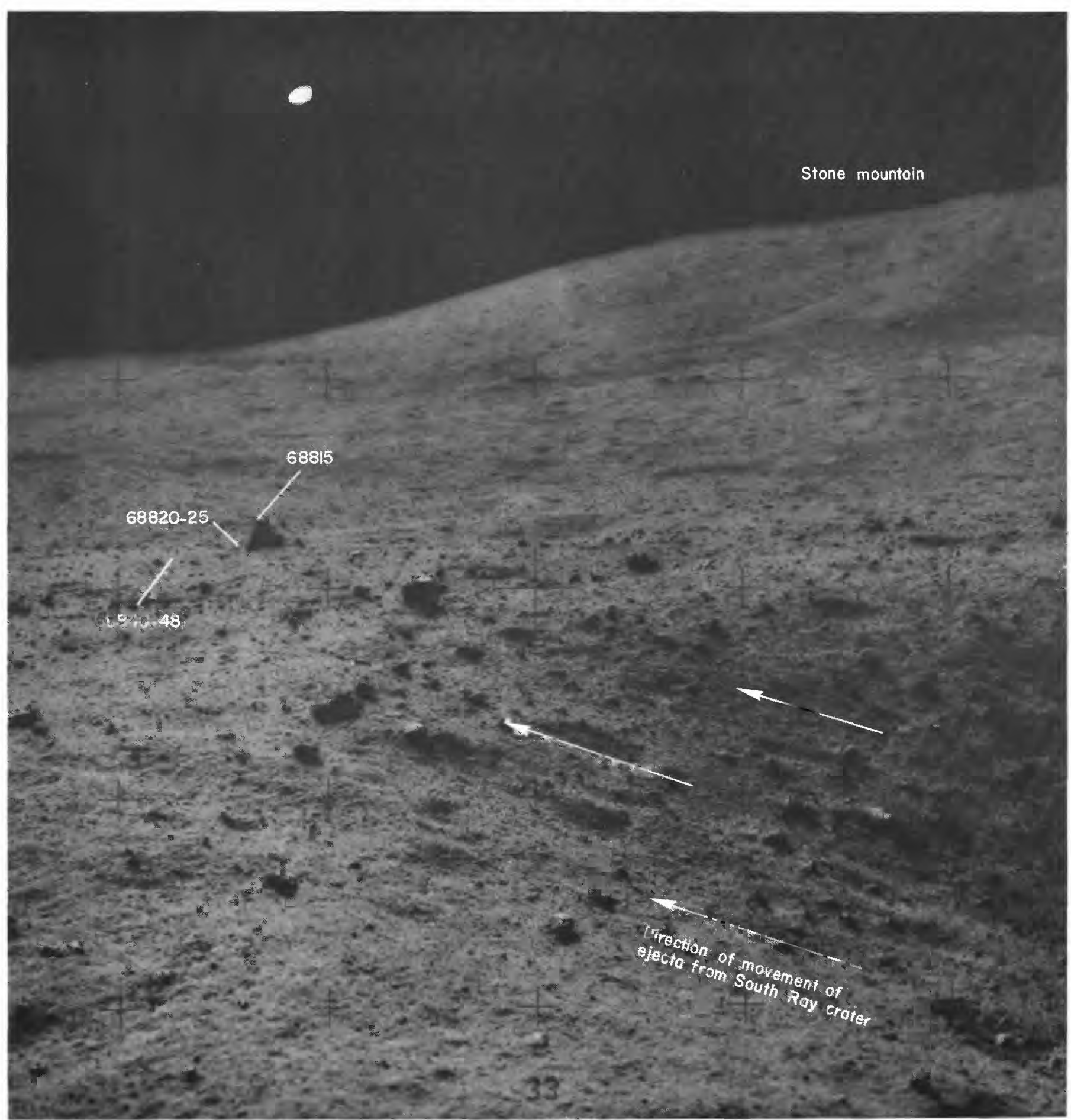

Figure 88A.-Location of rock sample 68815 chipped from boulder 3 (see chap. D3 for discussion of station 8), and soil samples $68820-25$ and 68840-48, before sampling in panorama photograph AS16-108-17673. View is east. Boulder 3, about $1 \mathrm{~m}$ across, is part of a blocky ray ejected from South Ray crater. Note elongate craters and discontinuous grooves probably caused by movement of ejecta away from South Ray. 

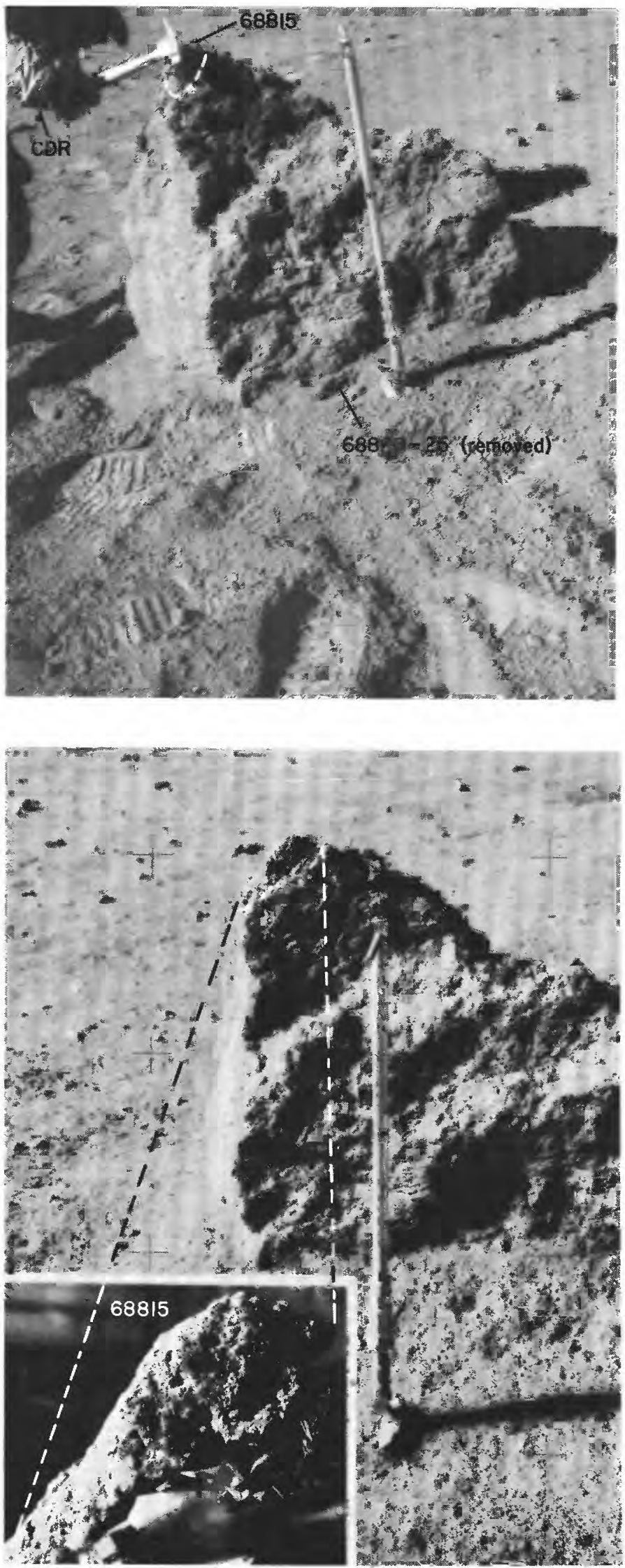

Figure 88B.-Sample 68815 shown being chipped from top of boulder 3 in photograph AS16-108-17701; view is southwest. Sample $68820-25$ (fillet soil) had already been collected when this picture was taken.
4 Figure 88 C.-Sample 68815 showing approximate lunar orientation reconstructed in LRL compared to an enlarged part of photograph AS16-108-17699 taken before sampling. View is south (inset photograph, S-72-41425). 


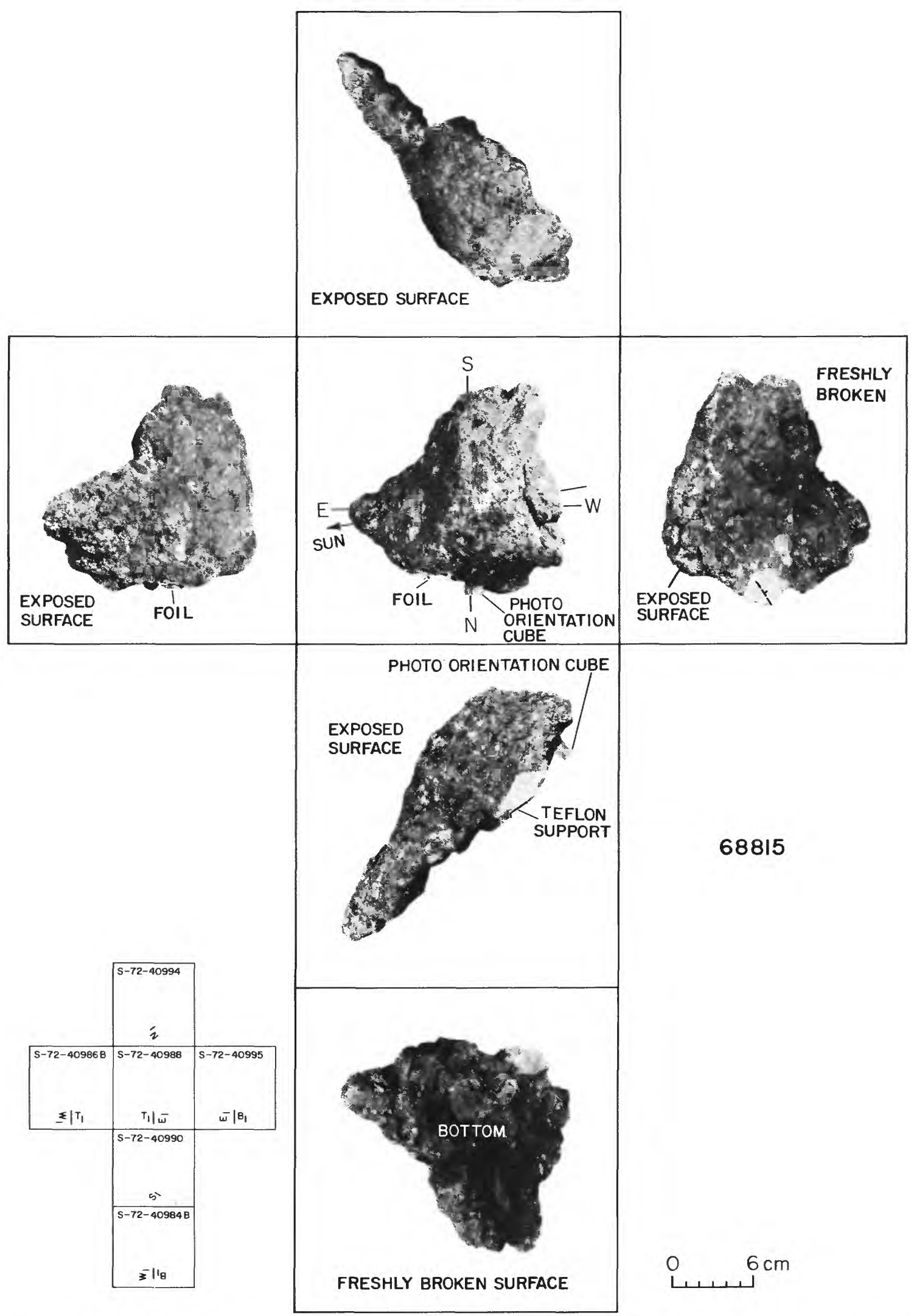

FIGURE $88 D$.- Orthogonal views of sample 68815 related to its lunar orientation at time of sampling. See chap. D3, figs. $9 E$ and $10 D$, for stereopair of $\mathrm{B}_{1}$ photographic view (freshly broken surface) and photomicrograph, respectively; and chap. E, fig. $4 D$, for photomicrograph of this type $B_{5}$ breccia. 
SAMPLE: $68815 ; 68820-24,25 ; 68840-44,45-48$

Station: 8

Landmark: Boulder \#3, approximately $40 \mathrm{~m}$ ENE from station 8 panorama site.

Rock type: Dark matrix breccia, type B5; soil and unclassified

fragments. See figures $88 A-D$ and $89 A-B$.

SURFACE CHARACTERISTICS OF SAMYLE AREA

Slopes: $3-5^{\circ}$ regional slope downward to the northeast.

Fragment population

Size range and distribution: Up to $1 \mathrm{~cm}$ abundant. $1-3 \mathrm{~cm}$

common; $3 \mathrm{~cm}$ to $1 \mathrm{~m}$ sparse.

Color: Medium gray.

Shapes: Generally angular. Smaller fragments are rounded.

Fillets: Small or absent.

Apparent burial: Mostly perched.

Dust cover: Crew noted absence of dust.

\section{Fines}

Color: Medium gray.

Craters

Compaction: Loose.

Size range and distribution: Up to $5 \mathrm{~cm}$ common; larger ones sparse.

Shape: Subdued.

Ejecta: None visible.

SAMPLE CHARACTERISTICS OF 68815

Size: $21 \times 15 \times 5 \mathrm{~cm}$; 1826 grams.

Color: Medium dark gray.

Shape: Angular, broken from top of boulder \#3.

Fillets: Boulder has small fillet on north side.

Apparent burial: Boulder is generally perched. Partially covered

by fillet.

Dust cover: None.

Comparison with other fragments in area: This $B 5$ breccia is the same as sample 68115, and probably not uncommon in the area.

Probable origin: The angularity of this boulder and its perched nature as well as comparison with other fragments in the area suggests it was ejected from South Ray crater.

SAMPLE CHARACTERISTICS OF 68820-25 (soil with 1 incidental fragment) Size: < $1 \mathrm{~cm}$ fines; 220 grams total weight; 68825, 8.66 grams. Color: Medium gray. Comparison with other soil in arca: Soil and fragments appear similar in color and texture to surrounding area. Probable origin: Crew reported an absence of dust on top of rock which suggests soil was not a fillet. Mixture of South Ray ejecta with local regolith.

SAMPLE CHARACTERISTICS FOR 68840-48 (soil with 4 incidental fragments) Size: < $1 \mathrm{~cm}$ fines, 449.32 grams total weight; > $1 \mathrm{~cm}$ fragments, $\overline{11.46}$ grams total weight. Color: Medium gray. Comparison with other soil in area: Appears typical of soil and fragments in this area. Probable origin: Locale and similarity to soil of nearby areas suggests South Ray crater ejecta. Mixture of South Ray ejecta with local regolith. 

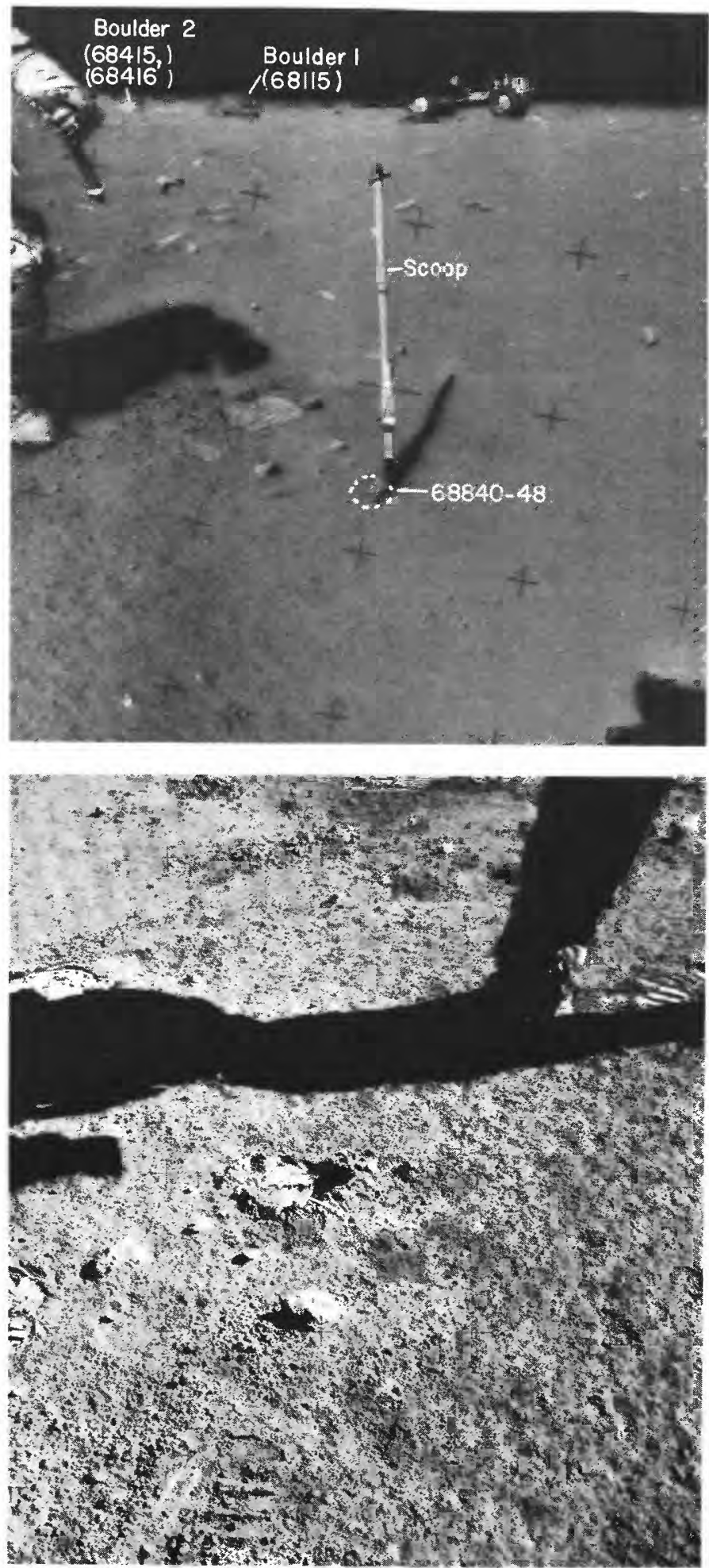

Figure 89A.-Location of samples 68840-48 (soil with incidental fragments) shown before sampling in part of photograph AS16108-17702. View is southwest toward LRV and boulders 1 and 2 from which samples 68115,68415 , and 68416 had already been collected. The LRV had been moved southeastward, closer to boulders 1,2 , and 3, after the station 8 panorama was taken (see pl. 7 and chap. D3, fig. 7).
Figure 89B.-Area of samples 68840 -48 shown after sampling in photograph AS16-107-17557; view is north. 


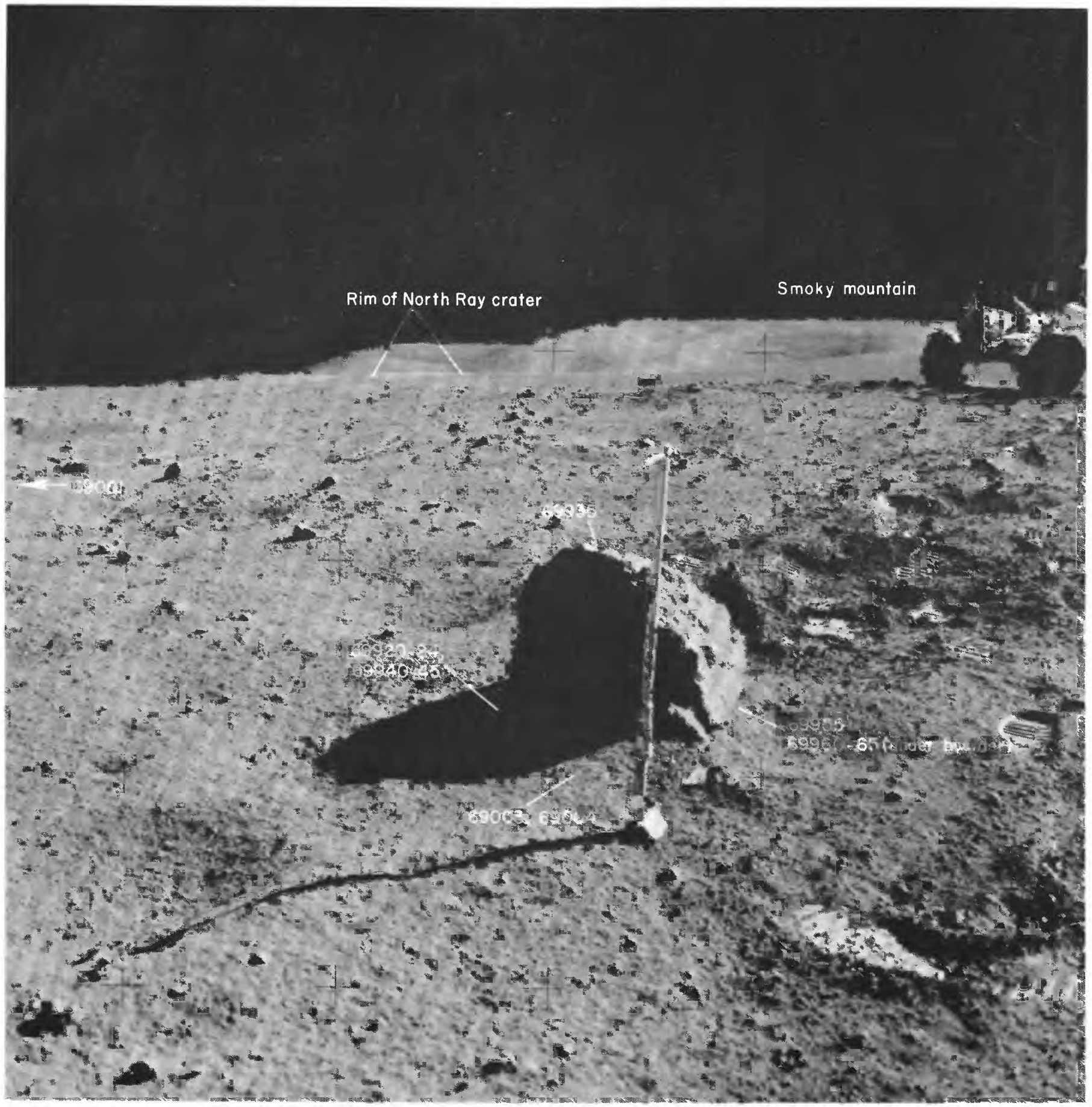

FIGURE 90-Locations of all samples collected at station 9 shown in photograph AS16-107-17560; view is north toward Smoky mountain and North Ray crater. Drive tube sample 69001 is located just off the left side of the photograph. Special surface samples 69003 and 69004 (contact soil sampling devices) were the only samples collected before this picture was taken. Samples $69920-24$ represent a special soil sample skimmed from the surface; 69940-45 soil (with an incidental fragment) from beneath the skim sample. 


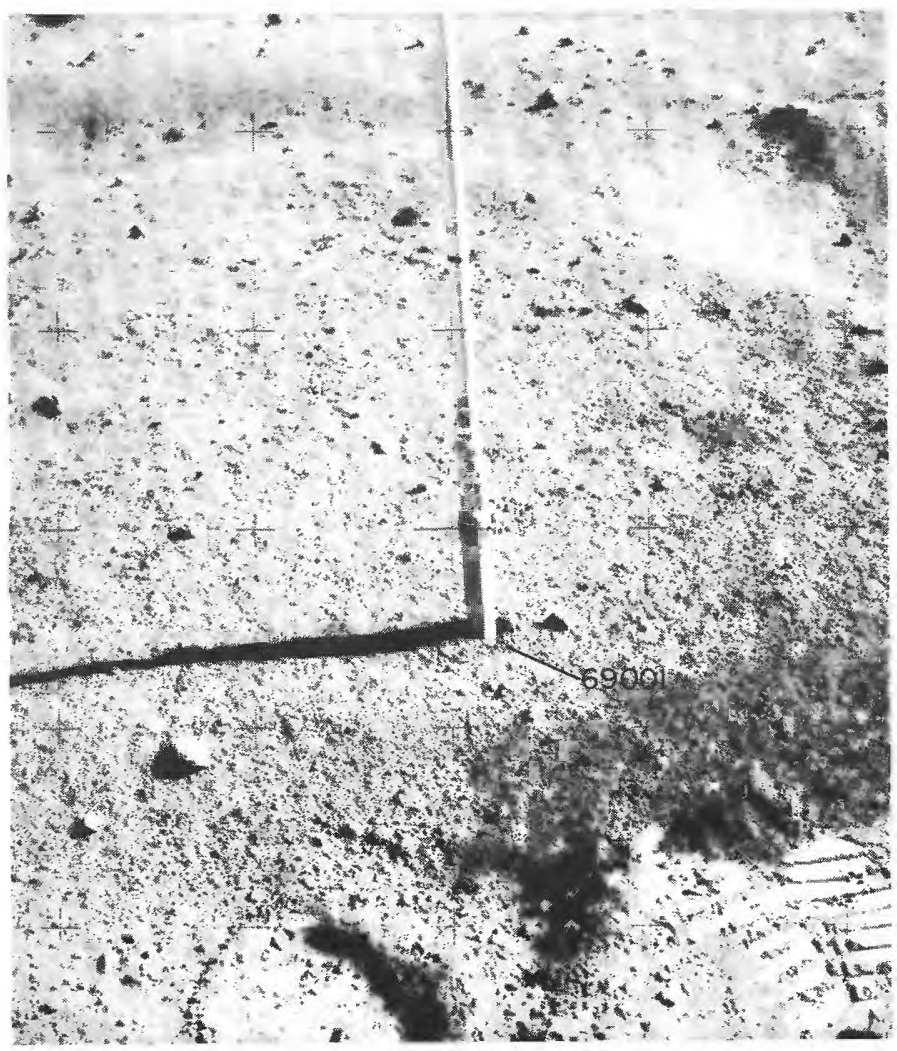

FIGURE 91-Single drive tube sample 69001 shown during sampling in photograph AS16-108-17742; view is north.

SAMPLE: 69001

Station: 9

Landmark: In relatively smooth area $20 \mathrm{~m}$ north of a $30-50 \mathrm{~m}$ subdued crater, and $10 \mathrm{~m}$ WSW from station 9 panorama site. Rock type: Single drive tube.

SURFACE CHARACTERISTICS OF SAMPLE AREA

Slopes: Level.

Fragment population

Size range and distribution: Up to $1 \mathrm{~cm}$ common; larger ones sparse. Largest fragment in vicinity of drive tube is $4-5 \mathrm{~cm}$. Color: Medium gray.

Shapes: Mostly rounded, a few angular.

Fillets: None visible. Apparent burial: Mostly perched. Some small fragments are partially buried. Dust cover: None visible.

Fines

Color: Medium gray.

Compaction: Loose around footprints.

\section{Craters}
Size range and distribution: $U p$ to $3 \mathrm{~cm}$ common; larger ones sparse.
Shape: Subdued.
Ejecta: Blocks probably represent ejecta from South Ray crater.

Size: Mostly< $1 \mathrm{~cm}$ fines; 558.3 grams.

Probable origin: Mostly local regolith possibly mixed with thin South Ray ejecta at the top of drive tube. 

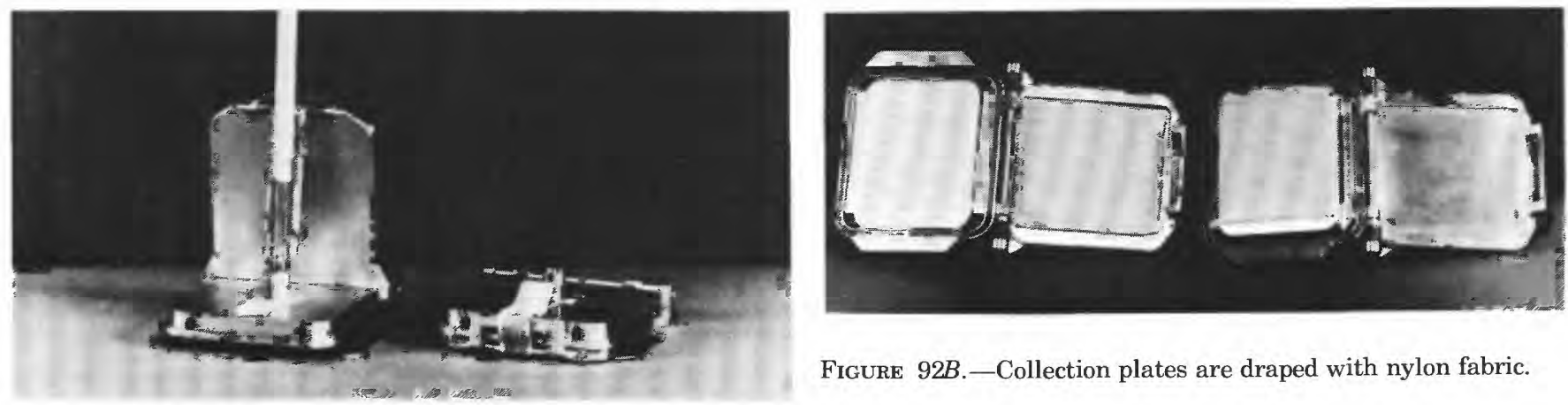

FiguRe 92B.-Collection plates are draped with nylon fabric.

Figure 92A.-Contact soil sampling devices (CSSD's) used to collect special soil samples 69003 and 69004 from uppermost regolith layer. (Photograph S-72-43792). CSSD in deployed position (left) and closed (right).

SAMPLE: 69003, 69004, (contact soil sampling devices, figures 92A-B); $69920-24 ; 69935 ; 69940-45 ; 69955 ; 69960-65$

Station: 9

Landmark: Boulder approximately $10 \mathrm{~m}$ south of station 9 panorama site. See figure 90 for location relative to the LRV.

Rock type: 69920-24, soil; 69935, B4 dark matrix breccia broken

from top of boulder; $69940-45$ soil with 1 incidental fragment of $C 2$

metaclastic rock; 69955, a $C l(F)$ fragment broken from bottom

of boulder; 69960-65, soil with incidental fragment.

SURFACE CHARACTERISTICS OF SAMPLE AREA

Slopes: Gentle regional slope downward to northeast. Locally

southwest into a 30-50 m crater.

Fragment population

Size range and distribution: Up to $1 \mathrm{~cm}$ abundant; $1-3 \mathrm{~cm}$

common; larger fragments sparse.

Color: Medium gray.

Shapes: Generally angular, several rounded in all size

fractions.

Fillets: None visible.

Apparent burial: Generally perched. Some rounded fragments are partially buried.

Dust cover: None visible.

Fines

Color: Medium gray.

Compaction: Moderately firm.

\section{Craters}

Size range and distribution: Up to $5 \mathrm{~cm}$ abundant; $5-30 \mathrm{~cm}$ common; large ones sparse.

Shape: Subdued.

Ejecta: The relatively few scattered blocks may be South Ray ejecta 
SAMPLE CHARACTERISTICS FOR 69940-44 (sCOOp sOil with one incidental fragment, collected beneath skim sample 69920-24).

Size: 69940-44, <I cm fines; 428.49 grams total weight.

$69945,3 \times 1.5 \times 1 \mathrm{~cm} ; 6.88$ grams (see figure 94).

Color: Medium gray.

Comparison with other soil and fragments in area: soil is probably

typical of local regolith; sample 69945 is the only type C2 frag-

ment $>_{1} \mathrm{~cm}$ collected at station 9. Other $C 2$ fragments were collected

in the station 8 rake sample.

probable origin: Soil mostly locally derived regolith; 69945

possibly South Ray ejecta, as indicated by its angularity and

freshly broken appearance.

SAMPLE CHARACTERISTICS FOR 69955 (fragment broken from bottom of boulder).

See figures $95 A-C$.

Size: $9 \times 6 \times 2 \mathrm{~cm} ; 75.94$ grams.

Color: Medium light gray.

Shape: Boulder is generally angular. Bottom of boulder is not appreciably less rounded than the top.

Dust cover: Bottom of boulder appears dust covered.

Comparison with other fragments in area: This $C I(F)$ fragment was collected from the same breccia boulder that yielded sample 69935, a B4 breccia.

Probable origin: Angularity, lack of a fillet, perched nature and resemblance to blocks at station 8 suggest that the block is

from South Ray crater. It is perched on the northeast rim of what appears to be its own secondary crater.

SAMPLE CHARACTERISTICS FOR 69960-65 (soil and 1 incidental fragment)

Size: $\quad<1 \mathrm{~cm}$ fines, 507.56 grams total weight; 69965, >I cm;

$\overline{1.11}$ grams.

Color: Medium gray.

Comparison with other soil in area: Soil from beneath boulder has same general color as surrounding soil, although it appears to be

"caked" (see Table 3, p. 49).

Probable origin: Locally derived regolith possibly mixed with

minor amount of South Ray ejecta. 


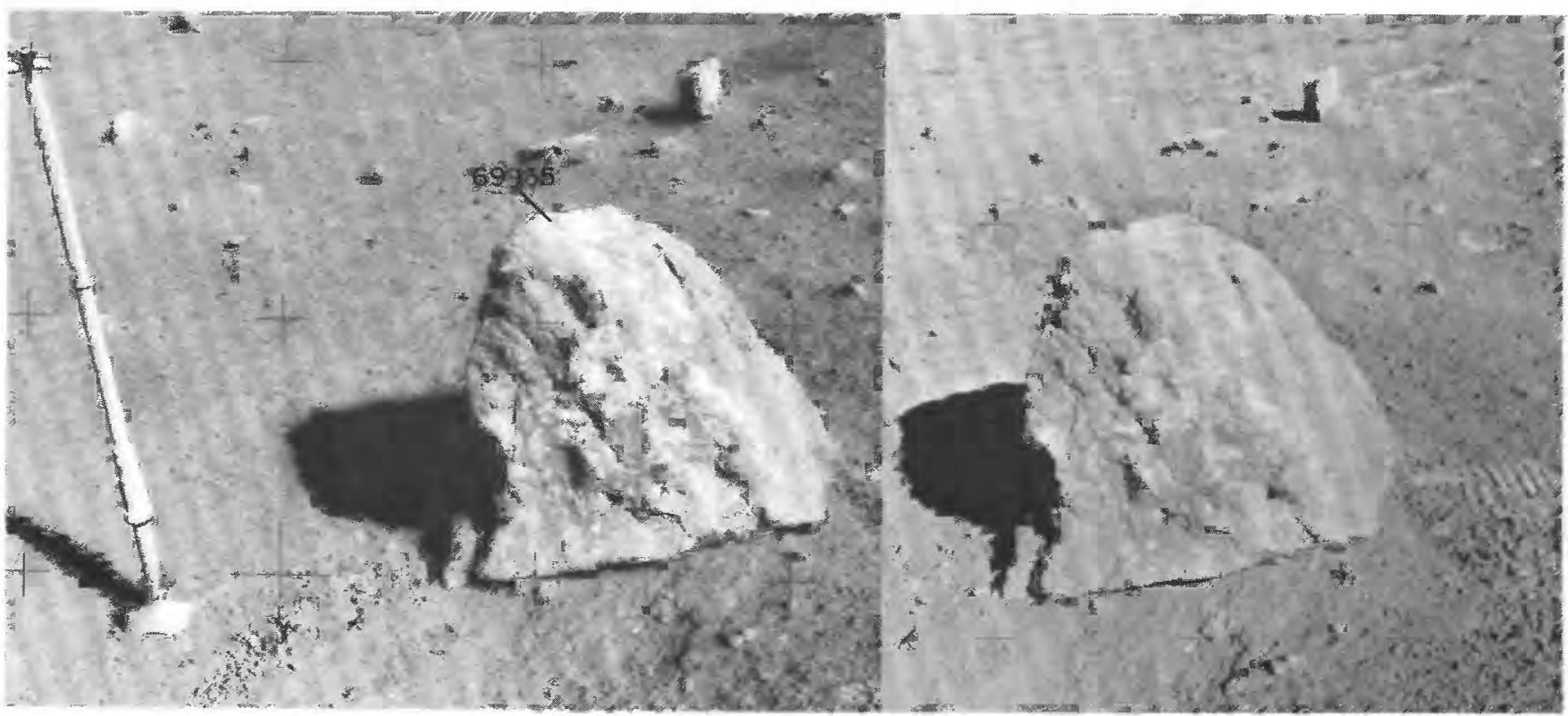

Figure 93A.-Sample 69935, chipped from top of station 9 boulder, shown before and after sampling in a stereopair made from photographs AS16-108-17740 (left) and 107-17571 (right). View is northwest.

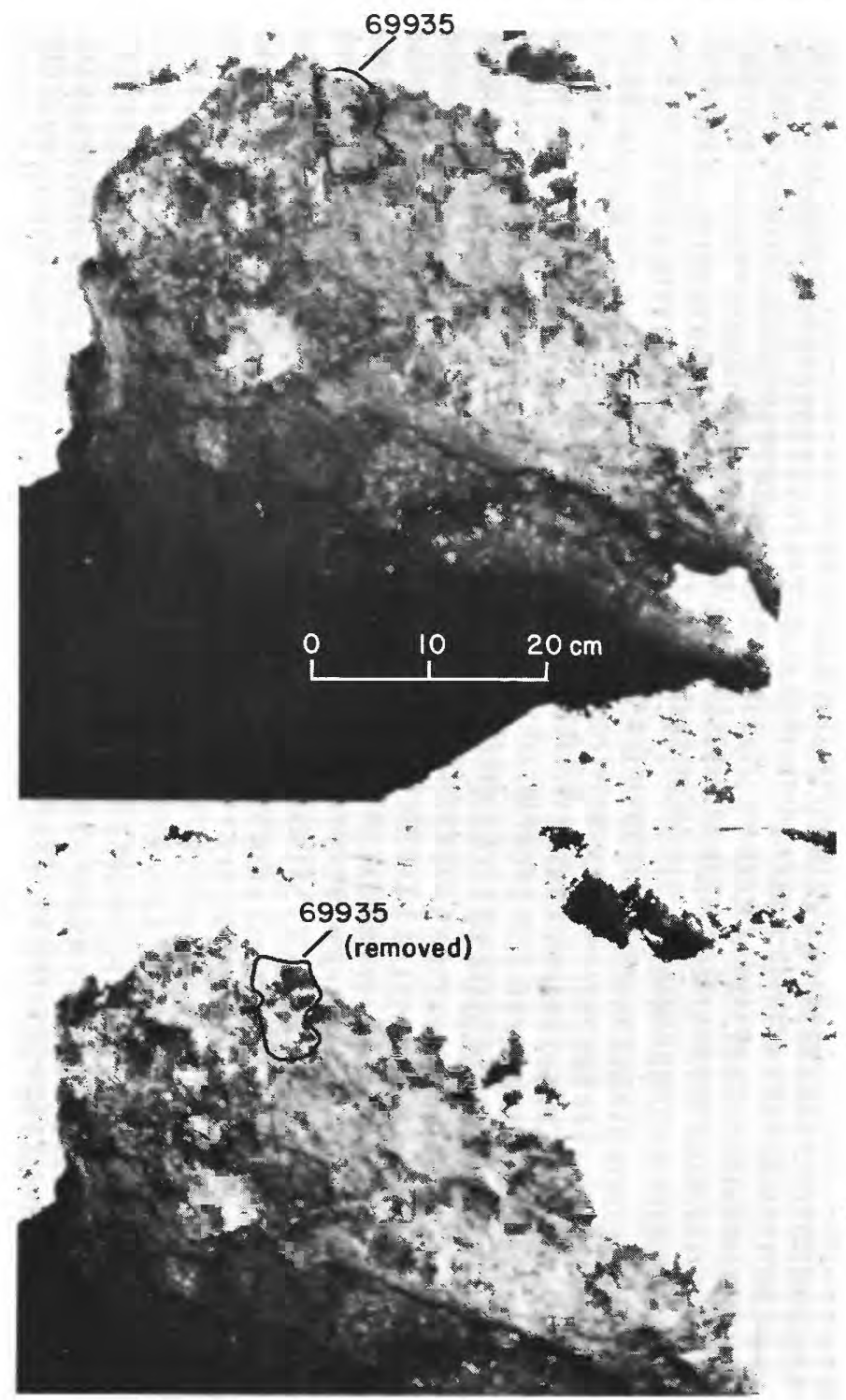

Figure 93B.-Sample 69935 shown before and after sampling in photographs AS16-107-17559 (top) and 107-17572 (bottom); view is northeast toward shadowed side of boulder. Purposely overexposed in printing to show details in shadowed area. Note that one angular light clast is approximately same size as sample 69935. Scale was determined from known dimensions of the sample. 


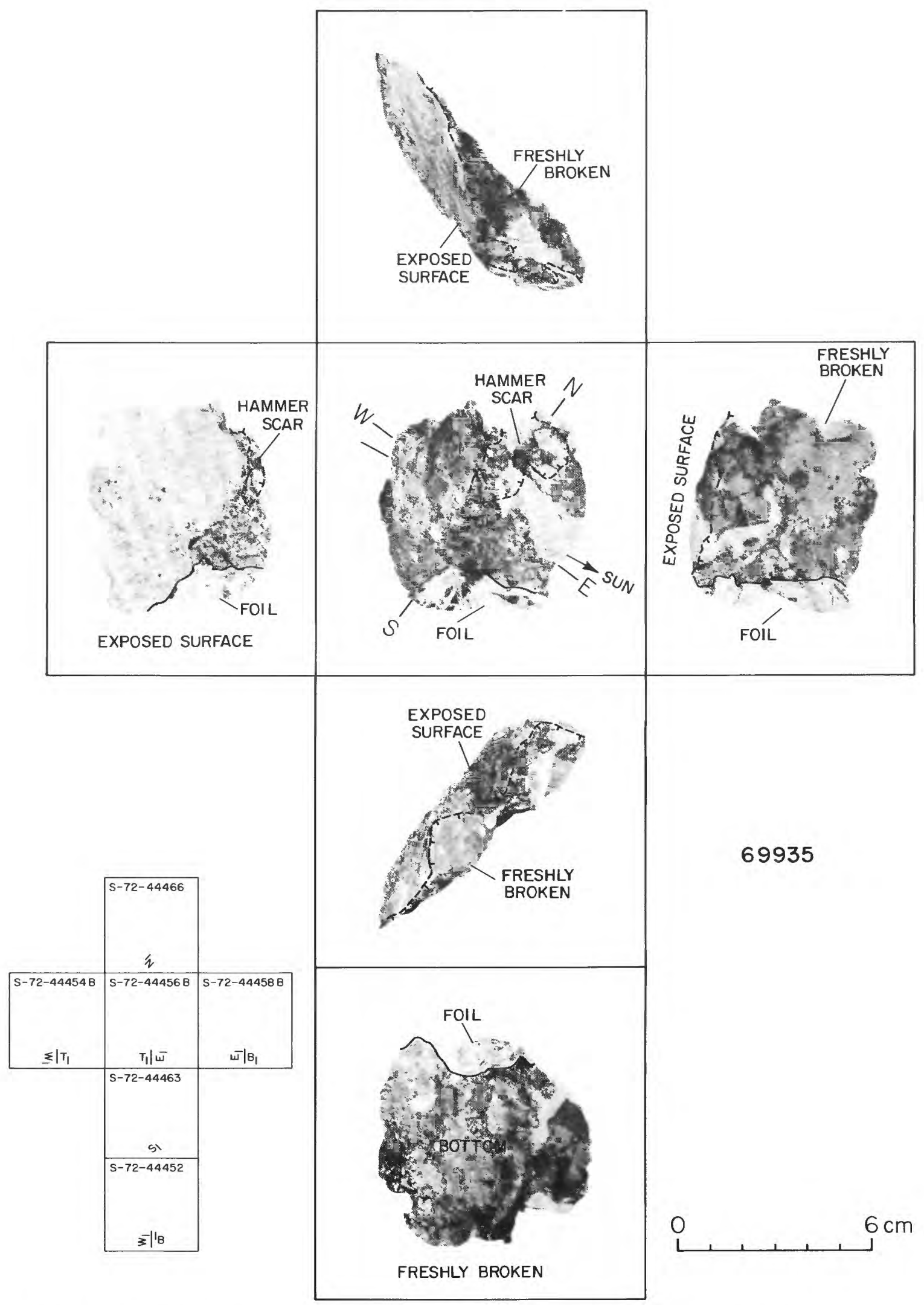

FIGURE 93C.-Orthogonal views of sample 69935 related to its lunar orientation at time of sampling from top of station 9 boulder. Compare these views with perspective shown in fig. $93 A$. $\mathrm{B}_{4}$ breccia. 


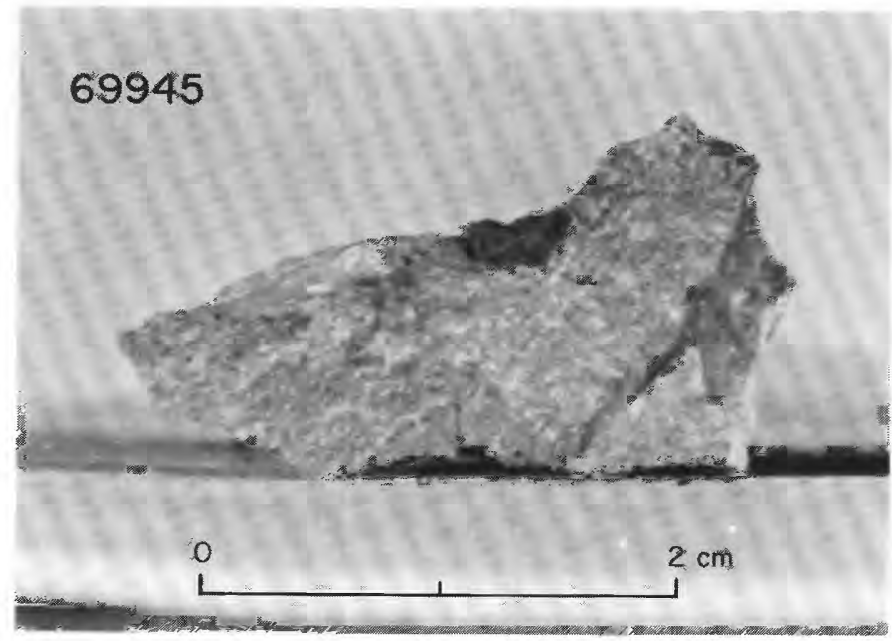

Figure 94-Sample 69945 in LRL (photograph, S-72-40137, N view). Metaclastic $\left(\mathrm{C}_{2}\right)$ fragment collected incidentally with soil sample 69940-44.

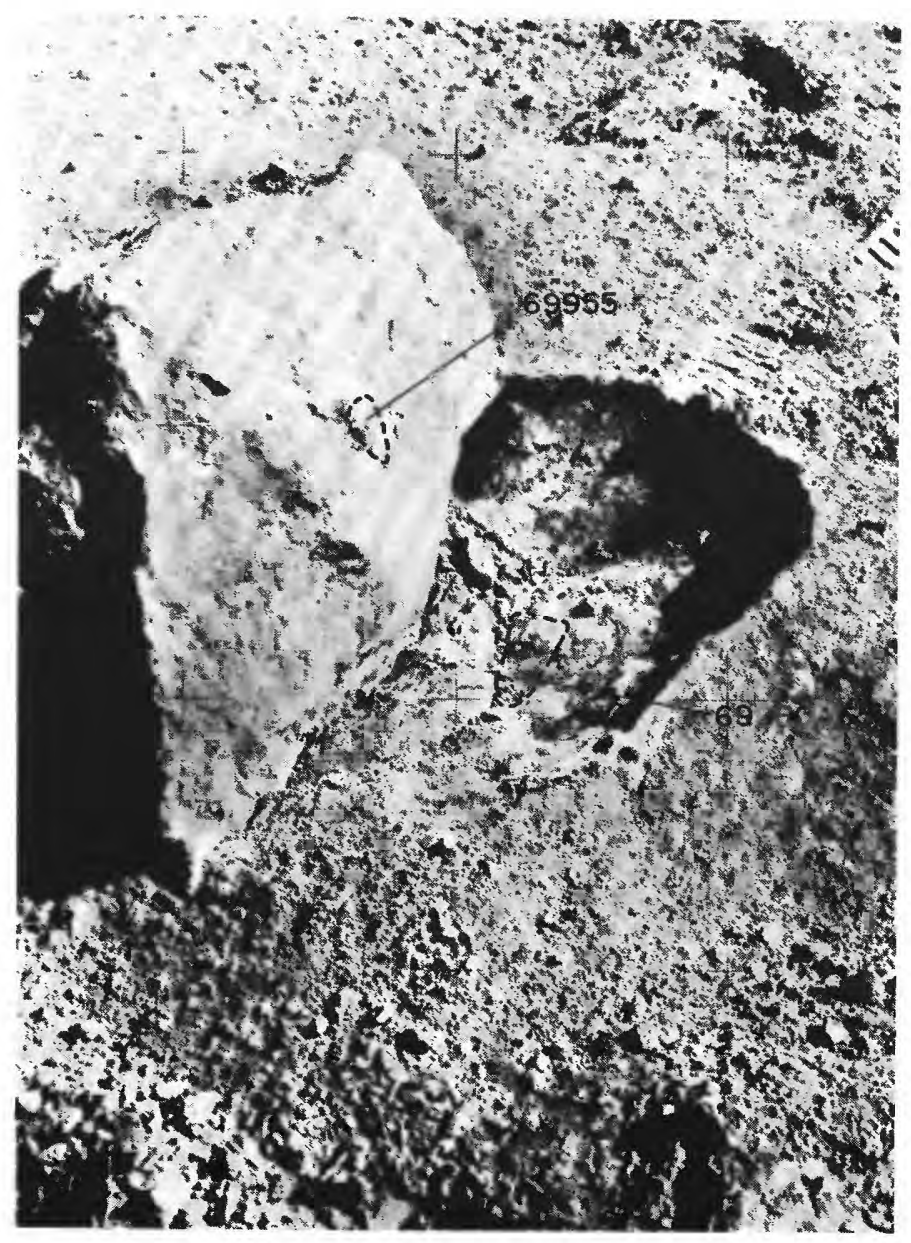

Figure 95A.-Sample 69955, chipped from bottom of station 9 boulder, and soil sample $69960-65$ from beneath the boulder, shown before sampling in part of photograph AS16-107-17574. View is north, after boulder was rolled.

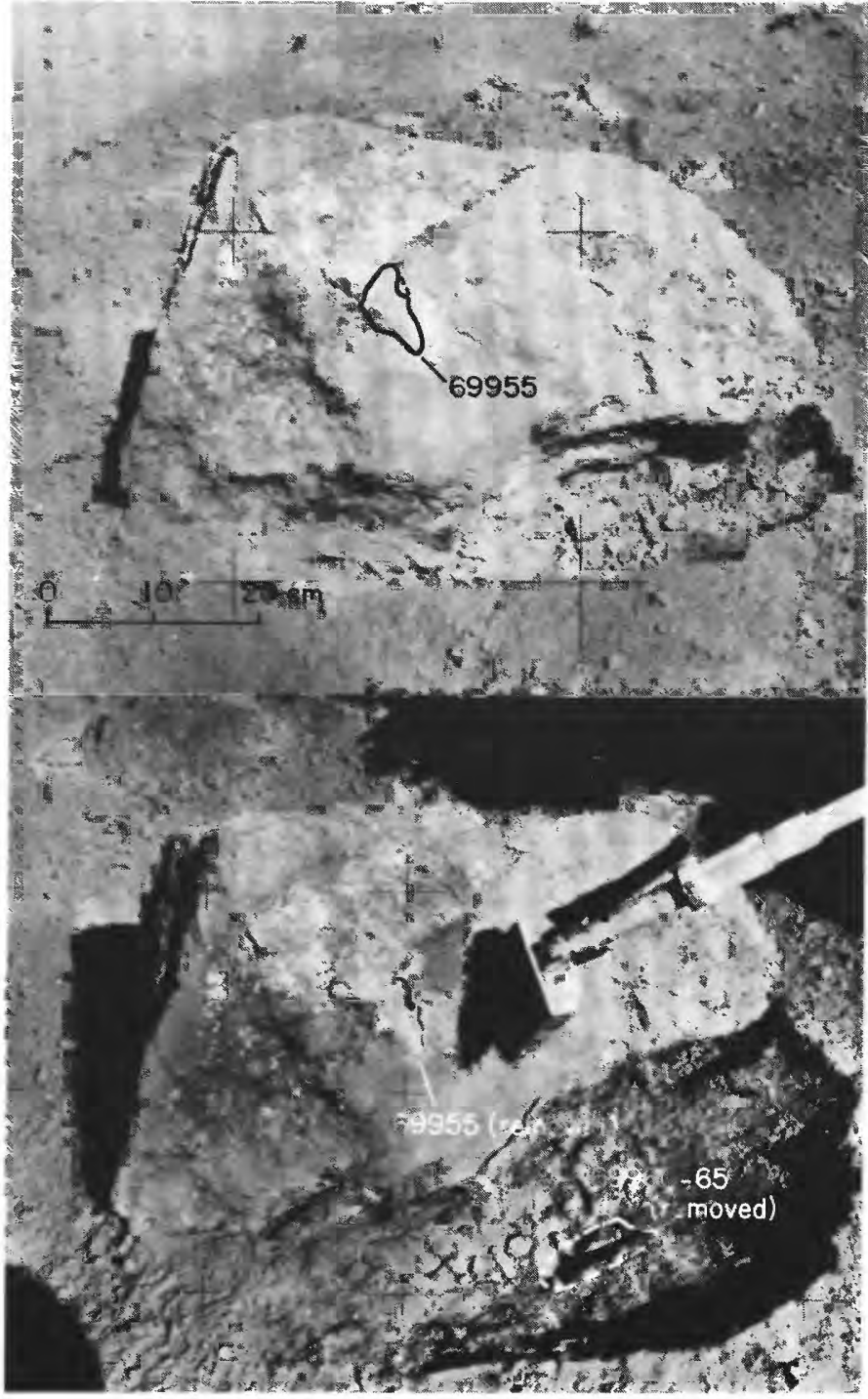

Figure 95B.- Sample 69955 shown before and after sampling in parts of photographs AS16-107-17575 (top) and 107-17579 (bottom); view is west. Postsampling picture also shows location of collected sample 69960-65. 


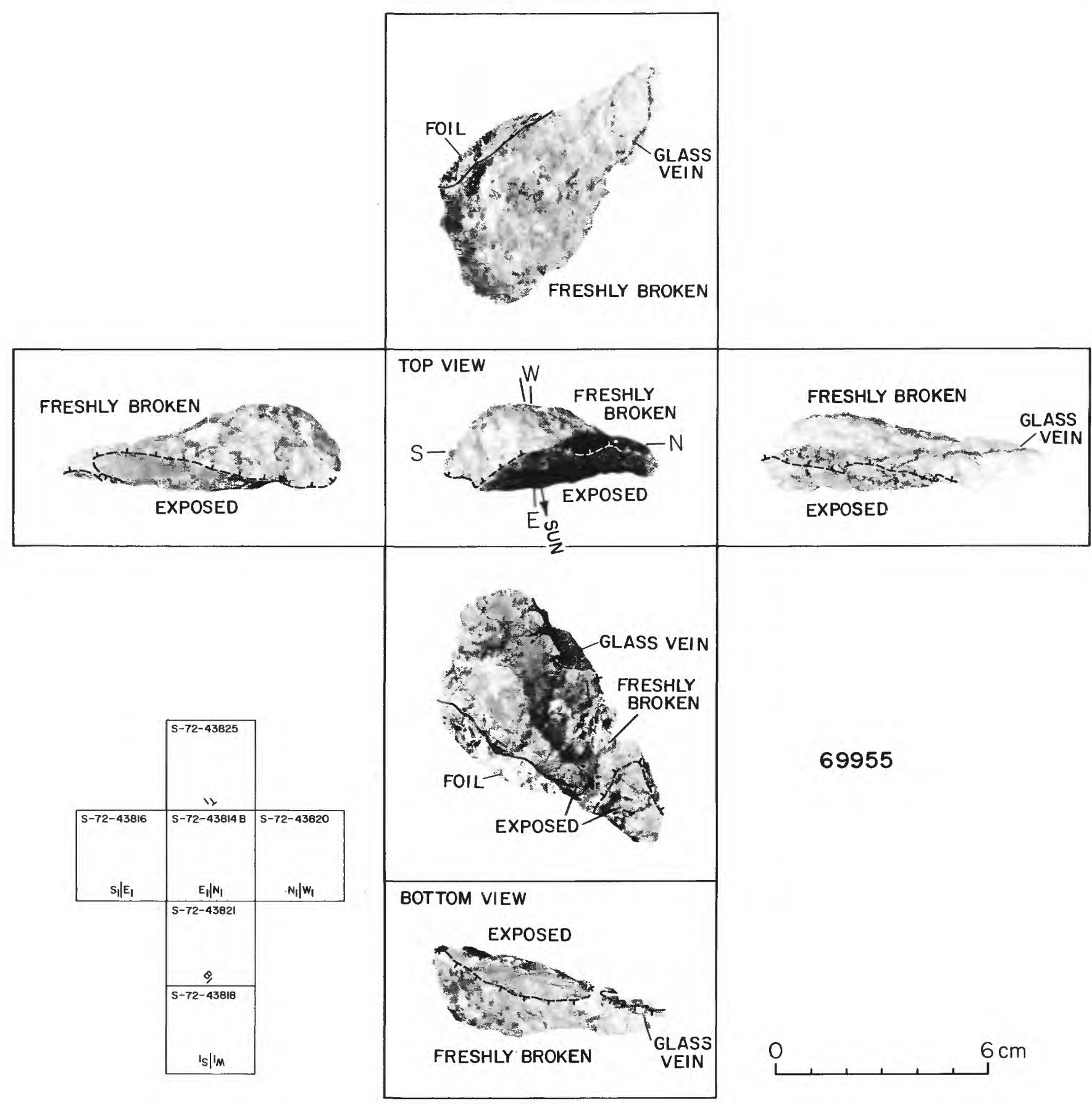

FIGURE 95C.-Orthogonal views of sample 69955 related to its lunar orientation before sampling, compared to photograph AS16-10717575 (fig. $95 B$ ). See chap. D3, figs. $9 F$ and $10 E$, for stereopair and a photomicrograph, respectively, of this type $\mathrm{C}_{1}(\mathrm{~F})$ crystalline rock. 


\title{
L2. APOLLO 16 LUNAR-SURFACE PHOTOGRAPHY
}

\author{
By Raymond M. Batson, Kathleen B. Larson, V. Stephen Reed, \\ Robert L. Sutton and Richard L. Tyner
}

\begin{tabular}{l} 
CONTENTS \\
Introduction \\
Photographic procedures \\
The photographic data set \\
Cartographic procedures -526 \\
\hline
\end{tabular}

\section{ILLUSTRATIONS}

FigURE 1. Photograph of astronaut John Young documenting a sample area with suit-mounted electric Hasselblad camera
2. Index of landing-site features photographed with the electric Hasselblad camera and $500-$ mm telephoto lens
3. Perspective grid used to make approximate measurements of sizes and distances of objects in Apollo surface pictures
4. Photograph of the Apollo 16 gnomon showing dimensions 531

\section{TABLES}

1. Apollo 16 film usage

2. Chronological listing of 70-mm Apollo 16 lunar surface pictures

529

3. Sequential listing within each 70-mm magazine, Apollo 16 lunar-surface pictures

4. Apollo 16 lunar-surface film usage by camera number

529

\section{INTRODUCTION}

Pictures taken on the surface of the Moon by the crew of Apollo 16 were used in three ways to support geologic investigation of the landing site: documentation of sample collection and illustration of crew commentary; determination of the precise location of stations, samples, traverse routes, and mensuration of other features of geologic interest; and measurement of the photometric variables, surface reflectance, and polarization. In total, 1,774 pictures were taken on the lunar surface with Hasselblad electric data cameras (fig. 1). (The camera is described by Kammerer, 1973). Most of these photographs were taken according to practiced procedures designed for geologic documentation.

The purpose of this chapter is to describe (a) photographic procedures used by the crew, (b) the photographic data set, and (c) cartographic methods. Photographic requirements and photometric utilization of the pictures are discussed in Muehlberger and others (1972). Unless otherwise specified, the picture surveys were taken on $70-\mathrm{mm}$ film using a $60-\mathrm{mm}$ lens.

\section{PHOTOGRAPHIC PROCEDURES}

By R. M. BATSON

Sample documentation pictures were taken to show the in situ character of a returned sample or of a feature that could not be returned. Documentation of samples included a single picture for photometric study taken downsun of the sample in place and a cross-sun stereoscopic pair. After the sample was collected, a picture was taken of the sample area from near the same place as the stereoscopic pictures to establish the identity of the collected sample by its absence when compared with presampling pictures. A final photograph was taken of the sample area and of the Lunar Roving Vehicle (LRV) to establish the locality of the sample within the station vicinity. Where time was short or footing awkward, one or more of these pictures were eliminated. A few stereopairs of features of interest, impractical to collect, were taken from less than $1 \mathrm{~m}$.

A special polarization survey was taken from the rim of North Ray crater in an attempt to gather information on lithology of distant materials (see Holt, this volume; pl. 8, pan 19). This panoramic series of photo- 


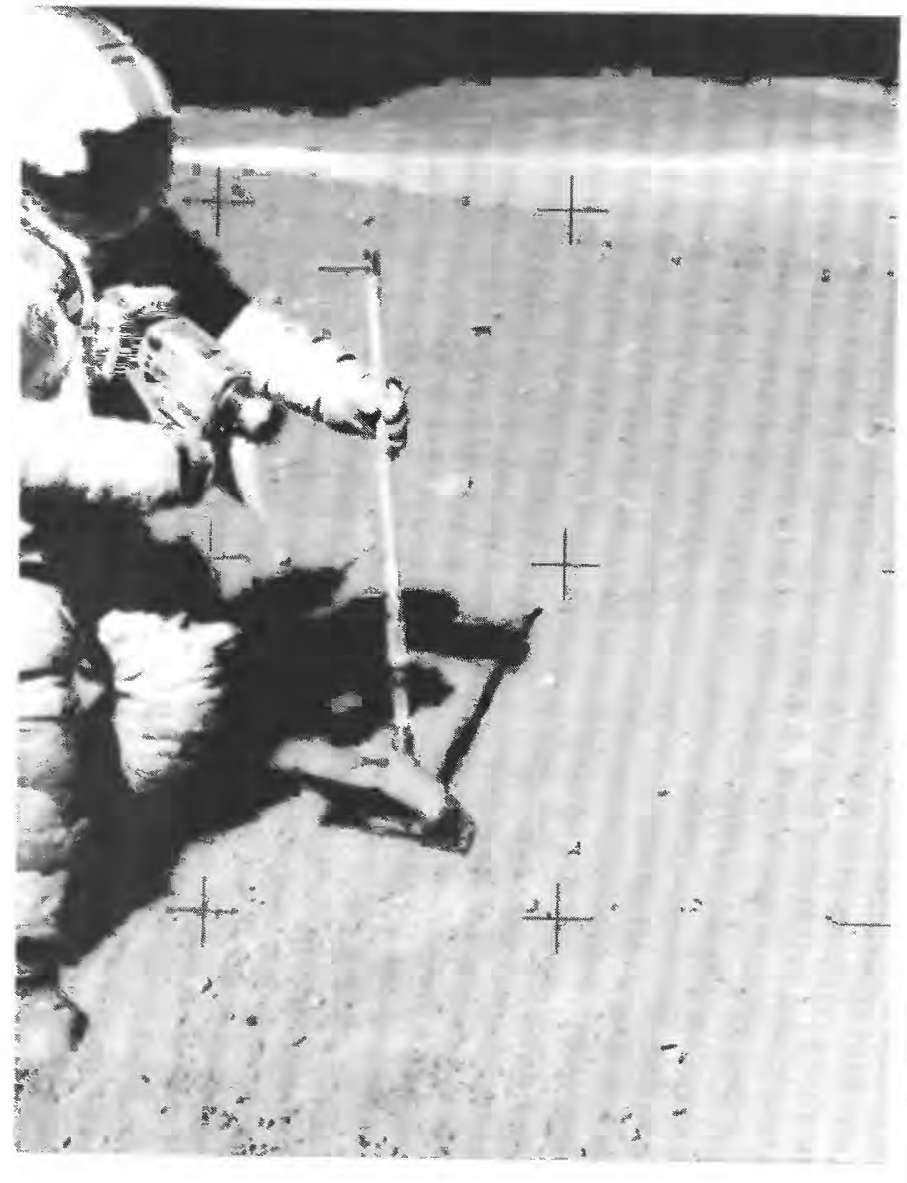

Figure 1.-Astronaut John Young photographing sample area with suit-mounted electric Hasselblad camera. (AS16-110-18019).

graphs was taken (three times) with a polarizing filter in three orientations $45^{\circ}$ apart. The survey was repeated from a second vantage point (pl. 9, pan 20), thereby providing stereoscopic coverage of the area together with the polarization information.

Panoramas were taken at each station to permit precise location of the station by resection and to illustrate and supplement geologic descriptions by the crew (pls. 3-8). A complete panorama consists of 15 or more overlapping photographs covering a total of $360^{\circ}$. Partial panoramas were taken of features such as House rock, Shadow rock, and Buster crater (pl. 4, pans 21 and 22; pl. 5, pan 7; pl. 7, pans 24 and 25). The overlap zones between pictures in panoramas can be viewed stereoscopically, as the aiming direction of the camera was changed and the lens position was shifted slightly each time a picture was taken. This provides a stereoscopic baseline a few centimeters long, useful for study of topography within 50 to $100 \mathrm{~m}$ of the camera.
To permit study of features inaccessible to the crew, telephoto pictures were taken with a $500-\mathrm{mm}$-focallength lens on the Hasselblad camera. Although a few frames were degraded by camera motion, they have more resolution than the $60-\mathrm{mm}$ pictures and contain information not otherwise available.

The lunar module pilot (LMP) took pictures at approximately regular intervals while the LRV was in motion. These photographs were used to reconstruct the traverse and to measure rock-fragment distribution over wide areas (Muehlberger and others, 1972). Twice during these "en route" sequences, the commander (CDR) drove the LRV in a tight circle while the LMP took photographs, resulting in what has been termed an "LRV" panorama." These photographs are not included in plates $3-11$.

In addition to pictures taken for geologic documentation, several were taken to illustrate ALSEP deployment and objectives of the mission traverses not related to geology (pl. 4, pan 3).

All of the pictures taken by John Young with the Hasselblad camera during EVA 3, have a smear on the image. This defect is produced by a smear made on the reseau plate during a magazine change before the traverse to North Ray crater.

\section{THE PHOTOGRAPHIC DATA SET}

By K. B. Larson, R. M. Batson, and R. L. SutTox

The photographic data set constitutes a catalog of all pictures taken on the lunar surface from both inside and outside the lunar module during the Apollo 16 mission using electric Hasselblad cameras with $60-\mathrm{mm}$ and $500-\mathrm{mm}$ lenses. A few pictures were taken from lunar orbit on magazine A (No. 113); these are not listed in the tabulations (tables 1-4). Camera coverage with the $500-\mathrm{mm}$ camera at four stations, west of LM, 2,4 , and 11 , is given in figure 2 ; statistics on film usage are contained in table 1 .

The tabulations (tables 2-4) are arranged for the following specific purposes:

1. Given a particular location or activity within the sequence of lunar surface events, to find the pictures taken at that time and their subject matter (table 2).

2. Given the number of a particular frame, to find its time in the sequence of lunar surface activity, the station at which it was taken, and the subject matter of the picture (table 3 ).

3. Given a specific frame number, to find the serial number of the camera with which it was taken (table 4). 


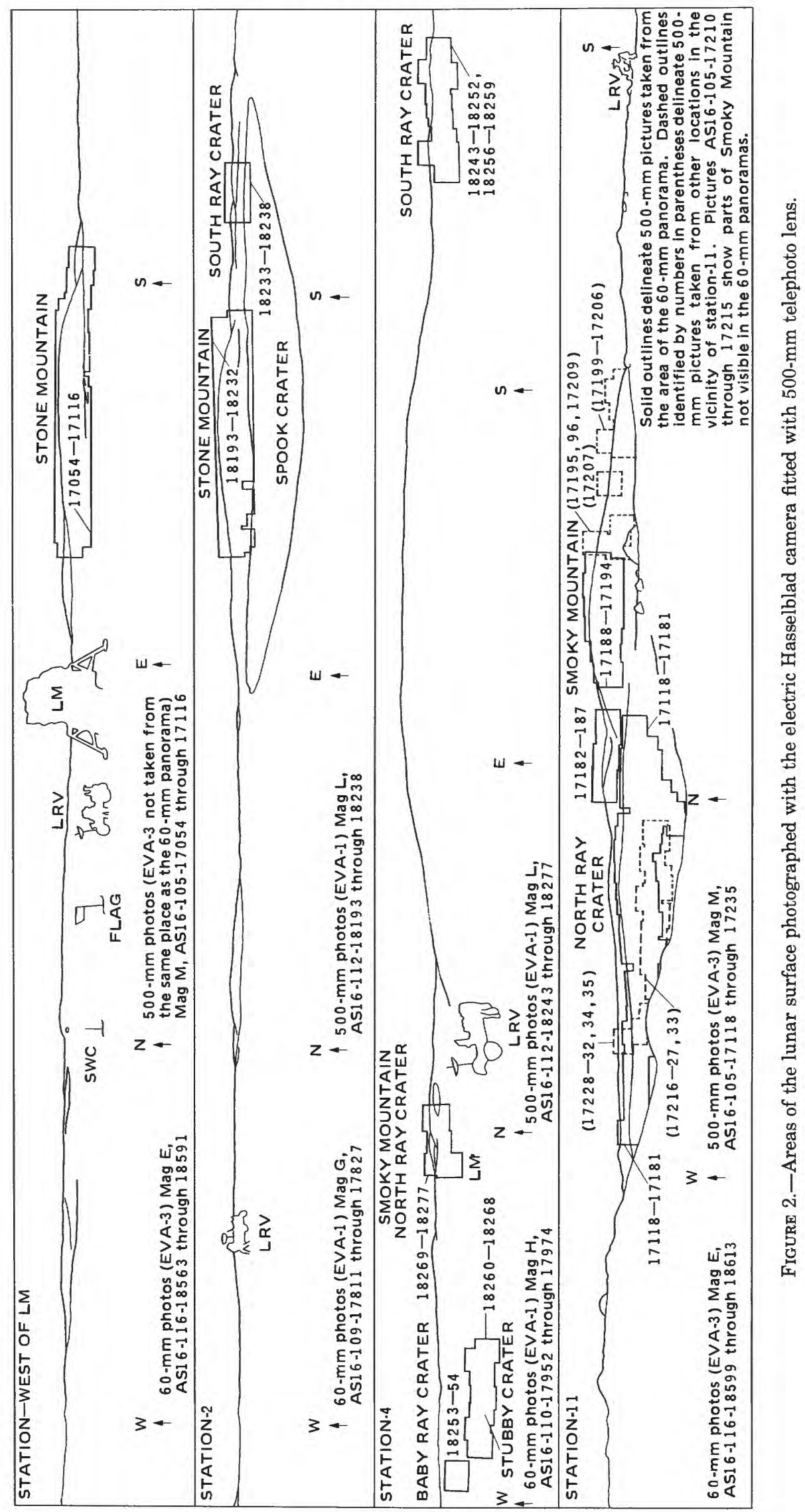


TABLE 1. Apollo 16 film usage

\begin{tabular}{|c|c|c|c|c|c|c|c|c|c|}
\hline Station & $\begin{array}{c}\text { Sample } \\
\text { documentation }\end{array}$ & Polarization & Panorama & 500 -mm lens & En route & Other & $\begin{array}{c}\text { Blank or } \\
\text { fogged }\end{array}$ & Magazine & Rate $^{1}$ \\
\hline \multicolumn{10}{|l|}{ EVA 12: } \\
\hline & --- & $-\cdots$ & 18 & $\ldots$ & $\ldots$ & 13 & $\cdots$ & 113 & --- \\
\hline ALSEP & $\cdots$ & $\cdots$ & 22 & $-\cdots$ & $\cdots$ & 17 & $\ldots$ & 113 & $\ldots$ \\
\hline ALSEP & 6 & $\ldots$ & $\ldots$ &.-- & -..- & $\ldots$ & $\ldots$ & 114 & 23 \\
\hline ALSEP & $\ldots$ & $\ldots$ & $\ldots$ & $\ldots$ & $\ldots$ & 1 & -..- & 109 & \\
\hline ALSEP-1 & 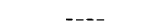 & $\ldots$ & & $\ldots$ & 28 & $\ldots$ & $\ldots$ & 109 & 19 \\
\hline n & 16 & $\ldots$ & 19 & $\ldots$ & $\ldots$ & $-\ldots$ & $\ldots$ & 109 & \\
\hline 1 - 1 & 27 & $\ldots$ & 18 & $\ldots$ & $\ldots$ & $\ldots$ & $\ldots$ & 114 & 68 \\
\hline 2 & 12 & $\ldots$ & 26 & 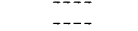 & 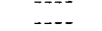 & 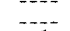 & $\ldots$ & 109 & \\
\hline 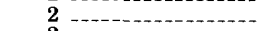 & -..- & $\cdots$ & $\ldots$ & & $-\ldots$ & 1 & ... & 114 & 191 \\
\hline $2-\cdots$ & -... & $\ldots$ & --- & 50 & $\ldots$ & $\ldots$ & $\ldots$ & 112 & \\
\hline 2-LM & .... & -... & $-\ldots$ & $\ldots$ & 14 & $\ldots$ & -... & 109 & 16 \\
\hline LM & $\ldots$ & $\cdots$ & $\ldots$ & -- & .... & 2 & $\ldots$ & 109 & $-\ldots$ \\
\hline LM & $-\cdots$ & & 3 & $-\cdots$ & - n & 5 & 2 & 114 & $\ldots$ \\
\hline Total & 61 & 0 & 106 & 50 & 42 & 39 & $\overline{2}$ & $\ldots$ & 44 \\
\hline $\begin{array}{r}\text { EVAZ: } \\
\text { LM }\end{array}$ & & $-\ldots$ & 21 & $-\ldots$ & $\ldots$ & 3 & EVA $2^{3}:$ & 107 & \\
\hline LM & 3 & -- & $-\ldots$ & 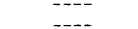 & $\cdots$ & 1 & $\ldots$ & 110 & $-\cdots$ \\
\hline LM-4 & $\ldots$ & $\cdots$ & $\cdots$ & $\cdots$ & 77 & $\ldots$ & $\ldots$ & 110 & 20 \\
\hline 4 & 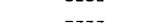 & $\ldots$ & & 35 & $\ldots$ & $-\ldots$ & $\ldots$ & 112 & \\
\hline $4-\cdots$ & 26 & $\cdots$ & 23 & 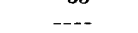 & --.- & $\cdots$ & $\ldots$ & 107 & 116 \\
\hline $4 \ldots$ & 5 & .... & 23 & $\ldots$ & $\ldots$ & $\ldots$ & $\ldots$ & 110 & \\
\hline $4-5$ & & $\ldots$ & & -..- & 16 & ...- & $\ldots$ & 110 & 42 \\
\hline$-1-2-1-2$ & 13 & $\ldots+$ & 28 & $\cdots$ & $\ldots$ & $\ldots$ & 1 & 110 & \\
\hline $5 \ldots$ & 18 & $\ldots$ & 20 & $\cdots$ & $\cdots$ & 2 & 1 & $\begin{array}{l}110 \\
107\end{array}$ & 76 \\
\hline $5-6$ & 10 & $\cdots$ & $\cdots$ & $\cdots$ & 21 & 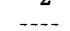 & $\ldots$ & 108 & 66 \\
\hline$\ldots$ & 7 & -... & 21 & $\ldots$ & -..- & $-\ldots$ & $\ldots$ & 108 & \\
\hline $6 \ldots$ & 15 & $\cdots$ & $-\ldots$ & $-\cdots$ & -..- & $\cdots$ & $\cdots$ & 107 & 112 \\
\hline $6-8$ & 10 & $\cdots$ & $-\cdots$ & --- & 29 & $\ldots$ & ...- & 108 & 5 \\
\hline 8 & 21 & $\cdots$ & 19 & -.-- & -.-- & $\ldots$ & $\cdots$ & 108 & 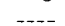 \\
\hline 8 & 31 & $\ldots$ & $\ldots$ & $\ldots$ & $\ldots$ & $\ldots$ & $\ldots$ & 107 & 63 \\
\hline $8-9$ & & $\ldots$ & $\ldots$ & (n- & 11 & $\ldots$ & $\ldots$ & 108 & 34 \\
\hline 9 & 4 & $\cdots$ & 26 & $\cdots$ & 11 & 1 & $\cdots$ & 108 & \\
\hline - & 23 & $\ldots$ & $\ldots$ & $\ldots$ & $\ldots$ & 3 & -... & 107 & 104 \\
\hline 9 & $\ldots$ & $\ldots$ & $\ldots$ & $\ldots$ & & 2 & $\ldots$ & 115 & \\
\hline $9-10$ & -.-- & $\ldots$ & $\ldots$ & $-\infty$ & 481 & $\ldots$ & $\ldots$ & 115 & 39 \\
\hline 10 & 4 & $\cdots$ & $\cdots$ & $\cdots$ & $\ldots+$ & $\ldots$ & 1 & 115 & \\
\hline (n)- & 5 & $\cdots$ & 19 & $\cdots$ & -- & - & $\ldots$ & 114 & 60 \\
\hline LM & -- & $\cdots$ & $-\ldots$ & $\cdots$ & $-\ldots$ & 4 & $\ldots$ & 115 & $\ldots$ \\
\hline LM & & & $\ldots$ & & & 3 & $\ldots+$ & 114 & 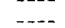 \\
\hline Total & 175 & 0 & 180 & 35 & 235 & 19 & 2 & - & 91 \\
\hline $\begin{array}{l}\text { EVA 3 } 3^{5:} \\
\text { LM }\end{array}$ & & & & \multicolumn{6}{|c|}{ EVA $3^{5}$ : } \\
\hline LM & --- & $\cdots$ & 29 & 63 & $\cdots$ & $\cdots$ & 1 & 105 & $-\cdots$ \\
\hline LM-11 & $\cdots$ & ... & $\ldots$ & $-\cdots$ & 159 & $\cdots$ & $-\cdots$ & 111 & 34 \\
\hline 11 & $\cdots$ & $\cdots$ & $-\cdots$ & 118 & $\ldots$ & $\cdots$ & -..- & 105 & \\
\hline 11 - & 46 & $\cdots$ & 23 & 110 & $-\cdots$ & $-\cdots$ & - & 116 & 215 \\
\hline 11 & 29 & 79 & 10 & $\ldots$ & -... & -1 & -... & 106 & \\
\hline $11-13 \ldots$ & & & & $\cdots$ & 29 & $\cdots$ & $\ldots$ & 106 & 45 \\
\hline 13 & 5 & -... & 27 & $\ldots$ & $\ldots$ & - & $-\ldots$ & 106 & $\ldots$ \\
\hline 13 & 9 & $\ldots$ & $\ldots$ & $\ldots$ & $\ldots$ & 2 & $\ldots$ & 116 & $\ldots$ \\
\hline 13 & $\ldots$ & $-\ldots$ & 4 & $\ldots$ & -- & 1 & --- & 117 & 99 \\
\hline $13-10$ & --- & $\ldots$ & -..- & $\cdots$ & 9 & $\ldots$ & -- & 116 & \\
\hline $13-10$ & $\ldots$ & $\ldots$ & --- & $\cdots$ & 70 & $\cdots$ & $-\ldots$ & 117 & 19 \\
\hline 10 & 4 & $\ldots$ & 23 & $\ldots$ & $\ldots$ & - & $-\cdots$ & 117 & \\
\hline 10 & 27 & $\ldots$ & $\ldots$ & $\ldots+$. & $\ldots$ & $\ldots$ & $-\ldots$ & 116 & 108 \\
\hline LM & 4 & $\cdots$ & $\cdots$ & - & $\cdots$ & 13 & $-\cdots$ & 116 & $-\ldots$ \\
\hline LM & 11 & $\cdots$ & $-\cdots$ & $\cdots$ & $\cdots$ & 16 & $\ldots$ & 117 & $-\cdots$ \\
\hline Total & 135 & 79 & 116 & 181 & 267 & 32 & 1 & $\ldots$ & 168 \\
\hline \multicolumn{9}{|l|}{ Apollo 16} & 94 \\
\hline
\end{tabular}

'Rates are given in photographs per hour at stations and photographs per kilometer

between stations. Totals are given in photographs per hour.

${ }^{3}$ The total for EVA-2 was 646 frames. "Includes five frames in "LRV panorama."

${ }^{5}$ The total for EVA-3 was 811 frames.

TABLE 4.-Apollo lunar surface film usage by camera number

\begin{tabular}{cc}
\hline Camera and Lens & Photographic frames \\
\hline Hasselblad Ser. No. 1033 & \\
(60-mm focal length). & $106-17239$ through 17417 (Mag K) \\
& $108-17585$ through 17744 (Mag I) \\
& $109-17746$ through 17864 (Mag G) \\
& $110-17866$ through 18032 (Mag H) \\
& $111-18034$ through 18192 (Mag J) \\
& $113-18279$ through 18382 (Mag A) \\
& $115-18471$ through 18562 (Mag D) \\
& $117-18726$ through 18854 (Mag F)
\end{tabular}

Hasselblad Ser. No. 1039 (60-mm focal length).

107-17419 through 17583 (Mag C) $114-18383$ through 18470 (Mag B) 116-18563 through 18724 (Mag E)

Hasselblad camera

(500-mm focal length). 105-17054 through 17235 (Mag M) 112-18193 through 18277 (Mag L)

Information on returned samples contained in the listings was compiled by various members of the Apollo
Field Geology Investigations Team. Detailed information concerning the lithology, petrology, and distribution of the samples is given in the field geology chapters and by Wilshire and others and Sutton (this volume).

The sequence of lunar surface photographs and the Apollo Elapsed Time (AET) at which the pictures were taken was determined by detailed study of the Air-toGround Voice Transcription (MSC-06802) and the lunar surface television video tapes. The letter " $C$ " prefixing photograph numbers indicates pictures taken on color film. Times assigned to panorama photographs and to pictures taken while the LRV was in motion were based largely on interpolation between the best known times of start and finish. At several stations, television showed the process of taking a panorama; for this, the times of individual frames could be measured directly. For LRV driving photographs, where crew de- 
scriptions could be matched to specific pictures within the sequence, times were assigned to those frames that served as control for the interpolation.

\section{CARTOGRAPHIC PROCEDURES}

$$
\text { By R. M. Batson, V. S. Reed, }
$$$$
\text { and R. L. TYNeR }
$$

Methods of making measurements and sketch maps used as illustrations in the chapters on field geology included:

1. Estimation of fragment size and distance by the use of perspective grids (fig. 3).

2. Photogrammetric contouring of sample areas through the use of analytical stereoplotters.

3. Angular measurements on panoramas for resection of stations and intersection of data points.

Some of these methods are discussed by Batson $(1969 a, b)$. A more general text in simple graphic photogrammetry was published by Williams (1969).

The use of a perspective grid assumes a flat surface and a known height of the camera above the surface. The accuracy of distance measurement varies directly with the accuracy with which camera height is known. A 5-percent error in this parameter will introduce a 5-percent error in distance and thereby in size measurements. Deviation from a level planar surface has the same effect as error in camera-height measurements at specific points. If the assumed camera height above the base of a rock is correct, the assumed height above the top of the rock will be in error by several percent, and its shape, as plotted with a perspective grid, will therefore be badly distorted.

While it may be possible to make reasonable corrections for rock shapes and sizes intuitively, undulations in the surface are less readily detectable. Despite these difficulties, the perspective grid method can be used effectively by one skilled in interpreting Apollo surface pictures.

Approximate scales can be placed on near-field objects in pictures containing the gnomon by using an ellipse template. The Apollo 16 gnomon (fig. 4) stands on three legs that, on a hard surface, define a circle $61.7 \mathrm{~cm}$ in diameter. The "fore and aft" scale and the "side-to-side" scale of areas in the vicinity of the gnomon can be determined by fitting an ellipse to the feet of the gnomon image. If correctly placed, the ellipse corresponds to a circle of known dimensions on the ground where the gnomon stands. Again, the fitting must be done by a skilled photointerpreter such that the long axis of the ellipse is placed as nearly as possible on the image at the intersection of the ground plane with a plane perpendicular to the line of sight of the camera. For measurements of small features near the gnomon, it is helpful to know that the color bands in the gray scale on the wand and on the chart on the gnomon leg are $2 \mathrm{~cm}$ wide. The scales on figures in the chapters on field geology were derived in this manner.

Photogrammetric measurement by stereopairs is the most accurate mapping method used on Apollo 16. An analytical stereoplotter was used to draw contour maps of some features. In theory, absolute orientation can be controlled by the gimbaled wand on the gnomon, which is oriented to lunar vertical, and the trace of the shadow of the wand on the surface, whose angular deviation from lunar north is known for any given time during the lunar day. Difficulty was encountered with this procedure when the swinging of the wand was not effectively damped on the Apollo 16 gnomon. The orientations could be determined accurately only if pictures were taken several seconds after the gnomon was deployed. Maps made with the analytical plotter have less than 1-percent variation in scale throughout. Those that contain the gnomon are correctly oriented (if the wand had stopped swinging when pictures were taken) with the lunar surface within $2^{\circ}$.

Traverse and station maps shown in the chapters on field geology (D1-4) were made primarily from the panoramas. An assembled panorama mosaic can be used in much the same way as a theodolite for measurements of both horizontal and vertical angles. The location of the sun and shadow cast by the astronaut serve to orient the panorama with respect to lunar east and west. Intermediate directions are located by interpolation.

The traditional surveying method of three-point resection (Davis, 1959, p. 1-49) was used to locate the panorama station on maps of the traverse area. By this method, the images of three or more features were identified on both the panoramas and a vertical photograph taken of the same area from lunar orbit. Azimuths to these points were measured on the panoramas and plotted on tracing paper as lines radiating from a point. The tracing paper was placed over the vertical photograph and oriented such that each ray intersected the image of the appropriate feature. The point from which the lines radiated was then marked and identified as the panorama station. On most stations where feature identification was undisputed, resection rays identified the camera's location within 1 or $2 \mathrm{~m}$. In general, the nearer the points are to the camera and the more points there are, the more accurately the station can be located.

The position of station 4 remains in dispute. The set of control points identified by the authors of this chapter are not accepted by some authors of other chapters. We believe that the location of station 4 determined by Sanchez (figs. 1-3, this volume) is in error by approximately $100 \mathrm{~m}$ to the east.

Station maps were prepared with perspective grid measurements on film camera panoramas and photo- 


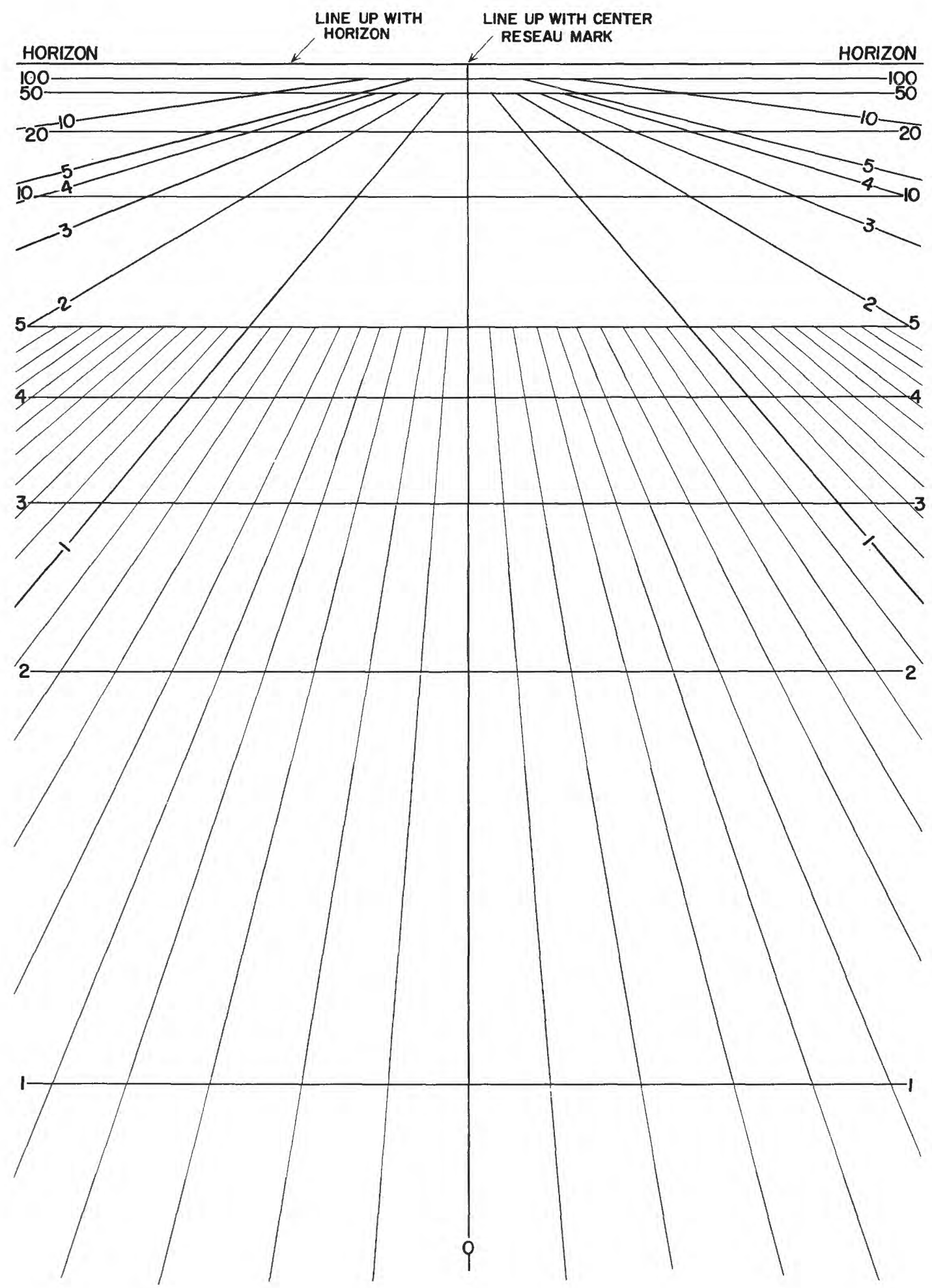

FigURE 3.-Perspective grid used to make approximate measurements of sizes and distances of objects whose images appear in Apollo surface pictures. The image is that part of a 1-m orthogonal grid with its origin under the perspective center of the camera and one axis parallel to the line of sight of the camera. The grid must be scaled to fit the picture on which it is being used. 
graphic copies of pictures in television panoramas. $\mid$ to determine the distance (as a function of the known Where possible, perspective grid measurements were verified by intersecting rays from different panorama stations to known points on the maps. In addition, backsight photographs toward the LRV taken as part of the procedure for photographing samples were used size of the vehicle) and, in some cases, the azimuth of sample collection areas from the LRV. The azimuth could be determined only when objects (in addition to the LRV) identifiable on the traverse map appeared in the backsight picture.

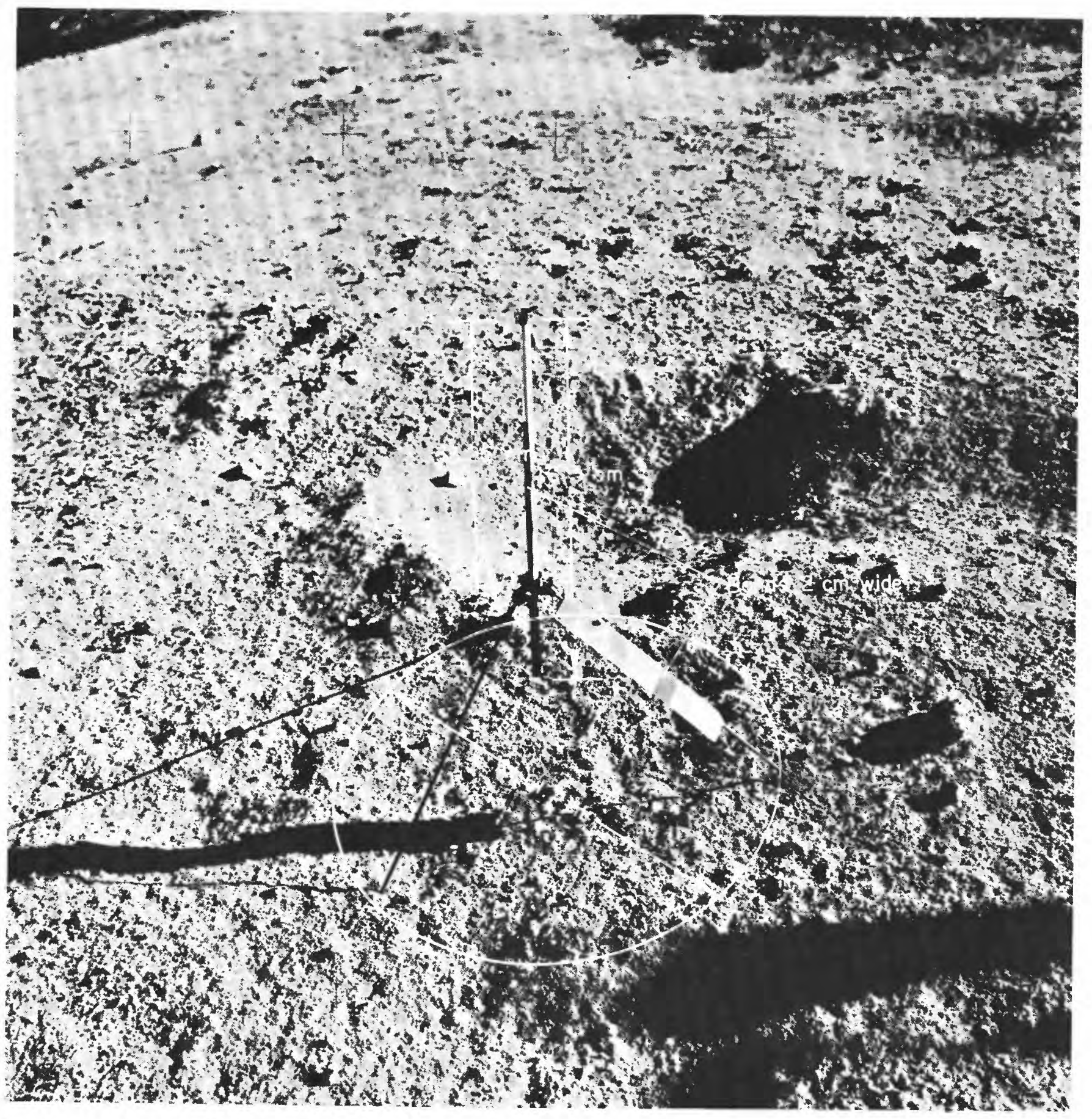

Figure 4.-The Apollo 16 gnomon, a device designed primarily for controlling precise stereophotogrammetric measurements with stereoplotters or with analytical photogrammetry. In simple graphic measurement, the ellipse around the 3 feet of the device, as well as the 2-cm-wide gray-scale bands on the wand and leg chart, can be used for determination of approximate scale in the vicinity of the gnomon (photograph AS16-114-18389). 


\title{
M. IMPACT GEOLOGY OF THE IMBRIUM BASIN
}

\author{
By R. E. Eggleton
}

The Imbrium basin and its geologic influence on the earthside of the Moon is portrayed in plate 12. This map represents a modification and reinterpretation of the geologic map of the near side of the Moon (Wilhelms and McCauley, 1971) at the same scale $(1: 5,000,000)$. It includes a grid of great circles and small circles radial and concentric to the Imbrium basin with the basin center taken as $37.83^{\circ}$ N., $20.00^{\circ}$ W.

Units mapped as products primarily of the Imbrium impact event are: materials of Montes Apenninus and the Alpes Formation (complex basin margin deposits), the Fra Mauro Formation (continuous ejecta blanket), the satellitic-crater materials and sculptured-terrain materials in the central and southern highlands (mainly locally derived material reworked by secondary cratering), pitted-terrain materials (materials reworked by small secondary or tertiary cratering), and terra-plains materials (a sequence of layers of feldspathic highlands-type rubble and (or) breccia deposited from fluidized clouds of basin-associated ejecta). 


\section{REFERENCES CITED}

Adams, J. B., and McCord, T. B., 1973, Vitrification darkening in the lunar highlands and identification of Descartes material at the Apollo 16 site, in V. 1, Proc. Fourth Lunar Sci. Conf., Houston: Geochim. et Cosmochim. Acta, Supp. 4, v. 1, p. 163-178.

Adler, I., Trombka, J. I., Schmadebeck, R., Lowman, P., Blodget, H., Yin, L., Eller, E., Podwysocki, M., Weidner, J. R., Bickel, A. L., Lum, R. K. L., Gerard, J., Gorenstein, P., Bjorkholm, P., and Harris, B., 1973, Results of the Apollo 15 and 16 X-ray experiment, in V. 3, Proc. Fourth Lunar Sci. Conf., Houston: Geochim. et Cosmochim. Acta, Supp. 4. v. 3, p. 2783-2791.

Agrell, S. O., Agrell, J. E., Arnold, A. R., and Long, J. V. R., 1973. Some observations on rock 62295, in Lunar Science IV, Abstracts: Houston, Lunar Sci. Inst., p. 15-17.

Ahrens, T. J., O'Keefe, J. D., and Gibbons, R. V., 1973, Shock compression of a recrystallized anorthositic rock from Apollo 15, in V. 3, Proc. Fourth Lunar Science Conf., Houston: Geochim. et Cosmochim. Acta, Supp. 4, v. 3, p. 2575-2590.

Albee, A. L. Gancarz, A. J., and Chodos, A. A., 1973a, Sanidinite facies metamorphism of Apollo 16 sample 65015, in Lunar Science IV, Abstracts: Houston, Lunar Sci. Inst., p. 24.

-1973b, Metamorphism of Apollo 16 and 17 and Luna 20 metaclastic rocks at about $3.95 \mathrm{AE}$ : Samples 61156, 64423, 14-2, $65015,67483,15-2,76055,22006$, and 22007, in V. 1, Proc. Fourth Lunar Sci. Conf., Houston: Geochim. et Cosmochim. Acta, Supp. 4, v. 1, p. 569-595.

Anderson, C. A., and Hinthorne, J. R., 1973, $207 \mathrm{~Pb} / 206 \mathrm{~Pb}$ ages and REE abundances in returned lunar material by ion microprobe mass analysis, in Lunar Science IV, Abstracts: Houston, Lunar Sci. Inst., p. 37-39.

Apollo Field Geology Investigation Team (AFGIT), 1973, Apollo 16 exploration of Descartes-A geologic summary: Science, v. 179, p. 62-69.

Apollo Lunar Geology Investigation Team (ALGIT), 1972a, Preliminary report on the geology and field petrology at the Apollo 16 landing site: U.S. Geol. Survey Interagency Report, Astrogeol$\operatorname{ogy} 48,59 \mathrm{p}$.

-1972b, Documentation and environment of the Apollo 16 samples-A preliminary report: U.S. Geol. Survey Interagency Report, Astrogeology 51, 252 p.

Baedecker, P. A., Chou, C. L., Sundberg, L. L., and Wasson, J. T., 1972, Extralunar materials in Apollo 16 soils and the decay rate of the extralunar flux 4.0 Gy ago: Earth and Planetary Sci. Letters, v. 17, p. 79-83.

Baldwin, R. B., 1963, The measure of the Moon: Chicago, Univ. Chicago Press, $488 \mathrm{p}$.

Baldwin, R. R., 1972, Mission description, in Apollo 16 preliminary science report: Natl. Aeronautics and Space Adm. Spec. Pub. 315 , p. $2-1$ to $2-10$.

Bansal, B. M., Gast, P. W., Hubbard, N. J., Nyquist, L. E., Rhodes, J. M., Shih, C. Y., and Wiesmann, H., 1973, Lunar rock types, in Lunar Sciences IV, Abstracts: Houston, Lunar Sci. Inst., p. 49.

Bastin, J. A., 1974, A new theory for the formation of the maria and Cayley type lunar regions: The Moon, v. 10, p. 143-162.

Batson, R. M. 1969a, Topographic mapping methods, in Surveyor Program Results: Natl. Aeronautics and Space Adm. Spec. Pub. 184, p. 42-45.

1969b, Photogrammetry with surface-based images: Appl. Optics, v. 8 , no. 7 , p. 1315-1322.

Batson, R. M., Larson, K. B., Reed, V. S., and Tyner, R. L., 1972, Preliminary catalog of pictures taken on the lunar surface during the Apollo 16 mission: U.S. Geol. Survey Interagency Report, Astrogeology 50, $69 \mathrm{p}$.

Behrmann, C., Crozaz, G., Drozd, R., Hohenberg, C., Ralston, C.,
Walker, R., and Yuhas, D., 1973, Cosmic-ray exposure history of North Ray and South Ray material, in V. 2, Proc. Fourth Lunar Sci. Conf., Houston: Geochim. et Cosmochim. Acta, Supp. 4. v. 2, p. 1957-1974.

Bence, A. E., Papike, J. J., Sueno, S., and Delano, J. W., 1973, Pyroxene poikiloblastic rocks from the lunar highlands, in V. 1, Proc. Fourth Lunar Sci., Conf., Houston: Geochim. et Cosmochim. Acta, Supp. 4, v. 1, p. 597-611.

Boudette, E. L., Schafer, J. P., and Elston, D. P., 1972, Engineering geology of the Apollo 16 (Descartes) traverse area: U.S. Geol. Survey open-file report, scale 1:12,500.

Boyce, J. M., Dial, A. L., and Soderblom, L. A., 1974, Ages of the lunar nearside light plains and maria, in V. 1, Proc. Fifth Lunar Sci. Conf., Houston: Geochim. et Cosmochim. Acta. Supp. 5, v. 1. p. 11-23.

Brown, G. M., Peckett, A., Phillips, R., and Emeleus, C. H., 1973, Mineral-chemical variations in the Apollo 16 magnesiofeldspathic highland rocks, in V. 1, Proc. Fourth Lunar Sci. Conf., Houston: Geochim. et Cosmochim. Acta, Supp. 4, v. 1, p. 505-518.

Brunfelt, A. O., Heier, K. S., Nilssen, B., and Sundvoll, B., 1973a, Geochemistry of Apollo 15 and 16 materials, in V. 2, Proc. Fourth Lunar Sci. Conf., Houston: Geochim. et Cosmochim. Acta, Supp. 4, v. 2, p. 1209-1218.

Brunfelt, A. O., Heier, K. S., Nilssen, B., Steinnes, E., and Sundvoll, B., 1973b, Elemental composition of Apollo 15 and 16 rocks, fines, and minerals, in Lunar Science IV, Abstracts: Houston, Lunar Sci. Inst., p. 100.

Butler, J. C., Greene, G. M., and King, E. A., Jr., 1973, Grain size frequency distributions and modal analysis of Apollo 16 fines, in V. 1, Proc. Fourth Lunar Sci. Conf., Houston: Geochim. et Cosmochim. Acta, Supp. 4, v. 1, p. 267-278.

Carlson, R. H., and Jones, G. D., 1965, Distribution of ejecta from cratering explosions in soils: Jour. Geophys. Research, v. 70, no. 8, p. $1897-1910$.

Carlson, R. H., and Roberts, W. A., 1963, Mass distribution and throwout studies: Seattle, Wash., Boeing Co., Proj. Sedan report PNE-217F, $144 \mathrm{p}$.

Chao, E. C. T., 1973, Preliminary genetic classification of Apollo 16 breccias, in Lunar Science IV, Abstracts: Houston, Lunar Sci. Inst., p. 129.

Chao, E. C. T., Hodges, C. A., Boyce, J. M., and Soderblom, L. A., 1975, Origin of lunar light plains: U.S. Geol. Survey Jour. Research, v. 3, no.4, p. 379-392.

Chao, E. C. T., Soderblom, L. A., Boyce, J. M., Wilhelms, D. E., and Hodges, C. A., 1973, Lunar light plains deposits (Cayley Formation)-a reinterpretation of origin, in Lunar Science IV, Abstracts: Houston, Lunar Sci. Inst., p. 127-128.

Compston, W., Vernon, M. J., Chappell, B. W., and Freeman, R., 1973, Rb-Sr model ages and chemical composition of nine Apollo 16 soils, in Lunar Science IV, Abstracts: Houston, Lunar Sci. Inst., p. 158.

Cooper, M. R., Kovach, R. L., and Watkins, J. S., 1974, Lunar nearsurface structure: Rev. Geophys. and Space Physics, v. 12, p. 291-308.

Crawford, M. L., 1974, Crystallization history of poikilitic sample 62235, in Lunar Science V, Abstracts: Houston, Lunar Sci. Inst., p. 142-144.

Cummings, David, 1972, Geologic map of the Clavius quadrangle of the Moon: U.S. Geol. Survey Misc. Geol. Inv. Map I-706 (LAC126).

Davis, R. E., 1959, Surveying, Section 1, in Urquhart, L. C., ed., Civil Engineering Handbook: New York, Mc Graw-Hill Book Co.

Delano, J. W., Bence, A. E., Papike, J. J., and Cameron, K. L., 1973, Petrology of the 2-4 mm soil fraction from the Descartes region 
of the moon and stratigraphic implications, in V. 1, Proc. Fourth Lunar Sci. Conf., Houston: Geochim. et Cosmochim. Acta, Supp. 4 , v. 1 , p. $537-551$.

Dence, M. R., Grieve, R. A. F., and Plant, A. G., 1974, The Imbrium basin and its ejecta, in Lunar Science V; Abstracts: Houston, Lunar Sci. Inst., p. 165-167.

Dennis, J. G., 1971, Ries structure, southern Germany, a review: Jour. Geophys. Research, v. 76, p. 5394-5406.

Dowty, E., Keil, K., and Prinz, M., 1974a, Igneous rocks from Apollo 16 rake samples in V. 1, Proc. Fifth Lunar Sci. Conf., Houston: Geochim. et Cosmochim. Acta, Supp. 5, v. 1, p. 431-445.

Dowty, E., Prinz, M., and Keil, K., 1974b, Ferroan anorthosite-A widespread and distinctive lunar rock type: Earth and Planetary Sci. Letters, v. 24, p. 15-25.

Drake, J. C., 1974, Mineralogy and chemistry of 61016-215, in Lunar Sci. V, Abstracts: Houston, Lunar Sci. Inst., 177-179.

Drozd, R. J., Hohenberg, C. M., Morgan, C. J., and Ralston, C. E., 1974, Cosmic-ray exposure history at the Apollo 16 and other lunar sites-Lunar surface dynamics: Geochim. et Cosmochim. Acta, v. 38 , no. 101 , p. $1625-1642$.

Duncan, A. R., Erlank, A. J., Willis, J. P., and Ahrens, L. H., 1973, Composition and interrelationships of some Apollo 16 samples, in V. 2, Proc. Fourth Lunar Sci. Conf., Houston: Geochim. et Cosmochim. Acta, Supp. 4, v. 2, p. 1097-1113.

Dyal, P., Parkin, C. W., Sonett, C. P., DuBois, R. L., and Simmons, G., 1972, Lunar portable magnetometer experiment, in Apollo 16 preliminary science report: Natl. Aeronautics and Space Adm. Spec. Pub. 315 , p. $12-1$ to $12-8$.

Eggleton, R. E., and Marshall, C. H., 1962, Notes on the Apenninian Series and pre-Imbrian stratigraphy in the vicinity of Mare Imbrium and Mare Nubium, in Astrogeology studies semiannual progress report, February 26, 1961, to August 24, 1961, pt. A: U.S. Geol. Survey open-file report, p. 132-137.

Eggleton, R. E., and Schaber, G. G., 1972, Cayley Formation interpreted as basin ejecta, in Apollo 16 preliminary science report: Natl. Aeronautics and Space Adm. Spec. Pub. 315, p. 29-7 to 29-16.

Eldridge, J. S., O'Kelley, G. D., and Northcutt, K. J., 1973, Radionuclide concentrations in Apollo 16 lunar samples determined by nondestructive gamma-ray spectrometry, in V. 2, Proc. Fourth Lunar Sci. Conf., Houston: Geochim. et Cosmochim. Acta, Supp. 4 , v. 2 , p. $2115-2122$.

El Goresy, A., Ramdohr, P., and Medenbach, O., 1973, Lunar samples from Descartes site-Opaque mineralogy and geochemistry, in V. 1, Proc. Fourth Lunar Sci. Conf., Houston: Geochim. et Cosmochim. Acta, Supp. 4, v. 1, p. 733-750.

Elston, D. P., Boudette, E. L., and Schafer, J. P., 1972a, Geology of the Apollo 16 (Descartes) landing site area: U.S. Geol. Survey open-file map, 1:25,000.

1972b, Geologic map of the Apollo 16 (Descartes) region: U.S. Geol. Survey open-file map, scale 1:100,000.

Elston, D. P., Boudette, E. L., Schafer, J. P., Muehlberger, W. R., and Sevier, J. R., 1972c, Apollo 16 field trips: Geotimes, v. 17, p. $27-30$.

Engelhardt, W. von, and Stoffler, D., 1968, Stages of shock metamorphism in crystalline rocks of the Ries basin, Germany, in Shock metamorphism of natural materials: French, B., and Short, N., eds.,: Baltimore, Mono Book Corp., p. 159-168.

Friedman, I., Hardcastle, K. G., Gleason, J. D., 1974, Water and carbon in rusty lunar rock 66095 : Science, v. 185 , p. 346-349.

Fruchter, J. S., Robyn, M. A., and Goles, G. G., 1974, Compositional affinities of clasts and matrix from breccia 66055, in Lunar Sci. V, Abstracts: Houston, Lunar Sci. Inst., p. 251-253.

Ganapathy, R., Morgan, J. W., Higuchi, H., Anders, E., and Anderson, A. T., 1974, Meteoritic and volatile elements in Apollo 16 rocks and in separated phases from 14306, in V. 2, Proc. Fifth Lunar Sci. Conf., Houston: Geochim. et Cosmochim. Acta, Supp. 5, v. 2, 1659-1683.

Gancarz, A. J., Albee, A. L., and Chodos, A. A., 1972, Comparative petrology of Apollo 16 sample 68415 and Apollo 14 samples 14276 and 14310: Earth and Planetary Sci. Letters, v. 16, p. $307-330$.

Gault, D. E., Horz, F., Brownlee, D. E., and Hartung, J. B., 1974, Mixing of the lunar regoliths, in Lunar Science V, Abstracts: Houston, Lunar Sci. Inst., p. 260-262.

Gilbert, G. K., 1893, The Moon's face: Philos. Soc. Washington Bull., v. 12 , p. 241-292.

Greeley, R., and Gault, D. E., 1970, Precision size-frequency distributions of craters for 12 selected areas of the lunar surface: The Moon, v. 2, p. 10-77.

Grieve, R. A. F., and Plant, A. G., 1973, Partial melting on the lunar surface, as observed in glass-coated Apollo 16 samples, in V. 1, Proc. Fourth Lunar Sci. Conf., Houston: Geochim. et Cosmochim. Acta, Supp. 4, v. 1, p. 667-679.

Grieve, R. A. F., Plant, A. G., and Dence M. R., 1974, Lunar impact melts and terrestrial analogs-Their characteristics, formation and implications for lunar crustal evolution, in V. 1, Proc. Fifth Lunar Sci. Conf., Houston: Geochim. et Cosmochim. Acta, Supp. 5 , v. 1 , p. $261-273$.

Hackman, R. J., 1966, Geologic map of the Montes Apenninus region of the Moon: U.S. Geol. Survey Misc. Geol. Inv. Map I-463.

Hartmann, W. K., and Kuiper, G. P., 1962, Concentric structures surrounding lunar basins: Arizona Univ. Lunar and Planetary Lab. Commun., v. 1, no. 12, p. 51-66.

Haskin, L. A., Helmke, P. A., Blanchard, D. P., Jacobs, J. W., and Telander, K., 1973, Major and trace element abundances in samples from the lunar highlands, in V. 2, Proc. Fourth Lunar Sci. Conf., Houston: Geochim. et Cosmochim. Acta, Supp. 4, v. 2, p. $1275-1296$.

Head, J. W., 1972, Small-scale analogs of the Cayley formation and Descartes Mountains in impact-associated deposits, in Apollo 16 preliminary science report: Natl. Aeronautics and Space Adm. Spec. Pub. 315 , p. $29-16$ to $29-20$. 1974, Stratigraphy of the Descartes region (Apollo 16) Implications for the origin of samples: The Moon, v. 11, p. 77-99.

Head, J. W., and Goetz, A. F. H., 1972, Descartes region-Evidence for Copernican-age volcanism: Jour. Geophys. Research, v. 77, p. 1368-1374.

Heiken, G. H., McKay, D. S., and Fruland, R. M., 1973, Apollo 16 soils-Grain size analyses and petrography, in V. 1, Proc. Fourth Lunar Sci. Conf., Houston: Geochim. et Cosmochim. Acta, Supp. 4. v. 1, p. 251-265.

Helz, R. T., and Appleman, D. E., 1973, Mineralogy, petrology, and crystallization history of Apollo 16 rock 68415, in V. 1, Proc. Fourth Lunar Sci. Conf., Houston: Geochim. et Cosmochim. Acta, Supp. 4, v. 1, p. 643-659.

Hodges, C. A., 1972a, Geologic map of part of the Descartes region of the Moon, Apollo 16 pre-mission map: U.S. Geol. Survey Misc. Geol. Inv. Map I-748, sheet 2, scale 1:50,000.

-1972b, Descartes highlands-possible analogs around the Orientale Basin, in Apollo 16 preliminary science report: Natl. Aeronautics and Space Adm. Spec. Pub. 315, p. 29-20 to 29-23. -1973 , Geologic map of the Langrenus quadrangle of the Moon: U.S. Geol. Survey Misc, Geol. Inv. Map I-739, (LAC-80) in scale 1:1,000,000

Hodges, C. A., Muehlberger, W. R., and Ulrich, G. E., 1973, Geologic setting of Apollo 16, in V. 1, Proc. Fourth Lunar Sci. Conf., Houston: Geochim. et Cosmochim. Acta, Supp. 4, v. 1, p. 1-25.

Hodges, F. N., and Kushiro, Ikuo, 1973, Petrology of Apollo 16 lunar highland rocks, in V. 1, Proc. Fourth Lunar Sci. Conf., Houston: 
Geochim. et Cosmochim. Acta, Supp. 4, v. 1, p. 1033-1048.

Hollister, L. S., 1973, Sample 67955-A description and a problem, in V. 1, Proc. Fourth Lunar Sci. Conf., Houston: Geochim. et Cosmochim. Acta, Supp. 4, v. 1, p. 633-641.

Holt, H. E., and Rennilson, J. J., 1970, Photometric and polarimetric properties of the lunar regolith, $\mathrm{Pt}$. B of Preliminary geology investigation of the Apollo 12 landing site, in Apollo 12 preliminary science report: Natl. Aeronautics and Space Adm. Spec. Pub. 235, p.157-161.

Horz, Friedrich, Carrier, W. D. III, Young, J. W., Duke, C. M., Nagle, J. S., and Fryxell, Roland, 1972, Apollo 16 special samples, in Apollo 16 preliminary science report: Natl. Aeronautics and Space Adm. Spec. Pub. 315, p. 7-24 to 7-54.

Howard, K. A., and Masursky, Harold, 1968, Geologic map of the Ptolemaeus quadrangle of the Moon: U.S. Geol. Survey Misc. Geol. Inv. Map I-566 (LAC 77, RLC 13).

Howard, K. A., Wilhelms, D. E., and Scott, D. H., 1974, Lunar basin formation and highland stratigraphy: Rev. Geophys. and Space Physics, v. 12, p. 309-327.

Howard, K. A., and Wilshire, H. G., 1975, Flows of impact melts at lunar craters: U.S. Geol. Survey Jour. Research, V. 3, no. 2, p. 237-251.

Hubbard, N. J., Rhodes, J. M. Gast, P. W., Bansal, B. M., Shih, C. Y., Wiesmarn, H., and Nyquist, L. E., 1973, Lunar rock types-The role of plagioclase in nonmare and highland rock types, in V. 2, Proc. Fourth Lunar Sci. Conf., Houston: Geochim, et Cosmochim. Acta, Supp. 4, v. 2, p. 1297-1312.

Huneke, J. C., Jessberger, E. K., Podosek, F. A., and Wasserburg, G. J., $1973 \mathrm{a},{ }^{40} \mathrm{Ar}-{ }^{39} \mathrm{Ar}$ measurements in Apollo 16 and 17 samples and the chronology of metamorphic and volcanic activity in the Taurus-Littrow region, in V. 2-Proc. Fourth Lunar Sci. Conf., Houston: Geochim. et Cosmochim. Acta, Supp. 4, v. 2, p. 17251756.

Huneke, J. C., Podosek, F. A., and Wasserburg, G. J., 1973b, An argon bouillabaisse including ages from the Luna 20 site, in Lunar Sci. IV, Abstracts: Houston, Lunar Sci. Inst., p. 403-405.

Husain, L., and Schaffer, O. A., 1973, ${ }^{40} \mathrm{Ar}-{ }^{39} \mathrm{Ar}$ crystallization ages and ${ }^{38} \mathrm{Ar}-{ }^{37} \mathrm{Ar}$ cosmic ray exposure ages of samples from the Apollo 16 landing site, in Lunar Sci. IV, Abstracts: Houston, Lunar Sci. Inst., p. 406-408.

Jackson, E. D., Sutton, R. L., and Wilshire, H. G., 1975, Structure and petrology of a cumulus norite boulder sampled by Apollo 17 in Taurus-Littrow Valley, the Moon: Geol. Soc. Am. Bull. v. 86, p. 433-442.

Jessberger, E. K., Huneke, J. C., and Wasserberg, G. J., 1974, Evidence for a $4.5 \mathrm{AE}$ age of plagioclase clasts in a lunar highlands breccia: Nature, v. 248, p. 199-202.

Johan, Z., and Christophe, M., 1974, Origin of pyroxene and silica exsolutions in anorthite from 60016,95 polished thin section, in Lunar Sci. Abstracts: Houston, Lunar Sci. Inst., p. 385-387.

Juan, V. C., Chen, J. C., Huang, C. K., Chen, P. Y., and Wang Lee, C. M., 1973, Petrology and chemistry of Apollo 16 gabbroic anorthosite 68416, in Lunar Science IV, Abstracts: Houston, Lunar Sci. Inst., p. 421-423.

1974, Petrology and chemistry of some Apollo 16 samples in Lunar Sci. V, Abstracts: Houston, Lunar Sci. Inst., p. 394-396.

Kammerer, Joachim, 1973, The moon camera and its lenses: Photogramm. Eng., v. 39, no. 1, p. 59-63.

Keil, Klaus, Dowty, Eric, Prinz, M., and Bunch, T. E., 1972, Description, classification, and inventory of 151 Apollo 16 rake samples from the LM area and station 5: NASA Misc. Pub. (unnumbered), $166 \mathrm{p}$.

Kirsten, T., Horn, P., and Kiko, J., $1973,{ }^{40} \mathrm{Ar}-{ }^{39} \mathrm{Ar}$ dating and rare gas analysis of Apollo 16 rocks and soils, in V. 2, Proc. Fourth
Lunar Science Conf., Houston: Geochim. et Cosmochim. Acta, Supp. 4, v. 2, p. 1757-1784.

Kovach, R. L., and Watkins, J. S., 1973, The velocity structure of the lunar crust: The Moon, v. 7, p. 63-75.

Kovach, R. L., Watkins, J. S., Nur, A., and Talwani, P., 1973, The properties of the shallow lunar crust-An overview from Apollo 14, 16, and 17, in Lunar Science IV, Abstract: Houston, Lunar Sci. Inst., p. 444-445.

Kovach, R. L., Watkins, J. S., and Talwani, Pradeep, 1972, Active seismic experiment, in Apollo 16 preliminary science report: Natl. Aeronautics and Space Adm. Spec. Pub. 315, p. 10-1 to $10-14$.

Kraut, F., and French, B., 1971, The Rochechouart meteorite impact structure, France-Preliminary geological results in meteorite impact and volcanism: Jour. Geophys. Research, v. 76, no. 23, p. 5382-5413.

Kridelbaugh, S. J., McKay, G. A., and Weill, D. F., 1973, Breccias from the lunar highlands-Preliminary petrographic report on Apollo 16 samples 60017 and 63335: Science, v. 179, p. 71-74.

Latham, G. V., Ewing, Maurice, Press, Frank, Sutton, George, Dorman, James, Nakamura, Yosio, Toksoz, Nafi, Lammlein, D., and Duennebier, Fred, 1972, Passive seismic experiment, in Apollo 16 preliminary science report: Natl. Aeronautics and Space Adm. Spec. Pub. 315, p. 9-1 to 9-29.

Laul, J. C., and Schmitt, R. A., 1973, Chemical composition of Apollo 15, 16, and 17 samples, in V. 2, Proc. Fourth Lunar Sci. Conf., Houston: Geochim. et Cosmochim. Acta, Supp. 4, v. 2, p. 13491367.

Laul, J. C., Schmitt, R. A., and Mason, B., 1974, Breccias 64435, 63335, and 63355, in Lunar Sci. V, Abstracts: Houston, Lunar Sci. Inst., p. 435-437.

Lucchitta, B. K., 1980, Geologic map of the north side of the Moon: U.S. Geol. Survey Misc. Geol. Inv. Map I-1062, scale 1:5,000,000.

Lunar Receiving Laboratory (LRL), 1972, Lunar sample information catalog, Apollo 16: NASA Misc. Pub. 03210, 372 p.

Lunar Sample Preliminary Examination Team (LSPET), 1972, Preliminary examination of lunar samples: Natl. Aeronautics and Space Adm. Spec. Pub. 315, p. 7-1 to 7-58.

1973, The Apollo 16 lunar samples-Petrographic and chemical description: Science, v. 179, p. 23-24.

McCauley, J. F., 1967, Geologic map of the Hevelius region of the Moon: U.S. Geol. Survey Misc. Geol. Inv. Map I-491 (LAC 56).

1969, Geologic map of the Alphonsus GA region of the Moon: U.S. Geol. Survey Misc. Geol. Inv. Map I-586 (RLC 15).

McGetchin, T. R., Settle, M., and Head, J. W., 1973, Radial thickness variation in impact crater ejecta: Implications for lunar basin deposits: Earth and Planetary Sci. Letters, v. 20, p. 226-236.

McKay, D. S., and Heiken, G. H., 1973, The South Ray crater age paradox, in V. 1, Proc. Fourth Lunar Sci. Conf., Houston: Geochim. et Cosmochim. Acta, Supp. 4, v. 1, p. 41-47.

Mark, R. K., Lee-Hu, C., Wetherill, G. W., 1974, Rb-Sr measurements on lunar igneous rocks and breccia clasts, in Lunar Sci. V. Abstracts: Houston, Lunar Sci. Inst., p. 490-492.

Marti, K., Lightner, B. D., and Osborn, T. W., 1973, Krypton and xenon in some lunar samples and the age of North Ray crater, in V. 2, Proc. Fourth Lunar Sci. Conf., Houston: Geochim. et Cosmochim. Acta, Supp. 4, v. 2, p. 2037-2048.

Mason, Brian, 1962, Meteorites: New York, John Wiley \& Sons, 274 p.

Mason, Brian, Simkin, T., Noonan, A. F., Switzer, G. S., Nelen, J. A., Thompson, G. and Melson, W. G., 1973, Composition of Apollo 16 fines 60051, 60052, 64811, 64812, 67711, 67712, 68821, and 68822, in Lunar Sci. IV, Abstracts: Houston, Lunar Sci. Inst., p. 505-507. 
Metzger, A. E., Trombka, J. I., Peterson, L. E., Reedy, R. C., and Arnold, J. R., 1973, Lunar surface radioactivity, Preliminary results of the Apollo 15 and Apollo 16 gamma-ray spectrometer experiment: Science, v. 179, p. 800-803.

Milton, D. J., 1964, Stratigraphy of the terra part of the Theophilus quadrangle, in Astrogeology studies annual progress report, July 1, 1963 to July 1, 1964, pt. A: U.S. Geol. Survey open-file report, p. $17-27$.

1968, Geologic map of the Theophilus quadrangle of the Moon: U.S. Geol. Survey Misc. Geol. Inv. Map I-546 (LAC 78).

-1972, Geologic map of the Descartes region of the moon: Apollo 16 pre-mission map: U.S. Geol. Survey Misc. Geol. Inv. Map I-748, sheet 1 , scale 1:250,000.

Moore, C. B., Lewis, C. F., and Gibson, E. K., Jr., 1973, Total carbon contents of Apollo 15 and 16 lunar samples, in Proc. V. 2, Fourth Lunar Sci. Conf., Houston: Geochim. et Cosmochim. Acta, Supp. 4 , v. 2 , p. $1613-1623$.

Moore, H. J., 1969, Subsurface deformation resulting from missile impact: U.S. Geol. Survey Prof. Paper 650-B, p. B107-B112.

1971, Craters produced by missile impacts: Jour. Geophys. Research, v. 76 , p. $5750-5775$.

Moore, H. J., Hodges, C. A., and Scott, D. H., 1974, Multi-ringed basins, in V. 1, Proc. Fifth Lunar Sci. Conf., Houston: Geochim. et Cosmochim. Acta, Supp. 5, v. 1, p. 71-100.

Morgan, J. W., Ganapathy, R., Higuchi, Hideo, Krahenbuhl, Urs, and Anders, E., 1974, Lunar basins-Tentative characterization of projectiles, from meteoritic elements in Apollo 17 boulders, in V. 2, Proc. Fifth Lunar Science Conf., Houston: Geochim. et Cosmochim. Acta, Supp. 5, v. 2, p. 1703-1736.

Morris, E. C., and Wilhelms, D. E., 1967, Geologic map of the Julius Caesar quadrangle of the Moon: U.S. Geol. Survey Misc. Geol. Inv. Map I-510 (LAC 60).

Morrison, D. A., McKay, D. S., Fruland, R. M., and Moore, H. J., 1973, Microcraters on Apollo 15 and 16 rocks, in V. 3, Proc. Fourth Lunar Sci. Conf., Houston: Geochim. et Cosmochim. Acta, Supp. 4, v. 3, p. 3235-3253.

Morrison, G. H., Nadkarni, R. A., Jaworski, J., Botto, R. B., Roth, J. R., 1973, Elemental Abundances of Apollo 16 samples, in Lunar Science IV, Abstracts: Houston, Lunar Sci. Inst., p. 545.

Muehlberger, W. R., 1974, Structural history of southeastern Mare Serenitatis and adjacent highlands, in V. 1, Proc. Fifth Lunar Sci. Conf., Houston: Geochim. et Cosmochim. Acta, Supp. 5, v. 1, p. 101-110.

Muehlberger, W. R., Batson, R. M., Boudette, E. L., Duke, C. M., Eggleton, R. E., Elston, D. P., England, A. W., Freeman, V. L., Hait, M. H., Hall, T. A., Head, J. W., Hodges, C. A., Holt, H. E., Jackson, E. D., Jordan, J. A., Larson, K. B., Milton, D. J., Reed, V. S., Rennilson, J. J., Schaber, G. G., Schafer, J. P., Silver, L. T., Stuart-Alexander, D., Sutton, R. L., Swann, G. A., Tyner, R. L., Ulrich, G. E., Wilshire, H. G., Wolfe, E. E., and Young, J. W., 1972, Preliminary geologic investigation of the Apollo 16 landing site, in Apollo 16 preliminary science report: Natl. Aeronautics and Space Adm. Spec. Pub. 315, p. 6-1 to 6-81.

Mutch, T. A., 1970, Geology of the Moon, a stratigraphic view: Princeton, N. J., Princeton Univ. Press, 324 p.

Nakamura, N., Masuda, A., Tanaka, T., and Kurasawa, H., 1973, Chemical compositions and rare-earth features of four Apollo 16 samples, in V. 2, Proc. Fourth Lunar Sci. Conf., Houston: Geochim. et Cosmochim. Acta, Supp. 4, v. 2, p. 1407-1414.

National Academy of Sciences-National Research Council, 1974, Panel on solid-earth problems-solid-earth geophysics, survey and outlook: NAS-NRC Pub. 1231, $197 \mathrm{p}$.

Nava, D. F., 1974, Chemistry of some rock types and soils from the Apollo 15, 16, and 17 lunar sites, in Lunar Science V, Abstracts:
Houston, Lunar Sci. Inst., p. 547-548.

Neukum, Gerhard, Horz, Friedrich, and Morrison, D. A., 1973, Crater populations on lunar rocks, in V. 3: Proc. Fourth Lunar Sci. Conf., Houston: Geochim. et Cosmochim. Acta, Supp. 4 v. 3, p. 3255-3276.

Nord, G. L., Lally, J. S., Hever, A. H., and Christie, J. M., 1973, Petrologic study of igneous and metaigneous rocks from Apollo 15 and 16 using high voltage transmission electron microscopy, in V. 1, Proc. Fourth Lunar Sci. Conf., Houston: Geochim. et Cosmochim. Acta, Supp. 4, v. 1, p. 953-970.

Nunes, P. D., Knight, R. J., Unruh, D. M., and Tatsumoto, M., 1974, The primitive nature of the lunar crust and the problem of initial $\mathrm{Pb}$ isotopic compositions of lunar rocks-A $\mathrm{Rb}-\mathrm{Sr}$ and U-Th-Pb study of Apollo 16 samples, in Lunar Sci. V, Abstracts: Houston, Lunar Sci. Inst., 559-561.

Nunes, P. D., and Tatsumoto, M., 1973, Excess lead in "Rusty Rock" 66095 and implications for an early lunar differentiation: Science, v. 182, p. 916-920.

Nunes, P. D., Tatsumoto, M., Knight, R. J., Unruh, D. M., and Doe, B. R., 1973, U-Th-Pb systematics on some Apollo 16 lunar samples, in V. 2, Proc. Fourth Lunar Sci. Conf., Houston: Geochim. et Cosmochim. Acta, Supp. 4, v. 2, p. 1797-1822.

Oberbeck, V. R., 1971a, A mechanism for the production of lunar crater rays: The Moon, v. 2 , no. 3, p. 263-278.

1971b, Implications of regolith thickness in Apollo 16 landing site: Natl. Aeronautics and Space Adm. TM X-62,089, 13 p., 5 figs.

1971c, Laboratory simulation of impact cratering with high explosives: Jour. Geophys. Research, v. 76, p. 5732-5749.

-1975, The role of ballistic erosion and sedimentation in lunar stratigraphy: Reviews Geophysics and Space Physics, v. 13, 337-362.

Oberbeck, V. R., Horz, Fred, Morrison, R. H., Quaide, W. L., and Gault, D. E., 1974a, Effects of formation of large craters and basins on emplacement of smooth plains materials, in Lunar Sci. V, Abstract: Houston, Lunar Sci. Inst., p. 568-572.

1974b, Smooth plains and continuous deposits of craters and basins, in V. 1, Proc. Fifth Lunar Sci. Conf., Houston: Geochim. et Cosmochim. Acta, Supp. 5, v. 1, p. 111-136.

-1975 , On the origin of the lunar smooth plains: The Moon, $v$. 12, p. 19-54.

Oberbeck, V. R., and Morrison, R. H., 1973, On the formation of the lunar herringbone pattern, in V. 1, Proc. Fourth Lunar Sci. Conf., Houston: Geochim. et Cosmochim. Acta, Supp. 4, v. 1, p. 107-123.

Oberbeck, V. R., Morrison, R. H., Wedekind, J., 1972, Lunar secondary craters, in Apollo 16 preliminary science report: Natl. Aeronautics and Space Adm. Spec. Pub. 315, p. 29-51 to 29-56.

Papanastassiou, D. A., and Wasserburg, G. J., 1972a, The Rb-Sr age of a crystalline rock from Apollo 16: Earth and Planetary Sci. Letters, v. 16, p. 289-298.

-1972b, Rb-Sr systematics of Luna 20 and Apollo 16 samples: Earth and Planetary Sci. Letters., v. 17, p. 52-63.

Pearce, G. W., and Simonds, C. H., 1974, Magnetic properties of Apollo 16 samples and implications for their mode of formation: Jour. Geophys. Research, v. 79, no. 20, p. 2953-2960.

Peckett, A., and Brown, G. M., 1973, Plutonic or metamorphic equilibration in Apollo 16 lunar pyroxenes: Nature, v. 242, p. 252-255.

Philpotts, J. A., Schuhmann, S., Kouns, C. W., Lum, R. K. L., Bickel, A. L., and Schnetzler, C. C., 1973, Apollo 16 returned lunar samples: lithophile trace-element abundances, V. 1, Proc. Fourth Lunar Sci. Conf., Houston: Geochim. et Cosmochim. Acta, Supp. 4, v. 2, p. 1427-1436. 
Phinney, W. C., and Lofgren, Gary, 1973, Description, classification, and inventory of Apollo 16 rake samples from stations 1, 4, and 13: NASA Misc. Pub., 69 p.

Pike, R. J. 1972, Geometric similitude of lunar and terrestrial craters: Internat. Geol. Cong., 24th sess. Montreal, Canada 1972 Proc. sec. 15, p. 41-47.

1974, Depth/diameter relations of fresh lunar craters: Revision from spacecraft data: Geophysical Research Letters, v. 1, n. 7, p. 291-294.

Pohn, H. A., and Wildey, R. L., 1970, A photoelectric photographic study of the normal albedo of the Moon: U.S. Geol. Survey Prof. Paper 599-E. 20 p.

Prinz, M., Dowty, E., Keil, K., and Bunch, T. E., 1973a, Spinel troctolite and anorthosite in Apollo 16 samples: Science, v. 179, p. 74-76.

-1973b, Mineralogy, petrology and chemistry of lithic fragments from Lunar 20 fines: Origin of the cumulate ANT suite and its relationship to high-alumina and mare basalts: Geochim. et Cosmochim. Acta, v. 37, p. 979-1006.

Quaide, W. L., and Ob:tieck, V. R., 1968, Thickness determinations of the lunar surface layer from lunar impact craters: Jour. Geophys. Research, v. 73, no. 16, p. 5247-5270.

Reid, A. M., Ridley, W. I., Warner, J., Harmon, R. S., Brett, R., Jakes, P., and Brown, R. W., 1972, Chemistry of highland and mare basalts as inferred from glasses in the lunar soils, in Third Lunar Sci. Conf., Jan. 10-13, 1972, Abstracts: Houston, Lunar Sci. Inst., p. 562-564.

Roberts, N. A. and Carlson, R. H., 1963, Project Sedan ejecta studies: Boeing Co. Prelim. Rept. PNE-217P, 62 p.

Roedder, E., and Weiblen, P. W., 1974a, Petrology of clasts in breccia 67915 , in Lunar Science V, Abstracts: Houston, Lunar Sci. Inst., p. $642-643$.

- 1974b, An unusual barred olivine chondrule in spinel troctolite 62295, in Lunar Sci. V, Houston, Abstracts: Lunar Sci., p. 639-641.

Rondot, J., 1971, Impactite of the Charlevoix structure, Quebec, Canada, in Meteorite impact and volcanism: Jour. Geophys. Research, v. 76 , no. 23 , p. $5414-5423$.

Rose, H. J., Jr., Cuttitta, F., Berman, S., Carron, M. K., Christian, R. P., Dwornik, E. J., Greenland, L. P., and Ligon, D. T., Jr., 1973, Compositional data for twenty-two Apollo 16 samples, in V. 2, Proc. Fourth Lunar Sci. Conf., Houston: Geochim. et Cosmochim. Acta, Supp. 4, v. 2, p. 1149-1158.

Schaber, G. G., 1969, Geologic map of the Sinus Iridum quadrangle of the Moon: U.S. Geol. Survey Misc. Geol. Inv. Map I-602.

Schaber, G. G., and Swann, G. A., 1971, Surface lineaments at the Apollo 11 and Apollo 12 landing sites, V. 1, Proc. Second Lunar Sci. Conf.: Cambridge, Massachusetts Inst. Tech. Press, p. $27-38$.

Schaeffer, O. A., and Husain, L., 1973, Early lunar history: Ages of 2-4 mm soil fragments from the lunar highlands, in V. 2, Proc. Fourth Lunar Sci. Conf., Houston: Geochim. et Cosmochim. Acta, Supp. 4, v. 2, p. 1847-1863.

-1974, Chronology of the lunar basin formation and ages of lunar anorthositic rocks, in Lunar Sci. V, Abstracts: Houston, Lunar Sci. Inst., p. 663-665.

Schultz, P. H., and Gault, D. E., 1974, Seismic effects from major basin formation on the Moon and Mercury: Natl. Aeronautics and Space Adm. Tech. Mem. TM X-62,388, 39 p.

Sclar, C. B., and Bauer, J. F., 1974, Shock effects in lunar rocks 60015 and 77017, in Lunar Sci. V, Abstracts: Houston, Lunar Sci. Inst., p. 687-689.

Sclar, C. B., Bauer, J. F., Pickart, S. J., and Alperin, H. A., 1973, Shock effects in experimentally shocked terrestrial ilmenite, lunar ilmenite of rock fragments in 1-10 mm fines $(10085,19)$, and lunar rock 60015, 127, V. 1, Proc. Fourth Lunar Sci. Conf., Houston: Geochim. et Cosmochim. Acta, Supp. 4, p. 841-859.

Scoon, J. H., 1974, Chemical analysis of lunar samples from the Apollo 16 and 17 collections; in Lunar Science V Abstracts: Houston, Lunar Sci. Inst., p. 690-692.

Scott, D. H., 1972, Structural aspects of Imbrium sculpture, in Apollo 16 preliminary science report: NatI. Aeronautics and Space Adm. Spec. Pub. 315, p. 29-31 to 29-33.

Shoemaker, E. M., 1960, Penetration mechanics of high velocity meteorites, illustrated by Meteor Crater, Arizona, in Structure of the earth's crust and deformation of rocks: Internat. Geol. Cong., 21st, Copenhagen 1960, Repts., pt. 18, p. 418-434.

-1971 , Origin of fragmental debris on the lunar surface and the history of bombardment of the Moon: Universidad de Barcelona, Inst. Investigaciones Geologicas de la Diputacion Provincial, v. 25.

1974, Synopsis of the geology of Meteor Crater, in Shoemaker, E. M. and Kieffer, S. W., eds., Guidebook to the geology of Meteor Crater, Arizona, 37t Ann. Mtg., Meteorit. Soc., Aug. 4, 1974, p. 1-11.

Shoemaker, E. M., and Hackman, R. J., 1962, Stratigraphic basis for a lunar time scale, in Kopal, Zdenek, and Mikhailov, Z. K., eds., The Moon: London, Academic Press, p. 289-300.

Short, N. M., and Forman, M. L., 1972, Thickness of impact crater ejecta on the lunar surface: Modern Geology, v. 3, p. 69-91.

Simmons, Gene, 1972, On the Moon with Apollo 16: Natl. Aeronautics and Space Adm. Pub. EP-95, 90 p.

Simonds, C. H., Warner, J. L., and Phinney, W. C., 1973, Petrology of Apollo 16 poikilitic rocks, in V. 1, Proc. Fourth Lunar Sci, Conf., Houston: Geochim. et Cosmochim. Acta, Supp. 4, v. 1, p. 613632.

Sjogren, W. L., Winberly, R. N., and Wollenhaupt, W. R., 1974, Lunar gravity-Apollo 16: The Moon, v. 11, p. 35-40.

Smith, J. V., and Steele, I. M., 1972, Apollo 16 rake samples 67515 to 68537-Sample classification, description and inventory: NASA report [unnumbered] $124 \mathrm{p}$.

Soderblom, L. A., and Boyce, J. M., 1972, Relative ages of some near-side and far-side terra plains based on Apollo 16 metric photography, in Apollo 16 preliminary science report: Natl. Aeronautics and Space Adm. Spec. Pub. 315, p. 29-3 to 29-6.

Steele, I. M., and Smith, J. V., 1973, Mineralogy and petrology of some Apollo 16 rocks and fines-General petrologic model of moon, in V. 1, Proc. Fourth Lunar Sci. Conf., Houston: Geochim. et Cosmochim. Acta, Supp. 4, v. 1, p. 519-536.

Stettler, A., Eberhardt, P., Geiss, J., Grogler, N., and Maurer, P., 1973, $\mathrm{Ar}^{39}$-Ar ${ }^{40}$ ages and $\mathrm{Ar}^{37}-\mathrm{Ar}^{36}$ exposure ages of lunar rocks, V. 2, Proc. Fourth Lunar Sci. Conf., Houston: Geochim. et Cosmochim. Acta, Supp. 4, v. 2, p. 1865-1888.

1974, Sequence of terra rock formation and basaltic lava flows on the Moon, in Lunar Sci. V, Abstracts: Houston, Lunar Sci. Inst., p. $738-740$.

Stoffler, D., Dence, M. R., Graup, G., Abadian, M., 1974, Interpretation of ejecta formations at the Apollo 14 and 16 sites by a comparative analysis of experimental, terrestrial, and lunar craters, in V. 1, Proceedings, Fifth Lunar Science Conference, Houston: Geochimica et Cosmochimica Acta, Supplement 5, v. 1, p. 137150.

Stoffler, D., Gault, D. E., Wedekind, J., and Polkowski, G., 1975, Experimental hypervelocity impact into quartz sanddistribution and shock metamorphism of ejecta: Jour. Geophys. Research, v. 80, p. 4062-4077.

Strangway, D. W., Gose, W. A., Pearce, G. W., and McConnell, R. R., 1973, Lunar magnetic anomalies and the Cayley Formation: Nature; Phys. Sci., v. 246, p. 112-115.

Stuart-Alexander, D. E., 1971, Geologic map of the Rheita quad- 
rangle of the Moon: U.S. Geol. Survey Misc. Geol. Inv. Map I-694 (LAC 114).

Stuart-Alexander, D. E., and Howard, K. A., 1970, Lunar maria and circular basins-a review: Icarus, v. 12, p. 440-456.

Stuart-Alexander, D. E., and Wilhelms, D. E., 1975, The Nectarian System, a new lunar time-stratigraphic unit: U.S. Geol. Survey Jour. Research, v. 3, no. 1, p. 53-58.

Swann, G. A., Bailey, N. G., Batson, R. M., Eggleton, R. E., Hait, M. H., Holt, H. E., Larson, K. B., Reed, V. S., Schaber, G. G., Sutton, R. L., Trask, N. J., Ulrich, G. E., and Wilshire, H. G., 1978, Geology of the Apollo 14 landing site in the Fra Mauro highlands: U.S. Geol. Survey Prof. Paper 880, 103 p.

Taylor, G. J., Drake, M. H., Hallan, M. E., Marvin, U. B., and Wood, J. A., 1973, Apollo 16 stratigraphy-the ANT hills, the Cayley plains, and a pre-Imbrian regolith, in V. 1, Proc. Fourth Lunar Sci. Conf., Houston: Geochim. et Cosmochim. Acta, Supp. 4, v. 1, p. 553-568.

Taylor, L. A., McCallister, R. H., and Sandi, Otto, 1973, Cooling histories of lunar rocks based on opaque mineral geothermometers, in V. 1, Proc. Fourth Lunar Sci. Conf., Houston: Geochim. et Cosmochim. Acta, Supp. 4, v. 1, p. 819-828.

Taylor, S. R., Gorton, M. P., Muir, P., Nance, W. B., Rudowski, R., and Ware, N., 1973, Composition of the Descartes region, lunar highlands: Geochim. et Cosmochim. Acta, v. 37, p. 2665-2683. 1974, Lunar highlands composition, in Lunar Science V, Abstracts: Houston, Lunar Sci. Inst., p. 789-791.

Taylor, S. R., and Jakes, P., 1974, The geochemical evolution of the Moon, in V. 2, Proc. Fifth Lunar Sci. Conf., Houston: Geochim. et Cosmochim. Acta, Supp. 5, v. 2, p. 1287-1305.

Tera, Fouad, Papanastassiou, D. A., and Wasserburg, G. J., 1973, A lunar cataclysm at $3.95 \mathrm{AE}$ and the systematics of the lunar crust, in Lunar Sci. IV, Abstracts: Houston, Lunar Sci. Inst., p. 723-725.

Trask, N. J., 1966, Size and spatial distribution of craters estimated from Ranger photographs, in P.2 of Ranger VIII and IX: JPL Tech. Rept., TR-32-800, p. 252-262.

Trask, N. J., and McCauley, J. F., 1972, Differentiation and volcanism in the lunar highlands-Photogeologic evidence and Apollo 16 implications: Earth and Planetary Sci. Letters, v. 14, no. 2, p. 201-206.

Turner, G., Cadogan, P. H., and Yonge, C. J., 1973, Argon selenochronology, in V. 2, Proc. Fourth Lunar Sci. Conf., Houston: Geochim. et Cosmochim. Acta, Supp. 4, v. 2, p. 1889-1914.

Ulrich, G. E., 1973, A geologic model for North Ray crater and stratigraphic implications for the Descartes region, in V. 1, Proc. Fourth Lunar Sci. Conf., Houston: Geochim. et Cosmochim. Acta, Supp. 4, v. 1, p. 27-39.

Ulrich, G. E., and Saunders, R. S., 1968, Advanced systems traverse research project report, with a section on problems for geologic investigations of the Orientale region of the Moon: U.S. Geol. Survey Interagency report, Astrogeology 7, $59 \mathrm{p}$.

U.S. Army Topographic Command, 1972, Topographic map of Descartes, scale 1:25,000, Washington, D.C.

Walker, David, Loghi, John, Grove, T. L., Stolper, Edward, and Hays, J. F., 1973, Experimental petrology and origin of rocks from the Descartes highlands, in V. 1, Proc. Fourth Lunar Sci. Conf., Houston: Geochim. et Cosmochim. Acta, Supp. 4, v. 1, p. 1013-1032.

Walton, J. R., Lakatos, S., Heymann, D., 1973, Distribution of inert gases in fines from the Cayley-Descartes region, in V. 2, Proc. Fourth Lunar Sci. Conf., Houston: Geochim. et Cosmochim. Acta, Supp. 4, p. 2079-2095.

Wanke, H., Baddenhausen, H., Dreibus, G., Jaguoutz, E., Kruse, H., Palme, H., Spettel, B., and Teschke, F., 1973, Multi-element analyses of Apollo 15, 16, and 17 samples and the bulk composition of the moon, in V. 2, Proc. Fourth Lunar Sci. Conf., Houston: Geochim. et Cosmochim. Acta, Supp. 4, v. 2, p. 1461-1481.

Wanke, H., Palme, H., Baddenhausen, H., Dreibus, G., Jagoutz, E., Kruse, H., Spettel, B., Teschke, F., and Thacker, R., 1974, Chemistry of Apollo 16 and 17 samples-Bulk composition, late stage accumulation and early differentiation of the Moon, in V. 2, Proc. Fifth Lunar Sci. Conf., Houston: Geochim. et Cosmochim. Acta, Supp. 5, v. 2, p. 1307-1335.

Warner, J. L., Simonds, C. H., and Phinney, W. C., 1973, Apollo 16 rocks: Classification and petrogenetic model, in V. 1, Proc. Fourth Lunar Sci. Conf., Houston: Geochim. et Cosmochim. Acta, Supp. 4, v. 1, p. 481-504.

1974, Impact induced fractionation in the lunar highlands, in V. 1, Proc. Fifth Lunar Sci. Conf., Houston: Geochim. et Cosmochim. Acta, Supp. 5, v. 1, p. 379-397.

Weiblen, P. W., and Roedder, E., 1973, Petrology of melt inclusions in Apollo samples 15598 and 62295, and of clasts in 67915 and several lunar soils, V. 1, Proc. Fourth Lunar Sci. Conf., Houston: Geochim. et Cosmochim. Acta, Supp. 4, v. 1, p. 681-703.

Wilhelms; D. E., 1970, Summary of lunar stratigraphy-telescopic observations: U.S. Geol. Survey Prof. Paper 599-F, p. 47 p.

1972, Reinterpretations of the northern Nectaris Basin, in Apollo 16 preliminary science report: Natl. Aeronautics and Space Adm. Spec. Pub. 315, p. 29-27 to 29-30.

Wilhelms, D. E., and McCauley, J. F., 1971, Geologic map of the near side of the moon: U.S. Geol. Survey Misc. Geol. Inv. Map I-703, scale 1:5,000,000.

Williams, J. C. C., 1969, Simple photogrammetry: London and New York, Academic Press, 211 p.

Wilshire, H. G., 1974, Provenance of terra breccias, in Lunar Science V, Abstracts: Houston, Lunar Sci. Inst., p. 846-847.

Wilshire, H. G., and Jackson, E. D., 1972a, Petrology and stratigraphy of the Fra Mauro Formation at the Apollo 14 site: U.S. Geol. Survey Prof. Paper 785, 26 p.

1972b, Lunar "dunite", "pyroxenite", and "anorthosite": Earth and Planetary Sci. Letters, v. 16, p. 396-400.

Wilshire, H. G., and Moore, H. J., 1974, Glass-coated lunar rock fragments: Jour. Geology, v. 82, p. 403-417.

Wilshire, H. G., Schaber, G. G., Silver, L. T., Phinney, W. C., and Jackson, E. D., 1972, Geologic setting and petrology of Apollo 15 anorthosite (15415): Geol. Soc. America Bull., v. 83, p. 10831092.

Wilshire, H. G., Stuart-Alexander, D. E., and Jackson, E. D., 1973, Apollo 16 rocks-Petrology and classification: Jour. Geophys. Research, v. 78, p. 2379-2392.

Wilshire, H. G., Wilhelms, D. E., and Howard, K. A., 1974, Lunar highlands volcanism-implications from Luna 20 and Apollo 16: U.S. Geol. Survey Jour. Research, v. 2, no. 1, p. 1-6.

Zisk, S. H., Masursky, Harold, Milton, D. J., Schaber, G. G., Shorthill, R. W., and Thompson, T. W., 1972, Apollo 16 landing site: Summary of earth-based remote sensing data: Apollo 16 preliminary science report: Natl. Aeronautics and Space Adm. Spec. Pub. 315, p. 29-105 to 29-110. 